\title{
Viviendas Europan (1988-2008) Una aproximación a los modos de vida en el cambio de siglo en España
}





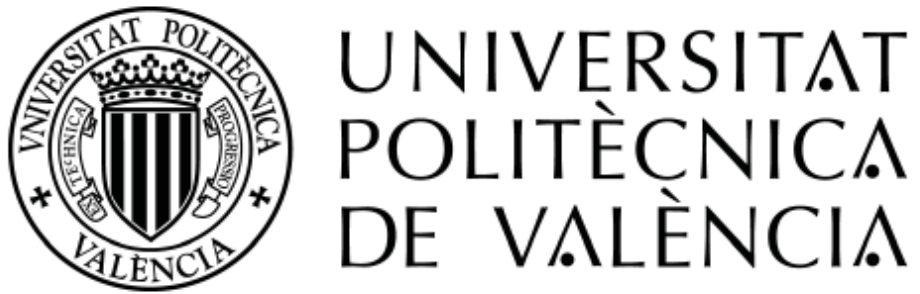

\section{VIVIENDAS EUROPAN (1988-2008)}

Una aproximación a los modos de vida en el cambio de siglo en España

Autor:

Marita Carmona Belda

Directores: Dr. D. Vicente Mas Llorens Dra. Da Elisa Valero Ramos 
Colección Tesis Doctorales

\section{(c) María Encarnación Carmona Belda}

Primera edición, 2014

(c) de la presente edición: Editorial Universitat Politècnica de València Telf.: 963877012 / www.lalibreria.upv.es

ISBN: 978-84-9048-186-8 (versión impresa)

Queda prohibida la reproducción, distribución, comercialización, transformación, y en general, cualquier otra forma de explotación, por cualquier procedimiento, de todo o parte de los contenidos de esta obra sin autorización expresa y por escrito de sus autores. 
ÍNDICE

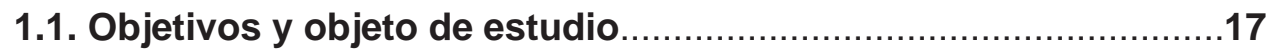

1.1.1. Objetivosgenerales................................................... 17

1.1.2. Objeto de estudio...................................................... 17

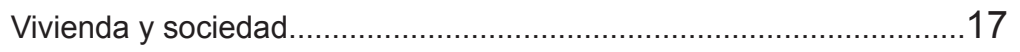

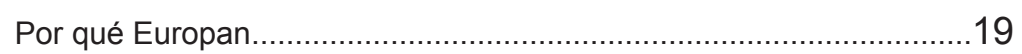

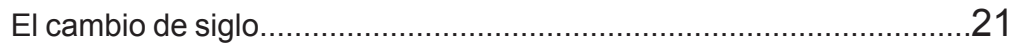

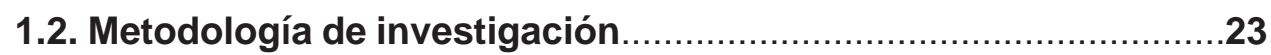

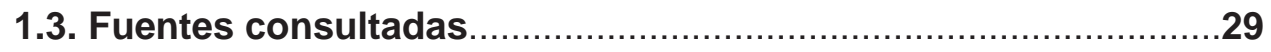

1.3.1. Comité Nacional en España.........................................29

1.3.2. Comité de expertos......................................................29

1.3.3. Equipos galardonados y edificios de viviendas Europa.....31

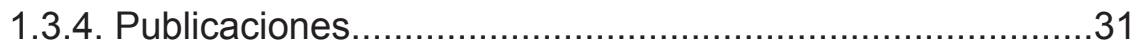

1.4. Estructura y contenido de la tesis.............................................33

\begin{tabular}{lr} 
2. ANTECEDENTES & 37 \\
\hline
\end{tabular}

2.1. Consideraciones preliminares sobre vivienda..........................39

2.1.1. Arquitectura doméstica................................................39

2.1.2. Vivienda protegida..................................................... 41

2.2. Los orígenes de Europan: PAN …...........................................53

2.3. Europan: "algo más" que un concurso de arquitectura.............57

3. EUROPAN: LABORATORIO DE IDEAS SOBRE EL HABITAR 65

3.1. El sustrato conceptual en arquitectura ...................................67 


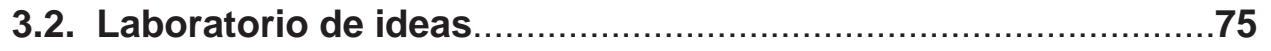

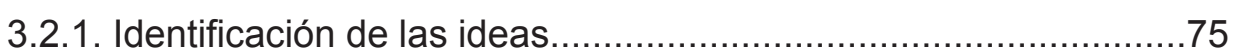

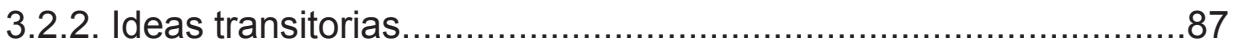

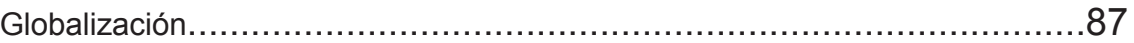

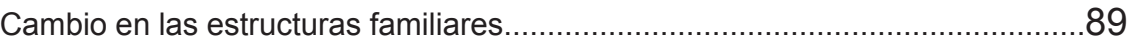

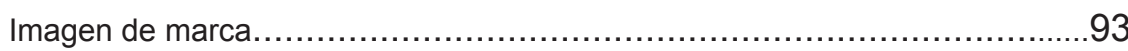

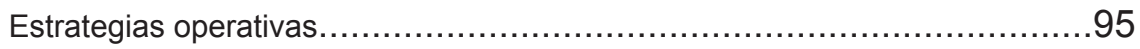

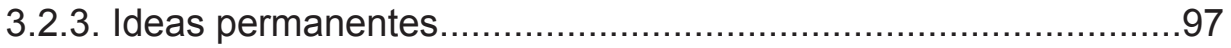

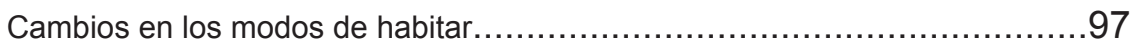

Hibridación versus zonificación......................................................99

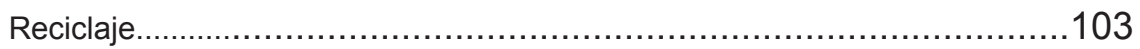

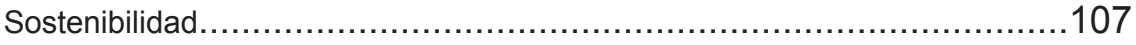

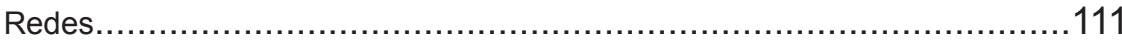

3.3. La evolución de la investigación en Europan: tabla resumen...113

\section{EUROPAN: DEL CONCURSO A LA REALIZACIÓN 119}

4.1. Edificios de viviendas construidos: fichas explicativas.

4.1.1. Edificios de viviendas Europan 1 (1988)..............................127

Aranguren\&Gallegos: torres de viviendas en Madrid.................................127

Ricardo Sánchez y Jose Ma Escobar: torres de viviendas Madrid...................139

Félix Pozo y Alberto Torres: bloque de viviendas en Zafra (Huelva)................149

Mercedes Peláez: viviendas unifamiliares y bloques en Vallecas (Madrid).......159

Mercedes Peláez: edificios de viviendas sociales en Ujo (Asturias).................169

Isabel B. y Ana M ${ }^{a} \mathrm{~N}$ : bloques de viviendas sociales en Pravia (Asturias)........175

Susana Aparici, Inma N y Fernando M: viviendas adosadas en Vallecas (Madrid)...........185

4.1.2. Edificios de viviendas Europan 2 (1990)...............................195

Matos\& Castillo: manzanas de viviendas sociales en Basauri (Bilbao)...........195

M ${ }^{a}$ Concepcion Carreiro y Cándido López: viviendas sociales en Ferrol..........205

4.1.3. Edificios de viviendas Europan 3 (1992)..............................215

Jaime Lopez y Jaime Latas: bloques de viviendas sociales en la M-30..........215

Enrique Johansson de Terry: viviendas sociales en Granada.........................225

Ma José D y Eva Prats: bloque de viviendas sociales y plaza en Guissona (Lérida).......235 
4.1.4. Edificios de viviendas Europan 4 (1994)..............................245

Nieto\&Sobejano: viviendas sociales en Sevilla frente a la S-30......................245

Eduardo Belzunce, Luis Día, Juan García, Jose Ma Lapuerta yFrancisco Burgos: torres y bloques de viviendas sociales en Mina del Morro (Bilbao)..................255

Pedro Palmero y Samuel Torres: viviendas sociales en Avilés........................265

Javier Fresneda, Javier Sanjuán y Javier Herreros: viviendas sociales en Avilés.............275

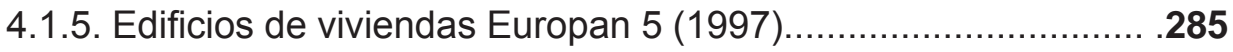

José Morales y Juan González Mariscal: torres y viviendas unifamiliares en Ceuta.......285

Elio García, Carlos Rodríguez y Javier Rodríguez: viviendas sociales en Avilés............295

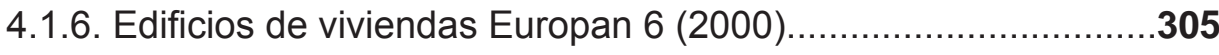

Mario Sanjuan, Iban Carpintero, Jose M ${ }^{a}$ T y Angel S: viviendas sociales Avilés..............305

Jorge Suarez y Lucía Salvador: viviendas sociales en Avilés..........................315

4.1.7. Edificios de viviendas Europan 7 (2002)................................325

Angela Moragues y Hevia Meyer: viviendas sociales en Lérida (Barcelona)....325

4.2. Otros edificios construidos de Europan.

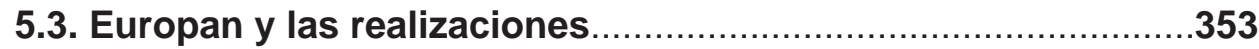

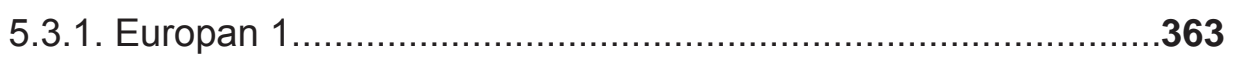

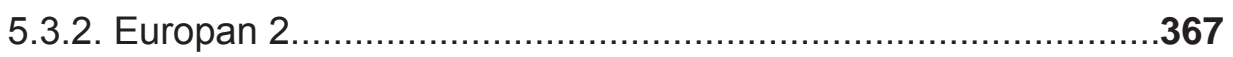

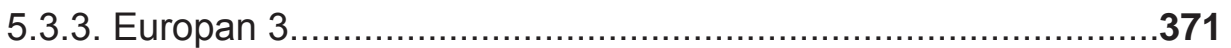

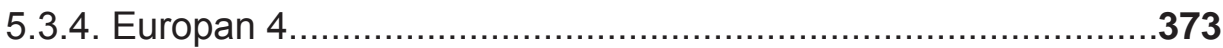

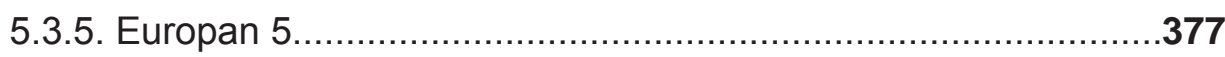

5.3.6. Europan 6

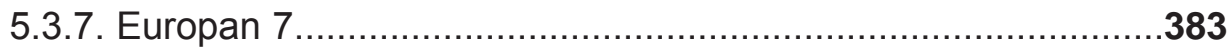


6.2. LogrosdeEuropan .393

7.2. Sobre vivienda. .403

7.3. Sobre Europan y los concursos .407

1. CARTA EUROPAN. .415

2. ENUNCIADOS EUROPAN. .417

3. ACTAS DE LOS JURADOS EUROPAN.. 446

4. ENTREVISTA AL COMITÉ NACIONAL DE EUROPAN .532 


\section{RESUMEN}

El objeto de estudio de esta investigación es el análisis de las viviendas Europan, el laboratorio de ideas sobre el habitar más importante de Europa. Este concurso ha influido en la arquitectura española en tres niveles: en el del trabajo de los "jóvenes" equipos de arquitectos, en el de la Administración Pública y en el de la materialización de la vivienda social experimental. Este último nivel constituye uno de los principales retos de Europan.

Dentro de la esfera de Europan, la presente tesis doctoral se centra en dos aspectos: el primero lo constituyen los planteamientos teóricos que han desarrollado los enunciados del concurso en los últimos veinte años y, el segundo aspecto lo constituyen los edificios de vivienda social construidos en España. Asimismo, se recopila la información dispersa de estos edificios y se analizan tomando como base unas fichas, de elaboración propia, en las que se ha redibujado cada uno de ellos.

La tesis se estructura en tres bloques. El primer bloque está formado por los capítulos primero y segundo que tratan de enmarcar la investigación ofreciendo una introducción y unos antecedentes. El segundo bloque es el cuerpo central de la tesis y está formado por cuatro capítulos (3, 4, 5 y 6). El capítulo tercero analiza Europan como laboratorio de ideas; el capítulo cuarto analiza los edificios de viviendas construidos; el capítulo quinto consta de una valoración de las aportaciones de Europan y, por último, el capítulo sexto son las conclusiones. El tercer bloque, de información complementaria, compendia la bibliografía y los anexos. Estos últimos recopilan documentos dispersos que ofrecen una visión de conjunto de Europan.

Por último, en esta tesis, tras el estudio de la teoría y la práctica de Europan, se ofrece una aproximación a los modos de vida en el cambio de siglo en España a través de sus aportaciones después de veinte años de existencia. La novedad de esta tesis reside en el hecho de que estamos ante un objeto de estudio no tratado hasta ahora en el ámbito de la investigación.

Palabras clave: Europan, laboratorio vivienda, concursos, vivienda social, crítica. 



\section{RESUM DE LA TESI}

L'objecte d'estudi d'aquesta investigació és l'anàlisi dels habitatges Europan, el laboratori d'idees sobre I'habitar més important d'Europa. Aquest concurs ha influït a l'arquitectura espanyola a tres nivells: en el de la feina dels "joves" equips d'arquitectes, en el de l'Administració Pública i en el de la materialització de I'habitatge social experimental. Aquest últim nivell constitueix un dels principals reptes de Europan.

Dins l'esfera de Europan, la present tesi doctoral es centra en dos aspectes: el primer el constitueixen els plantejaments teòrics que han desenvolupat els enunciats del concurs en els últims vint anys, i el segon aspecte el constitueixen els edificis d'habitatge social construïts a Espanya. Així mateix, es recull la informació dispersa d'aquests edificis i s'analitzen prenent com a base unes fitxes, d'elaboració pròpia, en què s'ha redibuixat cada agrupació.

La tesi s'estructura en tres bloques. El primer bloc està formado pels capítols primer i segon que tracten d'emmarcar la investigació oferint una introducció i uns antecedents. El segon bloc és el cos central de la tesi i està formado per quatre capítols ( $3,4,5$ i 6 ). Al capítols tercer s'analitza Europan com a laboratori d'idees; al capítol quart s'analitzen els edificis d'habitatges construïts; el capítol cinquè consta d'una valoració de les aportacions de Europan i, finalment, el capítol sext són les conclusions. El tercer bloc de la tesi, d'informació complementària, compendia la bibliografia i els annexos. Aquests últims recopilen documents dispersos que ofereixen una visió de conjunt de Europan.

Finalment, en aquesta tesi, després de l'estudi de la teoria i la pràctica de Europan, s'ofereix una aproximació a les formes de vida en el canvi de segle a Espanya a través de les seves aportacions després de vint anys de la seua existència. La novetat d'aquesta tesi rau en el fet de que estem davant un objecte d'estudi no tractat fins ara en l'àmbit de la investigació.

Paraules clau: Europan, laboratori habitatge, concursos, habitatge social, crítica 



\section{ABSTRACT}

The purpose of this research study is the analysis of Europan housing, the most important laboratory of living ideas in Europe. This competition has influenced the Spanish architecture at three levels: in the work of "young" teams of architects, in Public Administration and the realization of experimental social housing. This last level is one of the main challenges of Europan.

Within the sphere of Europan, this thesis focuses on two aspects: the first is the theoretical approaches that have developed statements of the contest in the last twenty years; the second aspect is the social housing built in Spain. Also, the scattered information of these buildings is collected, analyzed and redrawn and all this has been reflected on cards.

The thesis is structured in three parts. The first part comprises the first and second chapters that try to frame the study by providing an introduction and some background. The second part is the central body of the thesis and it is formed up of four chapters $(3,4,5$ and 6$)$. The third chapter analyzes Europan as a laboratory of ideas, the fourth chapter analyzes the housing built, the fifth chapter consists of an assessment of the contributions of Europan and finally, the conclusions are on chapter sixth. The third part of information summarizes the literature and the annexes. Last one collects scattered papers that offer an overview of Europan.

Finally, in this thesis, after studying the theory and practice of Europan, we offer an approach to the ways of life at the turn of the century in Spain through its contributions after twenty years of its existence. The novelty of this thesis lies in the fact that this is a subject of study not covered so far in the field of this research.

Keywords: Europan, laboratory housing, competition, social housing, critical. 

1. INTRODUCCIÓN 


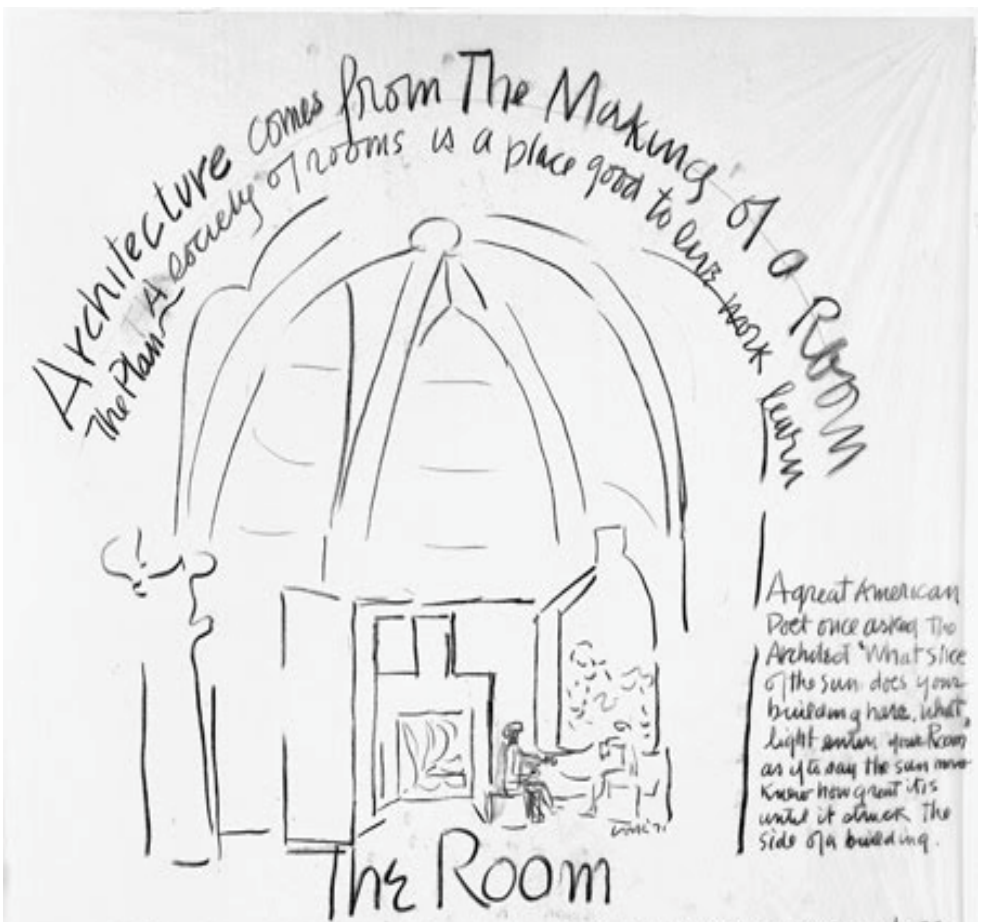

is The place of the mind. In a small room ove does MBT say what one nould in a large room I $\mathrm{M}$ a $200 \mathrm{~m}$ with ouly one other perieon could be jerena ino The vectors of each meet.

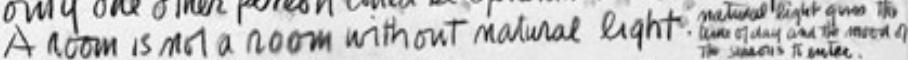

Ref.1.1. Louis I. Kahn. Architecture comes from the making of a room, 1971, Philadelphia Museum of Art

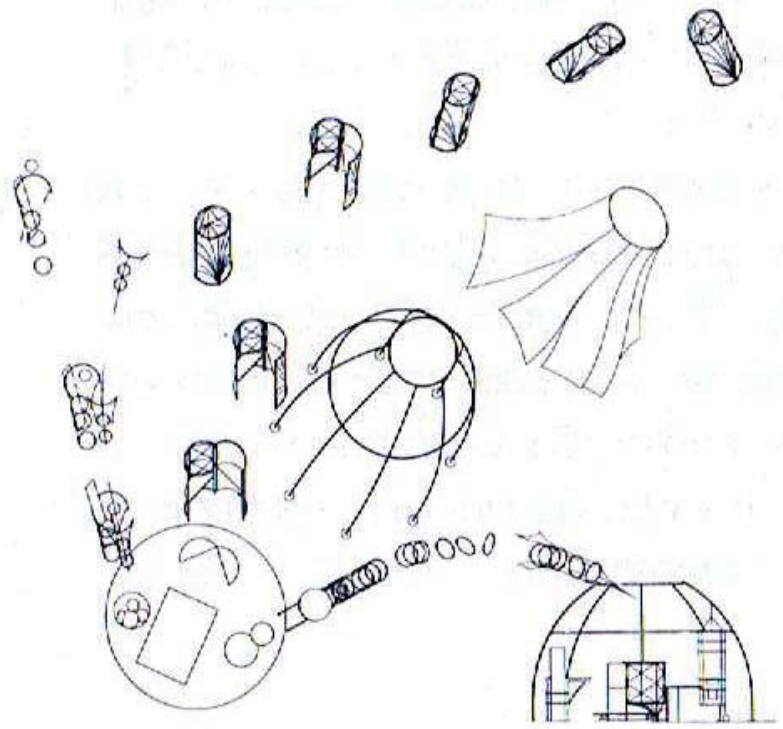

Ref.1.2.Toyo Ito, alojamiento para la Chica nómada, 1985 


\subsection{Objetivos y objeto de estudio}

\subsubsection{Objetivos generales}

La presente tesis abarca los siguientes objetivos:

En primer lugar, el estudio de los planteamientos teóricos de finales de siglo XX acerca de la vivienda social que han desarrollado los concursos Europan, el laboratorio de ideas sobre el habitar más importante de Europa.

En segundo lugar, la recopilación y el análisis de los edificios de vivienda social construidos con motivo de los concursos Europan en el ámbito español. Se ofrece una reflexión sobre el proceso evolutivo de cada realización pues se estudia el proyecto arquitectónico desde la fase de concurso a la materialización del mismo.

En tercer lugar, la valoración de la influencia de Europan a través de algunas aportaciones a la arquitectura española en los veinte años de su existencia.

Por último, el objetivo general es ofrecer una aproximación a los modos de vida en el cambio de siglo en España a través de las aportaciones de los concursos Europan.

\subsubsection{Objeto de estudio}

\section{Vivienda y sociedad}

La vivienda es uno de los retos principales de la arquitectura. La tesis se centra en el estudio de la vivienda urbana, que constituye el elemento fundamental de las ciudades. Se pretende investigar sobre las vanguardias arquitectónicas prestando especial atención a una selección de viviendas sociales construidas en España.

El término vivienda ${ }^{1}$ proviene del latín vivenda, de vivere, que quiere decir vivir. En castellano se utilizan distintas palabras para hacer referencia al término vivienda: casa - es la más común -, hogar, residencia, habitación,morada, etc.

Es reconocido por la mayoría que tener una vivienda digna es uno de los derechos fundamentales de la persona. En el artículo 48 de la Constitución española se afirma que "todos los españoles tienen derecho a disfrutar de una vivienda digna y adecuada. Los poderes públicos promoverán las condiciones necesarias y establecerán las normas pertinentes para hacer efectivo este derecho, regulando la

1 Vivienda. Del lat. vivenda, t. f. de -dus, p. f. de vivere, vivir. 1. Morada, habitación. 2.f.desus. Género de vida o modo de vivir. REAL ACADEMIA ESPAÑOLA. Diccionario de la Real Academia Española. 22a Edición. Ed. Espasa- Calpé. Madrid. 2001. 


\section{europan}
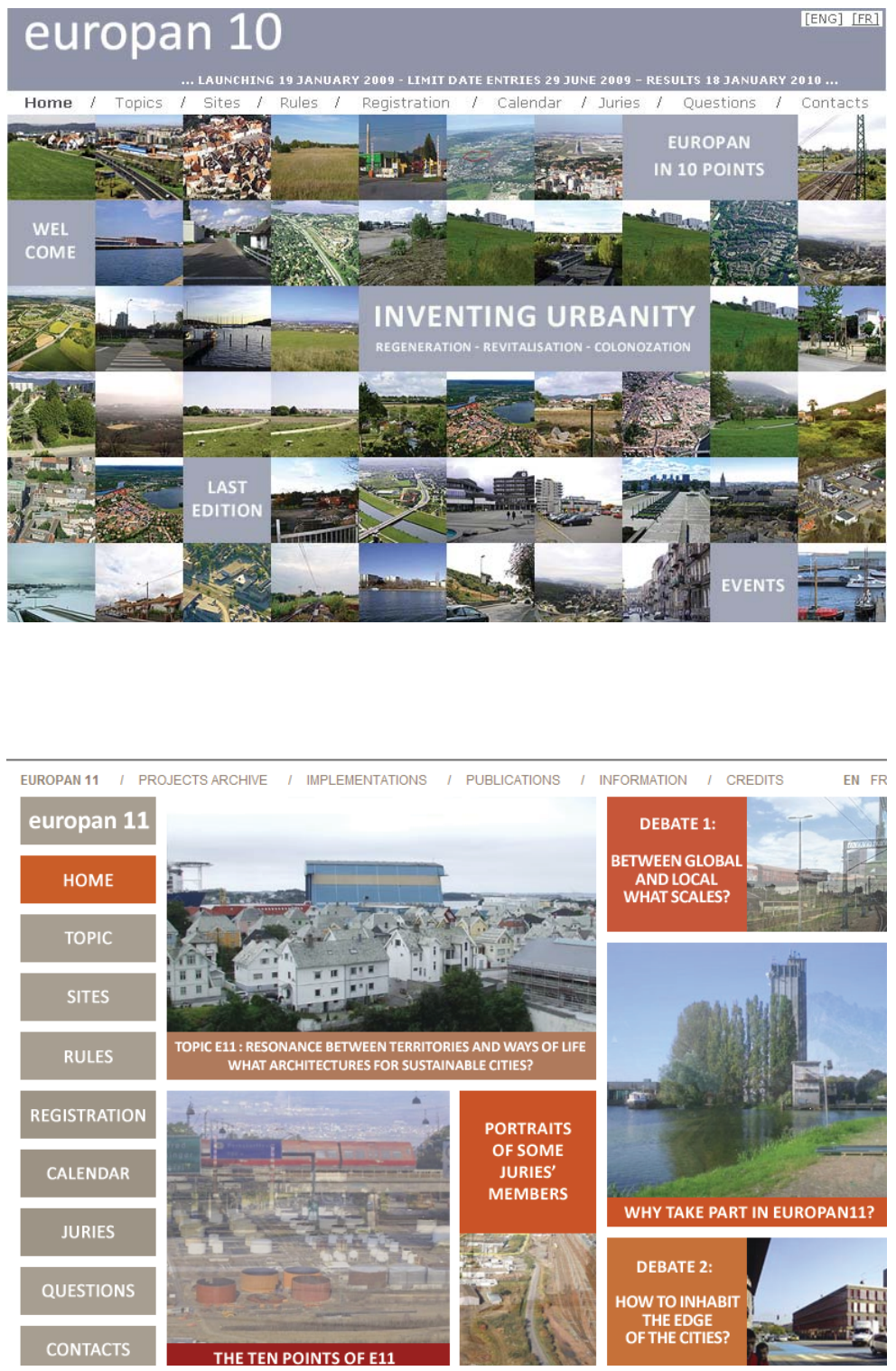

Ref. 1.3. Sitios web de Europan 
utilización del suelo de acuerdo con el interés general para impedir la especulación. La comunidad participará en las plusvalías que genere la acción urbanística de los entes públicos".

La vivienda es el soporte de los modos de vida y el resultado de los cambios que se producen en éstos y requiere, por tanto, una atención especial por parte de los arquitectos. Quizá los cambios en los últimos tiempos en los modos de vida se han sucedido demasiado rápido y la vivienda no se ha adaptado a éstos con la misma velocidad.

El interés de la investigación planteada reside en su carácter pionero pues es la primera que toma como base de datos de la investigación la muestra de los edificios construidos de vivienda social de los concursos Europan. Se pretende, a través de los planteamientos innovadores de Europan, buscar soluciones a los problemas habitacionales y se estudia la vivienda como parte integrante de una sociedad, partiendo de la premisa de que no se puede desligar en ningún momento de ésta.

\section{Por qué Europan}

De forma sintética, tal y como se encuentra en las bases del concurso, Europan "es un concurso periódico de ideas seguido de realizaciones con un tema, un reglamento y un calendario común a todos los países que lo organizan y cuyos participantes son arquitectos europeos menores de 40 años que estén en el ejercicio profesional en cualquier país de Europa". Los arquitectos, solos o en equipo - puede ser interdisciplinar - presentan propuestas en cualquiera de los emplazamientos elegidos. Europan es además un foro de debate sobre la vivienda, la arquitectura y el urbanismo que pretende reunir a todas aquellas personas, instituciones y Administración de diversos ámbitos - Estatal, Autonómico o Local que deseen participar en la labor de desarrollo de las ciudades.

Pero Europan no es sólo una organización en torno a unas bases y un calendario... El objeto primordial del concurso es aumentar el intercambio de ideas entre los profesionales europeos y extraer las reflexiones innovadoras así como la máxima calidad de la arquitectura y el urbanismo para las ciudades.

Se ha escogido el tema de los concursos Europan en sus diferentes convocatorias como hilo argumental de la tesis porque es un excelente medio de información acerca del pensamiento arquitectónico contemporáneo. En cada convocatoria de Europan se nombra un comité de expertos que analiza los problemas del momento en las ciudades participantes para afrontarlos desde la arquitectura. Se elige, por tanto, como marco de la investigación porque permite reflexionar acerca de las necesidades sociales del siglo XXI.

${ }^{2}$ AA.VV. Constitución española. Ed. Secretaría general del Senado. Dirección de estudios. Madrid. 2006 


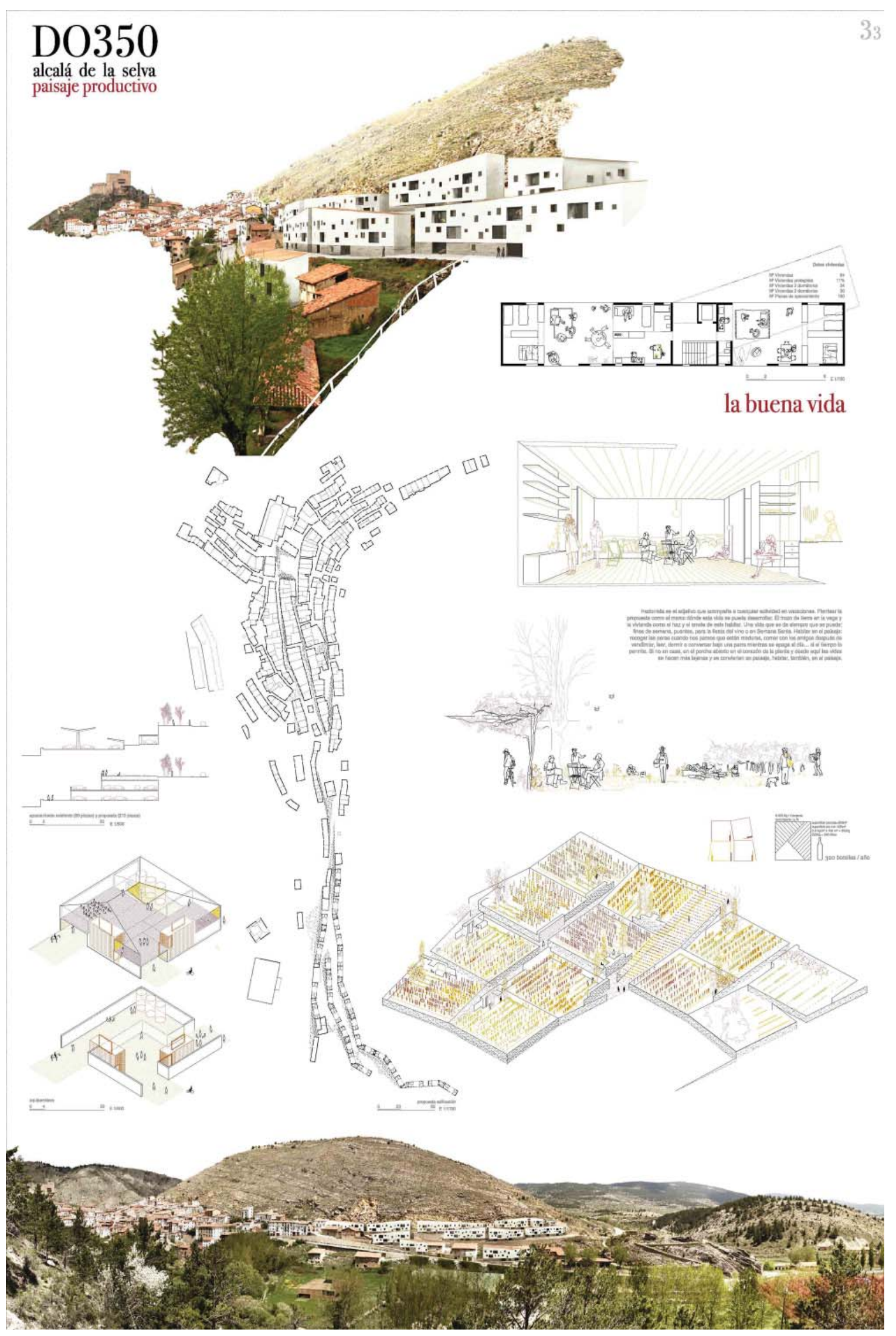

Ref. 1.4. Europan "habla" a través de sus paneles. Premiado Europan 11 en Alcala de la Selva. Pol Viladoms, Arnau Sastre, Cecilia Rodríguez. 
También se ha optado por el tema de los concursos Europan porque relaciona pensamiento y obra construida con unos planteamientos vanguardistas trazados por jóvenes arquitectos.

Para esta investigación se toman como referencia dos factores: por un lado,los planteamientos teóricos de Europan y por otro, los edificios de viviendas construidos. De estos últimos apenas se ha publicado nada en conjunto. En la mayoría de publicaciones aparecen los resultados de los concursos limitándose a hacer una mera enumeración y clasificación de los proyectos galardonados. En esta documentación apenas tiene lugar la reflexión y esta es precisamente una de las aportaciones de la tesis doctoral pues se presentan las realizaciones desde los planteamientos teóricos de concurso hasta la materialización de la ideación.

Se han elegido las muestras para la investigación los edificios de viviendas construidos en el territorio español. El objeto de esta selección ha sido principalmente el de acotar las muestras analizadas, pues hubiera sido una trabajo demasiado amplio recopilar todas las realizaciones existentes. Se podrían establecer las semejanzas y diferencias con otros países europeos participantes, pero, aunque este tema no deje de tener su interés, sería objeto de una tesis doctoral diferente a la planteada.

Otro motivo de la elección de Europan ha sido porque se considera como un excelente instrumento para la crítica arquitectónica. En la base del concurso predomina la libertad proyectual. Este hecho se manifiesta en su voluntad de trabajar en equipos jóvenes e interdisciplinares y hace que el trabajo acumulado sea interesante, innovador y de un sabor fresco a la arquitectura del momento.

\section{El cambio de siglo}

"Un milenio de buena construcción es tan difícil como cualquier otro, y merece la pena planificarlo ${ }^{3 "}$.

Para poder contrastar los cambios en los planteamientos teóricos y en las viviendas hace falta concretar no sólo el factor espacial, las muestras que se ensayan en el laboratorio, sino también el temporal.

El trabajo de un arquitecto se desarrolla dentro de unas coordenadas temporalespaciales y, como en cualquier ciencia, es necesario comprobar si ha habido una evolución, como afirma Saénz de Oiza: “(...) Una obra que no esté en su tiempo no es una obra de arquitectura, porque las obras tienen que estar ligadas tanto a su tiempo como a su lugar. Porque las obras de arquitectura, como las obras

${ }^{3}$ HITCHCOCK, Henry Russell y JOHNSON, Philip. El Estilo internacional: arquitectura desde 1922. Ed. Comisión de Cultura del Colegio Oficial de Aparejadores y Arquitectos Técnicos. Murcia. 1984. p. 100. 
VIVIENDAS EUROPAN (1988-2008) I Una aproximación a los modos de vida en el cambio de siglo en España 1. INTRODUCCIÓN

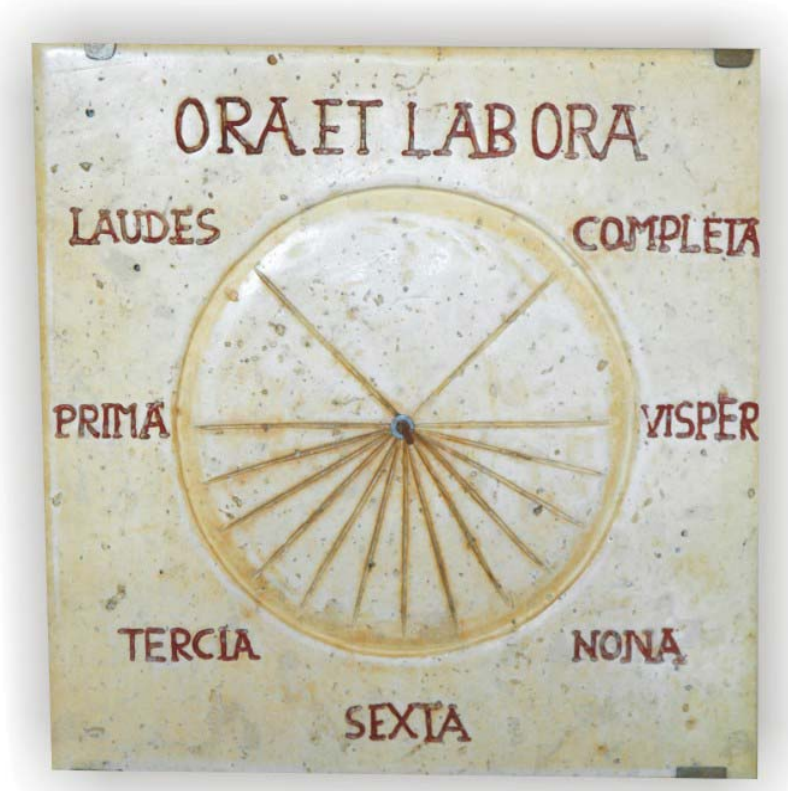

Ref.1.5.Reloj canónico

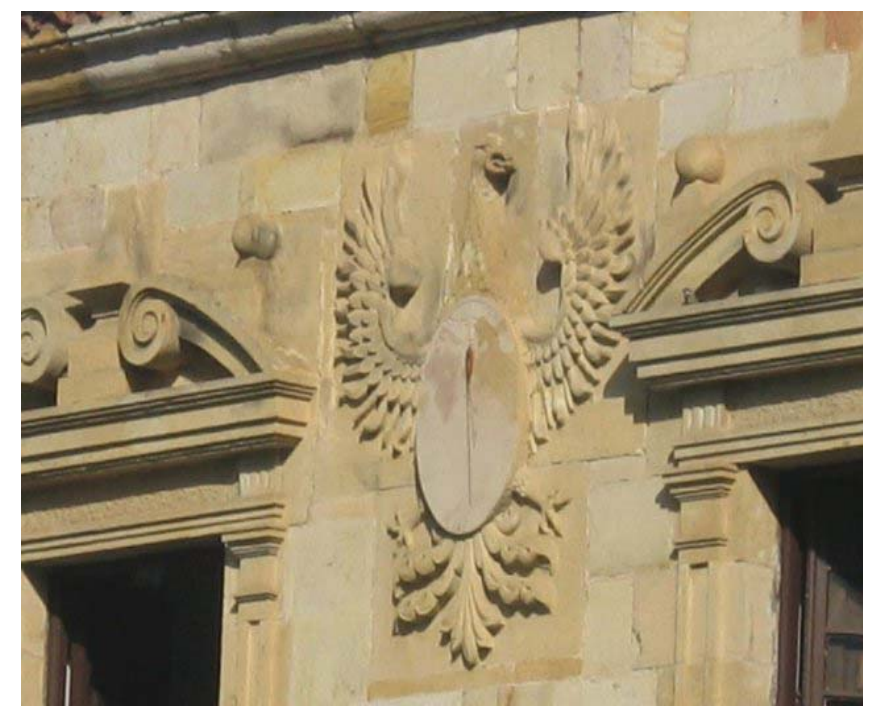

Ref.1.6. Reloj solar
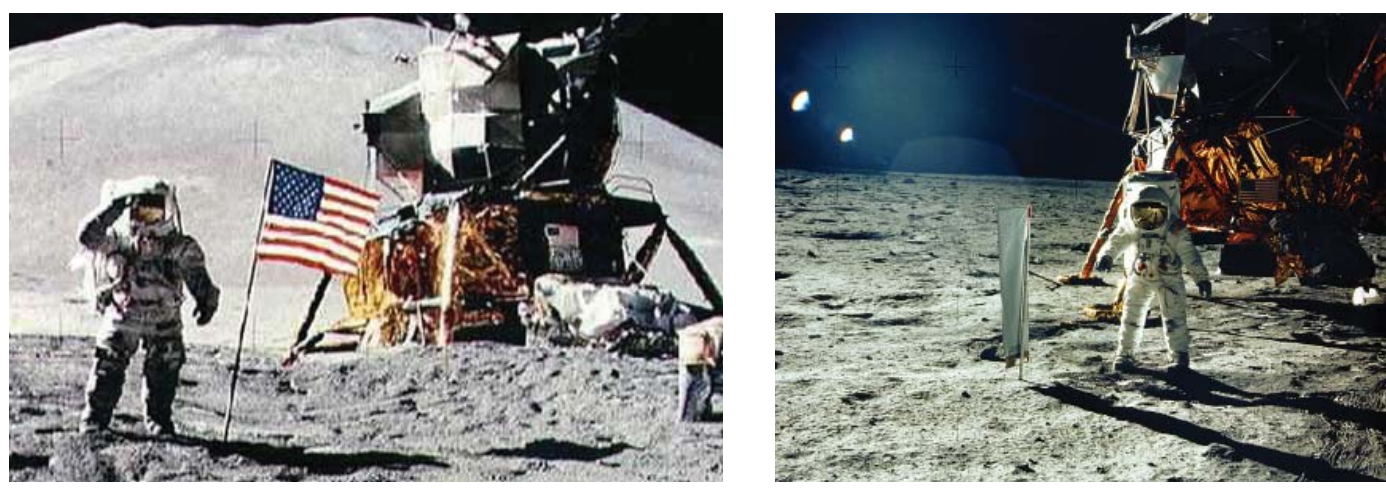

Ref.1.7. La llegada a la luna (1969) 
del lenguaje, sólo surgen hablando el lenguaje que se habla. Yo no podría hablar en este momento en esperanto, o en latín, o en coreano, porque no entenderíais nada. Luego el visaje tiene que ser el propio, el propio al que pertenece el lugar en el que se habla, y al tiempo en el que se habla.

Los dos factores importantes del arte, o de la ciencia de tu siglo son el espacio y el tiempo. Tú no puedes corregir un texto sino en función del tiempo en que se escribe. Espacio y tiempo son vectores claves en la arquitectura".

Delimitar el factor tiempo permite por un lado acotar la investigación, pues, si fuera un rango de tiempo más extenso, resultaría un trabajo tedioso y sería difícil de concluir; por otro lado, permite trabajar con precisión, que es un factor necesario para la labor arquitectónica. Como afirma le Corbusier: "Tengo 77 años y mi moral puede resumirse así: en la vida es necesario trabajar; es decir, hacer algo con modestia, con exactitud, con precisión. La única atmósfera posible para la creación artística es la regularidad, la modestia, la continuidad, la perseverancia.

(...) La única cosa transmisible es el pensamiento, la parte noble del fruto del trabajo. Este pensamiento puede llegar a ser, o no, una victoria sobre el destino más allá de la muerte y asumir, quizá, otra dimensión imprescindible ${ }^{5 "}$.

Veinte años de vivienda social no son nada para la historia de la arquitectura, pero se parte de la hipótesis de que pueden ofrecernos algunos datos interesantes. El período elegido comienza en 1988 y termina en el 2008. Comprende los años de existencia hasta el momento de Europan y de lo que se ha construido, también. Además dentro de este rango de tiempo hay representado un momento clave para la historia: el final de un siglo y el principio de otro.

Y, una vez definido los objetivos y el objeto de estudio se da paso en el siguiente apartado a explicar cómo se ha desarrollado la investigación.

\subsection{Metodología de investigación}

En primer lugar, el trabajo de la tesis ha sido el de la recopilación de datos.

En el trabajo de investigación previo a la tesis, se recopilaron y estudiaron las convocatorias de cada edición de Europan, las actas del Jurado, las publicaciones elaboradas con posterioridad a los concursos y algunos de los proyectos construidos. Fue una sorpresa descubrir que nadie se hubiera planteado estudiar con detenimiento y visión de conjunto las realizaciones de Europan.

Ya en la fase de tesis, se ha realizado por un lado la recopilación de datos a través de la relación directa con el Comité Nacional y los equipos autores de las

\footnotetext{
${ }^{4}$ AA.VV. "Francisco Javier Saenz de Oiza (1947-1988)". El Croquis 32-33. Madrid, 2002. p.17-19.

${ }^{5}$ CORBUSIER, Le. Obra completa (1910-1969).Vol. 8. Ed. Blume. Madrid. 1987. p.170.
} 

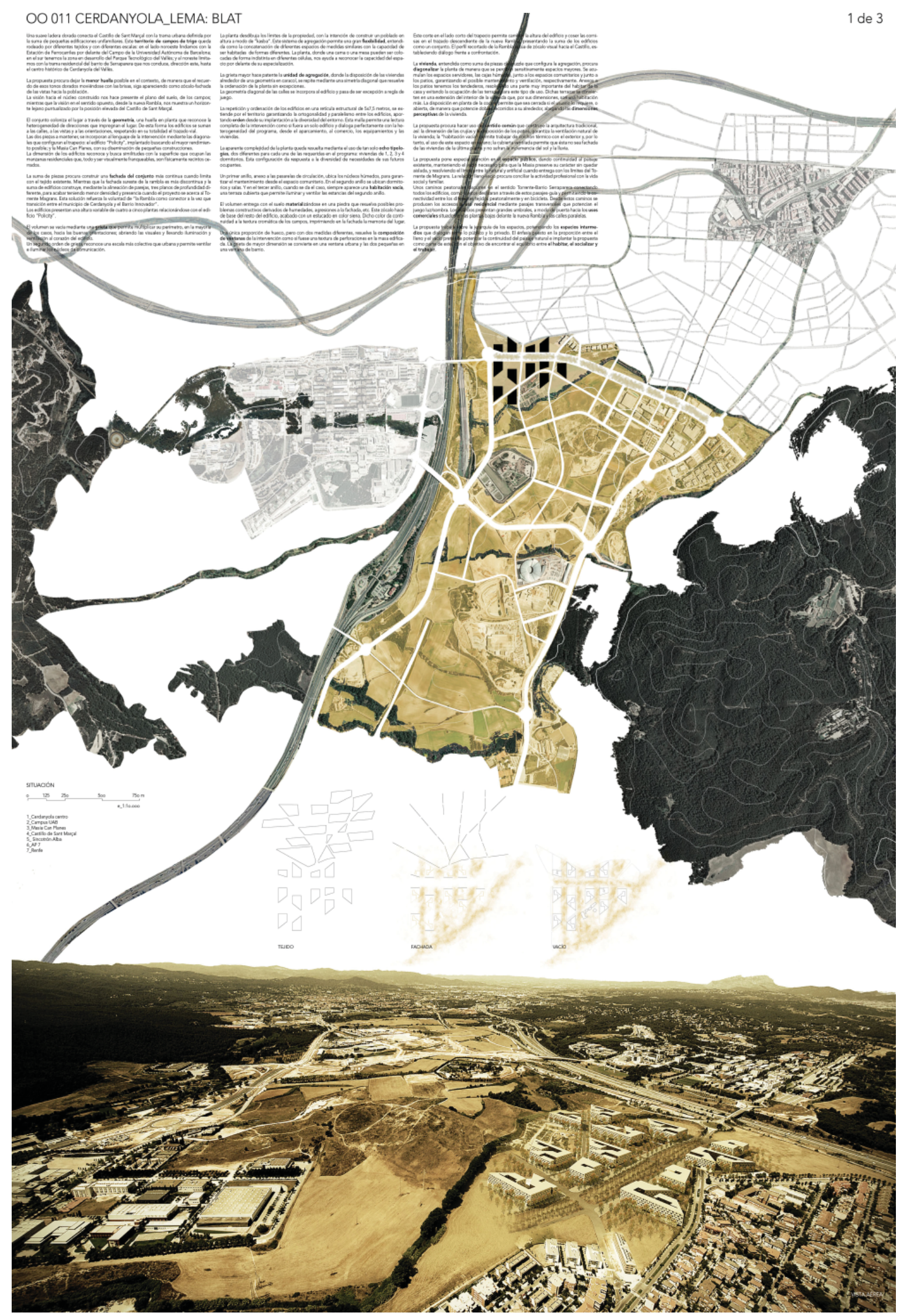

Ref.1.8. Europan 11. Premiado en Cerdanyola del Vallés. Josep Ferrando, Marc Nadal, David Recio. 
realizaciones. Con estos últimos se han mantenido conversaciones frecuentes y se ha procedido al intercambio de información necesaria para la redacción de la tesis.

Por otro lado, también se ha realizado esta recopilación de datos a través de la revisión y análisis de la información recabada en la bibliografía y archivos. Además de revisar la bibliografía específica de Europan también se ha consultado bibliografía básica sobre el tema de la vivienda. Se ha procurado indagar en el contenido teórico de los últimos veinte años a través de los planteamientos de los textos de Europan aunque cabe apuntar que también se ha acudido a los textos de los arquitectos del Movimiento Moderno y de los CIAM pues se han considerado como antecedentes necesarios para entender la vivienda actual.

Tras recopilar el material necesario se ha llevado a cabo la tarea del análisis de los datos.

Este análisis ha supuesto una lectura que ha requerido detenimiento, ponderación, estudio, serenidad. Se han analizado, por un lado los planteamientos teóricos o temas de reflexión de cada convocatoria y, por otro, los edificios de vivienda social construidos en España. Se ha observado, mientras se ha realizado esta tarea, una disparidad interesante entre la teoría planteada y los edificios de vivienda construidos. Tanto es así que parecía que se imbuía al lector en dos mundos totalmente diferentes, entre los que - a simple vista- existía poca relación: el mundo de las ideas y el de la construcción.

Para estudiar y analizar en primer lugar los temas de reflexión de cada convocatoria se ha elaborado una tabla-resumen de éstos que se encuentra en el capítulo tercero.

En segundo lugar, para estudiar y analizar cada edificio de vivienda social construido, se han redibujado unas fichas que se adjuntan en el capítulo cuarto, después de detallar su evolución proyectual. Básicamente esta tarea ha consistido en redibujar los edificios de vivienda construidos y obtener alguna información concreta que se pudiera utilizar en la investigación. Al comienzo del capítulo cuarto, se hace referencia al modo de elaborar las fichas. Fundamentalmente se divide en tres partes: en la primera, se redibuja el proyecto (el sistema de agrupación y una de las viviendas que suele ser la más representativa), en la segunda se recogen algunas imágenes identificativas del proyecto (sobre todo es común la imagen del emplazamiento y del conjunto) y, la tercera parte consiste en una información escrita con algunos datos de interés para identificar los proyectos y poder extraer algunas conclusiones (autores, emplazamiento, duración de las obras, si es el proyecto de concurso, el número de viviendas por superficie, el uso de la planta baja y del sótano y las referencias bibliográficas). Los planos de las fichas se han elaborado a la misma escala con el fin de que permitieran realizar comparaciones entre ellas. 


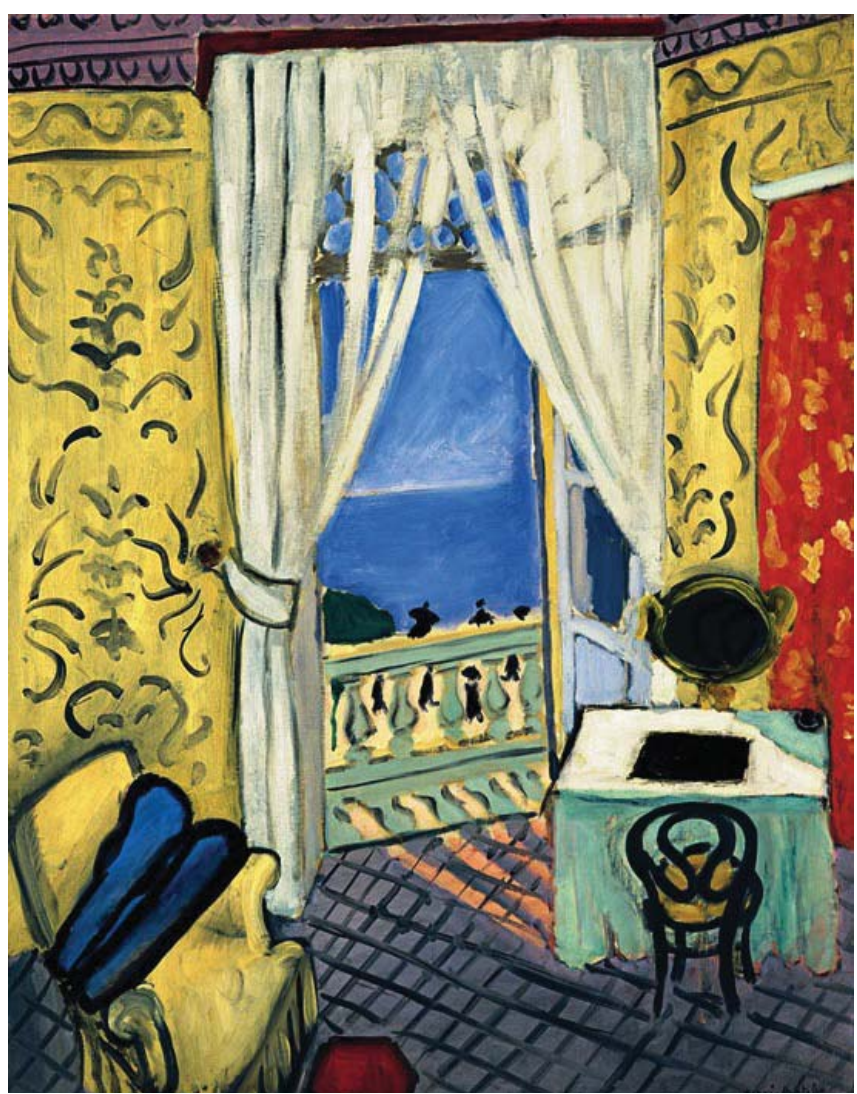

Ref. 1.9. Henri Matisse. Interior con funda de violin. MOMA. Madrid. 1918-1919

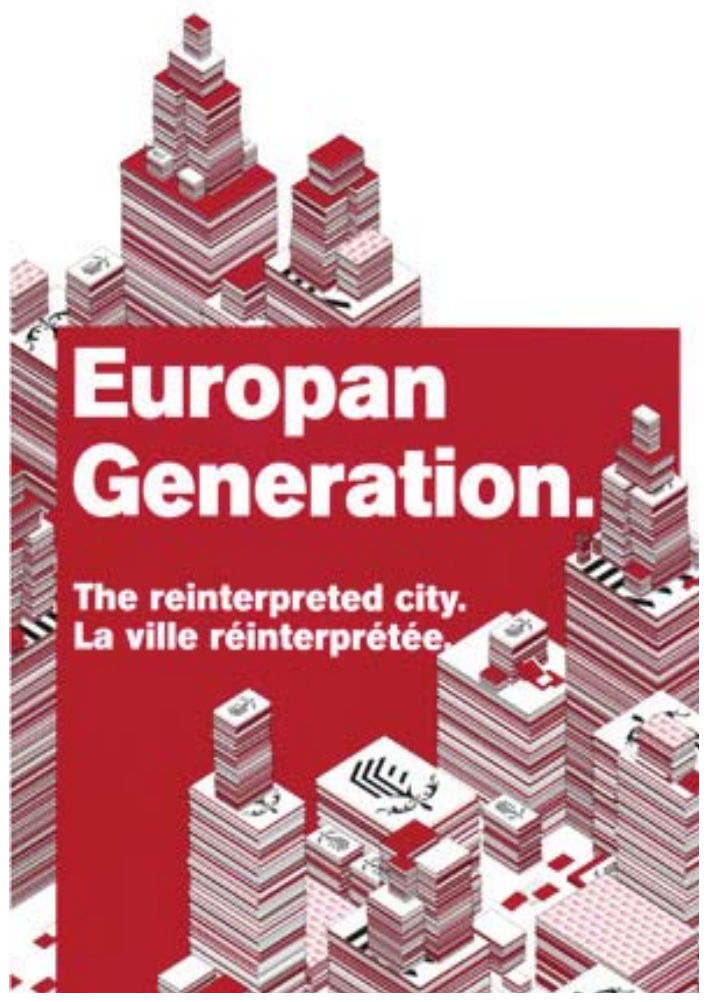

Ref.1.10. AA.VV. Europan generation, the reinterpreted city. Ed. Cite de I'Architecture. Paris. 2007. 
Una vez delimitado el análisis, una veintena de edificios de vivienda social construidos, ha sido necesario establecer un orden de narración de los mismos, pues muchos de estos datos se encontraban dispersos y esto podría dar lugar a confusión.

El orden cronológico de cada convocatoria parecía el modo más eficaz de sistematizar la información pues se pretendía obtener conclusiones acerca de la evolución proyectual (desde que se inicia en el concurso hasta que se construye). Además con este orden se ha podido situar cada edificio en el contexto arquitectónico y sociopolítico del país. Y así se ha realizado.

Una vez ordenados los datos, se ha procedido a aplicar el método comparativo ${ }^{6}$ en los edificios de viviendas construidos. Se han comparado los edificios de viviendas construidos dentro de una misma edición (es decir, de manera sincrónica) y, posteriormente a este análisis, se ha hecho una comparación diacrónica para poder obtener su evolución en el tiempo.

El último capítulo ha tratado de sintetizar algunas aportaciones de Europan a la vivienda mediante las ideas innovadoras de los equipos de jóvenes arquitectos galardonados, la tarea de comunicación con la Administración Pública y los edificios residenciales realizados. En este último apartado se ha podido contrastar la evolución que ha habido entre los planteamientos teóricos y prácticos, línea de investigación del Departamento de Proyectos Arquitectónicos en el que se enmarca la tesis.

Por último, se han obtenido unas conclusiones del trabajo desarrollado en la tesis que tratan de responder a los objetivos inicialmente planteados.

\footnotetext{
${ }^{6}$ Este método se puede realizar de muchas maneras, según los parámetros que se elijan. “(...) Los animales se dividen en (a) pertenecientes al Emperador, (b) embalsamados, (c) amaestrados, (d) lechones, (e) sirenas, (f) fabulosos, (g) perros sueltos, (h) incluidos en esta clasificación, (i) que se agitan como locos, (j) innumerables, (k) dibujados con un pincel finísimo de pelo de camello, (l) etcétera, (m) que acaban de romper el jarrón, (n) que de lejos parecen moscas. Esta presunta clasificación nos choca y sorprende porque viola completamente las condiciones formales de adecuación que esperamos satisfaga. En efecto, aunque el ámbito de objetos a clasificar parece ser el de los animales, algunos de los conceptos no se refieren a animales (como los dibujados con un pincel o las sirenas), otros no se sabe a qué se refieren (etcétera), los mismos animales caen bajo varios de estos conceptos (pertenecientes al Emperador, amaestrados), hay animales que no caen bajo ninguno de esos conceptos, etc". BORGES, Jorge Luis, "El idioma analítico de John Wilkins",en Obras Completas, Ed. Emecé, Barcelona, 1989.p.123.
} 
VIVIENDAS EUROPAN (1988-2008) I Una aproximación a los modos de vida en el cambio de siglo en España 1. INTRODUCCIÓN

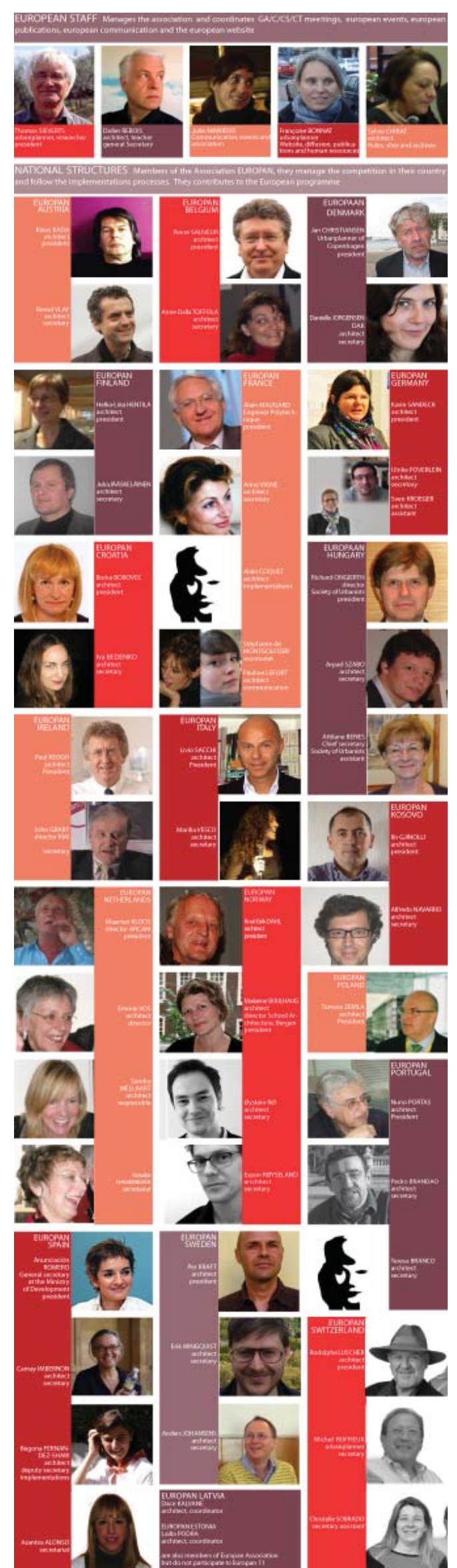

Ref.1.11. Comités Nacionales.

[On line] <http://www.europan-europe.com> (Consulta 2 de diciembre de 2011) 


\subsection{Fuentes consultadas}

\subsubsection{Comité Nacional en España}

Una de las principales fuentes de información ha sido el Comité Nacional de Europan ${ }^{7}$ que se sitúa en las dependencias del Consejo Superior de Arquitectos de España. En este Comité trabajan en la actualidad dos personas de forma permamente: la Secretaria General (Carmen Imbernón) y la Secretaria Adjunta (Begoña Fernández Shaw) ${ }^{8}$.

Tras realizar varias visitas a la Sede del Comité Nacional y revisar diversas publicaciones, se estableció una relación directa con el Comité que ha sido de gran ayuda para toda la tarea de documentación de los edificios de vivienda construidos.

Se ha realizado una entrevista que se considera como material de interés para conocer el funcionamiento y la contribución de Europan en España9.

\subsubsection{Comité de expertos}

Vivienda y sociedad ${ }^{10}$ van unidas de la mano, y es un factor que se debe tener en cuenta para poder establecer un correcto diagnóstico de los problemas actuales. Pero recopilar todos los datos que nos aportan las ciudades no es tarea fácil. Por eso, en Europan se reúne, previamente a cada edición, un comité científico de expertos y establece cuales son los problemas inmersos en las localidades, no en abstracto, sino los que, tras un análisis concienzudo, piensan que pueden ser importantes para su desarrollo.Se ha contactado con algunos miembros de este comité.

Una de las funciones del comité de expertos es la de realizar una radiografía

\footnotetext{
${ }^{7}$ Los datos de contacto son www.europan-esp.es, europan.esp@arquinex.es situado en el Paseo de la Castellana 12, 28046, Madrid, teléfonos: (+34) 915757401 o también puede ser (+34) 9143522 00, fax. (+34) 915757508

${ }^{8}$ En ocasiones también ha colaborado un administrativo.

${ }^{9}$ La entrevista puede consultarse de forma íntegra entre los documentros que se han recopilado en el ANEXO 4

${ }^{10}$ Así lo expresaba Kahn cuando narraba la historia de un poeta persa: "Había una princesa que paseaba por el jardín en primavera y, naturalmente, hacía un día estupendo. Después de atravesar el jardín observando todas las cosas, llegó al umbral de la casa y allí se detuvo en atónita admiración, inmóvil en el umbral miraba adentro. Y su doncella se le acercó exclamando: "Señora, señora. Mira afuera y verás qué maravilla ha creado Dios". Y la princesa respondió: "Sí, sí, pero mira adentro y verás a Dios". Dicho de otro modo, lo que el hombre ha creado es la verdadera manifestación de Dios". NORBERGSCHULZ,Christian. Kahn: Idea e imagen. Ed. Xarait. Madrid. 1990. p. 105.
} 
VIVIENDAS EUROPAN (1988-2008) I Una aproximación a los modos de vida en el cambio de siglo en España 1. INTRODUCCIÓN

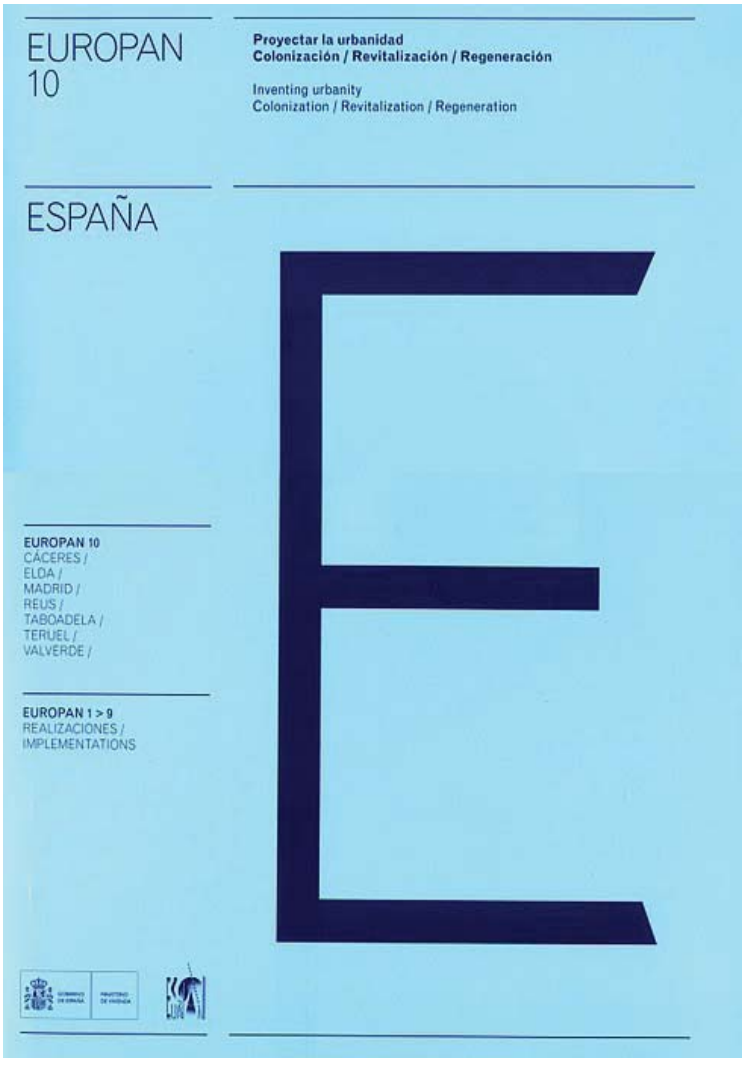

Ref.1.12. AA.VV. EUROPAN 10 España. Proyectar la urbanidad. Ed. Ministerio de la vivienda. Madrid. 2010.

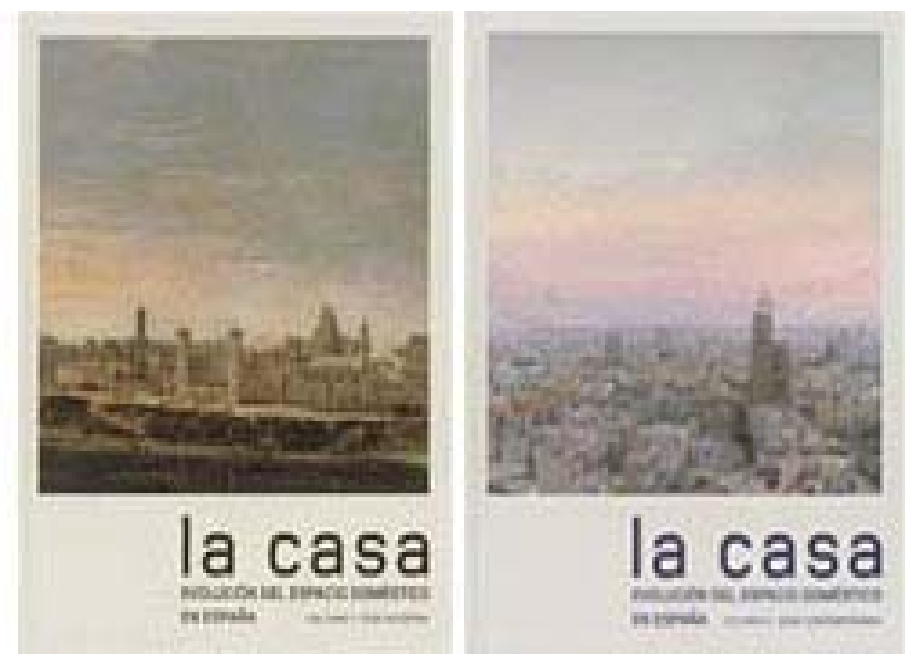

Ref.1.13. AA.VV. La casa. Evolución del espacio doméstico en España. 2 vol. Ed. El Viso. Madrid. 2006. 
de la sociedad lo más aproximada posible a la realidad y lo hace mediante los planteamientos de los enunciados que propone en cada una de las convocatorias (pueden consultarse en el ANEXO 2).

\subsubsection{Equipos galardonados y edificios de viviendas Europan}

Se ha establecido una relación directa con los equipos de arquitectura autores de los edificios de viviendas construidos, gracias a los cuales se ha podido realizar la investigación. Esta colaboración y disponibilidad ha sido de gran ayuda porque la inmensa mayoría del material de investigación se encuentra disperso y sin publicar.

También se ha visitado los edificios de viviendas construidos. La mayor parte de ellos se situan en Asturias y en Madrid. El resto, quedan dispersos por el territorio español.

\subsubsection{Publicaciones}

La bibliografía consultada se ha obtenido en gran medida de los fondos de la Biblioteca General de la Universidad Politécnica de Valencia y del Colegio Territorial de Arquitectos de Valencia. Entre esta bibliografía destacan las publicaciones específicas de los concursos Europan, que todo europanero debe tener.

Sobre la documentación acerca del contenido teórico de la vivienda ha sido de gran ayuda los dos tomos de la publicación del manual de La casa. Evolución del espacio doméstico en España ${ }^{11}$, pues son dos volúmenes que analizan la evolución de la vivienda en los siglos XIX y XX, previos al que analiza la tesis.

La documentación de esta publicación ha supuesto tres años de trabajo por parte de un equipo interdisciplinar de Madrid en la que la imagen de la casa urbana ha llegado a través de documentos diversos: tratados de arquitectura, libros técnicos de construcción, memoriales, crónicas de sociedad, relatos literarios, inventarios de bienes, tasaciones inmobiliarias, licencias de obras, ordenanzas municipales, libros de higiene y medicina, recetarios de cocina... La suma de estos relatos fragmentarios permite recomponer la imagen de la casa urbana en España y su progreso desde el siglo XVI hasta hoy, con ayuda de una iconografía también variada en la que se entremezclan dibujos técnicos o proyectos (plantas, alzados y secciones), vistas de ciudad, ilustraciones gráficas, anuncios o reclamos publicitarios, retratos, pinturas, etc.

En esta publicación se percibe la vivienda desde un marco más amplio que el espacial ${ }^{12}$. Además, en el mismo texto se introduce el concepto de vivienda como

\footnotetext{
${ }^{11}$ AA.VV. La casa. Evolución del espacio doméstico en España. 2 vol. Ed. El Viso. Madrid. 2006.

${ }^{12}$ Por ejemplo se afirma que "en muchas ocasiones se ha reflexionado sobre la forma de
} 
VIVIENDAS EUROPAN (1988-2008) I Una aproximación a los modos de vida en el cambio de siglo en España

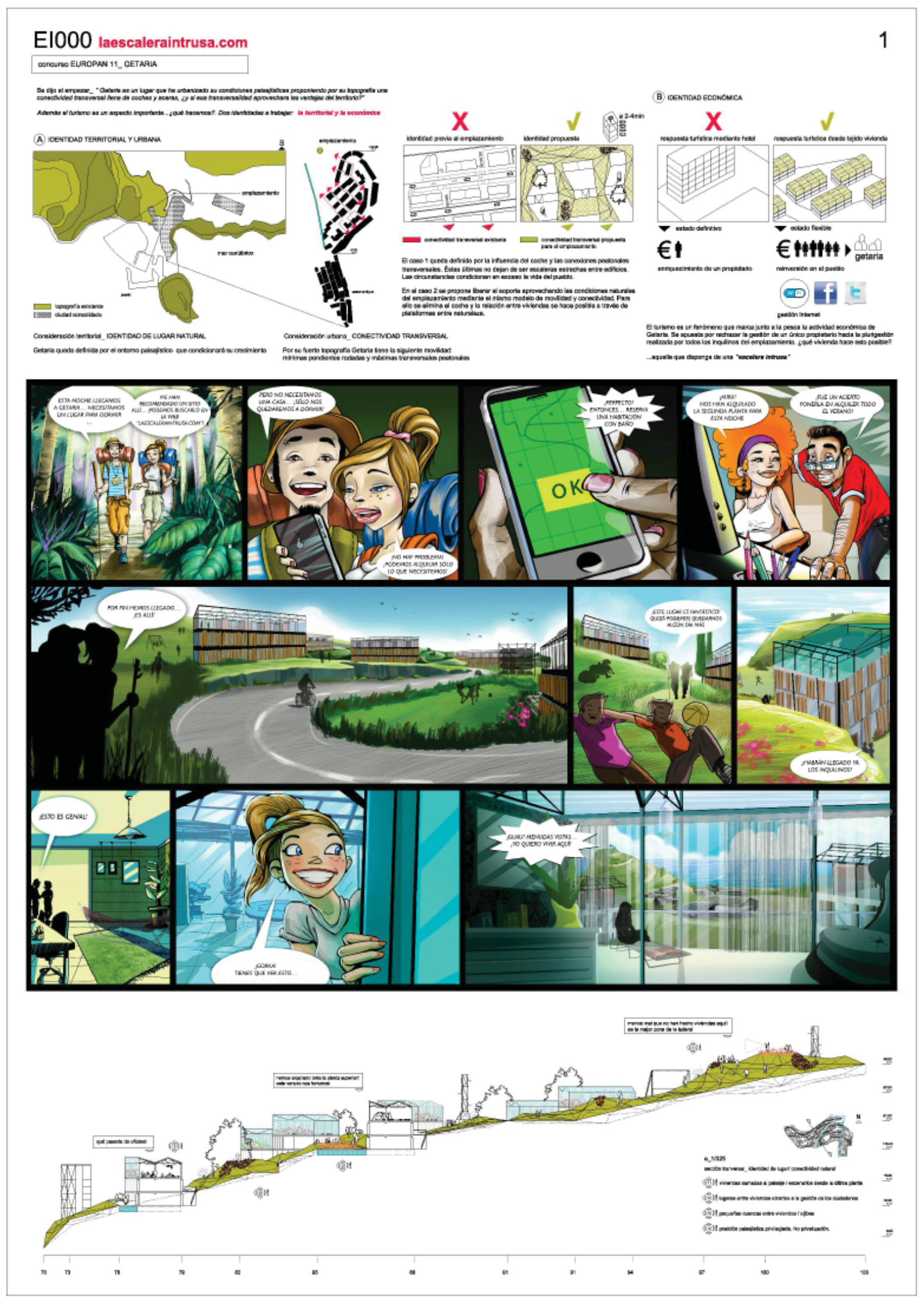

Ref.1.14. Premiado Europan 11 en Getaria. Jose Lopez, Jose Manuel Calvo, Guillermo Gosalvo. 
objeto experimental, como lugar "donde se aplican los más modernos principios para lograr el confort y practicar la sociabilidad propia del ser urbano, así como también para experimentar los inventos más actuales de la tecnología doméstica, aplicados a mejorar las condiciones de habitabilidad de la casa mediante la incorporación paulatina de instalaciones para la conducción y desagüe de aguas limpias y sucias, la evacuación de humos, la transformación y conservación de alimentos, el control de la temperatura, la iluminación artificial, la ventilación natural... todo aquello que contribuye a potenciar la comodidad y a facilitar la vida del individuo, mejorando asimismo su salud corporal y su estado de ánimo. Al ritmo de estas novedades, la casa experimenta también los cambios dictados por las modas, la ideología y la cultura, reflejando en su distribución, mobiliario y adorno no sólo la capacidad adquisitiva del propietario y su estatus social sino también los cambiantes criterios de cada época en cuanto a intimidad, relaciones familiares y sociales, moralidad, integración de la mujer y otros que van aflorando al abordar el estudio de los modos de habitar y la consiguiente evolución del espacio doméstico"13.

\subsection{Estructura y contenido de la tesis}

La tesis se desarrolla en tres bloques:

\section{Bloque 1: Prolegómenos (Capítulos 1 y 2 )}

El capítulo primero se ha dedicado a los aspectos generales de la investigación y trata de responder al por qué, qué, cuándo y cómo se ha desarrollado la tesis.

Previamente a abordar el tema de investigación, se ha considerado de interés realizar un capitulo de antecedentes (capítulo segundo) para situar el contexto histórico, arquitectónico y originario de los concursos Europan.

la casa, analizando su evolución a lo largo de la historia, y otras muchas veces se han formulado modelos que querían ser perfectos desde el punto de vista de la tipología. En España, el término "casa» va más allá de la circunscripción espacial y arquitectónica, pues alude tanto al edificio como al espacio doméstico que alberga y en el que se mora, incluyendo un marco privado emocional y psicológico. Equivale a lo que en el ámbito anglosajón se denomina "home" y en español se designa como hogar, ambas palabras con connotaciones alusivas a la confortabilidad, la armonía y el desarrollo placentero de la existencia. Con independencia de que la casa sea grande o pequeña, unifamiliar o de vecindad, en todas puede alcanzarse ese grado de plenitud gracias unos denominadores comunes que permiten estudiar su evolución de forma conjunta y en relación con los modos de habitar. Estos modos, por su parte, se han transformado al ritmo en que evolucionaba la sociedad y lo permitían los adelantos tecnológicos aplicados al perfeccionamiento y facilidad de la vida doméstica y de su espacio". Ibídem p.12.

${ }^{13}$ Ibídem, p.11. 
VIVIENDAS EUROPAN (1988-2008) I Una aproximación a los modos de vida en el cambio de siglo en España 1. INTRODUCCIÓN

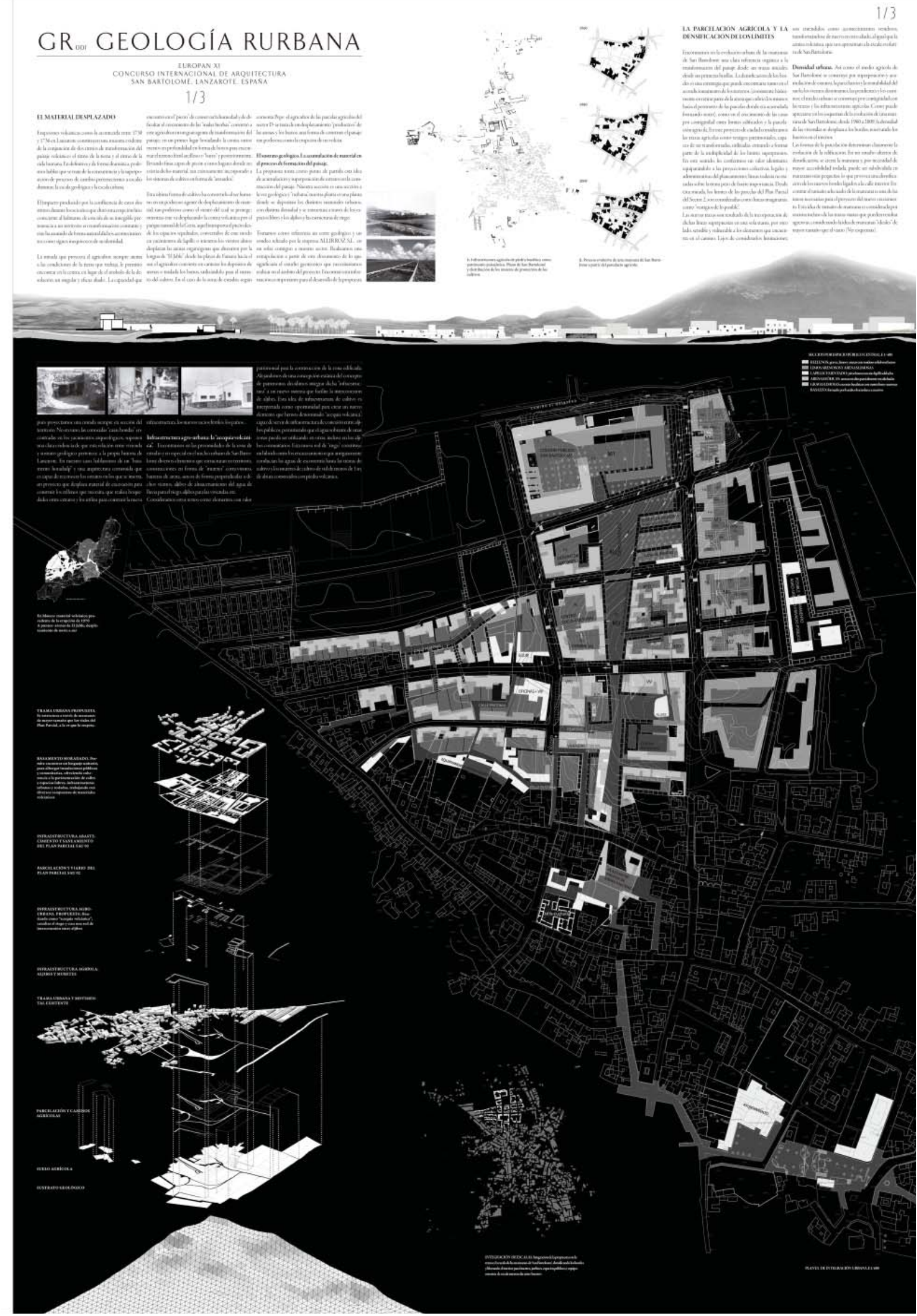

Ref.1.15. Premiado Europan 11 en San Bartolomé. F Javier Castellano, Tomas G, Luis Miguel, Paloma Baquero, Juan Antonio Serrano 
Bloque 2: Cuerpo central (Capítulos 3, 4, 5 y Conclusiones)

El capítulo tercero desarrolla el contenido teórico de los concursos Europan. Por un lado se identifican los temas de investigación que se se plantean en cada enunciado. Por otro, se elabora una tabla-resumen de éstos agrupándolos en transitorios y permanentes.

El capítulo cuarto analiza las realizaciones de Europan. El primer apartado se centra sobre todo en los edificios residenciales construidos en cada convocatoria. No se ha elaborado un análisis exhaustivo, sino que se ha tratado de desarrollar la evolución que ha habido en el proyecto desde la ideación hasta la construcción. La información obtenida se ha sintetizado en una ficha-resumen redibujada expresamente para la tesis. En el segundo apartado del capitulo se nombran, de modo informativo, otros edificios construidos distintos a uso residencial. Por último, en un tercer apartado del capítulo se enumeran los proyectos que se encuentran en fase de gestión en este momento.

El capítulo quinto realiza, con la información recopilada en los anteriores, una valoración sobre algunas aportaciones de Europan a la vivienda. En un primer apartado se comenta la contribución de Europan a las ideas innovadoras de los equipos de jóvenes arquitectos. En un segundo apartado, se desarrollan algunos aspectos del trabajo de Europan con la Administración Pública. Por último, en el tercer apartado y más extenso, se desarrollan en cada convocatoria algunas aportaciones que ha realizado a través de los edificios residenciales. En este apartado se ofrece una crítica acerca de si se han alcanzado en las realizaciones los objetivos teóricos.

El último capítulo de conclusiones responde a la pregunta de la tesis hacia dónde se dirige la vivienda del siglo XXI bajo el prisma de los concursos Europan.

\section{Bloque 3: Información complementaria (Bibliografía y Anexos)}

En el capítulo de la bibliografía se ha recopilado en primer lugar, la de carácter general, en segundo lugar la que hace referencia a la vivienda y, por último, la que corresponde al tema de Europan y los concursos.

El anexo trata de recopilar un material que se encuentra disperso y se considera interesante que esté unificado para facilitar la tarea del investigador. En el anexo 1 se recopila la Carta Europan: documento fundacional que contiene los datos principales del concurso. El anexo 2 lo constituyen los enunciados de las convocatorias. El anexo 3 está compuesto por las actas de los Jurados de cada edición. Por último, el anexo 4 es un trabajo inédito de elaboración propia y consiste en una entrevista que se realizó al Comité Nacional de Europan en España. 

2. ANTECEDENTES 


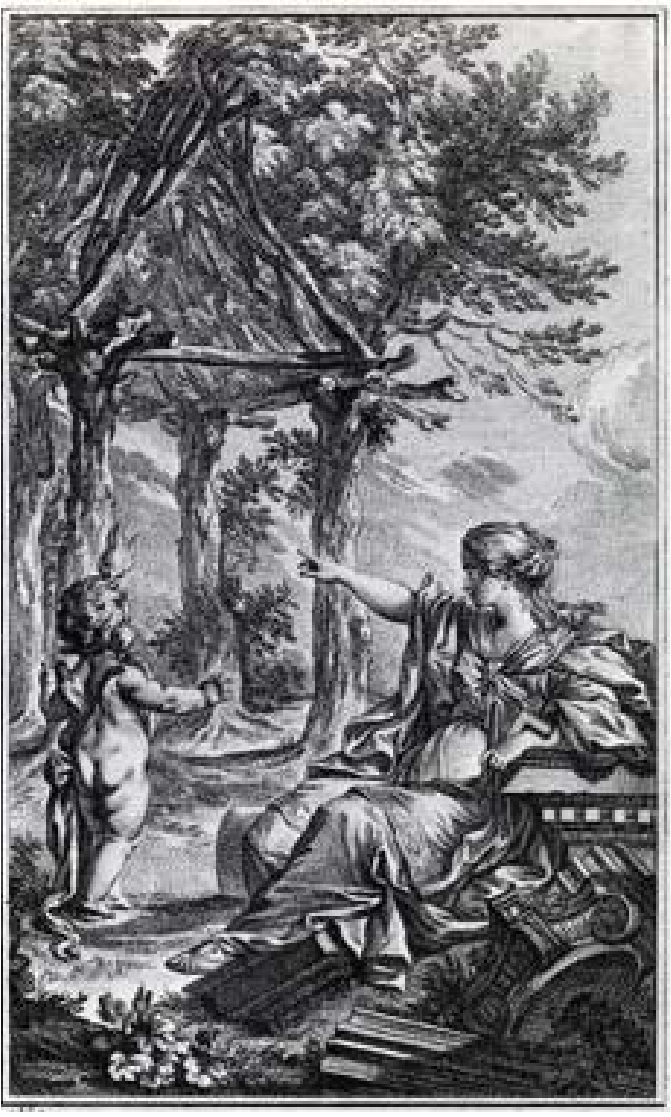

Ref.2.1. Cabaña primitiva de Laugier

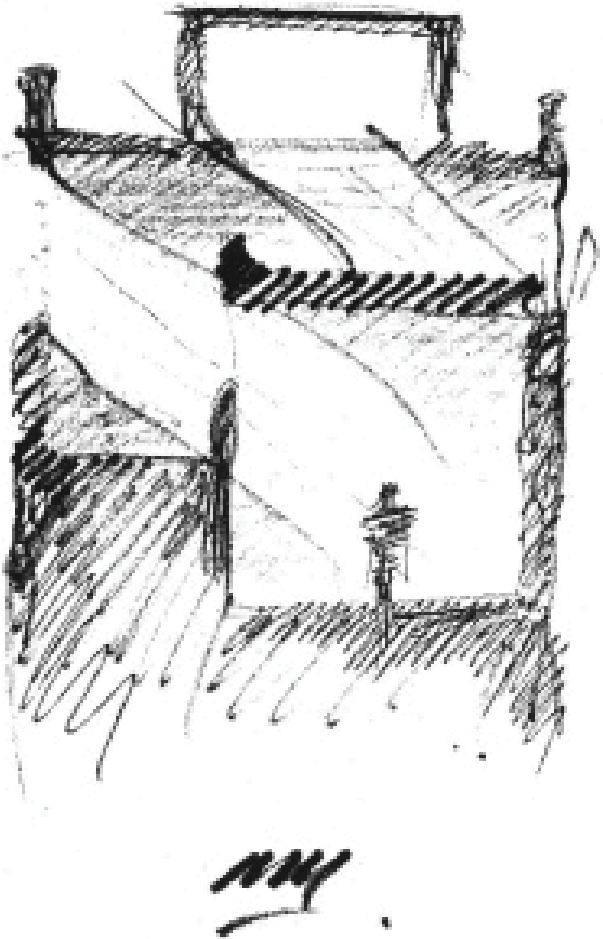

manch 72. 87

Ref.2.2. Boceto de Alberto Campo Baeza

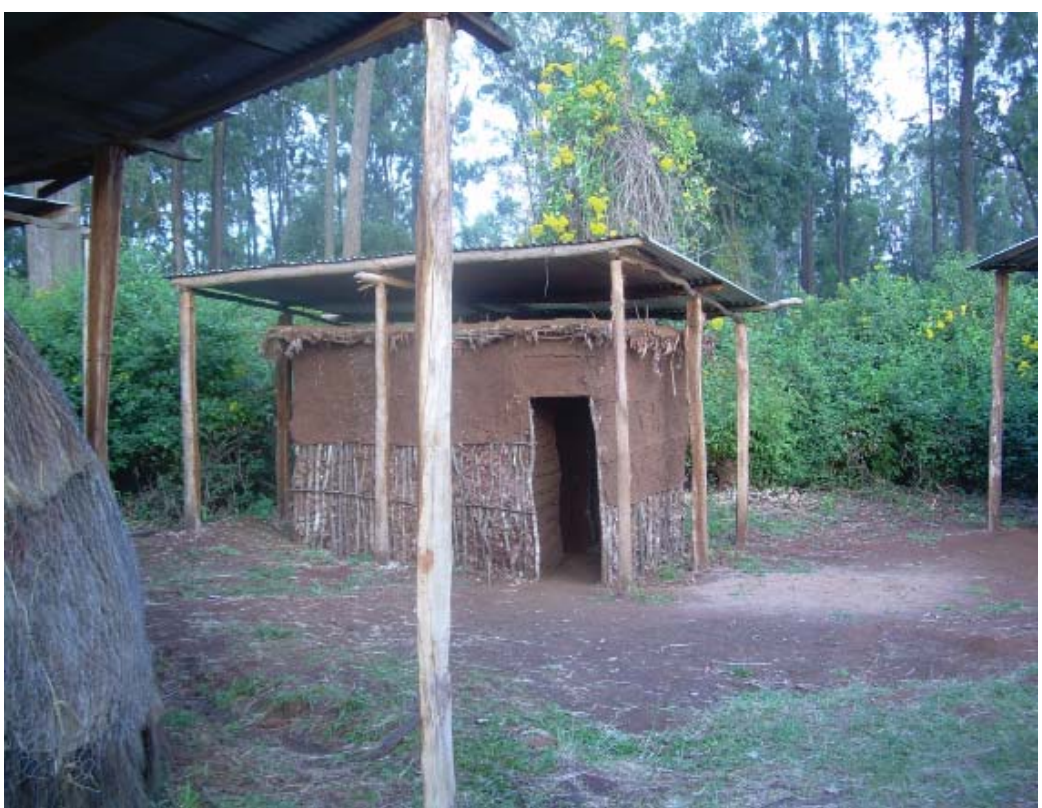

Ref.2.3.Vivienda tradicional de Kenia (Bomas de África) 


\subsection{Consideraciones preliminares sobre la vivienda}

\subsubsection{Arquitectura doméstica}

La vivienda es quizás el primer acto de la arquitectura. Guarecerse, buscar refugio o construcción es, para el hombre, una necesidad de primer orden ${ }^{1}$. La arquitectura doméstica es fruto de la sabiduría popular, que se basa en un anonimato y en el carácter vernáculo existente desde hace milenios.

Alberto Campo afirma en un conocido texto que primero fue la cueva, después la cabaña y, por último, “(...) al final llegó la casa. El guarecerse y el defenderse se transformaron en el habitar. $Y$ el hombre, dominado ya el espacio, conformado con los correspondientes planos, concibió la posibilidad de controlarlo. De proporcionarlo. Y vio que con la luz podía tensarlo. Y así, dominando la gravedad y la luz, de manera ya más consciente, perfeccionó la Arquitectura. Y la Arquitectura fue así una manifestación más, quizá la más humana, de la cultura. De esa cultura que va decantando el pensamiento del hombre a lo largo de los tiempos.

Si el hombre como animal se refugió en la cueva y como racional construyó la cabaña, el hombre culto, creador, concibió la casa como morada para habitarla. Y en eso estamos"."

En el siglo XX, las transformaciones que se presentan en la historia (como la guerra, el paso de la vida rural a la ciudad, la industrialización, etc.) cambian las circunstancias de las personas. En occidente (Europa y América) aparece por vez primera la conciencia de una arquitectura acorde al espíritu de los tiempos y los modos de vida ${ }^{3}$.

1 “¿Cuándo empezó la arquitectura?(...). La arquitectura es algo más que caparazones protectores. Al intentar porducir lugares para la acción ritual, debe arreglárselas para definir lo ilimitado, es decir, para limitar el espacio sin encerrarlo necesariamente en tres dimensiones. Lo consigue de dos maneras: mediante la circunscripción y mediante la enfatización(...). Una arquitectura de cobijo". KOSTOF, Spiro. Historia de la arquitectura. Ed. Alianza Forma. Madrid. 2003. p.43.

${ }^{2}$ CAMPO BAEZA, Alberto. La idea construida. Ed. COAM. Madrid.1996. p. 102.

3"De ahí, por tanto, que digo: ¡Haced una bienvenida de cada puerta y un rostro de cada ventana! Haced de cada lugar el terreno (el territorio del hombre es un terreno de en medio) que la arquitectura se propone articular. La intención, de nuevo, es desenmascarar el falso significado, y llenar de contenido al tamaño con todo lo que conlleva la talla oportuna.

(...) Ahora, el objeto de las imágenes recíprocas contenidas en la declaración "haced un puñado de sitios de cada casa y de toda ciudad, haced de cada casa una pequeña ciudad y de cada ciudad una gran casa" es desenmascarar la falsedad que se adhiere. Me parece que pasado, presente y futuro deben estar, como un continuo, activos en el interior de la mente. Si no es así, los artefactos que hagamos carecerán de profundidad temporal, de capacidad de asociación. Mi preocupación por la validez última de los divergentes $y$, a menudo, aparentemente incompatible, los conceptos de espacio y las soluciones 
VIVIENDAS EUROPAN (1988-2008) | Una aproximación a los modos de vida en el cambio de siglo en España

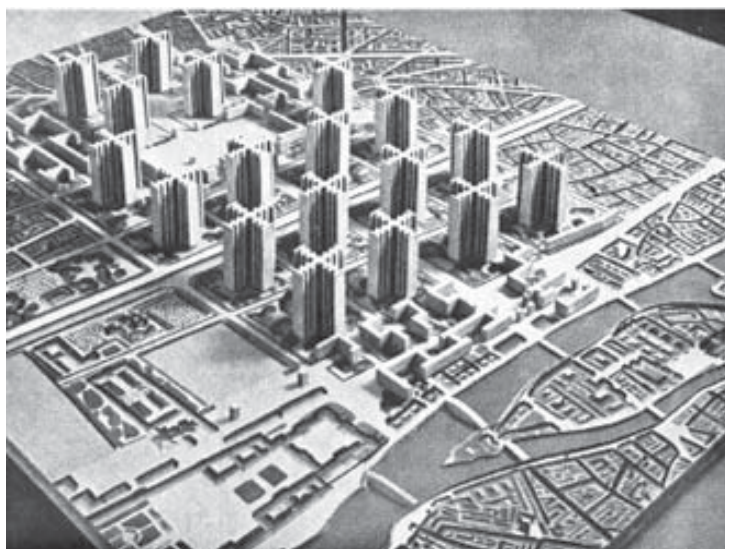

Ref.2.4. La ciudad del futuro de Le Corbusier, 1933

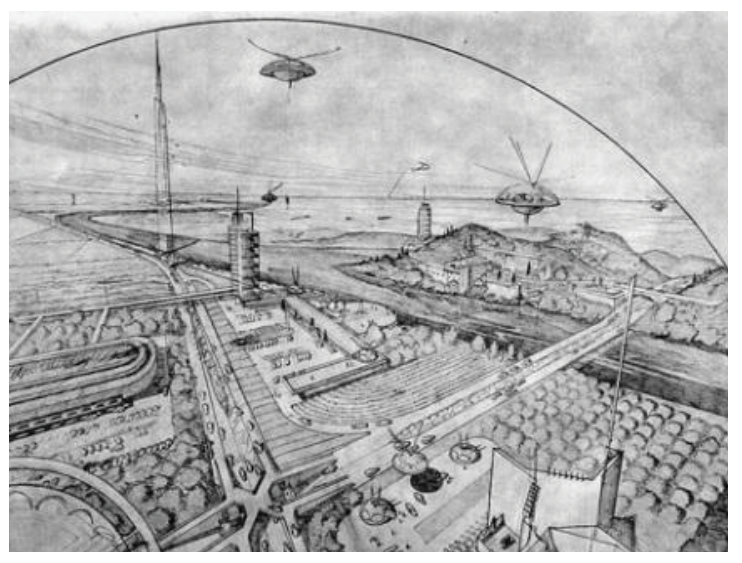

Ref.2.5. Broadacre City , Frank LLoyd Wright, 1934

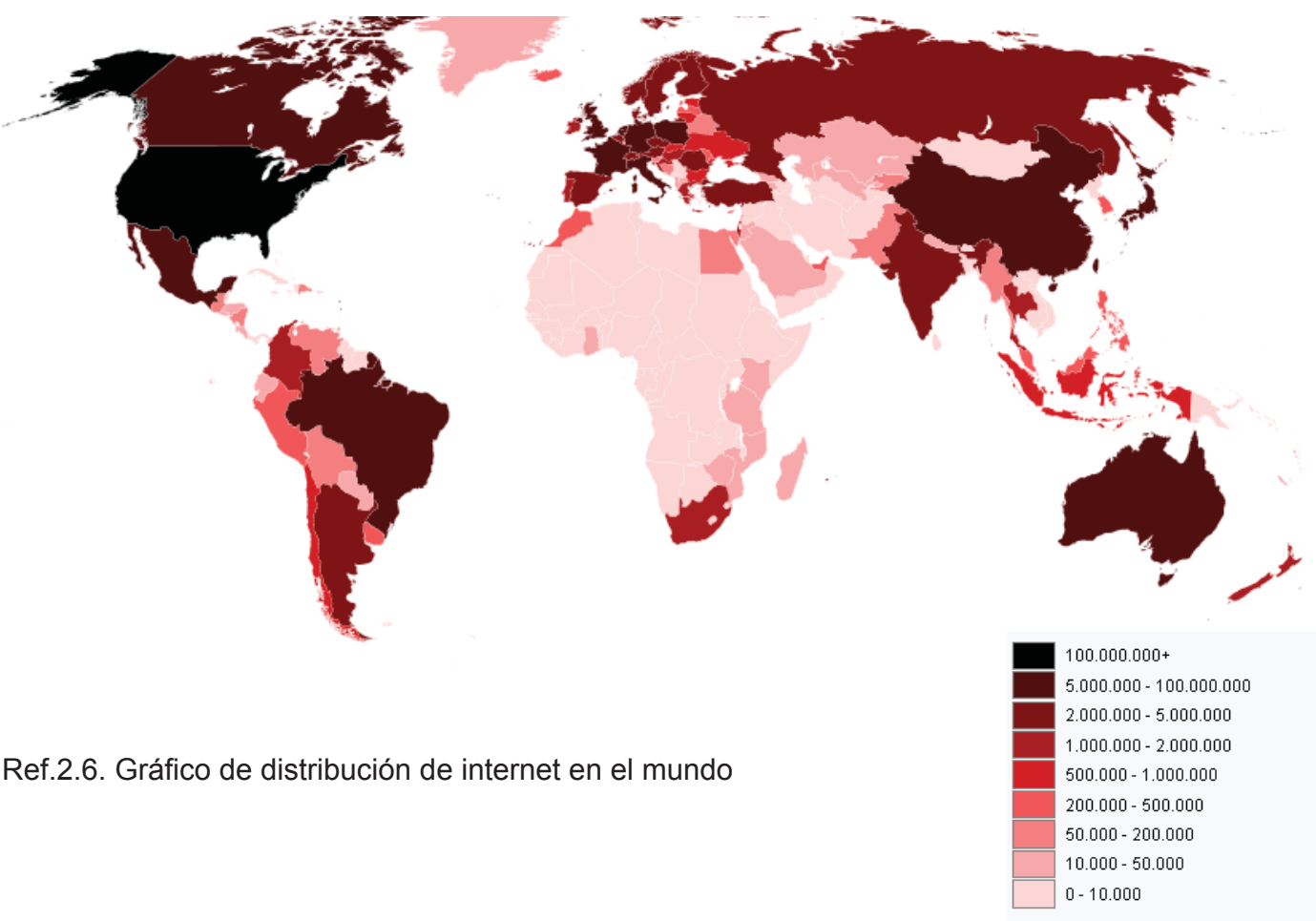


La tesis se centra en un período decisivo de la historia de la humanidad: el cambio de siglo, en el que se han producido grandes transformaciones sociales fundamentalmente debido a la revolución digital. El acceso a la información y la multipresencia permiten el ocio en casa, el homecinema, el homework, el teletrabajo,etc. Lo doméstico ha sufrido una revolución.

\subsubsection{Vivienda protegida}

Mucho es lo que se ha escrito sobre vivienda y no se pretende realizar una recopilación de la historia de ésta desde los orígenes hasta la actualidad.

La tesis centra su atención sobre jóvenes propuestas de vivienda urbana colectiva protegida.

Como se ha comentado en la introducción (al hacer referencia a las fuentes consultadas) se han tomado como referencia para la tesis dos volúmenes de un libro titulado La casa. Evolución del espacio doméstico en España ${ }^{4}$ que centra su atención en la vivienda en España durante los siglos XIX y XX. En éste se puede observar el cambio de concepto de vivienda a lo largo de la historia. En él se encuentran varios ejemplos. Por citar uno de un concepto idílico y que no se adecúa a los tiempos actuales: "la vivienda que se está gestando en el siglo XIX es una vivienda activa, dinámica, que nos presta un servicio. Se va transformando en una máquina que sirve al hombre pues le ilumina, le calienta, le limpia, le alimenta, le distrae. En la casa encuentran cariñoso albergue los ancianos padres para descansar, en sus postreros años, de las fatigas de la vida, rodeados de los seres queridos de su corazón y de los dulces recuerdos del pasado. La casa es estuche de la mujer, alma de la familia y reina del hogar, que gobierna a sus súbditos por el

accidentales, o circunstanciales, encontradas en épocas pasadas en diferentes lugares del mundo, debe ser entendida bajo la luz de lo anterior. Ha llegado la hora de reconciliarlos, de volver a unir el significado, humanamente esencial, dividido entre ellos. El hombre, después de todo, ha estado acomodándose físicamente en este mundo durante miles de años. Su genio natural ni ha aumentado ni disminuido durante ese tiempo. Es obvio que el alcance completo de esta enorme experiencia medioambiental puede ser contenida en el presente a no ser que miremos, como a través de un telescopio, el pasado, es decir, la totalidad del esfuerzo humano dentro de él. Esto no es una indulgencia histórica en sentido limitado, ni una cuestión de viajar hacia atrás, simplemente ser consciente de lo que existe en el presente, de lo que ha viajado hacia él; la proyección del pasado hacia el futuro vía el presente creativo. (...) Esta es, en mi opinión, la única medicina contra un sentimental historicismo, modernismo y utopismo. También contra un estrecho racionalismo, funcionalismo, y regionalismo. Una medicina contra todas las plagas combinadas". VAN EYCK, Aldo. "El interior del tiempo y otros escritos". en Revista Circo. 1996.37. [On line] $<$ http://www.mansilla-tunon.com/circo/epoca2/pdf/1996_037.pdf> (Consulta: diciembre 2009).

${ }^{4}$ AA.VV. La casa. Evolución del espacio doméstico en España. 2 vol. Ed. El Viso. Madrid. 2006. 


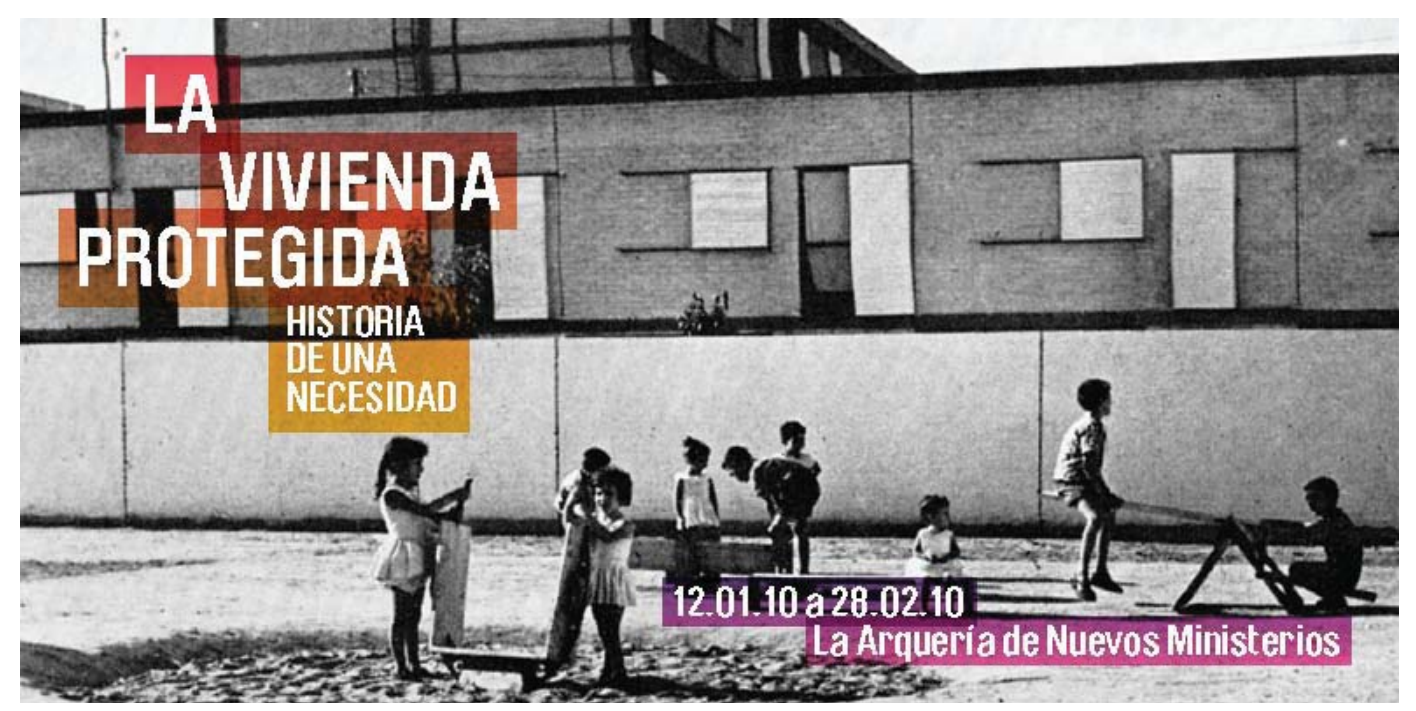

Ref.2.7. Cartel que anuncia la exposición de la vivienda protegida

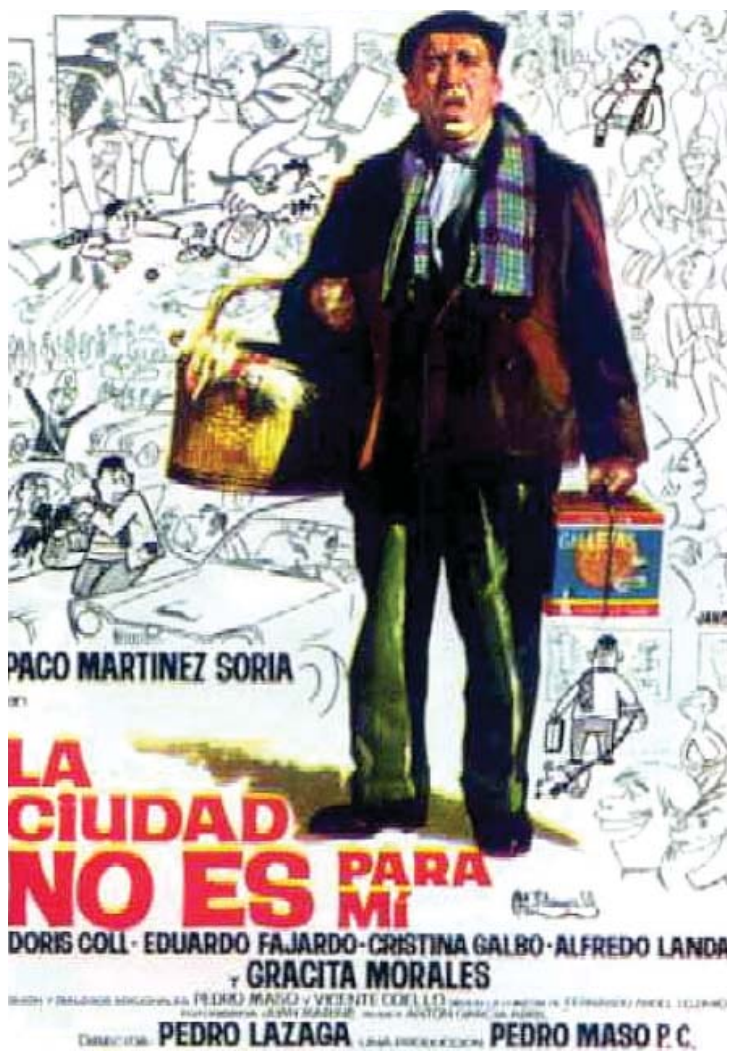

Ref.2.8. Comedia española que narra el cambio del campo a la ciudad 
amor. La casa es el santuario donde los hijos desarrollan su inteligencia, aprenden a balbucir el nombre de sus padres y a bendecir a Dios. La casa es el refugio a que el hombre se acoge para descansar del trabajo, donde aleja sus pesares y endulza sus amarguras. Allí, en torno del hogar, después de haber recibido el abrazo cariñoso de la compañera de su vida, rodeado de sus hijos, bajo la tierna mirada de sus padres, su corazón se ensancha abriéndose al amor de los suyos, la cabeza olvida los asuntos en que antes se debatiera, y todo su ser, con el reposo moral y material tan deseado, se apresta con nuevas fuerzas para proseguir la batalla de la vida ${ }^{5}$. Mucho ha cambiado desde entonces el ámbito de la vivienda.

En el año 2010 el Ministerio de Vivienda de España - aún todavía por entonces existente- y la Asociación de Promotores Públicos de vivienda y suelo organizaron una exposición de arquitectura denominada La vivienda protegida. Historia de una necesidad ${ }^{6}$ cuyo comisario fue Carlos Sambricio y en la que participó Ricardo Sánchez, uno de los galardonados cuyo proyecto pudo construirse en Europan 1 y que, posteriormente, ha formado parte del Jurado en Europan 5. Los contenidos de la exposición se dividían en cuatro salas.

La primera de ellas se denominaba los cuatro espacios y permitía conocer cómo era la evolución de los espacios de la cocina, el baño, el comedor y el dormitorio. La segunda sala estaba dedicada a la solución de un problema y recopilaba las propuestas que se habían ido dando a lo largo del último siglo de vivienda protegida. Las dos salas restantes se denominaban Diez ejemplos de excelencia y Rehabilitación urbana, asuntos tangenciales a esta investigación.

Se considera interesante profundizar en los contenidos de la segunda sala de aquella exposición. En ésta se agrupaban de manera esquemática los seis períodos en los que se ha divido la arquitectura de la vivienda social en España. A continuación se cita textualmente lo que se decía en el panel expositivo de la sala:

"El primer período corresponde a 1900-1926 y lo denomina una nueva forma de vida. Las leyes de casas baratas buscan dar solución a la falta de vivienda y también dinamizar la recesión económica tras la primera guerra mundial.

Es segundo período abarca de 1926 a 1939 y aparece la vivienda mínima. Tras la normalización de elementos la preocupación fue racionalizar los espacios y buscar su máximo aprovechamiento.

El tercer período es el de 1939 a 1949 y en él se afirma que se ha dado un paso

${ }^{5}$ REPULLÉS Y VARGAS. "La casa: habitación moderna desde el punto de vista artístico, Madrid", discurso en la RR.AA San Fernando, 24.V.1986. en AA.VV. La casa, evolución del espacio doméstico en España, tomo II, Ed. El Viso. Madrid. 2006. p.13.

${ }^{6}$ SAMBRICIO, Carlos y SANCHEZ LAMPREAVE, Ricardo. La vivienda protegida, historia de una necesidad. Ed. Ministerio de la vivienda, Madrid, 2010. 

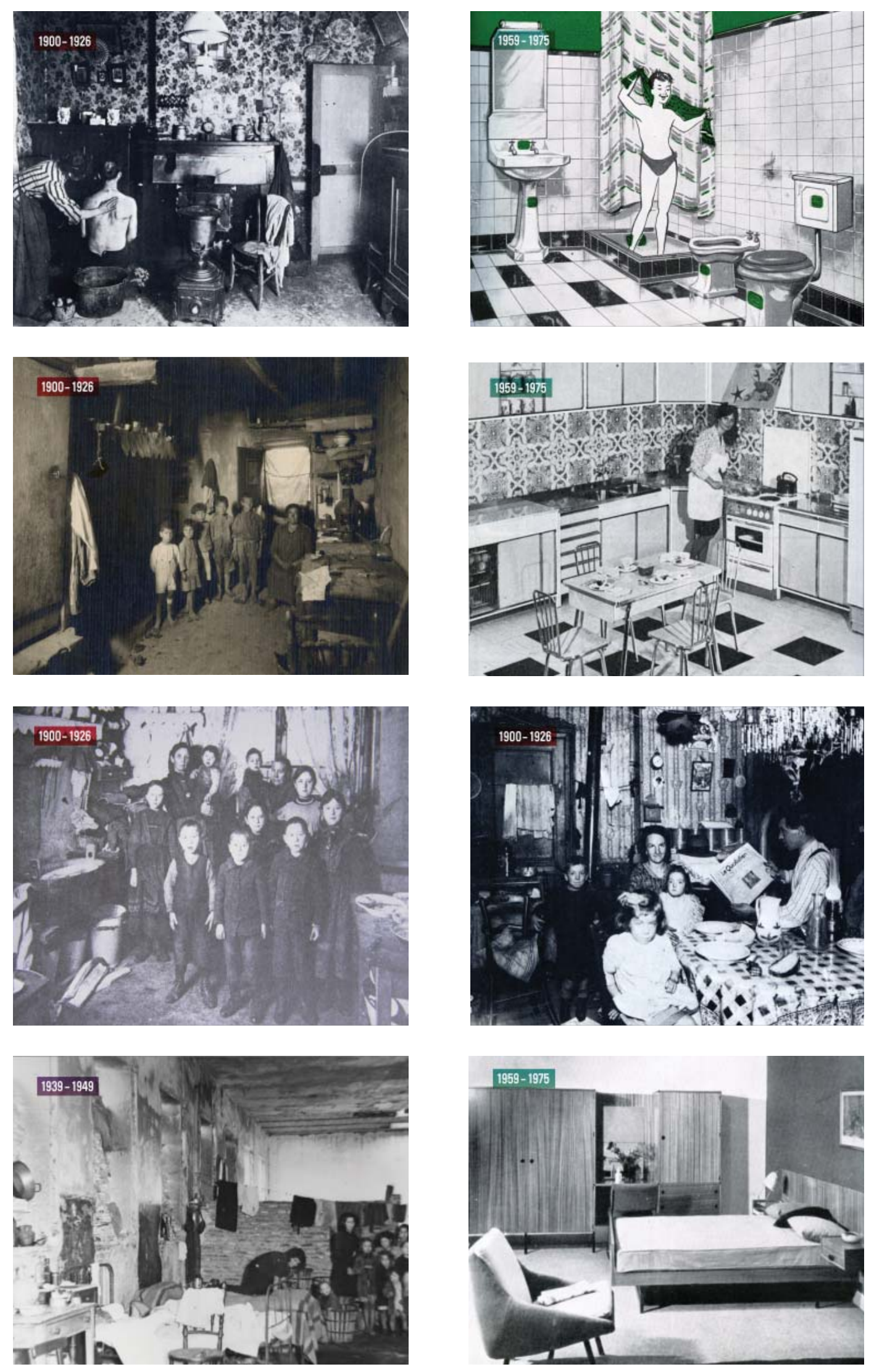

Ref.2.9. Imágenes de la exposición de "Vivienda protegida. Historia de una necesidad". Madrid 2010 
atrás. El rechazo a la cultura de la república supuso el alejamiento de formas de vida definidas en años anteriores.

El cuarto período es el de 1949 a 1959 y lo denomina como el gran momento de la vivienda. La masiva emigración por el fracaso de la política agraria hizo que se buscaran soluciones en las experiencias europeas desarrolladas tras 1945.

El quinto período es el de 1959 a 1975 en el que se observa un cambio de responsabilidad. El Gobierno, consciente de su incapacidad para resolver la demanda de vivienda protegida, cede al sector privado la responsabilidad de edificar este tipo de vivienda.

El sexto período es el de 1975 a 2010 y afirma que es en el que aparecen los nuevos comportamientos sociales. Los distintos gobiernos democráticos definen un nuevo tipo de vivienda, remodelando las que se encuentran en mal estado y sustituyendo las bolsas de pobreza por vivienda protegida".

Como se puede apreciar, la vivienda protegida en España ha sufrido muchas transformaciones. Actualmente se debe cambiar la política de vivienda social para que verdaderamente se adapte a las necesidades de las personas. Esto comportaría una revolución normativa en España y tal vez la pregunta que se debería formular es si es posible encontrar una normativa que se adapte a las necesidades actuales.

Alberto Campo lo expresa de modo muy gráfico cuando dice que "quemar las actuales normativas vigentes para proyectar viviendas protegidas sería una manera directa de hacer esta revolución. En vez de arquitectos neuróticos tratando de ponerle a las hermanastras de la Cenicienta el zapatito de cristal, labor imposible, tendríamos arquitectos liberados dispuestos a pensar y a crear con lógica. Socializar el suelo de una vez sería borrar de un plumazo, a los especuladores y a todos arquitectos uncidos a su carro, y hacer que la vivienda sólo valga lo que cuesta. Que el precio real es bastante menor de lo que impone este repugnante mercado actual ${ }^{7}$.

La vivienda protegida es uno de los temas de reflexión que debería ser prioritario en la política social, porque proyectar una vivienda es más que una simple construcción porque "La casa es nuestra segunda piel. Es el espacio donde habitamos y donde pasamos una buena parte de nuestra vida, el lugar donde nos guarecemos de las inclemencias del tiempo y nos cobijamos de los sinsabores cotidianos, confortados por fin de los rigores del trabajo y del ajetreo de cada jornada. En casa descansamos, comemos y dormimos, satisfaciendo así las necesidades más perentorias que nos imponen nuestra propia biología y nuestra

${ }^{7}$ CAMPO BAEZA,Alberto. La idea construida. Ed. Colegio Oficial de Arquitectos de Madrid. Madrid, 1996. p. 56. 


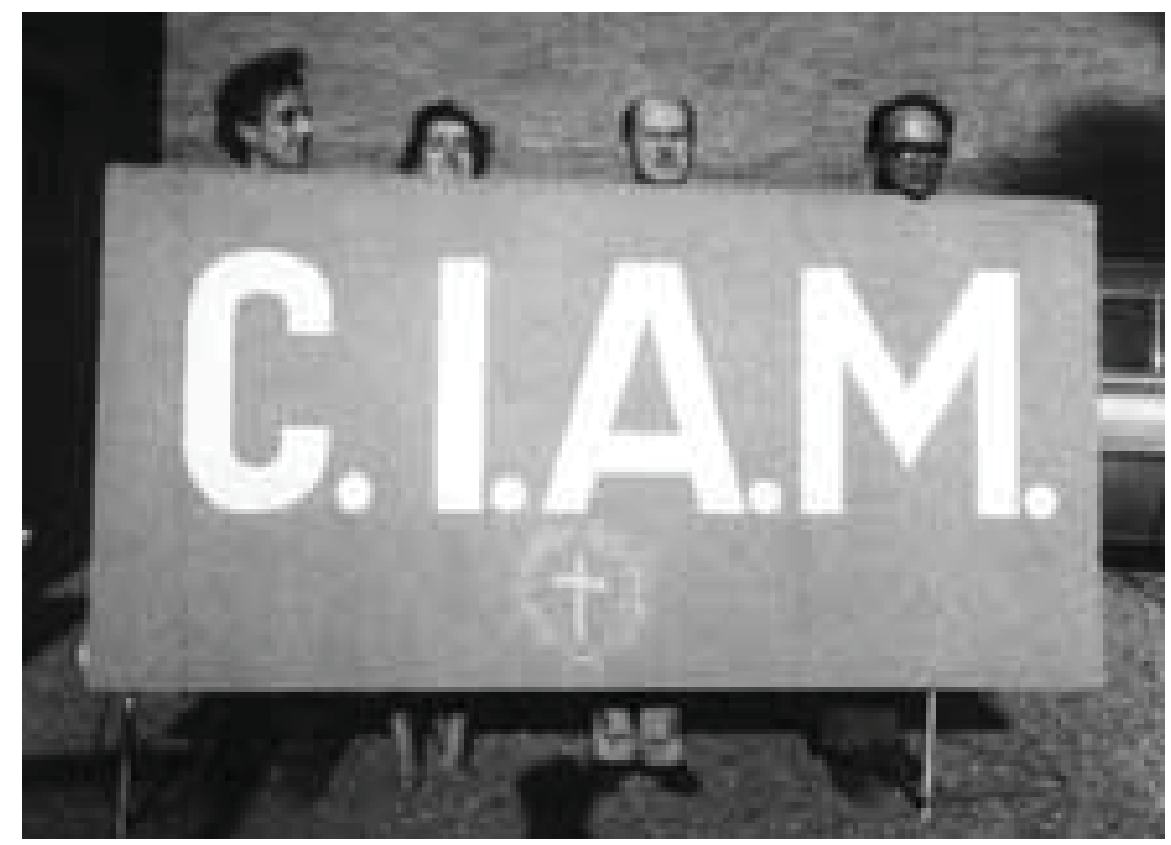

Ref.2.10. Defunción de los CIAM (1959)

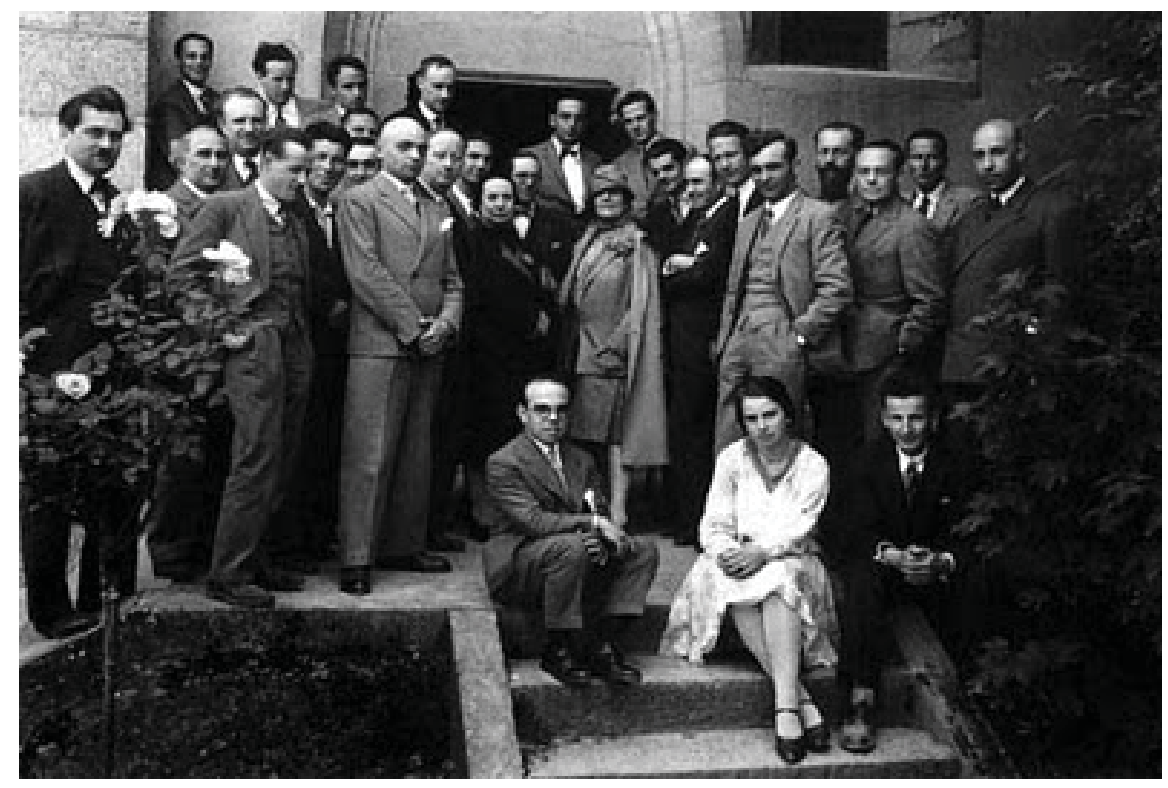

Ref.2.11. Componentes del CIAM. Destacaron Le Corbusier, Hans Meiier, Gerrit Rietveld, Siegrfried Giedion y Mart Stam 
mera condición física. Pero también, en casa nos aislamos y protegemos de las adversidades, refugiándonos y vivificando nuestro espíritu con el placer de las cosas íntimas y personales que nos nutren por dentro y satisfacen nuestra esencial necesidad de sosiego y armonía. No hay nada como nuestra casa, que se convierte asimismo en el espejo de nuestros gustos, ideas y aspiraciones; en ella recibimos a los amigos y celebramos fiestas familiares y reuniones sociales, atentos a que la imagen de la casa refleje nuestra propia imagen (...). Todos ponemos el alma en hacer de la casa el marco perfecto para el desarrollo de nuestra vida, en cuanto se refiere a comodidad y representatividad, personalizando nuestra morada más allá de los límites que imponen en la ciudad la avaricia del espacio y la regular identidad de las casas contiguas ${ }^{8 "}$.

Cuando se hable en la tesis de los edificios de viviendas construidos se entenderá en todo momento que se habla de vivienda social, de vivienda protegida. Éste es el ámbito de aplicación de la tesis.

Además de hablar sobre la vivienda protegida, también es necesario aludir a los CIAM debido a la repercusión importante que han tenido en el ámbito de las ciudades europeas. Se tratará de realizar un pequeño resumen que sintetice esta cuestión.

En 1928 tuvo lugar el primer CIAM, en el castillo de La Sarraz (Suiza), donde fue su fundación, por 24 arquitectos de diferentes países, entre los que se encontraban la dueña del castillo: Madame Mandrot, el importante historiador de arquitectura suiza Sigfried Giedion, que posteriormente fue el secretario general de los CIAM, y el considerado como uno de los referentes más claros e influyentes del Movimiento Moderno como fue Le Corbusier. Este primer Congreso obtuvo como resultado la Declaración de Sarraz, donde se demandaba la necesidad de que la arquitectura fuera separada de las Escuelas de Bellas Artes y estuviese más ligada al sistema económico general. Además apelaban a que los arquitectos tuviesen más influencia en la opinión pública en favor de la arquitectura.

CIAM, Congrès International d'Architecture Modern, era una organización constituida por arquitectos y urbanistas de todo el mundo durante el Movimiento Moderno desde su fundación en 1928 hasta su disolución en 1959.

La organización estaba compuesta por equipos que se reunían y trabajaban en común. Se organizaban Congresos donde se intercambiaban ideas y se elegía un tema para el siguiente Congreso. Estos Congresos y sus conclusiones influyeron enormemente en la arquitectura de la época. Fundaron los principios del Movimiento Moderno y todas las ideas extraídas estaban pensadas como instrumento social, para ayudar a mejorar la vida de las personas y de las ciudades mediante la

\footnotetext{
${ }^{8}$ AA.VV. La casa, evolución del espacio doméstico en España. Tomo I. Ed. El Viso. Madrid. 2006. p. 11
} 


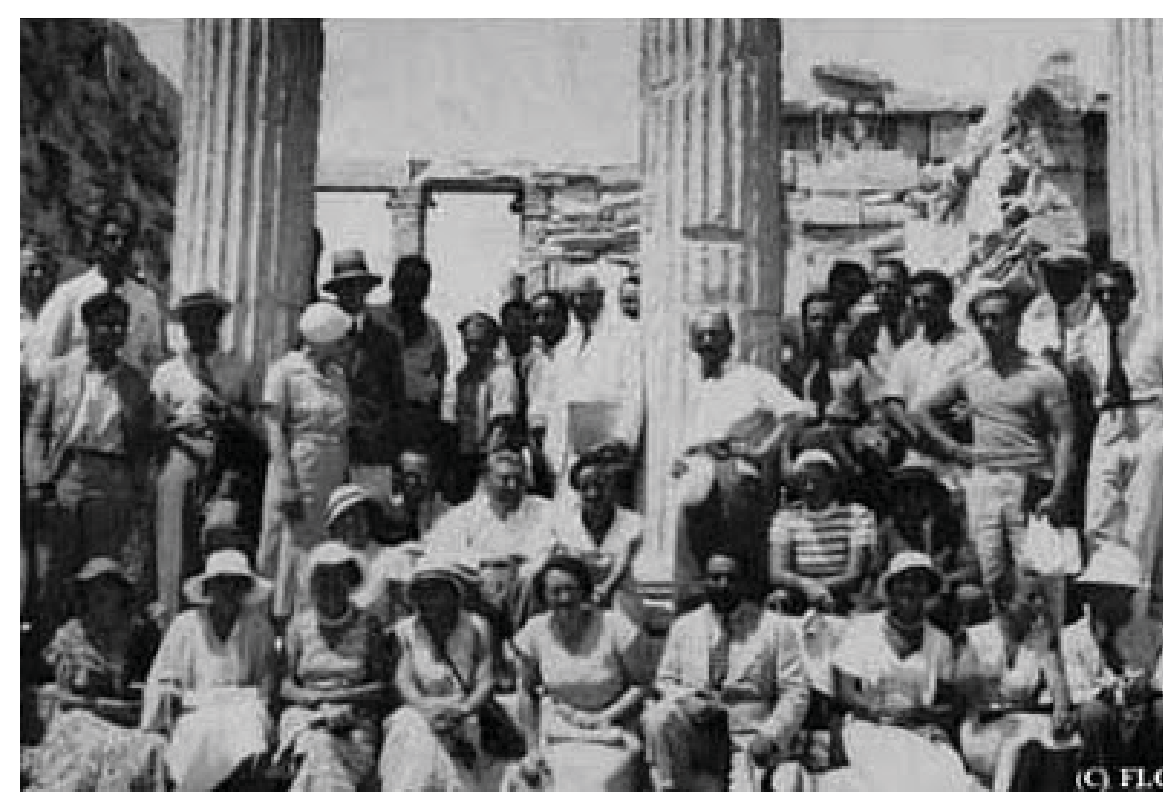

Ref.2.12. CIAM IV Atenas

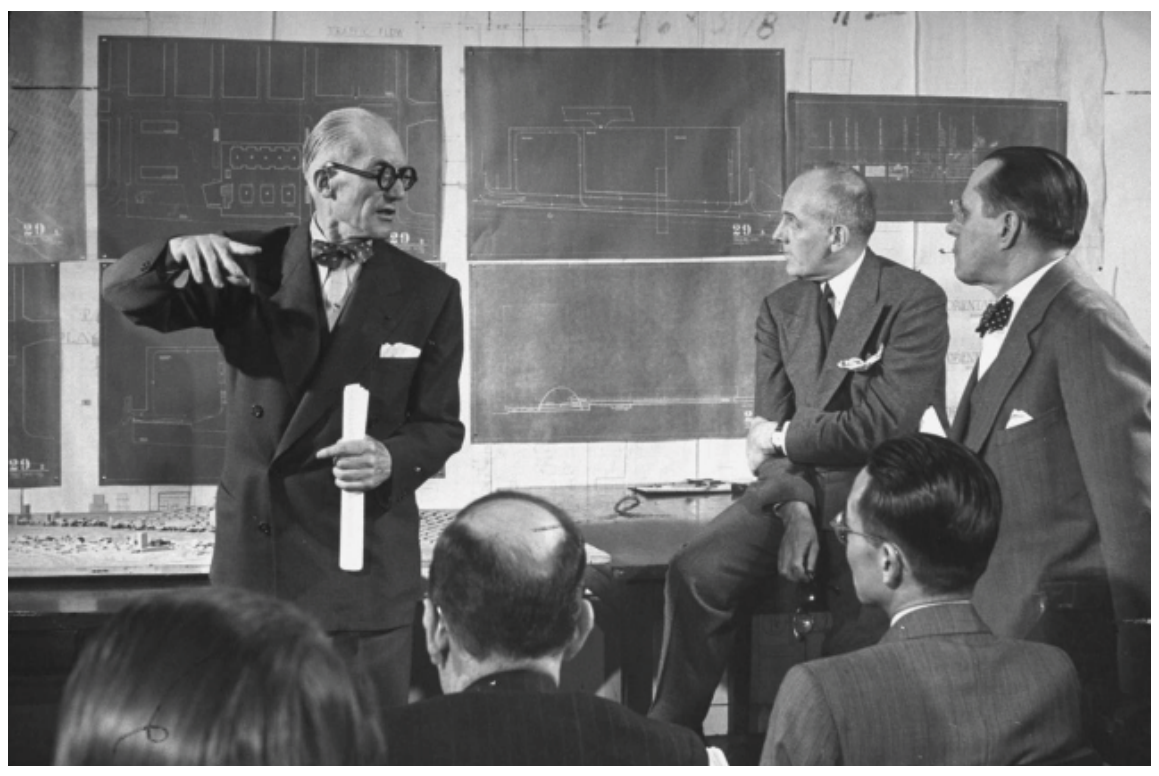

Ref.2.13. Le Corbusier dialogando con profesores 
arquitectura y el urbanismo.

Los trabajos realizados constituían una buena base para la discusión y para la obtención de conclusiones sobre cada tema propuesto. Las ideas y principios extraídos se reflejaban mediante algún tipo de documento, a modo de manifiesto, donde se daban a conocer las reflexiones y acciones que se debían tomar con respecto al tema tratado.

En 1929 en Frankfurt (Alemania) se llevó a cabo el CIAM II. El tema sobre el que se desarrolló, la vivienda mínima, vino como consecuencia de las aproximaciones que se habían hecho con respecto a las ciudades industriales, donde el diseño de la ciudad debía tener como propósito la mejora de las condiciones de habitabilidad y la adaptación a las nuevas bases sociales, tema abordado por Gropius en su conferencia sobre Las bases sociológicas de la vivienda mínima, donde además proponía el funcionamiento de zonas comunes como complemento a la vivienda mínima.

Durante el tercer CIAM en Bruselas en 1930, el tema principal fue la Planeación racional del lugar que se propuso como consecuencia de las ideas desarrolladas durante el Congreso anterior. Se hablaba de reducir los costes de producción y potenciar la producción en masa con viviendas funcionales en bloques lineales y en altura.

A partir de 1933 durante el CIAM IV se decidió enfocar la temática hacia el urbanismo y el planeamiento de ciudades. Este cuarto Congreso realizó sus conferencias a bordo del Patris III, durante una travesía de Marsella a Atenas. Fue durante este Congreso que el grupo formuló la Carta de Atenas. Documento que adoptó un concepto funcional de la arquitectura moderna, donde se proponía resolver los problemas a los que se enfrentaban las ciudades de entonces mediante la separación funcional de los lugares de residencia, ocio y trabajo, así como de la distribución de la población en bloques en altura de apartamentos separados entre sí por amplias zonas verdes.

Sobre la vivienda se obtuvieron varias conclusiones, sobre todo de carácter funcional, como que la vivienda debía primar sobre todos los usos, y además tenía que responder a unas condiciones de higiene y asoleamiento óptimas, así como que los bloques debían mantenerse alejados de las vías de circulación y estar vinculados a las amplias zonas verdes ubicadas entre ellos.

EI CIAM V realizado en Paris en 1937, fue uno de los menos conocidos. Trató de expandir la idea de la ciudad funcional dentro de la planeación al servicio de las masas y se trabajó sobre la vivienda y la reconstrucción. Para 1939 gran parte de los componentes del grupo se hallaban en el exilio -exceptuando a Le Corbusier y Alvar Aalto- trasladándose el CIAM con ellos y solo fue tiempo después que el urbanismo propuesto por el grupo fue llevado a cabo. 
VIVIENDAS EUROPAN (1988-2008) I Una aproximación a los modos de vida en el cambio de siglo en España 2. ANTECEDENTES

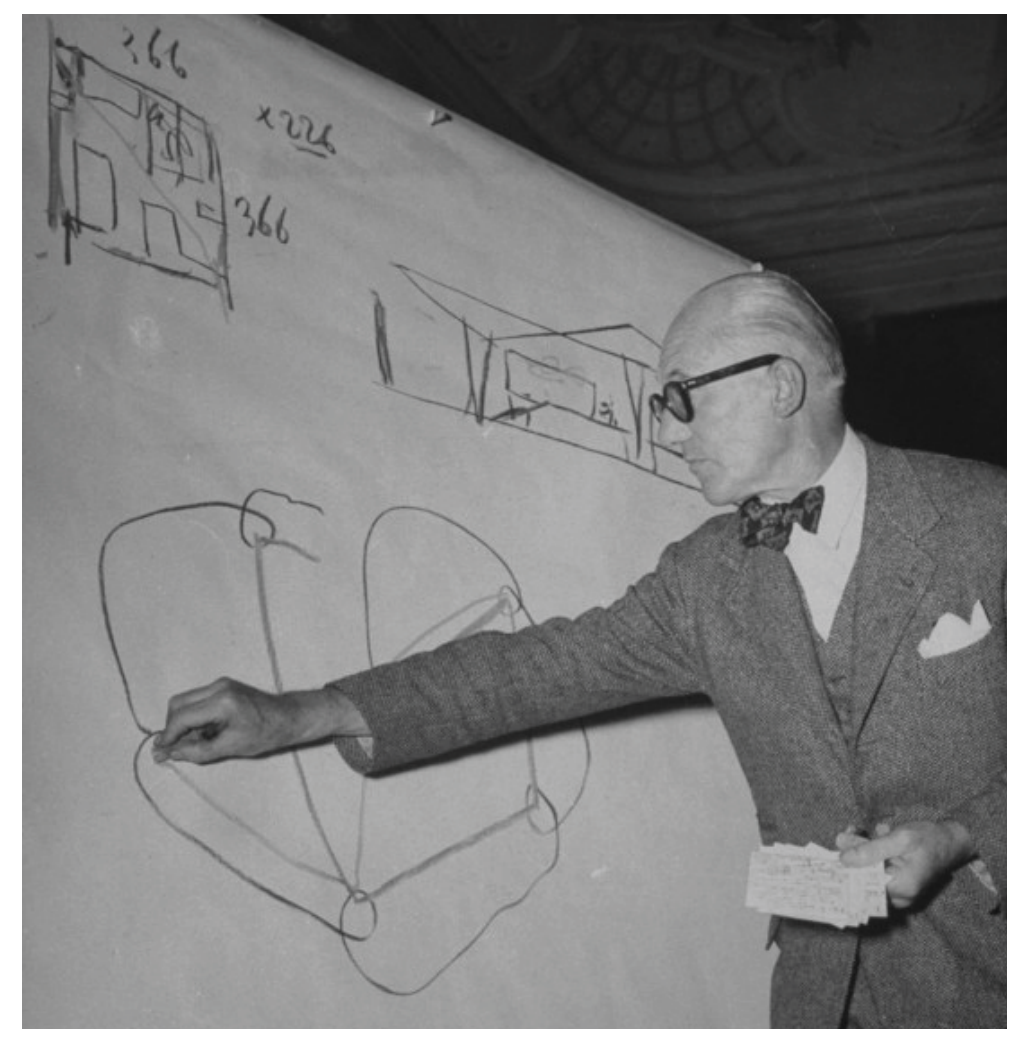

Ref.2.14. Le Corbusier dibujando

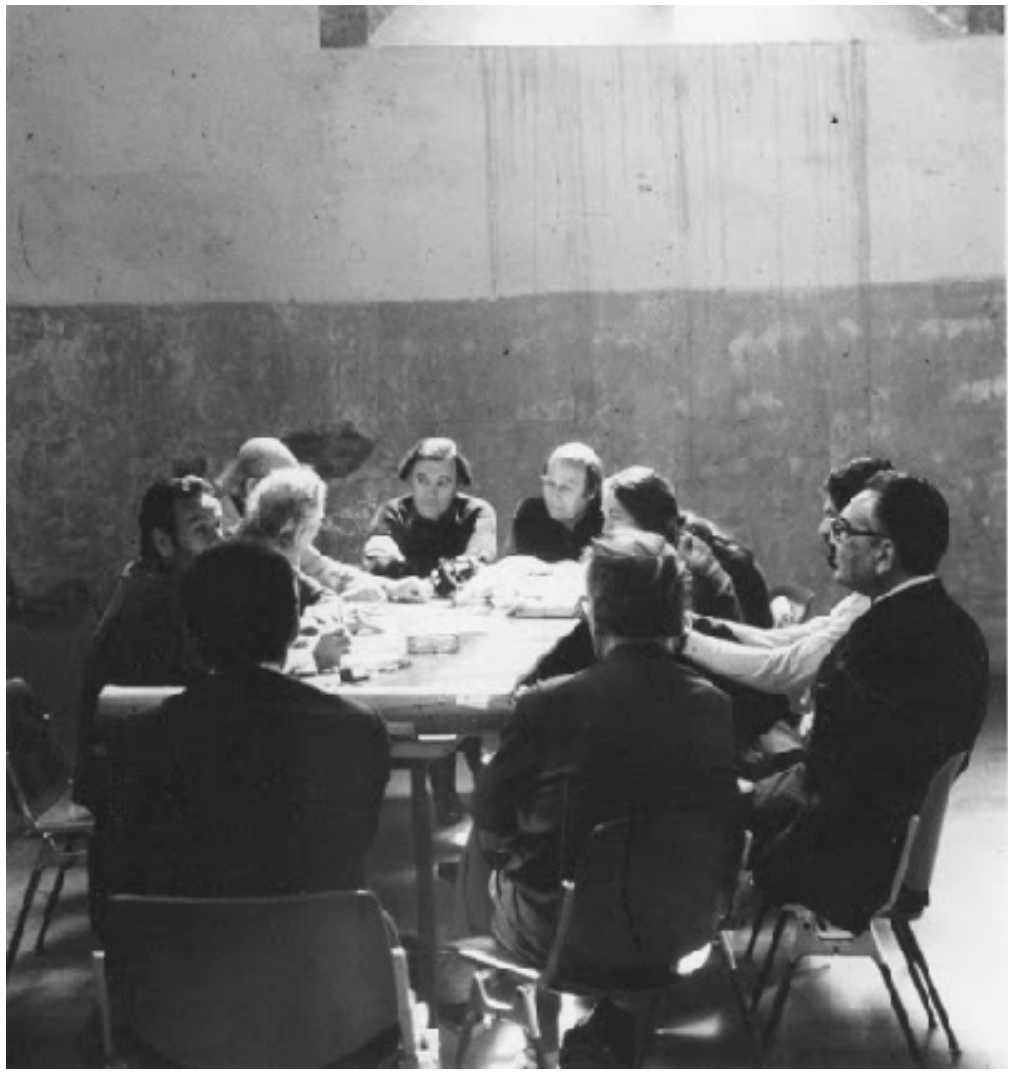

Ref.2.15. Reunión del Team X 
En el CIAM VI (diez años mas tarde del último Congreso y el primer CIAM después de la guerra, en 1947 en Bridgwater (Inglaterra)) se obtuvieron pocas conclusiones que surgieron bajo el tema sobre la reconstrucción de las ciudades devastadas por la II Guerra Mundial.

EI CIAM VII en 1949 en Bergamo (Italia) con el tema Sobre la arquitectura como arte con Sert como presidente, se habló de la relevancia del corazón de la ciudad como centro cívico. Este Congreso estuvo marcado por varios problemas producidos por las tensiones políticas y las diferencias arquitectónicas.

En 1951 en Londres, el CIAM VIII, se continuó desarrollando la idea sobre el corazón de la ciudad y se habló de la creciente descentralización de las ciudades. El objetivo de Sert era crear una red de corazones de ciudades para recentralizar las grandes áreas urbanas y favorecer "la relación personal del hombre con el hombre". Ya en esta época se proponía crear una isla para el peatón, que fuese el centro o el corazón de la ciudad. Así, en este Congreso se habían relacionado las cuatro funciones del CIAM (habitación, trabajo, transporte y recreación) con el concepto de corazón de la ciudad, que según el grupo, venía a ser la quinta función.

Celebrado en 1954 en Aix-en-Provence, (Francia), el CIAM IX enunció la Carta de habitación. Para entonces las diferencias entre los miembros del grupo eran tan grandes que una parte de los arquitectos, en su mayoría jóvenes, se separó de la organización y publicaron el Manifiesto Doorn, donde rechazaban las cuatro funciones que había enunciado el CIAM, y que sirvió como manifiesto fundacional para el posterior grupo llamado TEAM X.

EI TEAM $X$ fue el encargado de la organización del CIAM $X$ en Dubrovnik (Yugoslavia) en 1956. Tuvo como tema principal el Habitat humano, pero las diferencias entre los componentes del CIAM y de los llamados TEAM X llevaron a la ruptura total de consenso. Fue en 1959 durante el CIAM XI en Otterlo (Holanda), donde este nuevo grupo dio por terminados los Congresos CIAM y se distanciaron por completo de sus ideas procediendo a su disolución.

La Carta de Atenas es uno de los documentos más conocidos de la arquitectura del siglo XX que han dejado en herencia los CIAM. En ésta se describen por un lado las deficiencias observadas en las ciudades de la época respecto a las cuatro funciones (habitar, trabajar, recrearse y circular) y, por otro, plantean las acciones que deberían llevarse a cabo para evitar estos problemas. Se divide principalmente en tres partes. En la primera, se enuncian de manera general las características de las ciudades. La segunda habla del estado crítico actual de las ciudades. Es la parte más extensa y aborda las funciones anteriormente mencionadas. Primero se hace un análisis de cada una desde un punto de vista crítico para más tarde enunciar las condiciones que se deberían exigir en las ciudades para dar solución 


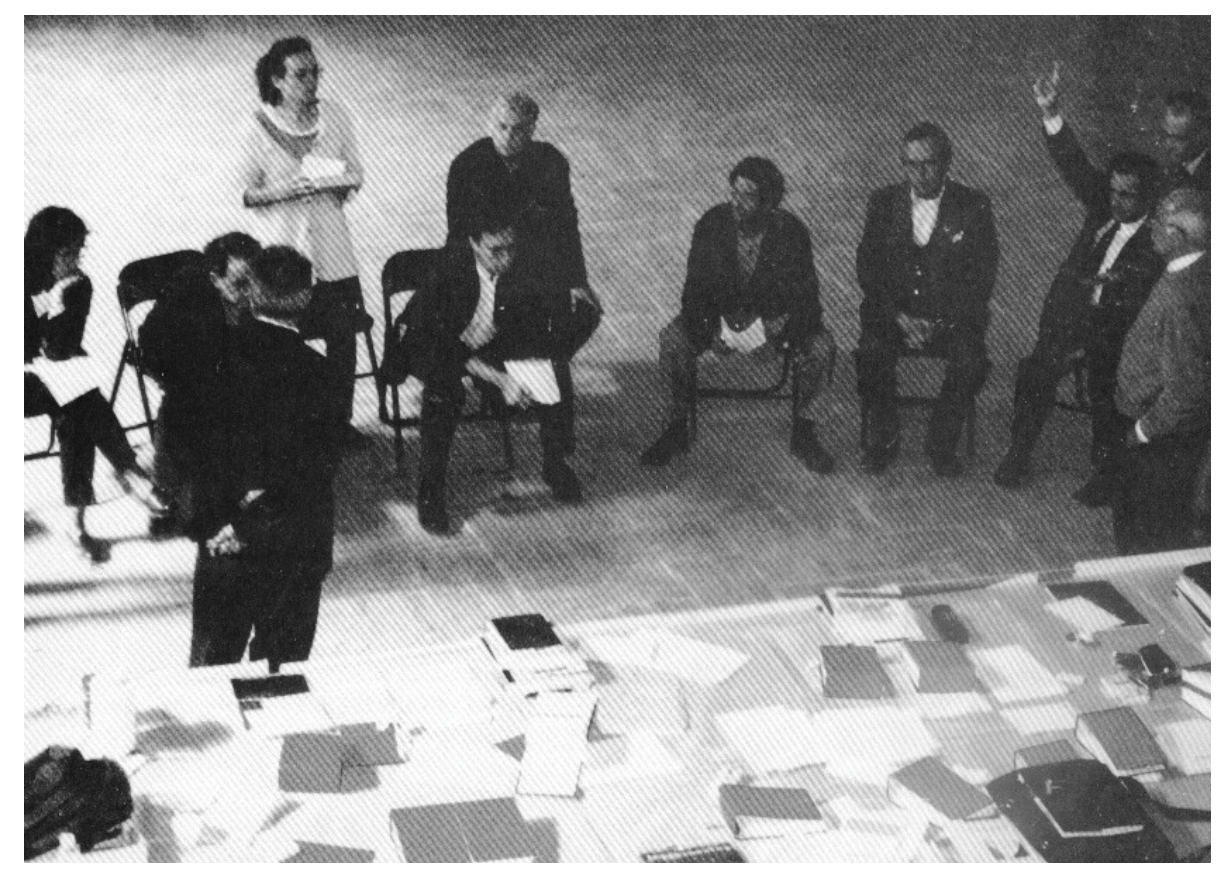

Ref.2.16. Reunión del jurado Europan IV

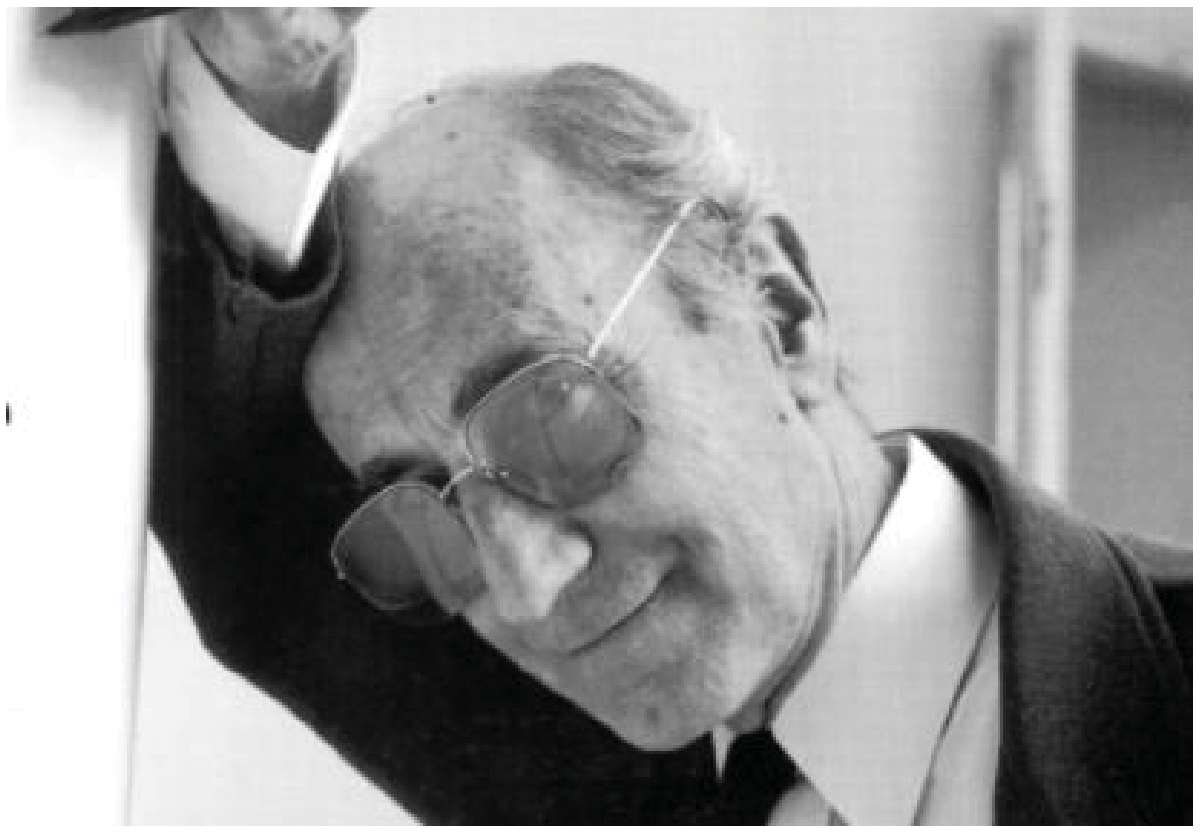

Ref.2.17. Alejando de la Sota 
a los problemas detectados.

Por último se enuncian unos puntos de doctrina, donde quedan reflejadas las acciones que se deben tomar con respecto a las ciudades.

Hasta el momento se ha redactado una breve historia de los CIAM, porque se podría afirmar que tuvieron un modo de trabajar novedoso a través de equipos multidisciplinares y miraron la ciudad desde distintas perspectivas.

Los concursos Europan, se han convertido cada vez más en una reflexión sobre la ciudad y, puede decirse que debaten algunos de los temas que ya se plantearon en su día en los CIAM, como se demostrará en el apartado tercero de la tesis.

\subsection{Los orígenes de Europan: PAN}

Existen dos publicaciones donde se relatan los orígenes de Europan: EUROPAN 88 Evolución de los modos de vida y arquitecturas de la vivienda ${ }^{9}$, y 10 años EUROPAN 5 España ${ }^{10}$.

Los antecedentes de los actuales concursos Europan se remontan a las antiguas competiciones PAN (Programme Architecture Nouvelle) ${ }^{11}$ realizadas en Francia desde principios de los años setenta (año 1971). Estas competiciones recurrían a los arquitectos jóvenes para contribuir con sus ideas innovadoras al desarrollo y la modernización de la arquitectura existente en Francia. La organización de la competición dependía del Ministerio francés de Construcción de Viviendas públicas. Por eso, aunque realmente llegaron a construirse pocos proyectos surgidos de la competición en comparación con la construcción general de viviendas en Francia, tuvieron una gran repercusión y aun hoy mantienen un valor simbólico por lo importantes, en cuanto a reflexión y debate. Cabe destacar que en 1975 las competiciones PAN insertan el contexto urbano, dato interesante pues este hecho también ocurrirá en los concursos Europan.

En 1985, PAN fue exportado a Japón, aunque no tuvo excesivo éxito, pues además de que hubo pocas propuestas presentadas, éstas mostraban claras diferencias de enfoque proyectual con la competición francesa. Esto pudo deberse a las diferencias culturales y las distintas maneras de entender la arquitectura de la vivienda entre franceses y japoneses, y fue lo que probablemente propició una escasa respuesta al tema propuesto por la competición por parte de los

\footnotetext{
${ }^{9}$ AA.VV. EUROPAN 88. Evolución de los modos de vida y arquitecturas de la vivienda. Ed. Ronchamp Ediciones. Madrid. 1988.

${ }^{10}$ AA.VV. 10 años EUROPAN 5 España. Ed. coproducida por EUROPAN/España, SEPES y el Ministerio de Fomento. Madrid.1999.

${ }^{11}$ AA.VV. PAN: programme architecture nouvelle, 20 ans de realizations. Ed. Broche. Paris. 1992.
} 
VIVIENDAS EUROPAN (1988-2008) I Una aproximación a los modos de vida en el cambio de siglo en España 2. ANTECEDENTES

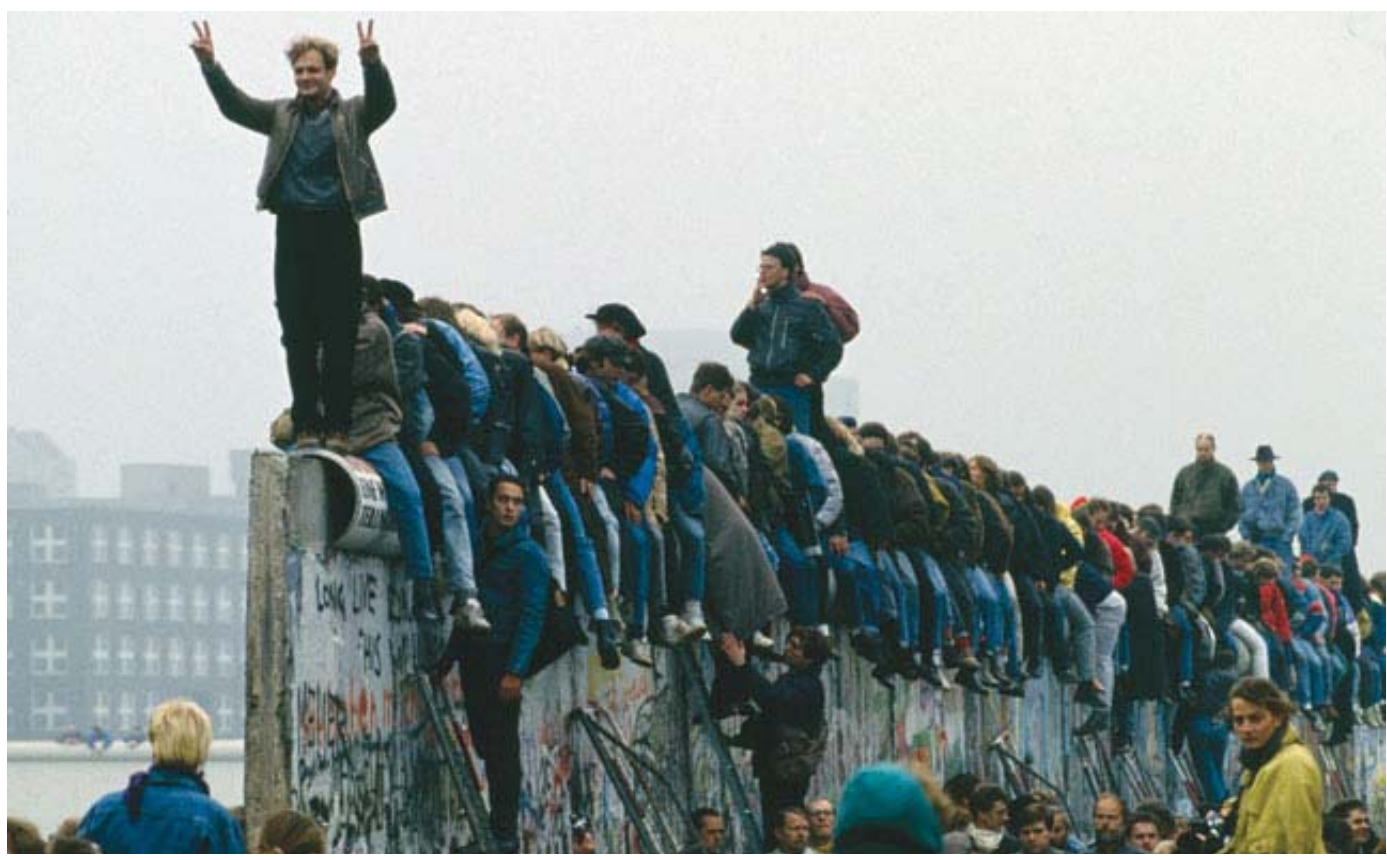

Ref.2.18. Caida del muro de Berlín, 1989

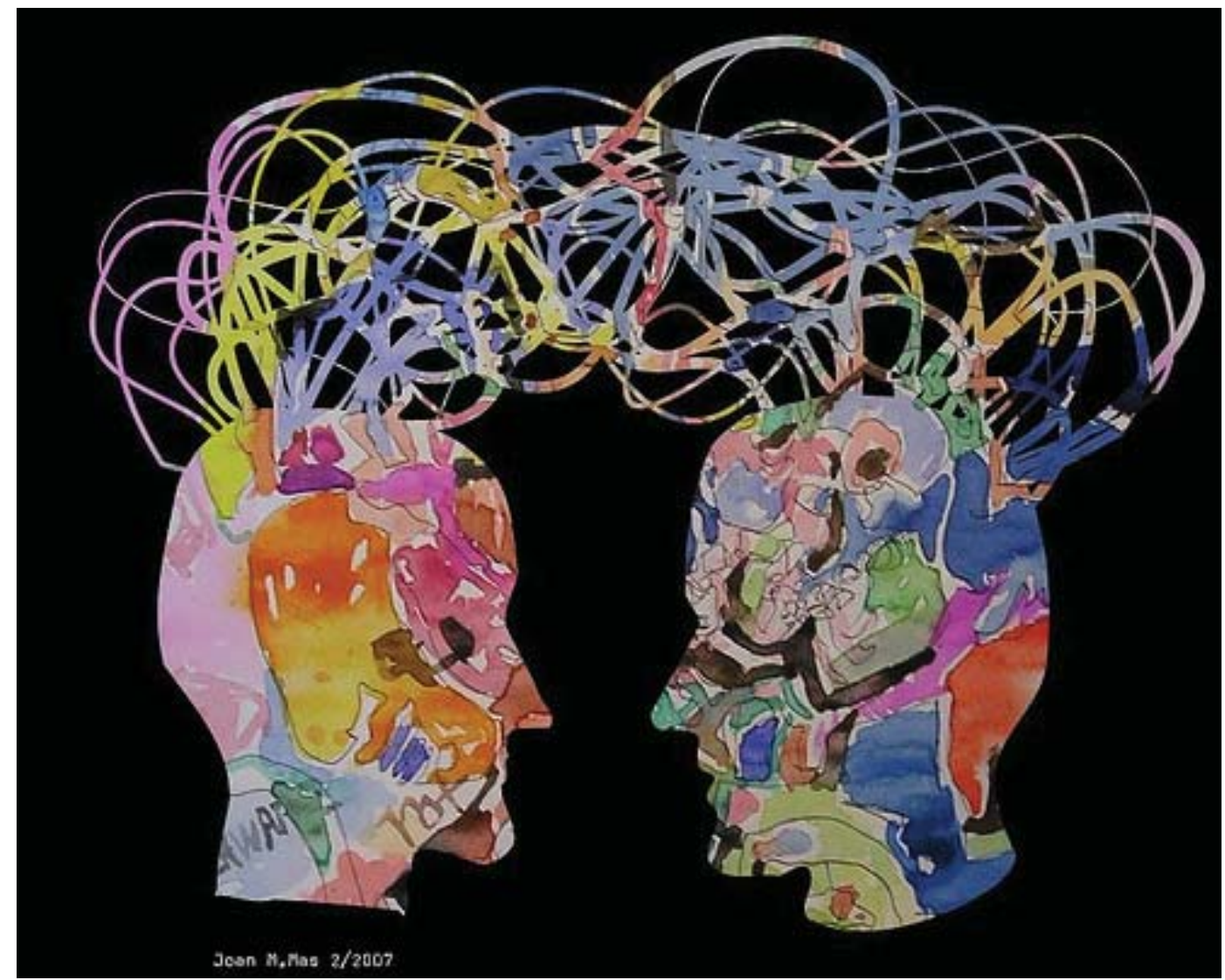

Ref.2.19. Communication (Joan M. Mas) 
participantes nipones.

Después de esta experiencia internacional se decidió ampliar la competición PAN a escala europea. Se crearon organizaciones Europan propias de cada país participante, respaldadas por diferentes instituciones nacionales.

En 1988 representantes de nueve países enunciaban un documento llamado la carta Europan ${ }^{12}$. Éste contenía los estatutos y los objetivos a cumplir por los concursos. Se optó porque cada competición nacional tuviese las mismas reglas y el mismo programa. Este documento está firmado por los Presidentes de cada Comité Nacional de Europan y en él se definen su finalidad, su estructura, sus temas y objetivos.

Fue en Berlín ese mismo año donde se produjo el primer encuentro entre las organizaciones nacionales y los participantes. Cada nacionalidad presentó un análisis de la arquitectura de su país a través de las viviendas, y esto permitió conocer los diferentes programas de competición. Además se establecieron los criterios de evaluación a aplicar por el Jurado.

Europan aparece en un momento clave: a finales del siglo XX. Es un concurso esclarecedor de la época, una radiografía necesaria para entender el momento histórico, un muestreo de los problemas afrontardos desde la ciudad.

"Tres aspectos principales como seña de identidad de Europan: éxito de la organización con un perseverante y riguroso esfuerzo en la búsqueda de la excelencia, oportunidad de debate y estudio sobre el modo en que se produce la ciudad contemporánea (creación de foros y actividades en torno al pensamiento arquitectónico, utilidad de las publicaciones que se realizan) y la adecuación de las condiciones de concurso y de la búsqueda de las oportunidades de proyecto a lo que el devenir de los tiempos y del espacio común de la convivencia que es la ciudad han ido marcando ${ }^{13}$ ".

El equipo de Europan está compuesto por un Comité Nacional, un grupo de expertos y un Jurado.

"Los jurados, como clave del éxito del resultado del concurso, son en Europan reconocidos y diversos. También se invita a un ganador de la edición anterior a formar parte del jurado de la siguiente, pudiendo éste participar en otros países para no perder oportunidades, ya que los cuarenta años llegan apenas sin darse cuenta. Tras el premio Europan 2, participar en el jurado Europan 3 constituyó la

\footnotetext{
12 La CARTA EUROPAN puede consultarse en el ANEXO.1

13 GARCÍA SOLERA, Javier, "Nuevos caminos" en AA.VV. Europan 10, Proyectar la urbanidad, colonización/revitalización /regeneración, Ed. Secretariado de Europan. Madrid. 2010. p.209.
} 

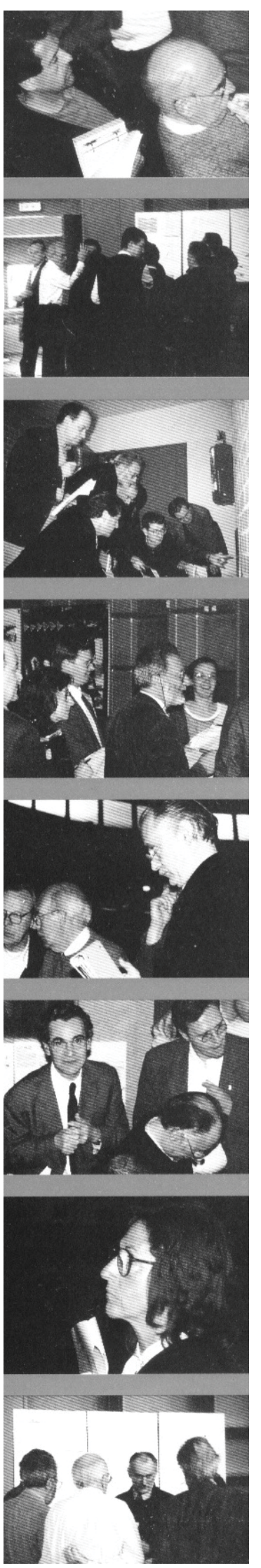

Ref.2.20. Jurados Europan 4
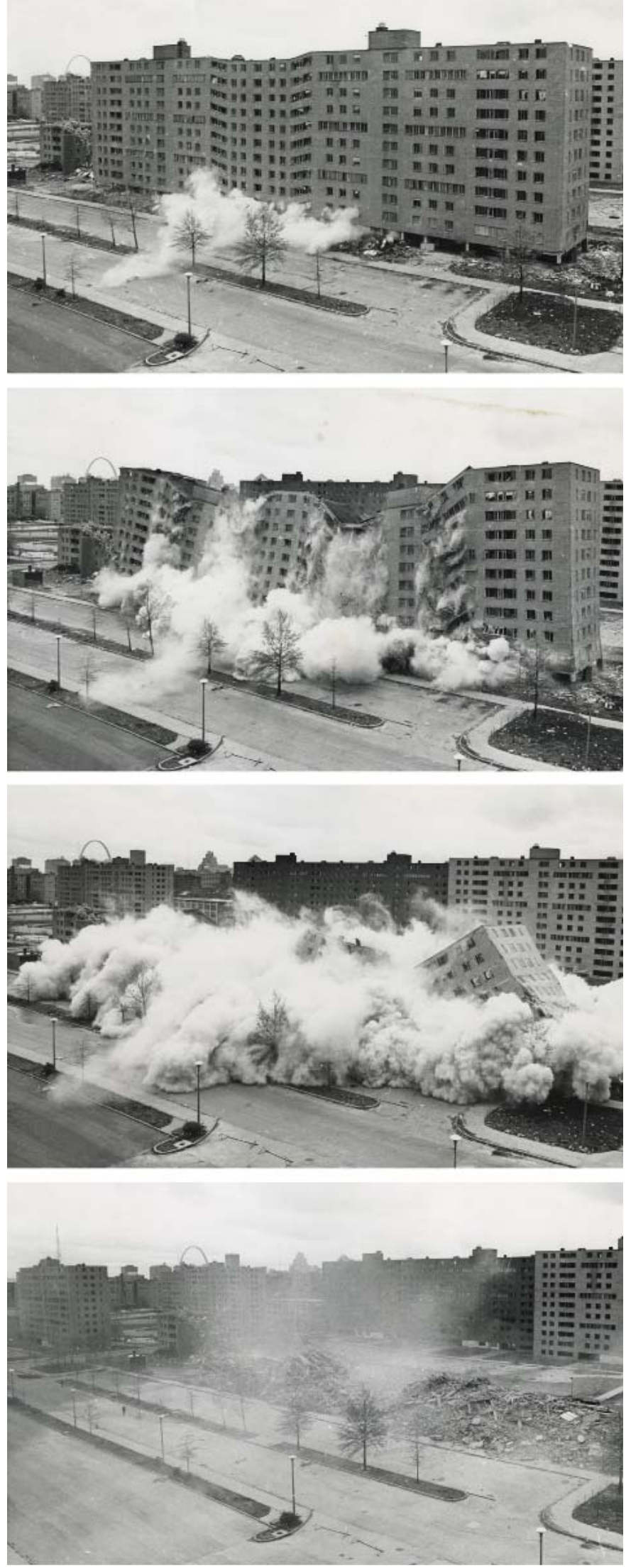

Ref.2.21. Demolición del conjunto Pruitt-igoe, Sant Louis, Missouri, 1972. Arquitecto Minoru Yamasaki 
abrumadora sorpresa de 1269 paneles para estudiar, analizar y consensuar como jurado desde punto de vista del participante ${ }^{14 "}$.

Europan no es tan sólo un concurso. Designa un foro de debate sobre la vivienda, la arquitectura y el urbanismo que pretende reunir a todas aquellas personas, instituciones y Administración del ámbito Estatal, Autonómico o Local, que deseen participar en la labor de desarrollo de las ciudades. El objeto primordial del concurso es aumentar el intercambio de ideas entre los profesionales europeos y extraer las reflexiones innovadoras así como la máxima calidad de la arquitectura y el urbanismo para nuestras ciudades.

"Europan España juega un papel fundamental como bisagra entre las administraciones, la sociedad y los arquitectos. En la medida en que el concurso proporcione soluciones útiles, inteligentes e innovadoras para una sociedad necesitada de ellas, el arquitecto recuperará un papel determinante en el debate de la ciudad y el territorio. Europan es una plataforma, una red, una herramienta y un catalizador de ideas, un canal que posibilita el contacto entre los distintos agentes y trabaja desde hace 20 años para generar entornos urbanos más creativos y estimulantes. Es competencia del comité científico reflexionar sobre el concurso y maximizar su potencial a través de las aportaciones e ideas de sus miembros. Tenemos dos años por delante y espero poder contribuir en la definición de un Europan aún más presente y demandado por nuestra sociedad ${ }^{15}$.

Es un concurso provocativo porque lleva a pensar, no deja indiferente. Pero ese idealismo de sus propuestas choca en la mayoría de veces con la realidad existente. Europan termina siempre con una publicación con la que se pretende comunicar a la sociedad la investigación realizada.

"En nuestro país el concurso Europan es considerado una plataforma de lanzamiento, una especie de ritual iniciático de entrada a la vida profesional, existiendo toda una cultura compartida entre estudiantes, recién titulados y profesionales, como lo indican el número de inscritos, propuestas presentadas y el éxito de las publicaciones ${ }^{16 "}$.

\subsection{Europan: "algo más" que un concurso de arquitectura}

En los últimos años, al alborear la crisis económica, se ha producido una inflación

\footnotetext{
${ }^{14}$ GARCÍA DE PAREDES, Ángela. "Europan: una ventana hacia la arquitectura" en AA.VV. , Europan 10, Proyectar la urbanidad, colonización/revitalización/regeneración, Ed. Secretariado de Europan. Madrid. 2010. p. 222.

15 TATO, Belinda. "Europan 9" en AA.VV. Europan 10, Proyectar la urbanidad, colonización/ revitalización /regeneración. Ed. Secretariado de Europan. Madrid. 2010. p. 257.

${ }^{16}$ Ibídem, p.257.
} 
VIVIENDAS EUROPAN (1988-2008) I Una aproximación a los modos de vida en el cambio de siglo en España 2. ANTECEDENTES

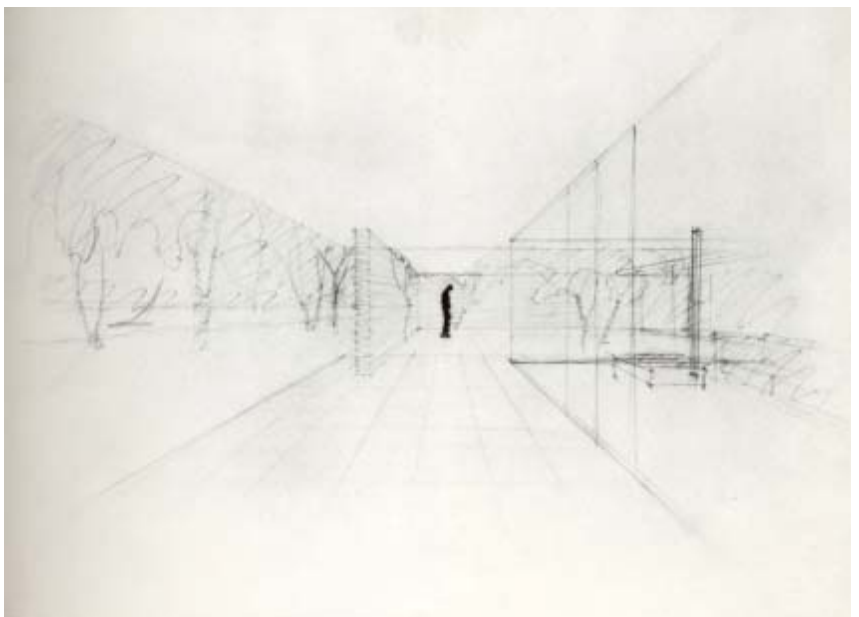

Ref.2.22. Boceto de Mies Van der Rohe

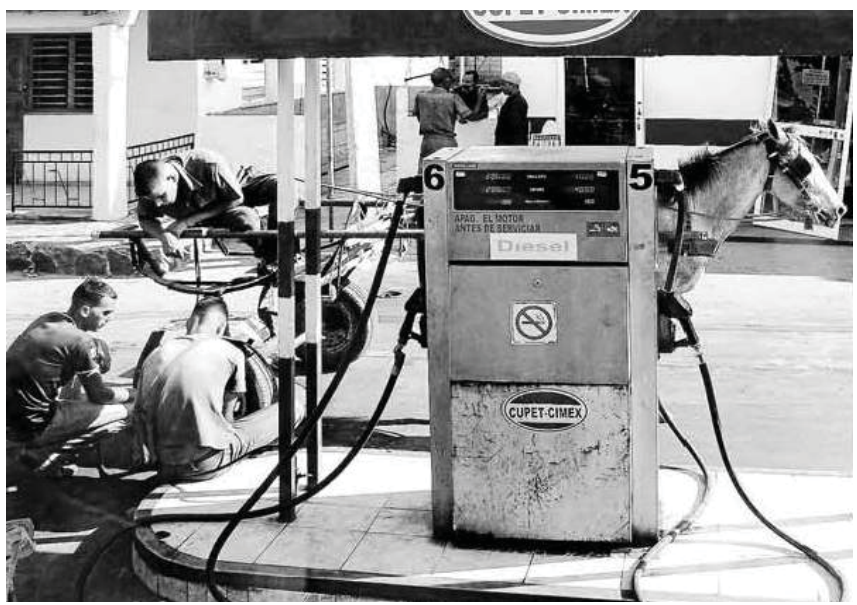

Ref.2.23. Algunos medios de transporte no consumen gasolina

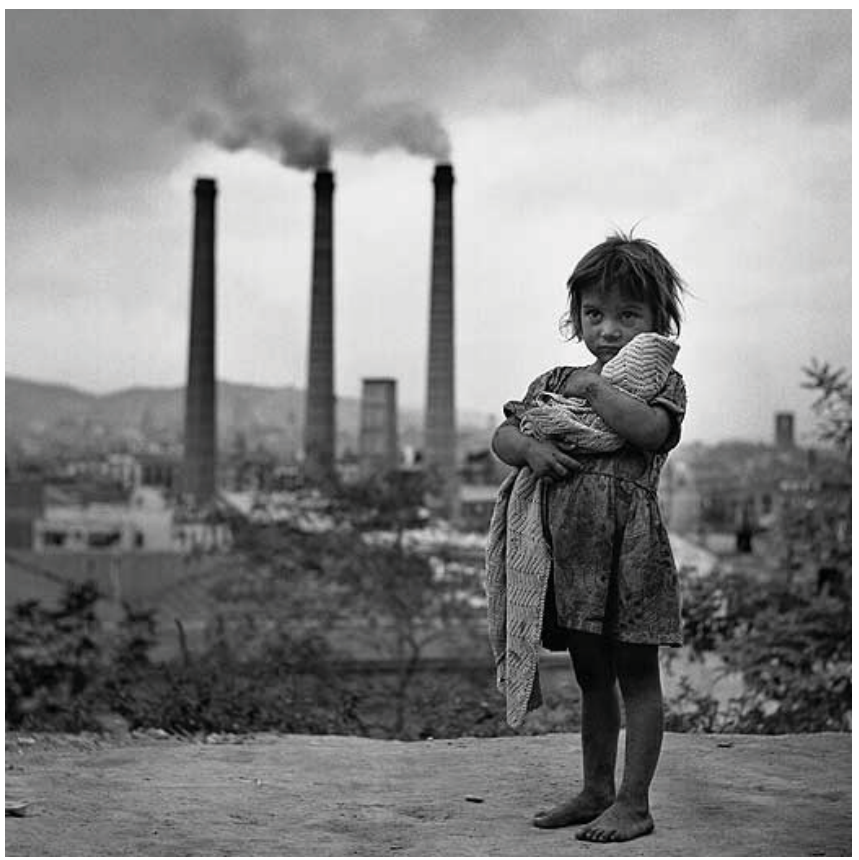

Ref.2.24. Algunos problemas: injusticia social y contaminación 
de las convocatorias de concursos como mecanismo de selección u obtención de un trabajo de arquitectura.

Realizar un resumen de los concursos de arquitectura en España, por delimitar de algún modo la investigación, no es una tarea sencilla. Sobre todo por el escaso material del que se dispone ${ }^{17}$. Cabe destacar el XIV Congreso Internacional de Expresión Gráfica Arquitectónica, que ha tenido como tema monográfico los concursos de Arquitectura que se ha celebrado en el Campus de la Universidad de Lusíada en mayo de 2012.

Si se comenzara a abordar el tema por los orígenes se podría sostener la hipótesis de que los concursos comenzaron como un mecanismo para elegir los mejores proyectos, y probablemente han existido desde que se ejerce el oficio de arquitecto. Quizá uno de los más célebres fue el de la cúpula de Santa María di Fiore de Florencia en 1418. También ha habido arquitectos, como Le Corbusier, que han tenido malas experiencias con motivo de estos (como por ejemplo el del Palacio de las Naciones de Ginebra, el de los Soviets de la ONU,etc.).

Si se investiga sobre la construcción posterior de los proyectos ganadores se podría decir que muchas obras han sido construidas tras la competición previa en concursos: la Opera de Sydney, el Centro Pompidou, el Arca de la Défense, el Forum de Tokio, el museo de Stuttgart, la Biblioteca Nacional de Argentina, el museo Guggenheim de Bilbao, el auditórium Walt Disney en Los Angeles, la catedral de Los Angeles, la Potzdamer Platz en Berlín, la terminal de pasajeros de Yokohama, el museo judío de Berlín y un largo etcétera.

Pero quizá se debería plantear otro medio de obtener encargos que sea más rentable para las horas de trabajo invertidas por los estudios de arquitectura.

"Los concursos abiertos se han convertido en una de las situaciones en las que la insostenibilidad del esfuerzo y del trabajo realizado, la ineficacia y bajísimo rendimiento del esfuerzo producido por todo un colectivo lo hace inaceptable e indefendible. La cantidad de horas empleadas, traducidas en una inmensa inteligencia productiva desplegada en el desarrollo de los trabajos por grupos de arquitectos generalmente de varios componentes, la inflación de ilusión y de esperanza, la cantidad de esfuerzo físico y emocional aplicado, están inmensa, y seguramente sin parangón en ninguna otra estructura profesional, que hacer que el proceso de concurso acabe siendo un dispendio del valor, inteligencia y de la calidad del trabajo realmente insostenible ${ }^{18 "}$.

\footnotetext{
17 Se puede acudir a la bibliografía recopilada entre la que destaca la publicación AA.VV. Libro blanco de los concursos. Ed. Colegio Oficial de Arquitectos de Madrid. Madrid. 2008.

${ }^{18}$ AA.VV. Europan 10, Proyectar la urbanidad, colonización/revitalización /regeneración, Ed. Secretariado de Europan. Madrid. 2010.p. 228.
} 


\section{Concursos de arquitectos o chapuzas}

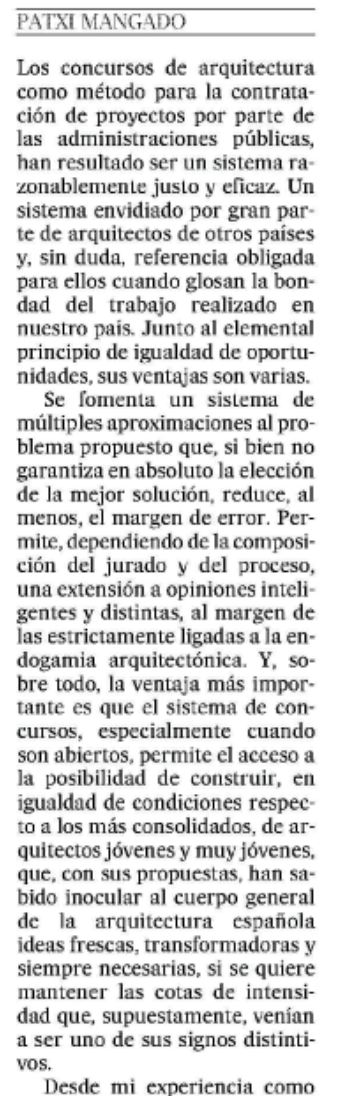

sos y como miembro de jurado en muchos, he de decir que la respues. ta por parte de los arquitectos ha sido siempre extraordinariamente generosa, presentándose an e cualquier convocatoria un más que nutrido número de trabajos, con una calidad que supera con creces la mezquindad económica con la que suelen plantearse. A los arquitectos se nos puede de. mandar por muchos errores, pero no es el de la entrega uno de ellos curndo a un concurso Sin eca cher bargo, cada vez mis, preguntas si ta conocida, al menos, mebien planteadas, sufi-

bien planteadas, sufi-

cientemente compensadas y con jurados de calidad contrastada. Creo sinceramente, que la

puesta es un no rotundo.
Cada vez más los concurso

Cada vez más los concurso de arquitectura, y por supuesto hay excepciones, están marcados por unas maneras que atentan contra la dignidad de los participantes en la medida que su trabajo es ninguneado o infravalorado en muchos de los casos. Enunciados y objetivos poco claros, situaciones de indefensión absoluta, jurados con manifiest: falta de capacidad para juzgar, ausencia de compromiso en ejecución, confusión entre calidad arquitectónica y baja de honorarios, todo ello y

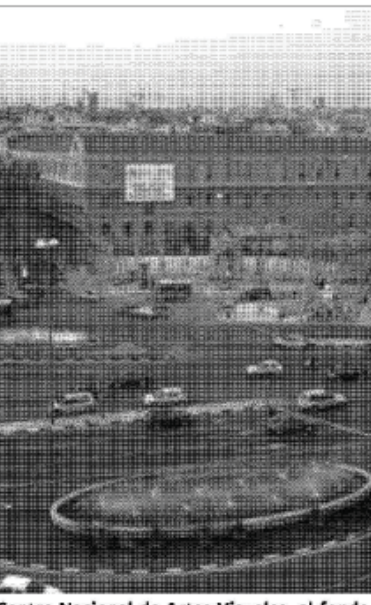

mis, son realidades queesin trás de un sistema, que, pese todo, sigue siendo el más razon ble y eficaz cuando se plante criterios serios y rigurosos. El último episodio que ilustr esta realidad, tiene que ver co el concurso para el proyecto del Centro Nacional de Artes Visua les en Madrid. El escenario es claro. Por un lado, una entida convocante, nada menos que Ministerio de Cultura, que encarga a una empresa pública, se supone con la capacidad y la solidez que debían ser propios de una estructura oficial la elabor ción de un concurso que al pare cer ha resultado ser ins, un modelo de desconoci- miento acerca de las condiciones legales que han de regir este tipo de convocatorias. Por otro, la maxima representación institucional de los arquitectos, el Consejo Superior de los Arquitectos, que hace una reclamación supuestamente justificada respecto a la manera como se hace la convocatoria, demostrando un celo que, ojalá, no sea sino el inicio de una actitud general extensible a otros muchos, muchisimos concursos chapuzas, quizá más modestos, pero no por ello menos gravosos para los participantes y que, hasta el momento, no han sido objeto de una preocupación tan esmerada por parte de quienes nos representan En medio de am Enmedio de ambos, como piezas olvidads, unos magnificos co a co a todos y unos ganadores que, estoy seguro, desconocedores de las posibilidades legales en las que ahora se mueve el concurso, han dado lo mejor de si mismos, han presentado un trabajo de enorme valor conceptual y material y que ahora ven como éste, no sólo no ha servido para nada, sino que aparece ligado a una convocatoria faisamente sos. pechosa, cuyo origen último no es sino la incompetencia de personas concretas que, simplemente, han hecho mal su trabajo. ¿Cuál es ahora la situación en la que quedan estos arquitectos? Este es otro ejemplo más de chapuza y desconsideración hacia la dignidad de los profesionales cuando éstos sólo pretenden dar lo mejor de sí mismos.

Patxi Mangado es arquitecto.
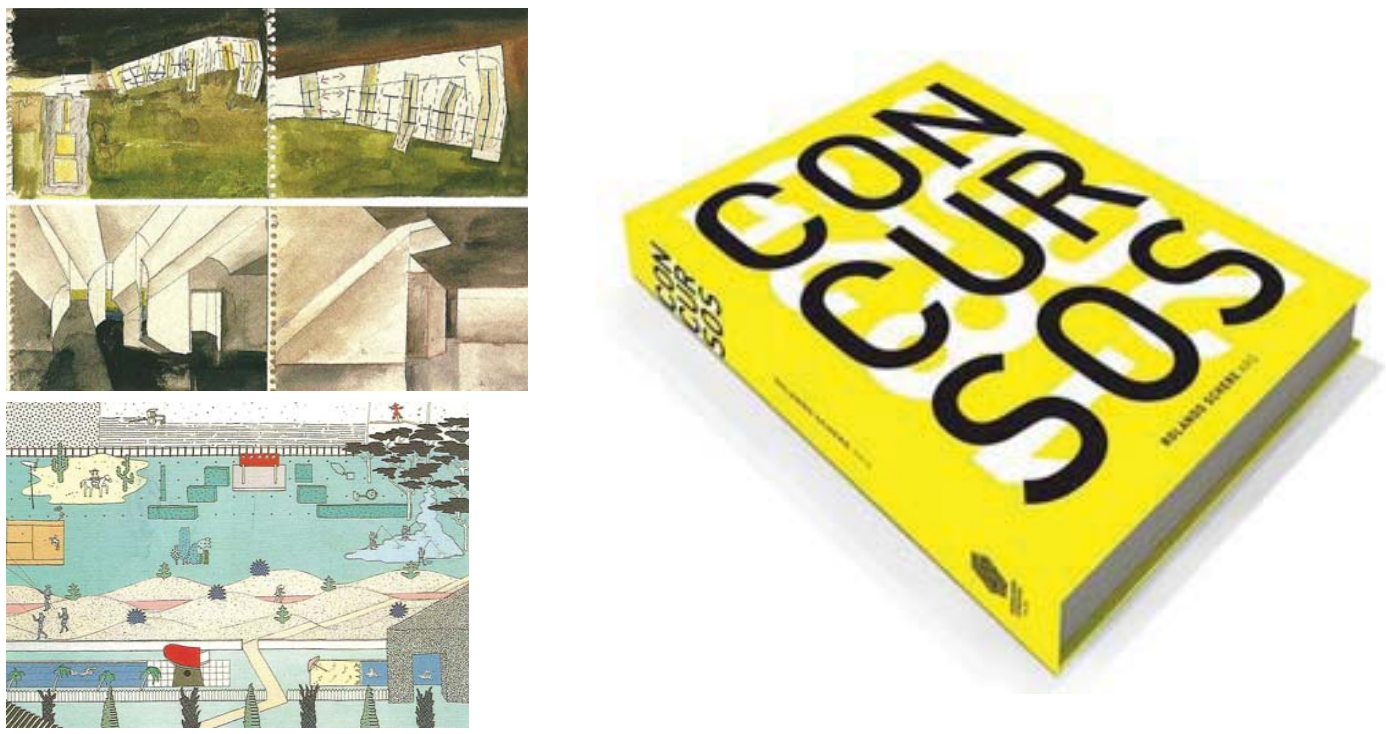

Ref.2.25. Bocetos de concurso:Steven Holl y Koolhaas 
También es interesante plantearse las valoraciones objetivas del Jurado, pues no es proporcional a veces el tiempo dedicado a examinar el material entregado con las horas de trabajo invertidas por los equipos.

"Hay otra cuestión aún más grave y alarmante que es la rapidez, la extrema superficialidad dada la escasez de tiempo dedicada al análisis de las propuestas, en el marco de esa la cantidad ingente de los trabajos, y con el tiempo limitado, o autolimitado, que el Jurado posee. Si lo aventuro, lo hago intentando arrancar una revisión crítica del proceso para que se produzca un despliegue de medidas, que confiera a Europan, y por extensión a los concursos de arquitectura, el esplendor y la veracidad que el concurso tuvo en su origen ${ }^{19 "}$.

El panorama de los concursos indudablemente ha cambiado en el siglo XXI. Es un modo de ejercer la profesión, ¿pero se puede vivir de esto?

"En definitiva, creo que la visión de la profesión como un modelo caduco, abocado a cambiar sus estrategias creativas, y por tanto poco útil para la sociedad, se contradice de pleno con el abigarrado mosaico de proyectos producidos en los últimos diez años en Europan, cuya acumulación y procesado colectivo han ido creando una nueva cultura del proyecto arquitectónica en España, en la que lo visual se impone como una herramienta de búsqueda e intensificación de las ideas, y no como un mero ornamento alejado del proceso intelectual del proyecto. Ambos aspectos están indisolublemente relacionados entre sí, y con un concurso, Europan, cuyo desarrollo y resultados nos transmiten una energía colectiva formidable, difícil de encontrar en el resto del panorama arquitectónico actual ${ }^{20 "}$.

Actualmente en España se recurre a los concursos como medio para obtener algún encargo por parte de organismos públicos. Pero el cambio que se ha producido también es el del objeto de concurso, pues se pasa de concursos de encargos modestos a otros que no son más que un reflejo de la arquitectura del espectáculo.

“(...) En los años sesenta todos los arquitectos de cierto renombre se dedicaban primordialmente al problema de la vivienda modesta. Recuerdo el concurso de Lima. Todos los arquitectos que ahora consideraríamos «estrellas» realizaban estudios sobre la vivienda pobre, la vivienda de urgencia, lo que yo llamaría «dignificación de la barraca de autoconstrucción». Esto se ha terminado. ¿Has visto alguna revista que publique artículos sobre autoconstrucción, sobre sistemas racionales para levantar chabolas en los países subdesarrollados, o sobre métodos de construcción más económicos? Antes hemos dicho que han desaparecido los modelos formales, pero también han desaparecido los modelos

\footnotetext{
${ }^{19}$ Ibídem,p.228.

${ }^{20}$ FRANCO,David, "Un mosaico de pequeñas utopías". En Europan 10, Proyectar la urbanidad, colonización/revitalización/regeneración, Ed. Secretariado de Europan. Madrid. 2010. p. 240.
} 
VIVIENDAS EUROPAN (1988-2008) I Una aproximación a los modos de vida en el cambio de siglo en España 2. ANTECEDENTES
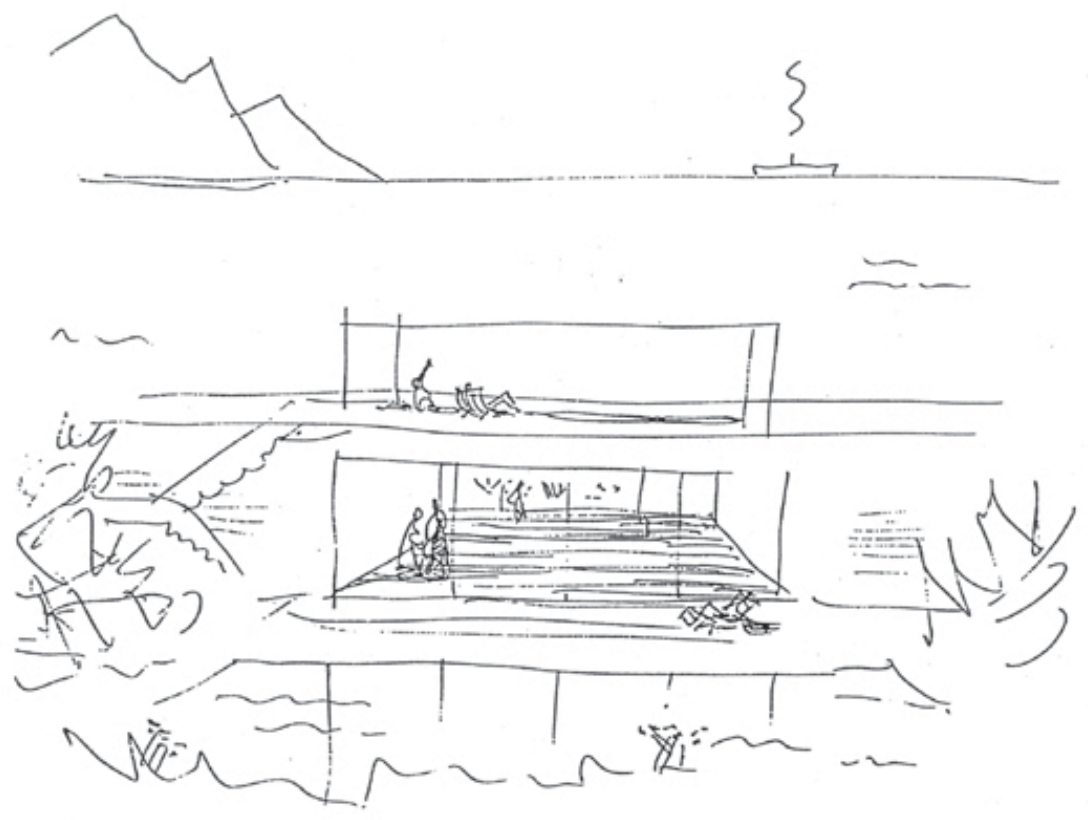

Ref.2.26. Boceto de viviendas en l'Alcudia, Mallorca, Alejando de la Sota.
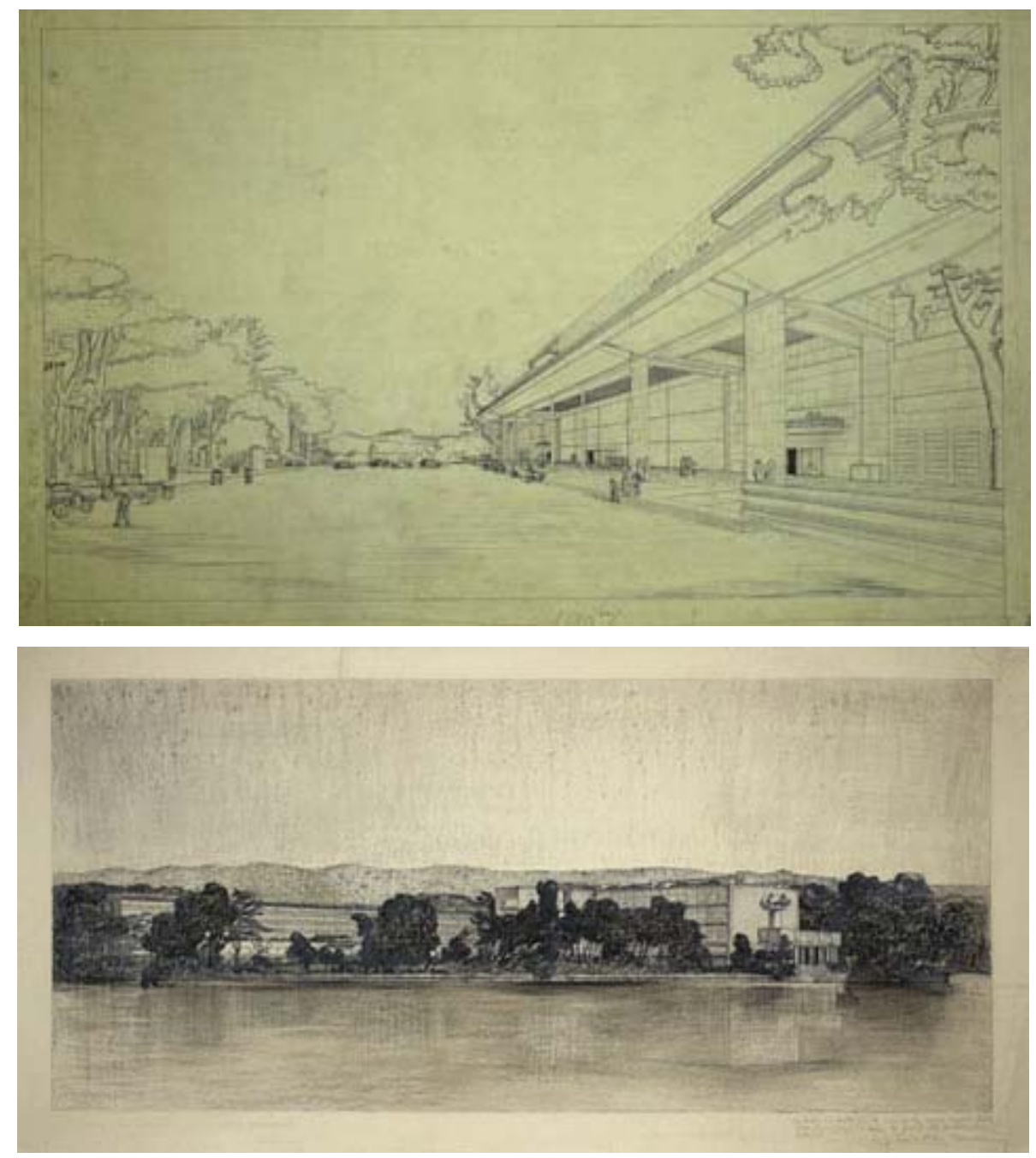

Ref.2.27. Bocetos para el Palacio de las Naciones, Mies Van der Rohe.. 
de contenido social. En cambio, lo que sí abunda son los modelos de contenido consumista. Nadie habla sobre los modelos de actuación social: hace años que ninguna conferencia, ni simposio ni revista trataba estos temas ${ }^{21}$ ".

Mucho se podría comentar de los concursos de arquitectura. Es un mundo tan amplio que requeriría realizar una tesis doctoral del tema definiendo algunas cuestiones como quién organiza el concurso, los Jurados, los grandes arquitectos concursantes de la historia de la arquitectura, aspectos legales de los concursos, acerca de los modos de representación de los concursos, la propaganda y la difusión que se hace de ellos y un largo etcétera que se podría alargar mucho más.

De la Sota escribió un artículo que hace referencia a los concursos de arquitectura en el que afirmaba:

"El fin de un concurso, previamente, es hacer una obra mejor; como consecuencia -saltando el encargo garantizado a un técnico reconocido-, da posible entrada a un nuevo valor joven o desconocido por aquello de la igualdad de oportunidades.

Para que la obra resulte efectivamente mejor deben concurrir una serie de circunstancias:

-bases del concurso buenas y clarísimas;

-que sean tenidos muy en cuenta, en el fondo y en la forma, por los concursantes; -que los plazos sean lógicos en el tiempo;

-que se realicen buenos trabajos;

-que se falle el concurso con acierto ${ }^{22 "}$.

Y tras los preliminares que se acaban de exponer se da paso al cuerpo central de la tesis.

${ }^{21}$ AA.VV.,Invitación a la arquitectura, Ed. Naos, Madrid, 2002, texto de Oriol Bohigas, p.26..

22 DE LA SOTA, Alejandro, Escritos, conversaciones, conferencias. Ed. Gustavo Gili, Barcelona, 2002, p.15. 

3. EUROPAN: LABORATORIO DE IDEAS SOBRE EL HABITAR 
VIVIENDAS EUROPAN (1988-2008) | Una aproximación a los modos de vida en el cambio de siglo en España

3. EUROPAN: LABORATORIO DE IDEAS SOBRE EL HABITAR

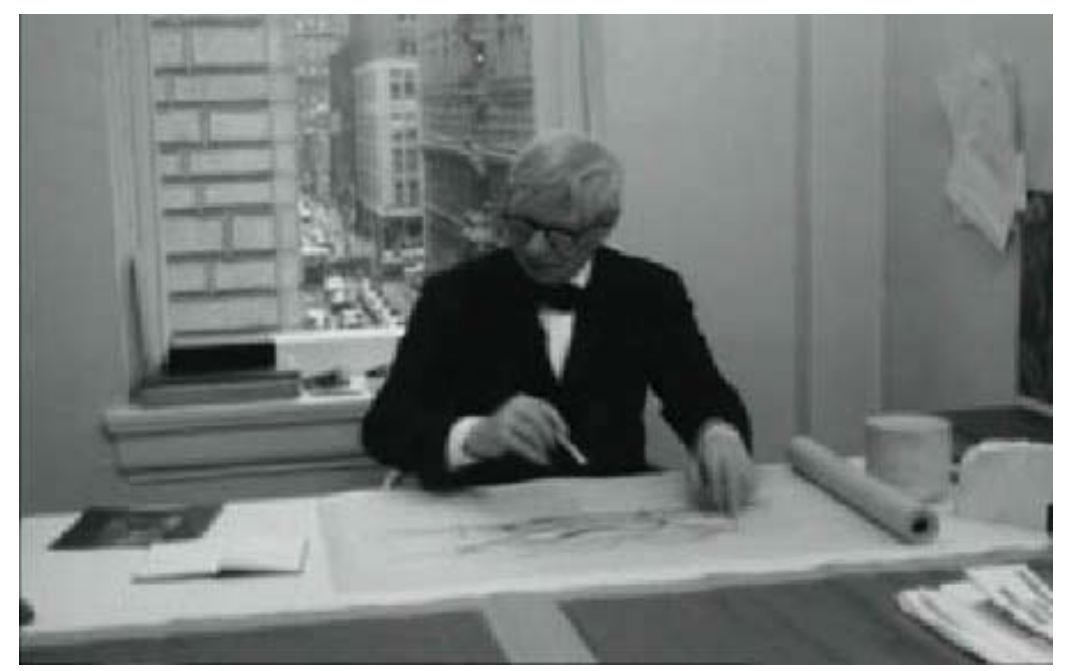

Ref.3.1. My Architect, Louis I. Kahn

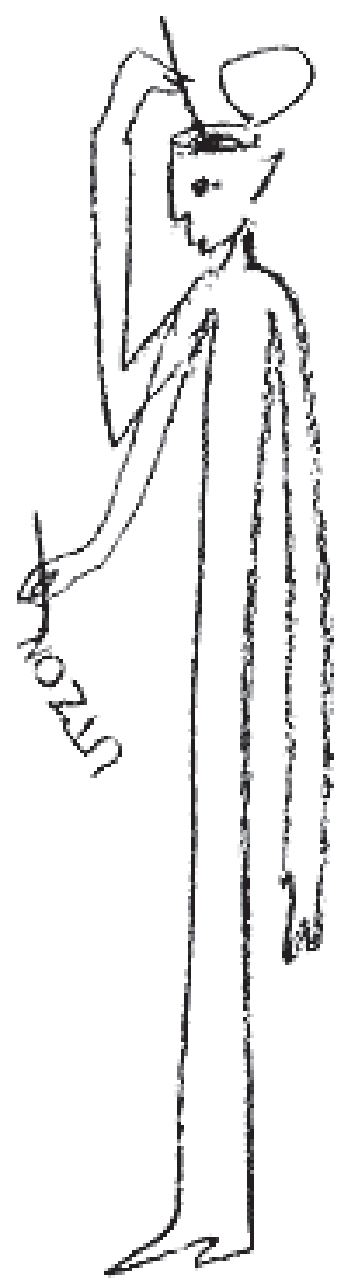

Ref.3.2. Boceto de Utzon 


\subsection{El sustrato conceptual en arquitectura}

La arquitectura, como todo arte, supone la unión entre pensamiento y técnica, entre el trabajo intelectual y la realización material. Este hecho es difícil de sintetizar, pero en este capítulo interesa recalcar esta doble vertiente: la capacidad de tener ideas y de llevarlas a la realidad. Se podría afirmar, de forma muy resumida, que la arquitectura es una disciplina que permite transformar las ideas en realidades, y por eso, el ocio, entendido como trabajo intelectual, es más que necesario.

Así pues, los arquitectos trabajan, en cierto modo, con las ideas. Por eso, en arquitectura, el primer paso necesario es aprender a pensar. Alberto Campo lo narra en aquella fábula que comienza así "había una vez, en un viejo país, un joven arquitecto que amaba apasionadamente la Arquitectura y que ¡insensato de él! era un artista que pensaba y construía casas. Era un pensador que construía. Era un constructor que pensaba. Y pensando y construyendo, soñando y haciendo realidad esos sueños, era inmensamente feliz. Había, en ese mismo país, otros arquitectos que creían poseer la exclusiva de la intelectualidad, que estaban convencidos de ser los únicos poseedores de la verdad. "Sin ideas, decía, no puede haber buena Arquitectura. La Arquitectura es algo más que sólo Forma”. "Sin construcción, explicaba, no puede haber verdadera Arquitectura: La Arquitectura es algo más que sólo idea ${ }^{2 "}$.

\footnotetext{
${ }^{1}$ Elisa Valero desarrolla el concepto de ocio cuando afirma que "la enseñanza de la arquitectura, a diferencia de otras titulaciones universitarias, se enclava en una Escuela, palabra que etimológicamente viene del término latino schola, que significa ocio. Y es que el ocio es uno de los fundamentos de la cultura occidental. Afirmación comprensible desde la disyuntiva ocio-negocio, y desde un planteamiento que identifica el ocio con el trabajo intelectual". VALERO RAMOS, ELISA. Ocio peligroso. Ed. General de Ediciones de Arquitectura, Valencia, 2006, p.5.
}

${ }^{2}$ AA.VV. Nuevos modos de habitar. Ed. Colegio Territorial de Arquitectos de Valencia. Valencia. 1995. p.54.

La fábula prosigue: ' $Y$ pensando y construyendo, soñando y haciendo realidad esos sueños, era, es, inmensamente feliz. Un día ¡Oh día feliz! nuestro eternamente joven arquitecto, el artista, soñó en vivir en una idea: en una blanca y cúbica cabaña. Pues siempre había pensado que en vez de buscar el Paraíso y en él la Cabaña, se trataba de construir la Cabaña y con ella el Paraíso. "Llegar a poder construir un ideal para habitar en él, discurría el artista, debe ser el súmmum de la felicidad para el hombre racional”. ¡Habitar un ideal! ¡Vivir en un sueño hecho realidad! Al día siguiente, ¡cuán largo se le hizo aquel día de casi más de un año!, nuestro artista, con la ayuda de otros locos que le entendieron, puso manos a la obra y ¡construyó la idea!

¡Y cómo latía su corazón cuando iban alzándose aquellos muros que proclamaban aquella realidad posible!

¡Y cómo tembló su espíritu cuando la LUZ decidió, atrapada, quedarse para siempre en aquellas paredes!

¡Y cómo se conmovió todo su ser cuando la BELLEZA penetró radiante en aquel espacio 


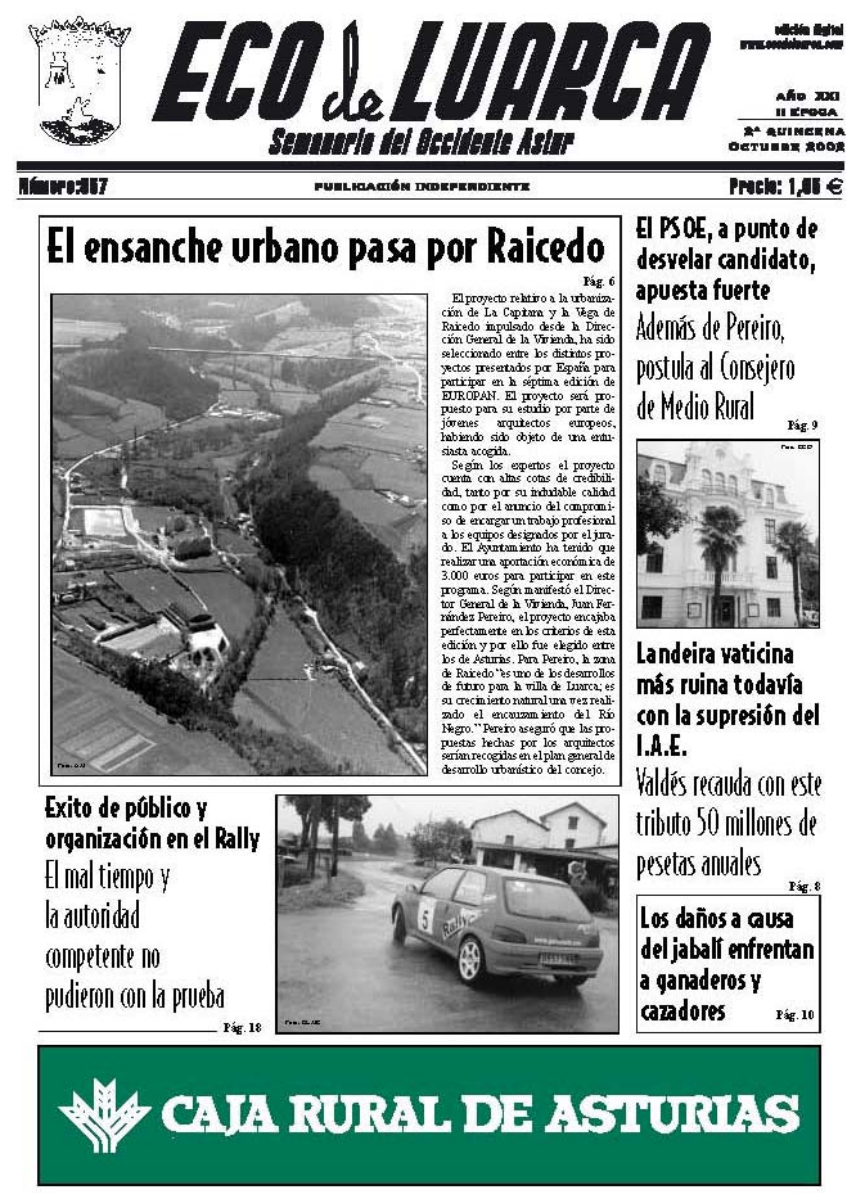

Ref.3.3. Publicación de un artículo tras la convocatoria Europan 7
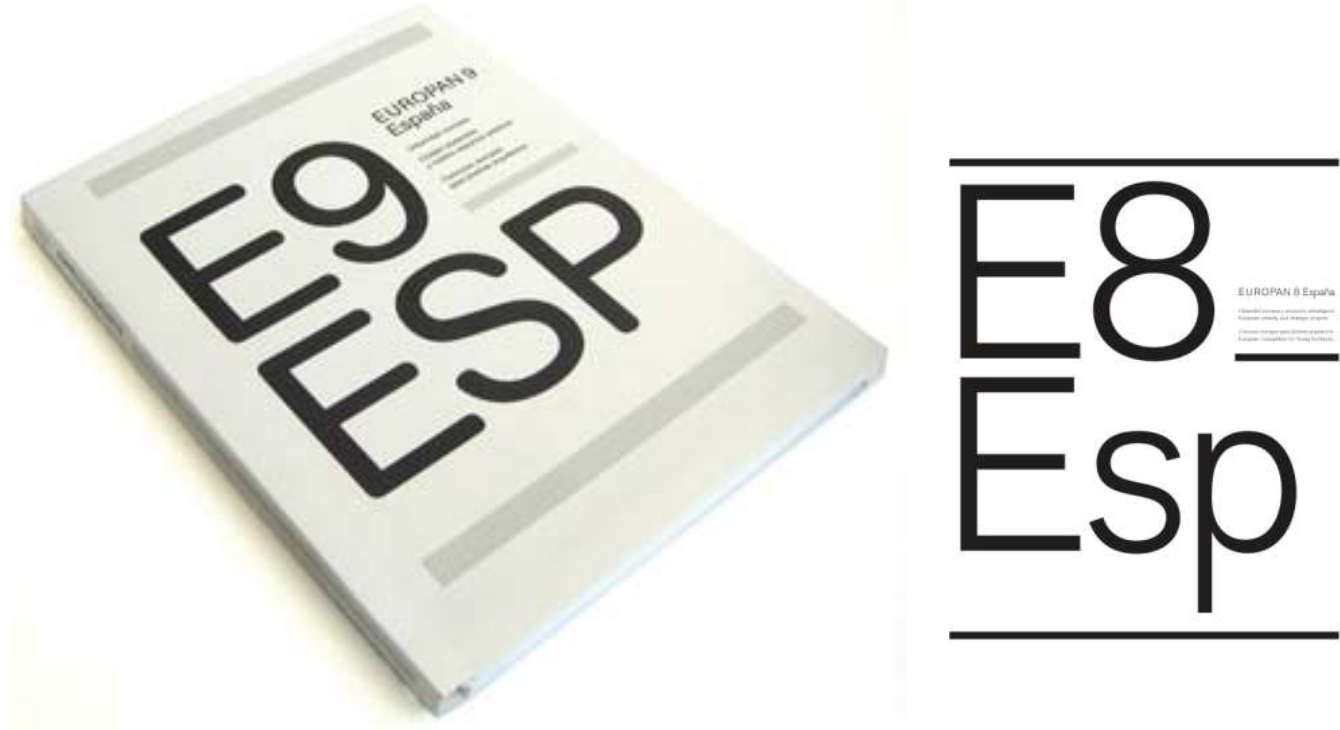

Ref.3.4. Distintas publicaciones de Europan 
Y como todo trabajo intelectual, la reflexión precisa requiere una serie de condiciones: recogimiento, calma, silencio y dedicación.

"Claro que la solución sería, lo es: pensar, lo más propio del hombre. Los arquitectos, pensar qué están haciendo. Quizás el problema de los arquitectos se resolvería dedicando tiempo, más tiempo a su trabajo. Para poder concebir con precisión estos espacios para habitar. Los usuarios, pensar cómo usar esos espacios. Para hacerlo adecuadamente. Y poder disfrutar de ellos. Y, quizás, volver a pensar, a conversar, a leer, a vivir, a habitar" ${ }^{3}$.

Estudiando las convocatorias de Europan realizadas hasta la fecha, se pueden obtener resultados interesantes, pues el material de trabajo de este laboratorio son las ideas que subyacen en los planteamientos de ciudad propuestos anteriormente por un grupo de expertos. Esto se hace posible porque una de las pretensiones de Europan es contribuir a los intercambios científicos y culturales en el campo de la arquitectura y de la vivienda, según se expresa en la carta Europan ${ }^{4}$.

Este capítulo radiografía los planteamientos generales de cada edición para abrir una vía de investigación en el mundo de las ideas acerca de la vivienda planteadas y poder así comprobar posteriormente su influencia en la arquitectura materializada o construida.

'La Historia de la Arquitectura, lejos de ser sólo una Historia de las Formas, es básicamente una Historia de las Ideas Construidas. Las formas se destruyen con el tiempo, pero las ideas permanecen, son eternas ${ }^{5}$.

Antes de comenzar el desarrollo de los siguientes apartados, se considera conveniente una aclaración previa acerca del término idea utilizado en la tesis.

para no abandonarlo jamás!

El artista creyó morir de felicidad.

Y al tercer día jtodavía dura ese día! Descansó. Y vio que lo que había hecho era bueno.

$Y$ vivió en aquella blanca y luminosa casa eternamente feliz.

Y los pájaros venían a posarse sobre ella.

Y los árboles que la circundaban le ofrecían su sombra y sus más sazonados frutos.

$Y$ el aire acariciaba la casa al atardecer.

$Y$ aunque el artista quiso refugiarse en el silencio, la Luz y la Belleza y la Arquitectura no cesaron de proclamar a los cuatro vientos lo que allí había sucedido (...)".

${ }^{3}$ CAMPO BAEZA, Alberto. La idea construida. Ed. Colegio Oficial de Arquitectos de Madrid. Madrid. 1996. p.12.

${ }^{4}$ La Carta Europan se puede consultar entre los documentos del ANEXO 1 de la tesis..

${ }^{5}$ CAMPO BAEZA, Alberto.lbídem, p. 13. 


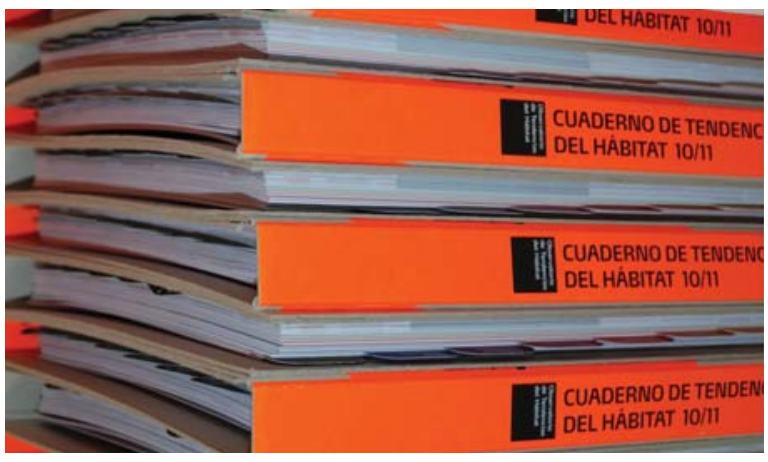

Ref.3.5. Cuaderno de tendencias del hábitat 2010/2011

\section{Nuevas formas de habitar}

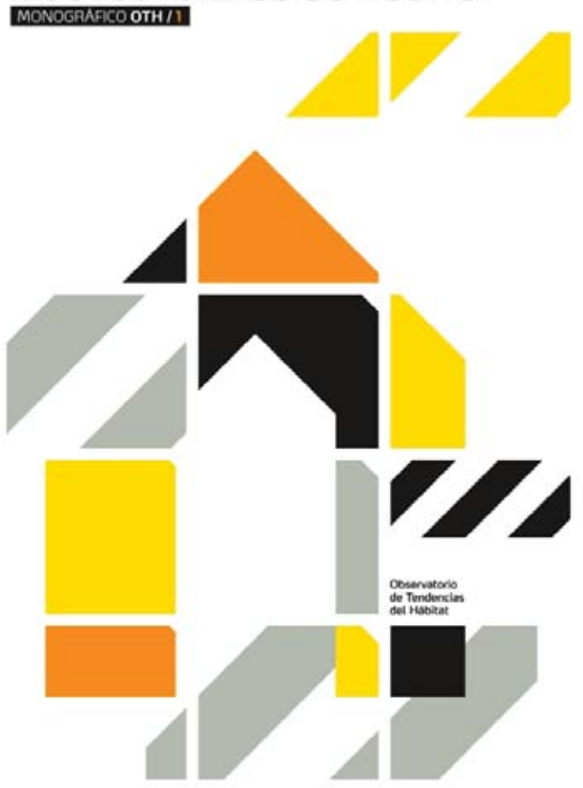

Ref.3.6. Publicación del Observatorio de Tendencias del Hábitat "Nuevas formas de habitar"

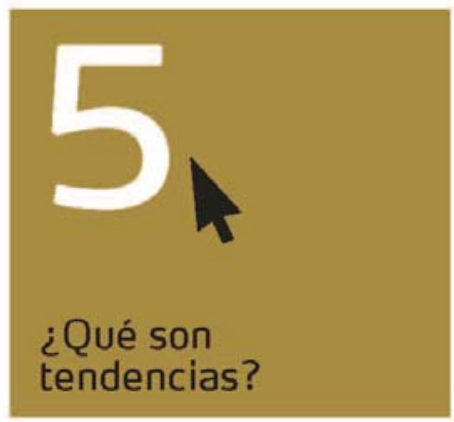

\section{¿Qué es tendencla?}

Definimos tendencia del hábitat como una serie de pautas comunes (estéticas, formales, funcionales y conceptuales) que lo identifican y que tienen propensión a evolucionar en el tiempo, es decir, no es un hecho puntual, sino con trascendencia en el tiempo.

El conocimiento de una tendencia implica comprender las causas que la impulsan, identificar su consumidor potencial, caracterizar cómo se manifiesta y el momento en el que se encuentra, es decir, si es incipiente o ya está asumida.

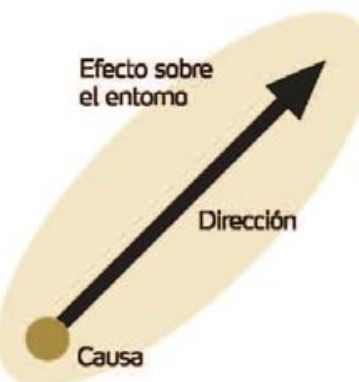

Ref.3.7. Explicación del término tendencia según el Observatorio de Tendencias del Hábitat 
Aunque por idea se entiende "el primero y más obvio de los actos de entendimiento", cuando se utilice este término en la tesis no se hará exactamente con esta acepción. Más bien se hace referencia a los temas de investigación o cuestiones propuestas en cada enunciado de Europan, podría ser un sinónimo del término inglés topic. Así pues durante este capítulo se hace referencia al término idea para hablar de los planteamientos teóricos de Europan.

También se podría utilizar el término tendencia, aunque implica una repercusión de las ideas mantenidas en el tiempo pues según el OTH (Observatorio de Tendencias del Hábitat ${ }^{7}$ ) se define este término como "una serie de pautas comunes (estéticas, formales, funcionales y conceptuales) que la identifican y que tienen propensión a evolucionar en el tiempo, es decir, no es un hecho puntual, sino con trascendencia en el tiempo". Se podría afirmar por lo tanto que el ser humano tiene capacidad de anticiparse a los cambios y puede participar en la generación de tendencias. Las ideas que se han clasificado como permanentes se podrían denominar tendencias, pero finalmente no se utiliza este término pues podría dar lugar a confusión ya que se utiliza más en otras disciplinas como, por ejemplo, el de la moda.

Es interesante leer un breve artículo de Mies y descontextualizarlo de la época en que fue publicado pues parece que lo ha escrito para este momento:

"La arquitectura no ha de ser objeto de especulación intelectual, en realidad sólo puede entenderse como Lebensvorgang (acto vital), y es la expresión de cómo se afirma el hombre respecto a su entorno y cómo pretende dominarlo. El conocimiento de la época, de sus tareas y sus medios, es un requisito imprescindible de la creación arquitectónica. La arquitectura es siempre la expresión espacial de una decisión intelectual.

El desarrollo del tráfico es cada vez mayor. El mundo se reduce cada vez más, cada vez se hace más visible hasta el rincón más alejado. La consecuencia es una mayor conciencia del mundo y de la humanidad.

La economía empieza a reinar, todo está al servicio de la utilidad. La rentabilidad se convierte en ley. La técnica aporta una visión economicista, transforma la materia en fuerza y la cantidad en calidad. La técnica presupone conocer las leyes de la naturaleza y trabajar con sus fuerzas. Se busca conscientemente la mayor utilidad de la fuerza. Nos encontramos ante un cambio de época ${ }^{8 "}$.

Como resultado de todo lo expuesto se podría decir que, si los arquitectos fueran

${ }^{6}$ Primera acepción del término idea en REAL ACADEMIA ESPAÑOLA. Diccionario de la Real Academia Española. 22ª Edición. Ed. Espasa- Calpé. Madrid. 2001.

7 "Es la unión de tres Institutos Tecnológicos para que empresas relacionadas con el hábitat de la Comunidad Valenciana puedan disponer de información y conocimiento de las tendencias y necesidades del mercado para elaborar estrategias de diseño, desarrollo del producto y posicionamiento del mercado".AA.VV. Nuevas formas de habitar. Ed. Impiva. Valencia. 2009. p.12.

${ }^{8}$ NEUMEYER, Fritz. Mies van der Rohe, La palabra sin artificio. Reflexiones sobre la arquitectura 1922-1968. Ed. El Croquis. Madrid. 1995. p.459. 
VIVIENDAS EUROPAN (1988-2008) I Una aproximación a los modos de vida en el cambio de siglo en España

3. EUROPAN: LABORATORIO DE IDEAS SOBRE EL HABITAR

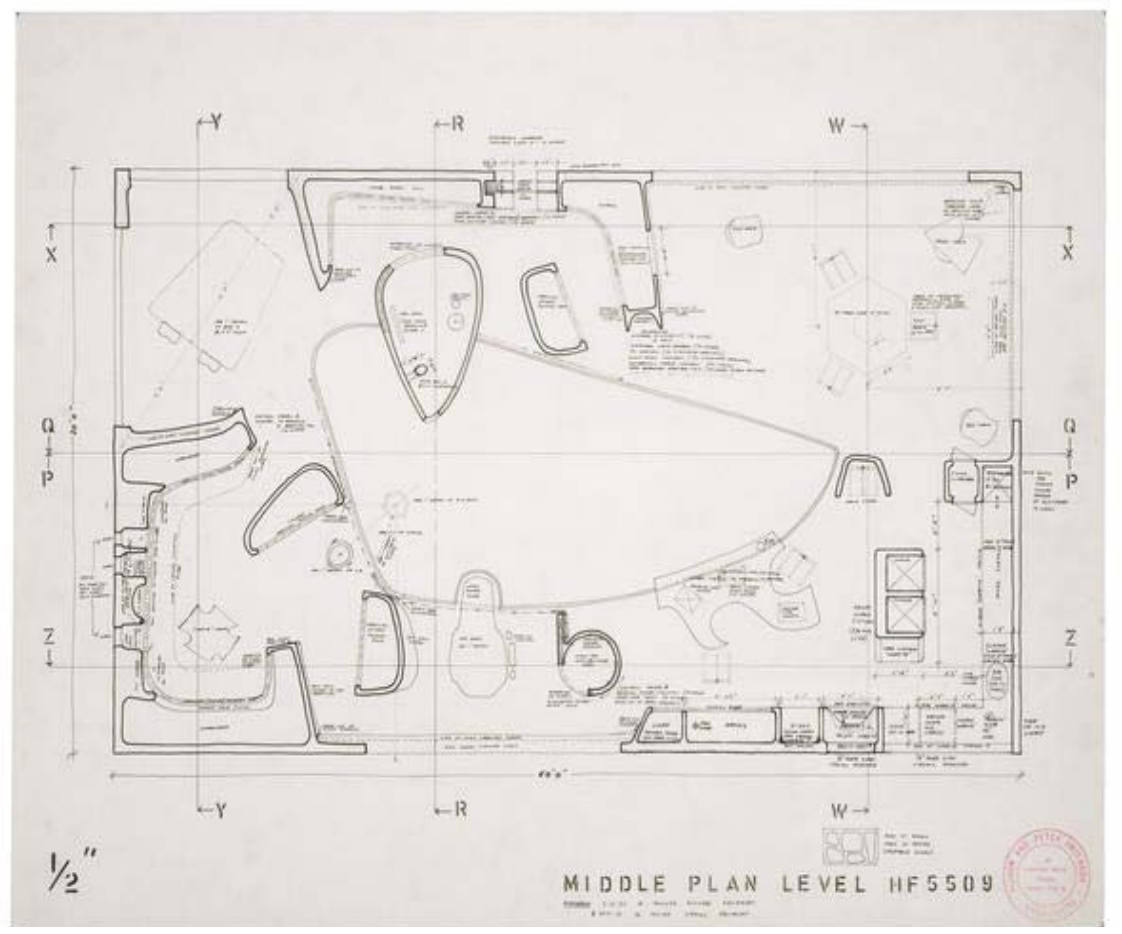

Ref.3.8. Alison \& Smithson. Plano de la casa del futuro

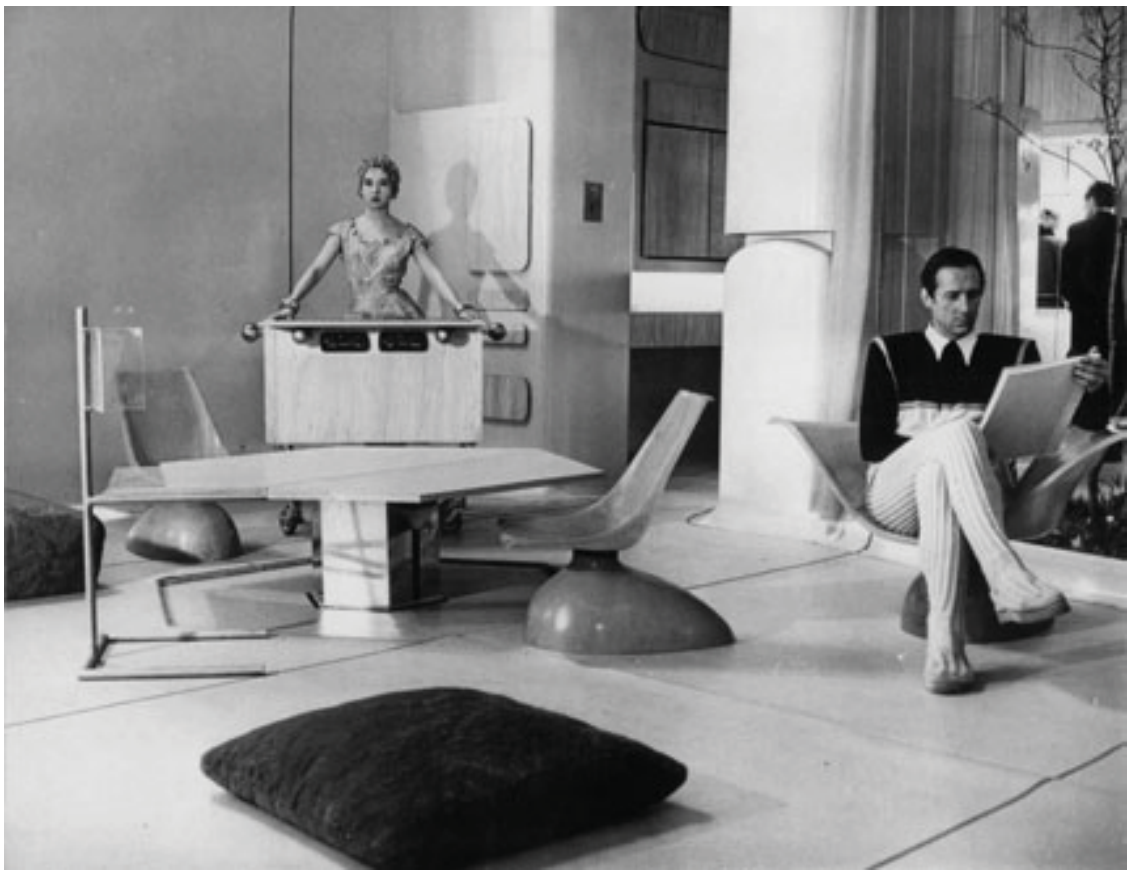

Ref.3.9. Alison \& Smithson. Casa del futuro 
capaces de identificar las ideas subyacentes del momento que representan las necesidades del ser humano, se podría elaborar una arquitectura de vanguardia que, como expresaba Mies, creara la forma desde la esencia del problema con los medios de nuestra época. ${ }^{9}$.

Hasta este momento se ha considerado que la arquitectura debe basarse en la toma de decisiones intelectuales y, por tanto, el sustrato conceptual de hoy, marcará la arquitectura del mañana. Pero también se hace necesario apuntar que cada decisión intelectual lleva consigo un esfuerzo que debe ser tenido en cuenta, toda creación parte del dolor, en palabras de Alejandro de la Sota:

"Es artista quien descubre lo bello que hay en las cosas; las criba por el tamiz de la belleza y luego las ofrece a los demás.

Es labor de artistas descubrir lo bueno de cada paisaje. Quiero decir que, cuando de crear paisaje se trate, paisaje grande o pequeño paisaje, jardín, es necesario usar solamente aquello que nos quedó en el tamiz.

La auténtica belleza de las cosas es algo así como un jugo tremendamente denso que sólo puede extraerse apretándolas con todas nuestras fuerzas hasta producir dolor en quien se aprieta y en lo apretado, solamente podremos hacer cosas bellas usando estos jugos. Si queremos, repito, crear paisajes, antes es necesario apretar paisajes, prensarlos.

No; no hay arte sin creación. Cada nueva forma debe ser sufrida con el dolor que todo nacimiento lleva consigo ${ }^{10}$.

Pero muchas veces las decisiones intelectuales no pueden llevarse a cabo, pues una cosa son las pretensiones, los deseos, y otra la realidad. Si estas ideas fueran acertadas, y hubiera una adecuación entre ambas realidades, una coherencia, tal vez el panorama actual de la arquitectura cambiaría.

A continuación se analizan las ideas en los enunciados de Europan.

${ }^{9}$ MIES VAN DER ROHE, Escritos, diálogos y discursos. Ed. Colegio Oficial de aparejadores de Murcia. Galería-Librería Yerba. Murcia. 1982. p.25 .

${ }^{10}$ DE LA SOTA, Alejandro. Escritos, conversaciones, conferencias. Ed. Gustavo Gili.Barcelona. 2002.p. 
VIVIENDAS EUROPAN (1988-2008) I Una aproximación a los modos de vida en el cambio de siglo en España

3. EUROPAN: LABORATORIO DE IDEAS SOBRE EL HABITAR

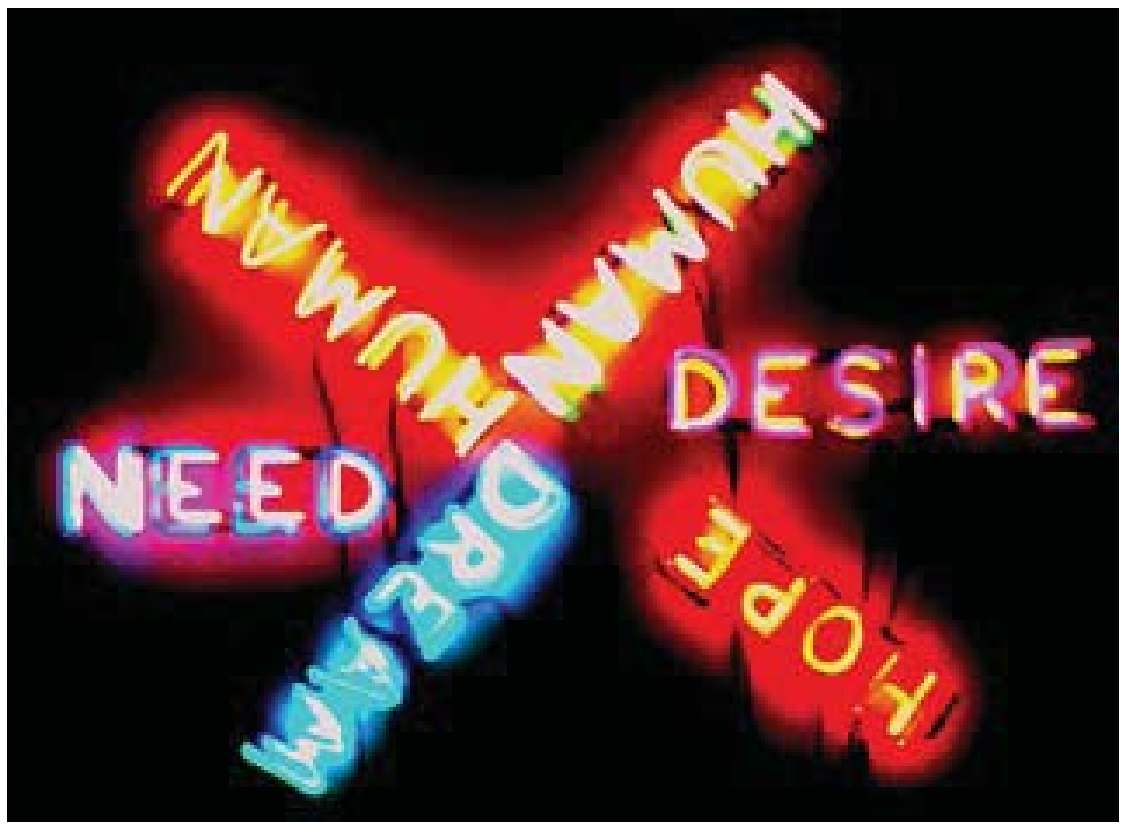

Ref. 3.10. Génesis de proyecto. Instalación de Bruce Nauman

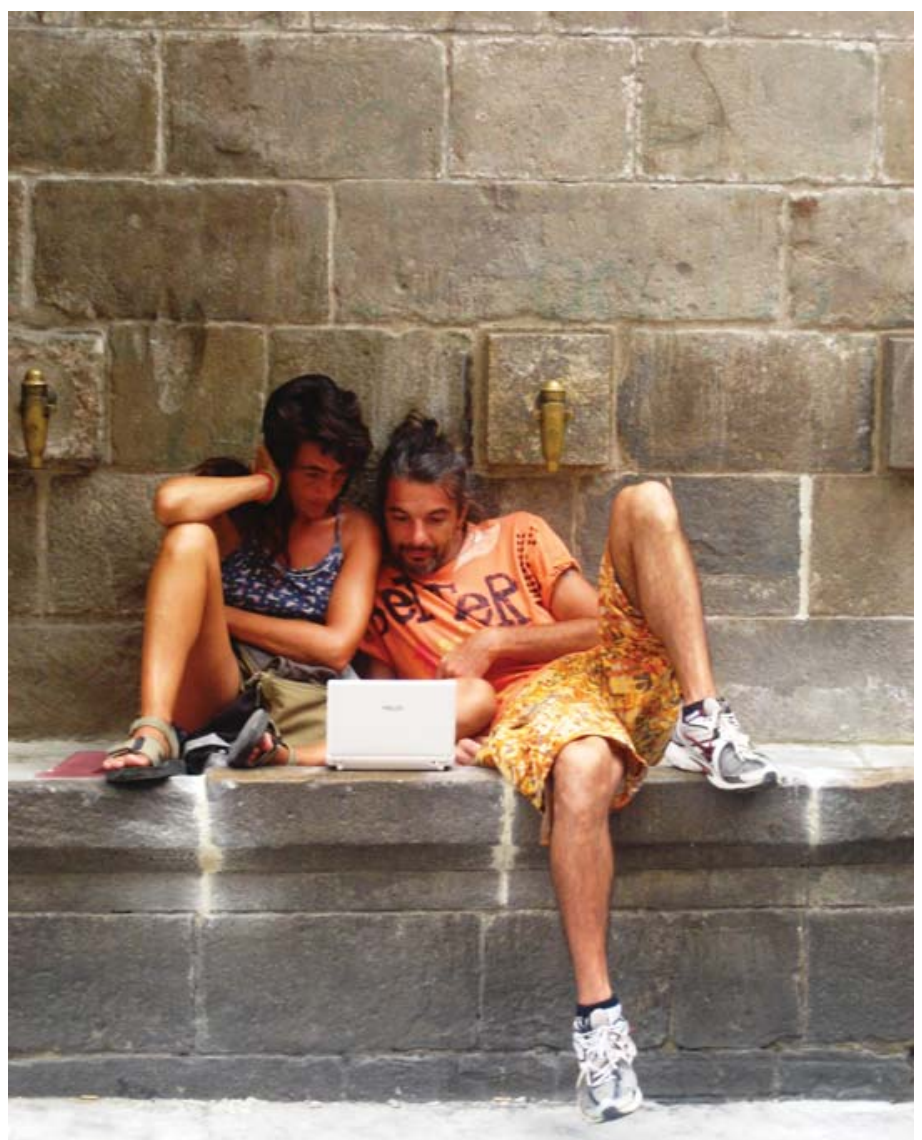

Ref.3.11. Internet llega a todos los rincones. Fotografía cotidiana en Barcelona. 


\subsection{Laboratorio de ideas}

\subsubsection{Identificación de las ideas}

Previamente al lanzamiento de cada convocatoria, Europan convoca una reunión con el Comité Científico y el Comité Técnico Europeo, compuesto por un grupo de expertos de todos los países participantes para concretar los temas de investigación y las propuestas de suelo.

Hasta el año 2011 los temas sobre los que se ha reflexionado en Europan han sido: Evolución de los modos de vida y arquitecturas de la vivienda (Europan 1), Habitar la ciudad: recualificación de zonas urbanas (Europan 2), En la ciudad como en casa: fortalecimiento de áreas urbanas (Europan 3), Construir la ciudad sobre la ciudad: transformación de áreas urbanas contemporáneas (Europan 4), Los nuevos paisajes del hábitat: desplazamiento y proximidad (Europan 5), Entre ciudades: dinámicas arquitectónicas y nuevas formas urbanas (Europan 6), El reto suburbano: intensificación urbana y diversidad residencial (Europan 7), Urbanidad Europea y Proyectos Estratégicos (Europan 8), Ciudad sostenible y nuevos espacios públicos (Europan 9), Urbanidad Europea (Europan 10) y Territorios y modos de vida en resonancia, arquitecturas para la ciudad sostenible (Europan 11).

Si se leen de forma continuada los textos de cada convocatoria, recopilados en el ANEXO 2 de la presente tesis, se observa que tienen cierto interés indagar en los planteamientos intelectuales.

Tras varias lecturas de estos textos se van a identificar en este apartado de la tesis las principales ideas para que, posteriormente, se puedan agrupar por temas y comprobar así su evolución en el tiempo.

Por cada convocatoria, estos temas de investigación son los siguientes:

- Europan 1. Aborda dos cuestiones fundamentales:

\section{1.- Cómo se vive en Europa ${ }^{11} \mathrm{y}$}

11 "Europan era una ventana abierta hacia Europa porque esa primera inscripción en 1990, en la que la nueva comunidad se empezaba a intuir, la hicimos en una moneda utópica y sugerente, de sonido musical, el ecu, un euro arcaico en el que nos esforzamos en asimilar las pesetas que aún permanecerían durante diez años más. El premio lo recibimos también en ecus y con el cambio orientativo a la moneda vigente, comprobamos que alcanzaba para construir una austera maqueta y completar el coste de los viajes a las exposiciones europeas". GARCÍA DE PAREDES, Ángela. "Europan: una ventana hacia la arquitectura", en AA.VV. Europan 10, Proyectar la urbanidad, colonización/revitalización/ regeneración. Ed. Secretariado de Europan. Madrid. 2010. p. 221. 
VIVIENDAS EUROPAN (1988-2008) | Una aproximación a los modos de vida en el cambio de siglo en España

3. EUROPAN: LABORATORIO DE IDEAS SOBRE EL HABITAR

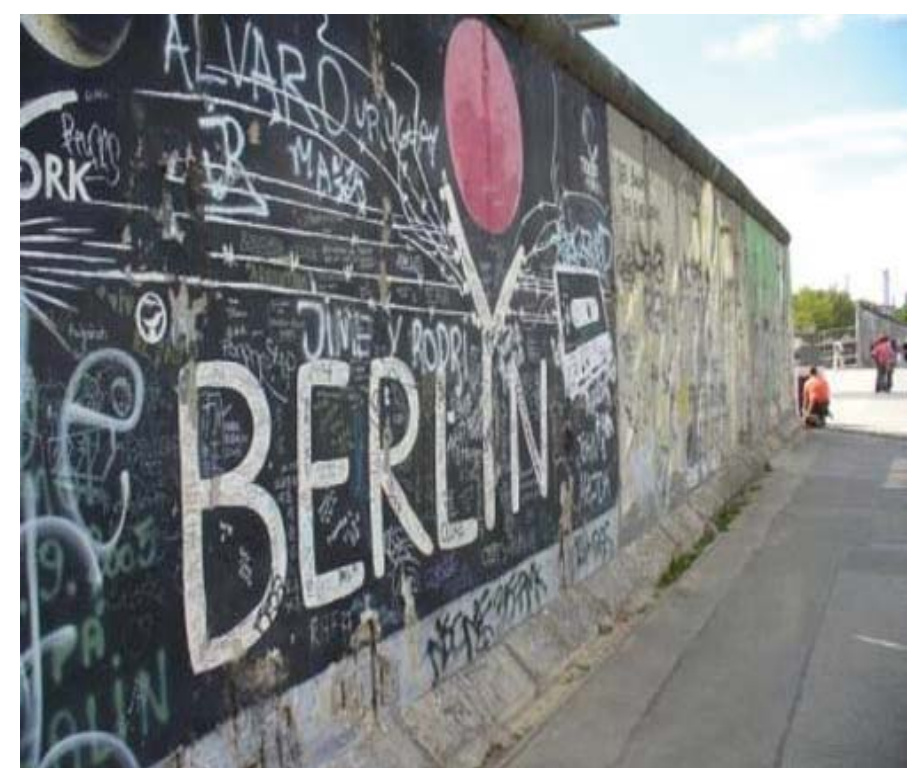

Ref.3.12. Imagen conmemorativa de la caída del muro de Berlín

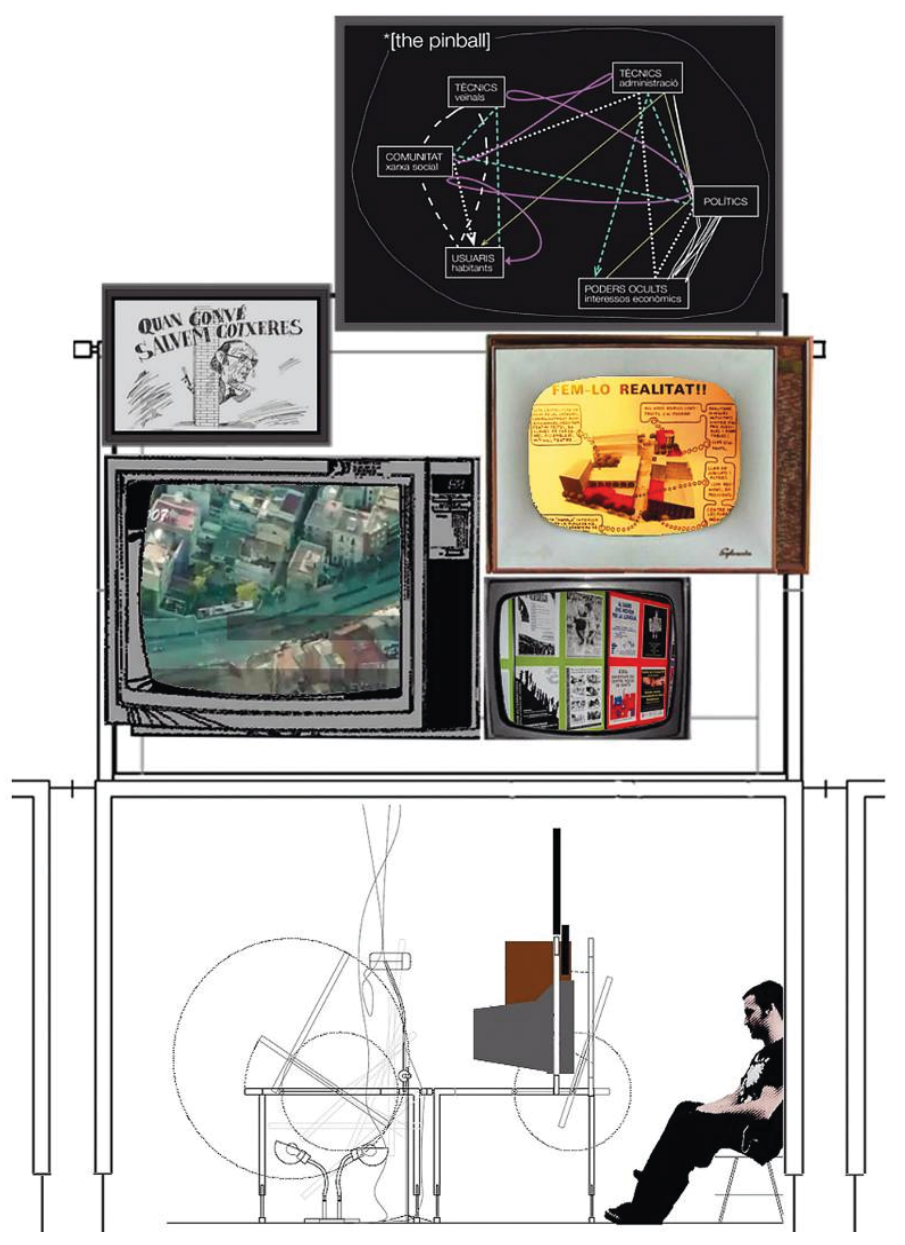

Ref.3.13. El televisor toma protagonismo en la vivienda 
2.- La transformación del hábitat (concretado en cuatro subtemas como el cambio en las estructuras familiares y el papel de la mujer en la sociedad, las nuevas formas de relación con el trabajo, la importancia del individualismo y del cuerpo y la aparición de las nuevas tecnologías).

- Europan 2. Se aproxima a seis ideas fundamentales:

1.- El hábitat y los modos de vida (que han ido transformándose identificando algunas causas como pueden ser los fenómenos demográficos, los cambios en los comportamientos sociales, la aparición del consumo de masas, etc.)

2.- La dinámica urbana. En esta edición de Europan se pasa de una escala de vivienda, a una mayor de barrio y a otra superior, de ciudad. Ésta última no puede ser pensada como un objeto acabado.

3.- La imagen de marca. La ciudad puede ser tratada como un producto de venta o consumo, olvidándose de la dimensión ecológica. Esto no sería positivo para la evolución de las ciudades: en este tema se propone considerar la atención acerca de la calidad del medioambiente y el fomento de la vida urbana teniendo en cuenta éste.

4.- El patrimonio urbano. Se plantea abordar la relación existente y la ciudad tradicional denominando la estrategia a seguir como cruce de temporalidades. Se cuestiona de qué modo puede la ciudad adaptarse a los cambios a medio plazo, sabiendo incorporar las permanencias a largo plazo.

5.- La multifuncionalidad. Se propone la viabilidad de la tradicional mezcla de usos y se habla de una ciudad atomizada. Se apuesta por la polifuncionalidad ya que en las ciudades existen actividades plurales.

6.- Las estrategias operativas. Se aborda la actuación en los proyectos de los promotores privados y la participación ciudadana. El ser humano es el protagonista del cambio que se va a dar en las ciudades, por lo tanto, es interesante que se le escuche, que se perciban sus carencias y sus intereses. Se trata de procurar que haya una mayor sensibilización del ciudadano con los temas que afectan a las ciudades porque, al fin y al cabo, todos queremos construir un mundo feliz. Se trata de encontrar procesos de realización democráticos, abiertos a la expresión y a la realización de los deseos de todos los ciudadanos.

Es interesante este planteamiento ya que se cuestiona también la relación que debe existir entre los técnicos y los ciudadanos afectados por su actuación en las ciudades.

- Europan 3. Plantea cuatro temas fundamentales:

1.- Los cambios en los modos de vida. Cómo actuar en los barrios existentes 
VIVIENDAS EUROPAN (1988-2008) | Una aproximación a los modos de vida en el cambio de siglo en España

3. EUROPAN: LABORATORIO DE IDEAS SOBRE EL HABITAR

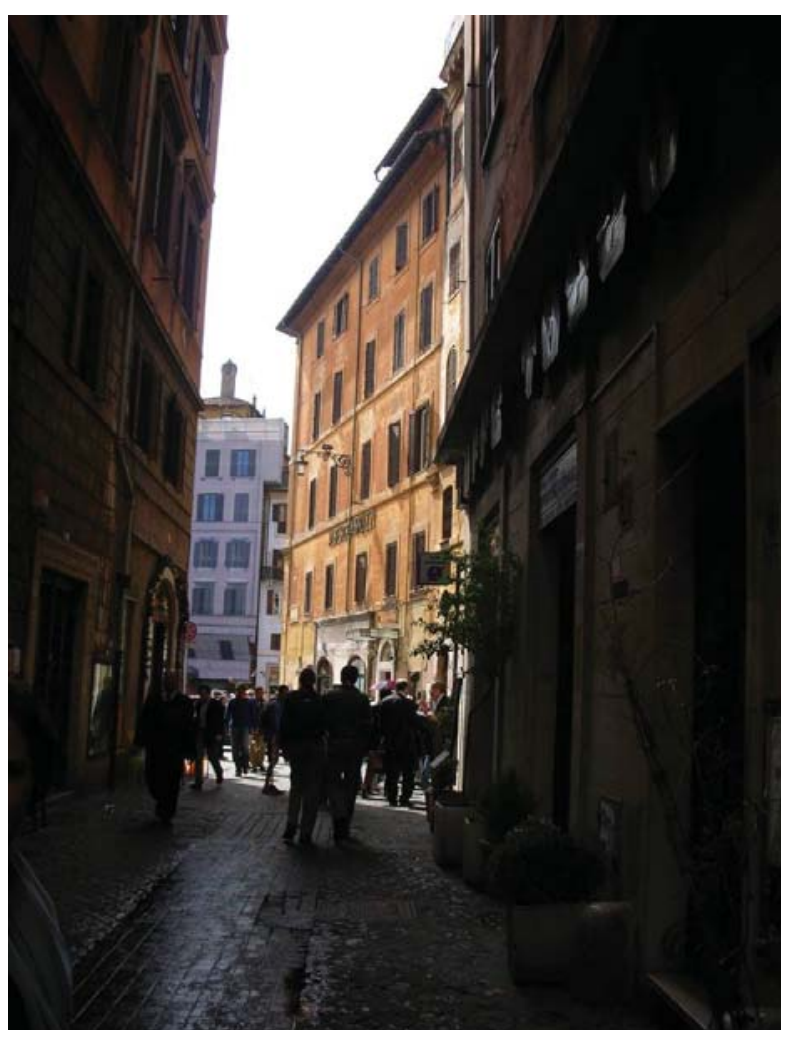

Ref.3.14. Calle en Roma previa al Panteón

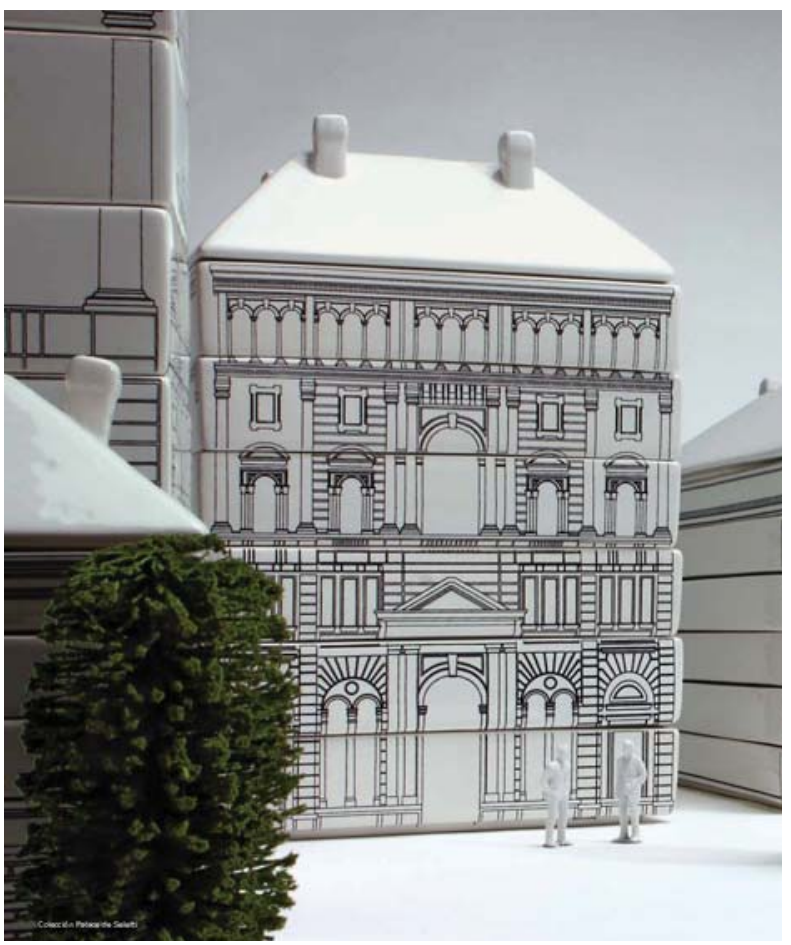

Ref. 3.15. Imagen de ciudad. Observatorio de Tendencias del Hábitat 
para hacerlos compatibles con los cambios en los modos de vida, basados en la pluralidad y que sean capaces de reactivarse.

2.- La relación que existe entre espacio privado y espacio público. Los barrios existentes son muy uniformes y no hay una buena gestión de los espacios existentes. Existen rupturas entre el espacio público y el privado: el espacio urbano está fragmentado. Se plantean como retos urbanos la convivencia de sociedades, la implantación de prácticas innovadoras, de tratar la mezcla de usos y la relación entre la vivienda y el trabajo (creando un empleo próximo al trabajo).

3.- La importancia de las relaciones sociales, debidas a los medios de comunicación y al uso del automóvil. Se amplía el entorno vital de las personas, debido a los cambios en las relaciones sociales.

4.- Potenciación de los valores ecológicos. La calidad de vida basada en estos valores es una premisa de la que no se debe prescindir en la ciudad.

- Europan 4. El enunciado de esta edición comienza con un preámbulo interesante: la construcción sobre la ciudad existente. Se puede observar un cambio en las estrategias de actuación pues no se trata de construir sobre la nada, sino que se empieza a hablar de términos como rehabilitación, reestructuración de lo existente, contar con la naturaleza como nuevo espacio público, crear microcentralidades comerciales y culturales,... se está hablando de la ciudad como un collage de distintas realidades existentes.

Esto lo resume en una pregunta global: ¿De qué manera construir los espacios contemporáneos de las ciudades europeas sobre las trazas de la dispersa ciudad moderna heredada del siglo XX?

Las ideas sobre las que se propone la investigación se agrupan en cuatro estrategias:

1.- Situarse, es decir, quitar prejuicios en la ciudad contemporánea con respecto a lo existente, plantea la cuestión de dónde se procede con una mentalidad abierta hacia lo existente.

2.- Transformar, se refiere a cambiar el uso de la ciudad preparándola para el futuro y teniendo en cuenta una política de enriquecimiento social.

3.- Heredar, es tener en cuenta la actitud con respecto a lo existente a partir de los datos geográficos y evaluando lo construido, también con respecto a una arquitectura menor.

4.- Conectarse, es unir las partes de una misma ciudad teniendo en cuenta el factor tiempo, situar el crecimiento urbano y unirlo a las trazas del pasado, sin 
VIVIENDAS EUROPAN (1988-2008) I Una aproximación a los modos de vida en el cambio de siglo en España

3. EUROPAN: LABORATORIO DE IDEAS SOBRE EL HABITAR

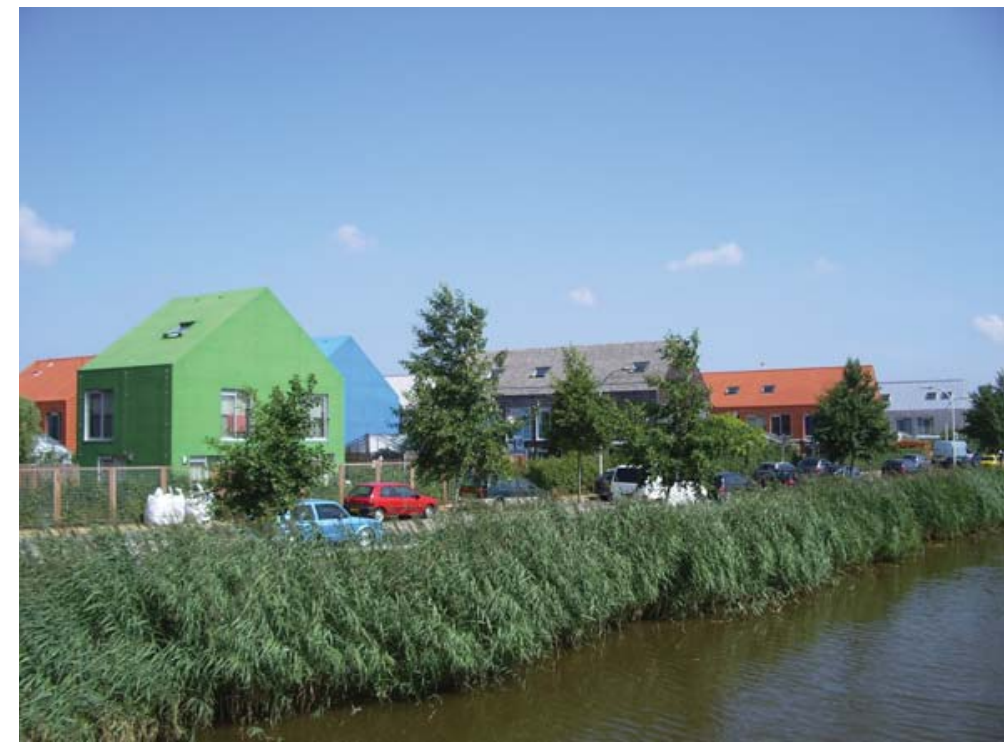

Ref. 3.16. Holanda, MVRDV

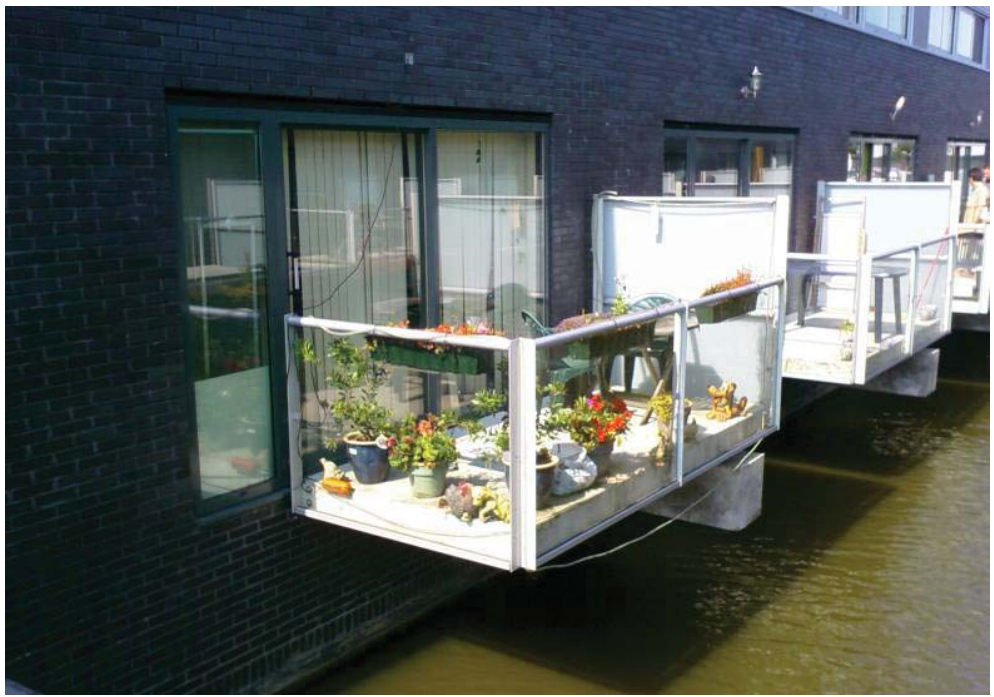

Ref. 3.17. Holanda, MVRDV

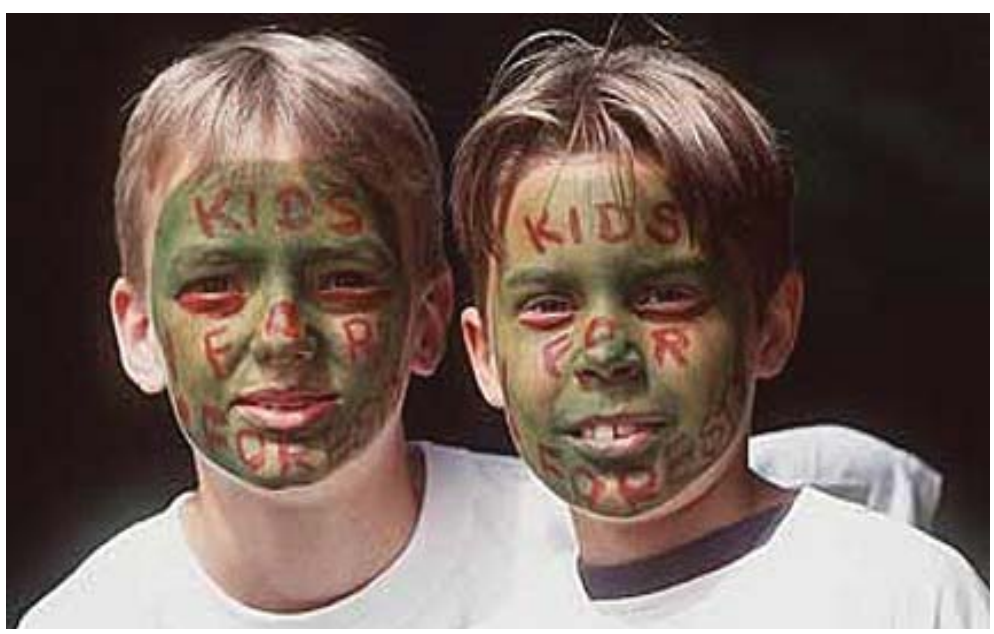

Ref 3.18. Imagen publicitaria de Greenpeace 
romper la estructura urbana existente.

- Europan 5. Al comienzo del texto de la convocatoria se realiza un preámbulo al igual que en la anterior, situando el campo de investigación elegido: los espacios urbanos abandonados debido a la existencia de redes de desplazamiento.

En esta edición se abordan seis ideas:

1.- Naturaleza y hábitat. Se cuestiona la conciliación de la densificación urbana y la naturaleza, si es posible poseer una vivienda altamente individualizada con la naturaleza.

2.- Desplazamientos y accesibilidad residencial. Se ha producido el fenómeno de la periferia tentacular. Las viviendas se sitúan en el extrarradio de las ciudades, por lo que necesitan una buena conexión con el centro de la ciudad y sobre todo, con los lugares de trabajo.

3.- Urbanismo inducido. En el texto no se expresa con claridad el propósito de esta idea, pero hay una referencia a la formalización de la ciudad, teniendo en cuenta la movilidad (idea anteriormente expuesta).

4.- Existencia de nuevos modos de vida, en los que se trata de responder a qué significa hoy en día habitar. Ofrece varias alternativas: poseer una parcela unifamiliar en la periferia, disponer de mayor espacio individual habitable, vivir en edificios colectivos próximos las áreas de servicios urbanos, vivir en contacto con la naturaleza, poder encontrar al paso de la vivienda espacios públicos habitados...

5.- Intensificación de usos. Se pretende crear barrios residenciales con vida urbana. Para esto es necesario crear una red de polos funcionales y proponerse programas plurales.

6.- Gestionar la complejidad. Lo que se plantea en esta cuestión es poder desarrollar los proyectos en el tiempo, integrando la forma urbanística, la programación y la definición arquitectónica.

- Europan 6. Tiene una estructura diferente en el texto de la convocatoria. En primer lugar plantea el contexto en el que se sitúa (espacios intermedios entre el centro y la periferia de las ciudades), después se propone las posibilidades de actuación en esas zonas y por último los emplazamientos.

1.-Actuación en las redes. En estas zonas intermedias es interesante reestructurar los viarios y contemplar todos los modos de desplazamiento contemporáneos (se proponen los coches, los transportes colectivos y las bicicletas). 
VIVIENDAS EUROPAN (1988-2008). I Una aproximación a los modos de vida en el cambio de siglo en España

3. EUROPAN: LABORATORIO DE IDEAS SOBRE EL HABITAR
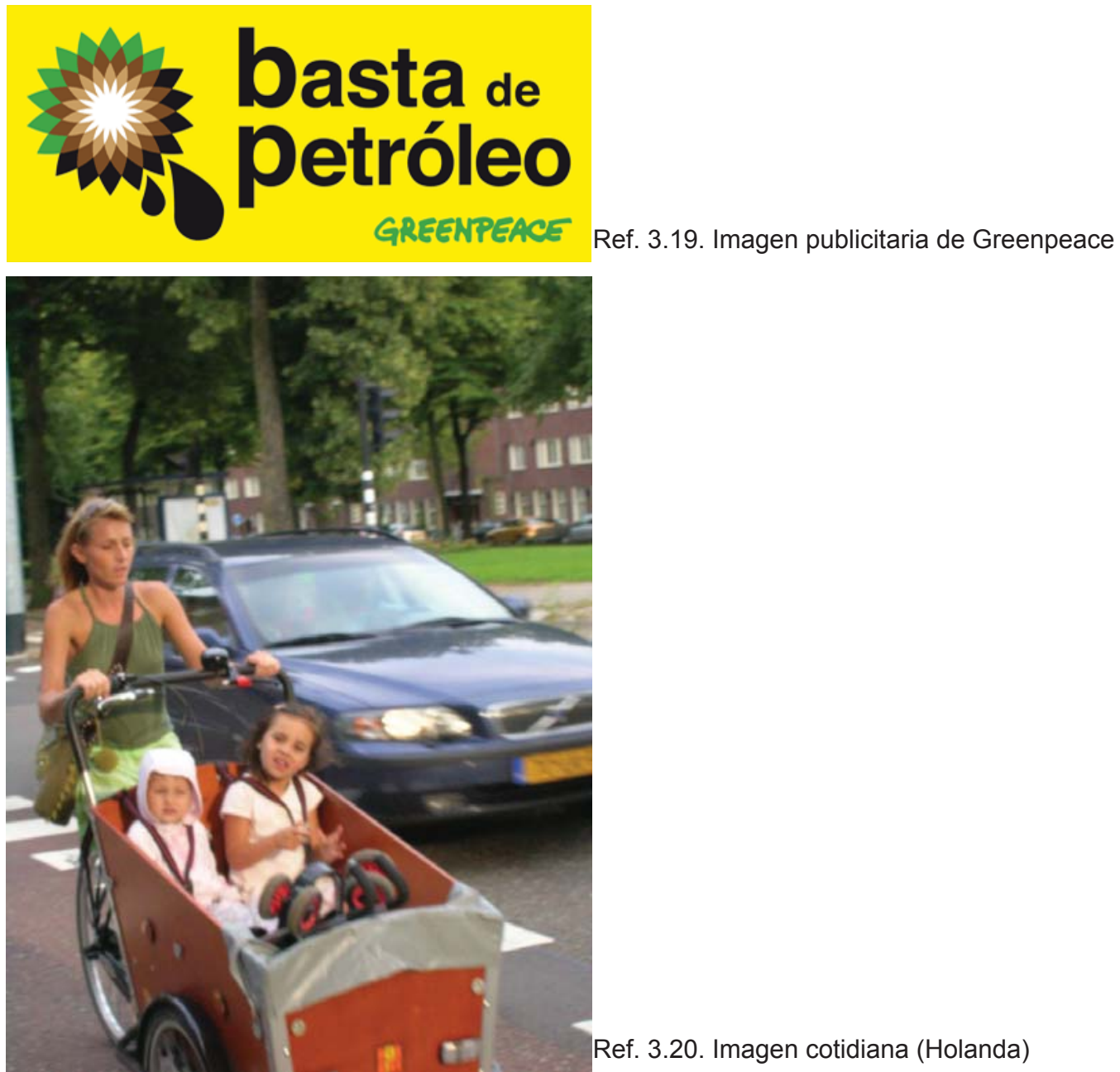

Ref. 3.20. Imagen cotidiana (Holanda)

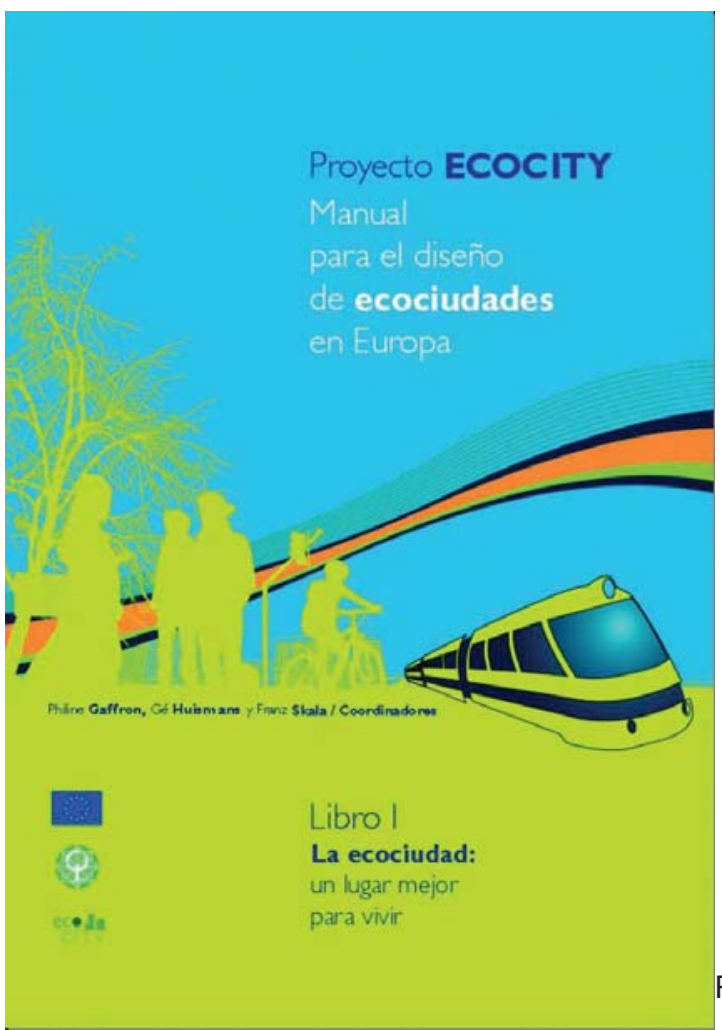

Ref.3.21. Manual de la Ecociudad 
2.- Actuación en la edificación. Se plantea aplicar una lógica urbana coherente, densificando áreas escasamente urbanizadas, sustituyendo edificios vetustos, reestructurando conjuntos de edificios heterogéneos e incorporando exigencias ecológicas en estas actuaciones.

3.- Actuando en el espacio público y en la calidad medioambiental. Revalorizando los espacios públicos existentes, insertando otros nuevos, tratando los espacios de transición entre las edificaciones y los espacios públicos, aplicando valores paisajísticos y gestionando los recursos.

- Europan 7. El texto de esta edición es muy breve. Lo contextualiza dentro de la ciudad dispersa. Aborda dos temas fundamentales

1.- Evolución en los modos de vida. Sigue apareciendo de forma concreta pues pone ejemplos como la diversificación de comportamientos en el seno de una misma familia, la movilidad profesional o la velocidad de los medios de transporte, entre otros.

2.- Sostenibilidad y ecología. Se habla de transformar la ciudad dispersa y dotarla de ciertos valores. Valores urbanos que permitan una ciudad sostenible y ecológica. Que estén basados en la nueva demanda social y cultural.

- Europan 8. El texto del enunciado tiene similitudes con el anterior: los dos primeros párrafos son idénticos al texto anterior. Los temas están bien definidos y es la primera convocatoria que plantea subtemas dentro de éstos. Este esquema de convocatoria de Europan es el que permanece vigente hasta el momento.

1.- Urbanizar con infraestructuras. Plantea cómo integrarlas dentro de la construcción de la ciudad.

2.- Generar lo nuevo. Se pretende poner freno a las extensiones urbanas y preservar el territorio natural.

3.- Reciclar el tejido. Existen tejidos híbridos en la ciudad suburbana. El planteamiento es que haya vida urbana dentro de estos tejidos, pero ¿Cómo?

4.- Construir con la naturaleza. Se plantea crear un equilibrio entre edificación y elementos naturales.

5.- Renovar para qué habitantes. Se trata de actuar para las personas que viven en el lugar, sin producir desplazamientos de la población.

- Europan 9. En esta edición no existe introducción. Anuncia inmediatamente los cuatro temas de reflexión, con los subtemas correspondientes: 
VIVIENDAS EUROPAN (1988-2008) I Una aproximación a los modos de vida en el cambio de siglo en España

3. EUROPAN: LABORATORIO DE IDEAS SOBRE EL HABITAR

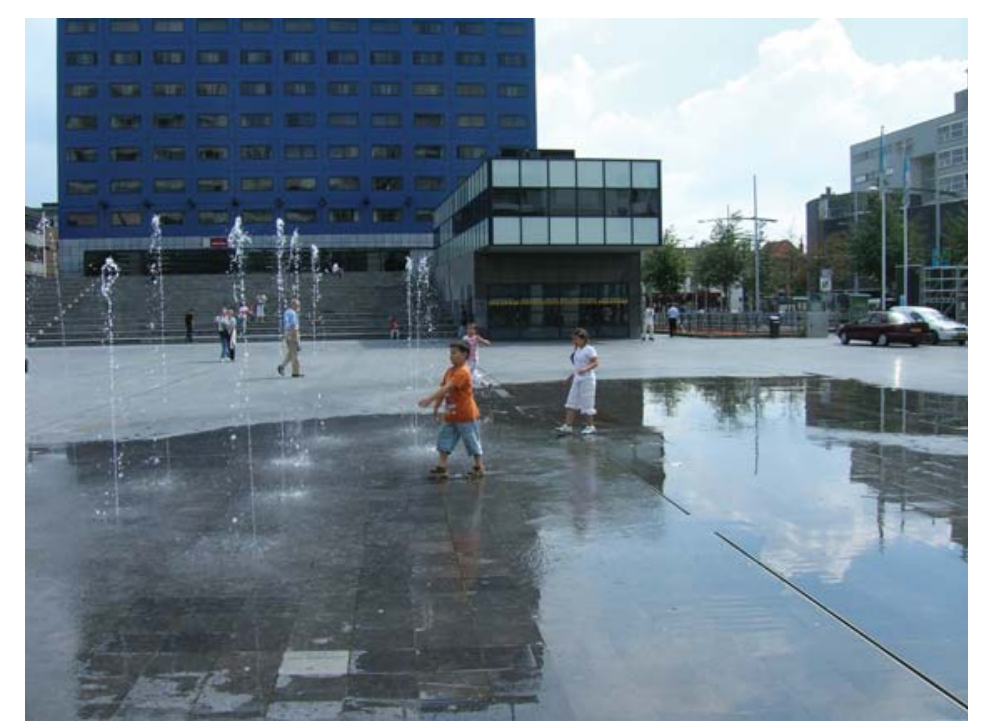

Ref. 3.22. La Haye, OMA,Amsterdam

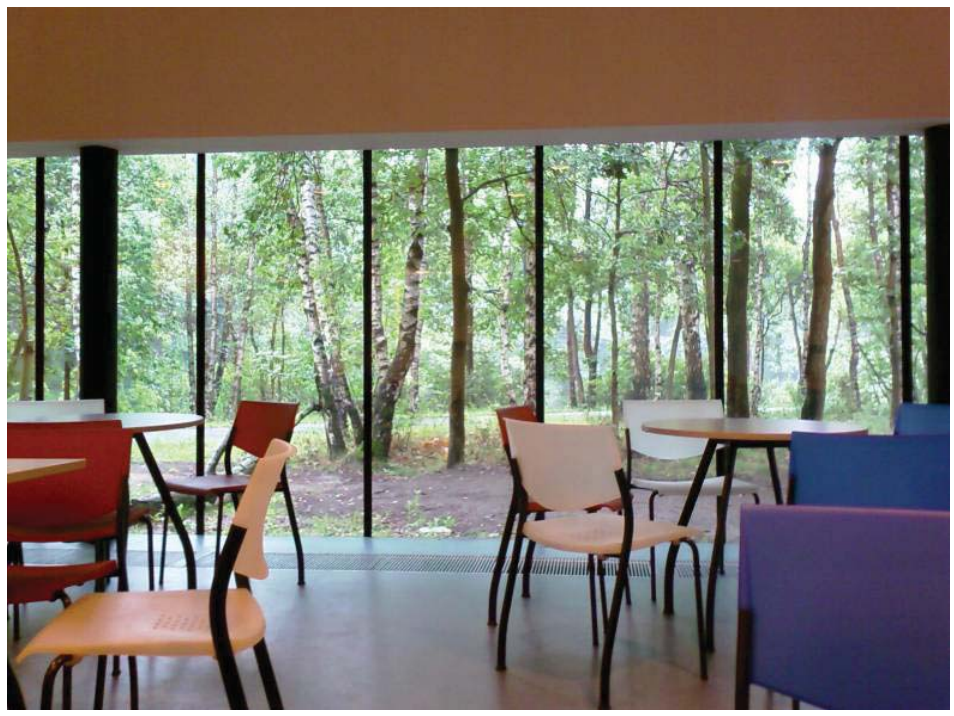

Ref.3.23.Museo en Amsterdam

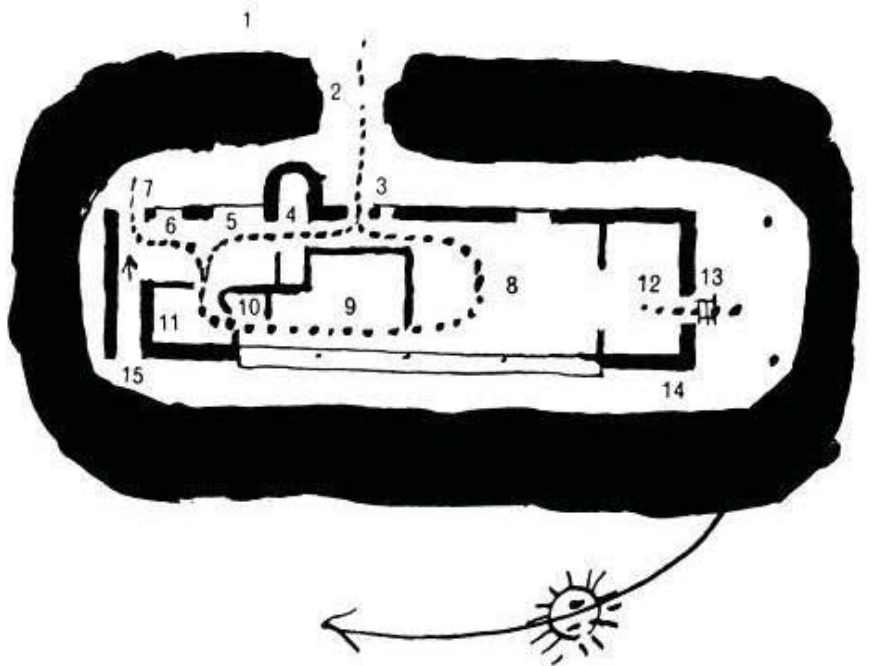

Ref.3.24. Une petit maison. Le Corbusier. Casa en el lago Leman. 1923 
1.- El crecimiento urbano a debate. Se habla de realizar un consumo moderado del territorio. Se plantea como posibilidad el desarrollar la ciudad a lo largo de una infraestructura o poner un límite a este crecimiento.

2.- Las redes en movimiento. Se plantea crear espacios urbanos dentro de las propias redes de desplazamiento, o alrededor de éstas.

3.- Las transformaciones locales. Se habla de "construir la ciudad sobre la propia ciudad", bien creando nuevos programas o bien generando nuevas dinámicas urbanas a través de la diversidad.

4.- Las oportunidades de espacio público. Se trata de crear espacios públicos conectados con los espacios vivos.

-Europan 10. Se introducen los temas de reflexión con unas ideas sueltas acerca de lo que es la urbanidad europea, la sostenibilidad, la escala y el programa que se propone y la interdisciplinariedad. Los temas a desarrollar (que también plantean subtemas) son:

1.- Regeneración. Se trata de recuperar áreas que han perdido su función. Dentro de los subtemas se plantea una transformación programática, una mutación paisajística o una transformación social.

2.- Revitalización. Se propone crear una nueva cultura mediante tres subtemas: la acupuntura urbana, los espacios públicos lineales y los polos magnéticos.

3.- Colonización. Este último tema trata de reflexionar acerca de habitar un área nueva. Se propone la creación de nuevas comunidades de individuos, la creación de trazas urbanas o proporcionar distintas escalas de sostenibilidad.

-Europan 11. Este es la última convocatoria a analizar hasta el momento. Comienza con la definición del término resonancia y elabora un preámbulo en el que pone de manifiesto el reto de la sostenibilidad para esta edición.

Esta convocatoria plantea tres propuestas de reflexión:

1.- Identidad. Se cuestiona cómo pasar de la escala de lo global a la local. Esto se puede realizar según los subtemas planteados: de la marginalidad a la relevancia (se plantea cómo puede cambiar la identidad de solares marginales), de la indefinición al carácter (se plantea cómo se pueden definir nuevos espacios urbanos y paisajísticos) y de una identidad obsoleta a una nueva identidad (se plantea cómo puede cambiar la identidad mediante la creación de nuevos programas).

2.- Usos. Se debe tener en cuenta lo existente, atribuyendo nuevos programas a 
VIVIENDAS EUROPAN (1988-2008) I Una aproximación a los modos de vida en el cambio de siglo en España

3. EUROPAN: LABORATORIO DE IDEAS SOBRE EL HABITAR
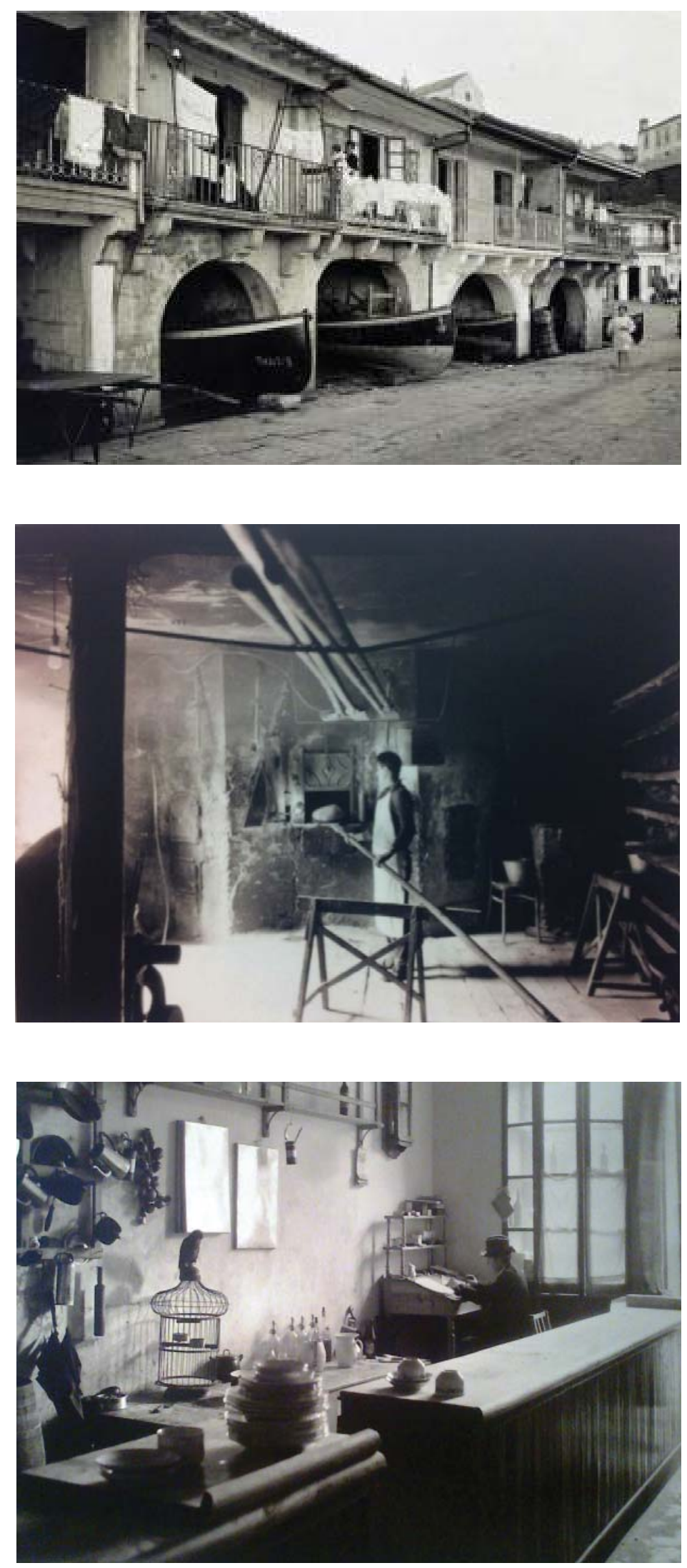

Ref.3.25.Fotos de Ruth. M Anderson. Exposición en Valencia 2011 
los emplazamientos, bien mediante tres subtemas: el de los espacios en desuso a la vida urbana, o el del aislamiento a la integración social o bien del espacio intermedio al espacio compartido en el que se reflexiona sobre el espacio público.

3.- Conectividad. Plantea la conexión existente entre lo global y lo local mediante tres subtemas: de la situación de borde a la incorporación, del espacio vacío al espacio de relación o bien del lugar al territorio.

Hasta el momento se ha realizado un resumen de las ideas de cada convocatoria. No se trata de interpretar estas ideas, pues sería una tarea pretenciosa, pero sería interesante poder intuir porqué se han planteado en cada momento. Ciertamente resulta un trabajo innovador porque no se ha realizado con anterioridad ${ }^{12}$. A continuación se va a tratar de clasificar las ideas hasta ahora analizadas. A unas se las ha denominado transitorias y a otras permanentes. Sobre éstas últimas se va a acentuar la atención de la tesis.

\subsubsection{Ideas transitorias}

A lo largo de los enunciados de las convocatorias de Europan, existen ideas que se plantean sin continuidad: se las ha denominado por este motivo transitorias. Algunas no vuelven a aparecer porque ya se han hecho realidad (son como un rayo de esperanza, luces de bengala que indicaban hacia dónde dirigir la mirada). Otras, por el contrario, aparecen por un motivo muy puntual, son evanescentes y, por lo tanto, carecen de interés. No obstante, se considera interesante nombrarlas todas tal y como se hace a continuación además de intentar buscar la razón de su planteamiento.

Estas ideas son: la globalización, el cambio en las estructuras familiares, la imagen de marca y las estrategias operativas.

\section{Globalización}

La idea de globalización aparece en la primera y segunda edición de Europan

\footnotetext{
${ }^{12}$ Quizá recuerde al famoso libro de Peter Collins cuando realizó un balance de dos siglos de la arquitectura y justificaba su actuación aludiendo a que anteriormente ya lo habían hecho otros. Collins afirmaba que "los cambios que se han producido en la apariencia de los edificios durante estos dos siglos han sido analizados exhaustivamente por Henry-Russell Hitchcock, al igual que los orígenes de la arquitectura contemporánea han sido analizados exhaustivamente por Sigfried Giedion; y puesto que los libros de estos dos autores son textos básicos (que pueden ser copletados posteriormente con pruebas adicionales, pero que serán siempre exposiciones clásicas sobre el tema), podría parecer pretencioso sugerir que un tercer enfoque pueda contribuir a la plena comprensión de este período" COLLINS, Peter. Los ideales de la arquitectura moderna: su evolución (1750-1950). Ed. Gustavo Gili. Barcelona. 1998. pp. 9-10.
} 
VIVIENDAS EUROPAN (1988-2008) I Una aproximación a los modos de vida en el cambio de siglo en España

3. EUROPAN: LABORATORIO DE IDEAS SOBRE EL HABITAR

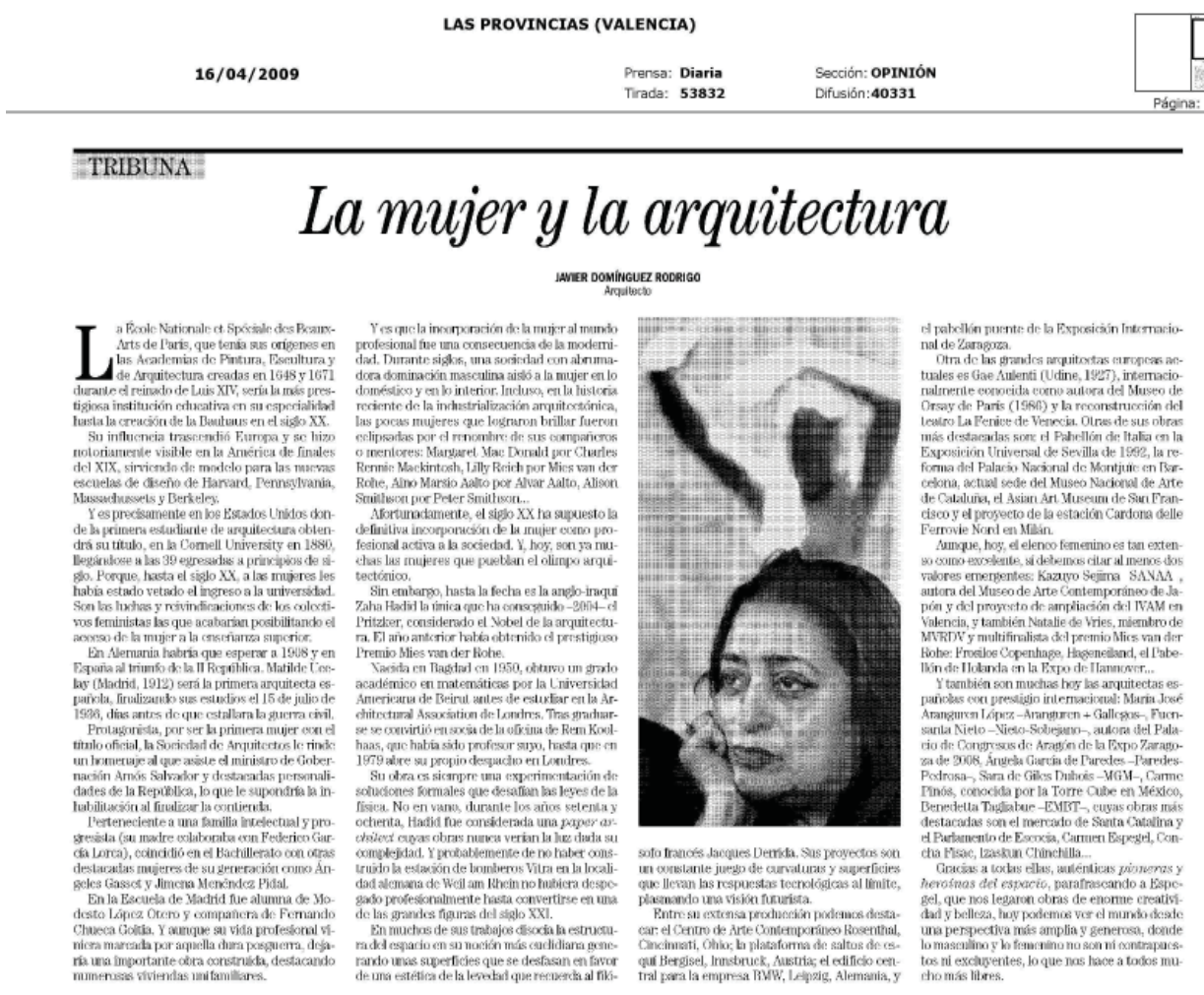

Ref.3.26. Mujer y arquitectura

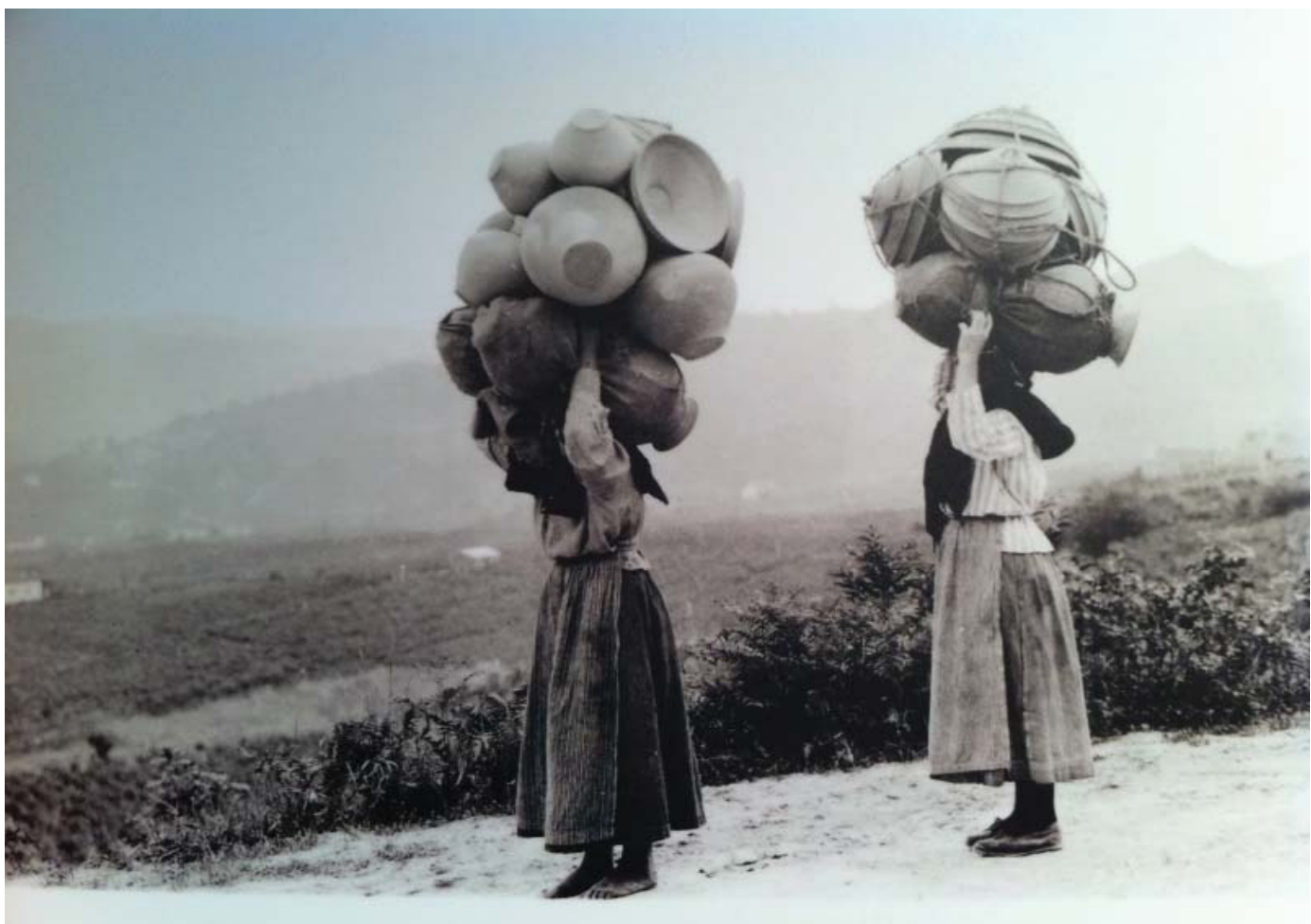

Ref.3.27. Fotos de Ruth. M Anderson. Exposición en Valencia. 2011. 
(años 1988-1990). En las convocatorias posteriores la globalización se da por supuesta, pues es algo ya superado, principalmente por el surgimiento y el uso de las nuevas tecnologías.

Esta línea de investigación se propuso probablemente debido al momento histórico que se estaba viviendo en 1989 con la caída del muro de Berlín y el final de la guerra fría, tal y como narra a continuación Friedman cuando trata de reflexionar acerca de la globalización afirmando que "la caída del Muro de Berlín el 9 de noviembre de 1989 desató una de las fuerzas que liberaron, en última instancia, a todos los pueblos cautivos del Imperio Soviético. Pero en realidad hizo mucho más que eso. Inclinó la balanza de poder en el mundo entero a favor de quienes defienden un gobierno democrático, consensuado y orientado al libre mercado, y en detrimento de quienes defienden el régimen autoritario y las economías dirigidas desde un poder central. La Guerra Fría había sido una lucha entre dos sistemas económicos (el capitalismo y el comunismo), y con la caída del Muro sólo una quedaba en pie y todas las personas debían orientarse hacia él de una u otra forma. Desde aquel momento cada vez más economías se organizarían de abajo arriba, siguiendo las demandas y las aspiraciones de las personas, y no de arriba abajo, siguiendo los intereses de una reducida camarilla gobernante. En cuestión de dos años dejó de haber un imperio Soviético tras el que esconderse o con el que sostener regímenes autocráticos en Asia, en Oriente Medio, en África o en Latinoamérica. Si no eras una democracia o una sociedad en proceso de democratización, si seguías empeñando en agarrarte a un sistema económico altamente regulado o planificado desde el poder central, se te consideraba metido en el lado equivocado de la historia ${ }^{13 "}$.

Una de las causas principales de la acción globalizadora posteriormente a 1990 es la aparición de las redes, tanto de transporte (que permiten mayor movilidad en el tráfico de personas y mercancías) como de nuevas tecnologías.

La globalización y la revolución digital ya han tenido lugar, con ésta última se han acortado las distancias en la forma de comunicación entre las personas. La globalización ya es una realidad, pues vemos a diario la mezcla social, la interculturalidad y el fácil intercambio de información desde cualquier punto del planeta.

\section{Cambio en las estructuras familiares}

Otro tema que aparece en Europan y que se podría considerar como una idea evanescente es el del cambio en las estructuras familiares. Sobre todo porque es un tema superado y nada innovador para el momento en el que se plantea (1988). Europan se cuestiona en su primera convocatoria qué papel podría desempeñar la

${ }^{13}$ FRIEDMAN, Thomas. La tierra es plana. Ed. Martínez Roca. Madrid. 2005. p. 58 
VIVIENDAS EUROPAN (1988-2008) I Una aproximación a los modos de vida en el cambio de siglo en España

3. EUROPAN: LABORATORIO DE IDEAS SOBRE EL HABITAR

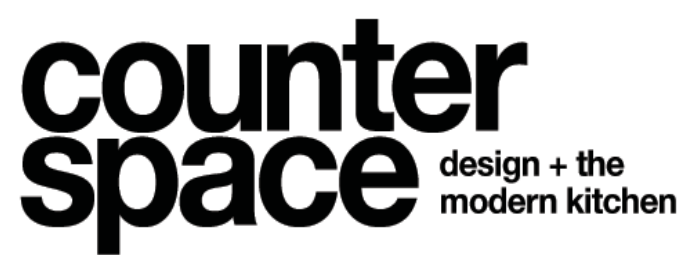

the museum of modern art september 15, 2010-may 2, 2011
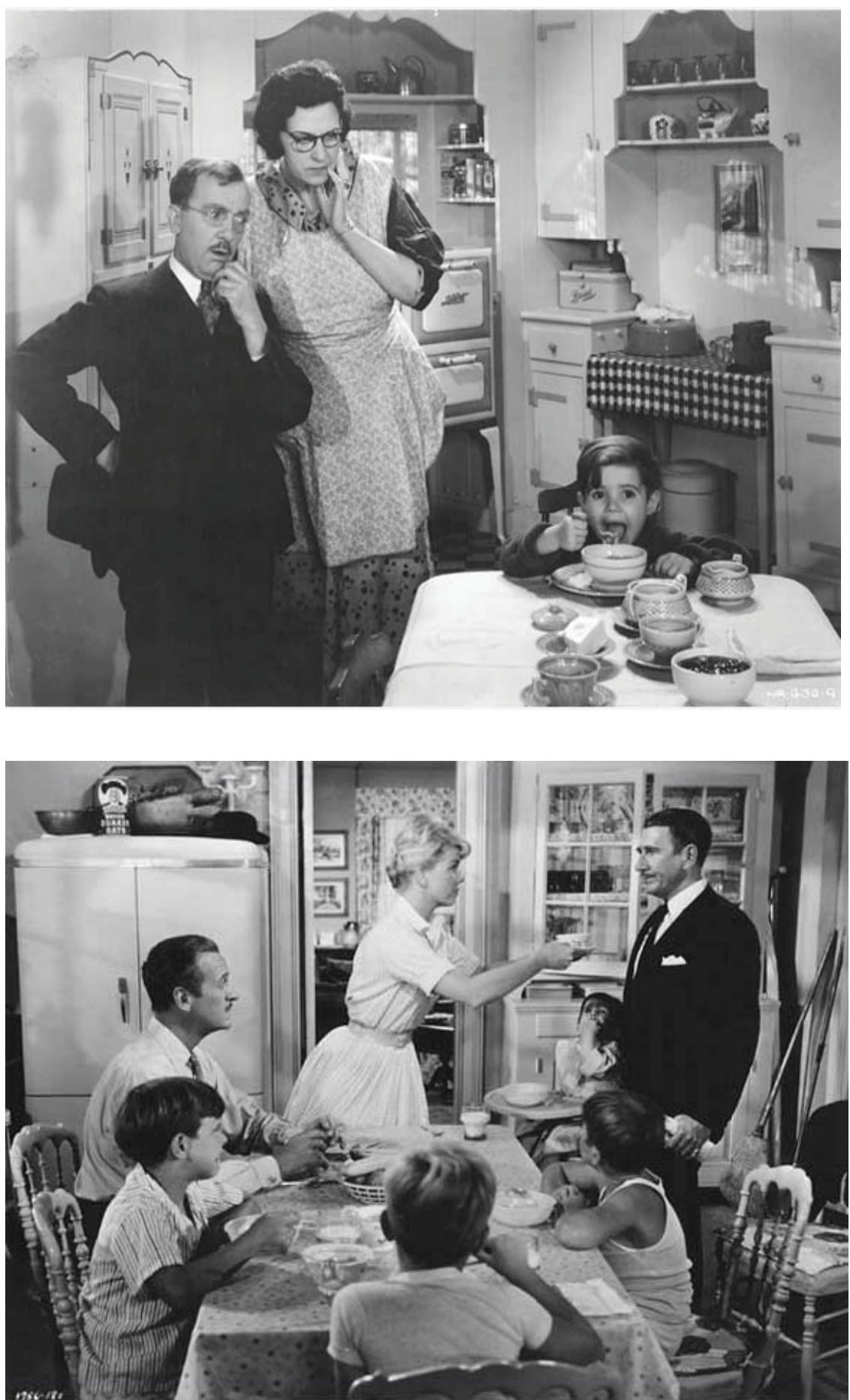

Ref. 3.28. Exposición en el MoMa acerca de la cocina. Counter Space: Design and the Modern Kitchen, September 15, 2010-May 2, 2011. 
mujer en la sociedad y el cambio en las estructuras familiares. Pero este tema se podría abordar también desde la sociología y, por su amplitud, podría ser motivo de otra tesis doctoral.

El motivo del planteamiento de esta cuestión es fundamentalmente la revolución que ha habido en el mercado laboral con el acceso de la mujer al mundo del trabajo.

Así lo desarrolla Blanca Lleó cuando afirma que "una de las causas que más ha transformado la organización familiar en el hogar, ha sido el acceso de la mujer al mundo del trabajo. Este proceso, que se inició de forma masiva en torno a la II Guerra Mundial, provocó la ruptura paulatina de la dicotomía tradicional entre el carácter femenino de lo privado y el masculino de lo público; del interior secreto y oculto frente al mundo exterior del intercambio y la producción. Semejante cambio social fue propiciado por la proliferación de los electrodomésticos en el hogar y por la escasez de mano de obra masculina en los tiempos de la confrontación bélica. Sin embargo, no han sido sólo estas circunstancias históricas, las que han determinado la transformación de la estructura social que habita la casa ${ }^{14 "}$.

Hasta principios del siglo XX, la mujer se asociaba más a lo doméstico, a la vida privada pues es el momento en el que un gran porcentaje de mujeres trabajaban sólo en el hogar. Lo demuestran los anuncios de la época. La cocina se asociaba a la mujer, era cosa de ella.

También es interesante lo que comenta al respecto Xavier Monteys en su libro Casa Collage en el que dedica un capítulo a "la cocina, un motor de cambios" Afirma que la cocina ha evolucionado de tal forma que tiene una nueva visión para el ciudadano de hoy, incluso llega a utilizar el término de ingenieras domésticas para hacer referencia a las personas que trabajan en ella. La cocina es un elemento tan esencial en la vivienda que el término hogar se deriva de ésta, en palabras del propio autor "hogar hace referencia a un modo de domesticar el fuego hasta convertirlo en fuente de calor y en energía para cocinar ${ }^{16 "}$.

La revolución del acceso de la mujer al mundo del trabajo ya se ha dado, al menos en la cultura europea.

Aunque todavía queda mucho camino para tratar de conseguir la igualdad de oportunidades y ganar la batalla de la conciliación de la vida privada y el trabajo.

\footnotetext{
${ }^{14}$ LLEÓ, BLANCA. El sueño de habitar. Ed. Gustavo Gili. Barcelona. 2005. p.188.

${ }^{15}$ MONTEYS, Xavier, y FUERTES, Pere. Casa collage. Un ensayo sobre la arquitectura de la casa. Ed. Gustavo Gili. Barcelona. 2002. pp. 104-112.

${ }^{16}$ Ibídem, p.104.
} 
VIVIENDAS EUROPAN (1988-2008) I Una aproximación a los modos de vida en el cambio de siglo en España

3. EUROPAN: LABORATORIO DE IDEAS SOBRE EL HABITAR

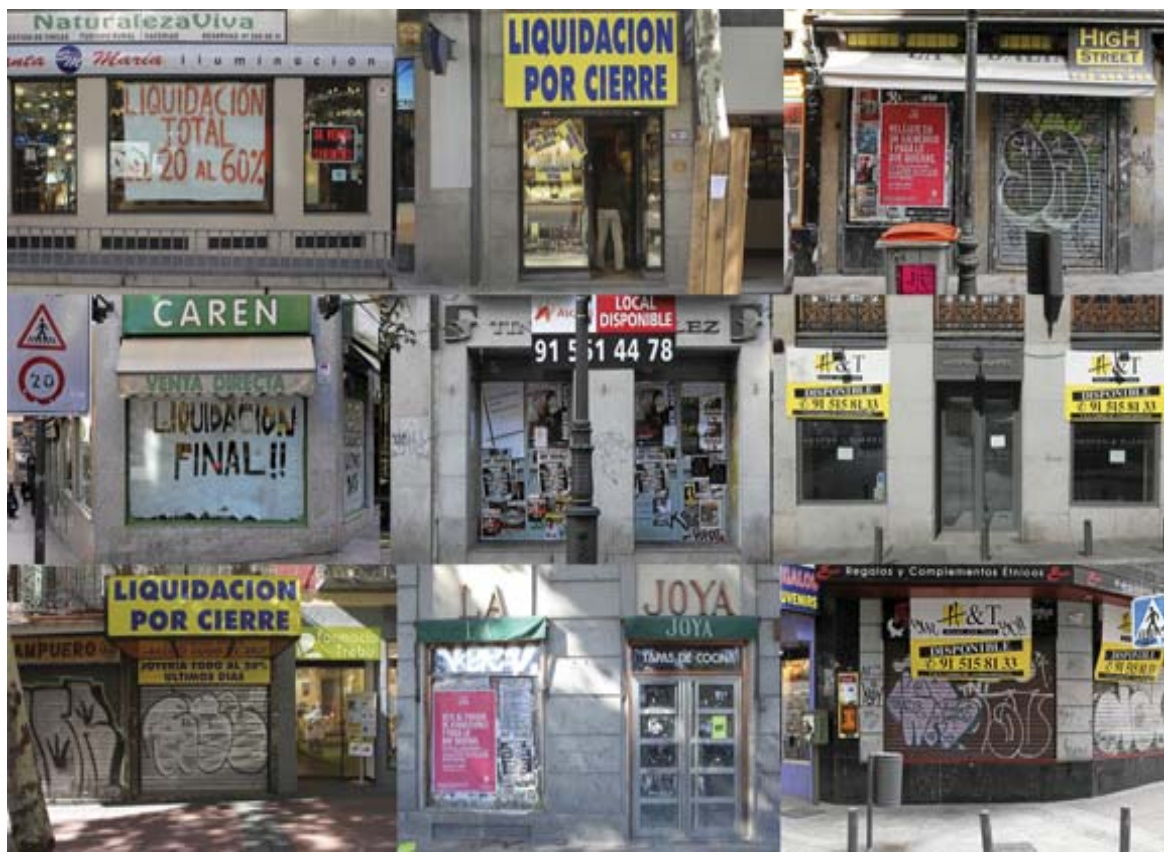

Ref.3.29. Anuncios gráficos sobre la crisis inmobiliaria

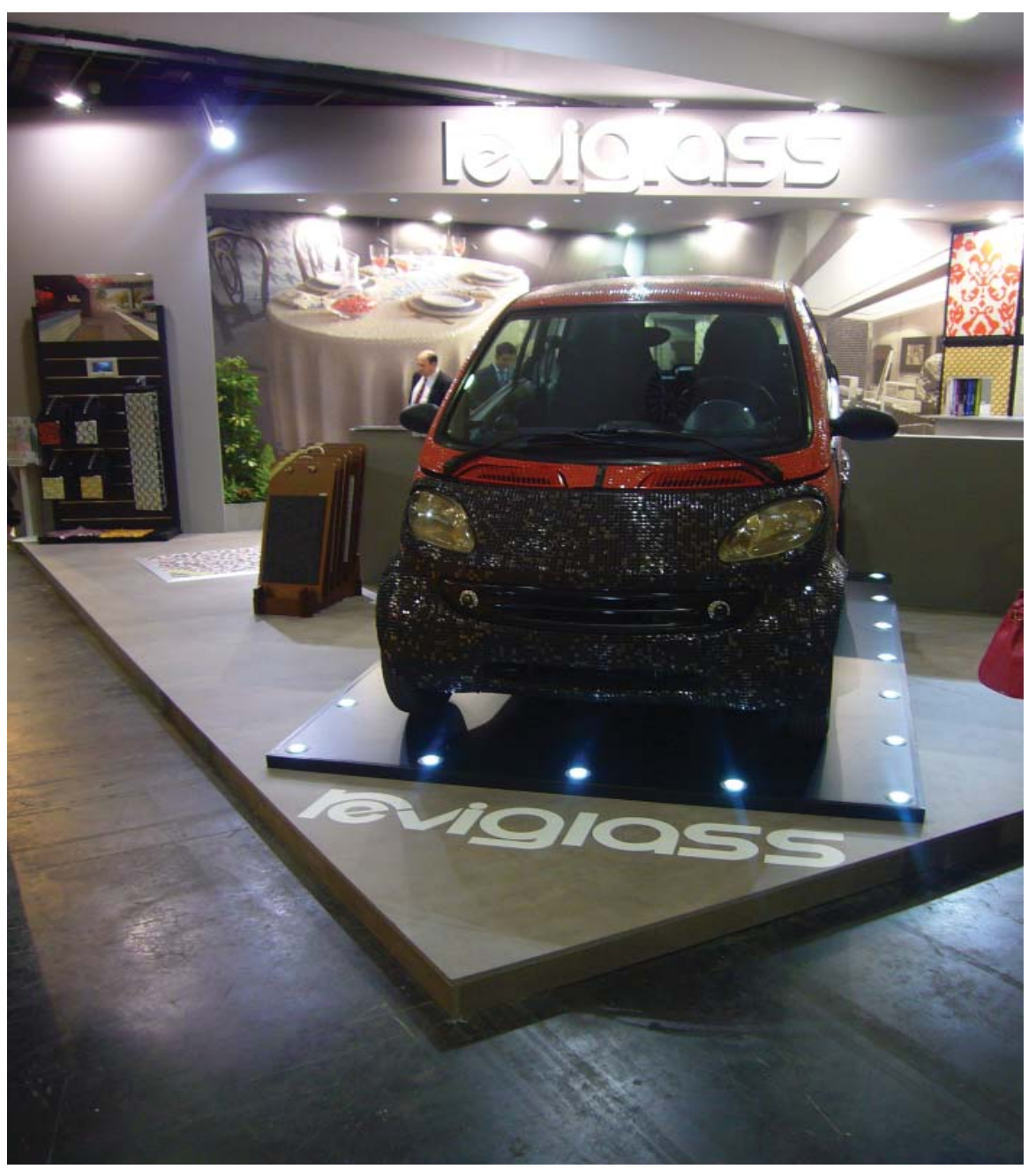

Ref.3.30. Smart de lujo en CEVISAMA 2011. 


\section{Imagen de marca}

La imagen de marca hace referencia la relación entre arquitectura, poder y espectáculo. Aparece en la segunda convocatoria de Europan (1990) y se aborda en esta de manera tangencial para no desviar el rumbo de la tesis.

La arquitectura de la apariencia, del formalismo ya ha sido anteriormente criticada: "La vida de un objeto de uso corriente depende de la duración de su material y su valor moderno es, precisamente, la solidez. Si abuso de la ornamentación en dicho objeto hago más breve su vida, puesto que, sujeto a los caprichos de la moda, tendrá que morir más pronto ${ }^{17 "}$.

Quizá este planteamiento se haga en Europan porque tiene mucho que ver con la arquitectura previa a los Juegos Olímpicos de Barcelona y la Expo de Sevilla en 1992. Este período se desarrolló en base a grandes construcciones de equipamientos públicos y, como dice el enunciado de Europan 2, se presentan las ciudades como producto de venta y consumo.

Alberto Campo en su artículo "Querido pequeño príncipe"18 hace alusión a la arquitectura que se construye en España en esta época. Está escrito con un estilo de una carta informal, en la que pretende destacar la figura del arquitecto, el valor de la buena arquitectura, que "no cuesta nada" y "es más que gratuita".

También lo narraba Paul Valery a modo de diálogo entre Fedro y Sócrates en el que se hace referencia a la triada Vitruviana:

"FEDRO: Cierto que estos son los caracteres de una obra completa.

SOCRATES:Solo la arquitectura los exige y lleva al punto culminante.

SOCRATES: Así pues, el cuerpo nos obliga a desear lo útil, o simplemente cómodo; y el alma nos pide lo bello; pero el resto del mundo, y sus leyes lo mismo que sus acasos, nos obliga a considerar en todo obra el aspecto de su solidez ${ }^{19}$.

Una pregunta que se debería formular es si la arquitectura puede desligarse de la política. Si no es así, si la política va bien, la arquitectura irá bien y viceversa. Siempre se actuará en base a ésta. La arquitectura será esclava de la política. Tal vez este tema resulta familiar por los momentos en los que se atraviesa la actual crisis económica y política.

No fue así en esos años, ya que "Europan nace en un momento de esplendor profesional que no se corresponde en nada al actual momento tan especialmente

\footnotetext{
17 LOOS, Adolf. Ornamento y delito. Ed. Gustavo Gili. Barcelona. 1972. p. 19.

18 CAMPO BAEZA, Alberto. La idea construida. Ed. Colegio Oficial de Arquitectos de Madrid. Madrid. 1996. p. 243.

${ }^{19}$ VALERY, Paul. Eupalinos, el arquitecto. Ed. Colección de arquitectura Colegio oficial de Aparejadores y Arquitectos técnicos de Alicante. Valencia. 1982. p.78
} 
VIVIENDAS EUROPAN (1988-2008) I Una aproximación a los modos de vida en el cambio de siglo en España

3. EUROPAN: LABORATORIO DE IDEAS SOBRE EL HABITAR

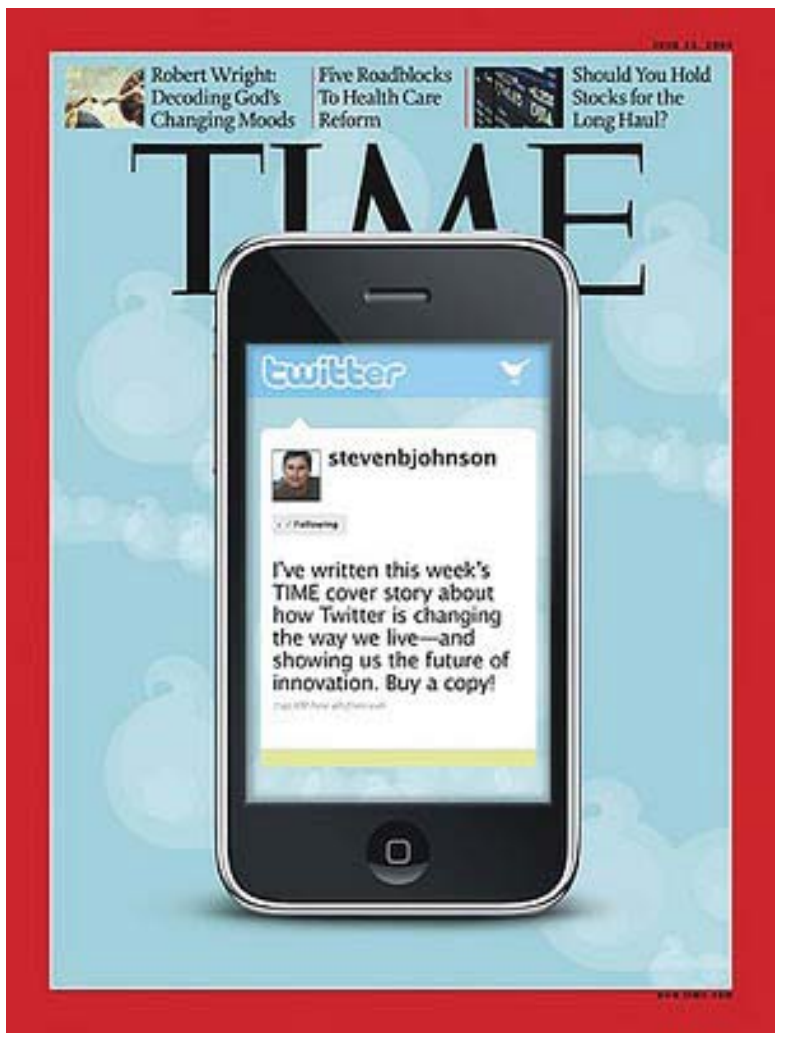

ref.3.31. La era digital

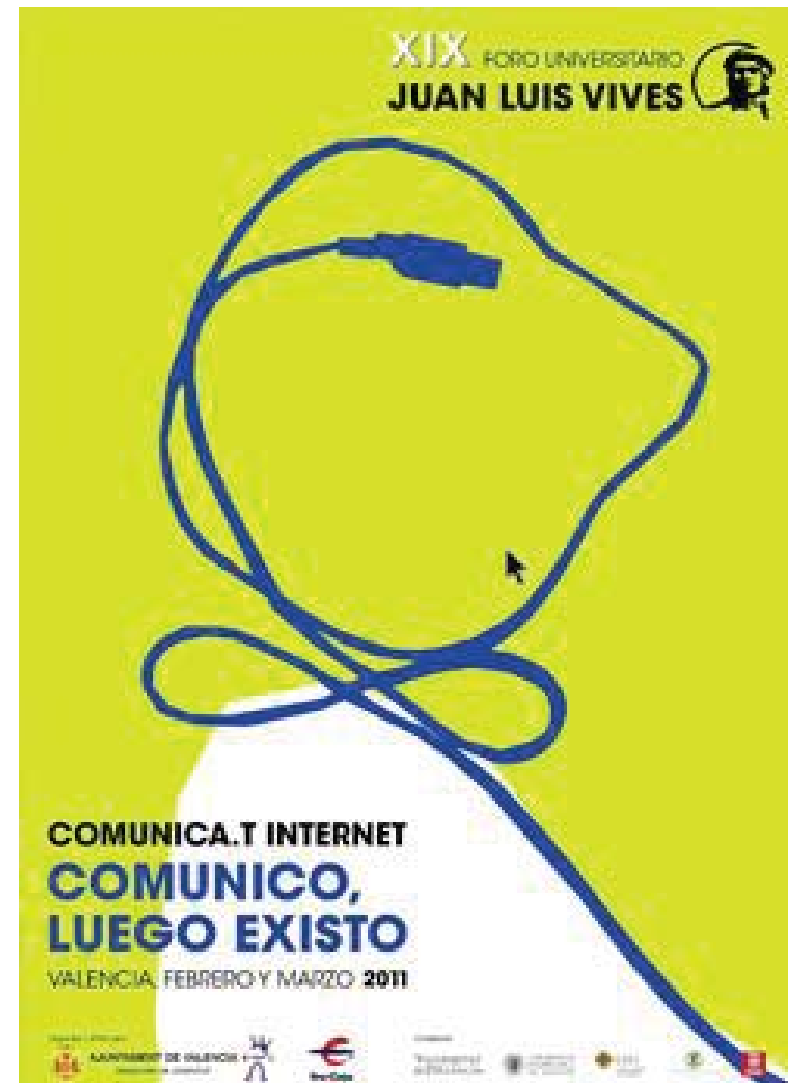

Ref. 3.32. Importancia de la comunicación 
crítico y convulso que vive la profesión, no sólo en términos del agotamiento de ciertos modelos profesionales, acuciados por las derivas e implicaciones que la crisis política y actual ha tenido en el modelo económico en la que el modelo se ha basado ${ }^{20 "}$

Europan no vuelve a nombrar este tópico y realmente su actitud esconde la idea de que las ciudades no son para ser admiradas, sino para ser vividas.

\section{Estrategias operativas}

El último tema de reflexión transitorio es el de las estrategias operativas a las que se hace referencia en la segunda convocatoria de Europan (1990) en el que se hace alusión a la participación ciudadana y Europan 5 (1997) también introduce el tema de la gestión de las ciudades, interesante para que los proyectos planteados puedan desarrollarse en el tiempo.

Ciertamente esta idea resulta innovadora en el momento en el que surge, pues es en el momento actual, con las nuevas tecnologías cuando se está desarrollando. La participación ciudadana es un tema complejo en relación con la arquitectura pues los ciudadanos no se terminan de convencer de que pueden influir sobre el futuro de las ciudades. La mayoría de veces se participa en función de los propios intereses personales y de las modas, así lo afirma Pawson cuando dice que "vivimos en un período en rápida transformación, que alimentamos con nuestra ansia por poseer la última novedad. Lo novedoso como fin en sí mismo esta sobre valorado. En lugar del placer en sus formas más profundas, anhelamos la distracción. Vivimos agobiados por ideas acerca del futuro cuando, en realidad, intentamos que el presente nos parezca novedoso y atrayente. En arquitectura eso se traduce en continuos programas de reformas. Lo cambiamos todo y nada. Si el motivo de nuestro interés por el futuro es el deseo de lograr un presente que nos satisfaga -en un plano físico, visual y psicológico- ¿acaso podemos desarrollar formas permanentemente interesantes, que existan al margen de la influencia de la moda y del paso del tiempo? Esto es lo que, en mi opinión, ofrece la estética de la simplicidad, con su vasto y paradójico potencial de riqueza y sensualidad ${ }^{21}$ ". Tal vez este tema de reflexión vuelva a retomarse explícitamente en sus enunciados dada la situación actual de las ciudades con una mayor tendencia a la implicación de los ciudadanos.

Hasta el momento se han expuesto las ideas que se han considerado como transitorias. Es interesante considerar que la mayoría de las ediciones de Europan tienen un hilo conductor, un lenguaje común, que se desarrolla y evoluciona a lo

${ }^{20}$ AA.VV. Europan 10, Proyectar la urbanidad, colonización/revitalización /regeneración. Ed. Secretariado de Europan. Madrid. 2010. p.227.

${ }^{21}$ PAWSON, John. "La expresión sencilla del pensamiento complejo". En El Croquis 127. Madrid, 2005, p.6. 
VIVIENDAS EUROPAN (1988-2008) I Una aproximación a los modos de vida en el cambio de siglo en España

3. EUROPAN: LABORATORIO DE IDEAS SOBRE EL HABITAR

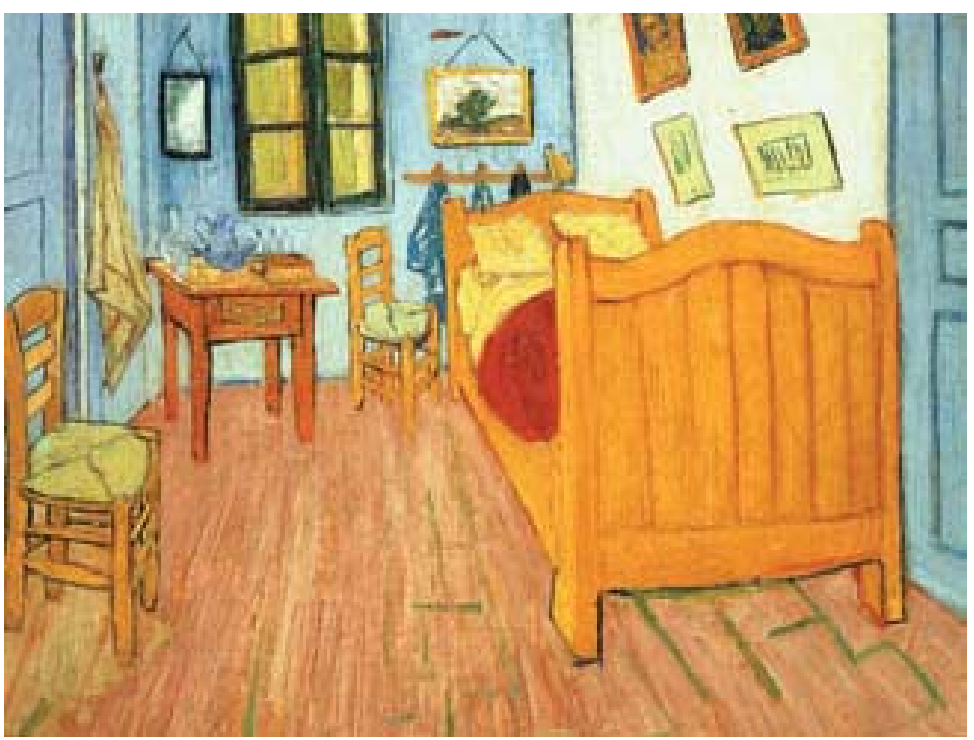

Ref.3.33. El dormitorio en Arles. Vincent Van Gogh. 1889.

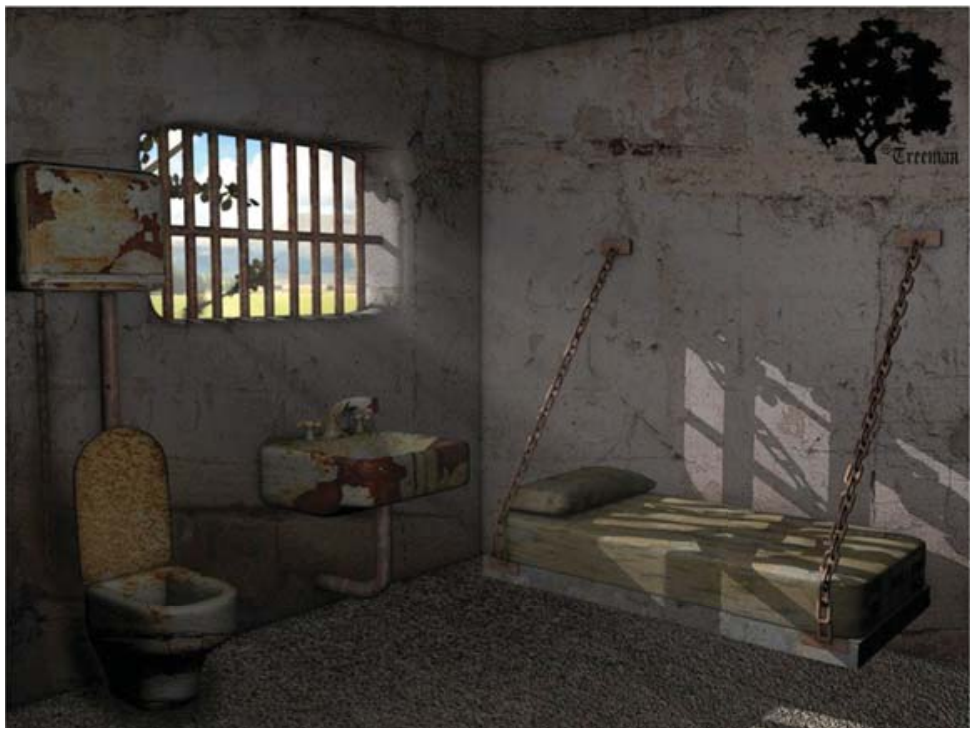

Ref.3.34. Celda

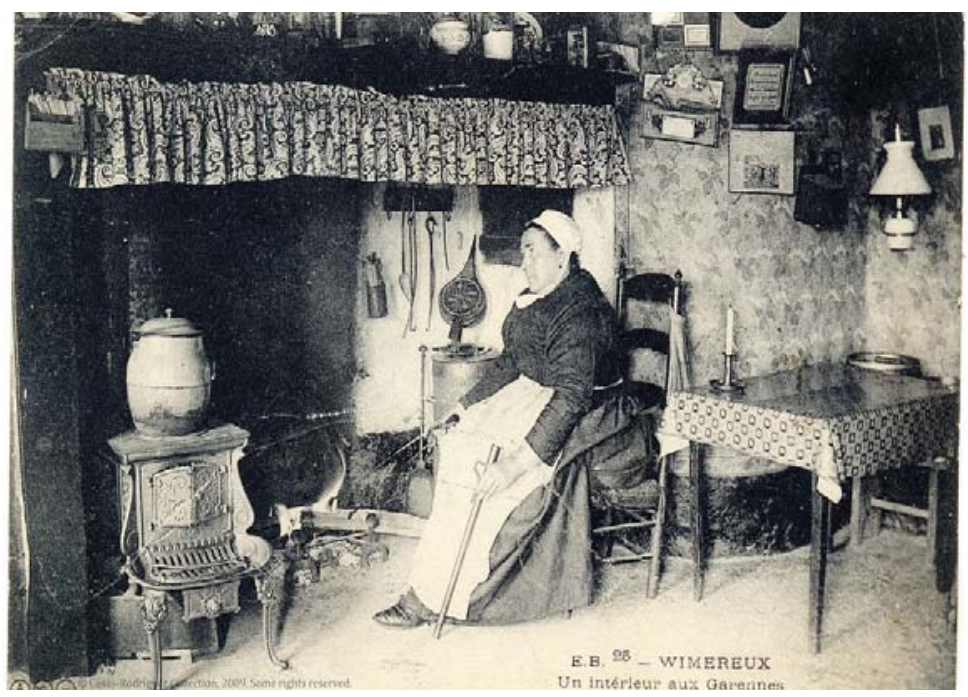

Ref.3.35. El hogar 
largo del tiempo y que, en el fondo, se plantea cuestiones universales que se han denominado en la presente tesis como ideas permanentes.

\subsubsection{Ideas permanentes}

Tras estudiar con una mirada global los enunciados propuestos por el Comité de Expertos, se ha llegado a la conclusión de que existen temas de investigación que tienen continuidad a lo largo de la historia de Europan y se han denominado ideas permanentes. Estas son:

\section{Cambios en los modos de habitar}

Este tema de investigación aparece en Europan desde los comienzos en 1988. Las convocatorias que lo plantean directamente son:

Europan 1: enuncia las transformaciones del hábitat desde el interior de la vivienda. Como anteriormente se ha comentado, Europan tiene un claro antecedente: Ios concursos PAN en Francia y parten del objetivo de investigar en arquitectura y vivienda a través de intercambios científicos y culturales ${ }^{22}$.

Europan 2: se centra en el hábitat y los modos de vida considerando los cambios en los fenómenos demográficos, en el consumo de masas y los comportamientos sociales, movido seguramente por la aprobación del Tratado de Maastrich por el que se crea la Unión Europea.

Europan 3: aumenta de escala y plantea algunos retos urbanos como el empleo y la convivencia de distintas sociedades. Quizá porque 1992 es un año en el que estadísticamente se multiplican las corrientes migratorias.

Europan 5 tiene un tema de reflexión específico denominado nuevos modos de vida. En esta convocatoria se cumplen diez años de la caída del muro de Berlín y EEUU se erige en el mundo como primera potencia mundial y modelo para Europa. Además comienza a hablarse del cambio de siglo y se piensa mucho en lo que pasará en el futuro.

Europan 7 y Europan 8 hablan de una evolución en los modos de vida hacia una autonomía de los individuos. Que vivimos en la cultura de la individualidad es un hecho. Cabe destacar también que en este período surge uno de los acontecimientos que conmovieron a España y fomentaron la desconfianza social en el mundo entero: el 11-S.

El resto de convocatorias no abordan esta cuestión directamente, sino que lo hacen de un modo que puede intuirse en sus enunciados: a través de ellos se

${ }^{22}$ Puede consultarse en la Carta Europan que se encuentra recopilada en el ANEXO 1. 
VIVIENDAS EUROPAN (1988-2008) | Una aproximación a los modos de vida en el cambio de siglo en España

3. EUROPAN: LABORATORIO DE IDEAS SOBRE EL HABITAR

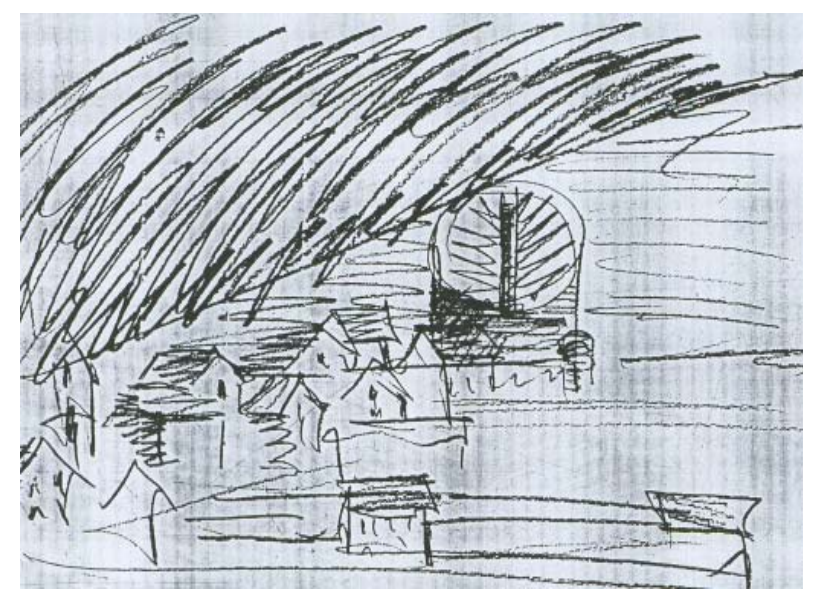

Ref. 3.36. Boceto. Iglesia de montaña. Mogno (Suiza). Mario Botta

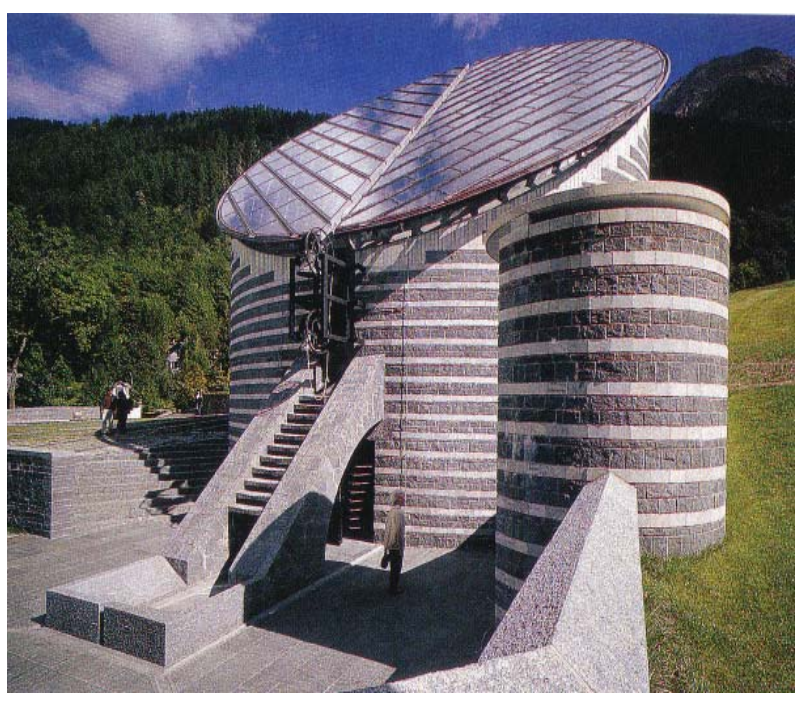

Ref.3.37. Idea construida.Iglesia de montaña. Mogno (Suiza). Mario Botta

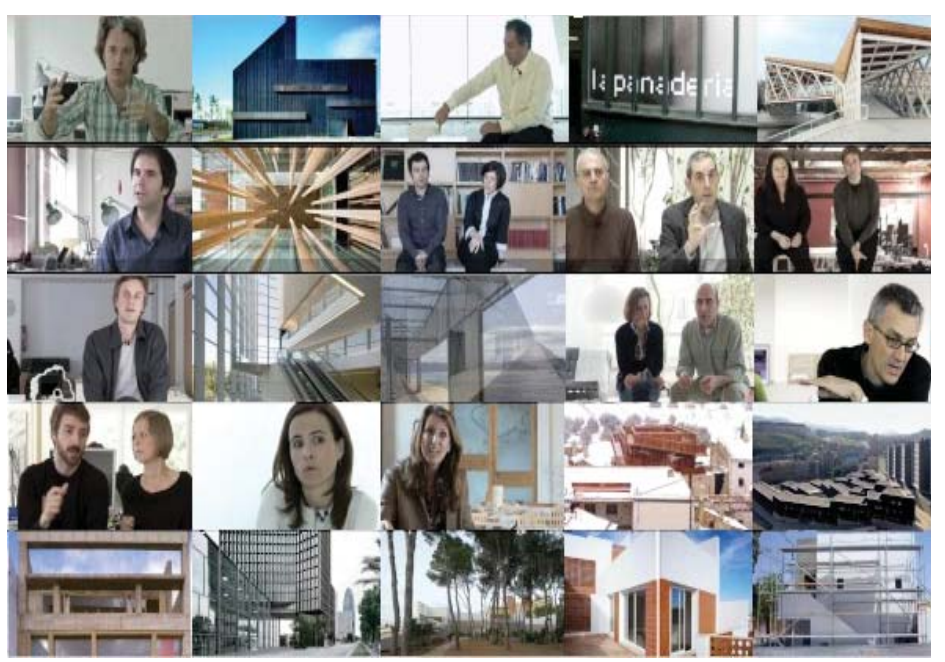

Ref. 3.38. Imágenes de la X Bienal de Arquitectura española 
muestra que lo que interesa realmente es que las personas tengan una mejor calidad de vida.

¿Por qué plantea Europan como tema de reflexión continuo los cambios en los modos de habitar? Porque Europan tiene presente en todo momento la perspectiva de lo social. Es decir, parte de la premisa de que el ser humano está inmerso en la sociedad y defienden que la arquitectura debe contar con esta faceta, pues la filosofía de Europan entiende que se construye para las personas. El perfil del arquitecto que busca Europan es un individuo que debe ser omnívoro. Es decir, un ser que se alimente de todo lo que rodea en un entorno siempre cambiante. En los enunciados de Europan se manifiesta que las ciudades deben estar configuradas para las personas y no viceversa porque las personas son seres positivamente espaciales y poseen la capacidad de crear espacios de interrelación. El hombre necesita el espacio para desplegar sus posibilidades internas y necesita por tanto crear ámbitos de diálogo. Tanto es así que se ha pasado de la famosa premisa cartesiana "pienso, luego existo" a la de "comunico, luego existo". La cultura del habitar es, en cierto modo, la cultura de la convivencia, de la comunicación interpersonal.

Así pues, los planteamientos de Europan manifiestan que el espacio vivido no tiene por qué ser sólo el espacio físico. Es el espacio real donde se desarrolla la vida del ser humano a lo largo del tiempo pues el hombre es un ser capaz de crear ámbitos. Europan pretende realizar la pregunta fundamental: qué significa hoy en día habitar la ciudad e intenta darle una respuesta a través de la arquitectura. Pero Europan considera que hace falta un estudio del concepto de habitar, en el que se combinan "·elementos físicos, espaciales, económicos, sociales y culturales ${ }^{23}$ ".

\section{Hibridación versus zonificación}

La mezcla de usos se aborda desde 1990. La zonificación trataba de concebir la ciudad como trozos diferentes que forman un collage. Se puede observar cómo en las primeras convocatorias Europan se plantea esta cuestión de un modo abierto cuando se pregunta qué funciones deben ser mezcladas y cuáles separadas.

Europan 2 empieza a hablar de multifuncionalidad y polifuncionalidad. Por multifuncionalidad se entendía la mezcla de funciones dentro de un mismo edificio. Esta es la primera idea acerca de la mezcla de usos y utiliza términos interesantes como mezcla de tejidos urbanos y coexistencia de las funciones en el espacio. Se habla de una reinterpretación, reconducción o abandono de la mezcla de usos heredada. Una de las causas podría ser la expansión de internet a través de la World Wide Web.

${ }^{23}$ AA.VV. La casa, evolución del espacio doméstico en España. tomo II. Ed. El Viso. Madrid. 2006. p. 87. 
VIVIENDAS EUROPAN (1988-2008) I Una aproximación a los modos de vida en el cambio de siglo en España

3. EUROPAN: LABORATORIO DE IDEAS SOBRE EL HABITAR

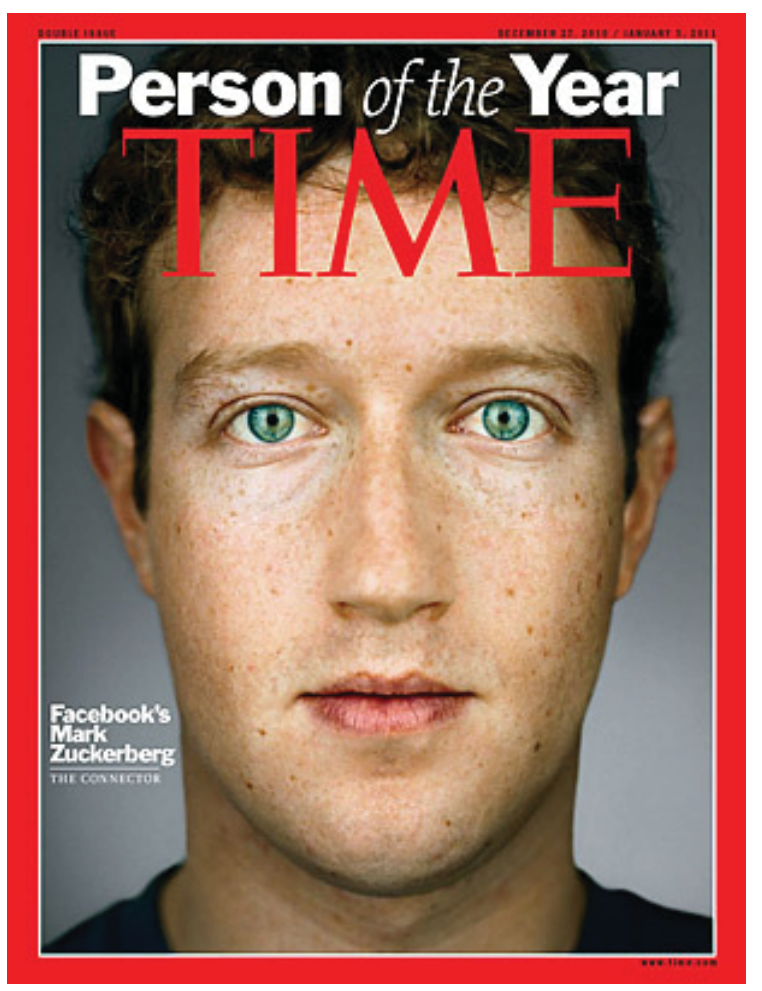

Ref.3.39. Creador de Facebook. Mark Zuckerberg.2007.

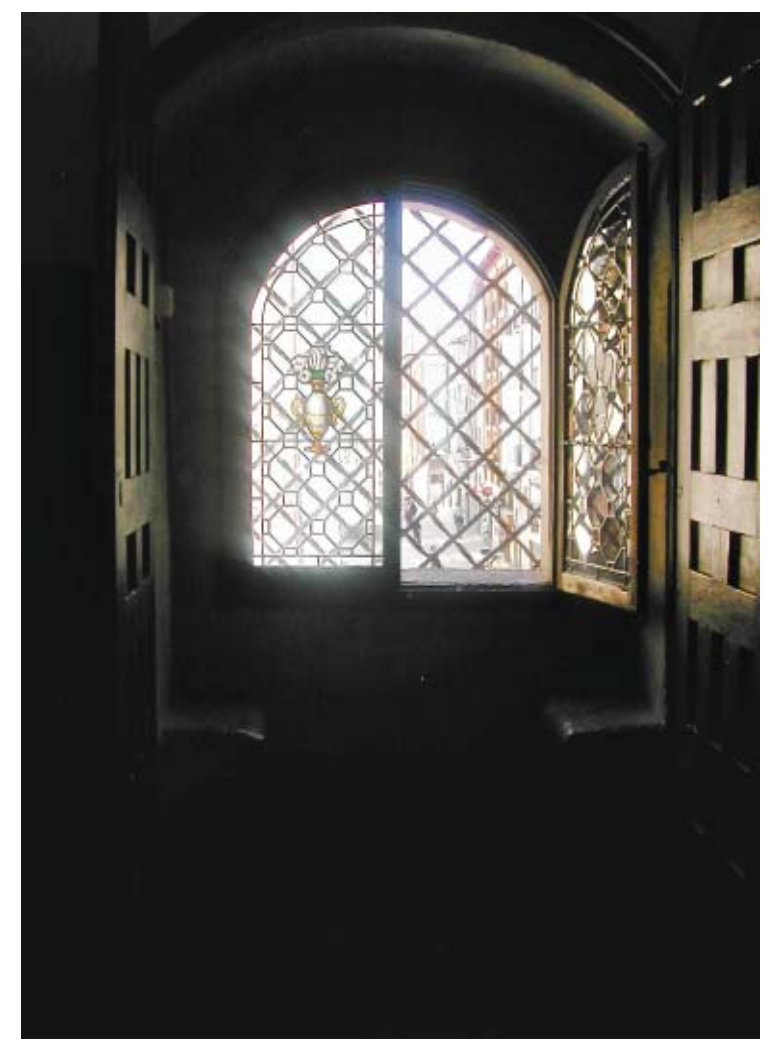

Ref.3.40. Lugar-ventana, Salamanca 
Europan 3 habla de la mezcla de usos y de la relación de vivienda trabajo intentando crear empleo próximo. Tras el auge de la economía en 1992, se entra posteriormente en una crisis económica. Tal vez por este motivo se plantea la mezcla de usos como uno de los factores de ahorro pues si hubiera una proximidad entre vivienda y trabajo se evitarían muchos desplazamientos innecesarios.

Europan 4 plantea la posibilidad de crear subprogramas, pues se actúa sobre espacios híbridos, con fragmentos autónomos y espacios baldíos. Europan 5 toma el matiz de la intensificación de los usos. Europan 6 habla de la mezcla de usos en la edificación: crear áreas densificadas con edificios heterogéneos. Europan 7 habla de una ciudad dispersa, de nuevos barrios residenciales. Europan 10 será el que proponga una regeneración de los espacios: dar el salto a los cambios de usos según las necesidades del ser humano.

En resumen, Europan plantea sutilmente que ha llegado la hora de la ruptura de las mallas históricas... de la división de la ciudad. Y se podría decir que, dentro de la hibridación, Europan hace referencia a dos temas fundamentales:

- La relación existente entre vivienda y trabajo. Pues, sobre todo con la aparición de las nuevas tecnologías, el trabajo se puede generar desde la vivienda, y en ésta debería existir algún espacio destinado a albergar este uso. La vivienda se plantea como un organismo complejo, por lo tanto, no puede estar compuesta por las mismas células, necesita la libertad de los músculos sueltos.

- La relación existente entre lo público y privado. Europan defiende que los proyectos de vivienda se deben concebir como proyectos integrales de espacio público y privado. La vivienda no es sólo espacio privado, aunque también éste es necesario porque "la casa, el domicilio, es el único bastión frente al horror de la nada, de la noche y de los oscuros orígenes; encierra entre sus muros todo lo que la humanidad ha ido acumulando pacientemente por los siglos de los siglos; se opone a la evasión, a la pérdida, a la ausencia, ya que organiza su propio orden interno, su sociabilidad, su pasión. Su libertad se despliega en lo estable, lo cerrado, y no en lo abierto ni en lo indefinido. Estar en casa es lo mismo que reconocer la lentitud de la vida y el placer de la meditación inmóvil ${ }^{24 "}$.

Europan defiende que si no hay actuación sobre el espacio público, aparece la creación de no-lugares, que son como crecimientos cancerígenos de la ciudad. Pero si tan sólo se proyecta el espacio privado nos encontramos con una célula que no pertenece al organismo. Si se concibe la vivienda como suma de estancias, se debe prestar atención a los espacios intersticiales que se generan entre éstas pues "si pensamos en la habitación como el lugar donde cada persona desarrolla su individualidad, las habitaciones tendrían que ser más grandes, más completas, con las instalaciones adecuadas y se tendría que pensar cada estancia de forma

${ }^{24}$ EDELMAN, Bernard. La Maison de Kant. Ed. Payot. Paris.1984. 
VIVIENDAS EUROPAN (1988-2008) I Una aproximación a los modos de vida en el cambio de siglo en España

3. EUROPAN: LABORATORIO DE IDEAS SOBRE EL HABITAR

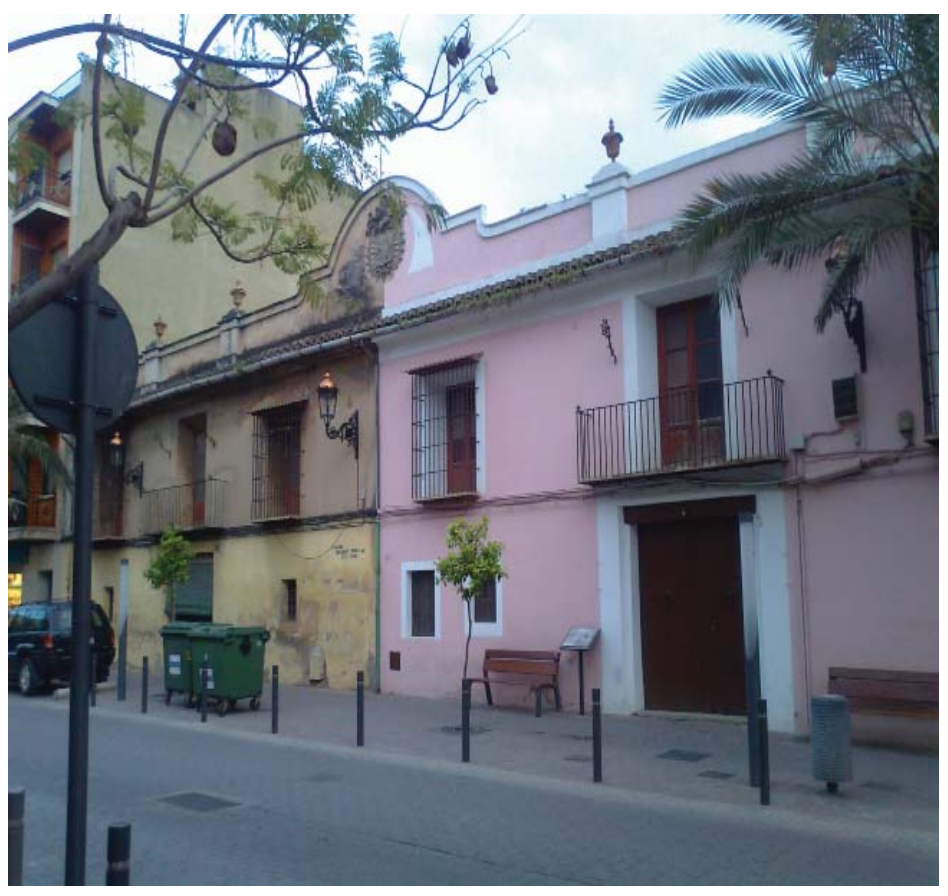

Ref.3.41. Fachada sin rehabilitar-fachada rehabilitada

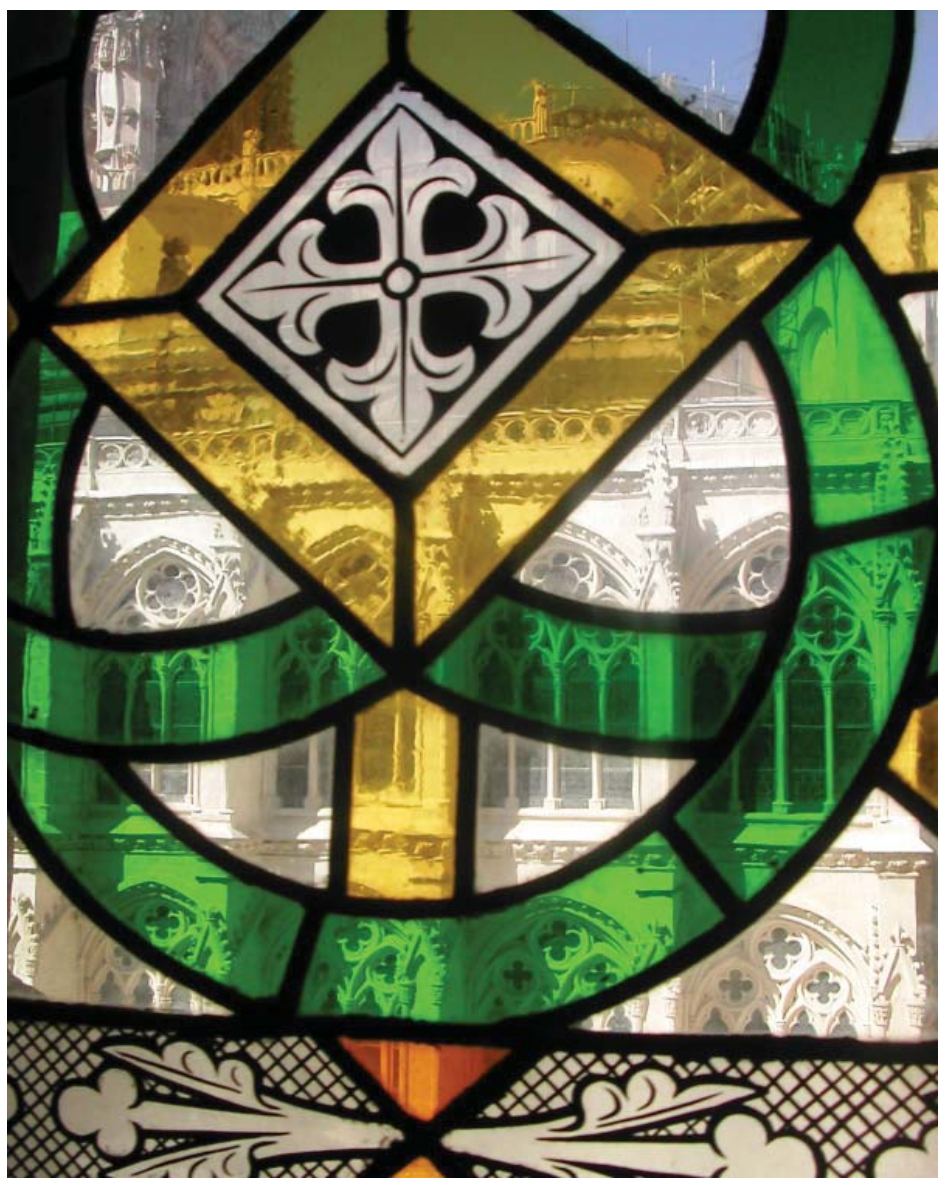

Ref.3.42. Percepción a través de la transparencia 
autónoma, es decir: se debería proyectar la casa como una suma de estancias ${ }^{25}$.

Europan se tiende a incorporar, al menos en teoría, el espacio de relación en los proyectos de vivienda y trata de encontrar una armonía entre lo público y lo privado, que sería lo ideal pues "conviene puntualizar que el espacio privado constituye también un importante elemento de la estructura social y, por tanto, sería erróneo imaginar que esté protegido y aislado del orden social. Esta idea es especialmente patente en la actualidad cuando la casa ha dejado de ser una "guarida", ha perdido su condición de "santuario" y se encuentra traspasada por todas las avenidas de la comunicación externa, agujereada por la informática y bien censada como unidad de consumo ${ }^{26 "}$.

Europan plantea que el tema de la hibridación de usos debería tener como uso privilegiado el residencial y, en función de éste, se articularían los demás pues "la vivienda no es una simple mercancía porque al ser habitada se convierte en hogar, algo íntimo, personal, espacio privilegiado para la vida humana ${ }^{27}$ ".

En la actualidad existen diversas líneas de investigación en este campo y se está tratando de definir el término ${ }^{28}$.

\section{Reciclaje}

Europan no considera sólo el factor espacial en las ciudades, sino que considera necesario incluir en su reflexión el factor temporal. Por eso parte de la base de que hace falta poder actuar sobre lo existente, con una intervención de cirugía.

Europan 8 (2004) introduce propiamente el término reciclaje en cuanto al tejido urbano: propone la posibilidad de crear tejidos híbridos con un planteamiento de evolución en los barrios y reforzar los puntos neurálgicos en la ciudad.

Pero la investigación acerca del reciclaje evoluciona a lo largo de cada convocatoria y se puede decir que va adquiriendo fuerza y carácter. Ya desde el comienzo, en Europan 2 (1990), se habla de patrimonio urbano. En esta convocatoria se afirma que "lo urbano es el cruce de las coexistencias sociales, económicas y del cruce de temporalidades". El factor tiempo hace referencia al pasado, presente y

${ }^{25}$ AA.VV. Nuevas formas de habitar Monográfico OTH/1. Ed.Impiva/ Generalitat Valenciana. 2009. p.31.

${ }^{26}$ AA.VV. La casa, evolución del espacio doméstico en España. Tomo II. Ed. El Viso. Madrid. 1996. p. 86.

${ }^{27}$ Ibídem, p.87.

28 "Hibridaciones: Introducir o extraer en una trama urbana los elementos necesarios para mixtificar/mezclar los usos y las formas, para obtener en las barriadas las ventajas de la ciudad tradicional" SOSA, Jose Antonio, Presentación del Glosario de Reciclaje urbano. Minuto 05:10. [On line] <http://www.youtube.com/watch?v=eEnjTwNrxMw\&context=C3519 a5eADOEgsToPDskLRBB0xBmFEXWw99NFqY39v>. (Consulta, 2 de enero 2012). 


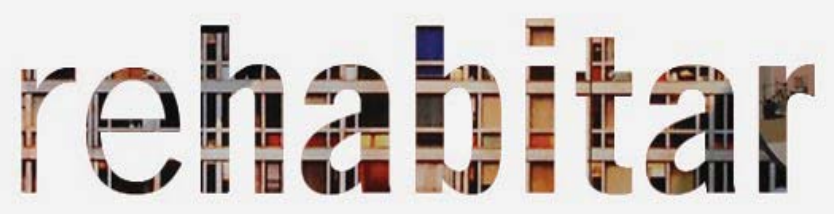

Ref.3.43. [On line] <http://rehabitar.blogspot.com.es>.Blog del grupo rehabitar, dirigido por Xavier Monteys

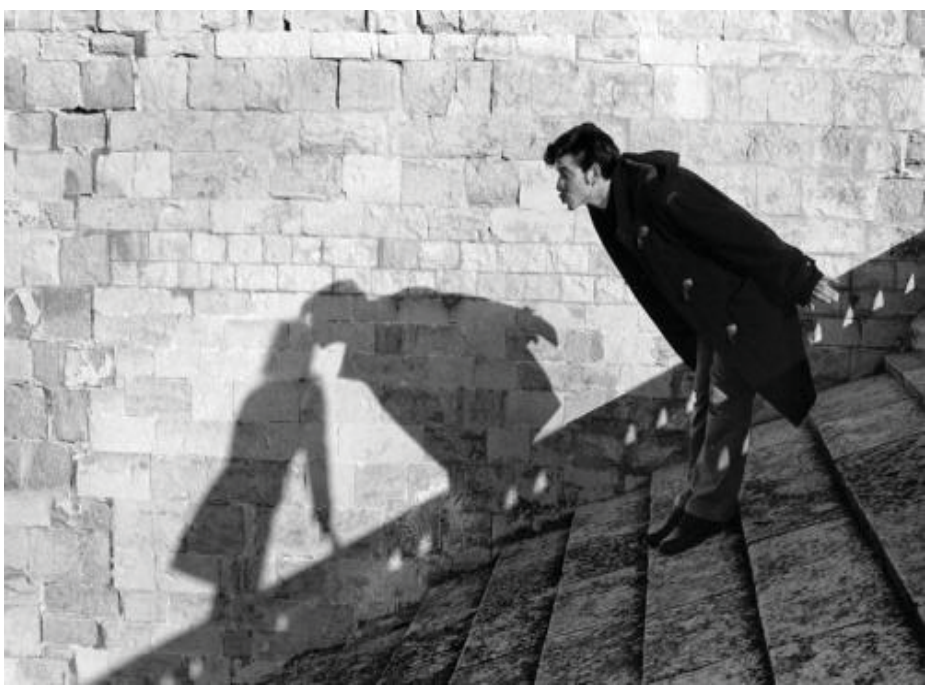

Ref.3.44. Manipulación de la realidad

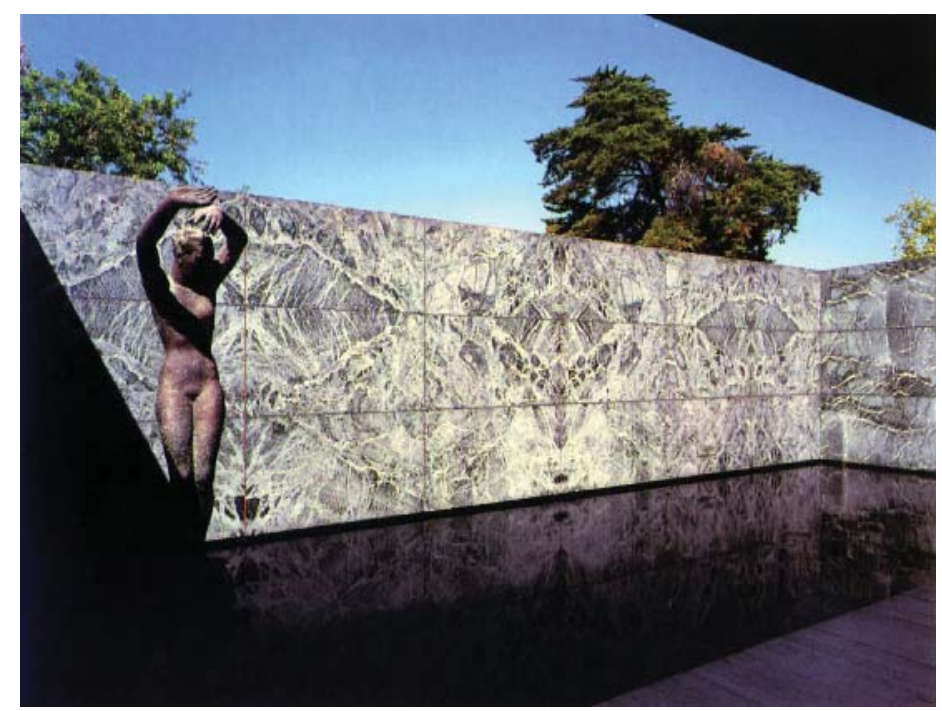

Ref.3.45. Pabellón de Mies van der Rohe. Barcelona 
futuro de las ciudades. ¿Qué nos dejan éstas a los ciudadanos de ahora? ¿Qué dejaremos a los ciudadanos del mañana? Recuerda a lo que ya decía Bradbury en su conocida novela cuando afirmaba que "cuando muere, todo el mundo debe dejar algo detrás, decía mi abuelo. Un hijo, un libro, un cuadro, una casa, una pared levantada o un par de zapatos. O un jardín plantado. Algo que tu mano tocará de modo especial, de modo que tu alma tenga algún sitio donde ir cuando tú mueras, y cuando la gente mire ese árbol, o esa flor que tú plantaste, tú estarás allí. "No importa lo que hagas -decía- en tanto que cambies algo respecto a cómo era antes de tocarlo, convirtiéndolo en algo que sea como tú después de que separes de ello tus manos. La diferencia entre el hombre que se limita a cortar el césped y el jardinero está en el tacto. El cortador de césped igual podría no haber estado allí, el jardinero estará allí para siempre ${ }^{29 "}$.

Europan 4 utiliza el término heredar como "definir una actitud con respecto a lo existente". Europan 6 habla de actuar en la edificación de varias formas: una es sustituyendo lo que denomina edificios vetustos y otra es reestructurando conjuntos de edificios heterogéneos.

Europan 8, como se ha afirmado al principio, plantea directamente reciclar el tejido. Detecta que "la ciudad suburbana ha generado tejidos urbanos híbridos formados por espacios fragmentados y objetos yuxtapuestos". Se plantea una reestructuración de los barrios heterogéneos para facilitar en ellos la vida urbana. Como solución a este problema se plantea hacer evolucionar los usos (transformando o sustituyendo la edificación) o reforzando barrios ya existentes.

Europan 9 habla de "transformaciones locales" en las que se proponen infiltrar (introducir nuevos programas en zonas industriales enclavadas y abrirlas al tejido urbano) o intensificar (añadir diversidad en los barrios existentes y generar nuevas dinámicas).

Europan 10 no habla de reciclaje sino de regeneración, que define como volver a brotar recuperando su función.

Por último Europan 11 plantea como primer tema de reflexión la búsqueda de una identidad.

Este tema de reflexión se está desarrollando actualmente por el grupo de investigación español de Reciclaje de Barriadas ${ }^{30}$, en el que "(...) la ciudad

${ }^{29}$ BRADBURY, Ray. Fahrenheit 451. Ed. Plaza \& Janes. Barcelona. 1982. p. 175.

30 "Reciclaje urbano: Reciclar, mejor que reconstruir o rehabilitar. Reconstruir: es volver a construir lo que ya existió. Rehabilitar: es habilitar una construcción decadente . Reciclar: es iniciar un nuevo ciclo, una nueva vida a partir de lo viejo. Eso sí, ese nuevo ciclo debe empezar con la misma población existente". SOSA, Jose Antonio. Presentación del Glosario de Reciclaje urbano. Minuto 12:00. [On line] < http://www.youtube.com/watch? 


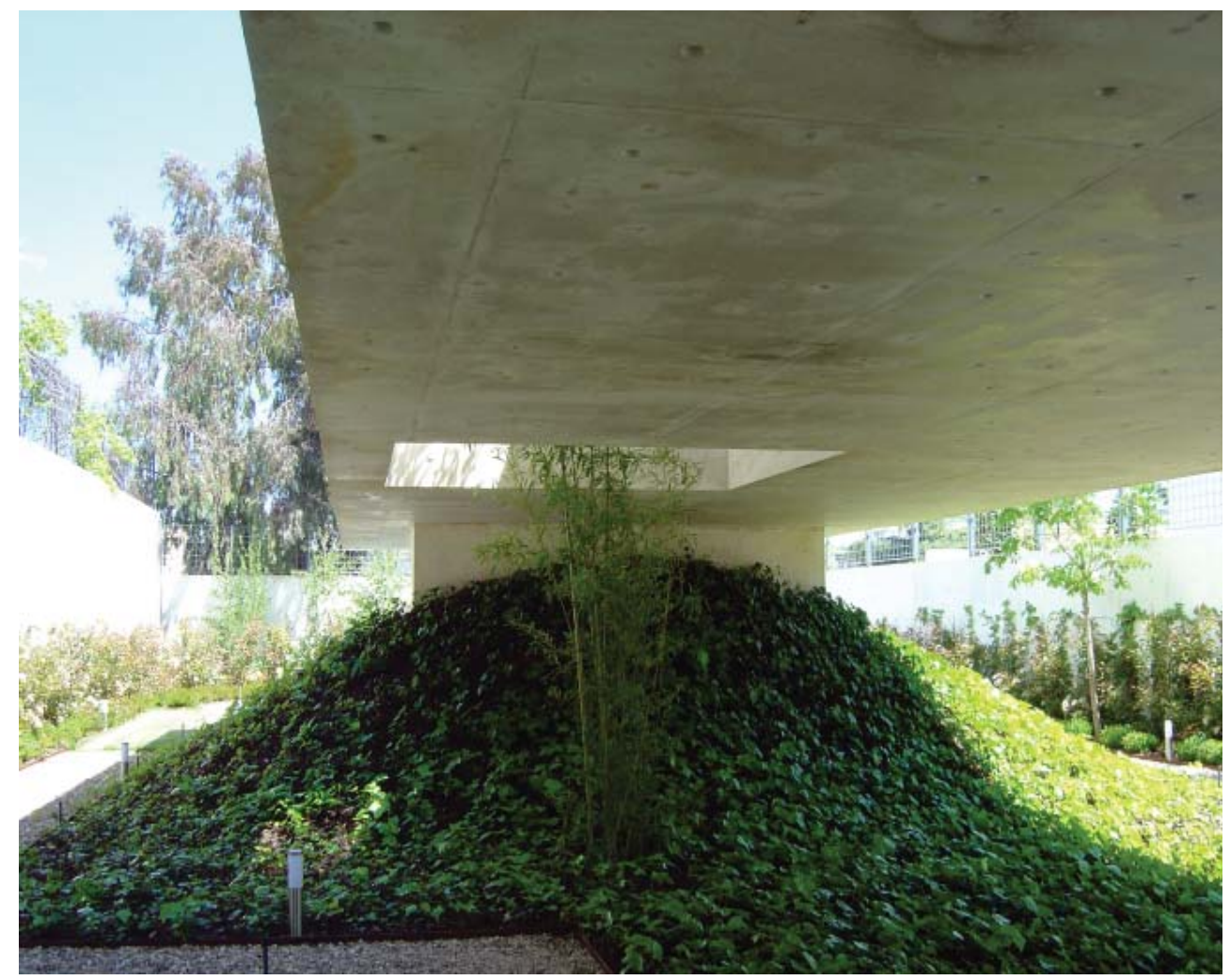

Ref.3.46. Vivenda unifamiliar, Ignacio Vicens, Madrid
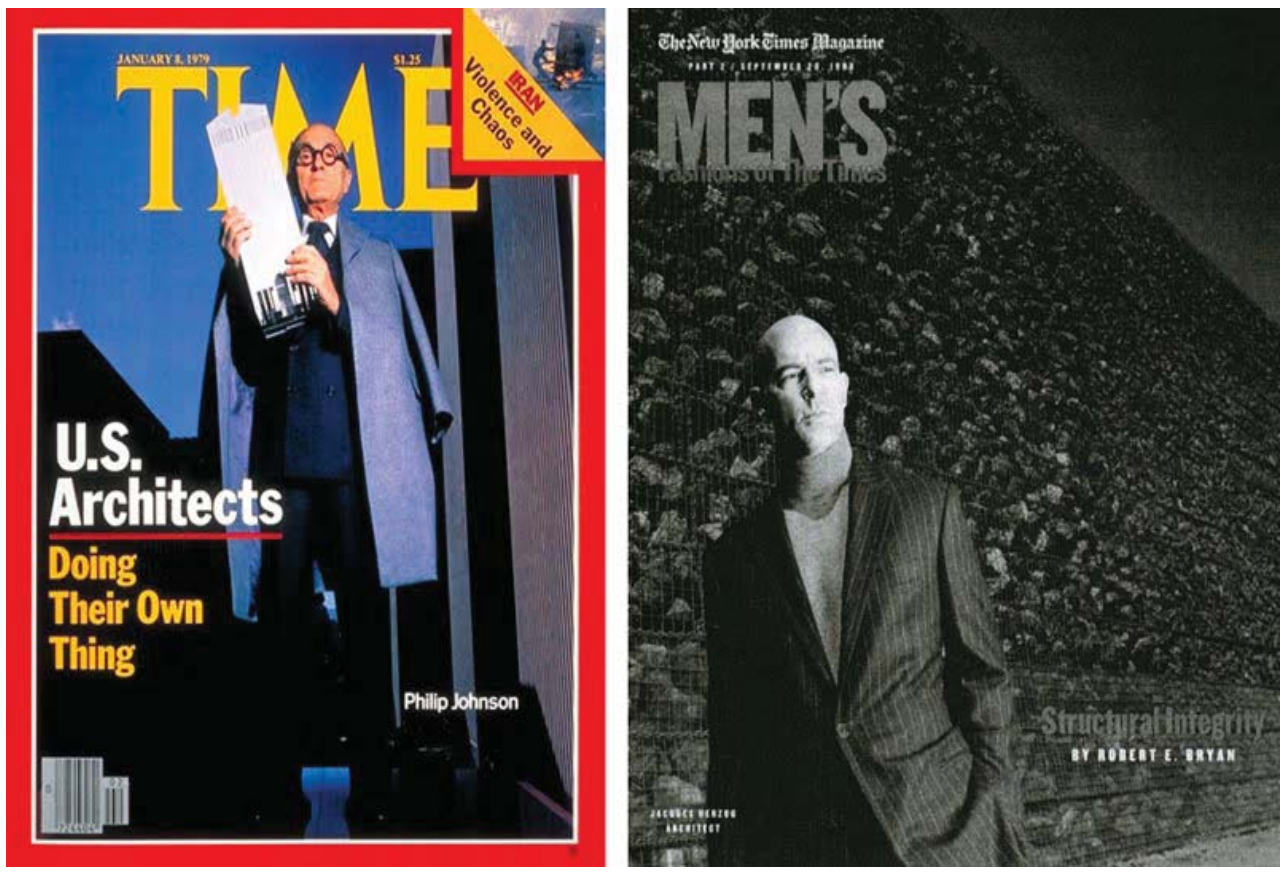

Ref.3.47. Los arquitectos en los medios de comunicación 
contemporánea se caracteriza fundamentalmente por la categoría de relación. Esa amplitud creadora que todo lo transforma. Surge con ella una nueva imagen y una nueva ordenación del mundo en la que el protagonismo no está en el objeto autónomo, sino en la capacidad de establecer vínculos. La referencia constante al otro. El edificio monumento ensimismado da paso al vacío como centro. El vacío cobra protagonismo como lugar donde todo es posible, el centro de relaciones que es apertura al otro y en la medida que esta relación sea real y no solo de razón, implica el cambio la modificación por interacción de las partes. Así se perfila la ciudad del siglo XXI, abierta a la vida, cruce de culturas y civilizaciones, capaz de reconocer sus lugares, su identidad propia y aceptar el peso de su historia, capaz en definitiva de afrontar el futuro con libertad y esperanza. Pero esta magnífica exposición es algo más que un importante evento cultural, se torna necesaria y adquiere su verdadero significado al descubrir que para aprender a amar las ciudades hay que poder verlas ${ }^{31 "}$.

Lo que se propone implícitamente en Europan es que se debería potenciar el paso de la barriada, que ha quedado obsolescente, al barrio. Esto se podría hacer redefiniendo y precisando el concepto de barrio, como se ha definido en el Congreso SB10mad ${ }^{32}$. Plantea transformar las viviendas existentes para que se pueda dar en ellas un nuevo ciclo de vida.

\section{Sostenibilidad}

La sostenibilidad comienza a plantearse por primera vez en Europan 3 (1992) en el que uno de los temas de reflexión es la potenciación de los valores ecológicos. En esta época comienza a hablarse a nivel mundial del calentamiento del planeta ${ }^{33}$.

v=eEnjTwNrxMw\&context=C3519a5eADOEgsToPDskLRBB0xBmFEXWw99NFqY39v>. (Consulta, 2 de enero 2012).

${ }^{31}$ Entrevista a Elisa Valero. Investigadora principal de Re:U. Abarán. 2008.

32 " El barrio se entiende como la unidad mínima que da forma y sentido a la ciudad ya que hace que se produzcan relaciones entre sus habitantes creando un entorno favorable para un mejor desarrollo de nuestras ciudades. Por otro lado, la barriada se define como una zona urbana segregada y marginada producto del efecto zoning que ha quedado inconexa con las otras zonas de la ciudad. Esta idea se vería irremediablemente unida con el concepto de urbanización, nuevas agrupaciones urbanas para clase social mediaalta formadas en los últimos años por el boom inmobiliario. Tanto la barriada como la urbanización aparecerían en la ciudad en forma de guetos diferenciándose una de la otra por la clase social que la habita" AA.VV. Edificación Sostenible. Revitalización y rehabilitación de barrios. Cuaderno de abstracts, Ed. Gobierno de España y Ministerio de la Vivienda, Madrid, 2010,p.15.

${ }^{33}$ Tadao Ando destaca la importancia de tener en cuenta la naturaleza en la arquitectura de tal forma que afirma que "la vida del ser humano no consiste en oponerse a la naturaleza ni en protegerse de esta, ni siquiera en tratar de vencerla. El objetivo de los hombres es unirse 
VIVIENDAS EUROPAN (1988-2008) | Una aproximación a los modos de vida en el cambio de siglo en España

3. EUROPAN: LABORATORIO DE IDEAS SOBRE EL HABITAR

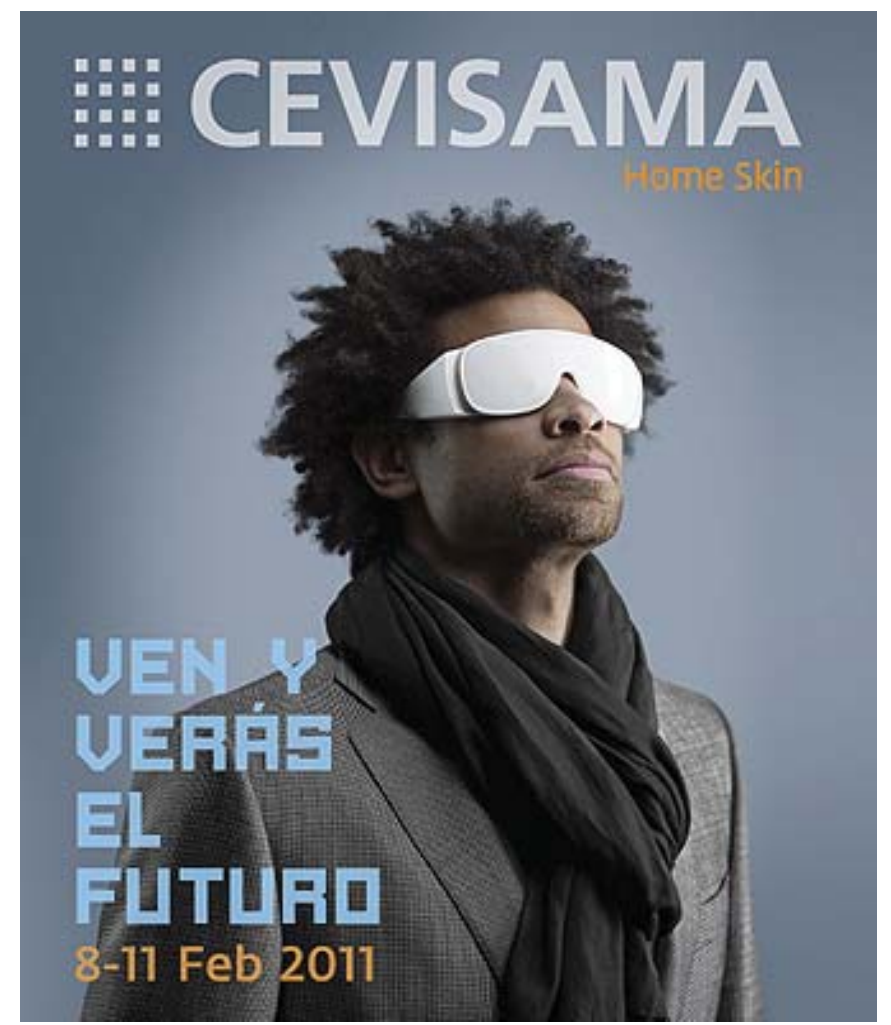

Ref.3.48. Publicidad acerca de las tendencias en el sector de la cerámica española

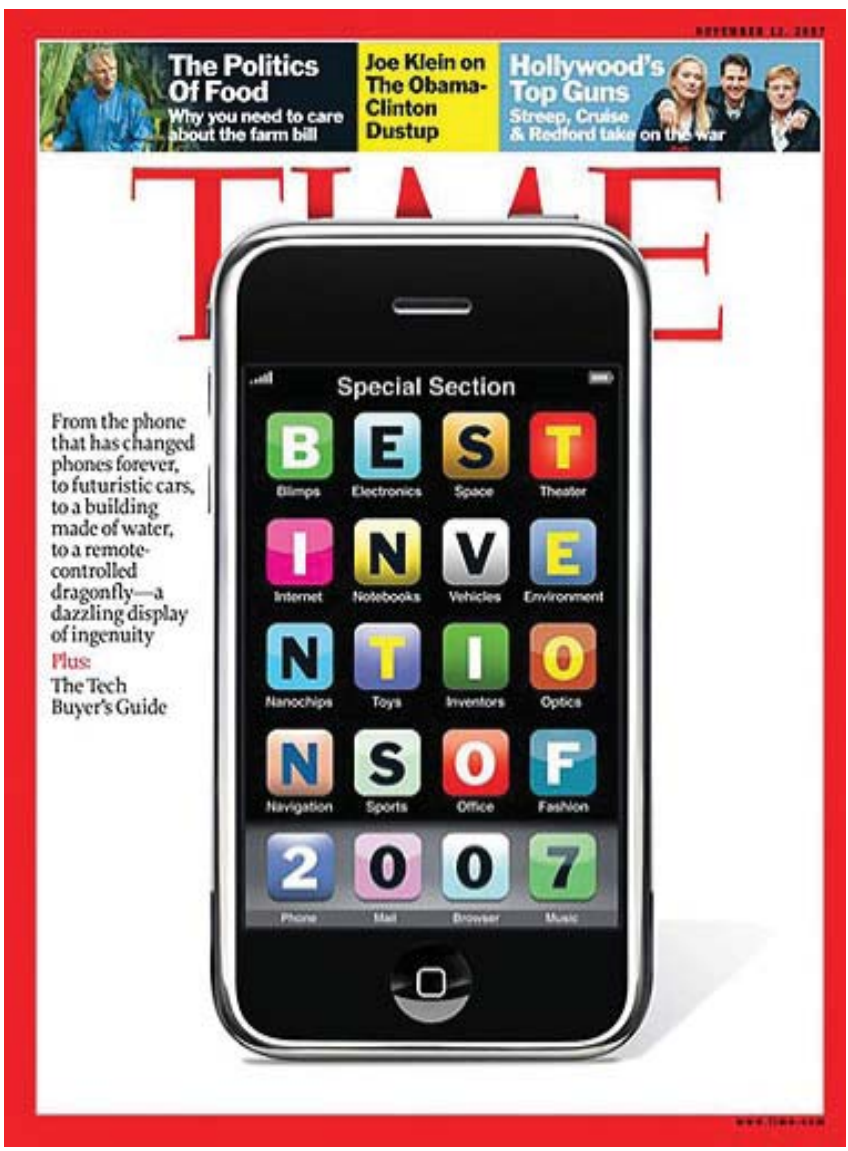

Ref.3.49. Nuevas tecnologías 
Ya lo adelantaba Bachelard cuando decía que "una vivienda en una gran ciudad carece de valores cósmicos. Por eso, cuando las casas ya no se ubican en entornos naturales, las relaciones entre el hombre y el espacio se vuelven artificiales. Todo se hace mecánicamente, y por doquier la vida íntima se extingue ${ }^{34 "}$.

Europan 5 lo asume como uno de sus temas principales de reflexión, de hecho el título de la convocatoria es "los nuevos paisajes del hábitat, desplazamiento y proximidad". Se detecta el problema de la "periferia tentacular", que no es más que el crecimiento masivo de las ciudades sin tener en cuenta el lugar como uno de los principales factores de un edificio de tal forma que "si un arquitecto trata de entender el paisaje y los agentes que intervienen en él, el resultado del diseño es un edificio que dialoga con el contexto estimulándolo. Cuando eso ocurre, uno sabe que ha diseñado un edificio que no se podría haber levantado en ningún otro lugar 35 ".

Europan 6 plantea una actuación sobre el espacio público y la calidad medioambiental: aplicando valores paisajísticos a los proyectos y gestionando los recursos.

Europan 7 trata el tema de la sostenibilidad superficialmente y Europan 8 lo convierte en uno de sus temas principales de reflexión, intentando armonizar la construcción con la naturaleza ${ }^{36}$.

a la naturaleza. Al contrario de lo que sucede en occidente, en Japón la cultura tiende a deshacer las barreras física entre las viviendas y la tierra, entre el interior el exterior (...). La presencia de la naturaleza: el agua, el viento, la luz, el cielo es lo que humaniza los espacios. Por ese motivo yo trato de diseñar proyectos en los que el agua, el viento, la luz convivan con las piedras" y concluye que: "Cuando la arquitectura se piensa desde esas coordenadas creo que se podría decir que uno deja de realizar obras y pasa a construir un paisaje. Algo así ocurre con el Templo del Agua o con el Museo de Arte Contemporáneo de Naoshima. Creo que en esos lugares, la arquitectura ayuda a contemplar la naturaleza desde un nuevo punto de vista". ANDO, Tadao. Arquitectura y espíritu. Ed. Gustavo Gili. Barcelona. 1998. p.53.

${ }^{34}$ BACHELARD, Gaston. La poética del espacio. Ed. Fondo de Cultura Económica. MexiCO, 1965.

${ }^{35}$ ANDO, Tadao. Ibídem. p.37.

36 "La vida del ser humano no consiste en oponerse a la naturaleza ni en protegerse de esta, ni siquiera en tratar de vencerla. El objetivo de los hombres es unirse a la naturaleza. Al contrario de lo que sucede en occidente, en Japón la cultura tiende a deshacer las barreras física entre las viviendas y la tierra, entre el interior el exterior (...). La presencia de la naturaleza: el agua, el viento, la luz, el cielo es lo que humaniza los espacios. Por ese motivo yo trato de diseñar proyectos en los que el agua, el viento, la luz convivan con las piedras". Y concluye: "Cuando la arquitectura se piensa desde esas coordenadas creo que se podría decir que uno deja de realizar obras y pasa a construir un paisaje. Algo así ocurre con el Templo del Agua o con el Museo de Arte Contemporáneo de Naoshima. Creo 
VIVIENDAS EUROPAN (1988-2008) I Una aproximación a los modos de vida en el cambio de siglo en España

3. EUROPAN: LABORATORIO DE IDEAS SOBRE EL HABITAR

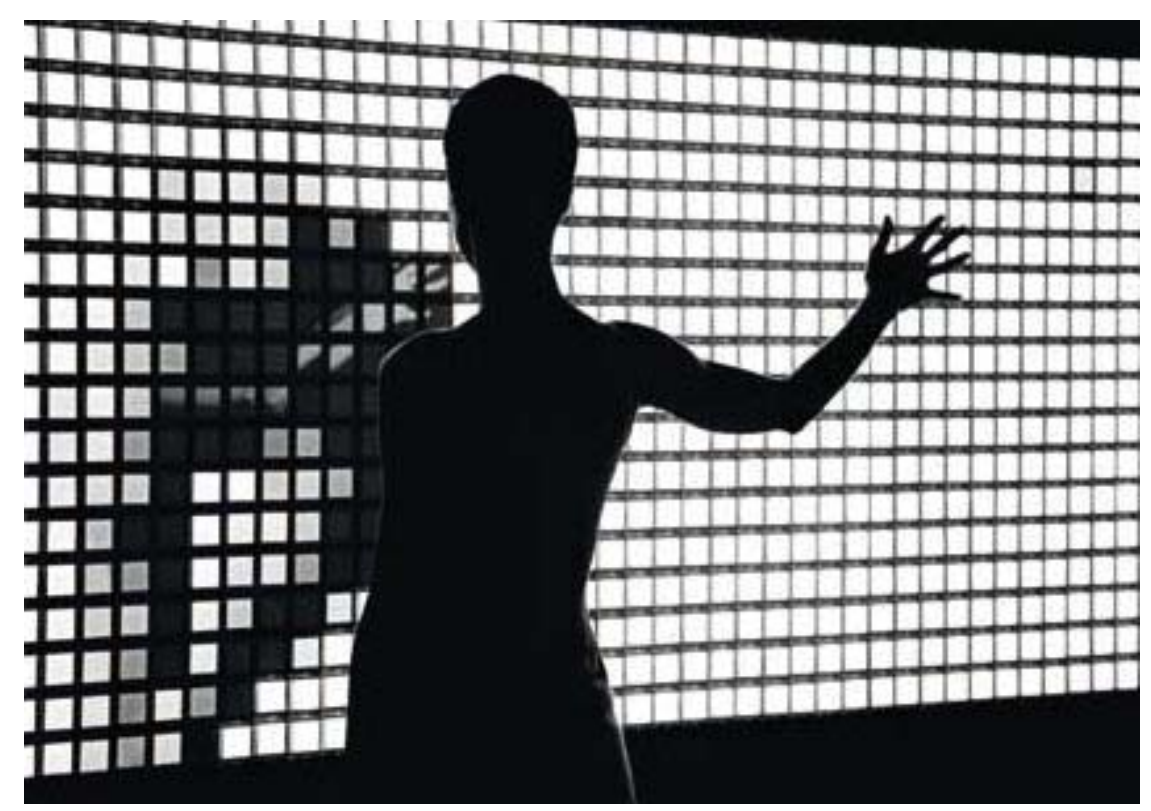

Ref.3.50. La era digital, imagen del OTH

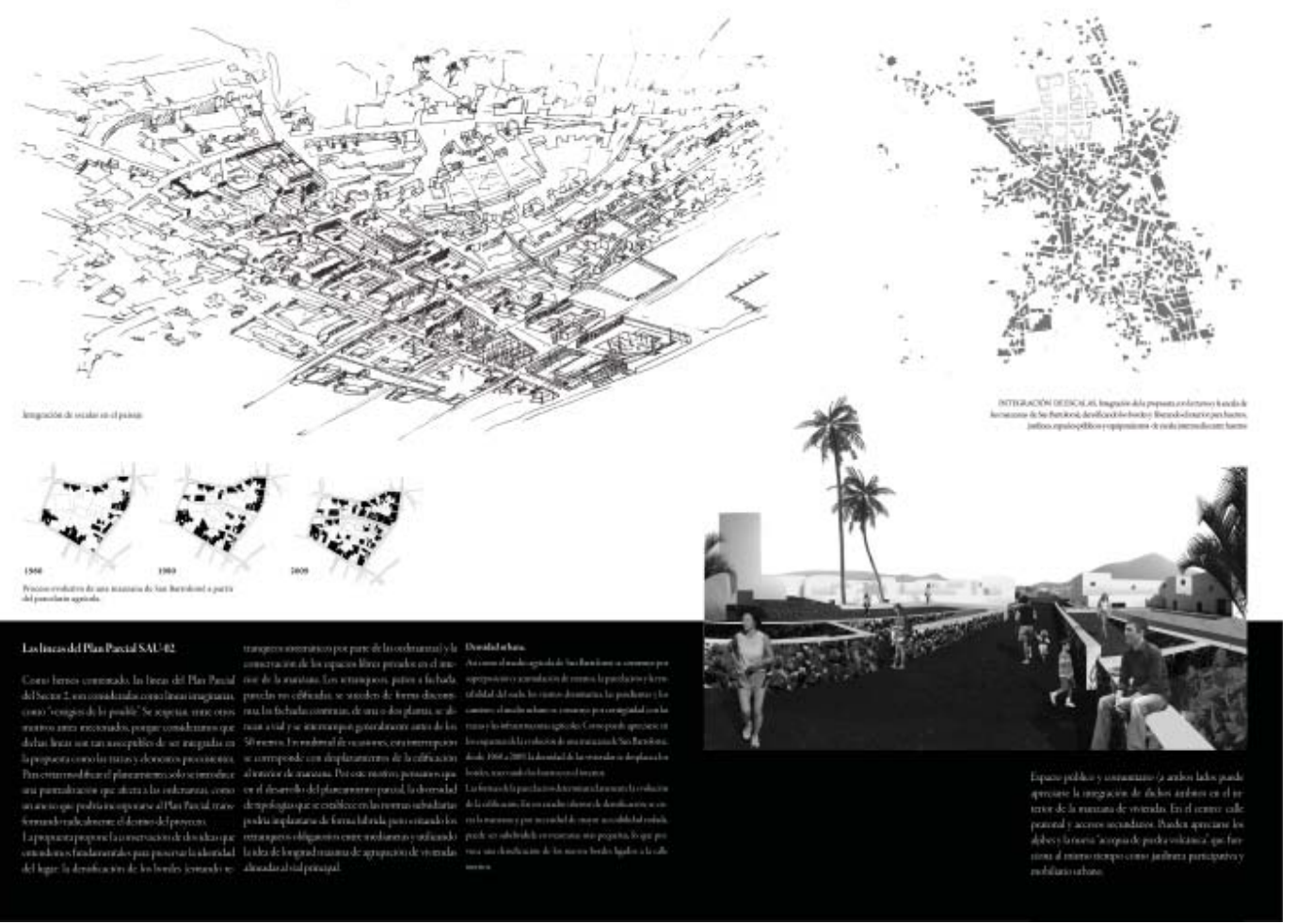

Ref.3.51. Premiado Europan 11 en San Bartolomé. F Javier Castellano, Tomas G, Luis Miguel, Paloma Baquero, Juan Antonio Serrano 
Europan 11 se basa en el tema de la sostenibilidad como afirma su enunciado cuando dice que "una ordenación territorial capaz de generar tanto estrategias de cambio, como una evolución urbana coherente a todas las escalas de sus componentes tanto medioambientales como humanos, no sólo refuerza el atractivo económico, social y cultural de una región o de un municipio, sino que, además, revaloriza su identidad". Introduce términos como "huerto urbano, el parque público, la zona agrícola o el biotopo natural y salvaje ${ }^{37 \text { ". }}$

\section{Redes}

Europan plantea las conexiones como otro de los temas de reflexión permanente. Se habla de dinámica urbana, de accesibilidad residencial, de redes, de urbanizar infraestructuras, de movimiento,...

Ya desde Europan 2 (1990) se plantea el tema de las dinámicas y formas urbanas en una ciudad fragmentada y parcelada estructurada a partir de redes y vías de circulación.

En Europan 3 se habla del uso de los medios de comunicación y la fragmentación del espacio urbano cuando se afirma que "sobre todo se modifican las nociones de distancia y de proximidad espacial, pues las relaciones sociales no se confunden con el entorno vital inmediato, sino que se amplían a la escala de la ciudad".

En Europan 4 se plantea las conexiones entre unas zonas de la ciudad y otras periféricas y Europan 5 se pregunta por el tema de los desplazamientos y la accesibilidad residencial.

En Europan 6 el primer tema de reflexión es actuar en las redes y como idea interesante aparecen las nuevas alternativas a los coches: el autobús, el tranvía y las bicicletas.

Europan 8 propone como primer tema de reflexión urbanizar con las infraestructuras: atravesando las redes o creando nuevas polaridades hacia estas.

Europan 9 también plantea como segundo tema de reflexión el de las redes en movimiento (uniendo, polarizando y diseminando los espacios).

Por último en Europan 11 se plantea el tema de la conectividad entre lo local y lo global.

Como se puede observar en todo lo analizado en los párrafos anteriores, el

que en esos lugares, la arquitectura ayuda a contemplar la naturaleza desde un nuevo punto de vista". ANDO, Tadao. Ibídem. p.154.

${ }^{37}$ El texto íntegro de la convocatoria puede consultarse en el ANEXO 2. 
VIVIENDAS EUROPAN (1988-2008) I Una aproximación a los modos de vida en el cambio de siglo en España

3. EUROPAN: LABORATORIO DE IDEAS SOBRE EL HABITAR

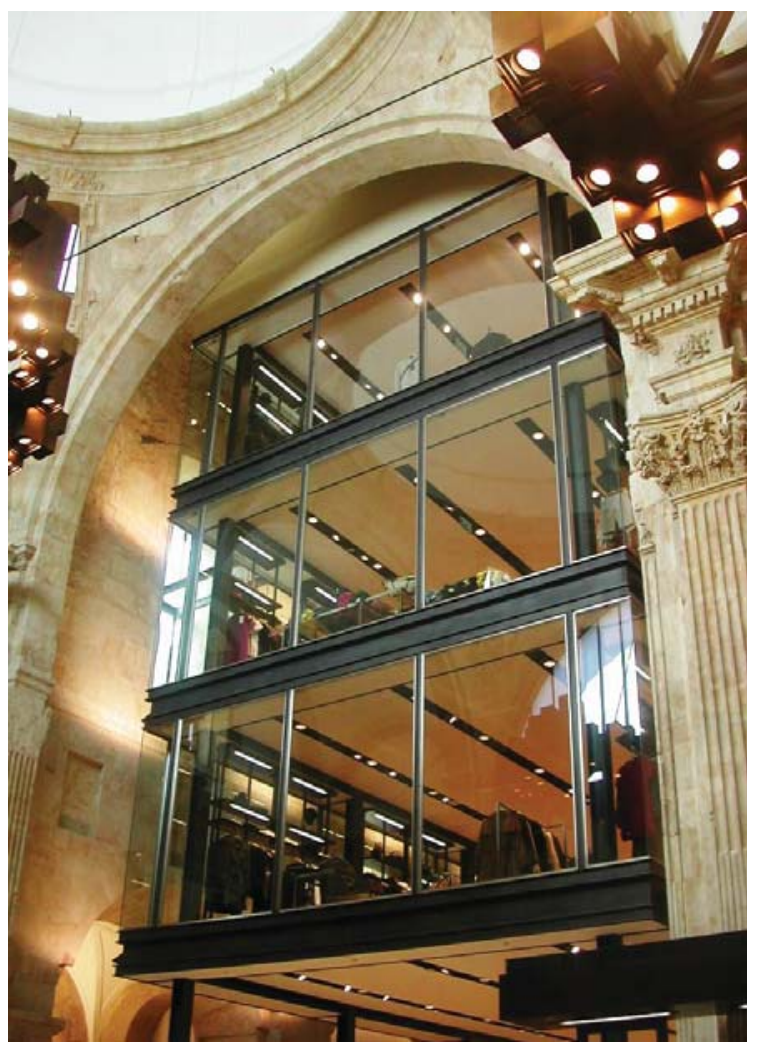

Ref.3.52. Rehabilitación tienda de Zara, Salamanca

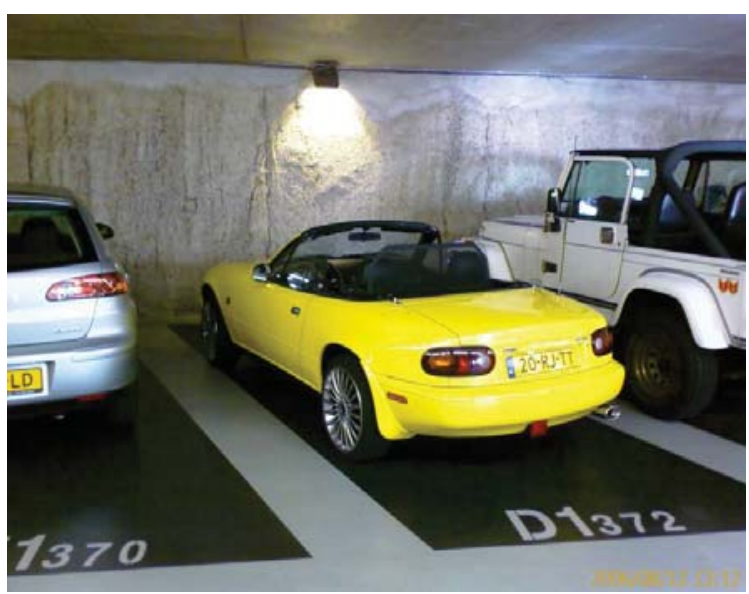

Ref.3.53. El automóvil, actualmente medio principal de transporte

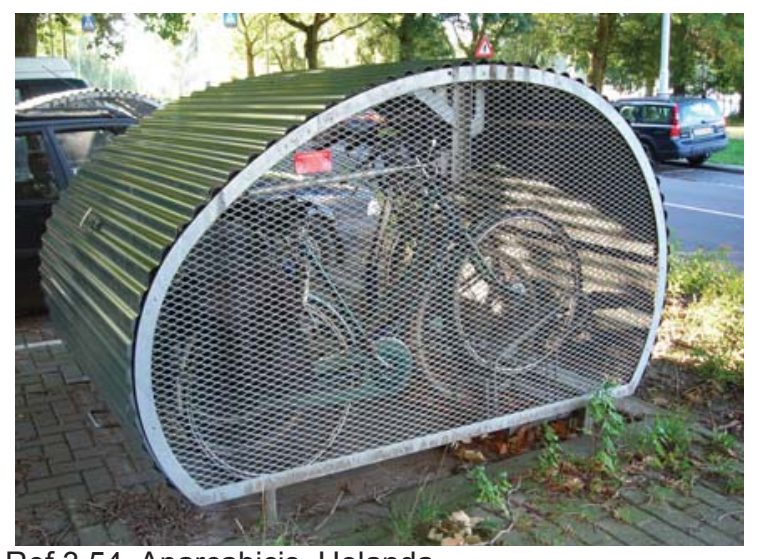

Ref.3.54. Aparcabicis, Holanda 
tema de las redes de infraestructuras (comunicación y transporte, instalaciones, digitales,...) es fundamental en las ciudades. En la cultura actual no se puede prescindir del automóvil pues "cualquier infraestructura viaria se justifica ante la opinión pública por la necesidad de aumentar la movilidad una gente que trabaja y vive en lugares distintos; lo que se consigue es meterlos en un circuito de circulación imposible que elimina estrangulamientos para crear otros. Cien años después, la gran utopía social de los nuevos urbanistas que veían en la circulación la clave de la urbanización y del trazado ha desembocado en esto. El automóvil, instrumento de movilidad y libertad se ha convertido así en una cárcel circulante de millones de personas ${ }^{38}$ ".

En general, la descentralización de la residencia, ha significado un cambio importante en la población que ha afectado de forma más acusada a los municipios medios y pequeños. Las familias se han desplazado de los municipios más centrales, a otros periféricos pues suelen tener un precio de vivienda más bajo. $Y$ aunque esta tendencia supone una mejora en la relación calidad precio, genera gastos importantes en tiempo y costes de desplazamientos, o de otras carencias en la búsqueda de servicios de proximidad.

El transporte es uno de los elementos que define las ciudades. "Para los nuevos crecimientos urbanos lo que se proponen son los eco-barrios. Carlos Verdaguer resume en tres rasgos esenciales la imagen de eco-barrio: la densidad, la mezcla de usos y el predominio de transporte público, ciclista y peatonal sobre la movilidad basada exclusivamente en el vehículo privado ${ }^{39 " . ~}$

De hecho, los grandes urbanistas, siempre tuvieron en cuenta el automóvil, pero ¿existe alguna alternativa a éste? "Un estudio muestra que las emisiones de CO2 esperadas para el 2050 producidas por vehículos podría ser reducida a los niveles del año 1999 sustituyendo los vehículos actuales por vehículos híbridos ${ }^{40 "}$. Es lo que está pasando con los vehículos eléctricos.

\subsection{La evolución de la investigación en Europan: tabla resumen}

Con lo analizado hasta el momento, se puede afirmar que Europan realiza una radiografía de los anhelos de la sociedad en aras de poder abordar los proyectos desde la complejidad existente, desde la interdisciplinariedad. Europan ha

38 [On line] <http://sites.google.com/site/josefinagomezm/documentos> (Consulta, 1 diciembre 2008). GOMEZ MENDOZA, Josefina. "El medio ambiente urbano". Anuario el País 2003.

39 [On line] <http//habitat.arq.upm.es>.(Consulta,2 noviembre 2008). VERDAGUER VIANA-CÁRDENAS, Carlos. De la sostenibilidad a los ecobarrios.

${ }^{40}$ AA.VV. Nuevas formas de habitar Monográfico OTH/1. Ed. Impiva/Generalitat Valenciana. Valencia. 2009. p.22. 
VIVIENDAS EUROPAN (1988-2008) I Una aproximación a los modos de vida en el cambio de siglo en España

3. EUROPAN: LABORATORIO DE IDEAS SOBRE EL HABITAR

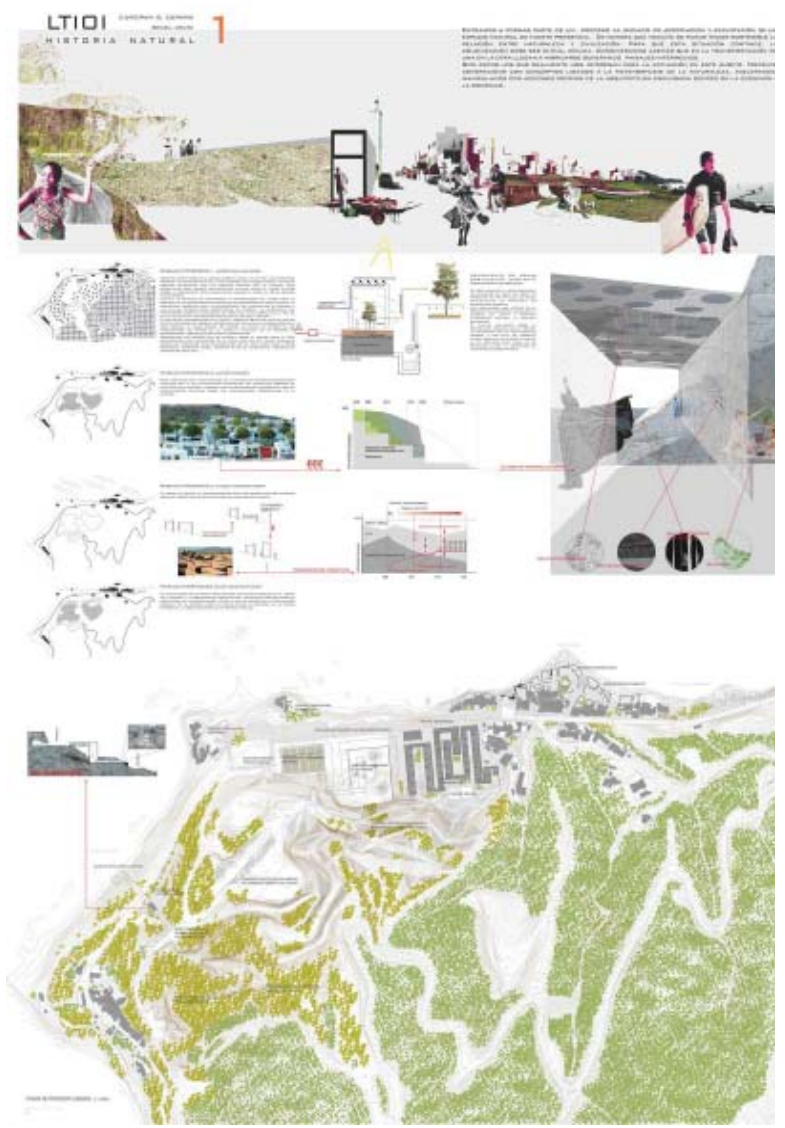

Ref. 3.55. Europan 8. Premiado en Ceuta. Juana Sánchez y Diego Jiménez

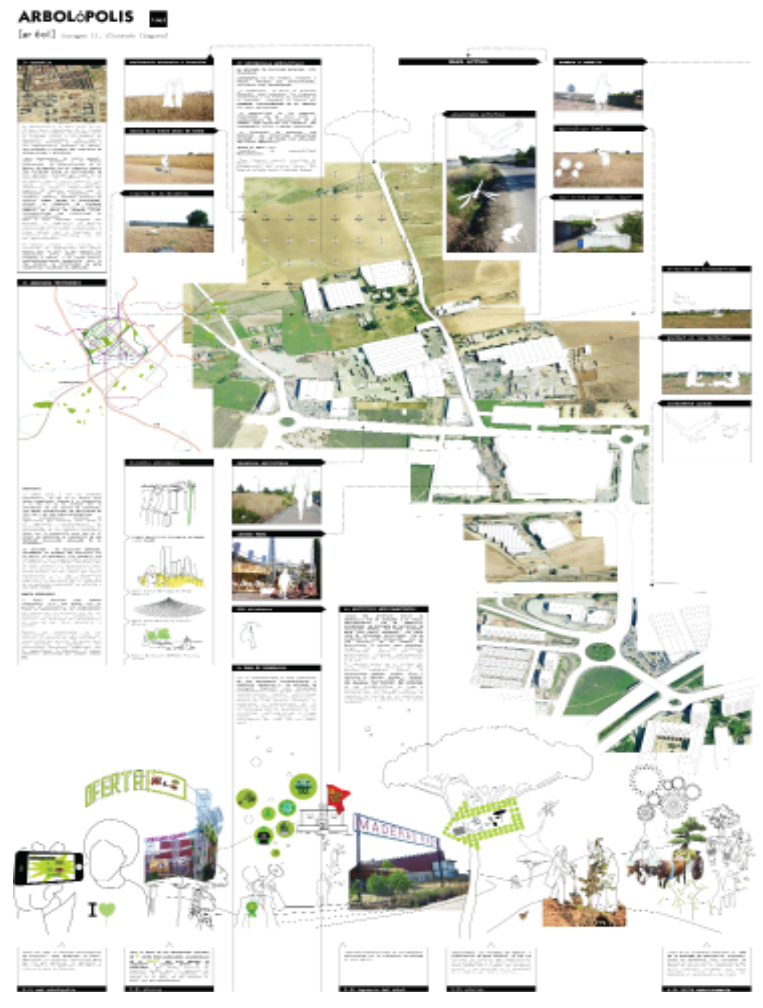

Ref. 3.56. Europan 11. Premiado en Alcorcón. Juana Sánchez y Diego Jiménez. 
planteado en sus convocatorias los principales problemas de las ciudades. $\mathrm{Ha}$ solicitado soluciones para éstos a sus concursantes de modo repetitivo. Se puede afirmar que también ha generado un nuevo enfoque de cómo debe mirarse la ciudad.

En resumen, Europan trata de responder a qué significa hoy habitar desde la propia ciudad cambiante, con una tendencia a la hibridación, tratando de que haya un nuevo ciclo de vida en la ciudad existente, con valores de sostenibilidad y creando redes de conexión.

La sociedad que mira Europan es aquella que está permanentemente cambiando. Una sociedad plural en la que surgen nuevos conceptos. "Junto a la sostenibilidad y la flexibilidad, que mejoran el bienestar y confort de los habitantes, existen otros ejes sobre los que se sustenta la innovación de las casas. Entre estos aspectos adicionales, destacan la creciente importancia por la protección de los habitantes (desarrollo de un hogar saludable que no sólo protege sino que aporta beneficios físicos y psíquicos a la persona), las posibilidades de experimentación (entendiendo la casa como un lugar para la creatividad cotidiana, hecho especialmente importante a partir del hogar digital) y la autorrealización en el hogar (donde la casa se convierte en una expresión del individuo y de sus logros en la vida) ${ }^{41}$ ".

Se ha elaborado una tabla resumen que se muestra en las páginas siguientes y se considera como una de las aportaciones fundamentales de la tesis. Esta tabla permite tener una visión general de las líneas de investigación de cada convocatoria de Europan narradas en este capítulo.

Hasta el momento se ha tratado de definir cuáles han sido los planteamientos intelectuales acerca de la vivienda desde la posición vanguardista de los concursos Europan. Pero Europan es también un instrumento que aborda, desde el punto de vista teórico-práctico, la complejidad de las ciudades tratando de implicar a la Administración Pública ${ }^{42}$. La siguiente pregunta a responder sería la de qué realizaciones han materializado este debate teórico. Esta cuestión tratará de resolverse en el siguiente apartado de la tesis.

\footnotetext{
${ }^{41}$ A.VV. La casa, evolución del espacio doméstico en España. tomo II. Ed. El Viso. Madrid. 2006. p.35.

42 "La elevación del alcance del concurso, ha elevado también el rango del discurso necesario en todo lo que el concurso conlleva: su paralelo teórico, su debate intelectual entre foros y jurados y la cada vez más necesaria implicación directa y comprometida de las administraciones públicas". GARCÍA SOLERA, Javier, "Nuevos Caminos", en AA.VV. Europan 10, Proyectar la urbanidad, colonización/revitalización /regeneración. Ed. Secretariado de Europan. Madrid. 2010. p. 209.
} 
TABLA RESUMEN. LA EVOLUCIÓN DE EUROPAN. LABORATORIO DE IDEAS SOBRE EL HABITAR

\begin{tabular}{|c|c|c|c|c|}
\hline europan 1 & europan 2 & europan 3 & europan 4 & europan 5 \\
\hline t 1988 & 1990 & 1992 & 1994 & 1997 \\
\hline (tiempo) & $\begin{array}{l}\text { TERRENOS BALDÍOS Y } \\
\text { DEGRADADOS }\end{array}$ & $\begin{array}{l}\text { BARRIOS } \\
\text { RESIDENCIALES } \\
\text { EXISTENTES }\end{array}$ & $\begin{array}{l}\text { PERIFERIAS DE LAS } \\
\text { CIUDADES }\end{array}$ & $\begin{array}{l}\text { REDES DE } \\
\text { DESPLAZAMIENTO EN } \\
\text { ESPACIOS URBANOS } \\
\text { ABANDONADOS }\end{array}$ \\
\hline $\begin{array}{l}\text { 1- cómo se vive hoy } \\
\text { en Europa } \\
\text { 2- transformación del } \\
\text { habitat: } \\
\text { - cambio en las } \\
\text { estructuras } \\
\text { familiares, papel de } \\
\text { la mujer } \\
\text { - nuevas formas de } \\
\text { relacion con el } \\
\text { trabajo } \\
\text { - individualismo y } \\
\text { cuerpo } \\
\text { - nuevas tecnologías }\end{array}$ & $\begin{array}{l}\text { 1- hábitat y modos } \\
\text { de vida } \\
\text { 2- dinámica urbana } \\
\text { 3- imagen de marca } \\
\text { 4- el patrimonio } \\
\text { urbano } \\
\text { 5- multifuncionalidad } \\
\text { 6- estrategias } \\
\text { operativas }\end{array}$ & $\begin{array}{l}\text { 1- los cambios en los } \\
\text { modos de vida } \\
\text { 2- relacion de } \\
\text { espacio privado y } \\
\text { espacio público } \\
\text { 3- importancia de las } \\
\text { relaciones sociales } \\
\text { 4-potenciacion de los } \\
\text { valores ecologicos }\end{array}$ & $\begin{array}{l}\text { 1- situarse, quitar } \\
\text { prejuicios en la } \\
\text { ciudad con respecto } \\
\text { a lo existente } \\
\text { 2- transformar, } \\
\text { cambiar el uso } \\
\text { preparando para el } \\
\text { futuro } \\
\text { 3- heredar, evaluar lo } \\
\text { construido } \\
\text { 4-conectarse, unir } \\
\text { las partes de una } \\
\text { misma ciudad }\end{array}$ & $\begin{array}{l}\text { 1- naturaleza y } \\
\text { habitat } \\
\text { 2- desplazamientos y } \\
\text { accesibilidad } \\
\text { residencial } \\
\text { 3- urbanismo } \\
\text { inducido } \\
\text { 4- existencia de } \\
\text { nuevos modos de } \\
\text { vida } \\
\text { 5- intensificacion de } \\
\text { usos } \\
6 \text { - gestionar la } \\
\text { complejidad }\end{array}$ \\
\hline $\begin{array}{l}\mathrm{i} \\
\text { (idea) }\end{array}$ & & & & \\
\hline
\end{tabular}

IDENTIFICACIÓN DE LAS IDEAS PERMANENTES

\section{CAMBIOS EN LOS MODOS DE HABITAR}

HIBRIDACIÓN VERSUS ZONIFICACIÓN

RECICLAJE

SOSTENIBILIDAD

REDES 


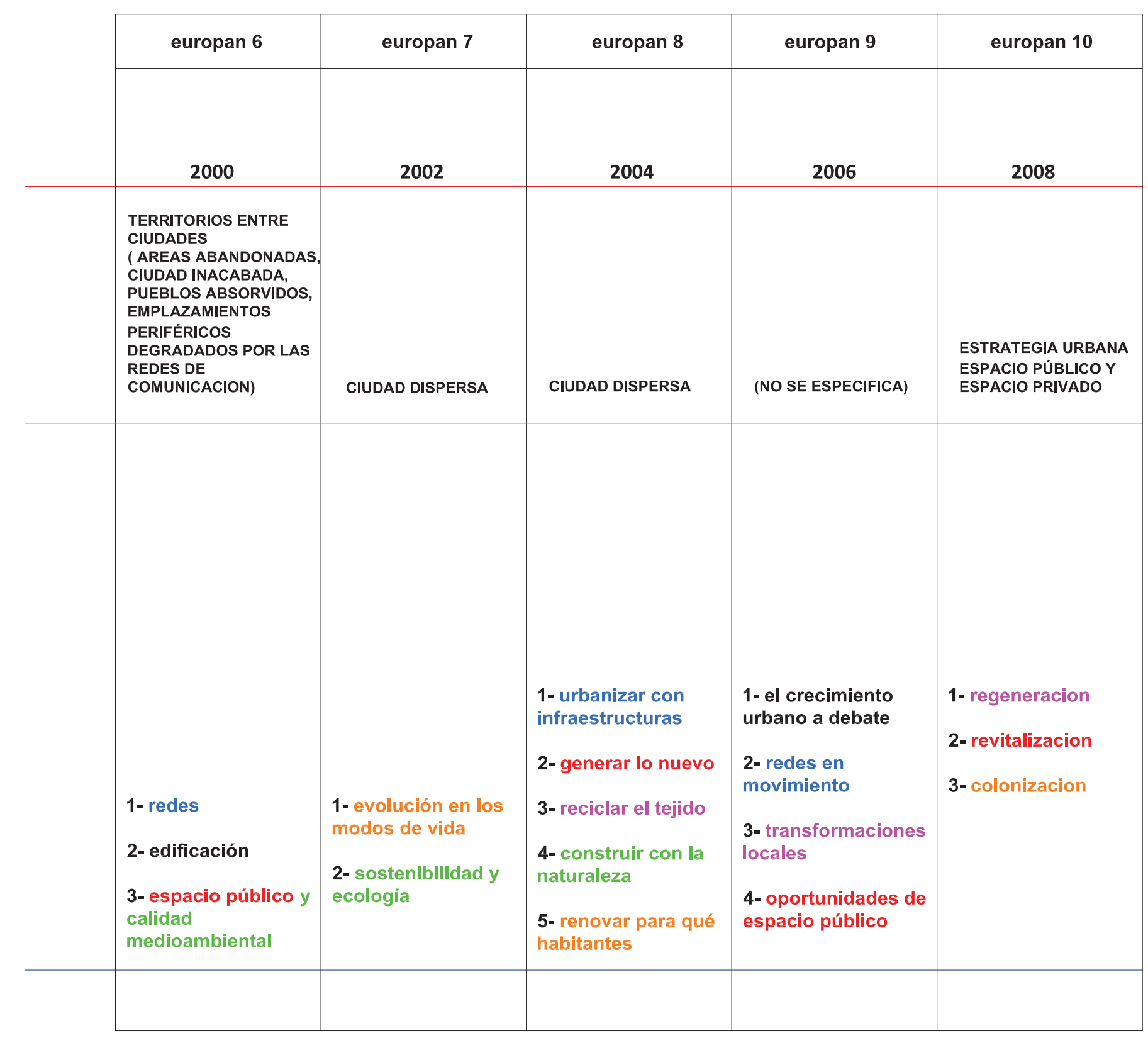





\section{EUROPAN: DEL CONCURSO A LA REALIZACIÓN}

"Hemos coronado unos cuantos ochomiles. Lo hemos hecho entre todos a lo largo de veinte años; unos desde el principio y siempre; otros desde distintos lugares en cada ocasión. Algunos vivimos los mejores momentos desde nuestros inicios al vernos ganadores y también los peores al frustrarse nuestras expectativas. Quedamos de algún modo en el camino; pero nos levantamos para volver porque la ruta que Europan abría era emocionante y seductora.

De enunciado fácil y difícil oportunidad: Europan nos proponía ser arquitectos (...)".

GARCÍA SOLERA,Javier 
VIVIENDAS EUROPAN (1988-2008) | Una aproximación a los modos de vida en el cambio de siglo en España

4. EUROPAN: DEL CONCURSO A LA REALIZACIÓN
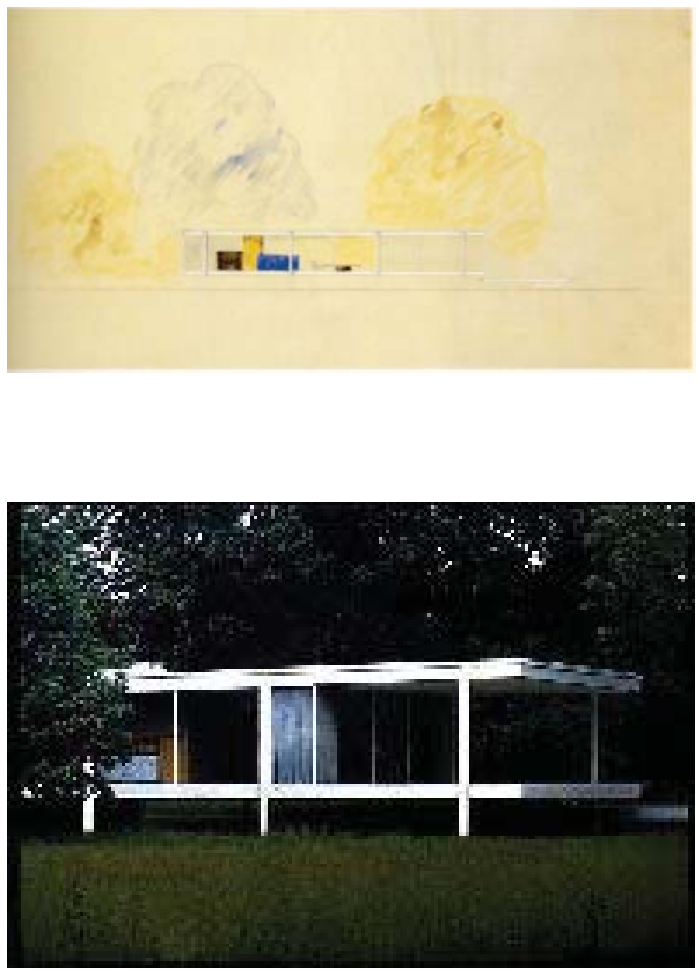

Ref. 4.1. De la ideación a la construcción. Casa Farnsworth (1951). Illinois. Mies van der Rohe
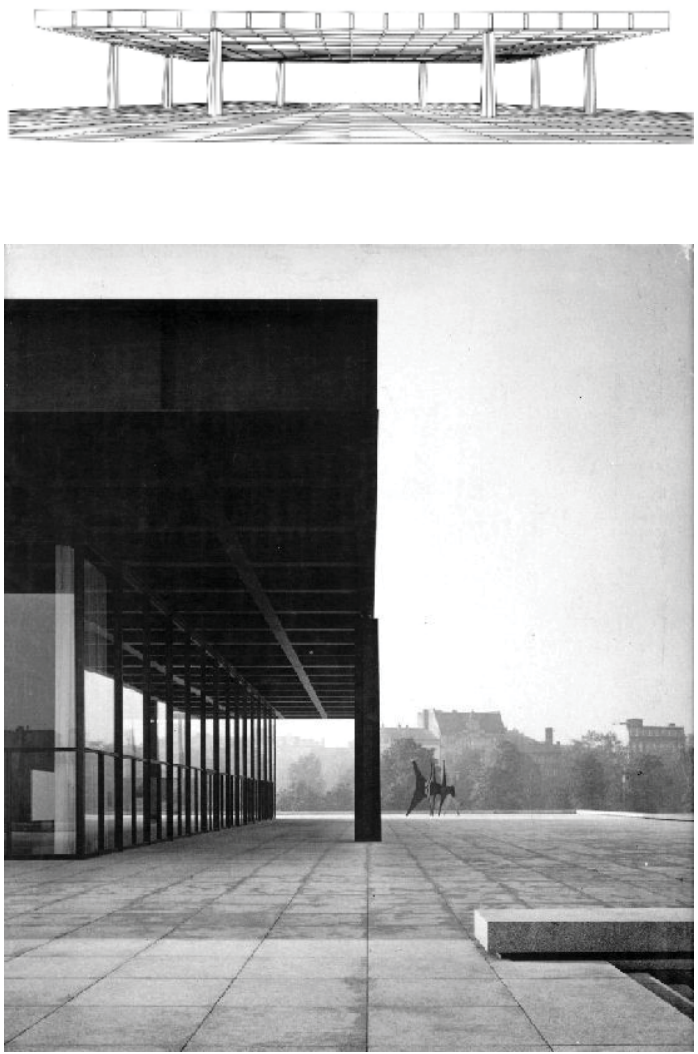

Ref.4.2. De la ideación a la construcción. Neue National Gallery (1968). Berlín. Mies van der Rohe 


\subsection{Edificios de viviendas construidos: fichas explicativas}

Una cosa son las ideas, los paneles, los proyectos desarrollados y otra lo que se ha construido. Tras analizar los temas de investigación de las convocatorias de Europan se procede a estudiar a continuación la veintena de viviendas sociales construidas con motivo de Europan en España hasta el año 2008. Posteriormente se responderá a la cuestión de si estos proyectos han respondido a las expectativas de cada convocatorias o, lo que es lo mismo, si es posible la materialización y de qué modo.

Es conocido por los que desarrollan el oficio de la arquitectura qué difícil es construir, llevar las propias ideas del papel a la realidad. No pocas veces hemos oído de labios de algunos profesores de las Escuelas de Arquitectura que "el papel lo sostiene todo". Alberto Campo lo ha sabido expresar en sus libros, sobre todo en la magistral exposición -también citada con anterioridad- "la idea construida" cuando firma que "la Arquitectura, como la poesía y la cocina, no se surte de "encuentros casuales" sino de búsquedas laboriosas. Pues laboriosa es la investigación del arquitecto que, con todos los datos encima de la mesa, piensa y mide, mide y piensa para llegar a "encuentros certeros". Y es que las ideas, en Arquitectura, tienen dimensiones y medidas ${ }^{1 "}$.

Se intenta más bien crear una reflexión acerca de la relación existente entre el mundo conceptual de las ideas de proyecto y el de la realidad de la obra construida. Fruto de estas consideraciones se intenta suscitar en los arquitectos una actitud previa de reflexión y buena práctica constructiva que podría ser el punto de partida para poder cambiar el panorama de la arquitectura actual española.

Construir un Europan no es tarea fácil. Intentar plasmar las cuestiones que se plantean en los enunciados, tampoco. Una pregunta la que se pretende responder en este apartado es si ha valido la pena los veinte años de Europan.

La respuesta quizá ya la adelantaba Belinda Tato cuando afirmaba que, "Transcurridos estos años es oportuno plantearse algunas cuestiones: ¿Qué ocurre después? ¿Cuántas realizaciones se llevan a cabo? ¿Es más interesante que el concurso aborde problemas urbanos complejos que implican infraestructuras, planeamiento, gestión, etc...; o que por el contrario se planteen situaciones más acotadas donde la viabilidad de una realización es posible a corto plazo? ¿Dónde está la multidisciplinariedad necesaria para abordar esos problemas? ¿Cuánto de experimental debe ser el concurso? ¿Se trata de un ejercicio de investigación o por el contrario tiene como objetivo primordial llevar a cabo una realización? ¿Entendemos por realización exclusivamente algo construido? ¿Consideramos, por ejemplo, el desarrollo de una herramienta de participación ciudadana una

${ }^{1}$ CAMPO BAEZA, Alberto. La idea construida. Ed. Colegio Oficial de Arquitectos de Madrid. Madrid. 1996. p.13. 
VIVIENDAS EUROPAN (1988-2008) I Una aproximación a los modos de vida en el cambio de siglo en España

4. EUROPAN: DEL CONCURSO A LA REALIZACIÓN

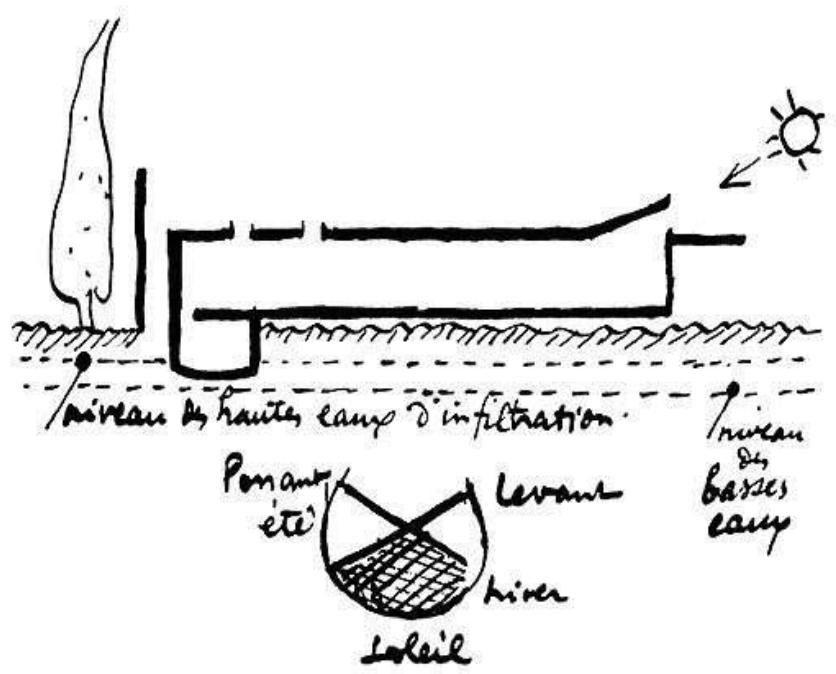

La coupo
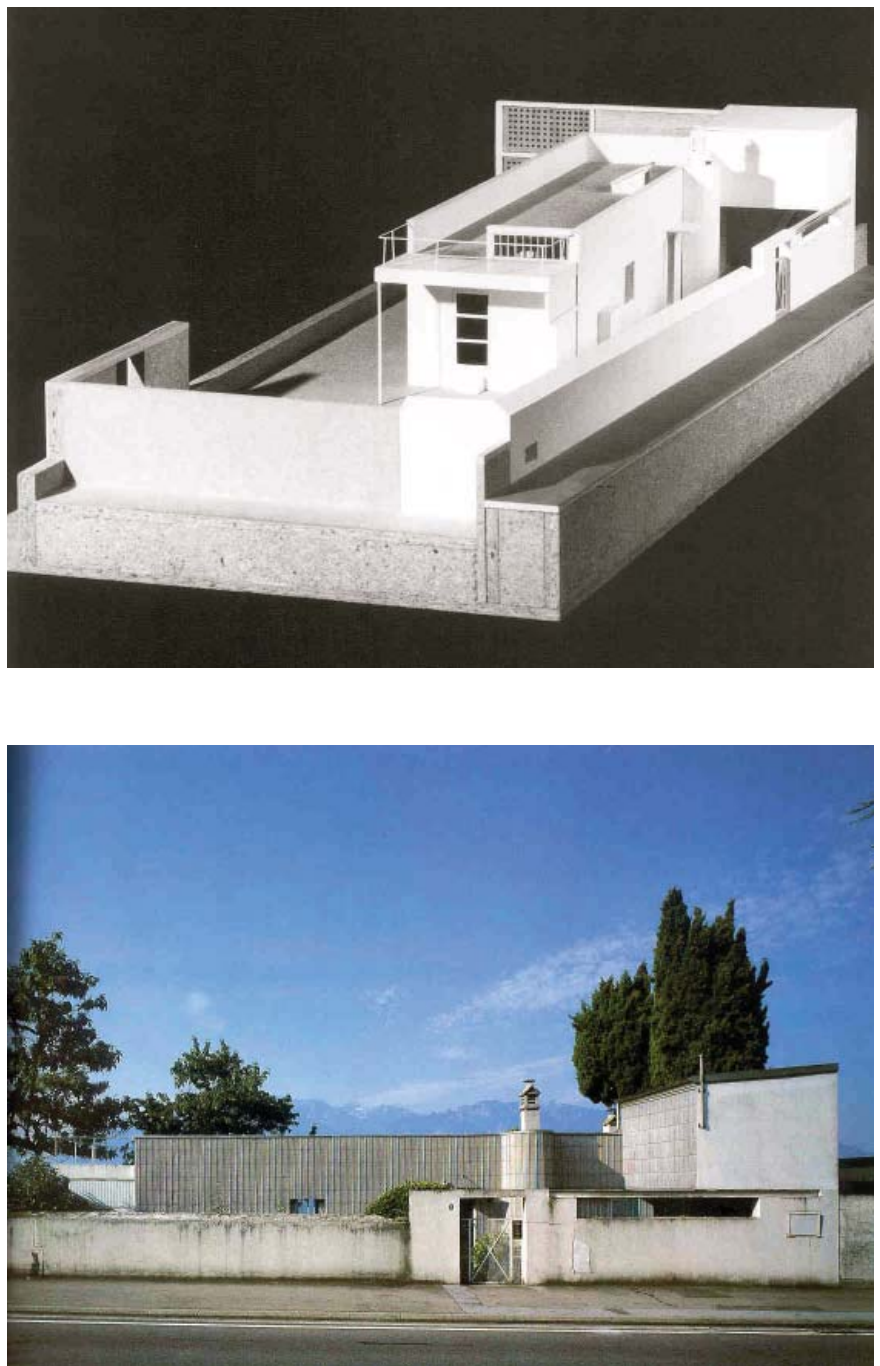

Ref.4.3. De la ideación a la construcción. Casa Leman (1925). Suiza. Le Corbusier 
realización? ¿Cuál es el criterio para elegir los emplazamientos? ¿Responden las propuestas presentadas a las expectativas de los potenciales clientes? ¿Responde el concurso a los retos urbanos que se plantean en la actualidad? ¿Cuál es el nuevo papel de la arquitectura en la sociedad? ¿Hay que reformular la profesión? Los arquitectos proponemos arquitectura, urbanismo, eficiencia energética, normativas, modelos de gestión..., pero ¿quiénes componen los jurados? ¿Solo arquitectos?..."

No se trata de inquietar al lector, sino de suscitar su capacidad de reflexión y poder llegar a algunas conclusiones, entre ellas, cómo pueden actuar los arquitectos para que se construya la buena arquitectura.

Ya afirmaba Paul Válery que construir es un arte, no es hacer cualquier cosa. Parafraseándolo dirá que "(...) entre todos los actos, el más completo es el de construir. Una obra requiere el amor, la meditación, la obediencia a tu más bello pensamiento, la invención de leyes por tu alma, y otra variedad de cosas que ella de ti mismo saca, cuando de poseerlas no abrigabas sospecha. Esta obra dimana de lo más íntimo de tu vida, y no se confunde, a pesar de ello, contigo. Si estuviera dotada de pensamiento, presentiría tu existencia, que jamás alcanzaría ella a establecer ni a concebir con claridad ${ }^{3}$.

Se puede comprobar cómo en la arquitectura de los grandes maestros como Mies, o le Corbusier existe una coherencia entre lo que piensan y lo que construyen. Actualmente no faltan las dificultades para poder construir lo deseado.

Por último, cabe hacer una reflexión previa antes de analizar los edificios de viviendas construidos. No se trata de un análisis exhaustivo de cada uno de ellos, sino de resaltar algunas cuestiones que han parecido interesantes en Europan. Para el análisis de cada edificio se ha elaborado una ficha resumen que se compone de tres partes.

En la primera parte de la ficha resumen se ha redibujado el edificio construido en planta en dos aspectos. Por un lado el sistema de agrupación de las viviendas, o planta de conjunto en la que se ha grafiado los núcleos húmedos, los accesos de las viviendas $y$, en color, los tipos de vivienda existente. Por otro lado, se ha elegido una vivienda para proceder al análisis más detallado de espacios y superficies útiles. En general, los proyectos se encuentran a la misma escala y con un grafismo homogéneo para facilitar de esta manera la comparación.

En la segunda parte de la ficha resumen se han recopilado imágenes más representativas del edificio construido. Una imagen que está presente en cada

2 TATO, Belinda. EUROPAN 10 España. Proyectar la urbanidad. Ed. Ministerio de la vivienda. Madrid. 2010,p.257.

${ }^{3}$ VALERY, Paul. Eupalinos, el arquitecto. Editorial Colección de arquitectura Colegio oficial de Aparejadores y Arquitectos técnicos de Alicante. Valencia. 1982. p.95 


\section{EI000 laescaleraintrusa.com}

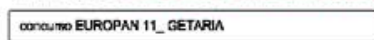

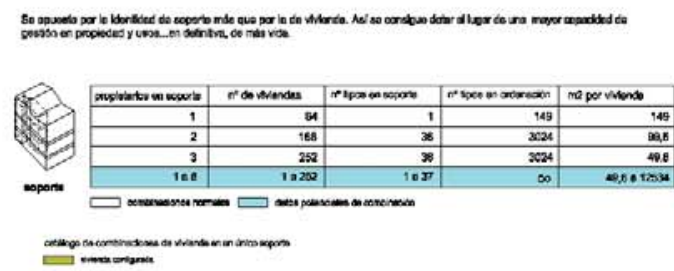

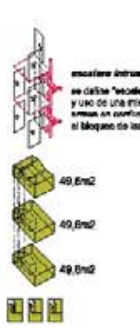

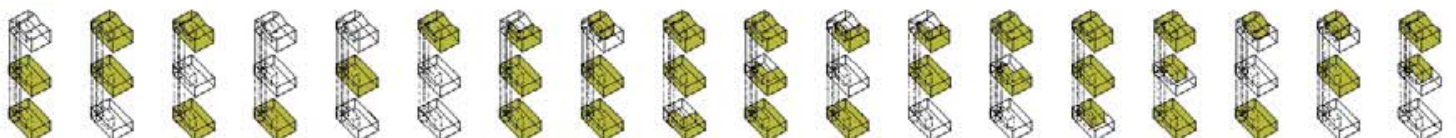

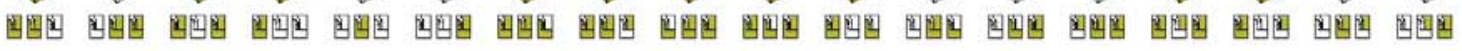
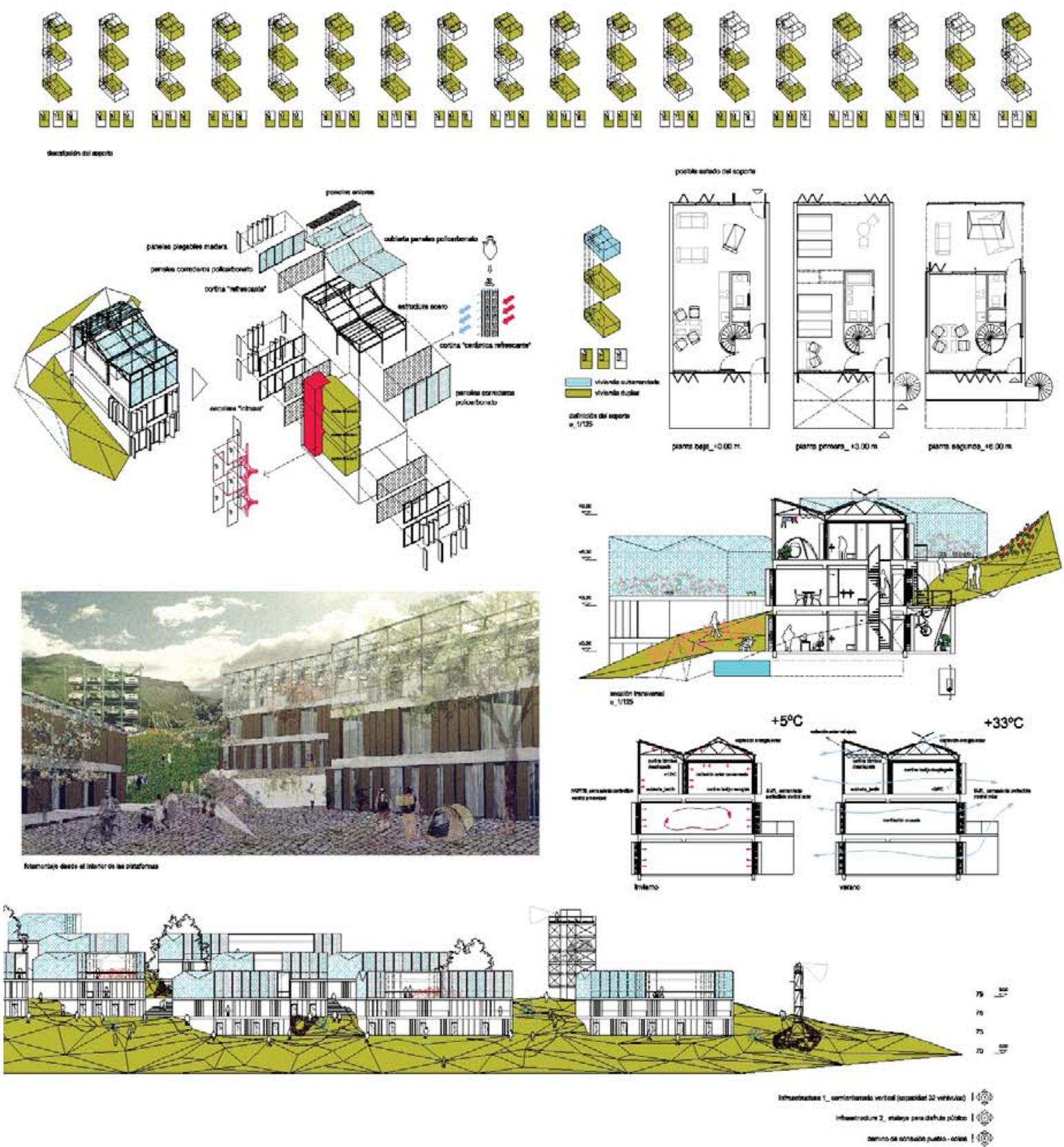

Ref.4.4. Premiado Europan 11 en Getaria. Jose Lopez, Jose Manuel Calvo, Guillermo Gosalvo 
proyecto es la de situación y emplazamiento pues de este modo se puede localizar con facilidad.

La tercera parte la constituye una columna de texto que ha se ha elaborado con la finalidad de que la información fuera lo más clara y completa posible.

En ésta se definen los siguientes parámetros:

a) Los que permiten identificar el edificio de viviendas construido:

- Los autores de proyecto

- El emplazamiento y la dirección exacta de la obra

b) Los que permiten valorar la evolución del proyecto:

- La duración de las obras

- Si es el proyecto de concurso (este dato es interesante para poder comparar la evolucion desde la ideación hasta la realización)

c) Los referentes a las viviendas y otros usos:

- El número de viviendas total

- El número de viviendas por superficie

- El uso de la planta baja y sótano

d) La bibliografía que existe del edificio en cuestión.

La tarea de recopilación de esta información ha sido costosa pues se encontraba muy dispersa, pero el resultado permite poder comparar las viviendas entre sí y analizar su evolución. 



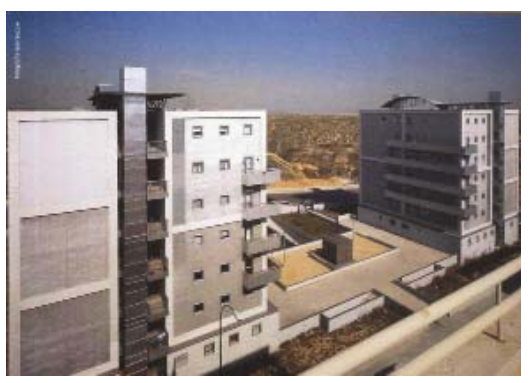

\subsubsection{Edificios de viviendas Europan 1 (1988)}

Aranguren y Gallegos: torres de viviendas en Madrid 

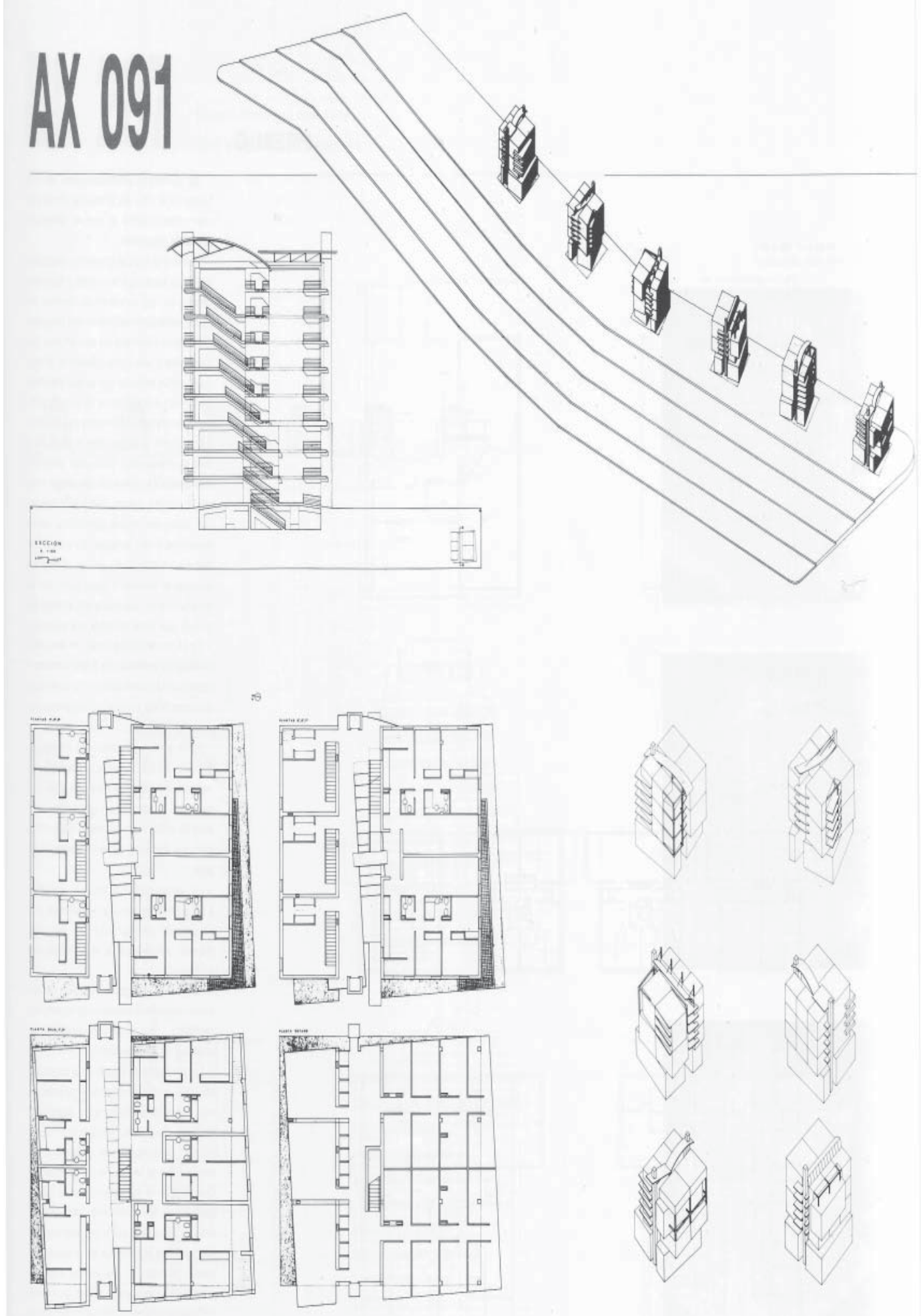

Ref. 4.5. Paneles de concurso 


\begin{tabular}{ll} 
& José González Gallegos \\
& Maria José Aranguren López \\
PREMIO & Cartos Iglesias Sanz \\
& Juan Manuel Ros Garcia \\
\hline
\end{tabular}
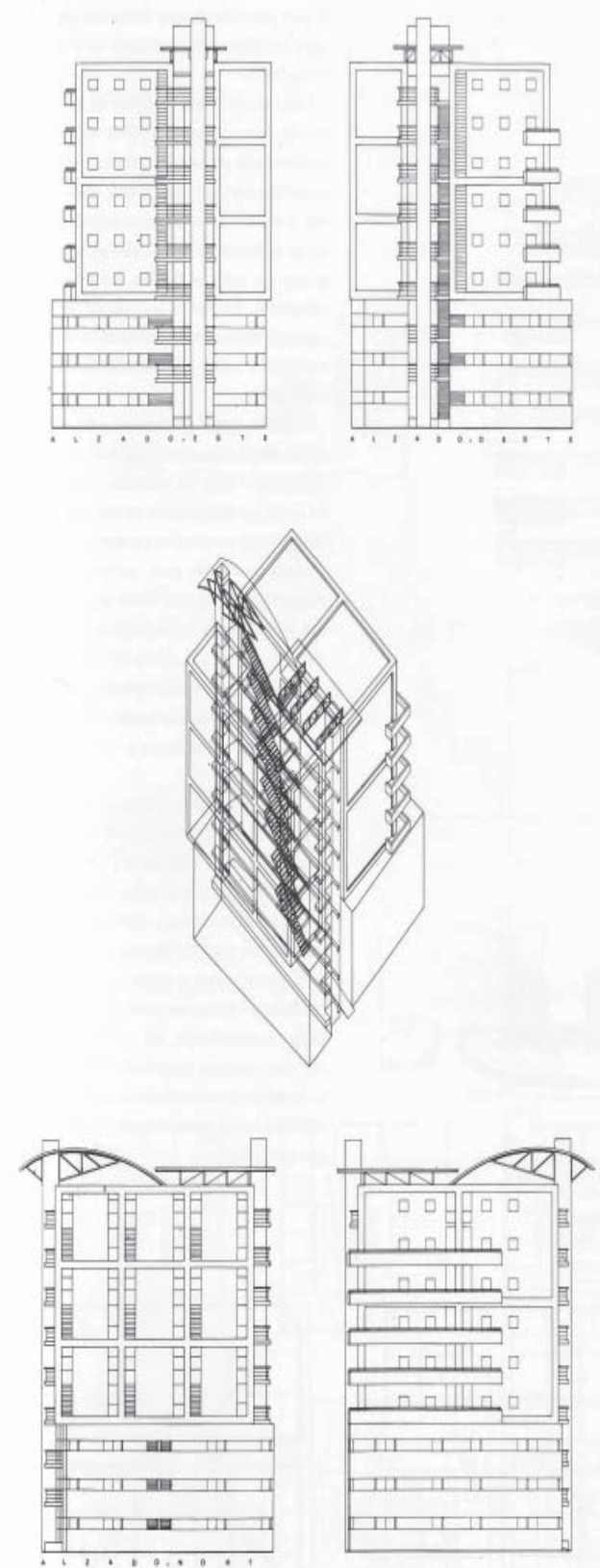

Ref. 4.6. Paneles de concurso
El objeto del proyecto sujeto a concurso, es la realización de seis torres colocadas linealmente frente al parque de Enrique Tierno Galvan y la autovia $M-30$.

En la propuesta que presentamos, se considera conveniente, disentar las seis edificaciones, no como absolutamente quales, sino como partes de un proyecio global que obtenga una estructura con: creta que abarque el desarrollo de la totalidad de la edificación estructurada en seis torres.

Se parte de la definición de una torretipo, desarrollada en los paneles 1 y 2 . y se planteará, a partir de ésta, una ley de seriación combinatoria, que nos permitirá componer las otras cinco torres, aceptando una estructura común y unas leyes constantes en la agrupación de todas ellas. Esta seriación se ilustra en of panel 3

E) concepto fundamental a la hora de abordar la definición de la torre de viviendas, vinculada a un paisaje urbano degradado en extremo, es aceptar como objetivo la no contextualización del objeto arquitectónico.

Dentro de una periteria intorme la torre se concibe como un elemento extrano. escultórico, con una fuerte configuración absiracta, que la libera de condicionantes ambientales de escasa relevancia.

La torre. y el conjunto de tocas ellas. se apoyan en dos vías de circulación rápida, como es la red de terrocarriles y la autovia M-30.

Esta peculiaridad las hace ser conce. bidas para ser vistas desde el tren o desde los coches, a gran velocidad, están dispuestas como esculturas, co. pias con fuerte realismo, copias de los restos y desechos arquilectónicos, de ese naufragio, que son las alueras do nuestras ciudades.

La torre se concibe como dos tormas en flotación, un cubo apoyado sobre ung base, tambièn de torma cubica, girando ambas entre si, descomponiéndose, llegando a crear una arquitectura no unita. tia, fragmentada y tragmentaria.

La edificación concebida como dos cubos girados se quiebra por una trania. correspondiendo al núcleo de comunicaciones, el cual, se abre a las fachadas desde unas plataformas voladas, que. dando cubiento en la parte superior de la edificación, por unas formas, resueltas en chapa plegada, que operan como formas blandas, superficies cristalinas que niegan el carácter cerrado del espacio.

El resto del programa como balcones o escaleras se genera como consecuencia de la descomposición del edifcio, son elementos girados, quebrados Hay que asumir lo que supone ef abandono de la Modernidad, la pérdida del centro, se tiende a una irresistible independencia del mundo de los objetos y de la máquina respecto del hombre. Se proyecta u opera por descomposición del objeto, este se concibe de manera escultorica, al cual se le puede quebrar o excavar.

Ahora bien, 10 hasta aqui expresado. no niega la necesicaod de resolver un edificio para ser habilado, ser vivido, para albergar en su seno un conjunto de viviendas que sean más habitables que en muchas de las convencionales torres de viviendas.

La necesidad de recuperar valencias perdidas en las agrupaciones de vivien. das, como la existencia de un verdadero espacio comunitario o vecinal, cuya refe. rencia histórica pudieran ser las corralas madrilentes, nos han animado a rasgar e: núcleo central de comunicaciones verti. cales, que surge de forma inmediata en torres de planta cuadrada y de las dimensiones en que nos movemos. hasta abrirse a las fachadas, permitiendo asi crear un espacio común, permeable. con desarrollo de corredores, que perm. tirán, sin duda, un mayor contacto entre los habilantes de la torre.

El giro de la torre cúbica, permite en cada momento, orientar las viviendas hacia mejores encuadres visuales o de soleamiento, produciéndose en las vi. viendas más tavorecidas, la apentura de terrazas corridas.

La diversidad de tipos y superficies de las viviendas, tarmbién permitirá, en principio, el contacto de personas con ditetentes raspos sociales, desde persones solteras a familias con y sin hijos, gracias a la existencia de viviendas en dúplex y de 1,2 y 3 dormitorios. 
VIVIENDAS EUROPAN (1988-2008) I Una aproximación a los modos de vida en el cambio de siglo en España

4. EUROPAN: DEL CONCURSO A LA REALIZACIÓN

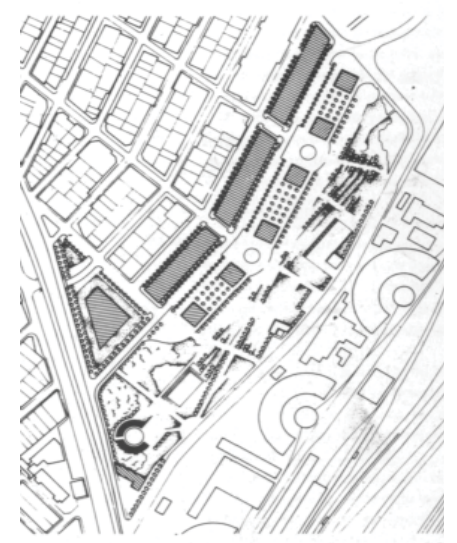

Ref. 4.7. Solar de concurso propuesto por la Empresa Municipal de la Vivienda
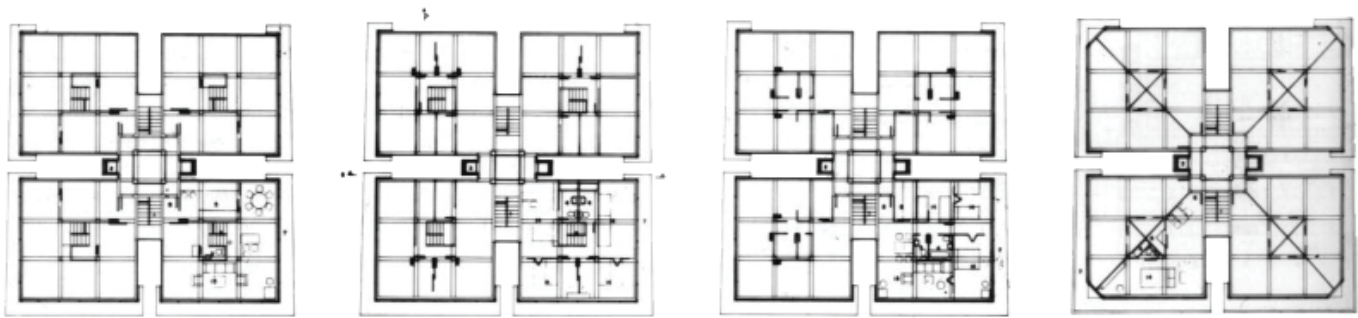

Ref.4.8. Plantas del proyecto de concurso de Gonzalo Cavanillas
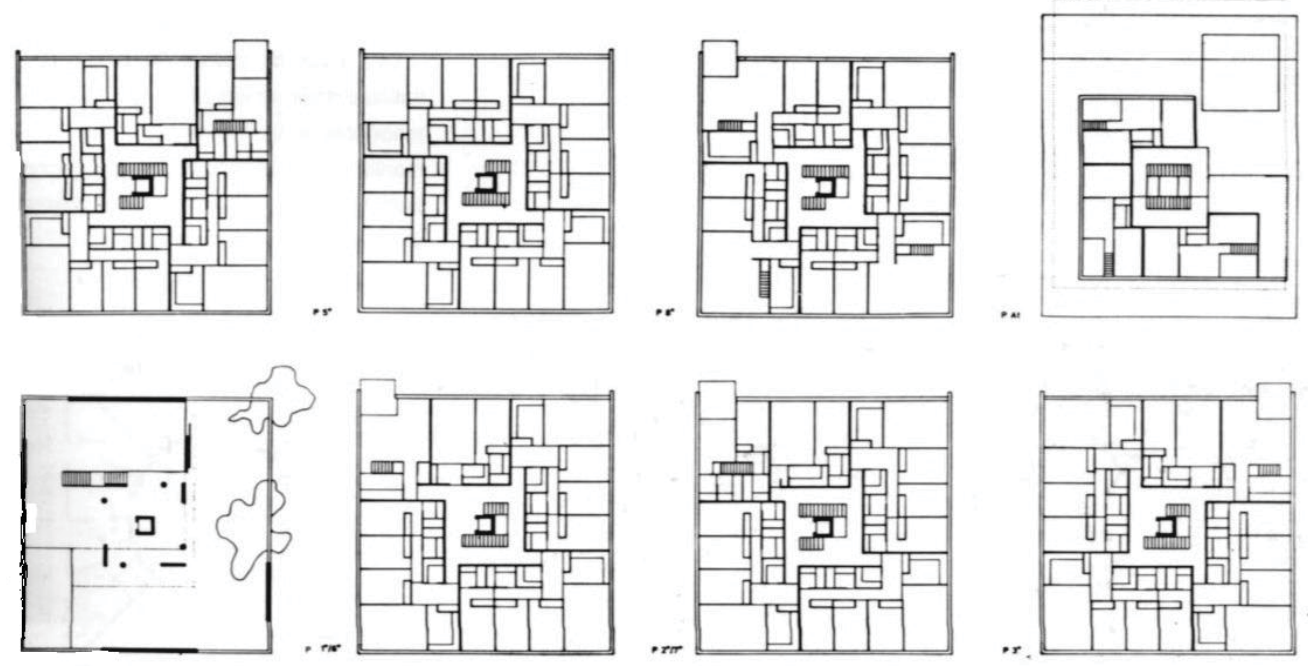

Ref.4.9. Plantas del proyecto de concurso de Mera, Sanvicente y Urzáiz
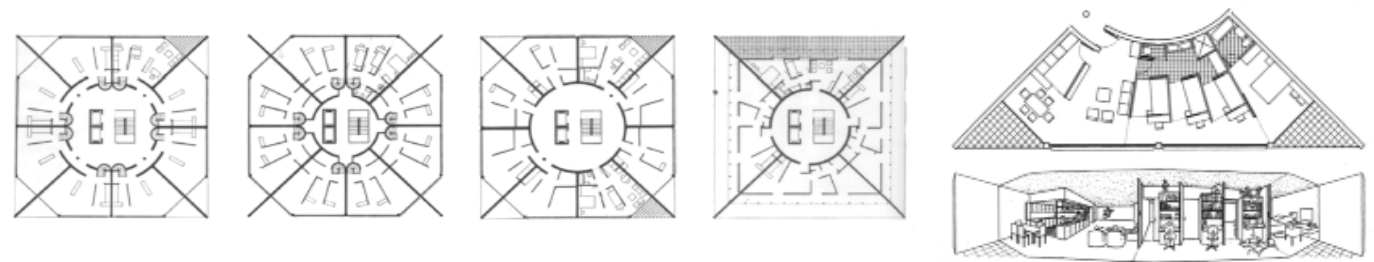

Ref.4.10. Plantas y perspectiva de proyecto de concurso de Magaz y Urquidi 


\section{Fase de concurso}

Aunque en un principio Europan 1 planteó la libre elección de los emplazamientos, la Empresa Municipal de la vivienda presenta un solar en Madrid en un emplazamiento frente a una vía de tráfico intenso (la M-30) en el Barrio de Entrevías. La ordenación urbanística del área propuesta pretendía rematar la trama de edificación cerrada de la zona con un conjunto de seis torres-tipo y una zona ajardinada que desciende en ladera hasta los terrenos del ferrocarril.

Los condicionantes urbanísticos eran bastante rígidos: las dimensiones de la torre debían estar comprendidas entre un máximo de 22×22 m y un mínimo de 18×18 $\mathrm{m}$, sin que existiera obligación de que la planta fuera cuadrada. Debía tener 10 plantas como máximo (incluyendo el sótano, en su caso), y se permitía un ático retranqueado $3 \mathrm{~m}$ respecto del plano de fachada. El número máximo de viviendas debía ser de 58 . También delimitaba la altura de cornisa $(27,5 \mathrm{~m})$ y las alturas de la planta baja (2,90 para uso de vivienda y 3,10 para locales comerciales).

Además existían unos condicionantes de programa. Las viviendas, de promoción pública, debían estar dirigidas a clases sociales poco solventes y debían oscilar desde uno hasta cuatro dormitorios.

Bajo el lema AX091, presentado por Aranguren y Gallegos,que puede observarse en los paneles de concurso de las páginas anteriores, se proponen 6 torres distintas en un proyecto global. Se define una torre-tipo y a partir de esta se plantea una seriación combinatoria.

El proyecto se concibe como un cubo, con una rasgadura de luz longitudinal y que corresponde con el núcleo de comunicaciones. Las torres parecen esculturas que se pueden quebrar y excavar. Se pretendía dar énfasis al espacio común interior, donde surgen las relaciones intervecinales, que parece aludir a las "corralas" madrileñas, como los propios autores indican.

Es interesante comparar el proyecto ganador con los proyectos seleccionados por el Jurado, entre los que se pueden observar varias alternativas:

- Gonzalo Cavanillas plantea un módulo tipo, trasladándolo también verticalmente. La propuesta pretende flexibilizar el espacio utilizando tabiques móviles y puertas correderas. Todas las viviendas nacen de un núcleo central que contiene los servicios y la estructura general. De esta forma se libera el espacio perimetral y se obtiene una óptima ventilación e iluminación.

- Mera, Sanvicente, y Urzáiz fueron seleccionados con una propuesta de vivienda modular en torre con disposición en esvástica. Proponen viviendas con una variación de uno a cuatro dormitorios, incluso con dobles alturas. El edificio se compone de tres cuerpos: una basamenta transparente que constituye un gran 

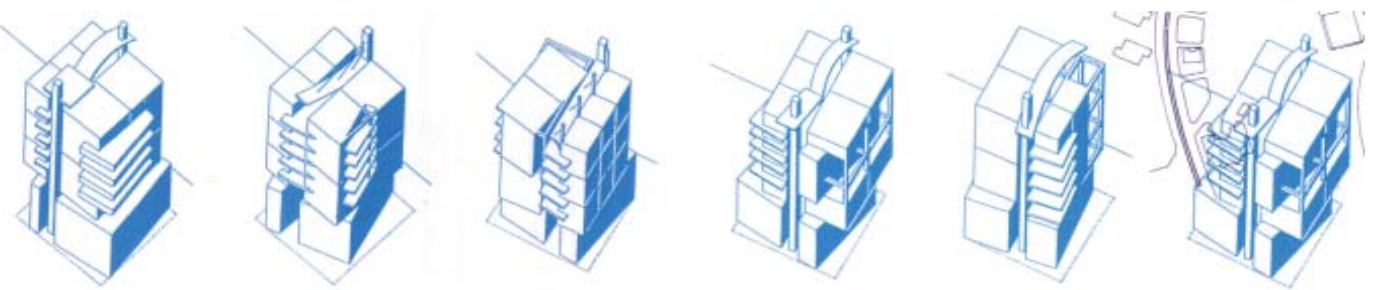

Ref.4.11.Torres planteadas en el concurso bajo el lema AX091

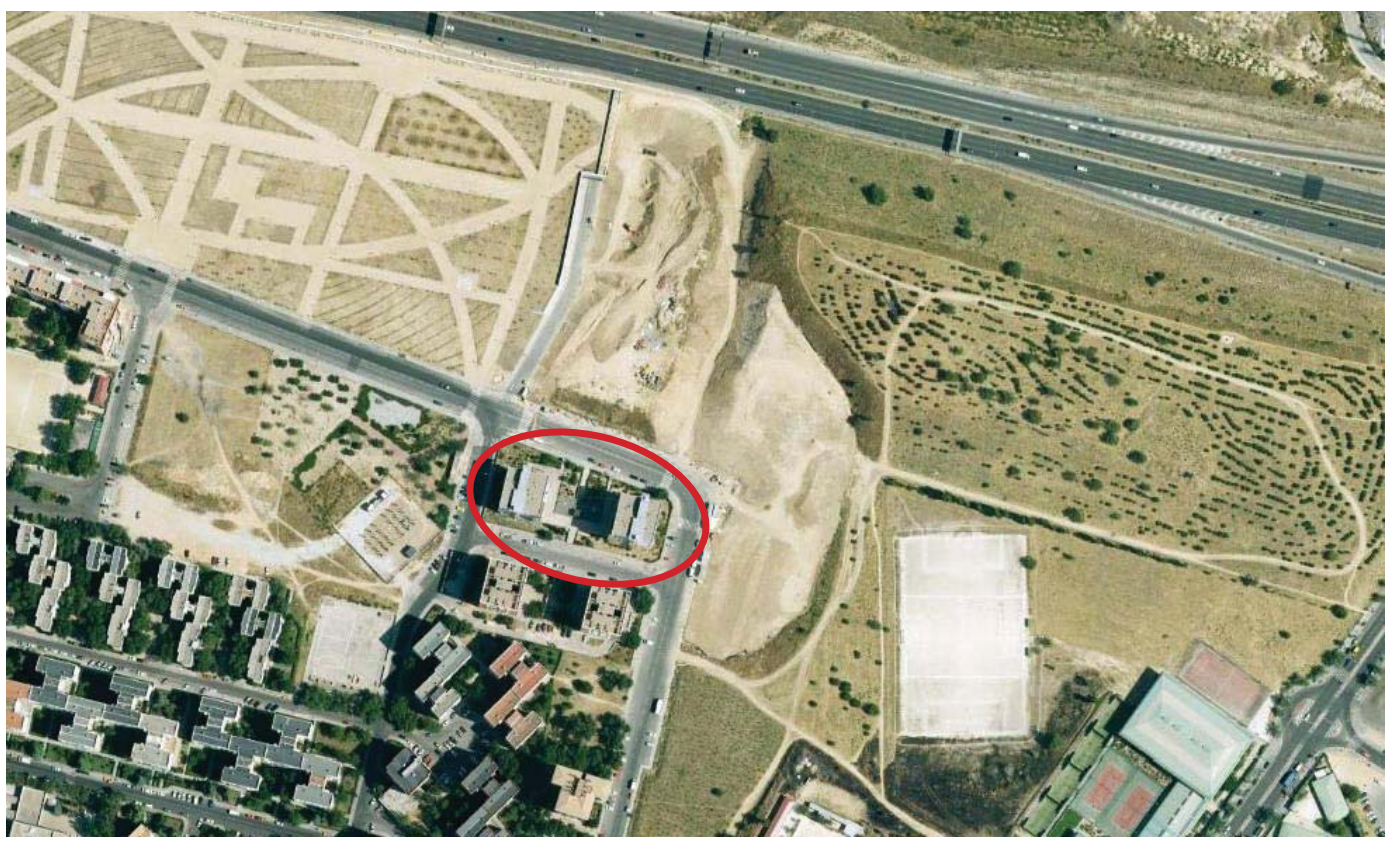

Ref.4.12. Solar donde se construyen las torres frente a la M-40
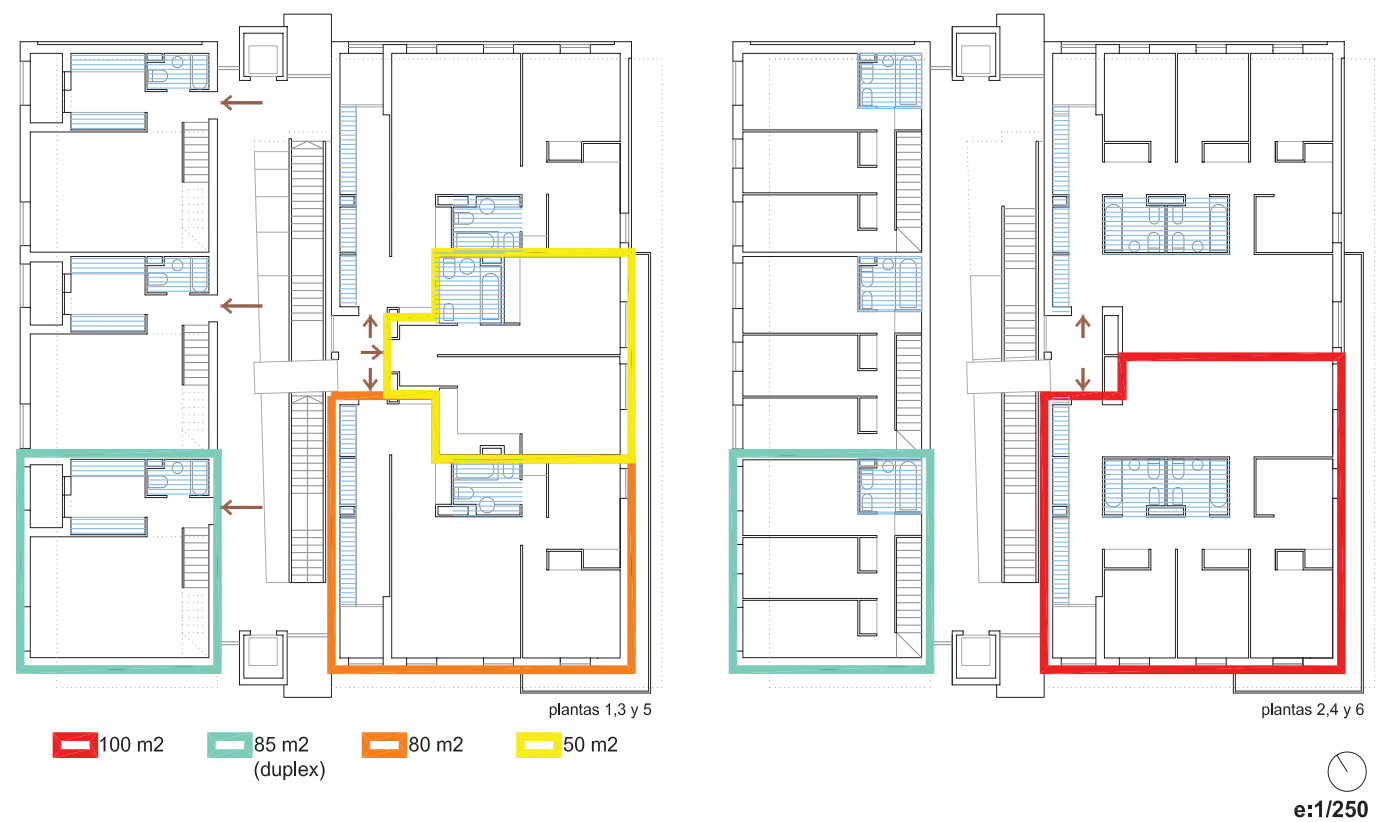

Ref.4.13. Plantas de las torres construidas 
espacio a doble altura, un cuerpo central compuesto de la combinación de viviendas y una coronación.

- Magaz y Urquidi desarrollan una torre de viviendas de forma radial, dando el máximo frente al exterior. Existe un núcleo de accesos que crea un espacio circular en el interior.

\section{Fase de realización}

Los proyectos de concurso presentados se caracterizaron por la descontextualización ya que el paisaje urbano ofrecía una degradación extrema. Los concursantes basaron sus propuesta en el estudio de las torres-tipo, como se ha visto anteriormente.

El proyecto premiado de Aranguren y Gallegos se construirá en otro solar en el noreste de Madrid junto a otra vía de tráfico intenso: la M-40. Las características del entorno se pueden considerar por lo tanto muy parecidas a las del solar de concurso.

Se construye en 21 meses: las obras comienzan en 1991 (dos años después de ser premiados en Europan 1) y acaban en abril de 1993.

El número de torres se reduce de seis a dos y el número de plantas de diez a siete. Cada torre tiene un total de 28 viviendas: 9 de ellas son dúplex desarrolladas en seis alturas.

Se puede decir que la obra construida tiene bastante semejanza con el planteamiento que tenían los arquitectos en el proyecto de concurso. La planta es un cuadrado de dimensiones $20 \times 20 \mathrm{~m}$ y la rasgadura vertical se refleja en el lucernario de la escalera, que introduce la luz en el edificio y permite que un simple espacio de recorrido sea más agradable y menos ténebre, potenciando la relación entre los habitantes.

La planta sótano se destina a garajes. En un principio, el uso de las torres se destina exclusivamente a vivienda.

Los accesos a las viviendas se realizan a través de un corredor intermedio, limitado en sus extremos por la comunicación vertical mediante ascensor. La escalera está situada como parte del corredor generando las circulaciones.

El giro de la torre permite orientar las viviendas en busca de la luz o de las buenas vistas. Los núcleos húmedos se sitúan en el interior del prisma y el espacio restante se compartimenta en función del número de estancias.

Las viviendas se pueden clasificar en función del número de espacios pues existen 
VIVIENDAS EUROPAN (1988-2008) I Una aproximación a los modos de vida en el cambio de siglo en España

4. EUROPAN: DEL CONCURSO A LA REALIZACIÓN

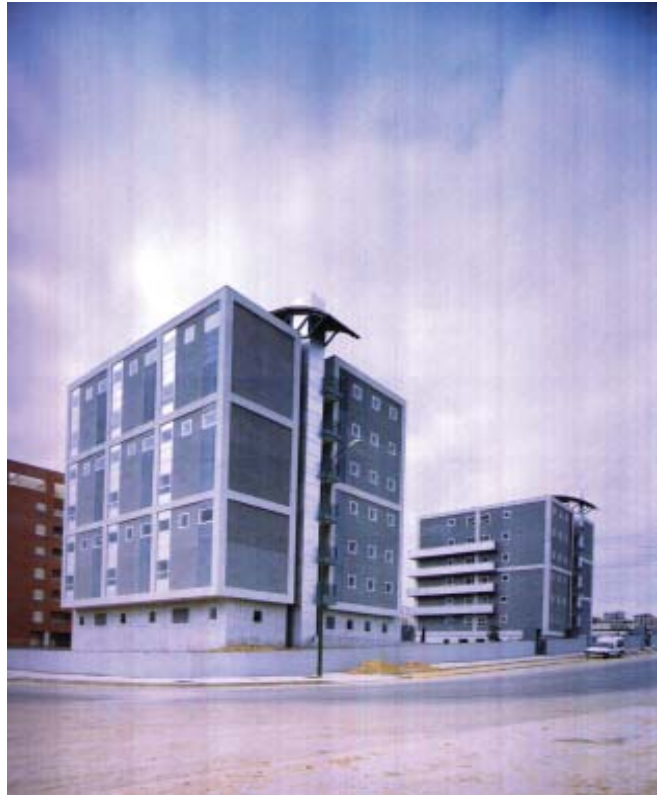

Ref.4.14. Vista actual de las torres

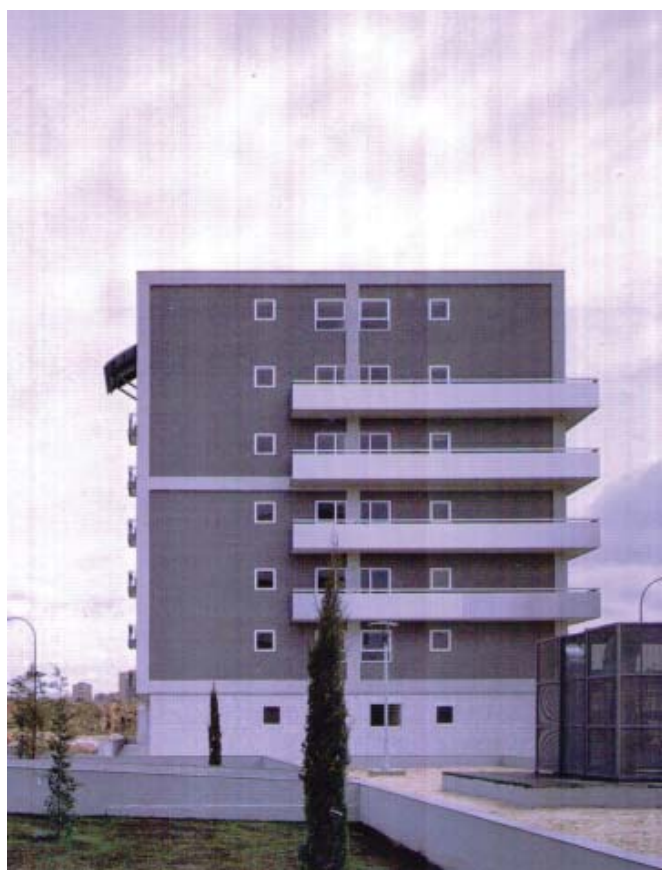

Ref.4.16. Alzado de una de las torres

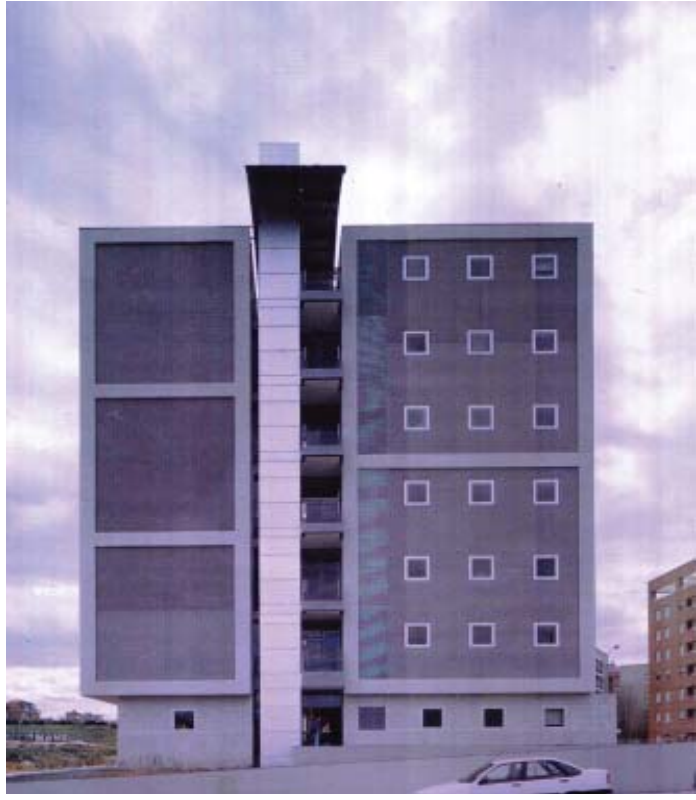

Ref.4.15. Alzado de una de las torres

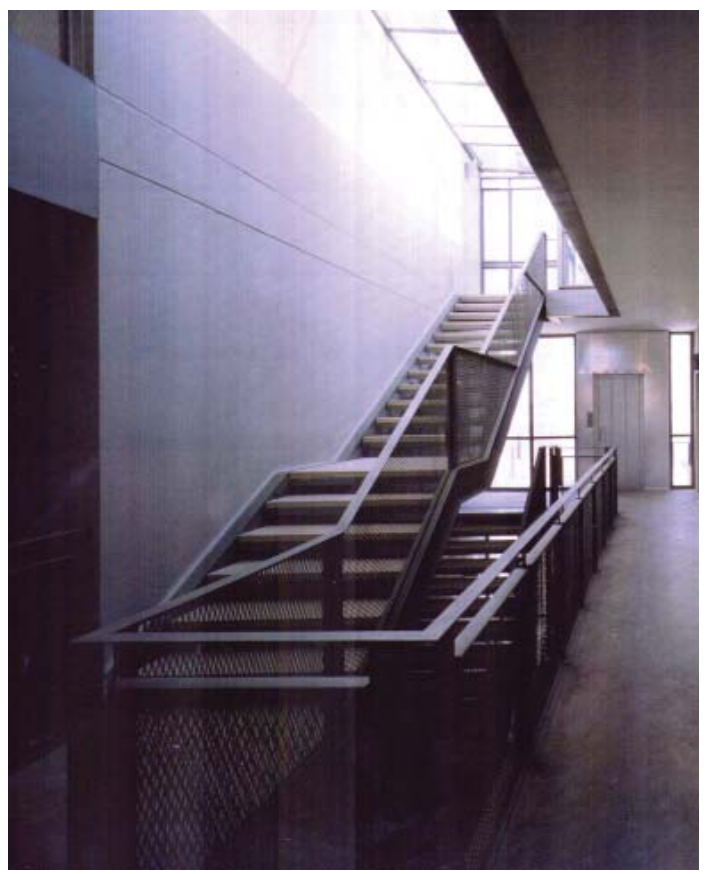

Ref.4.17. Escalera y rasgadura de luz 
viviendas de uno, dos, tres y cuatro domitorios, tal y como se pedía en el programa de concurso:

- Las viviendas de un dormitorio dividen el espacio en zona de día (el estar y la cocina forman un único espacio) y la zona de noche que se compone de un dormitorio con baño completo.

- Las viviendas de dos dormitorios se caracterizan por la compartimentación de estancias. En éstas la cocina y el estar no están unidos y los dormitorios comparten el baño.

- Las viviendas de tres dormitorios son dúplex. La zona de día se sitúa en la planta de acceso, en la que están la cocina, el cuarto de estar y un baño. En la planta superior se sitúan los tres dormitorios que sólo tienen un baño.

- Las viviendas de cuatro dormitorios articulan los espacios alrededor de los núcleos húmedos de forma que permiten liberar el perímetro iluminando naturalmente todas las estancias.

Las zonas comunes dan acceso a distinto número de viviendas: las plantas impares dan acceso a seis viviendas y las pares solo a dos.

Al ser una torre exenta existen viviendas en todas las orientaciones posibles. Esta característica apenas se tiene en cuenta en el tratamiento distinto de los huecos de fachada pues presentan una composición muy parecida en todas las fachadas.

Todas las viviendas agrupan sus zonas húmedas relativamente próximas a los accesos liberando las fachadas, y están en concordancia vertical con los pisos contiguos como suele proyectarse para un mayor aprovechamiento de las instalaciones. En general, las viviendas disponen de un pequeño distribuidor en su entrada, que da acceso directo a la cocina y estar. Al resto de estancias se accede o bien por un corredor que además contiene los lugares destinados a almacenaje o bien directamente desde el estar, dependiendo de la superficie y tipo utilizado.

En general, todas las estancias poseen ventilación natural, excepto los baños que situados en la zona central tiene ventilación forzada.

A la hora de la materialización de las torres influyó mucho el entorno: depósitos de gas, mástiles de tendido de alta tensión, señalizaciones viarias...etc. Es decir, se eligieron los materiales en función del contexto, por lo que se han colocado muchos elementos metálicos en los ascensores, cubiertas, ventanas, balcones, etc. para facilitar una continuidad urbana.

A continuación se adjunta una ficha-resumen. 


\section{VIVIENDA}

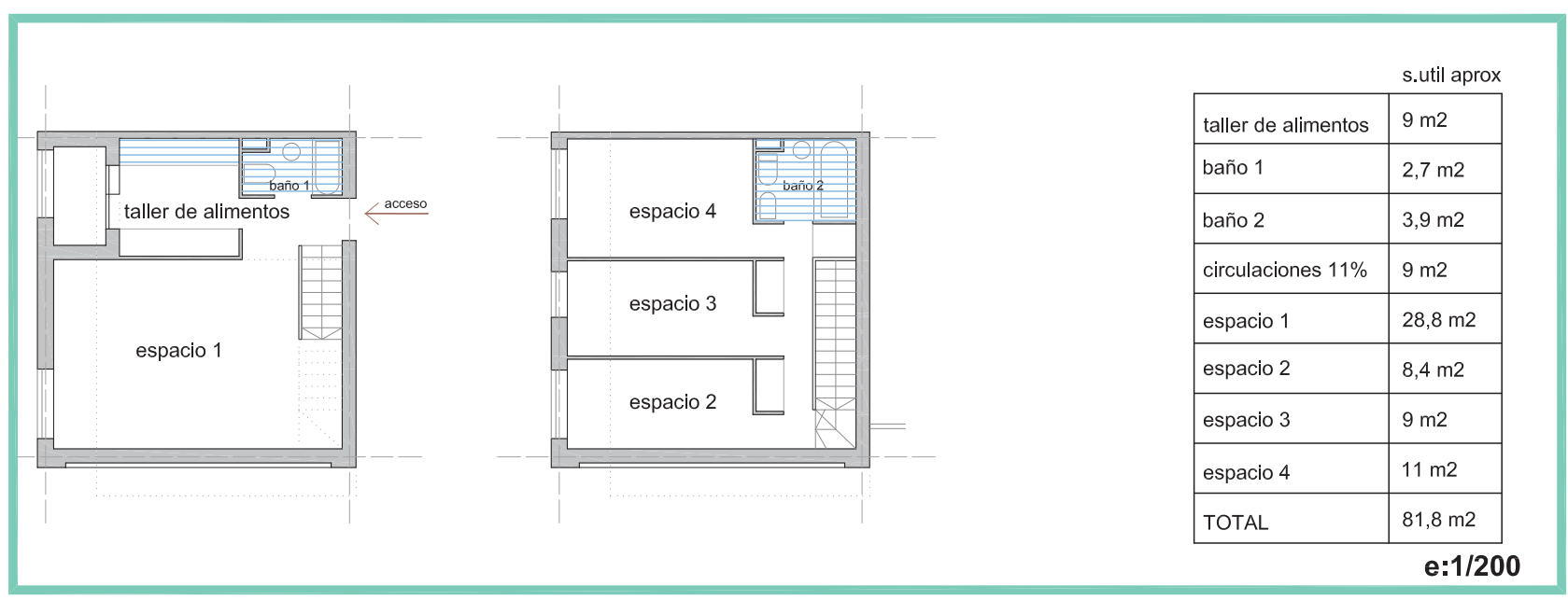

\section{SISTEMAS DE AGRUPACIÓN}

superficie construida total por planta: $\quad 488 \mathrm{~m} 2$

superficie construida zonas comunes por planta: 83 m2 (17\%)
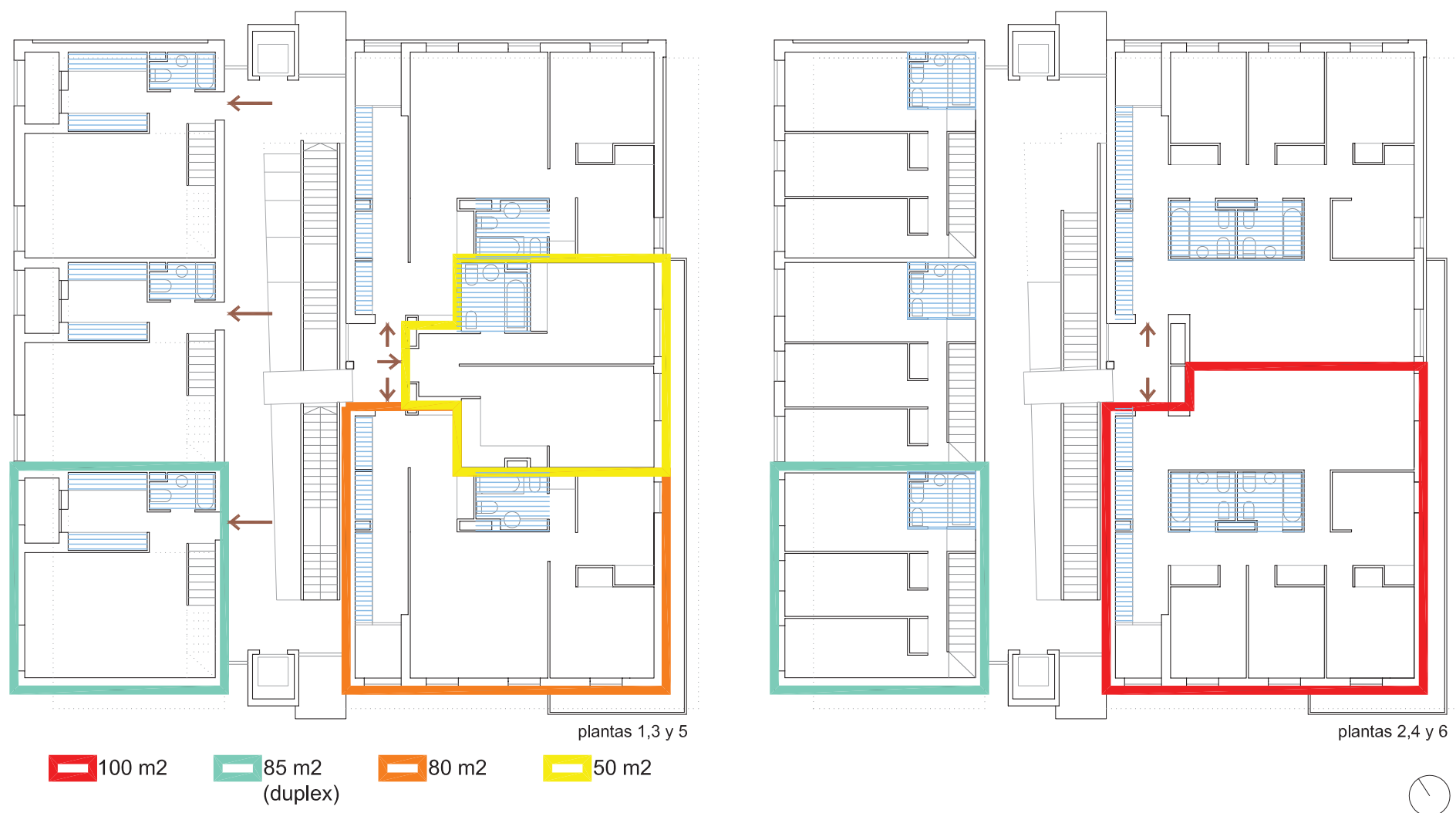

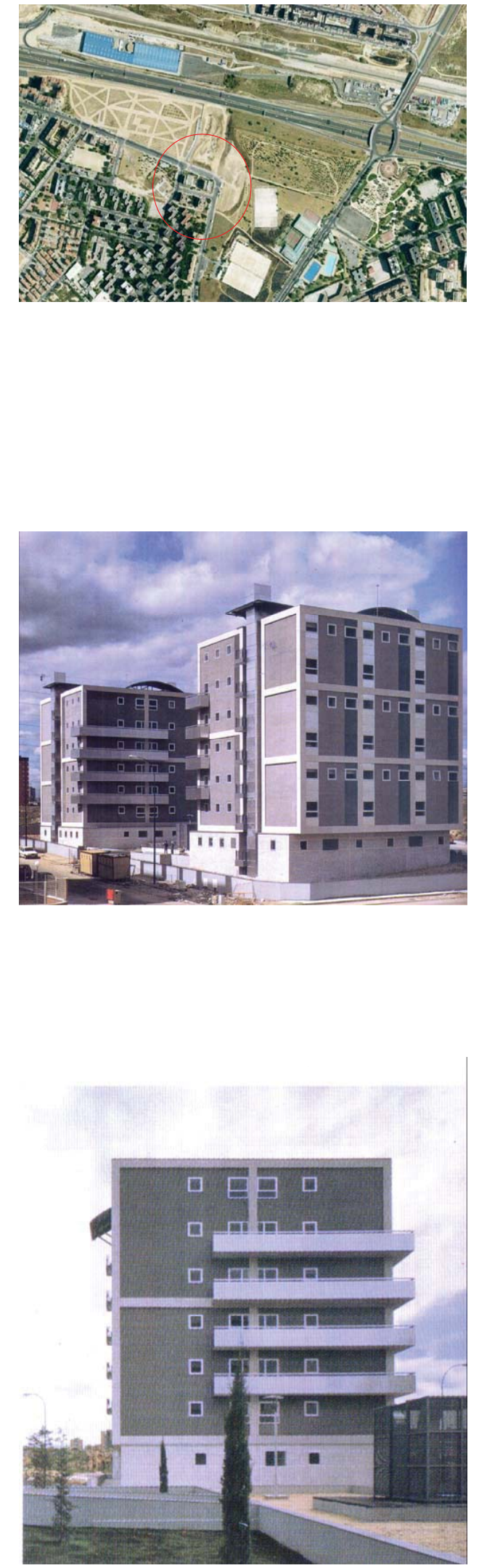

FICHA 1.1

\section{EUROPAN 1}

(año 1988)

\section{ARANGUREN\&GALLEGOS: 2 TORRES EN LA M-40}

\section{EMPLAZAMIENTO}

junto a la M-40,c/Roquetas de Mar $n^{\circ} 5$ y 7 , Madrid

COMIENZO DE OBRAS- FINALIZACIÓN DE LAS OBRAS julio1991- abril 1993 (27 meses)

¿ES EL PROYECTO DE CONCURSO?

$\mathrm{SI}$, aunque se suprimen torres (se pasa de 6 a 2)

y se modifica la altura

Nº DE VIVIENDAS TOTALES CONSTRUIDAS

28 viviendas por torre

56 viviendas total

$N^{\circ}$ DE VIVIENDAS POR SUPERFICIE

WIIA 4 viviendas

VIII 10 viviendas 5 viviendas

USO DE LA PLANTA BAJA

Viviendas

\section{USO DEL SOTANO}

Garaje, ampliado en la basamenta

\section{REFERENCIAS BIBLIOGRÁFICAS}

www.arangurengallegos.com

$\mathrm{A}+\mathrm{U}, \mathrm{n}^{\circ} 96: 08, \mathrm{pp} .66-79$

Casabella, n 618 , Diciembre 1994, p. 50, Madrid, 1989 "DOS TORRES DE VIVIENDAS EN HORTALEZA,

MADRID", Monográfica Europan (Atenas), año 1994, 50p.

"EUROPAN, REALISATIONS, IMPLEMENTATIONS",

Pandora Editions, Paris, Francia, 1991, p 22-23.

"EL CROQUIS" n० 62/63, 1993, p.82-103.

"20 AÑOS 20 PROYECTOS E.M.V.", P.40-47, Empresa

Municipal de la Vivienda, Madrid, 2002.

"A\&V", n 74, "Madrid, Madrid", p.18.

HOUSING, NUEVAS ALTERNATIVAS, NUEVOS

SISTEMAS", p.31,57, 71, Barcelona, 1998.

"NUEVOS MODOS DE HABITAR", COACV, p.254-269,

Conferencia titulada "La Experiencia de Europan".

"CATALOGO DE LA III BIENAL DE ARQUITECTURA

ESPAÑOLA 1993/1994", Madrid, p.168-169.

"ARQUITECTOS", CSAE, n 133, año 1994, p.62-63. 



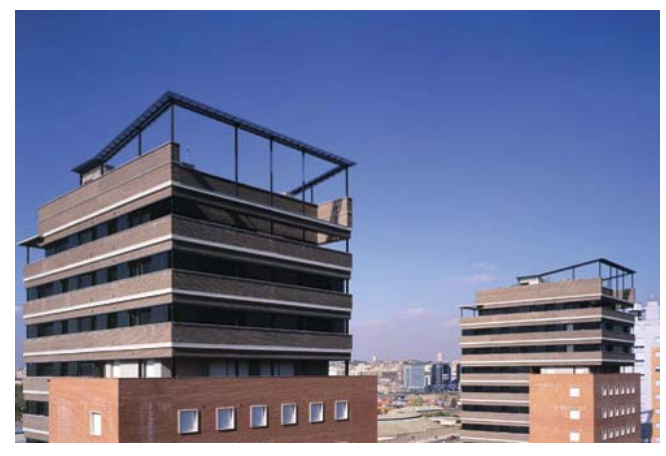

4.1.1. Edificios de viviendas Europan 1 (1988)

Ricardo Sánchez y José $M^{\mathrm{a}}$ Escobar: torres de viviendas en Madrid 


\section{EL 287

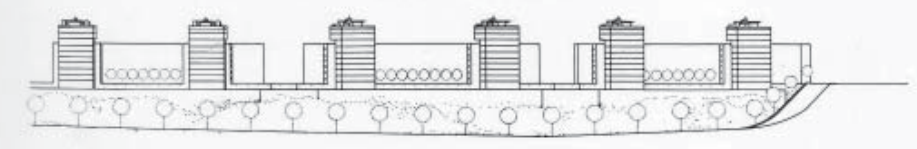

Maqueta: Lucas Recuenco

Maqueta: Lucas Recuenes

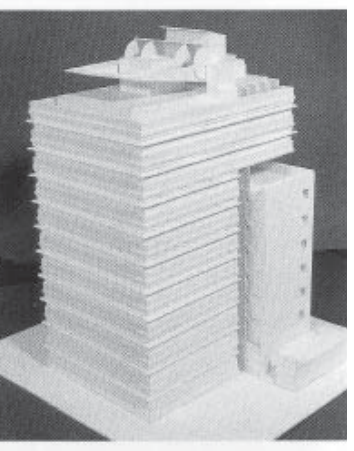

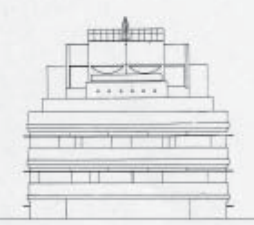

$\square \square \square \square \square \square$

ㅁㅁㅁ

ㅁㅁㅁ

प $\square \square \square \square$

ㅁㅁㅁ

ㅁㅁㅁ

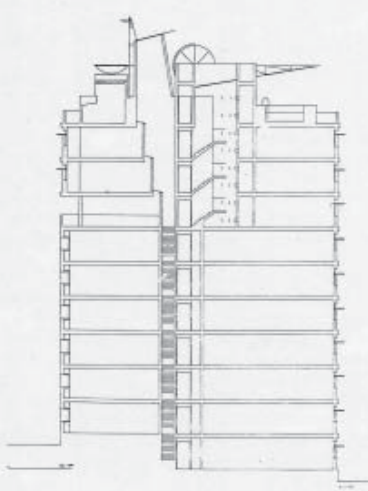

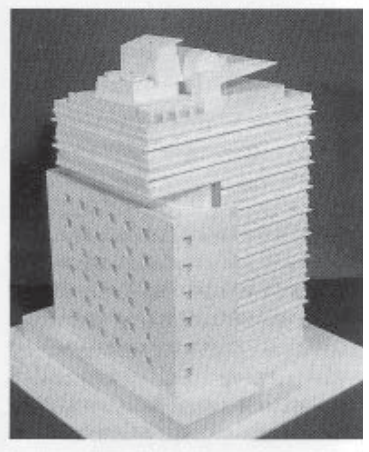

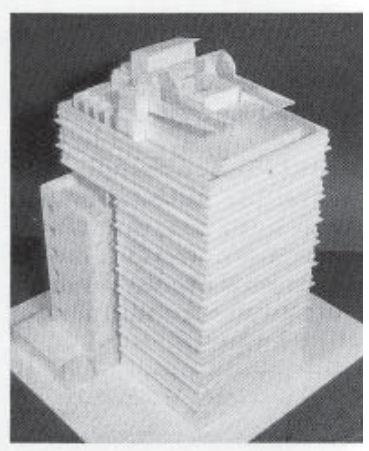

Ref. 4.18. Paneles de concurso 

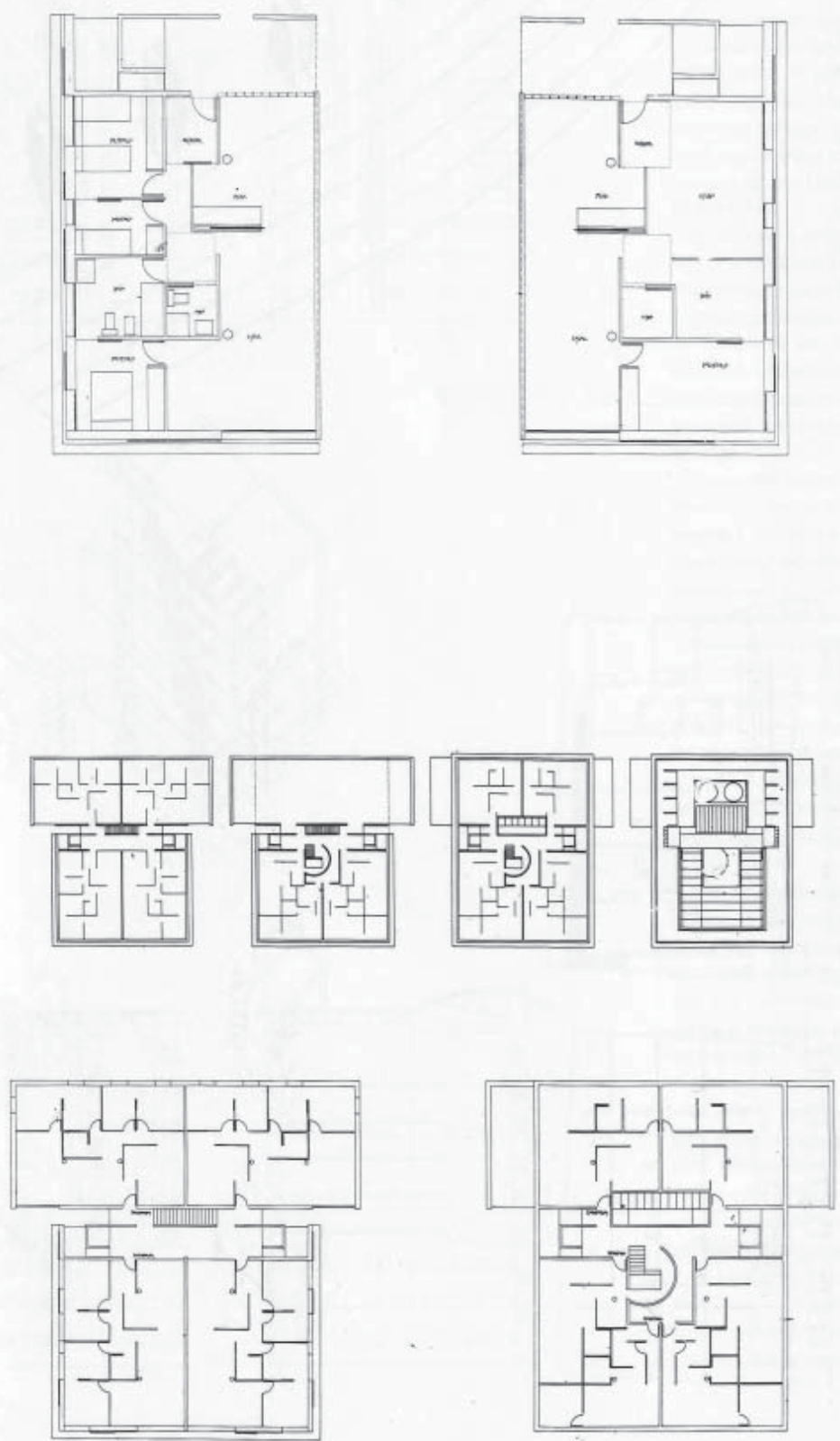

El particular emplazamiento de las torres de la Viña de Entrevias, es el primer condicionante al que el proyecto pretende responder.

Frente a la radical diferencia existente entre las fachadas Noroeste y Sureste propias de una definición de cornisa, se ha descoblado el edificio en dos bloques. El posterior mantiene las seis alturas, los materiales y una cienta reterencia al lenguaje de los edificios que se agoipan tras las torres. La perspectiva de la calle posterior queda asi contormada por los bioques, cortos y largos, que a un lado y otro, la regularizan. El bloque anterior. más atento a su condición de primera fila en la cornisa, monta sobre el primero. con todas las alturas permitidas, otros materiales y otro lenguaje. Es en la rendija que se abre entre ambos, donde se produce el acceso a cada torre, en la terraza inferior, separada del ámbito de la calle que corre paralela a la superior. En cada una de las torres, se han proyectado 26 viviendas de 3 dormitorios, 4 viviendas de 2 dormitorios y 12 viviendas de 1 dormitorio. En total, 42 viviendas por torre.

En la terraza intermedia, y mayorita. riamente en las cubiertas del edificio, se han previsto espacios para una lavandería, unos trasteros, un gimnasio, una zona de ninos y una piscina. Todos ellos. servicios comunes a las viviendas de la torre.

Un garaje común a las seis, se aloja a lo largo de la cornisa, ventilando por el escalón conformado por las dos terrazas sobre las que se asientan los edificios.

La estricta y exigente situación de las torres conlleva la asunción de su emplazamiento como modo de organizar le totalidad de las viviendas.

La resolución particular de la forre tipc obedece a dos requisitos inherentes: esta tipología edificatoria: la supresiór del patio, y la posibilidad de que el mayoi número de zonas de día se abra a las vistas sobre la $\mathrm{M}-30$ y el Parque Tierno Galvản. Con lo especificado en el apar. tado 1 , el estrechamiento del bloque anterior propiciado por la inexistencia de patio permite al posterior tener esa posibilidad de vistas. En las plantas altas, $\theta$ predominio longitudinal de las fachadas laterales, asegura la misma condición a sus viviendas. 
VIVIENDAS EUROPAN (1988-2008) | Una aproximación a los modos de vida en el cambio de siglo en España

4. EUROPAN: DEL CONCURSO A LA REALIZACIÓN

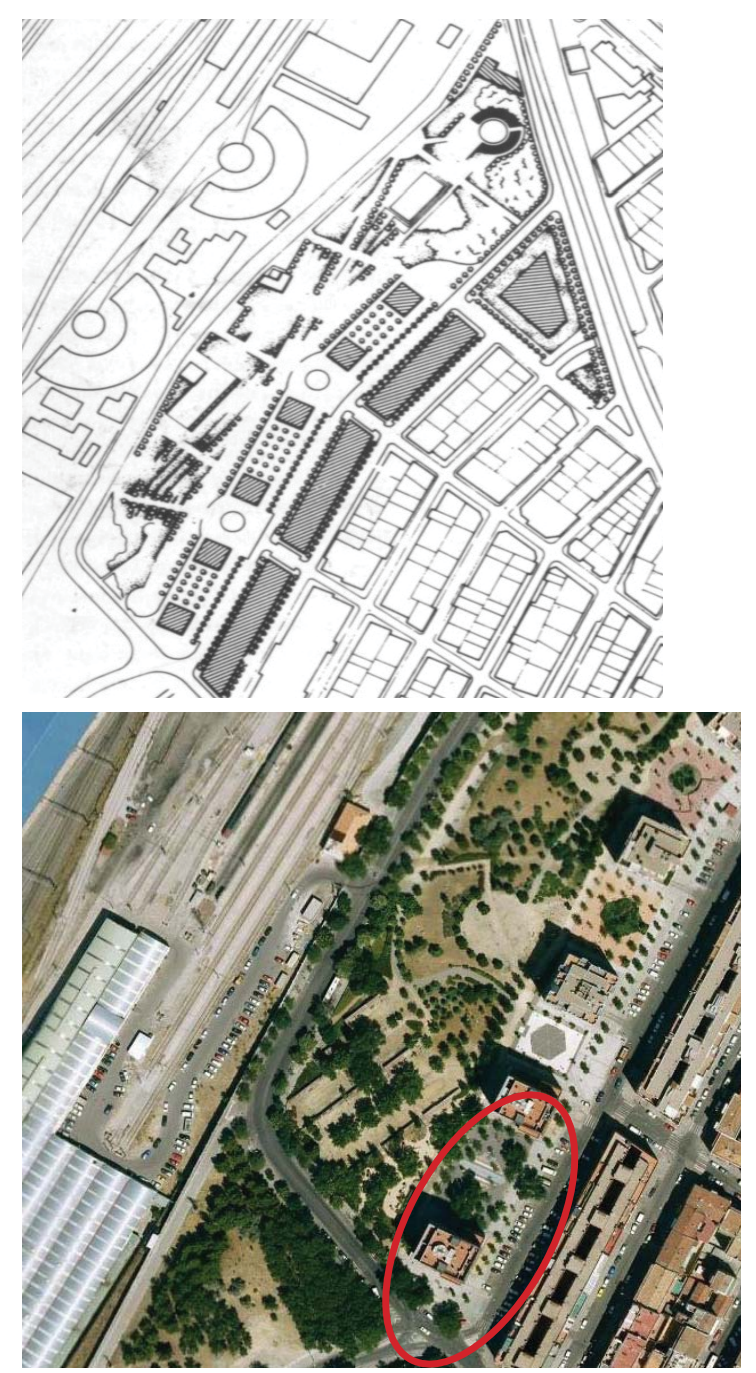

Ref. 4.20. Solar de Entrevías con las dos torres de Ricardo Sánchez y José Mª Escobar
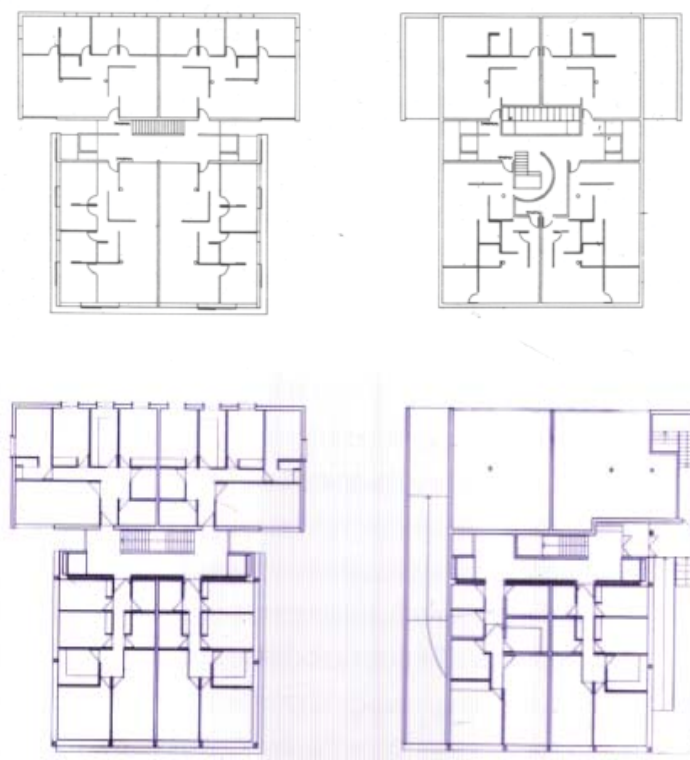

Ref. 4.21.Planta tipo concurso

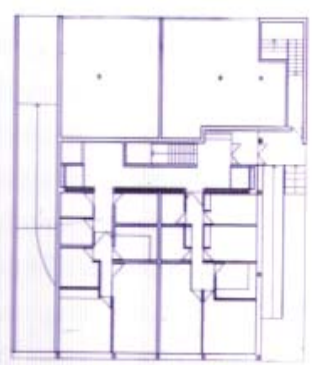

Ref.4.22. Planta baja y planta tercera 


\section{Fase de concurso}

El segundo proyecto que se ha construido en Europan fue también premiado en el emplazamiento de Entrevías en Madrid como el de Aranguren y Gallegos que se ha analizado en el apartado anterior. A diferencia de éste, pudo construirse en el solar donde fue proyectado.

Todo lo que se ha explicado en el apartado anterior en cuanto a las características del solar, será de aplicación en este proyecto: las dimensiones de la torre debían estar comprendidas entre un máximo de 22×22 m y un mínimo de $18 \times 18 \mathrm{~m}$, sin que existiera obligación de que la planta fuera cuadrada, debía tener 10 plantas como máximo (incluyendo el sótano, en su caso), y se permitía un ático retranqueado $3 \mathrm{~m}$ respecto del plano de fachada. El número máximo de viviendas debía ser de 58. También delimitaba la altura de cornisa en $27,5 \mathrm{~m}$ y las alturas de la planta baja (2,90 para uso de vivienda y 3,10 para locales comerciales).

Con el lema EL287, Ricardo Sánchez y José Mª Escobar presentan el conjunto de seis torres de viviendas en este solar, situado entre dos vías de circulación rápida: la red de ferrocarriles y la M-30, junto al parque Tierno Galvan.

Los autores tuvieron en cuenta la situación de borde por un lado, con la integración en la trama urbana por el otro, virtud que caracteriza al proyecto. Así, proponen desdoblar el edificio, consiguiendo que las torres posean una doble personalidad basándose en un tratamiento diferente en los alzados:

- El alzado sureste mantiene la escala de los edificios colindantes y utiliza materiales semejantes a los del entorno: planta baja y cinco alturas materializadas con ladrillo rojo.

- El alzado noroeste está orientado al parque y se puede percibir desde la vía de circulación rápida -la M-30- agota todas las alturas permitidas -hasta diez-. También utiliza otro lenguaje a través de los materiales a modo de bandejas horizontales.

En un principio se proyectaron 42 viviendas en cada torre: 26 viviendas de tres dormitorios, 4 viviendas de dos dormitorios y 12 viviendas de uno. Al ser dos torres exentas, lo que principalmente se pretendía era la iluminación y ventilación máxima de todas las estancias.

Hay un interés por enfatizar las zonas de relación, dotándolas de iluminación natural en la medida de lo posible y de dimensiones adecuadas.

Otra virtud que el proyecto inicial planteaba era la terraza intermedia y la cubierta con varios servicios comunes: una lavandería, trasteros, gimnasio, zona de niños y una piscina. Con este gesto se pretendía mezclar el espacio privado con otros semiprivados, de uso comunitario y favoreciendo la relación intervecinal, asemejándose a los conceptos que utiliza le Corbusier en las Unité de habitación. Aun- 
VIVIENDAS EUROPAN (1988-2008) I Una aproximación a los modos de vida en el cambio de siglo en España

4. EUROPAN: DEL CONCURSO A LA REALIZACIÓN
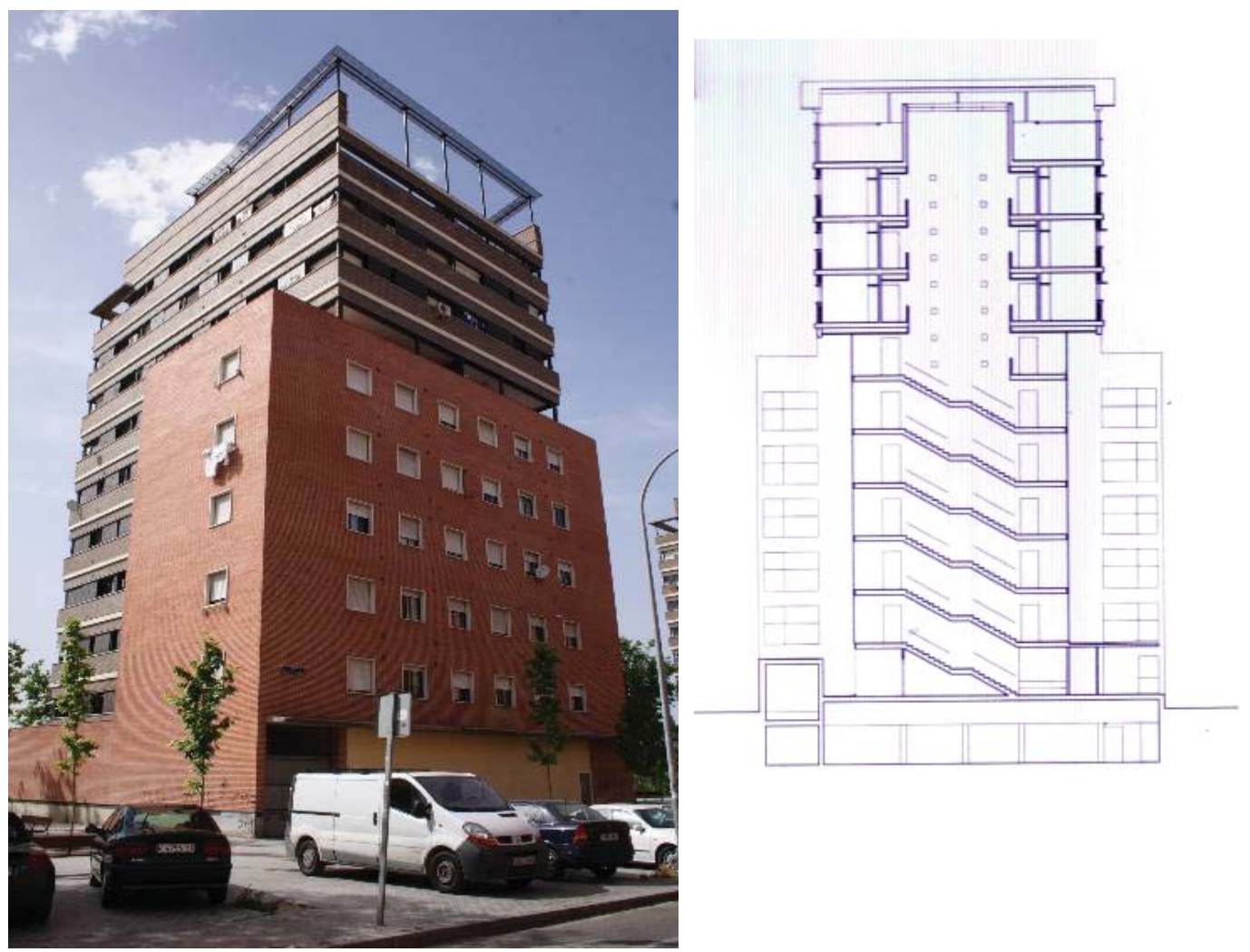

Ref. 4.23. Imagen desde la c/Concejo de Teverga

Ref. 4.24. Seccion
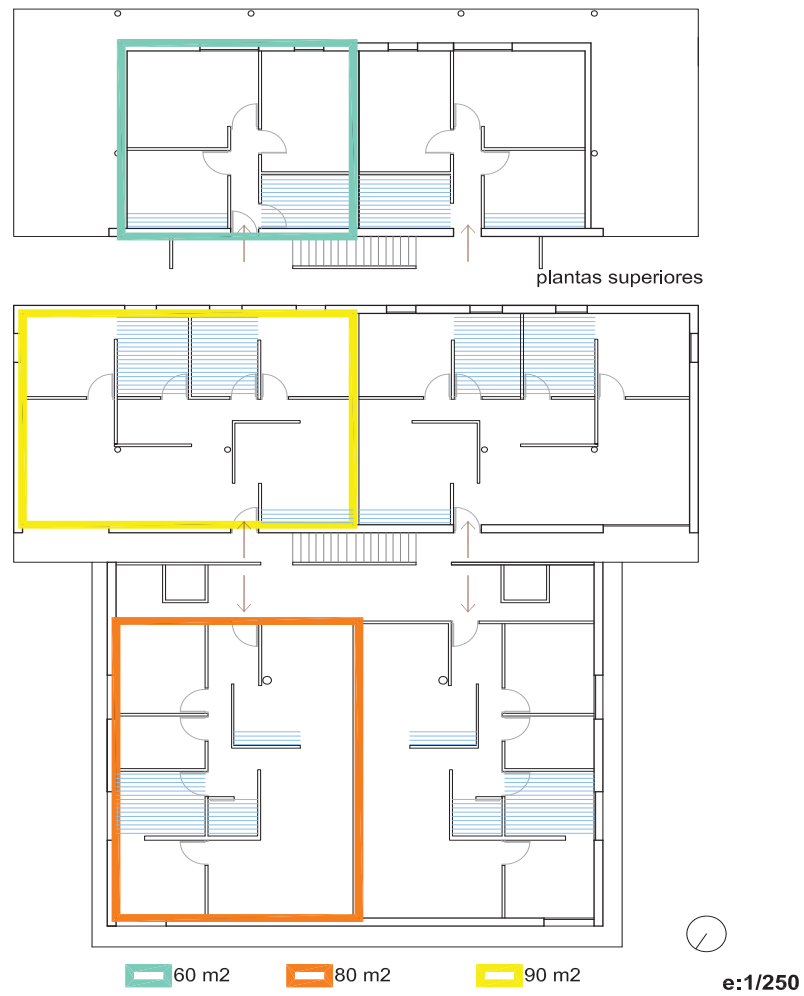

Ref. 4.25. Estudio de la planta-tipo 
que era la intención, no llegó a materializarse, como se verá a continuación.

\section{Fase de realización}

Finalmente sólo se construirán dos torres de las seis previstas, igual que ocurre en el proyecto de Aranguren y Gallegos. En el proyecto final quedan eliminados los servicios comunes de las viviendas planteados en el concurso y se aumenta el número de viviendas por torre para obtener una mayor rentabilidad en el edificio por parte de la empresa promotora.

Las obras duran 44 meses, comenzaron en 1993 y terminaron en junio de 1996. El motivo de que se alargaran tanto fue la suspensión de pagos por parte de la empresa constructora y el cambio de ésta.

Las torres tienen unas dimensiones de $25 \times 25 \mathrm{~m}$, aunque se estrechan en una de sus fachadas. Cada una tiene 43 viviendas. Si se analiza el programa de todo el edificio se puede observar:

- en la planta baja: existen dos locales comerciales y dos viviendas.

- en la planta primera hasta la planta quinta: existen cuatro viviendas por planta o seis por planta, en función del tipo de vivienda utilizado.

- en la planta sexta y siguientes: existen dos viviendas por planta (si son dúplex) o bien cuatro ya que la torre se estrecha y sólo permanecen las viviendas de la fachada noroeste.

El acceso a cada vivienda se realiza por un corredor central que contiene los núcleos de comunicación vertical y se ilumina naturalmente a través de la rasgadura existente entre las dos fachadas.

En cuanto a las viviendas, predominan las de dos dormitorios y tienen una superficie aproximada de unos $70 \mathrm{~m} 2$ construidos. Las de tres dormitorios son 15 en cada torre y tienen una superficie aproximada de unos $80 \mathrm{~m} 2$ construidos. A semejanza del proyecto de Aranguren y Gallegos, las torres tienen las zonas húmedas en el interior y distribuyen los espacios a lo largo de la fachada de mayor longitud buscando la iluminación natural.

La composición de las fachadas se mantiene como el planteamiento de concurso: la fachada noroeste está compuesta de bandejas horizontales y la sureste se caracteriza por la repetición del mismo hueco.

El proyecto se materializó con ladrillo naranja en el volumen de las seis plantas y un ladrillo más oscuro para el volumen de las diez plantas que se visualiza desde la M-30 (es el alzado del ferrocarril). Combina la seriación de huecos frente a la seriación horizontal y los movimientos verticales del tambor de las persianas y el horizontal de chapa. El acceso a la torre se producirá desde la macla de unión de estos dos alzados.

A continuación se adjunta una ficha-resumen. 


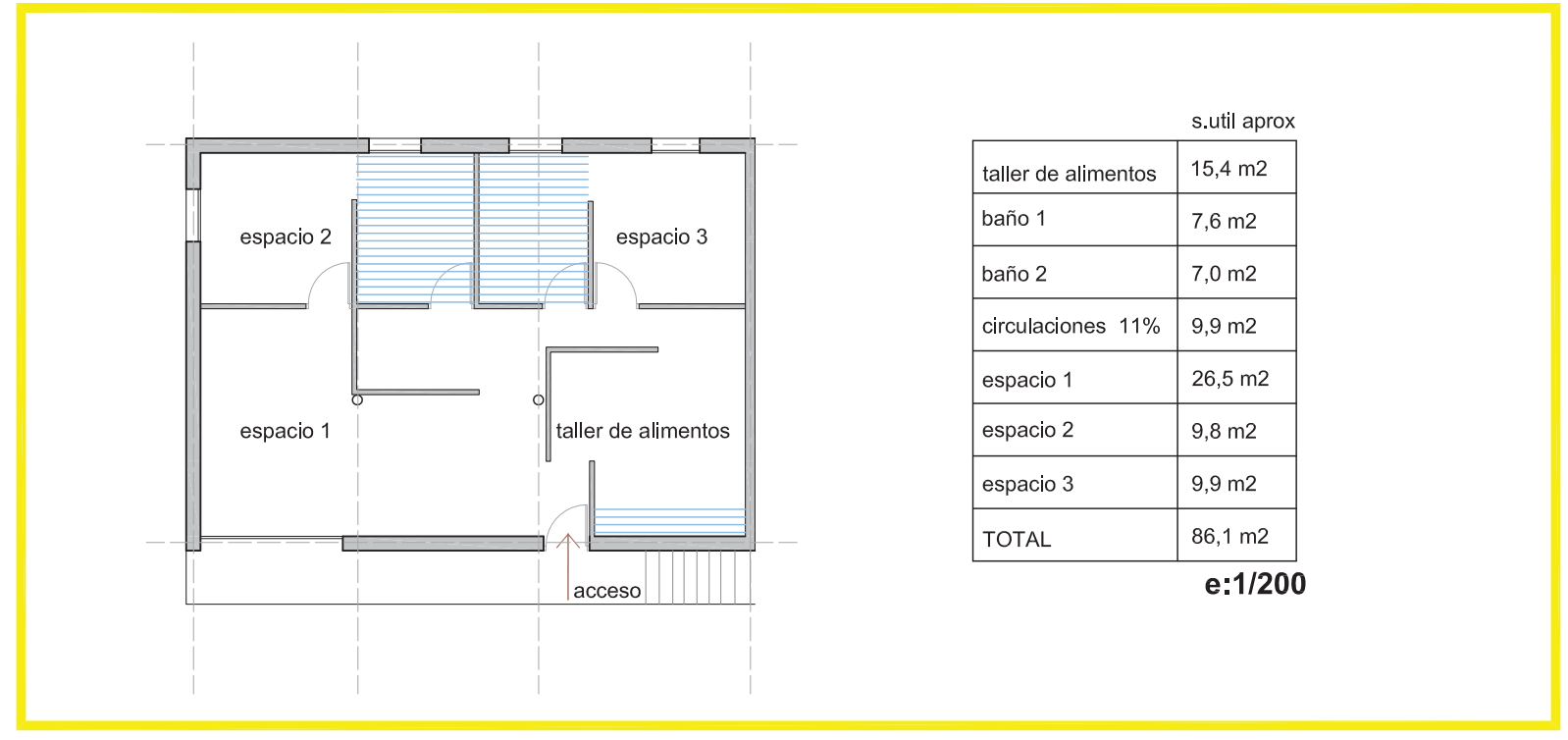

\section{SISTEMAS DE AGRUPACIÓN}

superficie construida total por planta:

$462 \mathrm{~m} 2$

superficie construida zonas comunes por planta: $60 \mathrm{~m} 2(14 \%)$
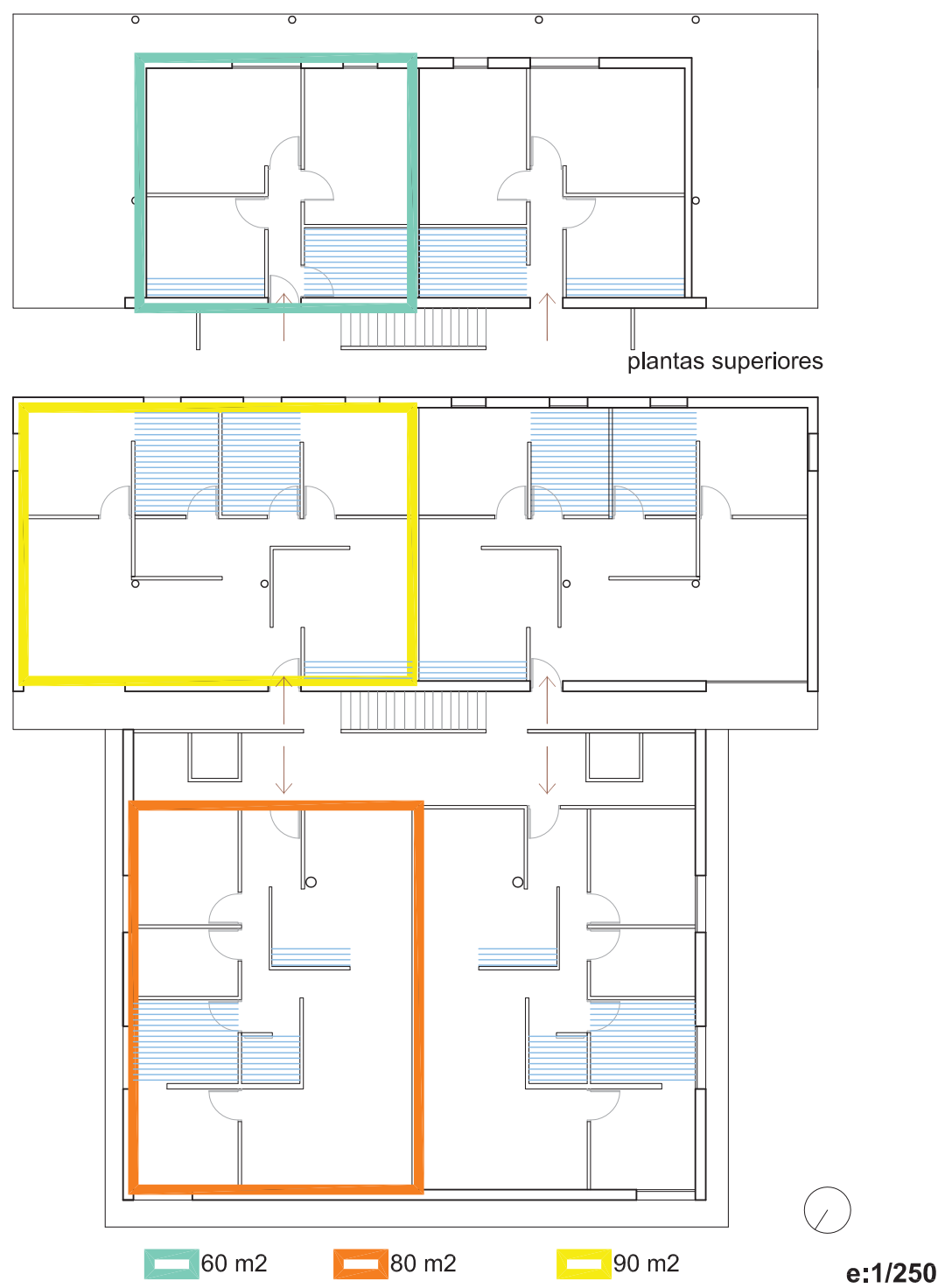

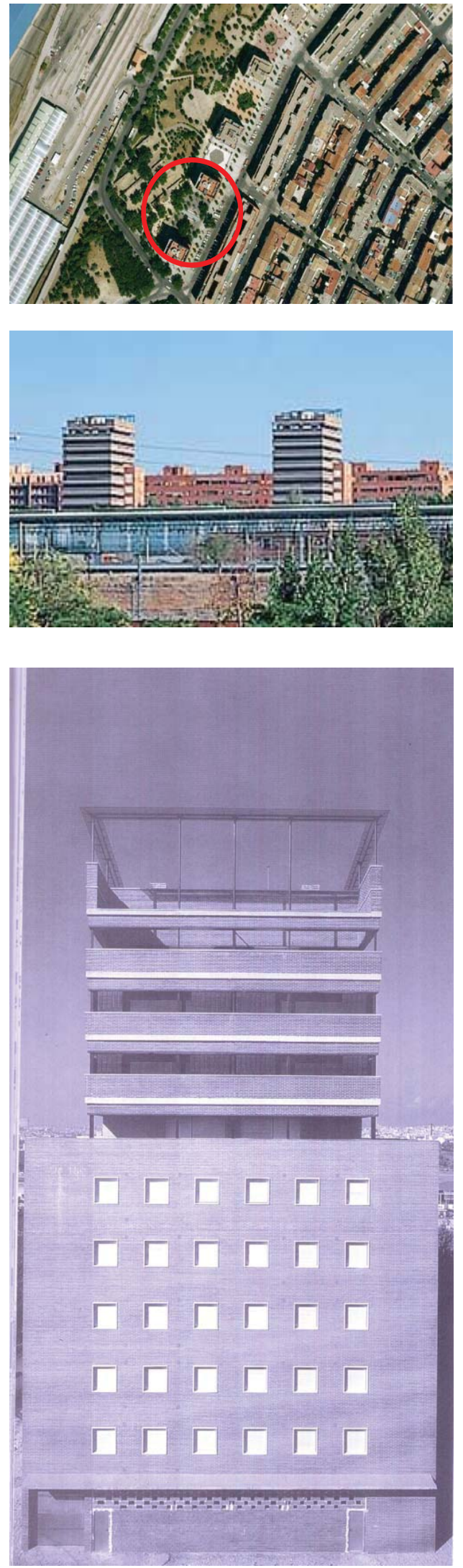

FICHA 1.2

\section{EUROPAN 1}

(año 1988)

RICARDO SÁNCHEZ Y JOSÉ Ma ESCOBAR: 2 TORRES EN LA M-30

EMPLAZAMIENTO

junto a la M-30, c/Concejo de Teverga $\mathrm{n}^{\circ} 22$ y 24 , Madrid

COMIENZO DE OBRAS- FINALIZACIÓN DE LAS OBRAS

1993- junio 1996 (44 meses)

¿ES EL PROYECTO DE CONCURSO?*

$\mathrm{SI}$, aunque solo se construirán dos torres de las previstas. Además, se eliminan los servicios comunes de las viviendas(lavandería, trasteros, gimnasio...)

$N^{\circ}$ DE VIVIENDAS TOTALES CONSTRUIDAS

43 viviendas por torre 86 viviendas total

No DE VIVIENDAS POR SUPERFICIE

(1 torre)

16 viviendas

VII 15 viviendas

VII/ 12 viviendas

USO DE LA PLANTA BAJA

Dos locales comerciales y dos viviendas

\section{USO DEL SOTANO}

Garaje

\section{REFERENCIAS BIBLIOGRÁFICAS}

- "Dos torres de viviendas en Viña de Entrevías, Madrid", Monográfico Europan, Paris, 1995.

- 10 años EUROPAN 5 España, Edición coproducida por EUROPAN/España, SEPES y el Ministerio de Fomento, 1999, España,p. 143.

- EUROPAN 10 España, "Proyectar la urbanidad", Madrid, 2010, p. 211 



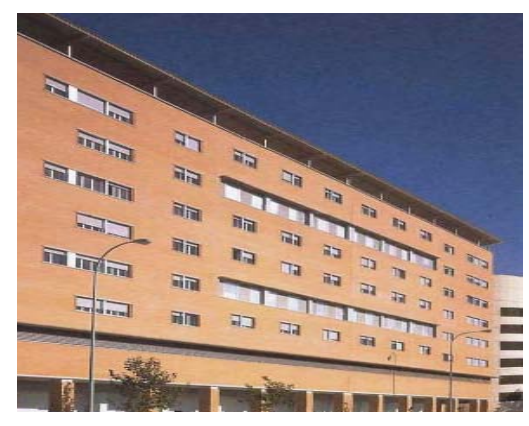

4.1.1. Edificios de viviendas Europan 1 (1988)

Félix Pozo y Alberto Torres: bloque de viviendas en Zafra (Huelva) 
VIVIENDAS EUROPAN (1988-2008) | Una aproximación a los modos de vida en el cambio de siglo en España

\section{$\sqrt{B} 501$ \\ Alberto Torres Galán \\ Colaboradores: \\ Miguel Guerrero de Mier, J. Antonio Pérez Puerto, Manuel Ruiz Benavente}
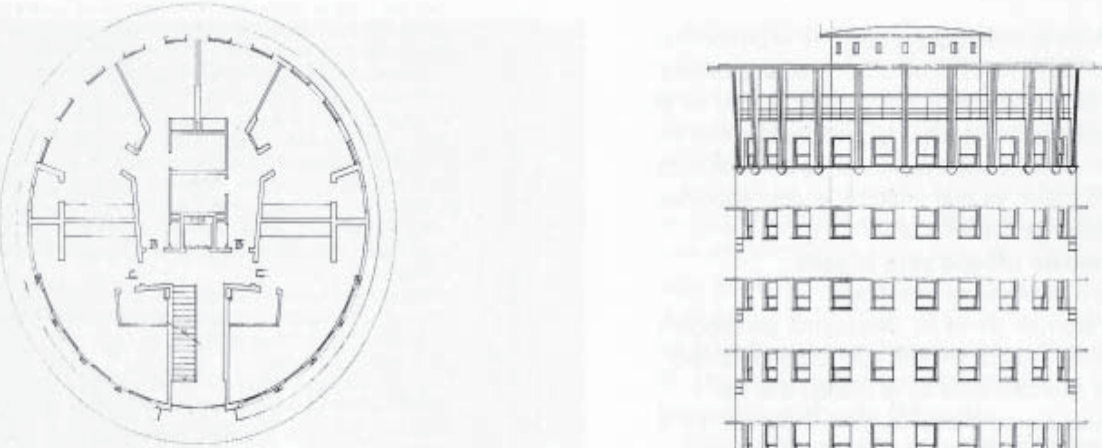

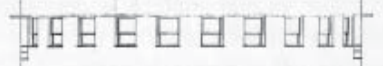

THEEEG日BU⿴囗十

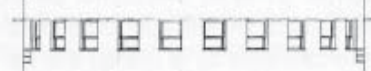

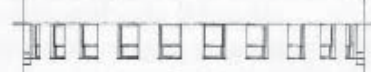

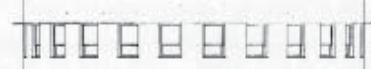

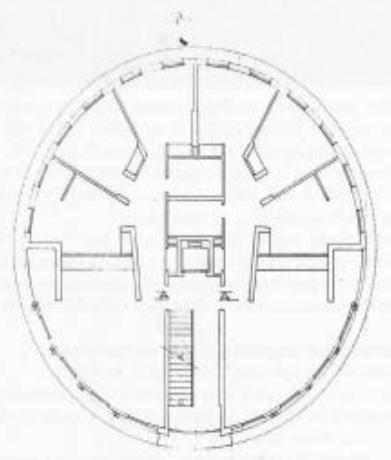

TEEE目目目明明

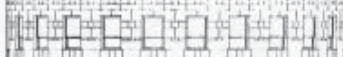

H.
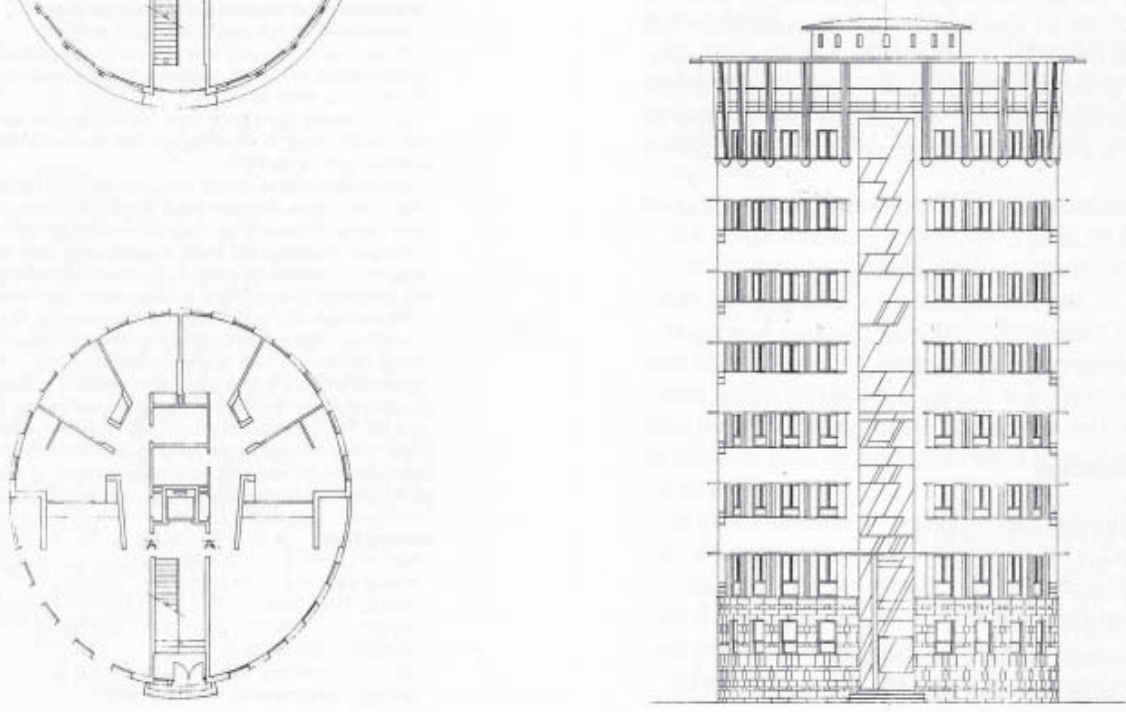

Ref. 4.26. Paneles de concurso 


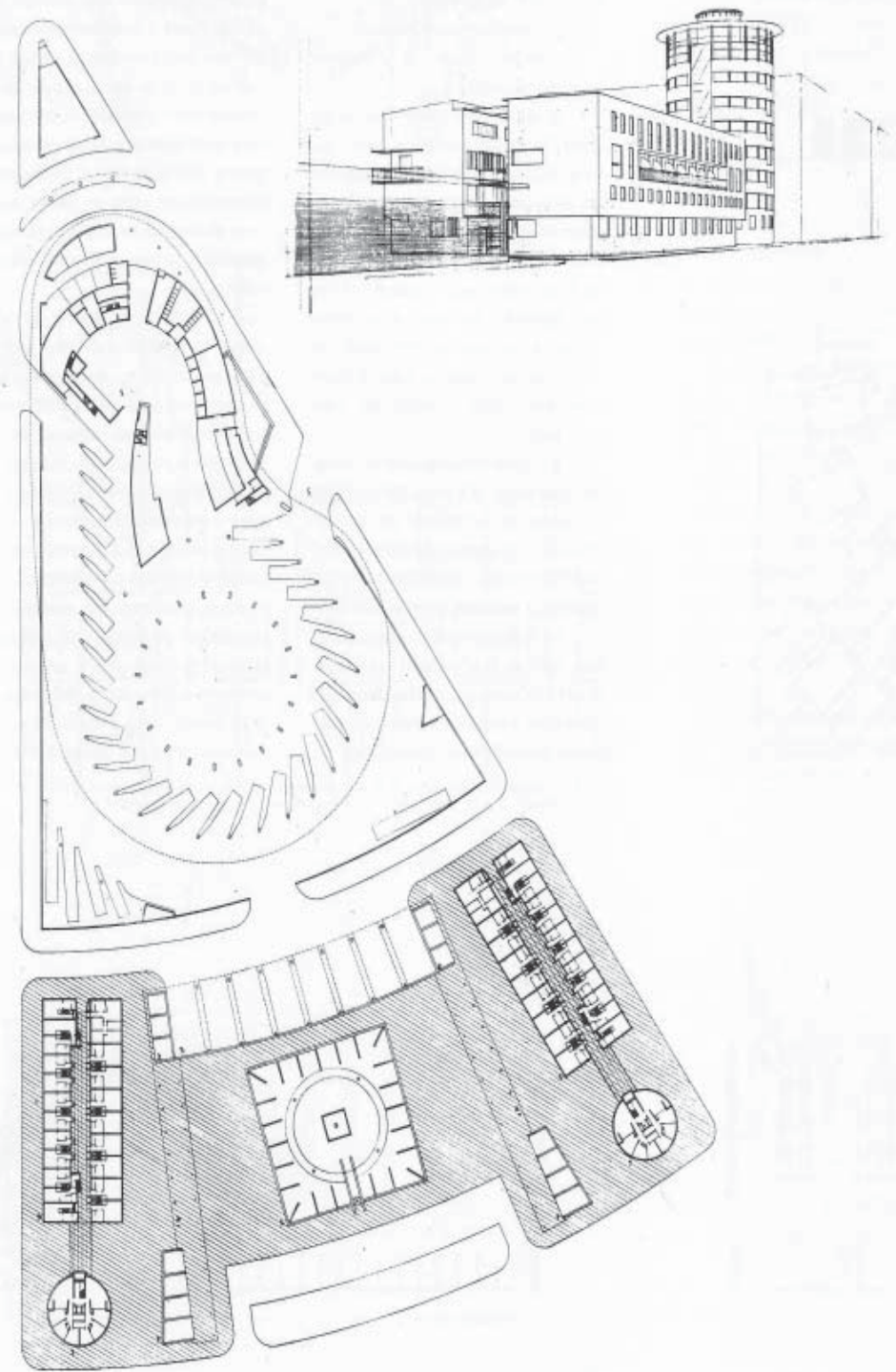

En nuestro contexio del Sur de Espana con la distancia a la que se ven las primeras experiencias renovadoras de la vivienda en la tradición de nuestro siglo, la investigación sobre la forma de la vivienda sólo puede entenderse en la linea de la cualificación disciplinar dentro de la Arquitectura, de aquellas prime. ras experiencias

Tan alejados de las vanguardias histó. ricas, y en un medio donde la producción de viviendas se ha caracletizado tantos años por la repetición indiscriminada de tipologias especulativas ya de la posque. Ira europea, observamos cómo no exis. tió nunca ese hilo conductor entre vanguardia y producción, que si es caracteristico del resto de Europa.

Nuestra propuesta intenta por ello ser alternativa en cuanto que la consideramos cualificadora y aprende màs de la concepción del proyecto de arquitectura que de las innovaciones tecnolígicas o de programa que puedan determinar formaimente dicha concepción.

Por ello, entendemos como innovador para la vivienda que actualmente se pro. duce en nuestro medio económico. social y culturalmente determinado, of insistir más en la idea de que aptendiendo de la tradición moderna de la arquitectura residencial, y renovande sus tipos adaptados a nuestro medio. más que la estéril dispersión de la bús. queda de la vivienda sofiada, donde e sonado individuo resolverá sus son̂adas necesidades:

El proyecto que presentamos se cues. tiona la ordenación propuesta para esta parcela por el Plan Especial, con edificaciones de ancho fijo, duras alineaciones a las calles principales $y$ alturas indis. criminadas de 8 plantas.

Así, proponemos la alineación a las calles principales que parten de la Estación de Autobuses con una edificación intermedia de 4 plantas que contiene un espacio cubierto con una veia, y ya retranqueado de la alineación y a eje con el edificio anterior, un edificio exento circular de 8 plantas que sirve de remate a la altura de las siguientes manzanas. A interior de la manzana se vuelca espacio libre, sobre el que aparecen las cubiertas inclinadas y donde se incluye una galeria con comercios y en la que se apoyan la bibloteca y el aparcamiento de autobuses previsto en el Plar Especial.

\section{Ref. 4.27. Paneles de concurso}


VIVIENDAS EUROPAN (1988-2008) | Una aproximación a los modos de vida en el cambio de siglo en España

4. EUROPAN: DEL CONCURSO A LA REALIZACIÓN
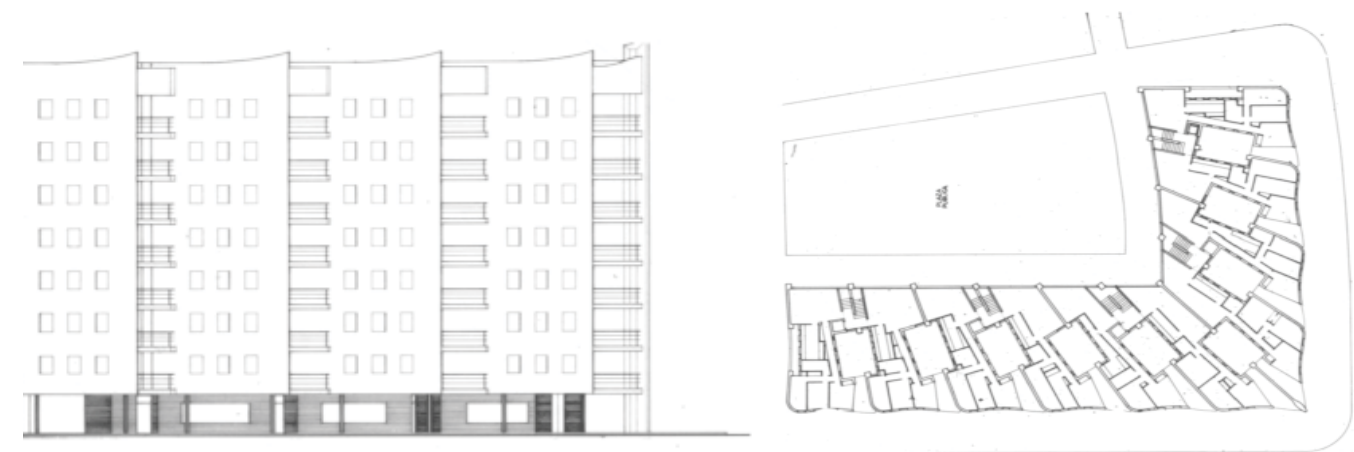

Ref.4.28. Alzado y planta de Vico Nieto

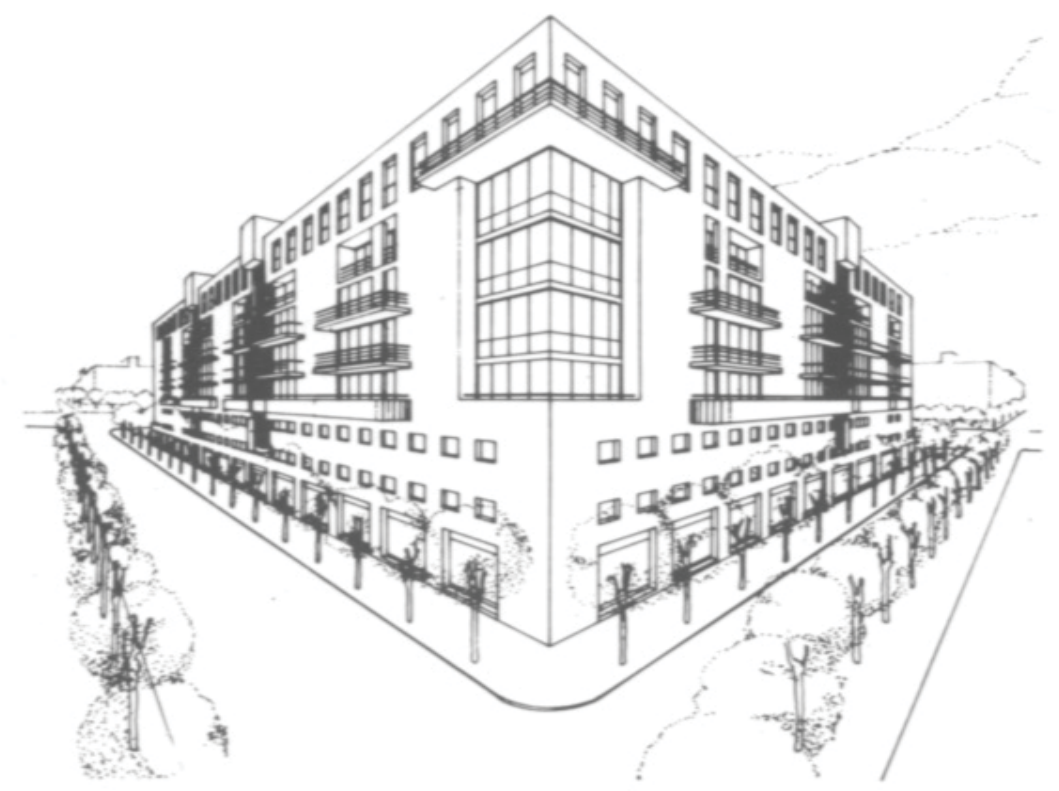

Ref.4.29. Perspectiva de Fernández Rubalcaba
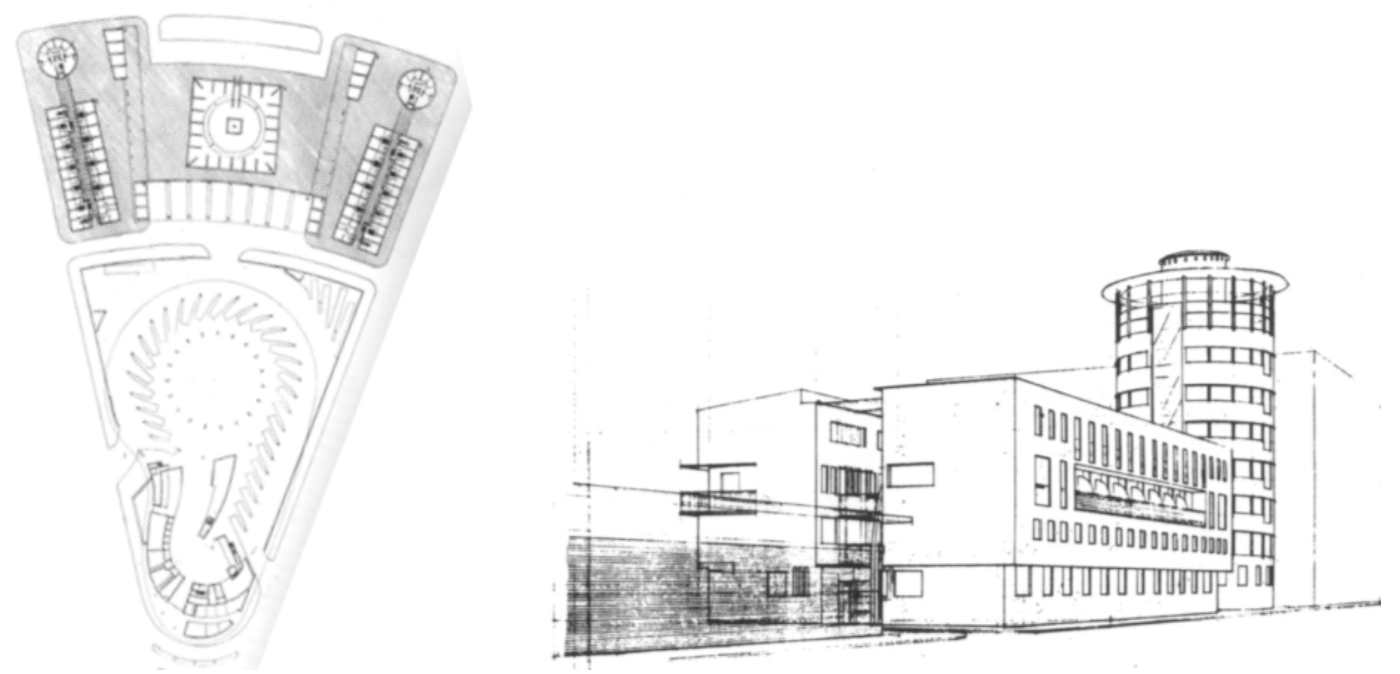

Ref. 4.30. Planta general y perspectiva propuesta JB501 


\section{Fase de concurso}

El solar propuesto en Huelva tiene unos antecedentes que deben tenderse en cuenta a la hora del proyecto de concurso pues es una zona cuya ordenación urbanística ha tenido relevancia en la ciudad.

En 1989, a los pies del río Oriol, entre la antigua estación de ferrocarriles de la línea Zafra-Huelva (que había sido desmontada en 1976), se situaba un solar vacío donde aún quedaban los talleres del puerto y algunos almacenes. El Plan General de Ordenación Urbana de 1964 ya preveía el cambio de uso a suelo urbano para albergar un uso residencial de unos 2000 habitantes junto con otros usos como el de zona verde y alguno industrial.

El solar propuesto se encuentra en esta zona de ordenación y estaba compuesto de dos parcelas con una superficie aproximada de $1344 \mathrm{~m} 2$ cada una. En éste se requerían unas 140 viviendas en total y algunos locales comerciales.

Para este emplazamiento el Jurado destacó los siguientes proyectos:

- Vico Nieto pretendía resolver el proyecto con un tipo único de tres crujías, creando patios interiores semiabiertos, vinculándolos a la vivienda.

- Fernández Rubalcaba, Díaz de Liaño, Benito de Ríos, y Aragón Serrano, propusieron dos bloques en $L$ de140 viviendas configurando un espacio interior permeable, similar al patio de manzana habitual. La vivienda tipo se desarrollaba en tres zonas: espacios comunes que vuelcan a la calle, zonas húmedas que se agrupan alrededor de los patios interiores y espacios privados (dormitorios) con conexión al patio de manzana.

- Bajo el lema JB501, con el que reciben una mención, Félix Pozo y Alberto Torres proponen una alineación a las calles principales. La ordenación se compone de dos edificios unidos mediante un corredor, uno de ellos rectangular de cuatro plantas, el más cercano a la estación y otro circular de ocho plantas rematando la parcela.

Más que plantear un edificio de viviendas, este proyecto de concurso plantea además la intervención en el espacio urbano.En el espacio central se plantea una galería de comercios, con la biblioteca y el aparcamiento de autobuses previsto en el plan especial., creando unos recorridos interiores en la manzana.

En cuanto a la volumetría, se popone un edificio rotundo, de formas puras y ordenado. Se plantean romper con la normativa impuesta en la ordenación de la zona, intentando no agotar las 8 alturas que ésta propone.

En el texto que presentan en el concurso hay una crítica hacia la desconexión existente entre vanguardia y producción, que es característico del resto de Europa, según afirman los autores.

Clasifican su propuesta de cualificadora, alternativa, intentando adaptar los tipos 


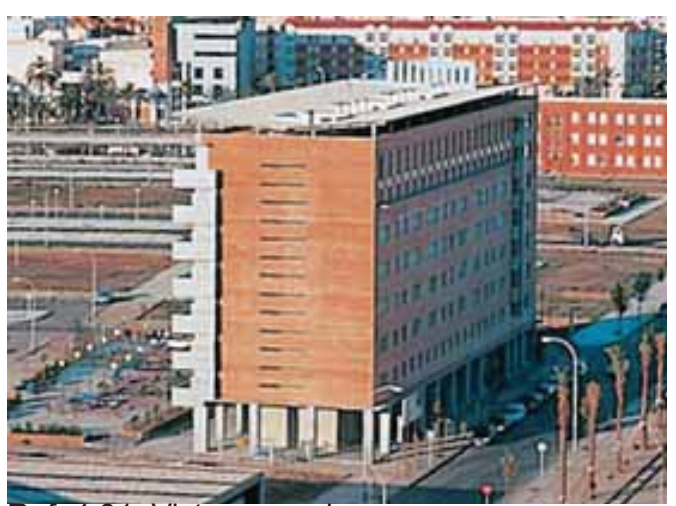

Ref. 4.31. Vista general

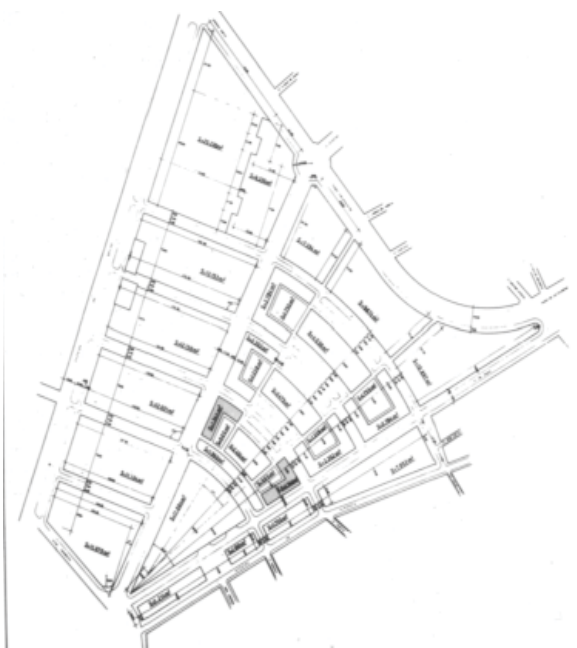

Ref.4.33. Planeamiento previsto

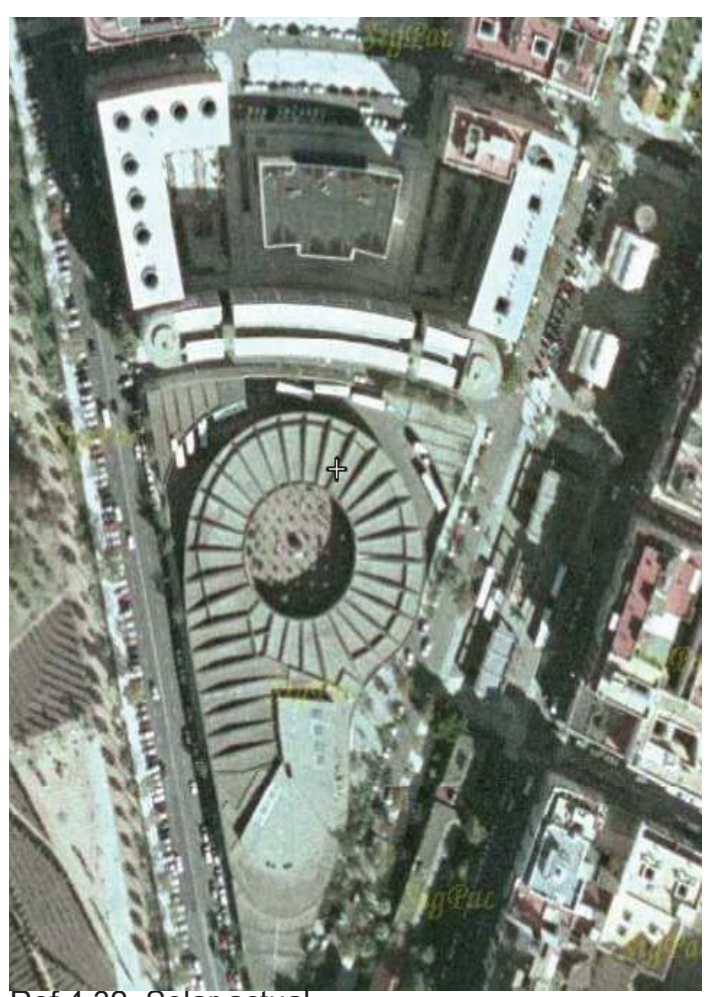

Ref.4.32. Solar actual
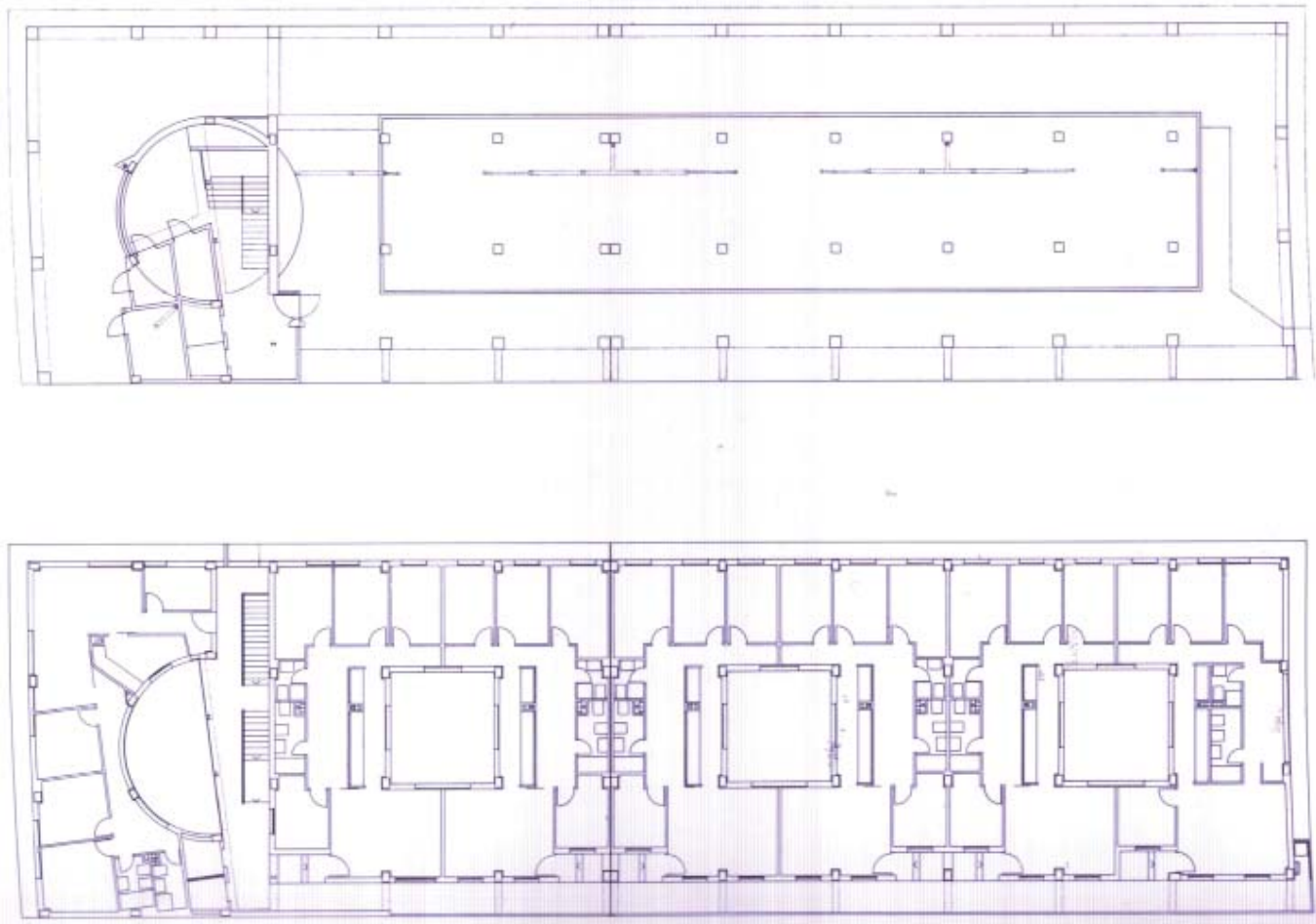

Ref.4.34. Plantas tipo de viviendas del proyecto construido 
de la arquitectura moderna a nuestro medio, según afirman los mismos.

\section{Fase de realización}

El proyecto construido varía mucho de la propuesta inicial. Finalmente el equipo mencionado sólo construirá 49 viviendas correspondientes a una primera fase de proyecto.Las obras duran 18 meses: desde mayo de 1991 hasta noviembre de 1993. Por distintos motivos, la segunda fase se construirá con posterioridad y las llevará a cabo otro equipo técnico.

El bloque finalmente tiene ocho plantas con orientación este-oeste y su fachada tiene una estética horizontal. Se conserva la alineación del proyecto de concurso, pero también varían las dimensiones, pues es un bloque longitudinal con unas dimensiones aproximadas de $19 \times 70 \mathrm{~m}$.

Al tener mucha profundidad se hace uso de tres patios interiores de forma cuadrada para iluminar los espacios centrales así como para proporcionar ventilación a las cocinas. Cada planta alberga siete viviendas, seis a lo largo del corredor y una singular en un extremo junto al núcleo de comunicación. Las zonas comunes junto al núcleo tienen una forma semicircular que hace que singulariza a la vivienda de esquina.

Las viviendas se distribuyen según zonas: en la fachada este se situan los espacios de día y los accesos, en la fachada oeste, mas compartimentada, los espacios de noche. En la zona central se sitúan las zonas húmedas: cocinas y baños. En general son grandes, previstas para familias de hasta 8 miembros y cada una tiene aproximadamente unos $120 \mathrm{~m}^{2}$. Las viviendas se han elevado respecto al corredor para conseguir la privacidad y guardar las vistas con respecto al interior de éstas.

En cuanto a la distribución, las viviendas son muy similares: el acceso a cada una se realiza a través de un corredor lineal situado en una de las fachadas. La entrada se hace directamente al estar, y este espacio está vinculado directamente a la cocina y a una zona intermedia que hace de distribuidor al resto de estancias y al baño.

La estructura se compone a base de pilares y vigas de hormigón, creando una retícula de 6x6m. Los materiales son muy comunes, propios a los de la zona: ladrillo para la mayor parte de las fachadas y la cubierta que está construida con un perfil invertido al habitual. La fachada lineal se construye con una chapa Talgo que sirve de barandilla de las galerías, produciendo líneas de sombra sobre las paredes pintadas de color gris azulado y protegiendo de la orientación oeste el paso a las viviendas.

A continuación se adjunta una ficha-resumen. 


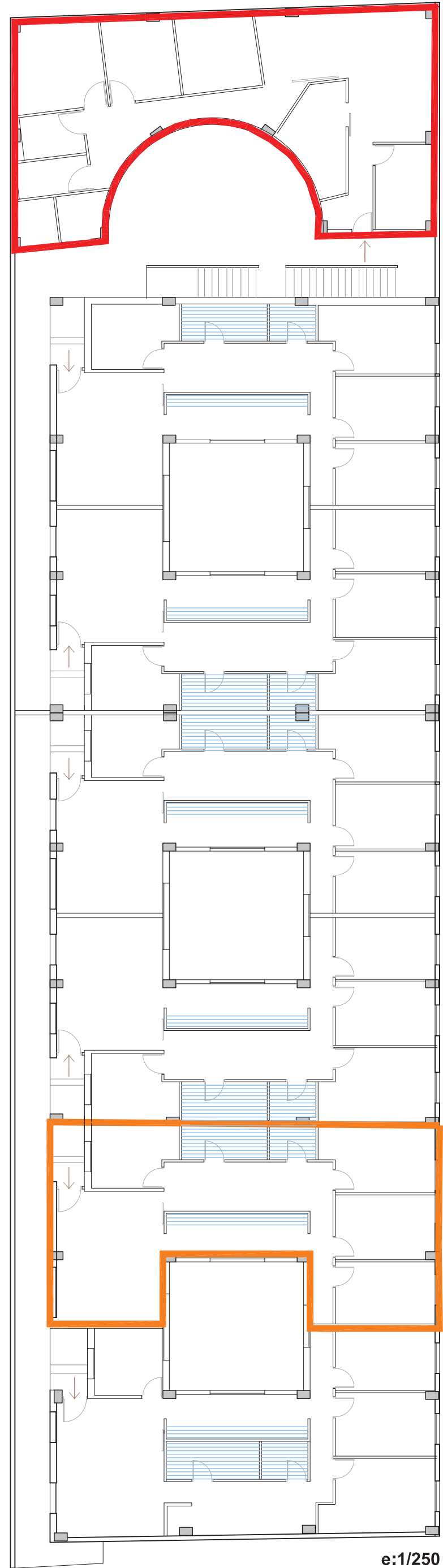

\section{SISTEMAS DE AGRUPACIÓN}

sup. construida total por planta:

$1325 \mathrm{~m} 2$

sup. construida zonas comunes por planta: $211 \mathrm{~m} 2$ (16\%)

\section{VIVIENDA}

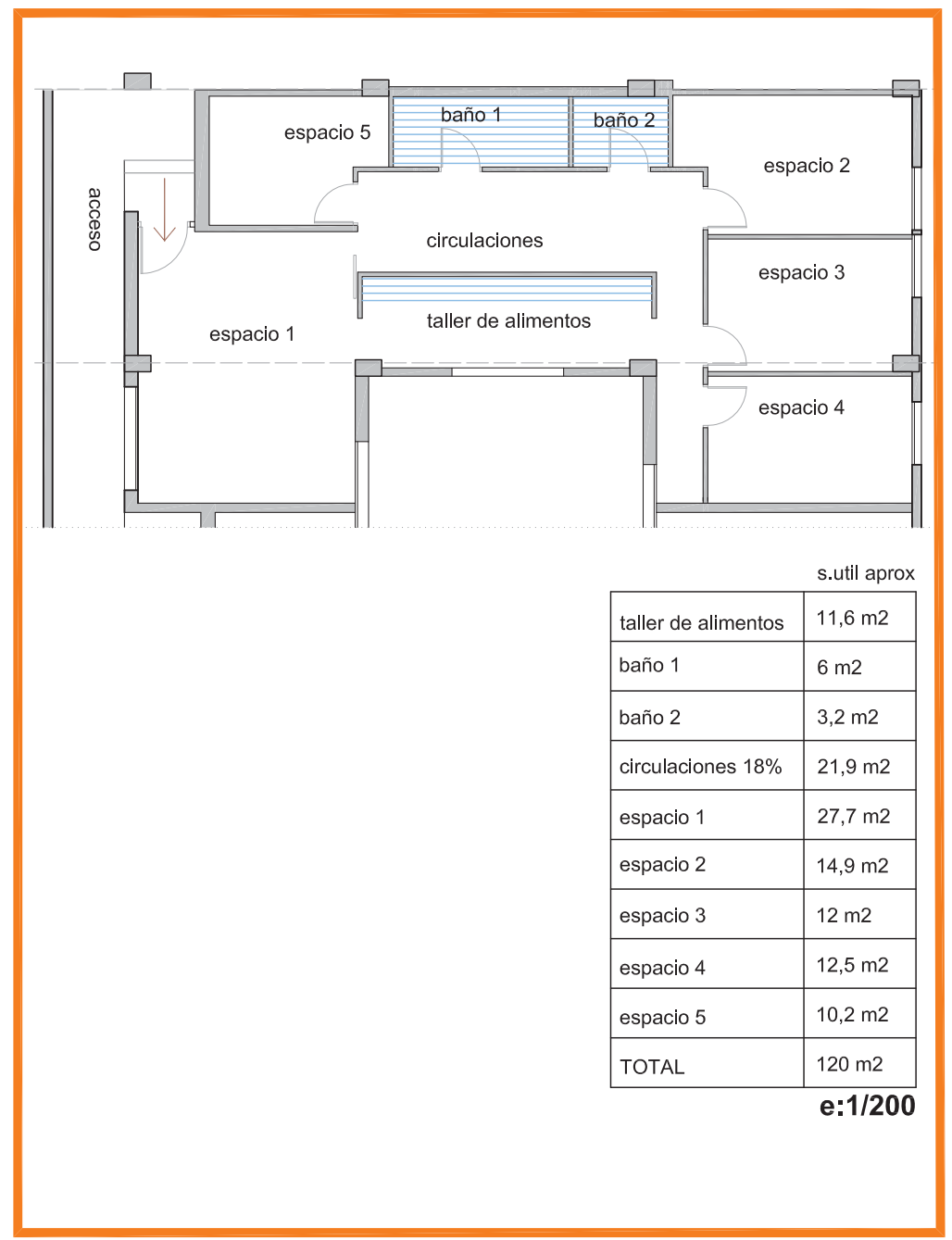


FICHA 1.3

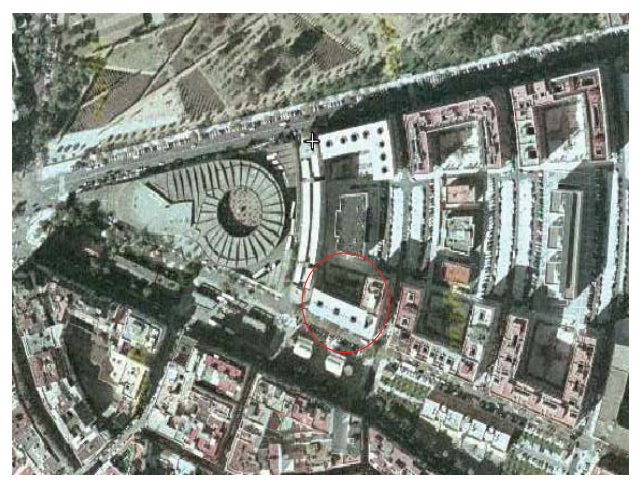

\section{EUROPAN 1}

(año 1988)

\section{FÉLIX POZO Y ALBERTO TORRES 49 VIVIENDAS EN ZAFRA (HUELVA)}

EMPLAZAMIENTO

c/Doctor Rubio $n^{\circ} 3$, Huelva

\section{COMIENZO DE OBRAS- FINALIZACIÓN DE LAS OBRAS \\ $1^{\text {a }}$ fase: 18 meses. \\ Desde junio 1991 hasta noviembre de 1993}

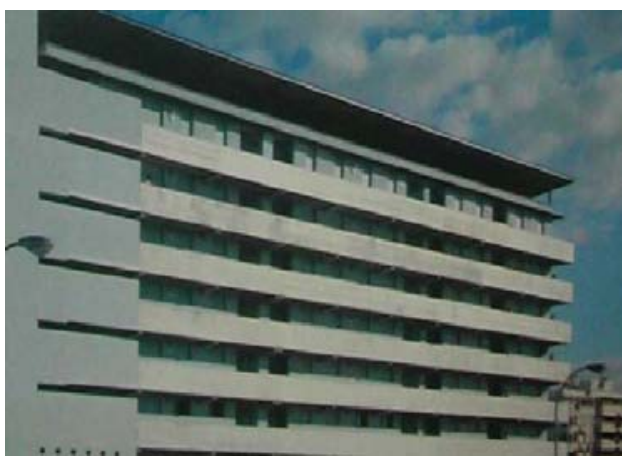

¿ES EL PROYECTO DE CONCURSO?

No. El proyecto planteaba 2 edificios unidos por corredor uno rectangular de 4 plantas y otro circular de 8 plantas rematando la parcela.

$N^{\circ}$ DE VIVIENDAS TOTALES CONSTRUIDAS

49 viviendas en el bloque lineal

$N^{\circ}$ DE VIVIENDS POR SUPERFICIE

VII 7 viviendas

VIII 42 viviendas

USO DE LA PLANTA BAJA

Dos locales comerciales y dos viviendas

\section{USO DEL SOTANO}

No existe sótano

\section{REFERENCIAS BIBLIOGRÁFICAS}

- "49 viviendas en Huelva”, Monográfico Europan, Paris, 1995

- "49 viviendas en el P.E.R.I. de la antigua estación de Zafra", Geometría: revistra semestral de arquitectura y urbanismo, n 17, p.82-85.

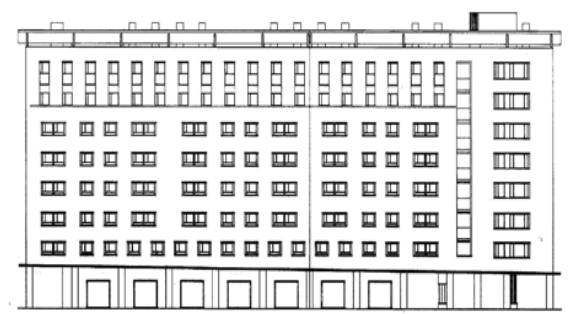
EUROPAN/España, SEPES y el Ministerio de Fomento, 1999, España,p. 149.
- 10 años EUROPAN 5 España, Edición coproducida por 



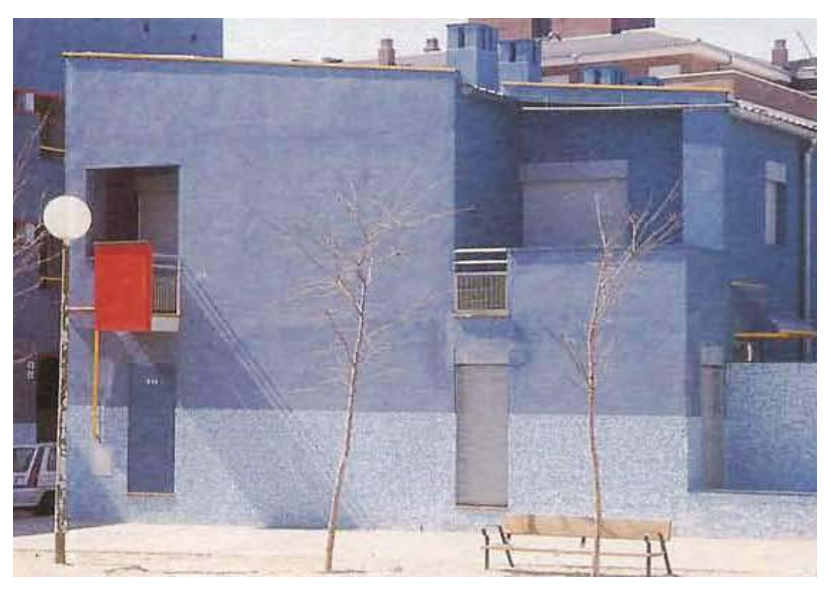

4.1.1. Edificios de viviendas Europan 1

Mercedes Pelaez: viviendas unifamiliares y bloques de viviendas en Vallecas (Madrid) 
VIVIENDAS EUROPAN (1988-2008) I Una aproximación a los modos de vida en el cambio de siglo en España

4. EUROPAN: DEL CONCURSO A LA REALIZACIÓN

\section{All 458}
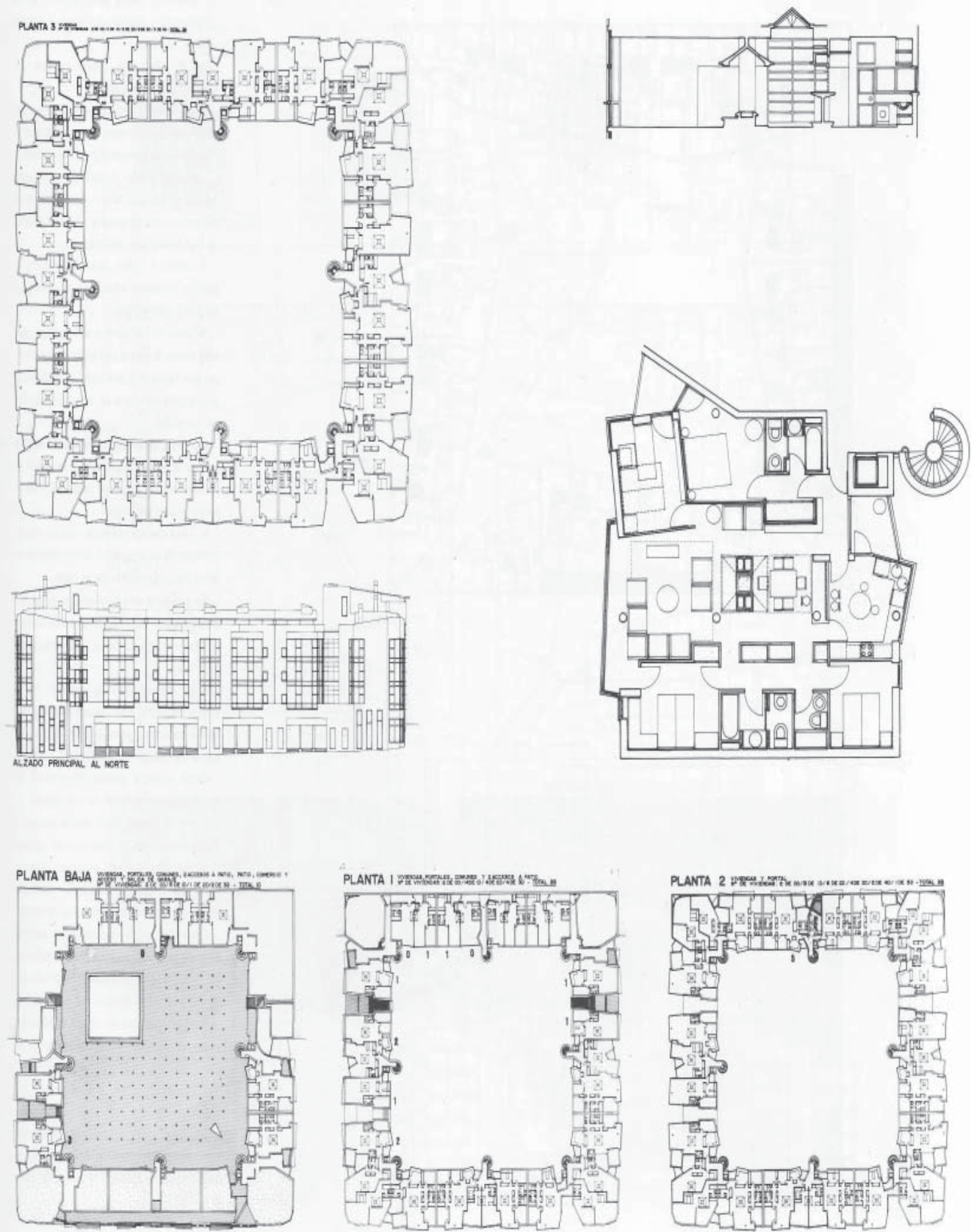

Ref. 4.35. Paneles de concurso 


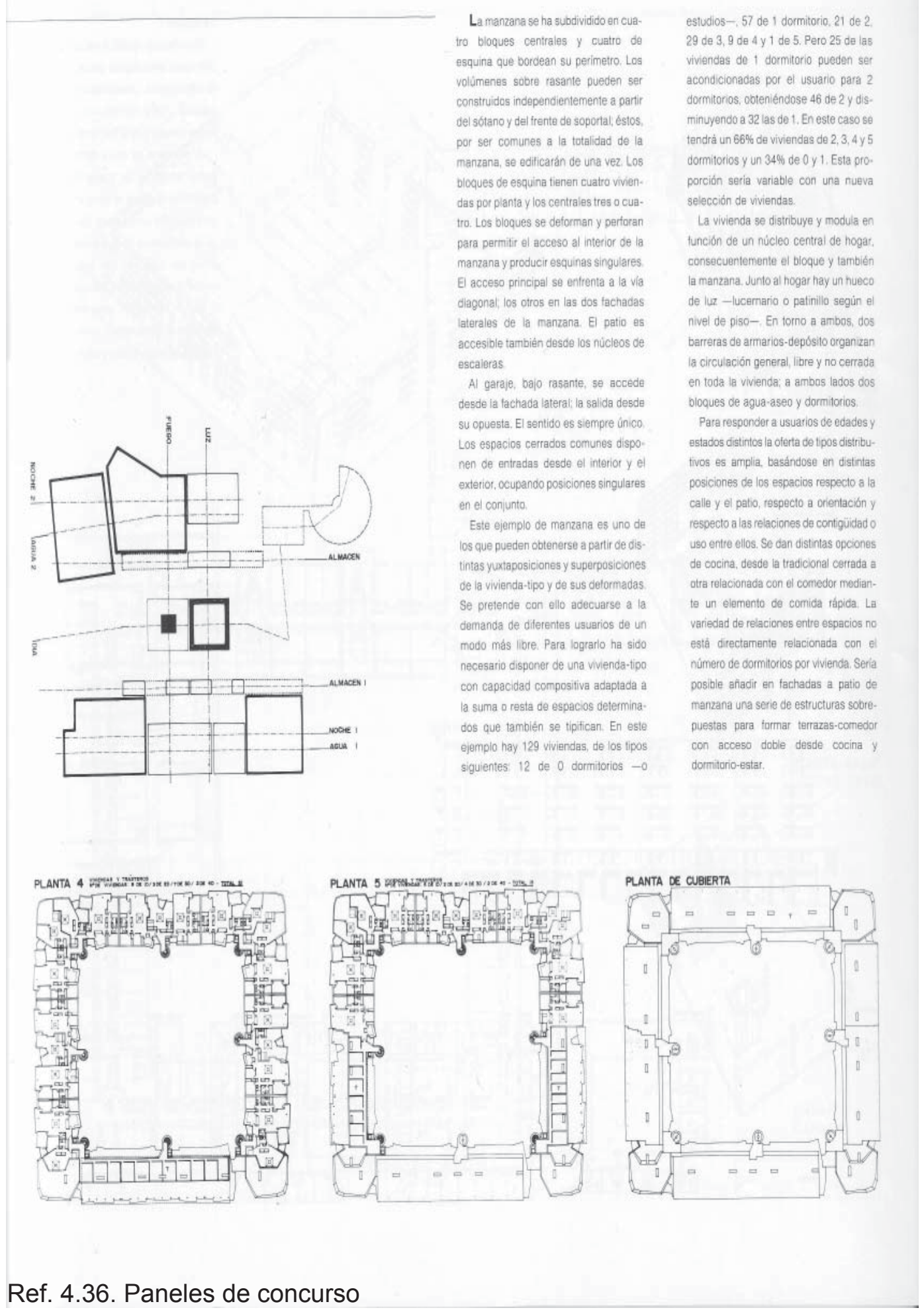


VIVIENDAS EUROPAN (1988-2008) | Una aproximación a los modos de vida en el cambio de siglo en España

4. EUROPAN: DEL CONCURSO A LA REALIZACIÓN

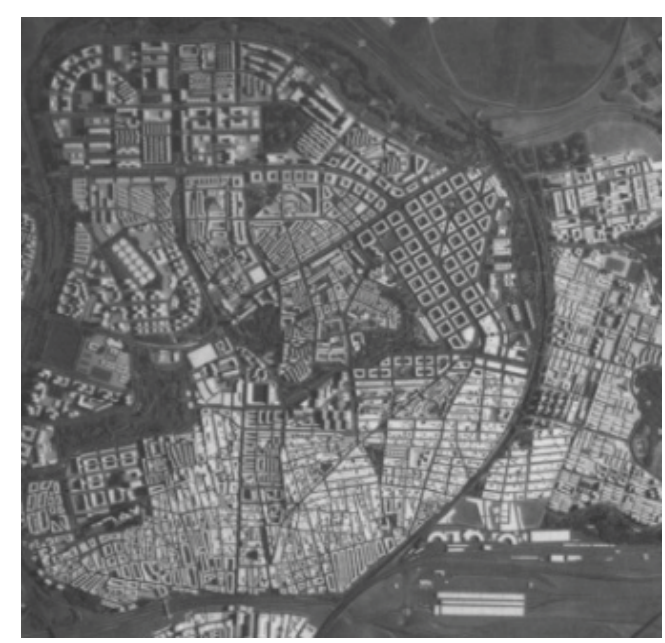

Ref. 4.37. Planeamiento Madrid -Sur, donde se encuentra el solar de concurso propuesto

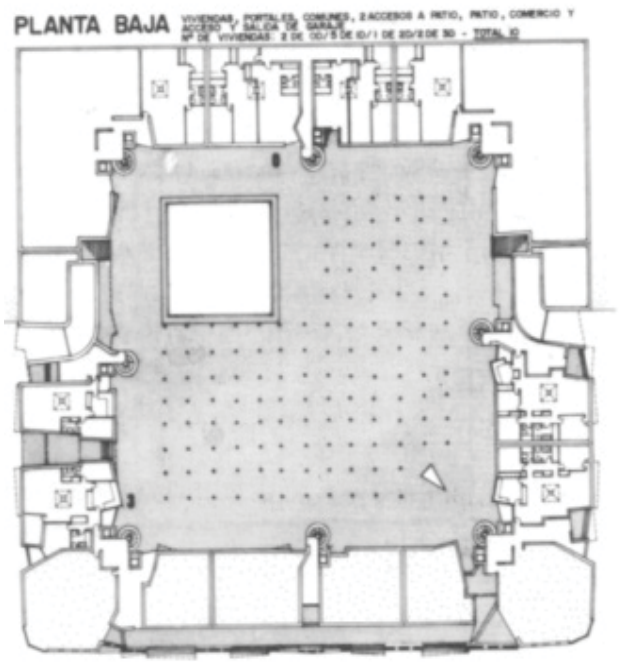

Ref.4.38. Planta baja

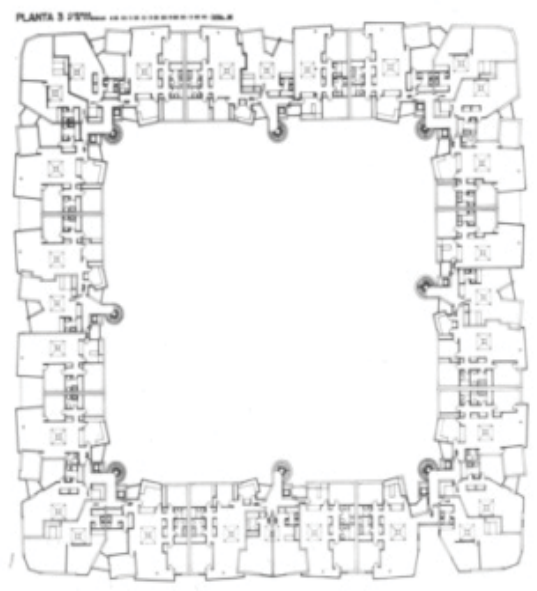

Ref.4.40. Planta tercera

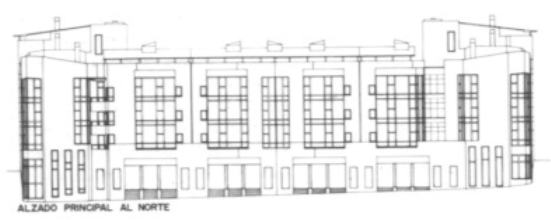

Ref.4.39. Alzado

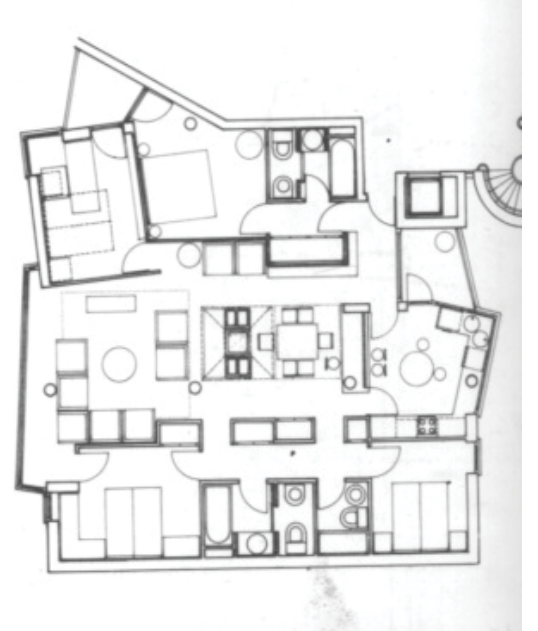

Ref.4.41. Vivienda tipo 


\section{Fase de concurso}

El solar de este proyecto está el situado en la zona de Madrid Sur, en una urbanización que se conocía con el nombre de Palomeras Bajas, en una zona que fue ordenada por un Peri. En este área se proporcionaron todos los datos referentes a esta ordenación urbanística y en concreto, para la manzana de concurso ser propuso un máximo de 140 viviendas, destinado fundamentalmente a parejas -de joven y avanzada edad-, a personas que vivían solas- también de joven y avanzada edad- y una proporción elevada para familias entre 4 y 5 componentes. Las familias numerosas no estaban contempladas en el conjunto. En el enunciado se habla de contemplar la gestión conjunta entre alquiler y venta de viviendas y de la posible edificación por fases. Se apunta que cada vivienda deberá tener como máximo una plaza de aparcamiento.

Con estos condicionantes, bajo el lema AM 458, la arquitecta plantea una manzana cerrada y flexible. Se compone de cuatro bloques centrales y cuatro en las esquinas, que se perforan permitiendo el acceso al interior de la manzana. El acceso a este patio también es posible desde los núcleos de comunicación.

Se proyecta una vivienda-tipo con capacidad para ser modificada sumando o restando espacios, creando por tanto un proyecto muy rico en diversidad de viviendas. Éstas son de carácter orgánico pues prácticamente se olvida de las líneas perpendiculares, lo que proporiona mucho movimiento a la planta. La propia autora comenta que este ejemplo de manzana es uno de los que pueden obtenerse a partir de distintas yuxtaposiciones y superposiciones de la vivienda-tipo y sus deformadas. Se pretende por ello adecuarse a la demanda de diferentes usuarios de un modo más libre .

El proyecto de concurso consta de 129 apartamentos de tamaños diversos para poder albergar en ellos distintos usuarios. Existen 12 estudios, 57 viviendas de un dormitorio, 21 viviendas de dos dormitorios, 29 viviendas de tres dormitorios, 9 viviendas de cuatro dormitorios e incluso una vivienda de 5 dormitorios.

Hay una posibilidad muy interesante de convertir 29 viviendas de un dormitorio en dos dormitorios, obteniéndose un total de 46 viviendas de 2 dormitorios y 32 de un dormitorio. Juega con la flexibilidad, con la variedad de individuos que pueden habitar estas viviendas.

Es curioso observar cómo las viviendas se distribuyen en torno al hogar situado en el centro, junto al que hay un hueco de luz. También existen distintas opciones de cocina, desde la tradicional cerrada a otra abierta más flexible unida al espacio de comedor.

En la fachada del patio interior también se plantea la posibilidad de añadir estructuras superpuestas para formar terrazas comedor con acceso doble desde la cocina y el dormitorio-estar. 


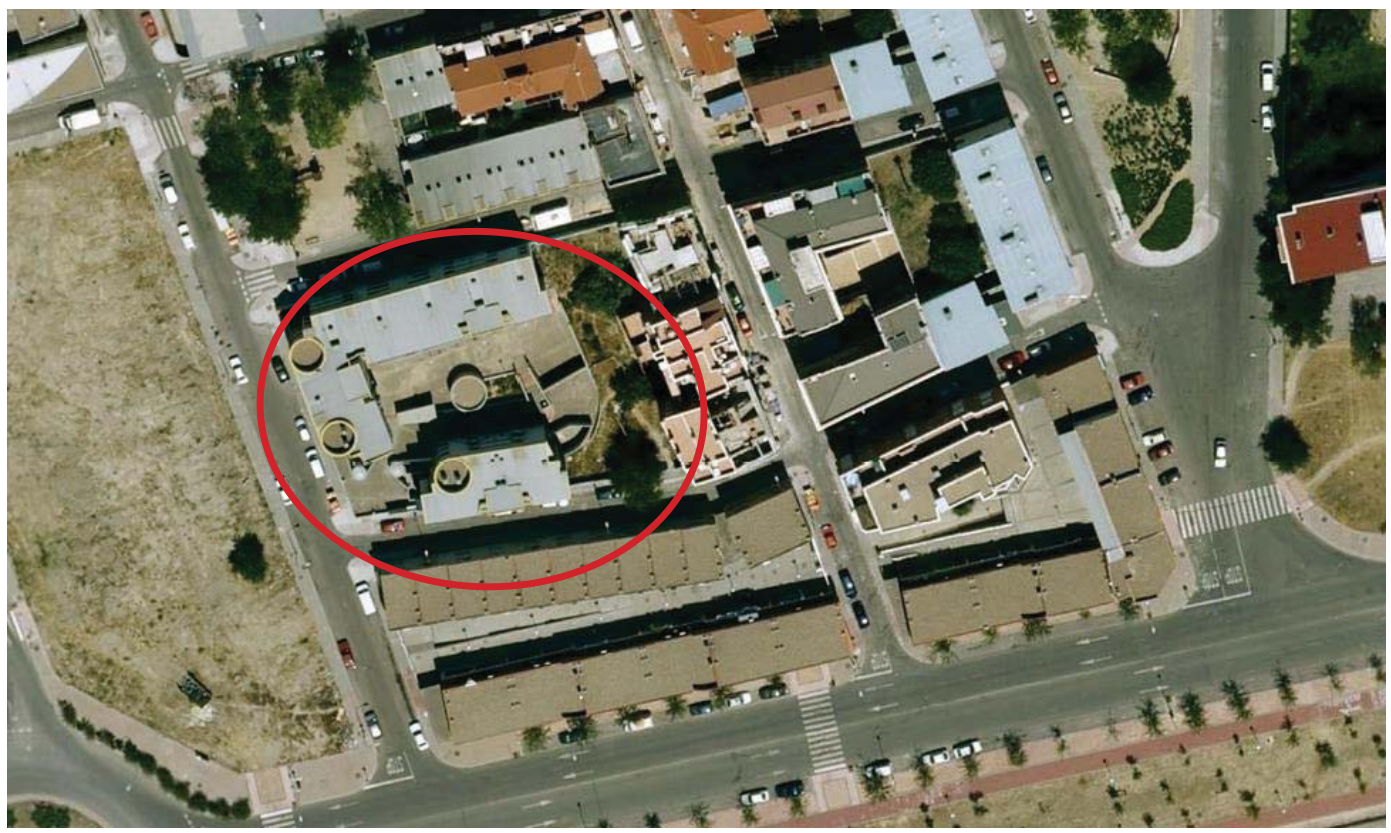

Ref. 4.42. Planta general: tres bloques de viviendas y unifamiliares

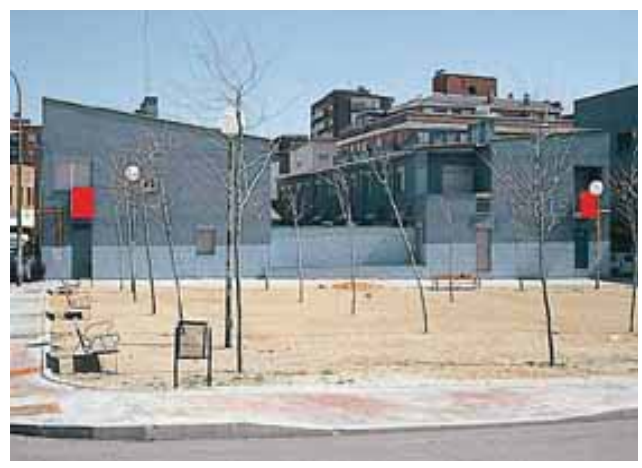

Ref.4.43. Viviendas unifamiliares

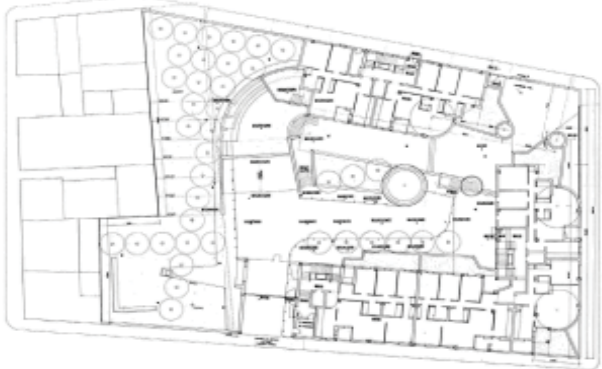

Ref.4.44. Planta de los tres Bloques de viviendas

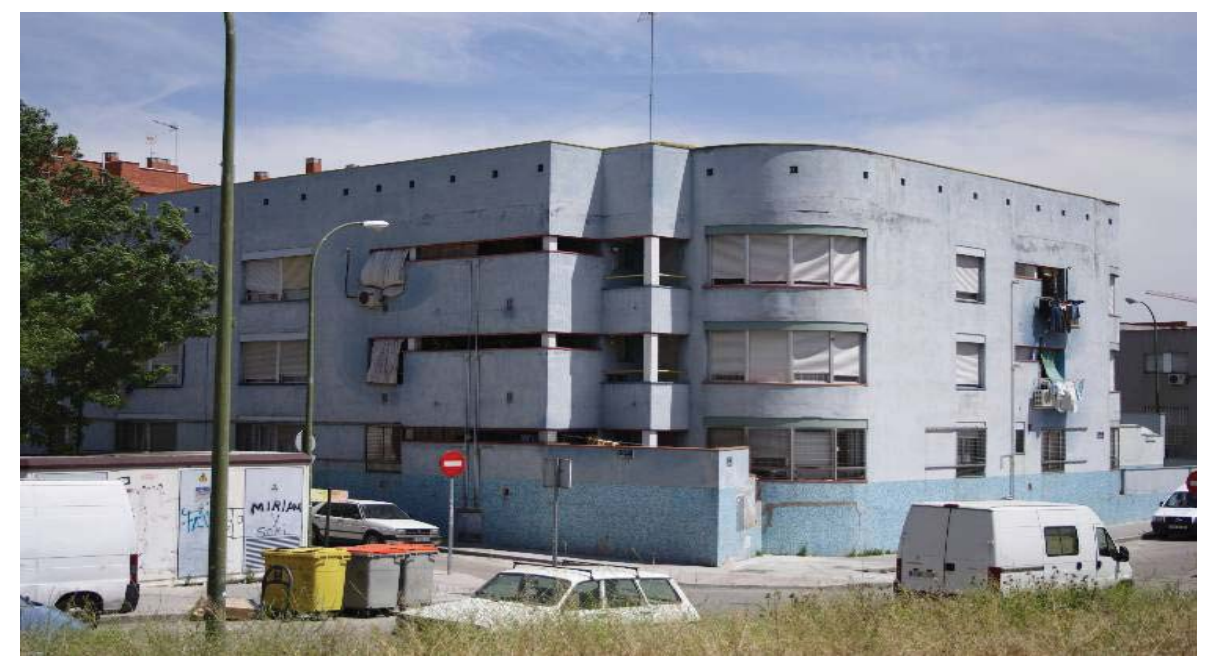

Ref. 4.45. Vista de los bloques de viviendas 


\section{Fase de realización}

Lamentablemente, el proyecto presentado en el concurso no llegó a materializarse. Más adelante, a la autora se le ofrecieron dos solares donde poder construir otros proyectos diferentes. Se trata ahora de comentar el primer proyecto, situado en la Villa de Vallecas. Se integra en el entorno del Barrio de Vallecas, aunque tiene cierto carácter de borde, por delimitar con la Avenida Villa de Vallecas, que ofrece una imagen de conjunto desde la lejanía. Son viviendas sociales sencillas, cons-truidas con escasez de medios económicos.

La obra construida se compone de viviendas unifamiliares distribuidas en dos parcelas. En la parcela de menor superficie se distribuyen 10 viviendas adosadas individuales de las que apenas se ha obtenido documentación. Algunas viviendas tienen pequeños huecos en gruesos muros de vivos colores y el entresuelo decorado con fragmentos de vidrio. En la parcela de mayor superficie existen 18 viviendas distribuidas en tres bloques de tres plantas con un jardín. Es muy interesante destacar este espacio interior que se proyecta en la manzana pues invita a la relación intervecinal. Es una obra que contempla el espacio urbano en su propuesta.

En los tres bloques existen tres núcleos de comunicación que dan acceso a una, dos, o tres viviendas según su ubicación. Las viviendas tienen bastante superficie, si se tiene en cuenta que están en un barrio de vivienda social como es el de Vallecas.

Si se estudian las viviendas se puede observar que el acceso suele hacerse mediante un espacio previo que distribuye a la cocina, el estar y a un corredor que conduce a las habitaciones y los baños. Podría decirse que las viviendas se dividen en dos zonas: las zonas de día (estar y cocina) que es la de mayor superficie, y la zona de noche, que agrupa en la mayoría de viviendas tres dormitorios dobles. Los núcleos húmedos (baños) se sitúan en la zona intermedia.

En la construcción de las viviendas se han utilizado materiales económicos: ladrillo y enfoscado para los bloques. En la imagen actual de éstas se percibe que el enfoscado se ha ido deteriorando. La imagen de los tendederos en las ventanas refleja que las viviendas están habitadas, aunque se podría haber pensado en un espacio menos público para llevar a cabo este tipo de tareas. También los aparatos de aire acondicionado en la fachada crean una imagen nada agradable. Para las cubiertas inclinadas se ha utilizado chapa metálica con pendiente hacia el patio interior de la manzana.

A continuación se adjunta una ficha-resumen. 


\section{VIVIENDA}

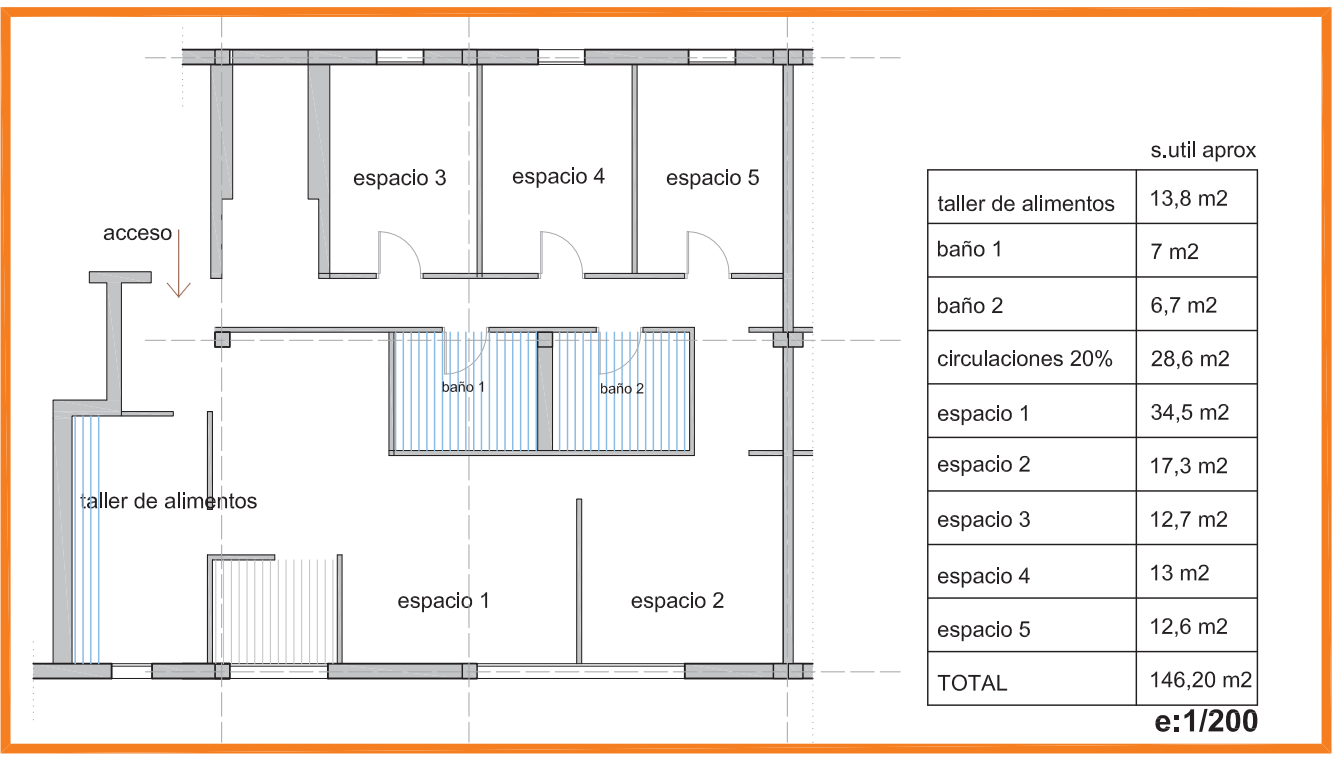

\section{SISTEMAS DE AGRUPACIÓN (BLOQUE)}

superficie construida total por planta: $\quad 1093 \mathrm{~m} 2$

superficie construida zonas comunes por planta: $157 \mathrm{~m} 2$ (14\%)

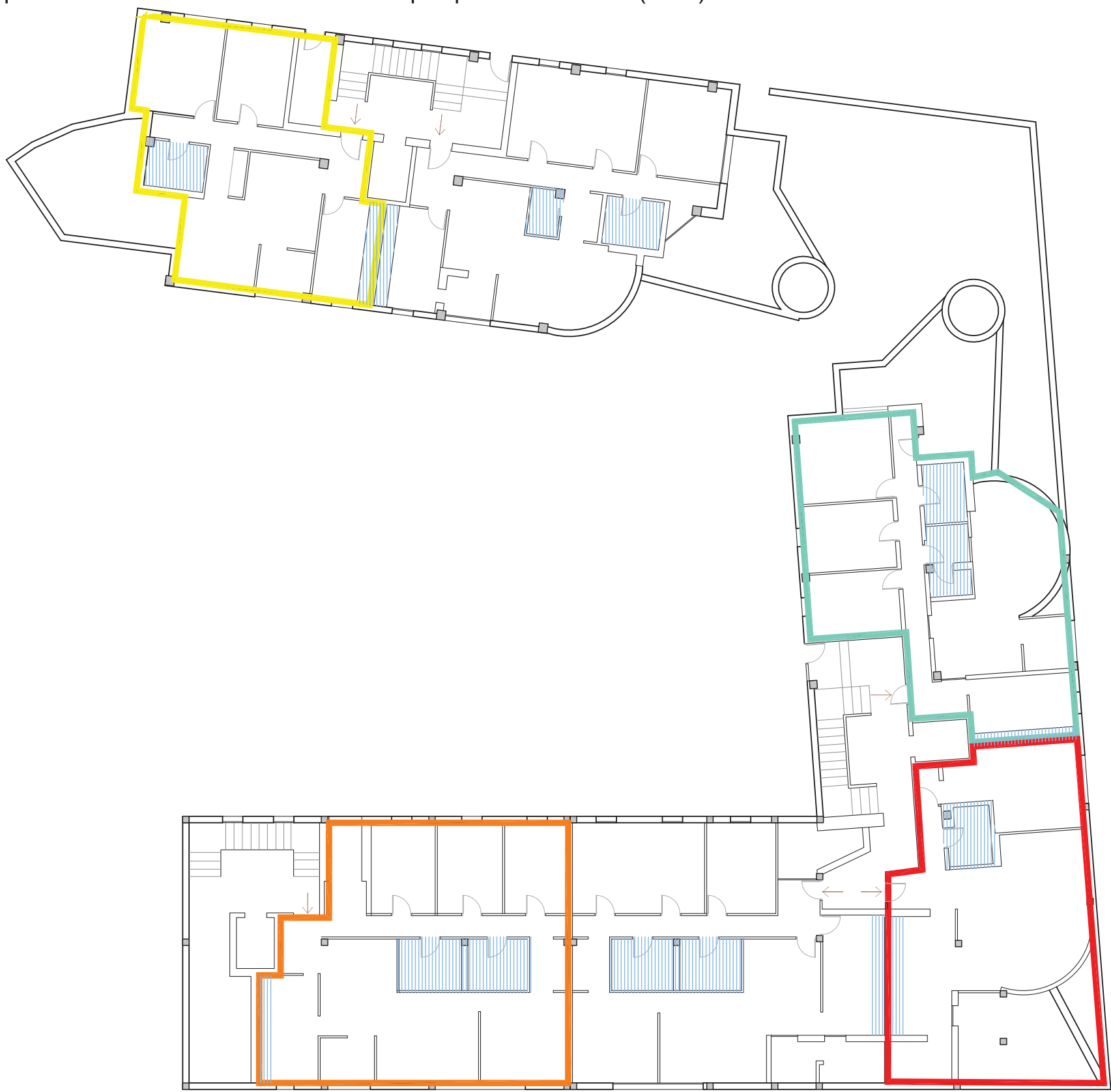




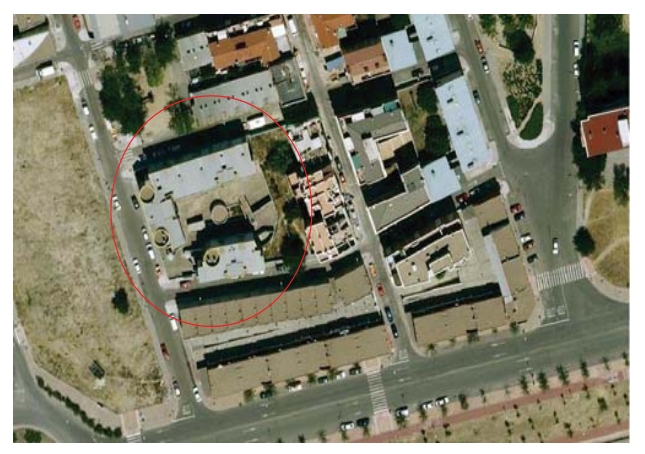

FICHA 1.4

\section{EUROPAN 1}

(año 1988)

\section{MERCEDES PELÁEZ \\ 28 VIVIENDAS EN VALLECAS (MADRID)}

EMPLAZAMIENTO

c/ de la Cabaña 12, Vallecas (Madrid)

COMIENZO DE OBRAS- FINALIZACIÓN DE LAS OBRAS

Fin: 1995

¿ES EL PROYECTO DE CONCURSO?

No. En el proyecto de concurso, con el lema AM 458 , la autora plantea una manzana cerrada, flexible, subdividida en cuatro

bloques centrales y cuatro de esquina, con 129 apartamentos

$N^{\circ}$ DE VIVIENDAS TOTALES CONSTRUIDAS

18 viviendas distribuidas en tres plantas con un jardín interior y 10 unifamiliares adosadas en la manzana contigua.

$N^{\circ}$ DE VIVIENDAS POR SUPERFICIE

(bloque)+10 unifamiliares adosadas

VIII 3 viviendas

VIII 6 viviendas

6 viviendas

VIIA 3 viviendas

USO DE LA PLANTA BAJA

Viviendas

USO DEL SOTANO

Garaje

\section{REFERENCIAS BIBLIOGRÁFICAS \\ - Arquitectos n 133 , Ideas y prácticas, Madrid, 1994, p.60 \\ - 10 años EUROPAN 5 España, Edición coproducida por EUROPAN/España, SEPES y el Ministerio de Fomento, 1999 , España,p. 148. \\ - EUROPAN 10 España, "Proyectar la urbanidad", Madrid, 2010, p. 212}





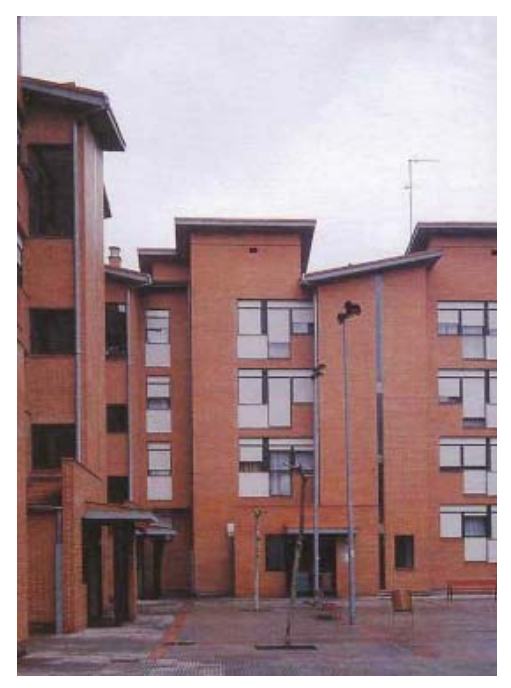

4.1.1. Edificios de viviendas Europan 1 (1988)

Mercedes Pelaez: edificios de viviendas sociales en Ujo (Mieres) 


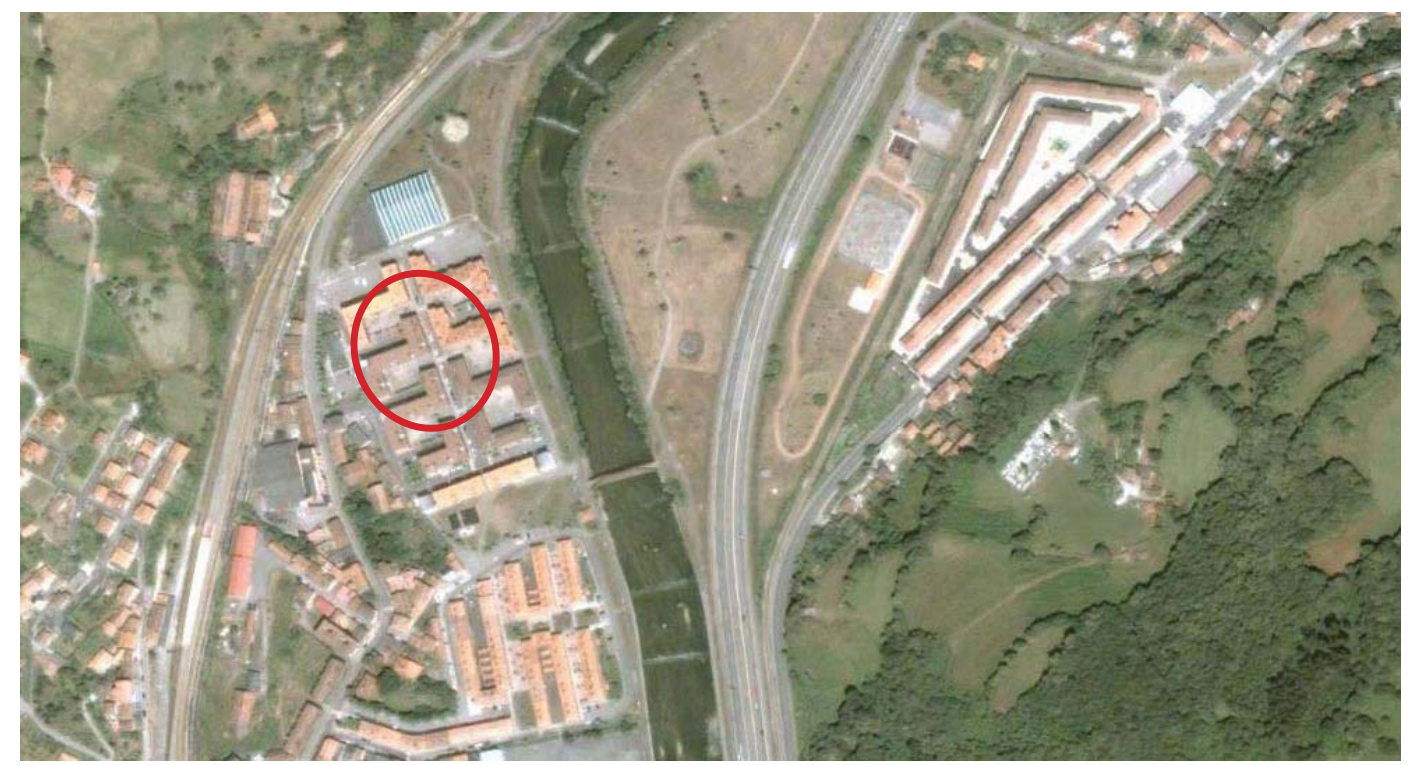

Ref.4.46. Planta de situación

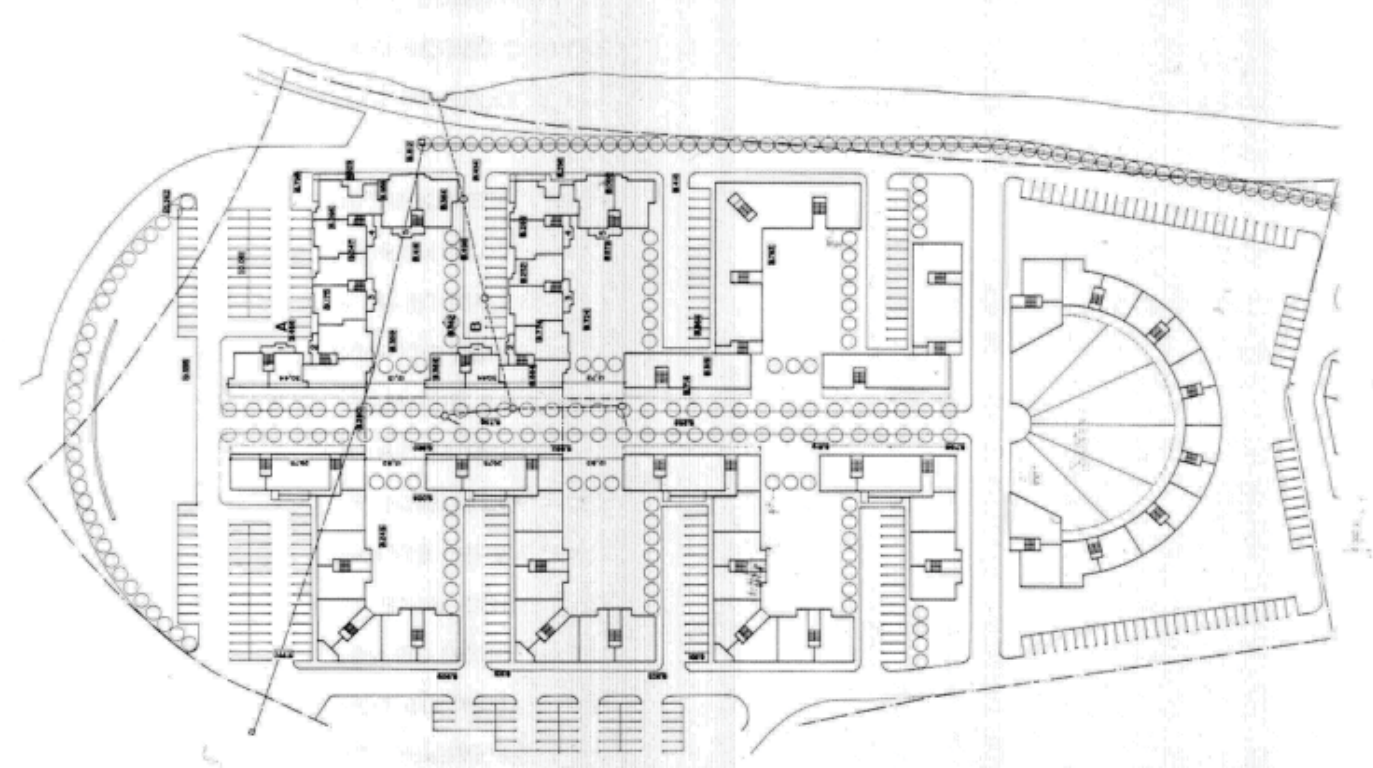

Ref. 4.47. Planta general de ordenación de la zona

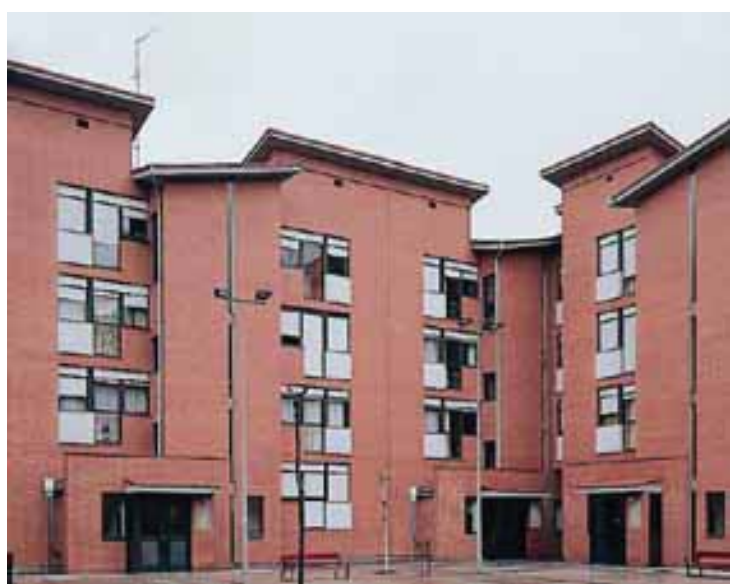

Ref.4.48. Fachadas interiores 


\section{Fase de concurso}

Se ha comentado en el apartado anterior pues el proyecto de concurso es de la misma autora.

\section{Fase de realización}

Como ya se ha comentado, el proyecto presentado en el concurso no llegó a materializarse y a la autora se le ofrecen dos solares donde poder construir. En este apartado se comenta el segundo proyecto que consiste en la construcción de varios bloques de viviendas sociales en Mieres (Asturias), en un emplazamiento singular, rodeado de vegetación y situado a orillas del río Caudal.

El conjunto lo componen 74 viviendas, en dos bloques de 37 viviendas cada uno. Más tarde se termina completando el planeamiento con una edificación de semejantes ca-racterísticas.

Para adaptarse al planeamiento que obligaba a integrar soportales en la fachada, en planta baja se ubican algunos servicios y un centro comercial.

Cada bloque contiene cinco escaleras pues no existe sistema mecánico de aparato elevador. Cada escalera presta servicio a dos viviendas por planta.

A diferencia del proyecto anterior, estas son viviendas de pequeñas dimensiones con un dormitorio, un baño, una zona de estar y cocina con una pequeña terraza.

En el acceso, todas las viviendas tienen un espacio inical que distribuye a la cocina y al estar. Desde éste se accede al resto de estancias y al baño. Las viviendas son pasantes y tienen las zonas húmedas permanecen en el interior liberando las fachadas.

La construcción de la obra es convencional, realizada con materiales económicos: fachadas de ladrillo cara vista, cerramientos de pvc y cubierta inclinada de teja cerámica.

A continuación se adjunta una ficha-resumen. 


\section{VIVIENDA}

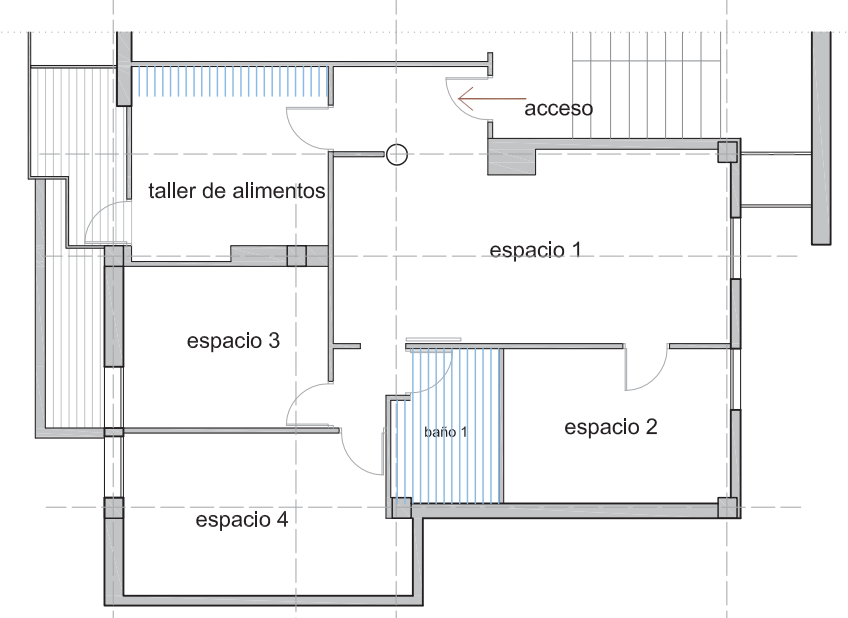

\begin{tabular}{|l|l|}
\multicolumn{1}{c}{} & \multicolumn{1}{l}{ s.util aprox } \\
\hline taller de alimentos & $15,8 \mathrm{~m} 2$ \\
\hline baño 1 & $6,5 \mathrm{~m} 2$ \\
\hline circulaciones 6\% & $7,4 \mathrm{~m} 2$ \\
\hline espacio 1 & $30 \mathrm{~m} 2$ \\
\hline espacio 2 & $14,5 \mathrm{~m} 2$ \\
\hline espacio 3 & $13,6 \mathrm{~m} 2$ \\
\hline espacio 4 & $18,5 \mathrm{~m} 2$ \\
\hline TOTAL & $79,3 \mathrm{~m} 2$ \\
\hline
\end{tabular}

\section{SISTEMAS DE AGRUPACIÓN}

superficie construida total por planta:

$1522 \mathrm{~m} 2$

superficie construida zonas comunes por planta: $112 \mathrm{~m} 2(7 \%)$

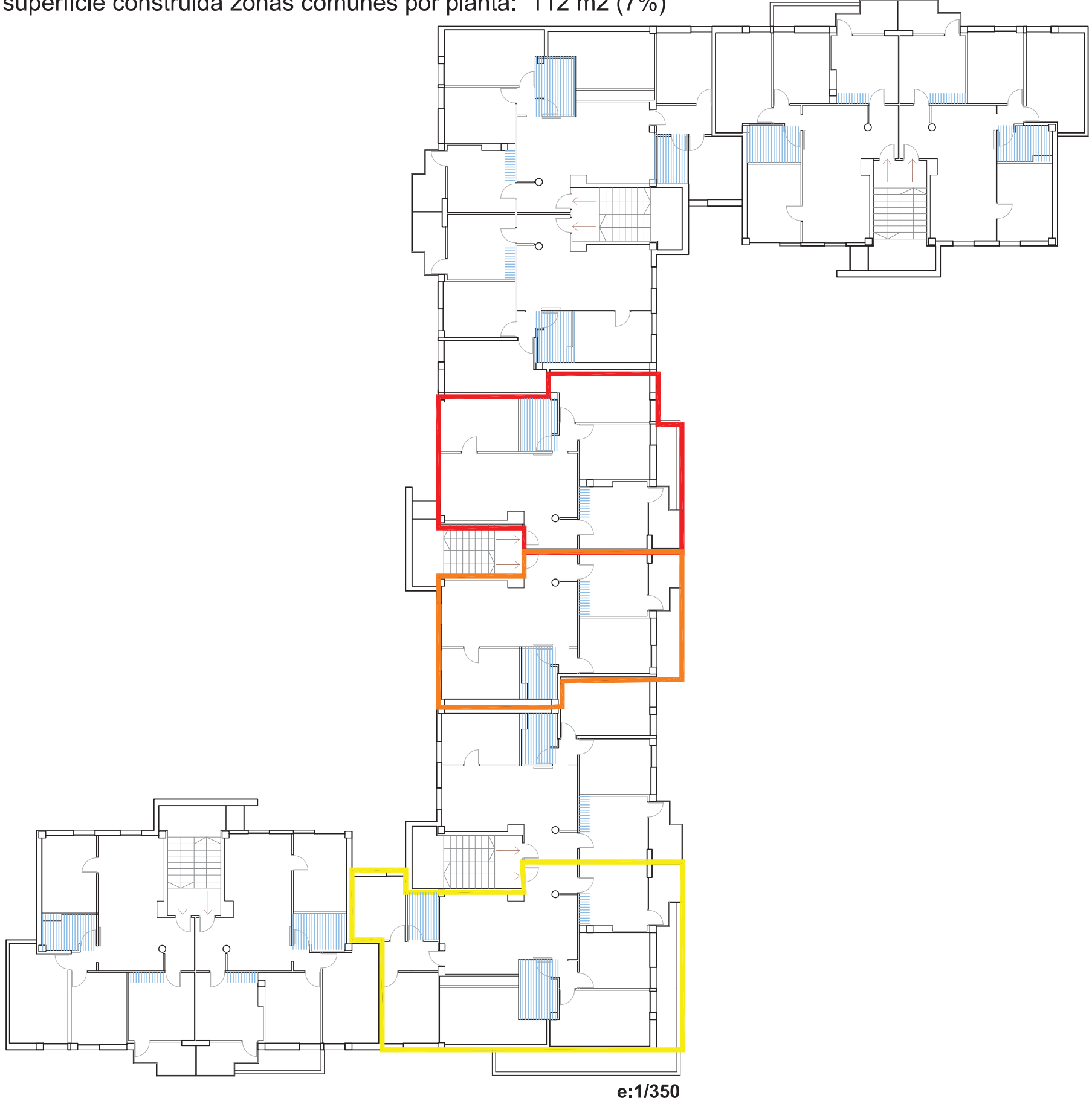



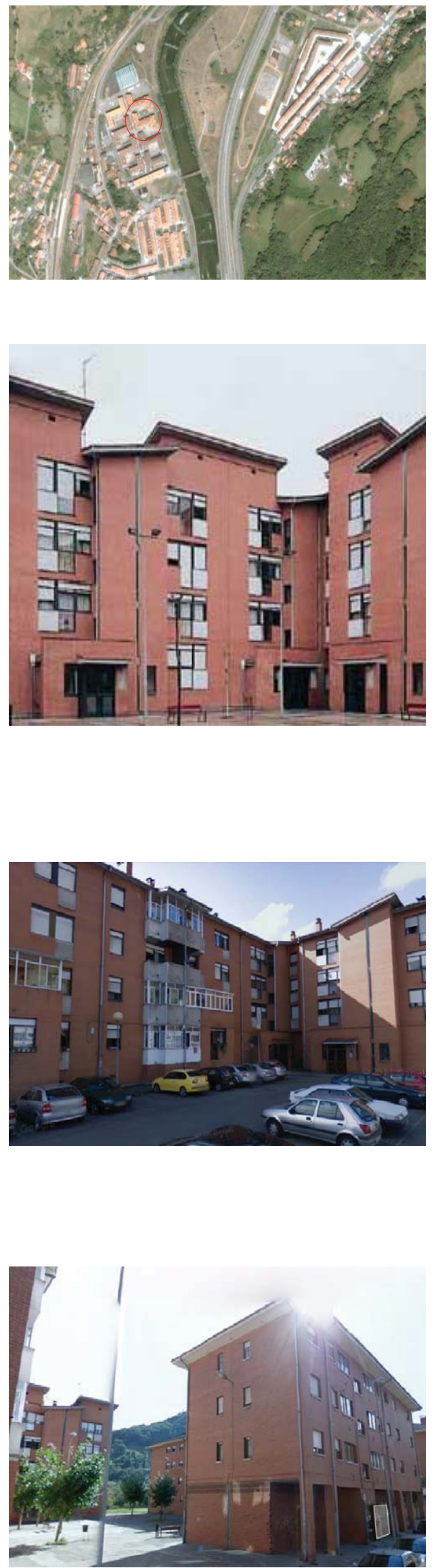

FICHA 1.5

EUROPAN 1

(año 1988)

\section{MERCEDES PELÁEZ \\ 74 VIVIENDAS EN UJO (MIERES)}

EMPLAZAMIENTO

Carretera General-Ujo, Mieres (Asturias)

COMIENZO DE OBRAS- FINALIZACIÓN DE LAS OBRAS

Fin: 1995

¿ES EL PROYECTO DE CONCURSO?

No. El conjunto lo componene 74 viviendas, en dos bloques (con forma de Z, de 37 viviendas cada uno). Se termina com-

pletando con una edificación parecida.

№ DE VIVIENDAS TOTALES CONSTRUIDAS

37 viviendas en cada bloque

N DE VIVIENDAS POR SUPERFICIE

VII 27 viviendas

VII 5 viviendas

5 viviendas

USO DE LA PLANTA BAJA

Bajos comerciales y servicios ya que el proyecto

se ha adaptado al planeamiento que le hace integrar soportales en fachada.

\section{USO DEL SOTANO}

No tiene

\section{REFERENCIAS BIBLIOGRÁFICAS \\ - Arquitectos n 133 , Ideas y prácticas, Madrid, 1994, p.61 \\ - 10 años EUROPAN 5 España, Edición coproducida por EUROPAN/España, SEPES y el Ministerio de Fomento, 1999, España,p. 148. \\ - EUROPAN 10 España, "Proyectar la urbanidad", Madrid, 2010, p. 213}





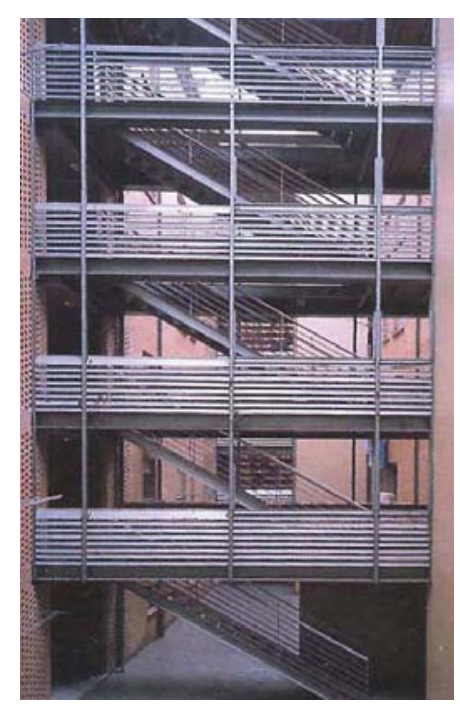

\subsubsection{Edificios de viviendas Europan 1 (1988)}

Isabel Bennasar y Ana $\mathrm{M}^{\mathrm{a}}$ Noguera: bloques de viviendas sociales en Pravia (Asturias) 
VIVIENDAS EUROPAN (1988-2008) | Una aproximación a los modos de vida en el cambio de siglo en España

4. EUROPAN: DEL CONCURSO A LA REALIZACIÓN

\section{NW257}

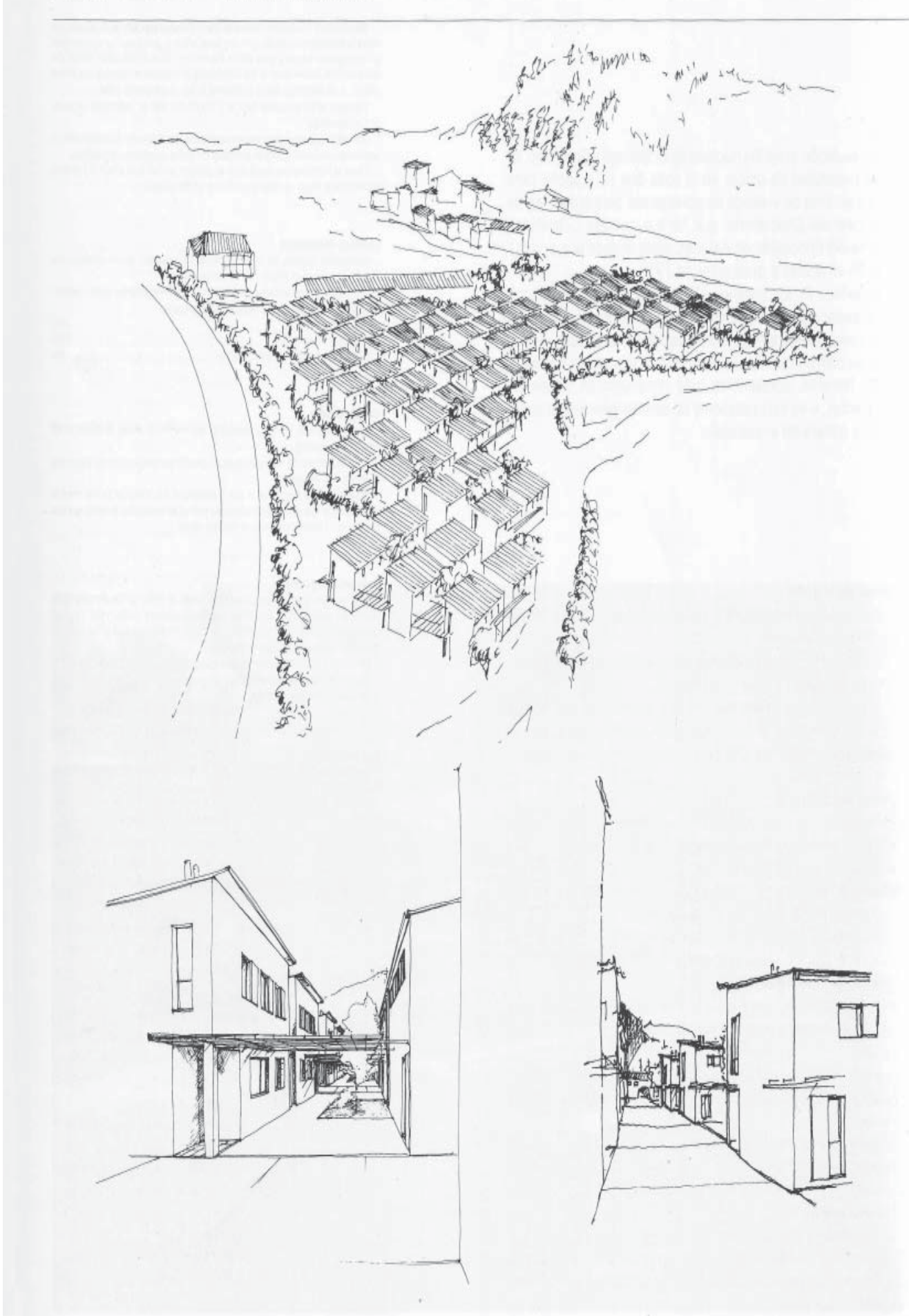

Ref. 4.49. Paneles de concurso 

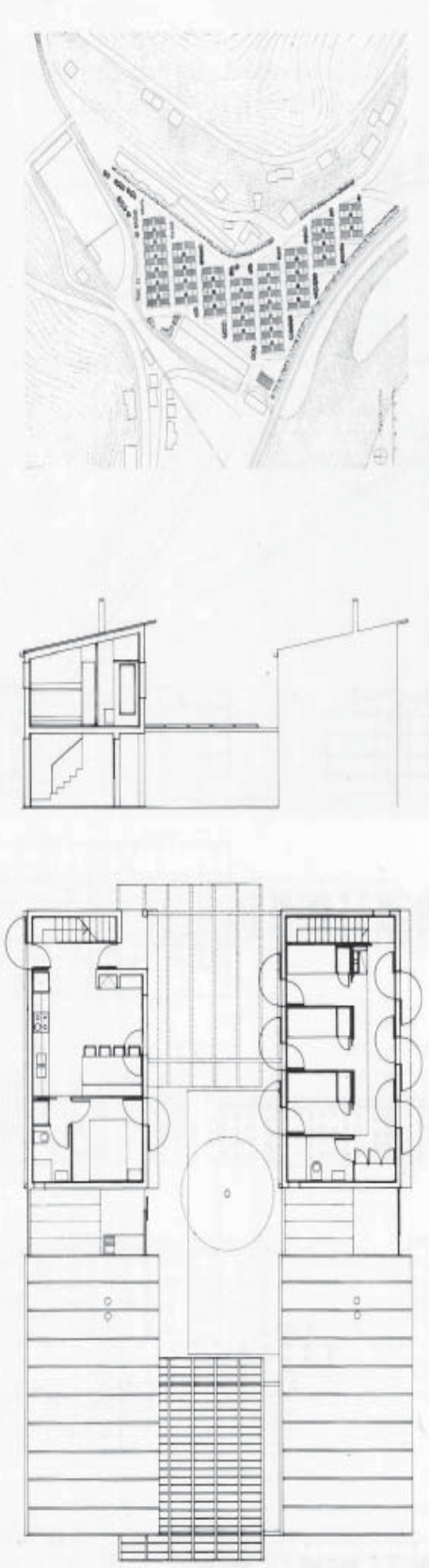

Viviendas destinadas a un grupo social marginado; solat en zona poce consolicada. Vacio dentro de un desor. den sin jerarquías. ¿Cómo situarnos? Todo ello se nos planteaba como un problema a resolver.

La teflexión sobre el caracteristico modo de vida y costumbres de esta gente nos iba a dar muchas pistas: evidentemente, no se trataba de crear unas yiviendas estándar, ni simplemente minimas.. Ni de pretender ordenar con ellas una zona caracterizada por is casualidad.

Se piensa la vivienda y su disposición urbanistica como algo destinado a unos usuarios determinados.

El barrio proyectado se ordena a partis de sí mismo, de sus propias leyes, y se sitúa en el vacio, solar del proyecto La implantación, la distribución de viales de acceso al barrio a partir de un eje o calle principal, se adapta al entorno (retranqueándose, dejando espacios-plazas teniendo en cuenta el rio, el tren...), pero no adopta la escasa organización urba. nistica de éste. Es un barrio con entidad en sí mismo, para una comunidad dilerenciada.

Vivienda que se ha de adaptar a un modo de vida, vivienda para chabolistas, económicamente sencilia, simple, repe. tible... Las viviendas se asientan individualmente sobre el terreno, en contacto con la calle, considerada como espacio de relación de la vecindad.

Una trama donde todas las vias están definidas por las casas del barrio propiamente dichas. Las viviendas se repiten perpendicularmente a las calles y están conectadas a ellas a través de patios abiertos: se entende la vida de esta comunidad como vida de barrio social. no tanto individual, vids en ta calle

Estos patios, espacios de las casas. orientados al sur, $y$, a la vez, abiertos a os viales de acceso son la base de la tormación de calies peatonales, espa. cios para estar, para vivir. Se crea una trama de calles peatonales finteriores de barrio) y viales, en el intento de compaginar la vida de esta gente en el exteriot. $x$ la protección minima de los espacios para estar. Los espacios peatonales y $\mathrm{e}$ viario se encuentran relacionados en una única unidad estructural, genera. dora del proyecto

Ref. 4.50. Paneles de concurso 
VIVIENDAS EUROPAN (1988-2008) I Una aproximación a los modos de vida en el cambio de siglo en España

4. EUROPAN: DEL CONCURSO A LA REALIZACIÓN

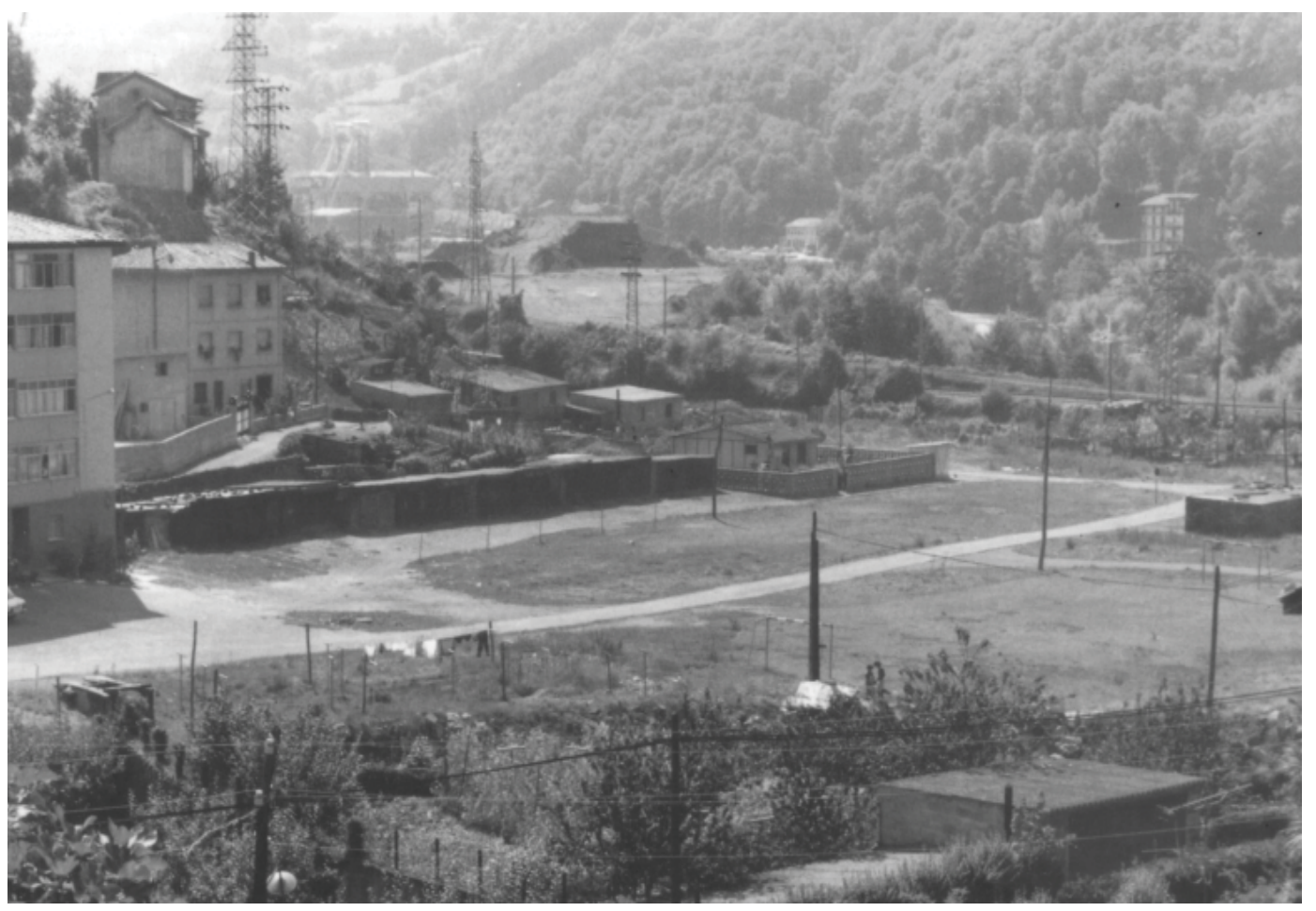

Ref. 4.51. Solar de concurso

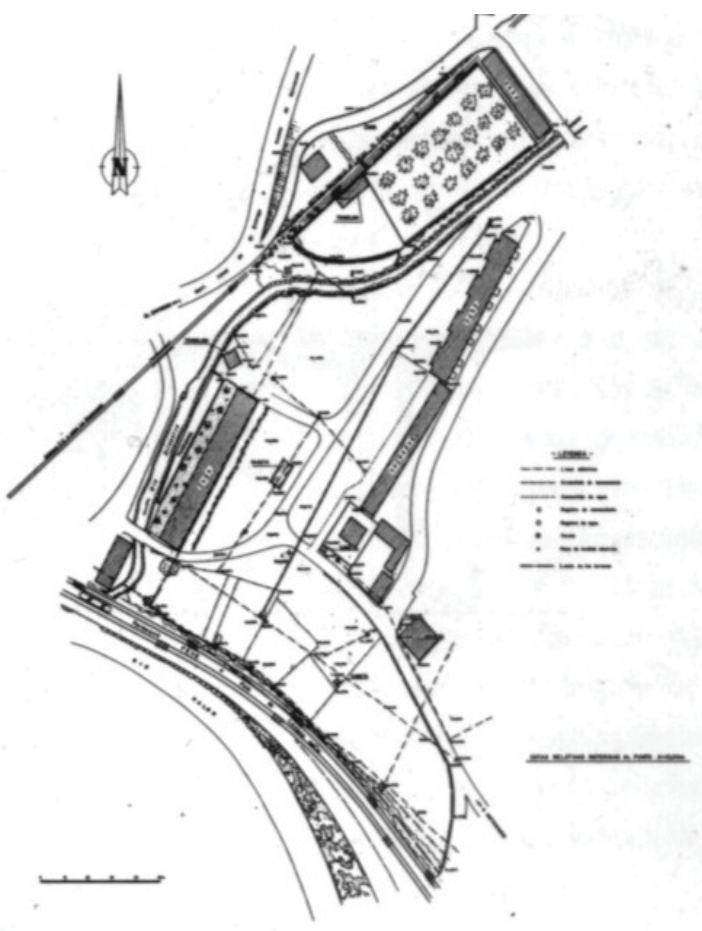

Ref.4.52. Ordenación de concurso
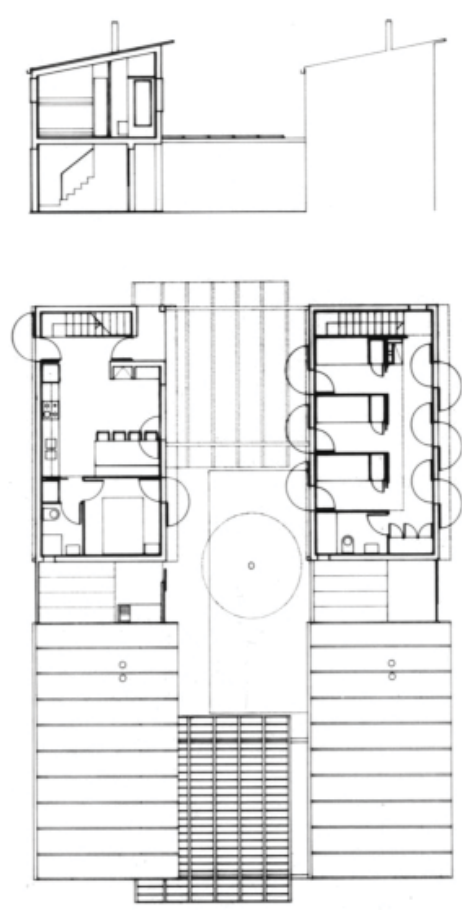

Ref.4.53. Viviendas tipo de concurso 


\section{Fase de concurso}

El solar propuesto para la convocatoria de Europan 1 en Asturias se encuentra en una zona poco consolidada, sin orden ni jerarquías y entra dentro del Plan de Erradicación del chabolismo que lleva a cabo la Comunidad Autónoma del Principado de Asturias, estimándose una primera fase de desarrollo de 30 viviendas.

Los criterios de diseño que se enuncian son: unos $60 \mathrm{~m} 2$ útiles por vivienda y se dan algunas indicaciones generales como la necesidad de la adecuación de los materiales al medio pra evitar un manteniento específico, así como la dotación de sistema de caldeo mediante chimenea-hogar o cocina calefactora. Se afirma también que será aceptada cuanquier solución que satisfaga las necesidades del grupo social al que va destinado.La mayoría de las viviendas que se planteen deben tener tres dormitorios.

El proyecto mencionado bajo el lema NN257 trata de responder al problema social del que se parte: el de la marginación. No tratan de crear viviendas estándar, ni mínimas. Se piensa primero en los usuarios para definir la vivienda: son viviendas para chabolistas.

Como se puede observar en los bocetos de concurso, el barrio proyectado se ordena a partir de una vía principal de la que parten los viales de acceso al barrio. Estos viales están definidos por las propias casas del barrio, por su propio orden y sus leyes, adaptándose al entorno pero sin modificar su forma previa ni su identidad.

Se propone un conjunto de viviendas unifamiliares que se asientan sobre el terreno para que este sector social se sienta en la calle mediante los espacios interiores o patios que se crean entre las viviendas. Llaman la atención los bocetos claros y cuidados que se presentan en el panel de concurso, con los que el Jurado puede tener una idea clara del resultado final.

Las viviendas se conectan a las calles mediante patios abiertos, orientados al sur y son la base, como ya se ha comentado, de ordenación de las calles peatonales, puesto que son la esencia del barrio, un barrio social con mucha vida en la calle.

Las circulaciones de las viviendas se reducen al mínimo, dando mayor amplitud a las zonas de servicios, cocina-estar y tendedero que se situan en la planta de acceso. En la planta superior se encuentran las habitaciones. Existe también un dormitori, el principal, que se encuentra en la planta baja.

Aunque en el proyecto de concurso no se definen los materiales, se trata de viviendas que deben tener un muy bajo coste económico y se intuye la construcción en ladrillo y cubierta de teja cerámica inclinada. 


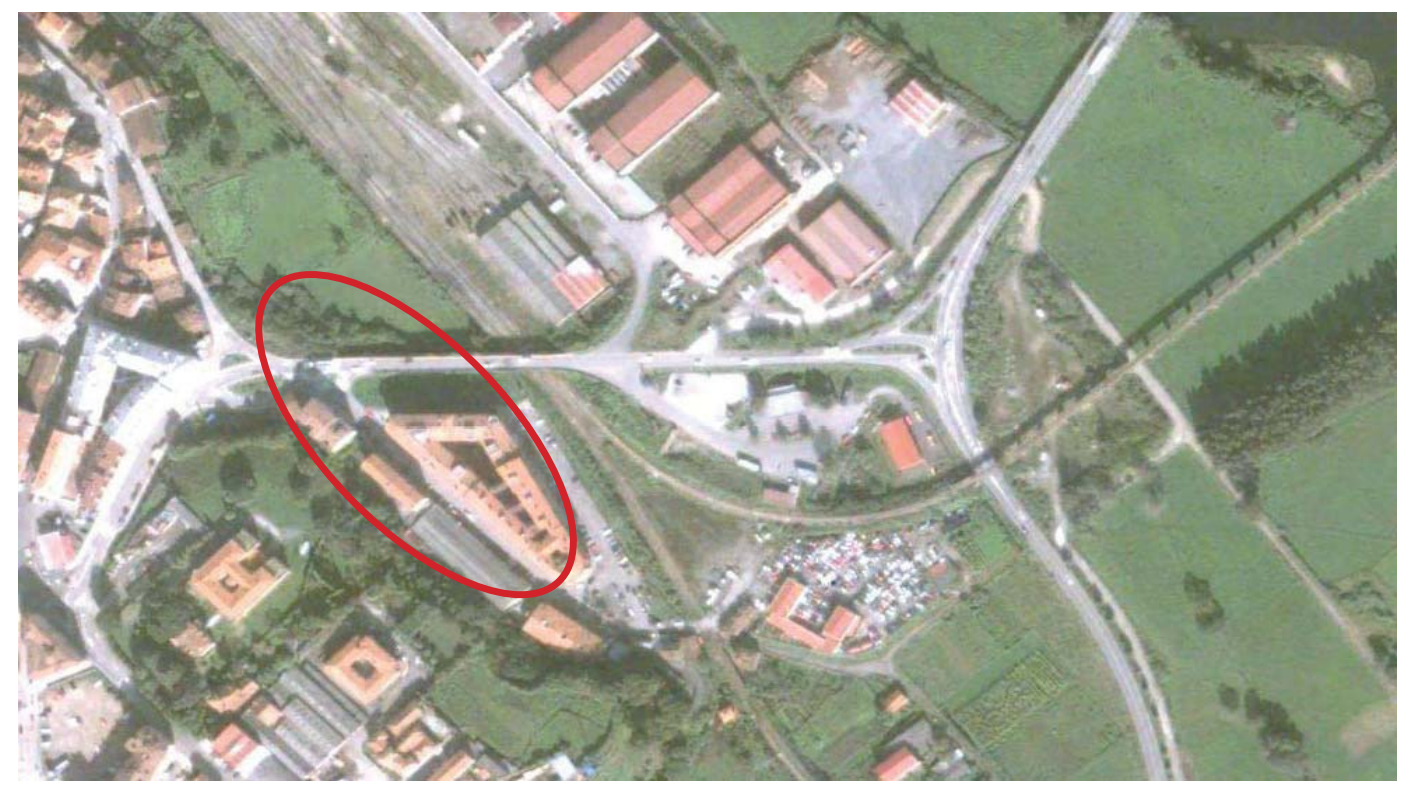

Ref.4.54. Planta de situación
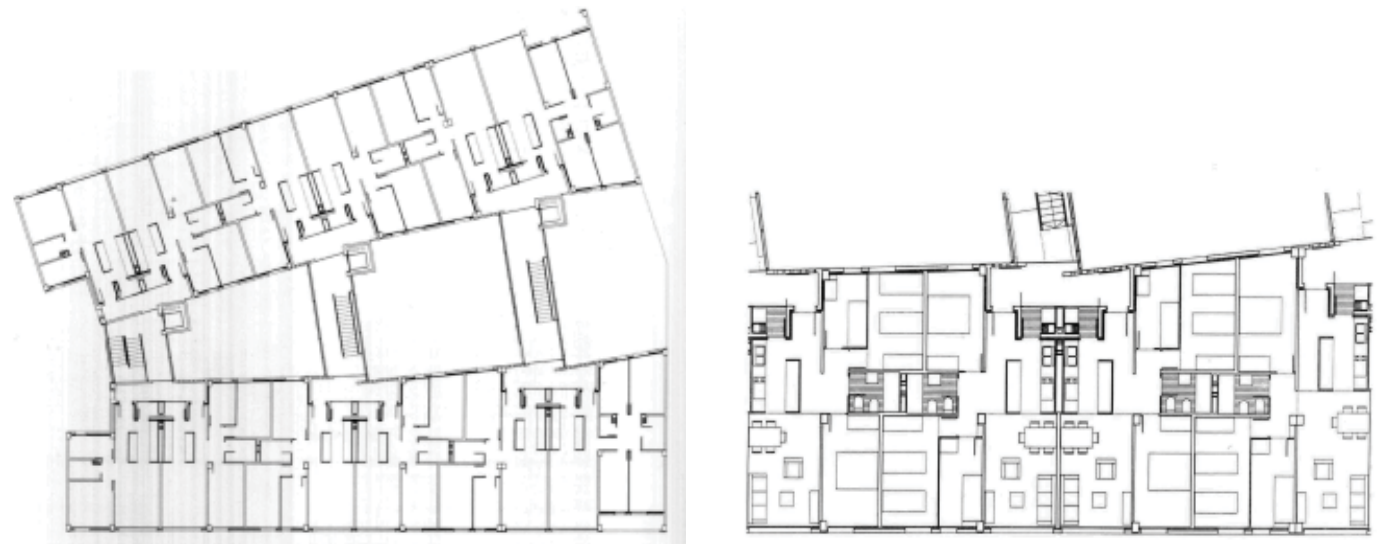

Ref.4.55. Planta conjunto

Ref.4.56. Viviendas construidas

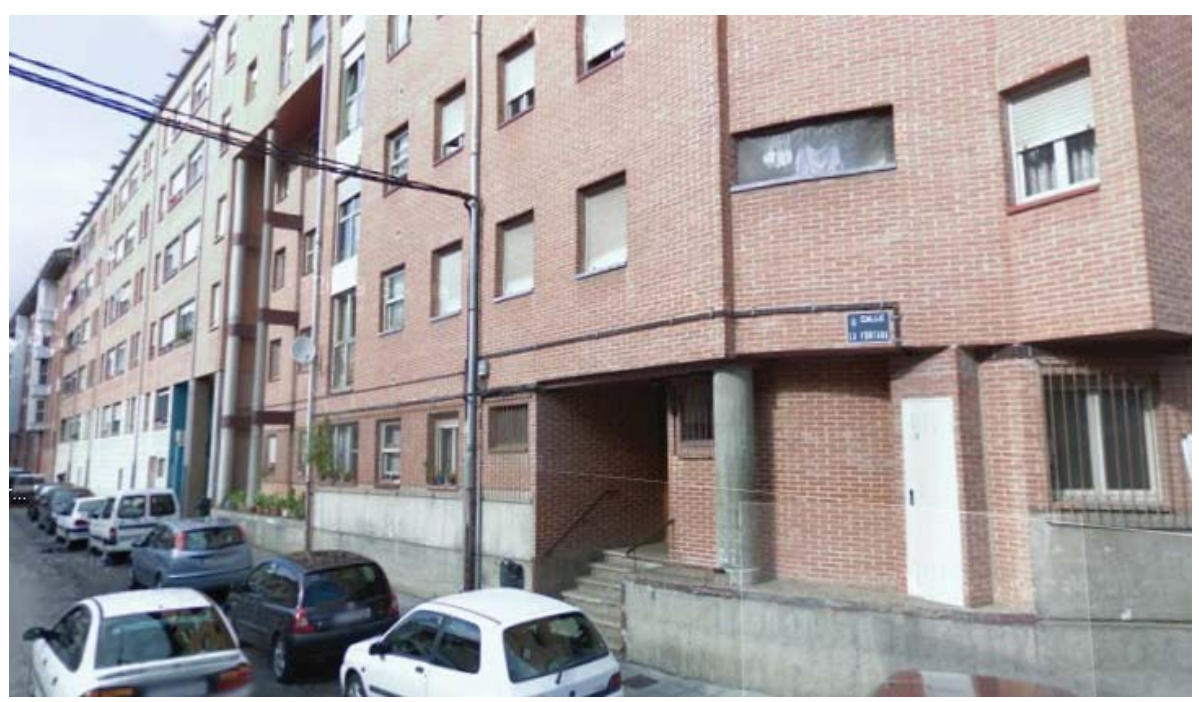

Ref.4.57. Imagen del bloque de viviendas construido 


\section{Fase de realización}

El proyecto presentado no llegó a materializarse.

Las autoras tuvieron la oportunidad de construir otro proyecto, en una población diferente, también en Asturias, Pravia, que se sitúa en una parcela triangular, destinada a la construcción intensiva de viviendas sociales.

La edificación se distribuye en dos bloques con patio central: uno de cinco plantas-orientado al Oeste - y otro de seis plantas - orientado al Este -. La planta semisótano está destinada a trastero.

Las viviendas, al igual que en el planteamiento del concurso, están destinadas a acoger a una población desfavorecida. Los bloques se conectan a las calles mediante patios abiertos; orientados a sur y base de ordenación de las calles peatonales.

Existen tres núcleos de comunicación y cada uno da acceso a una o dos viviendas. La entrada se realiza por un espacio semi-exterior conectado con pasarelas que conducen al acceso de las viviendas.

Las viviendas, de unos $100 \mathrm{~m}^{2}$, son en su mayoría de tres dormitorios, y al igual que el proyecto premiado, presenta poca variedad de tipos, pues juega con el mismo en todo momento. Las circulaciones interiores de las viviendas se reducen al mínimo, dando mayor amplitud a las zonas de estar, como se planteaba conceptualmente en el concurso.

A continuación se adjunta una ficha-resumen. 


\section{VIVIENDA}

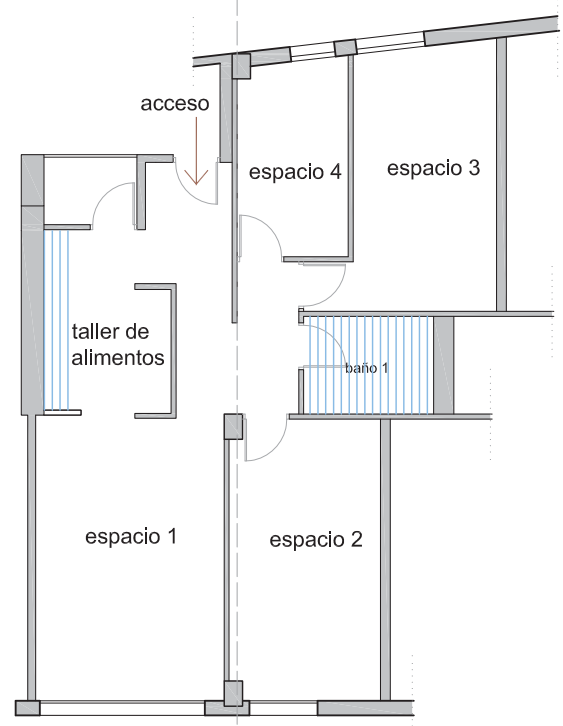

\begin{tabular}{|l|l|}
\multicolumn{1}{l}{} & s.util aprox \\
\hline taller de alimentos & $11,5 \mathrm{~m} 2$ \\
\hline baño 1 & $5,3 \mathrm{~m} 2$ \\
\hline circulaciones 13\% & $11,6 \mathrm{~m} 2$ \\
\hline espacio 1 & $21 \mathrm{~m} 2$ \\
\hline espacio 2 & $16,6 \mathrm{~m} 2$ \\
\hline espacio 3 & $15,7 \mathrm{~m} 2$ \\
\hline espacio 4 & $8 \mathrm{~m} 2$ \\
\hline TOTAL & $89,7 \mathrm{~m} 2$ \\
\hline & $\mathbf{e : 1 / 2 0 0}$
\end{tabular}

\section{SISTEMAS DE AGRUPACIÓN}

superficie construida total por planta:

453,88

roperficie construida zonas comunes por planta: $25,82 \mathrm{~m} 2$ (6\%)

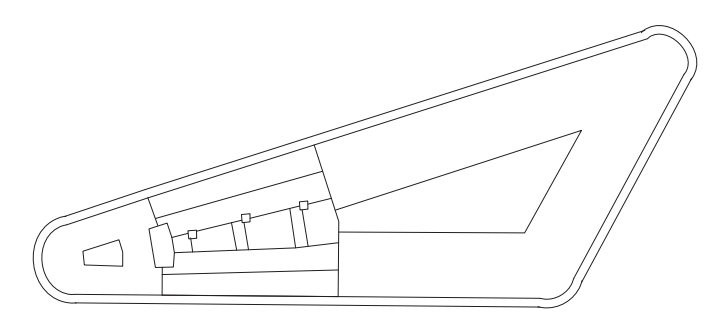

e: 3000

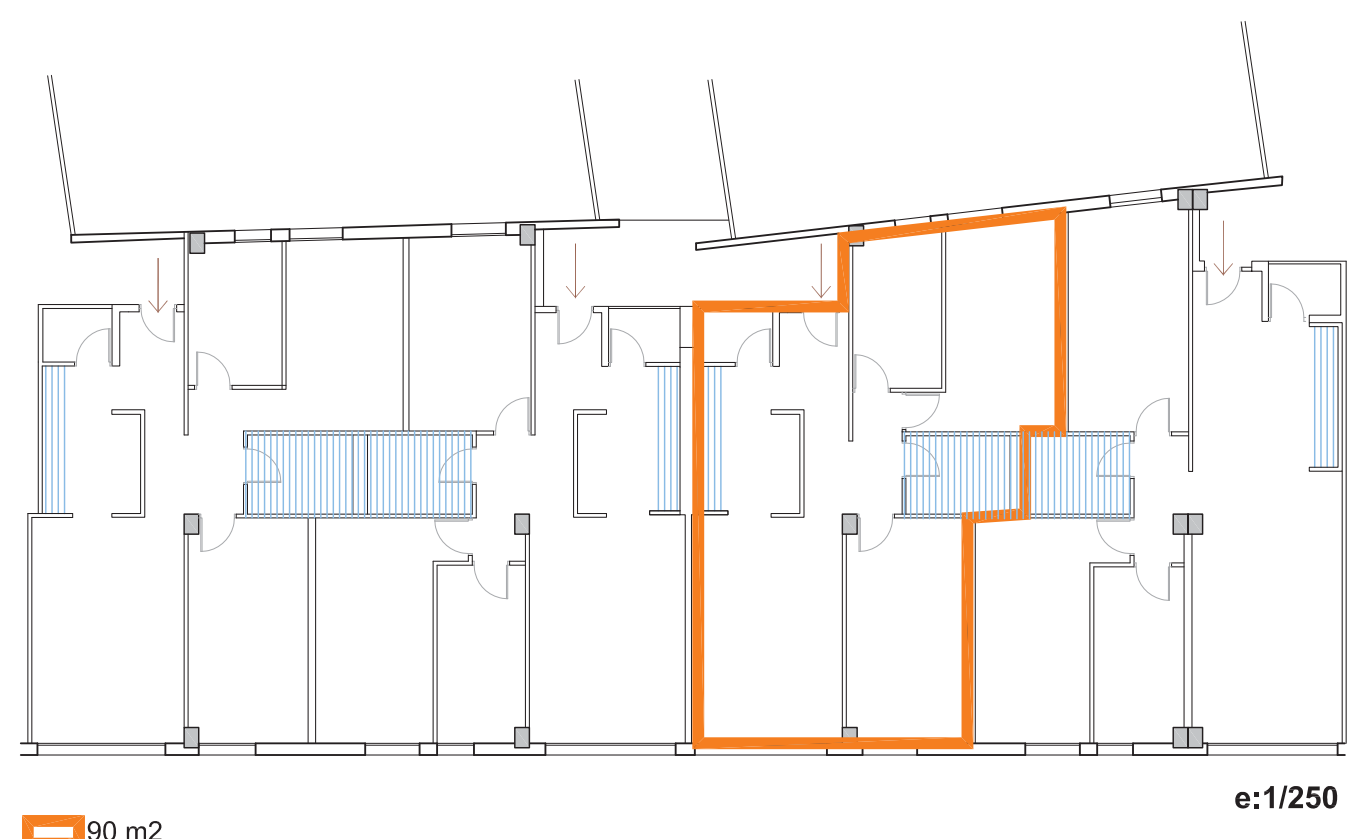



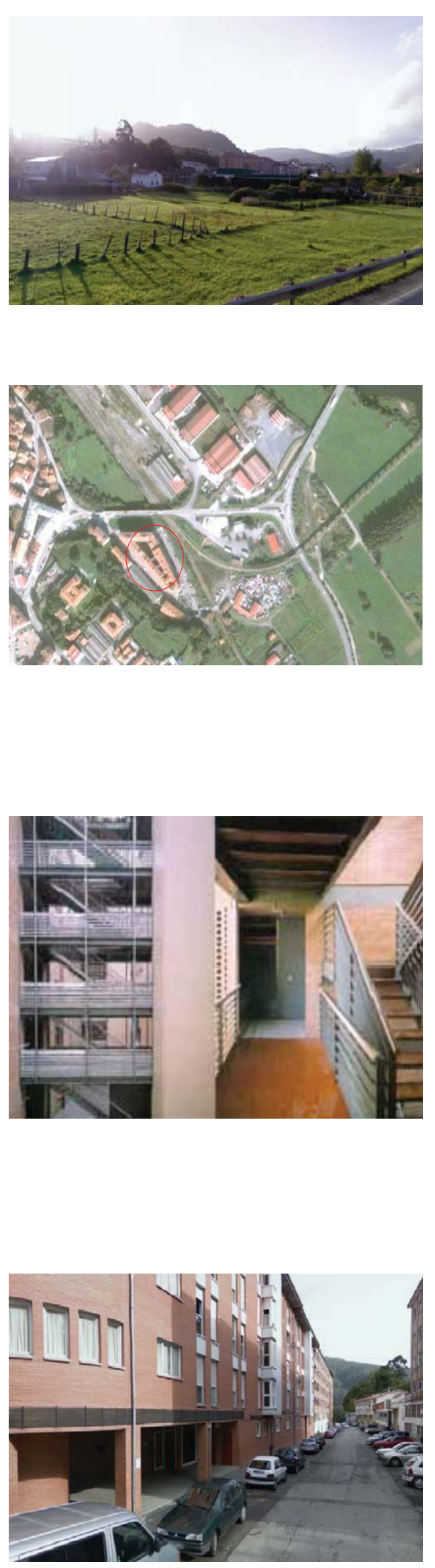

FICHA 1.6

\section{EUROPAN 1}

(año 1988)

\section{ISABEL BENNASAR Y ANA Ma NOGUERA 64 VIVIENDAS EN PRAVIA (ASTURIAS)}

EMPLAZAMIENTO

c/la Fontana, Pravia (Asturias)

COMIENZO DE OBRAS- FINALIZACIÓN DE LAS OBRAS Fin: 1995

¿ES EL PROYECTO DE CONCURSO?

No. Inicialmente el solar es El Entrego, posteriormente se modifica por otro situado en Pravia.

$N^{\circ}$ DE VIVIENDAS TOTALES CONSTRUIDAS

64 viviendas

N DE VIVIENDAS POR SUPERFICIE

III 64 viviendas

\section{USO DE LA PLANTA BAJA}

Viviendas y trasteros (semisotano)

\section{USO DEL SOTANO}

Garaje

\footnotetext{
REFERENCIAS BIBLIOGRÁFICAS

www.isabelbennasar.com

- Arquitectos nº 133, Ideas y prácticas, Madrid, 1994, p.128

- 10 años EUROPAN 5 España, Edición coproducida por EUROPAN/España, SEPES y el Ministerio de Fomento, 1999, España,p. 147.

- EUROPAN 10 España, "Proyectar la urbanidad", Madrid, 2010, p. 213
} 



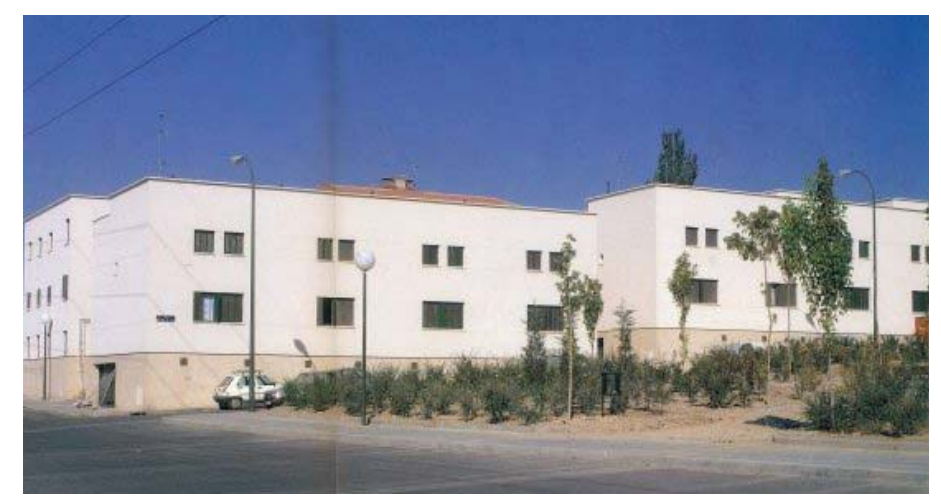

\subsubsection{Edificios de viviendas Europan 1 (1988)}

Susana Aparici, Inma Nuñez y Fernando Moliner: viviendas unifamiliares adosadas en Vallecas (Madrid) 
VIVIENDAS EUROPAN (1988-2008) | Una aproximación a los modos de vida en el cambio de siglo en España

4. EUROPAN: DEL CONCURSO A LA REALIZACIÓN

\section{1. $287=$}

44
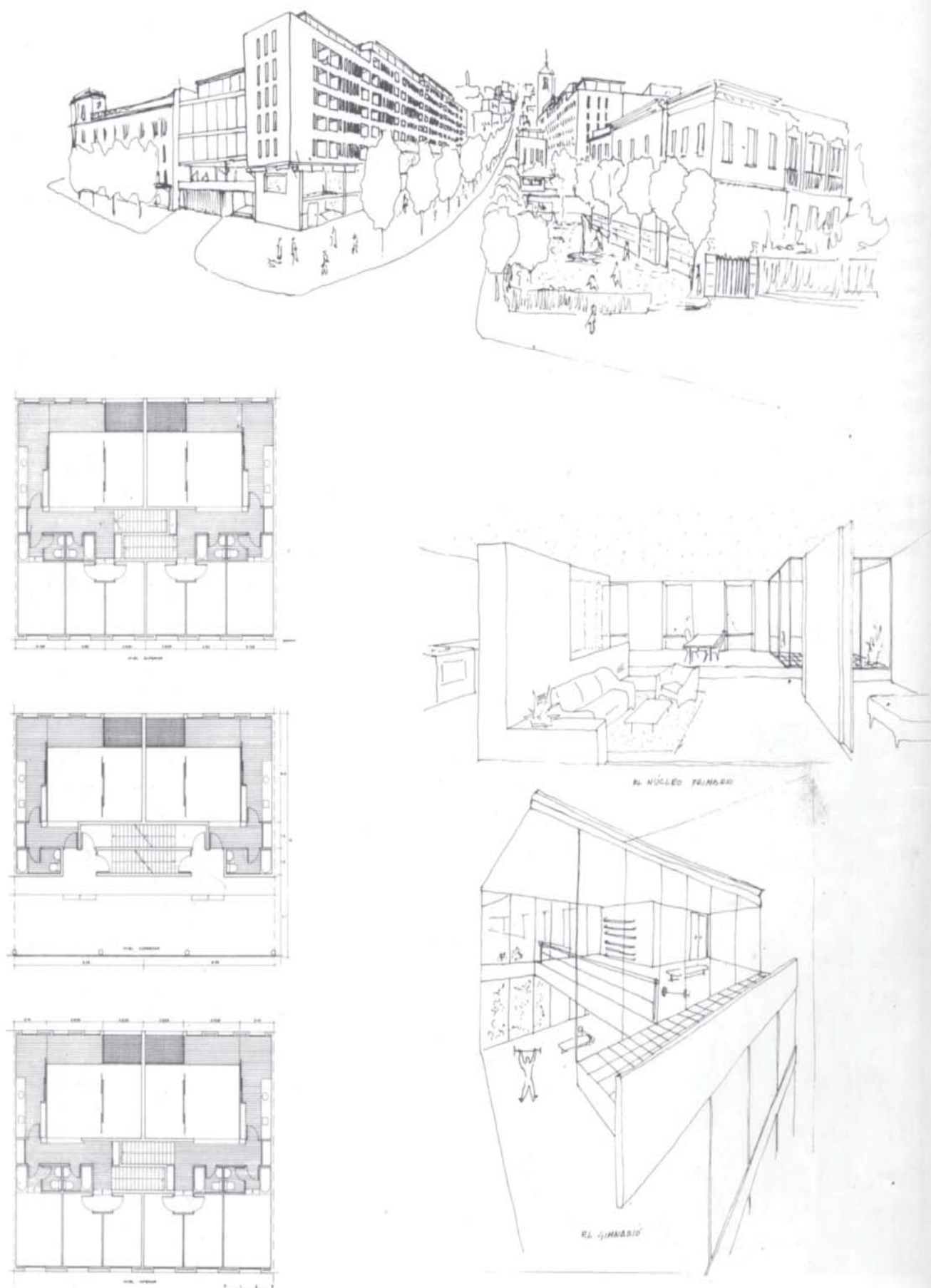

Ref. 4.58. Paneles de concurso 

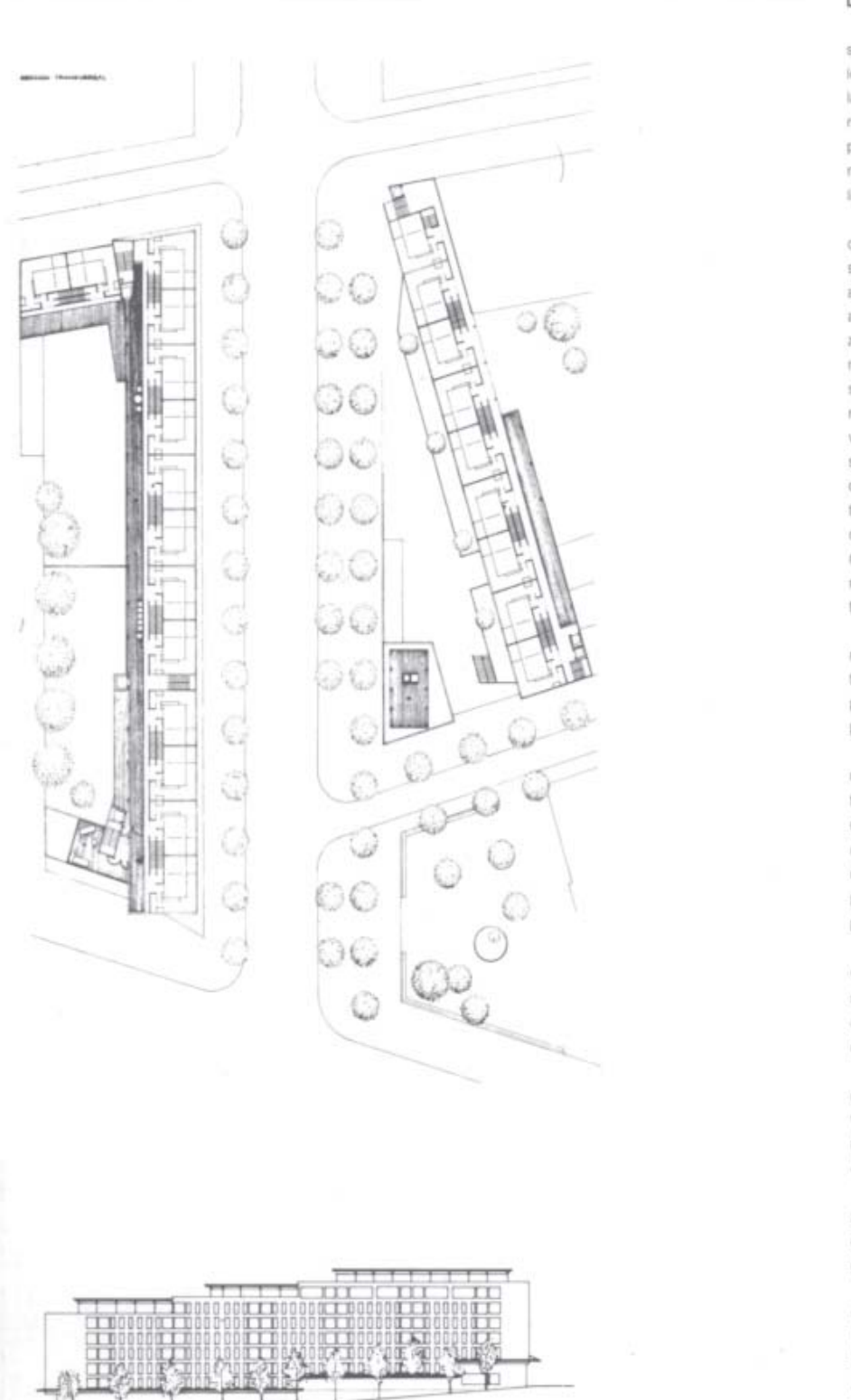

Los nuevos modos de vida

Hoy en dia las peraonas estanos semetidas a constantes caminos tanto a b iarpo de nuestras vidas como a io argo del dia. Si buscamos una caracte stica comùn a todas las personas que Jensamos en nuestro modo de vida, o al nenos una aspiración comin exs ia de la bertiad de poder elegirio

La vivanda en la ciudad, no tiene per zué estar predetorminaca. Habrá per. sonas a las que les gustern los espacios amplios casi sin tabiques ni muebies, $y$ allas que les gusten separadas por pie: ras a ia manera tradicionat, zy por que to ia viviende de dos piantas con el saión y la cocina atajo y los dormilorios armba? o at revés, incluato tia vivienda de tress pisos con buhardilla y sótano (como diris Bacheided). Habred guien yiva tole o en paraia, y quien tenga muchos hipos, quien trabaje en casa y quien la quiera solio paria dorImir y podriamos seguir asi enume: rando intinidad de modos de vida cast tantoa comio de personas

Sin ambarna exiaten una serie de hecesidades fisioiogicas comunes a lodos ellos, que hay que tener en cuenta. pero solucionadas éstas, ¿Dor quet no poder elegir al restio?

Nuestra propusta es un eieciciotice

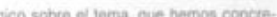
tado en el caso particular del solar objeto. del concurso, adaptindolo a sus cond: ciones especiales, por lo tanto hemos epresentado sobio aigura de las muchas poepibilidados gue se podrian dar.

\section{La viviende}

Existe un núcleo primatio o unidad de vivienda en el que hemos intentado eanolet todan bas nacesidades no solic de supertices gine tambien de calidad de espacios

Este nucleo consta de cocina-comedor, sala. dormitoria, cuarto de baho y terraza Las piezas principales se disponen en la tachada y el acceso se realiza desde el corredor.

Este corredor-estar acaba en unas tonas de servicios comuner, que en esile caso concreto hemos resuelto como gimnasio y guarderia.

En ips nimeies superior e intenor ofes corredor, ef resto de las piaras que completan el núcleo primario se colocian bajo y sobre dil de manera que las wiviendas so abren a tachadas opuentas parmitendo la ventilación transversal.

Ref. 4.59. Paneles de concurso 


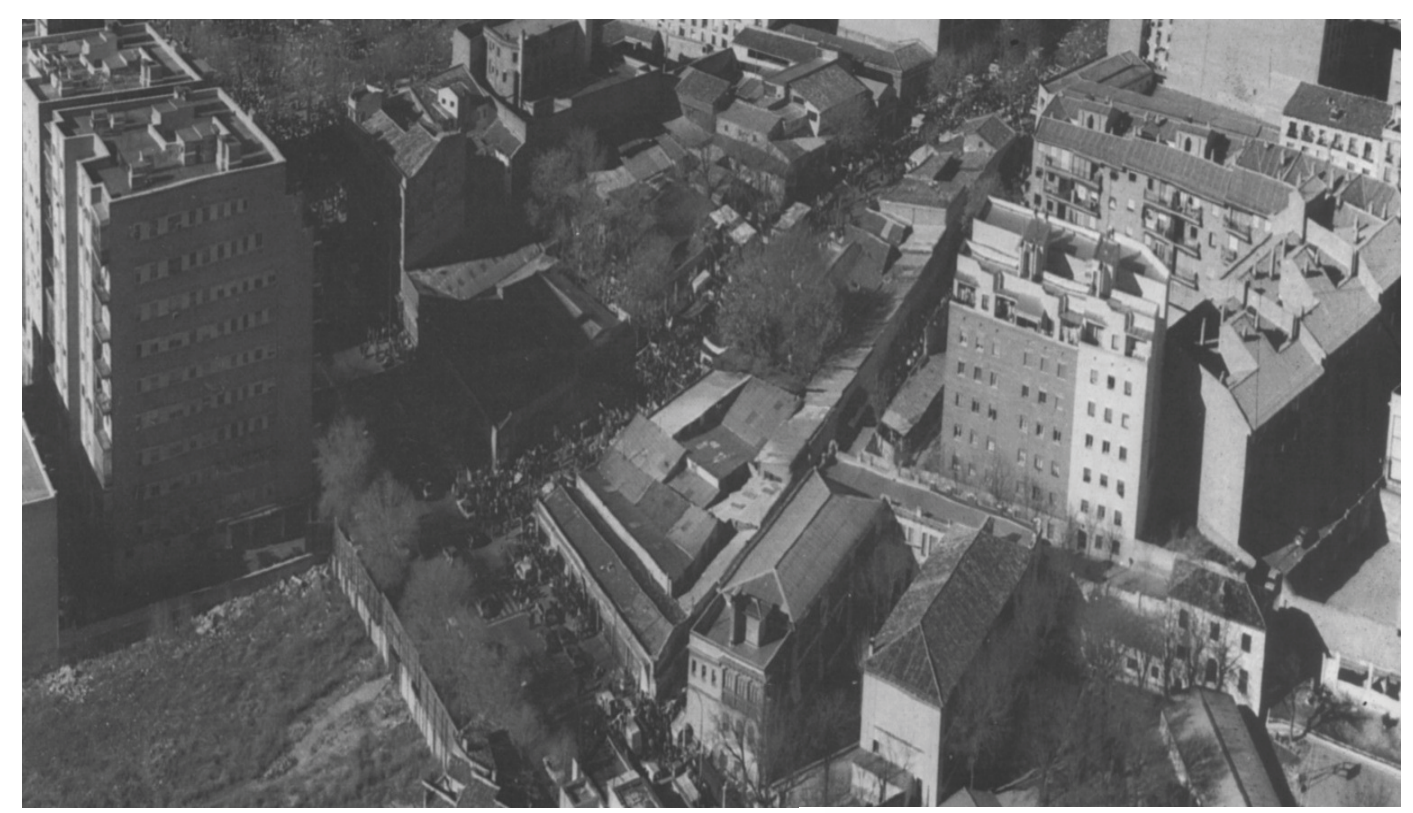

4.60. Solar de concurso
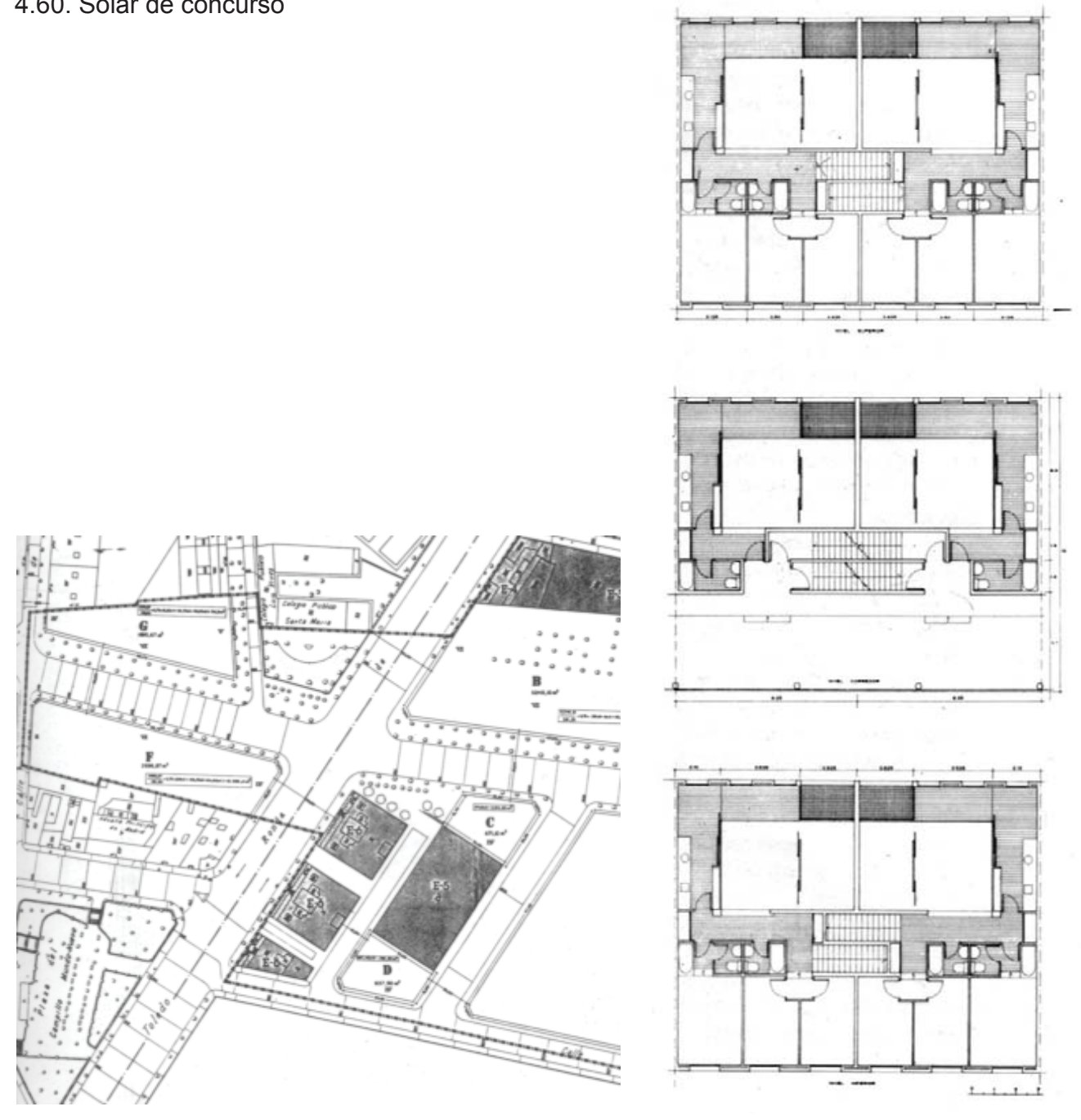

4.61. Planeamiento

4.62. Plantas 


\section{Fase de concurso}

El solar de concurso de Europan 1 se propuso en el Barrio de Ribera de Curtidores, en Madrid para la construcción de 150 viviendas. La ordenación del Plan General de Ordenación Urbana de la zona propone, entre otras cuestiones, la sustitución de almacenes de chatarra y objetos de derribo por otros nuevos, de carácter residencial y comercial, en las dos parcelas que se proponen. Se trataba de un núclo urbano consolidado, compuesto por manzanas cerradas.

Las condiciones que presentan en el enunciado del programa son: un máximo de $90 \mathrm{~m} 2$ por vivienda de cuatro dormitorios, $75 \mathrm{~m} 2$ para tres dormitorios $60 \mathrm{~m} 2$ para dos dormitorios y $45 \mathrm{~m} 2$ para las de un dormitorio. La planta baja se destinará para uso público (con soportales de $3 \mathrm{~m}$ de ancho), planta sótano para uso de garaje y las limitaciones de la ordenación en lo referente a la línea de cornisa y el fondo máximo edificable.

En el texto presentado a concurso porel equipo premiado, se plantean los diversos modos de vida: "habrá personas a las que le gusten los espacios amplios, sin tabiques ni muebles, y a las que le gusten separadas por piezas, a la manera tradicional, ¿y por qué no la vivienda de dos plantas con el salón y la cocina abajo y los dormitorios arriba? O al revés: incluso la vivienda de tres pisos con buhardilla y sótano... Habrá quien viva solo o en pareja, y quien tenga muchos hijos, quien trabaje en casa y quien la quiera sólo para dormir...y podríamos seguir así enumerando infinidad de modos de vida casi tantos como de personas".

La vivienda se plantea con agrupación por corredor, que hace también de estar o espacio común de relación y que está colmatado en sus extremos por espacios comunes (como gimnasio y guardería en el corredor) que además de ser un complemento para las viviendas favorecen la relación social entre los vecinos.

La unidad habitacional pretende resolver las necesidades básicas y comunes a los diferentes usuarios dotando de calidad a los espacios. Los autores hablan de un núclo primario o unidad de vivienda que consta de cocina-comedor, sala dormitorio, cuarto de baño y terraza. Las piezas principales se disponen en fachada y el acceso se realiza desde el corredor.

Las viviendas de los niveles superior e inferior del corredor, el resto de las piezas que completan el núcleo primario se colocan debajo y sobre él de manera que las viviendas se abren a fachadas opuestas y permitiendo la ventilación transversal.

\section{Fase de realización}

El proyecto mencionado en Europan 1 no se pudo realizar en el solar previsto. Más adelante al equipo se le ofreció un solar situado en Vallecas - muy próximo al de Mercedes Peláez que se ha analizadon anteriormente- con la necesidad de 


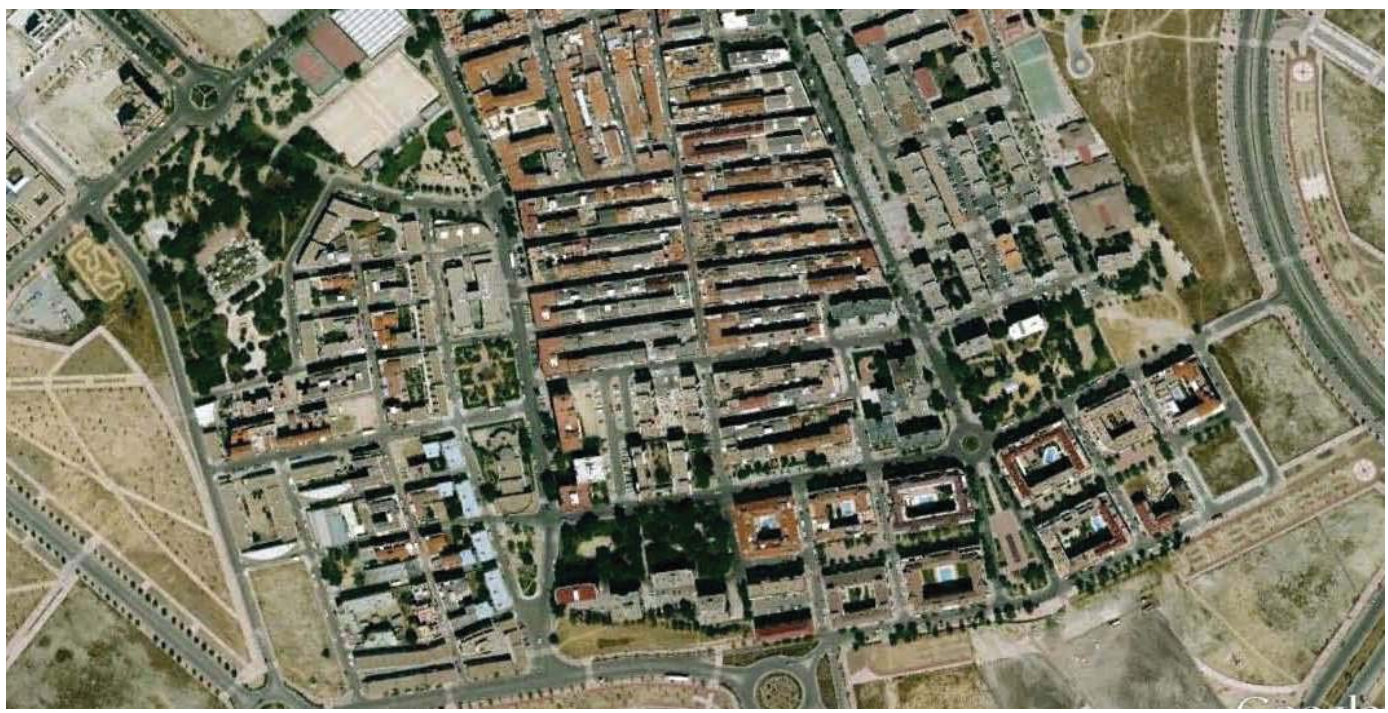

Ref.4.63. Planta general

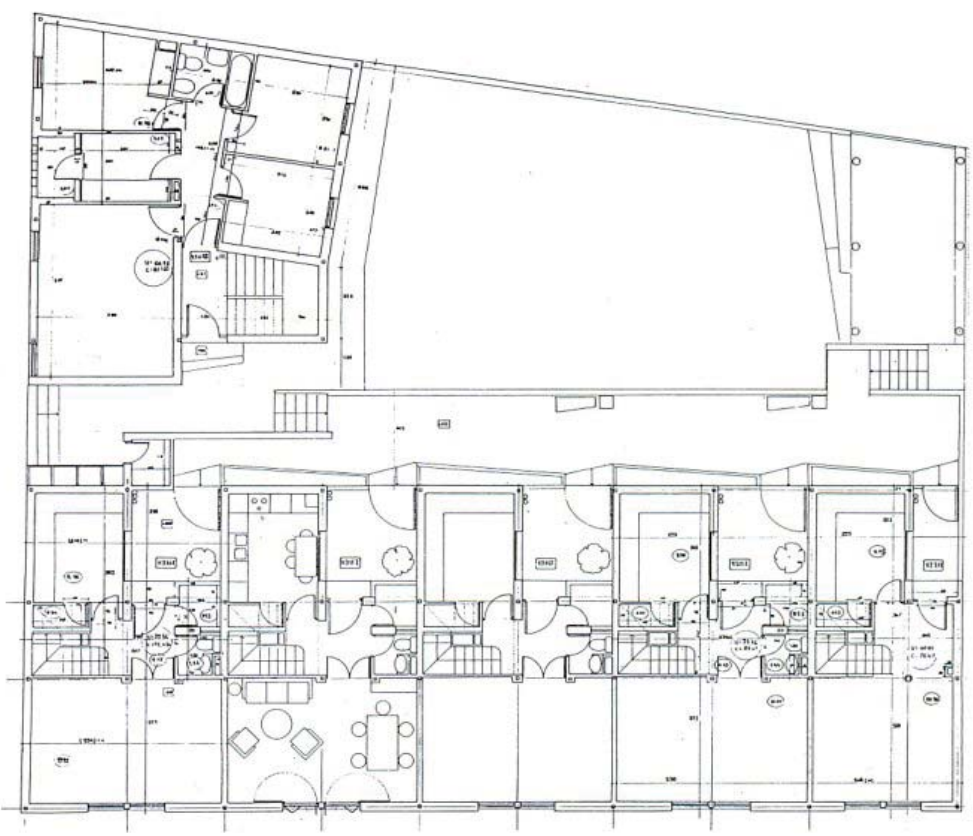

Ref.4.64.Planta general

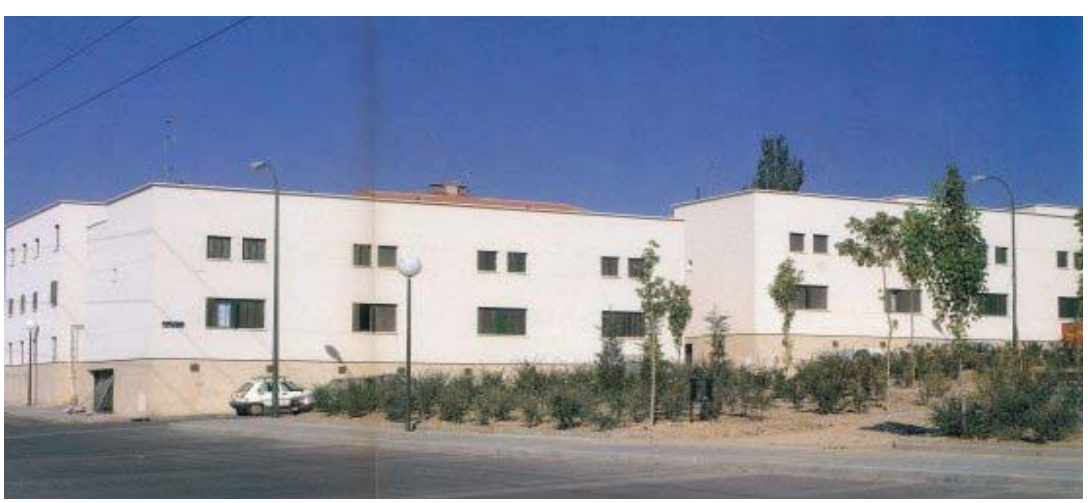

Ref.4.65. Alzado desde el parque 
adaptarse a rígidas normas urbanísticas, a la legislación sobre viviendas sociales del año 1991 y a limitaciones económicas severas.

Se ocupa el perímetro de la parcela para mantener el patio interior, obligando a cerrar el espacio interior. Se mantienen los espacios semi-exteriores del proyecto premiado, el corredor interior donde se desarrollan las relaciones de vecindad y las pasarelas horizontales de acceso.

El proyecto se desarrolla en tipología de manzana cerrada. Tres pequeñas parcelas que se adosan a viviendas ya existentes de baja calidad con la previsión de que algún día estas desaparezcan y se pueda completar la manzana.

En los frentes más largos de cada manzana, que vuelcan a una calle -en su año de nueva creación- y de un parque, se disponen cuatro bloques de viviendas unifamiliares adosadas. Éstas tienen dos plantas y se aprovecha el desnivel existente para crear unos semisótanos destinados a garajes. Los frentes más cortos de las manzanas se ocupan con pequeños bloques de viviendas colectivas de tres alturas en medianera, que cierran los servicios de uso privado. Las viviendas adosadas unifamiliares tienen una disposición en $\mathrm{L}$, que dan a un patio de acceso de cada vivienda.

La principal idea del proyecto ha sido la de dar un carácter más artesano y continuo al exterior de las manzanas con la creación, por un lado, de un zócalo de piedra que oculta los garajes $y$, por otro lado, un ritmo de ventanas ordenado y repetitivo.

En el interior tienen un espacio más libre con un mayor juego de volúmenes y con la creación de unos amplios paseos peatonales de acceso a las viviendas donde se han cuidado los detalles de la pavimentación, iluminación, jardinería, etc. De modo que estas zonas comunes son una extensión más de las viviendas.

La distribución interior de cada vivienda es muy sencilla: se divide siempre en cuatro módulos por planta.

Los accesos a las viviendas conducen a la zona de día, con estar y la cocina, que a su vez están separadas por la escalera. La planta superior se divide también en cuatro espacios: tres habitaciones con ventilación directa y una terraza. El baño queda en el espacio interior enfrentado a la escalera.

En cuanto a la materialidad, los acabados son económicos: enfoscado blanco para la fachada exterior y zócalo de piedra que le dota de una mayor calidad. Las líneas sencillas del proyecto hacen que la imagen exterior cause una buena impresión de las viviendas sociales a los viandantes.

A continuación se adjunta una ficha-resumen. 


\section{VIVIENDA}
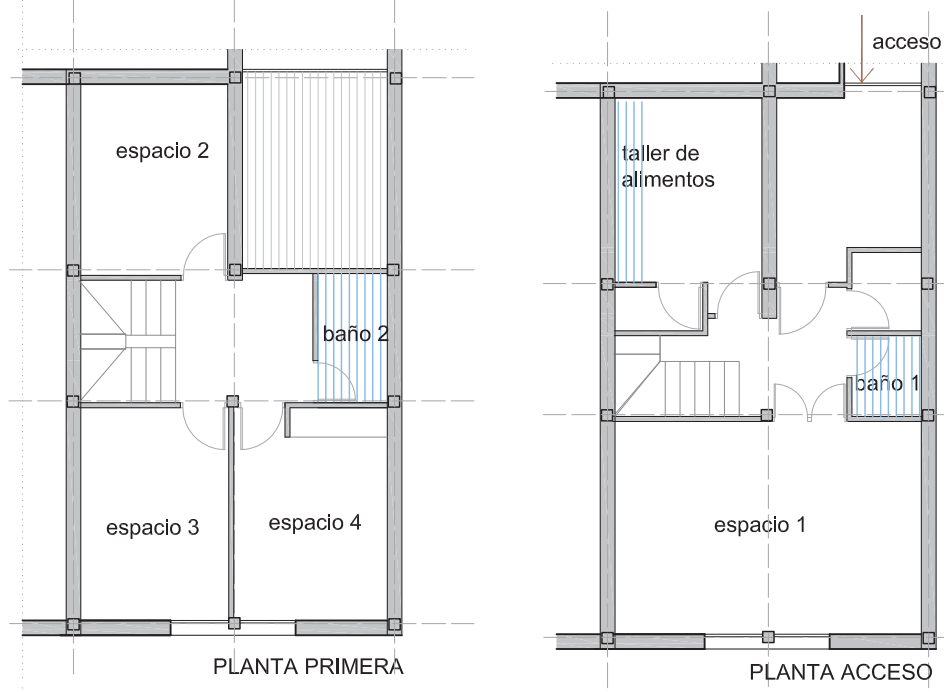

\begin{tabular}{|l|l|}
\hline \multicolumn{1}{l}{} & \multicolumn{1}{l}{ s.util aprox } \\
taller de alimentos & $14,2 \mathrm{~m} 2$ \\
\hline baño 1 & $3,4 \mathrm{~m} 2$ \\
\hline baño 2 & $3,68 \mathrm{~m} 2$ \\
\hline circulaciones 20\% & $21,5 \mathrm{~m} 2$ \\
\hline espacio 1 & $26,9 \mathrm{~m} 2$ \\
\hline espacio 2 & $11,58 \mathrm{~m} 2$ \\
\hline espacio 3 & $13 \mathrm{~m} 2$ \\
\hline espacio 4 & $13,26 \mathrm{~m} 2$ \\
\hline TOTAL & $107,52 \mathrm{~m} 2$ \\
\hline
\end{tabular}

\section{SISTEMAS DE AGRUPACIÓN}

superficie construida total por planta:

$570 \mathrm{~m} 2$

superficie construida zonas comunes por planta: 108 m2 (19\%)

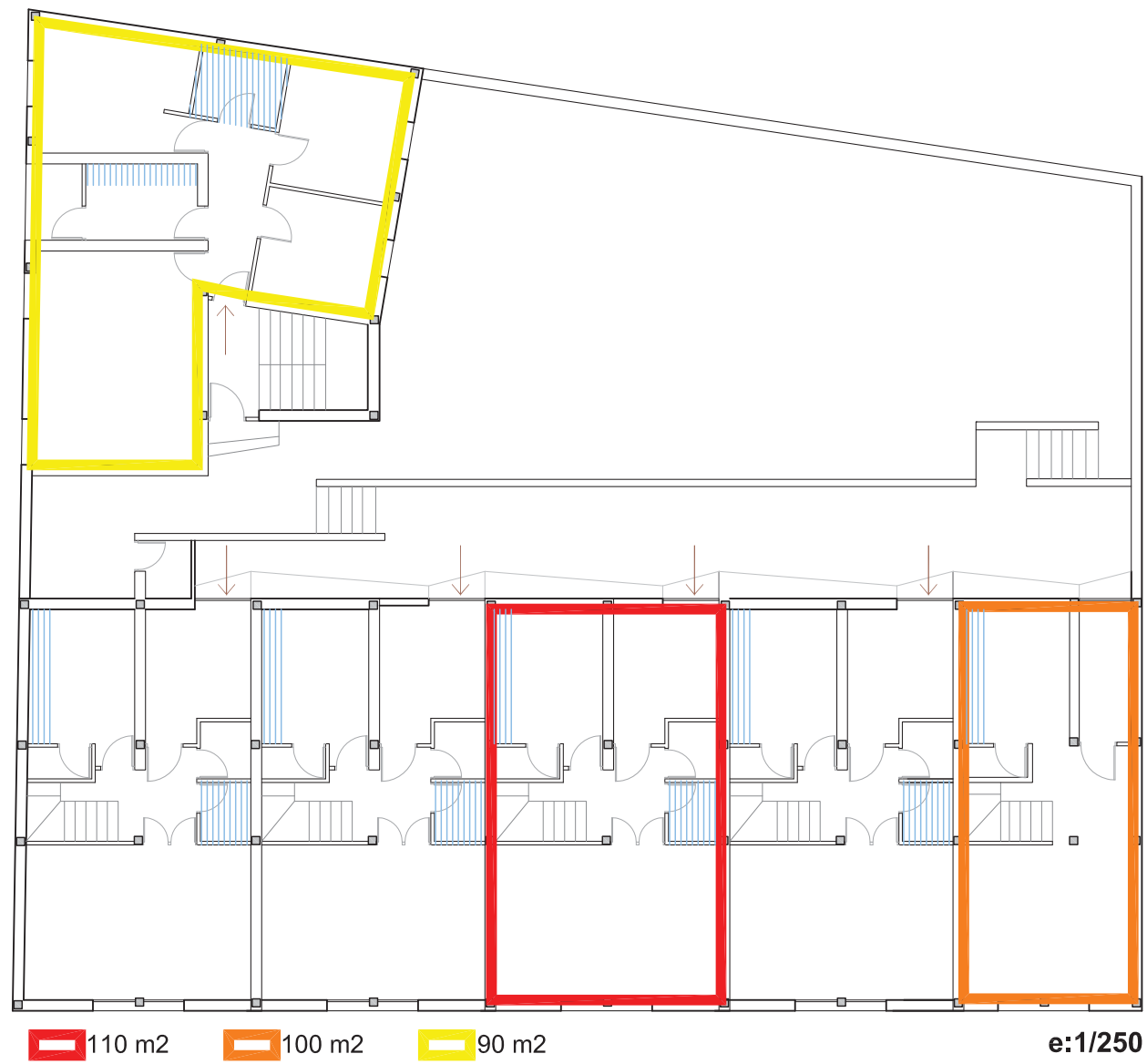




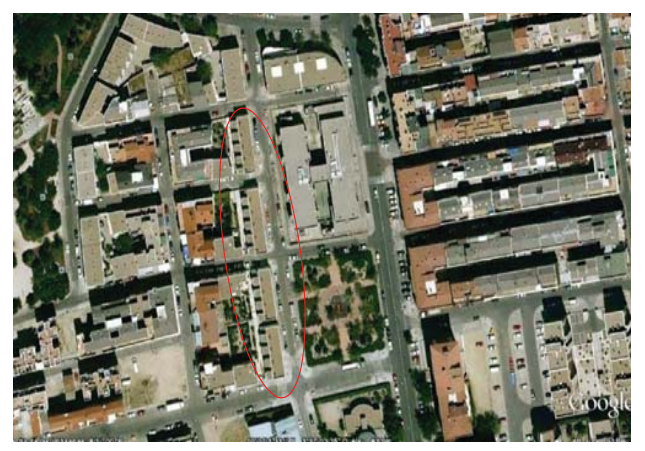

FICHA 1.7

\section{EUROPAN 1}

(año 1988)

SUSANA APARICI, INMA NUÑEZ Y FERNANDO MOLINER 30 VIVIENDAS EN VALLECAS (MADRID)

EMPLAZAMIENTO

c/Malpica de Tajo,Villa de Vallecas (Madrid)

COMIENZO DE OBRAS- FINALIZACIÓN DE LAS OBRAS

Fin: 1995

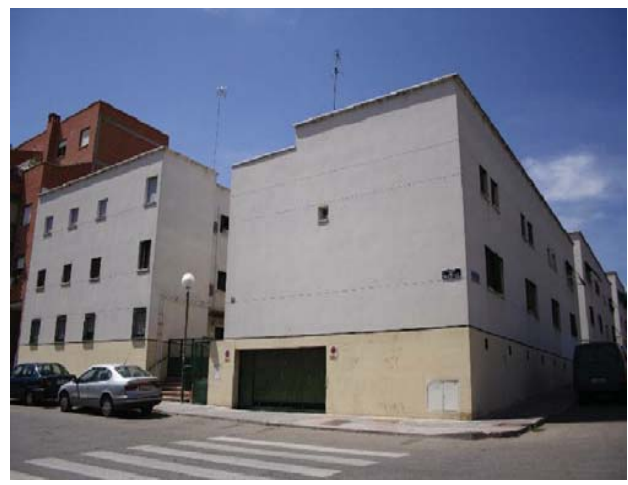

¿ES EL PROYECTO DE CONCURSO?

No. Se ocupa el perímetro de la parcela para mantener el patio interior, obligando a cerrar el patio. Se mantienen los espacios semiexteriores del proyecto premiado, el corredor interior $y$ las pasarelas horizontales de acceso

$\mathrm{N}^{\circ}$ DE VIVIENDAS TOTALES CONSTRUIDAS

30 viviendas

No DE VIVIENDAS POR SUPERFICIE

VII 20 viviendas

VIII 5 viviendas

5 viviendas

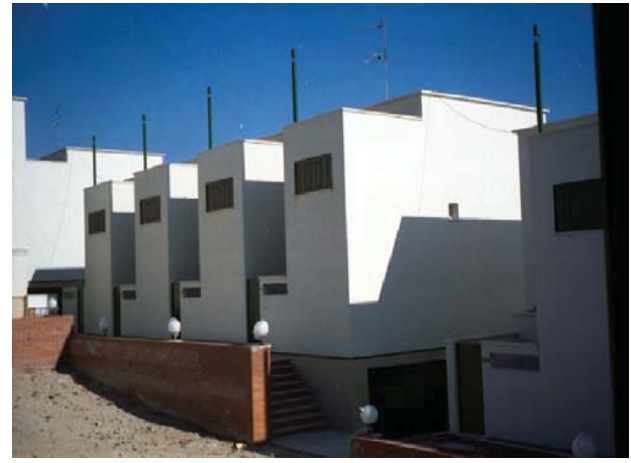

USO DE LA PLANTA BAJA

Viviendas

USO DEL SOTANO

Se emplea para trasteros y garajes

REFERENCIAS BIBLIOGRÁFICAS

- Arquitectos n 133, Ideas y prácticas, Madrid, 1994, p.125

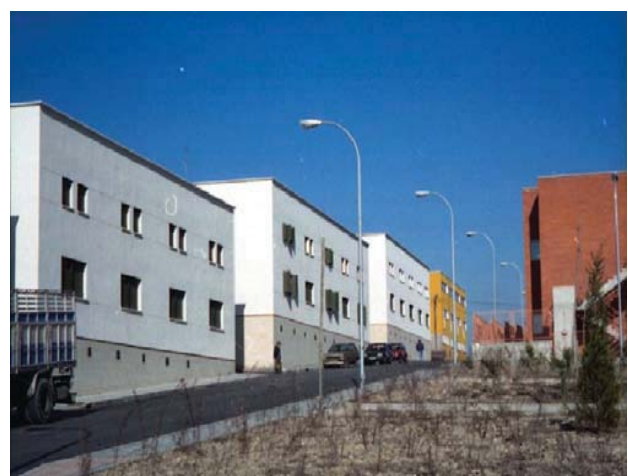

- 10 años EUROPAN 5 España, Edición coproducida por EUROPAN/España, SEPES y el Ministerio de Fomento, 1999, España,p. 144.

- EUROPAN 10 España, "Proyectar la urbanidad", Madrid, 2010, p. 212 



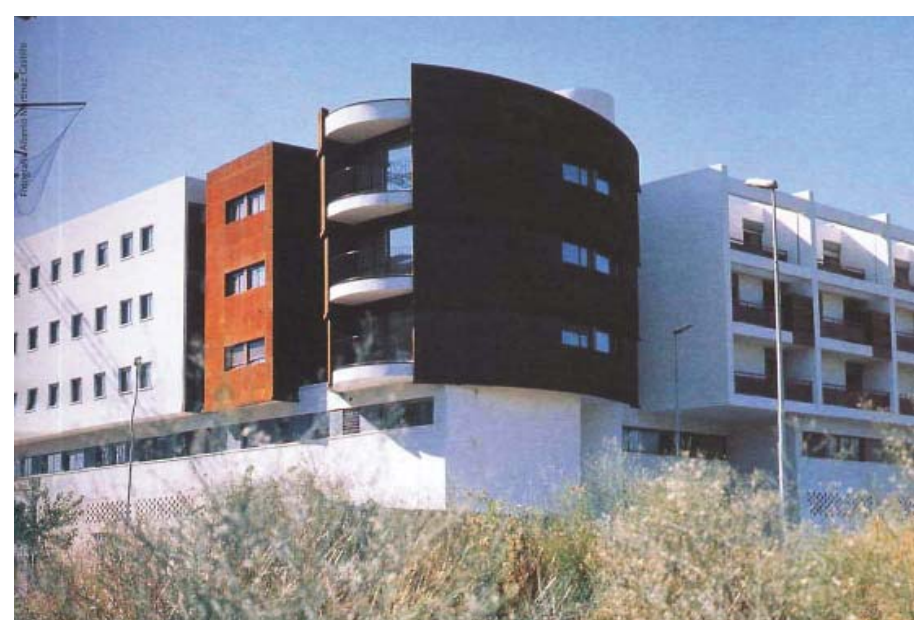

4.1.2. Edificios de viviendas Europan 2 (1990) Matos \& Castillo: manzanas de viviendas sociales en Basauri (Bilbao) 


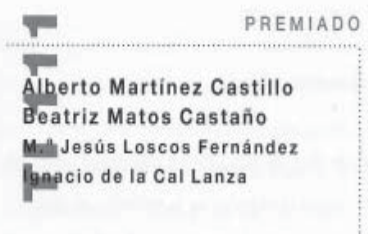

L.evar a cabo una reflexión sobre las relaciones entre las formas del espacio colectivo y la tipología del espacio construido está en la génesis del proyecto. La idea de organización de los espacios públicos y el parque en una serie de franjas, lineas de comunicación que estructuren la urdimbre sobre la que poder escribir diversas tramas se continúa en el interior de la manzana. De esta manera, diversas formas tipológicas se pueden llevar a cabo dentro de esta estructura general o urdimbre. Huir de la indiferenciación que produce tanto a nivel de imagen como de uso la creación de un único tipo de vivienda para la totalidad de la manzana, nos lleva a crear edificios dentro del edificio.

Las esquinas son puntos de discontinuidad, irregularidad en cualquier ordenación de manzana. La distribución de la vivienda al llegar a la misma siempre varía respecto de la unidad tipo que se viene repitiendo. El proyecto afronta esta situación variando no sólo distributiva sino tipológicamente las esquinas respecto de sus cuerpos contiguos. En cuanto a la imagen de las mismas al exterior, se intenta potenciar o crear situaciones paradójicas, aumentando o silenciando la expresión de las mismas.

Los materiales a emplear en el desarrollo del proyecto han sido muy importantes en la concepción del mismo. El diálogo que se debe establecer en lo social, en las diversas tipologias, en la manera de manifestarse al exterior, la imagen del edificio global, ha de establecerse también en los materiales. Diálogo o contraste entre materiales ligeros, modernos, tecnología actual frente a tradición. Las pequeñas torres de las esquinas contrastando no sólo por su forma sino por el brillo metálico que la incidencia del sol producirá en su superficie.

Ref. 4.66. Paneles de concurso 

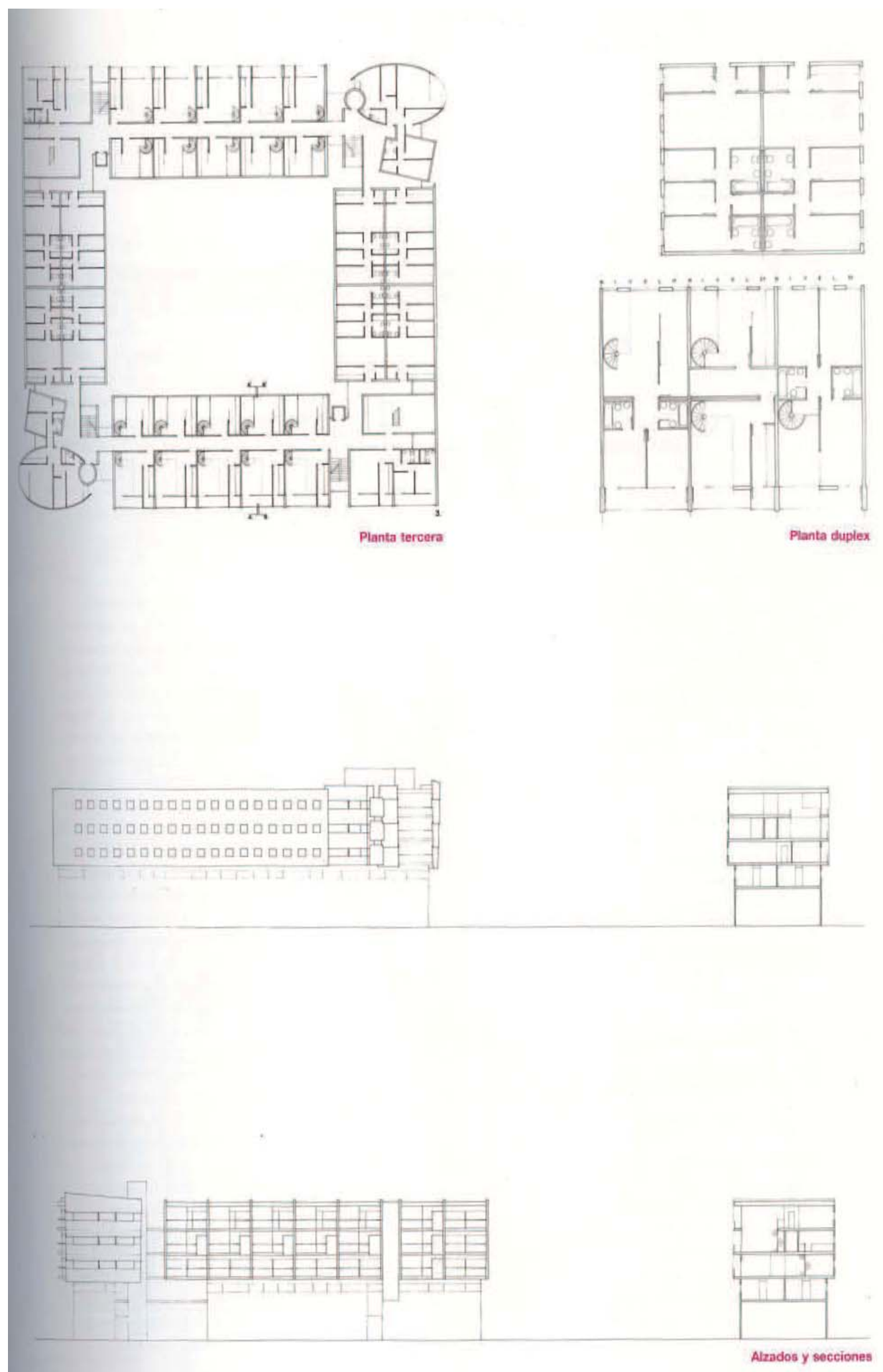
VIVIENDAS EUROPAN (1988-2008) | Una aproximación a los modos de vida en el cambio de siglo en España

4. EUROPAN: DEL CONCURSO A LA REALIZACIÓN
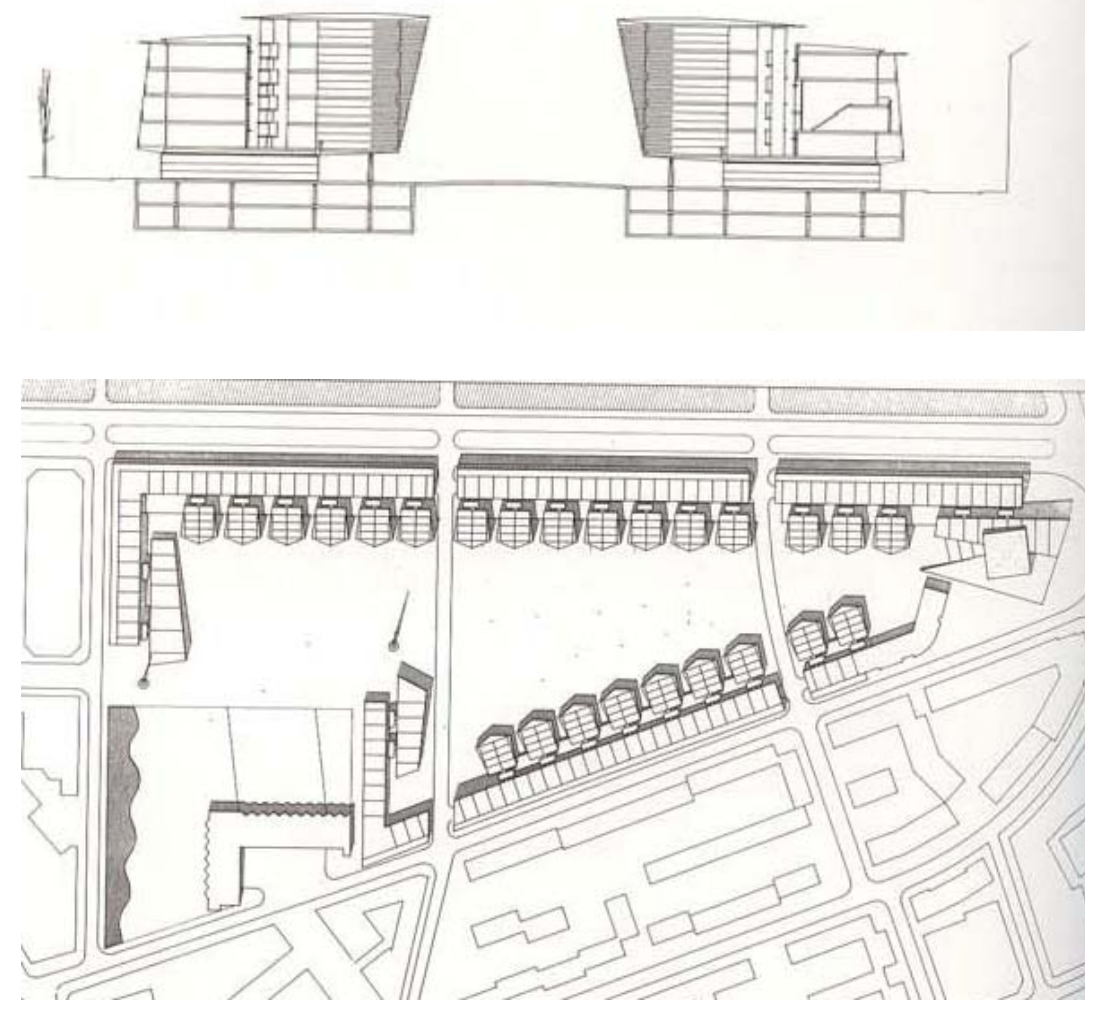

Ref. 4.68. Proyecto de Guardia, Barberá, Veciana, Diaz y Garcia
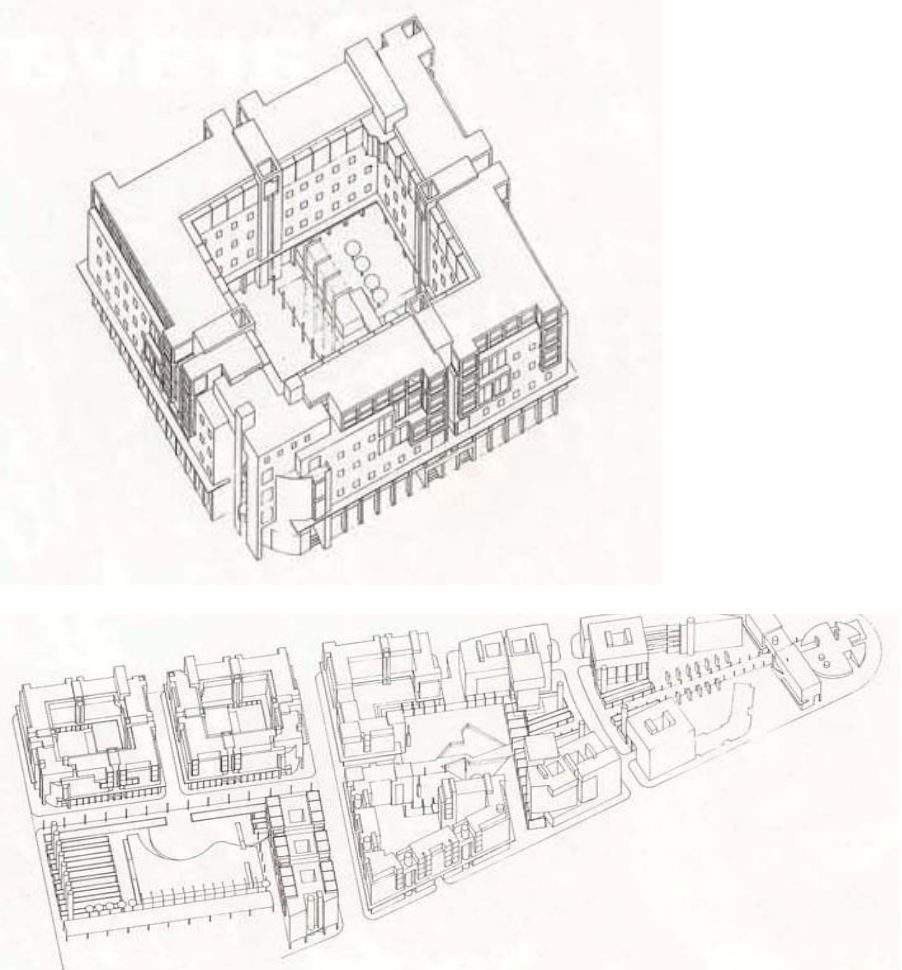

Ref.4.69. Proyecto de Batalla Celorio 


\section{Fase de concurso}

El solar propuesto para Europan 2 en Bilbao se encuentra en Basauri. La ciudad posee un terreno vacío para una próxima expansión urbana y lo ofrece a Europan para que se desarrollen en él distintas propuestas. El sector conforma el borde noreste de Basauri con una buena conexión respecto la ciudad, se abre hacia el norte y noroeste y como no existen edificaciones en altura, toda la zona posee un amplio panorama abierto, debido también al parque existente. En la ordenación del sector también se prevén equipamientos como centros escolares, guarderías, un centro cultural y se mantiene el ambulatorio existente.

Uno de los criterios que se tuvieron en cuenta para la elección del solar fue el que la actuación prevista debería repercutir ampliamente en sectores de población de baja renta.

Se puso de manifiesto en un escrito del Director de Arquitectura del Gobierno Vasco en ese período (D. Juan Ignacio Lasagabaster Gómez) que se trataba de recualificar una zona urbana, integrando en ella las nuevas exigencias resultantes de la transformación de los modos de vida, ocasionadas por la evolución de los fenómenos demográficos, desarrollo industrial y componentes sociales.

La variedad de propuestas para un mismo solar se refleja en las indicaciones del Jurado que destacó los siguientes proyectos:

- Guardia, Barbera, Veciana, Díaz y García planteaban una opción distinta a la manzana cerrada que proponía el planeamiento. Los autores de la propuesta son conscientes de el carácter de borde urbano y propone un elemento lineal que lo conforma. Configuraron un espacio público interior con algunos elementos públicos culminantes.

- Batalla Celorio es también finalista, pero con una propuesta de manzana cerrada, con un elemento lineal que conduce al interior de la manzana del centro cultural. El eje es, por lo tanto, el motivo central de la composición. Se ve como en esta edición de Europan, el urbanismo y la escala territorial cobran más protagonismo.

- Bajo el lema TI111, presentan su proyecto Alberto Martínez y Beatriz Matos. Plantean una tipología de manzana cerrada que se abre en las esquinas. Los autores intentan huir de la tipología única para toda la manzana intentando, según afirman, crear edificios dentro del edificio.

Las fachadas Este-Oeste se componen de viviendas simples que albergan en el espacio central las zonas húmedas y el resto de estancias vuelcan hacia la fachada. La fachada norte-sur se caracteriza por tener viviendas dúplex. Las viviendas de las esquinas se singularizan por la variación en la forma y la alteración en el material, aumentando o disminuyendo así su expresión en el exterior.

Un dato interesante es que se habla desde la fase de concurso de la importancia de la materialización del proyecto. Se pretende un contraste entre materiales ligeros y modernos frente a los tradicionales. 


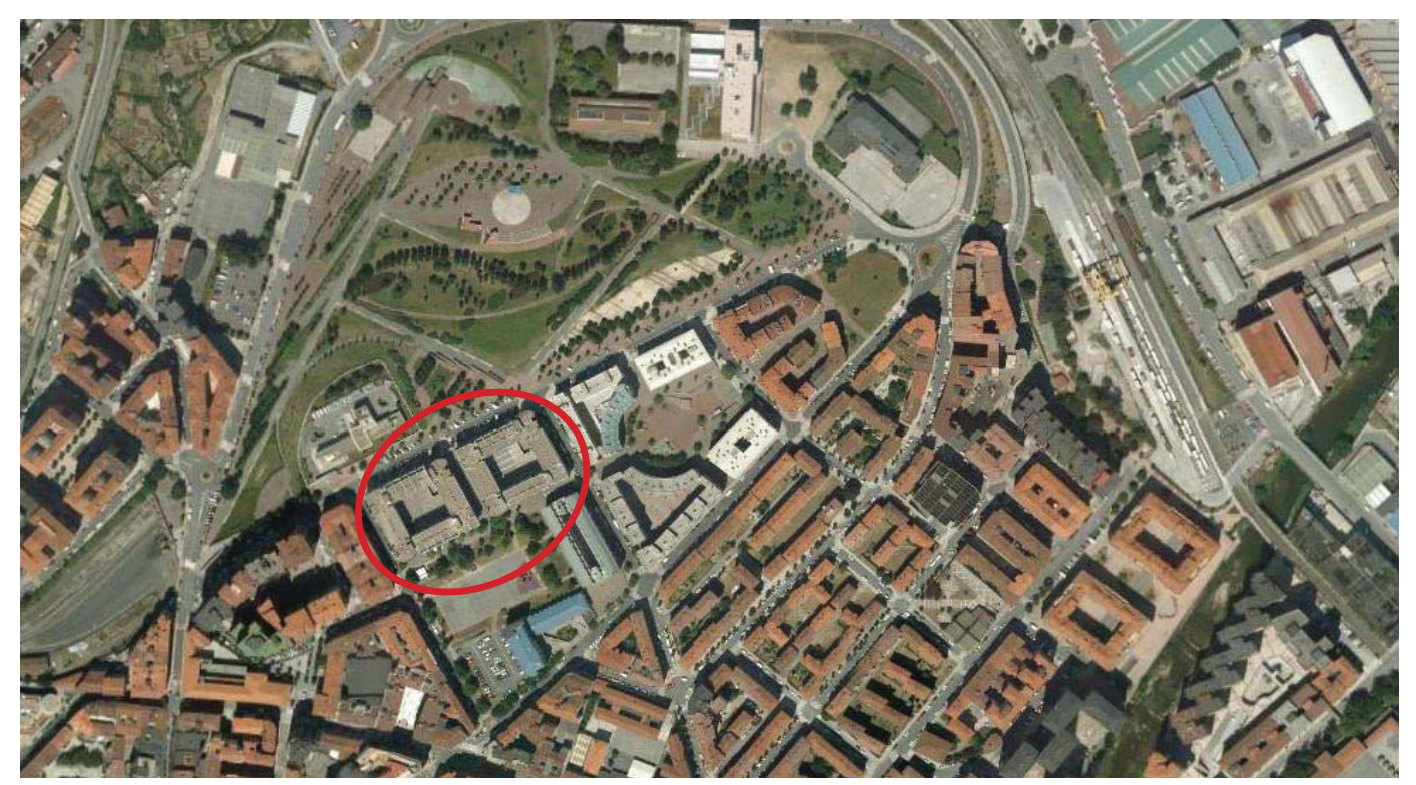

Ref.4.70. Plano de conjunto
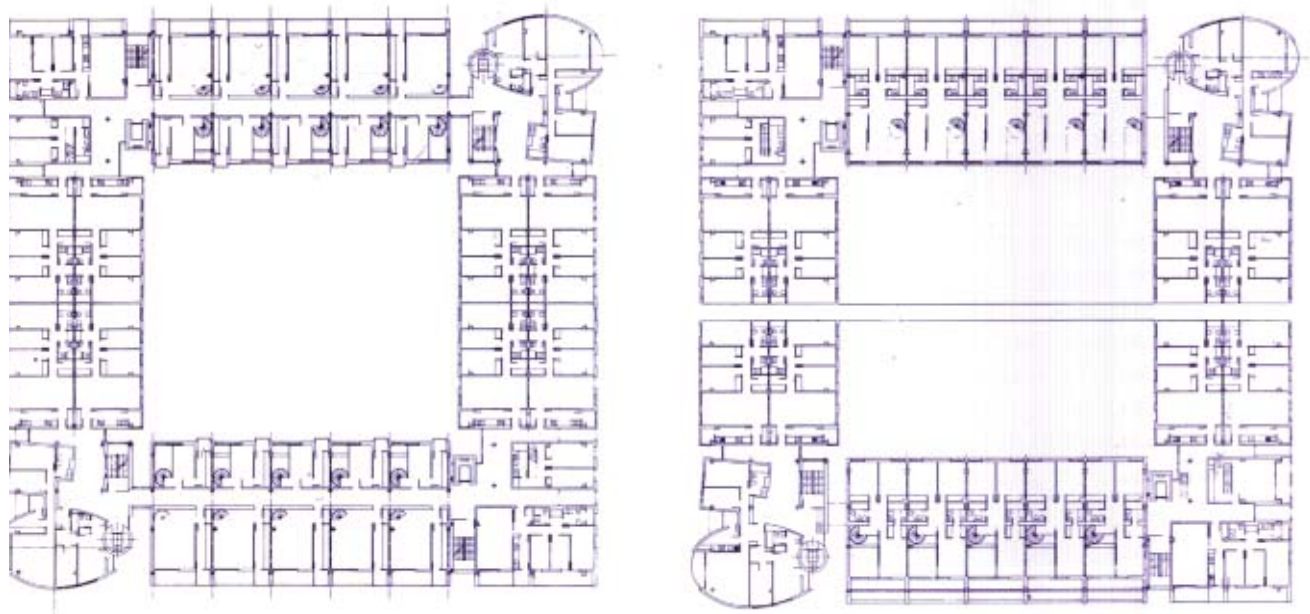

Ref.4.71. Plantas generales de concurso y construidas

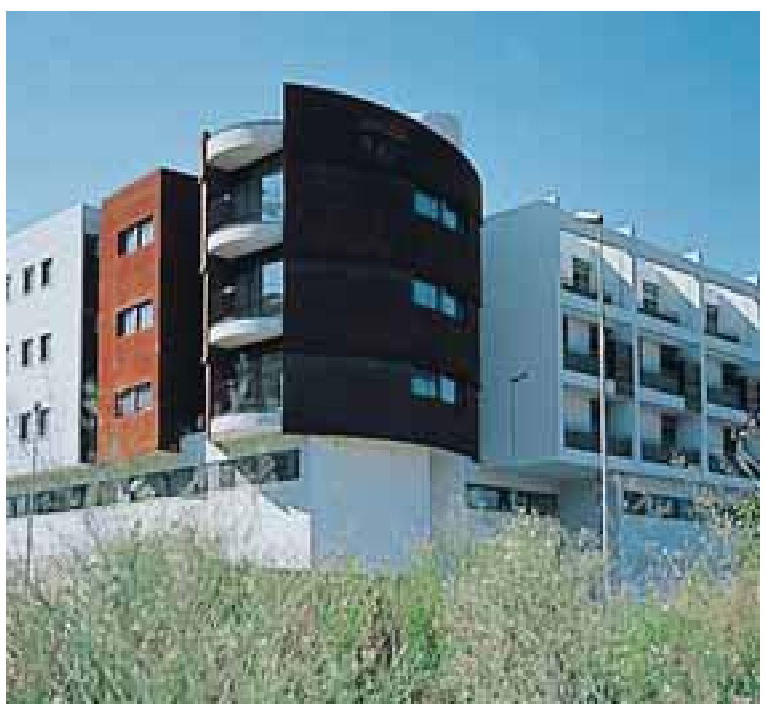

Ref.4.72. Esquina de conjunto, en la que se observa el cambio de material 


\section{Fase de realización}

El proyecto se construye en el mismo solar planteado para el concurso y propone construir las manzanas M1 y M2 de la ordenación. El proyecto básico se redactará en un mes, el de ejecución en dos y medio y la dirección de obra durará dos años y medio.

Los autores, como ya se ha comentado, pretendían crear "varios edificios dentro de un edificio". A cada uno de estos edificios lo denominan cuerpo y a cada cuerpo le corresponde un tipo de vivienda distinta. Se pretendía que cada cuerpo tuviera su propia autonomía. Las articulaciones entre los distintos cuerpos unas veces están llenas y otras vacías.

Es interesante el comentario que hacen los propios autores en cuanto a la variación de las viviendas: "La diversidad de los tipos de vivienda se produce por la voluntad de crear distintos edificios dentro del edificio; ello llevaría a una diversidad social de sus habitantes. La realidad demuestra que en viviendas de promoción pública dicha diversidad no la crean los tipos arquitectónicos sino los criterios políticos de adjudicación de las viviendas".

Las fachadas de las manzanas son repetitivas con un ritmo uniforme de huecos y no llegan a juntarse nunca en la esquina. Esto potencia la individualidad de cada cuerpo.

Los núcleos de comunicación están situados en las cuatro esquinas. A través de ellos se acceden a dos corredores que dan acceso a todas las viviendas.

Las viviendas son de $95 \mathrm{~m} 2$ aproximadamente. Cada manzana tendrá 80 viviendas divididas de la siguiente forma:

- Viviendas dúplex: 4 unidades de dos dormitorios y 20 de tres dormitorios.

- Viviendas simples: 10 unidades de dos dormitorios, 38 unidades de tres dormitorios y 8 unidades de cuatro dormitorios.

Cada tipología de vivienda sigue un esquema diferente. A algunas de ellas se accede por el corredor de acceso, y a la otras a través de unos vestíbulos situados en los extremos del corredor, cerca de los núcleos de comunicación.

Una parte de las viviendas tiene sus zonas húmedas en la parte central, dejando la fachada libre, aunque algunas tipologías dúplex las ubican en un lateral y en toda su longitud.

Las viviendas de esquina marcan los accesos al patio en planta baja. Se materializan de modo distinto: con acero corten exterior e interiormente. Los propios autores afirman que utilizan este material para hacer un homenaje a la memoria industrial del País Vasco.

A continuación se adjunta una ficha-resumen. 
VIVIENDA

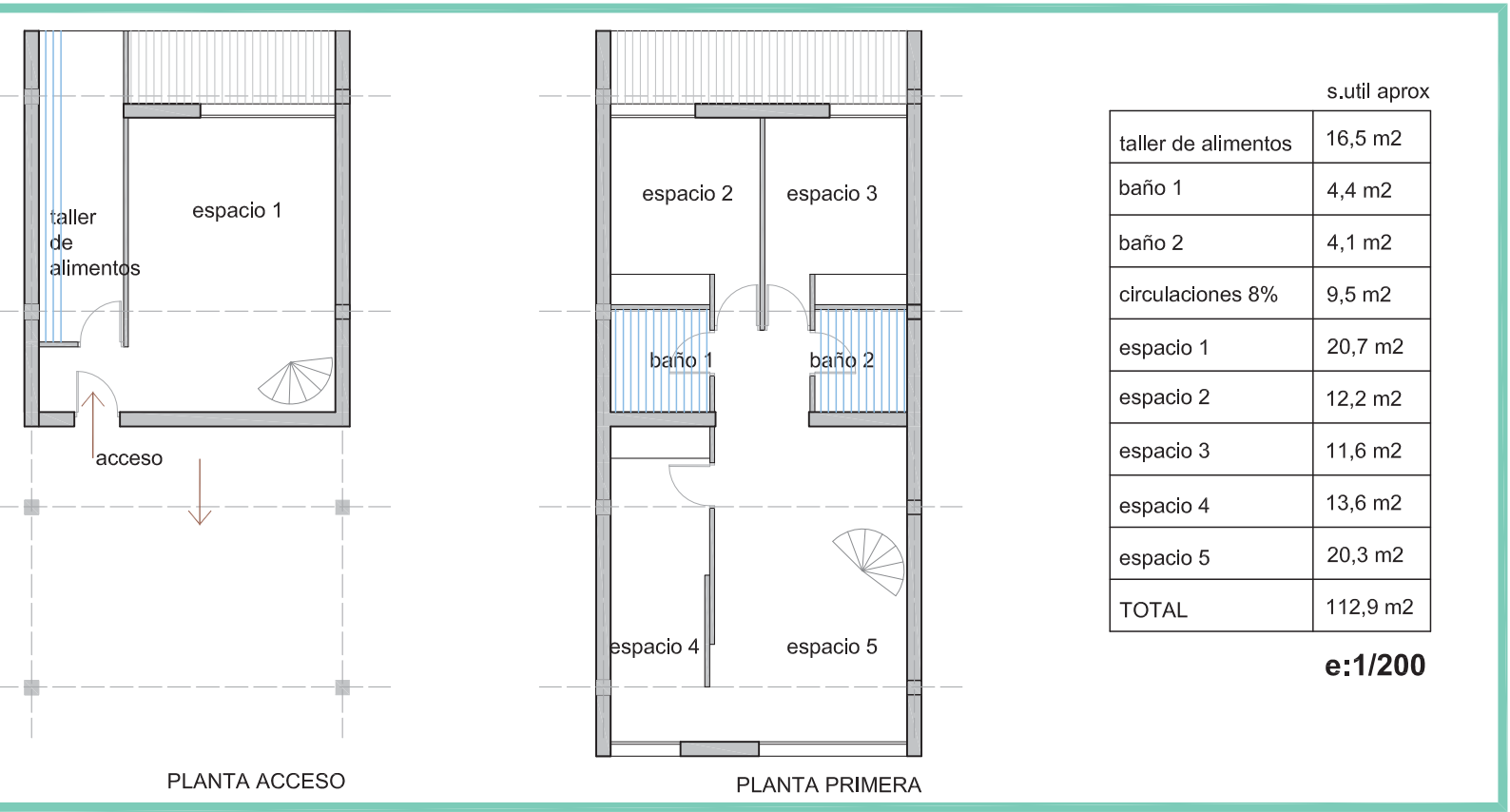

\section{SISTEMAS DE AGRUPACIÓN}

superficie construida total por planta:

$2830 \mathrm{~m} 2$

superficie construida zonas comunes por planta: 445 m2 (16\%)

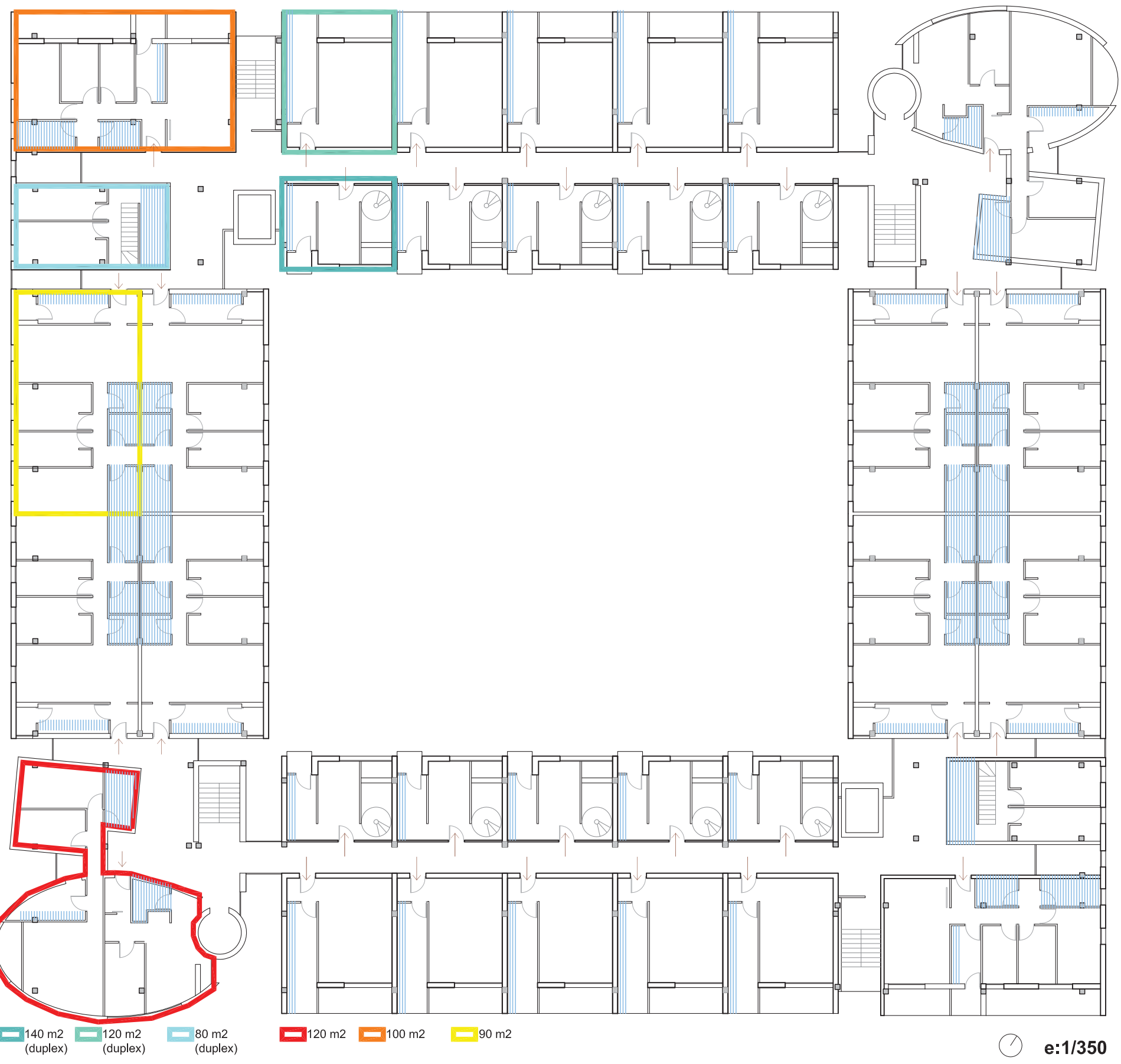



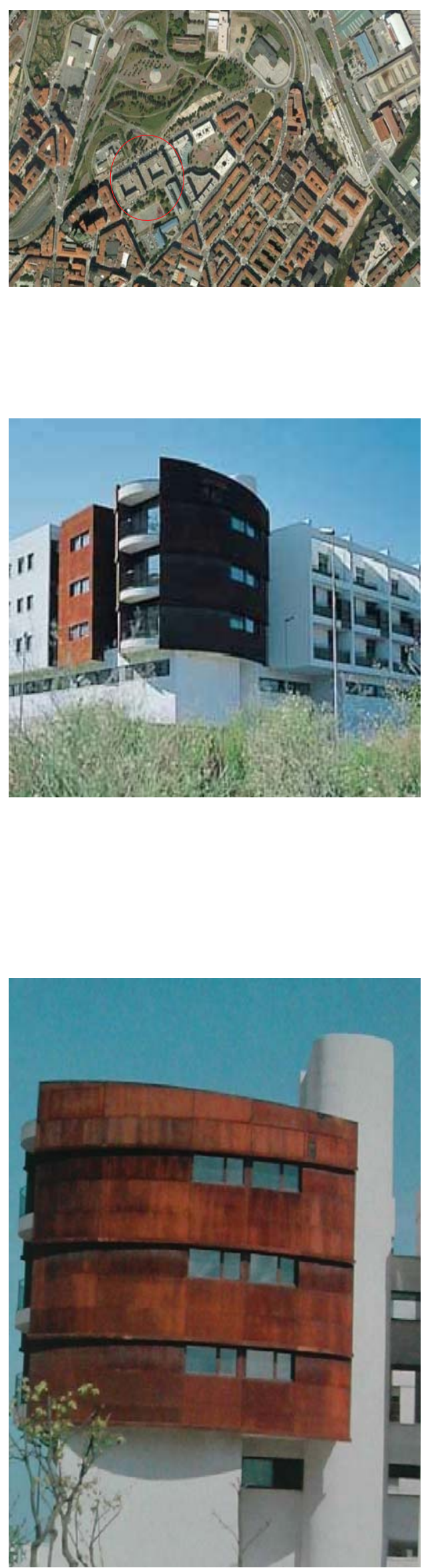

\section{EUROPAN 2}

(año 1990)

\section{MATOS \& CASTILLO: 160 VIVIENDAS EN BASAURI (BILBAO)}

EMPLAZAMIENTO

$c /$ de Uribarri $n^{\circ} 10$ y 12 , Bilbao

COMIENZO DE OBRAS- FINALIZACIÓN DE LAS OBRAS

El proyecto se construirá en 30 meses

(Finalizacion M1-Mayo 95, M2-Sept 1995)

¿ES EL PROYECTO DE CONCURSO?

SI, se corresponde con la propuesta al $100 \%$

No DE VIVIENDAS TOTALES CONSTRUIDAS

80 viviendas manzana

160 viviendas total

No DE VIVIENDS POR SUPERFICIE

58 viviendas 2 viviendas
VII 4 viviendas

VIII 4 viviendas

USO DE LA PLANTA BAJA

Locales y nucleos de comunicacion

USO DEL SOTANO

Garaje

\section{REFERENCIAS BIBLIOGRÁFICAS}

www.matoscastillo.com

- Arquitectos n 133, Ideas y prácticas, Madrid, 1994, p.64-65

- "2 manzanas de viviendas en Basauri-Bilbao", Monográfico Europan, Paris, 1997.

- 10 años EUROPAN 5 España, Edición coproducida por EUROPAN/España, SEPES y el Ministerio de Fomento, 1999, España,p. 151.

- EUROPAN 10 España, "Proyectar la urbanidad", Madrid, 2010, p. 218 



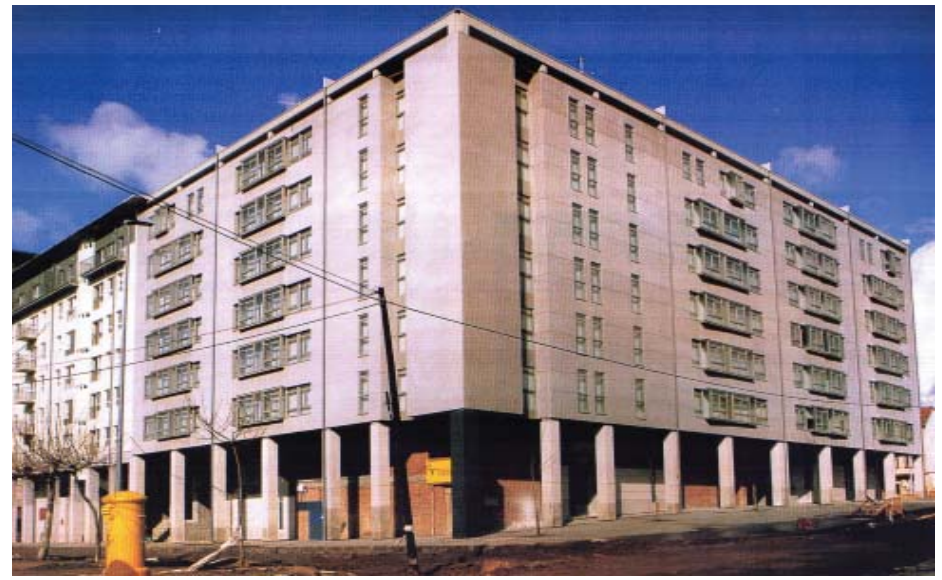

\subsubsection{Edificios de viviendas Europan 2 (1990)}

Ma Concepcion Carreiro y Cándido López: viviendas sociales en Ferrol 


\section{Forrol (Galicia)}

Terrenos vacíos para expansión urbana

\section{Manzana 9C:}

La superficie edificable residencial es de $8.100 \mathrm{~m}^{2}$, y la destinada a dotaciones, de $5.790 \mathrm{~m}^{2}$. El edificio ha de tener 7 alturas (Baja+6) y dos plantas bajo rasante. Se destinará el sótano, la planta baja y el patio a mercado; la primera planta a uso administrativo $y$ de servicios, $\mathrm{y}$ el resto a viviendas.

Se ha de mantener la prolongación de la Avda. Principal y la esquina con la carretera de Caranza. Las alineaciones restantes pueden adaptarse $+1 \mathrm{~m}, \mathrm{y}$ se permiten cuerpos que vuelen $+1 \mathrm{~m}$.

\section{Manzana 28A:}

La superficie edificable residencial es de $31.368 \mathrm{~m}^{2}$, y la complementaria de $3.090 \mathrm{~m}^{2}$. El edificio ha de tener 7 alturas $($ Baja +6$)$, todas destinadas a vivienda.

La edificación ha de ser en línea con doble fachada, manteniendo las alineaciones definidas. Podrán adaptarse las esquinas resolviendo la rótula entre la Avda. Principal y la calle 7, igual que la contigua de la manzana 9C. Se permiten cuerpos que vuelen $+1 \mathrm{~m}$.

\section{Manzana 28B:}

La superficie edificable es de $2.120 \mathrm{~m}^{2}$, destinada toda a uso educativo para EGB, a desarrollar en 3 alturas $($ Baja +2$)$, recomendándose que la volumetría se adapte a la ordenación en manzana, utilizando las alineaciones exteriores.
Vacant Lands For Urban Expansion

\section{Block 9 C}

The building surface for housing is $8.100 \mathrm{~m}^{2}$, and for equipment $5.790 \mathrm{~m}^{2}$. The building must have 7 stories (Ground floor +6 ) and two underground floors. The basement, the ground floor and the court yard will be allocated for market place, the floor for administrative and service usess, and the rest for housing.

The extension of the Avda. Principal and the corner with the road to Caranza must be maintained. The rest of the street lines can be adapted $+1-1 \mathrm{~m}$, and cantilevered volumes of $+1-1 \mathrm{~m}$ are allowed.

\section{Block 28A}

The building surface for bousing is $31.368 \mathrm{~m}^{2}$, complementary building surface $3.090 \mathrm{~m}^{2}$. The building must have 7 stories (Ground floor +6), all fo them for bousing.

The building, with two facades, must keep the defined street. The comer between the Avda. Principal and the 7 th street can be solved in the same way as the next one of block $9 \mathrm{C}$.

Cantilevered volumes $(+/ 1 \mathrm{~m})$ are allowed. Block 28 B

The building surface is $2.120 \mathrm{~m}^{2}$, in 3 stories (Ground floor +2 ), allocated for educational use (E.G.B., primary school), and it is

recommended that the composition of volumes be adapted to the block planning, using the extemal street lines.

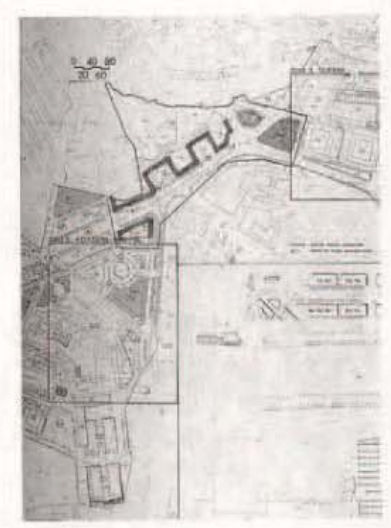

\section{Ref. 4.73. Paneles de concurso}




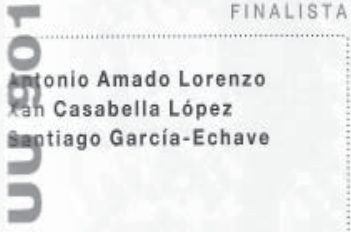

En el caso de esta actuación, y dado que el planteamiento urbanístico preexistente derterminaba formalmente la composición urbana del programa pedido, el tema planteado en Europan se limitó aqui al estudio de la relación entre el espacio urbano $y$ los edificios residenciales $y$ equipamientos.

En lo que respecta a los equipamientos, el edificio destinado a centro escolar de 8 unidades, tiene un planteamiento simétrico en dos alas, con patio central. Es un edificio de planta baja y un piso. En la planta inferior, se desarrolla la zona de administración, oficinas, 2 aulas en cada ala, comedor y aula polivalente. La zona de juegos para estas 4 aulas, corresponde al espacio central cubierto. Tiene esta planta una comunicación posterior muy permeable con la zona pública en la que se propone un espacio polideportivo con graderío cubierto. En el piso superior, otras 4 aulas con idéntica disposición a la de planta baja, biblioteca, laboratorios, y aula de pretecnologia. El espacio de juegos está aquí en la parte trasera, sobre cl comedor. La disposición de las aulas determina un corredor perimetral con vacio sobre el patio inferior.

El edificio de servicios administrativos, tiene un esquema similar al centro escolat en cuanto a su disposición en dos alas con un eje de simetría central. Espacio en planta baja cubierto para usos múltiples, dos núcleos de ascensores, y en las plantas superiores, corredor perimetral, con vacío central sobre la planta baja.

En lo que respecta a las viviendas, se optó por una solución con acceso a través de corredor perimetral por las fachadas norte y este u oeste seguin los casos, siguiendo la solución de la casa Bloc de José Luis Sert.

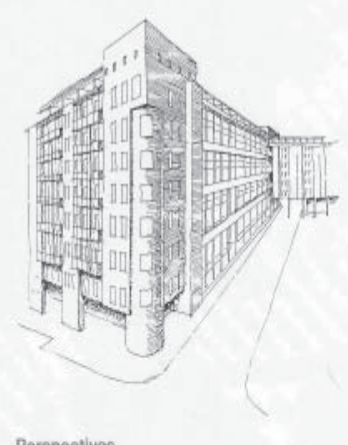

Perspectivas
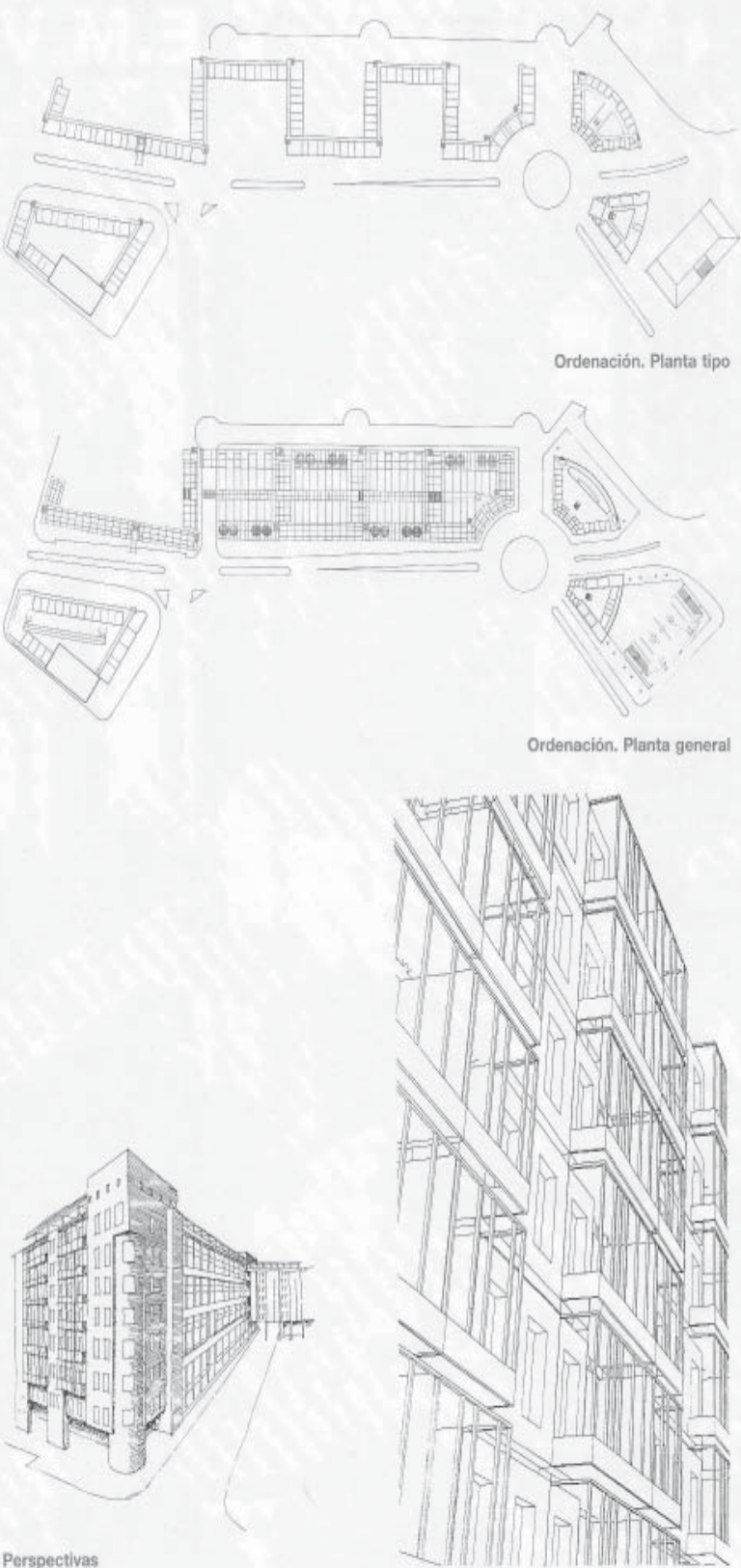

Ref. 4.74. Paneles de concurso 
VIVIENDAS EUROPAN (1988-2008) | Una aproximación a los modos de vida en el cambio de siglo en España

4. EUROPAN: DEL CONCURSO A LA REALIZACIÓN

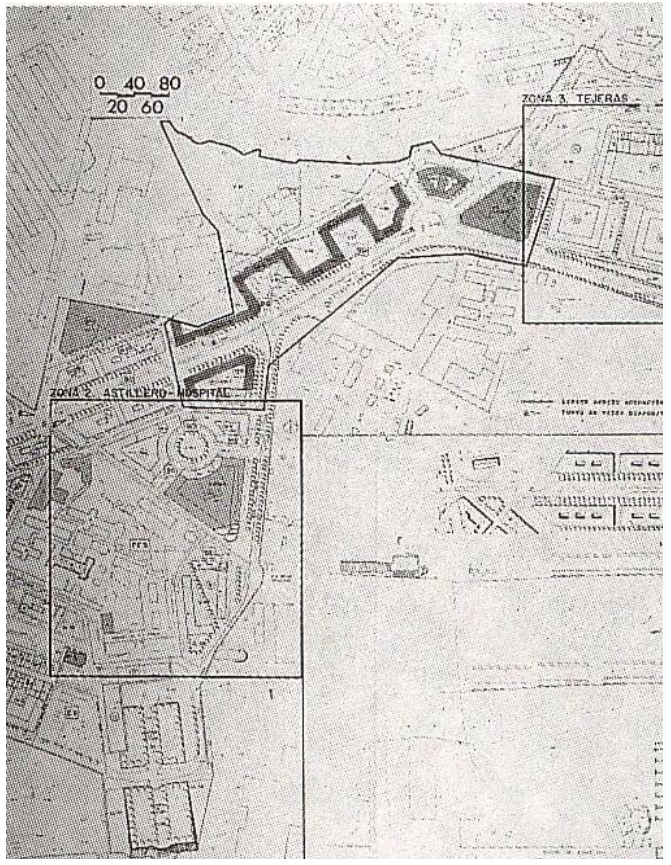

Ref.4.75. Planeamiento urbanístico

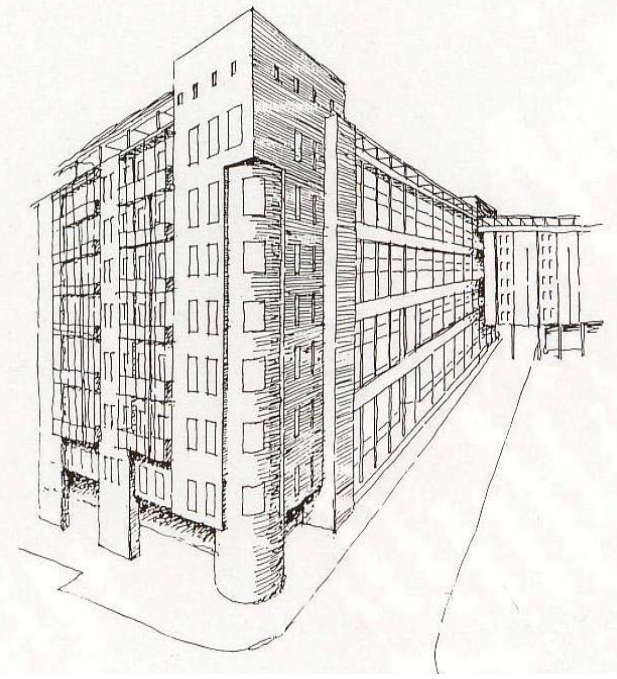

Ref.4.76. Perspectiva de concurso

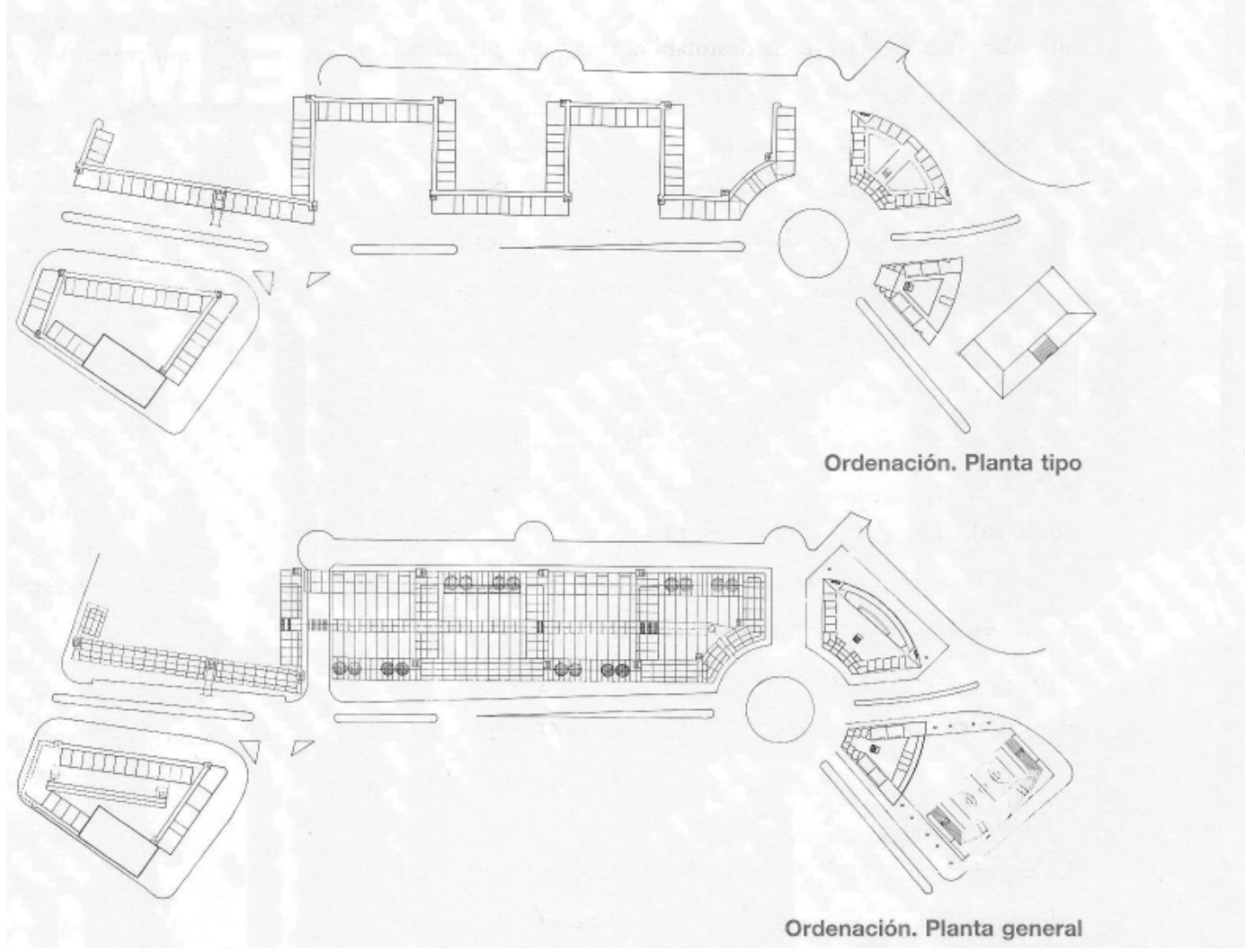

Ref.4.77. Propuesta de ordenación 


\section{Fase de concurso}

El solar que se propuso en Europan 2 en Ferrol tenía el lema de "terrenos vacíos para la expansión urbana". El concurso pretendía abarcar no sólo el tema residencial, sino también quería tratar la relación entre el espacio urbano, los edificios de viviendas y los equipamientos planteados, los cuales también debían ser tenidos en cuenta dentro del programa.

Los condicionantes de la ordenación eran los siguientes: debería tener siete alturas y dos plantas bajo rasante. Una novedad es que, en una de las manzanas que componían la ordenación, la planta sótano,planta baja y el patio se destinarían a mercado, y la primera planta a uso administrativo y de servicio. El resto serían viviendas. Se debía mantener la alineación definida, pudiendo haber vuelos de hasta un metro. Otra de las manzanas estaría destinada en su totalidad a un uso educativo, a desarrollar en tres alturas.

El proyecto premiado corresponde a Antonio Amado, lan Casabella y a Santiago García-Echave. Plantean una propuesta que tiene en cuenta la ordenación urbana y unas viviendas con acceso por corredor perimetral, siguiendo la solución de la casa Bloc de José Luis Sert.

Su propuesta estudia la relación entre el espacio urbano y los edificios residenciales y equipamientos. Dentro de la ordenación proponen un edificio destinado a centro escolar y que lo detallan detenidamente: "es un edificio de planta baja y un piso. En la planta inferior, se desarrolla la zona de administración, oficinas, dos aulas, comedor y aula polivalente. La zona de juegos se sitúa en el espacio central cubierto. En el piso superior situan otras cuatro aulas, la biblioteca, laboratorios y aula de pretecnología".

También plantean un edificio destinado a uso administrativo, similar al esquema del centro escolar en cuanto a su disposición en dos alas con un eje de simetría central.

Las viviendas no se definen en el panel de concurso. Los autores afirman que se opta por una solución con acceso a través de corredor perimetral por las fachadas norte y este u oeste, según los casos.

En la ordenación propuesta se trabajan las conexiones y recorridos de la planta baja, dotándola de algunas zonas verdes y espacios deportivos.

La perspectiva exterior que presentan los edificios residenciales es la de un volumen de líneas sencillas con singularidad en la esquina. Es un edificion cuya fachada sigue una seriación ordenada de huecos.

En definitiva, el proyecto se centra en la ordenación general. Más adelante, el 
VIVIENDAS EUROPAN (1988-2008) I Una aproximación a los modos de vida en el cambio de siglo en España

4. EUROPAN: DEL CONCURSO A LA REALIZACIÓN

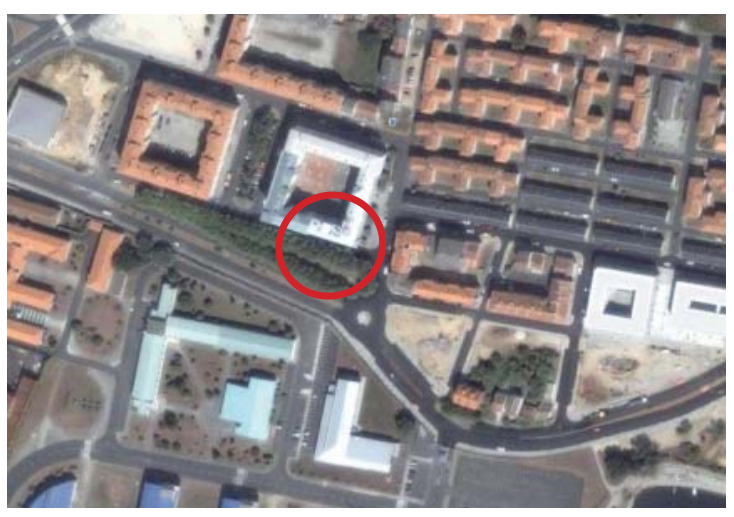

Ref.4.78. Emplazamiento en Ferrol

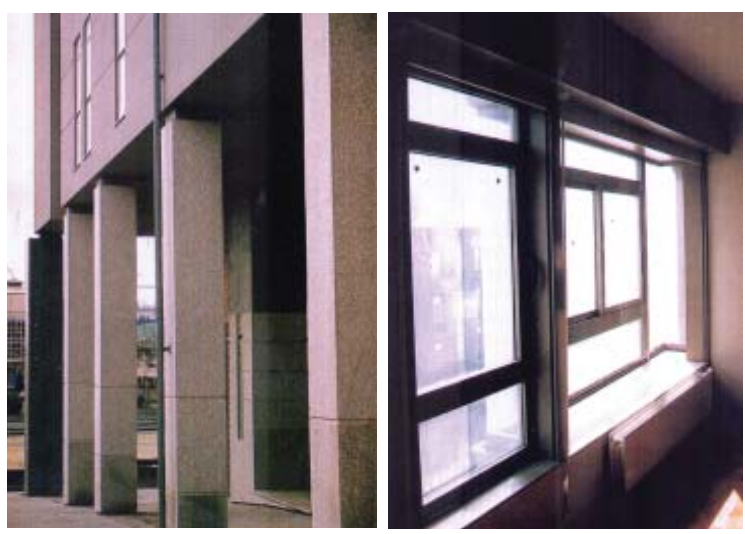

Ref.4.80. Pórticos y ventanales

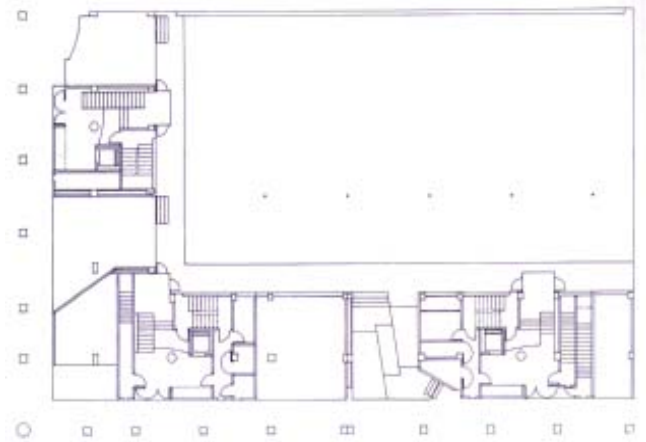

Ref.4.82. Planta baja

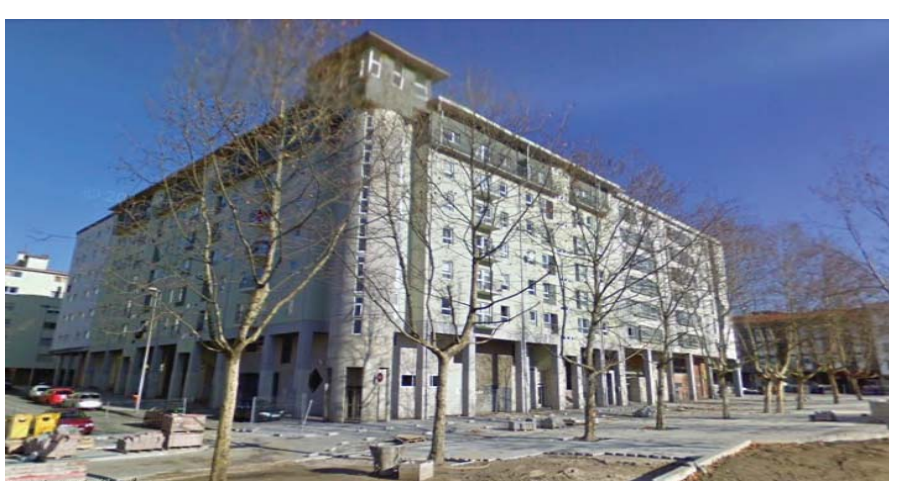

Ref.4.84. Perspectiva exterior

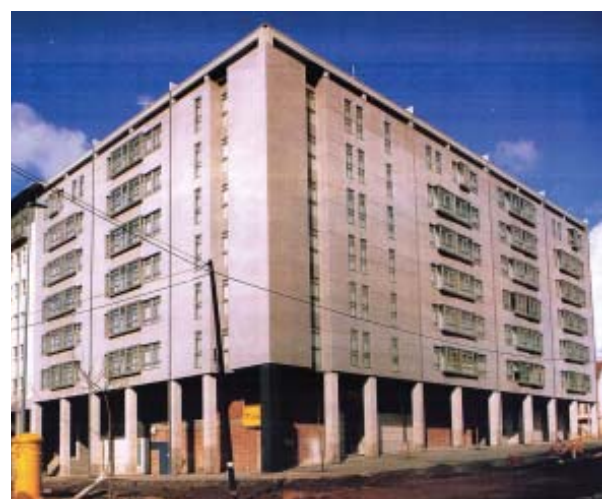

Ref.4.79. Perspectiva exterior

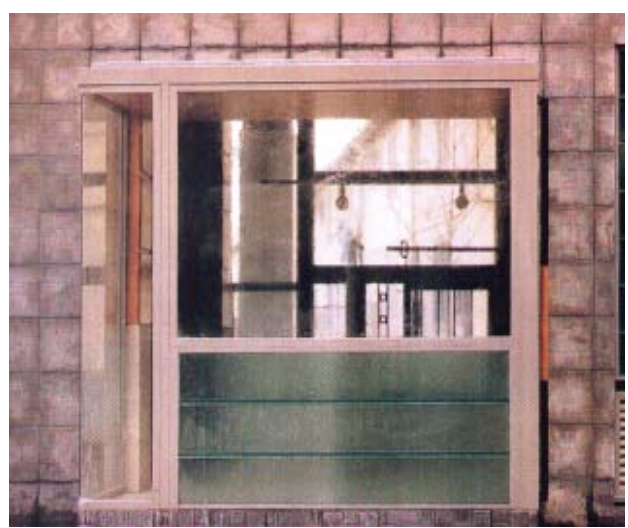

Ref. 4.81. Imagen desde el exterior

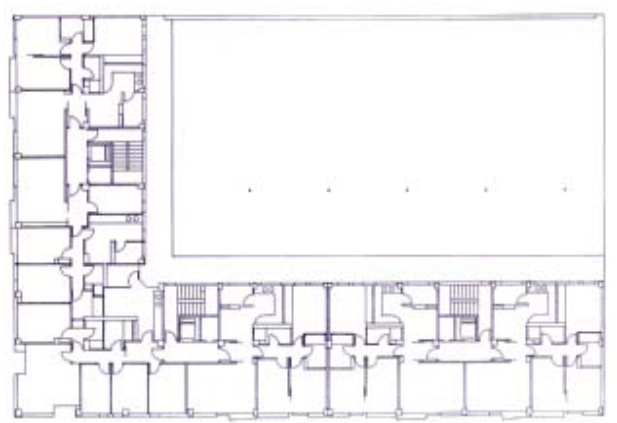

Ref.4.83. Planta general 
edificio de viviendas será el que se construya por otro equipo técnico gallego: $\mathrm{M}^{\mathrm{a}}$ Concepcion Carreiro y Cándido López, que habían participado con una propuesta para la plaza del árbol de Valencia y fueron seleccionados como finalistas.

\section{Fase de realización}

El proyecto construido se sitúa a las afueras de Ferrol en la ordenación propuesta, aunque se desarrolla sólo parte de unas viviendas sociales en esquina en una edificación de manzana cerrada.

La normativa obliga al tratamiento unitario de las fachadas con orientaciones y vistas distintas. En el pórtico de la planta baja se sitúan los comercios y tres núcleos de comunicación que dan acceso a dos viviendas respectivamente.

Cada vivienda tiene aproximadamente $100 \mathrm{~m} 2$ y el proyecto se caracteriza por la repetición de esta unidad. La vivienda se compone de un espacio de acceso, un estar, la cocina, tres dormitorios y dos núcleos húmedos. Todo ello se distribuye a través de un pequeño corredor central desde el acceso, al que vuelcan todas las estancias. En la publicación del proyecto hacen referencia a Kahn diciendo que lo toman como referencia en cuanto a la jerarquía de los espacios: servidores y servidos.

Existe un intento de flexibilidad al unir dos espacios destinados a dormitorios mediante una puerta corredera. Este gesto proporciona cierta movilidad aunque tal vez en la práctica no resulte muy funcional.

Los autores hacen referencia al estudio de la pieza formada por la cocinatendedero, para proteger la vision de la zona donde se cocina desde el vestíbulo de acceso a la vivienda.

El espacio principal lo constituye el de salón de mayores dimensiones que el resto. En la esquina, este espacio cobra aún mayor importancia y se asemeja a las almenas de una torre desde donde se puede divisar el paisaje.

Los arquitectos destacan el patio como lugar de relación y de acogida. Como en el proyecto que se planteó en el concurso, la solución de esquina cobra cierta resonancia.

Utiliza materiales como el hormigón y la carpintería metálica que permiten grandes ventanales para la captación de luz. Se adecúa además a la meteorología de la zona. También el pórtico sirve de resguardo para los días de lluvia abundantes en el lugar.

A continuación se adjunta una ficha-resumen. 


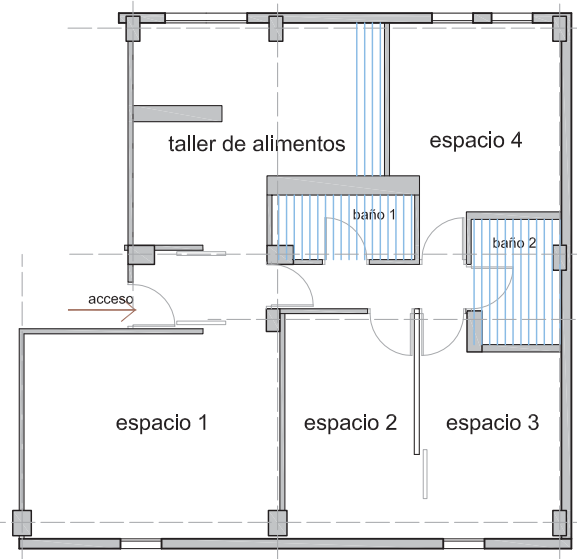

\begin{tabular}{|l|l|}
\hline taller de alimentos & $19,7 \mathrm{~m} 2$ \\
\hline baño 1 & $3,8 \mathrm{~m} 2$ \\
\hline baño 2 & $4,7 \mathrm{~m} 2$ \\
\hline circulaciones 8\% & $7,4 \mathrm{~m} 2$ \\
\hline espacio 1 & $21,9 \mathrm{~m} 2$ \\
\hline espacio 2 & $12 \mathrm{~m} 2$ \\
\hline espacio 3 & $11,7 \mathrm{~m} 2$ \\
\hline espacio 4 & $14 \mathrm{~m} 2$ \\
\hline TOTAL & $95,2 \mathrm{~m} 2$ \\
\hline
\end{tabular}

\section{SISTEMAS DE AGRUPACIÓN}

superficie construida total por planta:

$736 \mathrm{~m} 2$

superficie construida zonas comunes por planta: 76 m2 (10\%)

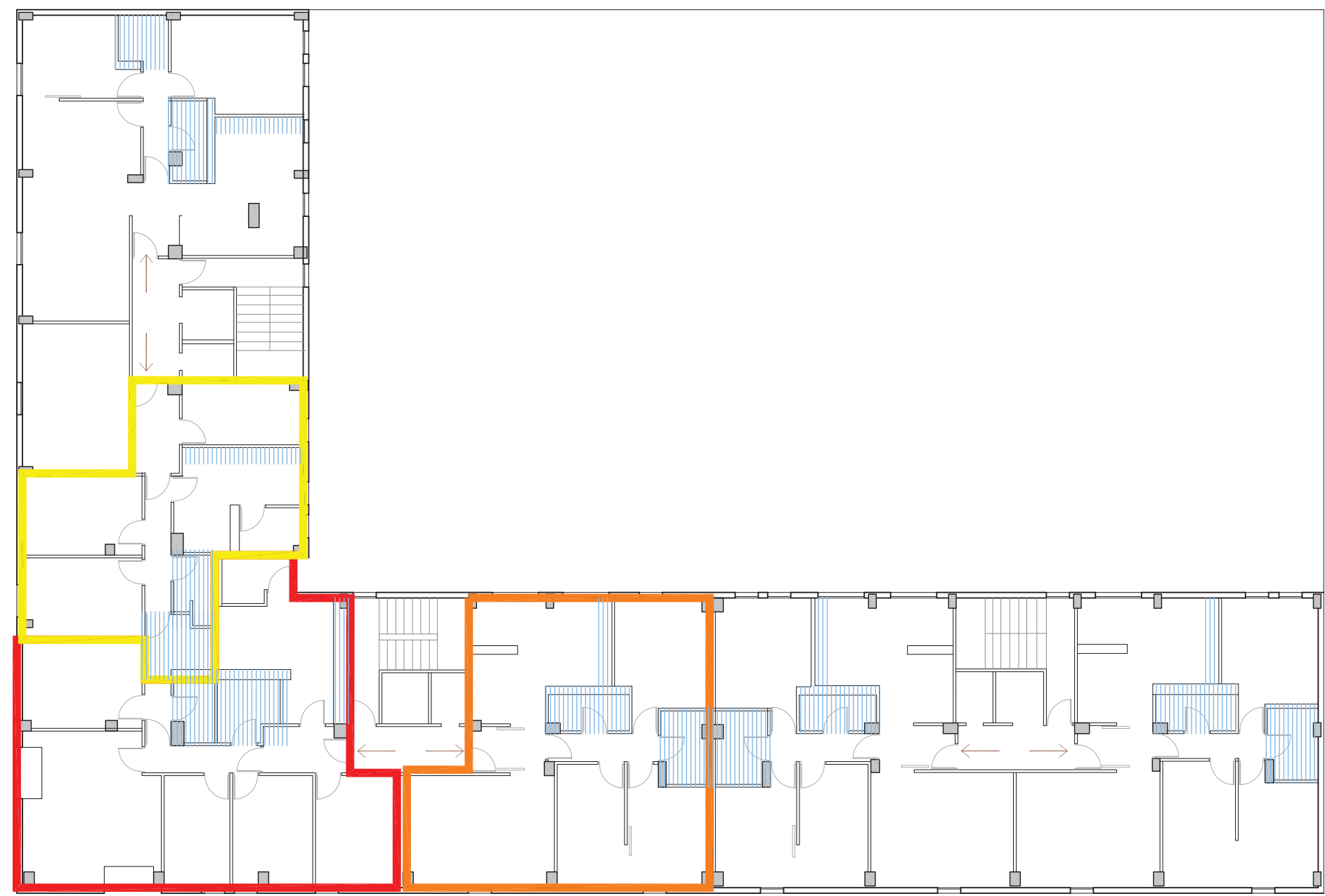




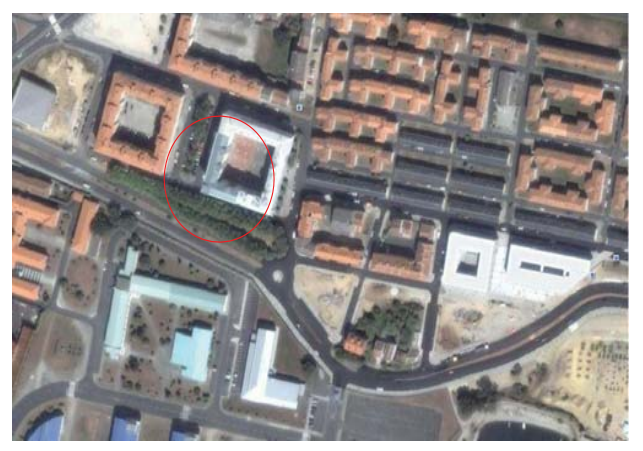

FICHA 2.2

\section{EUROPAN 2}

(año 1990)

Ma CONCEPCIÓN CARREIRO Y CÁNDIDO LÓPEZ: 36 VIVIENDAS EN EL FERROL

EMPLAZAMIENTO

Travesa de Bazán n 28-Rua Ponte Caranza, Ferrol

COMIENZO DE OBRAS- FINALIZACIÓN DE LAS OBRAS

Finalizan en mayo de 1993

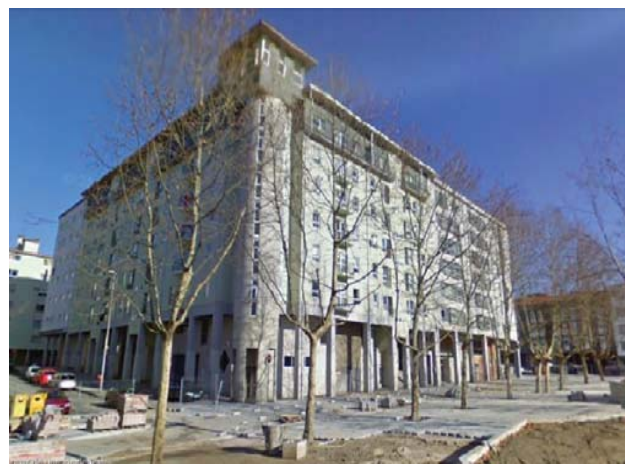

¿ES EL PROYECTO DE CONCURSO?

No

$\mathrm{N}^{\circ}$ DE VIVIENDAS TOTALES CONSTRUIDAS

36 viviendas

$N^{\circ}$ DE VIVIENDS POR SUPERFICIE

6 viviendas

VIII 6 viviendas

VIII 24 viviendas

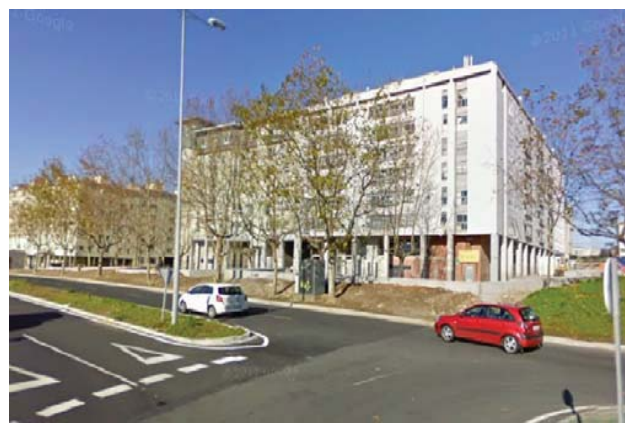

USO DE LA PLANTA BAJA

Existen 4 locales comerciales $y$ un paso para acce-

der al espacio interior de manzana

USO DEL SOTANO

Garaje

\section{REFERENCIAS BIBLIOGRÁFICAS}

- Arquitectos no 133, Ideas y prácticas, Madrid, 1994, p.127

- "Obradoiro", Edificio de viviendas de protección oficial en Ferrol, $n^{\circ} 25$, p.70-73.

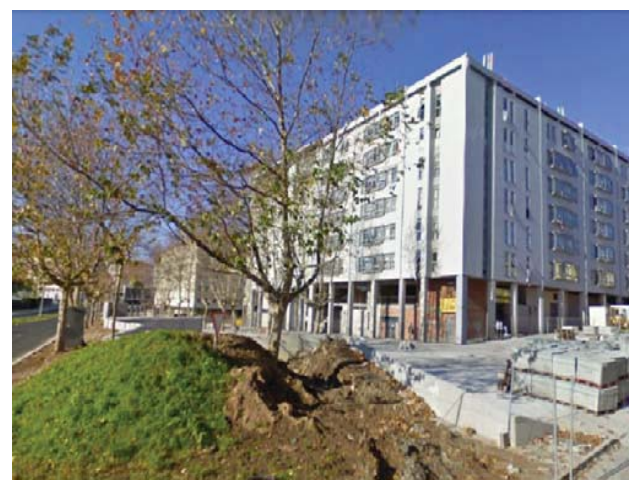





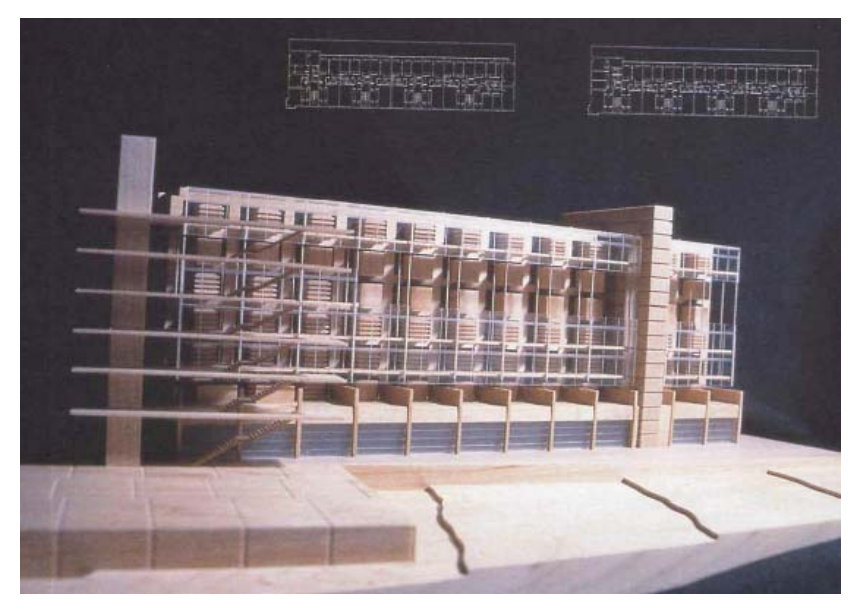

\subsubsection{Edificios de viviendas Europan 3 (1992)}

Jaime López y Jaime Latas: bloques de viviendas sociales en la M-30 



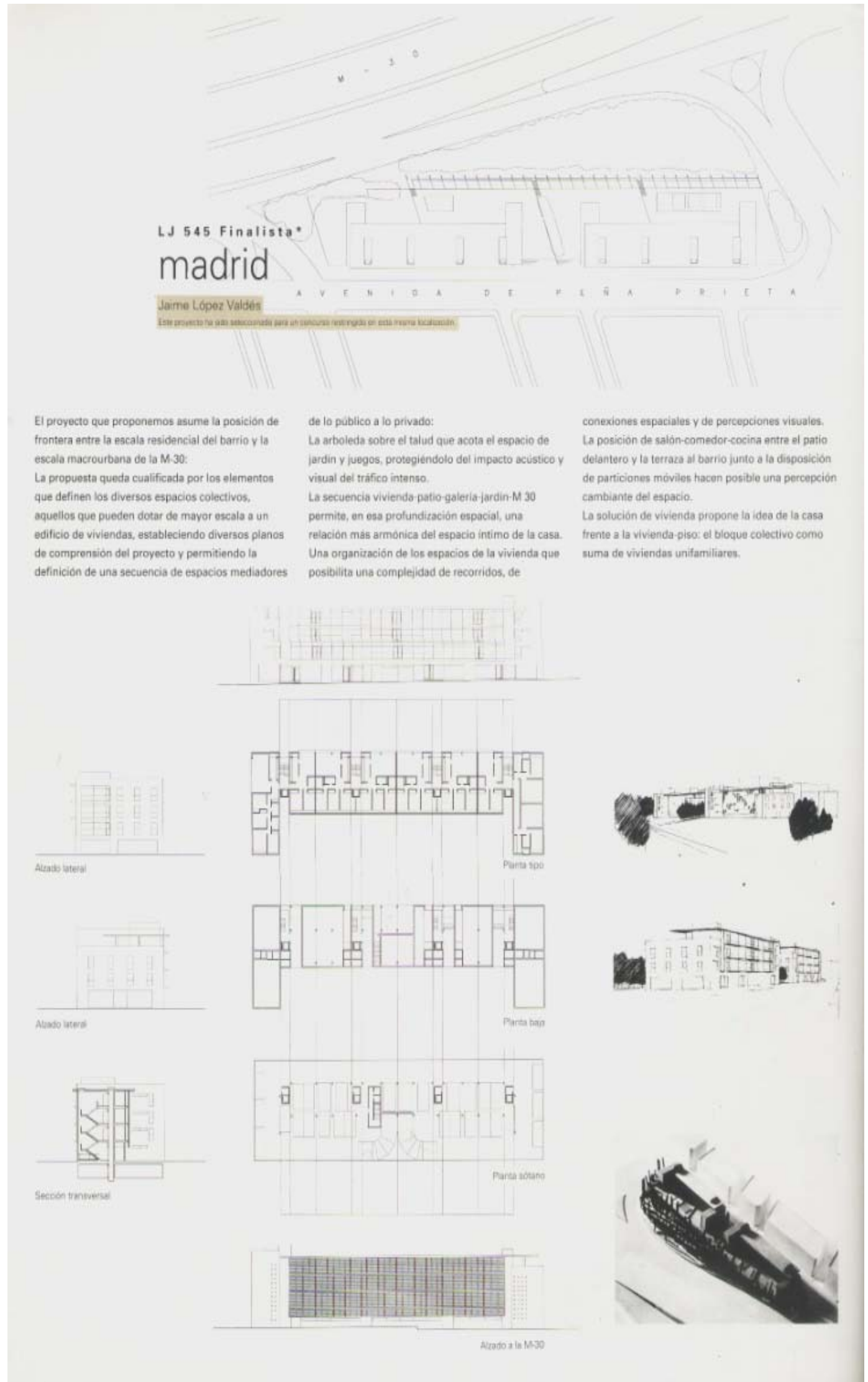

Ref. 4.85. Paneles de concurso 


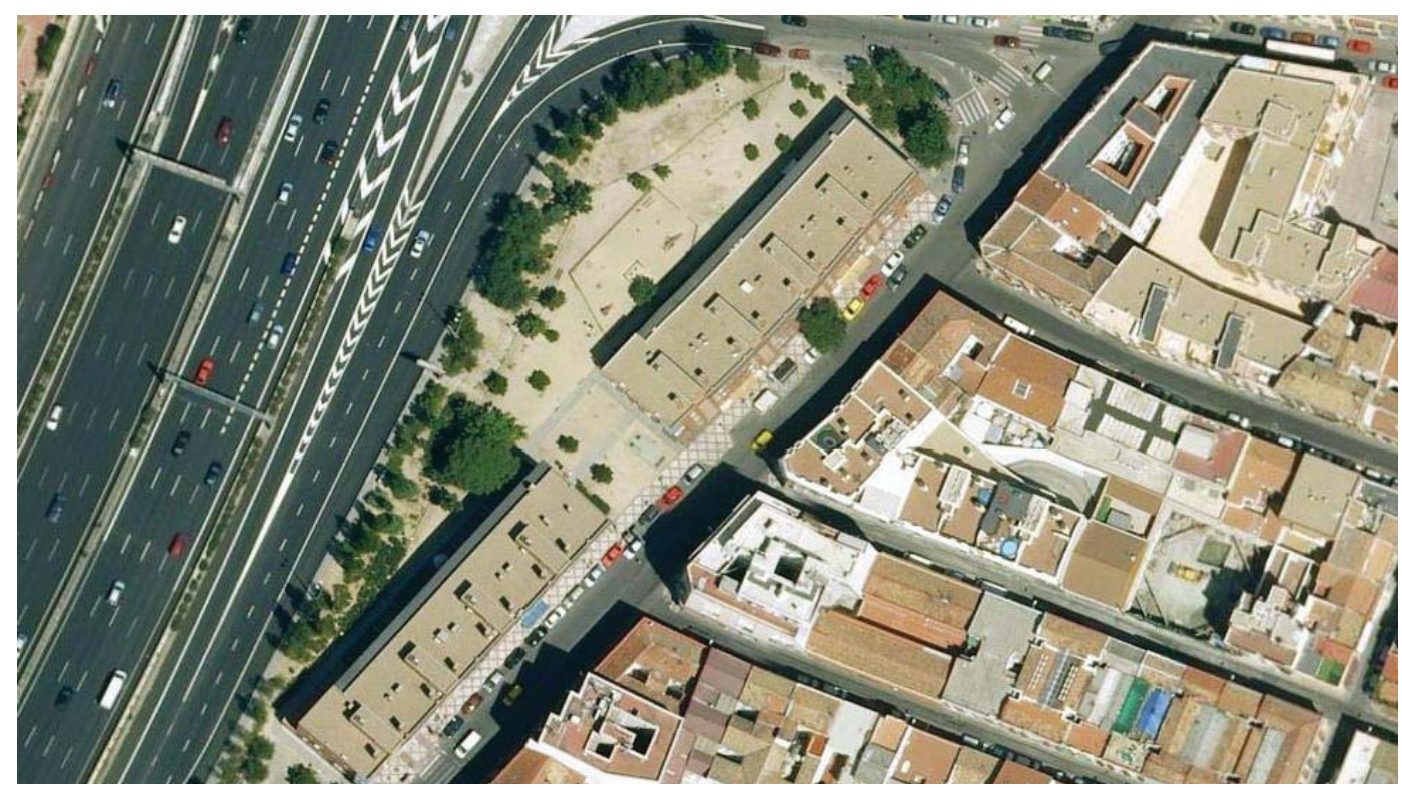

Ref.4.86. Solar de concurso que coincide con el solar en el que se construyó la obra

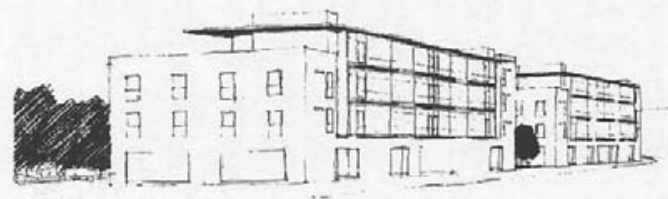

Ref.4.87. Perspectiva de concurso

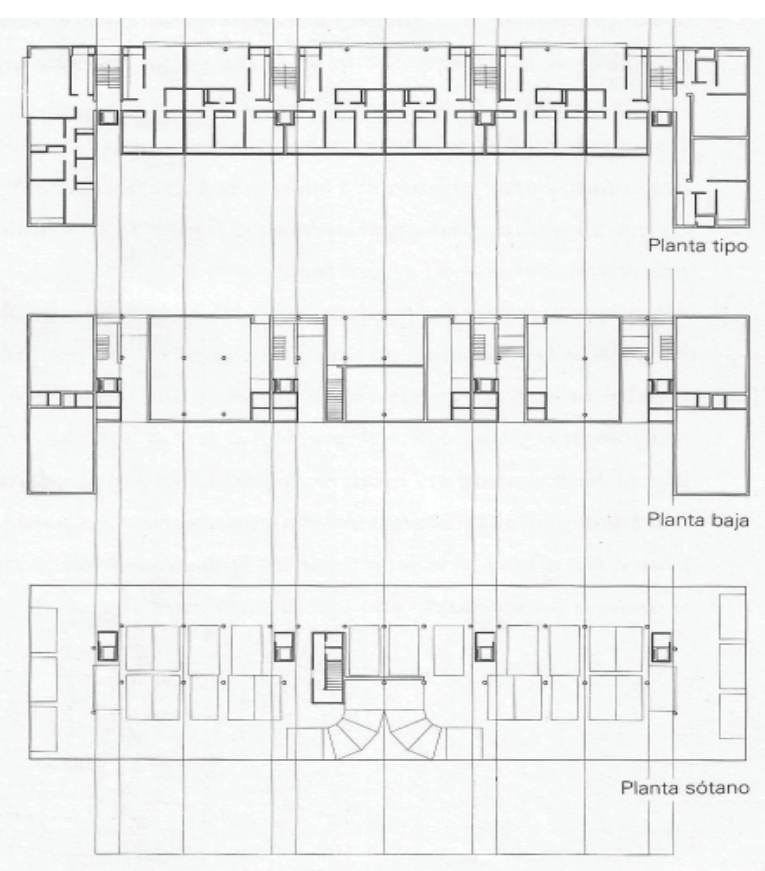

Ref.4.88. Plantas de concurso 


\section{Fase de concurso}

Se propone un solar como reestructuración de espacios vacíos, destinado a uso residencial, con comercial y almacenes en planta baja, espacios libres para áreas recreativas y aparcamiento bajo rasante. Es un solar céntrico, problemático y conflctivo debido al alto nivel de contaminacion acustica y ambiental producidos por los ruidos de la M-30 y la Avenida de la Paz, dos vías rápidas colindantes.

El Ayuntamiento propone esta actuacion para obtener viviendas social en el centro de la ciudad, expropiando terrenos en el PERI puente de Vallecas Norte. Se espera de la propuesta una actuación detonante que reordene el territorio. Se vacía el solar de edificios en mal estado. El programa de necesidades se ajusta a la legislacion de vivienda social que propone un $80 \%$ viviendas de tres dormitorios y el $20 \%$ de uno o cuatro.

El concurso quedó desierto porque ningún participante se ajustaba a la normativa urbanística, de tal modo que, seleccionados los proyectos que más se aproximaban a ella fueron invitados a una segunda vuelta ${ }^{1}$.

En el acta del Jurado se comenta expresamente del emplazamiento de Madrid que "al no haber sido posible, a juicio del Jurado, ningún premio o mención en el emplazamiento de Madrid, ya que todas aquellas propuestas que tenían la suficiente calidad incumplían en algún grado o caso las limitaciones urbanísticas que condicionaban el solar, conocidas por todos los concursantes. Para contribuir a la realización de un proyecto derivado de Europan en este emplazamiento decidió escoger entre las soluciones finalistas que más se aproximaban a cumplimiento de los requerimientos urbanísticos (...). Para la convocatoria de un concurso restringido, remunerado, organizado por el Comité Nacional Español de Europan, con la aprobación del Propietario Público de este suelo, y obtener en un plazo máximo de 3 meses una solución ajustada a las normativas urbanísticas que pasará de inmediato a su desarrollo como proyecto y a la posterior realización".

El proyecto finalista de Jaime López y Jaime Latas plantea un bloque de viviendas colectivo como suma o agrupación de viviendas unifamiliares y proponen una secuencia de espacios entre vivienda-patio-galería-jardín-M-30.

\footnotetext{
${ }^{1}$ Estos proyectos son:

- Benjamín Pleguezuelos Casinos y Mercedes Salesa Benito. Plantean dos bloques lineales que actúan como un solo edificio formando una barrera junto a la M-30, resaltando en su propuesta la importancia del aislamiento acústico.

- Ángel Iglesias Velasco y Eusebio Alonso García plantean el proyecto desde un punto de vista más urbanístico y crean una colina artificial.

- José Álvarez del Manzano, Fernando Auz Iglesia y Antonio Juarez Chicote centran su propuesta en las unidades de vivienda, eliminando las de tres dormitorios. Se plantean espacios más flexibles y menos compartimentados.
} 


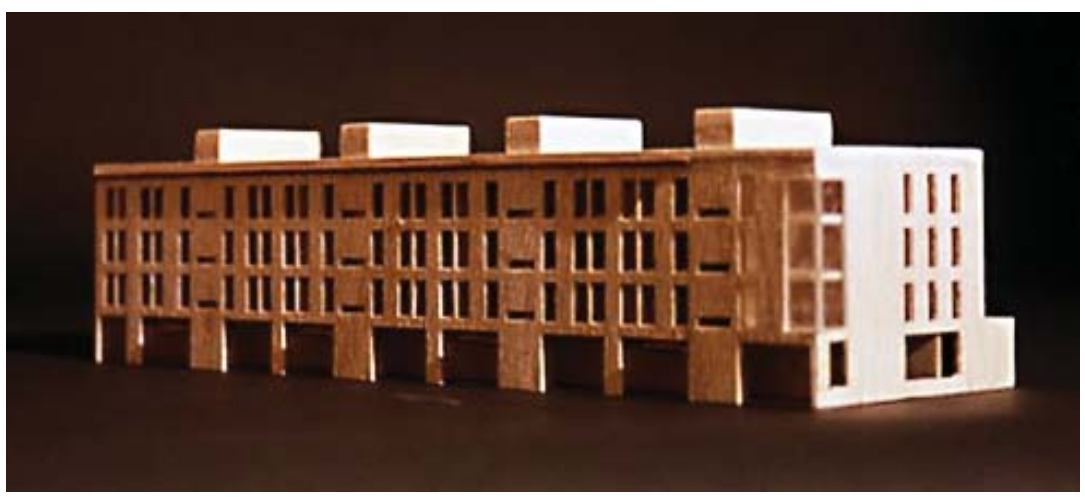

Ref.4.89. Maqueta de un bloque

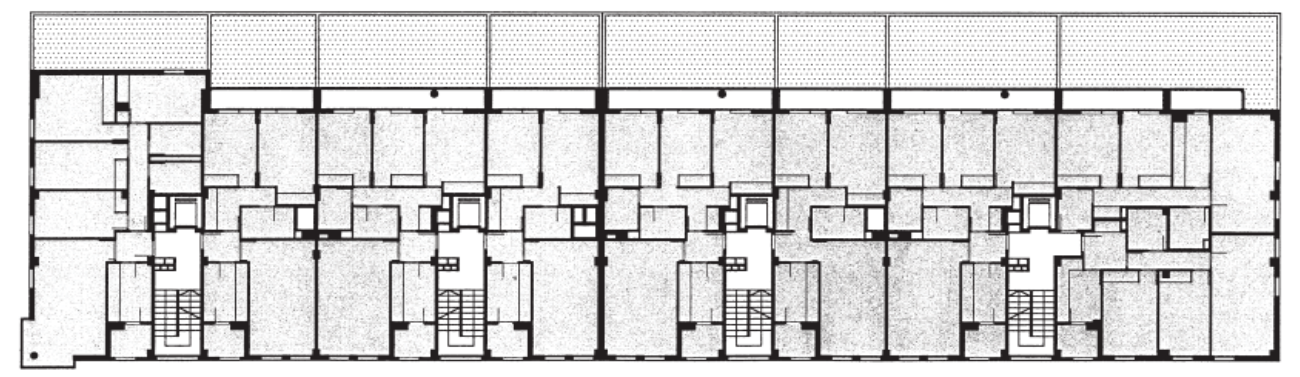

Ref.4.90. Planta tipo

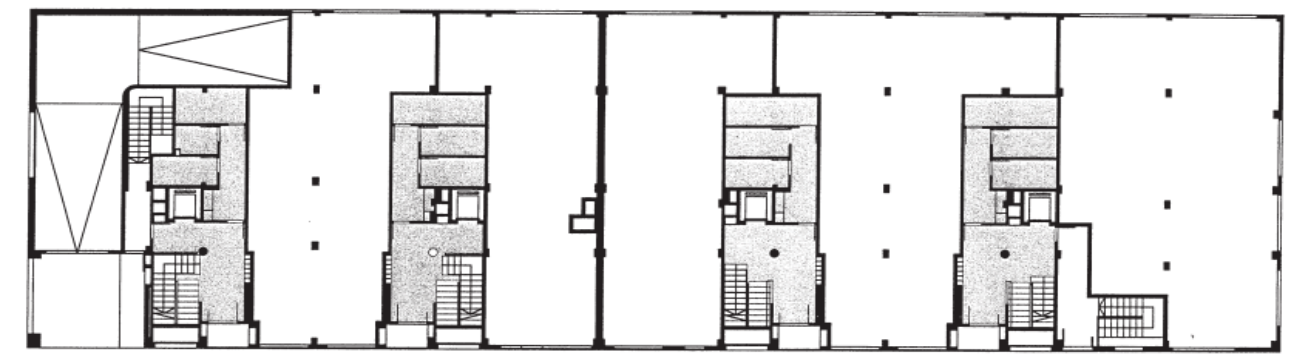

Ref.4.91. Planta baja

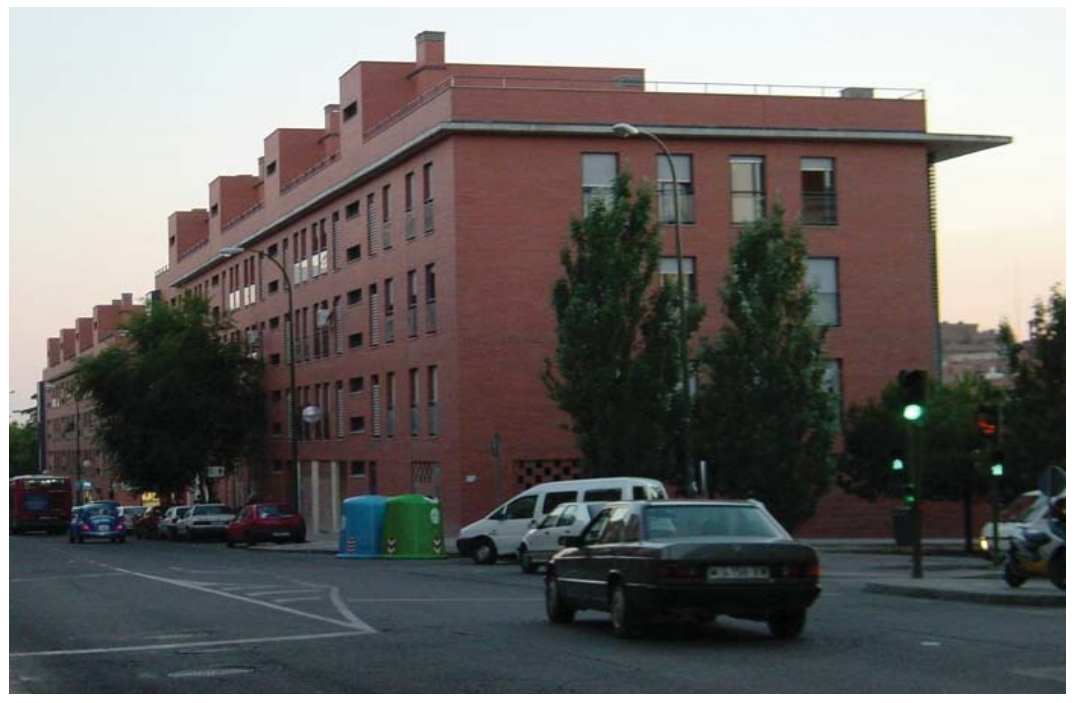

Ref.4.92. Perspectiva actual 
En los bocetos se observa la transición entre las vías de tráfico rodado y el parque que se plantea, desde el que se puede observar el bloque de viviendas a lo lejos. En las plantas se percibe una modulación y un orden que es de agradecer, aunque quizás predomina la repetición de los espacios y carece de cierta flexibilidad.

\section{Fase de realización}

Finalmente se realiza el concurso llevado a cabo por el equipo de Jaime López y Jaime Latas. Se construyen dos bloques de viviendas de cuatro plantas en el emplazamiento previsto y tiene cierto parecido con el planteamiento de concurso pues la idea principal la transición de espacios que planteaban se mantiene viva.

La inserción en el entorno urbano es adecuada, los espacios verdes con el parque situado al norte actúan de colchón acústico frente a la vía de tráfico rápido, la M-30.

Los autores afirman que la solución arquitectónica que se propone responde a dos escalas. Una macrourbana, la de la M-30, donde la concepción del edificio ha de ser rápida, en la que prevalecen criterios como la continuidad de las fachadas, su rotundidad, etc. La otra escala es la que se percibe desde la Avenida Peña Prieta, más cercana al individuo, en la que se plantea una imagen más fragmentada y personalizada. El volumen exterior se caracteriza por la repetición de los huecos y presenta una imagen másica.

El Planeamiento urbanístico supone una limitación en cuanto al fondo máximo edificable, limitado a 15 metros para las plantas tipo, y las condiciones en cuanto a soleamiento puesto que las viviendas son con doble orientación sin patios interiores.

En la planta baja se encuentran 5 locales comerciales, la rampa de acceso al garaje y los núcleos de comunicación, cuatro núcleos que sirven a dos viviendas por planta.

Se opta por unas viviendas con doble orientación, sin patios de luces. A éstas se accede desde el vestíbulo que queda en un espacio central y distribuye por un lado, a la cocina y el estar, y por el otro a un pequeño corredor que ubica las habitaciones. Esta zona de noche (en algunas viviendas de dos estancias y en otras de tres) está separada del exterior por una galería tipo corredor que actúa de colchón acústico. La solución de esquina es diferente como también planteaban en el proyecto de concurso aunque con algunas variaciones.

Los materiales empleados para la fachada son el ladrillo cara vista convencional y la carpintería metálica, esta última con el sistema de oscurecimiento en forma de lamas para la protección solar.

A continuación se adjunta una ficha-resumen. 


\section{VIVIENDA}

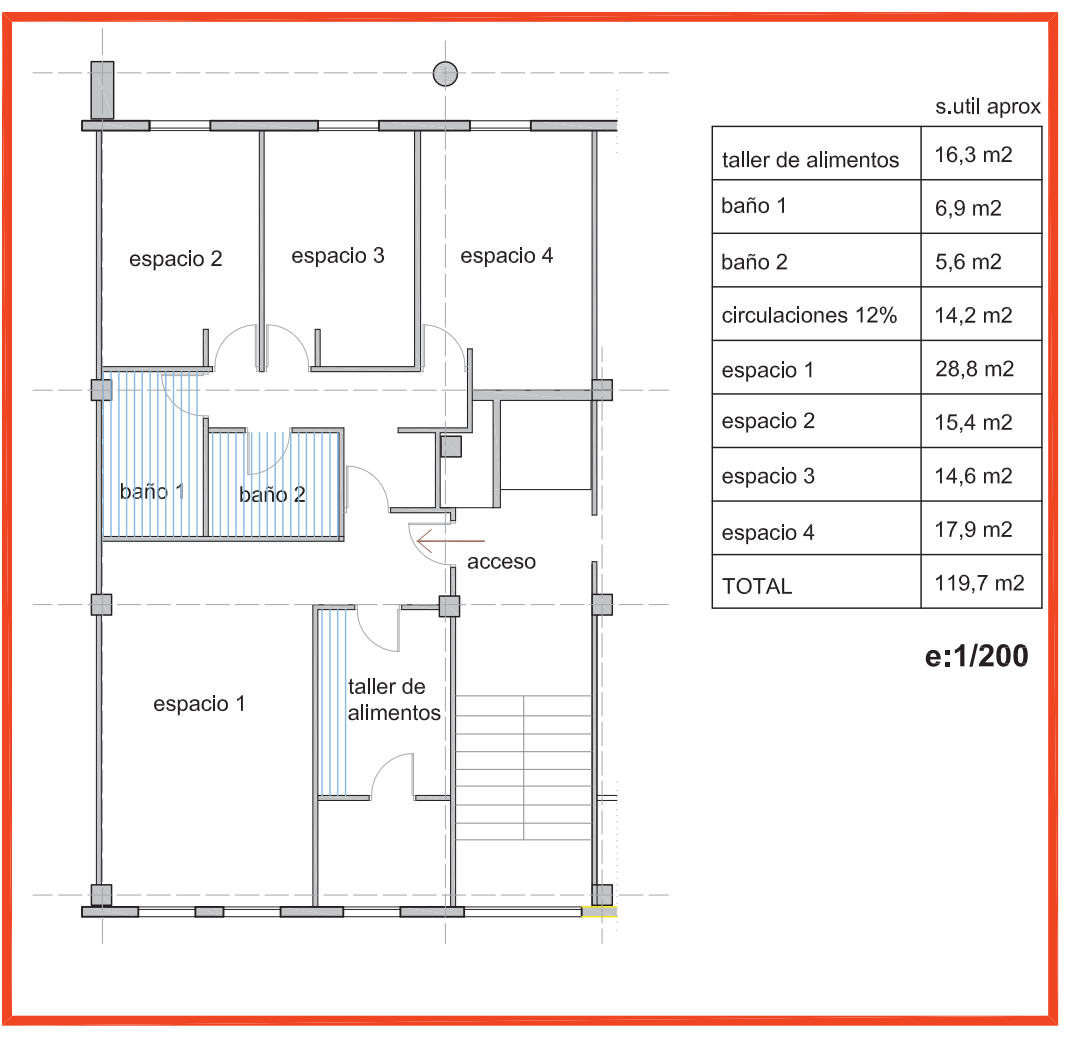

\section{SISTEMAS DE AGRUPACIÓN}

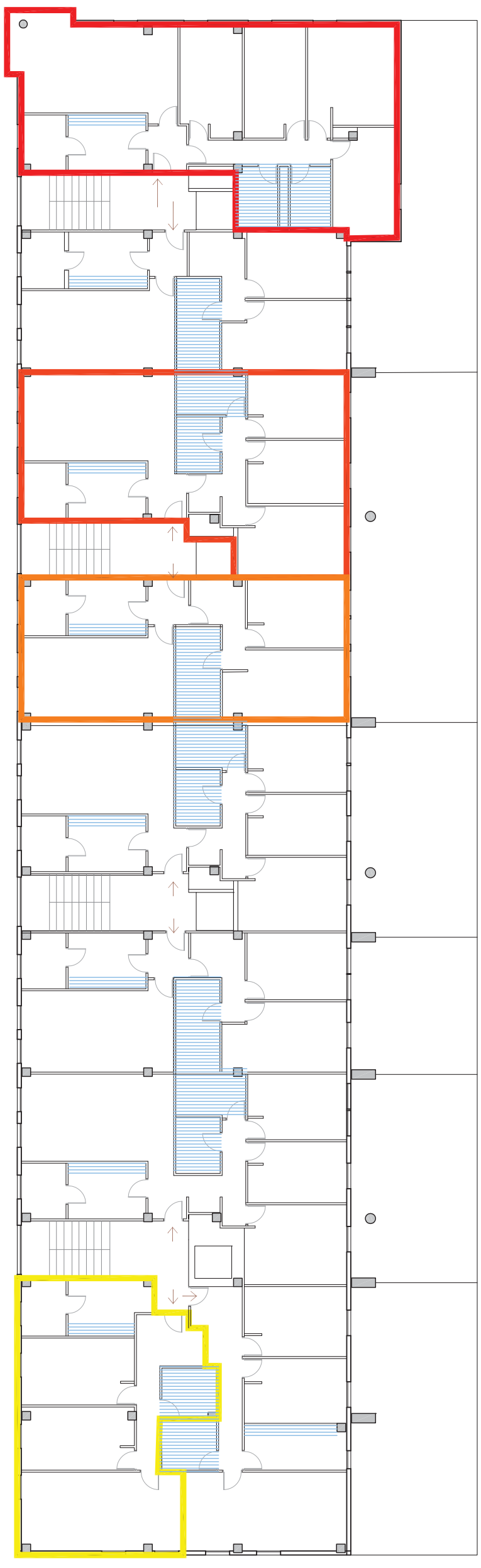




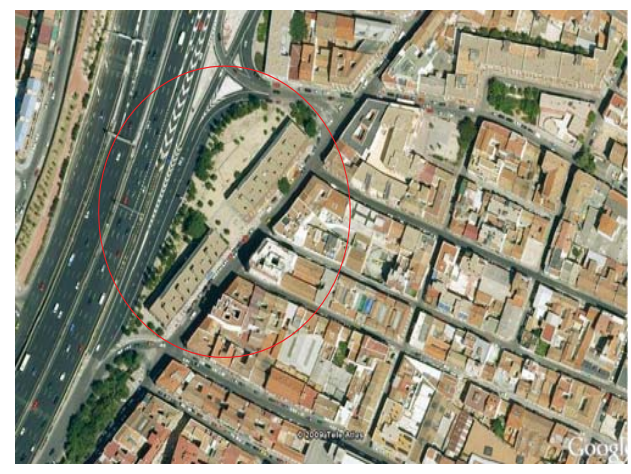

FICHA 3.1

\title{
EUROPAN 3
}

(año 1992)

\section{JAIME LÓPEZ Y JAIME LATAS: 60 VIVIENDAS EN MADRID}

\author{
EMPLAZAMIENTO
}

Avenida Peña Prieta $n^{0} 15$ y 17 , Madrid

COMIENZO DE OBRAS- FINALIZACIÓN DE LAS OBRAS

Fin: año 2000

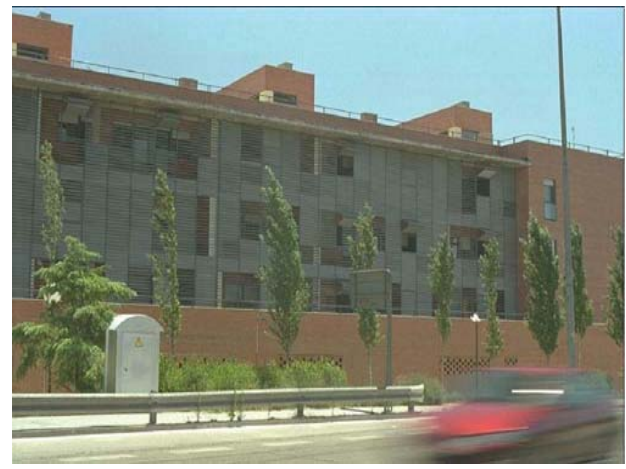

¿ES EL PROYECTO DE CONCURSO?

No. La solución de esquina se diferencia del resto de vi viendas tipo aunque en el proyecto de concurso se reflejaba más esta diferencia.

$N^{\circ}$ DE VIVIENDAS TOTALES CONSTRUIDAS

60 viviendas (en 2 bloques de 30)

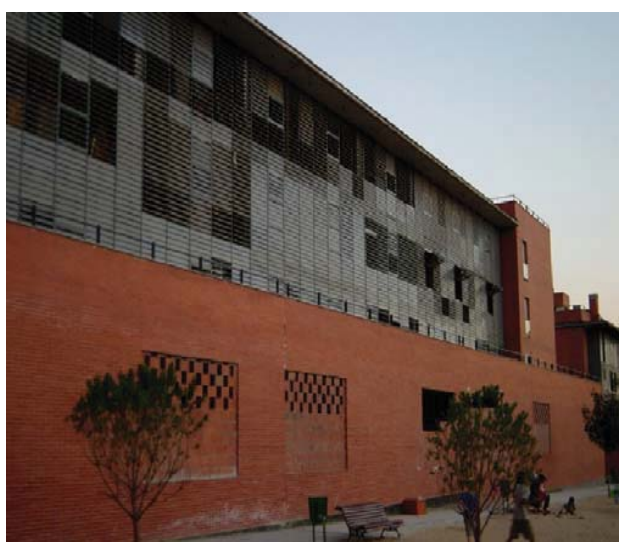

No DE VIVIENDAS POR SUPERFICIE

1 bloque

VIII 3 viviendas

VII 12 viviendas

VIII 9 viviendas

6 viviendas

USO DE LA PLANTA BAJA

Locales comerciales

USO DEL SOTANO

Garaje

\section{REFERENCIAS BIBLIOGRÁFICAS}

- AA.VV., Premios Calidad, Arquitectura y Vivienda 2003+2002 Ed. Artes Gráficas Palermo,S.L., Madrid, 2004, p. 154-155

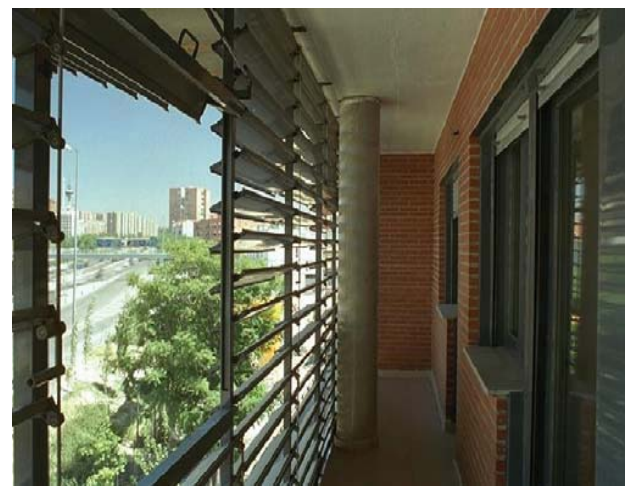

-- 10 años EUROPAN 5 España, Edición coproducida por EUROPAN/España, SEPES y el Ministerio de Fomento, 1999 España,p. 158 



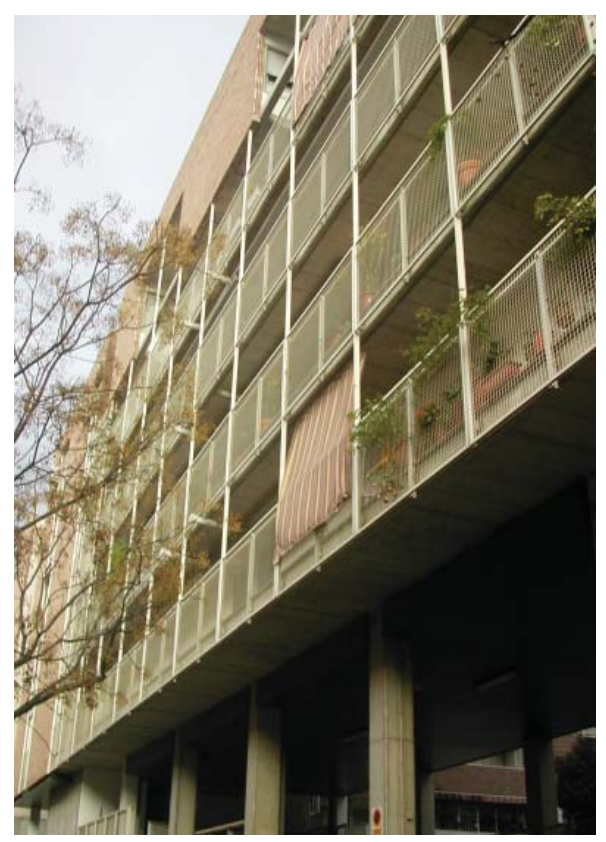

4.1.3. Edificios de viviendas Europan 3 (1992)

Enrique Johansson de Terry: viviendas sociales en Granada 
VIVIENDAS EUROPAN (1988-2008) | Una aproximación a los modos de vida en el cambio de siglo en España 4. EUROPAN: DEL CONCURSO A LA REALIZACIÓN

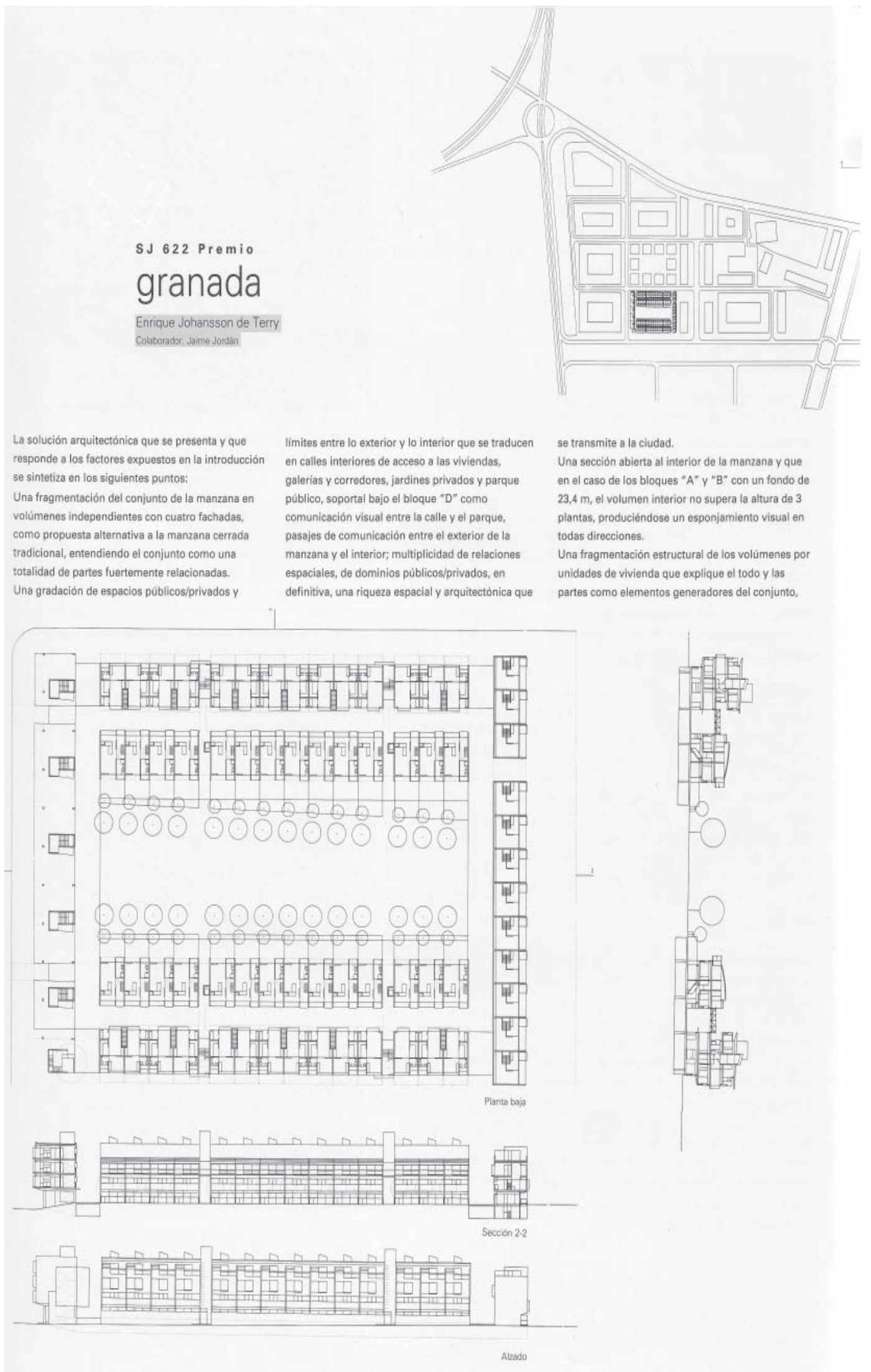

Ref. 4.93. Paneles de concurso 


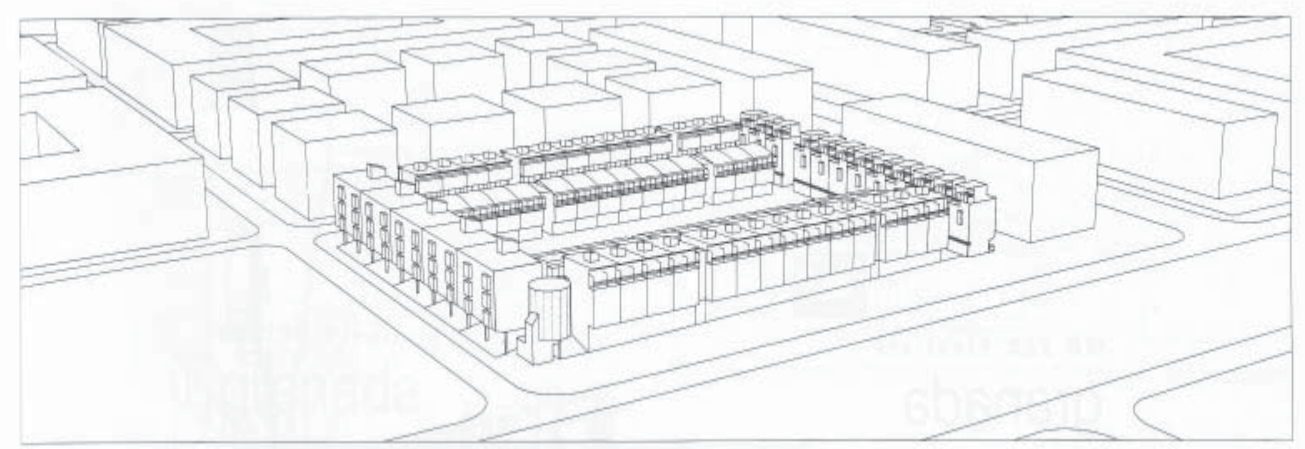

realizado mediante sensibles cambios de planos $y$ de materiales entre los elementos, posibilitando asi dicho entendimiento.

Una respuesta volumétrica en encuentros de los bloques con el perimetro exterior de la manzana, es decir retranqueo a modo de soportal de los bloques "A" $y$ "B", gran soportal de comunicación visual del bloque " $D$ " o el vacio existente en las viviendas taller del bloque "C", todos como espacios de relación entre lo público y lo privado, lo exterior y lo interior.

La racionalización en el proceso de diseño, nos marca y una modulación de $90 \mathrm{~cm} \times 90 \mathrm{~cm}$ que se ajusta perfectamente a las dimensiones del solar $y$ que genera un orden de medidas tanto en planta como en alzado y sección, que afecta al conjunto de todos los volúmenes de la propuesta.

El lugar y el clima, son condicionantes claves del proceso de diseño. La suave pendiente de la parcela hacia el Sur, determina el gran soportal que es frente de relación espacial/visual exteriorinterior de la manzana. La calle peatonal de lado Norte, potencia la posición de las viviendasitaller. Sirviendo de apoyatura a un posible desarrollo de mercado de artesania en la calle.
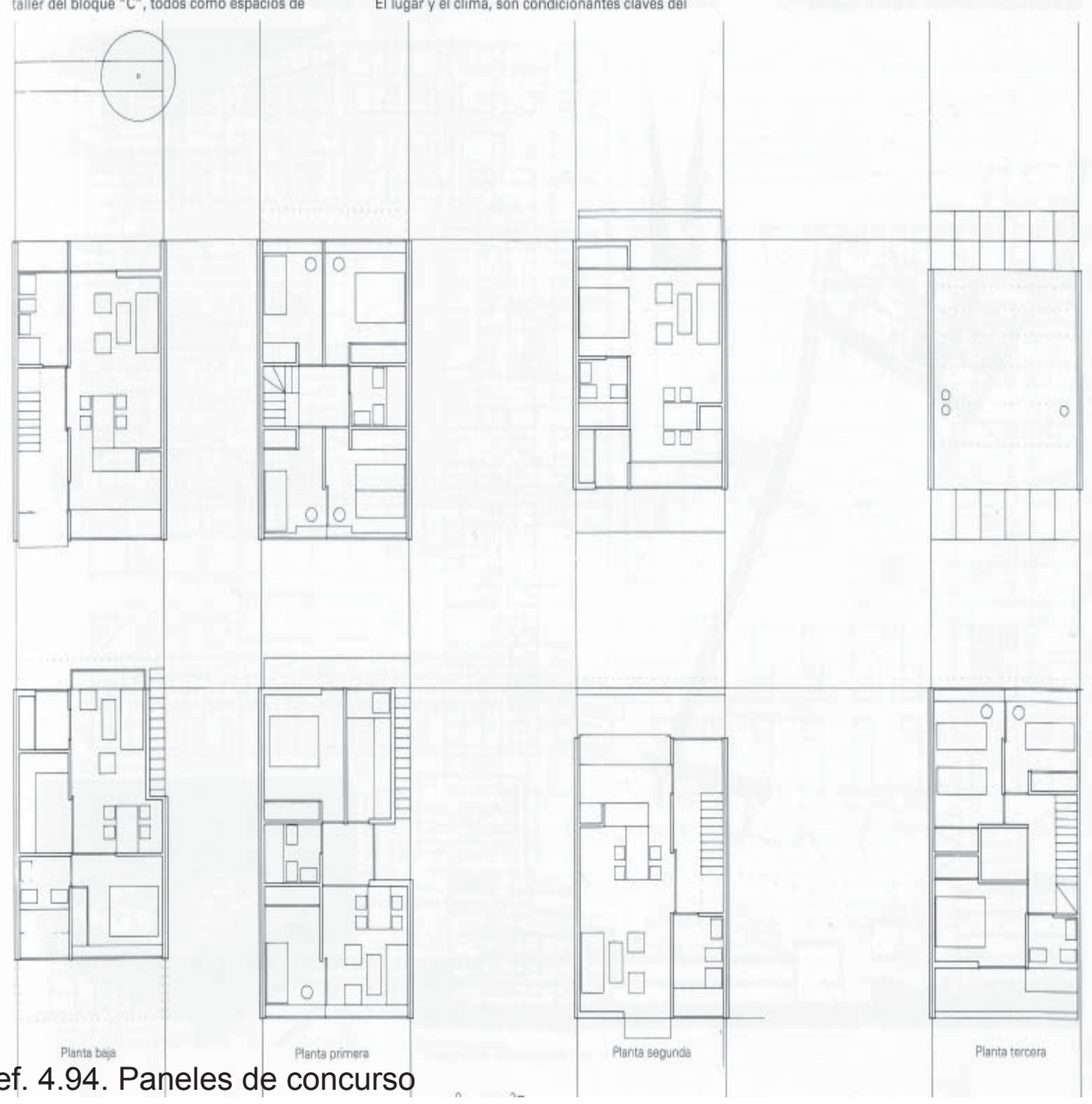
VIVIENDAS EUROPAN (1988-2008) I Una aproximación a los modos de vida en el cambio de siglo en España

4. EUROPAN: DEL CONCURSO A LA REALIZACIÓN

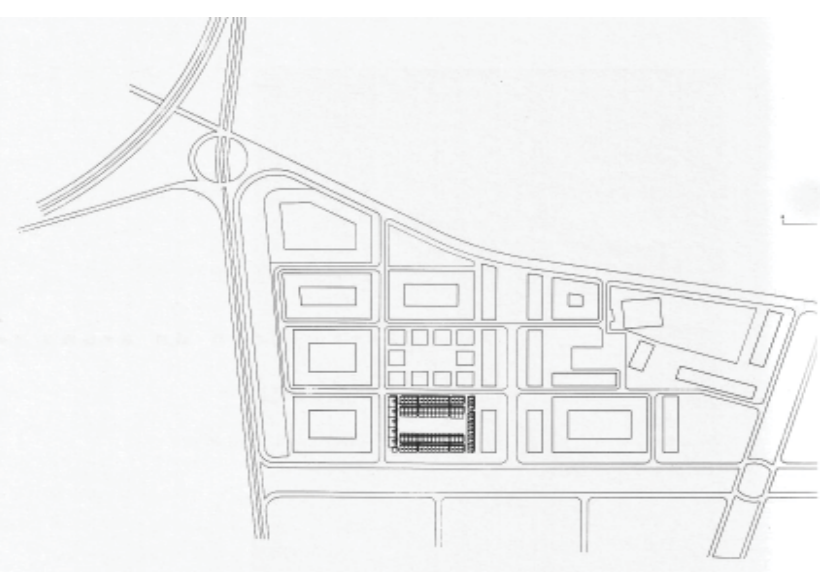

Ref.4.95. Solar de concurso

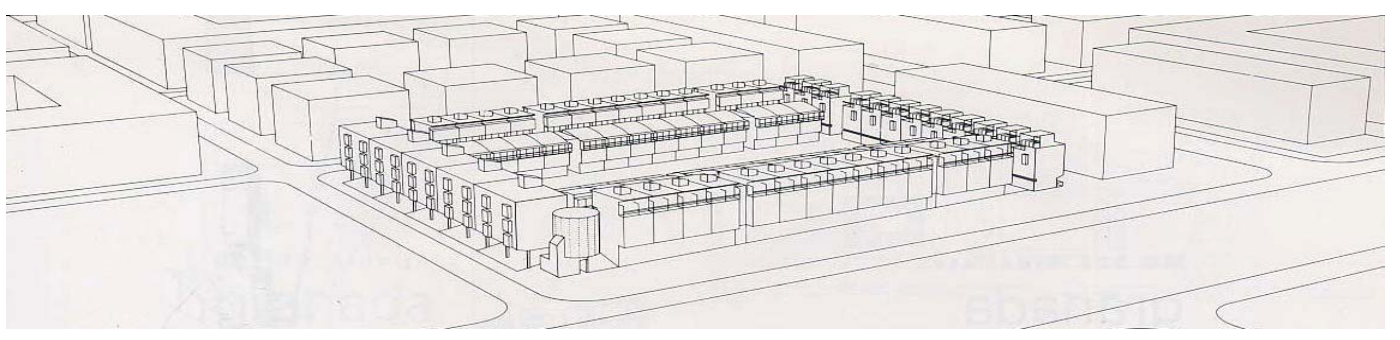

Ref.4.96. Perspectiva del conjunto

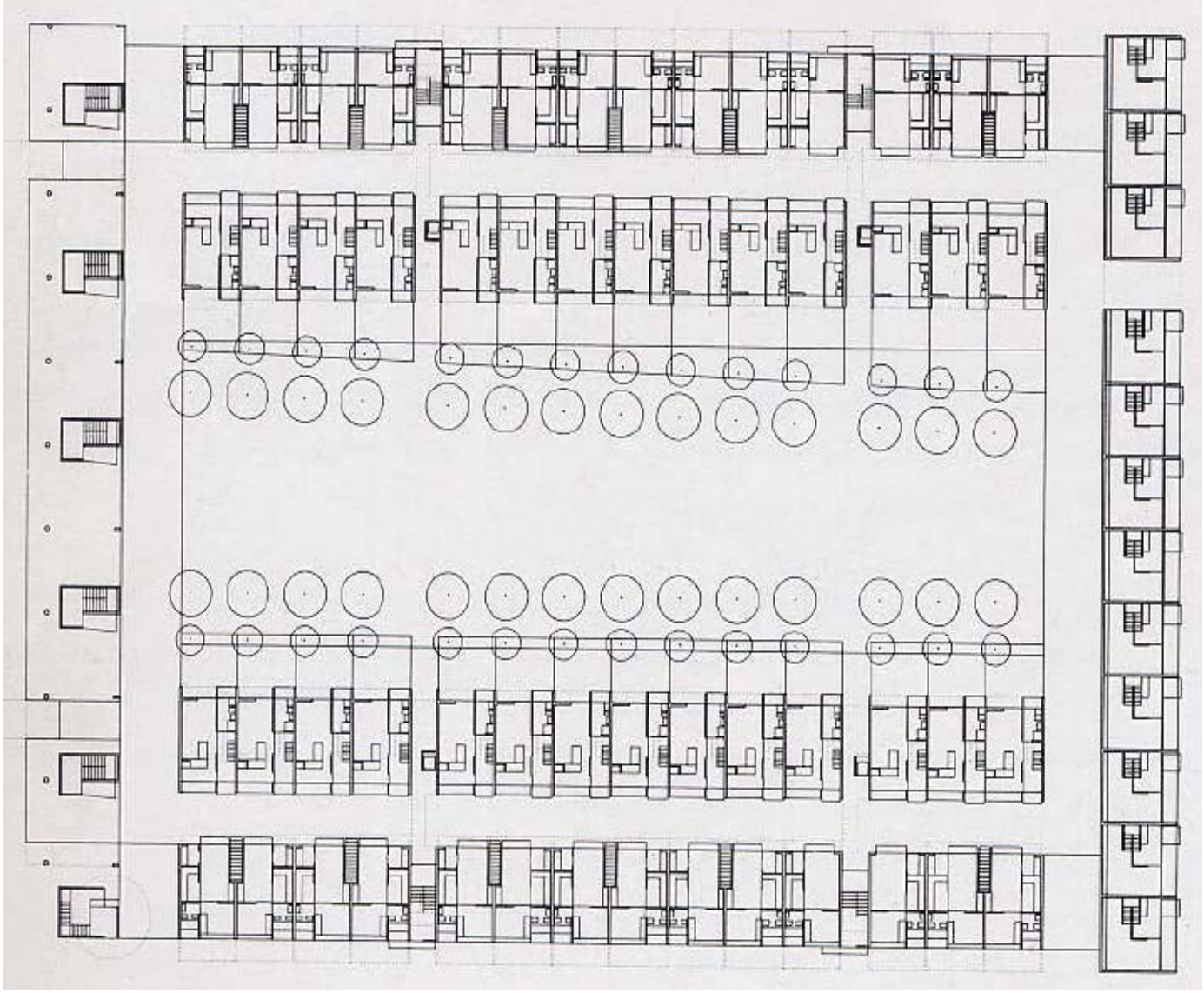

Ref.4.97. Planta de conjunto 


\section{Fase de concurso}

El solar propuesto para Europan 3 en el emplazamiento de Granada está situado en el Norte de la ciudad, en una zona de crecimiento bien conectada con el centro que fue desarrollada por el planeamiento en esta época. El solar tiene una forma rectangular, con circulación rodada en tres de sus lados. Lamentablemente, una población marginal fue la que se asentó en esta zona por lo que en el enunciado se planteaba crear viviendas de mayor calidad con su respectiva dotación de servicios. El objetivo del planeamiento era potenciar las áreas periféricas a través de estas propuestas.

El planeamiento limita a la tipología de manzana cerrada de tres plantas, que supone un $60 \%$ de la superficie. El resto se podía disponer a espacios que revitalizaran la ciudad.Se tiene una previsión de espacios libres y zonas verdes.

En la publicación de Europan para este solar sólo recopila el proyecto ganador que se otorga a Enrique Johansson de Terry.

El planteamiento del autor pretende fragmentar el proyecto en cuatro volúmenes independientes con cuatro fachadas, como una propuesta alternativa a la manzana cerrada residencial.

Este proyecto ofrece una reflexión entre el espacio público y el espacio privado. El autor intenta generar "multiplicidad de relaciones espaciales" y de "dominios públicos/privados".

Crea un espacio interior de manzana muy interesante en el que se mezclan zonas verdes, recorridos y patios de viviendas de planta baja. También se habla de poder desarrollar un posible mercado de artesanía en la calle bajo los soportales de la planta baja.

El módulo de referencia es de 90×90 cm a la que se ajustan totalmente las viviendas propuestas. El proyecto de concurso desarrolla varias unidades de vivienda y plantea una diversidad y flexibilidad en cada una de ellas.

En la composición de las fachadas se juega también con los condicionantes del lugar. El solar tiene una pendiente hacia el Sur, lo que determina los soportales en una de las fachadas que invitan a entrar al interior del espacio de la manzana.

Define en su planteamiento una vivienda con doble orientación y detalla cada una de las unidades por planta. Son viviendas con una clara modulación, tienen doble orientación e intentan optimizar al máximo el espacio. Propone una repetición de estos tipos en toda la manzana, por lo que no se plantea alternativas que podrían dotarle de cierta flexibilidad. 


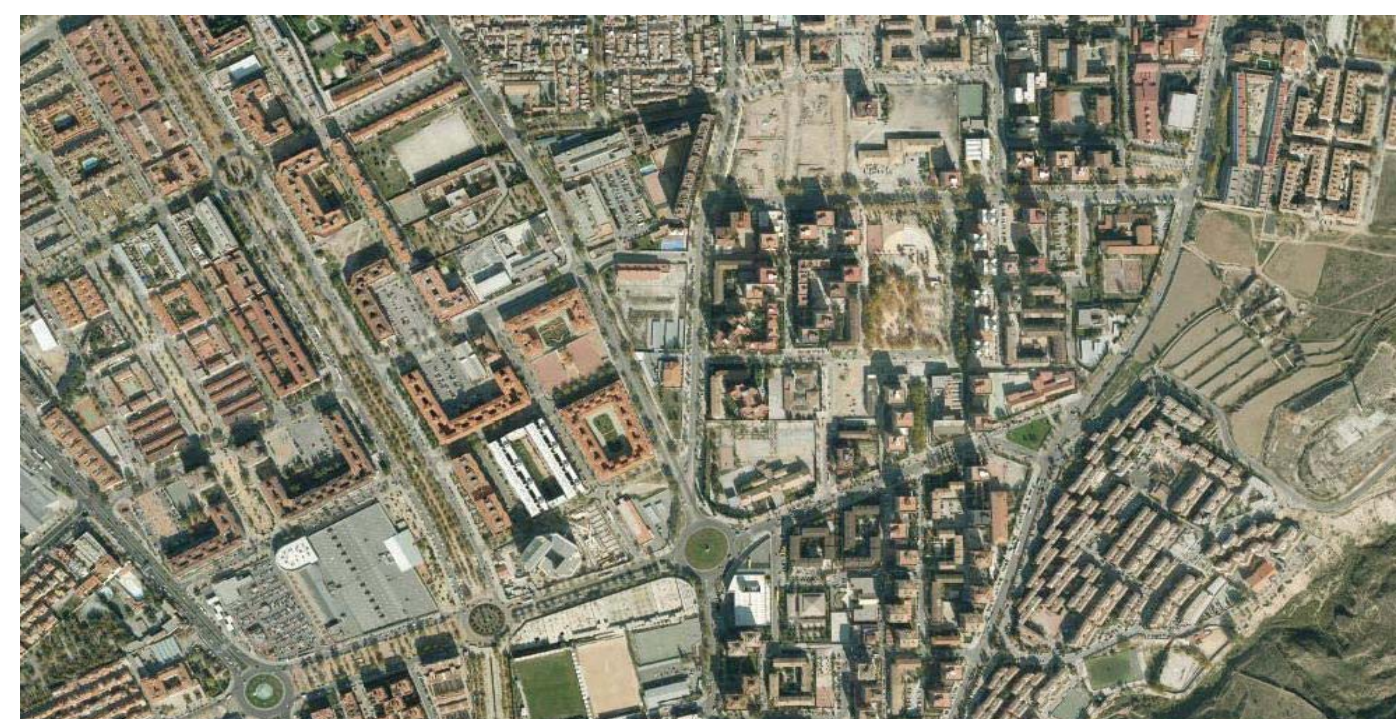

Ref.4.98. Solar donde se construye

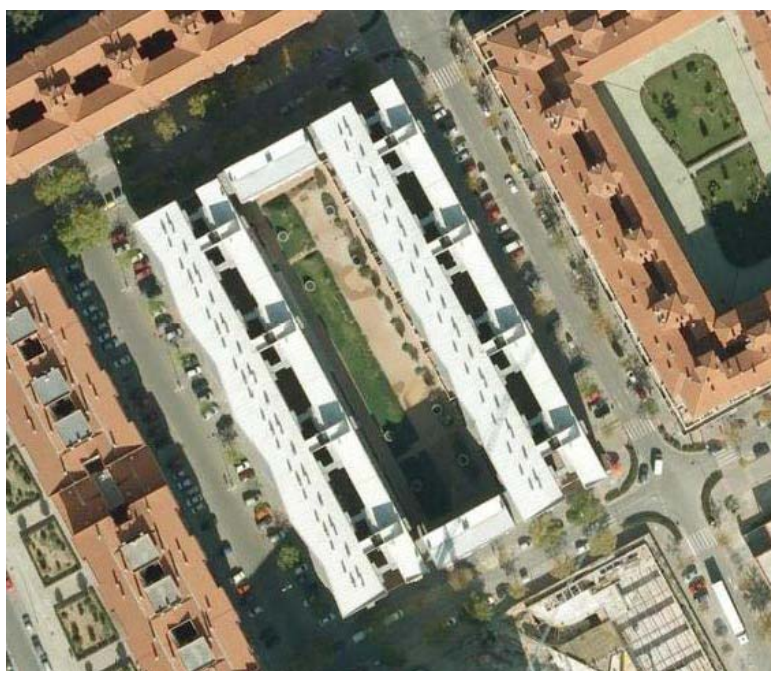

Ref.4.99. Planta de cubiertas

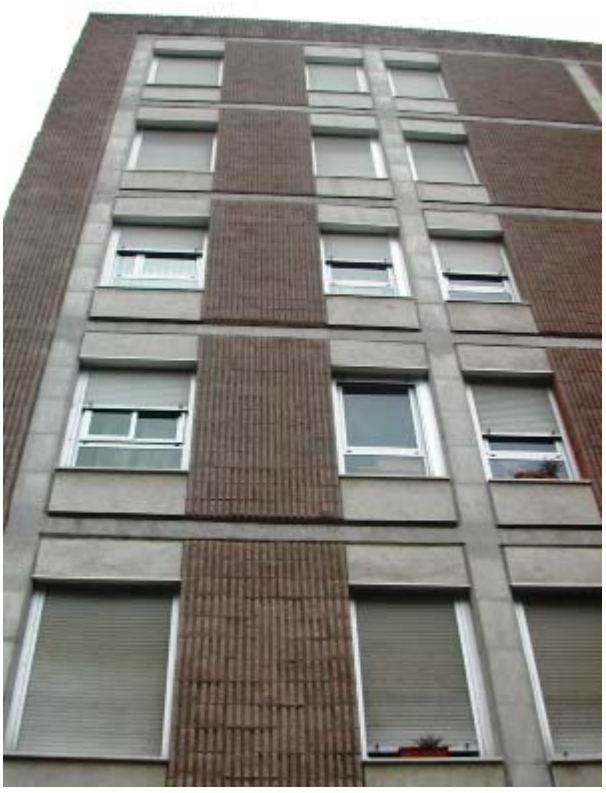

Ref.4.100. Fachada

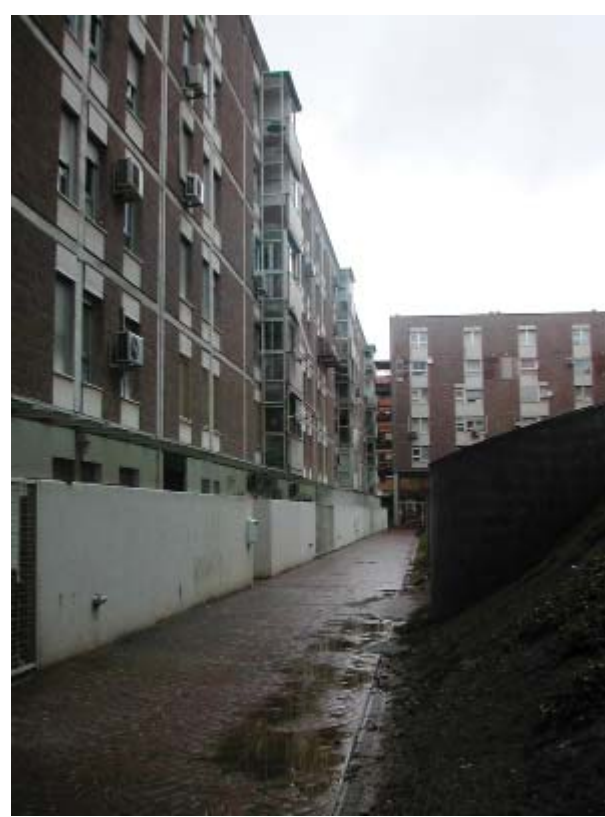

Ref.4.101. Interior manzana 


\section{Fase de realización ${ }^{1}$}

El proyecto no se construye en el solar previsto del concurso, situado en la periferia de Granada, pero sí en otro de condiciones muy similares en la misma zona y se aumenta la edificabilidado por planta. A simple vista no llama la atención, sobre todo porque el polígono residencial de Almanjayar ha quedado identificado con el edificio construido recientemente de la Consejería de Economía y Hacienda de la Junta de Andalucía.

Si se recorre el espacio interior de la manzana se puede observar que tiene un desnivel considerable dentro de ésta, por lo que parece que exista una pequeña montaña en el jardín interior más que un espacio de estancia dentro de ella.

Se observa en la visita que esta zona ha dejado de estar habitada por una población marginal, que era lo que se trataba de conseguir en las premisas de partida.

Se utilizan materiales sencillos como ladrillo, carpintería metálica y cubierta plana.

A continuación se adjunta una ficha-resumen.

\footnotetext{
${ }^{1}$ No se ha podido obtener material suficiente de la obra construida para poder realizar una valoración con respecto al proyecto de concurso por lo que las apreciaciones que se van a realizar serán las obtenidas de una simple visita a la obra construida.
} 

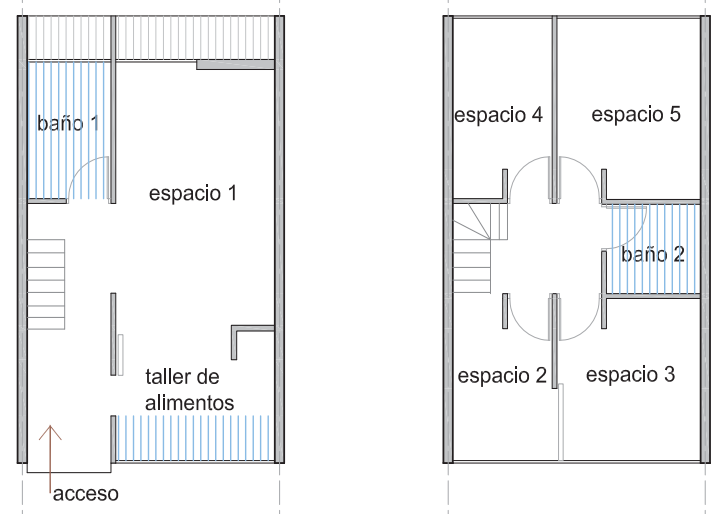

\begin{tabular}{|l|l|}
\hline \multicolumn{2}{|l}{ s.util aprox } \\
\hline taller de alimentos & $8,9 \mathrm{~m} 2$ \\
\hline baño 1 & $4,9 \mathrm{~m} 2$ \\
\hline baño 2 & $3,6 \mathrm{~m} 2$ \\
\hline circulaciones 14\% & $11,1 \mathrm{~m} 2$ \\
\hline espacio 1 & $18 \mathrm{~m} 2$ \\
\hline espacio 2 & $6,9 \mathrm{~m} 2$ \\
\hline espacio 3 & $10 \mathrm{~m} 2$ \\
\hline espacio 4 & $7,7 \mathrm{~m} 2$ \\
\hline espacio 5 & $11,2 \mathrm{~m} 2$ \\
\hline TOTAL & $82,3 \mathrm{~m} 2$ \\
\hline & $\mathbf{e : 1 / 2 0 0}$
\end{tabular}

\section{SISTEMAS DE AGRUPACIÓN}

superficie construida total por planta:

$3930 \mathrm{~m} 2$

superficie construida zonas comunes por planta: 652 m2 (17\%)

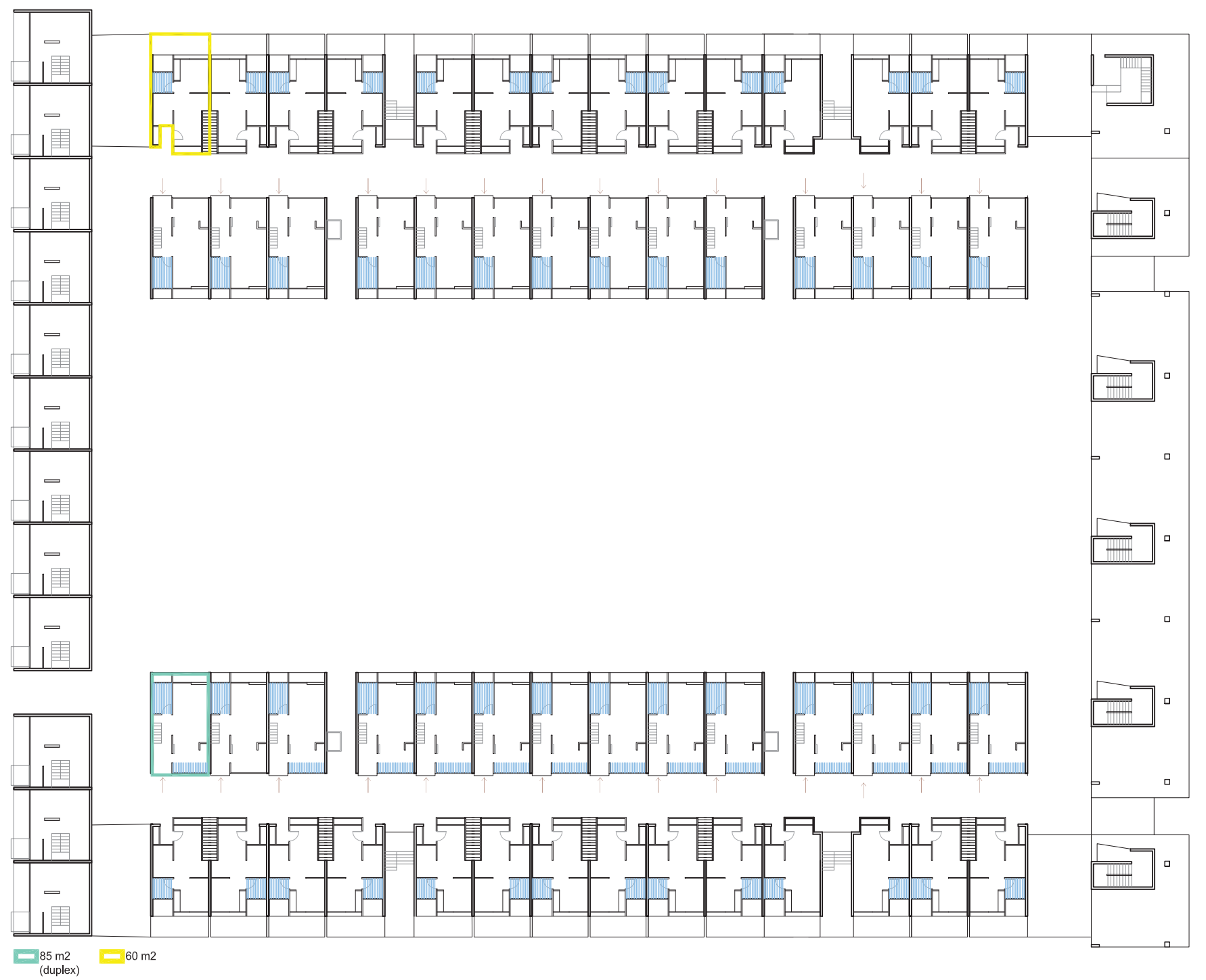



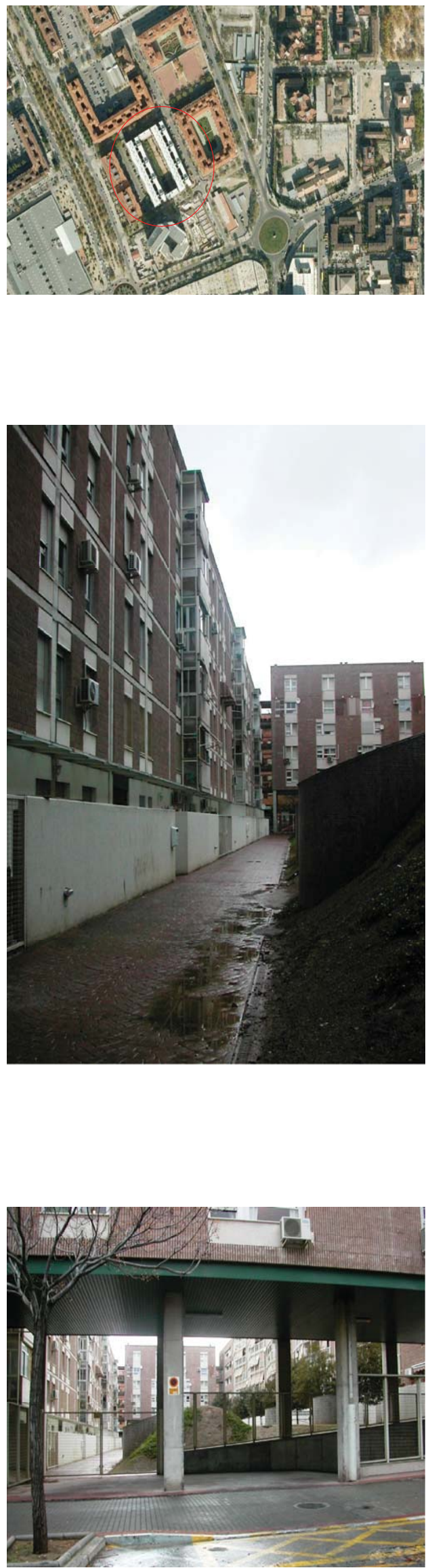

FICHA 3.2

\section{EUROPAN 3}

(año 1992)

\section{ENRIQUE JOHANSSON DE TERRY 252 VIVIENDAS EN GRANADA}

EMPLAZAMIENTO

c/Profesor Francisco Dalmau 4, Granada (Edificio Europan)

COMIENZO DE OBRAS- FINALIZACIÓN DE LAS OBRAS Fin: año 2002

¿ES EL PROYECTO DE CONCURSO?

No. Existían algunas vivendas en planta baja que, en la solución final se sustituyen por un paso de acceso al interior de manzana

$\mathrm{N}^{\circ}$ DE VIVIENDAS TOTALES CONSTRUIDAS

252 viviendas

\section{No DE VIVIENDAS POR SUPERFICIE}

(en el concurso 252 viv)

VIIT 84 viviendas

VIIA 168 viviendas

USO DE LA PLANTA BAJA

Viviendas y locales comerciales

USO DEL SOTANO

Garaje

\section{REFERENCIAS BIBLIOGRÁFICAS}

- 10 años EUROPAN 5 España, Edición coproducida por EUROPAN/España, SEPES y el Ministerio de Fomento, 1999, España,p. 157.

- EUROPAN 10 España, "Proyectar la urbanidad", Madrid 2010, p. 223 



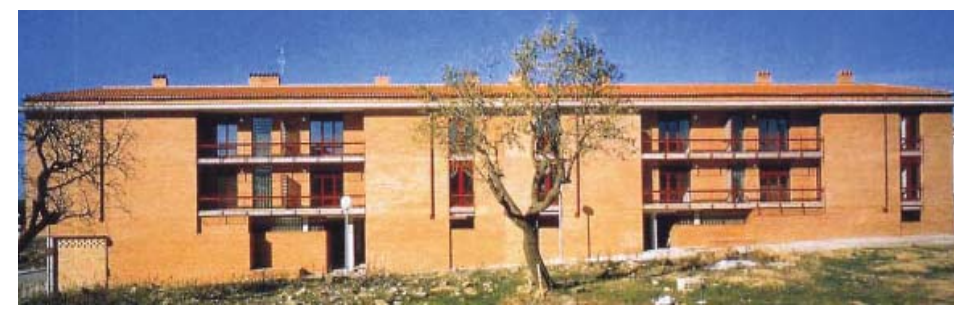

4.1.3. Edificios de viviendas Europan 3 (1992)

Ma José Duch y Eva Prats: bloque de viviendas sociales y plaza en Guissona (Lérida) 


\section{calella}

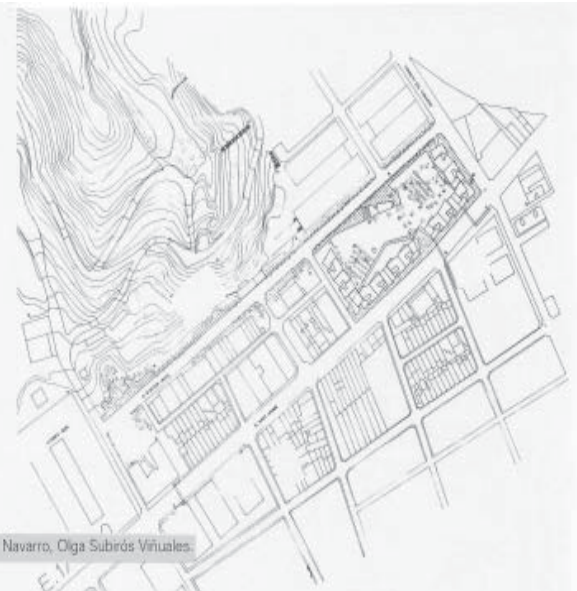

Se Duch Navarro. Eva Prats Güerre

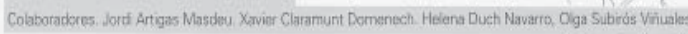

El solar, adyacente a la carretera nacional, $N-11$, fue anteriormente un camping lleno de árboles que nosotros intentamos preservar. El edificios fachada a la calle y a la zona arbolada.

Las viviendas cruzan de una a otra fachada y su distribución responde al paso de un espacio a otro. Entre estos dos extremos, las habitaciones y las escaleras se abren al patio.

El gran tráfico rodado de la carretera la ha convertido en una barrera al paso de los peatones. Ambos lados se conectan tan sólo con pasos

subterráneos. Su sección revela un proceso de crecimiento irregular a partir de unas primitivas viviendas de planta baja. Si este crecimiento se completa, definirá una sección muy cerrada reduciendo enormemente la cantidad de luz que actualmente llega a la calle.

Nuestro proyecto reconoce las cualidades de este proceso inacabado y se propone trabajar con las medianeras y la línea quebrada de las cornisas. La zona arbolada, el edificio y la calle se conectan en tres distintos niveles: desde el aparcamiento, a través del edificio en el nivel de planta baja y mediante una pasarela desde el primer nivel de viviendas.

El jardin se abre a norte hacia un paisaje màs distante formado por una pequeña colina que aบ

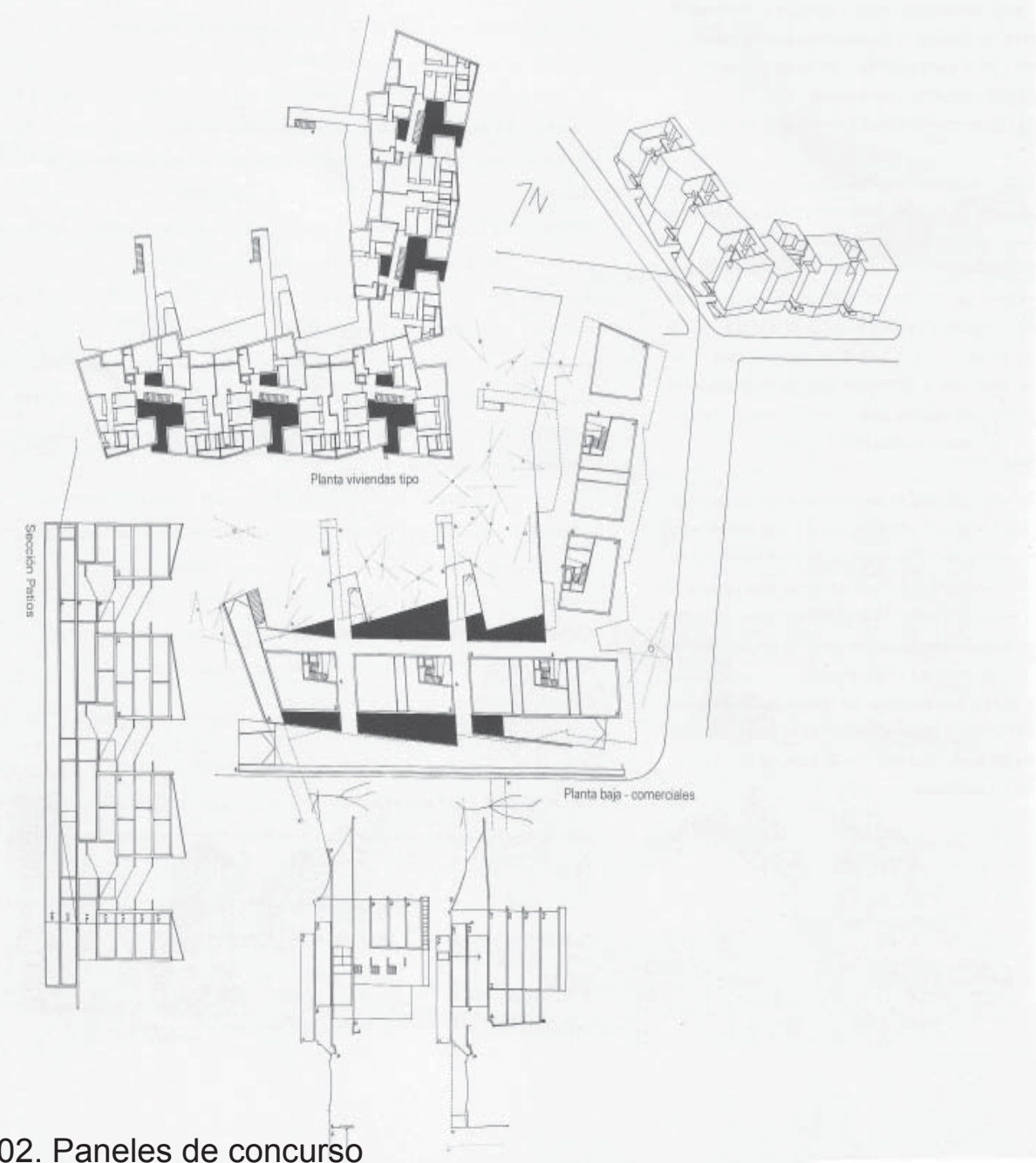

Ref. 4.102. Paneles de concurso 

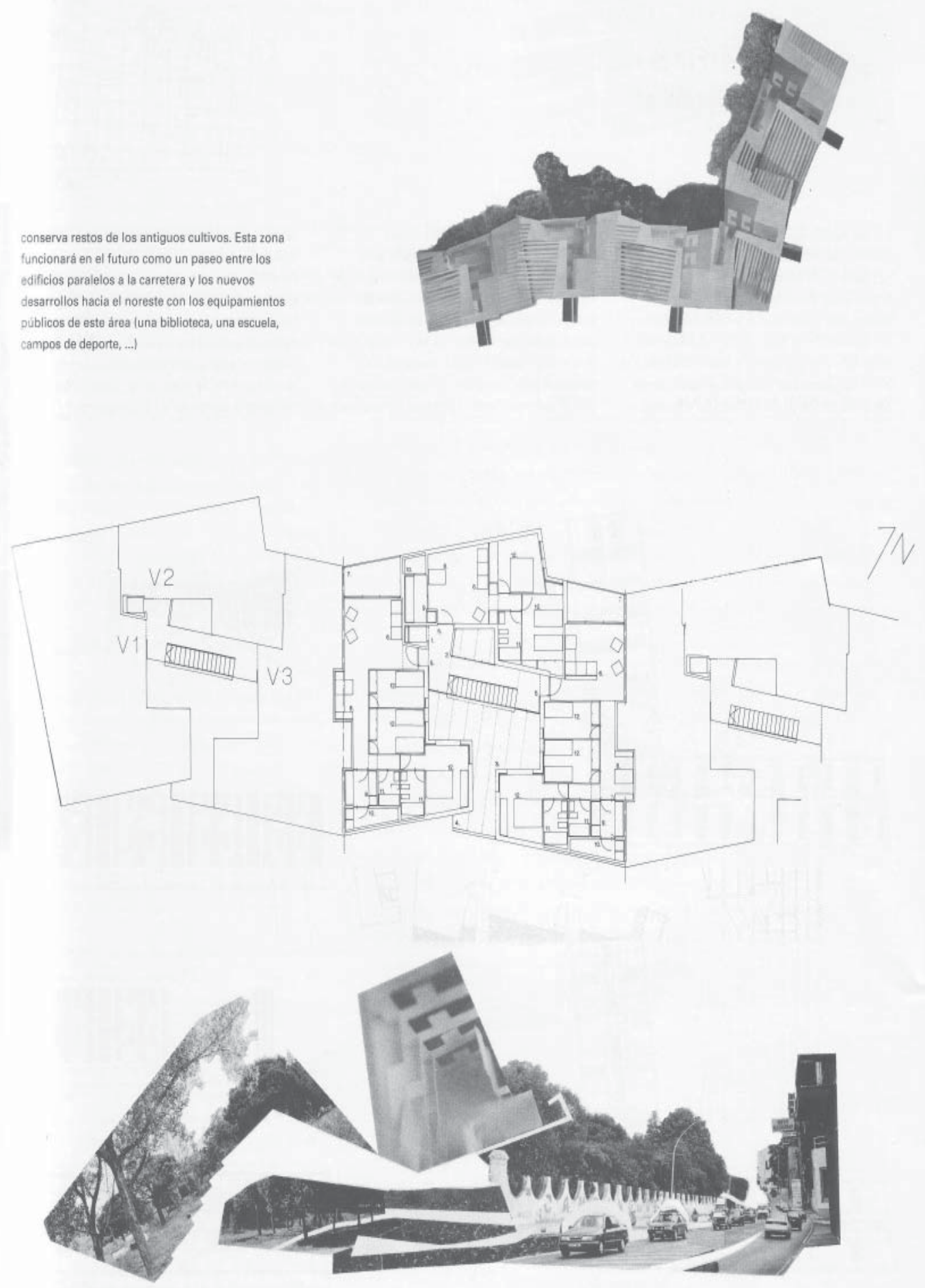

Ref. 4.103. Paneles de concurso 
VIVIENDAS EUROPAN (1988-2008) I Una aproximación a los modos de vida en el cambio de siglo en España

4. EUROPAN: DEL CONCURSO A LA REALIZACIÓN

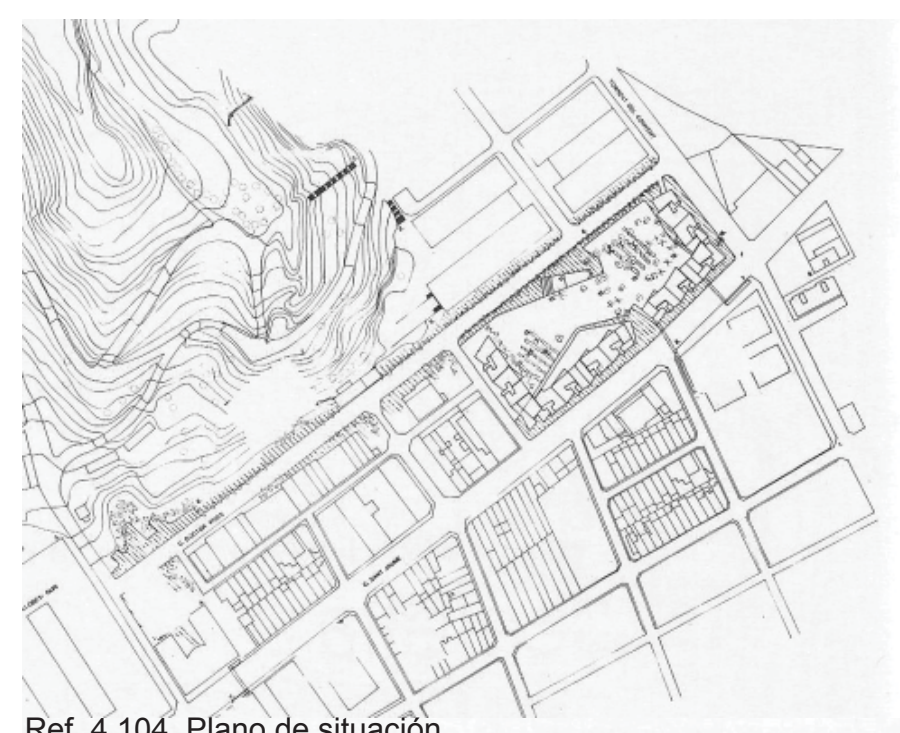

Ref. 4.104. Plano de situación
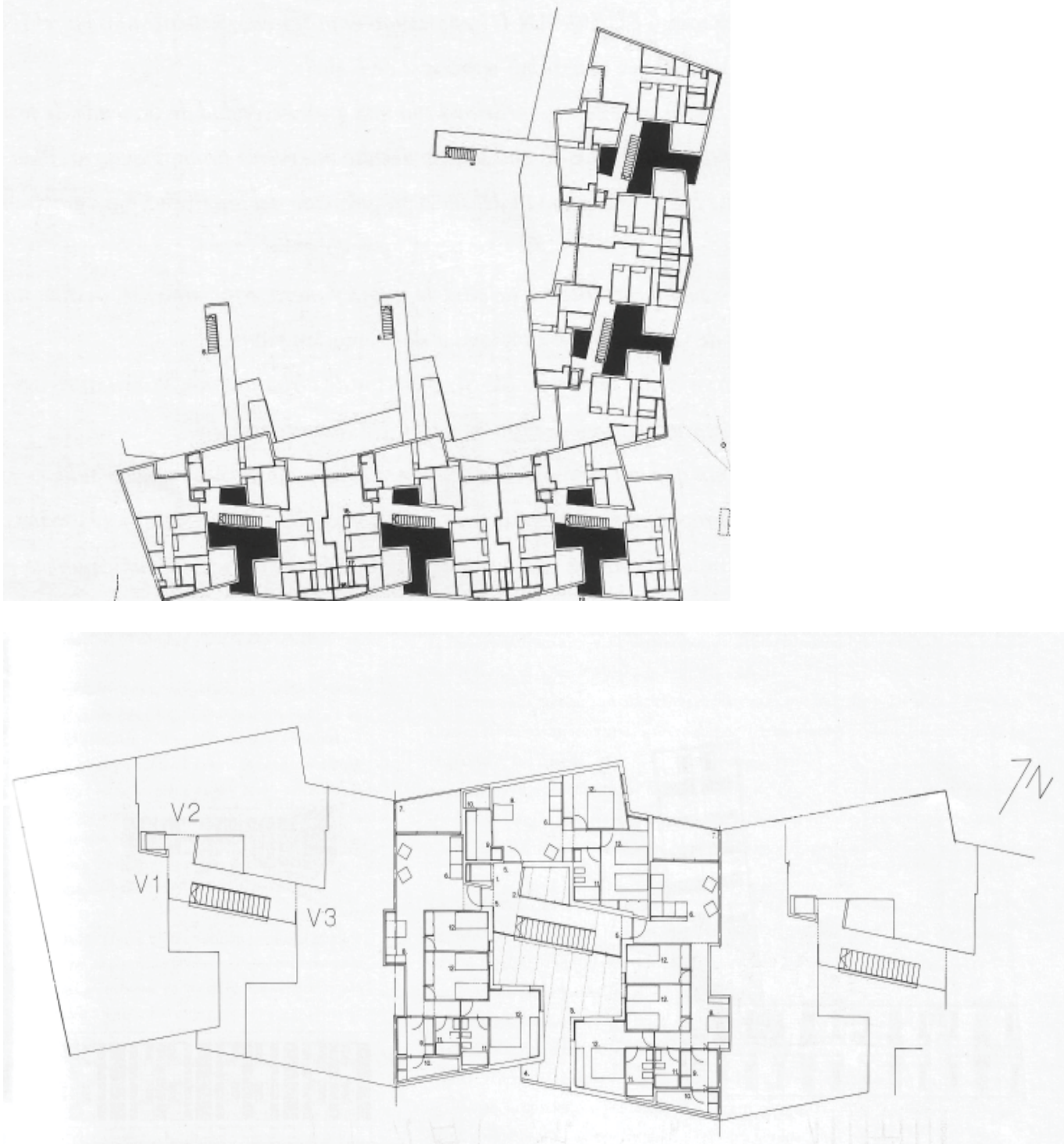

Ref. 4.105. Plantas de concurso 


\section{Fase de concurso}

Uno de los solares de concurso de Europan 3 se sitúa en Calella, Barcelona. El enunciado planteaba la relación entre lo nuevo y lo existente. Se encuentra junto a la carretera nacional, en una zona arbolada que anteriormente fue camping y es prácticamente plano. Se situa en el pie de una pequeña colina y posee vistas al mar. El planeamiento de esta zona prevé posiblidades de crear espacios libres y verdes y se insinúa en el enunciado la conservación de los existentes en el camping. Como consecuencia, la densidad debe ser baja y se parte de la premisa de que las viviendas deberían de ser de calidad aunque sujetas a los estándares de vivienda de protección oficial. Se propone además optimizar la superficie útil/ construida, utilizar soluciones constructivas apropiadas para el caso y teniendo en cuenta siempre las preexistencias.

Tras la deliberación del jurado se concede el galardon a dos proyectos:

- Ignacio Rubio Carvajal, finalista. Proponía una volumetría fragmentada uniendo la parcela con el contexto. Hay una intención clara de relacionar el espacio público con el privado, dejando en la planta baja una apertura entre ambos.

- Ma José Duch y Eva Prats, mencionadas. Proponen que las viviendas sean pasantes y así las habitaciones vuelquen a la zona del patio interior para resguardarlas del ruido de la calle. A nivel urbanístico, se crea un paso de peatones por debajo de la carretera para resguardar de la rapidez del tráfico. También proponen relaciones entre los bloques existentes a través de pasarelas entre ellos. Crean una plaza interior en el norte del solar y en su propuesta la desarrollan, aumentando la escala proyectual. Además se crean conexiones peatonales con los equipamientos públicos de este área.

En la propuesta presentada desarrollan unas viviendas donde el núcleo de escaleras se sitúa en el espacio central de cada bloque y sirve a dos viviendas por planta. El acceso a las viviendas se realiza por la sala de estar, que suele estar conectada con la cocina y el tendedero, que recae sobre una de las fachadas. Son viviendas de dos y tres dormitorios, generosas en su superficie.

\section{Fase de realización}

El solar propuesto en el proyecto de concurso no pudo gestionarse y el equipo premiado tuvo la oportunidad de plantear otro proyecto en Guissona (Lérida). Éste consistía en la ordenación de una manzana de esta localidad y también comprendía la ordenación de la plaza y el espacio exterior existente.

Se propuso ocupar el espacio perimetral de la manzana con los edificios residenciales y liberar el espacio interior planteando un espacio público que sirviera de parque a éstos. En primer lugar se construyeron los dos bloques laterales, 


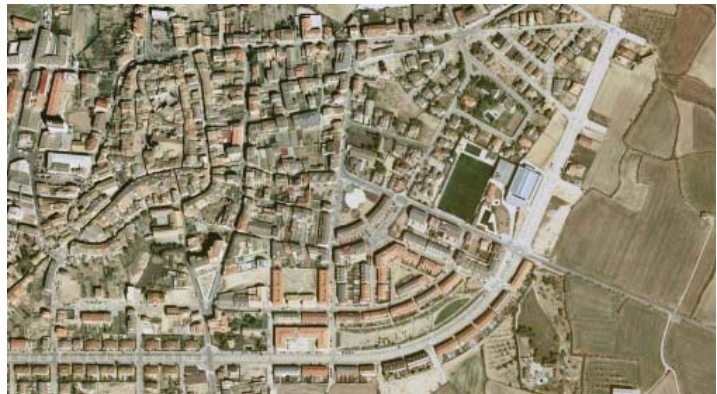

Ref. 4.106. Entorno

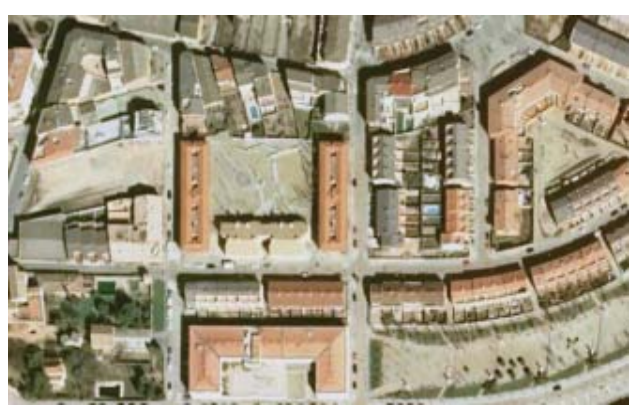

Ref.4.107. Planta situación

C. UEIDA

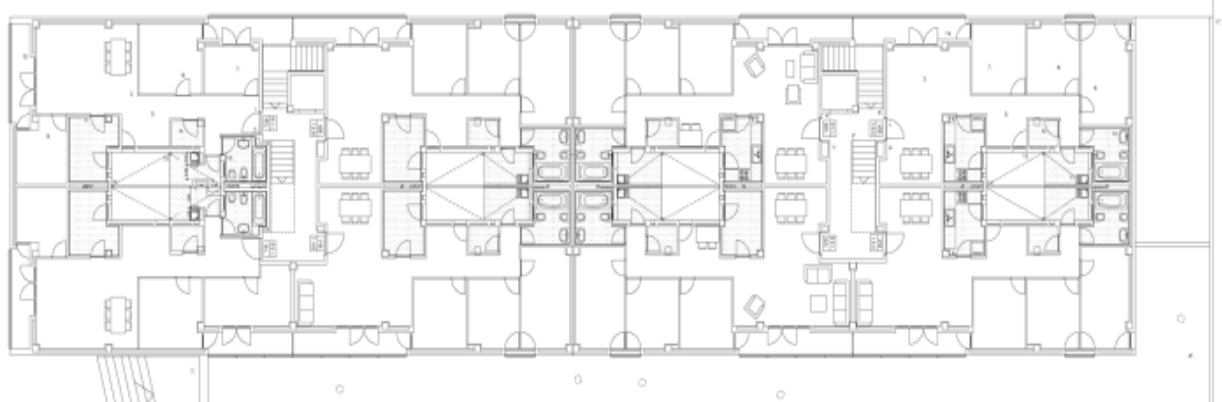

Ref.4.108. Planta de viviendas

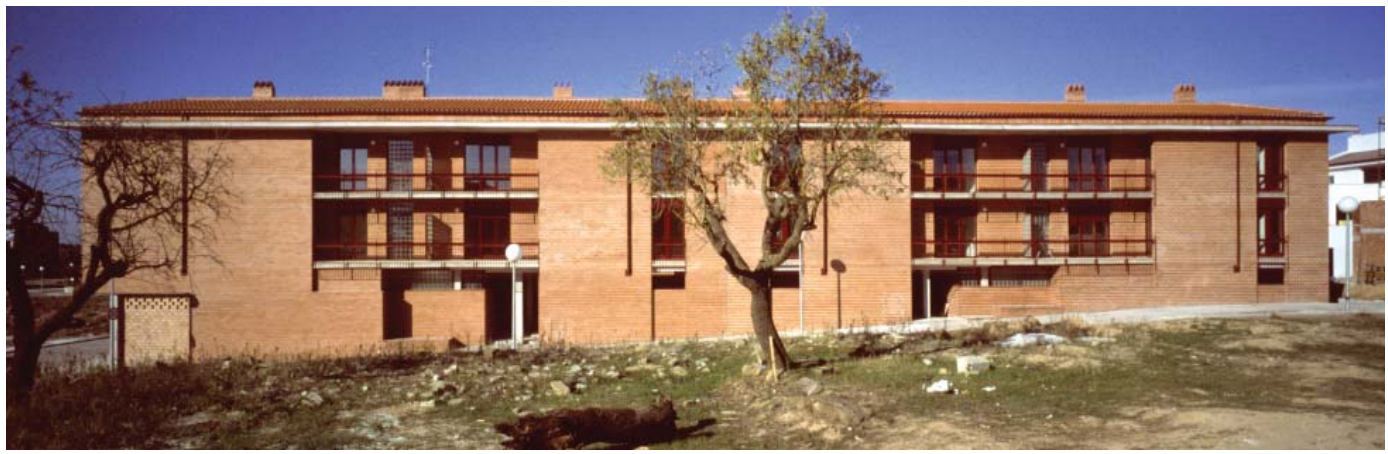

Ref.4.109. Fachada

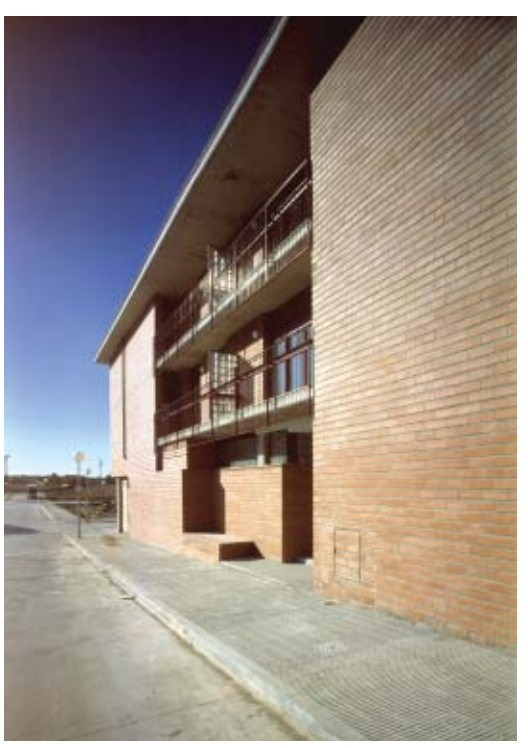

Ref. 4.110. Fachada

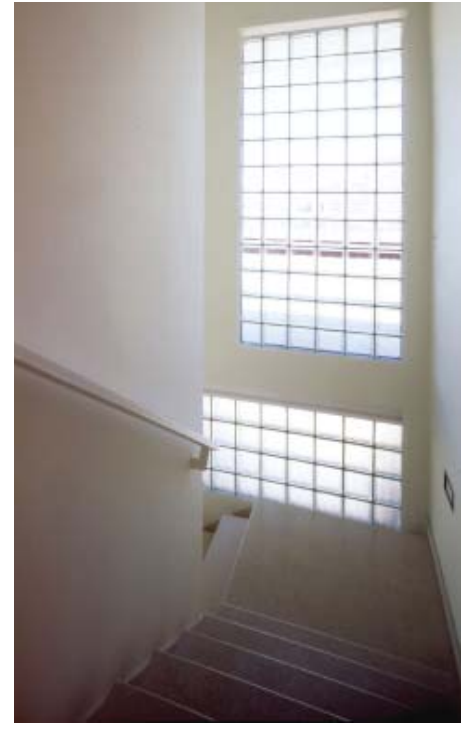

Ref.4.111.Escalera 
idénticos. Más adelante, se construyeron los bloques intermedios, que, según afirman los propios autores tienen mayor interés que las primeras.

Son bloques de viviendas de tres alturas, en el que cada uno tiene dos núcleos de comunicaciones que sirven a cuatro viviendas por planta. El bloque tiene cuatro patios interiores rectangulares hacia los que ventilan la cocina y los baños de dos viviendas.

Existen tres tipos distintos de viviendas (aunque dos tienen entre si una leve variación y son casi idénticas). Al más común, se accede directamente al estar y a través de él a un corredor que contiene las demás estancias: cocina, baños y habitaciones. El estar tiene una pequeña terraza que también tiene acceso directo desde la cocina.

En el otro, la vivienda tiene en su acceso un espacio de entrada, en el que se encuentran los dos baños. Más allá de este espacio encontramos primero la cocina con una galería y, después el estar, estancia a la que están vinculadas directamente las habitaciones y una pequeña terraza.

Los edificios están construidos en ladrillo y el aspecto exterior es el de un bloque de viviendas de protección oficial con algunas terrazas que le dan cierta calidez.

Quizá, lo más interesante del proyecto es el espacio urbano que genera. A éste se accede mediante el punto central de los dos bloques que se construyen posteriormente, o bien a través de las esquinas de la manzana. Los autores se esme-raron en el diseño de la plaza interior, dedicada fundamentalmente a los juegos de niños. Desde cada vivienda se puede visualizar este espacio, para tranquilidad de la familia. Se proyecta la vegetación con el fin de proporcionar sombra dentro del paisaje árido de la zona.

A continuación se adjunta una ficha-resumen. 


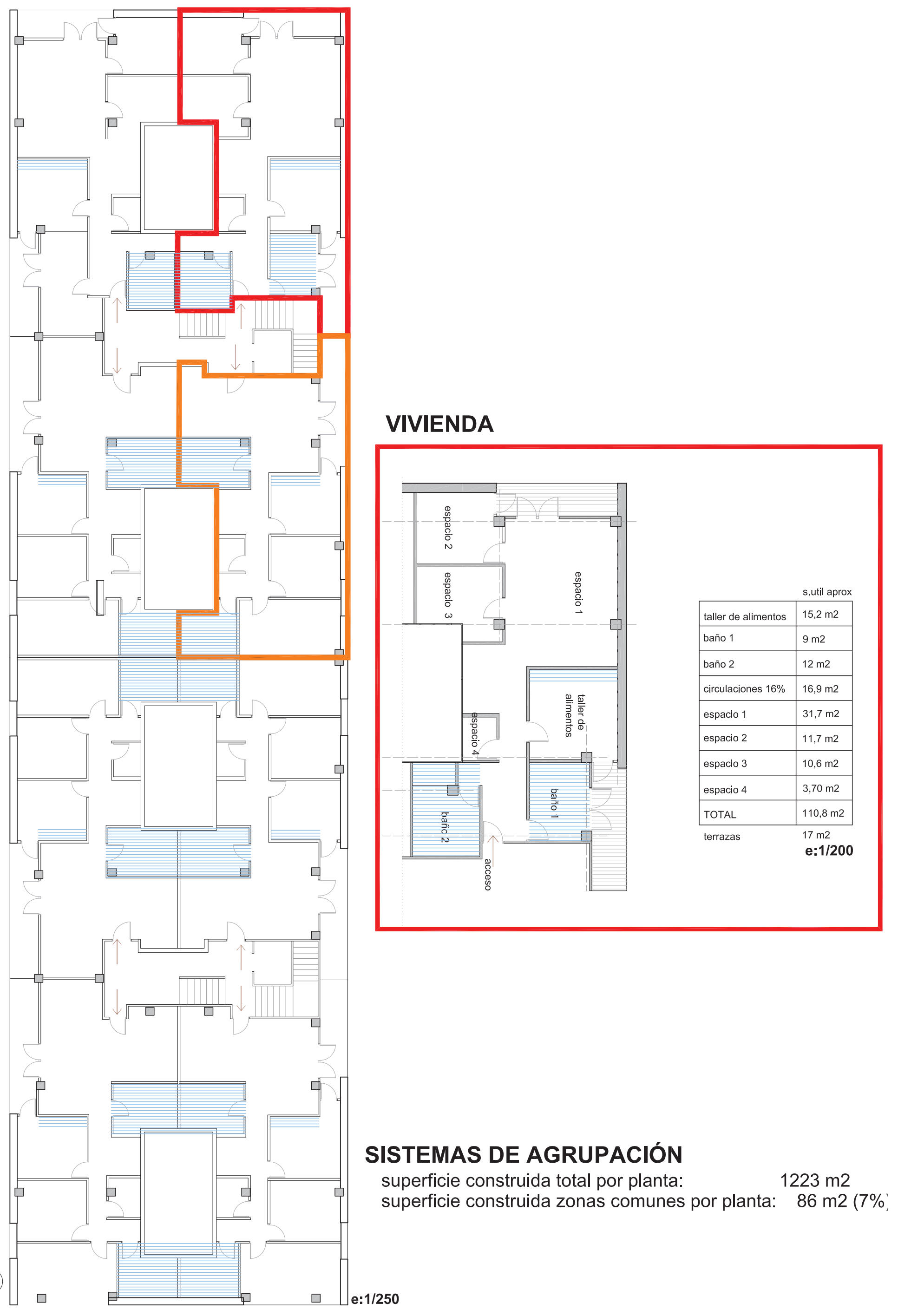



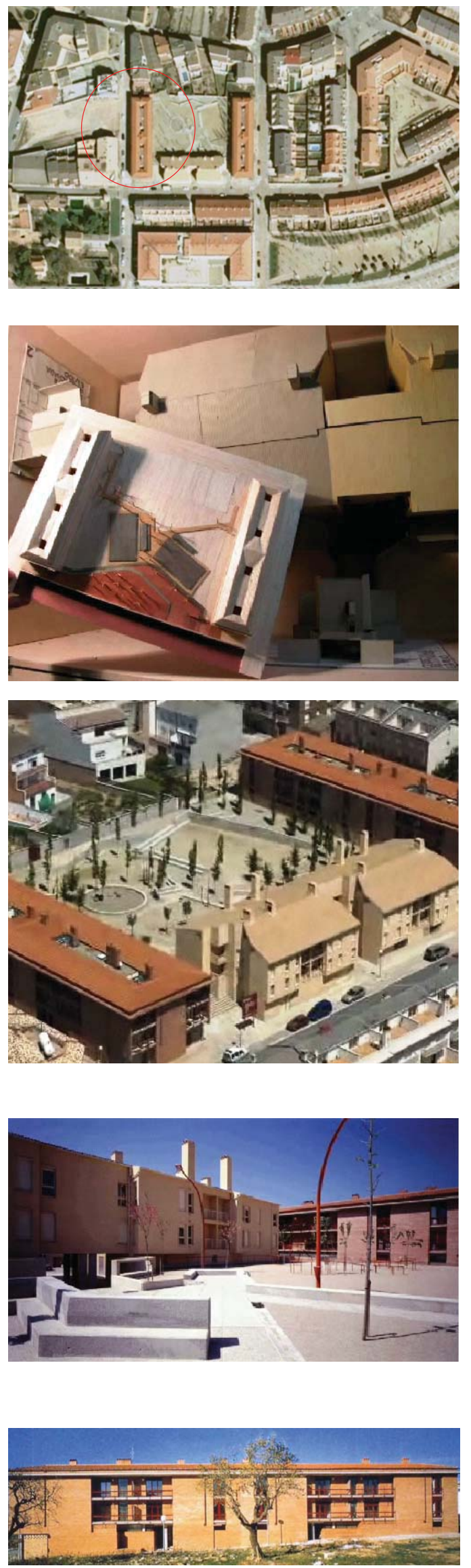

FICHA 3.3

\section{EUROPAN 3}

(año 1992)

\section{MaJOSÉ DUCH Y EVA PRATS: 32 VIVIENDAS EN GUISSONA (LÉRIDA)}

EMPLAZAMIENTO

c/Sant Pol n 17, Guissona (Lérida)

COMIENZO DE OBRAS- FINALIZACIÓN DE LAS OBRAS Fin: año 1998

¿ES EL PROYECTO DE CONCURSO?

No

$N^{\circ}$ DE VIVIENDAS TOTALES CONSTRUIDAS

32 viviendas (16 en cada bloque)

No DE VIVIENDS POR SUPERFICIE

VII 12 viviendas

VIII 4 viviendas

USO DE LA PLANTA BAJA

Viviendas

USO DEL SOTANO

No tiene

\section{REFERENCIAS BIBLIOGRÁFICAS}

www.flores-prats.com

- 10 años EUROPAN 5 España, Edición coproducida por

EUROPAN/España, SEPES y el Ministerio de Fomento, 1999, España,p. 164. 



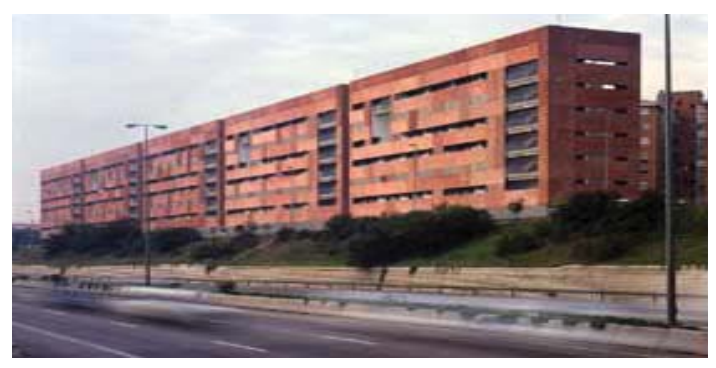

4.1.4. Edificios de viviendas Europan 4 (1994) Nieto\&Sobejano: viviendas sociales en Sevilla frente a la S-30 
VIVIENDAS EUROPAN (1988-2008) | Una aproximación a los modos de vida en el cambio de siglo en España

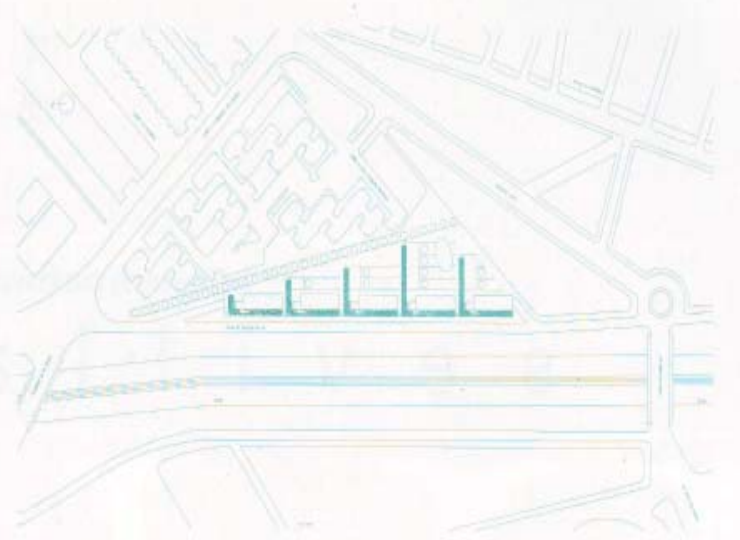

El solar objeto del concurso reflejo la condición residual de la que es resultado: su forma triangular y situación frente a la SE. 30 asi lo contirman. Entendemos la outo. via como barrera fisica real potenciando sin embargo la nueva percepción de la ciudad que estas caracteristicas producen. Lo escala del edificio o l SE-30 es muy diforente a la de la calle tradicional. Uno serie

premio

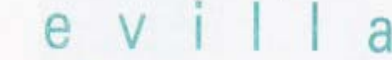

sf 754 Enrique Sobejano Garcia y Fuensanta Nieto de la Cierva colaborador: Elio Garcia

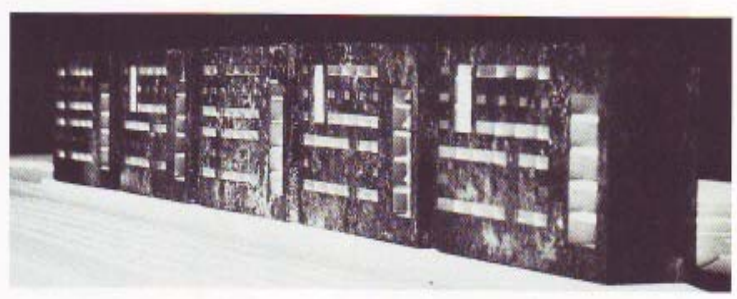

de cinco grandes diedros abrozarán los distintos cuerpos en los que se divide el edificio: pantallas cerrodas a la outopista y abiertas hacia el interior en una codeno de jardines comunitarios que se adoptan al trazado del solar.

Lo geometría de cada uno de los edificios se genera a portir de dos distintas unidades tipológicas: vivienda en dúplex con disposición alternodo en planta y media, y vivienda en planta úniç, ambas con ac. ceso desde corredores exteriores.

Las dos condiciones opuestos de los diedros originan el ritmo y tratamiento de los olzados: abstractos planos prefabricados de hormigón coloreodo sobre los que se recortan grandes huecos hacia lo autovia y retícula estructural de escala más cercano en las tachadas hacia los jardines, refle. jando lo altemancio de viviendas en dúplex.
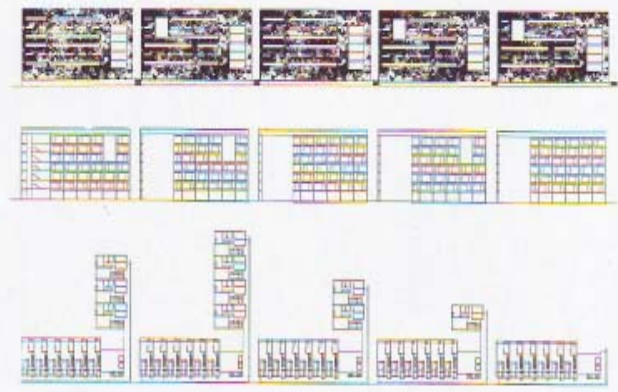

intut.
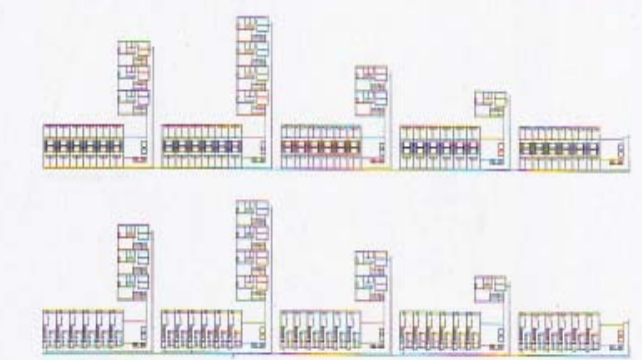

Rocionalidad y orden geométrico determi. nan la concepción del proyecto como respuesta a las discontinuidades que presen. ta la ciudad contemporánea y ol estricto programa de vivienda social requerido, en la contionzo de lograr un equilibrio entre las nuevas formas de vida y las limitacio. nes que exige la realidad.
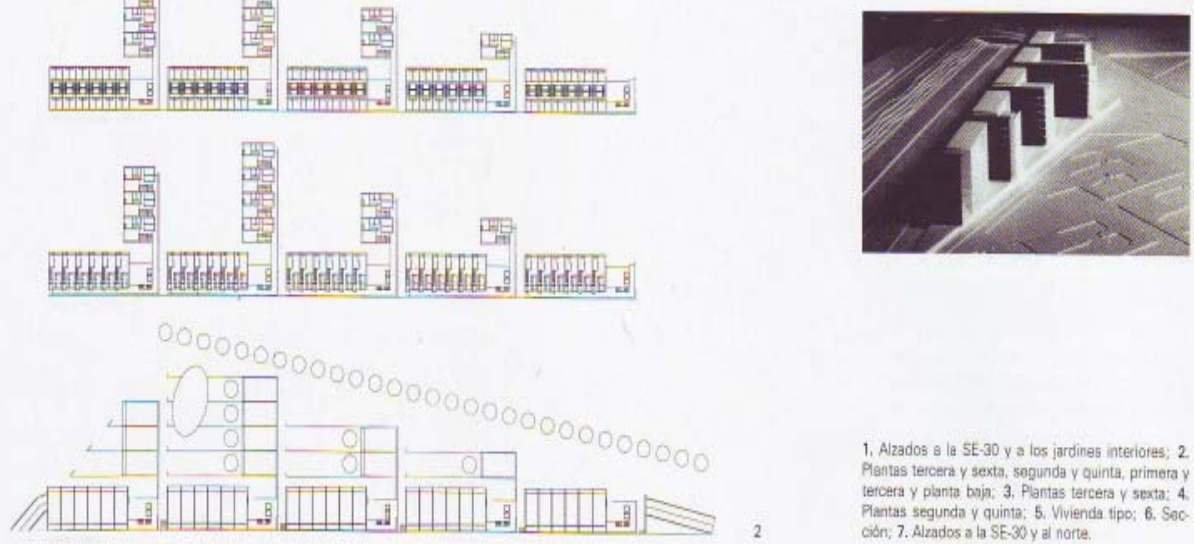

1. Alzados a la SE-30 y a los jardines interiores: 2 Pastas tercera y sexta, sepunda y quinta, primera tercera y panta bajin. 3. Plantias tercera y sexta: 4. Plantas segunda y quinta: 5 . Vivienda tipo; 6 . Sec cion; 7. Alzados a la SE-30 y al norte:

Ref. 4.112. Paneles de concurso 

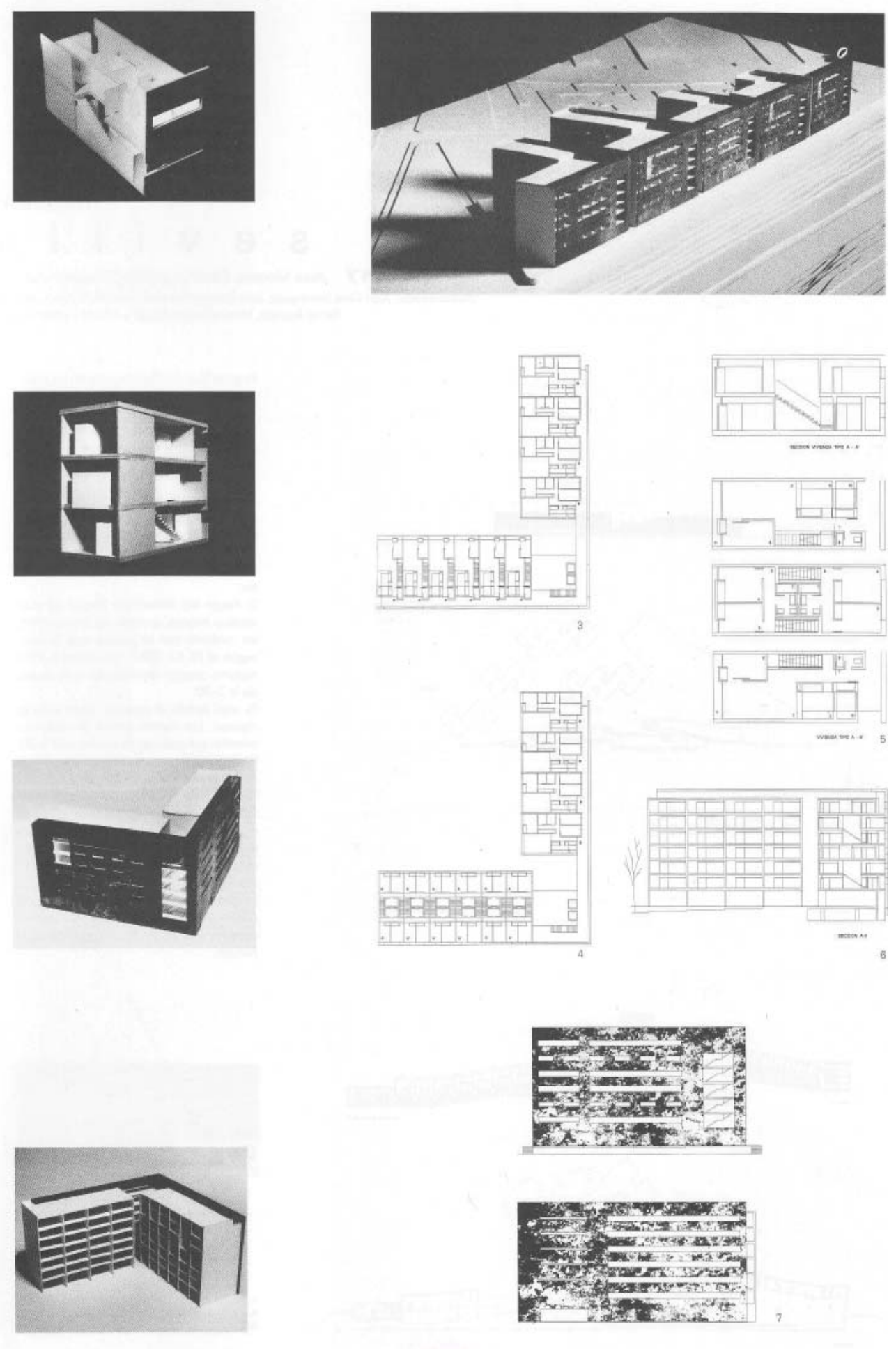

59

Ref. 4.113. Paneles de concurso 


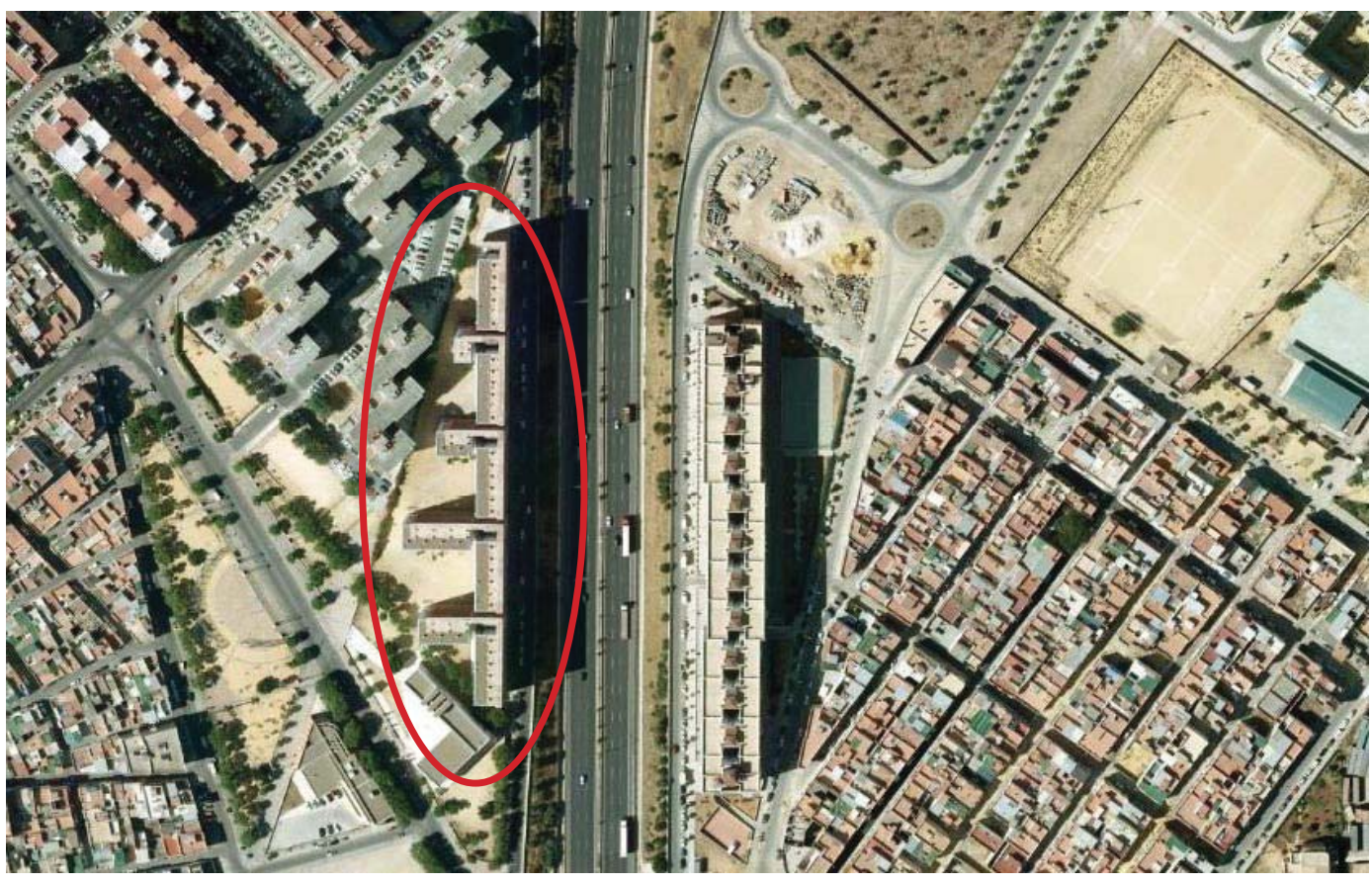

Ref. 4.114.Solar de concurso
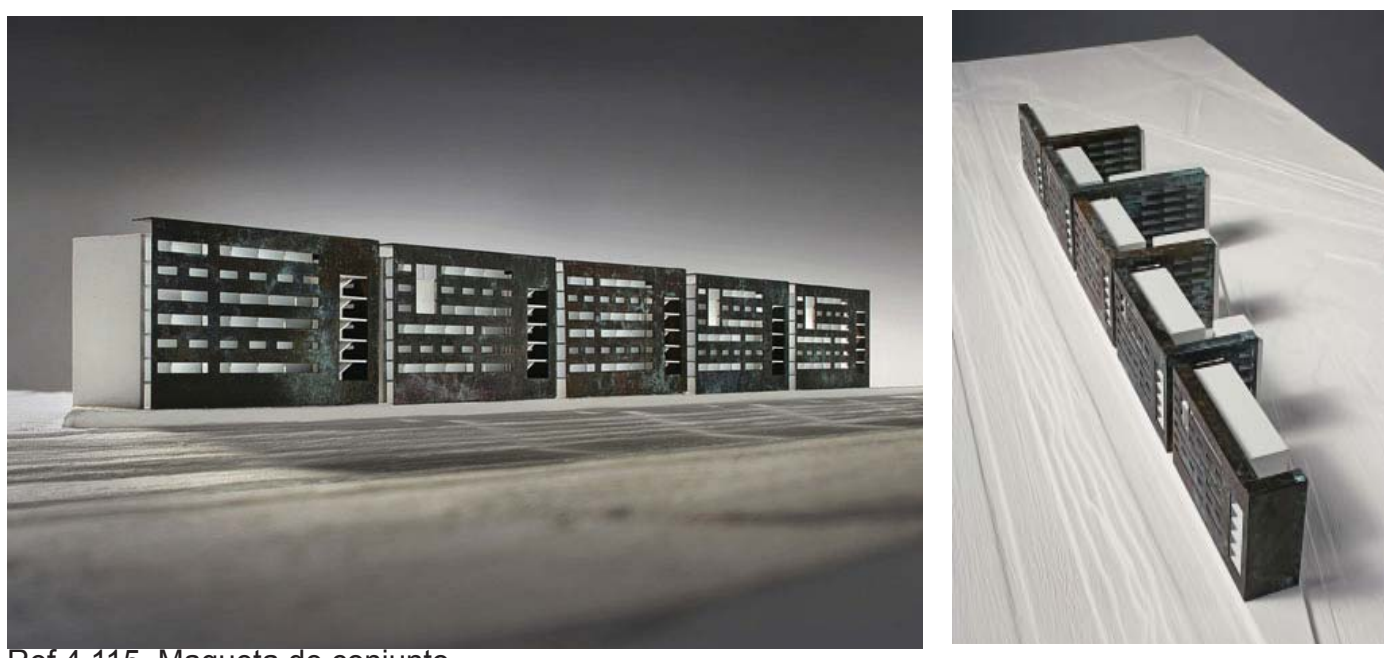

Ref.4.115. Maqueta de conjunto

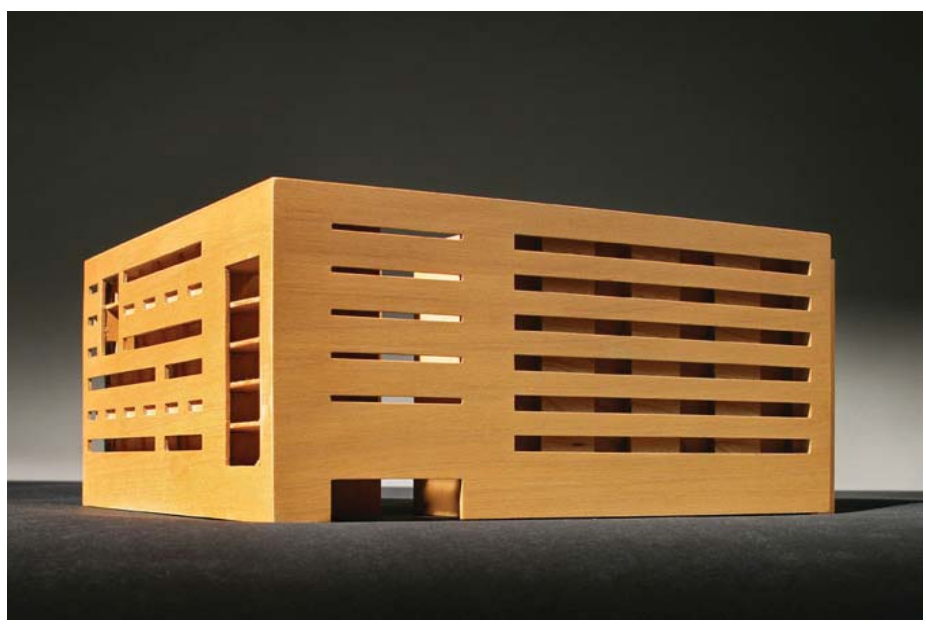

Ref. 4.116. Composición de la fachada 


\section{Fase de concurso ${ }^{1}$}

Sevilla es el escenario en el que se propone el subtema de trabajo de Europan 4 "conectar", es decir, crear las condiciones para cambiar lo existente. La ciudad de Sevilla ha sufrido varias transformaciones: a partir de los años 60 y 70 generó la aparición de áreas urbanas densas y dispersas, por lo que se acentuaron las discontinuidades. En los 90 las nuevas infraestructuras irrumpieron en la periferia. El año 92 fue clave debido a la Exposición Universal, aumentando los espacios intersticiales donde se necesitaban equipamientos y vivienda. El marco de actuación se localiza en un área degradada, entre la S-30 y la barriada García Lorca. El solar propuesto tiene forma triangular alargada, que en su PERI integraba tres parcelas que sumaban unos 8000 metros cuadrados, pero que por encima de todo, ofrecía inéditas posibilidades a través del paisaje urbano, a partir del trazado de la circunvalación viaria.

En el proyecto de concurso desarrollaron las unidades de habitación: por un lado, las viviendas dúplex tiene orientación este-oeste con acceso a través de corredores exteriores. Cada unidad ocupa una planta y media, volcando los espacios de estar al jardín y los corredores siempre a la autovía. Por otro lado, las viviendas simples tienen orientación norte-sur y se sitúan en el patio interior. Se accede a ellas también mediante corredor ${ }^{2}$.

${ }^{1}$ De las propuestas presentadas, el Jurado destacó las siguientes:

- Morales y González fueron mencionados. Resultaba interesante el espacio libre que crearon en el interior de la manzana y el diálogo que entablan las viviendas con el borde viario.

- Fátima Pablo Romero fue nominada finalista y planteó una opción muy distinta. De una manera abstracta presentó unas células curvilíneas que podían ocupar cualquier territorio, colonizándolo sin crear una pantalla con la vía de circulación.

- Fernández García Navas, Fuster Mortes y Rodríguez González, también fueron finalistas. Su propuesta planteaba un esquema en peine aparentemente análogo al de Nieto\&Sobejano, pero en el que primaba el orden interior barrial. Además, respondían con una solución tipológica más simple.

-Bajo el lema SF 754 presentaron su propuesta Nieto\&Sobejano. Concibieron el proyecto como una serie de pantallas ante la autopista para contrarrestar el flujo de vehículos. Ellos mismos comentaron su propuesta recalcando la importancia de crear una barrera frente a la circulación y la creación de un espacio interior con arbolado y más recogido, permitiendo así la multiplicidad de relaciones entre los vecinos.

'Los propios autores comentan su proyecto de la siguiente forma: "Cinco grandes diedros, cinco verdaderas pantallas acústicas protegen las viviendas de la vía de tráfico y se abren hacia el interior del solar en una cadena de jardines comunitarios. Sobre un garaje común se sitúan los cinco cuerpos en forma de "L" cuyos brazos ortogonales a la autovía varían de dimensión para adaptarse a la forma triangular del solar y conformar los espacios verdes posteriores. Se construyen 174 viviendas de las cuales 114 serán dúplex y 60 se desarrollarán en una única planta. Todas las viviendas tienen una superficie útil inferior a 


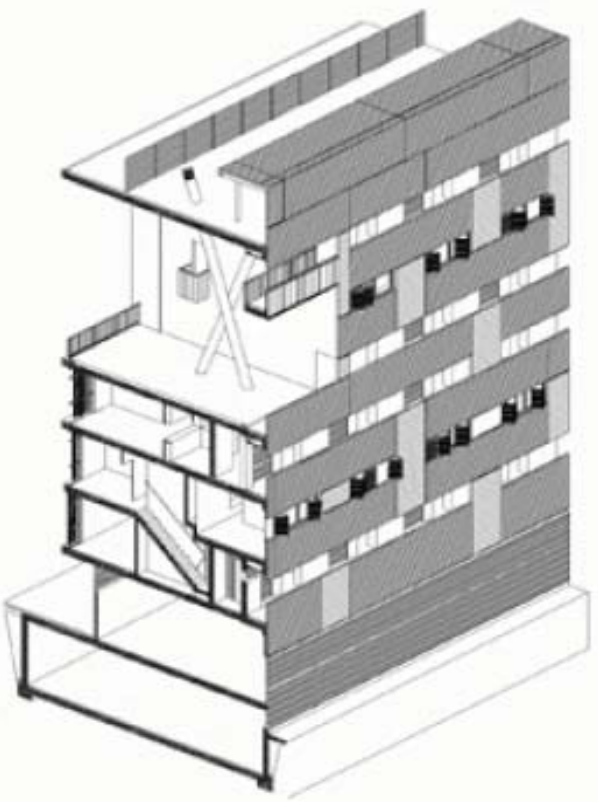

Ref.4.117.Sección

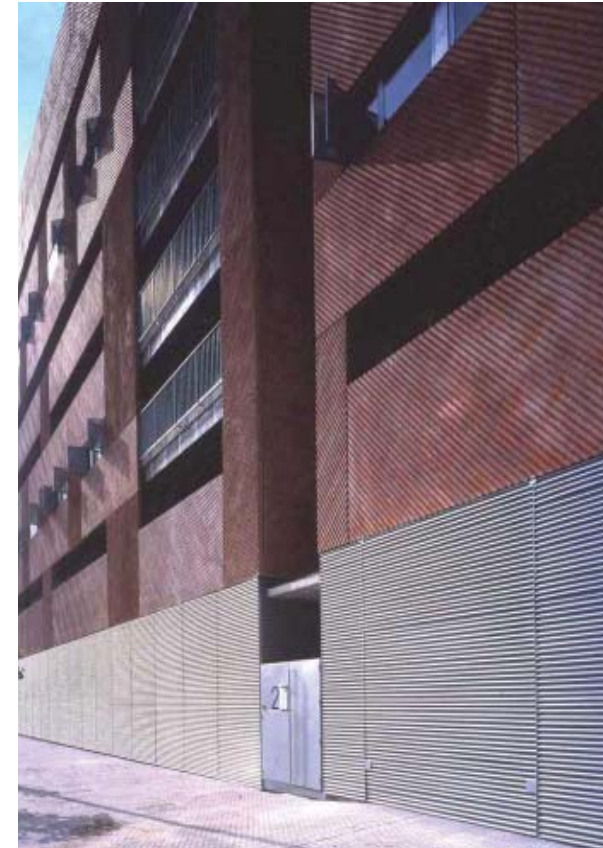

Ref.4.118. Zócalo metálico de planta baja

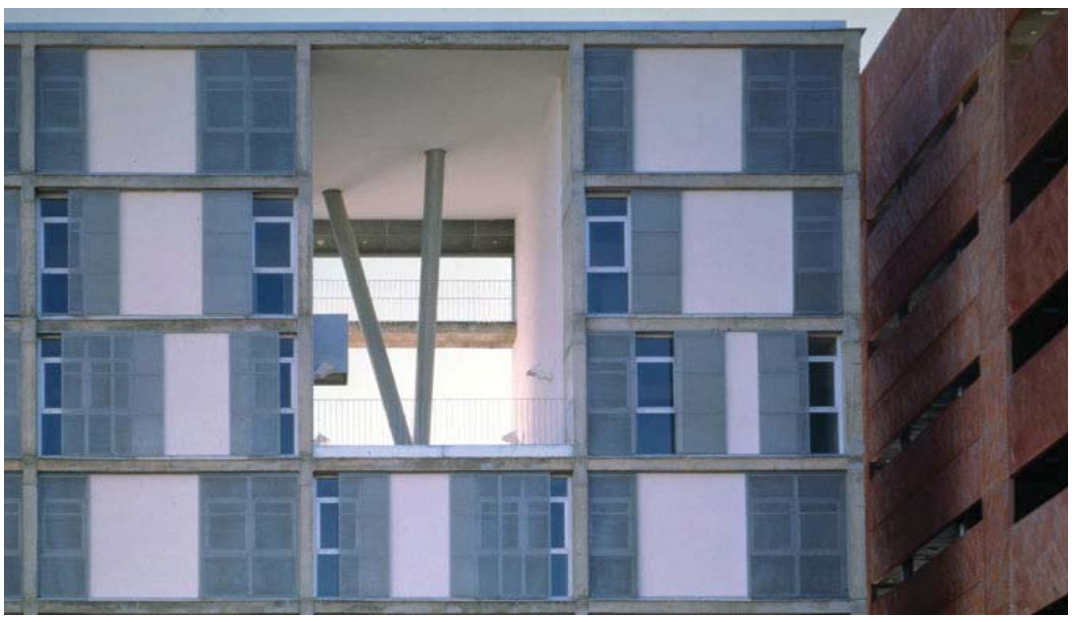

Ref.4.119. Fachada interior

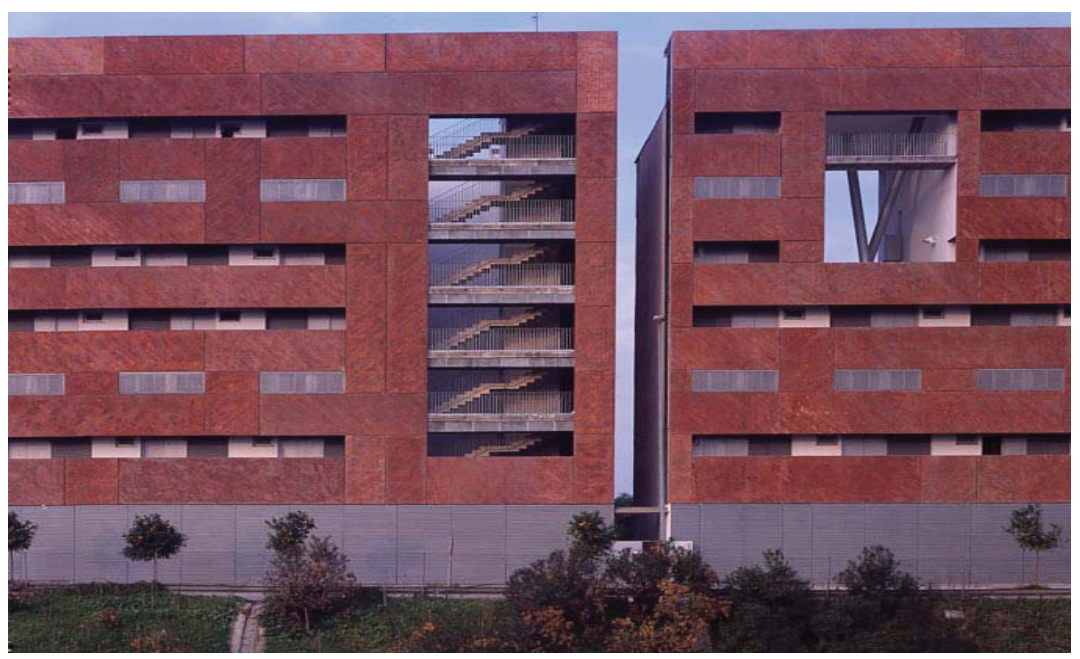

Ref.4.120. Fachada de la S-30 


\section{Fase de realización}

Este es un proyecto conocido y tiene la virtud de que ha sufrido pocos cambios con respecto al planteamiento de concurso. La obra tendrá una duración de 26 meses. Se construyeron 174 viviendas de las que 114 eran dúplex y 60 simples, 177 plazas de garaje, 114 trasteros y 3 locales comerciales.

Las viviendas, siguiendo lo que plantearon en el concurso, presentan una modulación estricta acorde con la estructura planteada. En algunos casos se queda vacía y crean terrazas o patios que actúan de miradores a la ciudad junto con los corredores, que son también una barrera para el sonido de la vía rápida. Tienen la intención de dividir el espacio en dos: público y privado. Existe una transición entre estos: desde el acceso por un elemento más recogido como es la plaza interior, hasta los corredores donde se encuentran los vecinos y donde incluso se generan plazas interiores dejando algunas unidades sin colmatar.

Cuando se accede a la vivienda, el espacio se encuentra compartimentado por las zonas húmedas de cocina y aseo, pero una vez se atraviesa este umbral, aparecen los espacios de estar que vuelcan a las plazas de acceso y que por tanto están separados de la vía rápida y del ruido.

Este proyecto presenta una "doble cara" al espectador:

Por un lado, la fachada roja, unitaria y con una composición ordenada que le proporcionan las hendiduras: unas veces horizontales que marcan la galería o corredor de acceso, que actúa de colchón acústico y mirador a la ciudad, y otras veces verticales que marcan las divisiones de las unidades residenciales.

La otra cara es una fachada pálida, de modulación rígida, mediante la propia estructura de hormigón que se combina con paneles metálicos. Es esta modulación en pórticos paralelos la que genera las fachadas interiores.

Se podría hablar del concepto de industrialización pues la fachada se resuelve con piezas prefabricadas de hormigón de grandes dimensiones, realizadas con moldes de chapa ondulada metálica, dispuesta en diagonal y pigmentada con óxido de hierro en una colocación voluntariamente irregular. Estos paneles producen infinitas variaciones de brillo, opacidad, color y textura. En un principio se concibe toda la fachada de hormigón, pero posteriormente en obra, se crea un zócalo metálico que recubre la planta baja y da acceso al garaje.

En cuanto a los espacios comunes, posee suficiente capacidad para albergar las nuevas tecnologías. Esto se debe a la gran dimensión que poseen las zonas comunes ya que todas las viviendas poseen una superficie útil menor de $70 \mathrm{~m} 2$. Existen tres locales comerciales en la planta baja que sirven a las viviendas y en el solar contiguo se ha construido un centro cultural que presta servicio a la zona residencial. A continuación se adjunta una ficha-resumen.

$70 \mathrm{~m} 2$, resueltas en dos únicas variantes ". AA.VV. Blanco y rojo. Monográfico n 20 . Ed. Monográfico Europan. Madrid. 2003.p.8. 


\section{VIVIENDA}

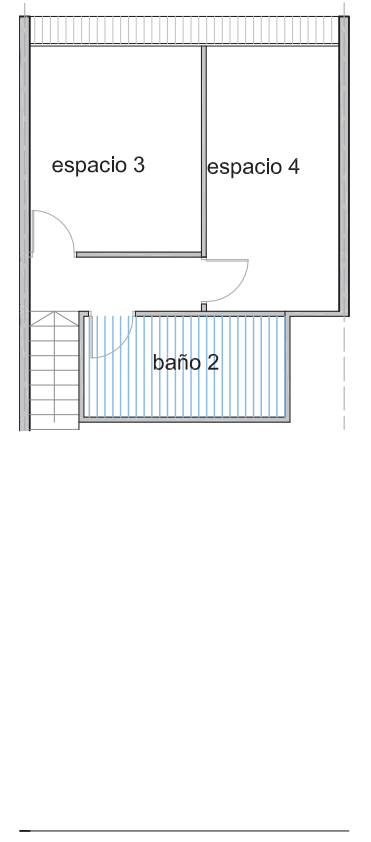

PLANTA PRIMERA

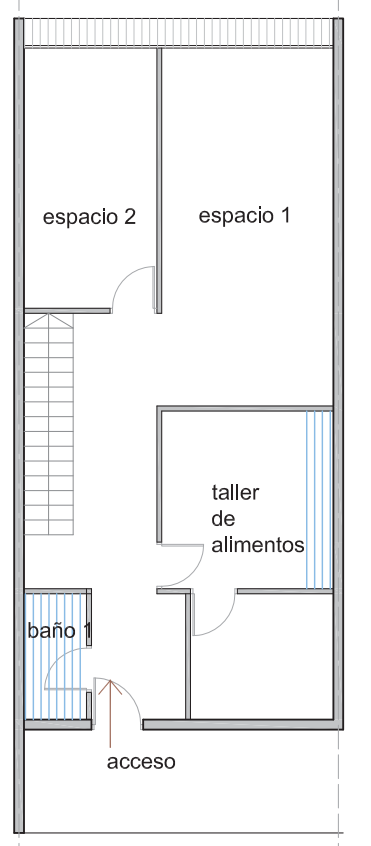

PLANTA BAJA

\section{SISTEMAS DE AGRUPACIÓN}

superficie construida total por planta:

$3930 \mathrm{~m} 2$

superficie construida zonas comunes por planta: $652 \mathrm{~m} 2$ (17\%)

\begin{tabular}{|l|l|}
\hline taller de alimentos & $21,8 \mathrm{~m} 2$ \\
\hline baño 1 & $3,3 \mathrm{~m} 2$ \\
\hline baño 2 & $8,4 \mathrm{~m} 2$ \\
\hline circulaciones & $22,4 \mathrm{~m} 2$ \\
\hline espacio 1 & $25,3 \mathrm{~m} 2$ \\
\hline espacio 2 & $14,3 \mathrm{~m} 2$ \\
\hline espacio 3 & $14,6 \mathrm{~m} 2$ \\
\hline espacio 4 & $14,5 \mathrm{~m} 2$ \\
\hline TOTAL & $124,6 \mathrm{~m} 2$ \\
\hline & $\mathbf{e : 1 / 2 0 0}$
\end{tabular}

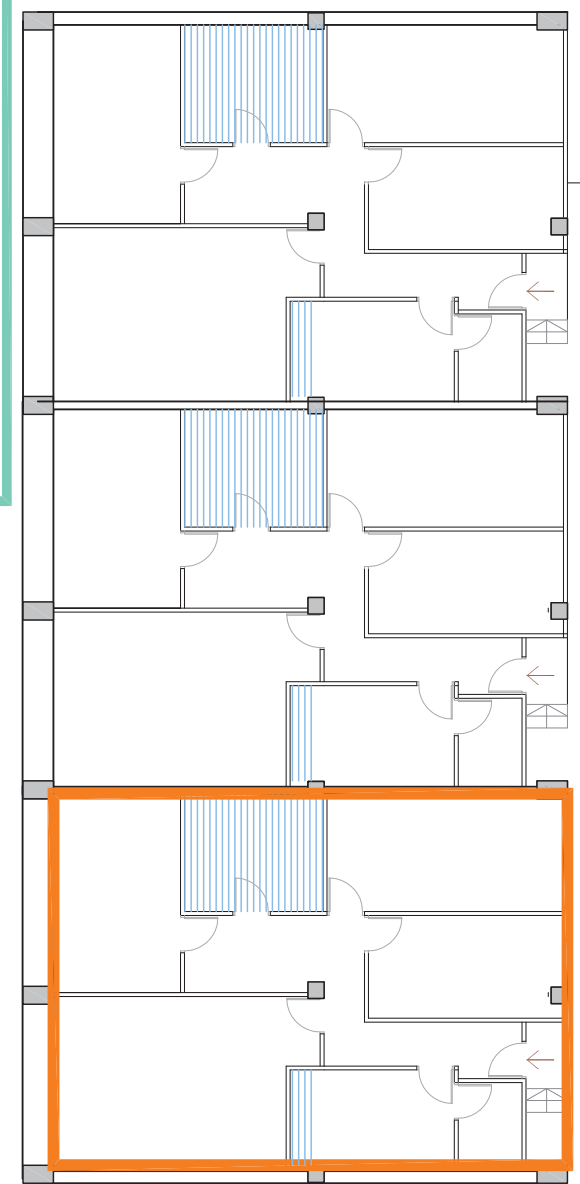

e: $1 / 3000$

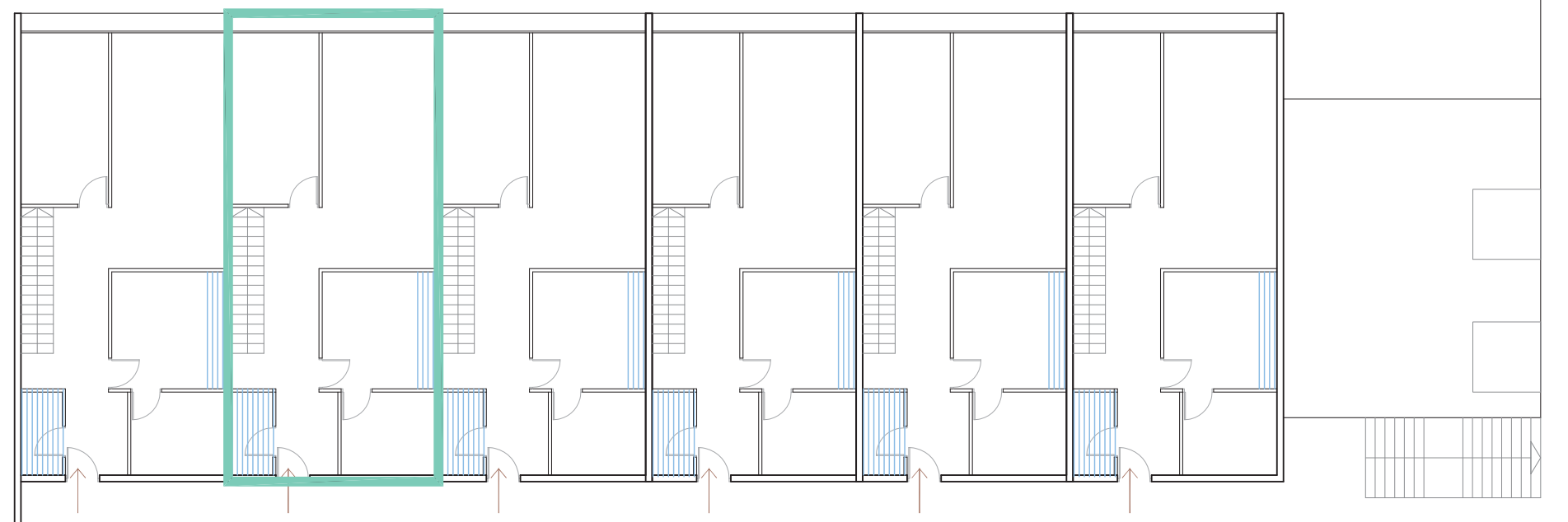



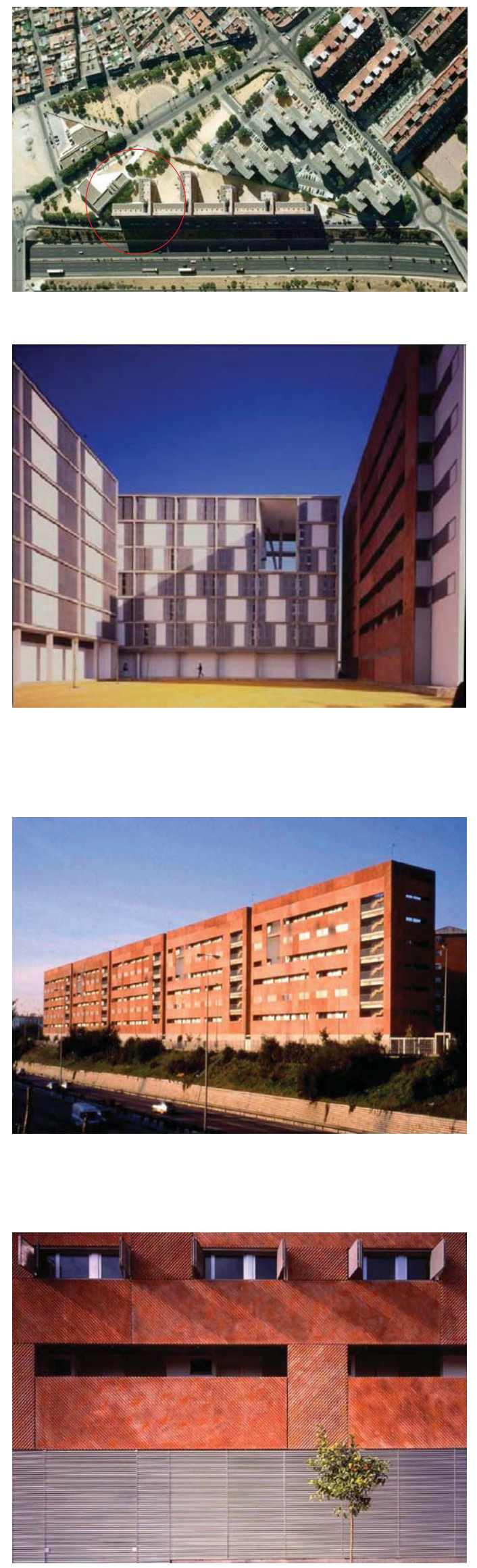

FICHA 4.1

\section{EUROPAN 4}

(año 1994)

\section{ENRIQUE SOBEJANO Y FUENSANTA NIETO: 174 VIVIENDAS SOCIALES EN SEVILLA}

EMPLAZAMIENTO

c/Rafael de León $n^{\circ} 1$, Sevilla

COMIENZO DE OBRAS- FINALIZACIÓN DE LAS OBRAS

septiembre 1999- abril 2002 (26 meses)

¿ES EL PROYECTO DE CONCURSO?

Si

$\mathbf{N}^{\circ}$ DE VIVIENDAS TOTALES CONSTRUIDAS

174 vivendas: 114 dúplex y 60 simples

No DE VIVIENDS POR SUPERFICIE

WII 108 viviendas

VIII 66 viviendas

USO DE LA PLANTA BAJA

3 Locales comerciales

USO DEL SOTANO

Garaje 177 plazas

\section{REFERENCIAS BIBLIOGRÁFICAS}

www.nietosobejano.com

- Monográfico nº 20, Blanco y rojo, Ed. Europan, Madrid, 2003. (Sobre las viviendas de Nieto y Sobejano en Sevilla).

- "En blanco l", Ed. Ediciones Generales de la Construcción, Valencia, 2004, p132-141. (Sobre las viviendas de Nieto y Sobejano en Sevilla).

-- 10 años EUROPAN 5 España, Edición coproducida por EUROPAN/España, SEPES y el Ministerio de Fomento, 1999, España,p. 166.

- EUROPAN 10 España, "Proyectar la urbanidad", Madrid, 2010, p. 229 



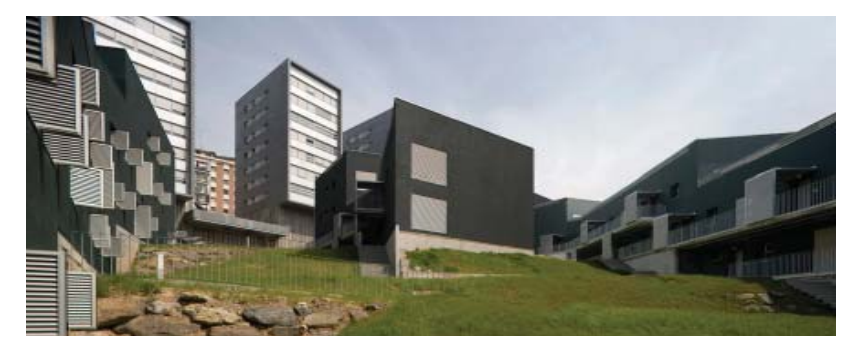

\subsubsection{Edificios de viviendas Europan 4 (1994)}

Eduardo Belzunce, Luis Díaz y Juan García, José M ${ }^{a}$ Lapuerta y Francisco Burgos: torres y bloques de viviendas sociales en Mina del Morro (Bilbao) 
VIVIENDAS EUROPAN (1988-2008) | Una aproximación a los modos de vida en el cambio de siglo en España

4. EUROPAN: DEL CONCURSO A LA REALIZACIÓN

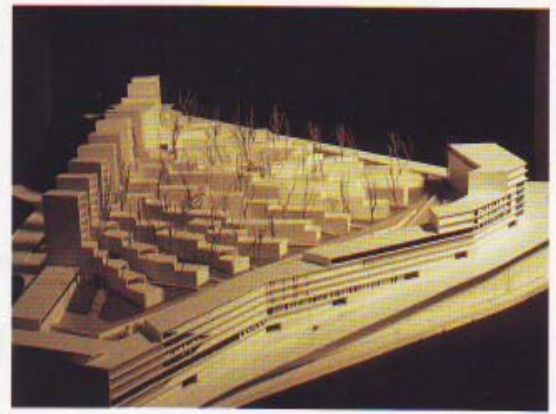

Desde el primer momento nos interesó la condición fronteriza del solar, a medio ca. mino entre muchas cosas disfintos: centro. periferia, lleno-vacio, urbano-minero, riomonte. Nos olroio lo tension que generaentes oposiciones. Et proy guegener

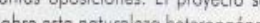
sobre esta natura tezo hetereogénea. La desaparición de un uso y la inmediata octivación del vacio que surge es siempre

\section{premio \\ b i l b a 0}

ga 221 Eduardo Belzunce Tormo, Luis Díaz Mauriño y Juan Garcia Millán

una oportunidad especial para la ciudad, el momento de proponer estrategios y ensayar modos de intervenir y reequilibrar. El casco viejo, somprendentemente próximo, planté la idea de unos edificios lorgos, estrechos y sinuosos. El Bilboo suburbial y fragmentario que asoma en lo alto se filtra a trovés de unos torrecitos, esbeltas como las púas de un peine, curys

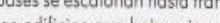
os edificios que bojan zigzogueando pegados al terreno. La ideo de 'olargodo. escolonodo-quebrado "fue también ứlizada paro resolver el edificio de borde que alberga los usos no residenciales.

Los espocios intersticiales son tan importantes como los espacios construidos. Ambos son complementarios y se estable. cen en lo pequeña escola. Nos interesa tro bajar sobre la creciente divergencig entre lo urbono y lo doméstico revalorando los espocios intermedios. Por eso los espacios libres son simultóneamente portal al aire libre, calle peatonal, patio de juegos parque arbolado en una ladera. El proyecto conserva el paiscie y en él se verifi. can los relaciones de vecindad, ni públicas ni privadas sino todo lo contrario.

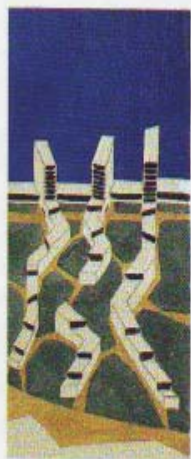

Ref. 4.121. Paneles de concurso 


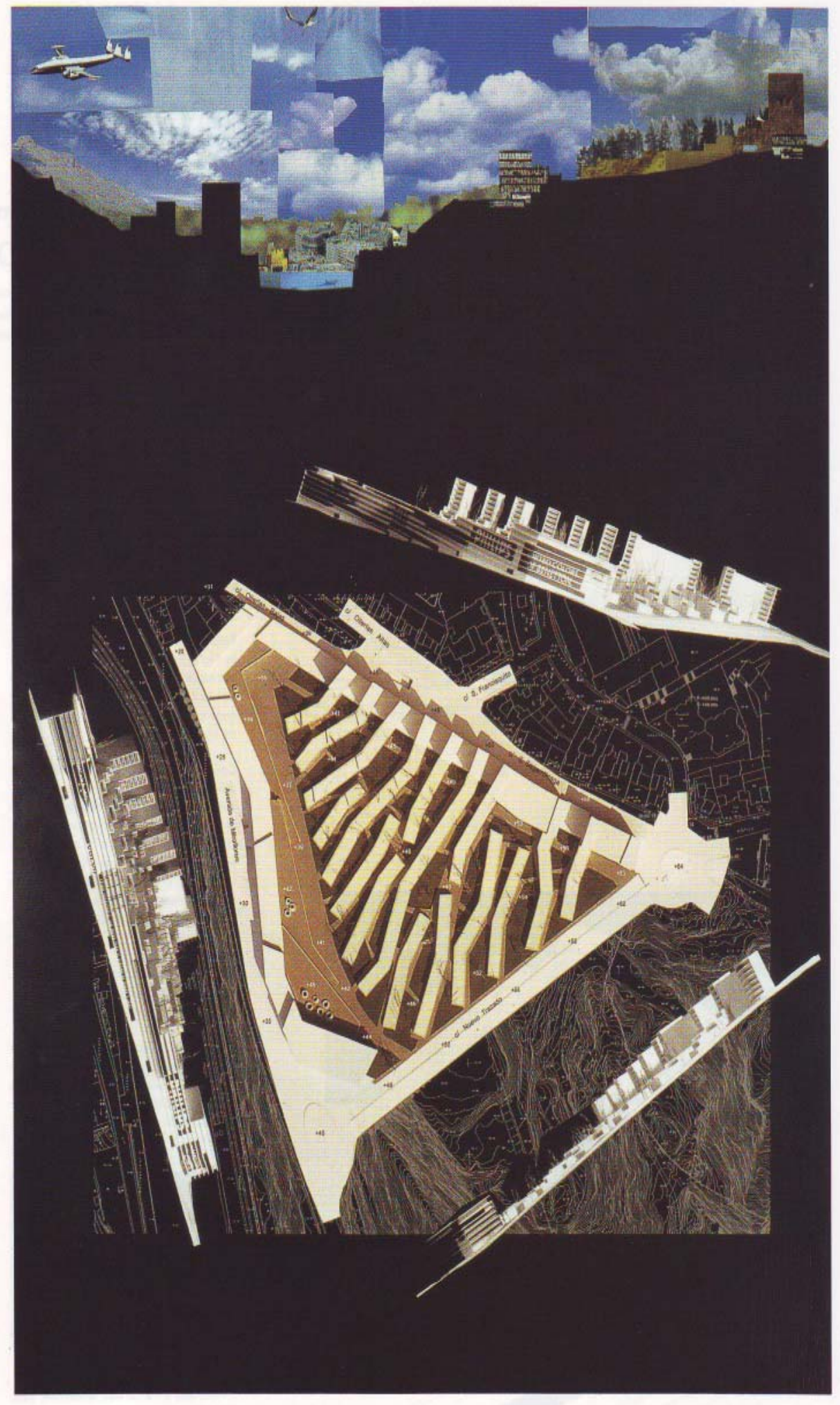

Ref. 4.122. Paneles de concurso 
VIVIENDAS EUROPAN (1988-2008) I Una aproximación a los modos de vida en el cambio de siglo en España

4. EUROPAN: DEL CONCURSO A LA REALIZACIÓN

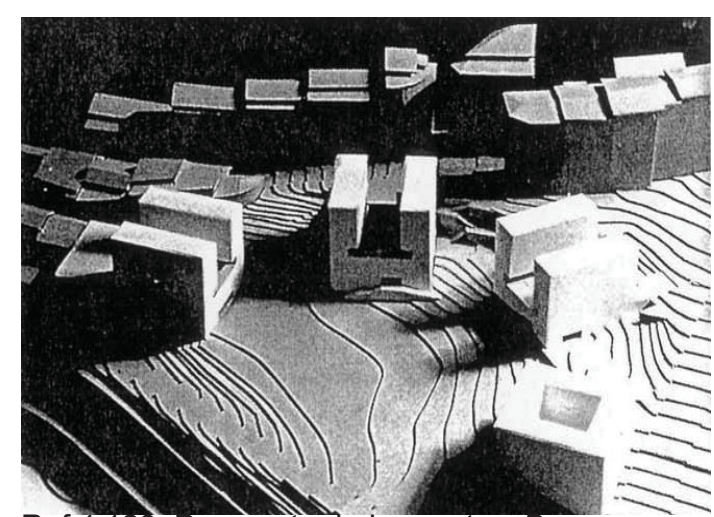

Ref.4.123. Propuesta de Lapuerta y Burgos

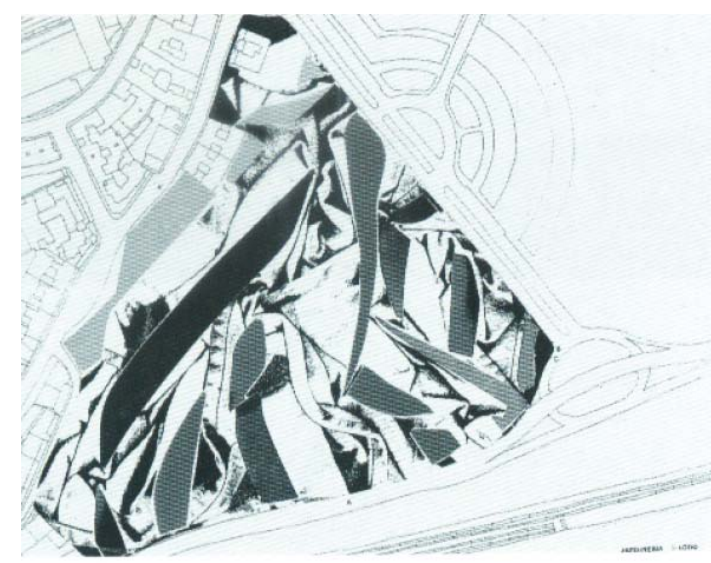

Ref.4.124. Propuesta de Soriano y Palacios

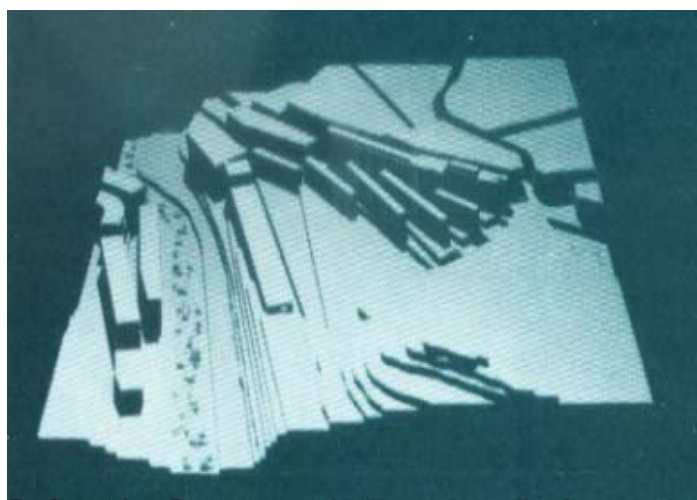

Ref. 4.125. Propuesta de Hurtado y Jiménez

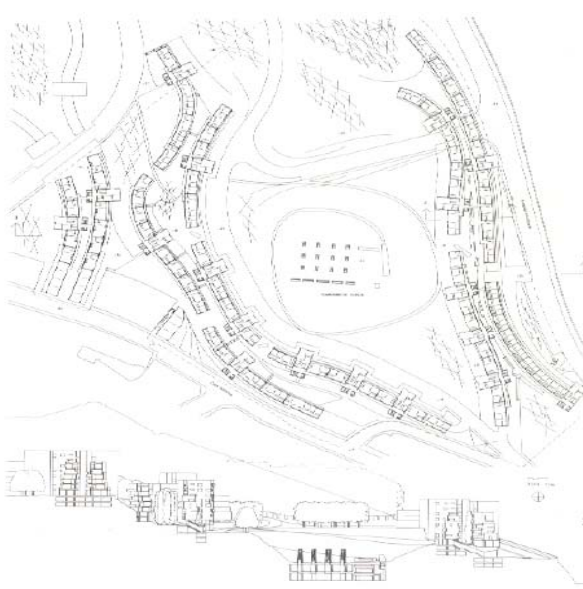

Ref. 4.126. Propuesta de Samaniego

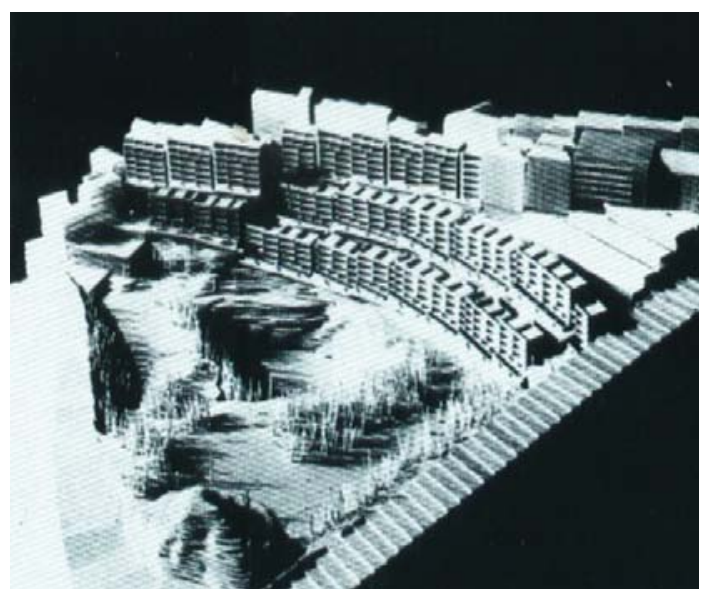

Ref. 4.127. Propuesta de Rodríguez y Hurtado 


\section{Fase de concurso}

El solar se encuentra en Bilabo y en esta edición se pretende recuperar un espacio con una fuerte potencialidad urbana. Se propone como subtema de trabajo el de "heredar" por la localización del área, al sudeste del término municipal, ya que tiene su historia, puesto que está situada donde antiguamente existían unas minas de hierro.

Tiene una orografía muy accidentada, con numerosas galerías en el subsuelo. Además, tras las inundaciones del 83 , el terreno se vio modificado por el encauzamiento del rio Nervión y presenta problemas de captación de agua debido a una capa de arcilla muy plástica que dificulta la filtración. Seguramente fue el motivo por el que en un principio fue calificado como suelo no urbanizable.

Se encuentra en un término intermedio entre el centro y la periferia, en "tierra de nadie", en el borde del barrio de Sagarminaga, de gran densidad edificatoria y levantado en los años 50 y 60 . Tiene una superficie aproximada de 4,9 hectáreas con forma irregular y linda con las calles de Ortutxueta, Santucha e Indalecio Prieto.

De las propuestas presentadas destacaron:

- José $\mathrm{M}^{\mathrm{a}}$ Lapuerta y Francisco Burgos. Fueron mencionados con una propuesta que apenas coloniza el territorio. Proponen unas piezas que se dejan caer sobre el terreno. Tres de ellas son semejantes y otra parece una manzana cerrada. Todas tienen una plataforma de acceso. Este equipo colaborará con el premiado en la construcción de 70 viviendas en bloques en altura que más adelante se comentarán.

- Federico Soriano y Dolores Palacios. Fueron finalistas con un planteamiento más orgánico.

- Juan Pablo Samaniego resulta finalista con una propuesta que da protagonismo al vacío urbano. Simulando el cráter de un volcán dispone las viviendas alrededor. - María Hurtado y César Jiménez proponen unos bloques lineales con un módulo de $9 \times 9$ en vivienda.

-Javier y Carlos Rodríguez Hurtado. Proponen "paisajes reciclados", densifican la arquitectura y liberan terreno en el interior de la parcela.

Bajo el lema ga221 el proyecto de Eduardo Belzunce, Luis Díaz y Juan García, resultó ganador. Se plantearon varias torres de las que surgían unas prolongaciones en horizontal simulando unos "tentáculos", que se distribuían en pendiente colonizando la parcela. Además se proyectó un edificio de borde que no se llegó a construir y que albergaba los usos no residenciales. En la presentación aparecen unas fotos de la maqueta, un collage significativo y algunos bocetos con un fuerte impacto visual.

El programa de necesidades inicial preveía 356 viviendas distribuidas en varias manzanas. Combinaba la dotación residencial con un uso terciario y otro de 
VIVIENDAS EUROPAN (1988-2008) I Una aproximación a los modos de vida en el cambio de siglo en España

4. EUROPAN: DEL CONCURSO A LA REALIZACIÓN

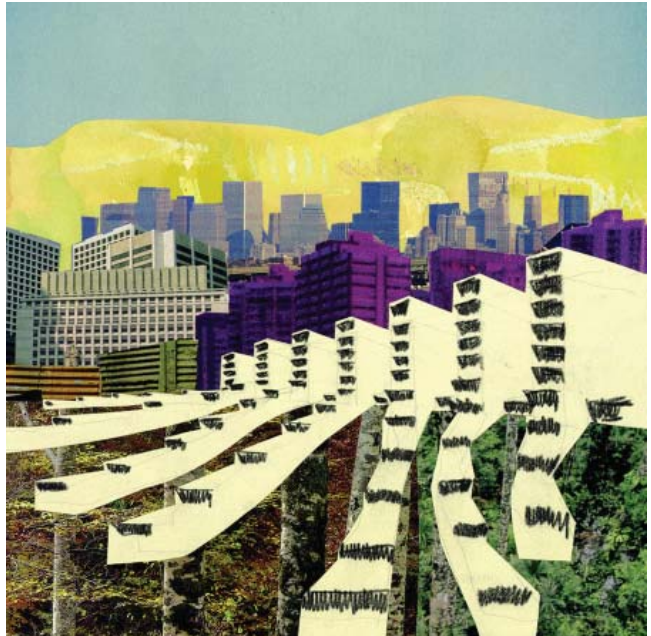

Ref. 4.128. Collage del proyecto premiado ga221

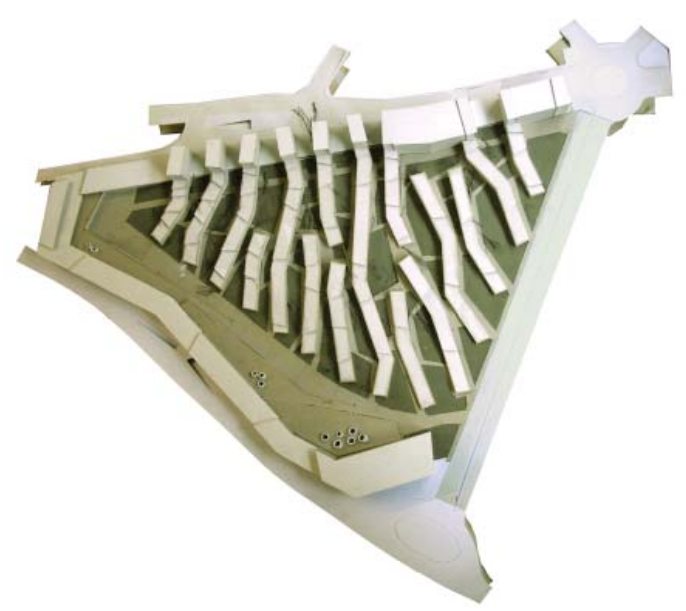

Ref.4.129. Maqueta de ga221

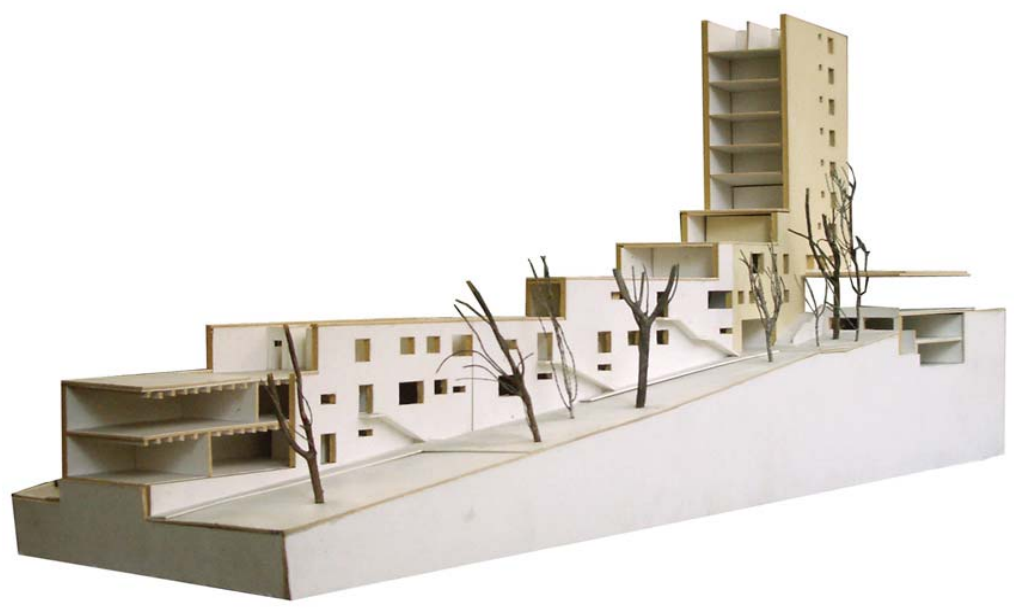

Ref.4.130. El elemento inicial: unía las torres con los brazos

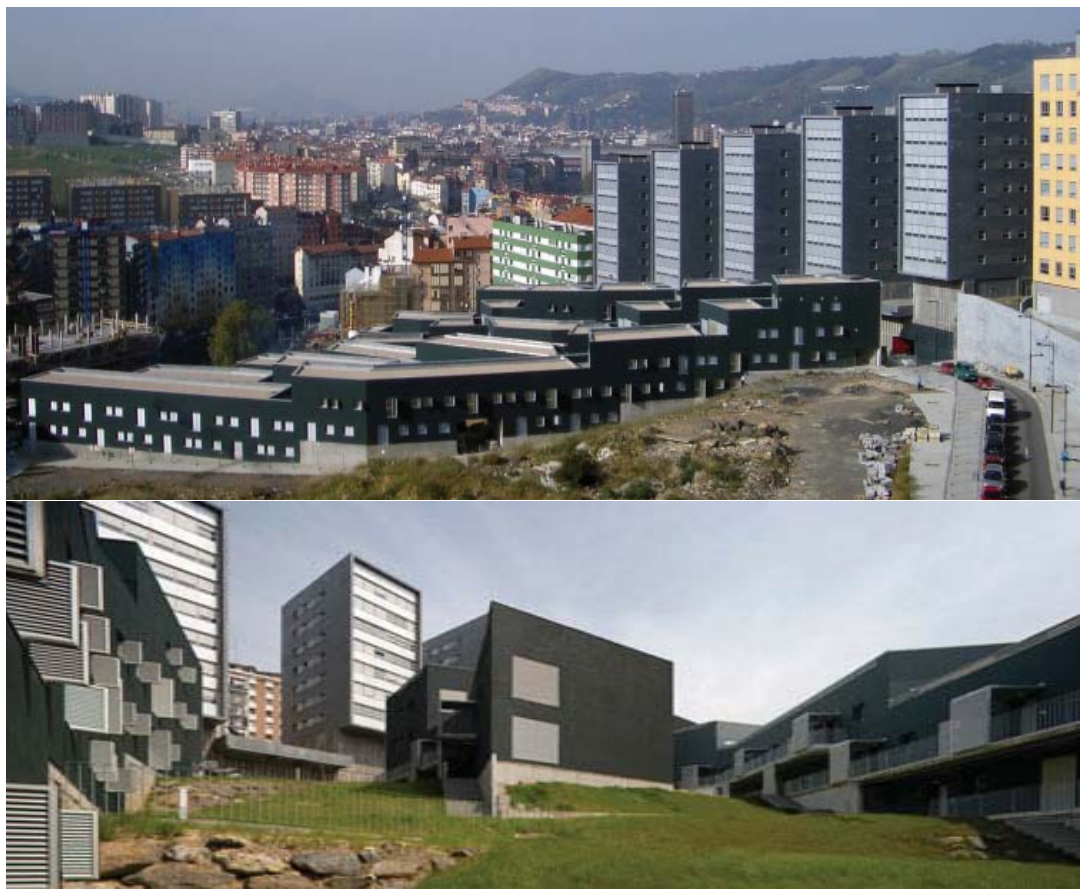

Ref.4.131. Proyecto construído 
equipamiento social y unía las torres con las viviendas que bajaban la pendiente existente.

\section{Fase de realización}

Finalmente el proyecto, motivado por la división en dos manzanas del planeamiento, se rompió en dos:

- el equipo premiado de Belzunce, Díaz y García, resolvió las 84 viviendas del clúster vecinal introvertido, de baja altura. El conjunto lo constituyen estas seis piezas residenciales que se desparraman por la pendiente. Los espacios libres entre ellas se estrechan o ensanchan, dotándolo de un movimiento que anula la monotonía. La topografía irregular hace que las viviendas se distribuyan irregularmente en su longitud, pero apilando los estratos de zonas húmedas en su altura.

- el equipo mencionado, de Lapuerta y Burgos construye 70 viviendas y genera la primera percepción visual desde la autovía a Bilbao de un peine con cinco torres. El barrio existente era muy denso por lo que se quería esponjar con espacios abiertos, soleados, con vistas lejanas desde las superficies libres entre las torres que actúan como miradores urbanos. Los bloques tienen viviendas semejantes a las unifamiliares en hilera y otras parecidas a las de acceso por corredor. Se accede a todas por este. Los accesos y zonas húmedas se sitúan en la orientación norte y las zonas de estar y dormitorios al sur.

A pesar de esta división de equipos el proyecto sigue fielmente la imagen de concurso. Los espacios intersticiales tienen su interés porque no son ni calle, ni plazas, ni jardines privados. La difícil orografía hace que estos no sean espacios donde uno pueda jugar al aire libre.

En el proyecto ganador de concurso se plantea una edificación de una crujía entre 2 muros de carga externos perforados, tanto para la torre como para las viviendas en pendiente. Posteriormente, cuando se construye, en ambos casos aparece una crujía central que divide el espacio en dos zonas. En el proyecto de las torres se crean dos viviendas en lugar de una -tal vez para optimizar el núcleo de comunicaciones- $y$ en el de las viviendas por corredor se crean dos bandas: la de espacios de estar y la de las instalaciones húmedas (baños y cocinas).

Los accesos son de 2 tipos: por corredor a través del jardín o por núcleo de comunicación vertical trasero en el caso de las torres. Las viviendas de la torre vuelcan a la mejor orientación y tienen vistas hacia el rio. Las viviendas de los brazos están en estrecho contacto con la naturaleza, ya que los jardines entre brazos se aterrazan con un aspecto natural y se crean espacios verdes entre los intersticios.

El proyecto pretendía desde la ideación colonizar la cota 0 , en palabras de los autores: "Se busca repartir la densidad en todo el solar, en vez de concentrar en puntos singulares la edificabilidad". También se pretendía que fuera muy accesible pero la difícil topografía hizo que fuera complicado aunque se consigue en la mayoría de los espacios interiores planteados.

A continuación se adjunta una ficha-resumen. 


\section{VIVIENDA}

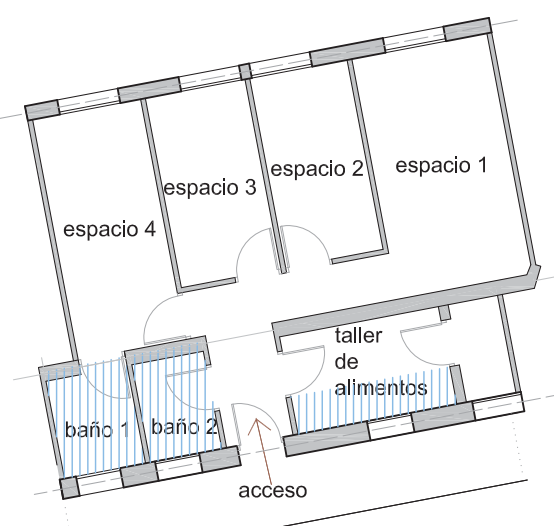

\begin{tabular}{|l|l|}
\hline taller de alimentos & $9,9 \mathrm{~m} 2$ \\
\hline baño 1 & $3,7 \mathrm{~m} 2$ \\
\hline baño 2 & $3,3 \mathrm{~m} 2$ \\
\hline circulaciones & $7,2 \mathrm{~m} 2$ \\
\hline espacio 1 & $13,9 \mathrm{~m} 2$ \\
\hline espacio 2 & $7,9 \mathrm{~m} 2$ \\
\hline espacio 3 & $8 \mathrm{~m} 2$ \\
\hline espacio 4 & $11,1 \mathrm{~m} 2$ \\
\hline TOTAL & $65 \mathrm{~m} 2$ \\
\hline
\end{tabular}

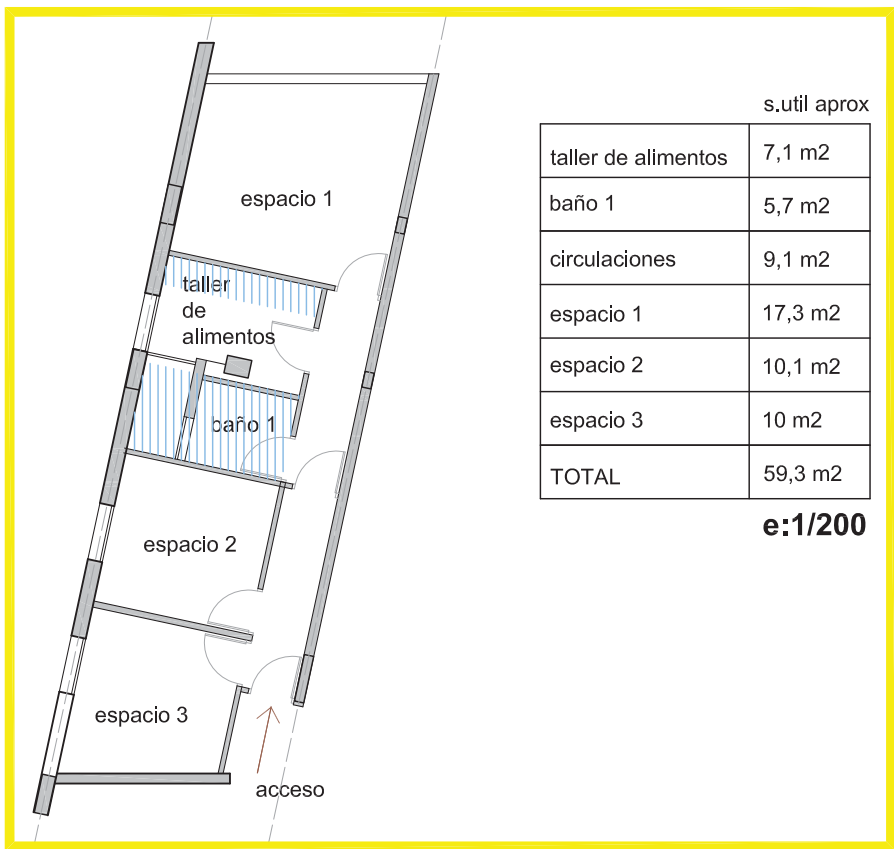

\section{SISTEMAS DE AGRUPACIÓN}

\section{BRAZO}

superficie construida total por planta: $\quad 264 \mathrm{~m} 2$

superficie construida zonas comunes por planta: 33 m2 (12\%)

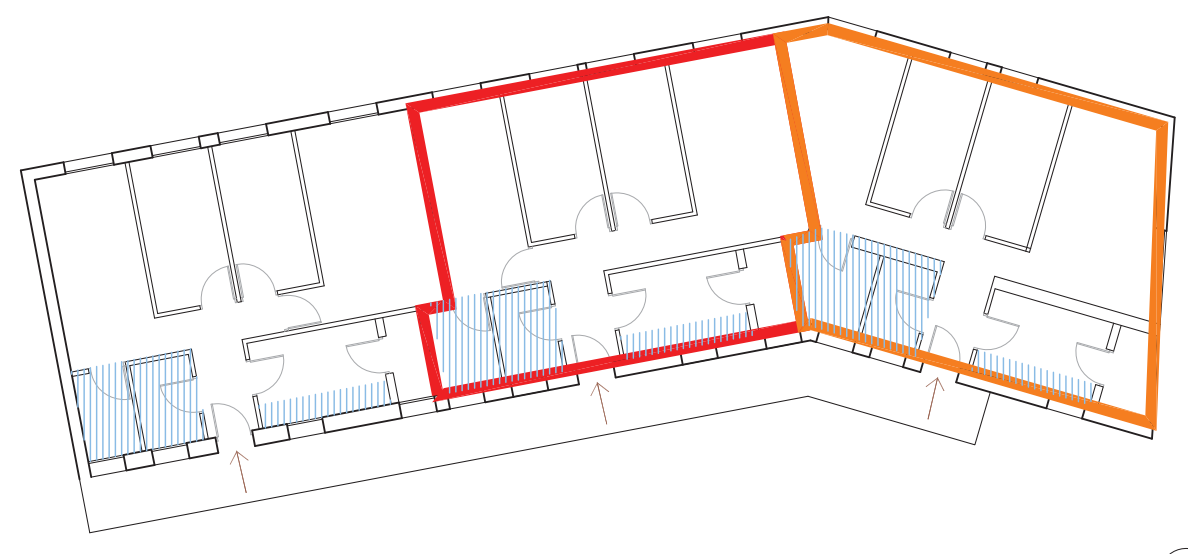

$\square 70 \mathrm{~m} 2 \quad-70 \mathrm{~m} 2$

BRAZO

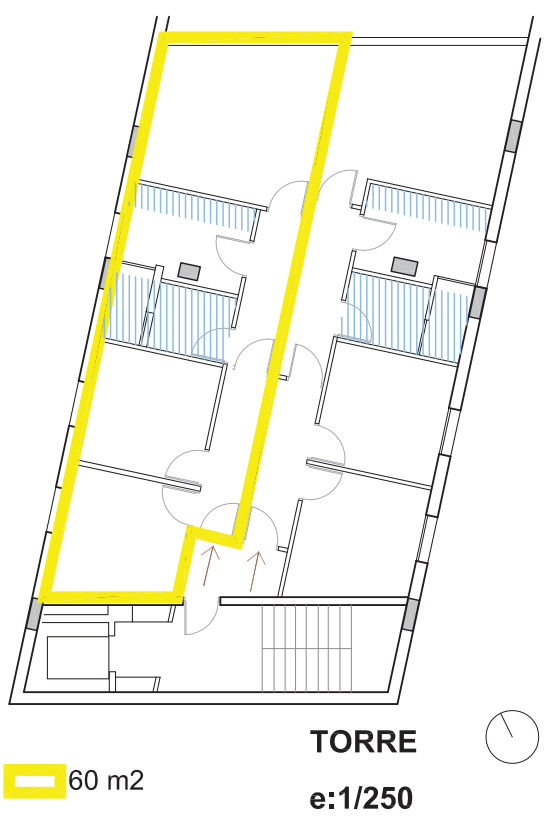

$173 \mathrm{~m} 2$

TORRE superficie construida total por planta: superficie construida zonas comunes por planta: 20 m2 (12\%) 

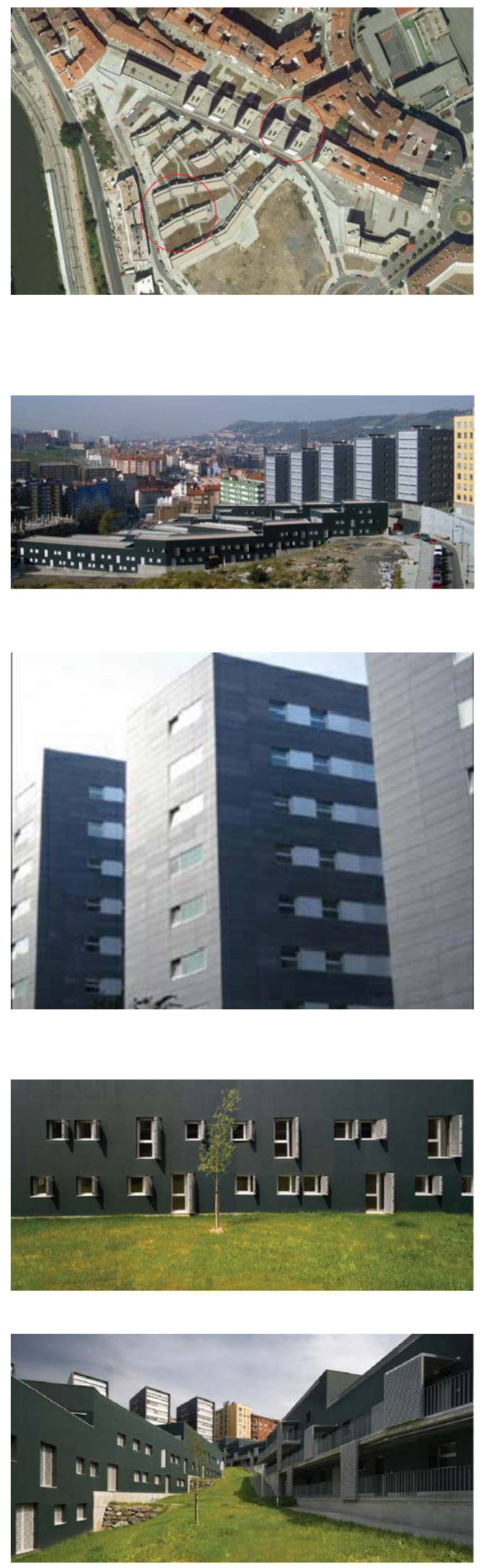

FICHA 4.2

\section{EUROPAN 4}

(año 1994)

EDUARDO BELZUNCE, LUIS DÍAZ Y JUAN GARCÍA_ LAPUERTA Y BURGOS : 70 (torres) + 84 (brazos) VIVIENDAS EN BILBAO (MINA DEL MORRO)

EMPLAZAMIENTO

c/Ortuxueta Kalea $n^{\circ} 1$, Bilbao

COMIENZO DE OBRAS- FINALIZACIÓN DE LAS OBRAS Nov 2002-hasta 2004

¿ES EL PROYECTO DE CONCURSO? El proyecto inicial, que combinaba la dotación residencial con un uso terciario y otro de equipamientos social y unía las torres con las viviendas que bajaban en pendiente, se "rompió" en dos. A pesar de ello, el proyecto intenta seguir fielmente la imagen de concurso.

$\mathbf{N}^{\circ}$ DE VIVIENDAS TOTALES CONSTRUIDAS

El programa inicial preveía 356 viviendas el equipo Belzune, Díaz y García resuelve 84; Lapuerta y Burgos construyen 70 viviendas

No DE VIVIENDAS POR SUPERFICIE torres

14 viviendas (por torre)

brazos

VIII

+84 viviendas (total)

USO DE LA PLANTA BAJA

Viviendas

USO DEL SOTANO

Garaje

\section{REFERENCIAS BIBLIOGRÁFICAS}

www.delapuerta.com

- X BIENAL de Arquitectura Española, p.

- 10 años EUROPAN 5 España, Edición coproducida por EUROPAN/España, SEPES y el Ministerio de Fomento, 1999, España,p. 167-168.

- EUROPAN 10 España, "Proyectar la urbanidad", Madrid, 2010, p. 229 



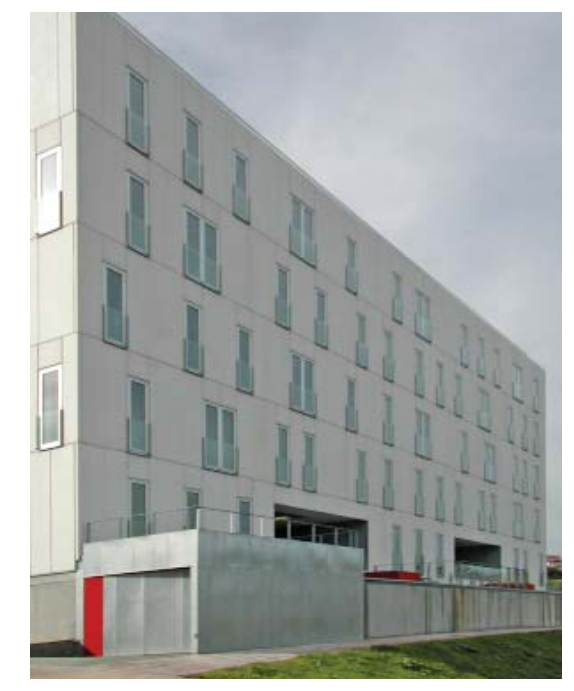

4.1.4. Edificios de viviendas Europan 4 (1994)

Pedro Palmero y Samuel Torres: viviendas sociales en Avilés 

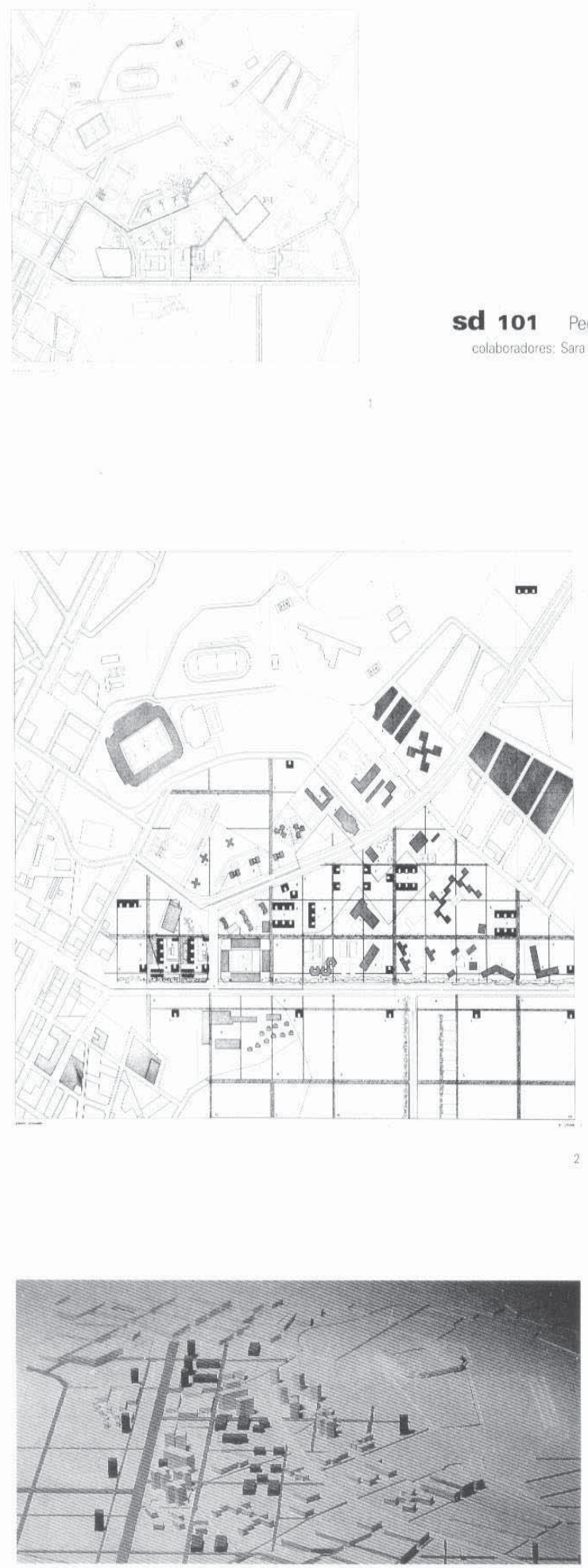

El hombre, ofimo, se manifiesta por el arden cuando solen ustedes de Poris en tren, żavé ven exienderse onte sus ojos, sino una inmentsa pies. ta en ordens Lucho contra Ia naturoleza para do. minarlo, paro clasificar, para estor a gusto, en uni gelabro, pora instarorse en un mundo humari que no sea el medio de la nafurcleza ontagonis. 10, un mundo nuestro, de orden geamérico. E

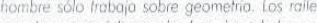
on de un paralelismo absoluto, los taludes sa

mención

a I i c a n t e

sd 101 Pedro Palmero Cabezas y Samuel Torres de Carvalho colaboradores: Sara Solé Wert, Pilar González González, Eduardo Verdejo Cesteros y

$$
\text { Javier Cruz Trevino }
$$

arealización de dibujios geométricos; los puenes, los vioducos, tas esciusas, los conales, todo esta creación urfarana y subutbona que se desareolla a lo leios en los campos, muestra uve, cuan. do el hombre actúa y quiere hacer acto de voliv? lod, se converite por tuezzo en un geómetro y creo sobre io geometria. Su presencia se traduce en que, en un parascie que es un hecho de la naturnlezo, presentandose bapo un aspecto accidentor el trabajo humano solo existe bojo tormas de rec las, verticoles, horizontales, etc. Y es asi coma se frazan las ciudades y como se hacen los casas. bajo el reinado del ángulo recto.

El hecho de reconocer en este unguio un valo decisivo y capiat es ya una afirmacion de orde generol muy imporiante, determiriante en estet-

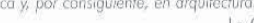

Le Corbusier

La Periferia....

La Periferia yo no existe La comunicación ha destruido el concepto de distancia, y casi el de tiempo, ha converido el centro en periferia y viceversa. La ciudad es hoy un continuo espacial que establece un inter cambio social y cultural aún por explotar.

Las industrias, la infravivienda, los núcleos habitacionoles antes considerados suburbones, los redes de int

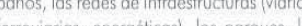
enroviarias, núcteos historicos, forman un lejido des. estructurado y deforme que lo hace cado vez mós inabordable. El crecimiento incontrolado de la ciudad establece además discontinuidades que impiden su entendimiento global.

Hemos buscado un mecanismo eficaz copaz de trabar la ciudad. Entendemos que hoy todo lo que constituye su estructura forma parte de un territorio «mestizon en el que lo existente tiene que ser considerado como un accidente más y no como algo que deba ser ignorado.

Pensamos en un sistema de ordenación que transformara la ciudad en otro organismo que integrara lo existente como algo que perteneciera al mundo del paisoje, del territorio. La troma ortogonal es la geometrio que da forma ol sistema y su dimensión quevello que reprodure lo scolo adecua. da al tamaño de la ciudad y del hombre.

Ref. 4.132. Paneles de concurso 

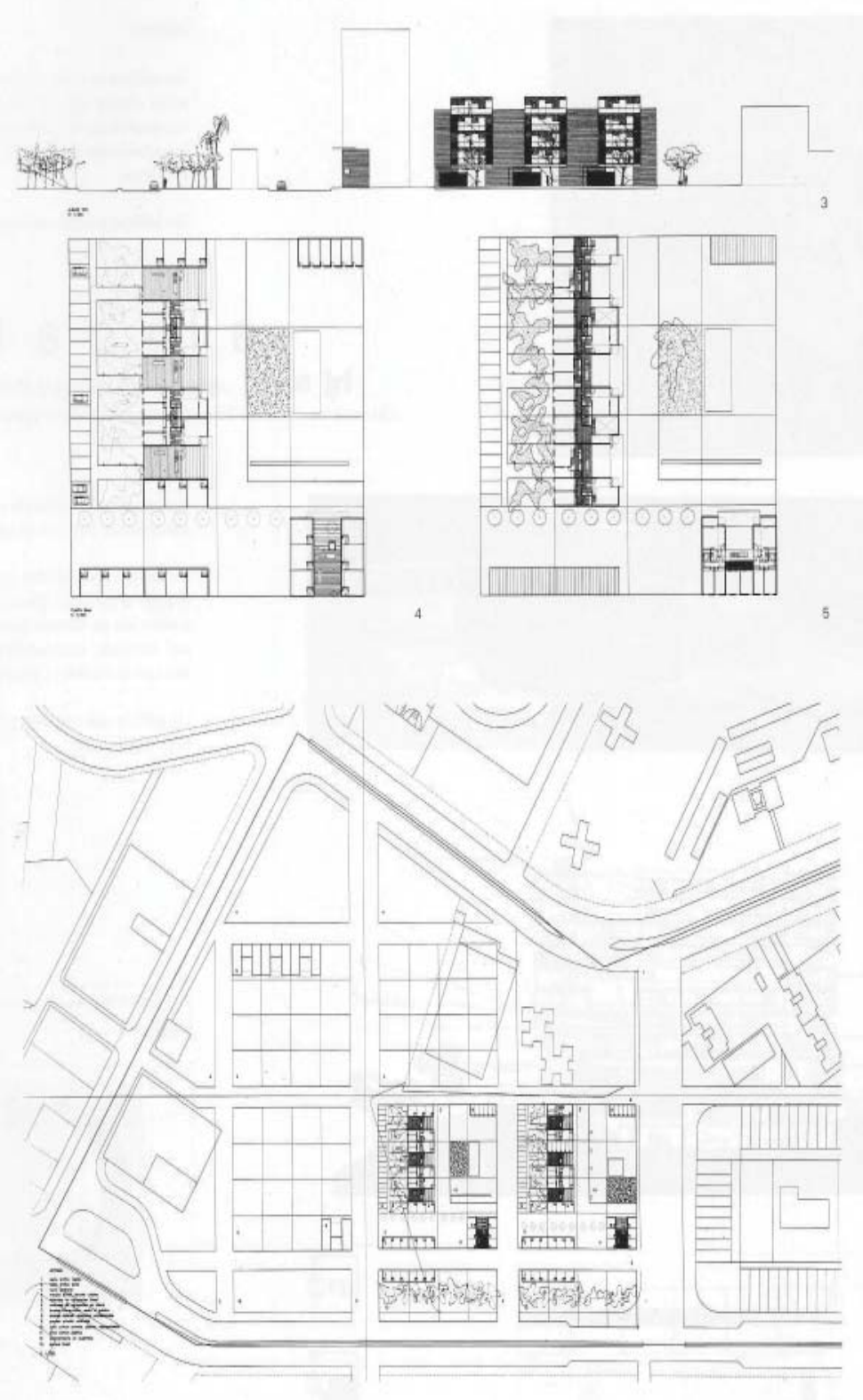

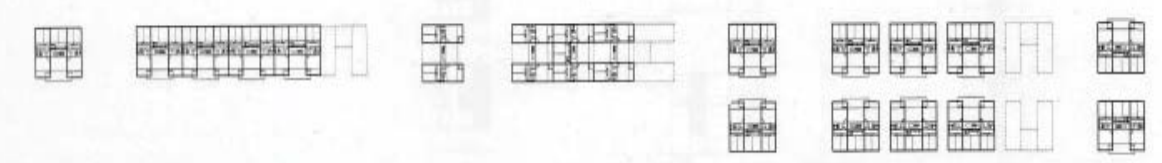

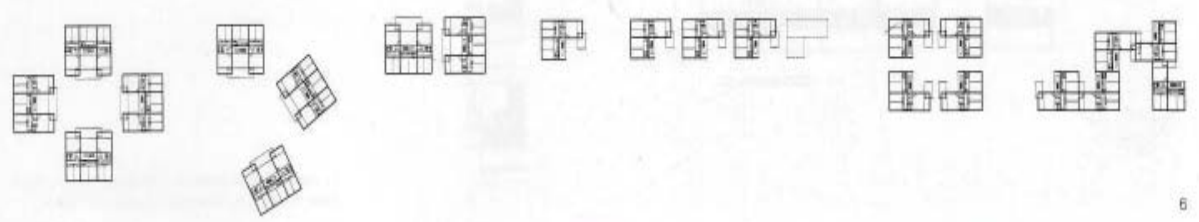




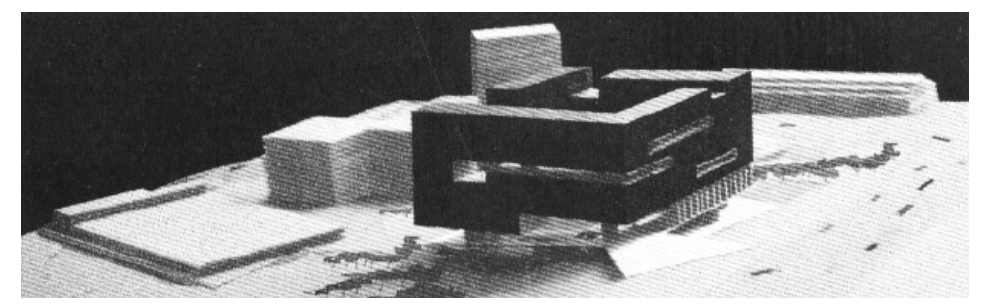

Ref.4.134. Maqueta del proyecto finalista

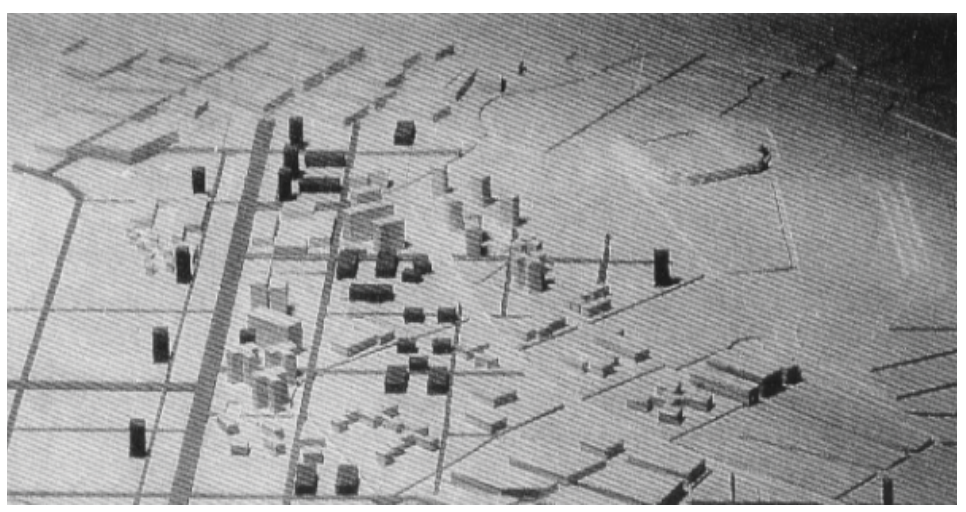

Ref.4.135. Maqueta del proyecto mencionado en el emplazamiento de Alicante

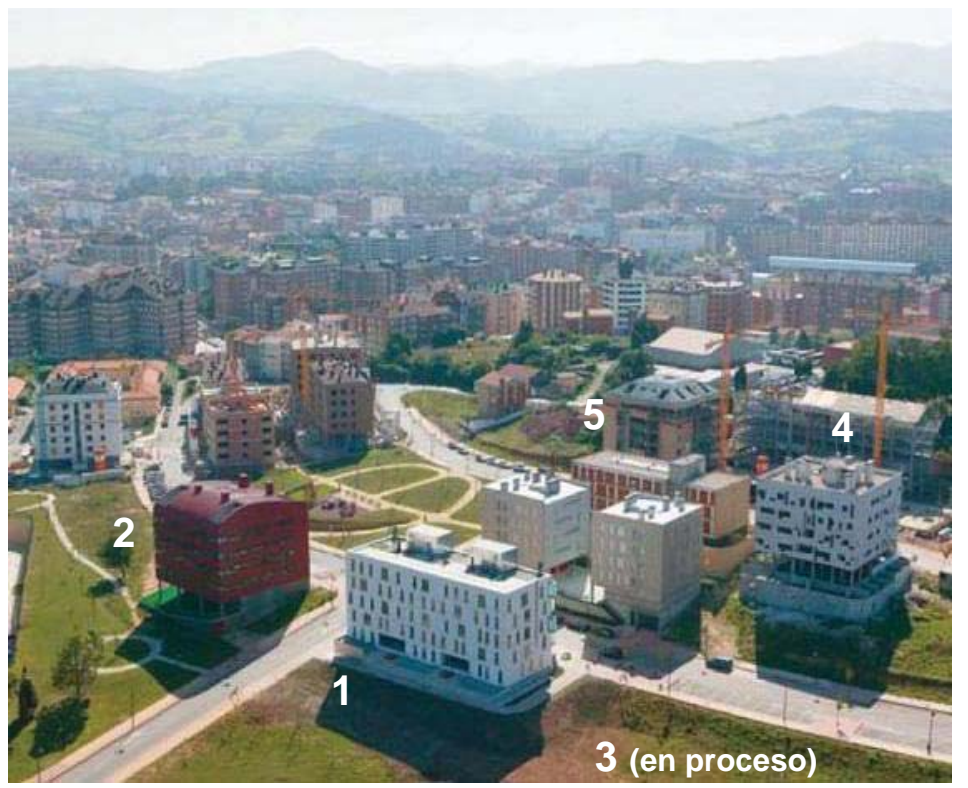

Ref.4.136. Proyectos en el Nodo:

1. Pedro Palmero y Samuel Torres

2. Javier Fresneda, J.Sanjuan y

J.Herreros

3. Mario Sanjuan, Iban Carpintero, Jose

$\mathrm{M}^{\mathrm{a}}$ Tabuyo y Angel Sevilla

4.Jorge Suarez y Lucia Salvador

5. Elio Garcia, Carlos y Javier Rodriguez 


\section{Fase de concurso}

El solar de Europan 4 se propone en un principio en el emplazamiento de Alicante. -Javier Maroto Ramos y Álvaro Soto Aguirre resultan finalistas. Proponen un edificio de viviendas económicas para alquilar o comprar, de uso flexible y que comparte sus espacios comunes con la ciudad.

- Pedro Palmero y Samuel Torres quedan mencionados. Presentan un proyecto de ordenación urbanística en el que citan a Le Corbusier.

El Jurado hace una valoración en particular de este proyecto y afirma que "entre aquellas propuestas en este emplazamiento que estructuraban el conjunto del área de estudio, el Jurado valoró en este trabajo la posibilidad de actuar en el lugar a partir de un trazado superpuesto que integre en una unidad lo existente y la actuación futura. La repetición de un modelo de "habitación" puede ser el cambio idóneo. Sin embargo, para que esta intervención colonizadora produzca los efectos deseables, parece necesario buscar los caminos oportunos para aumentar la intensidad de la intervención y lograr imponerse al desorden existente. Esta propuesta abre acertadas pautas para el planeamiento que pueden ser útiles, a las estrategias públicas de actuación en la zona".

Las tareas de gestión y seguimiento del solar de proyecto no harán posible su posterior desarrollo en él. Por esto, el Principado de Asturias ofrece la posibilidad de presentarse a un concurso restringido a varios arquitectos galardonados en Europan. El solar que ofrece se sitúa en el Barrio del Nodo de Avilés (tercera ciudad en importancia del Principado de Asturias debido a que a partir de los años 50 llega a cuadriplicar su población debido a la creación de trabajo por la apertura de Ensidesa) y engloba una serie de proyectos, construidos todos por arquitectos galardonados Europan. Es un solar sin preexistencias alrededor y con unas vistas importantes a un parque hacia el norte. Los proyectos que se construyen en este barrio corresponden a un total de 121 viviendas y los equipos son los siguientes: 23 viviendas de Pedro Palmero y Samuel Torres, 22 viviendas de Javier Fresneda, Javier Sanjuán y Javier Herreros, 32 viviendas de Mario Sanjuán, Iban Carpintero, José $M^{a}$ Tabuyo y Ángel Sevilla, 18 viviendas de Jorge Suarez y Lucía Salvador y 17 viviendas de Elio García, Carlos Rodríguez y Javier Rodríguez.

\section{Fase de realización}

Tras un cambio de solar, el equipo realiza un proyecto de ejecución en el Nodo con un proyecto que es un volumen puro que busca y mantiene el módulo desde la ideación. Ellos lo denominan un "dolmen dominante" construido en el paisaje como piedra sin devastar, con colores irisados que resplandecen en contacto con el sol y la lluvia. Se entiende como un basamento que casi se despega del terreno. Se pretende crear una continuidad entre suelo, fachada y cubierta. Los autores resumen el proyecto con la frase: "me gustaría vivir en un edificio con un no se qué". 
VIVIENDAS EUROPAN (1988-2008) I Una aproximación a los modos de vida en el cambio de siglo en España
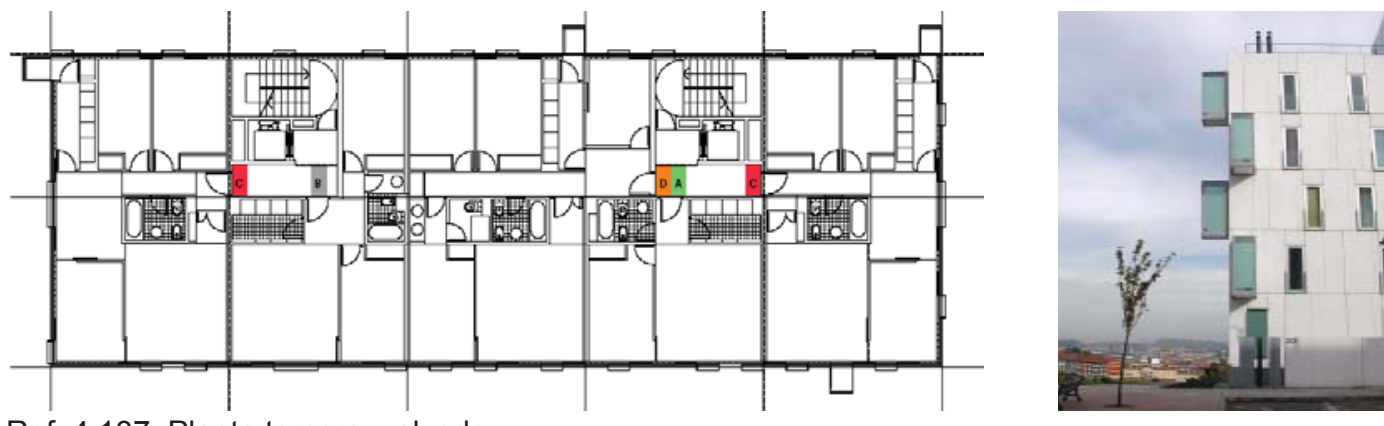

Ref. 4.137. Planta tercera y alzado

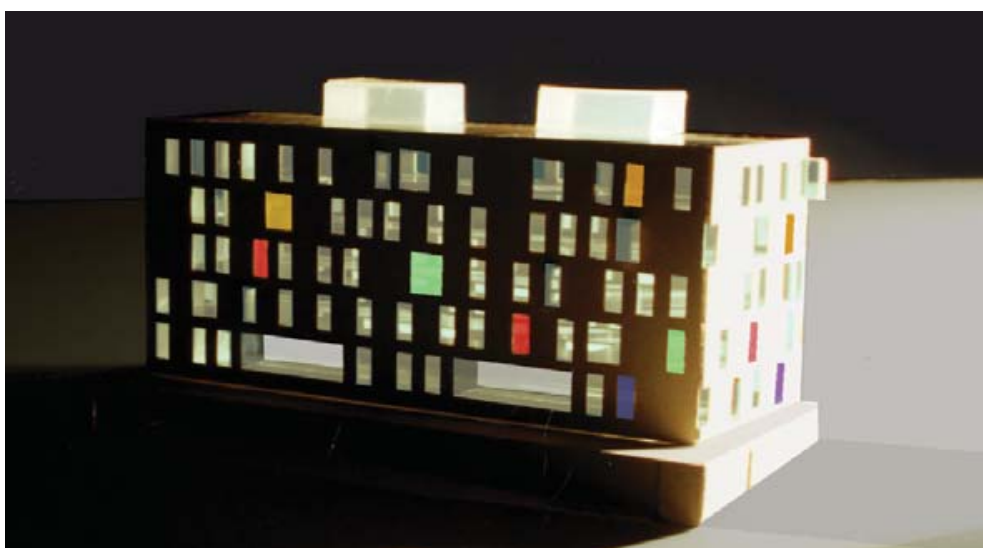

Ref.4.138. Planta baja

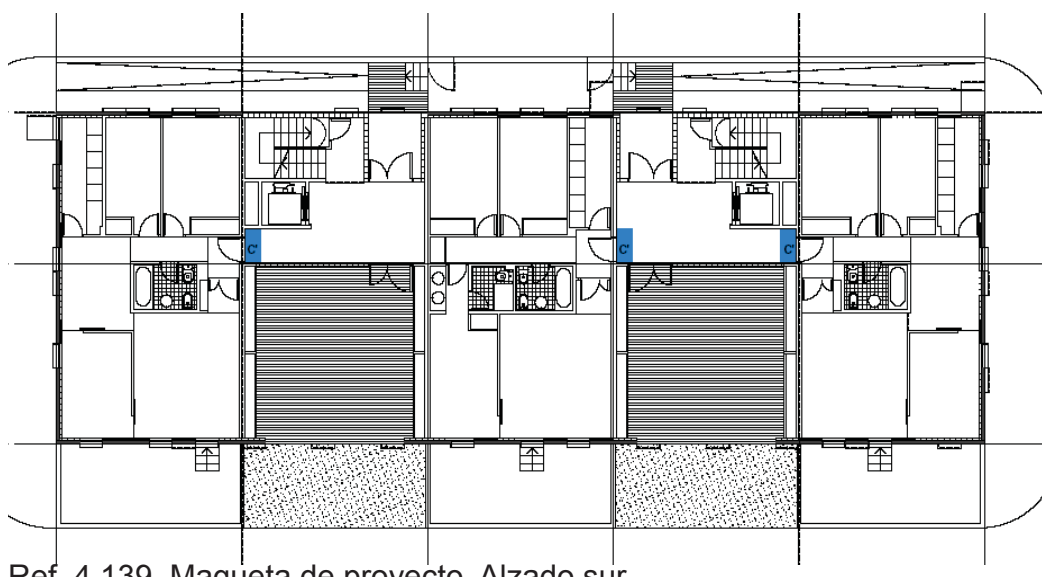

Ref. 4.139. Maqueta de proyecto. Alzado sur

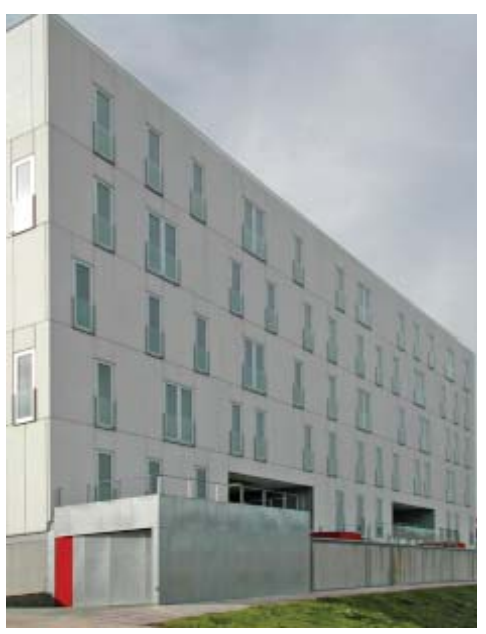

Ref.4.140. Alzado norte

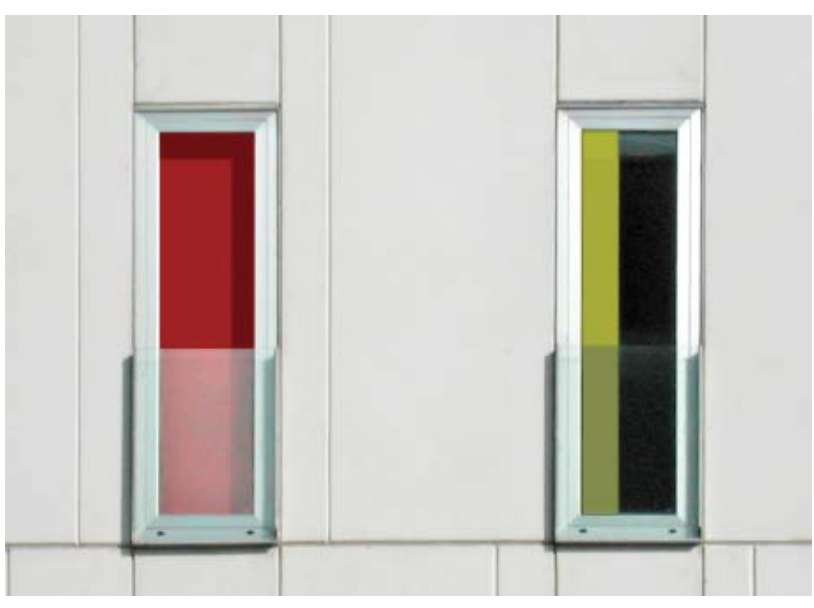

Ref.4.141. Los colores se tomaron de unos estudios de Le Corbusier 
En las viviendas, se ha dado prioridad a las zonas estanciales. Se disponen en cinco bandas transversales de 7 metros. En la dos y cuatro están los núcleos de comunicación vertical. A ellos pueden dar dos o tres viviendas de forma aleatoria en cada planta. Los núcleos húmedos en la zona central y solo las cocinas de las bandas impares dan a fachada con elementos volados. La mayoría de las unidades, salvo los estudios, tienen doble orientación. Las de la planta baja se priman con el uso de terrazas y los portales son dos grandes vacíos que atraviesan el edificio transversalmente, generando dos miradores y zonas de uso para la comunidad.A los garajes se accede por la cota más baja del solar y permite situar de forma racional una única calle con plaza a ambos lados. Entre garaje y planta baja se sitúan los trasteros con la máxima superficie permitida.

En cuanto a la materialidad, este proyecto presenta interés en el tema de la prefabricación, sobre todo en la fachada. La envolvente es una piel de paneles de hormigón de $0,875 \times 2,90 \mathrm{~m}$, teñido de color con pigmentos y tratados en la superficie de su cara vista con los encofrados de la mesa de vibrado. Sobre el panel se proyecta el aislamiento térmico y se trasdosa con la tabiquería de pladur, que oculta las instalaciones. Los suelos son de madera flotante y los techos de pladur. En el exterior, los suelos son continuos de hormigón y en las zonas de portal, es un pavimento continuo de color. La configuración de alzados se realiza con huecos aleatorios verticales de modulación regular y un elemento singular que caracteriza el bloque: los balcones volados del lavadero, que distinguen este elemento que siempre se intenta esconder.

En la maqueta de proyecto se pueden percibir los dos elementos de coronación, donde están situadas las instalaciones. En los proyectos de viviendas actuales, estos elementos suelen ser los actores secundarios, pero en este proyecto aparecen como "linternas en la noche" puesto que están materializados con uglas y se recalcan sobre el paisaje. Respecto a la estructura se puede decir que está construida con forjados de losas alveolares de 1,20 m dispuestos en sentido longitudinal sobre seis pórticos transversales de pilares y vigas prefabricados.

Las viviendas presentan un punto a favor de la versatilidad, ya que introducen elementos movibles dentro de la propia vivienda que permiten que éstas puedan agruparse y redistribuirse en las zonas de estar.

El oscurecimiento de las dependencias interiores se logra a base de paneles de madera correderos que se ocultan en la pared y coloreados según un estudio realizado por le Corbusier para una casa de pinturas. El proyecto se presenta en el año 2001, siete años después de haber ganado Europan.

A continuación se adjunta una ficha-resumen. 


\section{VIVIENDA}

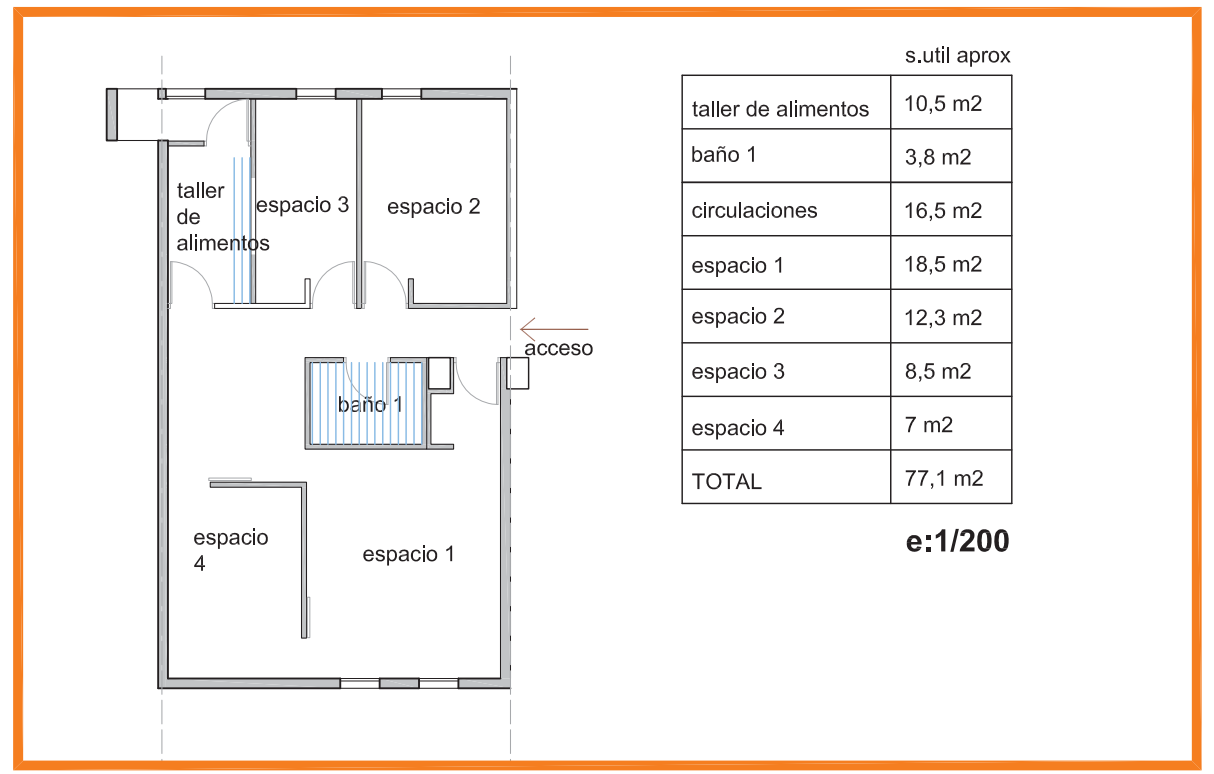

\section{SISTEMAS DE AGRUPACIÓN}

superficie construida total por planta:

$426 \mathrm{~m} 2$

superficie construida zonas comunes por planta: 48 m2 (11\%)

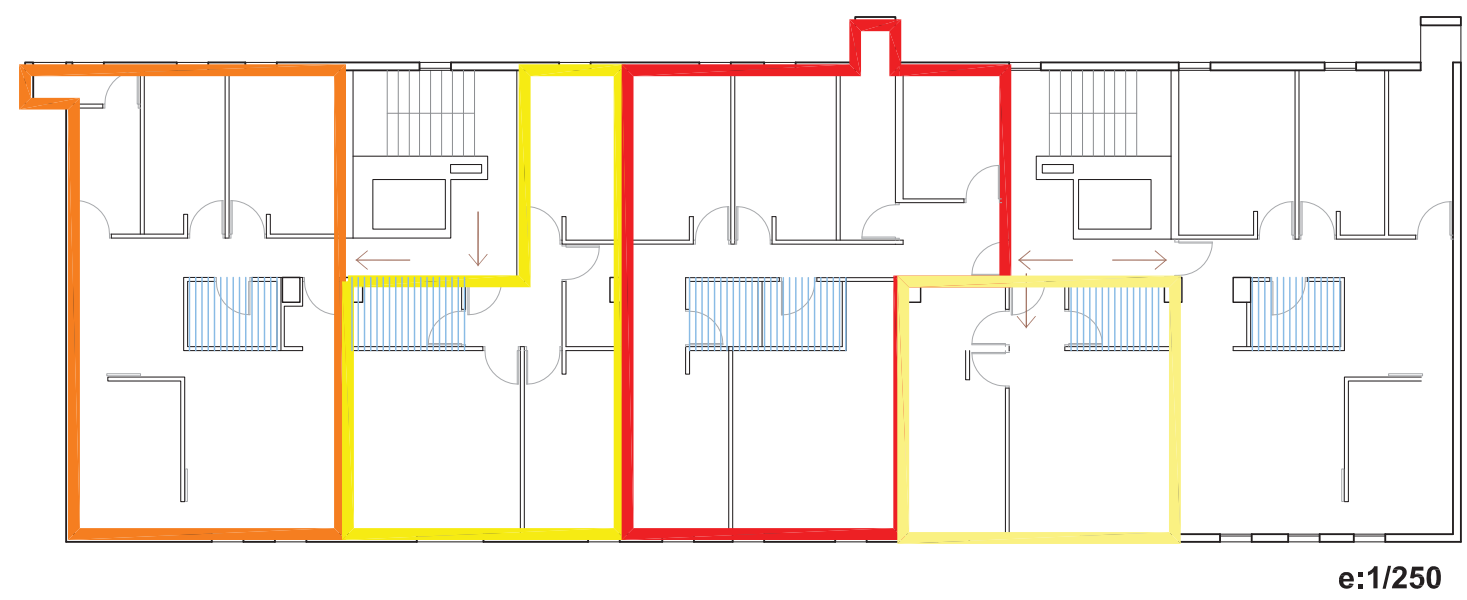

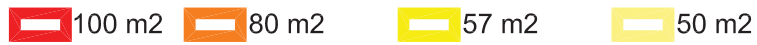



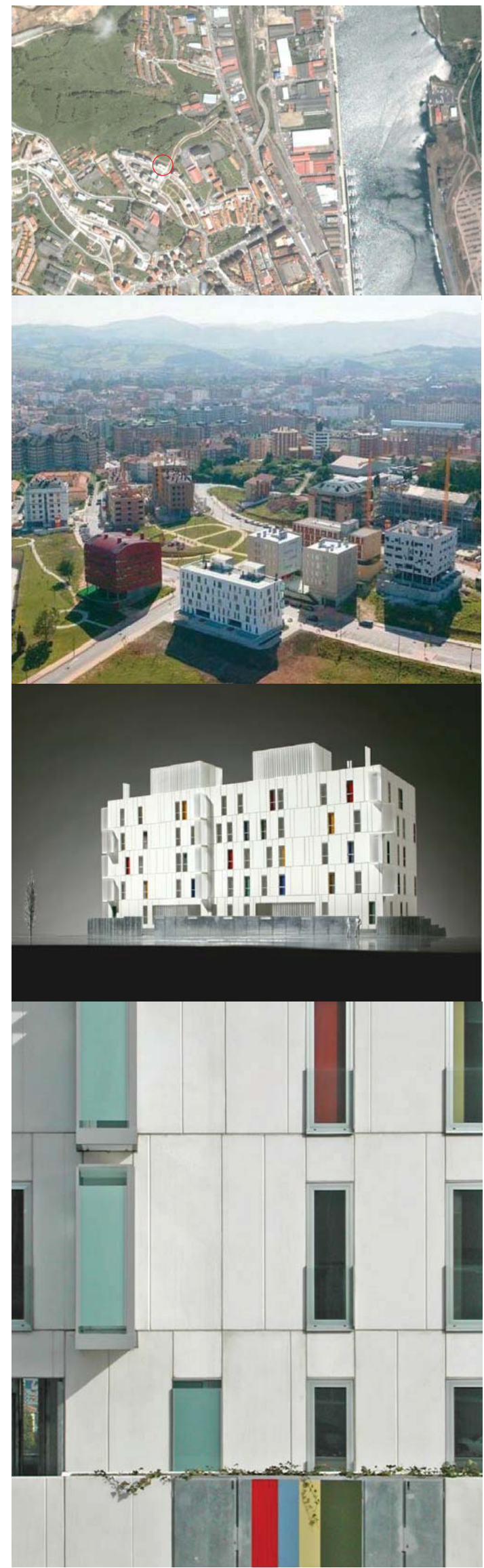

FICHA 4.3

\section{EUROPAN 4}

(año 1994)

\section{PEDRO PALMERO Y SAMUEL TORRES: 23 VIVIENDAS EN EL NODO (AVILÉS).}

EMPLAZAMIENTO

c/Balandro n 18, Avilés (Asturias)

COMIENZO DE OBRAS- FINALIZACIÓN DE LAS OBRAS

El proyecto se presenta en 2001 siete años después de haber ganado Europan

¿ES EL PROYECTO DE CONCURSO?

NO

$\mathbf{N}^{\circ}$ DE VIVIENDAS TOTALES CONSTRUIDAS

23 viviendas

NN DE VIVIENDAS POR SUPERFICIE

VIII 11 viviendas

VIII 6 viviendas

6 viviendas

USO DE LA PLANTA BAJA

Viviendas y portales con grandes vacíos que atraviesan el edificio transversalmente

\section{USO DEL SOTANO}

Garaje y trasteros (semisótano)

\section{REFERENCIAS BIBLIOGRÁFICAS}

www.equipo4d.com

- EUROPAN 10 España, "Proyectar la urbanidad", Madrid, 2010, p. 230 



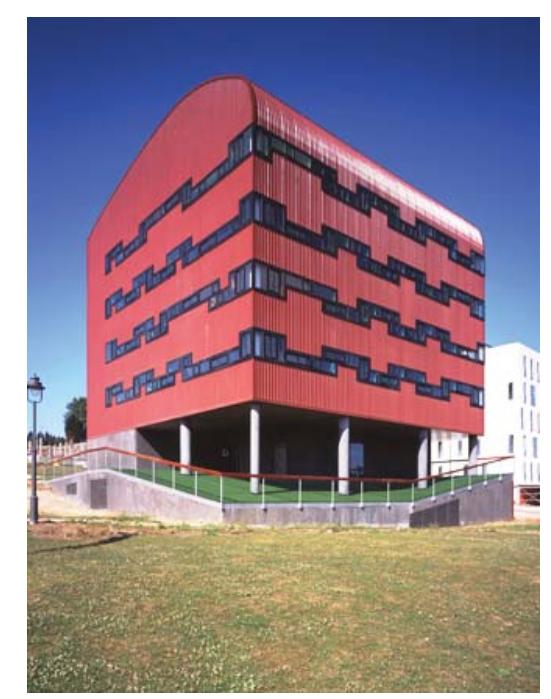

\subsubsection{Edificios de viviendas Europan 4 (1994)}

Javier Fresneda, Javier Sanjuan y Javier Herreros: viviendas sociales en Avilés 


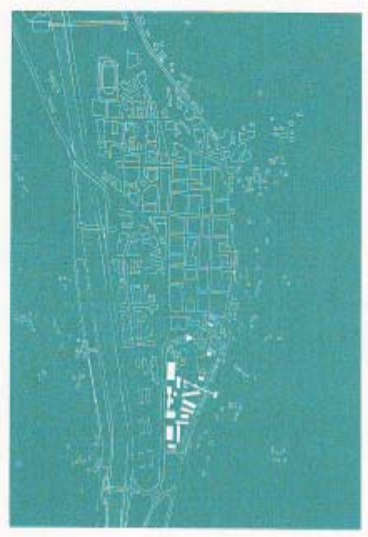

Proponemos resolver el analisis de los dis. tintos escalas territoriales y conceptuales implicodas en el proyecto desde las pautos que emergen de la identidad propia del emplazamiento; interpretar con coherencio la esencio del lugar para crear situaciones nuevas imbricadas con lo existente, que permitan afionzor usos y funciones emergentes.

\section{mención}

$m$ i e r e s

ab 987 Javier Fresneda Puerto, Javier Sanjuán Calle y Javier Herreros Ortega colaboradora: Ana Riaza

Tres son los lugares desde los que potencior un cambio de relaciones: la villa, el Pozo Barredo y la Montaño, referente del conjunto urbano.

Trobajamos modelando el vacío según relociones topológicas de implantación de los usos.

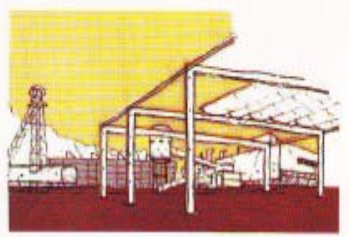

El proyecto se define en los bordes, conevio. nes entre herencios y proposición, comple. tando el tapiz urbano mediante un proceso de orden y control de la fuerza latente en el sustrato histórico-territorial.

Tráfico peatonal y rododo se segregan inte. grando occesos y aparcamientos de superficie en tomo a un anillo circulatorio perimetral, pora liberor un amplio espocio central de uso pectonal, catalizador de la actividad y de la gradación de la función pública y privoda. Este espacio se proyecta como argumento narrativo de cohesión entre tro. mo existente, nueva edificación, arqueologia industrial y la escenogrofía que proporciona la topogrofia del lugar.

Es un soporte diferenciado por ambientes, usos y relociones con la edificación, en tor. no al cual se dispone una banda de equi. pamiento de centrolidad: centros de ocio, comercio, culturo... Esto banda configuro la fachada desde el viario principal. En lo zona opuesta, en situación de mayor privacidad y reloción con el entorno, se lo. caliza el espacio residencial, según una geometría basoda en relociones espaciales y medioambientales.

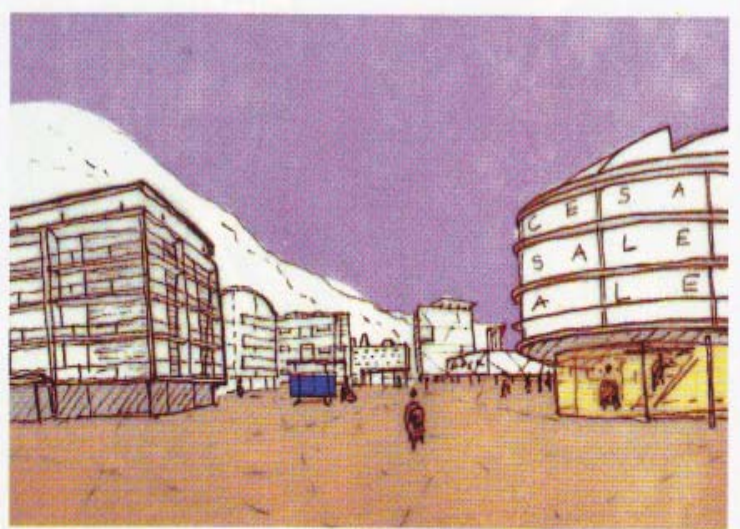

lgualmente importante ha sido la incorporación desde el principio del proceso proyectual del concepto de flexibilidad espacial y temporal. Una edificación basada en el control de lo no edificado permite un amplio margen de alteraciones $\mathrm{e}$ incidencias en los procesos de gestión y desarro. 110

La capacidod escenogrática de las piezos industriales, de la topográfía y de la tramo consolidada, se ha interpretado como la mejor herencio de una ciudad que busco en una zona devaluada una oportunidad precisa de transformación y desarrollo. 1. Ordenacón general y sección; 2. Esquemas expli-
catuos de la propuesta.

Ref. 4.142. Paneles de concurso 

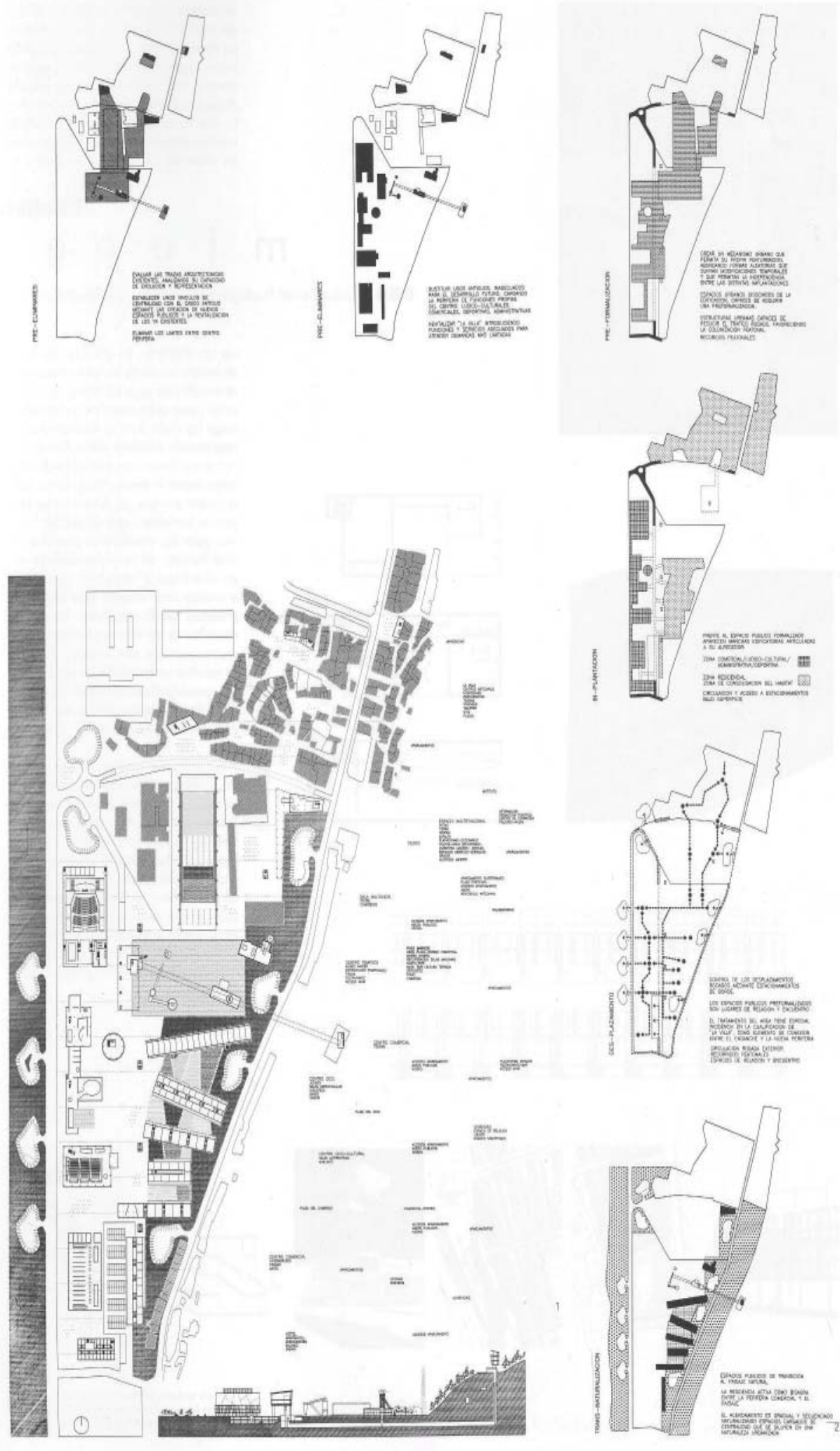

Ref. 4.144. Paneles de concurso

49 


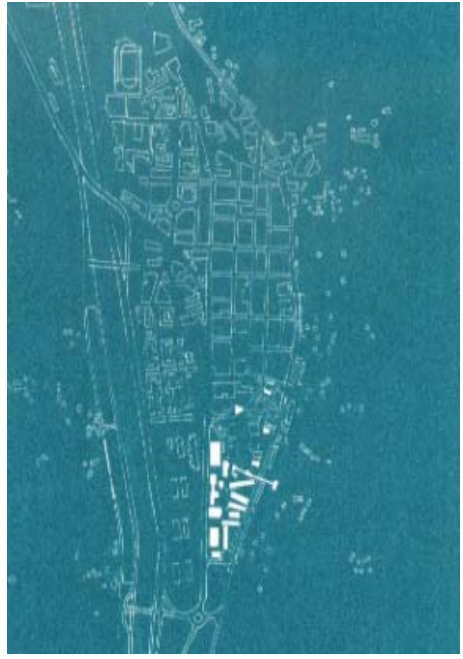

Ref.4.144.Plano de ordenación Mieres

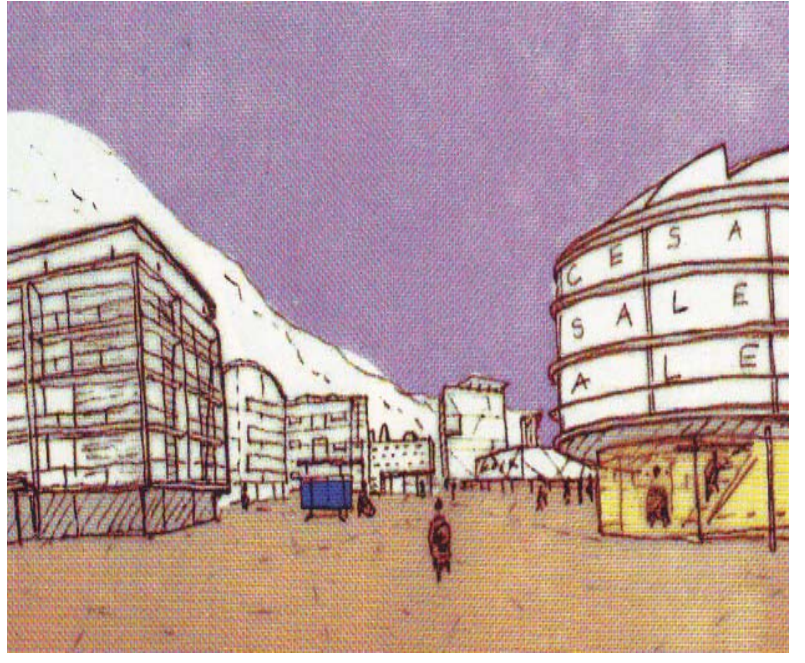

Ref.145. Perspectiva de concurso

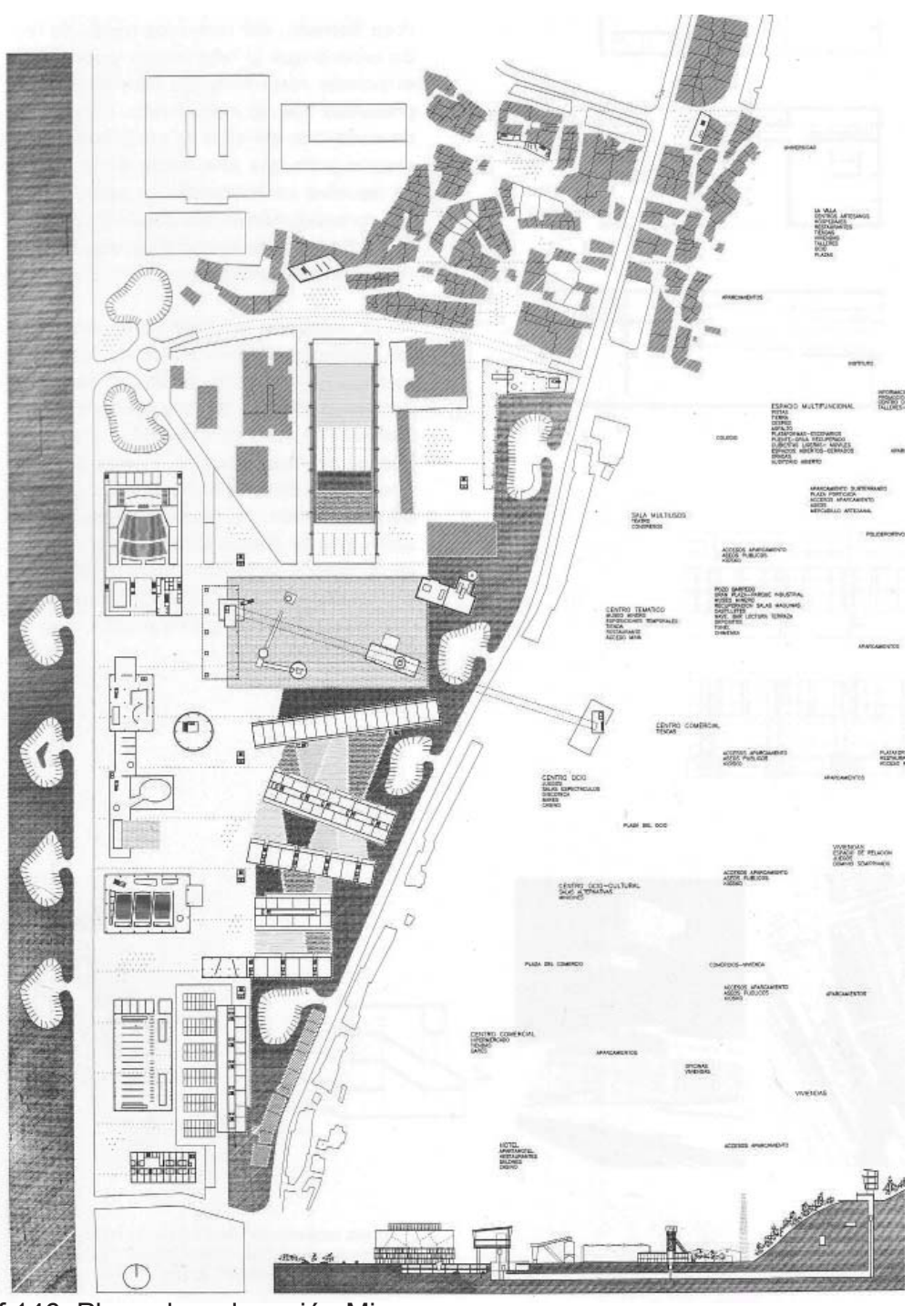

Ref.146. Plano de ordenación Mieres 


\section{Fase de concurso}

El emplazamiento del solar de concurso de Europan 4 propuesto por el Principado de Asturias se desarrolla en el emplazamiento de Mieres. En éste se encuentran dos ámbitos diferenciados: por un lado numerosas propiedades privadas en situación de deterioro ambiental progresivo y por otro unos terrenos liberados. En el norte del solar se encuentra la trama ortogonal del ensanche de Mieres, al oeste un barrio con viviendas de promoción pública y al sur un polígono industrial con predominio de actividades de distribución y almacenamiento de mercancías, al este el antiguo eje viario de la nacional Gijón-Madrid.

Se pretende rematar el terreno urbano de la ciudad, por lo que se propone una actuación de borde. Se trata sobre todo de un proyecto de rehabilitación, para regenerar entre 90 y 100 viviendas y $15000 \mathrm{~m} 2$ a urbanizar.Se trata también de proponer un espacio de equipamiento cultural para la zona de Mieres que tenga usos hotelero, minicines, ocio, etc. También un espacio para comercios, plazas de aparcamiento en superficie y otros usos terciarios. Además se propone construir 400 viviendas de nueva planta.

Entre las propuestas presentadas, el Jurado galardona a:

- Julio Daniel Rodríguez y Daniel Rivoira Zecca, presentan una propuesta en la que quedan finalistas. Hablan de relacionar la propuesta con el entorno desde un principio.

- Javier Fresneda, Javier Sanjuán y Javier Herreros (más conocidos como los javieres), presentaron un proyecto desde la esencia del lugar y su relación con la topología existente con el lema ab987.

Estos proyectos tienen en común que empiezan a utilizar una escala mayor para definir las propuestas de concurso. Se empiezan a ver planteamientos globales en los proyectos y los mismos autores comienzan a hablar de escala territorial. En concreto, el uso de esquemas que facilitan y explican las propuestas presentada es de agradecer.

Los autores quieren potenciar la capacidad escenográfica de las piezas industriales, la topografía y la trama consolidada. Se busca en esta zona devaluada una oportunidad para la transformación y el desarrollo.

El proyecto habla del lugar, factor que es tenido en cuenta desde el comienzo. Plantean un espacio central de uso fundamentalmente peatonal y en el que se localizan los equi-pamientos de ocio, comercio y cultura...

Pero, por otro lado, las piezas residenciales carecen de definición y no se puede comentar nada al respecto.

\section{Fase de realización}

Finalmente, el equipo de los javieres no pudo construir el proyecto mencionado 
VIVIENDAS EUROPAN (1988-2008) I Una aproximación a los modos de vida en el cambio de siglo en España

4. EUROPAN: DEL CONCURSO A LA REALIZACIÓN

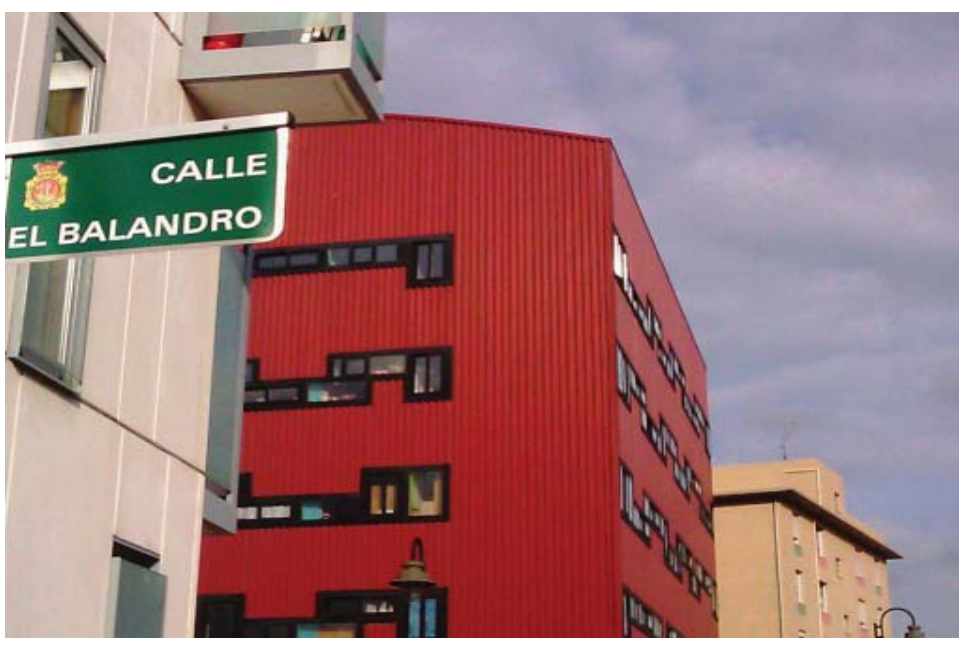

Ref. 147. Vista desde el acceso por c/Balandro

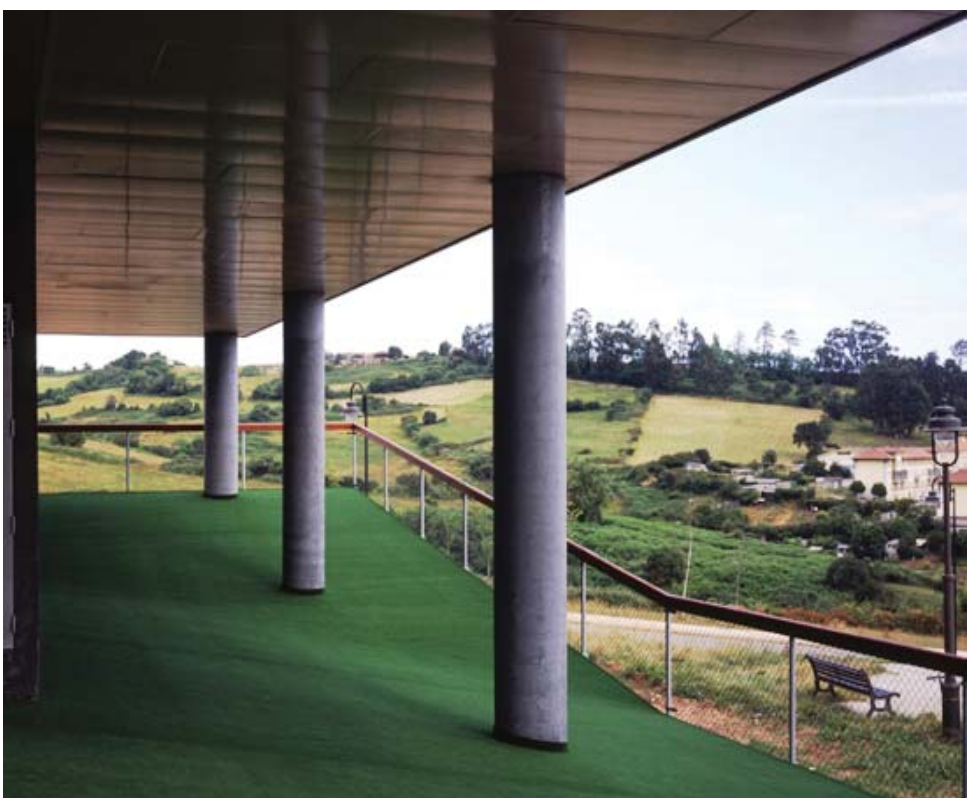

Ref.149. Tratamiento de la planta baja
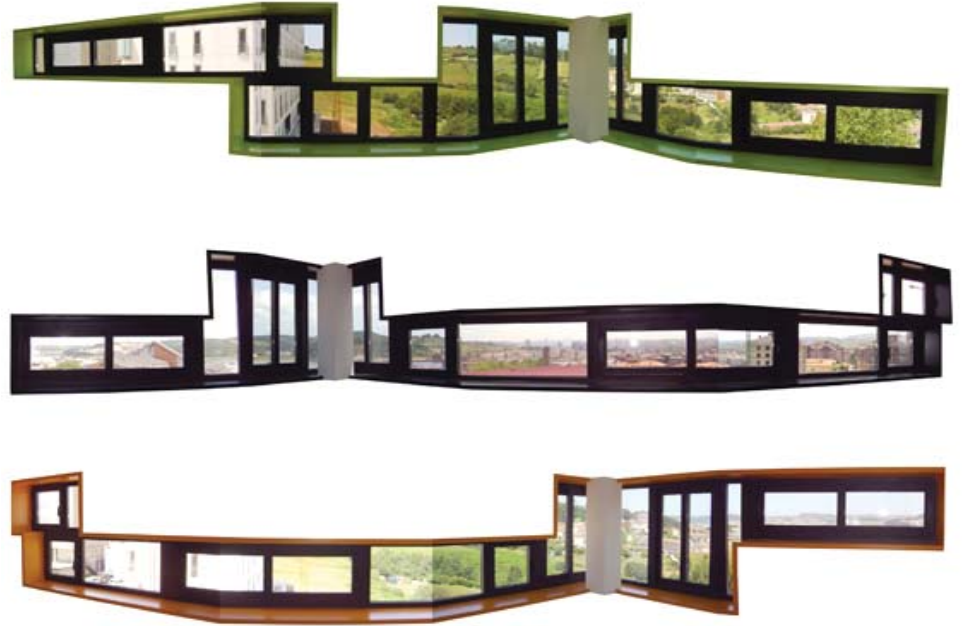

Ref.150. Fotomontaje de la ventana continua 
de Europan 4, pero sí participó en el concurso restringido en el barrio del Nodo en Avilés. Con este proyecto quedaron finalistas en la VIII bienal de arquitectura española. Se situará en la parcela contigua a la del proyecto de Pedro Palmero y Samuel Torres que se ha analizado anteriormente.

Se trata de 22 viviendas sociales contenidas en un volumen cúbico sobre pilares. Es un volumen único, que manifiesta su presencia desde la distancia. Juega con la idea que tenían en el concurso de potenciar su relación con la topografía. La cota cero se inclina simulando una rampa de acceso y se reviste con un material aterciopelado que lo asemeja al césped del paisaje. La principal búsqueda en la vivienda es la versatilidad y la flexibilidad. Esto lo consiguen al disponer en planta concéntricamente y distribuyen de dentro a fuera los espacios comunes (patios de iluminación y ventilación general, y de núcleos húmedos particulares), zonas de acceso común (ascensores, escalera y zonas intermedias de instalaciones, vestíbulos de viviendas, zonas húmedas de aseos y tendederos) y zonas estanciales de las viviendas.

Con esta organización se libera a las estancias de las servidumbres de las instalaciones permitiendo la posibilidad de variaciones en la distribución de las estancias servidas. Se abre a las cuatro orientaciones de modo que todas las estancias de todas las viviendas se vuelcan al exterior de modo isótropo, con la peculiaridad de que los estares van a las esquinas en la configuración de partida. Para conseguir disponer la totalidad de las viviendas demandadas es necesario distribuir 5 viviendas por planta en las tres primeras plantas (a partir de la primera planta) y 7 viviendas en la última planta, al aprovechar parcialmente el espacio bajo cubierta.

En planta baja se dispone el portal, el núcleo de acceso a viviendas con escalera, dos ascensores (uno de ellos adaptado) y las escaleras de acceso a planta sótano de trasteros. Además se ubican los locales de instalaciones y cuartos de basura.

Las crujías hacia las calles se liberan para disponer el local comercial.

El núcleo central de circulaciones verticales está relacionado con dos patios interiores. La estructura el edificio es de $3 \times 3$ crujías de tal forma que ningún pilar interfiere con la organización de las viviendas ya que un anillo estructural central contiene las instalaciones y otro el perímetro.

En la primera planta del sótano y vinculados a las viviendas, se sitúan los 22 trasteros correspondientes a las mismas. El ascensor adaptado baja hasta esta planta.

La solución estructural se reduce a un simple ejemplo de estructura de pórticos de hormigón armado con luces amplias que liberan al máximo la planta. Utiliza la chapa para la fachada, pero el resto de materiales serán los convencionales, a pesar de que la intención que tenían era la de construir en seco.

A continuación se adjunta una ficha-resumen. 


\section{VIVIENDA}

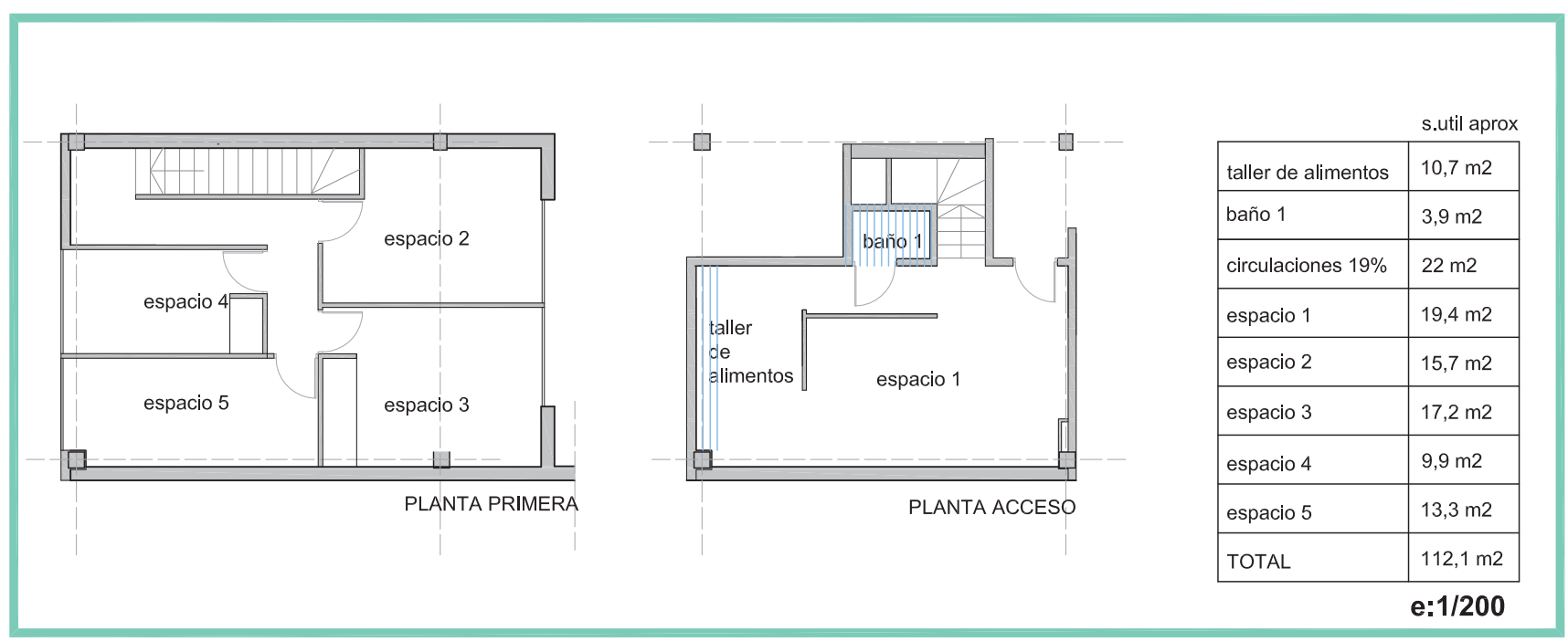

\section{SISTEMAS DE AGRUPACIÓN}

superficie construida total por planta:

$536 \mathrm{~m} 2$

superficie construida zonas comunes por planta: 72 m2 (14\%)

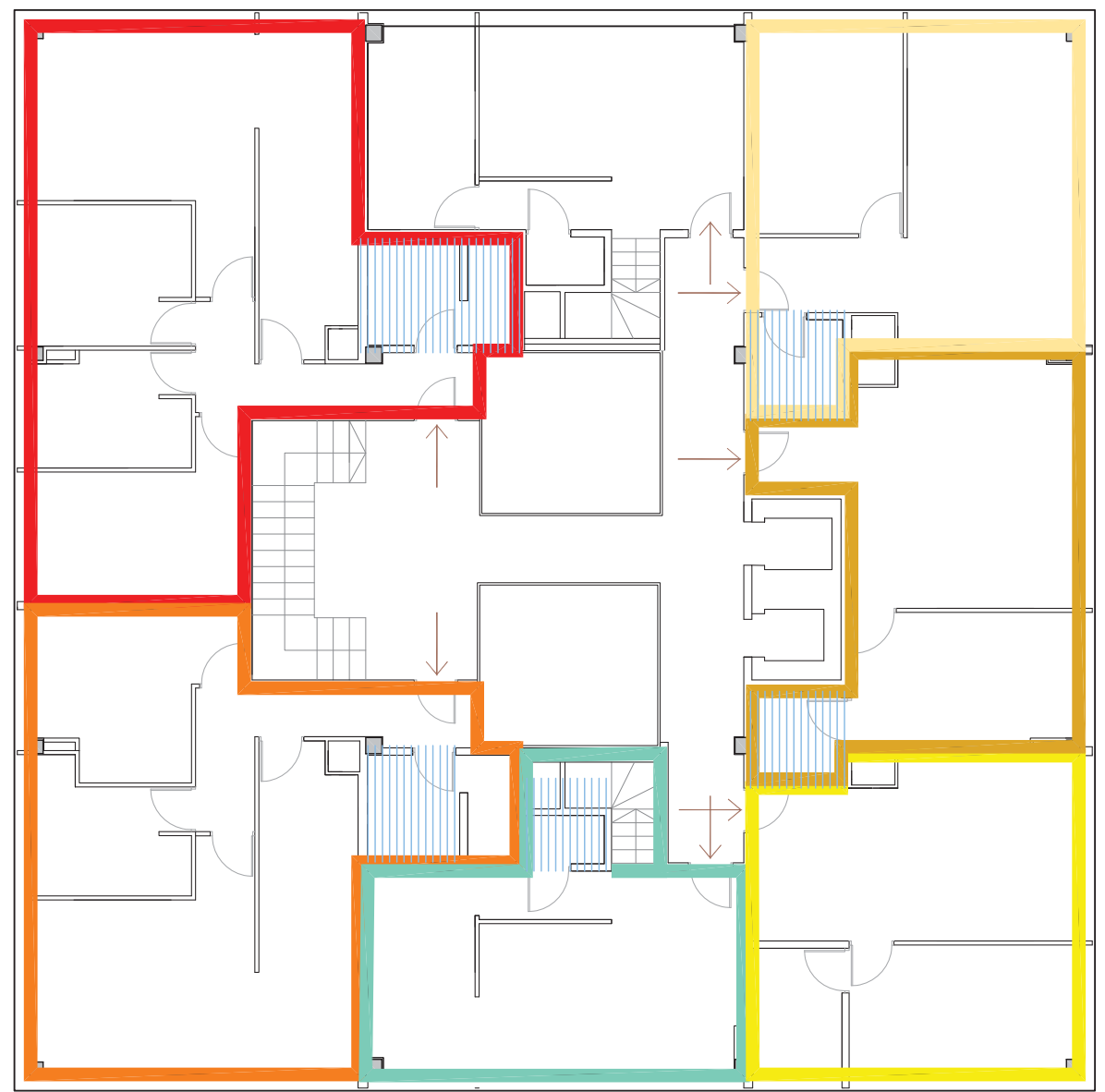

e: $1 / 250$ 

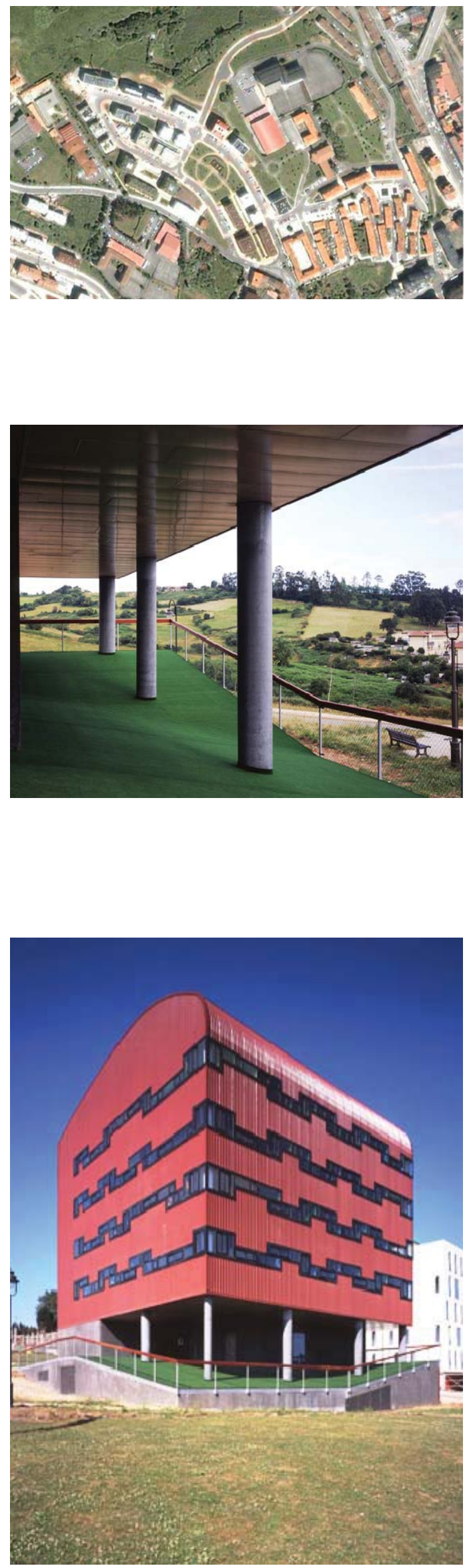

\section{EUROPAN 4}

(año 1994)

\begin{tabular}{c} 
JAVIER FRESNEDA, JAVIER SANJUÁN Y \\
JAVIER HERREROS: \\
22 VIVIENDAS EN EL NODO (AVILÉS) \\
\hline EMPLAZAMIENTO \\
c/Balandro $n^{\circ}$ 16, Avilés (Asturias)
\end{tabular}

COMIENZO DE OBRAS- FINALIZACIÓN DE LAS OBRAS

Fin: año 2004

¿ES EL PROYECTO DE CONCURSO?

No

N DE VIVIENDAS TOTALES CONSTRUIDAS

5 viviendas por planta en las tres primeras plantas

( a partir de la 1 ${ }^{\mathrm{a}}$ ) y 7 en la última planta. En total 22.

\section{N DE VIVIENDS POR SUPERFICIE \\ VIIA 4 viviendas 4 viviendas \\ WII 4 viviendas VII 4 viviendas \\ 2 viviendas 4 viviendas}

USO DE LA PLANTA BAJA

Portal, núcleo de acceso (escalera y dos ascensores) y escaleras de acceso a trasteros, locales de instalaciones y cuartos de basura. En las crujías hacia la calle el local comercial.

\section{USO DEL SOTANO}

Garaje y trasteros

\section{REFERENCIAS BIBLIOGRÁFICAS}

www.mtmarquitectos.com

- EUROPAN 10 España, "Proyectar la urbanidad", Madrid, 2010, p. 231 



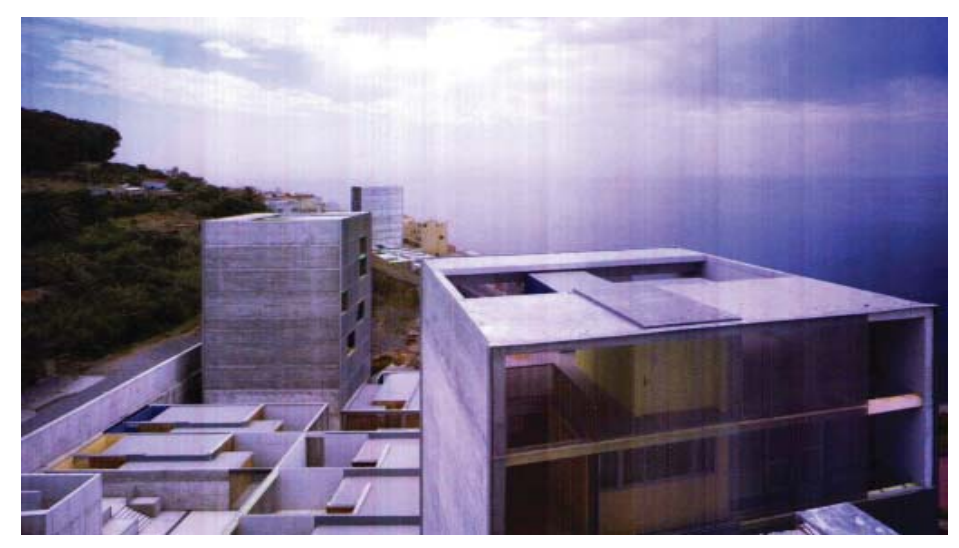

\subsubsection{Edificios de viviendas Europan 5 (1997)}

José Morales y Juan González Mariscal: torres y viviendas unifamiliares en Ceuta 


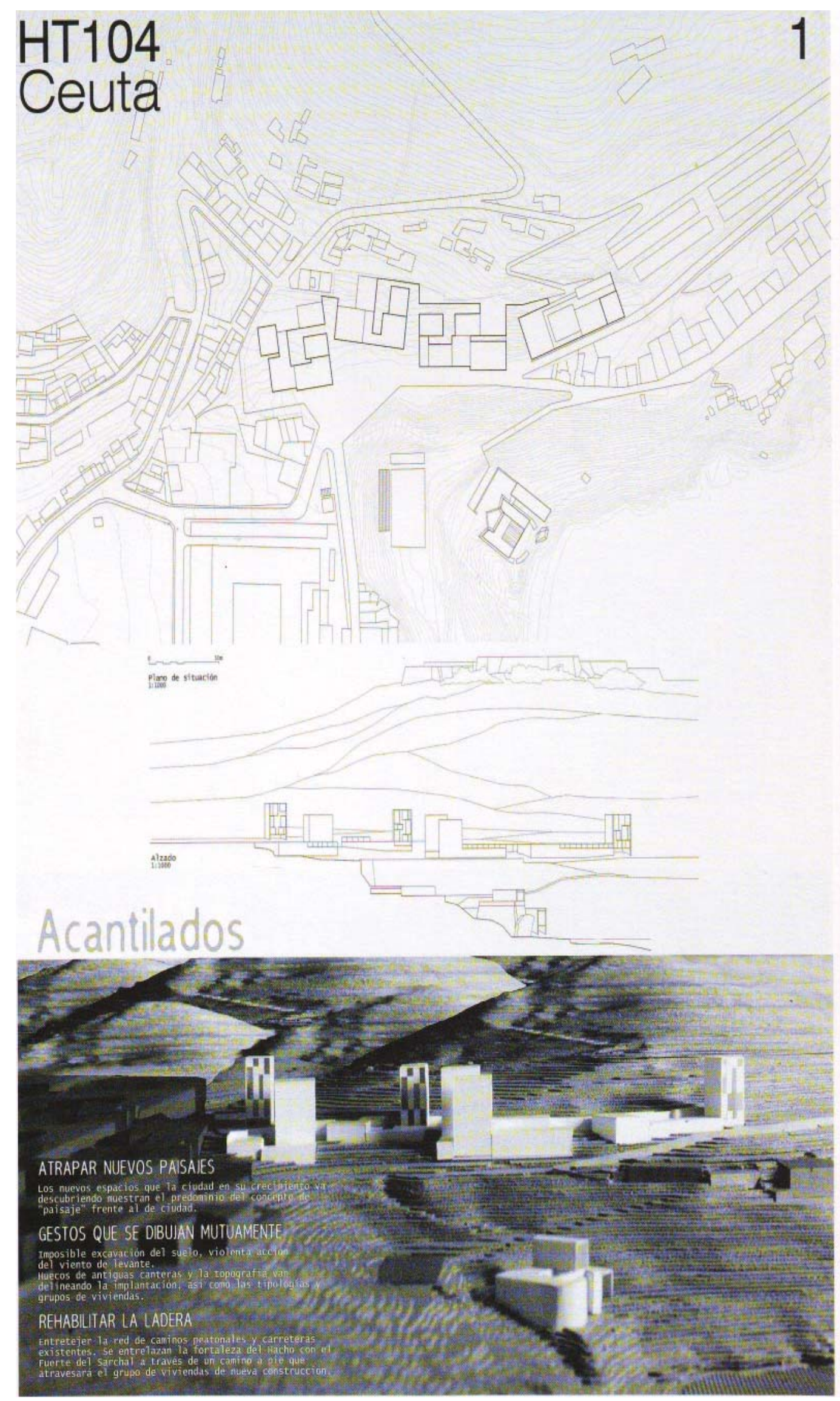

Ref. 4.151. Paneles de concurso 


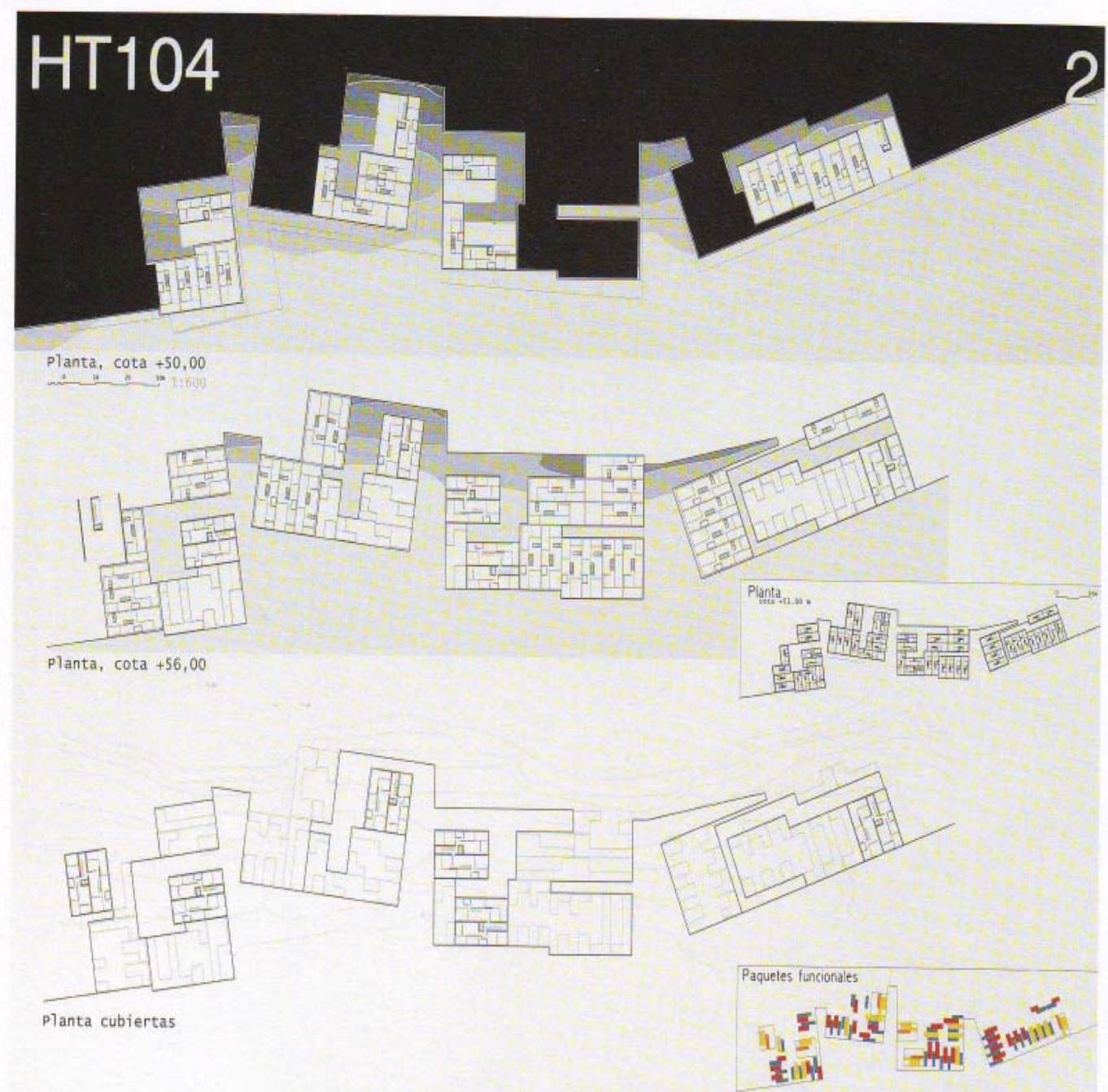

RACIMOS DE VIVIENDAS

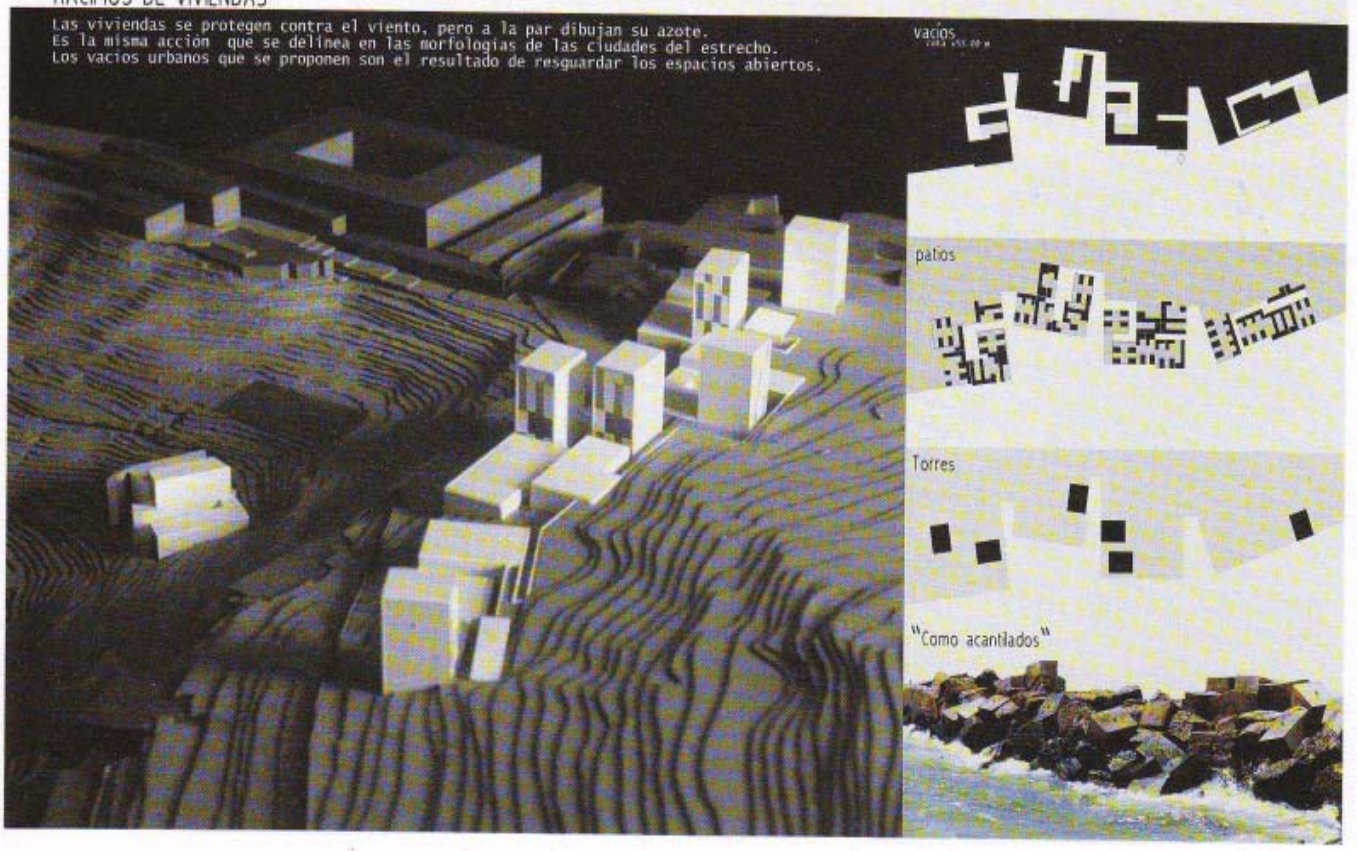

Ref. 4.152. Paneles de concurso 


\section{HT104}

viviendas unifamiliares

escala 1:280
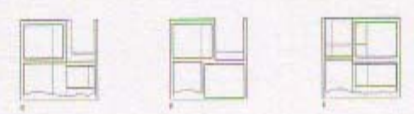

secciones
escanal: 400
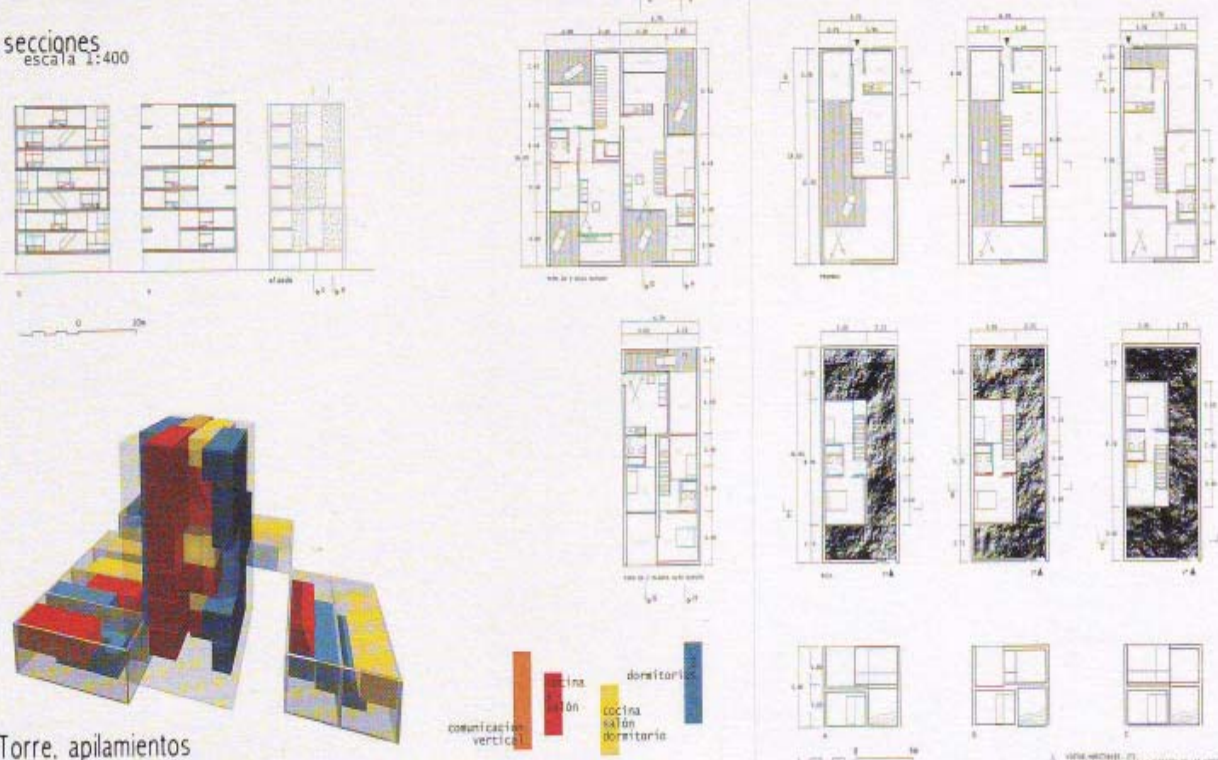

Torre, apilamientos
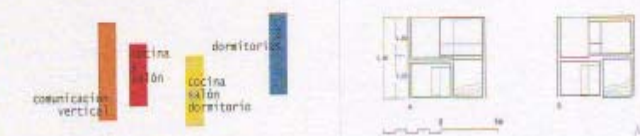

1:700
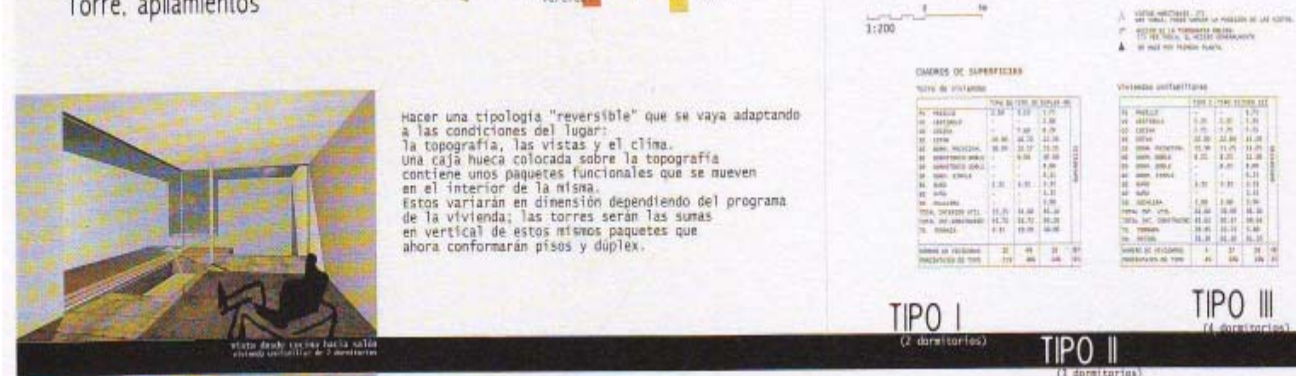

TIPO।

\section{TIPO ||}

TIPO ||
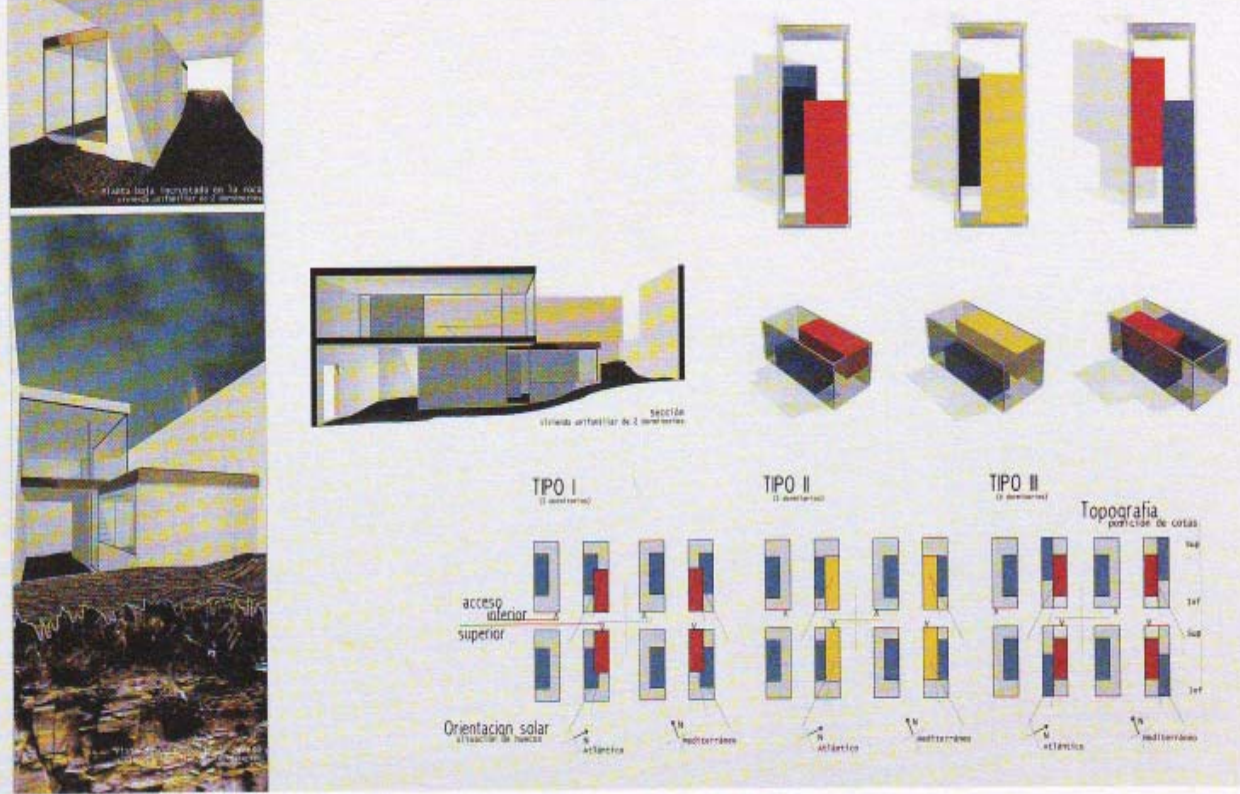

Ref. 4.153. Paneles de concurso 


\section{Fase de concurso}

El solar que se proponía en Europan 5 en el emplazamiento de Ceuta se situaba en Monte Hacho, un lugar plagado de fortificaciones e infraviviendas incrustadas en una montaña rocosa. Sufría la agresividad del viento de levante que sopla doscientos días al año a una media de $80 \mathrm{~km} / \mathrm{h}$. El emplazamiento, una antigua cantera, está lleno de fosos excavados para la extracción de la piedra.

Además la convocatoria suponía la oportunidad para investigar espacios urbanos abandonados situados con el encuentro de redes de comunicación, y pretender recuperarlos.

Los proyectos galardonados son tres:

- Enrique Delgado Cámara, Rubén Picado Fernández, Ma José De Blas Gutiérrez, presentan un proyecto muy parecido al que posteriormente se construirá: unas torres combinadas con una edificación de menor densidad y que va adaptándose a la topografía.

- $M^{a}$ José Pizarro Juanas, propone una edificación de baja densidad que se adapta a la topografía como pequeños gusanos.

- Por último José Morales y Juan González Mariscal proponen una combinación entre viviendas-patio y viviendas-torre. Tiene la virtud de que organizan pequeños módulos funcionales mediante colores y esto ayuda a primera vista a entender el proyecto.

Plantean el dominio de la concepción fundamental de paisaje frente al de ciudad. Se pretende colonizar la singularidad del lugar en su cota cero. Se entreteje la red de caminos y carreteras existentes. Se propone un paseo a pie por la ladera desde las viviendas ala punto más alto (la fortaleza del Hacho) y el más bajo (el fuerte del Sarchal).

También en la propuesta se trata de proteger a las viviendas del viento. Los vacíos urbanos que se proponen son el resultado de resguardar los espacios abiertos. Las torres se implantan sobre huecos existentes en las rocas, resultado de excavaciones pasadas.

De esta manera, clasifican las viviendas de la siguiente forma:

- Vivienda nicho. Es la que se encuentra protegida del viento. En algunas viviendas incluso se ha introducido la roca en su planta baja ya que excavar la montaña lo conciben como algo ilógico y costoso. La vivienda deberá construir su propia relación con el exterior. En las plantas superiores se situará la zona de día.

- Vivienda reversible. Es la que se puede intercambiar en sus espacios. Se ha pensado situar los accesos según convenga. Normalmente se accede por la planta primera desde la calle, en la que se sitúan cocina, salón y terraza,

Se propone utilizar hormigón prefabricado para la estructura ya que se deterioraría en menor medida. 
VIVIENDAS EUROPAN (1988-2008) | Una aproximación a los modos de vida en el cambio de siglo en España

4. EUROPAN: DEL CONCURSO A LA REALIZACIÓN

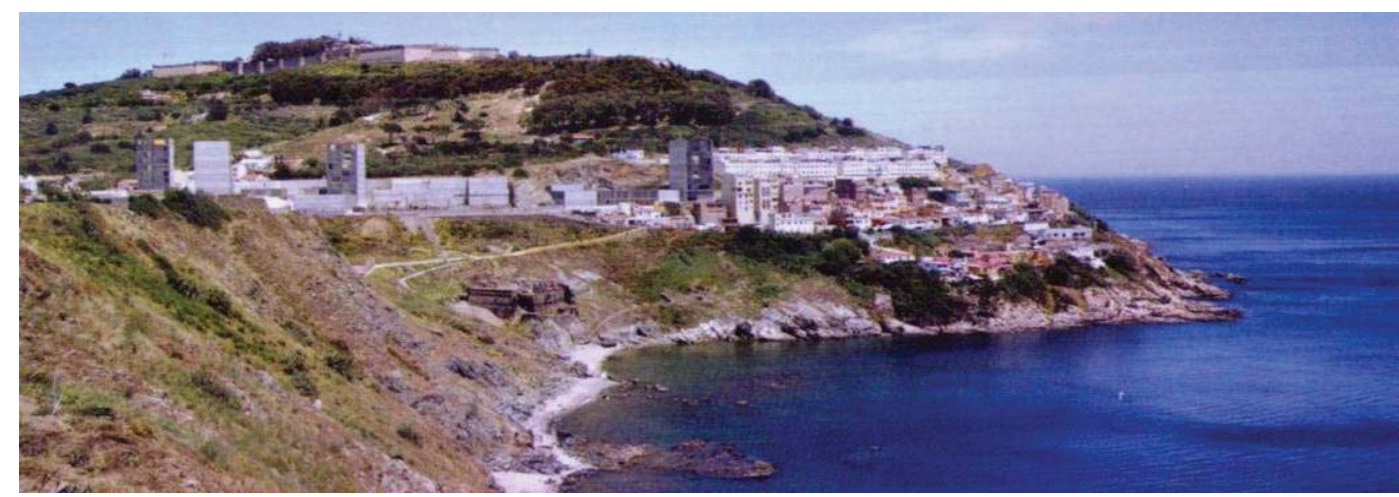

Ref.4.154. Mirando al atlántico

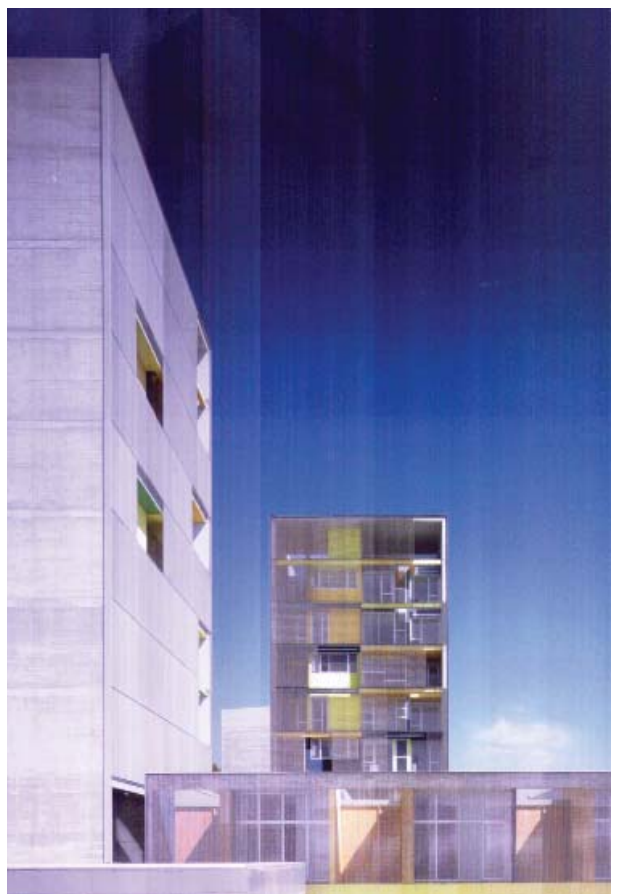

Ref.4.155. Planta del conjunto

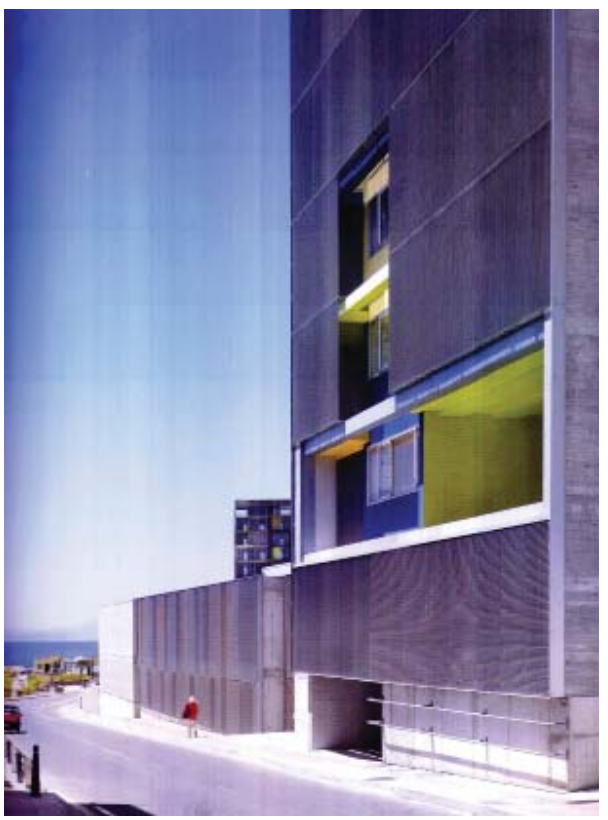

Ref.4.157. Vista desde la calle

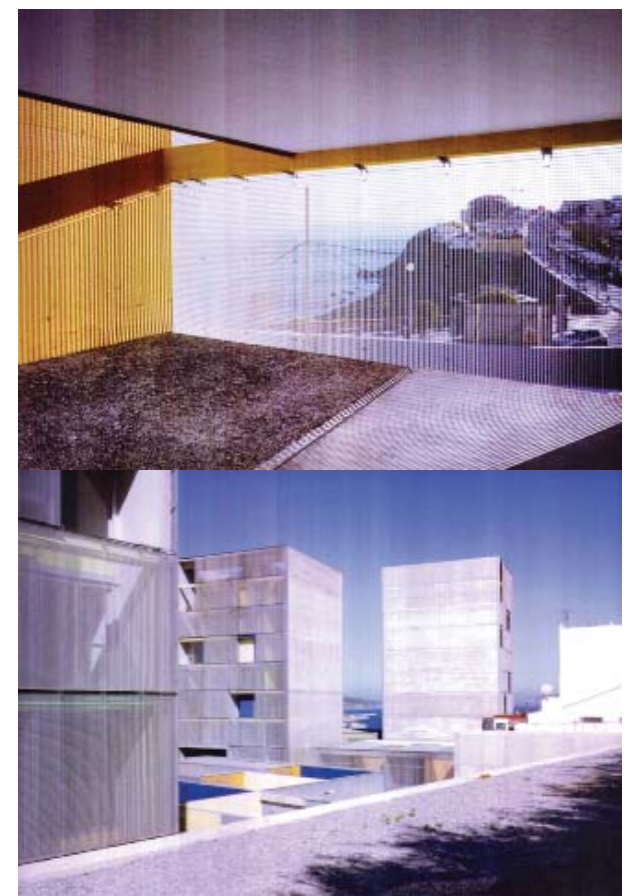

Ref.4.156. Terrazas mirando al mar

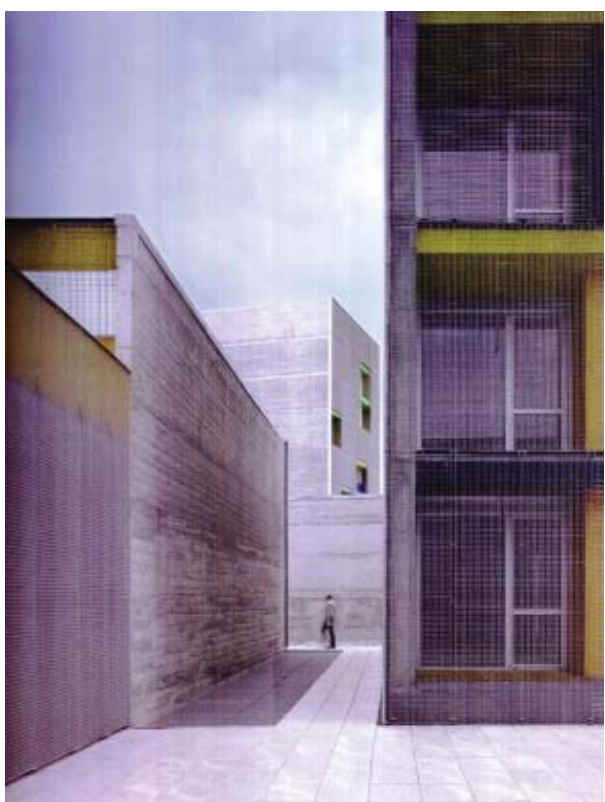

Ref.4.158.Tratamiento de la cota cero 


\section{Fase de realización}

Cabe puntualizar que seguirá en gran parte el proyecto que se presenta en el concurso basado en unas torres estratégicamente orientadas (unas miran al Atlántico y otras al Mediterráneo) con unas prolongaciones en la cota del terreno que son viviendas patio y actúan como "vacíos urbanos".

Se desarrolla la idea de "paquete funcional" que se representa de un color primario distinto: el azul representa dos dormitorios, el amarillo uno y una sala de estar y el rojo una sala de estar y una cocina.

Al situarse en un terreno con mucha pendiente, se realiza un plano de vacíos y también otro de patios (los de las viviendas unifamiliares).

El proyecto construido aumentará la superficie de actuación inicialmente prevista. En un principio, se contratará inmediatamente después del fallo del Jurado, más adelante quedó paralizado por un cambio político y, posteriormente, fue retomado el tema siguiendo las gestiones con normalidad.

Las nuevas viviendas se protegen del viento, al tiempo que dibujan su azote. El conjunto consta de 127 viviendas de protección oficial, de las cuales 41 son unifamiliares. Intentan respetar al máximo la topografía rocosa, como se pretendía desde el comienzo, tanto que ésta forma parte en algunos casos de las viviendas, y el resto se distribuyen en seis torres, llega a cada una de ellas clavada en las antiguas excavaciones de la cantera.

En la vivienda, para protegerse del viento, se utilizan los dos conceptos de concurso.

La vivienda patio tiene una orientación predominante norte-sur, aunque en algún caso giran y pasan a tener orientación este-oeste. Son viviendas permeables, moduladas con 6,70 $\mathrm{m}$ de ancho por $16 \mathrm{~m}$ de largo cada unidad.

En las torres permanece la misma modulación. Existen dos crujías unidas de $6,70 \mathrm{~m}$ cada una y $16 \mathrm{~m}$ de largo en cada vivienda. Tienen una doble orientación de modo que una de sus terrazas puede mirar hacia el Mediterráneo y otra hacia el Atlántico. En esta tipología se accede por la zona intermedia directamente al estar que está vinculado directamente a la cocina, a una gran terraza y a la escalera de acceso al piso superior, que a su vez hace de división entre el estar y dos pequeñas habitaciones y un baño vinculados a la terraza del estar y a otra más pequeña vinculada a la cocina. En el piso superior hay dos habitaciones más y un baño.La distribución de cada tipología de vivienda es similar, aunque a las viviendas unifamiliares se accede por un lado diferente y tiene una pequeña variación en el tamaño y disposición de las terrazas.

A continuación se adjunta una ficha-resumen. 
VIVIENDA
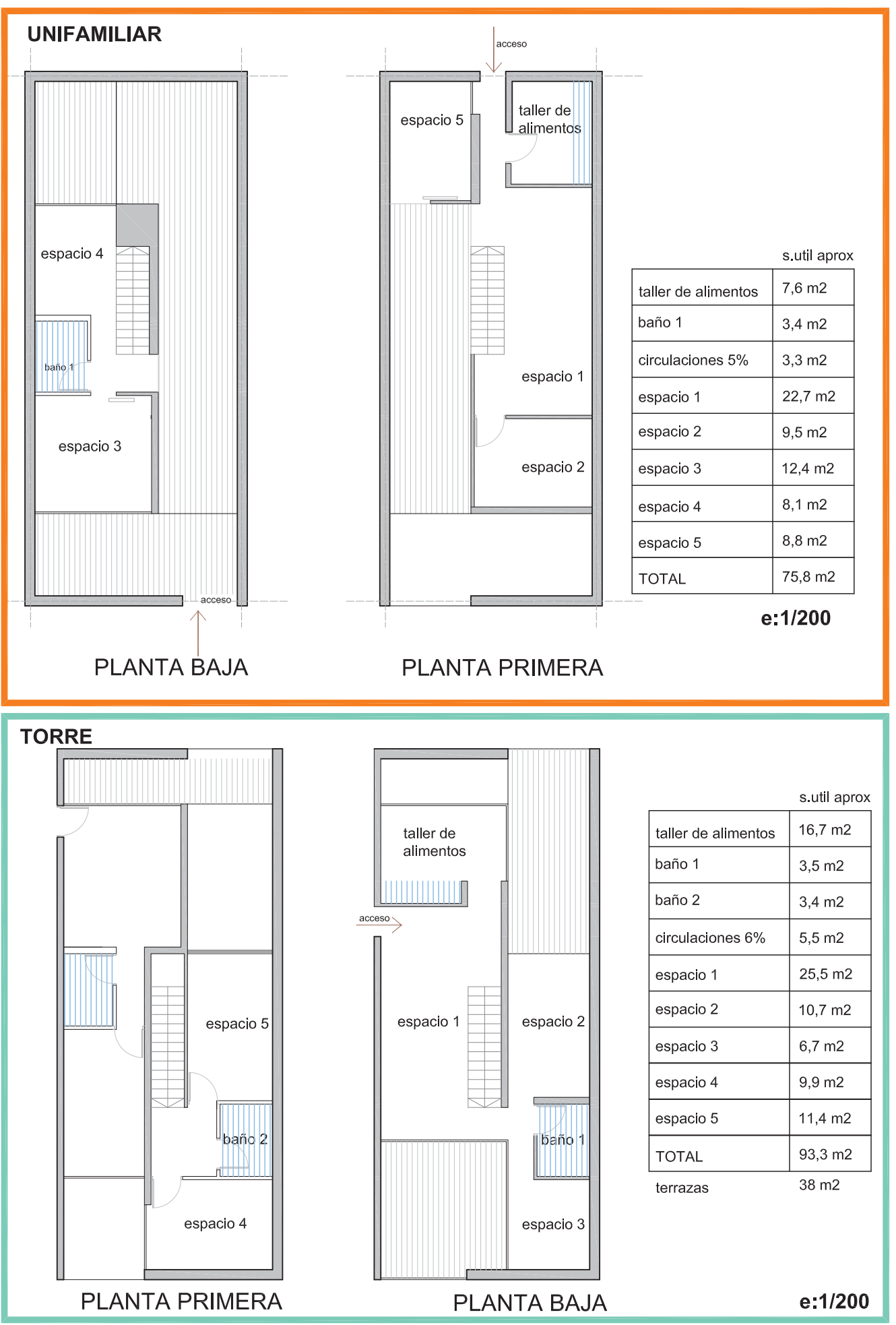

TORRE

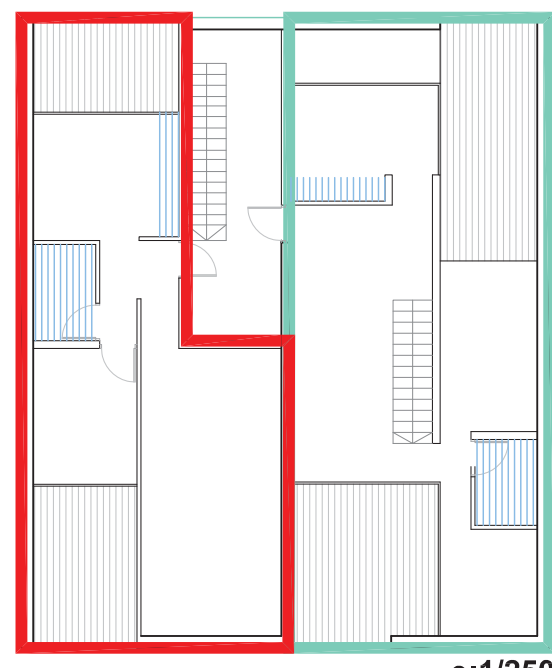

\section{SISTEMAS DE AGRUPACIÓN}

superficie construida total por planta:

$212 \mathrm{~m} 2$

superficie construida zonas comunes por planta: $19 \mathrm{~m} 2(9 \%)$ 

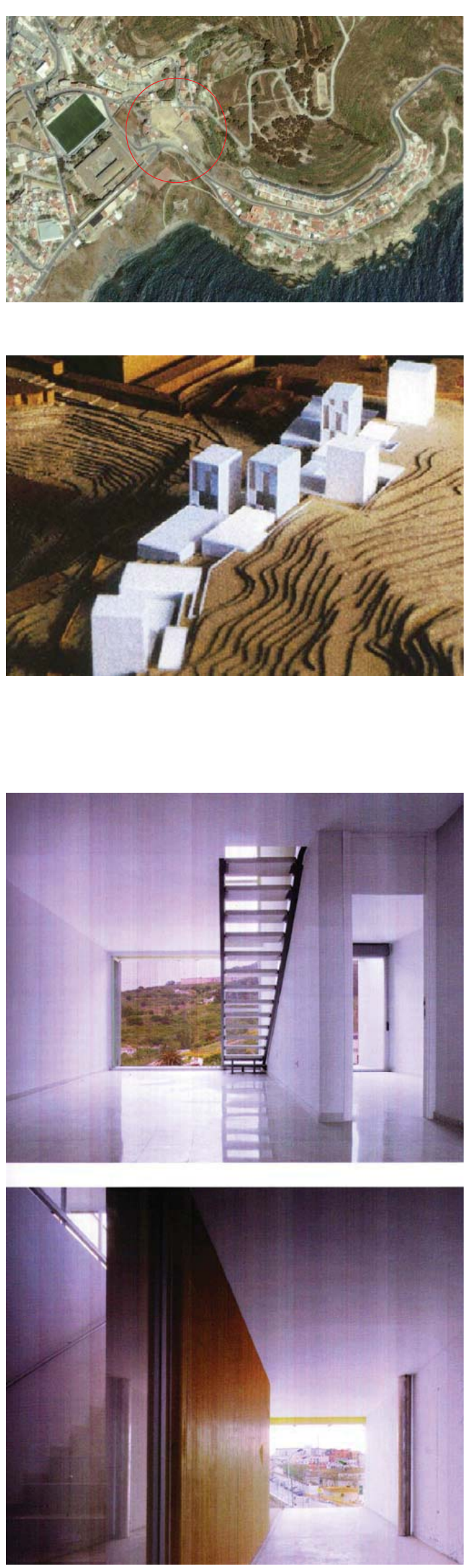

FICHA 5.1

\section{EUROPAN 5}

(año 1997)

\section{JOSÉ MORALES Y JUAN GONZÁLEZ MARISCAL: \\ 127 VIVIENDAS EN CEUTA}

EMPLAZAMIENTO

c/ de Seis $n^{\circ} 1$ y c/de la Escuela práctica $n^{\circ} 1$, Ceuta

COMIENZO DE OBRAS- FINALIZACIÓN DE LAS OBRAS 2004-2009

¿ES EL PROYECTO DE CONCURSO?

Sí. Se seguirá en gran parte el proyecto de concurso aunque aumentará la superficie de actuación inicialmente prevista

$N^{\circ}$ DE VIVIENDAS TOTALES CONSTRUIDAS

127 VPO (43 unifamiliares y 84 en seis torres)

No DE VIVIENDAS POR SUPERFICIE
$\begin{aligned} & \text { unifamiliares } \\ & \text { torre }\end{aligned}$
$\begin{aligned} & 4 \\ & 4\end{aligned}$ viviendas viv
43 viviendas
USO DE LA PLANTA BAJA
Viviendas
USO DEL SOTANO
Garaje

\section{REFERENCIAS BIBLIOGRÁFICAS}

www.morales-giles-mariscal.com

-2G, MGM, Morales Giles Mariscal, n51, p. 52-69. (Sobre las viviendas de Europan en Ceuta), p.

- VPOR2, REVISTA DE VIVIENDA 9, SEPT-DIC, p.10-15 - EUROPAN 10 España, "Proyectar la urbanidad", Madrid, 2010, p. 236 



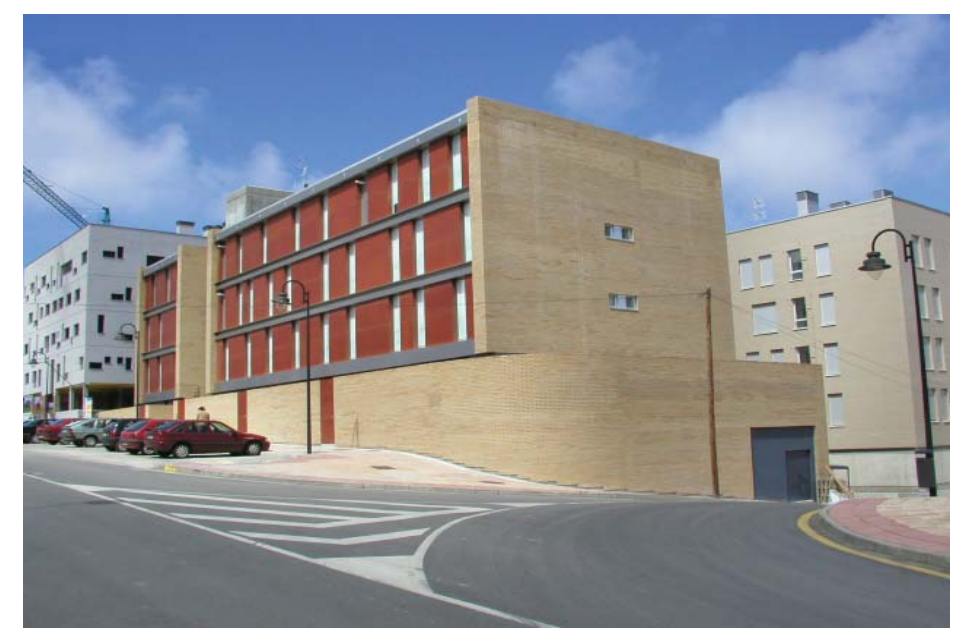

4.1.5. Edificios de viviendas Europan 5 (1997)

Elio García, Carlos Rodríguez y Javier Rodríguez: viviendas sociales en Avilés 

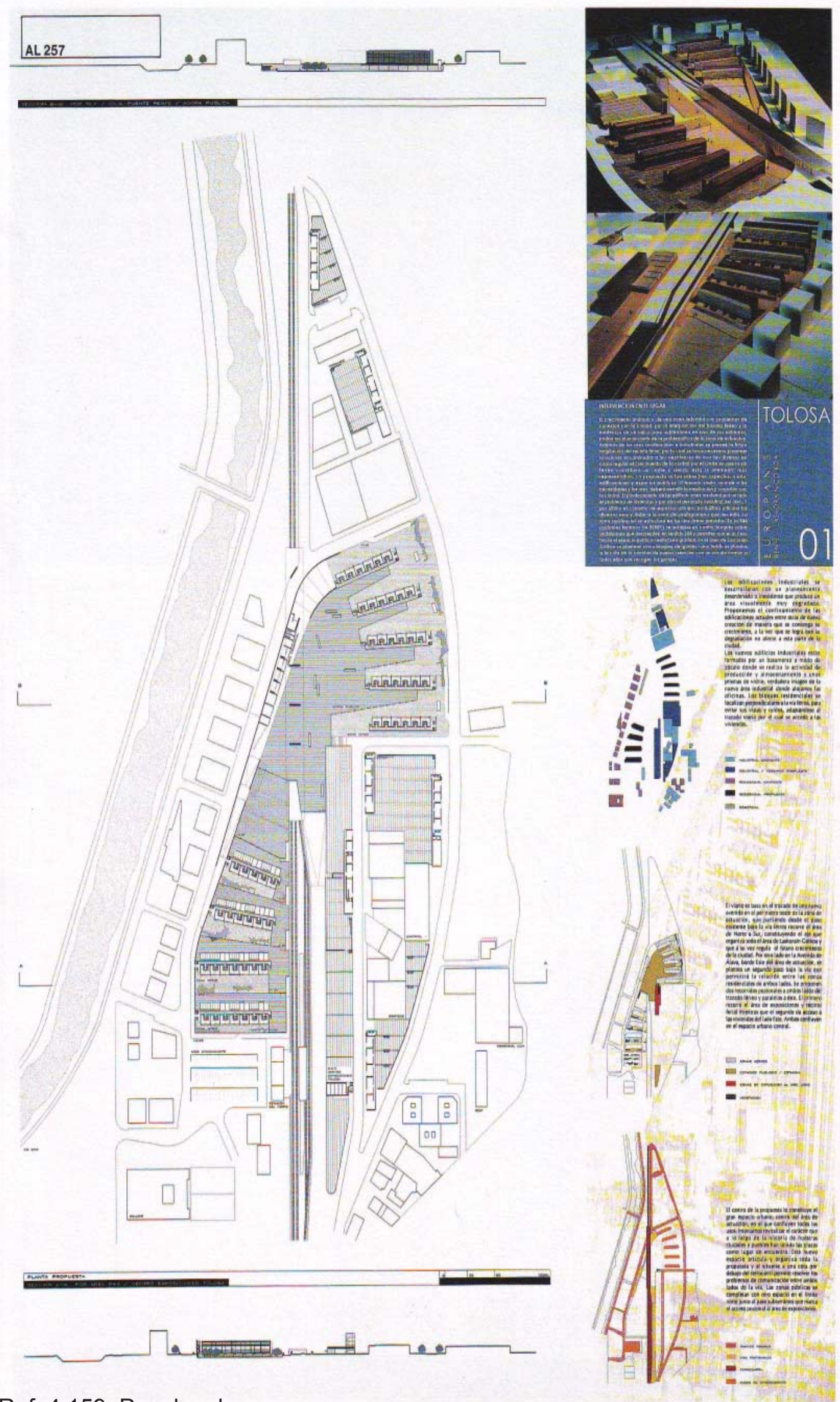

Ref. 4.159. Paneles de concurso 

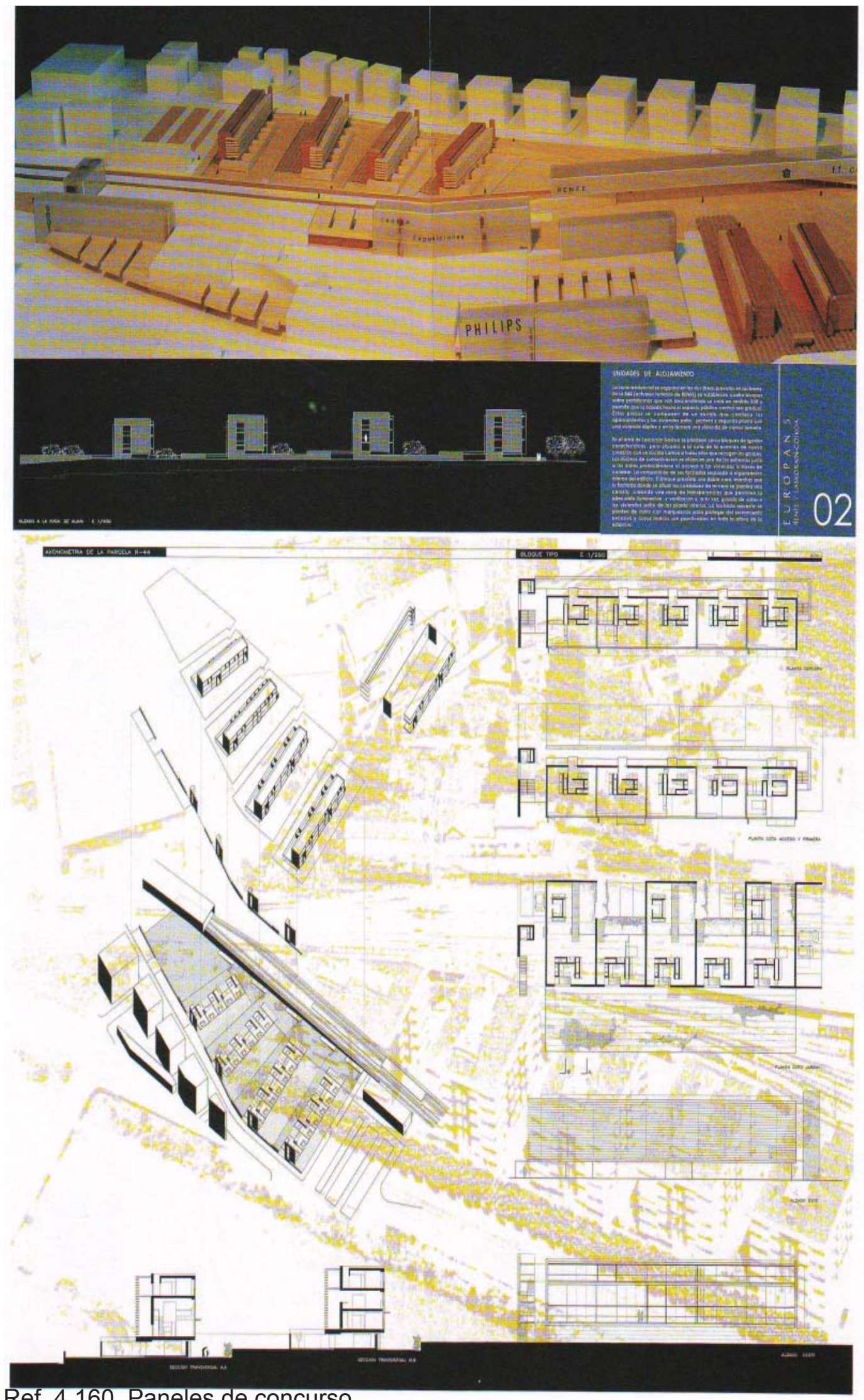

Ref. 4.160. Paneles de concurso 


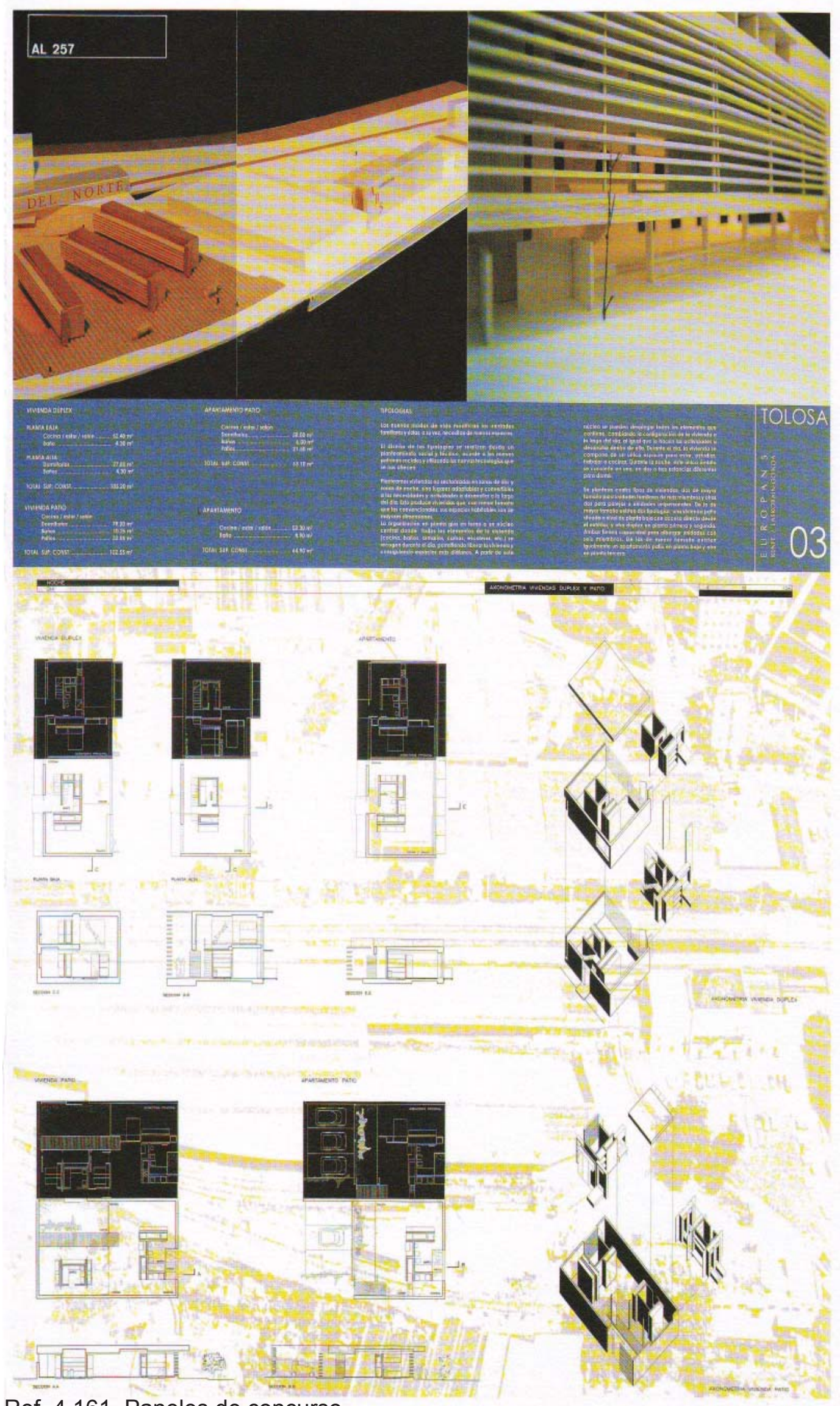

Ref. 4.161. Paneles de concurso 


\section{Fase de concurso}

En un principio se pretendían modificar las condiciones del planeamiento, y se aprovechó esta oportunidad para ofrecer el solar de Tolosa a la quinta edición de Europan. Esta zona además se encontraba dividida por el eje de comunicación del ferrocarril, la zona industrial de la ciudad había crecido de forma anárquica con problemas de conexión debido a este eje, ya que sólo existía un paso subterráneo en uno de sus extremos. Las condiciones topográficas eran excelentes y quedaba ubicada el margen de la trama urbana del municipio. Se pretendía desarrollar una política de vivienda protegida y algunos equipamientos municipales junto con una ampliación del recinto ferial.

Existió un único equipo mencionado. El centro de la propuesta lo constituía un espacio público urbano en el que confluyen todos los usos, como una zona de estancia y esparcimiento. Existía también una zona residencial formada por cuatro bloques que contenían un zócalo que alberga los aparcamientos y las viviendas patio, primera y segunda planta con viviendas dúplex y en la tercera apartamentos. La propuesta actuaba sobre tres aspectos: viario, edificaciones y espacios públicos. El trazado viario permite la conexión con la ciudad. Las edificaciones resolverán el tema residencial y el desarrollo industrial del área. Los espacios urbanos dotarán a la zona del protagonismo que necesita.

Los nuevos edificios industriales estaban formados por un basamento a modo de zócalo donde se realizaban la actividad de producción y almacenamiento y unos prismas de vidrio, donde se alojaban las oficinas. El espacio urbano estaba tratado desde el tradicional concepto de plaza como lugar de encuentro. Esta articulaba toda la propuesta y se situa a una cota inferior del ferrocarril por lo que permitía que se resolvieran los problemas de comunicación entre ambos lados de la vía. Se proponía que el paso subterráneo no fuera un lugar sucio, oscuro y degradado, como se acostumbra a ver, sino que se convierta en una zona de antesala al recinto ferial. Los edificios residenciales se sitúan perpendiculares a la vía férrea, para saltear sus vistas y ruidos.

Los autores argumentaban que "los nuevos modos de vida modificaban las unidades familiares y éstas a su vez necesitaban nuevos espacios. El diseño de las tipologías se realizaba desde un punto de vista social y técnico, acorde a los nuevos patrones sociales y utilizaban las nuevas tecnologías que se nos ofrecían". Los bloques se componen de un zócalo que contienen los aparcamientos y las viviendas patio, primera y segunda planta con viviendas dúplex y en la tercera apartamentos. Los núcleos de acceso se sitúan en los extremos, cerca de los viales. Se planteaban viviendas no sectorizadas en zonas de día y de noche, adaptables a las necesidades y actividades desarrolladas a lo largo del día. Son viviendas de menor tamaño que las habituales pero optimizan el espacio para desarrollar actividades. Se organizan en torno a un núcleo central (cocina, baños, armarios, camas, escaleras), que se recogen durante el día para liberar el espacio. 


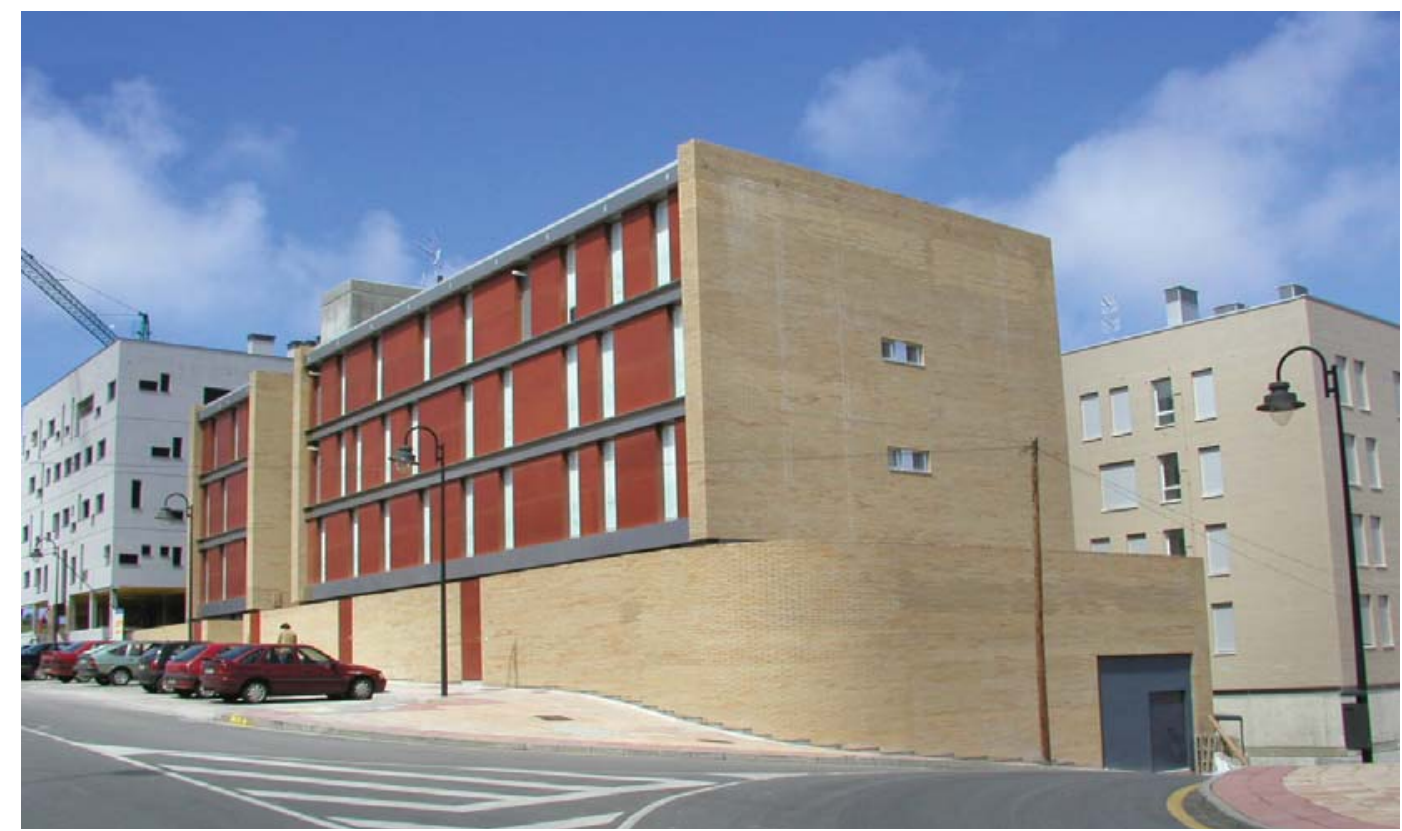

Ref. 4.162.Fachada principal

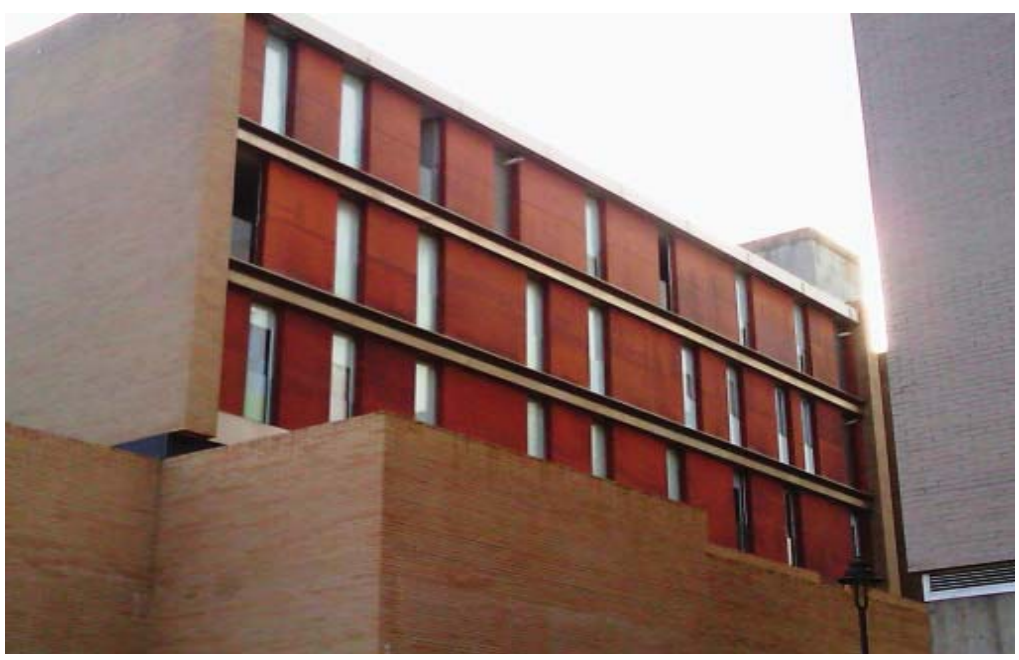

Ref.4.163. Fachada posterior

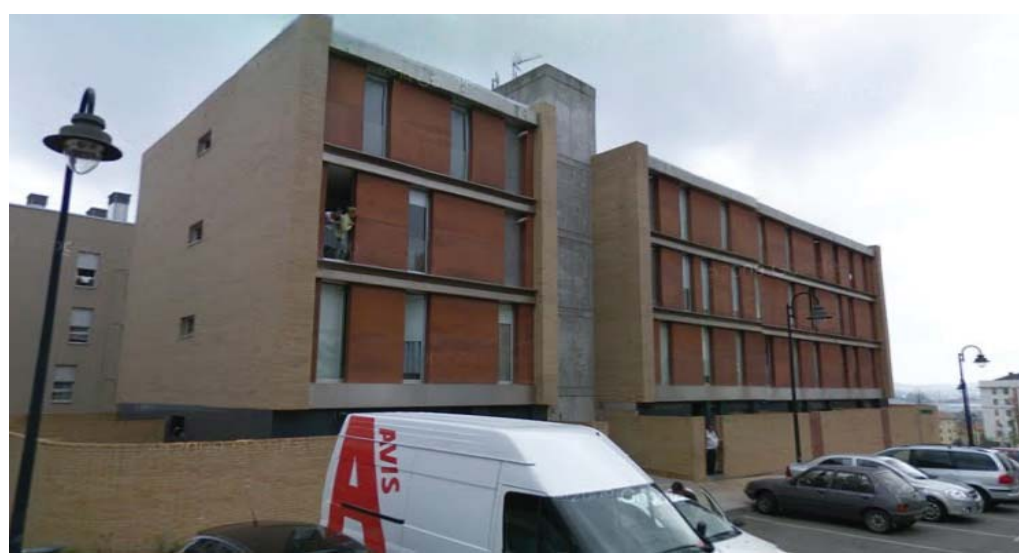

Ref. 4.164. El edificio habitado 
Existe un mismo espacio para estudiar, trabajar, estudiar y cocinar.

\section{Fase de realización}

Finalmente este equipo termina participando en el concurso restringido del Barrio del Nodo y construye un edificio de viviendas con mucho interés. El programa de necesidades responde al planteado por el Servicio de Edificación de la Consejería de Infraestructuras y Política Territorial del Principado de Asturias, y es de 17 viviendas, 17 trasteros y local. El número de viviendas permitido es alto con respecto a la edificabilidad exige reducir al máximo los espacios comunes, consiguiendo adaptarse al programa de necesidades con viviendas del mayor tamaño posible. Se plantea un único núcleo de comunicación que da acceso a las viviendas de planta segunda y tercera, ya que en planta baja se plantean viviendas dúplex con acceso desde el exterior. Esta solución permite conseguir que la relación de superficies de espacios comunes y de espacios privados sea muy inferior a lo habitual en este tipo de edificaciones.

El bloque de viviendas tiene un núcleo de comunicación vertical que da acceso a tres viviendas. Las dos viviendas tipo dúplex tienen un acceso independiente que no es por el núcleo vertical. Existen tres tipologías diferentes de vivienda de 2, 3 y 4 habitaciones. La unidad habitacional dúplex tiene en su planta de acceso el estar, la cocina y un baño a los que se acceden directamente desde un pequeño espacio distribuidor de entrada. La planta superior tiene cuatro habitaciones, distribuidas todas ellas de manera lineal a través de un pasillo y volcando a la misma fachada. El baño está situado en la parte interior justo a la escalera.

La construcción de viviendas de bajo coste no está reñida con la calidad, tanto en el diseño de las tipologías como en los materiales a emplear. Un adecuado planteamiento de éstas, conforma el bloque, así como en los detalles constructivos repercutirá en la calidad global de la propuesta.

Las fachadas responden a la organización interna del edificio permitiendo la entrada de luz natural y manteniendo la relación con el exterior. Una composición de fachada no condicionada por valores estéticos sino una consecuencia de la distribución interior. El uso de la fachada trasventilada se ha mostrado como el sistema más eficaz en los climas húmedos ante las infiltraciones, permitiendo la transpiración del interior de las viviendas. Una adecuada carpintería y sobre todo el estudio pormenorizado de las uniones de la carpintería con la fachada aseguran la estanqueidad del sistema. La fachada trasventilada permite la continuidad de la hoja exterior y del aislamiento térmico evitando los puentes térmicos habituales.

El uso de materiales prefabricados repercute en la calidad de los acabados finales y en la rapidez y facilidad de ejecución.

A continuación se adjunta una ficha-resumen. 


\section{VIVIENDA}

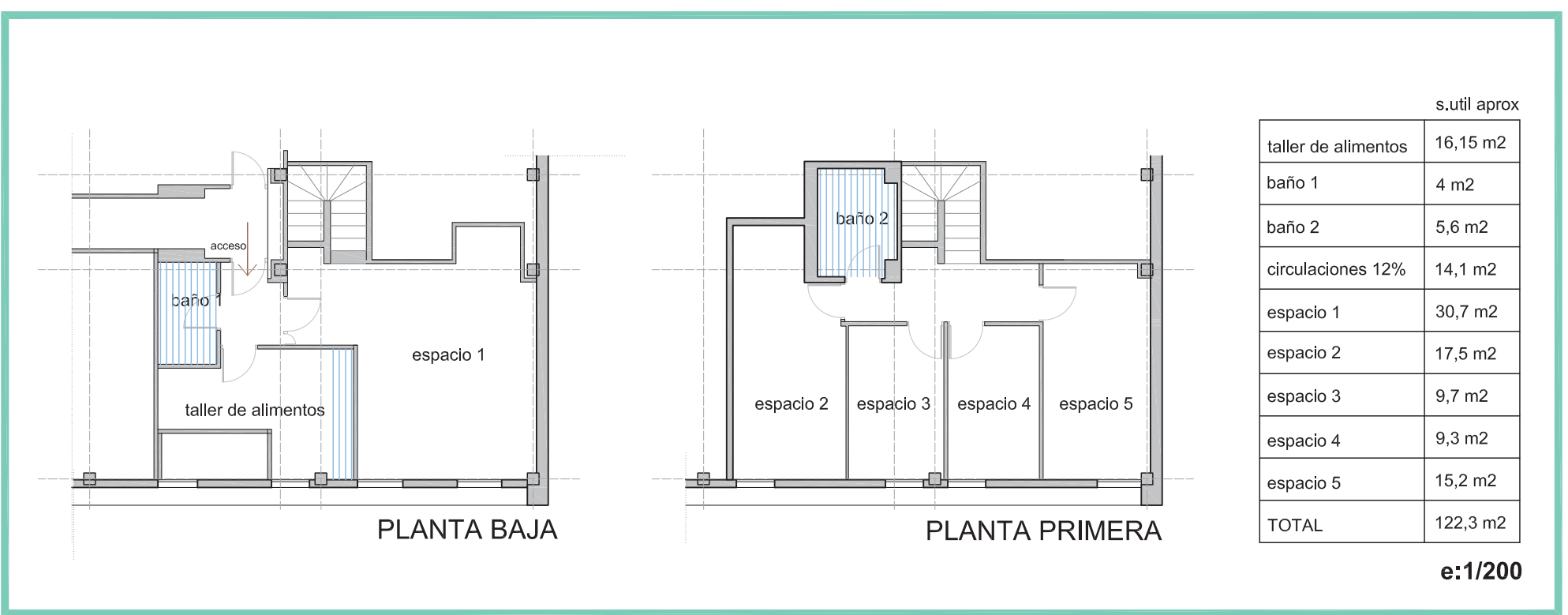

\section{SISTEMAS DE AGRUPACIÓN}

superficie construida total por planta:

$527 \mathrm{~m} 2$

superficie construida zonas comunes por planta: $41 \mathrm{~m} 2$ (8\%)

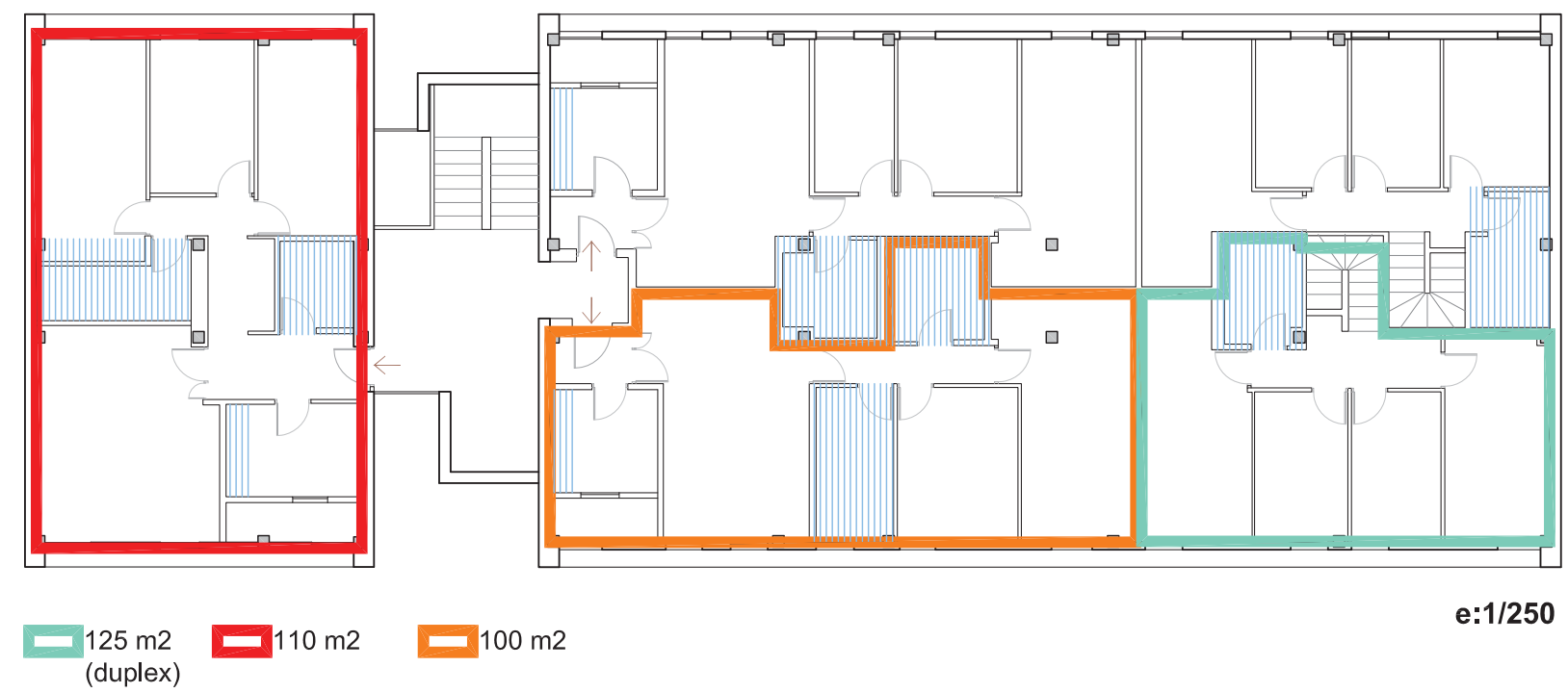



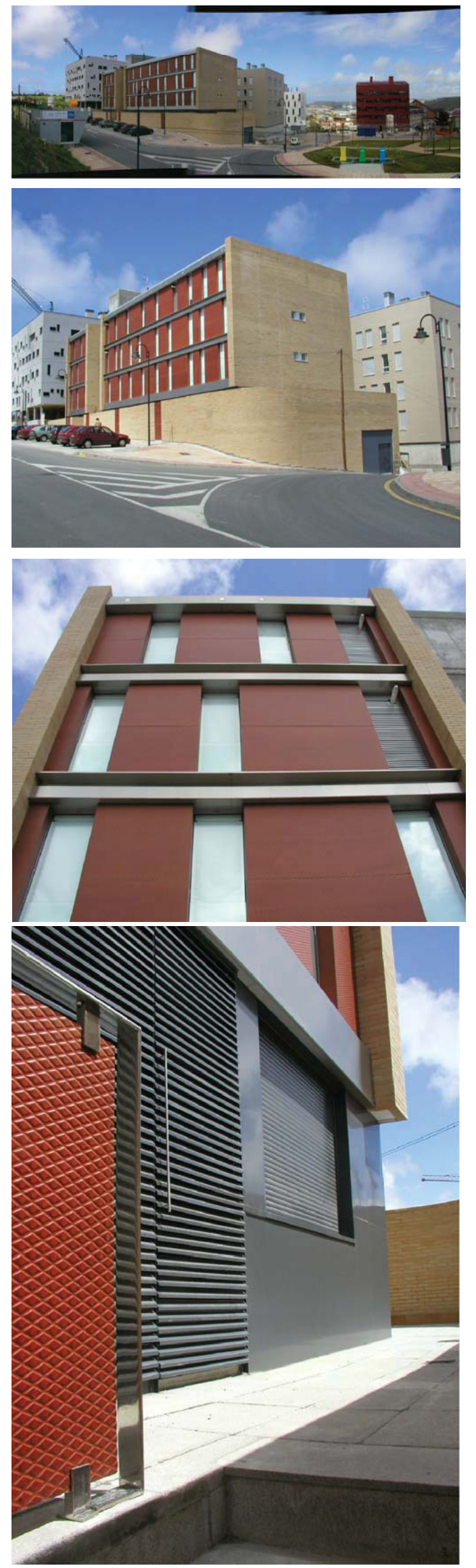

FICHA 5.2

\section{EUROPAN 5}

(año 1997)

ELIO GARCÍA, CARLOS RODRÍGUEZ Y JAVIER RODRÍGUEZ: 17 VIVIENDAS EN EL NODO (AVILÉS)

EMPLAZAMIENTO

c/Ría de Avilés $n^{\circ} 10$, Avilés (Asturias)

COMIENZO DE OBRAS- FINALIZACIÓN DE LAS OBRAS

Fin: año 2008

¿ES EL PROYECTO DE CONCURSO?

No

NNo DE VIVIENDAS TOTALES CONSTRUIDAS

17 viviendas

No DE VIVIENDS POR SUPERFICIE

WII 9 viviendas

VIII 4 viv

VII 4 viv

USO DE LA PLANTA BAJA

Viviendas y 1 local

USO DEL SOTANO

Garaje

\section{REFERENCIAS BIBLIOGRÁFICAS}

Garcia Rodriguez Alcoba oficina de arquitectura

- EUROPAN 10 España, "Proyectar la urbanidad", Madrid, 2010, p. 237 



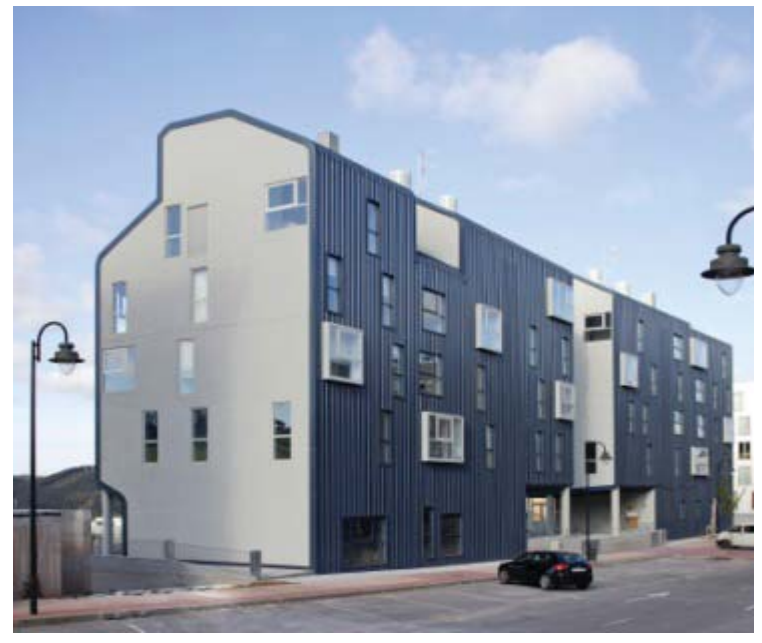

\subsubsection{Edificios de viviendas Europan 6 (2000)}

Mario Sanjuan,Iban Carpintero Jose $M^{\mathrm{a}}$ Tabuyo y Angel Sevilla: viviendas sociales en Avilés 


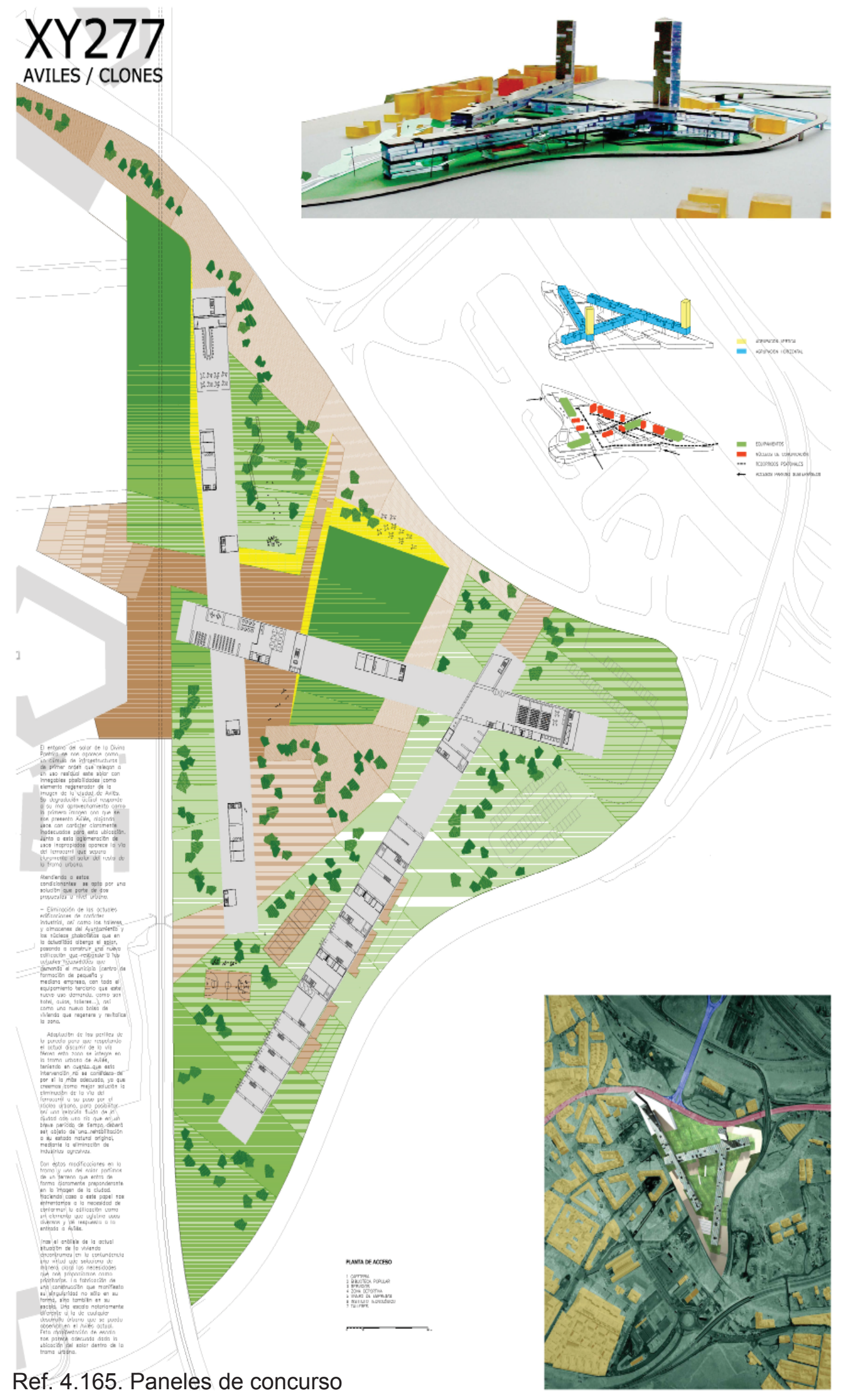



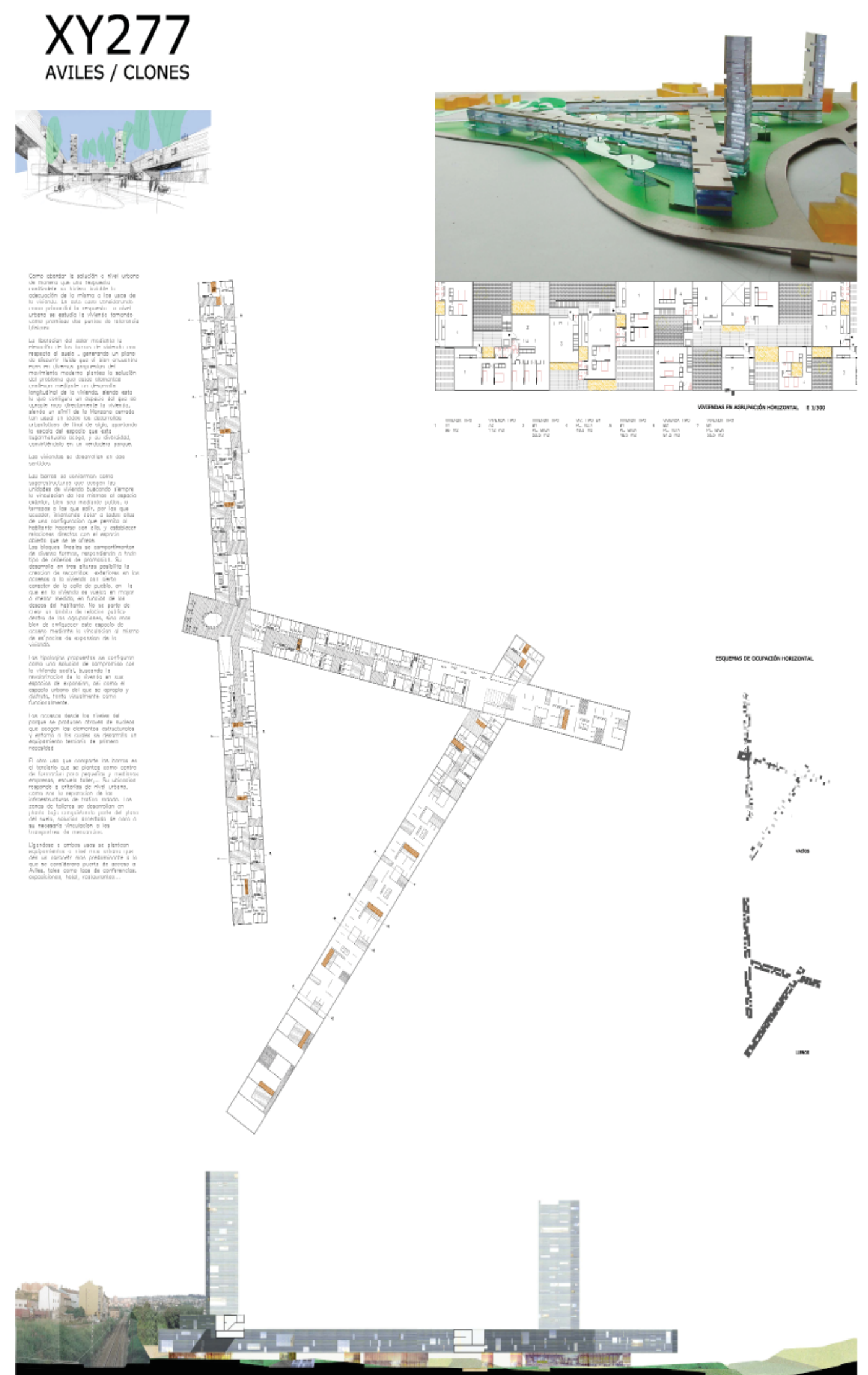

Ref. 4.166. Paneles de concurso 
VIVIENDAS EUROPAN (1988-2008) I Una aproximación a los modos de vida en el cambio de siglo en España 4. EUROPAN: DEL CONCURSO A LA REALIZACIÓN

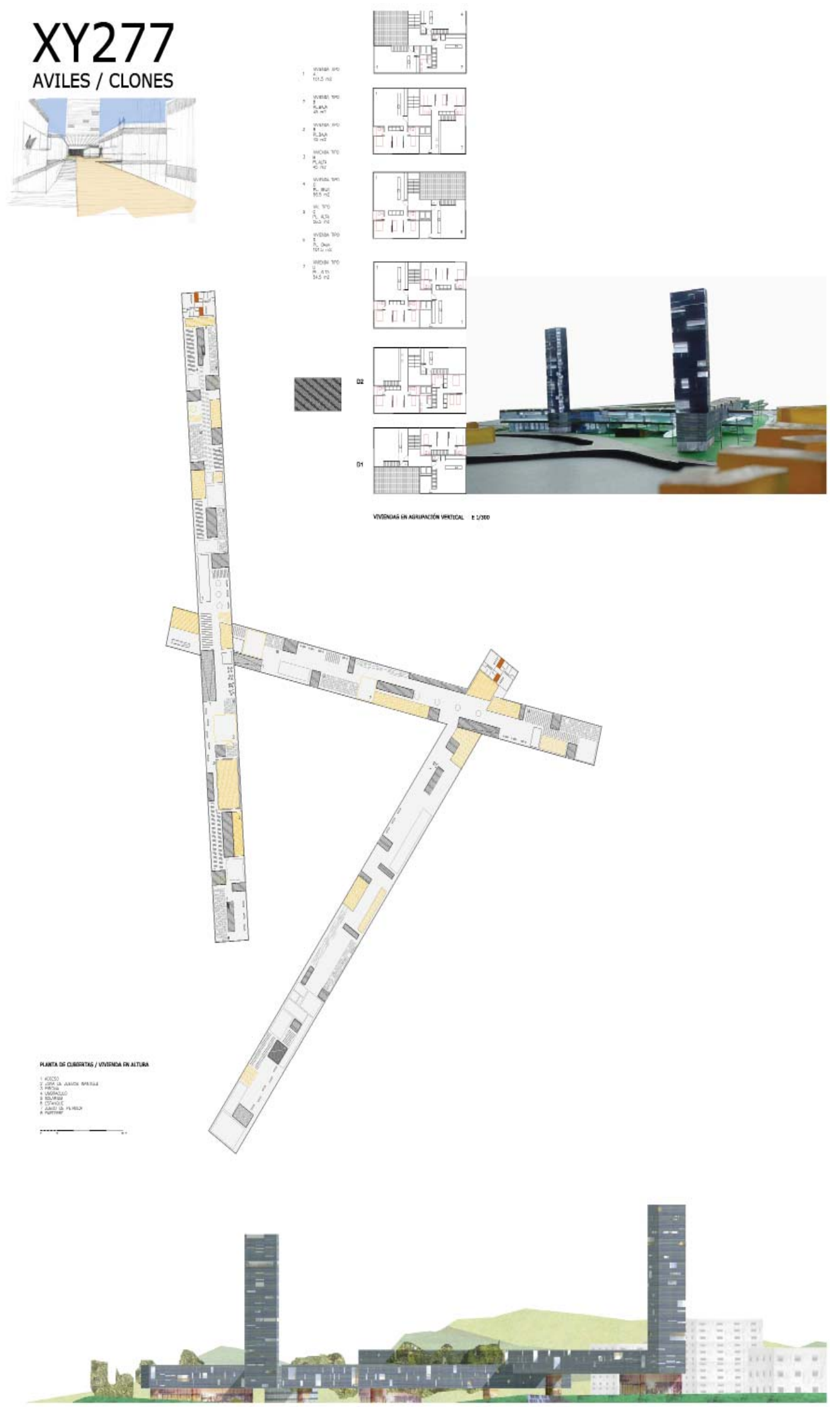

Ref. 4.167. Paneles de concurso 


\section{Fase de concurso}

El solar de concurso se situaba en Avilés, en el barrio de la Divina Pastora, que constituía una isla funcional que ha quedado apartada del centro urbano. Estaba delimitada por grandes arterias de comunicación. En su interior se mezclaban diversos usos: residencial de baja densidad con pequeños talleres industriales, naves industriales y almacenes, un aparcamiento de camiones y otro de maquinaria pesada, el Parque Móvil Municipal, y uno de los mayores asentamientos chabolistas que quedaban en el municipio.

Se pretendía generar nuevos y atractivos usos, sobre todo el de dotaciones educativas (institutos tecnológicos) de alta calidad. La propuesta de concurso potenciaba la creación de una imagen urbana con jerarquización de viarios, el uso residencial de baja/media densidad, usos terciarios y equipamientos compatibles. Se debía suprimir el uso industrial incompatible con el residencial y la eliminación del asentamiento chabolista, con realojo de la población. Se actuaba de dos formas: por un lado eliminando las construcciones que alberga el solar (naves industriales, instalaciones del Ayuntamiento y núcleo chabolista) para crear una nueva. Por otro lado se adaptan los perfiles de la parcela para que, respetando la vía férrea, se integre ésta en la trama urbana.

La propuesta mencionada se componía de dos torres y un basamento elevado, que se separaba del solar y que contenía una gran diversidad de usos: mezcla espacios dedicados a la formación de empresas con viviendas, en un proyecto en el que se tiene en cuenta la hibridación desde el comienzo de su concepción, tanto en los usos como en las propias viviendas planteadas. El plano del suelo se trata como contínuo, elevando sobre éste las edificaciones existentes.

En el edificio se busca la relación directa de las viviendas con el espacio exterior, mediante patios y terrazas pertenecientes a cada vivienda. Además se cuida el tratamiento urbano de las calles y plazas de acceso.

En la definición de los equipamientos se distinguen equipamientos de tamaño medio, que se desarrollan en planta baja, dando directamente a las vías de tráfico, y los equipamientos de alcance general, más vinculados a la entrada de Avilés, dando una imagen activa del solar. Los paneles presentados se caracterizan por su limpieza y claridad en la propuesta. Tanto es así que el Jurado afirma que se valora la elección de una pieza de gran escala y su capacidad de incorporación al centro de Avilés. Valora además positivamente la liberación del plano del suelo, tratándolo como un espacio verde. Pero también al Jurado le queda en duda la compatibilidad entre lo que se plantea y la posibilidad de que sean realmente viviendas sociales.

\section{Fase de realización}

El proyecto de concurso no llega a materializarse. Los arquitectos acceden 
VIVIENDAS EUROPAN (1988-2008) | Una aproximación a los modos de vida en el cambio de siglo en España

4. EUROPAN: DEL CONCURSO A LA REALIZACIÓN

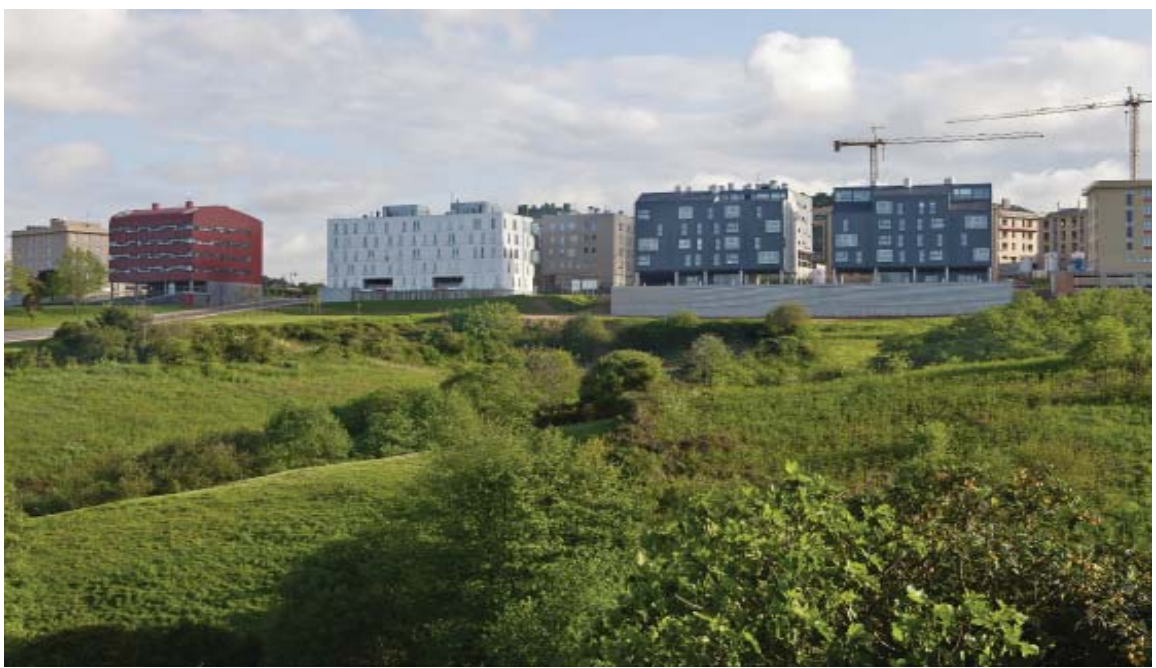

Ref. 4.168.Vista del conjunto

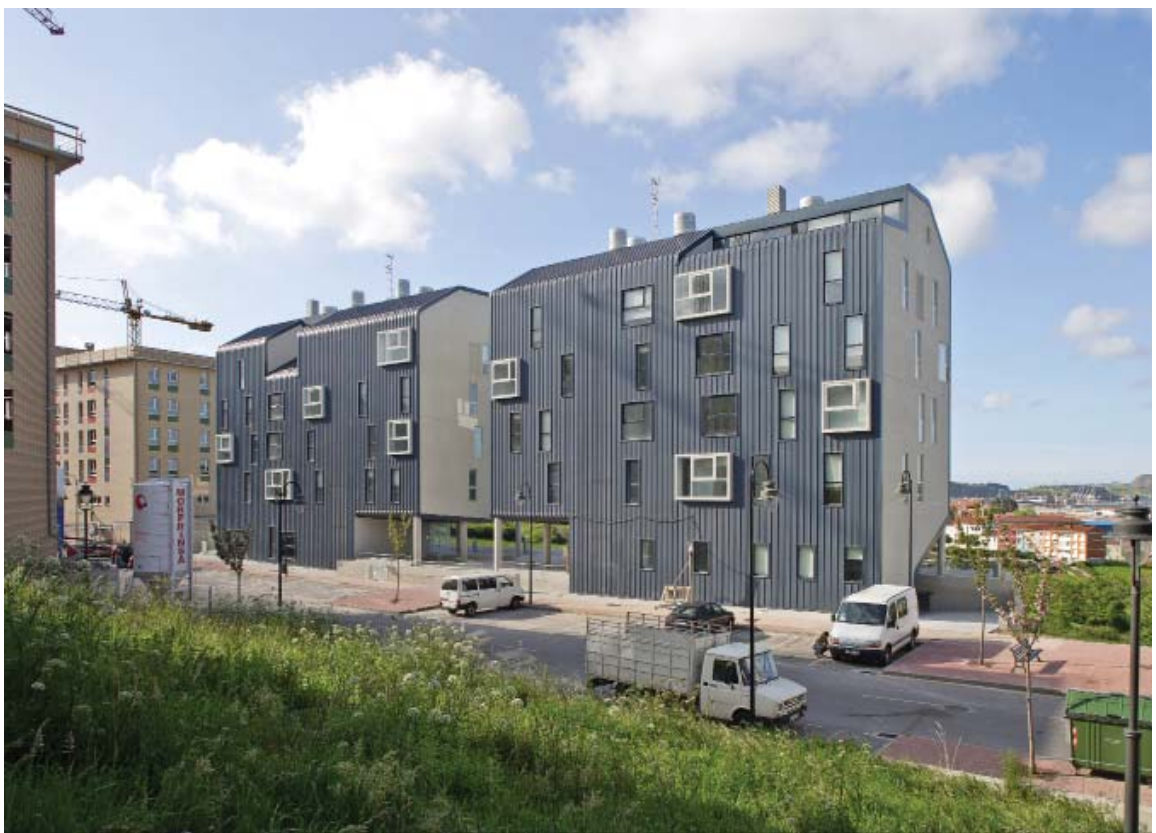

Ref.4.169.Alzado principal a la calle

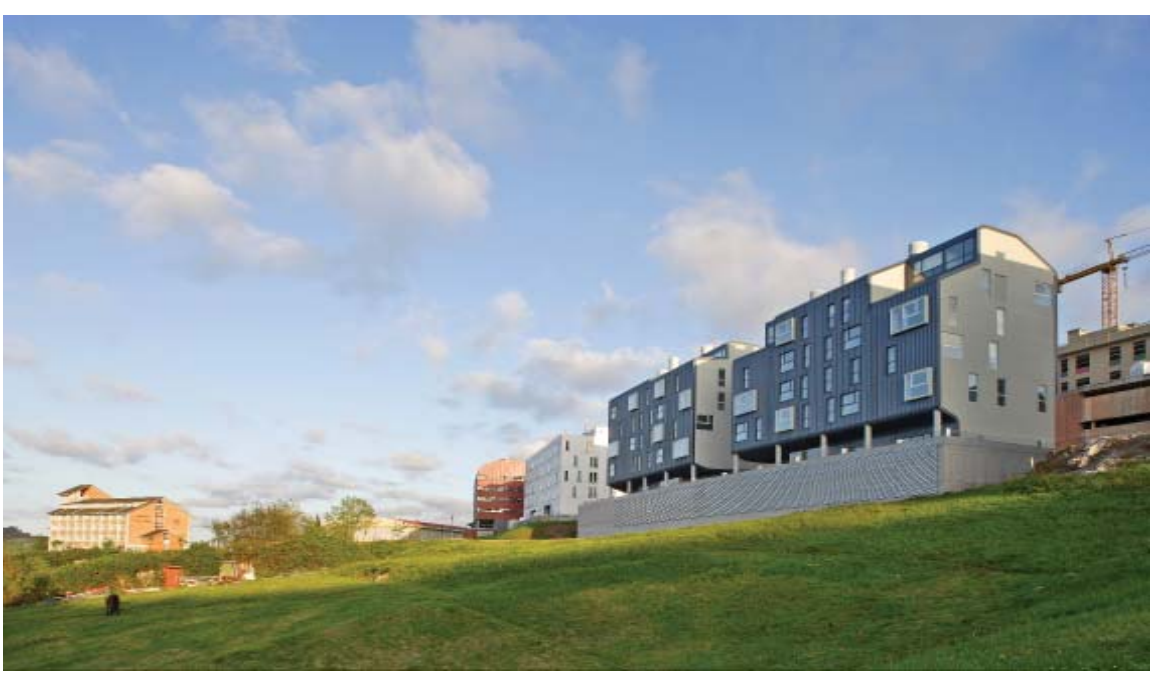

Ref.170. Alzado sur 
mediante concurso restringido a un solar en el Barrio del Nodo de Avilés. En el material del proyecto de ejecución que han aportado los propios autores se afirma que uno de los criterios generales a acometer es la creación de un conjunto que reinterprete, dentro del respeto, las tipologías de edificación en bloque.

Se plantean dos bloques de viviendas que responden al enclave donde se ubican con una forma rotunda y unitaria, capaz de hacerlos reconocibles desde cualquier punto, sin sacrificar la racionalidad y funcionalidad de las viviendas. Exteriormente se configuran como dos piezas con un envoltorio metálico que se pliega recorriendo las fachadas más largas, rompiéndose en la parte superior para dar luz a la planta bajo cubierta. Las fachadas laterales, en cambio, dejan ver lo que hay detrás del envoltorio, una piel tersa de revoco de colores que es ceñida por la chapa nervada. El acceso principal a la parcela se centraliza en el espacio entre los dos bloques, elevándose ligeramente con respecto a la calle, para conseguir una mayor independencia en la vivienda de planta baja y que el acceso al garaje sea lo más corto posible. Desde ese espacio central se accede a dos soportales cubiertos donde se sitúan las entradas a los portales. La plataforma de planta baja se concibe como un lugar para la comunidad, con bancos para sentarse y disfrutar de las vistas. En planta baja y con acceso independiente directo desde la calle, se reserva un local para uso comercial.

Existen varios tipos de viviendas, dependiendo de su tamaño y situación en los bloques, siempre dentro de los estándares de VPO. La planta tipo tiene en cada bloque dos viviendas de 3 dormitorios en sus extremos y en la parte central dos de 1 y 2 dormitorios respectivamente. En la planta cuarta se han dispuesto viviendas dúplex aprovechando el espacio bajo cubierta, para conseguir agotar la edificabilidad asignada. Hay tres dúplex en el bloque 20 (dos de 4 dormitorios y uno de 3 dormitorios) y dos en el bloque 19 (de tres dormitorios), y en todos ellos los salones disfrutan de un espacio de doble altura, así como de unas vistas inmejorables desde cualquiera de las plantas. Además el baño principal se sitúa siempre en la planta baja de los dúplex, para que pueda utilizarlo una persona de facultades limitadas, dejando un aseo en la planta superior. En planta baja se dispone una vivienda adaptada para minusválidos. La mitad de las viviendas son de tres dormitorios. Las viviendas mantienen su acceso en el punto de máximo ahorro de superficie para la tipología propuesta. El vestíbulo hace de nexo entre la zona de dormitorios y la zona de cocina, salón - comedor. En todas las ellas se busca la máxima apertura hacia las vistas privilegiadas, intentando que el mayor número posible de las viviendas abran sus salones hacia la fachada sureste donde se producen las mejores vistas.

Se ha procurado evitar la aparición de la estructura en las viviendas, de modo que sea posible la variación de la tabiquería sin depender de la situación de los pilares. Los materiales empleados son principalmente: chapa de acero nervada, revestimiento de paneles prefabricados de revoco continuo, carpinterías de aluminio y vidrio para el exterior; en el interior, guarnecido de yeso, revestimiento de madera, terrazo, gres.

A continuación se adjunta una ficha-resumen. 


\section{VIVIENDA}

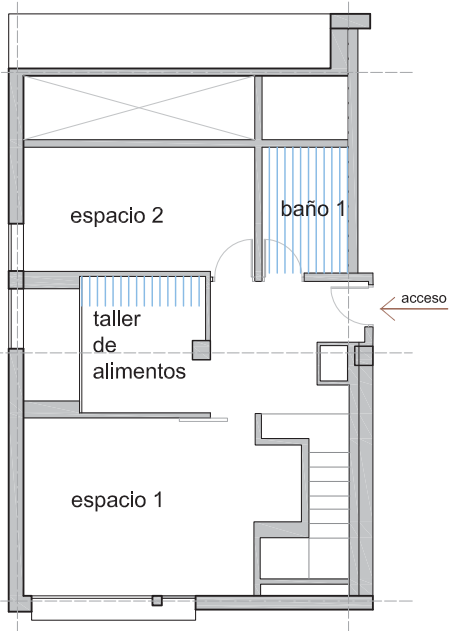

PLANTA BAJA

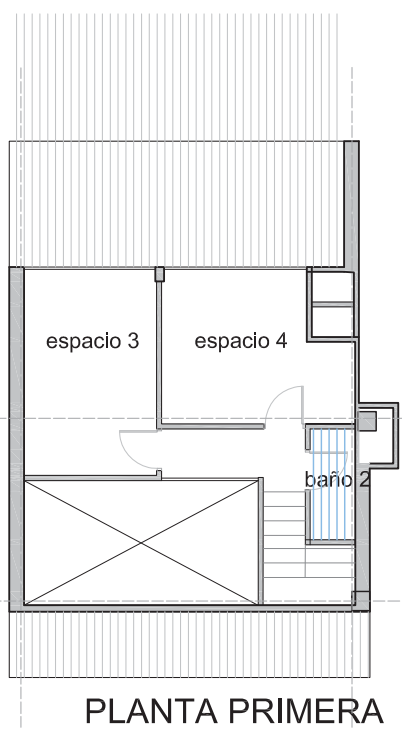

\begin{tabular}{|l|l|}
\hline \multicolumn{1}{|c}{ s.util aprox } \\
\hline taller de alimentos & $10,5 \mathrm{~m} 2$ \\
\hline baño 1 & $4,5 \mathrm{~m} 2$ \\
\hline baño 2 & $1,9 \mathrm{~m} 2$ \\
\hline circulaciones & $18,2 \mathrm{~m} 2$ \\
\hline espacio 1 & $16,8 \mathrm{~m} 2$ \\
\hline espacio 2 & $11,9 \mathrm{~m} 2$ \\
\hline espacio 3 & $11,3 \mathrm{~m} 2$ \\
\hline espacio 4 & $10,9 \mathrm{~m} 2$ \\
\hline TOTAL & $86 \mathrm{~m} 2$ \\
\hline & $\mathbf{e : 1 / 2 0 0}$
\end{tabular}

\section{SISTEMAS DE AGRUPACIÓN}

superficie construida total por planta: $307 \mathrm{~m} 2$

superficie construida zonas comunes por planta: $35 \mathrm{~m} 2(11 \%)$

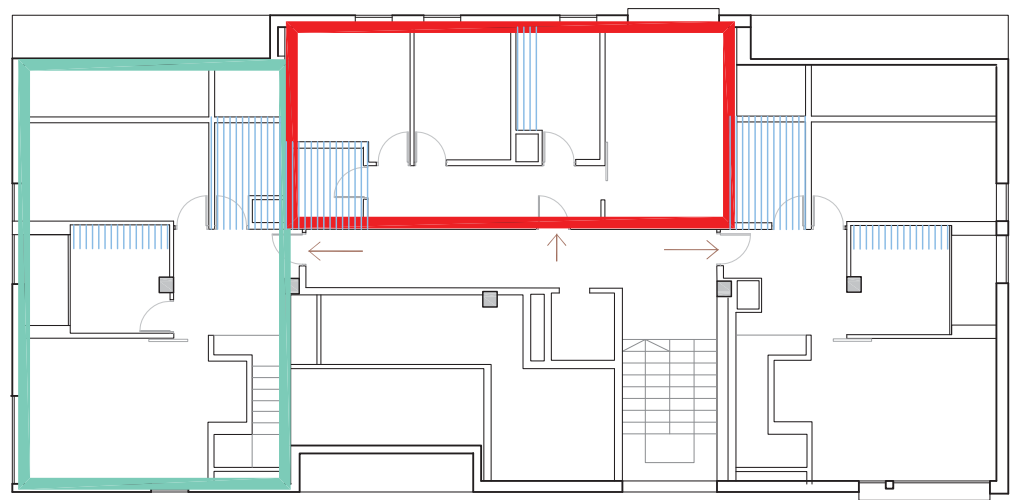

$0 \mathrm{~m} 2$

$\square 55 \mathrm{~m} 2$

e: $1 / 250$

(dúplex) 


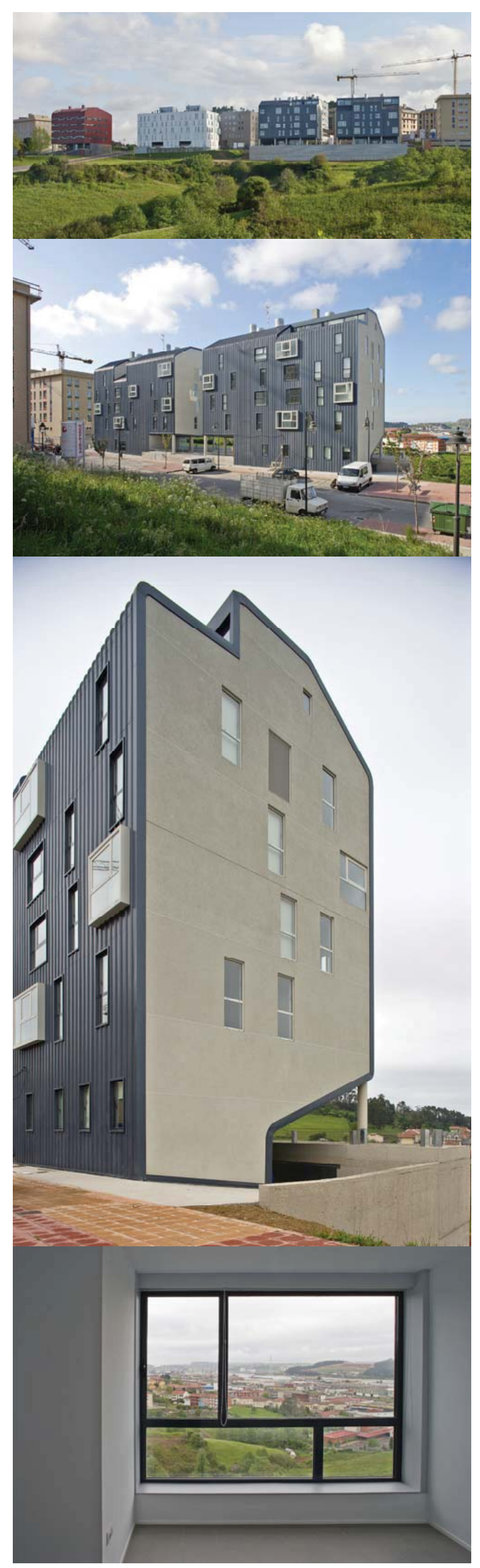

FICHA 6.1

\section{EUROPAN 6}

(año 2000)

MARIO SANJUAN, IBAN CARPINTERO, JOSÉ Ma TABUYO Y ÁNGEL SEVILLA

32 VIVIENDAS EN EL NODO (AVILÉS)

EMPLAZAMIENTO

c/Balandro $n^{\circ} 24$, Avilés (Asturias)

COMIENZO DE OBRAS- FINALIZACIÓN DE LAS OBRAS

Fin: año 2007

¿ES EL PROYECTO DE CONCURSO?

No

No DE VIVIENDAS TOTALES CONSTRUIDAS

16 viviendas por bloque

32 viviendas total

No DE VIVIENDAS POR SUPERFICIE

VIII 5 viv

VII 5 viv

एIII 6 viv

USO DE LA PLANTA BAJA

Local

USO DEL SOTANO

Garaje y trastero

\section{REFERENCIAS BIBLIOGRÁFICAS}

www.imagensubliminal.com/content/obra/viviendas-en-aviles

- EUROPAN 10 España, "Proyectar la urbanidad", Madrid, 2010, p. 243 



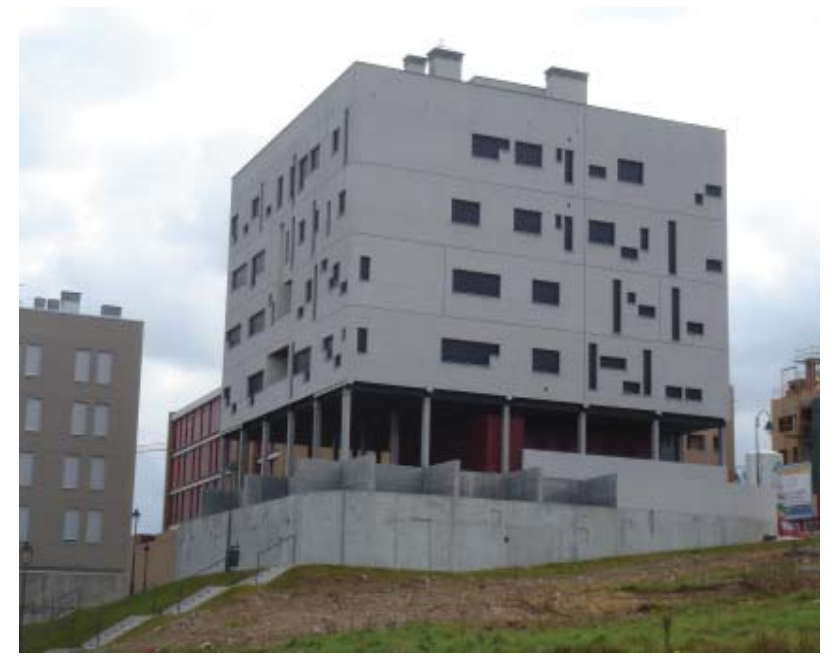

4.1.6. Edificios de viviendas Europan 6 (2000)

Jorge Suarez y Lucia Salvador: viviendas sociales en Avilés 


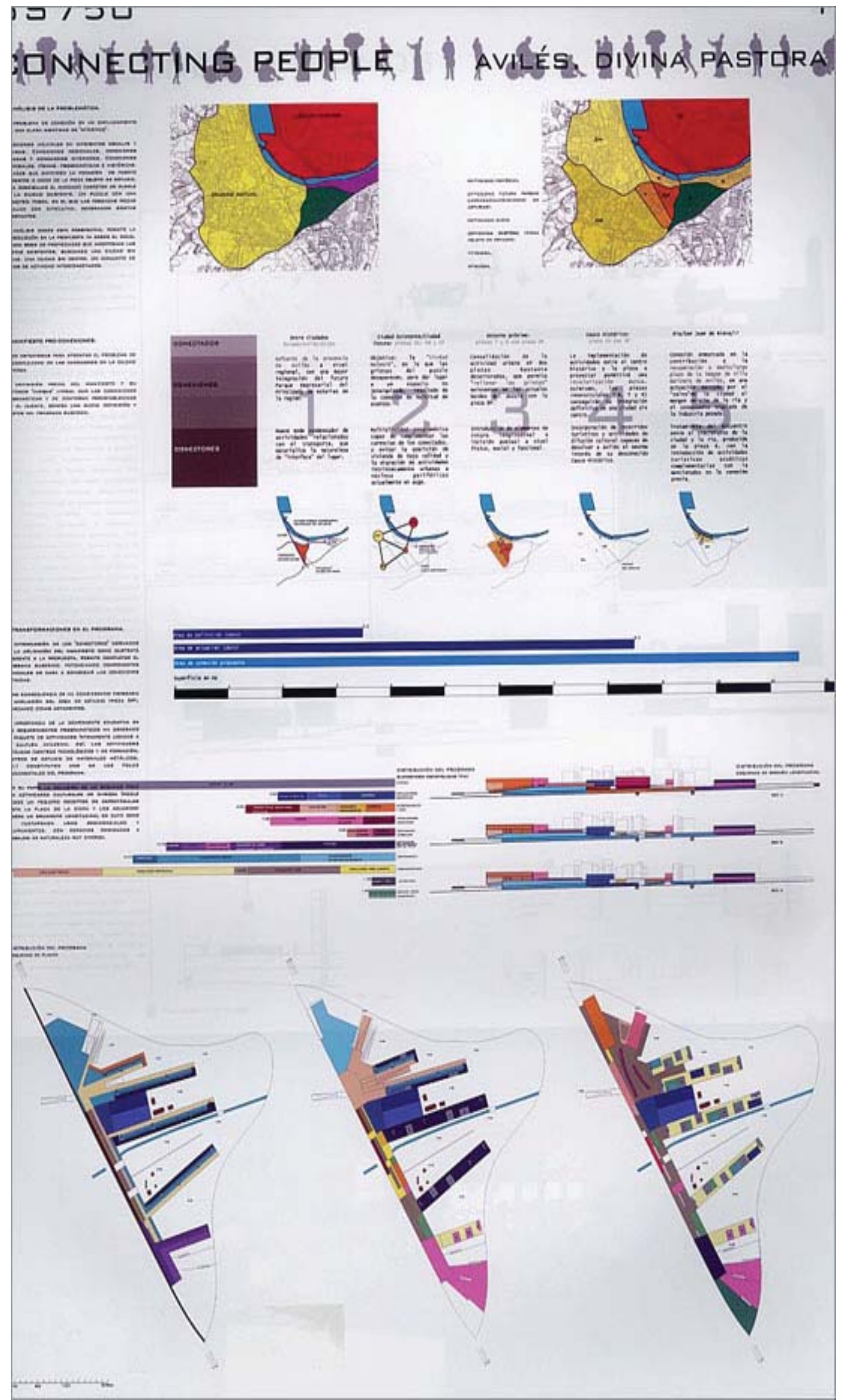

Ref. 4.171. Paneles de concurso 

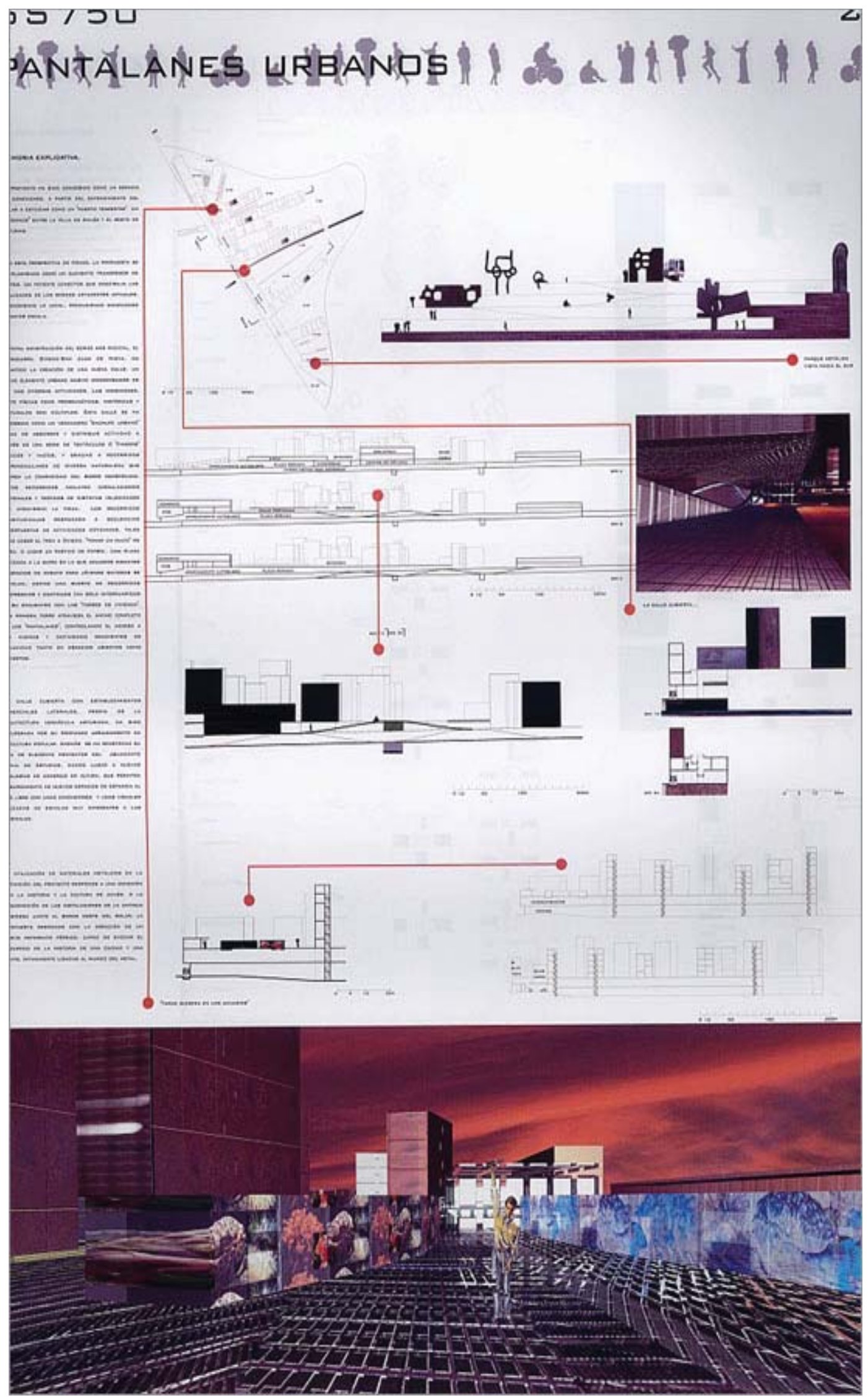

Ref. 4.172. Paneles de concurso 


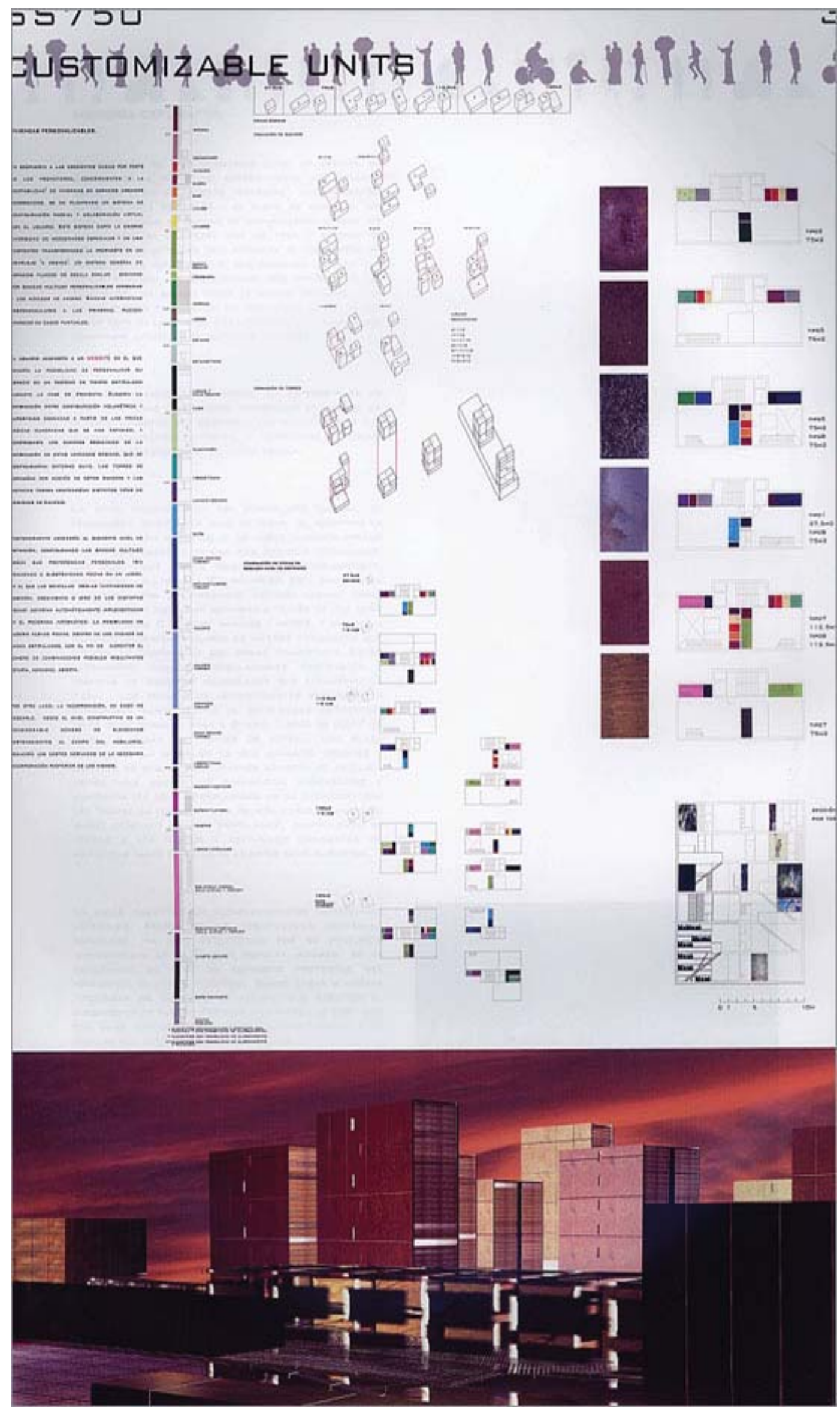

Ref. 4.173. Paneles de concurso 


\section{Fase de concurso}

Este proyecto se sitúa también en Avilés en el barrio de la Divina Pastora y fue finalista. Como se ha comentado anteriormente, constituía una isla funcional que ha quedado apartada del centro urbano. Estaba delimitada por grandes arterias de comunicación. En su interior se mezclaban diversos usos: residencial de baja densidad con pequeños talleres industriales, naves industriales y almacenes, un aparcamiento de camiones y otro de maquinaria pesada, el Parque Móvil Municipal, y uno de los mayores asentamientos chabolistas que quedaban en el municipio.

Se pretendía generar nuevos y atractivos usos, sobre todo el de dotaciones educativas (institutos tecnológicos) de alta calidad. La propuesta de concurso potenciaba la creación de una imagen urbana con jerarquización de viarios, el uso residencial de baja/media densidad, usos terciarios y equipamientos compatibles. Se debía suprimir el uso industrial incompatible con el residencial y la eliminación del asentamiento chabolista, con realojo de la población.

Fue concebido como un espacio de conexiones por estar rodeado de vías de comunicación y se proyecta como un enlace entre la ciudad existente y la ciudad futura, puesto que está situado en un área límite de la ciudad.

El proyecto intentaba desdibujar los límites actuales, produciendo conexiones a mayor escala. Además toma como base los recorridos en longitudinal que serán los que respondan a actividades cotidianas, generando recorridos continuos que únicamente estarían interrumpidos en su encuentro con las torres de vivienda.

Estudian el espacio público de modo que hablan de recorridos públicos que responden a una secuencia de actividades cotidianas como puede ser coger el tren a Oviedo, tomar un culín de sidra o jugar un partido de fútbol.

En cuanto a la vivienda, la intención de los autores es crear diversidad de viviendas que puedan estar personalizadas para cada usuario. Así proponen la conexión directa del futuro habitante con el arquitecto para que este adapte cada vivienda a las necesidades y preferencias de cada usuario.

\section{Fase de realización}

Finalmente el equipo se presenta también a un concurso restringido en el barrio del Nodo de Avilés, en el mismo emplazamiento donde se encuentran los anteriores. El edificio, ubicado al final de la calle Balandro y con el presupuesto más bajo de los cinco bloques sociales del No-Do -800.000 euros-, alberga dieciocho viviendas de protección pública que serán concedidas en régimen de alquiler. Con superficies que oscilan entre los 40 y 80 metros cuadrados, cuatro pisos disponen de una habitación, otros tantos tienen dos dormitorios, ocho son de tres habitaciones y dos viviendas disponen de cuatro dormitorios. Del total, ocho son dúplex. 
VIVIENDAS EUROPAN (1988-2008) I Una aproximación a los modos de vida en el cambio de siglo en España

4. EUROPAN: DEL CONCURSO A LA REALIZACIÓN

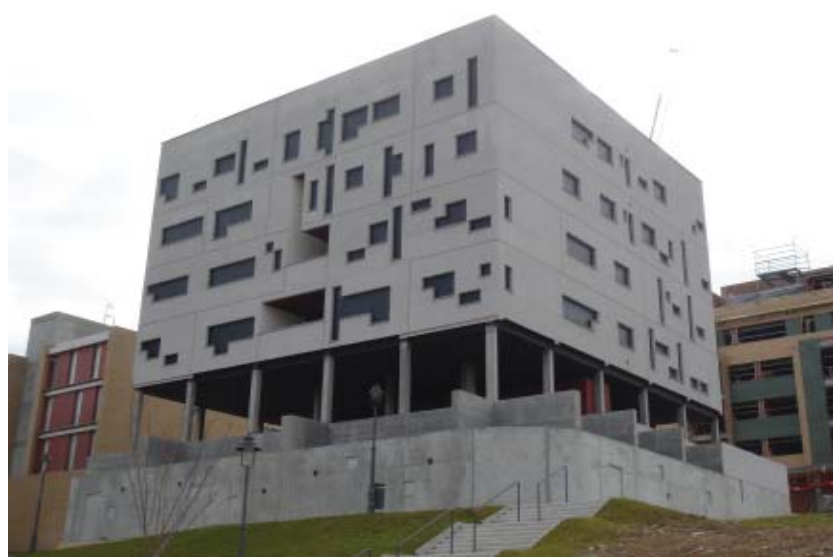

Ref.4.174. Vista del conjunto

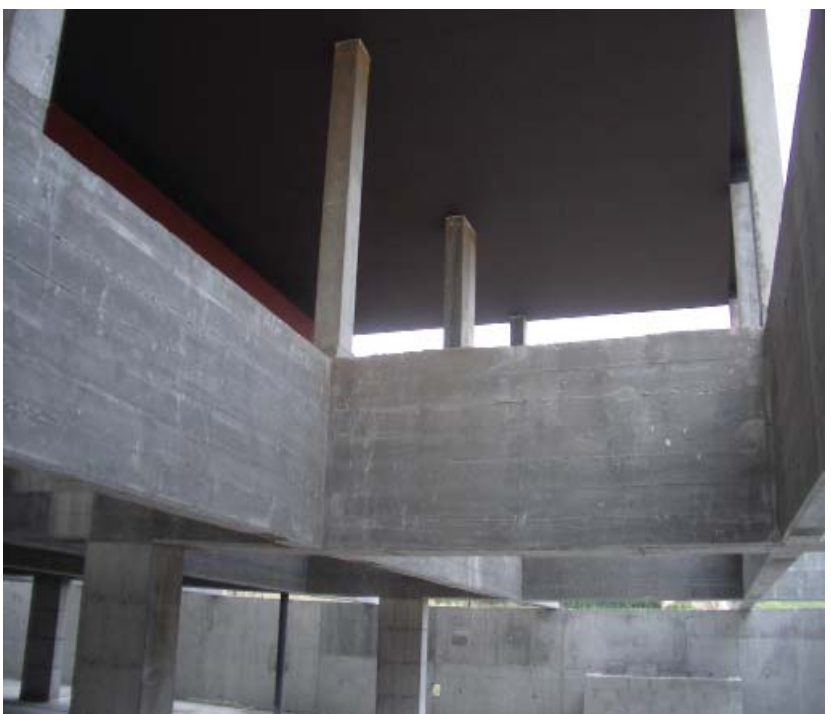

Ref.4.175.Estructura

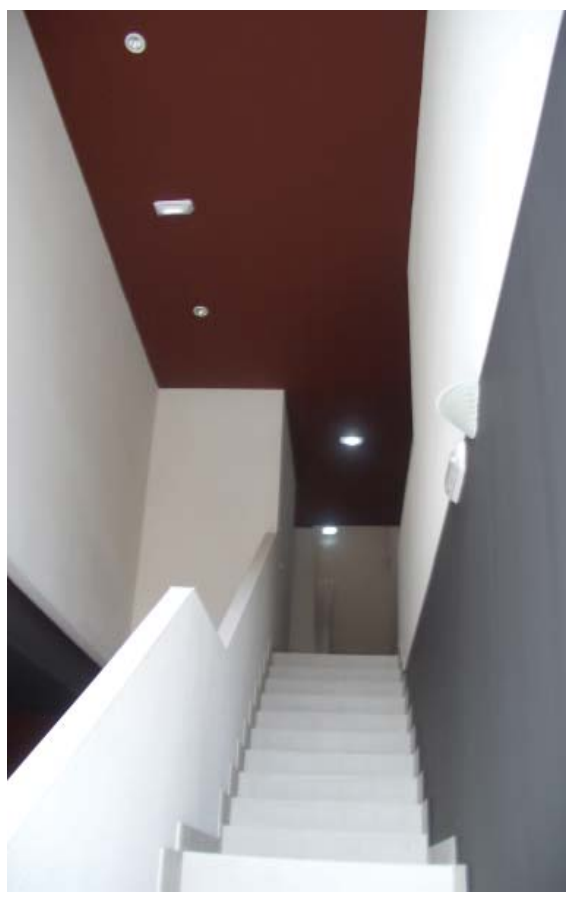

Ref.4.176. Escalera de una vivienda 
Ninguna de las dieciocho viviendas, que se distribuyen en cuatro plantas situadas sobre una planta baja de acceso que alberga el portal, es igual al resto. Jorge Suárez apostó por esta diversidad junto a la madrileña Lucía Salvador, coautora del proyecto, inspirados en un innovador diseño japonés que ambos descubrieron en Nueva York cuando preparaban el máster de arquitectura. "La idea es ir contra la tendencia general de construir tipos de vivienda estándar. Cada persona tiene gustos y necesidades concretas y, con este proyecto, el futuro usuario no tiene que ver un piso piloto sino visitarlos todos y escoger el que mejor le convenga. Estos pisos son realmente sociales porque no imponen al ciudadano un estilo de vida; le ofrecen varios", explicó.

El proyecto, aunque tiene un aspecto exterior másico, se ha concebido buscando el máximo soleamiento $\mathrm{y}$, en lo posible, las mejores vistas. Para ello el núcleo de comunicaciones verticales se ha situado en el interior del edificio, liberando la totalidad de la superficie de las fachadas para las viviendas. Se consiguen de este modo, viviendas absolutamente soleadas y ventiladas con altas cotas de salubridad.

Se ha ideado un programa capaz de generar una variedad de viviendas enorme por un lado, y de evitar la complejidad estructural y constructiva, y por tanto el incremento de costes, por otro. Como consecuencia de la aplicación de este programa, se han generado 18 viviendas diferentes, cada una con su identidad y su número. La variedad de viviendas proyectada, supone una nueva forma de concebir la vivienda contemporánea más acorde con las tendencias sociales actuales, y responde a la enorme diversidad de necesidades espaciales y de uso existentes en la sociedad moderna. Frente a soluciones que plantean viviendas seriadas para personas tipo, más en concordancia con las tendencias marcadas por las vanguardias de principios de siglo, el proyecto, por el contrario, abriría los abanicos de posibilidades presentando opciones muy diferentes de vivienda dentro de cada tipología definida. De esta manera, cada usuario tendría mayores opciones de encontrar una vivienda acorde con sus preferencias concretas.Por otro lado, la diversidad de viviendas creada, actúa como un potente generador de interacción y unidad social. En proyectos similares, ya construidos en otros países, los usuarios, intrigados por las diferencias existentes entre sus viviendas, establecieron relaciones y programaron fiestas encaminadas a dar a conocer al resto de la comunidad sus viviendas. El edificio se convierte, de este modo, en un verdadero bloque de viviendas sociales, dotado de una identidad y un carácter muy potentes. Esta relación entre los distintos usuarios que conviven en el inmueble, se potencia además mediante la creación de espacios de convivencia de cualidades muy diversas, diseminados entre las zonas de acceso a las viviendas. Espacios sugerentes y sorpresivos, que los usuarios irían conociendo y utilizando de forma progresiva, y en la medida en que se decidiesen a explorar su edificio.

A continuación se adjunta una ficha-resumen. 


\section{VIVIENDA}

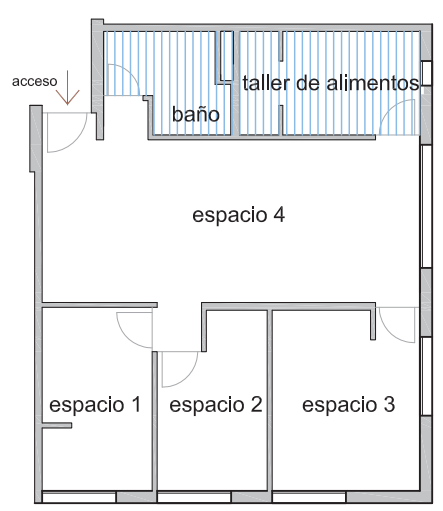

\begin{tabular}{|l|l|}
\hline taller de alimentos & $7,5 \mathrm{~m} 2$ \\
\hline baño 1 & $4 \mathrm{~m} 2$ \\
\hline circulaciones & $0 \mathrm{~m} 2$ \\
\hline espacio 1 & $8,3 \mathrm{~m} 2$ \\
\hline espacio 2 & $7,3 \mathrm{~m} 2$ \\
\hline espacio 3 & $11 \mathrm{~m} 2$ \\
\hline espacio 4 & $27 \mathrm{~m} 2$ \\
\hline TOTAL & $65,1 \mathrm{~m} 2$ \\
\hline
\end{tabular}

e: $1 / 200$

\section{SISTEMAS DE AGRUPACIÓN}

superficie construida total por planta:

$400 \mathrm{~m} 2$

superficie construida zonas comunes por planta: 54 m2 (13\%)

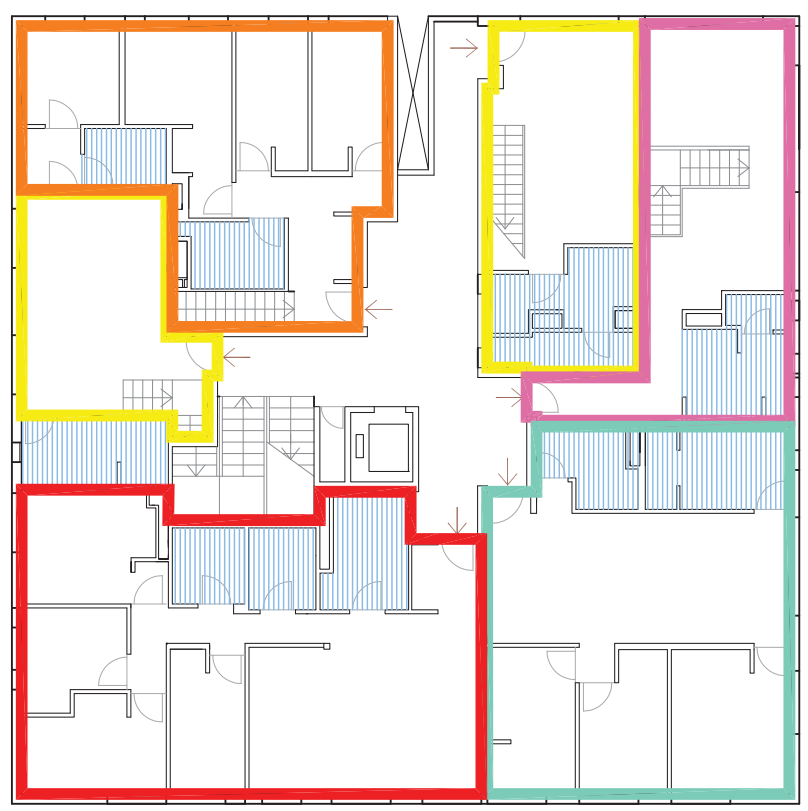



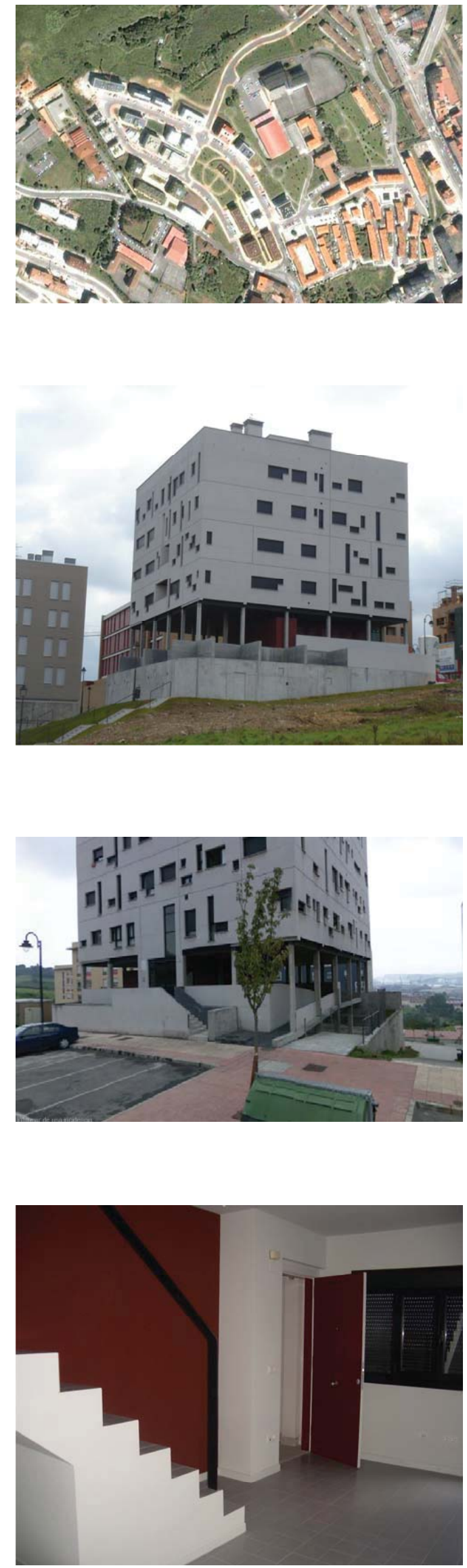

FICHA 6.2

\section{EUROPAN 6}

(año 2000)

JORGE SUÁREZ Y LUCIA SALVADOR

18 VIVIENDAS SOCIALES EN AVILÉS

\section{EMPLAZAMIENTO}

c/Ría de Avilés $n^{\circ} 8$, Avilés (Asturias)

COMIENZO DE OBRAS- FINALIZACIÓN DE LAS OBRAS

Fin: Año 2007

¿ES EL PROYECTO DE CONCURSO?

No

Nº DE VIVIENDAS TOTALES CONSTRUIDAS

18 viviendas

N DE VIVIENDAS POR SUPERFICIE

पII 2 viv
VII 5 viv 4 viv
पII 3 viv 4 viv

USO DE LA PLANTA BAJA

Trasteros

USO DEL SOTANO

Garaje

REFERENCIAS BIBLIOGRÁFICAS 



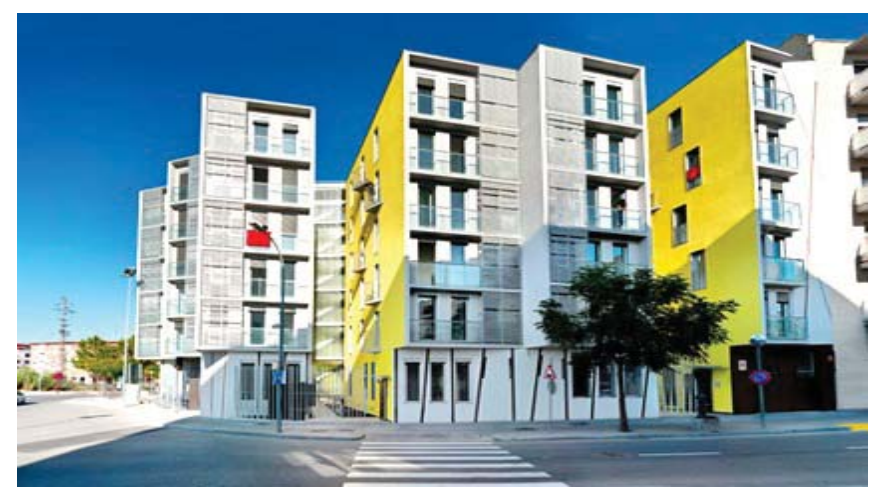

\subsubsection{Edificios de viviendas Europan 7 (2002)}

Angela Moragues y Hevia Meyer: viviendas sociales en Lérida 


\section{RO.203 \\ Interfacing Nature \& Urban}

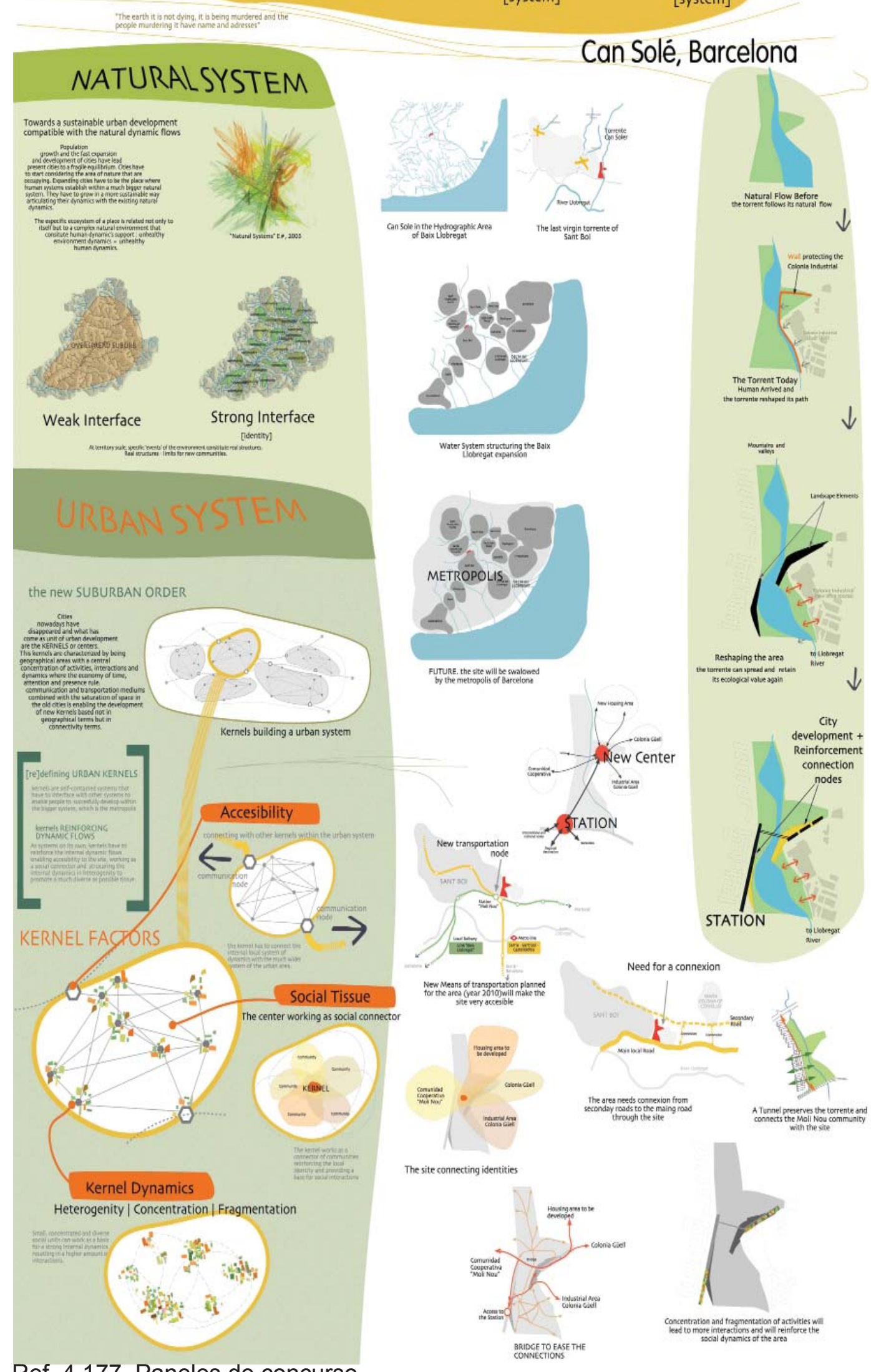

Ref. 4.177. Paneles de concurso 


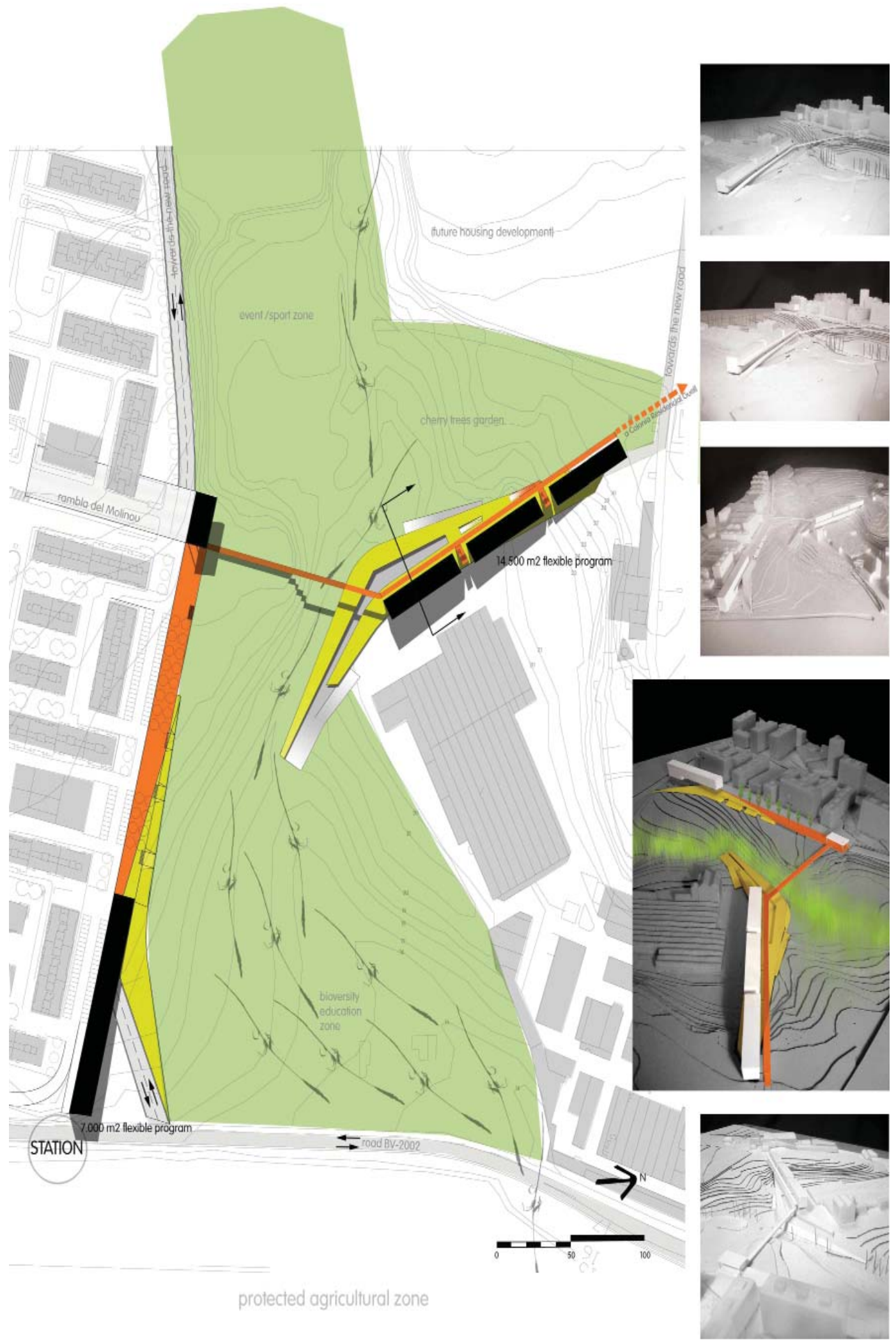

Ref. 4.178. Paneles de concurso 


\section{$\mathrm{RO} \cdot 203$}

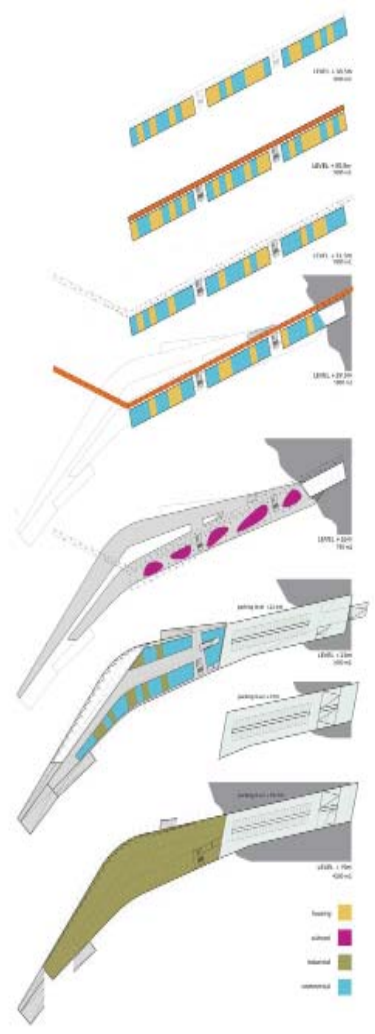

Can Solé, Barcelona
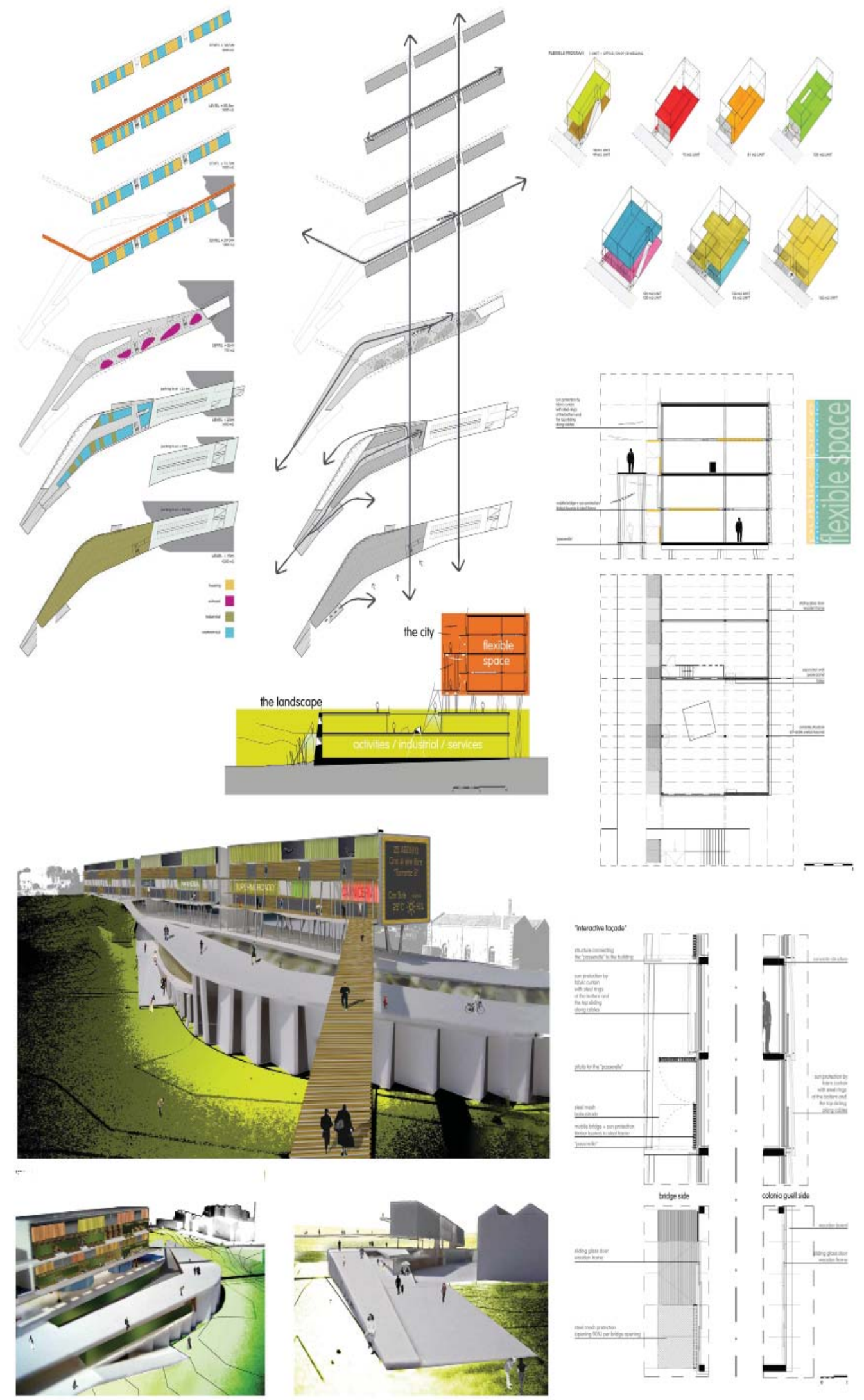

Ref. 4.179. Paneles de concurso 328 


\section{Fase de concurso}

El proyecto de concurso se realiza en un solar situado en Can-Solé, Barcelona. El emplazamiento se encuentra en la vaguada de los municipios de Santa Coloma del Cervelló y Sant Boi de Llobregat. En las propuestas se pretendía plantear que consiguieran la articulación de los tejidos urbanos existentes, definiendo una nueva imagen urbana del municipio de Sant Boi de Llobregat, el reforzamiento de la conexión internúcleos mediante un nuevo vial según la dirección del torrente así como la permanencia de elementos naturales a través de un programa que contemplaba los usos residencial, industrial y de equipamientos.

Se trataba de un proyecto, con palabras del Jurado, con "una solución muy individual generada a través de observaciones muy generales, el estudio meticuloso del sistema natural del emplazamiento y de la estructura de tráfico alrededor del mismo".

Los autores llegaron a una solución a la vez sensible y espectacular con un planteamiento de proyecto que se adaptaba a la topografía del solar. Los dos edificios de borde dibujan los barrios residenciales existentes y al mismo tiempo definen un espacio natural interesante que vivirá cambiosa lo largo de las distintas estaciones del año. El planteamiento general consistía en crear unos centros (que el equipo denomina Kernels) que sean sistemas auto-contenidos y su éxito residirá en la accesibilidad, en la conectividad social y en la dinamica (movimiento). Además planteaban un elemento paisajístico que denominan un dique habitado que asigna una nueva dirección al torrente, alejándolo del muro y desviándolo al centro del solar. Una vez el sistema natural esté recuperado, el segundo paso consiste en crear ciudad posándose sobre él. Los edificios suponían inyecciones programáticas al barrio vecinal e introducen (con su flexibilidad y capacidad de conectar) un espíritu fresco en este contexto cargado arquitectónicamente. La propuesta es elegante y absolutamente factible, particularmente porque tanto su actitud en el diseño como su respuesta garantizan la adaptabilidad necesaria para esta realización.

Los paneles que presentan a concurso están llenos de diagramas explicativos y esquemas. Es una propuesta con un contenido conceptual muy elevado y con un planteamiento de actuar sobre el terreno respetándolo al máximo.

El Jurado también afirma que la conexión entre ciudad y naturaleza es uno de los temas recurrentes de EUROPAN 7: este proyecto no solamente sugiere una unión simbólica de estos dos elementos antagónicos, sino también busca una sinergia entre dos sistemas para desarrollar una nueva constelación urbana. Esta es una actitud que sobrepasa con creces la retórica y puede ser la respuesta correcta para este muy interesante emplazamiento de Barcelona. 
VIVIENDAS EUROPAN (1988-2008) | Una aproximación a los modos de vida en el cambio de siglo en España

4. EUROPAN: DEL CONCURSO A LA REALIZACIÓN

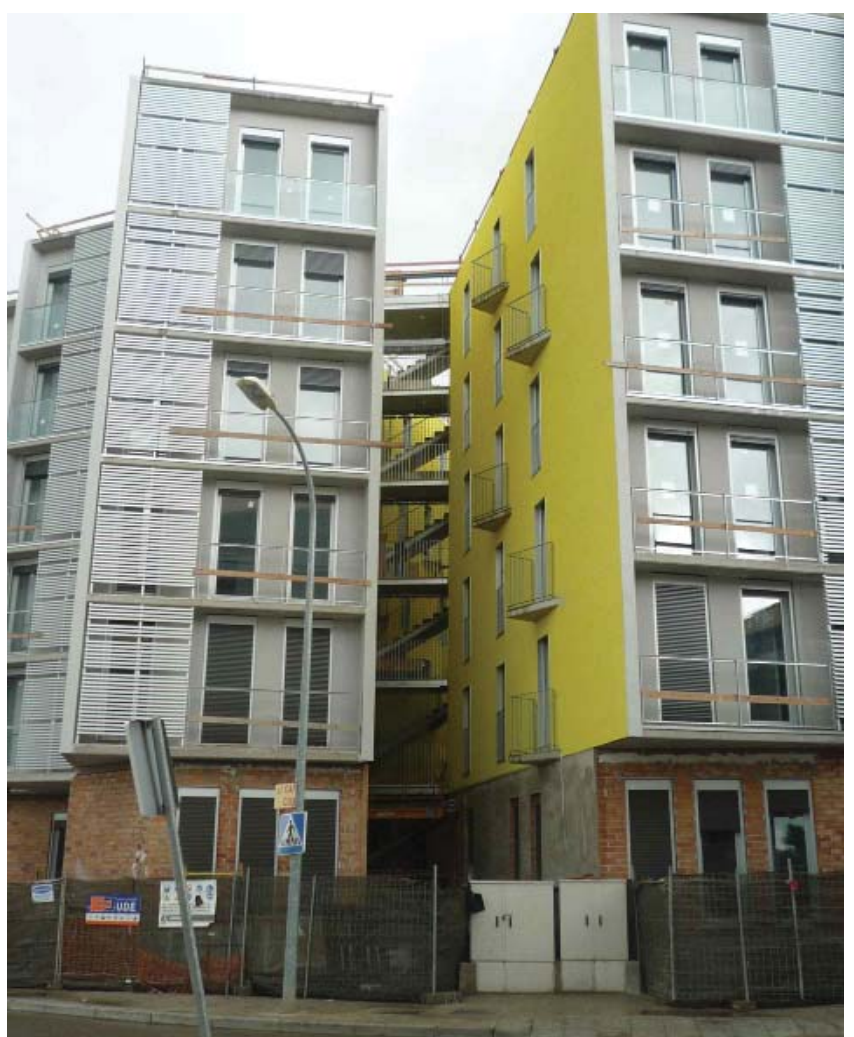

Ref.4.180. Acceso

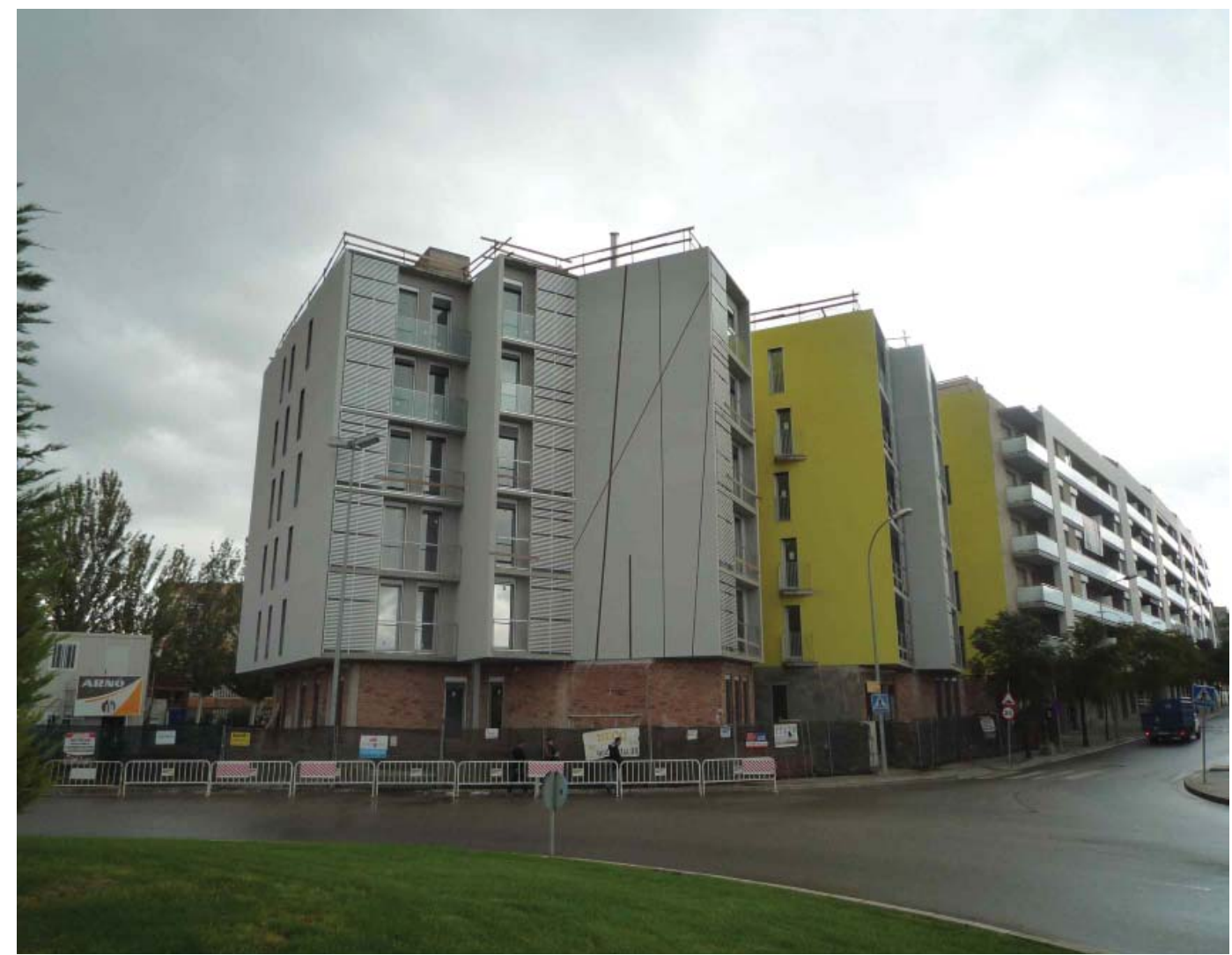

Ref.4.181. Vista del conjunto 


\section{Fase de realización}

Finalmente no se pudo obtener el solar propuesto en el concurso y el equipo pudo participar en otro situado en Lérida, en la Avenida Pio XII para construir 52 viviendas sociales.

Las autoras del proyecto proponen un edificio girado en forma de abanico, que busca la mejor orientación. Como el solar es complicado por su geometría y orientación, pues se situa en el borde de la ordenación junto a una rotonda, lo primero que puede venir a la mente es la idea de crear un bloque cerrado con patio de manzanas. Pero plantearon una solución distinta: se disponen dos patios estrechos y abiertos a fachadas opuestas (este-oeste) con el fin de favorecer las vistas al exterior de la parcela, ventilar los dormitorios y buscar la mejor iluminación. Los núcleos de comunicación vertical y accesos dividen el patio en dos y están protegidos con cerramiento de vidrio. La voluntad de encontrar una composición unitaria que da respuesta a la irregularidad de la parcela, ha hecho presente las líneas oblicuas que limitan con la rotonda y se compone con las mismas. El edificio tiene forma de ventana que se cierra al norte y se abre poco a poco a la entrada de este nuevo barrio.

Al mismo tiempo, el giro de las fachadas manifiesta la preocupación de encontrar una mejor orientación para todas las viviendas. La fachada norte busca una orientación al este y la sur hace lo mismo.

El edificio tiene cinco plantas sobre rasante y dos debajo. El primer patio da servicio, con la escalera, a cinco viviendas por planta, excepto en la planta baja que son cuatro. El segundo patio da servicio a cuatro viviendas por planta, excepto la planta baja que son tres. Se proyectan 18 viviendas de 3 dormitorios (de 70m2 su) y 34 viviendas de dos dormitorios (50m2 su).

El aspecto general común a todas las tipologías es la situación del módulo salón y cocina en las fachadas y los dormitorios en los patios abiertos. Las zonas húmedas se encuentran siempre en la zona central de cada uno de los bloques. Esta disposición de espacios permite siempre tener una vivienda con ventilación cruzada. La disposición de los dos patios estrechos pero abiertos a las dos fachadas favorecen las vistas al exterior de la parcela, la ventilación cruzada y la entrada de sol. El tratamiento de estos patios de proporciones atípicas es de gran importancia por el hecho de ser las dos entradas al edificio. Las fachadas se han proyectado buscando una composición repetitiva. Los pequeños balcones dispuestos aleatoriamente controlan la dimensión de cada patio, generando una estructura de los muros y cambiando la sensación del espacio envolvente.

Cabe destacar que el edificio se ha proyectado siguiendo criterios de sostenibilidad, innovación y máximo ahorro energético mediante la reducción de un $20 \%$ del coeficiente de transmisión térmica, la ventilación cruzada natural en las diferentes estancias privadas del edificio, la disposición de soluciones de ventana y la energía solar térmica.

A continuación se adjunta una ficha-resumen. 


\section{VIVIENDA}

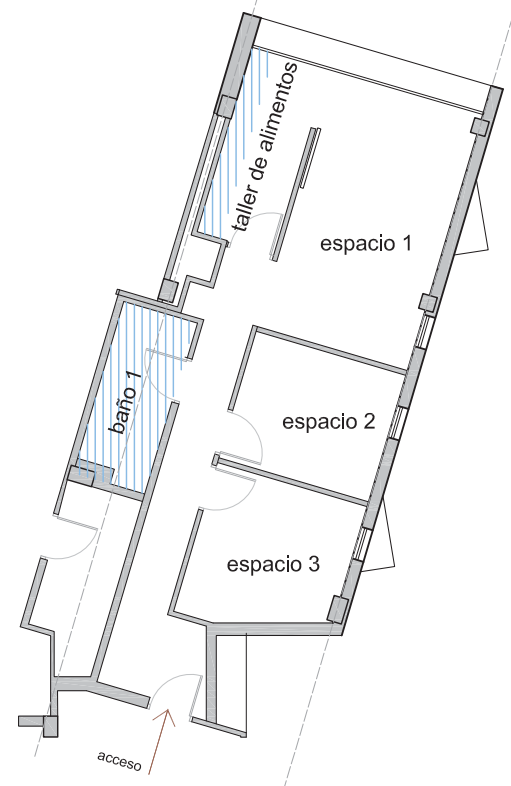

\begin{tabular}{|l|l|}
\hline taller de alimentos & $10,4 \mathrm{~m} 2$ \\
\hline baño 1 & $5,5 \mathrm{~m} 2$ \\
\hline circulaciones & $9,5 \mathrm{~m} 2$ \\
\hline espacio 1 & $17,2 \mathrm{~m} 2$ \\
\hline espacio 2 & $8,5 \mathrm{~m} 2$ \\
\hline espacio 3 & $9,2 \mathrm{~m} 2$ \\
\hline TOTAL & $60,3 \mathrm{~m} 2$ \\
\hline
\end{tabular}

\section{SISTEMAS DE AGRUPACIÓN}

superficie construida total por planta: $\quad 729 \mathrm{~m} 2$

superficie construida zonas comunes por planta: $74 \mathrm{~m} 2$ (10\%)

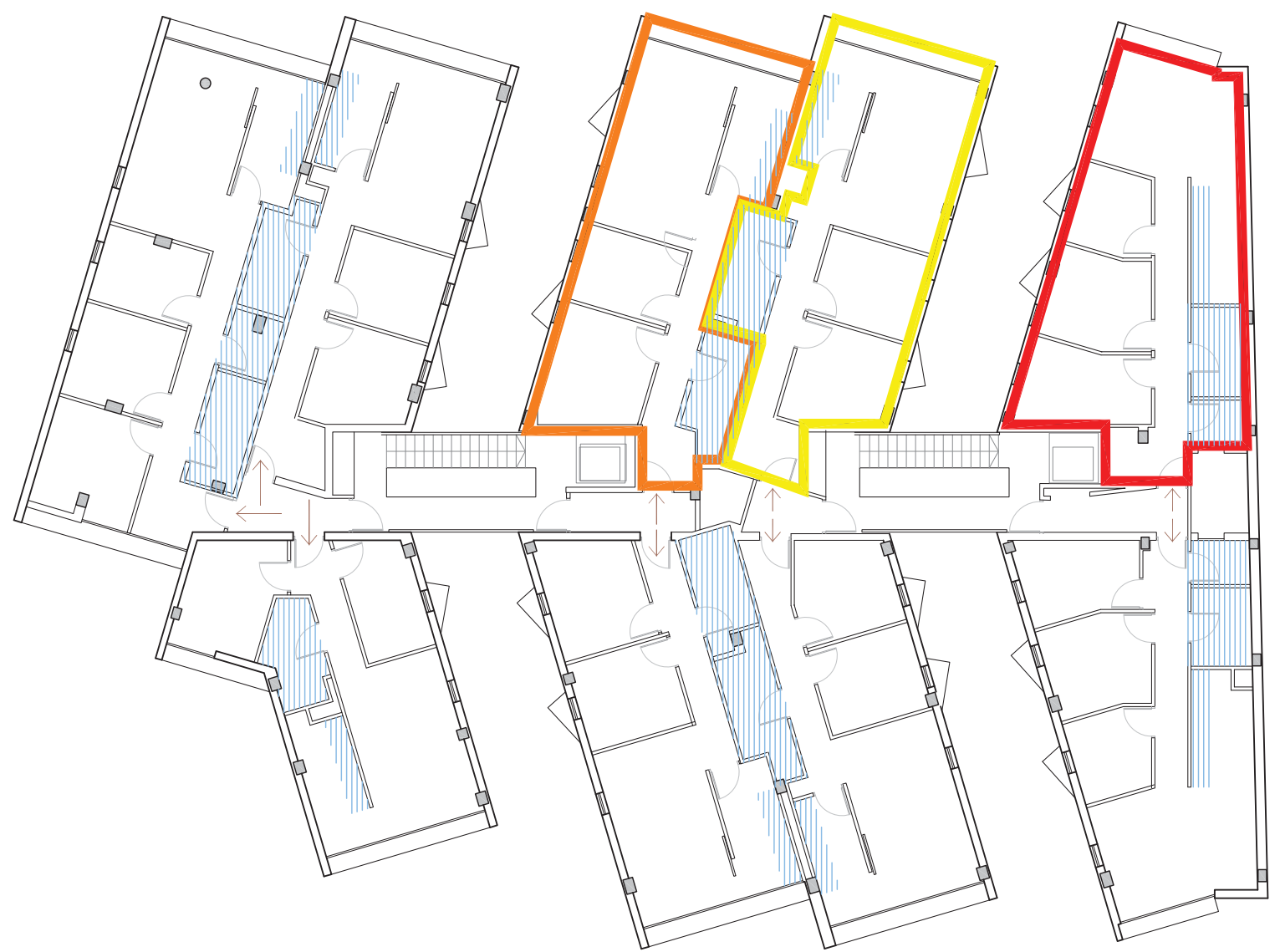




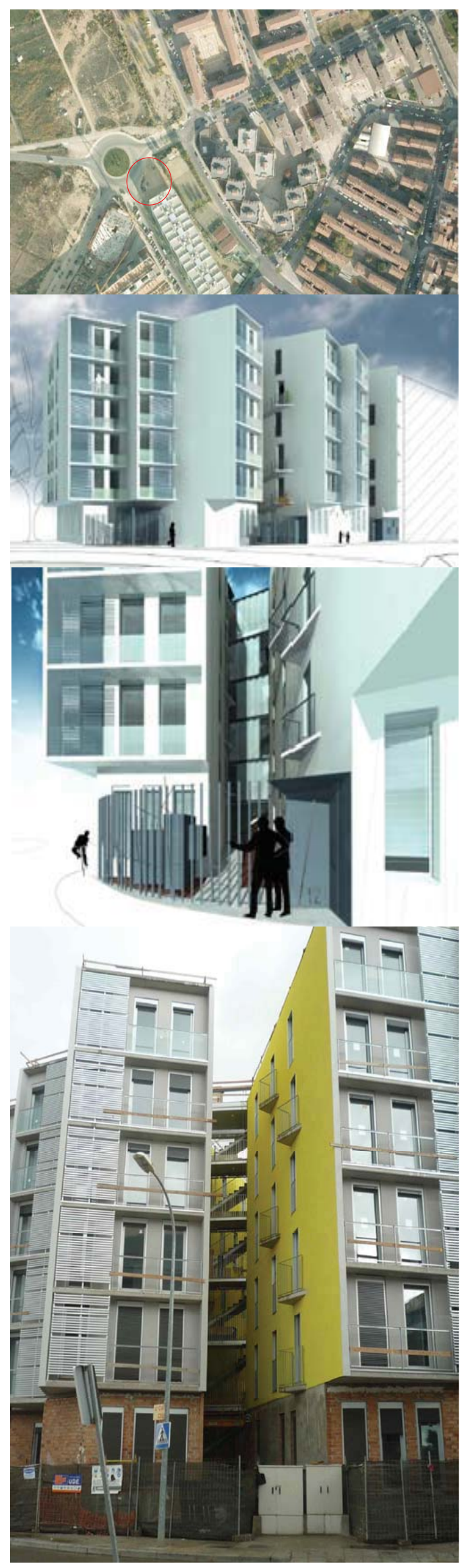

FICHA 7.1

\section{EUROPAN 7}

(año 2002)

\section{HEVIA MEYER Y ÁNGELA MORAGUES 52 VIVIENDAS EN LÉRIDA}

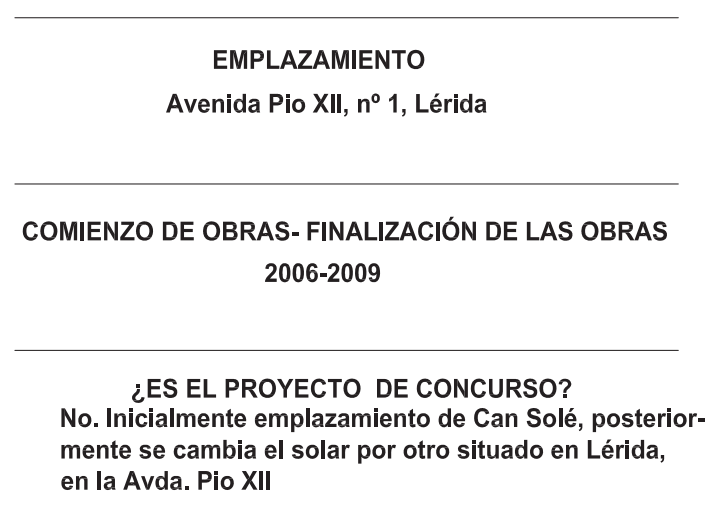

No DE VIVIENDAS TOTALES CONSTRUIDAS

52 viviendas sociales: 18 de 3 dormitorios, de $70 \mathrm{~m} 2$ su y 34 de dos dormitorios, de $50 \mathrm{~m} 2 \mathrm{su}$

No DE VIVIENDAS POR SUPERFICIE

VIII 5 viv

18 viv

VIII 29 viv

USO DE LA PLANTA BAJA

Locales y nucleos de acceso

USO DEL SOTANO

Garaje

\section{REFERENCIAS BIBLIOGRÁFICAS}

www.memoarq.com

- EUROPAN 10 España, "Proyectar la urbanidad", Madrid, 2010, p. 247 
VIVIENDAS EUROPAN (1988-2008) | Una aproximación a los modos de vida en el cambio de siglo en España

4. EUROPAN: DEL CONCURSO A LA REALIZACIÓN

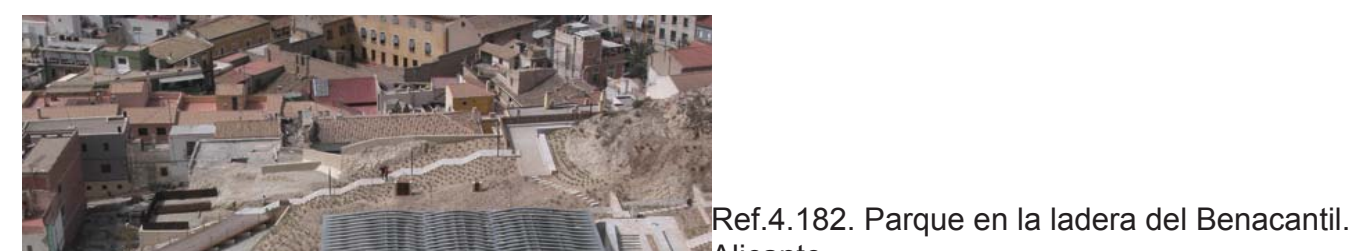
Alicante.

Ref.4.183. Renovación del antiguo mercado. Valladolid
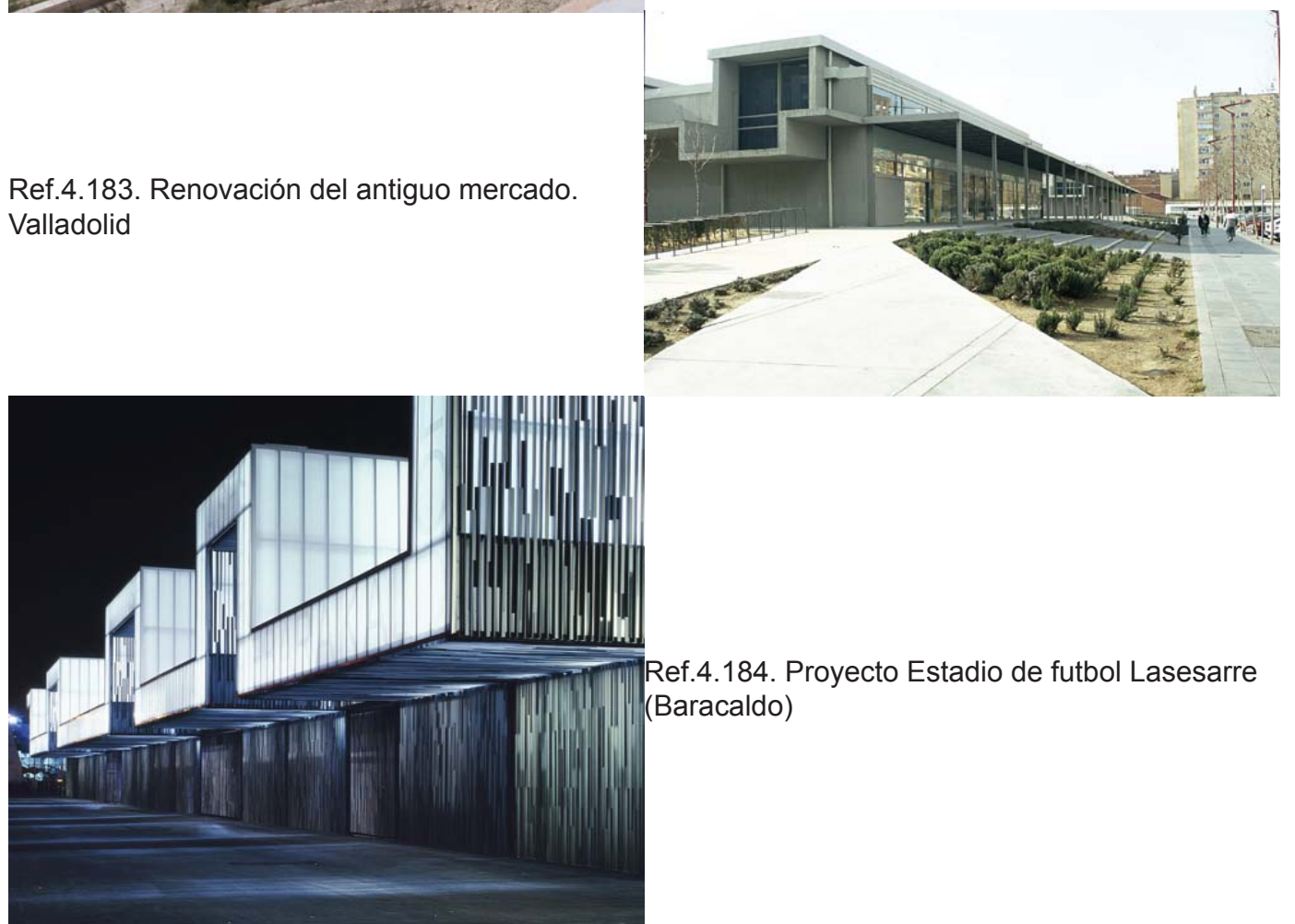

Ref.4.184. Proyecto Estadio de futbol Lasesarre (Baracaldo)

Ref. 4.185. Ordenacion de parque en Lasesarrre (Baracaldo)
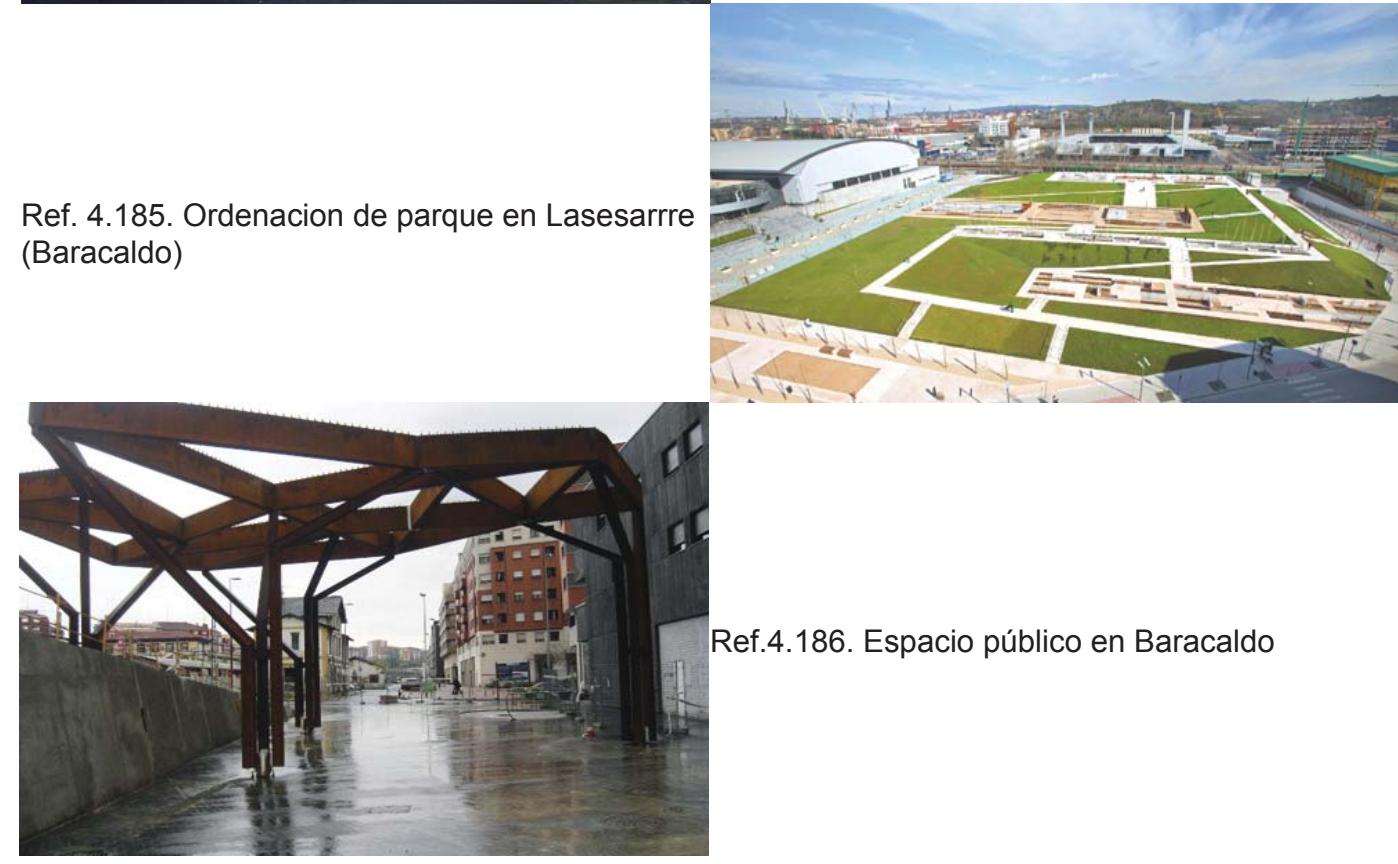

Ref.4.186. Espacio público en Baracaldo 


\subsection{Otros edificios construidos de Europan}

Pero en Europan no se han realizado sólamente edificios de uso residencial. Puesto que estos otros no son el objeto de estudio de la tesis, tan sólo se nombran los existentes ${ }^{1}$ hasta el momento -la mayoría de equipamientos y espacio público-:

- Europan 3 (1992). Parque en la ladera del Benacantil (Alicante). El equipo premiado (Fréderic Bonnet y Marc Pierre Bigarnet) tuvo dificultades para obtener el suelo necesario en el casco histórico. Como alternativa, se les ofrece la realización de un parque en la ladera del monte Benacantil en el que existen algunos elementos de edificación (un bar, un pabellón de agua y un restaurante).

- Europan 4 (1994). Renovación del antiguo mercado central (Valladolid). Eduardo de la Peña, Antonio Lleyda y Rafael Torrelo realizan en cuatro fases un equipamiento en el Barrio de Los Pajarillos. Apenas existe información disponible al respecto.

- Europan 5 (1997). Proyecto de Estadio de fútbol de Lasesarre (Baracaldo). Ninguno de los proyectos se ajustaba a los requerimientos urbanísticos por lo que la propiedad realizó tres encargos en el mismo emplazamiento. Eduardo Arroyo desarrolla un proyecto para el estadio de fútbol de Baracaldo.

- Europan 6 (2000). Ordenación del parque de Lasesarre (Barcaldo). El segundo proyecto que encargan es a Dirk Bertuleit y su equipo. Consisten en la ordenación de un parque. El enclave paisajístico en el que se encuentra es muy interesante y plantean la creación de una topografía artificial, creando distintos campos de juegos y actividades.

- Europan 6 (2000). Espacio público en Baracaldo. Este espacio público fue encargado de nuevo a los javieres como solución al resultado de estudio geotécnico, pues el emplazamiento no era apto para la construccion de viviendas, como se pretendia en el concurso. El proyecto, situado en un área industrial, busca crear un nuevo hito en el paisaje, marcando el acceso al centro de Baracaldo y disponiendo una nueva plaza.

- Europan 6 (2000). Planeamiento en Córdoba. Se encarga a Auxiliadora Gálvez. y apenas se tiene información al respecto, salvo que se han encargado diversos anteproyectos desde el año 2001 sin llegar ninguno a término hasta el momento.

- Europan 10 (2008). Estudio de detalle en el Hierro. Encargado a Silvia Alonso de los Rios, es la ultima realizacion urbanística finalizada hasta el momento. El objeto es definir la ordenación de la edificación en la citada Unidad de Ejecución,

\footnotetext{
${ }^{1}$ Toda la información disponible se puede consultar en [On line] < http://www.europan-esp. es/index.php>. (Consultada, enero 2012).
} 
VIVIENDAS EUROPAN (1988-2008) I Una aproximación a los modos de vida en el cambio de siglo en España

4. EUROPAN: DEL CONCURSO A LA REALIZACIÓN

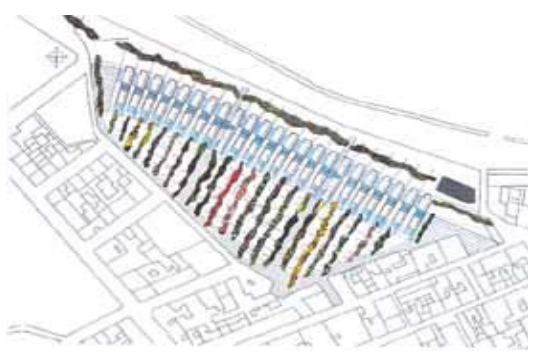

Ref.4.188. Alguazas

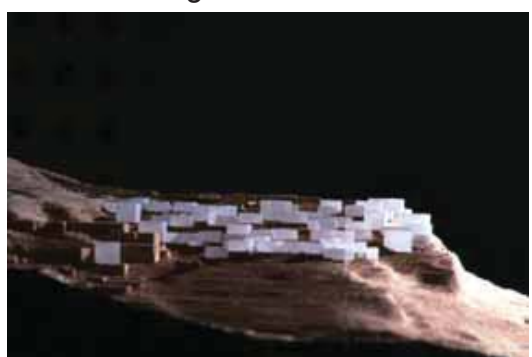

Ref.4.190. Almeria

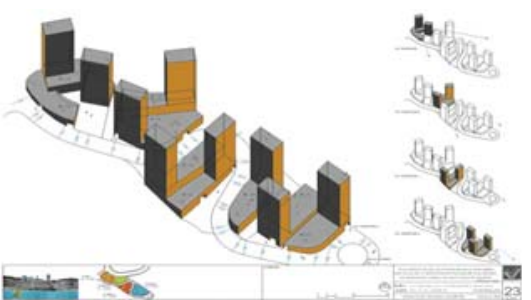

Ref.4.192. Santa Cruz de Tenerife

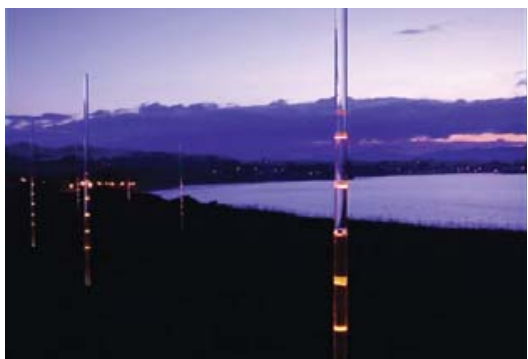

Ref.4.194. Vitoria-Gasteiz

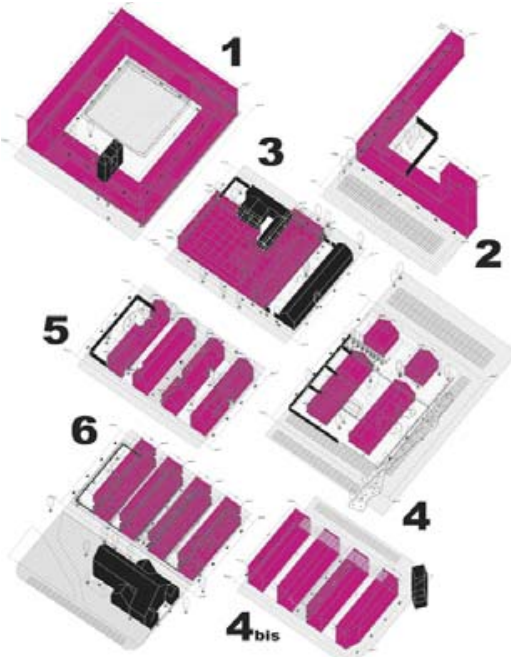

Ref.4.196. Guadalajara

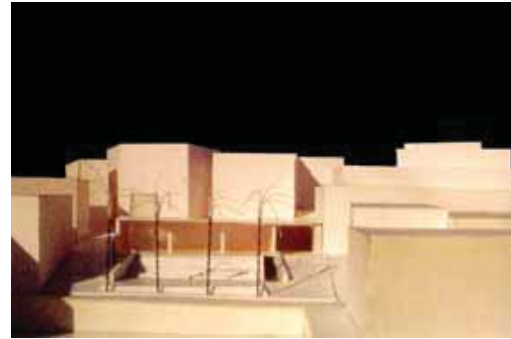

Ref.4.189. Alicante

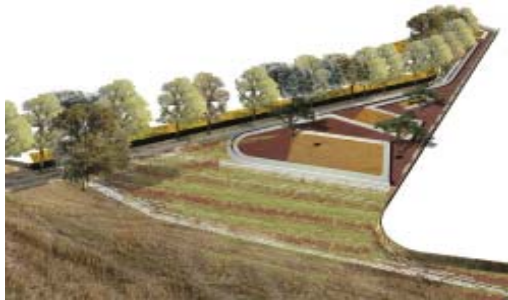

Ref.4.191. Burgos

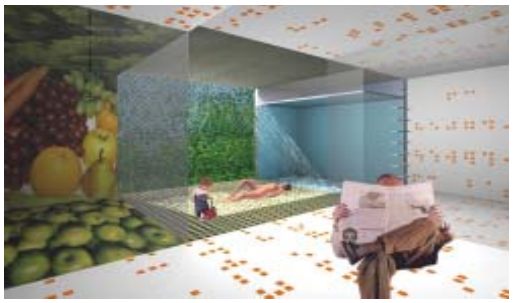

Ref.4.193. Valencia

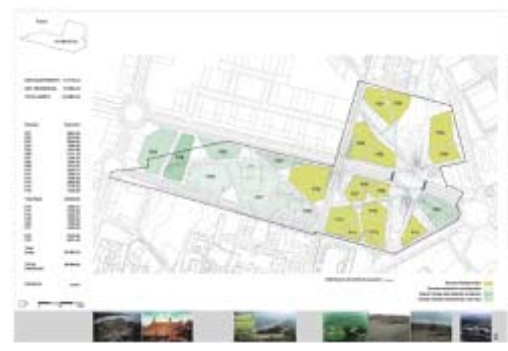

Ref.4.195. Luarca

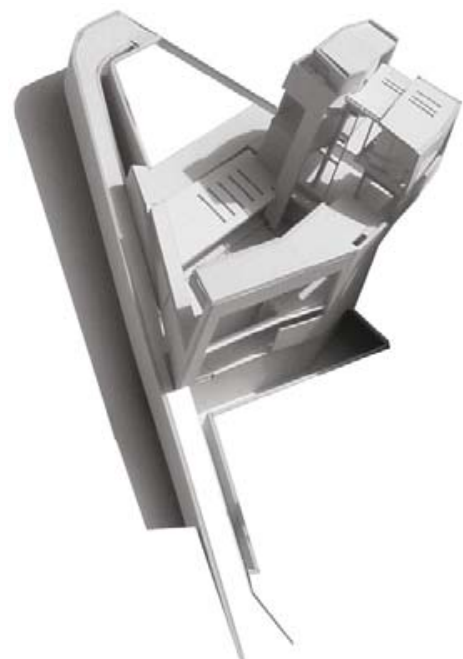

Ref.4.197. Cartes 
dentro de los parámetros establecidos en el Plan General de Ordenación Urbana del municipio y la normativa de referencia.

\subsection{Proyectos en fase de gestión}

Desde el Comité Nacional, se han impulsado para que lleguen a materializarse gran parte de los proyectos presentados a concurso. Por desgracia, la mayoría de éstos se encuentran en fase de gestión. En este apartado no se va a hacer referencia a las causas de su demora o retraso en la ejecución, sino que se tratará de enumerarlos para que el lector disponga de la información adecuada y pueda hacer una valoración en cuanto a la proporción de los mismos con respecto a los que se han construido².

\section{Europan 3}

- Alguazas. Viviendas y ordenación de espacios públicos. Felipe Pich Aguilera, Guillermo Maluenda, Teresa Battle.

- Alicante. Viviendas en la Plaza del Carmen. Esteban García Martínez.

\section{Europan 5}

- Almería. Viviendas en la Chanca. Alfonso Cano Pintos, Mª Julia Abarca Corrales.

\section{Europan 6}

- Burgos: Ordenación del área para uso residencial y equipamientos. Sabine Müller y Andreas Quednau.

- Santa Cruz de Tenerife. Viviendas y equipamiento. Raul del Valle Gonzalez.

- Valencia. Equipamiento y espacio público. Eduardo de la Peña Pareja y Antonio Lleyda Delgado.

\section{Europan 7}

- Vitoria- Gasteiz: ordenación del área e integración con el núcleo urbano para uso residencial. Hugo Araujo y Mariem Brieva.

- Luarca: ordenación del área, integración con el núcleo urbano para uso residencial. David Tapias, Cristina Goberna y Dario Jesus Mateo.

- Guadalajara: terciario y dotacional. Ruben Picado y Maria Jose de Blas.

\section{Europan 8}

- Cartes. Uso residencial de vivienda protegida. Miguel Angel Velarde, Miguel Angel Navas.

- Ceuta. Ordenación y remodelación de la barriada y desarrollo de espacio público. Juana Sanchez, Diego Jimenez, Angela Ruiz, Pedro Romero.

- Sagunto: Ordenacion del Sector al este de la via, integracion con el núcleo urbano

\footnotetext{
${ }^{2}$ Toda la información disponible se puede consultar en [On line] < http://www.europan-esp. es/index.php>. (Consultada, enero 2012).
} 
VIVIENDAS EUROPAN (1988-2008) I Una aproximación a los modos de vida en el cambio de siglo en España

4. EUROPAN: DEL CONCURSO A LA REALIZACIÓN

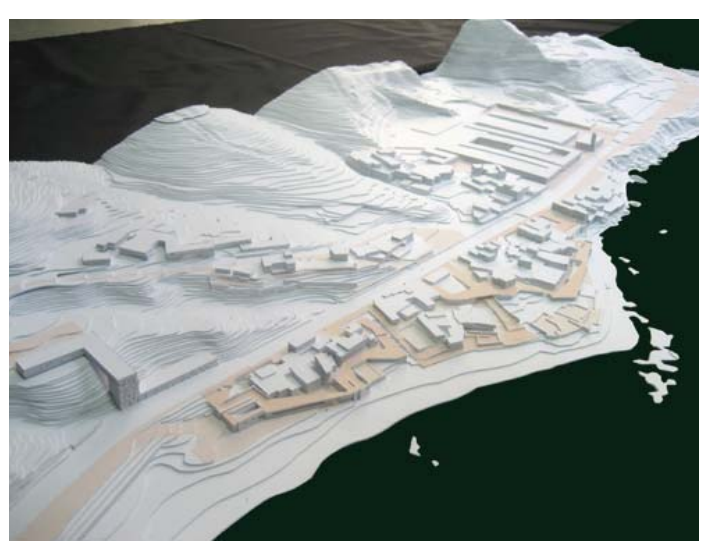

Ref.4.198. Ceuta

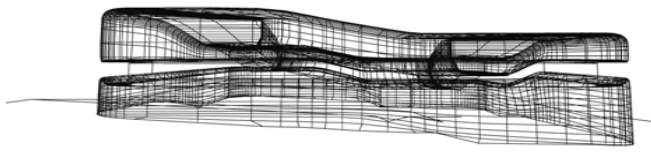

Ref.4.200. La Laguna

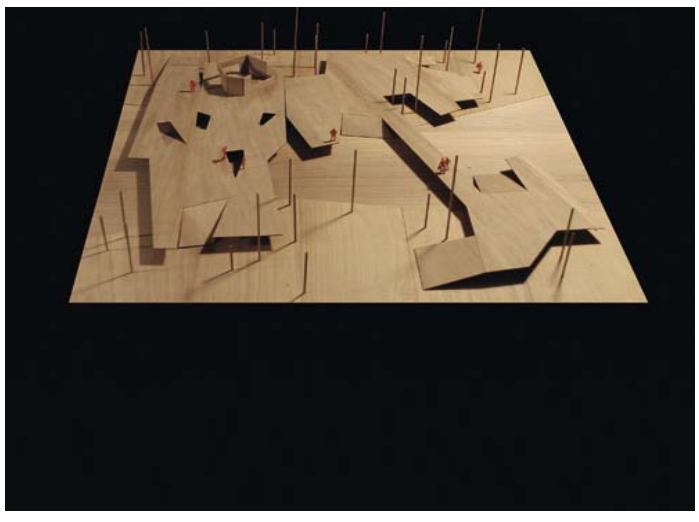

Ref.4.202. Soria

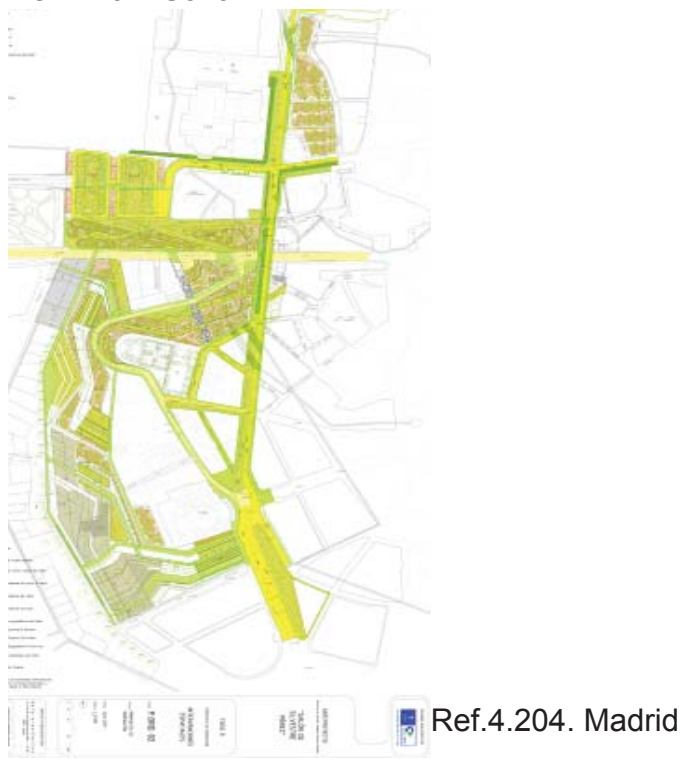

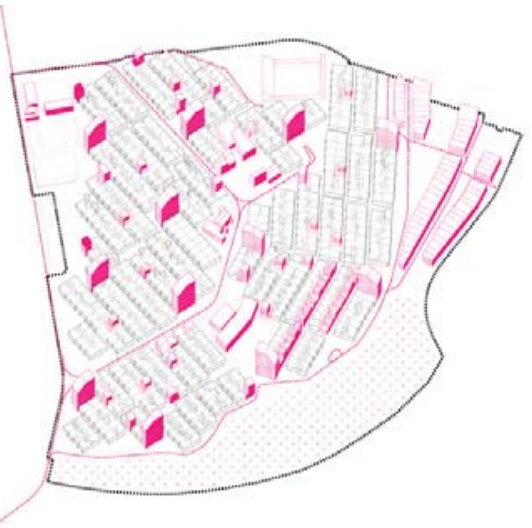

Ref.4.199. Badajoz

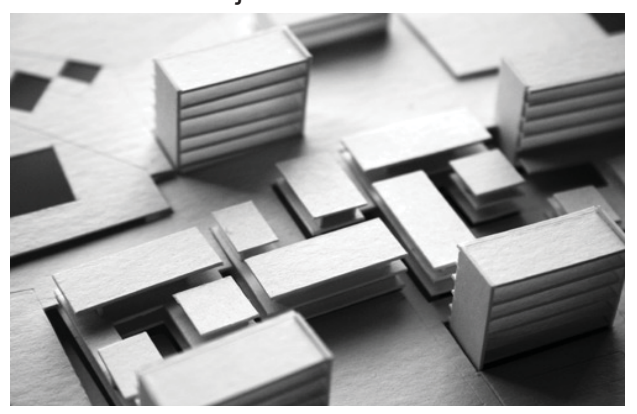

Ref.4.201. Poio

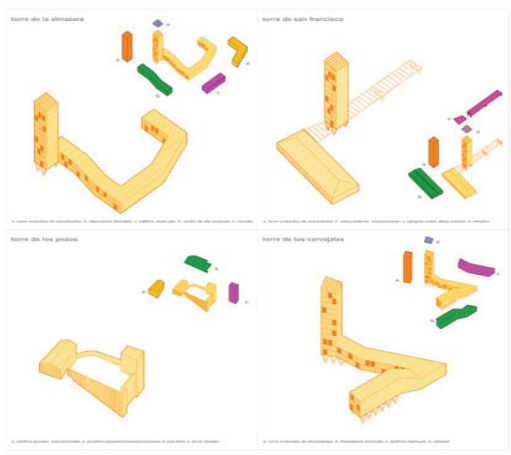

Ref.4.203. Caceres

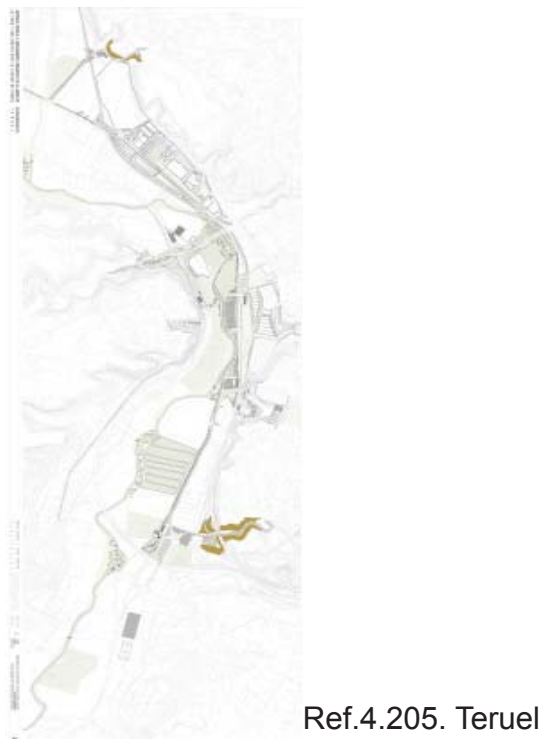


para uso residencial. Javier Guijarro y Elena Blanco.

- Caceres: Reordenación del ámbito de estudio y proyectos puntuales de intervención. Cristina Goberna y Urtzi Grau.

\section{Europan 9}

- Soria: Ordenación de los márgenes del Río Duero. Christian Sintes y David Domínguez.

- Santander: Viviendas de protección oficial (Previo cambio de Plan General). Miguel Ubarrechena.

- Poio: Viviendas. Camilo Manuel Rebocho, Bruno Oliveira, Mariene Pereira

- La Laguna: Viviendas. Daren Gavira Persad y Carolina Ruiz-Valdepeñas.

- Asturias: Estudio de detalle. Adelais Parera, Karla Diaz y Pablo Gil.

- Badajoz: Asistencia Técnica. Enrique Arenas y Luis Basabe.

\section{Europan 10}

- Cáceres: Estudio de profundización sobre la Robera del marco de Cáceres. Javier Garcia-Germán, Alicia García-Germán

- Reus: Elaboración de planeamiento. Aurelian Delchet, Gimena Repetto y Alexis Traficante.

- Madrid: Anteproyecto "Salon Silvestre Perez". Carolina Ruiz-Valdepeñas, Daren Juan Gavira.

-Elda: Estudios previos PERI. Diego Jiménez Lopez y Juana Sánchez Gómez.

“(...) Hemos realizado pues esas rutas. Pero cabe también mirar atrás, recorrerlas de nuevo, revisarlas. Ver y comprender por qué en alguna escalada se perdió algún compañero; saber por qué aquella otra fue hermosa pero no suficientemente segura y eficaz. No contentarnos con lo logrado, sino dolernos de que quizá aquellas rutas abiertas pudieran causar algún accidente por no estar suficientemente armadas.

Y, sobre todo, mirar lejos, otear el horizonte y vislumbrar nuevos ochomiles, más difíciles sin duda, de mayor compromiso, pero que esperan de nosotros para abrir nuevos caminos desde más arriba, más alto y desde allí ayudar al resto a subir de modo más amable el camino que para nosotros fue tan complicado" 

5. ALGUNAS APORTACIONES DE EUROPAN A LA VIVIENDA 
VIVIENDAS EUROPAN (1988-2008) I Una aproximación a los modos de vida en el cambio de siglo en España

5. ALGUNAS APORTACIONES DE EUROPAN A LA VIVIENDA

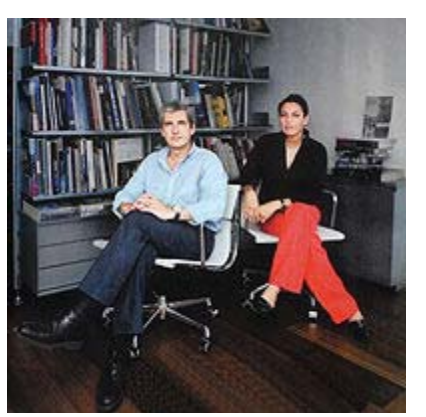

Ref.5.1. Aranguren y Gallegos

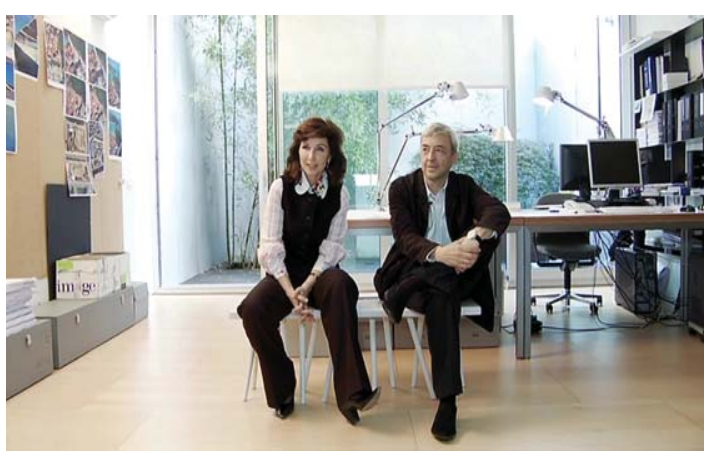

Ref.5.2. Nieto y Sobejano

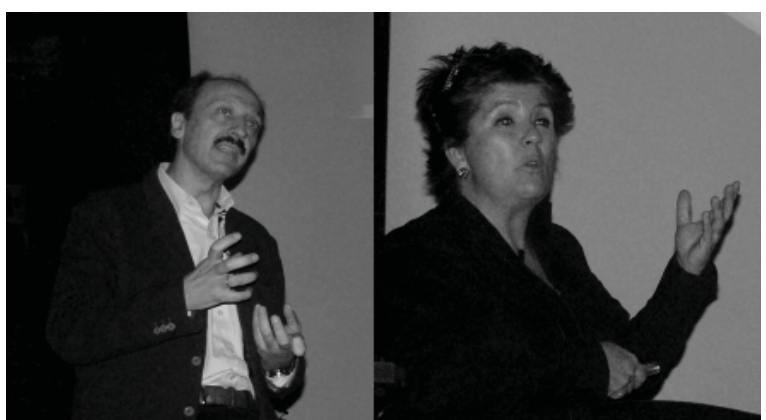

Ref.5.3. Matos y Castillo

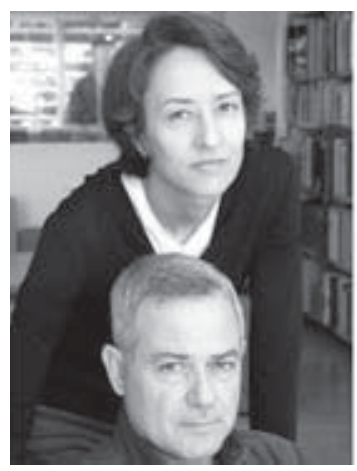

Ref.5.4. Paredes y Pedrosa

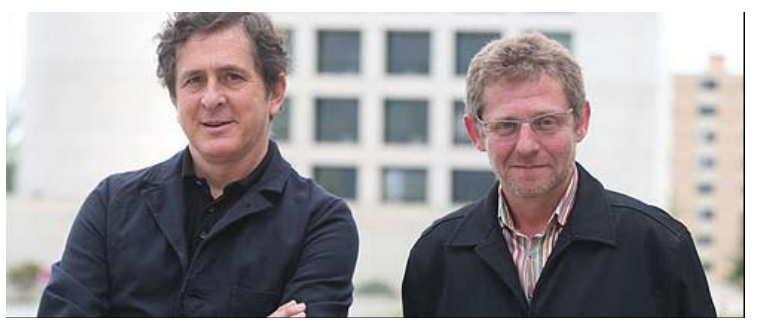

Ref.5.5. Tuñon y Mansilla 


\subsection{Europan y los equipos galardonados}

Europan proporciona una plataforma de lanzamiento para dar a conocer el trabajo de los arquitectos jóvenes galardonados tanto a nivel nacional como internacional.

Una vez fallado el concurso, se realiza un catálogo de resultados a escala nacional y europea que se distribuye a todas las Escuelas de Arquitectura, librerías especializadas, Colegios de Arquitectos y Bibliotecas de centros culturales, además de a los miembros del Comité Nacional.

Además de las publicaciones y notas de prensa cabe recalcar que se realiza una exposición itinerante que suele presentarse en los distintos emplazamientos que han participado en el concurso.

Aranguren y Gallegos, Nieto y Sobejano, Matos y Castillo, Paredes y Pedrosa, Tuñón y Mansilla,...son arquitectos de reconocido prestigio que, en algún momento al inicio de su trayectoria profesional, han sido concursantes de Europan.

Pero no es tan fácil ser un arquitecto-Europan. Europan les abre un panorama global de trabajo a los jóvenes equipos galardonados, pues forma redes y conecta los equipos galardonados entre sí. Ángela García de Paredes lo corrobora cuando afirma que "Europan ha llegado a su mayoría de edad constituyendo un auténtico acontecimiento para la arquitectura. Casi todos los nombres que aparecían en las primeras ediciones son ahora consolidados estudios de arquitectos europeos y nuestras primeras publicaciones y conferencias, nacionales y europeas, llegaron de la mano de Europan. Es ahora, con la perspectiva de veinte años, cuando se puede valorar la relación entre el concurso y los resultados, entre los proyectos y su materialización, entre las propuestas y el paso del tiempo"”.

Se podría afirmar que Europan es el trampolín para descubrir a muchos arquitectos jóvenes que formarán parte de los grandes arquitectos de la posteridad. Entre los recientes equipos de jóvenes arquitectos se encuentran algunos como Juana Sánchez y Diego Jiménez, equipo que ha sido galardonado en Europan 8, 10 y 11; Patricia y Luciano premiados en Europan 10 en Varsovia, etc.

La inexperiencia de los jóvenes equipos es uno de los factores que condicionan a la hora de la materialización posterior de los proyectos pues, en la mayoría de los casos, estos equipos se enfrentan con la construcción de la obra por primera vez.

1 GARCÍA DE PAREDES, Angela. "Europan: una ventana hacia la arquitectura" en EUROPAN 10 España. Proyectar la urbanidad. Ed. Ministerio de la vivienda. Madrid. 2010, p. 221 
VIVIENDAS EUROPAN (1988-2008) I Una aproximación a los modos de vida en el cambio de siglo en España

5. ALGUNAS APORTACIONES DE EUROPAN A LA VIVIENDA

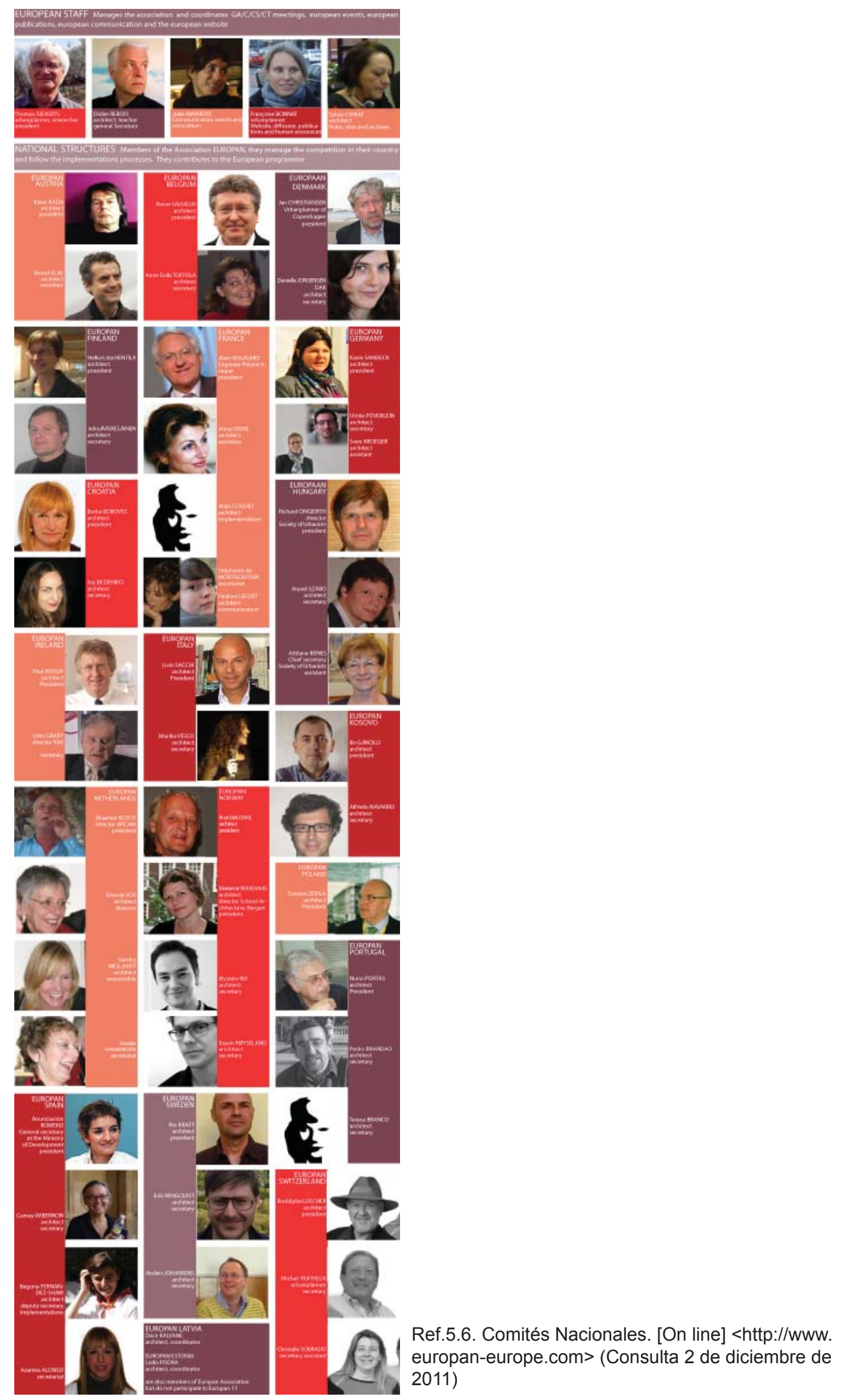




\subsection{Europan y la Administración Pública}

Europan es un concurso de ideas dotado de un premio en metálico pero su actuación va más allá de premiar unas ideas innovadoras.

A nivel de las Administración Autonómica y Local Europan tiene un largo camino que recorrer previo al lanzamiento de concurso. En cada convocatoria se publica un folleto de divulgación que se distribuye a través de los Miembros del Comité Nacional. En él se explican los objetivos del concurso y hace un resumen de las ediciones pasadas. El hecho de que en cada edición se tengan propuestas de suelo a concurso quiere decir que hay numerosos representantes de la Administración Pública interesados en participar en esta reflexión sobre el hábitat y el espacio público en la ciudad europea.

En principio se parte de que las Administración Pública que presenta suelo a concurso se comprometen a hacer todo lo que está en su mano para contratar a los equipos galardonados y desarrollar las ideas premiadas. Pero, por la inestabilidad temporal de la política, no siempre se consigue mantener en el tiempo la decisión tomada. Entonces el Comité Nacional de Europan actúa como intermediario invisible entre la Administración Pública y los equipos galardonados tratando de involucrar a los representantes que previamente han presentado sus iniciativas de suelo para el concurso de ideas.

Dependiendo de cada Administración Pública y su situación, una vez fallado el concurso, se puede contratar una cosa u otra dependiendo de su identidad (si es una Comunidad Autónoma, Ayuntamiento, representantes de suelo, etc.). A veces lo que se hace es convocar con posterioridad concursos restringidos entre los ganadores de Europan para que realicen otras intervenciones que puedan asumir.

Aunque son muchos representantes de la Administración Pública los que han trabajado con Europan, los que más proyectos han implantado han sido La Comunidad de Madrid y el Principado de Asturias.

Se puede decir que dos de los motivos que ha dificultado la tarea de construir los proyectos galardonados han sido: la dificultosa gestión con la Administración Pública (debido tal vez a la falta de compromiso e implicación por parte de ésta) y la difícil adaptación de los proyectos con ideas experimentales a la normativa existente rígida y, en algunos casos, obsoleta.

Muchos de los proyectos de concurso han quedado interrumpidos, o se han demorado en su realización porque, o no contemplaban la normativa existente, o proponían un cambio de ésta. De los veinte proyectos construidos, tan sólo seis ${ }^{2}$

${ }^{2}$ Estos proyectos son: dos torres de viviendas en la M-40 de Aranguren y Gallegos, dos torres de viviendas en la M-30 de Sánchez y Escobar, dos manzanas de viviendas en 
TABLA DE RESULTADOS DE EUROPAN (NOVIEMBRE 2011)

\begin{tabular}{|c|c|c|c|c|}
\hline & $\begin{array}{l}\text { PRESENTADOS } \\
\text { (actas del Jurado) }\end{array}$ & $\begin{array}{l}\text { GALARDONADOS } \\
\text { (actas del Jurado) }\end{array}$ & $\begin{array}{l}\text { OBRAS } \\
\text { CONSTRUIDAS }\end{array}$ & $\begin{array}{c}\text { № DE } \\
\text { VIVIENDAS }\end{array}$ \\
\hline EUROPAN 1 & 112 & $\begin{array}{c}30 \text { de los que hay } \\
5 P+5 M+20 F\end{array}$ & 7 & 385 \\
\hline EUROPAN 2 & 214 & $\begin{array}{c}27 \\
5 P+5 M+17 F\end{array}$ & 2 & 196 \\
\hline EUROPAN 3 & 423 & $\begin{array}{c}41 \\
4 \mathrm{P}+5 \mathrm{M}+32 \mathrm{~F}\end{array}$ & 3 & 352 \\
\hline EUROPAN 4 & 307 & $\begin{array}{c}29 \\
4 \mathrm{P}+7 \mathrm{M}+18 \mathrm{~F}\end{array}$ & 4 & 377 \\
\hline EUROPAN 5 & 245 & $\begin{array}{c}32 \\
4 P+7 M+21\end{array}$ & 2 & 144 \\
\hline EUROPAN 6 & 365 & $\begin{array}{c}33 \\
6 \mathrm{P}+9 \mathrm{M}+18 \mathrm{~F}\end{array}$ & 2 & 49 \\
\hline EUROPAN 7 & 286 & $\begin{array}{c}23 \\
7 P+7 M+8 F\end{array}$ & 1 & 52 \\
\hline EUROPAN 8 & 208 & $\begin{array}{c}29 \\
8 \mathrm{P}+8 \mathrm{M}+13 \mathrm{~F}\end{array}$ & En proceso & En proceso \\
\hline EUROPAN 9 & 176 & $\begin{array}{c}25 \\
7 \mathrm{P}+7 \mathrm{M}+11 \mathrm{~F}\end{array}$ & En proceso & En proceso \\
\hline EUROPAN 10 & 311 & $\begin{array}{c}33 \\
6 \mathrm{P}+7 \mathrm{M}+20 \mathrm{~F}\end{array}$ & En proceso & En proceso \\
\hline EUROPAN 11 & En proceso & En proceso & En proceso & En proceso \\
\hline TOTAL & 2647 & 302 & 21 & 1555 \\
\hline
\end{tabular}

P= PREMIADOS $\mid \mathrm{M}=$ MENCIONADOS $\mid \mathrm{F}=$ FINALISTAS

Ref. 5.7. Tabla de resultados de Europan. elaboración propia

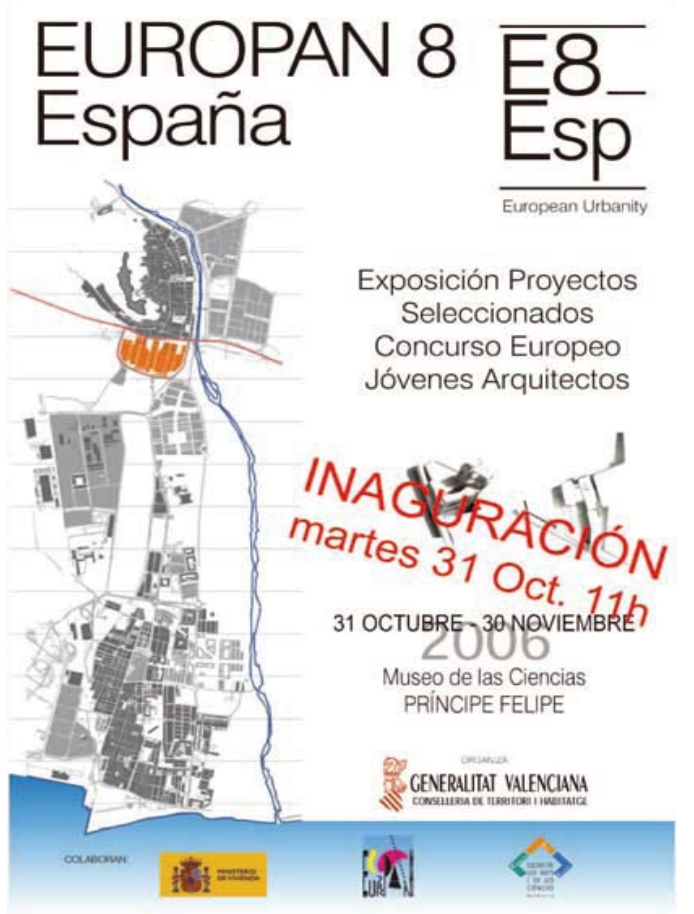

Ref.5.8. Exposición de Europan 8, a la que acudieron los equipos seleccionados para proponer alternativas a la actualización de la HD-91 
se adecúan al proyecto de concurso generalmente por esta difícil adaptación a la normativa existente de la que se está hablando, además de los fallos en la gestión.

Se deduce que la normativa actual es un handicap pues no hay coherencia entre topic y place y es una pena que se vislumbren buenos modos de hacer arquitectura, pero que después no puedan construirse. Se impone entonces la necesidad de reflexionar abiertamente sobre cuál debería ser la normativa que permitiera concretar un proyecto integral de ciudad porque la actual es muy rígida y le faltan mecanismos de actualización.

Pero antes de finalizar, cabe puntualizar una aportación positiva y es que Europan es un medio excelente para dialogar con la Administración Pública. Un ejemplo esclarecedor al pude asistir personalmente es el de la mesa de trabajo que se organizó desde el Observatorio Valenciano de la Vivienda con los equipos premiados de Europan 8 para estudiar la actualización de la HD- $91^{3}$ de la Comunidad Valenciana.

Esta tarea tuvo una duración de varios meses trabajando en red y concluyó con una reunión presencial de los equipos en Valencia el el 30 de noviembre de 2006 en el Museo Príncipe Felipe, aprovechando que finalizaba la exposición itinerante de Proyectos Seleccionados en el Concurso Europeo para Jóvenes Arquitectos Europan 8.

Los equipos que participaron fueron:

- $\quad$ Ava arquitectos (premiados en el Alcázar de San Juan).

- $\quad B+C$ arquitectos (premiados en Córdoba)

- $\quad$ Jekiff arquitectos (premiados en Sagunto)

- $\quad$ Martin Serrats (premiados en Austria)

- $\quad$ Mixuro (premiados en Checoslovaquia)

- $\quad$ Francisco Leiva y Marta Garcia Chico (premiados en Ceuta)

- $\quad$ Marta Martinez y Rafael Puggioni

La mayoría de ellos estudiaron a conciencia la HD-91 (Normas de habitabilidad y diseño de la Comunidad Valenciana vigentes en el momento). Las aportaciones que presentaron fueron interesantes y realizaron muchas sugerencias a la normativa.

Basauri de Matos y Castillo, las viviendas en Sevilla de Nieto y Sobejano y las viviendas en Ceuta de González y Mariscal.

${ }^{3}$ DECRETO 85/1989, de 12 de junio, del Consell de la Generalitat Valenciana, por el que se aprueban las Normas de Habitabilidad y Diseño de Viviendas en el ámbito de la Comunidad Valenciana.

ORDEN de 22 de Abril de 1991, del Conseller de Obras Públicas, Urbanismo y Transportes,por la que se aprueba la modificación y el texto refundido que desarrolla las normas de habitabilidad y diseño de viviendas en el ámbito de la Comunidad Valenciana. (D.O.G.V. de 22 de mayo de 1991). 
VIVIENDAS EUROPAN (1988-2008) I Una aproximación a los modos de vida en el cambio de siglo en España 5. ALGUNAS APORTACIONES DE EUROPAN A LA VIVIENDA

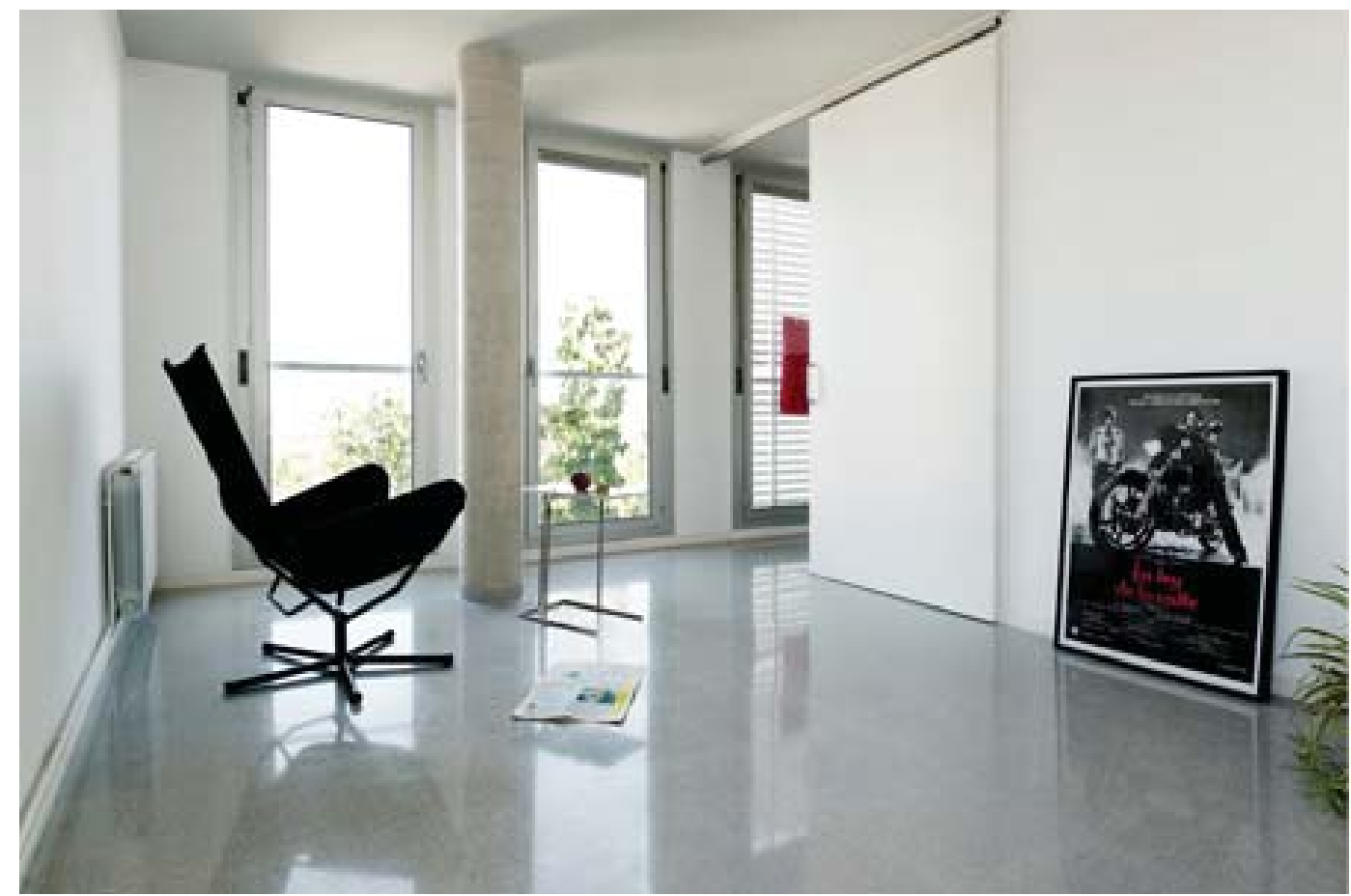

Ref.5.9. Interior de las viviendas de Hevia Meyer y Ángela Moragues , Lérida, Europan 7

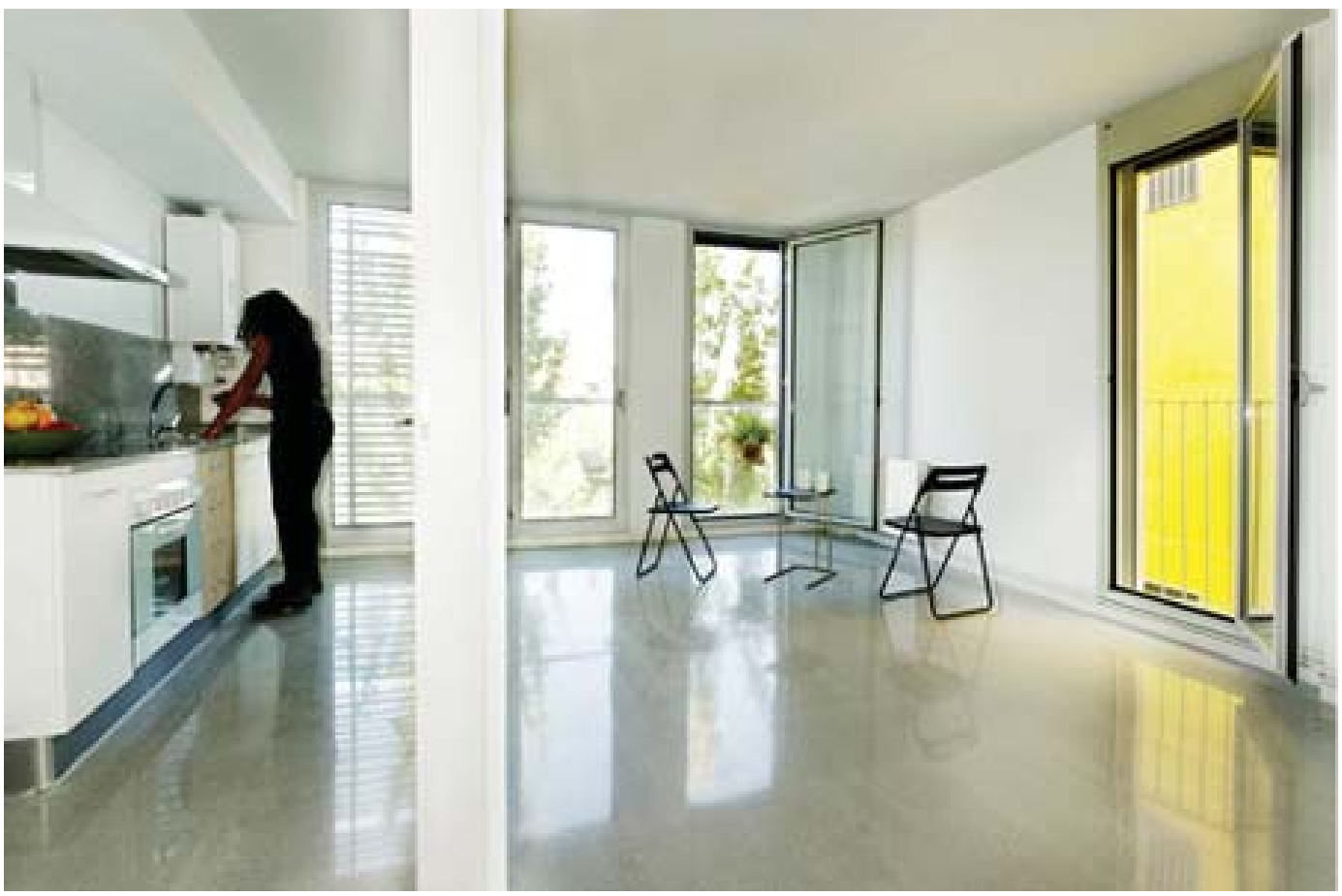

Ref.5.10. Interior de las viviendas de Hevia Meyer y Ángela Moragues , Lérida, Europan 7 
Entre ellas las principales contribuciones que realizaron podrían resumirse en tratar de definir el concepto de flexibilidad y de investigar acerca de las nuevas alternativas a los espacios en la vivienda.

Finalmente, salió a la luz la DC- $09^{4}$ en la que se intuyen algunas de las sugerencias que aportaron los equipos de trabajo de Europan 8, sobre todo cuando habla de la posibilidad de considerar edificios experimentales, que den lugar a la investigación en vivienda.

En definitiva, para poder investigar en vivienda, la normativa debería permitirlo de algún modo de tal forma que agilice el proceso de la construcción y garantice los mínimos vitales sin encorsetar la creatividad. La Administración Pública es un signo de contradicción ya que, por un lado impulsa a la construcción con el ofrecimiento de nuevos solares y, por el otro la paraliza a través de la normativa existente cuando esas ideas quieren ser llevadas a cabo ${ }^{5}$.

"Han pasado veinte años. Para todo. Para todos. Veinte años que son diez convocatorias de Europan. Que son y han sido el tránsito de un concurso que ha recorrido una andadura desde una Europa de nueve hasta una Europa de diecisiete. Veinte años para quien, como yo, comenzaba como arquitecto joven en su participación en aquel primer Europan y termina como Jurado de la décima convocatoria,(...). Son, sin embargo, pocos los que han realizado el camino completo; cumplido el objetivo básico, el determinante, aquello que nos empujaba a participar: construir"".

A continuación se adjunta una ficha resumen con todos los edificios de vivienda social construidos hasta el momento y que se han analizado previamente.

${ }^{4}$ DECRETO 151/2009, de 2 de octubre, del Consell de la Generalitat Valenciana, por el que se aprueban las exigencias básicas de diseño y calidad en edificios de vivienda y de alojamiento el ámbito de la Comunidad Valenciana.

ORDEN de 7 de diciembre de 2009, de la Consellería de Medio Ambiente, Agua y Urbanismo, por la que se aprueba las condiciones de diseño y calidad en desarrollo del Decreto 151/2009 de 2 de octubre, del Consell.

${ }^{5}$ Algunos de los proyectos que no se han realizado son: Europan 2 (Caravaca de la Cruz), Europan 3 (Alguazas y Alicante), Europan 4 (Aranda del Duero), Europan 5 (Cartagena), Europan 6 (Toledo), Europan 8 (Valladolid, Logroño y Alcazar de San Juan), etc.

" GARCÍA SOLERA, Javier. "Nuevos Caminos" en AA.VV. Europan 10, Proyectar la urbanidad, colonización/revitalización/regeneración, Ed. Secretariado de Europan. Madrid. 2010. p.209 

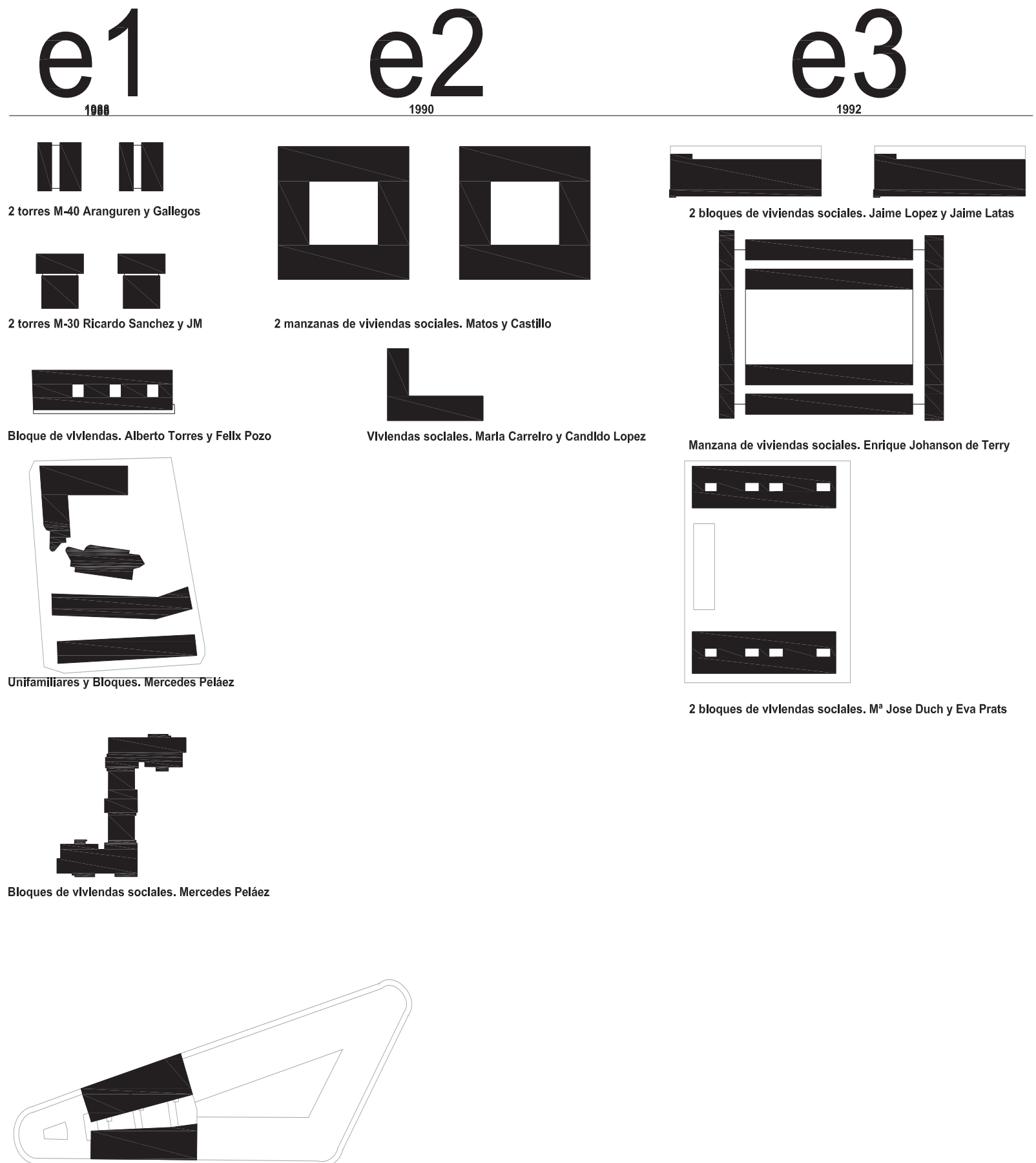

Bloques de viviendas sociales. Isabel B y Ana $\mathrm{M}^{\mathrm{a}} \mathrm{N}$

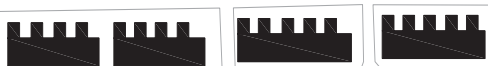


FICHA RESUMEN

\section{EUROPAN 1-7 \\ $E: 1 / 2500$}

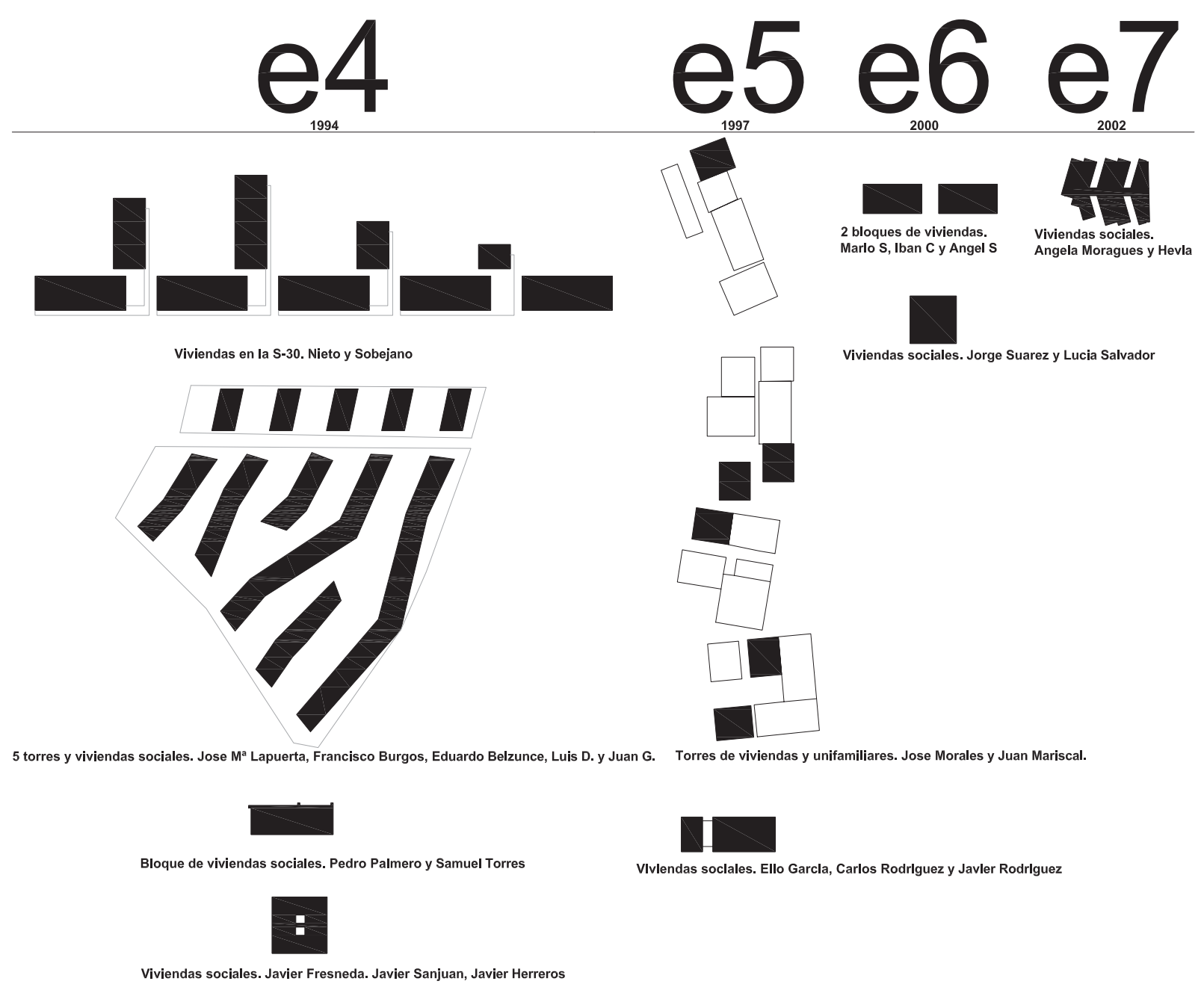


VIVIENDAS EUROPAN (1988-2008) I Una aproximación a los modos de vida en el cambio de siglo en España

5. ALGUNAS APORTACIONES DE EUROPAN A LA VIVIENDA

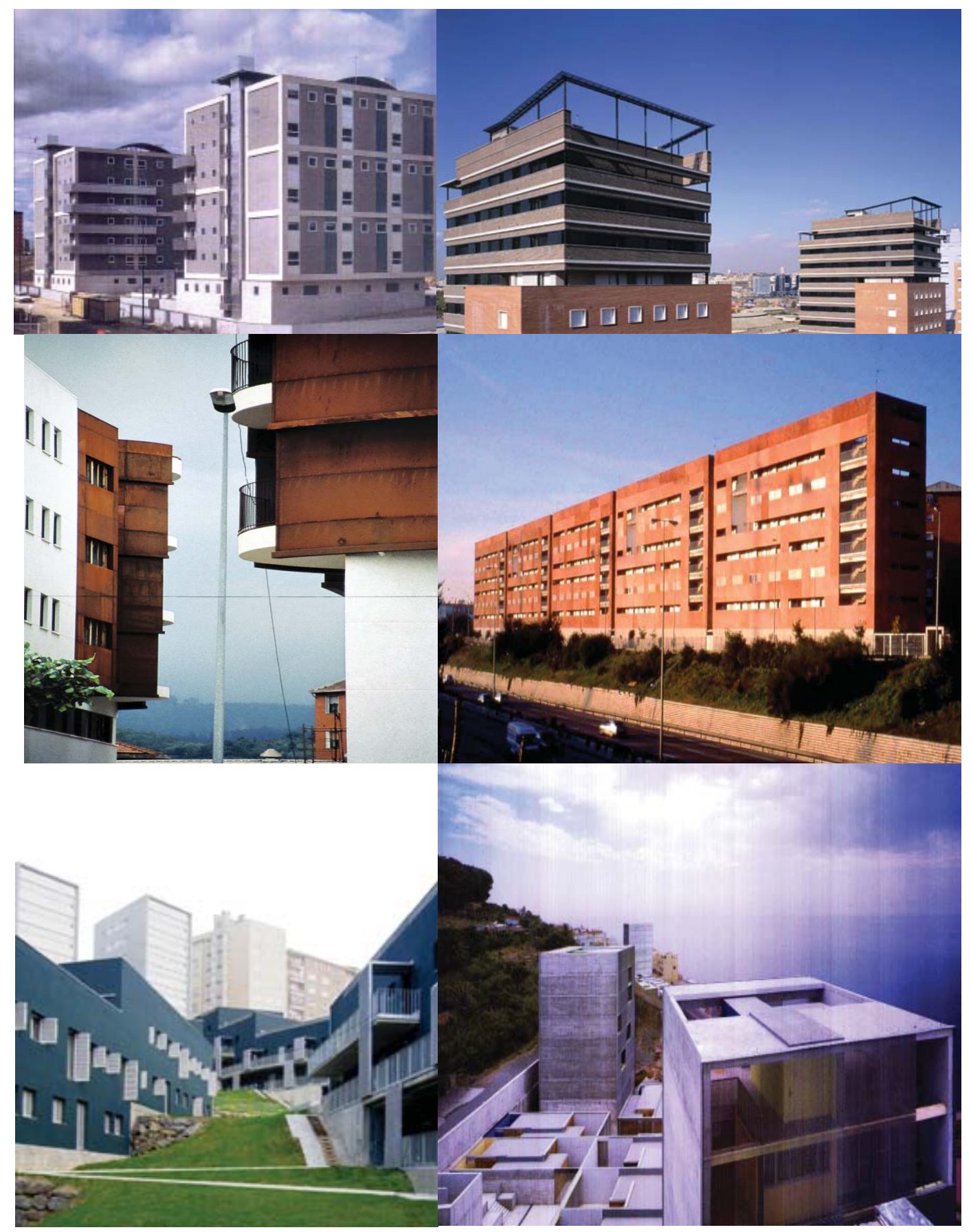

Ref.5.11. Edificios de viviendas sociales construidos como el planteamiento de concurso 


\subsection{Europan y las realizaciones}

Una de las principales aportaciones de Europan han sido las realizaciones.

Con los datos recopilados de cada edificio de viviendas se han elaborado unas tablas compararativas que permiten tener una visión de conjunto y de las que se extraen algunas conclusiones. Estas tablas comparativas se han realizado con el criterio de las tres escalas diferenciadas que propone Europan: la de la propuesta urbana, la propuesta de edificio y la propuesta de vivienda.

\section{Propuesta urbana}

En la propuesta urbana se toman como parámetros comparativos:

- El emplazamiento de concurso. Por lo general, si el emplazamiento de concurso varía, el proyecto que se construye también varía con respecto al que se presentó a concurso. Este parámetro indica en gran medida el grado de compromiso de la Administración Pública.

- Las modificaciones en el planeamiento. Con este parámetro se puede medir si el la obra construida ha tenido efectos sobre la normativa de la ciudad.

- El área de actuación. Este factor indica si se ha actuado sobre un solar determinado o se ha ampliado hacia algún espacio público determinado.

- El diálogo con el entorno urbano. Este indicador ayuda a valorar la influencia sobre el entorno de las obras realizadas.

\begin{tabular}{|c|c|c|c|c|}
\hline $\begin{array}{c}\text { TABLA } 5.1 . \\
\text { PROPUESTA URBANA }\end{array}$ & \begin{tabular}{|c|} 
Mismo \\
emplazamiento que \\
concurso
\end{tabular} & $\begin{array}{c}\text { Modifica } \\
\text { planeamiento }\end{array}$ & Area de actuación & $\begin{array}{c}\text { La actuación dialoga } \\
\text { con el entorno } \\
\text { urbano }\end{array}$ \\
\hline \multicolumn{5}{|l|}{ EUROPAN 1 (1988) } \\
\hline 1.1. Torres en Madrid & No & No & Solar residencial & No \\
\hline 1.2. Torres en Madrid & $\mathrm{Si}$ & No & Solar residencial & Si, parque frontal \\
\hline 1.3. Bloque en Zafra & $\mathrm{Si}$ & No & Solar residencial & No \\
\hline 1.4. Manzana en Vallecas & No & No & Solar residencial y "plaza" & No \\
\hline 1.5. Manzana en Ujo & No & No & Solar residencial & No \\
\hline 1.6. Bloque en Pravia & No & No & Solar residencial & No \\
\hline 1.7. Adosadas en Vallecas & No & No & Solar residencial y "recorridos" & $\mathrm{Si}$, recorrido lineal \\
\hline \multicolumn{5}{|l|}{ EUROPAN 2 (1990) } \\
\hline 2.1. Manzanas en Basauri & $\mathrm{Si}$ & No & Solar residencial y "plaza" & $\mathrm{Si}$, parque frontal \\
\hline 2.2. Manzana en Ferrol & No & No & Solar residencial & No \\
\hline \multicolumn{5}{|l|}{ EUROPAN 3 (1992) } \\
\hline 3.1. Bloques en Madrid & No & No & Solar residencial & Si, "plaza" frontal \\
\hline 3.2. Manzana en Granada & No & No & Solar residencial y "plaza" & No \\
\hline 3.3. Bloques en Guissona & No & No & Solar residencial y "plaza" & Si, plaza interior abierta \\
\hline \multicolumn{5}{|l|}{ EUROPAN 4 (1994) } \\
\hline 4.1. Manzana en Sevilla & $\mathrm{Si}$ & No & Solar residencial y "plaza" & Si, plazas abiertas \\
\hline 4.2. Torre y bloques en Bilbao & $\mathrm{Si}$ & No & Solar residencial y "parque" & $\mathrm{Si}$, recorridos interiores \\
\hline 4.3. Bloque en Aviles & No & No & Solar residencial & No \\
\hline 4.4. Bloque en Aviles & No & No & Solar residencial & No \\
\hline \multicolumn{5}{|l|}{ EUROPAN 5 (1997) } \\
\hline 5.1. Torres y unif.s en Ceuta & $\mathrm{Si}$ & No & Solar residencial y "plaza" & Si, plazas y recorridos \\
\hline 5.2. Bloque en Aviles & No & No & Solar residencial & No \\
\hline \multicolumn{5}{|l|}{ EUROPAN 6 (2000) } \\
\hline 6.1. Bloque en Avilés & No & No & Solar residencial & No \\
\hline 6.2. Bloque en Avilés & No & No & Solar residencial & No \\
\hline \multicolumn{5}{|l|}{ EUROPAN 7 (2002) } \\
\hline 7.1. Manzana en Lerida & No & No & Solar residencial & No \\
\hline
\end{tabular}



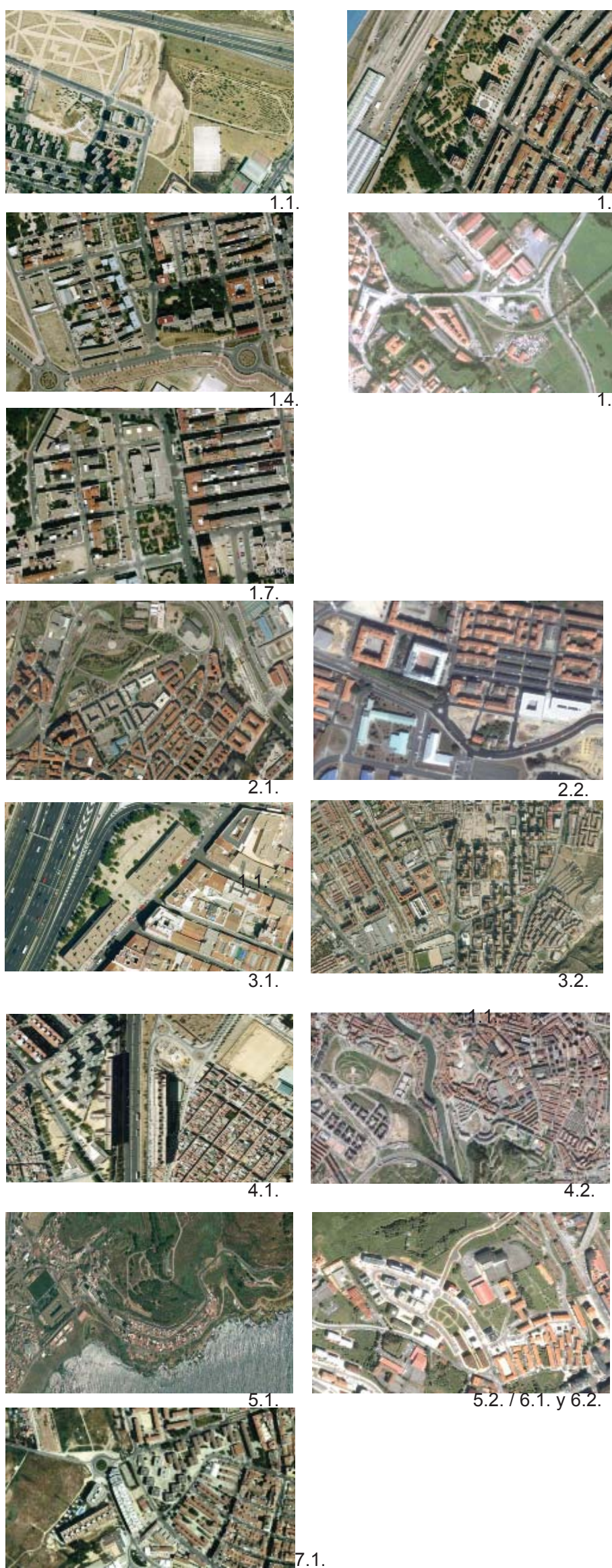

Ref. 5.12.Emplazamientos de lapropuesta urbana 354

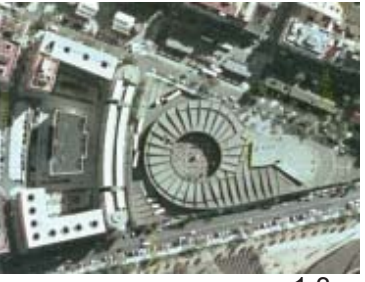

1.3.
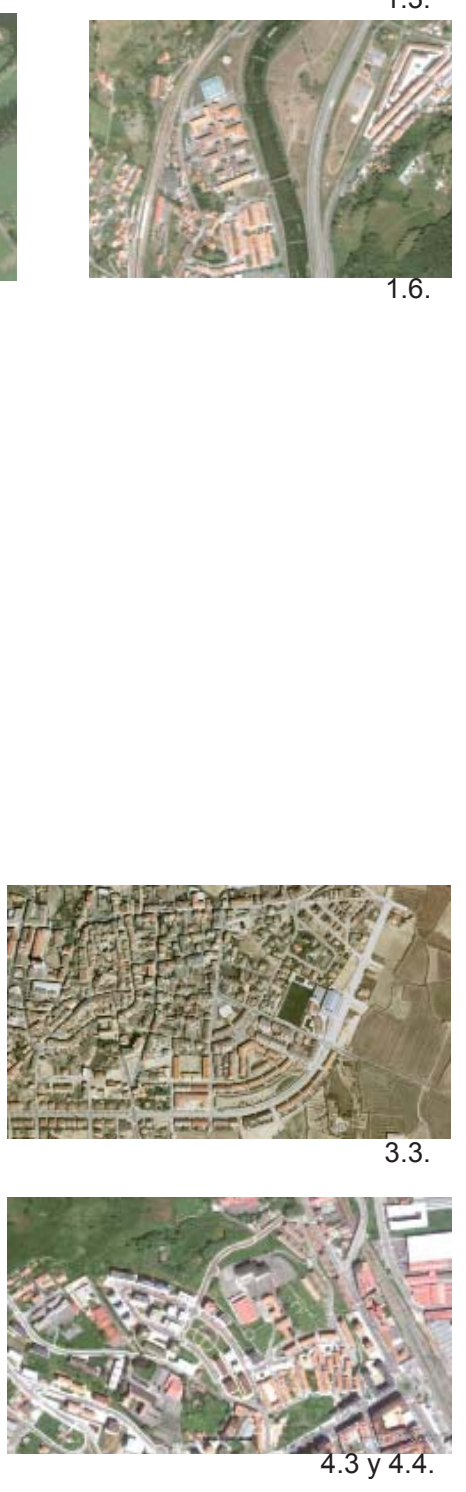
Como resultados generales, se pueden obtener los siguientes:

Con respecto al emplazamiento, un $28 \%$ de los proyectos que se han construido lo han mantenido ${ }^{7}$. Lo que indica que es complicado que la Administración Pública lleve a término lo que propusieron en un primer momento.

Con respecto a la modificación de la normativa, cabe decir que el $100 \%$ de lo construido hasta el momento se ha adaptado a la normativa existente. Tal vez también por este motivo se construyen pocos proyectos de concurso.

En cuanto al área de actuación se deduce de los resultados obtenidos que ésta se reduce la mayoría de veces al solar de las viviendas.

Por último, un 33\% de las obras construidas dialogan con el entorno, abriéndose hacia él y relacionándose con la ciudad.

\section{Propuesta edificio}

En esta escala se toman como parámetros:

- Los usos de cada planta. Se ha diferenciado por cotas $-1,0$ y superiores. Este factor es un indicador de las posibilidades reales de hibridación en cada obra.

- El porcentaje entre zonas comunes sobre la superficie total de la planta. Este parámetro permite identificar la cantidad de espacio de relación entre los habitantes dentro de un mismo edificio.

- La materialización de la envolvente y de la estructura. Estos factores permiten extraer resultados de los sistemas constructivos empleados en los edificios.

\footnotetext{
${ }^{7}$ Los edificios de vivienda construidos que se corresponden con el proyecto de concurso no abundan. A saber, las únicas ediciones que lo han logrado son cuatro hasta el momento, con seis proyectos:

- Europan 1: se realizan como en el concurso las dos torres de Aranguren y Gallegos y otras dos de Ricardo Sánchez y José $\mathrm{M}^{\mathrm{a}}$ Escobar en Madrid.

- Europan 2: se realizan como en el concurso dos manzanas de vivienda social en Bilbao. el proyecto de Matos y Castillo.

- Europan 4: se realizan como en el concurso el bloque de viviendas sociales de Nieto y Sobejano en Sevilla y la manzana en Bilbao de Eduardo Belzunce, Luis Díaz y Juan García junto con Jose Ma Lapuerta y Francisco Burgos.

- Europan 5: se realizan como en el concurso las viviendas sociales en Ceuta de José Morales y Juan Mariscal.
} 
VIVIENDAS EUROPAN (1988-2008) I Una aproximación a los modos de vida en el cambio de siglo en España 5. ALGUNAS APORTACIONES DE EUROPAN A LA VIVIENDA

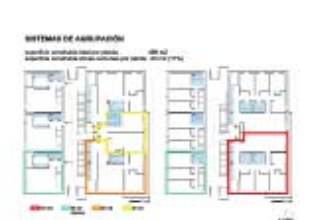

1.1.
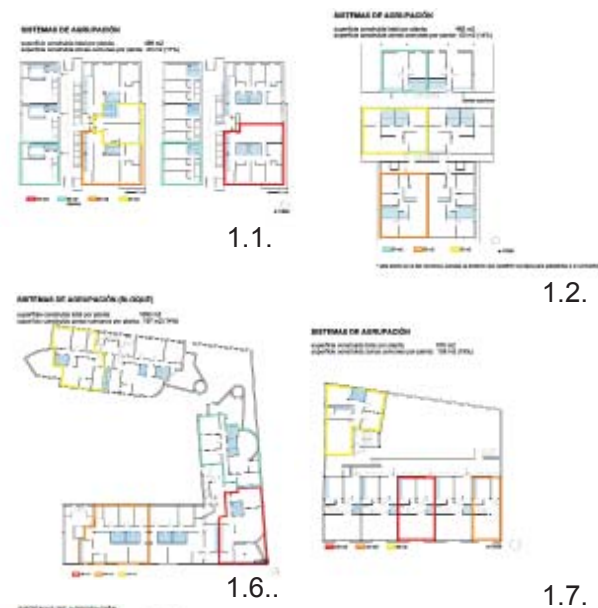

1.6.

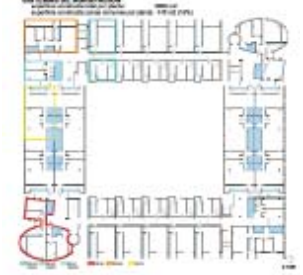

2.1.

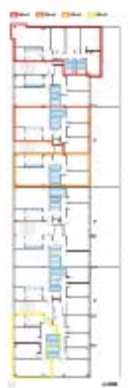

3.1.

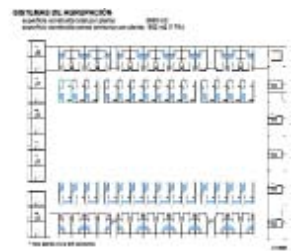

3.2 .
1.7.

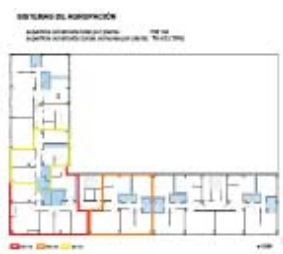

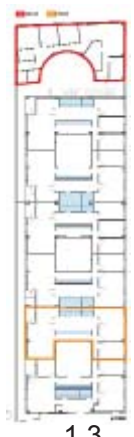

1.3.

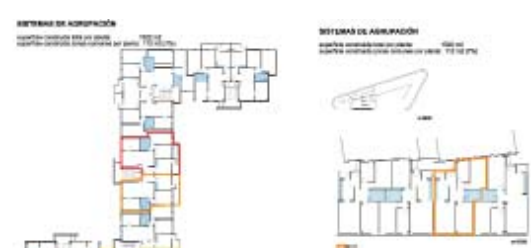

1.4
1.5.

2.2 .
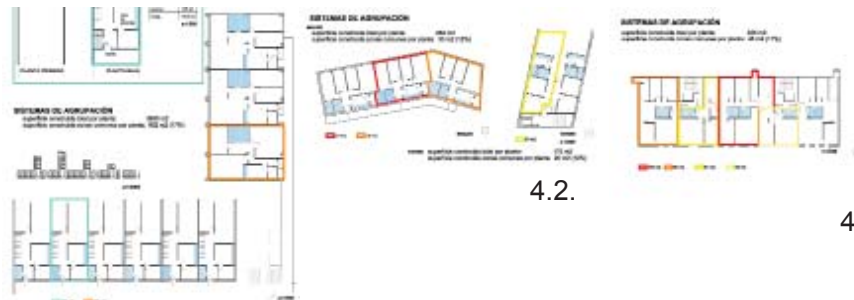

4.3.

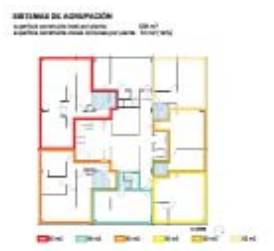

4.4 .

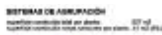
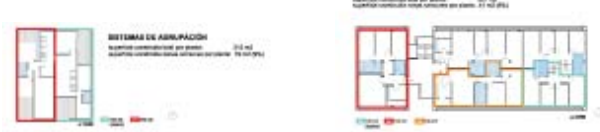

5.1.

5.2.
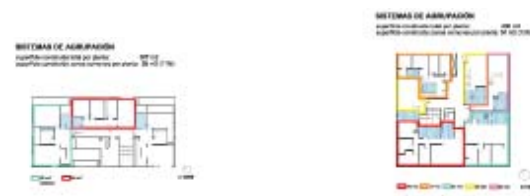

6.1.

6.2.

$\equiv$

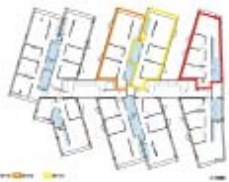

7.1

Ref. 5.13. Propuesta de edificios

356 


\begin{tabular}{|c|c|c|c|c|c|c|}
\hline $\begin{array}{l}\text { TABLA 5.2. PROPUESTA } \\
\text { EDIFICIO }\end{array}$ & $\begin{array}{l}\text { Uso } \\
\text { sótano }\end{array}$ & $\begin{array}{l}\text { Uso planta } \\
\text { baja }\end{array}$ & $\begin{array}{l}\text { Uso plantas } \\
\text { superiores }\end{array}$ & $\begin{array}{l}\% \text { Sup } \\
\text { zc/sup } \\
\text { total }\end{array}$ & Envolvente & Estructura \\
\hline \multicolumn{7}{|l|}{ EUROPAN 1 (1988) } \\
\hline 1.1. Torres en Madrid & Garaje & Viv/comercial & Vivienda & $17 \%$ & Hormigón prefab & Hormigón \\
\hline 1.2. Torres en Madrid & Garaje & Comercial & Vivienda & $14 \%$ & Doble ceramica & Hormigón \\
\hline 1.3. Bloque en Zafra & Garaje & Comercial & Vivienda & $16 \%$ & Doble ceramica & Hormigón \\
\hline 1.4. Manzana en Vallecas & Garaje & Vivienda & Vivienda & $14 \%$ & Doble ceramica+enf & Hormigón \\
\hline 1.5. Manzana en Ujo & Garaje & Comercial & Vivienda & $7 \%$ & Doble ceramica & Hormigón \\
\hline 1.6. Bloque en Pravia & Garaje & Comercial & Vivienda & $7 \%$ & Doble ceramica & Hormigón \\
\hline 1.7. Adosadas en Vallecas & Garaje & Vivienda & Vivienda & $19 \%$ & Doble ceramica+enf & Hormigón \\
\hline \multicolumn{7}{|l|}{ EUROPAN 2 (1990) } \\
\hline 2.1. Manzanas en Basauri & Garaje & Viv/comercial & Vivienda & $16 \%$ & Doble ceramica+enf & Hormigón \\
\hline 2.2. Manzana en Ferrol & Garaje & Comercial & Vivienda & $10 \%$ & Cerámica+ panel & Hormigón \\
\hline \multicolumn{7}{|l|}{ EUROPAN 3 (1992) } \\
\hline 3.1. Bloques en Madrid & Garaje & Comercial & Vivienda & $7 \%$ & Doble ceramica & Hormigón \\
\hline 3.2. Manzana en Granada & Garaje & Comercial & Vivienda & $17 \%$ & Doble ceramica & Hormigón \\
\hline 3.3. Bloques en Guissona & - & Viv/comercial & Vivienda & $7 \%$ & Doble ceramica & Hormigón \\
\hline \multicolumn{7}{|l|}{ EUROPAN 4 (1994) } \\
\hline 4.1. Manzana en Sevilla & Garaje & Comercial & Vivienda & $17 \%$ & Ceramica+panel & Hormigón \\
\hline 4.2. Torre y bloques en Bilbao & Garaje & Viv/comercial & Vivienda & $12 \%$ & Ceramica+panel & Hormigón \\
\hline 4.3. Bloque en Aviles & Garaje & Vivienda & Vivienda & $11 \%$ & Prefabricado & Hormigón \\
\hline 4.4. Bloque en Aviles & Garaje & Vivienda & Vivienda & $14 \%$ & Ceramica+Chapa & Hormigón \\
\hline \multicolumn{7}{|l|}{ EUROPAN 5 (1997) } \\
\hline 5.1. Torres y unif en Ceuta & Garaje & Vivienda & Vivienda & $9 \%$ & Hormigón & Hormigón \\
\hline 5.2. Bloque en Aviles & Garaje & Vivienda & Vivienda & $8 \%$ & Cerámica+Prefab & Hormigón \\
\hline \multicolumn{7}{|l|}{ EUROPAN 6 (2000) } \\
\hline 6.1. Bloque en Avilés & Garaje & Vivienda & Vivienda & $11 \%$ & Cerámica+Chapa & Hormigón \\
\hline 6.2. Bloque en Avilés & Garaje & Vivienda & Vivienda & $13 \%$ & Hormigón pref & Hormigón \\
\hline \multicolumn{7}{|l|}{ EUROPAN 7 (2002) } \\
\hline 7.1. Manzana en Lerida & Garaje & Vivienda & Vivienda & $10 \%$ & Ceramica+panel & Hormigón \\
\hline
\end{tabular}

De la tabla sobre las propuestas del edificio se obtienen los resultados siguientes:

- En cuanto al tema de la hibridación, los resultados son llamativos, pues, aunque Europan haya propuesto la hibridación como uno de los temas de reflexión más recurrentes es patente que los usos son los mismos en todos los edificios, tal vez debido a la adaptación a la normativa vigente.

- En cuanto a los espacios de relación en el edificio, normalmente varía desde el $7 \%$ hasta el $19 \%$ de la superficie total en planta. Estos espacios constituyen un espacio de transición entre lo público y lo privado y los resultados muestran que ha ido disminuyendo su presencia.

-En cuanto a la materialización de la envolvente, se pasa de construir con una piel de doble hoja cerámica a la combinación del ladrillo cerámico con un panel exterior o chapa. Se ejecutan un $19 \%$ de proyectos con sistemas de construcción prefabricados en fachada.

- En cuanto a la estructura, el 100\% de los edificios se ejecutan con hormigón. 
VIVIENDAS EUROPAN (1988-2008) I Una aproximación a los modos de vida en el cambio de siglo en España 5. ALGUNAS APORTACIONES DE EUROPAN A LA VIVIENDA

703 prize-winning teams in Europe

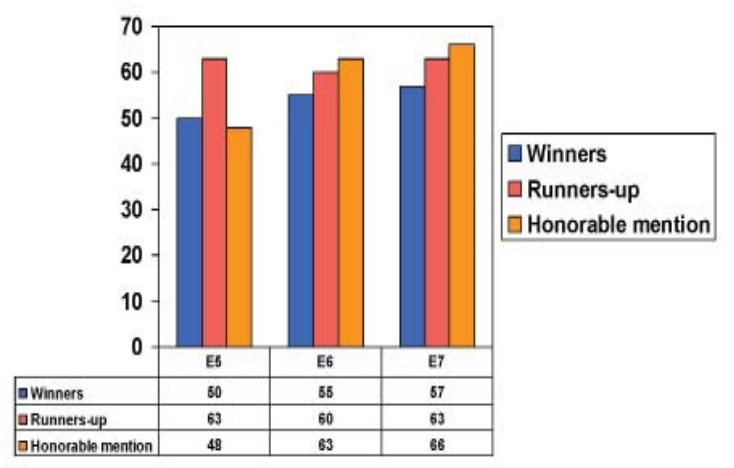

108 implementations

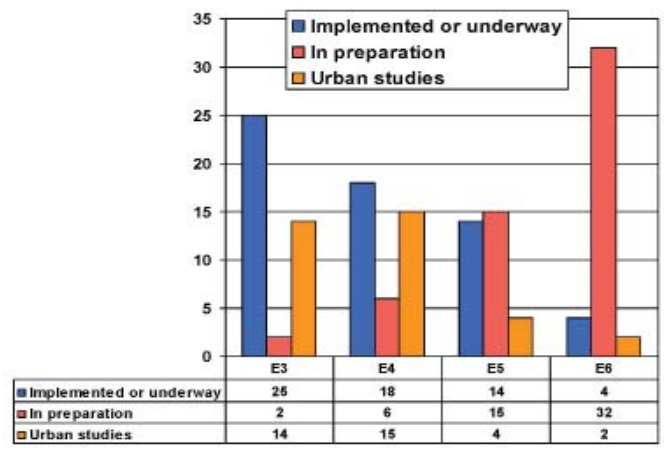

Ref. 5.14. Resultados de [On line] <http://www.europan-europe. com> (Consulta 2 de diciembre de 2011)

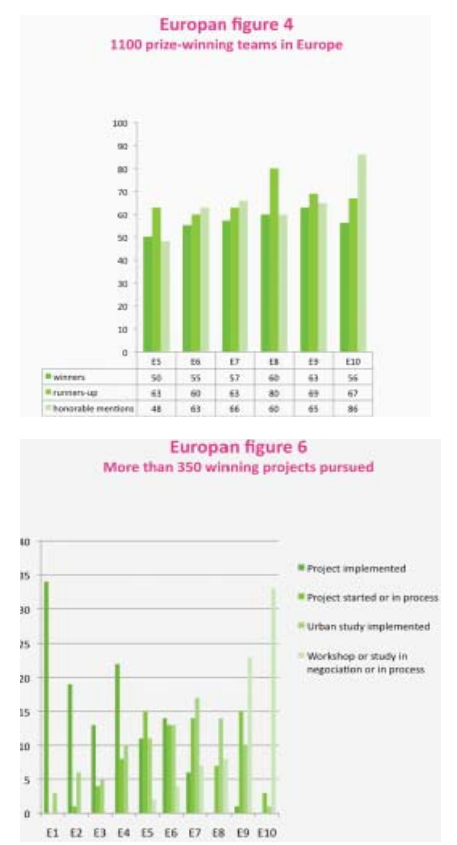

Ref.5.15. Resultados de Europan [On line] <http://www.europan-europe.com> (Consulta 2 de diciembre de 2011) 


\section{Propuesta vivienda}

En esta escala se seleccionan los siguientes parámetros:

- El número de espacios y superficie de la vivienda mayor. Con este dato se determina la evolución del número de espacios dentro de la vivienda y de la superficie construida en los que se inscriben (estos espacios no incluyen taller de alimentos ni zonas húmedas).

- El porcentaje de espacio de circulación sobre la superficie total. Este parámetro permite comprobar la evolución de los denominados pasillos en la vivienda.

- La relación del estar con el taller de alimentos es un factor que indica la posibilidad de transformación de estos espacios en uno solo. Próximo, continuo o unido.

- La existencia de un espacio de lavado y tendido.

- El número de cuartos húmedos.

- La flexibilidad de los tabiques indica la posibilidad de realizar distintas combinaciones de espacios dentro de la vivienda.

Cabe apuntar que en la mayoría de los edificios de vivienda se ha utilizado el término flexibilidad. Este concepto es muy recurrido por los arquitectos, pero casi no se sabe definir. En el Diccionario de la Real Academia Española ${ }^{8}$, la definición más aproximada de este término es la de "susceptible de cambios o variaciones según las circunstancias o necesidades". Quizá Rem Koolhaas ha sido uno de los que lo ha definido con precisión cuando afirma que "la flexibilidad es la anticipación exhaustiva a todos los cambios posibles. Muchos cambios son impredecibles. Es la creación de una capacidad de amplio margen que permite diferentes e incluso opuestas interpretaciones y usos". En este sentido también se podría hablar de adaptabilidad.

- La ventilación cruzada permite determinar la calidad de una vivienda debido a que se considera un factor que favorece la sostenibilidad.

8 "Flexible.(Del lat. flexibǐlis).1. adj. Que tiene disposición para doblarse fácilmente. 2. adj. Que en un enfrentamiento se pliega con facilidad a la opinión, a la voluntad o a la actitud de otro o de otros. Carácter, persona flexible. 3. adj. Que no se sujeta a normas estrictas, a dogmas o a trabas. Ideología, legislación flexible. 4. adj. Susceptible de cambios o variaciones según las circunstancias o necesidades. Horario, programa flexible. 5 . m. Cable formado de hilos finos de cobre recubiertos de una capa aislante, que se emplea como conductor eléctrico. 6. m. sombrero flexible". REAL ACADEMIA ESPAÑOLA. Diccionario de la Real Academia Española. 22ª Edición. Ed. Espasa-Calpé. Madrid. 2001.

${ }^{9}$ KOOLHAAS, Rem. S, M,L, XL. Ed. Klonecellipress. New York. 1995. 
VIVIENDAS EUROPAN (1988-2008) I Una aproximación a los modos de vida en el cambio de siglo en España 5. ALGUNAS APORTACIONES DE EUROPAN A LA VIVIENDA
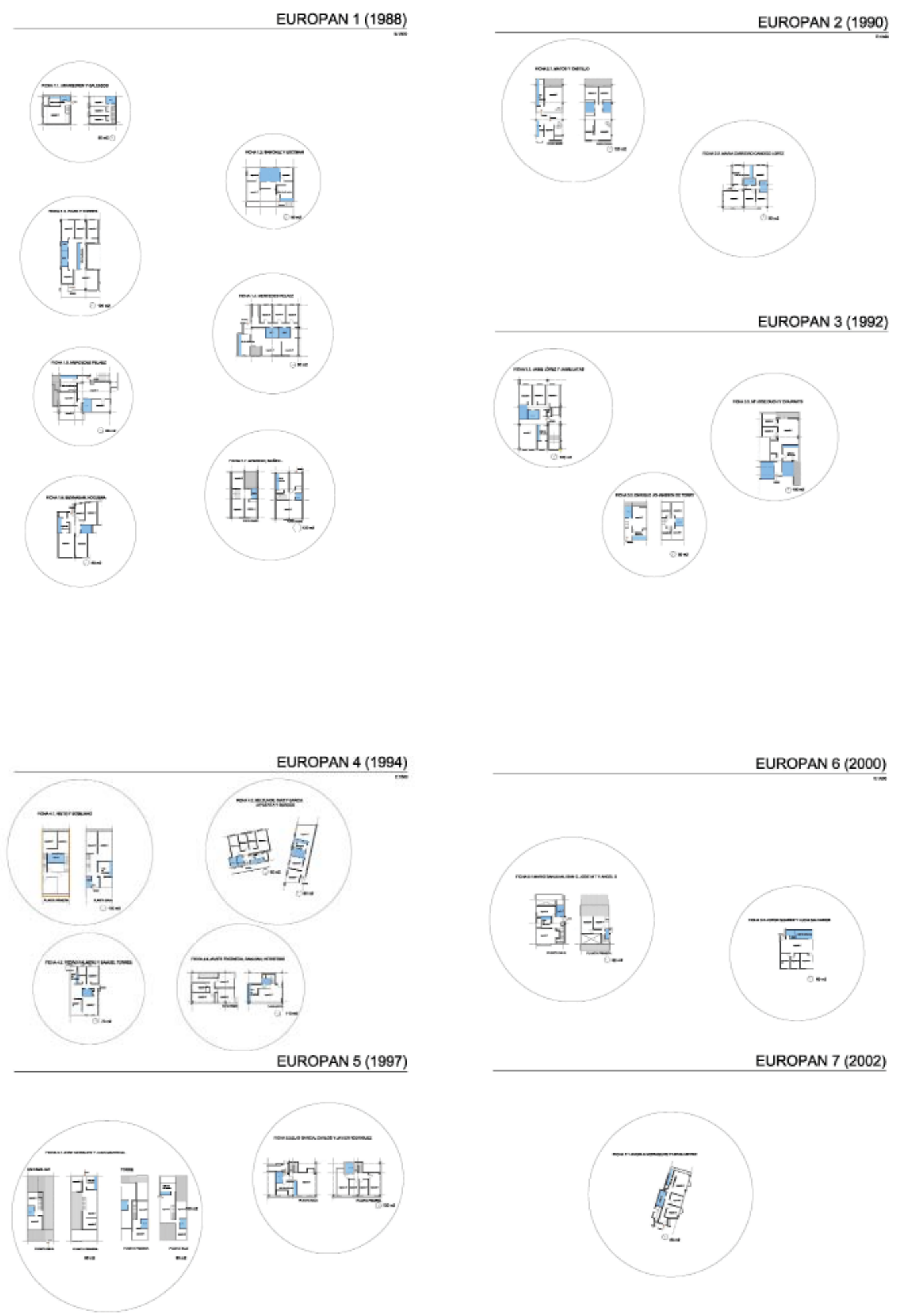

Ref. 5.16. Propuestas de viviendas 
- La iluminación natural de todas las estancias es otro factor que permite determinar la calidad de una vivienda.

\begin{tabular}{|c|c|c|c|c|c|c|c|c|}
\hline $\begin{array}{c}\text { TABLA } 5.3 . \\
\text { PROPUESTA VIVIENDA }\end{array}$ & $\begin{array}{l}\text { Número de } \\
\text { espacios/su- } \\
\text { perficie máx }\end{array}$ & $\begin{array}{l}\% \text { sup } \\
\text { circ/sup } \\
\text { total }\end{array}$ & $\begin{array}{l}\text { Relación } \\
\text { estar-taller } \\
\text { alimentos }\end{array}$ & $\begin{array}{l}\text { Lavado/ } \\
\text { Tendido }\end{array}$ & $\begin{array}{l}\text { Núcleos } \\
\text { húmedos }\end{array}$ & $\begin{array}{l}\text { Flexibi- } \\
\text { lidad } \\
\text { tabiques }\end{array}$ & $\begin{array}{l}\text { Ventilación } \\
\text { cruzada }\end{array}$ & $\begin{array}{l}\text { Luz natural } \\
\text { en estancias }\end{array}$ \\
\hline \multicolumn{9}{|l|}{ EUROPAN 1 (1988) } \\
\hline 1.1. Torres en Madrid & $5 / 100 \mathrm{~m} 2$ & $11 \%$ & Proximo & $\mathrm{Si}$ & 2 & No & No & $\mathrm{Si}^{*}$ \\
\hline 1.2. Torres en Madrid & $3 / 90 \mathrm{~m} 2$ & $11 \%$ & Continuo & No & 2 & No & No & $\mathrm{Si}^{*}$ \\
\hline 1.3. Bloque en Zafra & $5 / 120 \mathrm{~m} 2$ & $18 \%$ & Proximo & No & 2 & No & $\mathrm{Si}$ & $\mathrm{Si}^{*}$ \\
\hline 1.4. Manzana en Vallecas & $5 / 150 \mathrm{~m} 2$ & $20 \%$ & Proximo & $\mathrm{Si}$ & 2 & No & $\mathrm{Si}$ & $\mathrm{Si}^{*}$ \\
\hline 1.5. Manzana en Ujo & $6 / 190 \mathrm{~m} 2$ & $6 \%$ & Proximo & $\mathrm{Si}$ & 1 & No & No & $\mathrm{Si}^{*}$ \\
\hline 1.6. Bloque en Pravia & $4 / 90 \mathrm{~m} 2$ & $13 \%$ & Continuo & $\mathrm{Si}$ & 1 & No & $\mathrm{Si}$ & $\mathrm{Si}$ \\
\hline 1.7. Adosadas en Vallecas & $4 / 110 \mathrm{~m} 2$ & $20 \%$ & Proximo & No & 2 & No & $\mathrm{Si}$ & $\mathrm{Si}$ \\
\hline \multicolumn{9}{|l|}{ EUROPAN 2 (1990) } \\
\hline 2.1. Manzanas en Basauri & $5 / 120 \mathrm{~m} 2$ & $8 \%$ & Proximo & $\mathrm{Si}$ & 2 & $\mathrm{Si}$ & $\mathrm{Si}$ & $\mathrm{Si}^{*}$ \\
\hline 2.2. Manzana en Ferrol & $4 / 100 \mathrm{~m} 2$ & $8 \%$ & Proximo & $\mathrm{Si}$ & 2 & $\mathrm{Si}$ & $\mathrm{Si}$ & $\mathrm{Si}^{*}$ \\
\hline \multicolumn{9}{|l|}{ EUROPAN 3 (1992) } \\
\hline 3.1. Bloques en Madrid & $4 / 120 \mathrm{~m} 2$ & $12 \%$ & Proximo & $\mathrm{Si}$ & 2 & No & $\mathrm{Si}$ & $\mathrm{Si}^{*}$ \\
\hline 3.2. Manzana en Granada & $5 / 90 \mathrm{~m} 2$ & $14 \%$ & Continuo & $\mathrm{Si}$ & 2 & No & $\mathrm{Si}$ & $\mathrm{Si}^{*}$ \\
\hline 3.3. Bloques en Guissona & $3 / 130 \mathrm{~m} 2$ & $16 \%$ & Proximo & $\mathrm{Si}$ & 2 & No & No & $\mathrm{Si}^{*}$ \\
\hline \multicolumn{9}{|l|}{ EUROPAN 4 (1994) } \\
\hline 4.1. Manzana en Sevilla & $4 / 130 \mathrm{~m} 2$ & $18 \%$ & Proximo & $\mathrm{Si}$ & 2 & No & $\mathrm{Si}$ & $\mathrm{Si}^{*}$ \\
\hline 4.2. Torre y bloques en Bilbao & $4 / 70 \mathrm{~m} 2$ & $11 \% / 15 \%$ & Proximo & $\mathrm{Si}$ & 1 & No & No & $\mathrm{Si}$ \\
\hline 4.3. Bloque en Aviles & $4 / 80 \mathrm{~m} 2$ & $21 \%$ & Proximo & No & 1 & $\mathrm{Si}$ & $\mathrm{Si}$ & $\mathrm{Si}^{*}$ \\
\hline 4.4. Bloque en Aviles & $5 / 90 \mathrm{~m} 2$ & $19 \%$ & Unido & $\mathrm{Si}$ & 1 & $\mathrm{Si}$ & No & $\mathrm{Si}^{*}$ \\
\hline \multicolumn{9}{|l|}{ EUROPAN 5 (1997) } \\
\hline 5.1. Torres y unif en Ceuta & $5 / 100 \mathrm{~m} 2$ & $5 \% / 6 \%$ & Proximo & $\mathrm{Si}$ & 2 & $\mathrm{Si}$ & $\mathrm{Si}$ & $\mathrm{Si}^{*}$ \\
\hline 5.2. Bloque en Aviles & $5 / 120 \mathrm{~m} 2$ & $12 \%$ & Proximo & $\mathrm{Si}$ & 2 & No & No & $\mathrm{Si}^{*}$ \\
\hline \multicolumn{9}{|l|}{ EUROPAN 6 (2000) } \\
\hline 6.1. Bloque en Avilés & $4 / 90 \mathrm{~m} 2$ & $21 \%$ & Proximo & $\mathrm{Si}$ & 2 & No & No & $\mathrm{Si}^{*}$ \\
\hline 6.2. Bloque en Avilés & $4 / 65 \mathrm{~m} 2$ & $21 \%$ & Proximo & $\mathrm{Si}$ & 1 & No & No & $\mathrm{Si}^{*}$ \\
\hline \multicolumn{9}{|l|}{ EUROPAN 7 (2002) } \\
\hline 7.1. Manzana en Lerida & $4 / 65 \mathrm{~m} 2$ & $16 \%$ & Continuo & $\mathrm{Si}$ & 1 & $\mathrm{Si}$ & No & $\mathrm{Si}^{*}$ \\
\hline
\end{tabular}

De la tabla de las propuestas de viviendas se obtienen los siguientes resultados:

- Respecto al número de espacios (no incluyen taller de alimentos ni zonas húmedas) la mayoría de las viviendas tienen 4 espacios y una superficie media de $100 \mathrm{~m} 2$, disminuyendo aproximadamente la mitad de superficie en las últimas convocatorias, pero no el número de los espacios, lo que indica que siguen existiendo las mismas necesidades resolviéndose en menos espacio.

- El porcentaje de espacios de circulación en las viviendas varía entre un $6 \%$ y un $21 \%$ con respecto a la superficie total. En las últimas convocatorias, este espacio de circulación no ha disminuido, sino que ha aumentado con unas proporciones que le permiten ser una estancia más de la vivienda.

- En el 90\% de las viviendas el espacio de estar está próximo al espacio del taller de alimentos. 


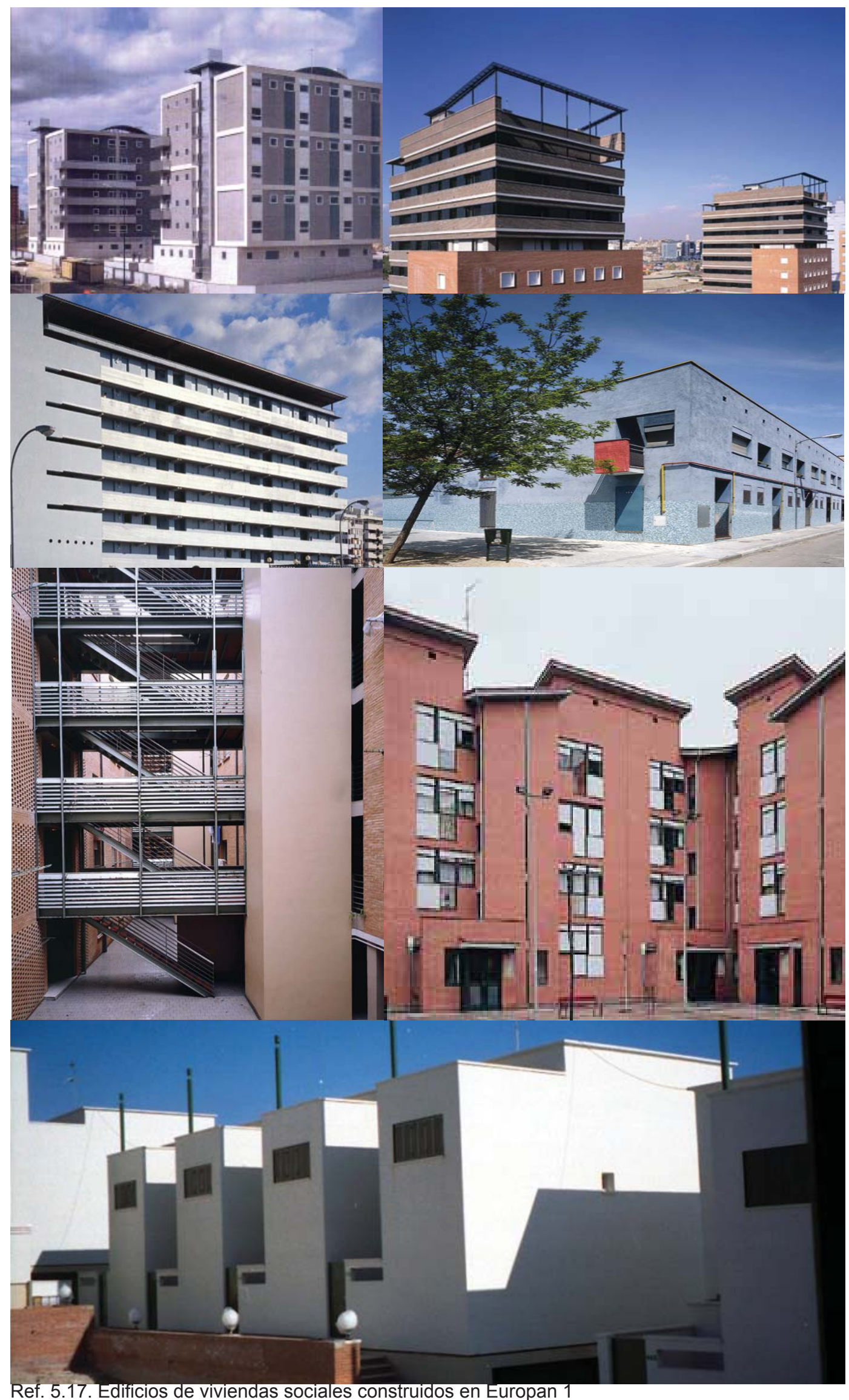


- En el $80 \%$ de las viviendas existe un espacio para lavado y tendido.

- El 66\% de las viviendas tienen dos núcleos húmedos.

- Tan sólo un $28 \%$ de las viviendas plantean la flexibilidad mediante la movilidad en algunos de sus tabiques.

- Sólo el 52\% plantean viviendas con ventilación cruzada.

- El 90\% de las viviendas tienen iluminación natural en todas las estancias, excepto en los núcleos húmedos, que se resuelven mediante la ventilación forzada.

A la vista de los resultados se percibe que existen ciertas similitudes en las viviendas construidas y que, ciertamente, ha habido poca evolución en los planteamientos de éstas.

\subsubsection{Europan 1}

La primera edición de Europan plantea en la convocatoria de concurso un enunciado de carácter general con cuestiones amplias sobre los modos de habitar (uno de los temas fundamentales que se planteaban era la evolución de los modos de vida, desde el espacio interior de las viviendas, como se ha comentado en el apartado 3.2.1. cuando se identificaban los temas de investigación de cada convocatoria).

En los paneles de concurso presentados pues en éstos se pueden encontrar ciertas similitudes. En primer lugar, se podría decir que existe una homogeneidad en el grafismo y los medios de representación. Predomina el blanco y negro, las perspectivas a mano y el modo tradicional de dibujo técnico: la planta, los alzados y, sólo en algunos casos, la sección ${ }^{10}$ ". En segundo lugar se puede decir que, en general, son proyectos que se plantean con independencia del lugar, del contexto en el que se insertan. Se observa que apenas dialogan con la cota cero, tal vez porque el tema de concurso se basaba en la evolución de los modos de vida

\footnotetext{
10 Según afirma Ángela García de Paredes, "Europan era una ventana abierta hacia la reflexión sobre la vivienda y los nuevos modos de vida, obsoletos ya los de un movimiento moderno que ya era historia. "Modos de vida y arquitectura de la vivienda" era la reflexión para Europan 1 que catalizaba unos grupos sociales distintos a la familia tradicional que precisaban una vivienda distinta, versátil y tecnificada. La propuesta de tipos de vivienda modernos, pragmáticos y eficientes, adaptados a las necesidades de los nuevos tiempos y no a la repetición de modelos pseudo burgueses, se dibujaba en los tres paneles A1 de las primeras ediciones Europan. Era absurda la repetición del modelo, en escala comprimida, de la vivienda del pasado siglo cuando se había modificado el modo de vida de sus habitantes". GARCÍA DE PAREDES, Ángela García de Paredes. "Europan: una ventana hacia la arquitectura" en EUROPAN 10 España. Proyectar la urbanidad. Ed. Ministerio de la vivienda. Madrid. 2010. p. 221
} 


\section{EUROPAN 1 (1988)}

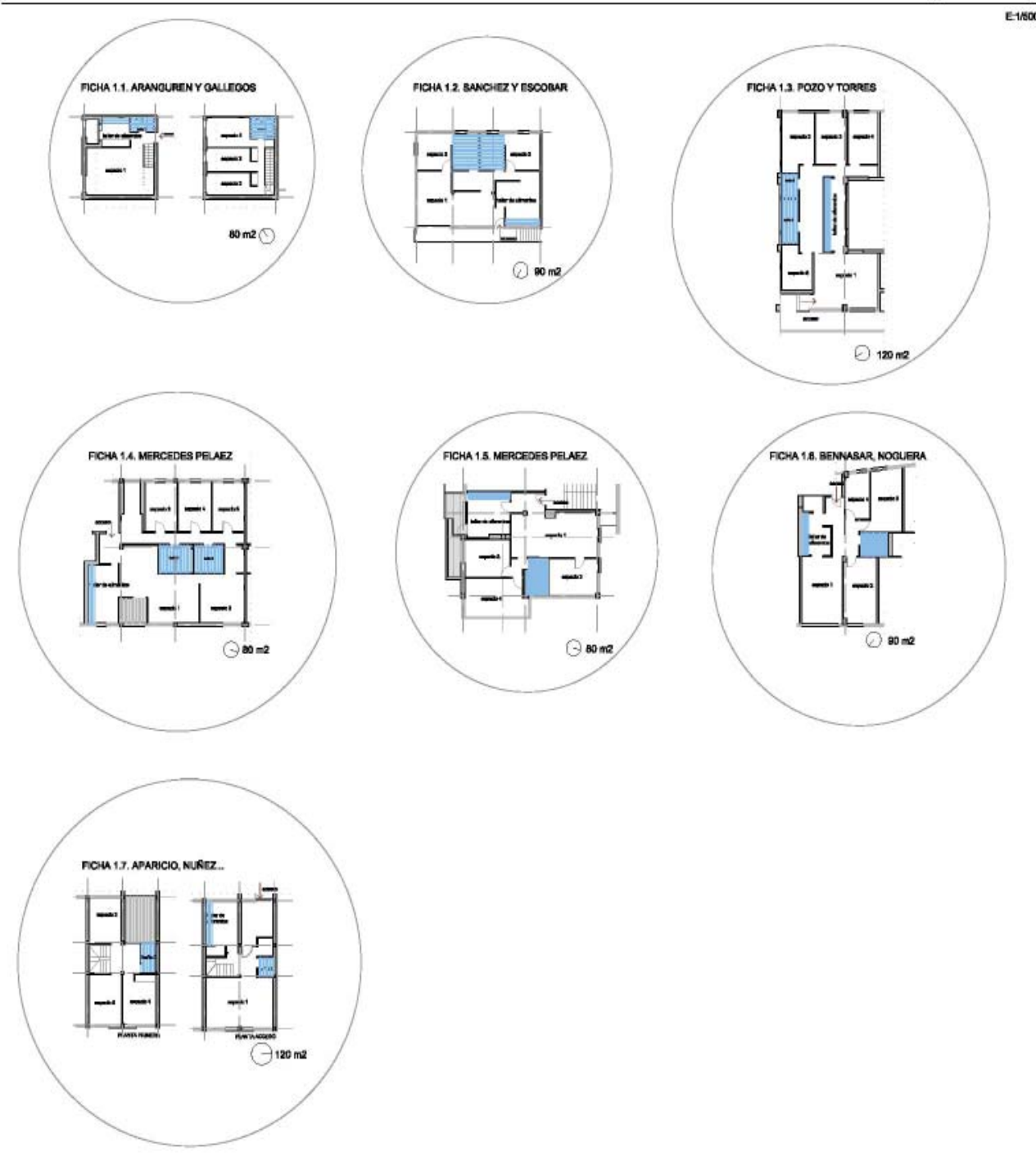

Ref. 5.18. Viviendas Europan 1 
concibiéndolo desde el espacio interior de los propios proyectos. En tercer lugar, y como consecuencia de lo anterior, los proyectos se dibujan en una escala de proyecto y no de ciudad que será la tendencia predominante del resto de las convocatorias de Europan ${ }^{11}$ ".

Europan 1 ha sido la edición en la que más obras se han construido: un tercio del total de los proyectos construidos hasta el 2008 (7/21), y esto ya es mucho. Éstas han sido previamente analizadas en el apartado 4.1 y se sitúan en los emplazamientos de Madrid (4), Asturias (2) y Huelva (1). La construcción de las viviendas sociales suele comenzar dos o tres años después del fallo de concurso.

Si se observan las viviendas propuestas, tanto en el proyecto de concurso como en la realidad, se tiende a la repetición de un estándar. Se puede afirmar que, en general predominan las viviendas grandes concebidas para familias que tienen una media de $100 \mathrm{~m} 2$. Se percibe un intento de flexibilizar la planta: moviendo tabiques y agrupando los espacios de instalaciones. En cuanto al programa, las viviendas son similares: predominan las de tres y cuatro dormitorios y una sala de estar con dos núcleos húmedos. El espacio principal -de mayor dimensión- es el de la sala de estar unida a la cocina donde se desarrolla la vida comunitaria.

Los espacios comunes suelen tener la superficie imprescindible sin derroches de metros cuadrados. Las torres de Aranguren y Gallegos y las de Ricardo Sánchez plantean una rasgadura en el volumen que divide el edificio en dos y permite tener un espacio algo más amplio para las relaciones vecinales. No obstante, salvo en el caso de Mercedes Pelaez e Isabel Bennasar en Vallecas que actúan en la ordenación interior de las manzanas, en los demás edificios se actua tan solo en el ámbito de proyecto.

El uso de los edificios es puramente residencial, dotándolo de garaje, no en todos los casos, en la planta sótano. En la planta baja por lo general existen algunos locales comerciales.

La estética de los edificios corre a cargo del buen uso del ladrillo cerámico. Son volúmenes puros y ordenados cuya composición se basa en la repetición del módulo.

Europan 1 cierra su edición con la construcción de 385 viviendas y se plantea como un ejercicio para resolver la falta de vivienda social en algunos solares concretos de las ciudades anteriormente nombradas.

11 García Solera afirma que "lo que empezó siendo un concurso para la realización de viviendas en un solar concreto y bajo una normativa realista y también concreta ha evolucionado hacia una experiencia desde la que abordar la investigación del modo que la ciudad completa se puede y debe desarrollar". GARCÍA SOLERA, Javier. "Nuevos Caminos". En en EUROPAN 10 España. Proyectar la urbanidad. Ed. Ministerio de la vivienda. Madrid. 2010. p.209. 
VIVIENDAS EUROPAN (1988-2008) I Una aproximación a los modos de vida en el cambio de siglo en España

5. ALGUNAS APORTACIONES DE EUROPAN A LA VIVIENDA

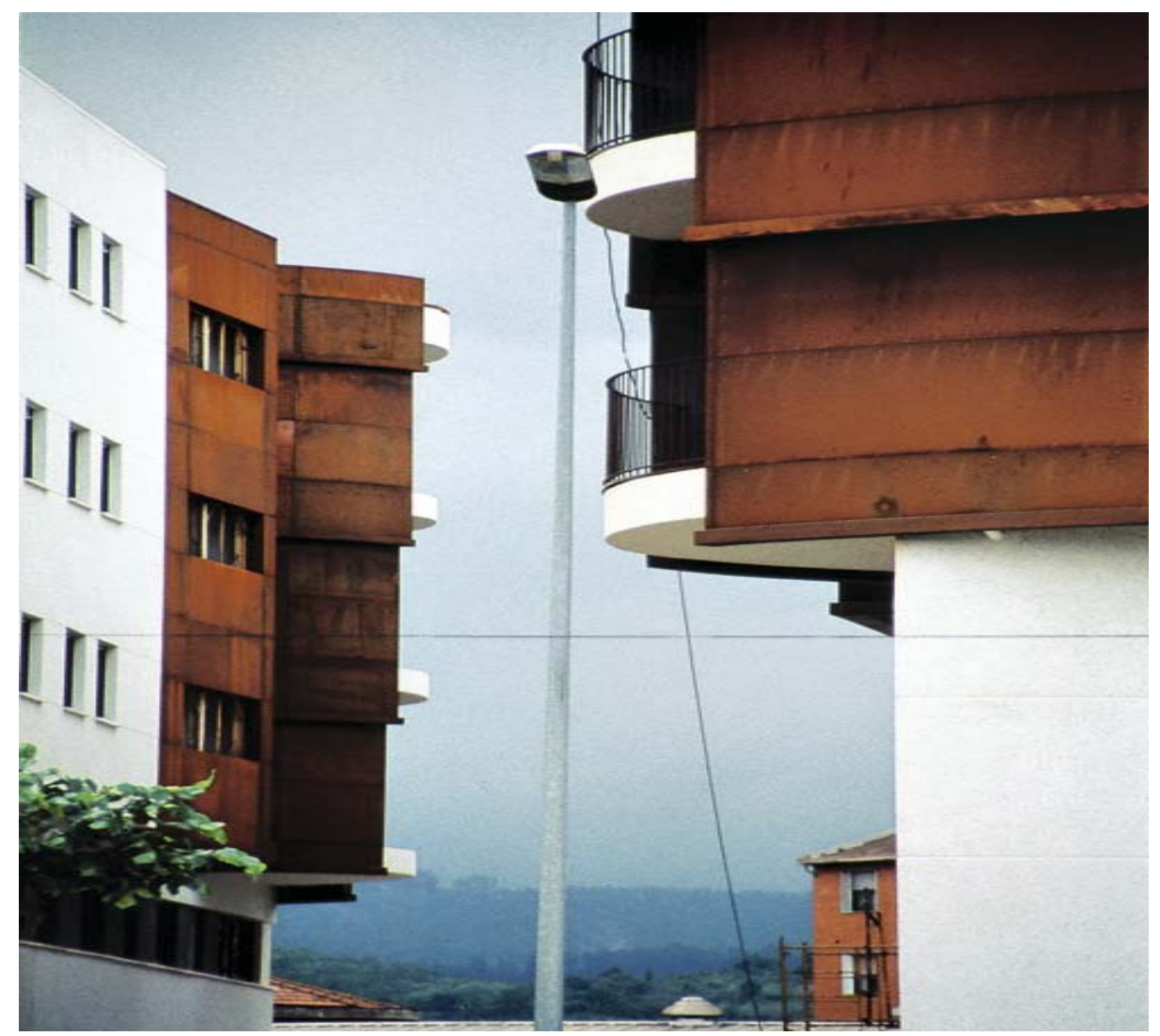

Ref. 5.19 Dos manzana de viviendas construidas de Matos y Castillo, Bilbao, Europan 2

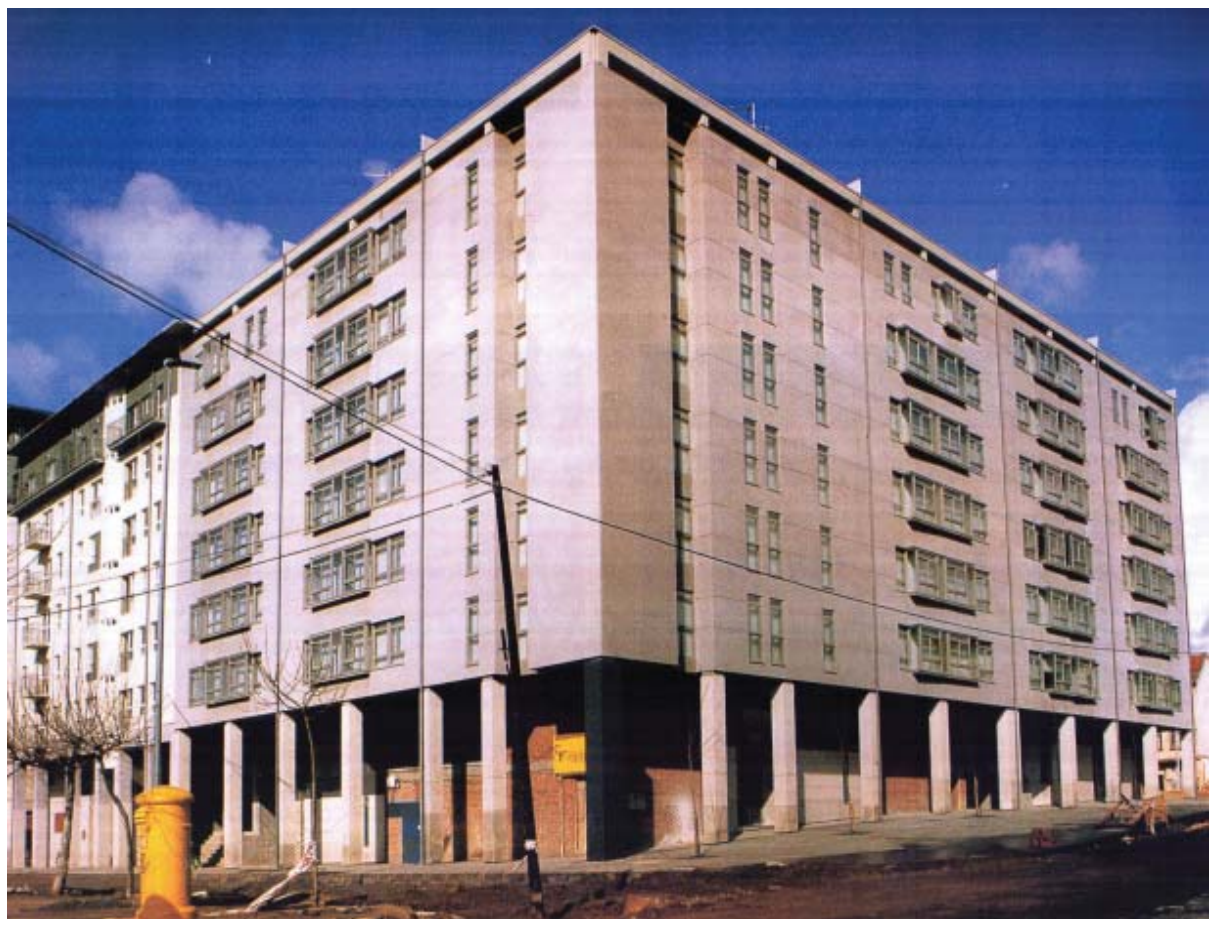

Ref. 5.20 Edificio de viviendas construido de $\mathrm{M}^{\mathrm{a}}$ Concepcion Carneiro y Cándido López, Ferrol, Europan 2 


\subsubsection{Europan 2}

El enunciado de Europan 2 plantea unos temas de investigación que abren el proyecto de arquitectura a una concepción de inserción en la ciudad. Son temas interesantes: el hábitat y los modos de vida, la dinámica urbana, la imagen de marca, el patrimonio urbano, la multifuncionalidad y las estrategias operativas (éstos se han analizado previamente en el apartado 3.2.1.).

En los paneles de concurso se puede observar, como se ha comentado con los de Europan 1, un grafismo común, aunque se empieza a vislumbrar el uso de la informática en las formas de representación ${ }^{12}$.

En Europan 2 se construyen dos obras que no pueden prescindir de su entorno, ambas con una morfología de manzana cerrada: una de ellas consta de dos manzanas en Basauri y otra de ellas es un edificio en esquina que completa la manzana existente en Ferrol. La obra de Basauri se construye en el emplazamiento previsto y es uno de los pocos que sigue fielmente el proyecto de concurso.

¿Se puede afirmar que ha habido investigación en las obras construidas de Europan 2? Por un lado, se percibe claramente que uno de los temas planteados en el concurso era el de abarcar la escala urbanística, ampliando la de los emplazamientos. Así lo manifiesta Ángela García de Paredes cuando afirma que "Europan era también una ventana abierta hacia la reflexión sobre la ciudad, el espacio de todos, "Habitar la ciudad, recualificación de emplazamientos urbanos" era el eje de Europan 2, el primer concurso que hicimos y que ganamos, estrenados Paredes y Pedrosa en 1990. La construcción de vivienda brindaba la oportunidad, más allá de la estricta resolución de un tipo, de redibujar el tejido urbano. Se trataba no solo de dar respuesta precisa a las necesidades de alojamiento que imponía la situación social, sino de valerse de la capacidad de ordenación del proyecto para articular el espacio urbano en beneficio de la ciudad, abandonando la tónica de imposición de series de construcciones impersonales fundamentadas en el cumplimiento de normativas ${ }^{13}$.

Matos y Castillo afirman que "el hecho de que sean dos manzanas es fundamental para establecer un nuevo fragmento urbano y propiciar una narración, un diálogo entre ambas. A nivel urbano, no las entendemos como dos unidades independientes: son una única intervención. Intentan crear un espacio de relación,

\footnotetext{
12 "Como afirma Ángela de García de Paredes cuando comenta que "los que participamos en Europan 2 sabíamos que estos ejemplos (Sert y Terragni) eran historia y que a través de esa ventana se intuía una nueva forma de abordar la arquitectura. Porque ya no cabían los héroes solitarios, dibujantes que trazaban sus ideas sobre papel, sino grupo de arquitectos que directamente y a través de un teclado y una pantalla dábamos forma a nuestros proyectos". GARCÍA DE PAREDES, Ángela. Ibídem p. 221.

${ }^{13}$ Ibídem.
} 


\section{EUROPAN 2 (1990)}
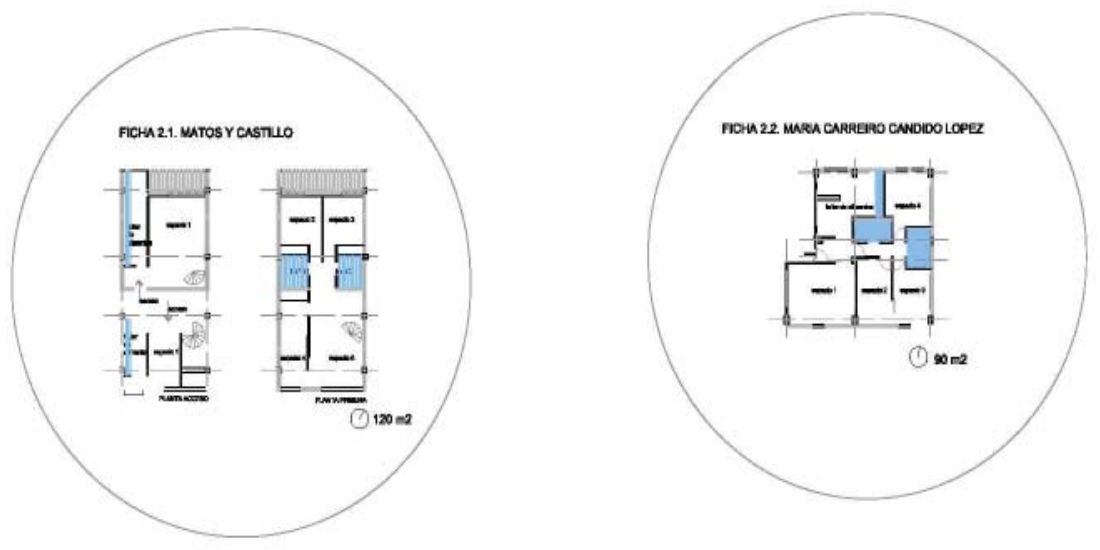

Ref. 5.21. Viviendas Europan 2

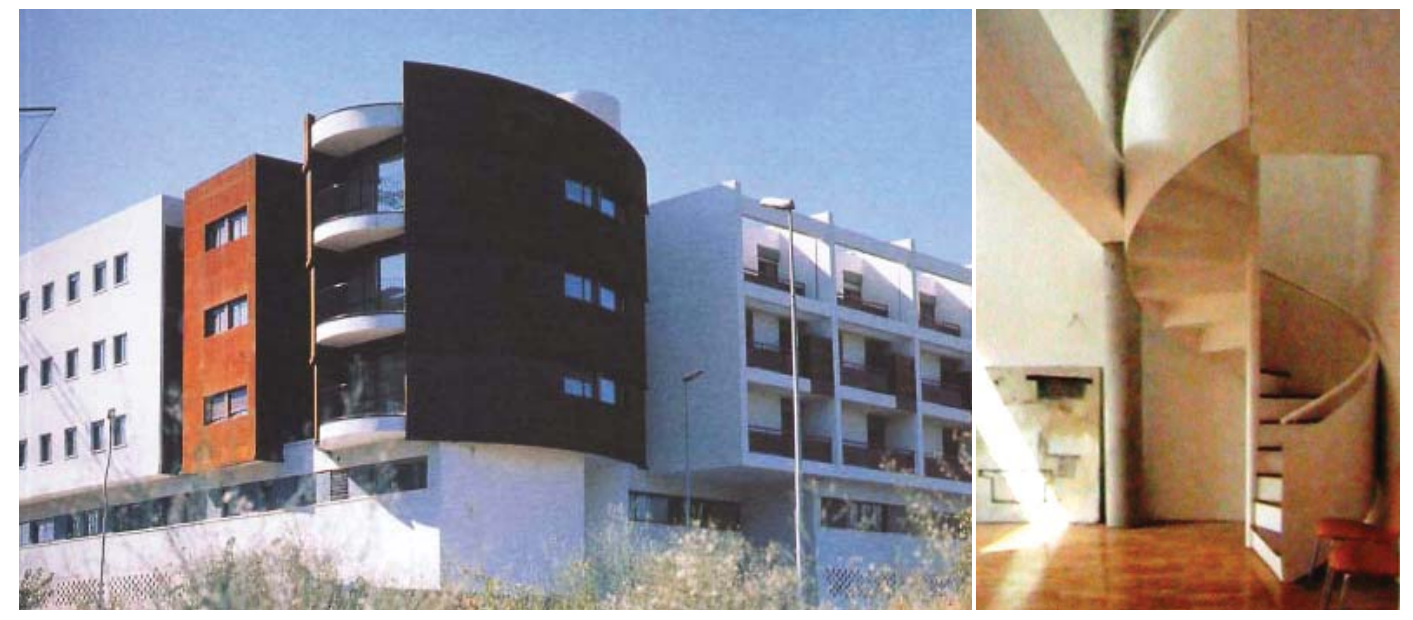

Ref.5.22. Dos manzana de viviendas construidas de Matos y Castillo, Bilbao, Europan 2 
de conexión entre el parque y la plaza, en lugar de ser frontera ${ }^{14 "}$. Con este gesto de hacer ciudad los autores abren el proyecto de arquitectura el contexto más amplio, necesario para realizar una arquitectura basada en las premisas del lugar. Además también afirman que pretenden crear "varios edificios dentro de un edificio ${ }^{15}$ " con el mecanismo de la variación de tipos, pero siguen en la repetición de un modelo como ya se hizo en Europan 1.

Sin embargo, el proyecto de Ferrol parece algo más confuso en cuanto a su relación con la ciudad. Aunque plantea la transparencia de espacios en la planta baja al utilizar el patio de manzana como elemento de relación haciendo referencia a las enseñanzas de Kahn en cuanto a espacios servidores y servidos ${ }^{16}$.

Los espacios públicos apenas se integran gráficamente en el proyecto y se quedan sin desarrollar. Las zonas comunes del edificio de Basauri son más amplias que el de Ferrol, pero se tratan como meros espacios de circulación o corredores.

Se puede decir que no se ofrece ninguna respuesta ante la cuestión de la hibridación. Se crean viviendas sociales y se trata de insertar el espacio público en los proyectos planteados. La cota 0 empieza a colonizarse: las plantas bajas de los edificios son las que permiten un cierto cambio de uso que no sea residencial. En el caso de Ferrol se crean unos soportales que permiten un acceso a los comercios de la planta baja, incluso un acceso al patio interior de la manzana. Si se observa la planta baja de Basauri, los espacios que plantean los autores del proyecto son viviendas y quedan ordenados según el módulo estructural. Los accesos a las plantas superiores permanecen en las esquinas y permiten abrir el patio de manzana.

En cuanto al programa, las viviendas son similares: predominan las de tres dormitorios y una sala de estar con dos núcleos húmedos de modo análogo a la edición anterior.

En la estética de los edificios construidos predomina cierto formalismo y se manifiesta en la diferenciación de la solución en esquina de ambos, bien utilizando un cambio de material o resaltándola en el volumen.

Europan 2 cierra su edición con la construcción de 196 viviendas (aproximadamente la mitad que la edición anterior) y se plantea como un ejercicio para integrar los edificios de vivienda social en el entorno urbano.

\footnotetext{
${ }^{14}$ AA.VV. 2 manzanas de viviendas en Basauri-Bilbao. Monográfico Europan. Paris. 1997. p.9.

${ }^{15}$ Ibídem, p.11.

16 "Edificio de viviendas de protección oficial en Ferrol". n² 25. En Obradoiro. p.71.
} 
VIVIENDAS EUROPAN (1988-2008) I Una aproximación a los modos de vida en el cambio de siglo en España

5. ALGUNAS APORTACIONES DE EUROPAN A LA VIVIENDA

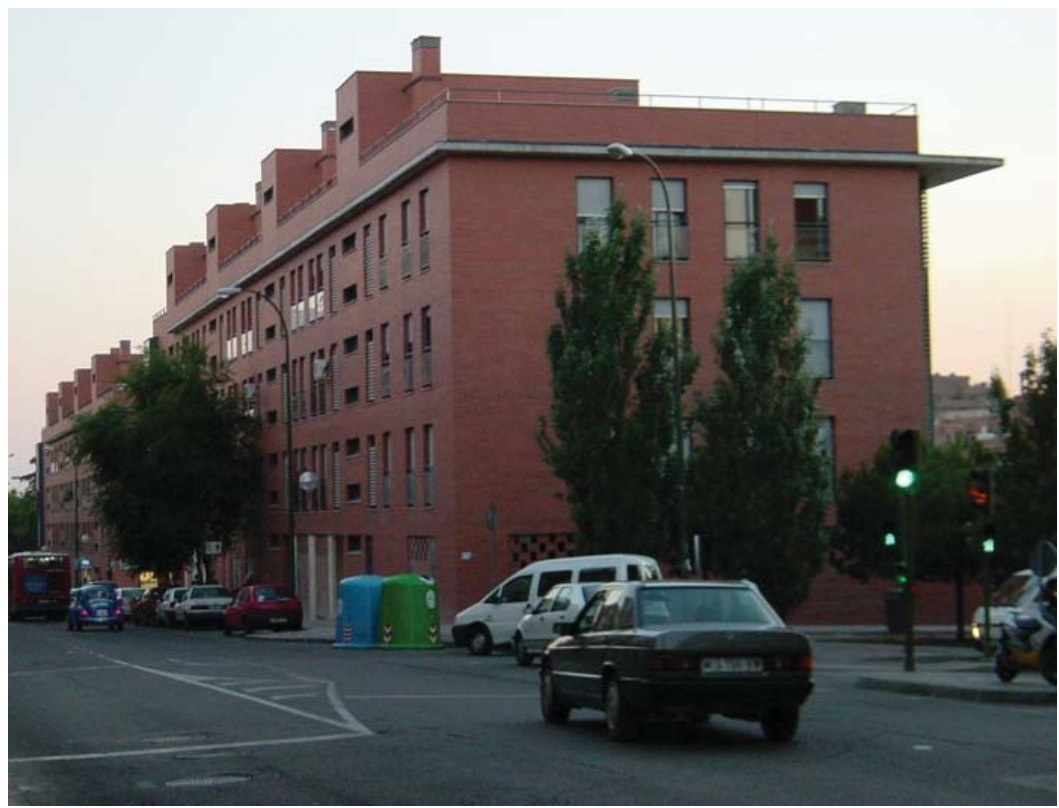

Ref. 5.23. Edificio de viviendas construido de Jaime López y Jaime Latas, Madrid, Europan 3

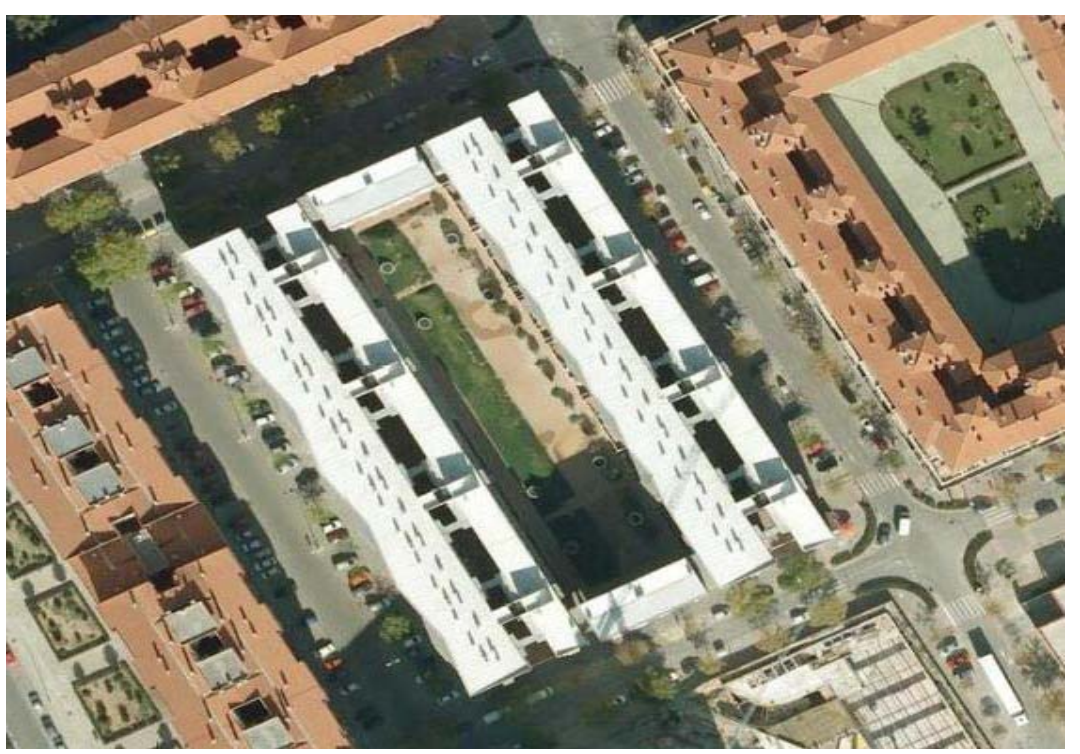

Ref.5.24. Manzana de viviendas construida de Enrique Johanson de Terry, Granada, Europan 3

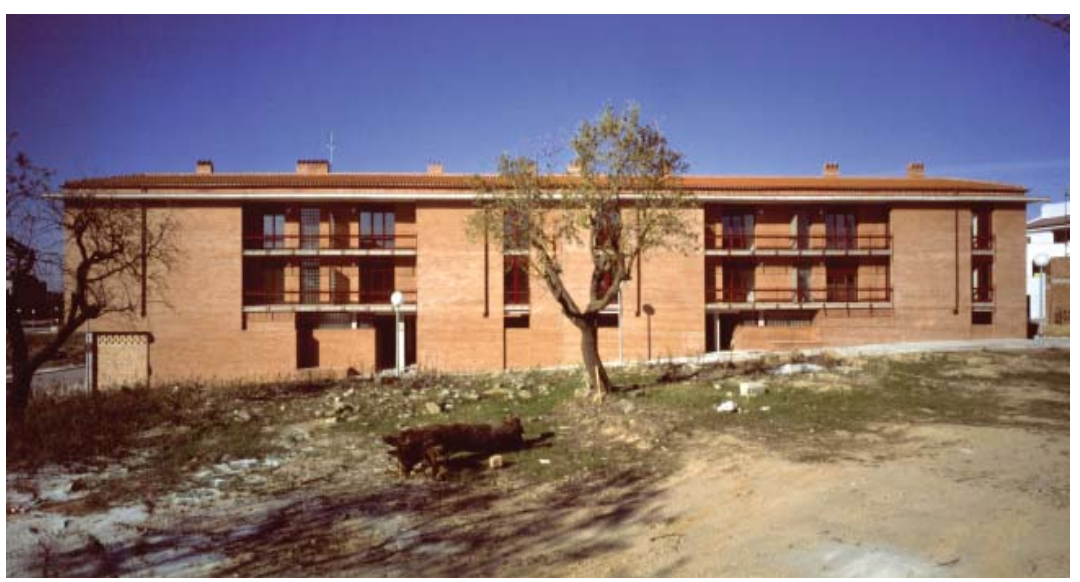

Ref.5.25. Dos edificios de viviendas construidos de Mãosé Duch y Eva Prats,Guisona (Lérida), Europan 3 


\subsubsection{Europan 3}

El aumento de participación de equipos en esta convocatoria es notable, pues corresponde casi al doble de las anteriores como afirma Ángela García de Paredes comentando que es complicado la selección de los galardonados debido al gran número de paneles a analizar por parte del Jurado ${ }^{17}$.

Tanto es así que, hasta el momento, Europan 3 es la convocatoria con mayor índice de participación de equipos con un total de 423 equipos, además será en esta edición (junto con la de Europan 1 y 4) donde se construya un gran número de viviendas.

Europan 3 plantea cuatro temas de investigación principales (analizados previamente en el apartado 3.2.1): los cambios en los modos de vida, la relación entre espacio público y privado, la importancia de las relaciones sociales y la potenciación de los valores ecológicos.

Se pretende reactivar barrios ya existentes, en cuanto a las aspiraciones de los europeos para vivir en una ciudadanía plural.

En esta convocatoria se construyen tres obras que quieren dar respuesta a las cuestiones planteadas en los emplazamientos de Madrid, Granada, y Guissona.

¿Se puede afirmar que ha habido investigación en las obras construidas de Europan 3? El tema de reflexión principal al que tratan de responder es la relación que existe entre el espacio público y privado. Las obras se resuelven desde la ciudad, pues en los tres casos hay una intención de ordenar el interior de la manzana. Se reflexiona sobre el espacio público existente, además del espacio privado de las propias viviendas. Pero se puede afirmar que la actuación sobre el espacio público es escasa, como se ha desarrollado con anterioridad al analizar cada uno de los proyectos en sus respectivos apartados.

Otro tema que apenas se desarrolla en lo construido es el de la hibridación (la relación vivienda-trabajo-ocio es una de las planteadas en el enunciado). En el caso de las tres obras, siguen planteando el residencial a partir de la primera planta, la planta baja se destina a locales comerciales y el sótano a aparcamiento, como en la mayoría de los edificios de vivienda social existentes.

En cuanto a la investigación acerca de los valores ecológicos, se observa la intención de relacionar el espacio residencial con las zonas verdes (tanto en el

\footnotetext{
17 "Los jurados, como clave del éxito del resultado del concurso, son en Europan reconocidos y diversos. También se invita a un ganador de la edición anterior a formar parte del jurado de la siguiente, pudiendo éste participar en otros países para no perder oportunidades, ya que los cuarenta años llegan apenas sin darse cuenta. Tras el premio Europan 2, participar en el jurado Europan 3 constituyó la abrumadora sorpresa de 1269 paneles para estudiar, analizar y consensuar como jurado desde punto de vista del participante". GARCÍA DE PAREDES, Angela."Europan: una ventana hacia la arquitectura”. Ibídem. p. 222.
} 


\section{EUROPAN 3 (1992)}
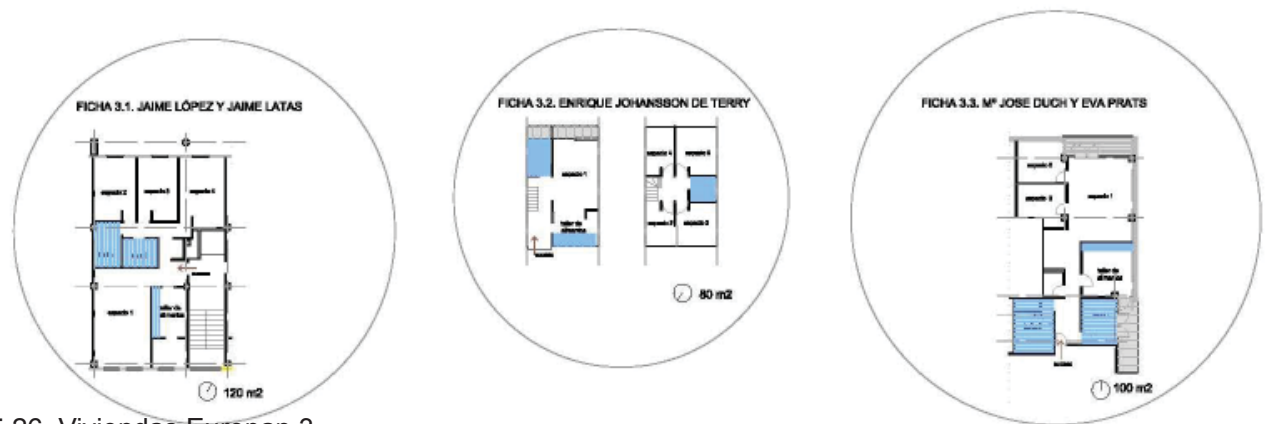

Ref. 5.26. Viviendas Europan 3

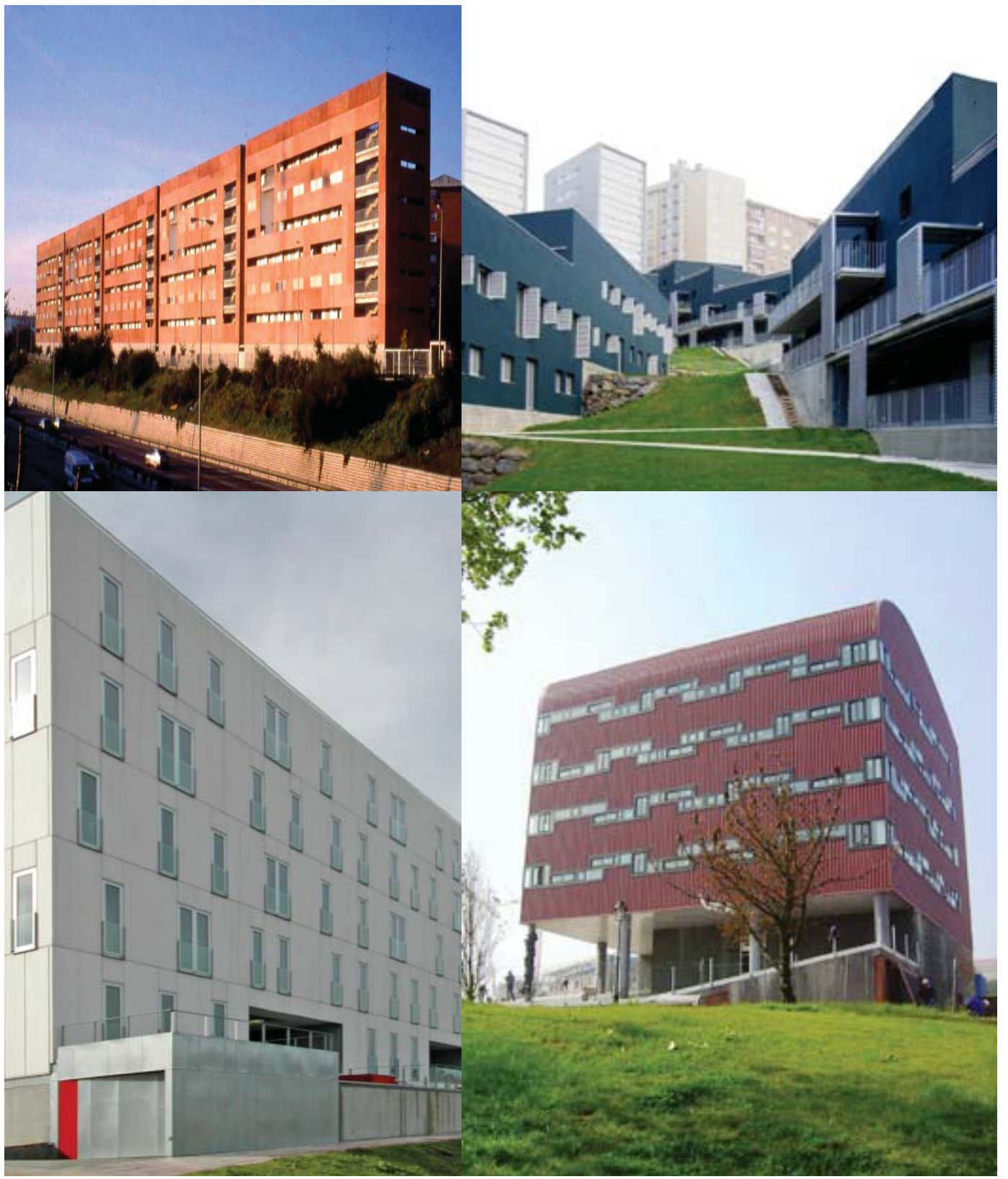

Ref. 5.27. Edificios de viviendas construidos de Europan 4 
interior de la manzana en el caso de Granada y Guisona como en el tratamiento de la zona de borde frente a la vía de tráfico en Madrid,). Existe un intento de crear espacios intermedios de relación con el exterior como son las terrazas, pues en los tres casos las viviendas suelen tener una terraza exterior.

Las viviendas siguen siendo amplias: la mayoría tienen tres espacios y la sala de estar (con una media de 100 m2) y tienden a agrupar los núcleos húmedos en el interior de los bloques.

En cuanto a los espacios comunes en el propio edificio, cabe de afirmar que se reducen al mínimo. Se trata de escaleras de acceso a los bloques de dimensiones muy limitadas para poder albergar algún uso adicional.

En cuanto a la estética de los edificios predomina el uso del ladrillo cerámico visto y los volúmenes puros y rectangulares.

Europan 3 termina su edición con la construcción de 352 viviendas y con esta convocatoria se comienza a percibir la importancia de la integración de éstas con el espacio público.

\subsubsection{Europan 4}

Esta convocatoria plantea la construcción sobre la ciudad actual y los temas de investigación han sido: la afinidad por lo existente, la previsión de futuro en la actuación en la ciudad, la capacidad de heredar en los proyectos con respecto a lo existente y las conexiones urbanas (previamente analizados en el apartado 3.2.1).

De las cuatro obras construidas, la mitad se realizan en el emplazamiento previsto de concurso e intentan seguir fielmente el proyecto presentado. La obra en Sevilla de Nieto y Sobejano sigue al $100 \%$ este planteamiento. La de Bilbao sufrirá algunas modificaciones debido a que se encarga a dos equipos diferentes, como se ha comentado al hablar del proyecto en el apartado 4.1.

El contexto en el que se construyen estos proyectos son las periferias de las ciudades, áreas que están abandonadas y en las que se pretenden crear focos de vida para la ciudad en Sevilla, Bilbao y Avilés. Se combina distintas morfologías: bloques en $L$, torres y bloques lineales, y una última híbrida entre bloque y torre. Estos proyectos introducen el factor residencial en unas zonas de la ciudad que apenas tenían actividad, dotándoles de vitalidad.

En el enunciado se propone poner en marcha cambios de uso e innovar preparando a la ciudad para las necesidades del futuro... pero ¿cómo se traducen estas ideas en arquitectura? ¿Se puede afirmar que ha habido investigación en las obras construidas de Europan 4? Europan 4 marca un rumbo distinto en cuanto a 


\section{EUROPAN 4 (1994)}

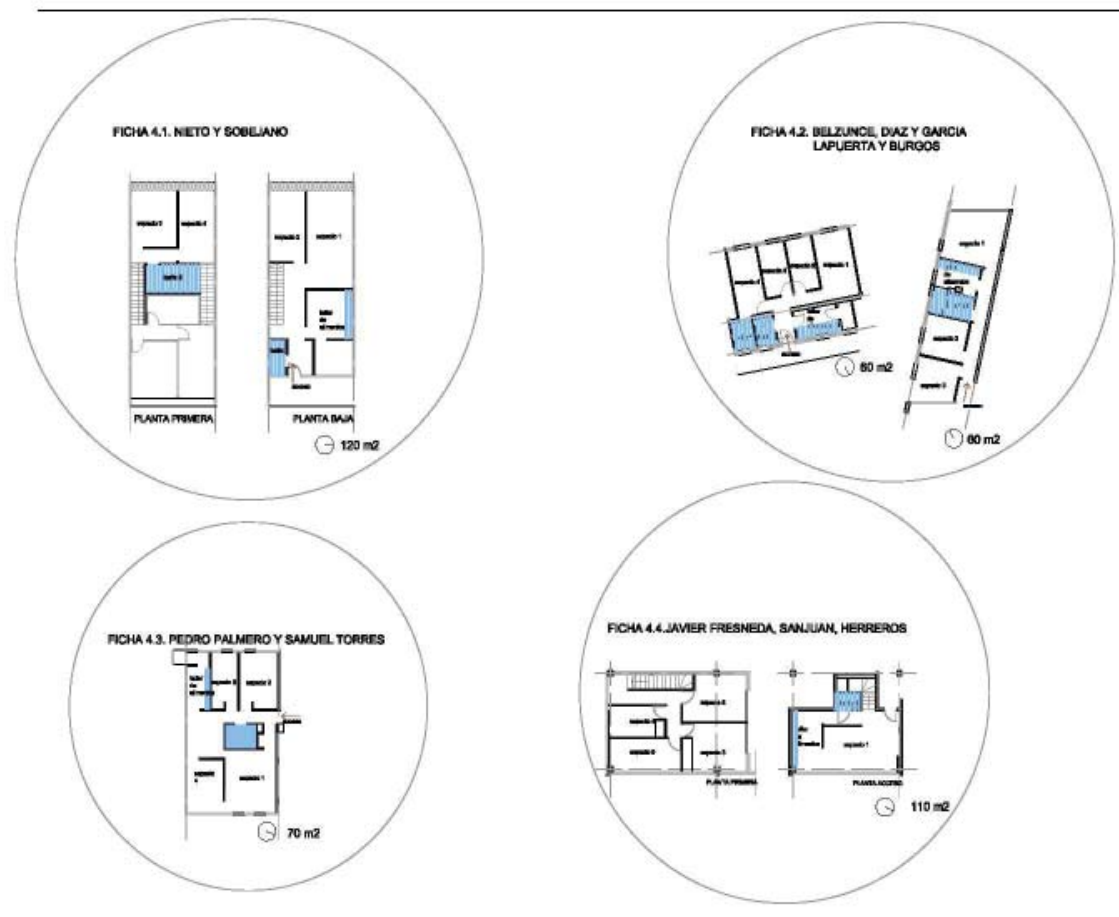

Ref. 5.28. Viviendas Europan 4

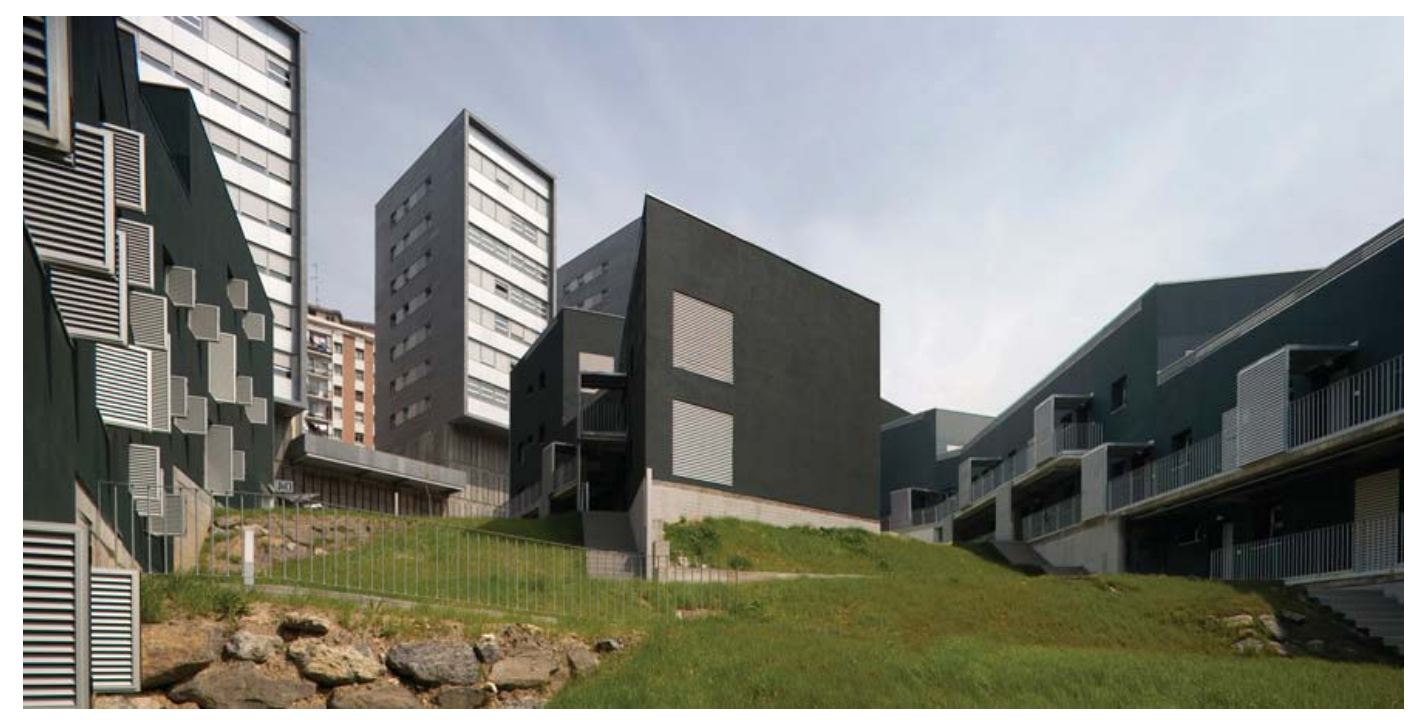

Ref. 5.29. Edificios de viviendas construidos de Europan 4, en Bilbao. 
los planteamientos de vivienda, como se tratará de explicar a continuación pues se construyen cuatro proyectos de vivienda social con una riqueza y variedad de tipología que mejoran las propuestas que se han visto hasta el momento. Pero esta no será la principal aportación, sino la utilización de materiales ligeros y prefabricados para la construcción huyendo de los sistemas constructivos tradicionales. En este sentido, sí que se podría afirmar que ha habido un avance tecnológico: en el de la construcción de los propios proyectos.

Las viviendas de Sevilla se caracterizan por el uso predominantemente residencial. No existen equipamientos comunes en la obra construida aunque posteriormente, en la misma manzana, se realizará una construcción independiente para un equipamiento cultural. Cabe destacar que se trata de un modo interesante el tema de los espacios comunes de los corredores, donde los habitantes pueden relacionarse y utilizar como extensión de sus propias viviendas: éstos se conciben como miradores a la ciudad y sus dimensiones son generosas. Además se estudia el espacio interior de la vivienda y se le dota de calidad que se manifiesta en gestos como la búsqueda de la transparencia, de los espacios a doble altura, etc.

Estas viviendas poseen ventilación cruzada y tienen cerramientos metálicos que les proporcionan protección solar. En el proyecto de concurso se elige la opción de no colmatar todo el espacio para crear espacios verdes en el interior, y aunque la intención es esa es cierto que en el proyecto construido podrían estar mucho más poblados de vegetación. Los paneles prefabricados de hormigón utilizados para la fachada, son una novedad con respecto al sistema tradicional de construcción de fachada de doble hoja de ladrillo.

Las viviendas de Mina del Morro de Bilbao tienen el interés de mezclar dos sistemas distintos de agrupación: las torres y los bloques de baja densidad que descienden por el terreno. Estos tienen mayor interés pues permiten una colonización del espacio público y una relación de las viviendas con éste más interesante que el de las torres. Pero aún así en ambos casos se tiende a la rigidez pues se abusa de una excesiva repetición del módulo y de la unidad de vivienda estudiada. Los dos proyectos tienen en común que se apropian del espacio interior del solar y lo integran dentro de la obra, siendo un espacio de relación entre los habitantes importante para la vida cotidiana.

Los otros dos proyectos de Avilés, no se construyen con respecto a lo planteado en el concurso. Al final, cada edificio se ha desarrollado en el terreno propuesto pero no se abren al entorno y no parece que haya un diálogo con el contexto. Por ejemplo, las viviendas de Javier Fresneda, Sanjuan y Herreros, más conocidos por los javieres, pretenden crear ciudad, a pesar de que, en este caso, se construya en un solar que carece de preexistencias.

Como ellos mismos afirman, "cuando proyectamos una vivienda estamos haciendo ciudad. La ciudad se convierte de forma involuntaria en nuestro segundo hogar. $Y$ como tal en un ser diferenciado y múltiple, mestizo en sus planteamientos y abierto 
VIVIENDAS EUROPAN (1988-2008) | Una aproximación a los modos de vida en el cambio de siglo en España 5. ALGUNAS APORTACIONES DE EUROPAN A LA VIVIENDA

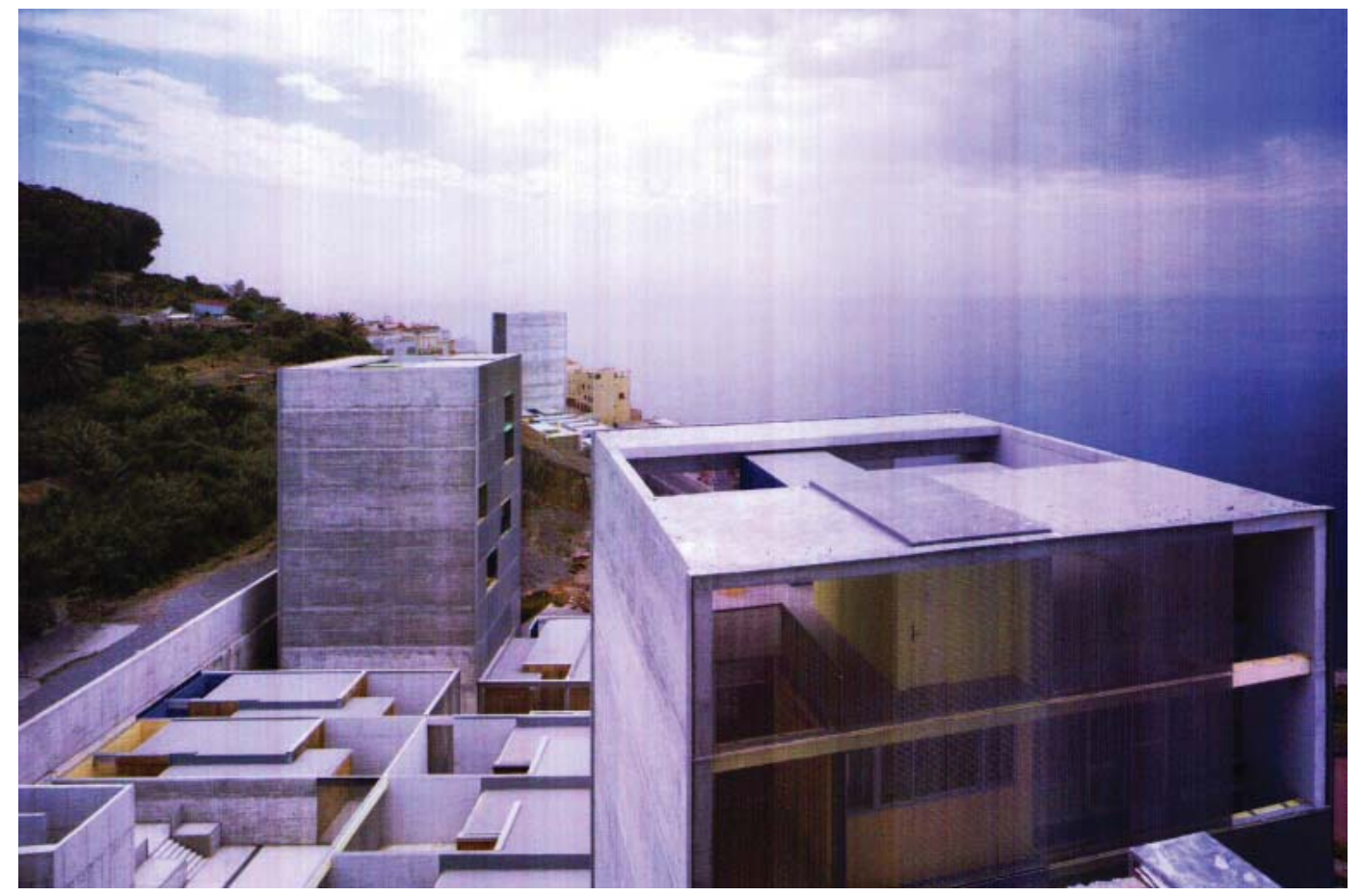

Ref. 5.30. Edificios de viviendas construidos de José Morales y Juan González Mariscal,Ceuta, Europan 5

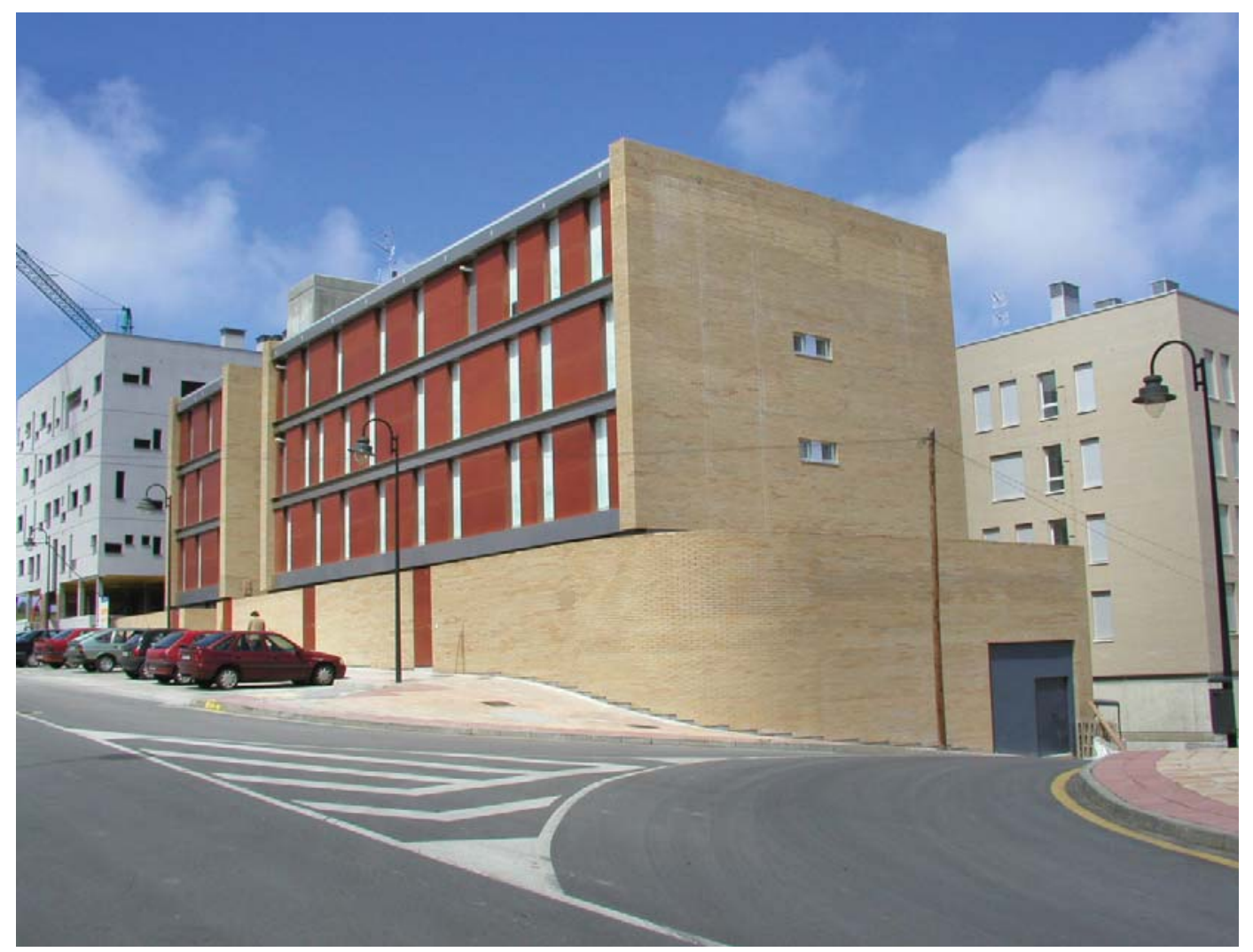

Ref. 5.31. Edificio de viviendas construido de Elio García, Carlos Rodríguez y Javier Rodríguez,Avilés, Europan 5 
en sus resultados. Cuando empezamos a realizar este pequeño trozo de ciudad, pretendíamos que el volumen construido estableciera distintas relaciones con su entorno, haciendo posible ese ser diferenciado y múltiple en el que creemos ${ }^{18 "}$.

Los dos proyectos de Avilés plantean viviendas más pequeñas y tienen en cuenta el módulo.En ellas se pretende investigar acerca de la flexibilidad y los nuevos modos de vida. Por ejemplo las viviendas de Palmero y Torres están destinadas al colectivo de mujeres que han sufrido malos tratos; o, como reflejan los javieres cuando afirman que "en el interior la vivienda se piensa como un espacio continuo supeditado a los elementos fijos por razones estructurales (pilares en el perímetro o patios centrales), energéticas y mecánicas(núcleos húmedos con ventilación natural a través de los patios). Con esta organización conseguimos liberar a las estancias de las servidumbres permitiendo la posibilidad de variaciones en la distribución de las estancias servidas ${ }^{19}$.

En cuanto a la estética de los edificios se puede afirmar que dan un giro con respecto a las ediciones anteriores pues se combina una hoja de ladrillo cerámico con una de paneles prefabricados o chapa, dotándolo de una piel exterior que adquiere color y viste a los edificios con aires de modernidad.

Europan 4 cierra su edición con 377 viviendas construidas y utiliza de nuevos materiales que permiten agilizar el proceso constructivo.

\subsubsection{Europan 5}

Esta convocatoria plantea seis temas de investigación que han sido analizados previamente en el apartado 3.2.1, entre los que destacan: la naturaleza y el hábitat, los desplazamientos, el urbanismo inducido, la existencia de los nuevos modos de vida, la intensificación de usos y la gestión de la complejidad.

En los proyectos presentados a concurso, Europan 5 comienza a adquirir un grafismo característico ${ }^{20}$ : los paneles cobran vida, están llenos de diagramas, esquemas, ideas y collages que desarrollan imágenes virtuales de la arquitectura

\footnotetext{
${ }_{18}^{18}$ Memoria de proyecto (proporcionada por los propios autores).

19 Ibídem

20 "No creo que exista, en este sentido, un estilo europan, como muchas veces se ha afirmado, sino que más bien el concurso es un indicador extraordinariamente sensible de lo que se cuece, tanto en los estudios más jóvenes como en las escuelas. De hecho, y como muestra de esa riqueza, en algunas de las propuestas ganadoras con más interés en las últimas ediciones, hemos podido observar el cuestionamiento teórico de los ámbitos disciplinares a que aludía anteriormente, aunque siempre resuelto con una gran calidad formal y arquitectónica" FRANCO, David. "Un mosaico de pequeñas utopías". en en EUROPAN 10 España. Proyectar la urbanidad. Ed. Ministerio de la vivienda. Madrid. 2010. p. 239.
} 


\section{EUROPAN 5 (1997)}
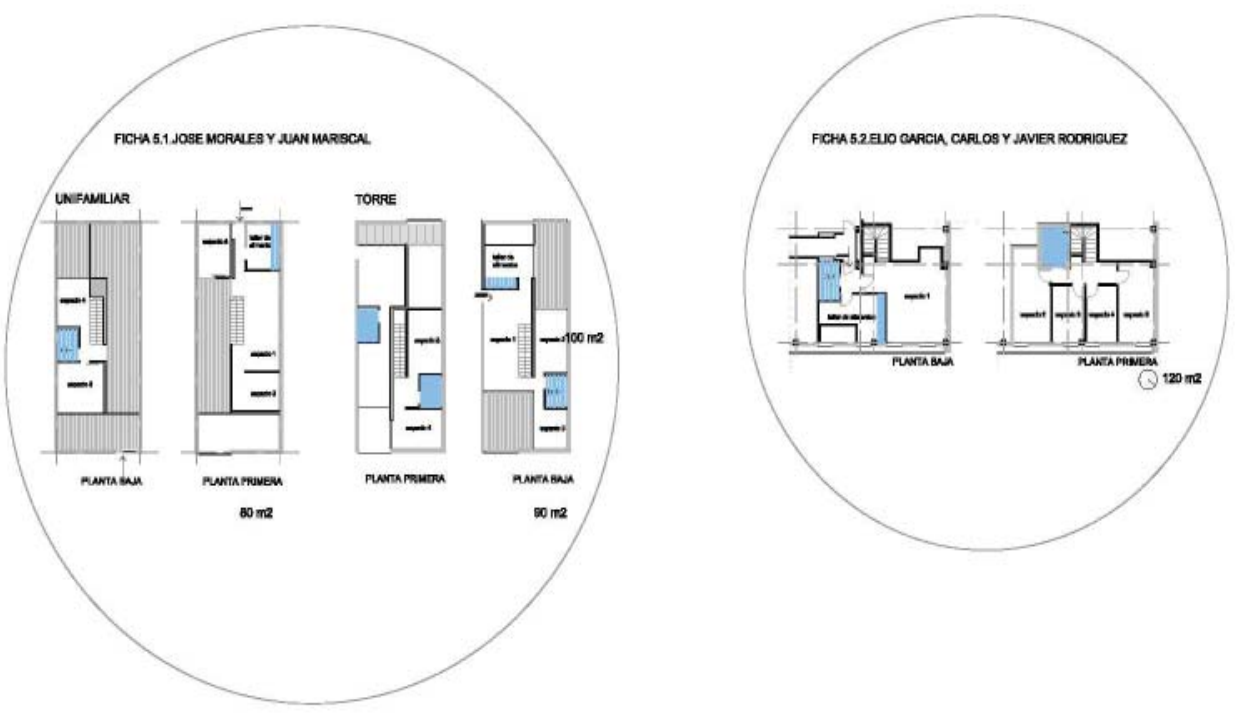

Ref. 5.32. Viviendas Europan 5

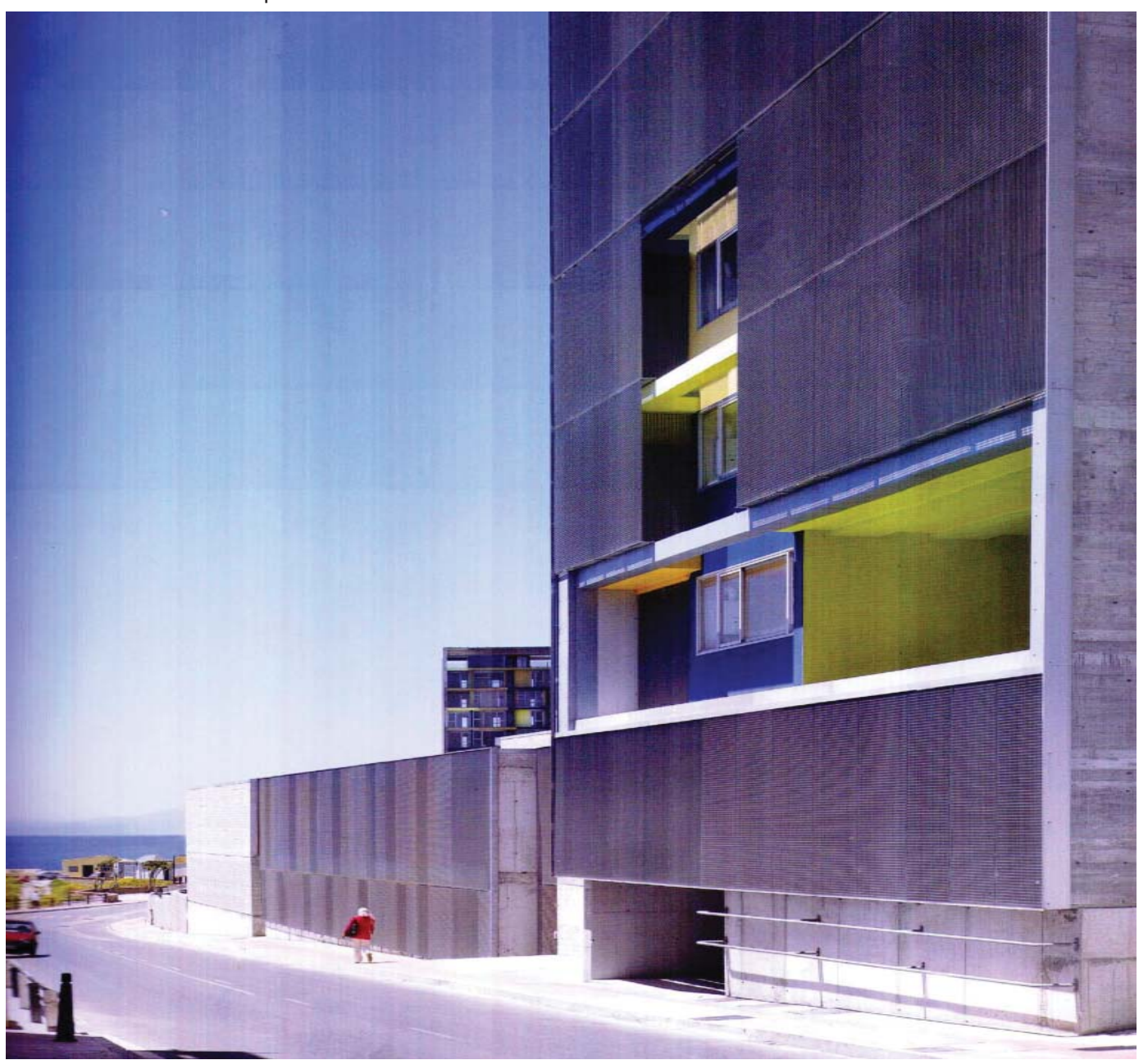

Ref. 5.33. Edificios de viviendas construidos de José Morales y Juan González Mariscal,Ceuta, Europan 5 
y, mueven a la reflexión del observador. En Europan 5 los proyectos tienen en cuenta la ciudad,en tanto en cuanto la escala comienza a ser mucho mayor que la que se representaba en las convocatorias anteriores. Progresivamente va haciendo zoom para ampliarse en cada panel de concurso y finaliza con los tipos de vivienda (estas son las tres escalas de las que se ha hablado con anterioridad).

De los dos proyectos que se construyen sólo el de Ceuta se realiza tal y como se planteaba en el concurso. Esta será el última obra construida (hasta el momento) en uno de los emplazamientos propuestos y que sigue el proyecto de concurso.

¿Se puede afirmar que ha habido investigación en las obras construidas de Europan 5? El tema de investigación de la naturaleza y el hábitat se plantea como uno de los elementos más importantes. Como se ha analizado previamente en el capítulo 4.1.5, el proyecto de Ceuta se basa en el lugar y no puede prescindir de éste pues las viviendas se organizan en función de la topografía, la orientación y el viento.

En el planteamiento de la convocatoria de Europan 5 se propone una "intensificación de usos" y, aunque en el inicio del texto de la convocatoria se hace una fuerte crítica al zoning, este proyecto y el otro construido en Avilés se siguen caracterizando por el uso puramente residencial.

El tema de las conexiones con la ciudad parece que se concreta sólo en el proyecto de Ceuta, pues intenta crear recorridos peatonales para relacionarlo con el entorno. El de Avilés es un proyecto rotundo en sí mismo, no se desarrolla el espacio público ni su conexión con el edificio en el proyecto.

En estos edificios se utilizan también materiales prefabricados que demuestran una mejor tecnología. Por ejemplo Elio García, Carlos y Javier Rodríguez afirman que "la construcción de viviendas de bajo coste no está reñido con la calidad, tanto en el diseño de las tipologías como en los materiales a emplear. Un adecuado planteamiento en las tipologías y en el conjunto de éstas, que conforman el bloque, así como en los detalles constructivos repercutirá en la calidad global de la propuesta. Las fachadas responden a la organización interna del edificio permitiendo la entrada de luz natural y manteniendo la relación con el exterior. Una composición de fachada no condicionada por valores estéticos sino una consecuencia de la distribución interior ${ }^{21}$ ".

En cuanto a la investigación en vivienda, el proyecto de Ceuta es quizá uno de los más interesantes en el planteamiento tipológico, como ya se comentó en el análisis. Cabe puntualizar que es una vivienda que, dentro de sus dimensiones algo limitadas, permite muchas posibilidades de combinaciones distintas y da juego a que la flexibilidad pueda ser una realidad.

${ }^{21}$ Memoria del proyecto (proporcionada por los propios autores). 
VIVIENDAS EUROPAN (1988-2008) I Una aproximación a los modos de vida en el cambio de siglo en España

5. ALGUNAS APORTACIONES DE EUROPAN A LA VIVIENDA

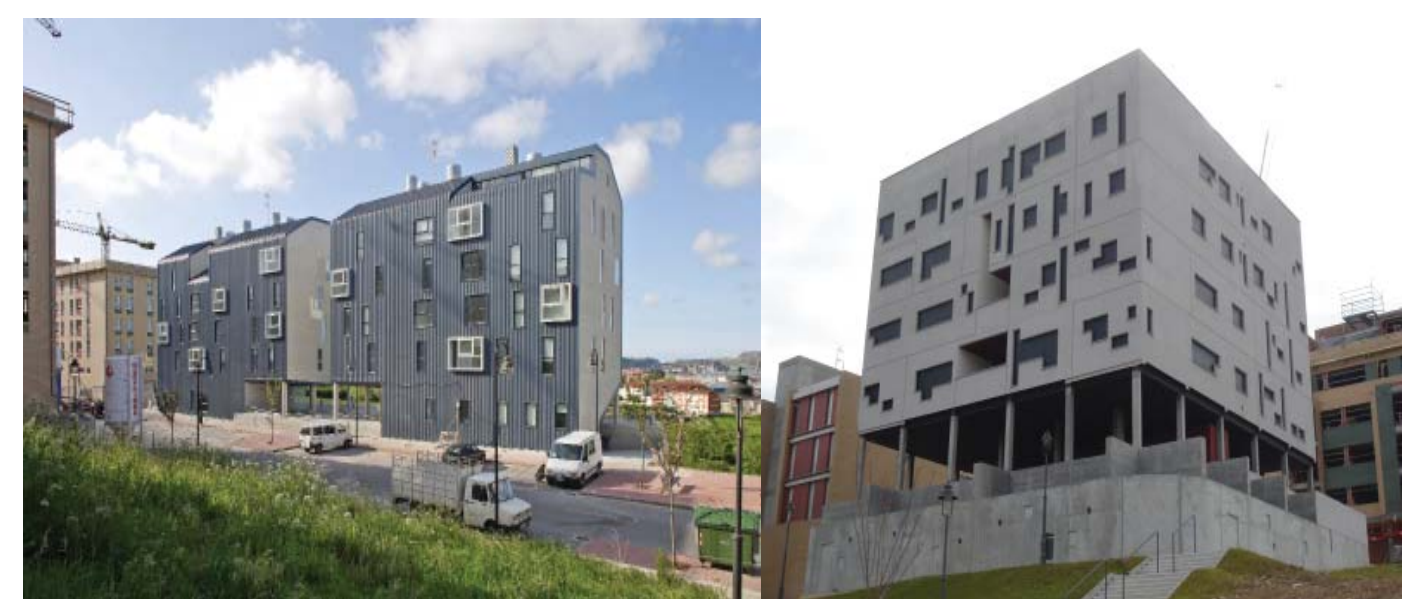

Ref.5.34. Edificios de viviendas construidos de Europan 6

\section{EUROPAN $6(2000)$}
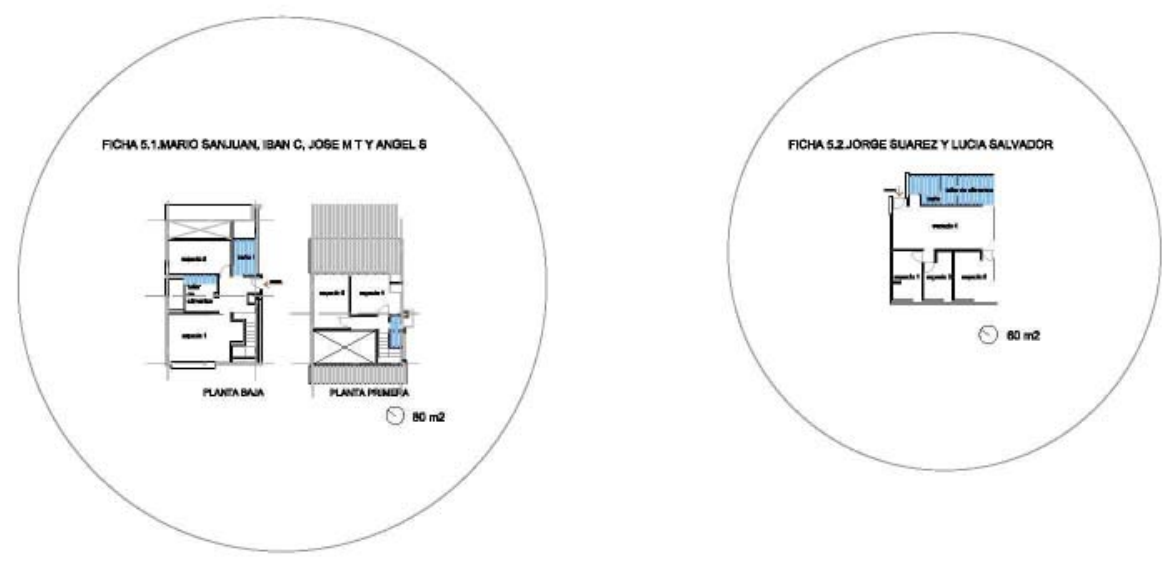

Ref. 5.35. Viviendas Europan 6 
En cuanto a la estética de los edificios, esta edición presenta dos obras con unos materiales actuales y que se adecuan a la estética del momento (utiliza hormigón visto y compone unas fachadas que permiten tener visuales hacia el entorno).

Europan 5 concluye su edición con 144 viviendas construidas. A partir de este momento la materialización de las viviendas entra en declive en Europan y se percibe cómo plantea estrategias de actuación en la ciudad, sin concretarlo en grandes construcciones de edificios de vivienda social.

\subsubsection{Europan 6}

Esta convocatoria plantea tres temas de investigación que han sido analizados previamente en el apartado 3.2.1 y son: la actuación en las redes, la edificación y en el espacio público.

Por desgracia, no se construye ninguno de los proyectos de concurso, por lo que las obras construidas en Avilés se puede decir que no son muy representativas de los temas de investigación propuestos.

Al tratarse de dos edificios de viviendas construidos en las afueras del mismo barrio del Nodo en Avilés, sin preexistencias, la investigación se centra propiamente en los propios edificios de viviendas.

Las de Jose $\mathrm{M}^{\mathrm{a}}$ Tabuyo plantean espacios interiores sugerentes y se puede observar cómo con pocos medios se puede obtener una arquitectura con una calidad espacial interesante. El uso que plantea es puramente residencial sin actividad comercial de ningún tipo. El paisaje entra dentro del propio edificio, convirtiéndose en un mirador hacia éste. Las nuevas tecnologías, la relación con el mundo del trabajo...está presente en los espacios creados en el interior de la vivienda aunque no es un edificio heterogéneo como planteaba el enunciado de concurso.

Las viviendas de Lucía Salvador y Jorge Suarez aunque es un proyecto rotundo introduce una reflexión sobre las tipologías interesante, como ellos mismo afirman cuando dicen que "el proyecto se ha concebido buscando el máximo soleamiento y, en lo posible, las mejores vistas. Para ello el núcleo de comunicaciones verticales se ha situado en el interior del edificio, liberando la totalidad de la superficie de las fachadas para las viviendas. Se consiguen de este modo, viviendas absolutamente soleadas y ventiladas con altas cotas de salubridad. El edificio se compone de 18 viviendas. Se ha ideado un programa capaz de generar una variedad de viviendas enorme por un lado, y de evitar la complejidad estructural y constructiva, y por tanto el incremento de costes, por otro. Como consecuencia de la aplicación de este programa, se han generado 18 viviendas diferentes, cada una con su identidad y su número. La variedad de viviendas proyectada, supone una nueva forma de concebir la vivienda contemporánea más acorde con las tendencias sociales 
VIVIENDAS EUROPAN (1988-2008) I Una aproximación a los modos de vida en el cambio de siglo en España 5. ALGUNAS APORTACIONES DE EUROPAN A LA VIVIENDA
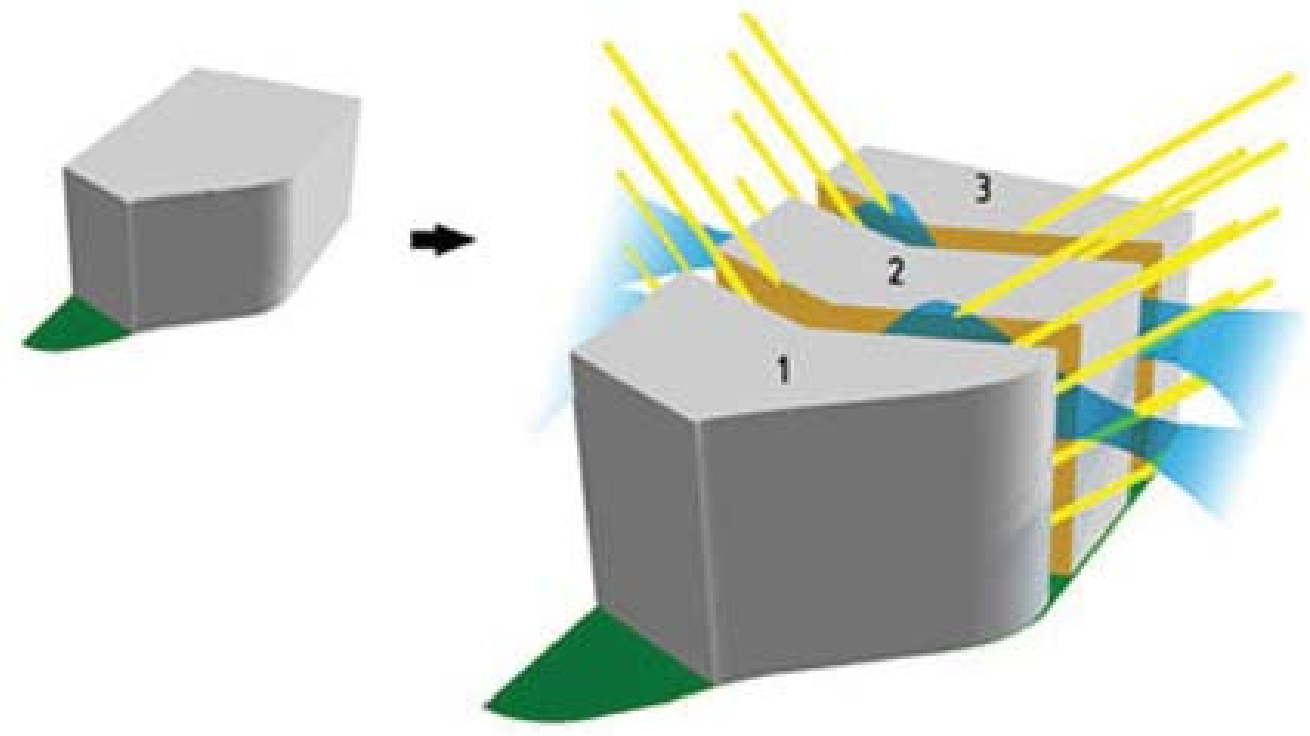

Ref.5.36. Estudio de soleamiento y ventilación. Edificio de viviendas de Hevia Meyer y Ángela Moragues, Lérida, Europan 7

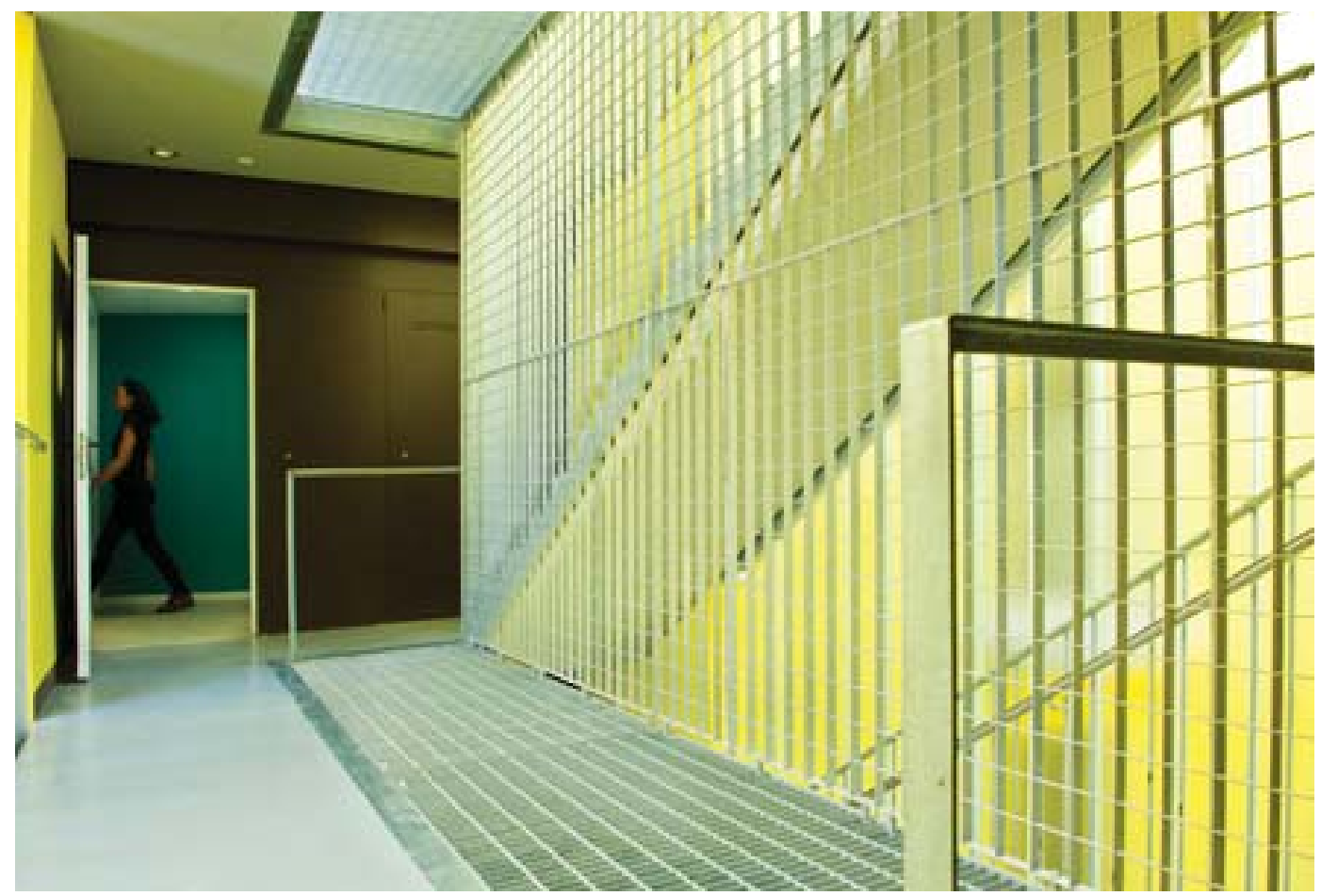

Ref.5.37. Edificio de viviendas de Hevia Meyer y Ángela Moragues, Lérida, Europan 7 
actuales, y responde a la enorme diversidad de necesidades espaciales y de uso existentes en la sociedad moderna. Frente a soluciones que plantean viviendas seriadas para "personas tipo", más en concordancia con las tendencias marcadas por las vanguardias de principios de siglo, el proyecto, por el contrario, abriría los abanicos de posibilidades presentando opciones muy diferentes de vivienda dentro de cada tipología definida. De esta manera, cada usuario tendría mayores opciones de encontrar una vivienda acorde con sus preferencias concretas ${ }^{22}$.

En cuanto a la estética de los edificios a pesar de utilizar materiales actuales quizá el primer caso lo hace con mayor acierto que el segundo pues éste quizá peca de cierto "formalismo".

Europan 6 cierra su edición con tan solo 49 viviendas construidas.

\subsubsection{Europan 7}

Esta es la última edición que, hasta el momento de redactar la tesis, tiene obras construidas $^{23}$. Como sólo se ha realizado un edificio de viviendas en Lérida se considera que esta muestra no es significativa pues se construye un proyecto diferente al de concurso al tratarse de un emplazamiento y un encargo distinto. Europan 7 plantea dos temas de investigación que han sido analizados previamente en el apartado 3.2.1. y son la evolución de los modos de vida y la ecología y sostenibilidad.

Angela Meyer proyecta unas viviendas con forma de peine con un resultado visual reconocible. Son viviendas adaptadas y accesibles con las que se pretenden crear nuevos barrios residenciales. La planta baja con locales comerciales y tiene dos plantas de sótano destinada a garajes.

Parece ser que esta obra pretende ser un referente en cuanto al tema de investigación de la sostenibilidad, como las propias autoras afirman en la memoria del proyecto al afirmar que "el edificio toma así forma de abanico que se cierra hacia el norte y se abre poco a poco a medida que nos adentramos en este nuevo barrio. El giro de las fachadas manifiesta también la intención de encontrar una mejor orientación para todas las viviendas. Intentando evitar el típico bloque cerrado con patio de manzana central, se disponen dos patios estrechos y abiertos a fachadas

\footnotetext{
${ }^{22}$ Memoria del proyecto (proporcionado por los propios autores).

23 "El desarrollo de los proyectos ganadores de una determinada edición de Europan puede seguir sendas diferentes, llegando a resultados de muy distinta naturaleza, cuya taxonomía completa tendrá que catalogarse en otro momento pues en la edición que nos ocupa (E-7 España) la evolución no ha llegado (¿aun?) a producir el tipo de implementación más deseada: la obra construida con total fidelidad a la propuesta de concurso. En realidad, ese tipo de resultado final es rara avis, por motivos también variados, que tampoco es cuestión de analizar aquí". ARROYO, Carlos. "Una taxonomía incompleta". en en EUROPAN 10 España. Proyectar la urbanidad. Ed. Ministerio de la vivienda. Madrid. 2010. p. 245.
} 


\section{EUROPAN 7 (2002)}

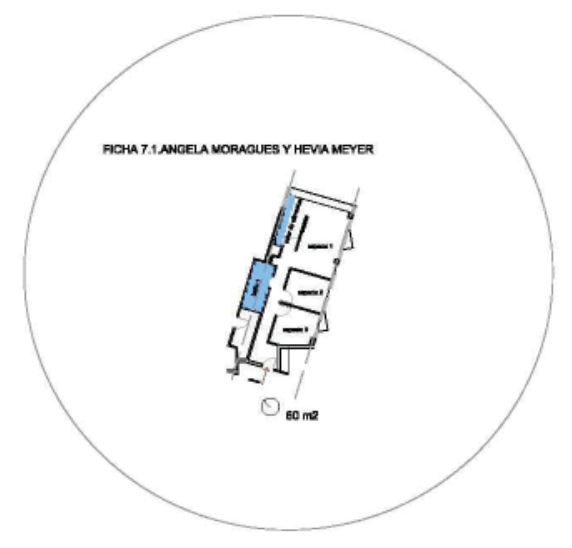

Ref. 5.38. Viviendas Europan 7

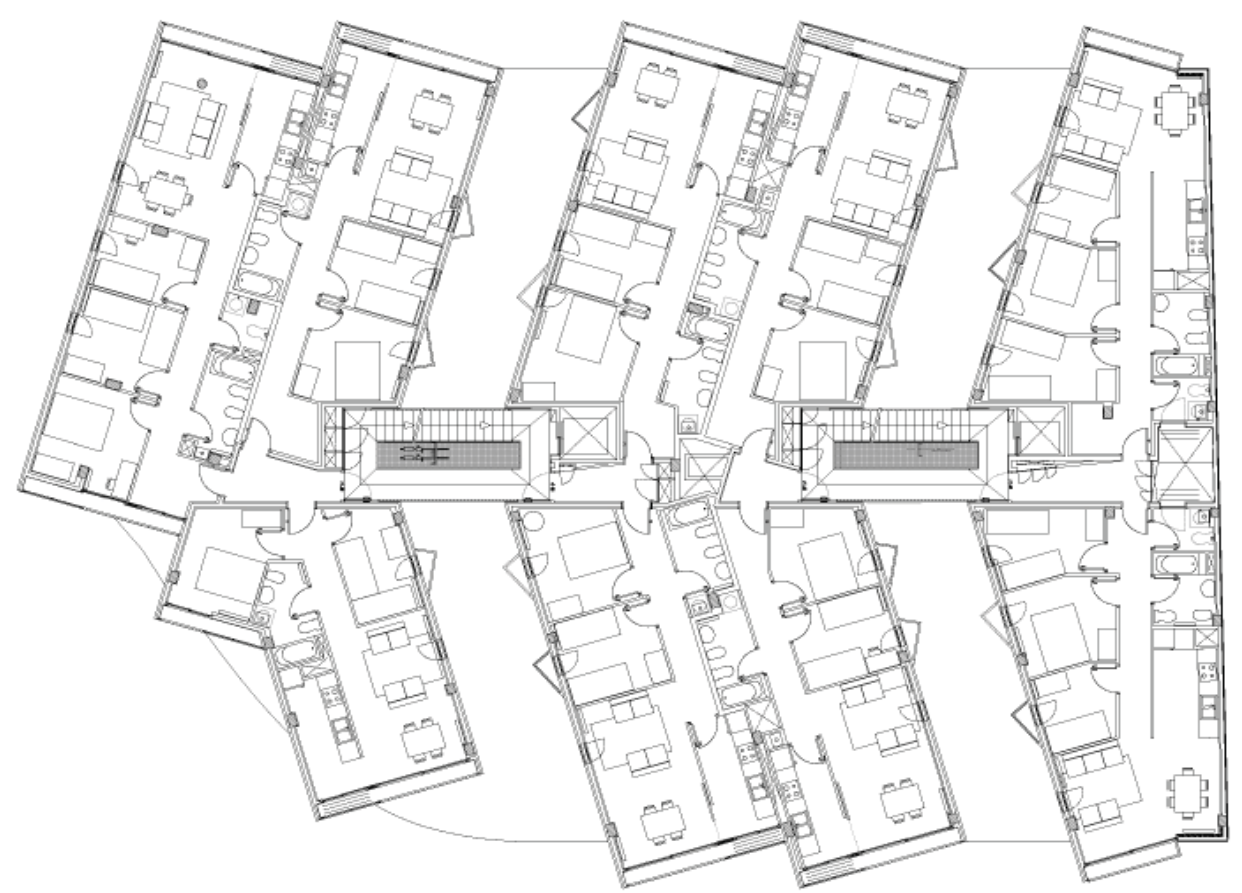

Ref. 5.39. Planta de las viviendas Europan 7 
opuestas con el fin de favorecer las vistas al exterior de la parcela, la ventilación de los dormitorios y la entrada del sol. El tratamiento de la fachada en estos patios de proporciones atípicas se proyecta a partir de una composición no repetitiva de huecos y un juego de balcones esporádicos que controlan la escala del espacio ${ }^{24 " .}$

Como ya se comentó, esta es una de las primeras obras que constuyen como equipo tal y como comenta uno de los miembros del comité científico. "Otro equipo, el de Angela Moragues y Hervé Meyer (MeMoArq), que junto con Birgit Hopff y Enric Gili fuera el ganador en Barcelona, ha terminado recientemente el conjunto de viviendas que les fue encargado en consecuencia, si bien en un emplazamiento alternativo propuesto en Lleida por el Instituto Catalán del Suelo, una de las instituciones que patrocinaba el emplazamiento original.

Analizando estas viviendas en abanico, su posición su posición respecto al contexto, la interacción con el sol y el aire, la relación entre el conjunto y las piezas individuales, podemos decir (al margen de las cuestiones del lenguaje) que, en otro contexto y a otra escala), MeMoArq aplica en esta obra algunas de las estrategias de aquel proyecto ganador.

Visitando su página web (www.memoarq.com), vemos que colocan esta obra como protagonista de su imagen pública, al ser el trabajo de mayor tamaño que han construido (en el sentido de la palabra más querido por los arquitectos). Se cumple así otro de los objetivos de Europan, posibilitar que estudios jóvenes accedan a un encargo de una escala mayor ${ }^{25}$ ".

En cuanto a la estética, este edificio es reconocible desde lejos y vuelve a pecar de cierto formalismo como algunos de los anteriores.

Europan 7 cierra su edición con 52 viviendas sociales construidas.

(...)

Quizá Europan como laboratorio tendría que ser más exhaustivo con los resultados obtenidos y estudiar la evolución de éstos con una investigación direccional.

Europan ha realizado diversas aportaciones a la arquitectura española y se puede concluir este capítulo diciendo que el esfuerzo intelectual de Europan ha valido la pena porque ha creado una nueva cultura arquitectónica ${ }^{26}$.

Hasta el momento se ha expuesto el cuerpo central de la tesis y se procede a continuación a extraer algunas conclusiones del trabajo desarrollado.

\footnotetext{
${ }^{24}$ Memoria del proyecto (proporcionada por los propios autores).

${ }^{25}$ ARROYO, Carlos Ibídem. p. 245.

26 "El imprescindible papel de Europan como laboratorio solo tiene sentido si las ideas desarrolladas terminan influenciando sobre la realidad (...). También es resultado deseable el derivado del efecto prestigiador del premio, que puede contribuir al lanzamiento de una carrera, o significar un punto de inflexión (...) Pero el tipo de resultado que encontramos imprescindible es el que construye una nueva cultura arquitectónica". ARROYO, Carlos. "Una taxonomía incompleta". Ibídem. p. 246.
} 

6. CONCLUSIONES 


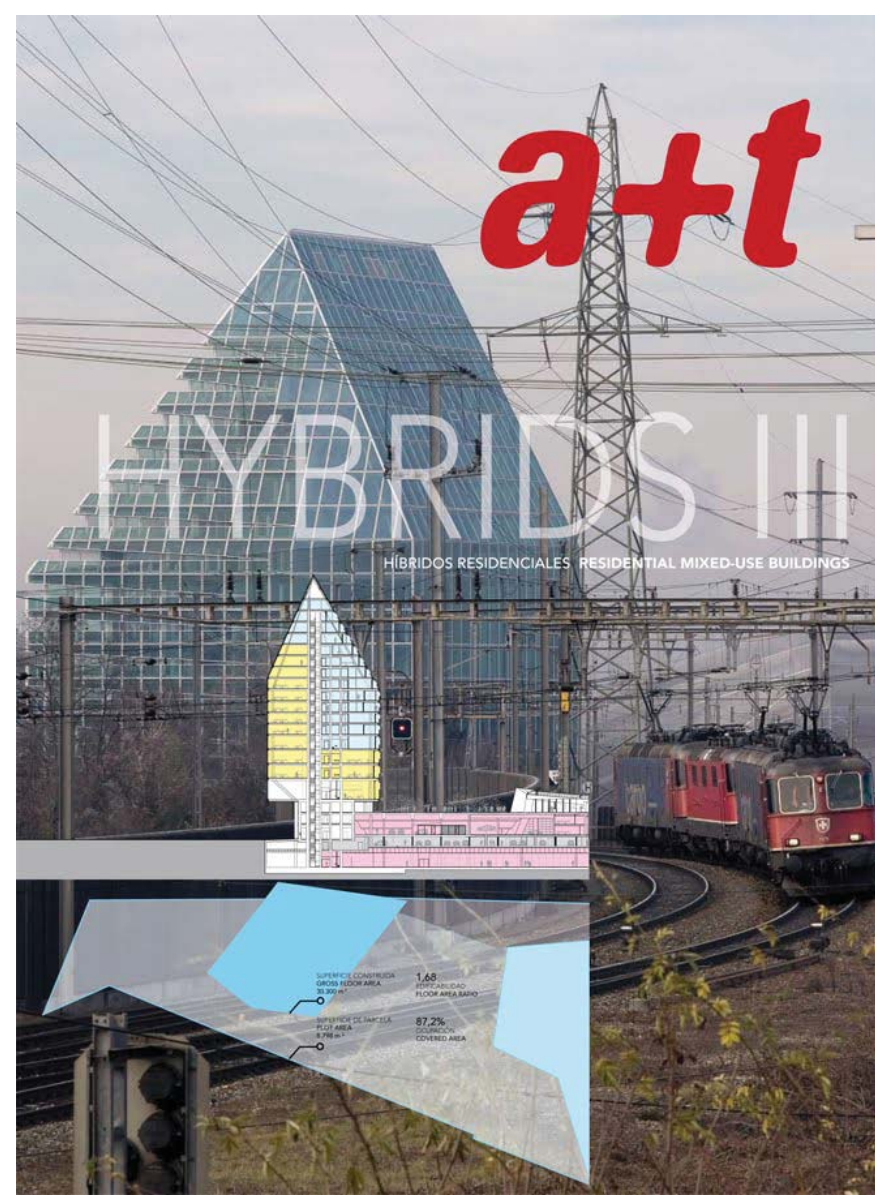

Ref.6.1. Publicación sobre edificios híbridos residenciales

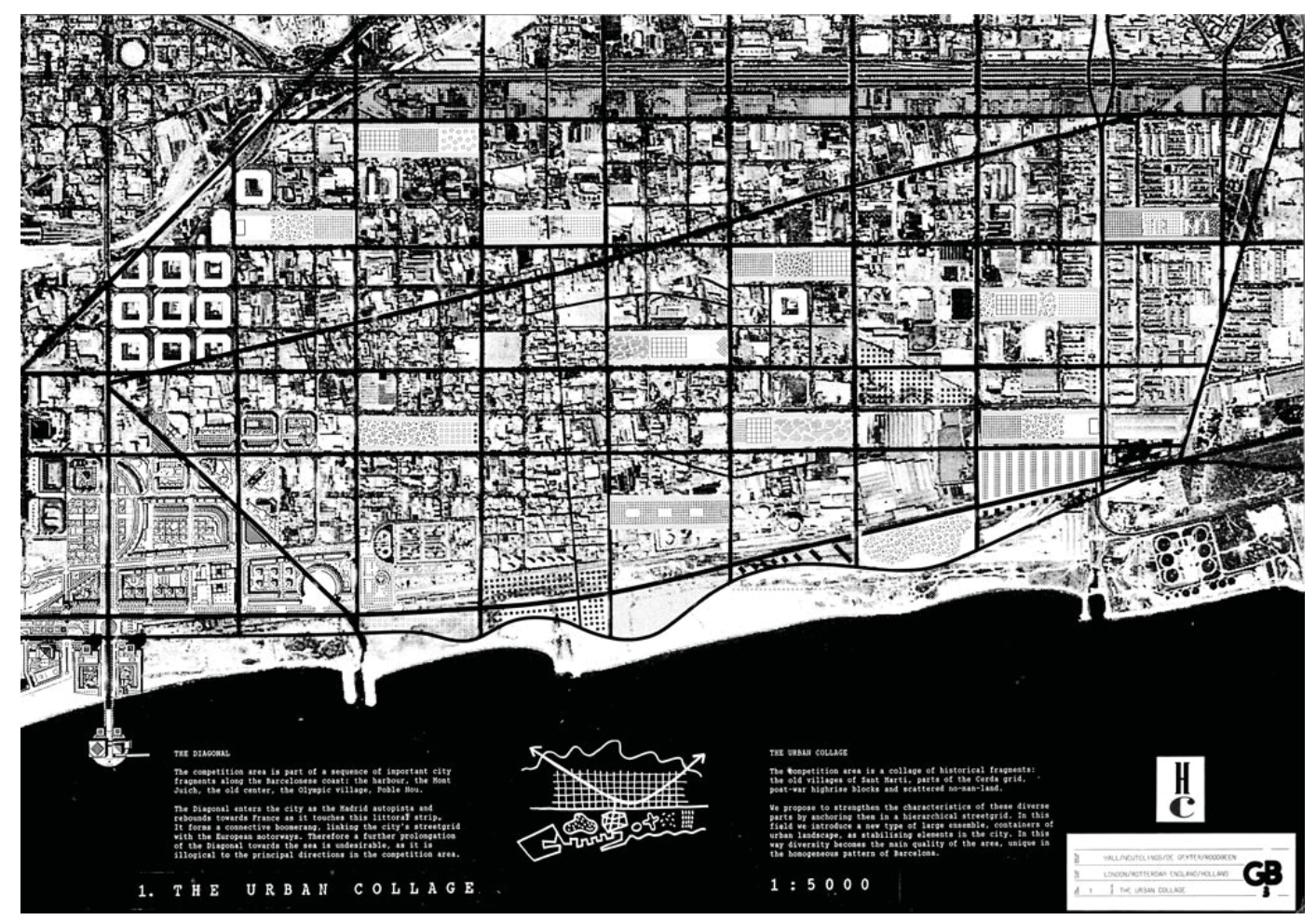

Ref.6.2. Collage de la ciudad de Barcelona,Exposición Arquitectura sin lugar (1968-2008), Barcelona. 


\section{CONCLUSIONES}

Europan ha cumplido más de veinte años y ha influido en la arquitectura nacional e internacional fundamentalmente en tres niveles: en el del trabajo de los jóvenes equipos de arquitectos, en el de la Administración Pública y en el de la materialización de la vivienda social experimental.

En cuanto a los jóvenes equipos, Europan les proporciona una plataforma de lanzamiento para dar a conocer sus propuestas a nivel europeo.

En el nivel de las Administración Pública, Europan ha fomentado la implicación social, pues su alto grado de participación demuestra que estos organismos están interesados en la reflexión sobre el hábitat y el espacio público de la ciudad europea.

Europan ofrece una aproximación a los modos de vida en el cambio de siglo en España con sus retos ${ }^{1}$ pendientes de resolver y sus logros con respecto a la vivienda del siglo XXI.

\section{Los retos de Europan}

\section{a) La hibridación² en los edificios de vivienda social}

Este primer reto queda patente en la tabla comparativa 5.2. de las propuestas edificios. La tabla muestra que no se ha conseguido materializar ningún proyecto de edificio híbrido pues en todos ellos el sótano se destina a garaje, la planta baja a uso comercial o residencial y las plantas superiores, exclusivamente, a uso residencial.

La cuestión de la hibridación se propone desde las primeras convocatorias, pero no se ha materializado de ninguna manera. ¿Por qué motivos? El motivo fundamental lo constituye la normativa existente que paraliza la ejecución de los proyectos de concurso planteados. También han faltado planteamientos innovadores.

Pero para poder actualizar la normativa existente hace falta, en primer lugar, un cambio de mentalidad en las personas que trabajan en la Administración Pública. La herencia del siglo XX ha sido la ciudad zonificada y fragmentada. La zonificación ha sido una de las herramientas más utilizada para controlar las variables urbanísticas. El reto de Europan consiste en desvincular el urbanismo de la lógica del mercado de suelos, tan instalada en los proceso de toma de decisiones en la

\footnotetext{
${ }^{1}$ Estos retos que se plantean quizá no se han logrado por la falta de recursos humanos y económicos para su seguimiento en la organización.

${ }^{2}$ El término hibridación hace referencia a la mezcla del uso residencial con todos los demás, evitando el modelo de ciudad dispersa. La zonificación trataba de concebir la ciudad como trozos diferentes que forman un collage. Pero la hibridación requiere un orden superior.
} 


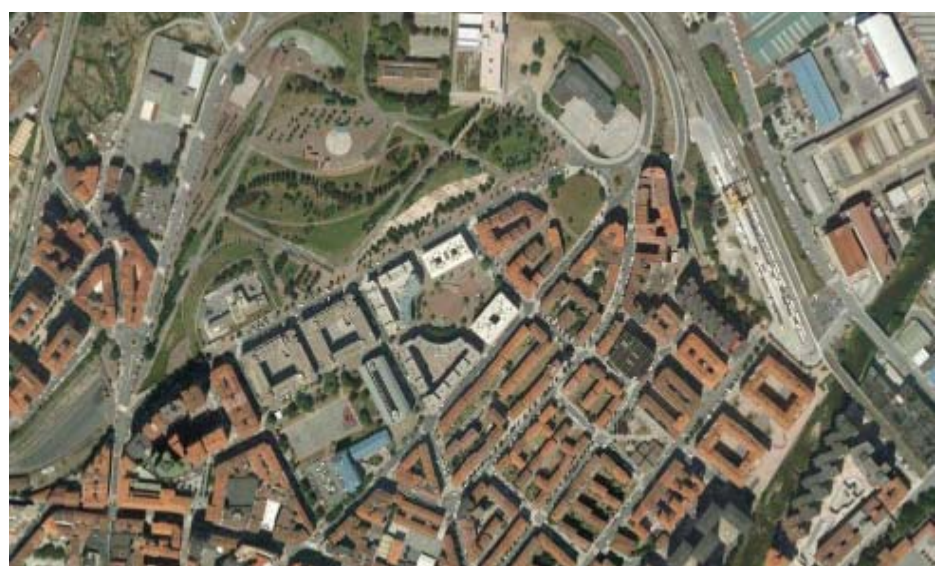

Ref.6.3. Europan 2. Bilbao. Matos y Castillo

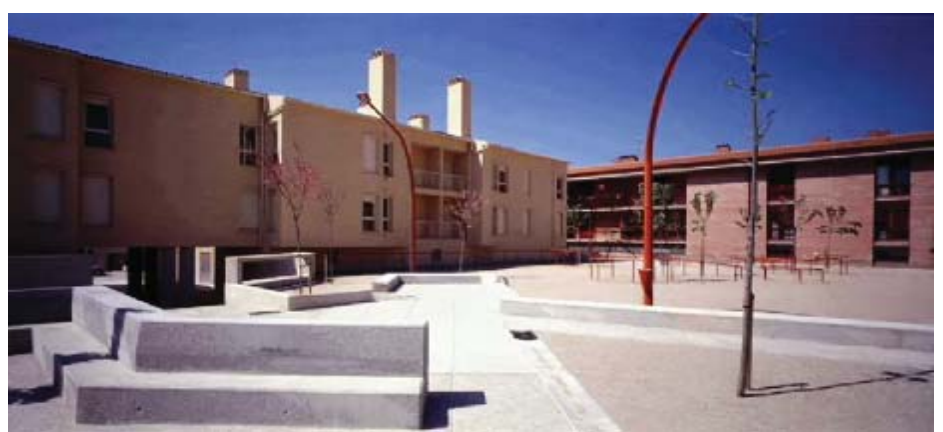

Ref.6.4. Europan 3. Lerida. Duch y Prats

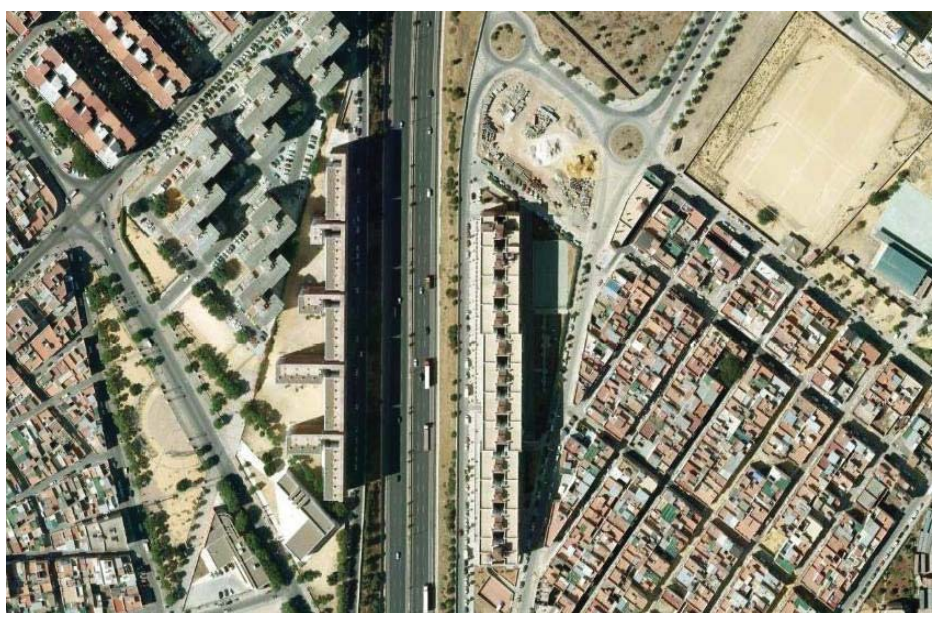

Ref.6.5. Europan 4. Sevilla. Nieto y Sobejano

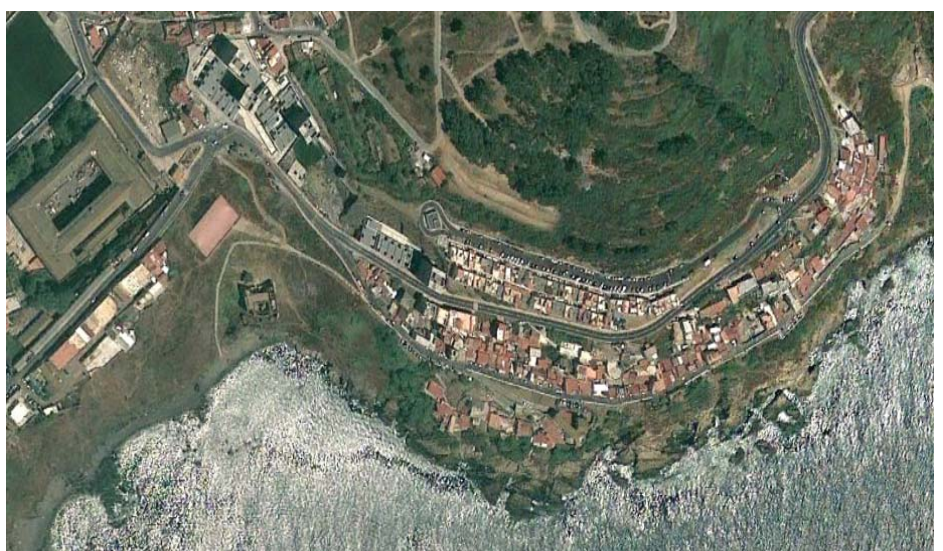

Ref.6.6. Europan 5. Ceuta. Morales y Mariscal 
ciudad. Frente a planteamientos que conducen a una "guetificación" basada en el urbanismo de la zonificación, se puede reproponer una ciudad híbrida.

Es decir, una ciudad de uso intensivo, para ser vivida las veinticuatro horas del día. Este enfoque requiere un cambio de planteamiento para trazar nuevos modelos urbanos superadores de los CIAM.

Europan plantea, desde la primera convocatoria (1988), la relación existente entre la vivienda y el trabajo, aunque no ofrece ninguna realización donde se haya experimentado. Sobre todo, la vivienda del siglo XXI se prepara para la posibilidad de que los habitantes trabajen en ella teniendo en cuenta la revolución digital producida en el cambio de siglo ${ }^{3}$.

\section{b) La integración de los espacios de relación en los edificios de vivienda social $^{4}$}

Europan considera, al menos en sus enunciados, que es esencial estudiar el espacio público que existe en la "ciudad de la complejidad". Los proyectos actuales de viviendas, según los enunciados, no sólo responden al espacio interior de éstas, sino que deben dar un paso más tratando de explicar la relación que existe entre el espacio residencial y el espacio público. Éste no es un espacio "vacío" (como se le ha denominado en muchos análisis de la ciudad).

El espacio de relación se ha analizado en los edificios de vivienda social construidos de dos formas: o bien en el interior del edificio (a través de las zonas comunes), o bien en el exterior de este, estudiando la relación con la cota cero y los espacios públicos.

En la tabla comparativa 5.2 de la propuesta de edificios se demuestra que el porcentaje de zonas comunes sobre el espacio total construido va en detrimento, como si se tratara de un espacio residual.

Otro de los motivos por el que falta que el espacio público exterior se integre en los proyectos de vivienda es la rigidez de la normativa existente y la manera de gestionar estos espacios desde la Administración Pública. Los edificios construidos que han desarrollado el planteamiento de concurso han tenido la intención de construir con el objeto de relacionarse y dialogar con la ciudad (Sánchez y Escobar en Madrid, Matos y Castillo en las manzanas de Basauri, Nieto y Sobejano en Sevilla, Burgos y Delapuerta en Bilbao y Morales y Mariscal en Ceuta).

\footnotetext{
${ }^{3}$ Se debería potenciar la capacidad de trabajar cerca o incluso en el mismo lugar de residencia, porque el outsourcing (la externalización) es un fenómeno a abolir en la ciudad actual. La ciudad contemporánea responde a las nuevas tecnologías que capacitan para trabajar desde cualquier parte del mundo sin necesidad de viajar. Con este fenómeno reduce los desplazamientos excesivos por causa del trabajo y la vivienda del siglo XXI debe estar preparada para ello con espacios que respondan a estas necesidades.

${ }^{4}$ Tal vez el motivo principal por el que falta esa integración sea el económico, pues no sale rentable ya que supone un incremento en el precio de las viviendas.
} 
VIVIENDAS EUROPAN (1988-2008) I Una aproximación a los modos de vida en el cambio de siglo en España

6. CONCLUSIONES

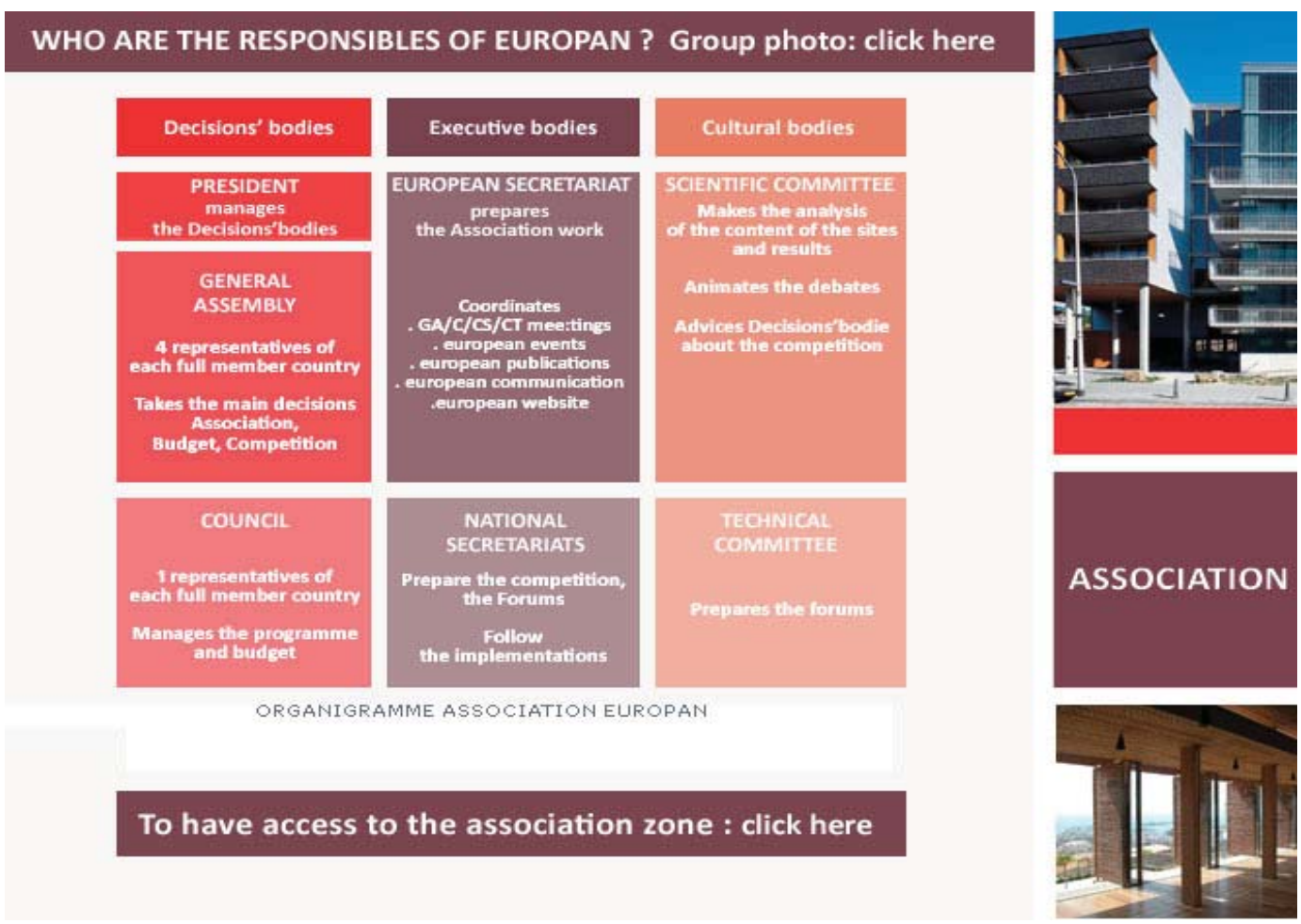

Ref.6.7. Información en [On line] <http://www.europan-europe.com> (Consulta 2 de diciembre de 2011)

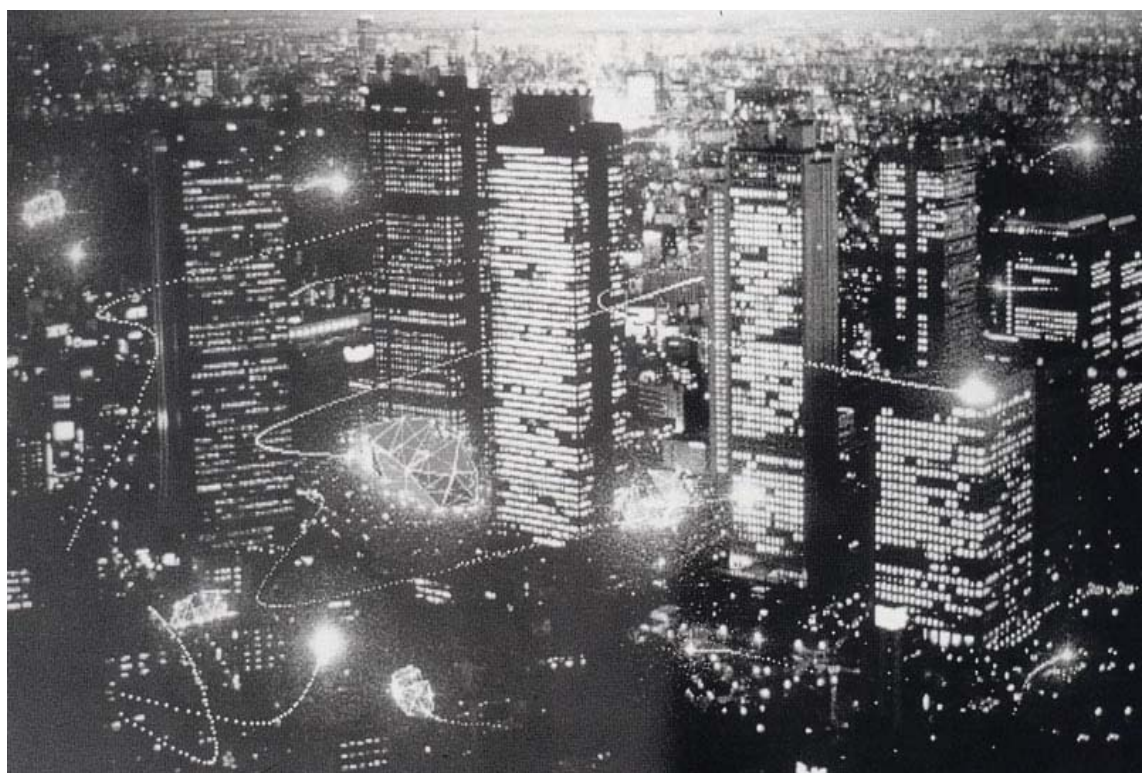

Ref.6.8. Proyecto para la mujer nómada, Toyo Ito, 1985. 


\section{c) La vivienda como servicio, no como icono}

Existe en Europan un gran contraste entre el planteamiento de sus enunciados de una arquitectura de vanguardia y los resultados: tanto de las propuestas de concurso como de las viviendas construidas ya que poco a poco se tiende a lo "convencional".

En la tabla comparativa 5.3 de las propuestas de las viviendas, se llega a la conclusión de que no ha habido mucha evolución en los planteamientos de concurso y en las realizaciones: siguen teniendo un número de espacios análogos, con funciones semejantes y unos criterios higiénicos aproximados.

Si se comparan entre sí las viviendas más representativas (redibujadas en las fichas de elaboración propia), se puede observar cómo el espacio de las viviendas sigue estando compartimentado y se aprecia que lo que más ha variado ha sido la disminución de la superficie de cada vivienda. Se vive con menos espacio de vivienda, compartiendo necesidades funcionales básicas semejantes, con las mismas particiones.

En este sentido, Europan no ha buscado una vivienda diferente, sino que más bien se ha preocupado especialmente por la forma, como si se tratara de un icono. Esto contrasta en gran manera con la filosofía de Europan, que, a través de sus enunciados, ha reflejado un nuevo modo de mirar la arquitectura dirigiéndola hacia donde están las necesidades de las personas: el homework, los modos de vida, la relación con la naturaleza y el medio ambiente, la movilidad, la adaptación rápida a los cambios sociales,etc. Esta última es una de las necesidades más importantes que Europan ha detectado en el cambio de siglo. Se ha producido una circunstancia novedosa que ha consistido en una mayor movilidad de individuos generada fundamentalmente porque las relaciones sociales son menos estables. Plantea que las ciudades deben responder a estos cambios y, por lo tanto, también la vivienda. Es decir, Europan trata de captar las necesidades del siglo $X X I$, pero sus planteamientos se diluyen cuando se miran las transformaciones de las viviendas construidas.

\section{Los logros de Europan}

\section{La vivienda entendida desde la ciudad}

Esta es la principal aportación de Europan a la vivienda. El concurso ha ido ampliando la escala de sus actuaciones: desde la escala de vivienda, a la de edificación, después a la urbana y, por último, a la territorial. La primera edición comenzó con un zoom a nivel proyectual actuando sobre solares existentes, y las últimas ediciones han planteado actuaciones de hectáreas. Europan ha establecido un amplio análisis, de forma intencionada, para abordar la complejidad de las ciudades y, desde ahí, descender al problema de la vivienda. 


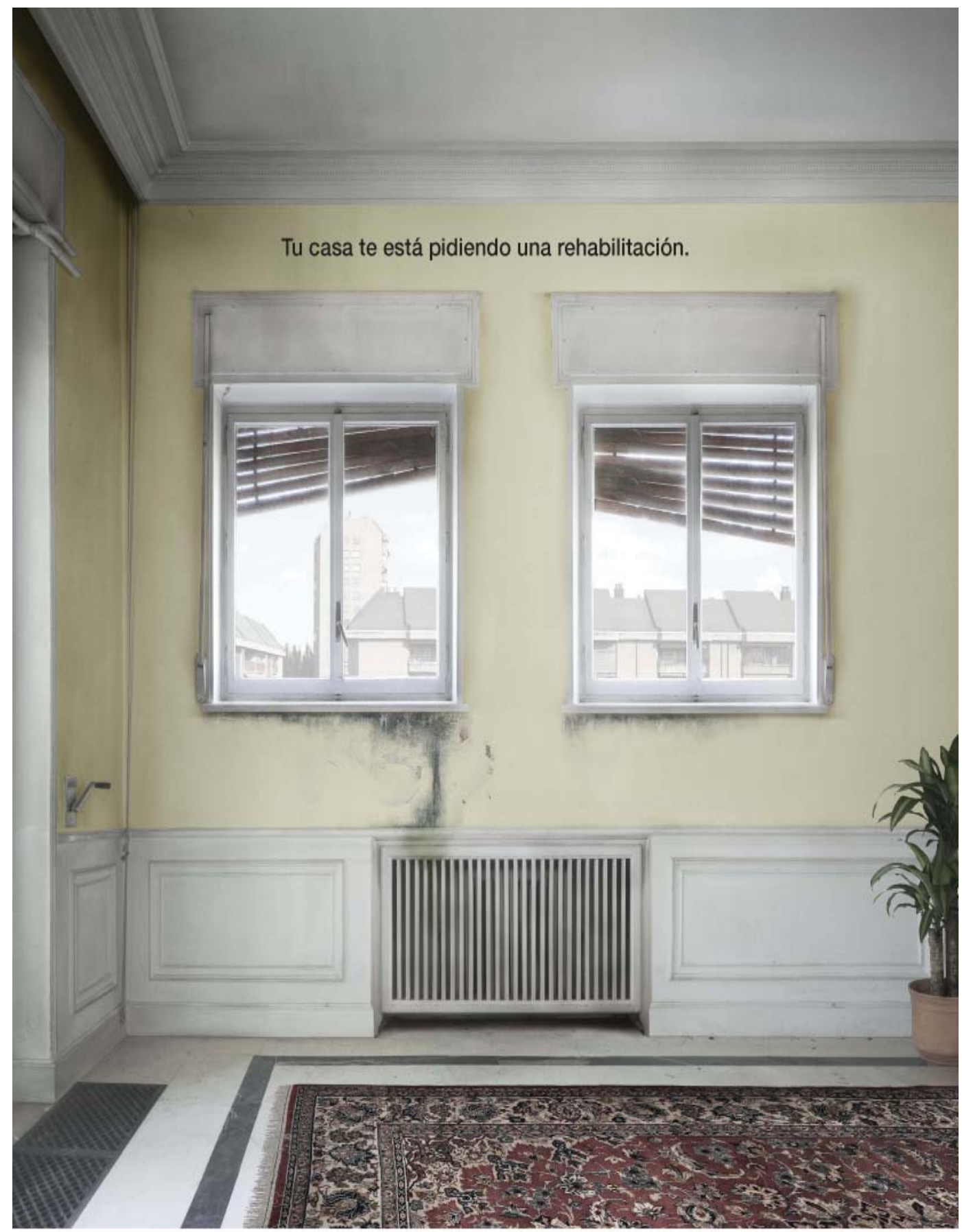

\section{Mejora tu calidad de vida. Revaloriza tu vivienda.}

Si crees que tu hogar puede ser un lugar mejor, êste es el momento. Ahora, además de las ayudas para la rehabitación de viviendas que otorga el Ministerio de Fomento, podrás ahorrarte en tu declaracóón de la renta hasta $4.000 €$ por las obras que realices en tu vivienda*. Además, por muchas de estas obras, pagarás sólo el 8\% de IVA. Aprovecha esta oportunidad. Infórmate en wWw.tomento.gob.es

AYUDAS PARA LA REHABILTTACIÓN DE VIVIENDAS.

$8 \%$ DE IVA | AHORRA HASTA $4.000 €$ EN TU IRPF | PARAEL $98 \%$ DE VIVIENDAS

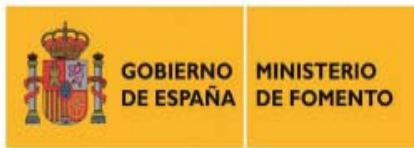

Sólo hasta el 31 de diciembre de 2012

Ref.6.9. Anuncio del Gobierno de España para promover la rehabilitación 
Europan enfatiza en sus enunciados que la vivienda no es un ente aislado tanto en el espacio como en el tiempo ${ }^{5}$, sino que se encuentra dentro de un elemento complejo llamado ciudad. La vivienda se ha planteado y entendido en sus enunciados como parte de un conjunto, no como un proyecto aislado en el espacio, parecido a la isla de Robinson Crusoe. Ese enfoque propone al arquitecto hacerse muchas más preguntas antes de trabajar: ¿cómo repercute este proyecto en el conjunto?, ¿qué aporta el proyecto a la ciudad?, ¿cómo dialoga con ella?, ¿cómo trata el espacio público?, etc.

En cuanto a la incorporación del factor temporal, Europan parte de la base de que la ciudad, por su condición de organismo vivo, no puede ser pensada como un objeto terminado o congelado. Entiende que los proyectos de vivienda están abiertos a las conexiones y a la transformación de lo existente.

Europan ha elaborado una reflexión sobre el concepto de reciclaje ${ }^{6}$ que incorpora el factor temporal en la ciudad y la estudia potenciando lo existente. Por eso, parte de la premisa de que hace falta poder actuar sobre lo existente, con una intervención de cirugía. Los planteamientos de Europan en este aspecto han ido evolucionando: desde los comienzos cuando se proponían solares aislados, hasta la integración de estos en la ciudad, pasando, en estas últimas ediciones, a una propuesta de nuevas estrategias que revitalicen las áreas residenciales sin apenas consumir nuevo suelo.

La tabla comparativa 5.1. de las propuestas urbanas muestra que una tercera parte de los edificios construidos dialogan con el entorno, se abren hacia la ciudad. Coincide, además, el hecho de que esos proyectos son los que se han desarrollado conforme a los planteamientos de concurso, por lo que se deduce que existe una voluntad de diálogo con la ciudad desde los proyectos premiados. Pero, paradójicamente, los enunciados de Europan son más propositivos que sus realizaciones, pues no han propuesto soluciones que reflexionen sobre el factor temporal de las ciudades, sobre lo ya existente.

Una de las razones por las que se demuestra que Europan entiende la vivienda desde la ciudad ha sido el descenso en la construcción de viviendas ${ }^{7}$.

\footnotetext{
${ }^{5}$ Plantea en las últimas convocatorias temas de reflexión a escala urbana como la actuación sobre las redes, la dinámica urbana, la accesibilidad residencial y la urbanización de las infraestructuras.

${ }^{6}$ Este término aparecerá en Europan 8 (año 2004), aunque ya se haya considerado indirectamente en los planteamientos conceptuales de las convocatorias anteriores.

${ }^{7}$ Los resultados de las realizaciones han sido variados en los distintos países participantes. España es -junto con Francia y Holanda- uno de los países en los que más se han implementado. Pero lo cierto es que Europan ha ido construyendo cada vez menos viviendas. De los 302 proyectos galardonados en España se construye tan sólo una veintena de edificios que viene a ser aproximadamente un $7 \%$ de los premiados y un $0,7 \%$ de los presentados. Se ha hecho patente que Europan ha construido cada vez menos
} 

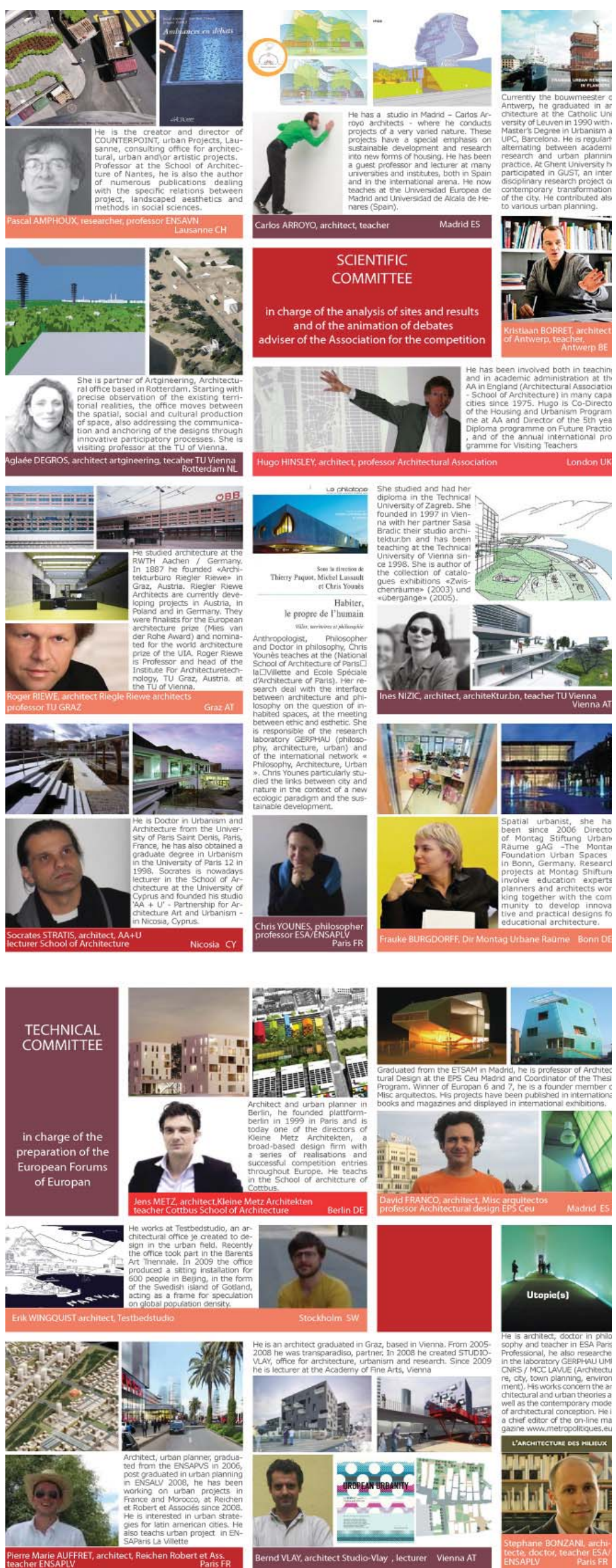

Ref. 6.10 Comité científico europeo Información [On line] $<$ http://www.europan-europe.com> (Consulta 2 de diciembre de 2011) 
Algunos de los motivos de este descenso han sido: la difícil concreción de los contenidos de sus enunciados (por su amplitud), el complejo sistema de gestión de la Administración Pública, la falta de adaptación a la normativa existente, la inexperiencia de los equipos, el alargamiento de los proyectos en el tiempo y la alta frecuencia en su edición, lo que supone pocos intervalos de tiempo para actuar.

Además de estas razones, existe otro motivo por el que Europan ha dejado de construir: la apuesta por el no consumo de nuevo suelo en la ciudad .

Europan ha ido proponiendo en sus enunciados estrategias para revitalizar los barrios existentes, ya que plantea que el crecimiento de las ciudades tiene que ser cualitativo, no cuantitativo. En este sentido, Europan es la fuente de creación de una nueva cultura arquitectónica que no consiste en construir a toda costa, sino que se basa en la cultura de la "invisibilidad", de una arquitectura menos preocupada por la forma.

Es cierto que Europan aún no se ha planteado directamente en ninguna convocatoria no consumir nuevo suelo. Pero, con la situación actual en la que se encuentra España y los resultados obtenidos, sería una opción válida a la hora de investigar en vivienda. De este modo, la Administración Pública no tendría que realizar tanto esfuerzo para aportar solares, sino que "solo" sería necesario estudiar qué áreas residenciales están quedando obsoletas para realizar una actuación de reciclaje urbano y proponer en ellas el concurso Europan.

Existe el prejuicio de que, si no hay actuación visible, no existe actuación. Y como no se valora, por lo tanto, no se paga. Ya lo intuían algunos de los grandes arquitectos. Cuando, en un momento determinado, Kahn le pidió a Barragán diseñar los jardines del Instituto Salk, este último respondió que no había lugar para un jardín en ese sitio y que lo dejara así porque lo que había era suficiente. Se cuenta entonces que Kahn le preguntó cuánto tenía que pagarle por aquella aportación ya que, "aparentemente", no había hecho casi nada...

edificios de viviendas. ¿Por qué motivo? ¿Se está extinguiendo la actuación de Europan? ¿Están decayendo las propuestas que se realizan en cada edición?

8 Según el Comité Nacional de Europan la continua sucesión bianual de convocatorias va más aprisa que la posibilidad de investigar en la vivienda experimental. En este sentido sería conveniente un nuevo planteamiento que permita rentabilizar la inversión de tiempo y de dinero. Sería necesaria la evaluación de resultados obtenida en cada convocatoria a través de las realizaciones. 

7. BIBLIOGRAFÍA 


\subsection{General}

ALEXANDER, Christopher, El modo intemporal de construir. Ed. Gustavo Gili. Barcelona, 1979.

------Un lenguaje de patrones. Ed. Gustavo Gili. Barcelona, 1980.

ANDO, Tadao. Arquitectura y espíritu. Ed. Gustavo Gili. Barcelona. 1998.

AA.VV., En el corazón de la ciudad. Ed. Hoepli. Barcelona, 1961 (2ºdición). -----Incursiones arquitectónicas, ensayo a cuatro bandas. Ed.Universidad de Granada. Granada. 2009.

-----“Spain Builds. Arquitectura en España 1975-2005” en A\&V Monografías de arquitectura y vivienda. $\mathrm{n}^{\circ}$ 113. Madrid. 2005.

---- X Bienal de Arquitectura española. Ed. Fundación Caja de Arquitectos. Madrid. 2010.

----- Invitación a la arquitectura. Ed. Naos. Madrid. 2002.

-----Las herramientas del Arquitecto. Ed. Ed. Ediciones Generales de la Construcción. Valencia. 2003.

-----“Francisco Javier Saenz de Oiza (1947-1988)". El Croquis n 32-33. Madrid. 2002.

ARGAN Giulio Carlo. Sobre el concepto de tipología arquitectónica. Ed. Escuela Técnica Superior de Aarquitectura de Barcelona. Barcelona. 1974.

BACHELARD, Gaston. La poética del espacio. Ed. Fondo de cultura económica. México, 1965.

BARRAGÁN, Luis. Luis Barragán: Escritos y conversaciones. Ed. El Croquis. Madrid. 2000.

BENÉVOLO, Leonardo, La proyectación de la ciudad moderna. Ed. Gustavo Gili. Barcelona. 1978.

----- Historia de la arquitectura moderna. Ed. Gustavo Gili. Barcelona. 1990.

BOESIGER, W. (y GIRSBERGER, H.). Le Corbusier 1910-1965. Ed. Gustavo Gili. Barcelona.1987.

BORGES, Jorge Luis. Obras completas. Ed. Emecé. Barcelona. 1989.

BRADBURY, Ray. Farenheit 451. Ed. Plaza\&Janes. Madrid. 1988.

CANIGGIA, Gianfranco (y MAFFEI, Gian L.), Tipología de la edificación. Estructura del espacio antrópico. Ed. Naos. Madrid. 1995.

CANO LASO, Julio. Conversaciones con un arquitecto del pasado. Diálogo de la técnica y del espíritu. Ed. Fundación Esteyco. Madrid.1996.

CAPITEL, Antón y BALDELLOU, Miguel Ángel, Arquitectura española del siglo XX. Enciclopedia Summa Artis. Volumen XL. Ed. Espasa Calpe. Madrid. 1995. 
CAMPO BAEZA, Alberto, La idea construida. Ed. Colegio Oficial de Arquitectos de Madrid. Madrid. 1996.

----- Aprendiendo a pensar. Ed. Nobuko. Buenos Aires. 2009.

----- Pensar con las manos. Ed. Nobuko. Buenos Aires. 2009.

----- La estructura de la estructura. Ed. Nobuko. Buenos Aires. 2010.

CENTELLAS SOLER, Miguel. Los pueblos de colonización de Fernández del Amo. Arte, arquitectura y urbanismo. Ed. Fundación Caja de Arquitectos. Barcelona. 2010.

COLLINS, Peter. Los ideales de la arquitectura moderna: su evolución (17501950). Ed. Gustavo Gili. Barcelona. 1970.

DE LA SOTA, Alejandro. Escritos, conversaciones, conferencias. Editorial Gustavo Gili. Barcelona. 2002.

DE FUSCO, Renato. Historia de la arquitectura contemporánea. Ed. Celeste. Madrid. 1994.

EDELMAN, Bernard. La Maison de Kant. Ed. Payot. Paris.1984.

EDWARDS, Brian. Guía Básica de la Sostenibilidad. Ed. Gustavo Gili. Barcelona. 2008

FRIEDMAN, Thomas. La tierra es plana. Ed. Martínez Roca. Madrid. 2005.

GARCÍA-BURGOS, Alberto. Modernidad atemporal. Ed. General de Ediciones de Arquitectura.Valencia. 2011.

GARCÍA VÁZQUEZ, Carlos. Ciudad hojaldre. Visiones urbanas del siglo XXI. Ed. Gustavo Gili. Barcelona. 2005.

HERNÁNDEZ PEZZI, Carlos. Ciudades contra burbujas. Ed. Los libros de la catarata. Madrid. 2010.

HITCHCOCK, Henry Russell y JOHNSON, Philip. El Estilo internacional: arquitectura desde 1922. Ed. Comisión de Cultura del Colegio Oficial de Aparejadores y Arquitectos Técnicos. Murcia. 1984.

IÑIGUEZ VILLANUEVA, Manuel. La columna y el muro. Fragmentos de un diálogo. Ed. Fundación Caja de Arquitectos. Barcelona. 2001.

KAHN, Louis. Conversaciones con estudiantes. Ed. Gustavo Gili. Barcelona. 2002.

KOSTOF, Spiro. Historia de la arquitectura. Ed. Alianza Forma.Madrid. 2003.

LE CORBUSIER, Obra completa (1910-1969). Ed. Blume. Madrid. 1987.

LOOS, Adolf. Ornamento y delito. Ed. Gustavo Gili. Barcelona. 1972. 
MARCHÁN FIZ Simón. La arquitectura del siglo XX.Textos. Ed. Alberto Corazón. Madrid. 1974.

MARTÍ ARÍS, Carlos. Variaciones de la identidad. Ensayo sobre el tipo en arquitectura. Ed. Del Serbal. Barcelona. 1993.

----- De la periferia urbana a la ciudad policéntrica. Sevilla. 2005.

MAS LLORENS, Vicente. En principio. El marco ético de la arquitectura moderna. Ed. Ediciones Generales de la Construcción. Valencia. 2004.

MARTÍ CIRIQUIÁN, Pablo, La construcción de la ciudad europea a través de los CIAM. Tesis de la Universidad Politécnica de Valencia. Valencia. 2001.

-----Análisis de unidades residenciales contemporáneos: Urbanismo II. Ed. Club Universitario. Alicante. 2011

MIDANT, Jean-Paul. Diccionario de Arquitectura del siglo XX. Ed. Aka. Madrid. 2003.

MIES VAN DER ROHE, Ludwig. Escritos, diálogos y discursos. Colegio Oficial de aparejadores y arquitectos técnicos. Murcia. 1981.

MONTANER, Josep Maria, (y HEREU, Pere, OLIVERAS, Jordi), Textos de arquitectura de la modernidad.Ed. Nerea. Donostia-San Sebastian.1994.

----- La modernidad superada. Ed. Gustavo Gili. Barcelona. 2011.

MOSTERÍN, Jesús. Conceptos y teorías en la ciencia. Ed. Alianza Universidad. Madrid. 1984.

NEUMEYER, Fritz. Mies van der Rohe. La palabra sin artificio. Reflexiones sobre la arquitectura 1922-1968. Ed. El Croquis. Madrid. 1995.

NORBERG-SCHULZ, Christian. Kahn: Idea e imagen. Ed. Xarait. Madrid. 1981.

PAWSON, John. La expresión sencilla del pensamiento complejo. Ed. El croquis. Madrid. 2005.

PERA, Martí y AGUADO, Andrea. After Architecture: Tipologías del después. Ed. Actar. Barcelona. 2009.

PEREZ IGUALADA, Javier. Arquitecturas comparadas. Ed. General de Ediciones de Arquitectura. Valencia. 2008.

PIÑON PALLARES, Helio. Reflexión histórica de la arquitectura moderna. Ed. Península. Barcelona. 1981.

RODRIGUEZ CHEDA, J.M. Alejandro de la Sota. Construcción, idea y arquitectura. Ed. Colegio Oficial de Arquitectos de Galicia. Santiago de Compostela. 1994.

ROGERS, Richard, (y GUMUCHDJIAN, Philip), Ciudades para un pequeño planeta. Ed. Gustavo Gili. Barcelona. 2002. 
SIZA, Alvaro. Imaginar la evidencia. Ed. Abada. Madrid. 2003.

SOLAGUREN-BEASCOA DEL CORRAL, F., Arne Jacobsen. Ed. Gustavo Gili. Barcelona. 1989.

SOSA DÍAZ-SAAVEDRA, José Antonio. Contextualismo y abstracción. Tesis doctoral Universidad de las Palmas. 1995

STEELE, James. Arquitectura y revolución digital. Ed. Gustavo Gili. Barcelona. 2001.

TORRES CUECO, Jorge. Le Corbusier: visiones de la técnica en cinco tiempos. Ed. Caja de arquitectos. Barcelona. 2004.

VALÉRY, Paul. Eupalinos, el arquitecto. Ed. Colección de arquitectura Colegio oficial de Aparejadores y Arquitectos técnicos de Alicante. Valencia.1982.

VALERO RAMOS, Elisa, Ocio Peligroso, Ed. General de Ediciones de Arquitectura, Valencia, 2006.

----- Universidad Laboral de Almería 1971-1974(J. Cano, A. Campo, M. Martín, A. Más). Ed. Colegio de Arquitectos de Almería. Almería. 2008.

----- La materia intangible, reflexiones sobre la luz en el proyecto de arquitectura. Ed. Generales de la construcción. Valencia. 2004.

VAN DER ROHE, Mies, Burohaus G, n 1, 1923.

VAN EYCK, Aldo. El interior del tiempo y otros escritos. Revista Circo, 1996.37.

VIDOTTO, Marco. Alison+Smithson, Obras y Proyectos. Ed. Gustavo Gili, Barcelona. 1997.

WILLIAMS, Christopher. Artesanos de lo necesario. Ed. H. Blume. Madrid. 1978.

ZUMPTOR, Peter. Atmósferas. Ed. Gustavo Gili. Barcelona. 2006.

\subsection{Sobre vivienda}

ÁBALOS, Iñaki. La buena vida. Visita guiada a las casas de la modernidad. Ed. Gustavo Gili. Barcelona. 2000.

AICHER, Otl. La cocina para cocinar. El final de una doctrina arquitectónica. Ed. Gustavo Gili. Barcelona. 2004.

ALFARO HOFMANN, Andrés. Mecanització de la casa: una historia de l'electrodomestic. Ed. Generalitat de Valencia. Valencia. 1995.

ÁLVAREZ MONZONILLO, Jose María. El futuro del ocio en el hogar. Ed. Fundación Autor. Madrid. 2004. 
AA.VV. Edificación Sostenible. Revitalización y rehabilitación de barrios. Cuaderno de abstracts. Ed. Gobierno de España y Ministerio de la Vivienda. Madrid. 2010.

---- La casa. Evolución del espacio doméstico en España. 2 vol. Ed. El Viso. Madrid. 2006.

----- Nuevas formas de habitar. Ed. Impiva (OTH). Valencia. 2009.

----- Nuevos modos de habitar. Ed. Colegio Territorial de Arquitectos de Valencia. Valencia. 1995.

----- La vivienda que aún no tenemos. Ed. Tribuna de la Construcción. Valencia. 2002.

---- Vivienda, nuevas maneras de hacer. Ed. Actar. Barcelona. 2002.

----- Vivienda, innovación y proyecto. Ed. Actar. Barcelona. 2000.

---- ¡Hogar! El imaginario arquitectónico en la revista ¡Hola!. Ed. Actar. Barcelona. 2006.

----- Vivienda y sostenibilidad en España. 2 vol. Ed. Gustavo Gili. Barcelona. 2007.

----- Plus. La vivienda colectiva, territorio de excepción. Ed. Gustavo Gili. Barcelona. 2007.

----- El cuarto de baño en la vivienda urbana. Una perspectiva histórica. Ed. Fundacion Colegio Oficial de Arquitectos de Madrid. Madrid. 2001.

----- Cuaderno de tendencias del hábitat 08/09. Ed. Impiva. Valencia. 2007.

----- Cuaderno de tendencias del hábitat 10/11. Ed. Impiva. Valencia. 2009.

----- Legislación sobre vivienda: Normativa Estatal y Autonómica, $4^{\circ}$ edición. Ed. Tecnos. Madrid. 2011.

---- "Vivienda". n 176. en Arquitectos, Ed.Colegio Oficial de Arquitectos de Madrid, Madrid. 2005.

-----“La construcción de la ciudad”. n 178. en Arquitectos, Ed.Colegio Oficial de Arquitectos de Madrid. Madrid. 2006.

----- Concurso para la construcción de 5688 viviendas protegidas. Ed.

Colegio Oficial de Arquitectos de Madrid. Madrid. 2008.

----- La Casa, el arquitecto y su tiempo. Ed. Colegio Oficial de Arquitectos de Madrid. Madrid. 1990.

- La vivienda en la Escuela Técnica Superior de Arquitectura de Madrid. Lecciones prácticas para el siglo XXI. Ed. Colegio Oficial de Arquitectos de Madrid. Madrid. 1995.

----- Tipologías de la vivienda colectiva en Madrid, 1860-1970. Ed. Colegio Oficial de Arquitectos de Madrid. Madrid. 1982.

----- La vivienda en la Escuela de Roma. Lecciones prácticas para el siglo XXI. Ed. Colegio Oficial de Arquitectos de Madrid. Madrid. 1997.

-----“Casa, cuerpo, sueños”, n 12 de A\&V Monografías de arquitectura y vivienda. Madrid. 1987.

---- "El espacio privado", n 14 de A\&V Monografías de arquitectura y vivienda. Madrid. 1988.

-----“Casas de los maestros", $\mathrm{n}^{\circ} 132$ de A\&V Monografías de arquitectura y vivienda. Madrid. 2008.

AYMONINO, Carlo. La vivienda racional. Ed. Gustavo Gili. Barcelona. 1973.

BÉLEZE, M La casa y sus accesorios. Manual de economía doméstica. Ed. Carlos Bailly-Bailliere. Madrid. 1872.

BLAT, Juan. Vivienda obrera y crecimiento urbano (Valencia 1835-1936). Tesis doctoral de la Universidad Politécnica de Valencia. Valencia. 2000. 
BORGIA SORROSAL, Sofia. El derecho constitucional a una vivienda digna. Ed. Dikinson. Madrid. 2010.

CORTÉS ALCALÁ, Luis. La cuestión residencial: bases para una sociología del habitar. Ed. Fundamentos, Madrid, 1995.

DELOUNDER, Loüisa F. La cocina y otros espacios domésticos. Manual práctico. Ed. Gustavo Gili. Barcelona. 2009.

FERNÁNDEZ GALIANO, Luis, La quimera moderna. Ed. Herman Blume. Madrid. 1989.

-----El espacio privado. Cinco siglos en veinte palabras. Ed. Ministerio de Cultura. Madrid. 1991.

FRAMPTON, Kenneth. Estudios sobre cultura tectónica. Ed. Akal Arquitectura. Madrid. 1999.

FRENCH, Hillary, Nueva vivienda urbana. Ed. Gustavo Gili. Barcelona. 2006.

----- Vivienda colectiva paradigmática del siglo XX. Ed. Gustavo Gili. Barcelona. 2009.

GALLEGO, Manuel. Alejandro de la Sota, viviendas en la Alcudia, Mallorca. Cuadernos de investigación de la Exposición Arquitecturas Ausentes del Siglo XX. Ed. Rueda. Madrid. 2004.

GARCIA UYARRA, Angel. La casa en España. Cuadernos de la dirección general para la Vivienda y Arquitectura, Ed. Ministerio de Obras públicas y Urbanismo. Madrid. 1987.

GIEDION, Siegfried. La mecanización toma el mando. Ed. Gustavo Gili, Barcelona. 1978.

GIMÉNEZ, Antonio. La vivienda colectiva. Ed. Pencil. Alboraya. 2005.

GILI GALFETTI, Gustavo, Mi casa, mi paraíso. Ed. Gustavo Gili. Barcelona. 1999. ----- Pisos piloto: células domésticas experimentales. Ed. Gustavo Gili. Barcelona.1997.

HERREROS, Juan. Vivienda y espacio doméstico en el siglo XXI. Ed. La casa encendida. Madrid. 2007

HEWEL, Dirk Van Der \& RISSELADA, Max. De la casa del futuro a la casa de hoy. Alison y Peter Smithson. Ed. Poligrafa. Barcelona. 2008.

IBAÑEZ, Jesús. Por una sociología de la vida cotidiana. Ed. Siglo XXI. Madrid. 1994.

KOOLHAAS, Rem. S, M,L, XL. Ed. Klonecellipress. New York. 1995.

LE CORBUSIER, La vivienda del hombre. Ed. Espasa-Calpe. Madrid. 1945.

----- La ciudad del futuro. Ed. Infinito. Buenos Aires. 1962.

----- Una pequeña casa. Ed. Infinito. Buenos Aires. 2005. 
LLEÓ, Blanca. El sueño de habitar. Ed. Gustavo Gili. Barcelona. 2005.

---- Aproximaciones a la investigación en arquitectura. Ed. Nobuko. Buenos Aires.2012.

MANCEBO ROCA, Juan Agustín. "Arquitectura futurista". Ed. Síntesis. Madrid. 2008.

MONTANER, Josep Maria. Habitar el presente. Vivienda en España: sociedad, ciudad, tecnología y recursos. Ed. Ministerio de la vivienda. Madrid. 2006.

MONTEYS, Xavier, y FUERTES, Pere. Casa Collage. Un ensayo sobre la arquitectura de la casa. Ed. Gustavo Gili. Barcelona. 2002.

MOORE, Charles, (y ALLEN, Gerald) Dimensiones de la arquitectura (1976). Ed.Gustavo Gili. Barcelona. 1978.

---- La casa: Forma y diseño. Ed. Gustavo Gili. Barcelona. 1977.

MORALES, José. La disolución de la estancia. Transformaciones domésticas 1930-1960. Ed. Editorial Rueda. Madrid. 2005.

NAVARRO BALDEWEG, Juan. La habitación vacante. Ed. Pretextos. Girona. 1999.

PARICIO, Ignacion. La vivienda contemporánea. Ed. Instituto de Tecnología de la construcción de Cataluña. Barcelona. 2000.

PARODI, Aníbal. Puertas Adentro. Interioridad y espacio doméstico en el S.XX. Ed. Universidad Politécnica de Cataluña. Barcelona. 2005.

RAPOPORT, Amos. Vivienda y cultura. Ed. Gustavo Gili. Barcelona. 1972.

RYKWERT, Joseph. La casa de Adán en el paraíso. Ed. Gustavo Gili. Barcelona. 1974.

SAMBRICIO, Carlos. Un siglo de vivienda social (1903-2003). Ed. Nerea.Madrid. 2003.

----- (y SANCHEZ LAMPREAVE, Ricardo). La vivienda protegida, historia de una necesidad. Ed. Ministerio de la vivienda. Madrid. 2010.

SMITH, Elisabeth A.T. Case Study Houses. Ed. Taschen. Colonia. 2002.

SMITH, Wallace. Sociología y economía de la vivienda. Ed. Agencia para el Desarrollo Internacional. Buenos Aires.1973.

SMITHSON, Peter y Alison. Cambiando el arte de habitar. Versión castellana de Sofía Estévez. Editorial Gustavo Gili. Barcelona. 2001.

TORRES CUECO, Jorge, (coordinador) y otros. Casa por casa. Reflexiones sobre el habitar. Ed. General de Ediciones de Arquitectura. Valencia. 2009.

VERDAGUER, Carlos. De la sostenibilidad a los Ecobarrios. Ed. Caritas española. Madrid. 2000. 
WESTON, Richard. Evolución arquitectónica de la casa del s.XX. Ed. Blume. Barcelona. 2002.

ZABALBEASCOA, Anatxu, Las casas del siglo XXI, Ed. Gustavo Gili, Barcelona, 1998.

ZUMPTOR, Peter. The house: the Works and the concepts of Tony Fretton, Peter Zumthor. Roger Diene, Ed. Gta Verlag. Zurich. 2010.

\subsection{Sobre Europan y los concursos}

\section{En general}

AA.VV. Libro blanco de los concursos. Ed. Colegio Oficial de Arquitectos de Madrid. 2008.

-----"Los concursos". n 128. Arquitectos. Ed. Colegio Oficial de Arquitectos de Madrid. Madrid. 2004.

-----“Estructuras de formación". no 180. Arquitectura. Ed. Colegio Oficial de Arquitectos de Madrid. Madrid. 2006.

-----"Los concursos de arquitectura". n 266. Arquitectura. Ed. Colegio Oficial de Arquitectos de Madrid. Madrid. 2010.

-----Concursos, Case Study. Ed. Instituto Monsa de Ediciones. Barcelona. 2011

----- Concursos de Arquitectura. Actas del 14 Congreso Internacional de Expresión Gráfica Arquitectónica. Ed. Universidad de Valladolid. Valladolid. 2012.

\section{Sobre Europan}

AA.VV. PAN: programme architecture nouvelle, 20 ans de realizations. Ed. Broche. Paris. 1992.

------EUROPAN 2/3/4, From ideas to implementation 1993-1999, 38 urbanarchitectural projects. Ed. Europan. Atenas. 1999.

-----Europan generation, the reinterpreted city. Ed. Cite de I'Architecture. Paris. 2007.

-----Europan 1 to 6, Negotiated projects. Ed. Secretariado Europeo. París. 2005.

-----Living in the French topics. Ed. Secretariado Europeo. París. 2000.

-----Dwelling in the year 2000. Ed. Secretariado Europeo. París. 2000.

-----"Ideas y prácticas", n 133 en Arquitectos. Ed. Colegio Oficial de Arquitectos de Madrid. Madrid. 1994.

\section{Artículos sobre Europan}

BARROS DA ROCHA E COSTA, Hugo António; GIMÉNEZ RIBERA, Manuel; GILABERT SANZ, Salvador. "Análise gráfica dos resultados do Concurso Europan". Concursos de Arquitectura. Actas del 14 Congreso Internacional de Expresión Gráfica Arquitectónica. Ed. Universidad de Valladolid. Valladolid. 2012. pp.771-776.

CANET ROSELLÓ, Juana. "El concurso Europan como sistema de producción de arquitectura y ciudad en las tres últimas convocatorias Europan 8,9 y10 en España 
y por españoles en Europa". Concursos de Arquitectura. Actas del 14 Congreso Internacional de Expresión Gráfica Arquitectónica. Ed. Universidad de Valladolid. Valladolid. 2012. pp.789-794.

CARMONA, Marita (y DE LATORRE, Irene). "Viviendas Europan España”. en CIAB 3. Congreso Internacional de Arquitectura Blanca. Ed. Generales de Arquitectura. Valencia. 2008. pp. 158-159.

----- "Del blanco al negro" en CIAB 4. Congreso Internacional de Arquitectura Blanca. Ed. Generales de Arquitectura. Valencia. 2010. pp. 218-219.

-----“Viviendas Europan: ¿es posible materializar la "utopía”?" en CIAB 5. Congreso Internacional de Arquitectura Blanca. Ed. Generales de Arquitectura. Valencia. 2012. pp. 192-193.

GALVAN, Noelia. "Concursos, arquitectura invisible", XIII Congreso Internacional de Expresión gráfica arquitectónica. Actas Volumen II. Ed. De la Universidad Politécnica de Valencia.Valencia. 2010. pp.75-79.

\section{Monográficos sobre Europan}

\section{Europan 1}

AA.VV. EUROPAN 88. Evolución de los modos de vida y arquitecturas de la vivienda. Ed. Ronchamp Ediciones. Madrid.1988.

-----EUROPAN 1, Lifestyles, housing architecture. Editions Regirex, Techniques et Architecture. Paris. 1989.

\section{Europan 2}

AA.VV. EUROPAN 2. Habitar la ciudad, recualificación de emplazamientos urbanos. Ed. Artes Gráficas Palermo. Madrid. 1991.

-----EUROPAN 2, European results, Living in the town, recualification of urban sites. Ed. Regirex 1991. Techniques et Architecture. Paris.1991.

\section{Europan 3}

AA.VV. EUROPAN 3 España. En la ciudad como en casa. Urbanizar los barrios residenciales. Ed. Estudio N. Madrid. 1994.

-----EUROPAN 3 European Results, At home in the town, urbanising residential areas. Ed. Europan. Paris. 1994.

\section{Europan 4}

AA.VV. EUROPAN 4 España. Construir la ciudad sobre la ciudad. Transformación de áreas urbanas contemporáneas. Ed. Ministerio de Fomento. Madrid, 1996.

-----EUROPAN 4, European Results, Constructing the town upon the town, transformation of contemporary urban sites. Ed Europan. Paris. 1997. 


\section{Europan 5}

AA.VV. 10 años EUROPAN 5 España. Ed. coproducida por EUROPAN/España, Ed. SEPES y el Ministerio de Fomento. Madrid.1999.

-----EUROPAN 5, European Results, New Housing landscapes, Travel and proximity. Ed. Europan. Paris. 1999.

\section{Europan 6}

AA.VV. Catalogue EUROPAN 6. In-between cities, architectural dynamics and new urbanity. Ed. Europan. Paris. France. 2001.

-----EUROPAN 6 España. Entre ciudades. Ed. Gráfica Futura. Madrid. 2001.

\section{Europan 7}

AA.VV. EUROPAN 7 España. El reto suburbano: intensificación urbana y diversidad residencial. Ed. Gráfica Futura. Madrid. 2003.

-----EUROPAN 7. European Results. Ed. Europan. Paris. 2003.

\section{Europan 8}

AA.VV. EUROPAN 8 España. Urbanidad europea y proyectos estratégicos. Ed. Ministerio de vivienda. Madrid. 2006.

-----Catalogue of Europan 8 results. European Urbanity and strategic projects.

Ed. Europan. Paris. 2006.

\section{Europan 9}

AA.VV. EUROPAN 9 España. Ciudad sostenible y nuevos espacios públicos. Ed. Ministerio de vivienda. Madrid. 2008.

-----Catalogue of Europan 9 results. Sustainable city and new public spaces. Ed. Europan. Paris. 2008.

\section{Europan 10}

AA.VV. EUROPAN 10 España. Proyectar la urbanidad. Ed. Ministerio de la vivienda. Madrid. 2010.

----Europan 10, European results book. Inventing urbanity, Regeneration Revitalization - Colonization. Ed. Europan. Paris. 2010.

\section{De edificios construidos de Europan}

AA.VV. Dos torres de viviendas en Hortaleza, Madrid. Ed. Monográfico Europan. Atenas. 1994.

-----Dos torres de viviendas en Viña de Entrevías, Madrid. Ed. Monográfico Europan. Paris. 1995.

49 viviendas en Huelva. Ed. Monográfico Europan. Paris. 1995. 
-----Dos manzanas de viviendas en Basauri, Bilbao. Ed. Monográfico Europan. Paris. 1997.

-----"Edificio de viviendas de protección oficial en Ferrol". n² 25. En Obradoiro. Ed. Colegio Oficial de Arquitectos de Galicia. Santiago. pp.70-73.

-----Premios Calidad, Arquitectura y Vivienda 2002-2003. Ed. Artes Gráficas Palermo,S.L.Madrid. 2004.

-----Blanco y rojo. Monográfico n 20. Ed. Monográfico Europan. Madrid. 2003.

-----En blanco I, Ed. Ediciones Generales de la Construcción.Valencia. 2004.

----MGM, Morales Giles Mariscal, n51, en 2G. Ed. Gustavo Gili. Barcelona. 2000.

------EUROPAN 5 España Ceuta.Los nuevos paisajes del hábitat. Desplazamiento

y proximidad. Edición Especial coproducida por EUROPAN España, la Consejería de Fomento y Medio Ambiente de la Ciudad Autónoma de Ceuta y EMVICESA. Ceuta.1999

-----EUROPAN IV Bilbao. Construir la ciudad sobre la ciudad. Transformación de áreas urbanas contemporáneas. Edición Especial coproducida por EUROPAN España y la Dirección General de Vivienda y Arquitectura de la Consejería de Ordenación del Territorio, Vivienda y medio Ambiente del Gobierno Vasco. Bilbao. 1997

-----EUROPAN IV Cartagena. Edición Especial coprudicida por EUROPAN España, el Ayuntamiento de Cartagena y la Consejería de Política Territorial y Obras Públicas de la Región de Murcia. Murcia. 1997.

-----EUROPAN IV Aranda de Duero. Construir la ciudad sobre la ciudad. Transformación de áreas urbanas contemporáneas. Edición Especial coproducida por EUROPAN España, el Ayuntamiento de Aranda de Duero y la Consejería de Fomento de la Junta de Castilla y León, Aranda del Duero.1996.

-----EUROPAN IV Valladolid. Construir la ciudad sobre la ciudad. Transformación de áreas urbanas contemporáneas. Edición Especial coproducida por EUROPAN España, el Ayuntamiento de Valladolid, la Demarcación de Valladolid del Colegio Oficial de Arquitectos de Castilla y León Este y la Consejería de Fomento de la Junta de Castilla y León. Valladolid. 1997. 


ANEXOS.DOCUMENTACIÓN 



\section{CARTA EUROPAN ${ }^{1}$}

Nosotros, presidentes de los comités nacionales de Europan, signatarios de la presente carta, deseamos participar:

- en la dinámica de Europa, contribuyendo en el campo de arquitectura y de la vivienda a los intercambios científicos y culturales. Estos intercambios deben permitir un mejor reparto de lo que nos es común, beneficiarnos de las experiencias de cada uno mientras afirmamos nuestras características, regionales y locales;

- en el desarrollo y renovación de la arquitectura, ofreciendo a los jóvenes arquitectos la posibilidad de expresar en proyectos ideas nuevas, y ayudando a realizar operaciones que pongan en vigor sus ideas.

Para eso hemos creado Europan.

Europan es un conjunto de concursos de arquitectura, organizados simultáneamente en todos los países miembros, en torno al mismo tema y con las mismas modalidades. Los premiados en estos concursos de ideas, recibirán ayudas para acceder a las demandas arquitectónicas siguiendo la base de las propuestas desarrolladas en sus proyectos.

Para realizar las sesiones nacionales de Europan los países participantes se comprometen:

- A confiar la organización, la financiación y la difusión de los concursos a comités nacionales de Europan compuestos por arquitectos, representantes de las administraciones, promotores e investigadores;

- A participar en el comité europeo formado por representantes de los comités nacionales, y a respetar las reglas comunes aprobadas por el comité;

- A construir según las reglas fijadas en el reglamento marco, jurados nacionales compuestos por personalidades de profesiones representativas del campo de la arquitectura y de la construcción de la vivienda de cada país, al igual que de miembros europeos;

- A abrir todos los concursos nacionales a los jóvenes arquitectos europeos;

- A ayudar a la propuesta en marcha de sus ideas en las realizaciones de todos los premiados, indistintamente y fuese cual fuese su nacionalidad, pero conforme a las reglas del ejercicio de la profesión de arquitecto de cada país.

\footnotetext{
${ }^{1}$ AA.VV. EUROPAN 88. Evolución de los modos de vida y arquitecturas de la vivienda.
} Ronchamp Ediciones. Madrid. España. pp.14-15. 
Conforme a dichas disposiciones, los signatarios citados a continuación, deciden realizar el primer texto sobre el Europan en relación con el tema Evolución de los modos de vida y arquitectura de la vivienda.

DIETER DREIBHOLZ, Consejero de Arquitectura del Land de Styria representando a JOSEPH JECKY, Consejero adjunto al ministro federal de Educación, Arte y Deportes, presidente del Comité Europan de Austria.

DANNIELE SARLET, Directora General de la Administración de la Ordenación del Territorio y de la Vivienda, representante del presidente del Comité Europan de Bélgica.

JAVIER SAEZ COSCUELLA, Ministro de Obras Públicas y Urbanismo, Presidente del Comité Europan de España.

JEAN MAHEU, Presidente del Centro Georges Pompidou, Presidente del Comité Europan de Francia.

ALEXISI VOULGARIS, Secretario Especial para la Vivienda, Ministerio del Medio Ambiente, de la Ordenación del Territorio y de Obras Públicas, Presidente del Comité Europan de Grecia.

ENRICO FERRI, Ministro de Obras Públicas, Presidente del Comité Europan de Italia.

C.H.TILLMANS, Arquitecto responsable de la FEAC, representando al presidente del Comité Europan de los Países Bajos.

JURGEN ECHTERNACH, Secretario de Estado Parlamentario Adjunto al Ministro Federal de la Ordenación del Territorio, de la Construcción y de Urbanismo, presidente del Comité Europan de la República Federal de Alemania.

RODOLPHE LUSCHER, Arquitecto FAS/SIA, Presidente del Comité Europan de Suiza. 


\section{ENUNCIADOS DE EUROPAN}

\section{EUROPAN 1 Evolución de los modos de vida y arquitecturas de la vivienda ${ }^{2}$}

¿Cómo se vive hoy en Europa? ¿Cuáles son las evoluciones comunes y las disparidades entre los países? ¿Qué papel podrían desempeñar el cambio en las estructuras familiares y el papel de la mujer en la sociedad, las nuevas formas de relación con el trabajo, la importancia del individualismo y del cuerpo así como la aparición de las nuevas tecnologías en la transformación del hábitat?

El tema, "Evolución de los modos de vida y arquitectura de la vivienda "invitaba a reflexionar sobre el interior de las viviendas europeas de mañana.

2 [On line] <http://www.europan-esp.es/03_ediciones_anteriores_temas.php?id_ anterior=2>, (Consulta, 1 de junio de 2010) 


\section{EUROPAN 2. Habitar la ciudad, recualificación de zonas urbanas ${ }^{3}$}

El objetivo de Europan 2 es llamar a la reflexión sobre las posibilidades de recomposición urbana a partir de nuevas estrategias en las cuales el hábitat desempeñaría un rol principal o determinante. Se trata de cualificar o de recualificar un emplazamiento resituándolo en la evolución general del barrio, de la ciudad e incorporando las nuevas exigencias que dictan los cambios de modos de vida y su pluralidad. Se trata también de proponer los procesos de puesta en práctica más adecuados a las nuevas realidades urbanas contemporáneas.

Existen variadas oportunidades de suelo. Podrán ser utilizadas para llevar a cabo lógicas urbanas que tengan mejor en cuenta la vivienda. Se trata de recurrir a emplazamientos existentes en prácticamente todas las ciudades europeas, tanto en los barrios céntricos como en la periferia, terrenos baldíos, de uso obsoleto, áreas degradadas o abandonadas. Todos ellos emplazamientos sensibles que podrían desempeñar un papel urbano determinante en la evolución de las ciudades y que los promotores vinculados a EUROPAN 2 someten a la reflexión de los concursantes.

\section{Hábitat y modos de vida}

El cambio en los fenómenos demográficos y de los comportamientos sociales, el aumento del consumo de masas, la inflexión sufrida por las relaciones sociales, dan buena cuenta de los cambios en los modos de vida. Resulta importante detectar los invariables, los cambios y valorar su impacto sobre las formas del hábitat y su entorno.

Porque si los cambios de hábitos y de expectativas de las personas inciden en el espacio interno de su vivienda, también implican une adaptación de la relación de la vivienda con su barrio, con la ciudad, de sus formas urbanas y otras funciones (comercio, trabajo, ocio, cultura, etc.). Esta adaptación se vuelve más imperativa cuanto, en el contexto de homogeneización del espacio interior de las viviendas que se viene observando desde hace decenios, la situación urbana de la vivienda, los servicios y prolongaciones externas de que dispone se convierten en criterio determinante para su uso y su calidad. Además, la divulgación de las técnicas de comunicación y el aumento de las circulaciones, acarrean un enorme cambio en las relaciones entre el hábitat y las demás funciones urbanas así como entre los diferentes barrios de la ciudad. ¿Qué relación ha de tener el hábitat con los espacios de trabajo, de ocio y para la cultura? Cuales deben ser sus relaciones funcionales y simbólicas con los espacios públicos y las redes de comunicación?

\section{Dinámicas y formas urbanas}

La actual renovación del desarrollo urbano en paralelo a los cambios económicos y tecnológicos, viene acompañada por la transformación de las formas urbanas.

3 [On line] <http://www.europan-esp.es/03_ediciones_anteriores_temas.php?id_ anterior=3>. (Consulta, 1 de junio de 2010). 
El crecimiento de los transportes y de las comunicaciones, induce de forma simultánea concentraciones y extensiones de las aglomeraciones. La ciudad actual ya no puede ser pensada como un objeto terminado o congelado. Fragmentada y parcelada se estructura a partir de redes y vías de circulación. En este contexto, ¿qué valor y que rol debemos atribuir a las formas urbanas tradicionales y a las antiguas centralidades? ¿Qué forma y qué estatus puede hoy revestir una operación de recomposición urbana?

\section{Imagen de marca}

La apertura europea y los cambios económicos imponen a las ciudades un proceso de competencia del que depende su dinámica de desarrollo. Las ciudades deben presentarse como productos de venta y de consumo. Para ocupar el mejor lugar en esta carrera, tratan de atraer y guardar para sí actividades dinámicas y modernas: terciario cualificado, industria de lata tecnología, investigación y población de profesionales, ingenieros y técnicos, toda una fama necesaria para su funcionamiento. Necesitan, por lo tanto, forjarse una imagen de marca y dotarse de estructuras urbanas capaces de responder a estas exigencias. Esta es la razón por la cual la dinámica de las ciudades parece hoy polarizada en torno a nuevos conceptos, tanto económicos como urbanos. Tecnópolis, complejos comerciales, centros de congresos, grandes equipamientos culturales, deportivos o de ocio, se presentan como los motores de la transformación urbana y de su dinamismo. Por su papel económico y su aportación en términos de imagen de marca, su actividad y su presencia tienen repercusiones que, más allá del impacto directo en el medioambiente, pueden modificar completamente la estructura funcional, sociológica, estética y urbana de un barrio, una ciudad e incluso una región. Pero muy a menudo, estos equipamientos dejan poco lugar para el hábitat y la urbanidad. Sin embargo, el hábitat sigue siendo la parte esencial del paisaje urbano. Su peso sigue siendo fundamental. Además, su presencia en los barrios orientados hacia los grandes equipamientos, impone una creciente atención por la calidad del medioambiente y el fomento de la vida urbana.

Ya se trate de los grandes equilibrios intraurbanos o de la limitación del impacto de los variados tipos de contaminación ligados a la actividad urbana a nivel local, la escala y las formas de intervención en la ciudad revisten una dimensión ecológica que es preciso tener en cuenta. ¿Qué papel cualitativo puede desempeñar el hábitat en operaciones de recomposición urbana? ¿Qué impacto puede tener en un proceso de transformación de la ciudad? ¿Se trata de un factor entre tantos otros o es un eslabón fundamental en esta búsqueda?

\section{$\underline{\text { Cruce de temporalidades }}$}

Como en el caso del patrimonio urbano, las antiguas estructuras sociales y los antiguos modos de producción perduran y siguen constituyendo una parte importante del tejido económico y social de la ciudad. Lo urbano es el lugar de las coexistencias sociales y económicas y del cruce de temporalidades. Debe poder 
adaptarse tanto a las exigencias de lo cotidiano como a los cambios a medio plazo, sabiendo incorporar las permanencias a largo plazo. Debe, por lo tanto, ser pensado en términos de generaciones. ¿Están las nuevas formas de desarrollo polarizadas en la economía, centradas en algunas actividades y en torno a ciertas categorías sociales, adaptadas a los cambios futuros y a las posibles involuciones de este crecimiento? Las formas urbanas que producen, ¿son capaces de incorporar los invariables económicos y sociales? ¿Cuál es su papel y su lugar con respecto a la ciudad tradicional?

¿De qué forma puede, una operación de recomposición urbana que incorpora vivienda, puede responder a estas exigencias? ¿Qué actitud adoptar frente a la tendencia "natural" a segregar social y funcionalmente barrios que han llevado a sobrevalorar algunos lugares y a abandonar otras zonas? ¿Debemos tratar de poner freno a esta tendencia cuando se interviene en la ciudad o, por el contrario, aceptarla y crear nuevos lazos y nuevas comunicaciones entre las áreas urbanas?

\section{$\underline{\text { Multifuncionalidad }}$}

La esencia misma de la ciudad es la existencia de una actividad plural. Pero en la ciudad contemporánea, atomizada, la polifuncionalidad reviste nuevas formas. De la mezcla de los tejidos urbanos tradicionales a las zonificaciones rígidas del urbanismo moderno, el vecindario o la coexistencia de las funciones en el espacio, pueden adoptar formas muy diversas. ¿Qué funciones deben ser mezcladas o separadas? ¿Debe, la tradicional mezcla de usos, ser reinterpretada, reconducida o abandonada? ¿Hemos de tratar de extenderla o de reservarla para algunas áreas urbanas? ¿Es preciso tratar de inventar nuevas formas de mezcla o, por el contrario, aceptar la tendencia a la especialización de los fragmentos urbanos y trasladar la pregunta de las conexiones a la escala urbana, mediante el desarrollo de las redes de comunicación?

Esta pregunta fundamental sobre la escala y la calidad de la polifuncionalidad debe ir acompañada por una reflexión sobre el alcance que pueden tener las soluciones propuestas. ¿Se puede aún elaborar respuestas y principios generales, o debemos adoptar las respuestas a cada aglomeración o incluso a cada emplazamiento en función de sus características y de los deseos de los habitantes?

\section{Estrategias operativas}

Paralelamente al renacer del crecimiento urbano, los modos de gestión y de intervención urbana se transforman. El urbanismo contemporáneo se caracteriza por la búsqueda de modelos de eficacia y de escalas de intervención pertinentes, lo cual lleva a algunos países a la descentralización, mientras otros reconcentran los organismos y los poderes responsables de la ordenación. De manera general, los procedimientos del urbanismo son menos globalizadores, menos dirigistas que en el pasado. También se caracterizan por el peso añadido de los promotores privados en intervenciones urbanas. ¿Que proyecto de ciudad podría federar las a menudo contradictorias energías que concurren en la transformación de una 
ciudad? ¿Cómo utilizar el poder de inducción de una simple operación? ¿De que proceso de realización debe estar dotado para que sea capaz de incorporar en su dinámica otras operaciones para poder generar un movimiento de recomposición más amplio?

La creciente sensibilidad de los ciudadanos hacia la calidad de su entorno, también implica plantear la cuestión de su participación en su definición. ¿Podemos imaginar aproximaciones y procesos de realización democráticos, abiertos a la expresión y a la realización de los deseos de los habitantes? Y en esta óptica, ¿cual sería el papel de los técnicos y su aportación a la ciudadanía afectada?

La extensión de este haz de preguntas que afecta tanto a los procesos de realización como a las formas urbanas, implica la existencia de varias escalas de respuestas que deberán ser claramente expresadas e incorporadas en las propuestas entregadas al concurso. 


\section{EUROPAN 3. En la ciudad como en casa, urbanizar barrios residenciales ${ }^{4}$}

El tema de la tercera convocatoria de EUROPAN se sitúa en la intersección de aquél propuesto para el primer concurso, que estudiaba el interior de la vivienda en función de la evolución de los modos de vida, y del tema del segundo. La revalorización del lugar que ocupa la vivienda en los espacios urbanos en vías de reconversión. ¿Cómo urbanizar los barrios residenciales existentes para hacerlos compatibles con los cambios en los modos de vida -que afectan a la vivienda, el trabajo y al ocio-, así como con las aspiraciones de los europeos de vivir una ciudadanía plural? ¿De qué manera reactivar esos barios? ¿Cómo enfocar hoy en día las relaciones entre el espacio privado y los espacios públicos de la ciudad? ¿Cuál es el estatus de los espacios de transición, a partir de la evolución de las relaciones entre intimidad y urbanidad?

En numerosas ciudades europeas, los barrios residenciales padecen una uniformidad tanto espacial como funcional y social. Una determinada gestión del espacio y unos modos de producción normativos han llevado a provocar rupturas que acentúa las polarizaciones entre el espacio público y el espacio privado. Estas polarizaciones, ni facilitan la diversidad de los modos de vida ni son propicias para reorganizar los tiempos sociales; tampoco permiten las apropiaciones múltiples y colectivas de los espacios de la ciudad.

El uso de los medios de comunicación y la fragmentación del espacio urbano, modifican las nociones de distancia y proximidad espacial; las relaciones sociales no se confunden ya exclusivamente con el entorno vital inmediato o con la vida doméstica, sino que se amplían a la escala de la ciudad. Estos hechos implican numerosos retos urbanos; se trata de posibilitar la convivencia de sociedades y culturas diversas, de favorecer la implantación de prácticas innovadoras, de tratar la mezcla de usos, la relación vivienda-trabajo, las posibilidades y modalidades de creación de empleo próximo al trabajo. Se trata también de luchar contra las contaminaciones ambientales y la sensación de inseguridad, de potenciar la calidad de vida, teniendo en cuenta los valores ecológicos.

Los protagonistas urbanos deben apostar por el entorno de la vivienda, ese espacio hoy ignorado, para convertirlo en el tema capaz de suscitar una reflexión arquitectónica a escala europea, inscrita en las transformaciones sociales y económicas en curso. Se trata, frente a las discontinuidades urbanas, de replantear las categorías arquitectónicas interior/exterior, público/privado. ¿Cuáles son los puntos de contacto entre la vivienda y el espacio público? ¿Cómo introducir en la ciudad los espacios de la movilidad como el automóvil? ¿De qué forma tener en cuenta las exigencias de los servicios colectivos y la apropiación individual de los espacios exteriores? ¿Qué lugar se reserva para lo urbano?

4 [On line] <http://www.europan-esp.es/03_ediciones_anteriores_temas.php?id_ anterior=4>. (Consulta, 1 de junio de 2010) 
EUROPAN 4. Construir la ciudad sobre la ciudad, transformación de espacios urbanos contemporáneos $^{5}$

Europan 4 ha elegido las periferias de las ciudades como campo de investigación. En efecto, asistimos al final de la dependencia de las áreas periféricas con respecto al centro de la ciudad y a su emancipación para conformar una ciudad-puzzle. Se trata de reflexionar sobre los desarrollos múltiples de estos nuevos territorios urbanos donde se mezclan redes de infraestructuras, microcentralidades, espacios híbridos, fragmentos autónomos y espacios baldíos. EUROPAN 4 propone a los jóvenes arquitectos europeos concebir proyecto capaces de inscribirse en los espacios contemporáneos existentes en la ciudad, lugares que, aunque con una identidad propia, se encuentran en plena mutación social. Todos son intersticios estratégicos capaces de albergar las nuevas dinámicas urbanas.

-rehabilitación-reestructuración de lo existente pero también articulación de las nuevas extensiones.

-densificación de determinados espacios pero también valoración de la naturaleza como nuevo espacio público.

-creación de micro-centralidades comerciales y culturales, pero también resolución del habitat urbano.

Sobre este telón de fondo metropolitano, cuya diversidad quedara expresado en los 60 solares propuesto a concurso en los diferentes países europeos participantes, EUROPAN 4 hace un llamamiento a los jóvenes arquitectos europeos para plantearse las evoluciones de la creación arquitectónica.

- ¿De qué manera los arquitectos pueden estar más atentos a los usos urbanos y ayudar a una mejor integración de posprogramas en las nuevas sociabilidades que empiezan a aparecer en la ciudad?

-¿Cómo, desde el análisis del contexto, tener en cuenta a la evolución de los espacios y del paisaje contemporáneo aun careciendo de valor patrimonial?

- ¿Cómo construir lo nuevo a partir y sobre las trazas de lo antiguo?

- ¿De qué manera articular el proyecto-objeto con el proceso proyectual integrando movilidad, tecnología e inestabilidad programática propias de la ciudad moderna?

El tema de EUROPAN 4 puede resumirse en una pregunta global: ¿De qué manera construir los espacios contemporáneos de las ciudades europeas sobre las trazas de la dispersa ciudad moderna heredada del siglo XX?

EUROPAN 4 propone a los jóvenes arquitectos 4 temas de trabajo:

5 [On line] <http://www.europan-esp.es/03_ediciones_anteriores_temas.php?id_ anterior=5>. (Consulta, 1 de junio de 2010). 


\section{Situarse}

Desde el final de siglo XIX de la industrialización, la ciudad tradicional ha estallado, diseminando por su periferia fragmentos múltiples. Situarse, es ante todo afrontar la ciudad contemporánea sin prejuicios para comprender mejor sus evoluciones recientes

\section{transformar}

Transformar es, finalmente, poner en marcha cambios de uso e innovar preparando la ciudad para las necesidades del futuro, teniendo en cuenta los ritmos diferenciales entre lo edificado y el espacio público e incluyendo el proyecto en una política de enriquecimiento social.

\section{$\underline{\text { heredar }}$}

Heredar es definir una actitud con respecto a lo existente, a partir de los datos geográficos de un lugar (sus líneas de fuerza, el funcionamiento del suelo, los elementos paisajísticos) pero también evaluando lo construido, teniendo en cuenta la arquitectura menor y su capacidad de evolucionar.

\section{$\underline{\text { conectarse }}$}

Conectarse, es crear las condiciones, mediante el proyecto, para un proceso de transformación de lo existente, transformar el valor de la herencia en una herramienta de proyecto encontrando una lógica urbana de conservación, construcción, derribo. Es situar el crecimiento urbano y los nuevos proyectos en las trazas del pasado, basándose en la estructura urbana existente y es, además, incorporar el factor tiempo. 


\section{EUROPAN 5. Los nuevos paisajes del hábitat, desplazamiento y proximidad ${ }^{6}$}

EUROPAN ha elegido como campo de investigación los espacios urbanos abandonados de las ciudades europeas que están situados en el encuentro con redes de desplazamiento. En los últimos 50 años, el crecimiento de las ciudades europeas ha supuesto un enorme consumo de amplios territorios periféricos con el fin de implantar las nuevas zonas y sus infraestructuras. Las periferias se han ido formando a partir de las líneas determinadas por el desplazamiento y por los fragmentos edificados. Entre ambos, han subsistido espacios poco o en absoluto afectados por esta situación. Paralelamente, las ciudades han dejado en barbecho espacios de territorio cuyas funciones resultaban ya obsoletas. Suficientes razones todas ellas que fomentaron la aparición de una ciudad encajonada, compuesta por espacios dejados a cuenta a raíz de un proceso de urbanización extensivo.

Mientras las visiones unificadoras de la ciudad están en crisis, se plantea de qué forma recuperar estos espacios intersticiales para convertirlos en lugares habitables. ¿De qué manera crear nuevas formas de paisaje urbano? Y, si ya no se pretende controlar la forma global de la ciudad, ¿cómo transformar todos estos emplazamientos contemporáneos residuales y dispares en terrenos con valor? ¿De qué forma crear entidades residenciales, paisajísticas y arquitectónicas como partes nuevas insertas en el puzzle de la ciudad existente, en el tapiz desgarrado y discontinuo de la metrópolis moderna?

En torno a este reto, EUROPAN 5 propone a los jóvenes arquitectos varios temas formulados como preguntas dirigidas tanto al proyecto arquitectónico como a las políticas urbanísticas. Estos temas pueden cruzarse, induciendo respuestas en forma de proyectos de ideas. A partir de situaciones concretas seleccionadas en varias ciudades europeas, estos proyectos deberán inscribirse en el marco de culturas urbanas muy diferentes, pero afectadas por las mismas preguntas.

\section{Naturaleza y hábitat}

Naturaleza y edificación se mezclan sin orden aparente y las parcelas de viviendas proliferan. ¿Es este proceso irreversible? ¿De qué manera evitar el fenómeno de la periferia tentacular? ¿Se pueden conciliar la densificación urbana, los espacios colectivos y la naturaleza con el deseo de los habitantes de poseer una vivienda altamente individualizada.

\section{Desplazamiento y accesibilidad residencial}

En la ciudad de las funciones fragmentadas y de los múltiples desplazamientos, la cuestión de la accesibilidad a las áreas residenciales es de capital importancia. ¿En función de qué criterios y con qué tratamiento espacial pueden estas redes favorecer las conexiones urbanas, evitando convertirse en factores de ruptura

6 [On line]. <http://www.europan-esp.es/03_ediciones_anteriores_temas.php?id_ anterior=6>. (Consulta, 1 de junio de 2010). 
espacial?

$\underline{\text { Un urbanismo inducido }}$

¿De qué forma relacionar el espacio abstracto de la movilidad con el más físico y sensible de los barrios residenciales? ¿Cómo inducir entonces nuevas formalizaciones de la ciudad?

Nuevos modos de vida

¿Cómo proyectar el espacio de la proximidad, del vecindario y de los encuentros, propio de las áreas residenciales? ¿Qué significa hoy en día habitar la ciudad? ¿Será acaso poseer una vivienda unifamiliar en una parcela de la periferia? ¿Disponer de mayor espacio individual habitable? ¿Vivir en edificios colectivos próximos a las áreas de servicios urbanos? ¿Vivir en contacto con la naturaleza? ¿O poder encontrar al paso de la vivienda espacios públicos habitados?

\section{Intensificación de los usos}

¿Qué tipos de programas son capaces de generar, ya sea en sí mismos, ya sea en su entorno, barrios residenciales con vida urbana? ¿Debe crearse una red de polos funcionales, deben proponerse diversos programas plurales o bien explotar las oportunidades contextuales en su diversidad socio-económica?

\section{$\underline{\text { Gestionar la complejidad }}$}

Poner a prueba la capacidad del proyecto para integrar los diferentes parámetros de la complejidad urbanística y de su gestión: multiplicidad de los intervinientes, mezcla de los interlocutores públicos y privados, inestabilidad programática, cambio de los usos que afectan al espacio urbanístico y arquitectónico que debe ser proyectado como un proceso no estático, con idas y vueltas continuas entre la idea global, las múltiples formalizaciones y las puestas en obra escalonadas en el tiempo. ¿Cómo crear un proyecto lo suficientemente fuerte como para que pueda ser desarrollado en el tiempo, integrando la permanente negociación entre la forma urbanística, la programación y la definición arquitectónica? 


\section{EUROPAN 6. Entre ciudades, dinámicas arquitectónicas y nuevas formas urbanas $^{7}$}

Las ciudades europeas están formadas por varias ciudades. La mayoría de ellas poseen un centro urbano estabilizado, con valores patrimoniales, resultante de una evolución continua hasta la primera mitad del siglo XX. Poseen, además, áreas dispersas, fruto de los procesos de zonificación de los años 60-80, que forman fragmentos urbanos yuxtapuestos o atomizados entre infraestructuras grandes áreas residenciales, barriadas, zonas industriales, "new towns"...

Sin embargo, también existen territorios urbanos de origen remoto, producidos por la extensión continua de los centros fuera de sus límites primitivos, durante los siglos XVIII y XIX y en la primera mitad del XX -arrabales, barrios industriales, pueblos urbanizados, antiguas áreas fortificadas y desmilitarizadas, etc... Estas áreas, que se formaron en torno a un trazado que mezclaba la primitiva estructura rural y los nuevos viarios, se han convertido hoy en fragmentos intersticiales situados entre la ciudad/centro y la ciudad moderna.

Sobre esta malla estructurante, la edificación se ha ido desarrollando a golpes, en función de las necesidades, propiciando la aparición de espacios en los que se mezclan edificios de gran altura, viviendas unifamiliares, industrias, almacenes, viarios contemporáneos...

EUROPAN 6 propone explorar estos territorios para sacar a la luz su identidad latente y potenciar su desarrollo.

\section{¿POR QUÉ? USOS POTENCIALES Y NUEVOS VALORES URBANOS}

Estos territorios, marginados social y físicamente, olvidados por el urbanismo propio de la ciudad expansiva -si no es para atravesarlos o utilizarlos como áreas de servicio - se han convertido hoy en piezas estratégicas dentro del proceso de formación de la ciudad/puzzle contemporánea, por varias razones: por su localización, por su patrimonio arquitectónico pendiente de revalorizar, por la creciente tendencia de las políticas municipales a mezclar el espectro social en los barrios, por la nueva oferta funcional que puede convertir estas zonas en escenarios de una nueva forma de vida urbana. Esto que no es sino el fruto de la combinación de los valores urbanos existentes -con su potencial de memoria social y cultural- y de aquellos resultantes de la evolución de los modos de vida urbanos.

Este cambio es la resulta de nuevas dinámicas sociales y espaciales que tratan de aprovechar las ventajas de localización y contexto que ofrecen estos territorios entre-ciudades:

- dinámica de los modos de vida con una demanda de diversificación de las formas de hábitat periféricas adaptadas a diferentes tipos de población (parejas jóvenes,

7 [On line] <http://www.europan-esp.es/03_ediciones_anteriores_temas.php?id_ anterior=7>. (Consulta, 1 de junio de 2010). 
estudiantes, personas mayores) así como de servicios como tiendas o centros comerciales de barrio.

- dinámica cultural relacionada con el tiempo libre y con la creciente importancia del ocio urbano, con una demanda de espacios accesibles (cines, teatros, cafés, salas de concierto) y de equipamientos sociales y deportivos.

- dinámica turística si los territorios tienen una historia que les permite inscribirse en un recorrido de turismo cultural urbano capaz de generar espacios interactivos.

- dinámica de las formas de trabajo relacionadas con las nuevas tecnologías con creación de pequeñas empresas terciarias punteras, de talleres artesanales que necesitan cierta centralidad o de negocios de trabajo a domicilio.

- dinámica de las redes urbanas alrededor de los intercambiadores de transporte multimodales (tren-tranvía/ coche-autobús/ aparcamiento-coches-tranvía....)

Estas dinámicas ofrecen la oportunidad de articular - con combinaciones diferentes según el contexto - programas complejos donde se mezclan hábitat, trabajo, ocio y desplazamientos.

En cuanto a la planificación urbana, los responsables de municipios próximos a la ciudad/centro -responsables políticos, oficinas técnicas de urbanismo y la arquitectura- han comenzado a interesarse por las mutaciones que afectan a estos segmentos de ciudad, con la voluntad de poner en práctica políticas más o menos dinámicas. También los promotores privados apuestan cada vez más por estas áreas, con las que pueden responder a la demanda de un nuevo tipo de cliente. En términos de ordenación urbanística, estos emplazamientos ofrecen un buen campo de investigación sobre los procesos de gestión urbanística y de puesta en práctica que pueden servir de base para llevar a cabo proyectos innovadores en los que se mezclen inversores privados y municipales, esto es, razones de ámbito público y privado.

\section{¿CÓMO? REVALORIZANDOLOEXISTENTEY DINAMIZANDO LOS PROCESOS ARQUITECTONICOS}

Por su estructura viaria y sus espacios híbridos, estos emplazamientos intermedios poseen un patrimonio existente, reflejo y memoria de un desarrollo urbanístico banal, que puede, no obstante, dar lugar a proyectos que permitan, gracias a una dinamización de sus espacios, crear una ciudad compleja, intensa, múltiple, moderna y coherente.

Esta cohesión se puede alcanzar de diferentes maneras:

Actuando en las redes:

- Reestructurando los viarios y la trama existente, en función de las morfologías y de los modos de desplazamiento contemporáneos. 
- Abriéndose a la gran variedad existente de medios de transporte complementarios: coches; transportes colectivos (autobús, tranvía) y bicicletas.

Actuando en la edificación:

- teniendo en cuenta el parcelario y la reestructuración parcial del suelo según una lógica urbana coherente

- densificando áreas escasamente urbanizadas - interior de manzanas, solares vacíos, zonas situadas en el encuentro con redes modernas

- sustituyendo viejas edificaciones por edificios de nueva planta naves carentes de valor, edificios vetustos

- reestructurando conjuntos de edificios heterogéneos

- incorporando a la arquitectura las exigencias de tipo ecológico

Actuando en el espacio público y en la calidad medioambiental:

- revalorizando los espacios públicos existentes (calles, plazas, parques, espacios naturales)

- insertando nuevos espacios públicos que se articulen a los ya existentes de acuerdo con la voluntad de reestructuración morfológica

- tratando los espacios de transición entre las edificaciones y los espacios públicos

- aplicando valores paisajísticos

- gestionando los recursos

El deterioro de la imagen de estas áreas, a menudo vetustas, que crecen ajenas a los valores patrimoniales de la ciudad/centro y a la modernización de las áreas funcionales, revela la necesidad de revalorizar su identidad mediante la arquitectura, la reestructuración morfológica, la diversificación tipológica, la mejora de la imagen arquitectónica y las intervenciones innovadoras en el espacio público.

Esta demanda confiere a los concursos EUROPAN un papel estratégico en este "mercado urbano".

Los emplazamientos, elegidos todos por su situación entre-ciudades, pueden clasificarse en cuatro categorías:

- áreas abandonadas cuya función obsoleta ofrece oportunidades de desarrollo

- la ciudad inacabada: arrabales, antiguos o modernos, manzanas inacabadas, bloques de viviendas sociales de posguerra, conjuntos edificados heterogéneos susceptibles de ser reestructurados. 
- pueblos absorbidos: antiguas estructuras rurales engullidas por la ciudad que permiten la creación de áreas residenciales densas de escasa altura.

- emplazamientos urbanos periféricos, degradados por las redes de comunicación, que pueden transformarse con nuevos modos de desplazamiento (carreterasaparcamiento-tranvía o autobús, tren-autobús, etc. ...) que permitan la concatenación de los medios de transporte y la creación de micropolaridades urbanas 


\section{EUROPAN 7. EI reto suburbano, intensificación urbana y diversidad residencial ${ }^{8}$}

Todas las ciudades se enfrentan a su propia extensión, al estallido y a la fragmentación urbana. El creciente uso del automóvil, la proliferación de centros comerciales periféricos, la multiplicación de complejos destinados al ocio o el crecimiento de zonas empresariales, parecen conducirnos de manera inexorable a un modelo urbano que podríamos calificar como «ciudad dispersa». Sin embargo, comprobamos la tendencia a intervenir en los territorios contemporáneos con el fin de reorganizarlos, retomando la tradición de planificación de las ciudades europeas aunque asociada a objetivos relacionados con la durabilidad urbana.

Esta necesidad de transformación progresiva de la ciudad contemporánea, se hace posible gracias a las oportunidades de suelo y a la aparición de una demanda de innovación espacial propiciada por la evolución de los modos de vida. Si la creciente autonomía de los individuos, la diversidad de comportamientos en el seno de una misma familia, la movilidad profesional o la velocidad de los medios de transporte, potencian la formación de ciudades de grandes distancias, también es cierto que, a cambio, asistimos a una gran demanda de vida social de barrio, que debe ser reelaborada desde nuevas bases. La pregunta que se plantea a los arquitectos es como transformar la ciudad dispersa para conferirle nuevos valores. EUROPAN 7 propone abordar esta problemática situada en la interfase entre la escala urbana y la escala arquitectónica.

¿De qué manera convertir la ciudad de la dispersión y los desplazamientos en ciudad sostenible, ecológica y con valores urbanos sobre la base de la nueva y emergente demanda social y cultural? ¿Cómo proceder para que la creación de nuevos barrios residenciales, con tipologías y programas innovadores, con programas de usos complejos, se convierta en una herramienta estratégica de cualificación las áreas suburbanas?

8 [On line] <http://www.europan-esp.es/03_ediciones_anteriores_temas.php?id_ anterior=8>. (Consulta, 1 de junio de 2010). 


\section{EUROPAN 8. España, urbanidad europea y proyectos estratégicos ${ }^{9}$}

Todas las ciudades se enfrentan a su propia extensión, al estallido y a la fragmentación urbana. El creciente uso del automóvil, la proliferación de centros comerciales periféricos, la multiplicación de complejos destinados al ocio o el crecimiento de zonas empresariales, parecen conducirnos de manera inexorable a un modelo urbano que podríamos calificar como «ciudad dispersa». Sin embargo, comprobamos la tendencia a intervenir en los territorios contemporáneos con el fin de reorganizarlos, retomando la tradición de planificación de las ciudades europeas aunque asociada a objetivos relacionados con la durabilidad urbana.

Esta necesidad de transformación progresiva de la ciudad contemporánea, se hace posible gracias a las oportunidades de suelo y a la aparición de una demanda de innovación espacial propiciada por la evolución de los modos de vida. Si la creciente autonomía de los individuos, la diversidad de comportamientos en el seno de una misma familia, la movilidad profesional o la velocidad de los medios de transporte, potencian la formación de ciudades de grandes distancias, también es cierto que, a cambio, asistimos a una gran demanda de vida social de barrio, que debe ser reelaborada desde nuevas bases. La pregunta que se plantea a los arquitectos es como transformar la ciudad dispersa para conferirle nuevos valores.

EUROPAN 8 propone abordar esta problemática situada en la interfase entre la escala urbana y la escala arquitectónica.

¿De qué manera convertir la ciudad de la dispersión y los desplazamientos en ciudad sostenible, ecológica y con valores urbanos sobre la base de la nueva y emergente demanda social y cultural? ¿Cómo proceder para que la creación de nuevos barrios residenciales, con tipologías y programas innovadores, con programas de usos complejos, se convierta en una herramienta estratégica de cualificación las áreas suburbanas?

\section{Tema 1: Urbanizar con las infraestructuras}

Las infraestructuras fragmentan el espacio suburbano. ¿De qué manera integrarlas en la construcción de la ciudad?

GT 1-A [Atravesar las redes]

¿Qué tipo de conexiones o de interfases urbanas pueden ser creadas para salvar las barreras que generan las redes pesadas (ferrocarril, autopistas...)?

GT 1-B [Crear nuevas polaridades gracias a las redes]

¿Pueden las redes convertirse en baza para crear nuevos núcleos urbanos?

$9 \quad$ [On line]. <http://www.europan-esp.es/03_ediciones_anteriores_temas.php?id_ anterior $=9>$. (Consulta, 1 de junio de 2010). 


\section{Tema 2: Generar lo nuevo}

Para poner freno a las extensiones urbanas y preservar el territorio natural, la ciudad se amplía en terrenos baldíos o en emplazamientos vacíos. ¿Cómo generar ahí nuevos barrios?

\section{GT 2-A [Transformar por fases]}

Grandes emplazamientos industriales, en parte o totalmente obsoletos ofrecen suelo para desarrollar en ellos barrios urbanos.

¿De qué forma gestionar su urbanización en el tiempo?

GT 2-B [Sustituir por un nuevo trozo de ciudad]

Algunos emplazamientos urbanos sin valor patrimonial edificado requieren la creación de fragmentos urbanos totalmente nuevos. ¿Cómo introducirlos y conectarlos con su contexto?

GT 2-C [Ampliar los límites urbanos]

¿Cómo utilizar estratégicamente los emplazamientos de borde urbano para dar respuesta al crecimiento?

\section{Tema 3: Reciclar el tejido}

La ciudad suburbana ha generado tejidos urbanos híbridos formados por espacios fragmentados y objetos yuxtapuestos.

¿De qué manera reestructurar estos barrios heterogéneos para facilitar en ellos vida urbana?

GT 3-A [Hacer evolucionar los usos: transformar o sustituir la edificación]

Algunas áreas fueron concebidas como enclaves monofuncionales (hábitat, industria, cuarteles...).

¿Cómo destinarlas espacialmente a usos urbanos contemporáneos?

GT 3-B [Reforzar barrios existentes]

¿Cómo conferir una dinámica urbana a fragmentos de ciudad descualificados, inyectándoles nuevas funciones y una estructura de espacios públicos?

\section{Tema 4: Construir con la naturaleza}

La demanda ciudadana de habitar en la ciudad y a la vez cerca de la naturaleza 
plantea la siguiente pregunta:

¿Cómo construir paisajes urbanos que mantengan el equilibrio entre edificación y elementos naturales?

GT 4-A [Construir en la naturaleza]

¿De qué manera aunar naturaleza y construcción en emplazamientos naturales por urbanizar?

GT 4-B [Valorizar un paisaje urbano]

¿Cómo plantear la relación entre espacio urbano y territorio natural, ya se trate de construir frente a un patrimonio natural o de crear un paisaje natural relacionado con lo edificado?

\section{Tema 5: Renovar, ¿Para qué habitantes?}

A veces los cambios urbanos suponen derruir el espacio existente para crear uno nuevo.

¿Permite, esta renovación, no desplazar a la población?

GT 5A: [Gestionar la mezcla social]

¿Cómo hacer que coexista la población antigua con la nueva? 


\section{EUROPAN 9. Urbanidad Europea. Ciudad Sostenible y nuevos espacios} públicos ${ }^{10}$.

\section{Crecimiento urbano a debate}

Puesto que un acercamiento sostenible a la extensión de las ciudades implica el consumo moderado de territorio, ¿cómo afrontar de forma eficaz las mejores potencialidades de expansión?

\section{a) Alinear}

Desarrollar la ciudad a lo largo de la huella longitudinal de una infraestructura, afrontando de forma simultánea la gran escala de la franja urbana y la escala local de los bordes.

\section{b) Limitar}

Extender la ciudad hacia un límite natural. La forma de concebir ese límite y la elaboración de sus conexiones tendrán un impacto decisivo sobre el futuro del lugar.

\section{Redes en movimiento}

¿Existe un modo novedoso de afrontar las redes de desplazamiento, no sólo como medios de transporte, sino también como elementos para incentivar la intensidad y la urbanidad?

\section{a) Unir}

Modificar las redes para interconectar fragmentos urbanos. La transformación de las infraestructuras de transporte permite unir entre sí diferentes trozos de ciudad.

\section{b) Polarizar}

Concentrar en el punto de conexión actividades que remiten a la escala de la red y al espacio circundante.

\section{c) Diseminar}

Extender el impacto de la conexión. Gestionar el efecto de la red de conexión, concentrando o diseminando.

\section{Transformaciones locales}

¿Qué tipo de nuevo proyecto urbano se podría proponer para construir « la ciudad sobre la ciudad » en zonas obsoletas o en barrios activos por modernizar?

\footnotetext{
$\overline{10}$ [On line]. <http://www.europan-esp.es/03_ediciones_anteriores_temas.php?id_ anterior=4>. (Consulta, 1 de junio de 2010).
} 


\section{a) Infiltrar}

Introducir nuevos programas en zonas industriales enclavadas y abrirlas al tejido urbano.

\section{b) Intensificar}

Añadir diversidad en los barrios existentes y generar nuevas dinámicas.

\section{Oportunidades de espacio público}

¿Cómo crear nuevos tipos de espacios públicos, no como formas artificiales desligadas de las dinámicas sociales, sino en relación con los espacios vivos, beneficiándose de las oportunidades que ofrece el territorio urbano existente?

\section{a) Cruzar}

Crear espacios de " movilidad de bajo impacto », ligados a una nueva percepción de territorios urbanos inexplorados, mediante la combinación de diferentes redes, de velocidad y escala variadas.

\section{b) Compartir}

Tener en cuenta el vacío urbano para crear nuevos tipos de espacios públicos y reconsiderar las situaciones intermedias. Entre la plaza y el dormitorio, toda una colección de ejemplos cuestiona la tradicional línea de reparto entre lo público y lo privado. 
EUROPAN 10. España, Proyectar la urbanidad. Colonización, Revitalización. Regeneración ${ }^{11}$.

\section{URBANIDAD EUROPEA}

La creación de espacios urbanos es competencia de arquitectos y paisajistas. Los edificios que configuran los espacios públicos, el mobiliario en ellos dispuesto, el diálogo que se establece con los elementos naturales (agua, aire, vegetación), las vías que los bordean o cruzan, son artífices del ambiente concreto que se desea crear.

El urbanismo está ligado al paisaje, al ambiente, y al entorno. Sus espacios se perciben desde distintos puntos de vista, bien sea desde una ventana o desde la movilidad del conductor o del peatón. Se trata, por tanto, de situar el concurso entre la planificación urbana y la construcción de edificios para forzar una reflexión sobre la relación entre espacio público y espacio privado, sobre "la arquitecturización del urbanismo".

\section{VIDA RESIDENCIAL, DISTANCIA Y PROXIMIDAD}

Pese a la creciente autonomía de los individuos, la diversidad en el seno de una misma familia, la movilidad profesional, la velocidad de los medios de comunicación que genera la creación de ciudades de grandes distancias, también se observa una gran demanda de vida social residencial de barrio, que ha de ser reformulada a partir de nuevas bases. ¿Cómo convertir la creación de los nuevos barrios residenciales tipológicamente innovadores y la complejidad de los programas en herramientas estratégicas capaces de cualificar áreas urbanas en proceso de transformación?

\section{SOSTENIBILIDAD}

La sostenibilidad es una necesidad que aparece como consecuencia directa de la creciente consciencia de la interdependencia a escala del planeta. Las ciudades europeas deben por lo tanto respetar los parámetros del desarrollo sostenible.

Trabajar con este objetivo no significa solamente tener en cuenta criterios cuantificables de lo sostenible, supone también incidir en el necesario mensaje a través del proyecto arquitectónico y urbano.

\section{ESCALA Y PROGRAMA}

ESCALA URBANO-ARQUITECTÓNICA.

EUROPAN apuesta por favorecer proyectos estratégicos con capacidad de repercusión en el desarrollo de un área urbana más amplia que el propio emplazamiento, en cualquiera de las situaciones propuestas: reconversión de áreas de la ciudad consolidada, rehabilitación de emplazamientos complejos, de espacios industriales obsoletos, o recalificación de barrios con dificultades.

Si bien resulta complicado precisar la dimensión exacta que un emplazamiento de EUROPAN debe tener, es importante trabajar en una escala intermedia entre

\footnotetext{
11 [On line] <http://www.europan-esp.es/03_ediciones_anteriores_temas.php?id_
} anterior=1>. (Consulta, 1 de junio de 2010). 
territorio y edificio, la escala "urbano-arquitectónica".

\section{PROGRAMA}

Los emplazamientos presentarán un programa que refleje:

- la estrategia urbana de los responsables para el propio emplazamiento

- las expectativas urbanas generales de la ciudad

- las características concretas del emplazamiento

- los usos y los programas previstos.

\section{INTERDISCIPLINARIEDAD}

Frente a la complejidad y la multiplicidad de temas que deben ser contemplados en los emplazamientos de escala urbano-arquitectónica, EUROPAN recomienda la formación de equipos mixtos con profesionales de diferentes disciplinas: arquitectura, urbanismo, paisajismo, artes, ingenierías, etc

\section{TEMA 1 REGENERACIÓN}

Se dice que un organismo regenera una parte perdida o dañada, si ésta vuelve a brotar recuperando su función. En EUROPAN 10, este tema concierne a los emplazamientos cuya transformación plantea la siguiente pregunta: En áreas con una fuerte identidad, pero cuyas funciones han quedado obsoletas, ¿cómo conseguir su adaptación a una nueva dinámica de usos?

\section{1-A TRANSFORMACIÓN PROGRAMÁTICA}

Transformar significa adoptar una nueva identidad. En algunos emplazamientos de EUROPAN 10 es más importante cambiar los usos que el espacio. Sin embargo, ¿puede la adaptación a nuevas formas de vida urbana conseguir cambiar la identidad del lugar?

\section{B MUTACIÓN PAISAJÍSTICA}

La mutación de un objeto supone un cambio en su estructura. En EUROPAN 10, existe un grupo de emplazamientos de gran escala y con fuerte carácter paisajístico, en el que es necesario introducir nuevos usos. ¿Se puede conservar la identidad del territorio si cambia su "estructura"?

\section{1-C TRANSFORMACIÓN SOCIAL}

Transformar es pasar de una entidad a otra. Muchas transformaciones urbanas implican un cambio social en el área, a través de la exclusión de los antiguos habitantes. Especialmente en la renovación de barrios residenciales, ¿cómo mejorar la calidad de vida evitando la exclusión social?

\section{TEMA 2 REVITALIZACIÓN}

La revitalización es el esfuerzo deliberado, organizado y consciente que realizan miembros de un grupo para crear una nueva cultura. En EUROPAN 10, remite a emplazamientos cuya transformación se aborda respondiendo a la pregunta de 
cómo intensificar la vida urbana en áreas espacial y socialmente degradadas.

\section{2-A ACUPUNTURA URBANA}

La acupuntura trata problemas de salud actuando en puntos específicos que afectan al sistema global. Algunos emplazamientos de EUROPAN 10 son mayores que su dimensión real. ¿De qué manera intervenciones puntuales pueden generar efectos a escala territorial?

\section{B ESPACIOS PÚBLICOS LINEALES}

Los espacios de componente lineal pueden desempeñar un importante papel en la estructura de las áreas urbanas existentes. Sin embargo, ¿cómo relacionar este desarrollo con su entorno, reforzando, además, su carácter público?

\section{C POLOS MAGNÉTICOS}

Un imán es un material o un objeto que produce un campo magnético, atrayendo o repeliendo otros imanes. Algunos emplazamientos de EUROPAN 10 brindan la ocasión de crear imanes urbanos. ¿Qué condiciones tienen que darse en un lugar específico -cambios e intensificación de usos, incremento de las sinergias públicas y privadas- para reactivar el espacio atrayendo a los ciudadanos

\section{TEMA 3 COLONIZACIÓN}

La colonización se produce cuando una o más especies pueblan un área nueva. El término deriva del latín colere, "habitar, cultivar, frecuentar, practicar, atender, guardar, respetar". En EUROPAN 10, afecta a los emplazamientos situados en las periferias de las ciudades, cuya transformación se acomete a través de la aplicación de una nueva filosofía de ocupación sostenible del territorio.

\section{3-A UNA NUEVA COMUNIDAD}

Una comunidad es un grupo organizado en torno a valores comunes y a una cohesión social, que comparte una ubicación geográfica, por lo general mediante unidades sociales mayores que la unidad familiar. En EUROPAN 10, la transformación de un grupo de emplazamientos pasa por la creación de nuevas unidades residenciales. ¿Cómo pueden, estas nuevas áreas, convertirse en ecobarrios?

\section{3-B TRAZAS URBANAS}

La traza ecológica, que mide la demanda de ecosistemas, está representada por la cantidad de terreno biológicamente productivo necesario para regenerar los recursos que consume una comunidad en un sitio específico. En EUROPAN 10, algunos emplazamientos son estrictamente desarrollos urbanos. ¿Es posible evaluar en qué tipo de estructura urbana el territorio colonizado es más eficaz desde el punto de vista ecológico?

\section{3-C ESCALAS DE SOSTENIBILIDAD}

Los edificios consumen mucho terreno además de energía y agua, alterando la calidad del aire y de la atmósfera. En 2006, la edificación usó el 40 por ciento 
de la energía total consumida en toda la Unión europea. En muchos de los emplazamientos de EUROPAN 10, se subraya la necesaria atención que es preciso prestar a la arquitectura sostenible. Sin embargo, en los nuevos desarrollos urbanos, ¿cómo integrar la sostenibilidad a distintas escalas, desde la edificatoria a la urbana? 


\section{EUROPAN 11. Territorios y modos de vida en resonancia. Arquitecturas para la ciudad sostenible ${ }^{12}$}

RAE: resonancia. (Del lat. resonantia). 1. f. Prolongación del sonido, que se va disminuyendo por grados. 2. f. Sonido producido por repercusión de otro. 3. f. Cada uno de los sonidos elementales que acompañan al principal en una nota musical y comunican timbre particular a cada voz o instrumento. 4. f. Gran divulgación o propagación que adquieren un hecho o las cualidades de una persona en alas de la fama. 5. f. Fís. Fenómeno que se produce al coincidir la frecuencia propia de un sistema mecánico, eléctrico, etc., con la frecuencia de una excitación externa. 6. f. Quím. Estado de ciertas moléculas cuya estructura y propiedades resultan de la contribución de varias fórmulas de valencia.

\section{Transformación y adaptación de los territorios urbanos en su búsqueda de sostenibilidad}

Una ordenación territorial capaz de generar tanto estrategias de cambio, como una evolución urbana coherente a todas las escalas de sus componentes tanto medioambientales como humanos, no sólo refuerza el atractivo económico, social y cultural de una región o de un municipio, sino que, además, revaloriza su identidad.

\section{Reto}

La intervención urbana sostenible obliga a abordar la cuestión de la naturaleza y de su relación con la ciudad y el territorio, con especial atención a la diversidad de las condiciones del lugar. La naturaleza ha de ser entendida en su acepción más amplia: el huerto urbano, el parque público, la zona agrícola o el biotopo natural y salvaje, incluyendo desde los espacios naturales hasta aquellos recuperados y urbanizados.

\section{Apuesta}

Una ciudad o una aglomeración que trata de inscribirse en una lógica sostenible, debe moderar su extensión horizontal con el fin de limitar el consumo de terrenos no urbanizado, evitando así el expolio de su territorio. Incluso, en algunos casos, debe reciclar o disminuir su territorio edificado con el objetivo de recomponer a partir de lo existente. Cualquiera que sea su escala, los lugares interactúan entre sí y resulta indispensable desarrollar estas relaciones e interdependencias mediante sistemas que van de lo local a lo global. Estos nexos deben igualmente permitir el acceso al conocimiento y al intercambio de ideas. De esta forma, debe calibrarse la clara adaptación de lo existente al contexto actual, con el fin de responder a las exigencias de futuro.

\footnotetext{
12 [On line] <http://www.europan-esp.es/02_01_europan_temas.php>. (Consulta, 1 de junio de 2010).
} 


\section{Expectativas}

Apostar por cierto grado de sostenibilidad urbana supone mejorar la calidad de vida. Con este objetivo, los concursantes de EUROPAN 11 deben proponer estrategias de desarrollo medioambiental inscritas en un proceso evolutivo sensible a la identidad de cada lugar. Se trata de conseguir un método para que un desarrollo se adecúe a la escala del lugar, pese a las incógnitas que depara el tiempo. La interdisciplinariedad resulta necesaria para alcanzar este objetivo que el arquitecto no puede afrontar en solitario.

\section{ESCALA URBANO-ARQUITECTÓNICA Y PROGRAMA}

Inventar la ciudad europea a partir del contexto urbano contemporáneo, supone abarcar desde la escala territorial hasta el ámbito doméstico. La escala de los emplazamientos de EUROPAN no se define en términos de superficie sino por su intensidad, su capacidad de influencia para crear ciudad y su potencial de desarrollo. Se trata de cuantificar el carácter futurible del emplazamiento. EUROPAN se sitúa, por lo tanto, entre la ordenación urbana y la edificación, abriendo así el campo a la reflexión sobre la relación entre espacio público y privado, "arquitecturizando la urbanidad". Distinguimos así dos familias de dos escalas:

Ámbito del proyecto urbano y arquitectónico:

- La parcela (lugar concreto de hábitat)

- El barrio (conjunto de edificaciones que agrupan hábitat y servicios complementarios)

Ámbito estratégica:

- La ciudad (espacio urbano de hábitat y de usos diversos y mezclados)

- La región metropolitana (conglomerado espacial formado por unidades autónomas interrelacionadas)

\section{PROCEDIMIENTO}

A partir del tema genérico «urbanidad europea: ciudad sostenible y nuevos espacio públicos», las ciudades europeas proponen emplazamientos urbanos a través de las estructuras nacionales de EUROPAN. El Comité Científico europeo clasifica los emplazamientos por familias temáticas con el doble objetivo de ofrecer a los concursantes una mejor lectura de los objetivos a alcanzar en cada lugar y de estructurar los debates entre los diferentes interlocutores de EUROPAN, jóvenes arquitectos, responsables de los emplazamientos, jurados, a lo largo de los eventos europeos que jalonan la convocatoria.

El Forum de Lanzamiento de EUROPAN 11 que tiene por objetivo comparar y concretar los objetivos de los emplazamientos, perfeccionando los programas propuestos. 
Los concursantes entregan su proyecto en el país en el que se encuentra el emplazamiento.

Cada país participante organiza su propio jurado nacional que no cuenta con la participación directa de los representantes de suelo.

Los jurados nacionales se reúnen una primera vez para seleccionar, en función de la calidad de las ideas propuestas, un máximo del $20 \%$ de los proyectos entregados.

El Forum de los Jurados y de las Ciudades es el segundo gran evento europeo de la edición del concurso. Organizado en torno a las propuestas preseleccionadas por los diferentes jurados nacionales, pretende profundizar en el diálogo entre los responsables de suelo y el jurado.

Los jurados nacionales se reúnen por segunda vez para fallar los proyectos según las categorías de premio, mención y finalista. Los premios están dotados desde los presupuestos nacionales.

Es competencia y responsabilidad del propietario, o gestor del suelo a concurso, el encargo de las propuestas premiadas a los equipos ganadores. La organización de EUROPAN/España ofrece mediación y ayuda para pasar de las ideas de concurso a la puesta en práctica de los proyectos urbanos y/o arquitectónicos.

El Forum de los Resultados brindará la ocasión de capitalizar las ideas de las propuestas premiadas.

\section{Identidad}

Afrontar la relación entre lo local y lo global supone considerar la cuestión de la identidad y de las variables visibles e imaginarias que conforman el carácter de un lugar, lo cual nos plantea una paradoja: Cuanto más identificables son las ciudades a escala global, mayor es su riesgo de perder identidad a escala local. ¿Cómo resolver esta contradicción? ¿Cómo conciliar las diferentes escalas y crear una imagen contemporánea de la urbanidad europea?

\section{A - DE LA MARGINALIDAD A LA RELEVANCIA}

Algunos emplazamientos, desocupados y carentes de personalidad o de un uso concreto, apelan a la imaginación para ser transformados en lugares cargados de sentido. Necesitan ser regenerados y reincorporados en la ciudad, ya sea conectándolos a las infraestructuras existentes, ya sea construyendo una nueva identidad que los ciudadanos podrían hacer suya, evitando así la aparición de nuevos enclaves. Sin embargo, en esos procesos de transformación, resulta importante identificar las preexistencias y el patrimonio que es preciso conservar.

\section{B - DE LA INDEFINICIÓN AL CARÁCTER}

Aunque estos emplazamientos no carecen de valor, su estado actual resulta 
insatisfactorio. Les acompaña una gran demanda de mejoras y de mayor visibilidad. Los programas planteados en algunos casos deberían dinamizar las estructuras existentes a través de la esperada creación de nuevos espacios urbanos y paisajísticos.

\section{C - DE UNA IDENTIDAD OBSOLETA A UNA NUEVA IDENTIDAD}

Dado que la ordenación actual resulta obsoleta, inadecuada o simplemente infra explotada, aparece la voluntad de crear un nuevo estado de cosas a través de la introducción de nuevos programas, de un valor añadido y de una mejor conexión con los espacios circundantes. Todos los emplazamientos deben, igualmente, tener en cuenta el patrimonio cultural ya se trate, concretamente, de edificaciones existentes o, en un sentido inmaterial, de la memoria colectiva ligada a su pasado.

\section{Usos}

Atribuir un nuevo programa a un emplazamiento es una estrategia con muchas repercusiones en diferentes campos que abarcan desde la propia arquitectura a la vida social o económica. En los emplazamientos que pertenecen a esta categoría, el mayor reto de los programas es redefinir la relación entre lo global y lo local. Aunque el punto de partida sea diferente para cada emplazamiento, se pueden identificar tres subgrupos en función de la relación con el contexto y de sus dimensiones relativas,

\section{A - DE LOS ESPACIOS EN DESUSO A LA VIDA URBANA}

Los terrenos baldíos son improductivos: ya se trate de zonas verdes (agrícolas), marrones (industriales) o grises (asfalto), los terrenos infrautilizados llevan a los municipios a poner en marcha nuevos programas. ¿Qué estrategias permitirán llevar hasta estos terrenos la riqueza de la vida urbana? ¿Cómo proyectar nuevas zonas urbanas para que puedan ofrecer las máximas ventajas con el mínimo impacto medioambiental? ¿Cuáles son las vías para conseguir la convivencia contemporánea?

\section{B - DEL AISLAMIENTO A LA INTEGRACIÓN SOCIAL}

Una serie de parcelas, un terreno aislado, un claro en el bosque; a veces una intervención puntual puede cambiar todo un contexto. ¿Qué tipos de programas podrían estimular las zonas del entorno? ¿De qué forma el proyecto puede ser una plataforma abierta a la integración social y económica? ¿Cuál es la pieza que puede completar este puzzle?

\section{C - DEL ESPACIO INTERMEDIO AL ESPACIO COMPARTIDO}

Los espacios intermedios pueden ser simples vacíos que no invitan a vivirlos o 
a permanecer en ellos, que no suscitan ningún sentido de la apropiación. Son lugares de paso, adaptados a los automóviles. ¿Cómo transformar un espacio vacío en espacio público? ¿Cómo animar a los paseantes a que lo frecuenten? ¿Qué tipo de programa podría ser referencia de la vida urbana compartida?

\section{Conectividad}

En el marco de lo sostenible, el tema de la conectividad afecta a los métodos de dependencia (interconexión) entre lo global y lo local, entre escalas de espacio y de tiempo, entre los entornos naturales y sociales. Lo existente se revisa a la luz de la relación entre movilidad, prácticas urbanas y espacios públicos.

\section{A - DE LA SITUACIÓN DE BORDE A LA INCORPORACIÓN}

¿Cómo pasar de una situación de frontera (infraestructura, topografía) al cosido, a la conexión? El límite (entre ciudad y campo, lo urbano y lo suburbano, entre barrios, etc.) puede ser sometido a numerosos cambios con el objetivo de fomentar nuevas conectividades urbanas.

\section{B - DEL ESPACIO VACÍO AL ESPACIO DE RELACIÓN}

Los emplazamientos que forman parte de esta categoría están considerados como "restos" de las infraestructuras o de las zonas verdes de determinados barrios. Ofrecen la posibilidad de construir nuevas viviendas y de crear un nuevo espacio de relación, no sólo entre diferentes tejidos urbanos de la ciudad, sino también entre diferentes grupos de ciudadanos. El vacío relativo de estos espacios permite crear un espacio público sostenible, de gran calidad, como marco de los futuros desarrollos que tratarán de establecer vínculos entre los diferentes fragmentos del entorno.

\section{C - DEL LUGAR AL TERRITORIO}

Los entornos urbanos contemporáneos son resultantes de múltiples procesos que inyectan nuevas dinámicas en los entornos locales y convierten las microactividades locales en actividades de escala territorial e incluso global. Se crean nuevas conexiones o se refuerzan las existentes en las principales áreas metropolitanas. Algunos municipios unen sus fuerzas, agrupándose, para promover esa conectividad.

Cuando las dinámicas a escala territorial dominan los entornos locales, resulta urgente reevaluar la relación entre lo global y lo local. ¿De qué forma puede, un lugar, aprovechar esa presencia territorial para crear conexiones sin, por ello, quedar sobrepasado por sus consecuencias? 


\section{ACTAS DE LOS JURADOS EUROPAN}

EUROPAN 1 (1988). ACTA DEL JURADO REUNIDO EN MADRID, EN LA EMPRESA MUNICIPAL DE LA VIVIENDA DEL EXCMO, AYUNTAMIENTO DE MADRID, LOS DIAS 10, 11 Y 12 DE MARZO DE 1989 PARA SELECCIÓN ENTRE LAS PROPUESTAS PRESENTADAS AL CONCURSO EUROPAN EN ESPAÑA, DE CINCO PREMIOS Y CINCO MENCIONES ${ }^{13}$

Abierta la sesión día 10 de marzo, a las 10:30 horas, y estando presentes 6 de los miembros con voto del jurado (Sr.de la Dehesa, Sr. Mora. Sara de la Mata, Srta. Aranguren y Sr. Pérez Pita) y estando también presentes la observadora del secretario europeo (Sra. Valabregue) y el Secretario de EUROPAN/España (Sr. Velez) fue aprobada por una unanimidad la Propuesta de Organización de las Sesiones elaboradas por el Secretariado Nacional y fue designado Presidente del Jurado D. Manuel de la Dehesa. A lo largo de esta primera sesión se incorporaron al Jurado D. José Llinas Carmona y D. Guillermo Vázquez Consuegra, quienes previamente habían excusado su demora.

Se encontraban expuestos, a disposición de los jurados, en la Sala de conferencias de la Empresa Municipal de la Vivienda del Excmo. Ayuntamiento de Madrid un total de 112 trabajos que correspondían.

32 al Emplazamiento de Madrid, Viña de Entrevías.

20 al Emplazamiento en Madrid, Ribera de Curtidores.

8 al Emplazamiento en HUELVA, Estación de Zafra.

14 al Emplazamiento en Madrid, Madrid/sur.

14 Emplazamiento en Madrid, Buitrago de Lozoya.

13 al Emplazamiento de Valencia, Burriana.

1 al Emplazamiento en Asturias, Lugones(Siero)

5 al emplazamiento en Asturias. El Entrego.

5 no emplazados en ninguno de los solares propuestos para el concurso en España.

Se dio lectura al acta elaborada por el Comité de Expertos que durante los días anteriores habían examinado cada una de las propuestas presentadas, consignado en una ficha específica el cumplimiento o no de las bases generales del concurso. Este comité de expertos estuvo constituido por representantes de cada una de las entidades propietarias de suelo público ofrecido como emplazamiento de las propuestas y por representantes de los cuatro promotores principales de EUROPAN en España. Este documento firmado por cada uno de los expertos y el Secretario de EUROPAN/España, se adjunta a este acta, así como las fichas complementadas al efecto.

Cada uno de los representantes de las entidades propietarias del suelo para el

${ }^{13}$ AA.VV. EUROPAN 88, Evolución de los modos de vida y arquitecturas de la vivienda. Ed. Ronchamp Ediciones. Madrid. España. pp.22-23. 
emplazamiento de las propuestas hizo una explicación resumida, ilustrada con diapositivas, de las características, condicionantes y programa de cada uno de los solares.

Cada uno de los miembros del Jurado, examinados individualmente todos y cada uno de los 112 trabajos presentados, al final de la sesión, dejo elaborada una lista con aquellas propuestas votadas para una selección de 30 finalistas.

Desde el comienzo de la segunda sesión se incorporó al Jurado el Prof. Kenneth Frampton. Jurado Iternacional, quien también elaboró una lista similar a las de los anteriores. Recogidos todos los votos y hecho el cómputo de los mismos, fueron seleccionadas finalistas 30 propuestas presentadas bajo los siguientes códigos:

GC-790, TR-280, XY-111, GL-725, ZL-287, EM- 451

HE-111, LC-226, AV-747, LL-333, JB-501, II-000

EL-193, NR-747, AM-458, JB-007C,WS-101,AA-111

EA-020, FF-615, SX-001, AA-373, EL-287, CR-777

PI-505, UB-700, NN-257, AM-735, AF-985, AX-091

No presentándose, por parte de ninguno de los jurados, otras propuestas a discusión, para sustituir algunas de las ya seleccionadas se procedió a la consideración y discusión colectiva de cada una de las 30 propuestas finalistas y por nueva votación quedaron seleccionadas para una siguiente fase las siguientes: GC-790, ZL-287, GL-725, PI-505, NN-257, AM-458, El-287

LC- 226, AV-747, LL-333, AF-985, AA-111, EA-020, FF-615

AX-091, UB-700, JB-501, EL-193

Con esta leccio, quedo finalizada la segunda session del Jurado, habiendose discutido al termino de la reunion posibles propuestas reconsideradas por miembros del Jurado que no alternaron la seleccion anterior.

Abierta la tercera y ultima de las sesiones del Jurado, procedió a la propuesta de los cinco premiados, siendo, por votación y tras nuevo examen de los paneles, escogidos los siguientes:

AX-091

EL-287

GL-725

AV-747

EL-193

Finalmente se procedió a la votación para cinco menciones que según las bases del concurso deberían ser otorgadas, siendo, tras examen de los trabajos, escogidas las siguientes:

$\mathrm{NN}-257$

ZL-287

AM-458

$\mathrm{PI}-505$

JB-501 
Una vez aprobado el resultado por todos los components del Jurado, el Presidente procedió a la apertura de los sobres con la identificación de los códigos premiados y mencionados siendo los autores de las propuestas los siguientes profesionales. PREMIOS

AX-091: José González Gallegos, Madrid

EL-287: Ricardo Sánchez Lampreave, Madrid

GL-725: Javier Frechilla, Madrid

AV- 747: Javier García Solera Vera, Alicante

EL- 193: Alberto Daniel, Claudia Liebermam, Suiza

\section{MENCIONES}

NN-257: $M^{a}$ Isabel Bennasar, Ana $M^{a}$ Noguera, Menorca

ZL-287: Susana Aparici, Madrid

AM- 458: Mercedes Peláez, Madrid

PI-505: Manuel Gausa, Aurelio Santos, Montserrat Torras, Barcelona JB-501: Felix Pozo Soro, Sevilla

De todos los cuales fue comprobada la inscripción correcta y el cumplimiento de los requerimientos en las bases del concurso.

Madrid, 12 de marzo de 1989 
EUROPAN 2 (1990). ACTA DEL JURADO REUNIDO EN MADRID EN LA SEDE DEL MUSEO ESPAÑOL DE ARTE CONTEMPORÁNEO (MEAC), LOS DIAS 26,27,28 Y 29 DE ABRIL DE 1991 PARA LA SELECCIÓN DE CINCO PREMISO Y CINCO MENCIONES ENTRE LAS PROPUESTAS ACEPTADAS AL CONCURSO EUROPAN 2, EN ESPAÑA, SOBRE DIEZ EMPLAZAMIENTOS EN SUELO PÚBLICO ${ }^{14}$

El día 26 de abril, después de haber sido expuestos al jurado cada uno de los emplazamientos por parte de un representante del propietaria público del suelo, y leído el informe de la comisión de expertos sobre los trabajos presentados a concurso, se procede a iniciar las sesiones de deliberación a las 11:30 de la mañana estando presentes todos los miembros del jurado:

D. Luis Alvarez Lopez

$\mathrm{D}^{\mathrm{a}} \mathrm{M}^{\mathrm{a}}$ José Aranguren López

D. Manuel de la Dehesa Romero

D. José Antonio Corrales Gutiérrez

D. Manuel Gallego Jorreto

D. Panos Koulermos

D. Josep Martorell Codina

D. Fernando Ubeda Rives

D. Vicente Verdú

Y también $D^{a}$ Ursula Para vicini, Observadora del Comité Europeo.

D. Antonio Vélez, Secretario de Europan/España.

Se procede a la elección, por unanimidad, de $D^{a}$ María José Aranguren como presidente del Jurado.

Queda establecido a continuación el procedimiento para llegar a una primera selección de propuestas entre las 214 presentadas y a la toma en consideración del resumen de la comisión de expertos cuyo texto acompaña a la presente acta. En este sentido se considera necesario que las propuestas bajo los lemas VC451 (Valencia) y CR 001 (Alcalá de Henares) que vienen acompañadas de maqueta, no sean presentadas al jurado sin antes retirar dichas maquetas del resto de la documentación, igualmente queda eliminada la propuesta bajo el lema ZZ777 (Sevilla) por presentar cuatro paneles en lugar de los tres requeridos en las bases.

Quedan en lugar a parte estas propuestas, junto con las que previamente han retirado los expertos para ser examinadas por el jurado, (como efectivamente sucedió), si lo considera necesario cualquier miembro, a lo largo de las sesiones. Quedan igualmente a disposición de los miembros del jurado las fichas redactadas por cada uno de los expertos para cada una de las propuestas.

Se determina como procedimiento adecuado para la primera selección que cada

${ }^{14}$ AA.VV. EUROPAN 2. "Habitar la ciudad, recualificación de emplazamientos urbanos". Ed. Artes Gráficas Palermo.Madrid. 1991. pp.7-17. 
miembro del jurado proceda a una valoración personal entre 0 y 3 de cada una de las propuestas presentadas. En la sesión del día 27 se procede al examen de estos resultados, siendo descartadas inicialmente para la selección aquellas propuestas que no han recibido puntos por ningún miembro del jurado, siempre que leída esta calificación el jurado que ha puntuado esté conforme con la eliminación. Las propuestas restantes son de nuevo examinadas por los miembros del Jurado una a una, procediéndose por mayoría, en cada caso, al mantenimiento o eliminación para la selección final.

En una segunda vuelta y a propuesta individual de algunos de los jurados se suman a esta selección inicial aquellos trabajos que, una vez examinados de nuevo, merecen por mayoría su inclusión entre las propuestas finalistas.

De este modo se llega a la selección de 27 propuestas bajo los lemas: WU185, (Mendillorri), MS 957, AA111, GU

El día 28 de abril se abre la sesión de discusión entre los miembros de jurado sobre los trabajos finalistas, que son separados de los restantes. El jurado decide que deberán ser votados inicialmente todos estos trabajos para los cinco premios y que, una vez terminada esta votación, se proceda entre las restantes de estas 27 a una votación para las cinco menciones. Es opinión generalizada del jurado que entre estas 27 propuestas finalistas se reúne la suficiente calidad para poder otorgar cinco premios y las cinco menciones que permiten las bases generales del Concurso. Igualmente, se hace hincapié en que estos 27 trabajos son los únicos que incluyen propuestas premiables.

Previamente a cada una de estas votaciones los jurados procedieron, una a una, a la exposición de sus puntos de vista sobre las propuestas seleccionadas agrupadas por emplazamientos, pero dejando explícito el que premios y menciones no se distribuirían por emplazamientos sino por la calidad general de cada trabajo.

Para los cinco premios, tras dos vueltas de votaciones para solucionar empates en votos, y siempre por mayoría, quedaron atribuidos a los premios los trabajos siguientes:

\section{LB 313 (Caravaca, Murcia)}

Fundamentalmente por la corrección de la propuesta y un buen tratamiento del espacio público con atención a la topografía y a las vistas privilegiadas, por la cuidada solución de los detalles y tipologías edificatorias en relación con el complejo emplazamiento. Se valoró positivamente en esta propuesta la introducción correcta de la arquitectura actual en el contexto existente.

YL 100 (Mendillorri, Navarra)

Especialmente atendiendo a las intenciones de inserción en pauas de la arquitectura de la zona, al excelente tratamiento del borde entre el conjunto edificado y el valle 
y por su valor como alternativa tipológica válida para el desarrollo del programa. Se ha tenido en cuenta, no obstante, que es preciso un esfuerzo para la adaptación de esta propuesta a los requerimientos concretos del futuro proyecto a edificar.

GP090 (Madrid, EMV)

Por sus claras pautas de organización de la edificación en relación con la trama urbana existente (acierto en establecer calles que dan continuidad a las que deben conservarse ofreciendo un intenso carácter urbano al alinear los edificios a lo largo de ellas). Se valora la limpieza de los edificios propuestos y el atractivo de la mayoría de las soluciones para las plantas de las viviendas, aún teniendo en cuenta que se hará necesario a la hora de un desarrollo detallado una mayor flexibilidad y permeabilidad de las plantas bajas.

JS 666 (Sevilla)

Por su valor como objeto en su paisaje actualmente sin condicionantes salvo los topográficos y su carácter de escultura apta para recibir los usos propuestos en el programa.

\section{TI111 (Basauri)}

Como propuesta de edificaciones correcta para los fuertes condicionantes impuestos por la ordenación a que está sujeta la zona, y por la riqueza tipológica de las soluciones de vivienda dentro de los límites de la manzana cerrada.

También tras dos vueltas de votaciones para la selección de los trabajos para las cinco menciones, entre las 22 propuestas restantes, el resultado fue:

NL 714 (Meaques, Madrid)

Por la positiva valoración de la propuesta como definitoria de una nuevazona urbana, compatible con una posterior diversidad de las intervenciones arquitectónicas del programa completo de edificación previsto por el propietario del suelo. También se valoraron positivamente las imágenes ofrecidas para algunos hitos edificatorios.

333 (Alcalá de Henares)

En esta propuesta el jurado ha destacado la claridad y sencillez de la solución, así como la riqueza de los espacios interiores cuya creación se propone. Se consideró un trabajo sensible a la articulación con los elementos existentes.

\section{AA888 (Valencia)}

Se valoró positivamente la potencialidad de las ideas, su contenido teórico y las consideraciones urbanas que esta propuesta contiene, a pesar del limitado desarrollo de la idea que fue subrayado por alguno de los miembros del jurado en las discusiones para la selección.

AG962 (Alcalá de Henares)

A pesar de no haber unanimidad en el jurado en cuanto al lenguaje arquitectónico 
y respecto a la presentación gráfica, fue valorada positivamente la capacidad de la propuesta para dar una solución limpia y serena al programa, así como por la correcta solución de los espacios, con secciones y detalles sensibles respecto a las condicionantes de la zona y el carácter de la ciudad.

\section{ES333 (Madrid, EMV)}

Se valoró muy positivamente la capacidad de la propuesta para lograr un espacio libre, importante en una zona hoy excesivamente densa, que además puede ser compatible con la continuidad de la trama urbana. Igualmente se consideró correcto el desarrollo más pormenorizado de las distintas tipologías de edificación.

Se comprobaron las fichas redactadas por los expertos de cada una de las propuestas premiadas o mencionadas y se procedió a la apertura por parte de la Presidenta, en presencia de la Observadora del Comité Europeo y del Secretario de Europan/España.

Fue una decisión unánime del jurado que en caso de que algunas que las propuestas premiadas tuviese que ser desechada, una vez abiertos los sobres que desvelan el anonimato del equipo redactor, por incumplimiento de los reglamentos, no se concedan los premios a otras propuestas.

En Madrid, a veintinueve de abril de 2001 


\section{EUROPAN 3 (1992). ACTA DEL JURADO DE EUROPAN 3/ESPAÑA ${ }^{15}$}

En el dia 13 de enero de 1994, en la Sede de la Consejería de Política Territorial de la Comunidad de Madrid, se reunió, en una primera sesión, la totalidad de los miembros del Jurado de Europan III/Spain, integrado por las siguientes personas:

D. Miguel de Oriol e Ybarra

D. Nuno Portas

D. Manuel de la Dehesa

D. Jose Manuel Rey Pichel

Mr. Bengt Ahiquist

D. Jose Luis Catón

D. Joaquín Gómez Martínez

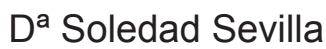

$D^{a}$ Angeles García de Paredes

Además, asistían a la reunión la Observadora designada por la Organización Europea, Da. Virginia Guiandelly y el Secretario del Comité Nacional de Europan/ España D. Antonio Vélez Catray. Esta primera sesión tuvo lugar después de haber recibido la explicación de cada uno de los grupos de expertos por parte de los propietarios de suelo objeto de concurso en esta edición española de Europan.

Los expertos, expusieron las características fundamentales del solar, los condicionamientos de cada uno de los solares a concurso y un resumen del resultado del examen previo, no eliminatorio de ninguna de las propuestas, de cada una de ellas.

En esta primera reunión, fue elegida por unanimidad como Presidenta del Jurado $D^{a}$ Angela García de Paredes Falla, la más joven de sus componentes.

A continuación la totalidad del Jurado procedió a examen de un total de 423 propuestas aceptadas a concurso según la siguiente distribución por solares:
Alicante 126
Granada 27
Alguazas 30
Madrid 157
Arrigorriaga 21
Orense 29
Calella 24
Requena 19

Tras examen de estas propuestas, en segunda sesión del Jurado, por eliminación se seleccionaron un total de 112 propuestas distribuidas por emplazamientos de

15 AA.VV. EUROPAN 3 España. En la ciudad como en casa. Urbanizar los barrios residenciales. Ed. Estudio N. Madrid. 1994. p.10-14. 
la siguiente forma:

Alicante 27

Granada 10

Alguazas 9

Madrid 33

Arrigorriaga 10

Orense 11

Calella 7

Requena 5

En la totalidad de los casos, cada una de las propuestas fue valorada al menos por seis de los miembros del Jurado.

En la tercera sesión del Jurado procedió, propuesta a propuesta, a una selección de 39 finalistas a las que posteriormente se añadieron otras dos, a petición de varios miembros del Jurado.

Estas propuestas eran consideradas por el Jurado con la calidad mínima para optar a las menciones o premios a conceder en esta edición. Las propuestas finalistas así escogidas se relacionan en hoja adjunta.

Entre estas propuestas aquellas presentadas bajo los lemas GT-234 y MM-030, ambas emplazadas en Madrid, fueron destacadas por el Jurado como propuestas de un contenido teórico positivo pero incompatible con las necesidades reales del programa y la normativa que afecta a este solar.

El Jurado en su última sesión decidió otorgar a los siguientes premios:

SJ-622: Enrique Johanson de Terry

FF-011: Luis Foncuberta Rueda y Aurora Fernandez Rodriguez

XV-105: Fernando Olba Rallo

FC- 111: Felipe Pich-Aguilera, Guillermo Maluenda

Igualmente decidió adjudicar menciones por el siguiente orden:

OM-480: Fernando Pardo Calvo

AC-345: Esteban García Martínez

V-123: Victor Garcia Gil

XY-903: Maria José Duch Navarro, Eva Prats Guerra

FM-003: Frederic Bonnet, Marc Pierre Bigamer

Al no haber sido posible, a juicio del Jurado, ningún premio o mención en el emplazamiento de Madrid, ya que todas aquellas propuestas que tenían la suficiente calidad incumplían en algún grado o caso las limitaciones urbanísticas que condicionaban el solar, conocidas por todos los concursantes.

Para contribuir a la realización de un proyecto derivado de Europan en este emplazamiento decidió escoger entre las soluciones finalistas que mas se 
aproximaban a cumplimiento de los requerimientos urbanísticos las propuestas:

BJ- 700: Benjamín Legüeceros Casino, Mercedes Salera Benito

LJ- 545: Jaime López Valdés

TR-005: José Álvarez del Manzano, Fernando Auz Iglesias, Antonio Juárez Chicote IA- 660: Ángel Iglesias Velasco, Eusebio Alonso García

Para la convocatoria de un concurso restringido, remunerado, organizado por el Comité Nacional Español de Europan, con la aprobación del Propietario Público de este suelo, y obtener en un plazo máximo de 3 meses una solución ajustada a las normativas urbanísticas que pasará de inmediato a su desarrollo como proyecto y a la posterior realización.

La aparición de los equipos así seleccionados en esta segunda convocatoria será voluntaria por parte de los mismos. Estos resultados no podrán ser considerados firmes hasta tanto transcurra el plazo específico en las bases del concurso para la comprobación de la validez de las inscripciones por parte del Secretario General Europeo.

Las propuestas premiadas o mencionadas que a partir de este momento puedan pasar a fase de mayor profundización de cara a la realización, deberán ser adaptadas por sus autores a los requerimientos específicos del propietario público de suelo, que se explicitarán en el encargo del correspondiente trabajo. El acto de entrega de premios se celebrará en lugar, fecha y hora que se comunicará a todos los equipos finalistas, y dentro del plazo de 90 días, a partir de la proclamación oficial de resultados. 


\section{EUROPAN 4 (1994). ACTA DE FALLO DEL JURADO DE EUROPAN IV ESPAÑA ${ }^{16}$}

A las 13 horas del día 19 de abril de 1996, el jurado de Europan IV en España, presidido por D. Pedro Casariego Hernandez- Vaquero y constituido por:

Da María del Corral López-Dóriga

D. Carlo Aymonino

D. Matti Sanaksenaro

D. Gerardo Mingo Pinacho

D. Victor Lopez Cotelo

D. Jose SEgui Perez

D. Jose $M^{a}$ Torres Nadal

D.Luis de Fontcuberta Rueda

Junto con D. Didier Rebois en calidad de Observador por parte de la Organización Europea y D. Antonio Velez Catrain como Secretario, acuerdan otorgar, siguiendo las bases de esta convocatoria, los siguientes premios y menciones seleccionados (sin jerarquía dentro de cada una de las categorías entre la totalidad de propuestas presentadas a concurso en España:

4 premios

Que corresponden a las siguientes propuestas (por orden alfabético de los Emplazamientos) Lema GA 221 en el emplazamiento de Bilbao Lema KW 100 en el emplazamiento de Cartagena Lema MA 230 en el emplazamiento de Palma de Mallorca Lema SF 754 en el emplazamiento de Sevilla

7 menciones

que corresponden a las siguientes propuestas (por orden alfabético de los Emplazamientos) Lema SD 101 en el emplazamiento de Alicante Lema AD 133 en el emplazamiento de Aranda del Duero Lema CT 696 en el emplazamiento de Bilbao Lema AB 987 en el emplazamiento de Mieres Lema SG 137 en el emplazamiento de Palma de Mallorca Lema ON 017 en el emplazamiento de Sevilla Lema GS 341 en el emplazamiento de Valladolid

Para llegar al resultado final arriba expuesto, los miembros del Jurado en su totalidad se reunieron por primera vez en Madrid el día 15 de abril, después de haberles sido expuestas en detalle, en la Escuela Técnica Superior de Arquitectura de

\footnotetext{
${ }^{16}$ AA.VV. EUROPAN 4 España. Construir la ciudad sobre la ciudad. Transformación de áreas urbanas contemporáneas. Madrid. 1996. p.11-14.
} 
Madrid, las características de cada uno de los emplazamientos por los respectivos representantes de los propietarios de suelo a concurso.

En esa misma sesión, previa a la constitución del jurado, fue expuesto igualmente un resumen del examen de la totalidad de propuestas por parte de los expertos designados al efecto por los propietarios del suelo. Estos expertos habían elaborado, para cada una de las propuestas, una ficha que recogía su opinión desde el punto de vista del programa y del cumplimiento de las bases. El jurado, en su primera sesión, acordó por amplia mayoría la designación de D. Pedro Casariego Hernández-Vaquero como Presidente del mismo y esbozó el procedimiento a seguir para alcanzar un número máximo de 5 premios y 5 menciones, según la dotación económica prevista en el Comité Nacional de EUROPAN/España.

Igualmente acordó admitir a concurso la única propuesta llegada a la sede de EUROPAN/España en fecha posterior a la fijada por las bases, ya que ésta había sido remitida en origen dentro de las fechas establecidas por el reglamento del concurso.

A lo largo de la siguiente jornada el jurado propuso, de forma conjunta, pasar a una fase posterior de discusión y debate un total de 180 propuestas entre las 307 presentadas, cuyos lemas se recogen en un anexo a este acta. El procedimiento utilizado fue el de admitir a esa fase posterior toda propuesta que contase al menos con el apoyo de un miembro del jurado.

Entre las 180 propuestas el jurado, por mayoría entre sus miembros y de forma conjunta, escogió 39 propuestas entre las que debían quedar englobadas las propuestas finalistas. Los lemas correspondientes a estas 39 propuestas se recogen en el anexo a este acta.

Por el mismo procedimiento de mayoría entre sus miembros el jurado seleccionó, siempre de forma conjunta, las 29 propuestas finalistas cuyos lemas se recogen en el cuadro anexo a este acta.

Dentro de estas propuestas finalistas, que serán objeto de publicación en el catálogo nacional de resultados y que formarán parte de la exposición que organice en el futuro EUROPAN/España, el jurado, por mayoría, estableció aquellas propuestas que deberían ser objeto de premio y las que deberían ser objeto de mención. DE este modo, los miembros del jurado acordaron que fuesen premiadas las cuatro propuestas señaladas al comienzo de este texto y propuso, si ello era posible, aumentar hasta siete el número de menciones a otorgar. Esta proposición del jurado pudo ser asumida por la dotación económica global de los galardones, prevista por el Presupuesto de EUROPAN IV/España.

Los criterios que a lo largo de las sesiones de selección y debate han prevalecido han sido los de señalar la calidad de los trabajos independientemente de su 
distribución por emplazamientos; que esta calidad se contemplase tanto desde el punto de vista de los valores concretos arquitectónicos o del contenido urbanístico como también desde la capacidad de respuesta al programa planteado, así como al tema general de esta Cuarta Edición de EUROPAN "Construir la Ciudad sobre la Ciudad".

Este jurado considera que las propuestas, tanto premiadas como mencionadas, independientemente de su contenido más o menos próximo a la edificación o al planeamiento, son suficientemente capaces de desencadenar procesos de intervención sobre cada uno de los respectivos emplazamientos por parte de los arquitectos o equipos de arquitectos reconocidos en este fallo.

El jurado desea dejar constancia de que en el emplazamiento de l'Hospitalet de Llobregat no ha sido posible llegar a premiar o a otorgar menciones a ninguna de las propuestas presentadas, ya que todas las propuestas seleccionadas en las primeras etapas del fallo bien suponían opciones excesivamente densificadas o bien, en opciones alternativas, no ofrecían el grado de concreción y desarrollo que permitiese al propietario de suelo desencadenar el proceso de intervención en el suelo sometido a concurso.

Del mismo modo, el jurado desea subrayar, en el caso del emplazamiento de Palma de Mallorca, su convencimiento de que es deseable reducir los mínimos edificables sugeridos a los concursantes a lo largo del proceso de concurso, para cualquier etapa posterior de actuación que se deduzca de este fallo.

En relación con el emplazamiento de Mieres, el jurado considera que las respuestas más adecuadas al sitio y al programa son aquellas que se preocupan de la recuperación del sector antiguo (La Villa) mediante pequeñas intervenciones, y que además no proponen alcanzar la totalidad del programa inmobiliario señalado en las bases para las zonas libres de edificación (zona de los Pozos). En este sentido va, claramente, la decisión del jurado.

En los casos de Alicante y Aranda de Duero parecen igualmente apropiados, a criterio del jurado, aquellos trabajos presentados a concurso que abordan la complejidad de toda la zona y no los que se limitan solamente a la implantación sobre el terreno de la edificación permitida. El jurado considera que el resultado del concurso en su conjunto para estos terrenos puede proporcionar vías de actuación sobre el área previas a la definición de proyectos de edificación en los terrenos disponibles.

El jurado también desea subrayar, en relación con el emplazamiento de Valladolid, su decisión de destacar, como más acordes con sus criterios, aquellas propuestas que han optado por la conservación en parte o en su totalidad del edificio del antiguo mercado existente. 
Los valores que esencialmente han motivado al jurado en cada caso concreto a otorgar finalmente los premios y menciones ya señalados, han sido, de forma resumida:

\section{PREMIO BILBAO (GA 221)}

Sensible solución tipológica que ordena el conjunto de forma clara resolviendo la transición de escalas desde la más doméstica a la más urbana.

El tratamiento de borde de forma escalonada para el uso terciario y el de la zona residencial conformado por unas pequeñas torres coronando el basamento de edificios alargados, sinuosos, que resuelven la implantación de una difícil topografía, contribuyen a la imagen del conjunto que tiene grandes posibilidades de desarrollo posterior.

\section{PREMIO CARTAGENA (KW100)}

El atractivo de una ordenación de volúmenes que se muestra flexible y fresca, logrando una deseada permeabilidad, fue uno de los aspectos más positivamente valorados por el jurado.

Se aprecia una inteligente combinación de alineaciones, volúmenes, trayectos, perforaciones, escalas, tipologías, etc., que pueden resolver los problemas que se concentran en este solar, encarnando una pieza articulada y articuladora que vitaliza el cuerpo existente a mantener mediante una intervención esmerada, que convendría que no llegase a ser excesiva.

\section{PREMIO. PALMA DE MALLORCA (MA 230)}

Entre todas las propuestas presentadas en Palma de Mallorca, era ña única que creaba una acertada conexión entre la ciudad y el mar, que enfrenta a éste a una fachada rota, asimilando inteligentemente el edificio existente a mantener. Las torres propuestas contribuyen además a amortiguar la diferencia conceptual con respecto al edificio existente. El zócalo pétreo implantado (recuerdo, a juicio del jurado, de la muralla histórica próxima) refuerza la fachada y da sustancial apoyo a sus torres.

El tratamiento de los extremos del solar implantando edificios singulares de uso público formaliza coherentemente la conexión con las rondas y con el nudo hacia el aeropuerto.

La tipología de las viviendas, globalmente acertada por su articulación, permite al jurado presumir la suficiente flexibilidad y oficio en los autores de cara a la futura intervención.

\section{PREMIO. SEVILLA (SF 754)}

A las características físicas de la parcela, fachada de la autovía S-30; forma triangular residual de una ordenación urbana y centro de barriada, se responde mediante un orden geométrico que configura un único edificio fragmentado en cinco volúmenes en forma de $L$ que se adaptan armónicamente al perímetro del terreno.

La solución tipológica y disposición de la vivienda conseguirán aislar los espacios 
libres interiores, ajardinados, de la incomodidad de la autovía y desarrollan frente a ésta corredores de acceso exteriorizados en fachadas de acertada imagen y de sensible composición formal

MENCIÓN. ALICANTE (SD 101)

Entre aquellas propuestas en este emplazamiento que estructuraban el conjunto del área de estudio, el jurado valoró en este trabajo la posibilidad de actuar en el lugar a partir de un trazado superpuesto que integre en una unidad lo existente y la actuación futura.

La repetición de un modelo de "habitación" puede ser el cambio idóneo. Sin embargo, para que esta intervención colonizadora produzca los efectos deseables, parece necesario buscar los caminos oportunos para aumentar la intensidad de la intervención y lograr imponerse al desorden existente.

Esta propuesta abre acertadas pautas para el planeamiento que pueden ser útiles, a las estrategias públicas de actuación en la zona.

MENCIÓN, ARANDA (AD 133)

En el caso de esta Mención los valores más claros a juicio del jurado fueron el de la imagen consecuente con las características de una ciudad intermedia o pequeña, como puede ser Aranda de Duero, y la lograda conexión a través de los cuerpos edificados propuestos en el uso residencial, entre los núcleos de viviendas ya consolidadas en la zona.

Igualmente se consideró correcta y flexible la tipología tanto de bloque como de viviendas que se recogían en la propuesta. Se apreció un buen conocimiento por parte del equipo concursante de las variables topográficas y del viario existente.

\section{MENCIÓN. BILBAO (CT 696)}

Propuesta en la que su radicalismo, con la creación de cuatro bloques de imagen cúbica y diferentes tratamientos, enlazados por una calle que penetra en los dos centrales, favorece la creación de un gran salón urbano.

La colocación de las torres en los bordes del lugar y su forma abierta hacia las distintas direcciones del paisaje son, junto con la relación que desde la edificación se establece con la topografía, las grandes cualidades de la propuesta.

Las viviendas doblemente orientadas son una hermosa aportación al sitio y al proyecto.

Ante la rotundidad de las piezas arquitectónicas se echa de menso un mayor estudio de los espacios públicos y de relación.

\section{MENCIÓN. MIERES (AB 987)}

Se valora positivamente la conservación inteligente del casco antiguo revitalizado por ligeras intervenciones en plazas y por propuestas apropiadas de utilización, así como por el tratamiento del gran solar al disponer de una sugerente variedad de edificios. El destino del suelo disponible se liga al concepto de flexibilidad espacial y temporal.

La interconexión de los espacios, objeto de concurso y su adecuación al terreno 
considerando las edificaciones interpuestas, aportan una imagen deseable para el conjunto.

\section{MENCIÓN. PALMA DE MALLORCA (SG 137)}

Hay en el proyecto una acertada continuación de la extensión de la trama urbana hasta el mismo borde del mar y la construcción de la mayor parte de la edificación en forma de torre.

La continuidad se consigue con la superposición de usos y funciones en varios niveles que aportan al lugar una riqueza y una complejidad realmente sugerente. Las penetraciones en canal, los accesos peatonales en la playa, por ejemplo.

Las torres tienen el valor de referencia en una situación de borde como es el solar de concurso. Finalmente cabe destacar el efecto combinado de las dos formas de actuación al resolver tanto los problemas de edificabilidad e implantación de las torre, como el enriquecimiento de situaciones en la planta baja.

\section{MENCIÓN. SEVILLA (ON 012)}

Quizás el mayor acierto del proyecto radique en su propuesta de ordenación. El fraccionamiento de sus elementos arquitectónicos, organizados a lo largo de la directriz de la Autovía, confiere al conjunto la imagen urbana que requiere una operación con estas limitaciones. Ese entendimiento de "fragmento" dentro de un orden global, confiere a la propuesta esas características urbanas que requiere el oficio de "hacer ciudad", interpretando la ciudad como una suma de fragmentos dentro de un orden global.

El tratamiento de sus diferentes alturas, u la rótula que uno de los fragmentos como referencia ordenadora del conjunto, podría ser otra de sus atractivas apuestas.

\section{MENCIÓN. VALLADOLID (CS 345)}

El jurado valora muy positivamente el mantenimiento de al menos una de las naves del mercado mediante un nuevo uso como contenedor de equipamientos culturales e igualmente la implantación del volumen del auditorio como remate integrador de la estructura de la edificación existente.

Las viviendas, servicios de Cafetería, centro para la Tercera Edad, etc., como nueva construcción autónoma, cierran acertadamente el espacio central. La malla estructural es fácilmente utilizable para distintas funciones y su volumetría podrá atender a las futuras necesidades reales.

Al jurado le parece una solución óptima: la adecuación de un espacio público, ya existente, a las nuevas necesidades que implican el cambio o el desarrollo de esa zona de la ciudad. Es positiva la opinión del jurado en cuanto a la relación que se propone entre los edificios de nueva planta y los que se conservan.

En su sesión final, el 19 de abril de 1996, el presidente del jurado, en presencia de los miembros del mismo, procedió a la apertura de los sobres que contenían los nombres de los autores correspondientes, siendo esta la correspondencia de 
los mismos:

LEMA GA 221: Eduardo Belzunce, Luis Díaz Mauriño, Juan García Millán.

LEMA KW 100: José González Gallegos

LEMA MA 230: Luis Martínez Santamaría

LEMA SF 754: Enrique Sobejano, Fuensanta Nieto

LEMA SD 101: Pedro Palmero Cabezas, Samuel Torres de Carvalho

LEMA AD 133: Ángela García de Paredes, Ignacio García Pedrosa

LEMA CT 696: Jose María Lapuerta, Francisco Burgos

LEMA AB 987: Javier Fresneda Puerto, Javier Sanjuan Calle, Javier Herreros Ortega

LEMA SG 137: Susanne Fritzer

LEMA ON 017: José Morales Sánchez, Juan Giles Domínguez, Juan González Mariscal

LEMA CS 341: Eduardo de la Peña, Antonio Lleyda

Los nombres que responden a los lemas de la totalidad de los proyectos finalistas se incluyen en el documento anexo a este acta.

El resultado del fallo reflejado en este documento no tendrá carácter definitivo hasta tanto los premiados y mencionados no hayan sido objeto de las reglamentarias comprobaciones por parte de la organización europea.

En Madrid, a 19 de abril de 1996, firman la presente acta: 


\section{EUROPAN 5 (1997). ACTA DE FALLO DE JURADO DE EUROPAN 5/ESPAÑA ${ }^{17}$}

El presente documento consta de dos partes que corresponden sucesivamente a las dos etapas en que se ha desarrollado en nuestro país el fallo del concurso en esta quinta edición.

Ello ha sido debido a la necesidad, por acuerdo entre todas las organizaciones nacionales, de llegar a una selección de finalistas que sirvieron de base para un debate sobre la aproximación de los concursantes a los temas de comunes del concurso en todos los emplazamientos. Esto tuvo lugar en París los días 18,19 y 20 de febrero de 1999, con la presencia y participación de miembros de los jurados en esta edición, de representantes de los propietarios de suelo a concurso, expertos vinculados a la organización europea del concurso y miembros de las diferentes organizaciones nacionales.

\section{Primera fase}

Valladolid, 26,27 y 28 de noviembre de 1999

En Valladolid, auspiciada por el Ayuntamiento de esta ciudad y en los locales cedidos por los recintos Feriales de Castilla y León, tuvieron lugar las sesiones de trabajo de la Primera Fase del Fallo de Europan 5 España que se desarrollaron del siguiente modo:

\section{Jueves 26 de noviembre de 1998}

A las 12:45 horas del jueves día 26 de noviembre de 1998 comenzó la presentación y descripción de los diferentes emplazamientos presentados a concurso en España. En esta reunión inicial, que fue interrumpida para el almuerzo, asistieron todos los miembros del jurado con excepción de D. Elías Torres Tur, a quien fue transmitido, pocas horas después, un resumen de esta exposición por los miembros del Secretariado.

D. Miguel Fisac Serna, por razones de su avanzada edad, no pudo desplazarse a Valladolid, siendo sustituido en el Jurado por D. Carlos Ferrán Alfaro-suplente anunciado en la convocatoria española- y D. Kees Christiansee por D. Ricardo Sánchez Lampreave, también anunciado en esa convocatoria.

Esta exposición fue complementada con las aclaraciones que los miembros del jurado y también el secretario solicitó de los técnicos responsables designados por los propietarios de suelo a concurso. Estos mismos técnicos fueron quienes, previamente a las sesiones, cumplimentaron la información concerniente al grado de respuesta de los concursantes al programa y a las condiciones concretas de cada emplazamiento. Para cada propuesta presentada fue elaborada una ficha técnica que estuvo en todo momento a disposición de los miembros del jurado

${ }^{17}$ AA.VV. 10 años EUROPAN 5 España. Ed. EUROPAN/España. Ed. SEPES y el Ministerio de Fomento. Madrid. 1999. pp.13-15. 
durante el trabajo de esta primera fase.

A las 17:30 horas de la tarde del mismo día se constituyó el jurado, quedando designado Presidente, a propuesta de D. Gerardo Mingo Pinacho- representante en el Jurado del Ministerio de Fomento- D. Carlos Ferrán Alfaro, sobre todo teniendo en cuenta su dilatada experiencia y su conocimiento directo de la mayoría de los emplazamientos a concurso, así como su condición de Asesor del Comité Nacional Español de Europan.

Así, el jurado quedó constituido del siguiente modo:

Presidente

D. D. Carlos Ferrán Alfaro

Miembros extranjeros

D. Gonzalo Byrne, Arquitecto, Portugal

D. David Chipperfield, Arquitecto, Gran Bretaña

D. Klas Tham, ARquitecto, perteneciente a EUROPAN/Suecia

Miembros españoles

D. Gerardo Mingo Pinacho, Arquitecto, Subdirector General de ARquitectura Del M;inisterio de Fomento.

D. Carlos Sambricio, Catedrático de Historia de Arquitectura de La Escuela Técnica Superior de ARquitectura de Madrid.

D. Elías Torres Tur, Arquitecto

D. Ricardo Sánchez Lampreave, Arquitecto, Premiado en EUROPAN/España.

\section{Secretario}

D. Antonio Velez Catrain, Arquitecto, Secretario General EUROPAN/España

En esta primera reunión, tras la designación del Presidente, el Jurado estableció por unanimidad unas mínimas instrucciones para el desarrollo de esta fase del Fallo, compatible en todos sus extremos con el Reglamento General-Bases- de esta quinta edición de EUROPAN.

En concreto, quedó establecido el objetivo de llegar a una selección de un mínimo de 30 y un máximo de 50 propuestas finalistas, cuyos extractos gráficos y escritos serían trasladados a la Organización Europea para la preparación de los debates que tendrán lugar en Paris en Febrero de 1999, antes de la Sesión Final del presente fallo. Los compromisos de algunos de los miembros del jurado fueron expuestos con la finalidad de que pudiese alcanzarse el objetivo de esta primera fase del fallo antes de las 15:00 horas del sábado día 28 de noviembre.

El secretario subrayó que el objetivo de esta primera fase del fallo debería ser el de seleccionar aquellas propuestas que, reuniendo la calidad suficiente a criterio 
del jurado, constituyesen una base de discusión global, a nivel europeo, en torno a la respuesta al Tema de Europan 5. Igualmente insistió en que los criterios de selección no deberían atender a un reparto equilibrado por emplazamientos, sino a la calidad concreta de los trabajos presentados.

El Secretario también comunicó al jurado que en esta ocasión no se contaba con ningún observador designado por la Organización Europea y que esto se debía a que la persona en principio propuesta por el Secretariado Europeo no podía acudir en las fechas de la celebración, así como a la necesidad de contar en cualquier caso con un observador que pudiese manejar el castellano o el inglés, lenguas en las que se desarrollaría el fallo. La larga experiencia española, el hecho de contar con la presencia de Klas Tham, jurado en otras ediciones y miembro de EUROPAN /Suecia: así como la experiencia del Secretario tanto como jurado, como observador y como organizador en otras ediciones y secciones nacionales, a criterio de la Organización Europea, consultada antes de dar comienzo a las sesiones de trabajo, obviaban este requisito.

Antes de comenzar el examen de las propuestas, fueron sometidas a criterio de los miembros del jurado las únicas tres excepciones en las propuestas recibidas hasta el día 26 de noviembre:

- una propuesta conteniendo cuatro paneles en lugar de los tres reglamentarios.

- Dos propuestas que llevaban incorporadas en bajorrelieve maquetas de las propuestas.

- Una propuesta no llevaba lema y le fue adjudicado por los organizadores un lema provisional hasta tanto fuese desvelado el anonimato.

El jurado por unanimidad decidió que los organizadores aportasen el panel menos relevante de los cuatro presentados en primer caso y no eliminar dicha propuesta del concurso. El Prof. Tha, de todos modos ha querido dejar constancia de la improcedencia del concursante, aunque se sumó a la aceptación de la propuesta a concurso.

En el caso de las otras dos propuestas, se consideró, unánimemente que las que las maquetas incorporadas al panel tenían el mismo carácter que las fotos que otros concursantes de modo generalizado incluían en su presentación.

El jurado fue advertido que el plazo de la recepción de las propuestas acababa el lunes día 30 de noviembre y que en el caso que alguna llegase con posterioridad al desarrollo de esta gase, excepcionalmente sería examinada por sus miembros antes de dar comienzo a la segunda fase. (El cambio de calendario aprobado por la Organización Europea no permitía a su vez retrasar esta reunión del jurado de EUROPAN 5/España y así fue advertido por el Secretariado Español a la Organización Europea). El número total de propuestas recibidas y aceptadas a concurso fue de 245 distribuidas por emplazamientos del modo siguiente: 
Almaría,59/Amurrio, 6/ Barakaldo, 48/ Cartagena, 17/ Cauta, 53/Paterna, 16/ Puertollano, 8/ Tolosa,13/Tudela, 26

Los miembros del Jurado, a su criterio,y contando con la incorporación de D. Elías Torres Tur, procedieron a examinar las propuestas presentadas a concurso en esta convocatoria, dispuestas por emplazamientos y acompañadas de la ficha técnica elaborada por los expertos designados por los propietarios de suelo a concurso.

Viernes 27 de noviembre de 1998

A las 12:30 horas el Presidente reunió la totalidad de los miembros del jurado para proceder a puntualizar los acuerdos sobre los criterios de selección y a un primer examen conjunto de las propuestas, una vez examinadas todas ellas de forma individual. Los acuerdos fueron los siguientes:

- Se procedería por eliminación de aquellas propuestas que a Juicio mayoritario de los miembros no respondiesen con suficiente calidad y coherencia a la convocatoria.

- A lo largo de todo el desarrollo de esta primera fase los miembros del jurado podrían retrotraer la discusión a cualquier propuesta que hubiese sido eliminada si alguno de estos lo consideraban necesario.

- El resultado de esta fase del fallo sería irreversible para el desarrollo de la segunda dase y todas las propuestas seleccionadas en esta primera fase constituirían aquellas a publicar como finalistas, y entre estas se encontrarían todas las propuestas que obtendrán premio o mención en esta convocatoria.

- Antes de proceder a la eliminación de cualquier propuesta se procedería a un examen, y en su caso a una discusión conjunta ante la misma, por una mayoría sensible de los miembros del jurado.

-Se procedería a tantas rondas eliminatorias como fueran necesarias hasta que se alcanzase un número inferior a 50 propuestas.

- Debería quedar claro para los miembros del jurado que en esta primera fase el objetivo no era conceder premios ni menciones, sino llegar a la selección a discutir en las reuniones de Lille a nivel europeo.

Siguiendo este procedimiento y contando con los votos de la totalidad de los miembros del jurado, se llegó a las 15:30 horas a la selección de 122 propuestas, distribuidas por emplazamientos del siguiente modo:

Almería,33/ Amurrio, 3/ Barakaldo, 22/ Cartagena, 10/ Ceuta,23/ Paterna,9/ Puertollano,5/ Tolosa,7/ Tudela, 10.

Procediendo siempre por mayoría de 5 votos, tras una segunda votación y contando igualmente con los votos de la totalidad de los miembros del jurado, se llegó a las 21:30 horas a la selección de 63 propuestas, distribuidas por emplazamientos del siguiente modo:

Almería,17/ Amurrio, 1/ Barakaldo, 8/ Cartagena, 8/ Ceuta,14/ Paterna,4/ Puertollano, 1/ Tolosa,1/ Tudela, 5. 
El jurado, al final de esta selección, quedó emplazado por el Presidente a lograr el número inferior a 50 propuestas seleccionadas a lo largo de la mañana del día 28.

Sábado 28 de noviembre de 1998

Dieron comienzo a su trabajo los jurados a las 10:00 horas, procediendo previamente a examinar individualmente las 63 propuestas ya seleccionadas. El presidente reunió al jurado a las 12:00 horas para proceder a examinar conjuntamente una a una a todas las propuestas seleccionadas.

En esta sesión el Presidente representó a D. Gerardo Mingo Pinacho, quien previamente le había aportado sus criterios para esta última selección. Al tenerse que ausentar D. David Chipperfield a las 13:15 horas dejó instrucciones precisas sobre las propuestas que no habían sido aún votadas, trasladando el secretario al Presidente, en cada propuesta sometida a votación, el criterio del Sr. Chipperfield. A las 14:30 el jurado había llegado a la selección de 31 proyectos distribuidos de la siguiente manera:

Almería,8/ Amurrio, 1/ Barakaldo, 5/ Cartagena, 4/ Ceuta,6/ Paterna,3/ Puertollano, 1/ Tolosa,1/ Tudela, 2.

Reunidos de nuevo todos los miembros presentes del jurado se acordó previo examen y discusión, al inclusión de 1 propuesta más correspondiente al enlazamiento de Ceuta, habiendo sido rechazada por mayoría la propuesta de uno de los miembros del jurado de incluir en la selección final una propuesta más a las ya seleccionadas para el emplazamiento de Tudela.

Así la selección final fue de 32 proyectos finalistas distribuidos por emplazamientos como sigue:

Almería,8/ Amurrio, 1/ Barakaldo, 5/ Cartagena, 4/ Ceuta,7/ Paterna,3/ Puertollano, 1/ Tolosa, 1/ Tudela, 2.

El jurado dio por terminada la sesión, última de esta fase, acordando hacer un esfuerzo por acudir las mismas personas a la segunda fase que podría desarrollarse en la última semana de febrero o la primera de marzo de 1999. También agradecieron los miembros la hospitalidad del Ayuntamiento de Valladolid y las condiciones en que se había desarrollado esta fase del dallo en el Recinto Ferial. El Presidente, haciéndose portavoz de todos los miembros del jurado felicitó a los organizadores, en concreto al equipo del Secretariado, y al equipo auxiliar de apoyo, por el trabajo previo y por el desarrollo en estos días.

\section{Segunda fase}

Madrid, 5 y 6 de marzo de 1999

Se inició la sesión a las 11:00 horas del viernes día 5 de marzo de 1999contando con la presencia de todos los miembros del jurado a excepción de D. David 
Chipperfield quien se incorporó al mismo a las 15:00 horas de ese día. También se contó con la presencia, desde el inicio de estas sesiones con la observadora designada por la organización europea, Sylvie Chirat, miembro de la estructura permanente del Secretariado Europeo de EUROPAN. Asistía, también desde el inicio de la sesión, D. Antonio Velez Catraín, Secretario de EUROPAN/España y secretario del jurado. Continuó ejerciendo las funciones del Presidente del Jurado D. Carlos Ferrán Alfaro, elegido al comienzo de la anterior fase. Participaron en las sesiones como apoyo al jurado en los aspectos técnicos $D^{a}$ Carmen Imbernón y $D^{a}$ Ana Kurson, ambas miembros permanentes del Secretariado de EUROPAN/ España.

En primer lugar el jurado acordó aceptar a concurso la propuesta que bajo el lema KZ 700 no había podido ser abierta en las sesiones de Valladolid por problemas de envío no imputables al concursante. Esta propuesta fue desempaquetada en local aparte de las sesiones y sin la presencia de ninguno de los miembros del jurado ni del secretariado. Se acordó esperar a la llegada del Sr. Chipperfield para su inclusión o no entre las propuestas finalistas ya seleccionadas en la primera fase. Tras la incorporación del Sr. Chipperfiel, el jurado acordó no incluir esta propuesta entre las propuestas finalistas que habían llegado a esta segunda fase.

Inmediatamente, el jurado, de común acuerdo, decidió proceder en una primera tanda al examen de las propuestas finalistas, acordándose que se procedería de forma positiva, proponiendo cada miembros las que deberían ser consideradas los premios o menciones. El jurado acordó destacar las siguientes propuestas, merecedoras de ese reconocimiento por los valores que se recogerían en el documento final del fallo, y serían incluidas en las publicaciones y exposiciones derivadas de esta edición del concurso en España:

BK 166, AM 905, FS 636,PH 001, GE 299, HT 104, AL 111, SE 019, AL 257

Antes de finalizar la jornada del viernes 5 de marzo, el jurado procedió a votar selectivamente, primero aquellas propuestas merecedoras de una de las menciones y con posterioridad a las que se atribuía calidad suficiente para la categoría del premio. En estas rondas de votaciones y debates en torno a cada una de las propuestas finalistas, se incorporó el voto del Sr. Chipperfield, dando éste por válida la selección anterior. El jurado procedía siempre conjuntamente y fueron seleccionados para Menciones los trabajos presentados bajo los lemas: FS 836, AL III

Con inmediata posterioridad y también una a una debatió la propuesta a premios, quedando seleccionados, con carácter definitivo dos trabajos presentados bajo los siguientes lemas:

BK 166, CE 299

Se dio por terminada esta primera jornada acordando el jurado reunirse la mañana siguiente para revisar el resultado obtenido y proceder a una última votación para 
las menciones y premios, así como para proponer determinados reconocimientos a los trabajos presentados dignos, a criterio mayoritario del jurado, de ser reseñados entre los finalistas de la primera fase de este fallo.

A las 10:30 horas del sábado 6 de marzo, el jurado, y otros miembros no votantes del mismo todos presentes, procedieron a instancias de D. David Chipperfield a revisar todas las propuestas finalistas excluyendo los tres premios ya atribuidos, para considerar la posibilidad de variar, con criterios comparativos, por nuevas inclusiones o por exclusiones, el número de propuestas que optaban a una mención. La selección definitiva fue la siguiente:

GR 232, SI 111, FS 836, PH 001, XY 223, AL III, OM 026, AL 257

En este momento algunos miembros del jurado cuestionaron al Secretariado sobre la posibilidad de incrementar el número de menciones a conceder ya que los premios otorgados no alcanzaban el número máximo de 5 permitidos por la convocatoria del concurso den España.

El secretario expuso que manteniendo el tope máximo global de la partida disponible en presupuesto para el total de premios y menciones, no había impedimento para que el jurado actuase según sus criterios e hizo una referencia al resultado en España de la anterior edición en la que se concedieron 4 premios y 7 menciones. Antes de proceder a la propuesta definitiva de menciones fueron tomadas por unanimidad las siguientes decisiones:

Promover la categoría de premio, la propuesta bajo el lema PH 001 en el emplazamiento de Barakaldo por considerar que su contenido y su desarrollo destacaban entre las menciones y eran equiparables a los de los premios ya decididos.

Algunos miembros del jurado solicitaron destacar entre las restantes propuestas finalistas por aspectos concretos de su contenido y su relación con el tema y/o con el lugar:

AB 987, SE 019, BK 999, UG III, MP 528, AT 101, CD 340

Finalmente, y como última votación del jurado, se procedió a decidir las propuestas merecedoras de una mención que fueron las siguientes:

GR 232, SI III, FS 836, XY 223, AL III, OM 026, AL 257

Antes de la decisión final, el jurado solicitó al secretario que como anexo al Acta del Jurado se incluyesen la reseña las razones que en cada caso habían motivado al conjunto del jurado a la consideración de las tres categorías de reconocimientos (Premios, Menciones, Menciones de Honor), a las que cada miembro del jurado, si lo consideraba oportuno podría añadir los comentarios que estimase oportunos de cara a las publicaciones derivadas de este fallo. 
Una vez ratificada la decisión del jurado de conceder 4 Premios y 7 Menciones, entre el total de propuestas finalistas en esta quinta edición de EUROPAN/ España, el Secretario, en presencia de todos los miembros del jurado y de la observadora de la Organización Europea procedió a la apertura de los sobres que desvelaban el anonimato de los autores de los 32 trabajos finalistas que habían sido objeto de debate, votación y decisión en esta segunda fase del fallo. Los autores de estas propuestas son los siguientes:

Finalistas

GC-201: Jaime Coll López, Judith Lecrerc

AM 905: Angel Verdasco Novalvos, Luis Rojo de Castro, Begoña Fernández-Shaw JC-165: Jesús de la Fuente Moreno, Carmen Cabranes

RR-007: Laura Peretti, Marta Sforni

IE-844: Mónica García, Alessandro CarusoSanto Caccamo, Juan Llamazares, Pablo Lorente, Stefanía Cassarino.

XV-555: Ana Riaza Espinosa de los Monteros, Javier Herreros Ortega,

ID-117: Javier Valdés Fernández de Alarcón

IT-321: Idis Turato, Sasa Randic, Maja Matulja

YA-199: Alvaro Soto Aguirre, Clarissa Rosenow

BE-205: Jose Luis Bezos Alonso

SU-617: Fernando Antón Carbonero

IA-085: Iñigo Casero Portugal, Arturo López Bachiller

ST-246: Julio César Moreno

EC-444: Jose María Lapuerta Montoya, Fernando Gaforio

UG-111: Antonio Juárez Chicote, Javier García-Germán, Rocio Monasterio

BK-999: Alain Chiffoleau, Pierre Deat, Lucas Froment

CD- 340: Eduardo Miralles Millón, Mauricio Bertet, Mariano Molina, Loli Bruns

MP-528: Paloma Iniesta Ayerra, Angeles Nuez Díaz

AT-101: Manuel Gausa, Oleguer Gelpi, Aureli Santos, florence Ravenau, Ignasi Pérez

AB-987: Javier Fresneda, Javier Sanjuan Calle, Javier Peña Galiano

SE-019: Jesus Ulargui, Sergio de Miguel, Eduardo Pesquera

Menciones

GR-232: Oscar Rueda Jiménez

SI-111: David Sim, Jesús Mateo Muñoz

FS-836: Federico Soriano, Dolores Palacios

XY-223: Sandra Topfer, Dirk Bertuleit, Jorge Siewekw, Jens Weisener

AL-111: Enrique Delgado Cámara, Rubén Picado, Maria José de Blas, Maria Antonia Fernández

OM-026: Maria José Pizarro Juanas

AL-257: Elio García García, Carlos Rodríguez Alcoba, Javier Rodríguez Alcoba

Premios

BK-166: Alonso Cano Pintós, Maria Julia Abarca Corrales 
PH-001: Eduardo Arroyo

GE-299: Juan Hevia Ochoa de Echagüen, Fernando García Pino, Manuel García de Paredes, Nuria Ruiz García

HT-104: José Morales Sánchez, Juan González Mariscal

Madrid, 6 de marzo de 1999 


\section{EUROPAN 6 (2000). ACTA DEL FALLO DEL JURADO DE EUROPAN 6 ESPAÑA ${ }^{18}$}

\section{PRIMERA FASE.}

Cartagena, del 4 al 7 de abril de 2001

En Cartagena, auspiciadas por el Ayuntamiento de esa ciudad, en los locales cedidos por la Universidad Politécnica de Cartagena, Campus de la Muralla del Mar, tuvieron lugar las sesiones de trabajo de la primera fase del fallo de EUROPAN 6/España.

$D^{a}$. Nathalie de Vries, por encontrarse en estado de gestación, había declinado su participación en el Jurado, siendo sustituida por D. Frédéric Bonnet -suplente aprobado para la convocatoria española - y $D^{a}$. Francine Houben por Mr.Gerard Maccreanor, no anunciado en la convocatoria ya que la vocal titular informó de su ausencia a tan sólo siete días de la celebración de la sesión de trabajo. Igualmente, $D^{a}$ Beth Galí sustituyó a $D^{a}$ : Carmen Pinós quién, por motivos personales, se encontró imposibilitada para formar parte del jurado. Finalmente, $D^{a}$. Dolores Alonso -suplente aprobada en la convocatoria española - ostentó el voto de D. Gerardo Mingo Pinacho quién se uniría al Jurado español en segunda fase.

Así, el Jurado estuvo formado por los siguientes miembros:

$D^{a}$. Elena Orteu quién delegó su voto en D. Juan Gómez Acosta, Decano de C.O.A.Murcia, Consejero del Consejo Superior de los Colegios de Arquitectos de España.

$D^{a}$. Dolores Alonso, miembro suplente del Jurado, en representación de D. Gerardo Mingo Pinacho, Subdirector General de Arquitectura del Ministerio de Fomento, ausente en esta primera fase del Jurado.

$D^{a}$. Beth Galí, Arquitecto

D. Carlos Puente, Arquitecto

D. Eduardo Arroyo, Arquitecto, Premio EUROPAN 5/España

Mr. David Cohn, Crítico, U.S.A.

D. Javier Maderuelo, Crítico

M. Frédéric Bonnet, Arquitecto, Francia, Mención EUROPAN 3/España

Mr. Gerard Maccreanor, Arquitecto, Reino Unido/Holanda, Premiado en EUROPAN/ Holanda

Las jornadas de trabajo transcurrieron del siguiente modo:

\section{Miércoles 4 de abril de 2001}

A las 17:30 horas, en el salón de Grados de la Universidad Politécnica, dio comienzo, a cargo de los responsables del suelo o de las personas designadas a

\footnotetext{
${ }^{18}$ AA.VV. EUROPAN 6 España.Entre ciudades. Ed. Gráfica Futura. Madrid. 2001. pp.7-9.
} 
estos efectos, la presentación y descripción de los emplazamientos españoles a concurso.

El emplazamiento de Avilés fue expuesto por D. Manuel Carrero de Roa, representante del Principado de Asturias.

El emplazamiento de Ceuta fue expuesto por D. Alberto Weil, representante de EMVICESA

El emplazamiento de Barakaldo fue expuesto por D. José Alberto Fuldain, de Bilbao Ría 2000, en presencia de D. Javier Iriarte, Director General de Vivienda del Gobierno Vasco

El emplazamiento del Cuartel de Sánchez Aguilera fue presentado por $D^{a}$. María Carneiro y D. Xosé Lastra, del Ayuntamiento de Ferrol.

El emplazamiento de Lorca fue expuesto por D. José Luis Fernández Romero del Ayuntamiento de Lorca en presencia de D. Josías Martínez, Concejal de Urbanismo de ese Ayuntamiento y de $D^{a}$. Carmen García Loira, representante de la Dirección General de Vivienda y Ordenación del Territorio de la Comunidad Autónoma de la Región de Murcia.

El emplazamiento de Punta Pedreña fue expuesto por D. Higinio Ortega, representante del Ayuntamiento de Marina de Cudeyo.

El emplazamiento de Santa Cruz de Tenerife fue expuesto por D. Enrique Seco, representante de VISOCAN.

El emplazamiento de Toledo fue expuesto por D. Eduardo Aragoneses, representante de la Dirección General de Urbanismo y Vivienda de la Junta de Comunidades de Castilla La Mancha.

El emplazamiento de Nazaret fue expuesto por D. Alberto Sanchís, representante de la Dirección General de Vivienda y Arquitectura de la Generalitat Valenciana.

A las 21:00 horas, a la llegada de la Alcaldesa de Cartagena, del Director General de Arquitectura, Vivienda y Ordenación del Territorio y del Decano de la Universidad de Cartagena, se interrumpieron las sesiones explicativas.

\section{Jueves 8 de abril de 2001}

Al comienzo de esta jornada se reanudó la sesión explicativa de los emplazamientos a concurso que no habían sido expuestos el día anterior.

El emplazamiento de Burgos fue presentado por Da . Dolores Díaz Pisón, arquitecto representante del Ayuntamiento de esa ciudad. 
El emplazamiento del Corcel de Écija fue presentado por D. Pedro García del Barrio, Gerente de Urbanismo del Ayuntamiento de Córdoba quién fue asistido por D. José Andrés Torres Martín y por D. Daniel Aguilera Nuñez.

Acontinuación, los miembros del Jurado se reunieron en primera sesión, decidiendo allí el método de trabajo a seguir para llevar a cabo la selección de un máximo de 73 propuestas entre las 365 entregadas para esta convocatoria de EUROPAN/ España. Ese $20 \%$ de propuestas seleccionadas serían analizadas por el Comité Científico Europeo, con ocasión del Forum de las Ciudades y de los Jurados a celebrar en Karlskrona, Suecia, entre el 17 y el 20 de mayo de 2001. La Secretario del Jurado recordó que el Comité Nacional Español de EUROPAN había previsto un máximo de 7 premios y 7 menciones que habrían de ser fallados a lo largo de la segunda reunión del jurado, en Marina de Cudeyo, en el mes de junio de 2001. Igualmente, indicó que se podría en esa ocasión designar propuestas finalistas, destinadas a ser divulgadas y publicadas a escala nacional.

Fue nombrado Presidente del Jurado D. Eduardo Arroyo Muñoz, Arquitecto Premiado en EUROPAN 5, Miembro de Honor del Comité Nacional Español de EUROPAN quién había igualmente participado en las sesiones para la selección de los emplazamientos a concurso.

El Jurado así constituido estableció por unanimidad los siguientes criterios para la selección de los trabajos:

- Los trabajos a seleccionar debían reunir la calidad suficiente para constituir una base de discusión global, a nivel europeo, en torno al tema de EUROPAN 6.

- Las propuestas serían preseleccionadas atendiendo a criterios de calidad y no en función de la obtención de un reparto equilibrado de premios por emplazamientos. - Los proyectos preseleccionados en esta primera fase serían la base para la selección definitiva, en el mes de junio de 2001, en Santander, de las propuestas finalistas, mencionadas y premiadas.

- Cualquier miembro del jurado podría, a lo largo del fallo, someter a un nuevo debate un proyecto eliminado.

- Se procedería a tantas rondas eliminatorias como fueran necesarias para la obtención de un máximo de 73 propuestas.

El número total de propuestas recibidas fue de 365 , distribuidas por emplazamientos del siguiente modo:

Avilés, 14 - Barakaldo, 62 - Burgos, 23 - Ceuta, 9 - Córdoba, 73 - Ferrol, 14 - Lorca, 28 - Marina de Cudeyo, 27 -Toledo, 29 - Santa Cruz de Tenerife, 51 Valencia, 35.

Tras el examen individual de todas las propuestas por parte de los miembros del jurado, el viernes día 6 de abril a las 12:00 horas se llevó a cabo una primera selección de 220 propuestas distribuidas por emplazamientos como sigue: 
Avilés, 5 - Barakaldo, 38 - Burgos, 12 - Ceuta, 3 - Córdoba, 43 - Ferrol, 9 - Lorca, 23 - Marina de Cudeyo, 16 - Toledo, 17 - Santa Cruz de Tenerife, 31 - Valencia, 23 Tras esta selección se llevó a cabo una sesión conjunta en la cual se analizaron las propuestas que tan solo habían obtenido un voto, llegándose a un total de 130 propuestas según el siguiente reparto:

Avilés, 5 - Barakaldo, 25 - Burgos, 8 - Ceuta, 3 - Córdoba, 25 - Ferrol, 4 - Lorca, 12 - Marina de Cudeyo, 11 - Toledo, 6 - Santa Cruz de Tenerife, 18 - Valencia, 13

El jurado estableció los siguientes criterios y prioridades para el análisis de los diferentes emplazamientos:

Avilés

- Crear densidad

- Disolver los límites del emplazamiento y liberar espacio

- Potenciar las condiciones de centralidad y trabajar la relación con la ría, vehículo para la regeneración de esta zona.

- Atender a la condición de límite del solar entre el entorno urbano y el rural.

\section{Barakaldo}

- Valorar el simbolismo del lugar

- Convertir el emplazamiento en fachada de la ría

- Responder al lugar con criterios de intensidad urbana

\section{Burgos}

- Valorar cual es la imagen de la ciudad que se percibe desde la autopista.

- Atender a la importancia del ritmo, a la percepción del movimiento.

- Atender a la relación entre la trama urbana y su disolución, bajo la autovía, en un entorno rural

Ceuta

- En el emplazamiento de Ceuta se buscaron criterios de intervención que confirieran cierta coherencia entre la zona de la mezquita y el área del cuartel.

\section{Córdoba}

- Importancia del tratamiento del borde del río.

- Recuperar un tejido urbano cohesionado, dando importancia a como se vive más que a una imagen de arquitectura.

- Potenciar lugares urbanos ligados al clima.

- Trabajar la permeabilidad entre los barrios contiguos y el borde del río.

- En general, se observó en las soluciones una gran dificultad para acometer la escala del emplazamiento.

Ferrol

- El objetivo fundamental es permitir la permeabilidad entre la ciudad histórica y los barrios situados al Norte del emplazamiento. Se valoró el tratamiento de las 
conexiones entre las estaciones de autobuses y de trenes con la trama urbana existente.

Lorca

- El jurado valoró tanto la forma de intervención en el tejido urbano como la resolución de las diferentes tipologías edificatorias.

Marina de Cudeyo

- En el caso de este emplazamiento se tuvieron en cuenta fundamentalmente criterios paisajísticos basados en las escalas de intervención y en la nueva imagen de la bahía de Santander. Se tuvo en cuenta la manera de realojar a las familias afectadas por el derribo de los dos edificios existentes.

Toledo

- La escala del emplazamiento, los criterios de densidad y de centralidad y la resolución del programa mixto vivienda/trabajo a resolver por los concursantes constituyeron los ejes de partida para la valoración de las propuestas presentadas para este emplazamiento. Se observa la falta de referencias urbanas existentes en la actualidad

\section{Santa Cruz de Tenerife}

En este emplazamiento en el cual la topografía desempeña un papel fundamental, se desprendían fundamentalmente, las siguientes actitudes en las propuestas:

- Proyectos en "cascada" que crean espacios públicos en la cota más elevada.

- Propuestas mediante objetos que ordenan la vistas, a favor o en contra de la topografía

- Edificios que se sirven de la carretera para ubicar los edificios.

- Tratamiento de los elementos naturales.

Valencia

Al tratarse de un emplazamiento con un programa poco definido, el jurado decidió valorar más una actitud global respecto al barrio que una resolución formal, con el objetivo de regenerar un barrio enclavado en una zona deprimida. Se valoró fundamentalmente:

- La actitud con respecto al patrimonio industrial

- La recuperación de aspectos paisajísticos

- El tratamiento de la trama y de la escala

- La creación de posibles programas que fomentasen la regeneración del barrio.

Teniendo en cuenta estos criterios y procediendo siempre por un mínimo de 2 votos por proyecto el sábado día 7 de abril, a las 13:00 horas, se llegó a la selección de 58 propuestas distribuidas por emplazamientos del siguiente modo:

Avilés, 3 - Barakaldo, 10 - Burgos, 4 - Ceuta, 2 - Córdoba, 10 - Ferrol, 2 - Lorca, 4 - Marina de Cudeyo, 5 - Toledo, 4 - Santa Cruz de Tenerife, 7 - Valencia, 7. 
A partir de esta selección, el Presidente del Jurado instó a los vocales a examinar las diferentes propuestas eliminadas, con el fin de detectar aquellas que podrían ser recuperadas por responder al nivel general de los proyectos hasta ahora seleccionados.

De este modo, fueron recuperadas 8 propuestas, llegándose a un total de 66 propuestas seleccionadas para ser analizadas en la segunda fase del jurado.

Avilés, 5 - Barakaldo, 11 - Burgos, 4 - Ceuta, 2 - Córdoba, 10 - Ferrol, 2 - Lorca, 4 - Marina de Cudeyo, 5 - Toledo, 6 - Santa Cruz de Tenerife, 10 - Valencia, 7

Los lemas de los proyectos de esta forma preseleccionados en esta primera fase del jurado son los siguientes:

AA333, AG933, AL112, AL679, AN177, AS262, AZ109, BM102, CP696, DZ010, EB055, EM000, ET000, ET743, FM105, FR242, FY078, GN484, GO439, G0814, HD050, HD475, HZ375, KA584, LC968, LH004, LM186, LP292, LS132, LU345, LX005, LL068, MB235, MD912, ME770, MM027, MM111, MO966, NA194, NS360, OA281, OM005, PC201, PK036, PK221, PL347, PO110, PO256, PS187, QB068, RH318, SA007, SF618, SH611, SS750, TE502, TO100, TO222, VA072, VL357, WW007, XC537, XL012, XX121, XY2342, XY277.

El Jurado dio por terminada la sesión, acordándose hacer un esfuerzo por que acudieran a la segunda fase los mismos miembros que en esta ocasión. D. Javier Maderuelo solicitó aplazar su decisión hasta fechas posteriores por desconocer a fecha de hoy su disponibilidad durante el mes de junio.

La Secretario agradeció al Presidente y a cada uno de los miembros del jurado su dedicación y responsabilidad durante estas jornadas especialmente complejas tanto por el número de propuestas analizadas como de emplazamientos muy diversos, así como al equipo auxiliar de apoyo su trabajo previo y a lo largo del desarrollo de las sesiones. El Presidente hizo igualmente votos para volver a contar con su colaboración en la segunda fase del jurado.

También agradecieron los miembros la hospitalidad del Ayuntamiento y de la Universidad cuya colaboración había contribuido en gran medida al buen desarrollo de los días de trabajo y especialmente al Decano del Colegio Oficial de Arquitectos de Murcia, anfitrión especial de estas jornadas transcurridas en un ambiente de trabajo grato y cordial.

\section{SEGUNDA FASE.}

Marina de Cudeyo 14 y 15 de junio de 2001

\section{Jueves 14 de junio de 2001}

Se inició la sesión a las 11:00 horas del jueves día 14 de junio de 2001 contando con la presencia de todos los miembros del jurado. Asistía, también desde el inicio 
de la sesión, $D^{a}$. Carmen Imbernón, Secretaria General de EUROPAN/España y Secretario del jurado. Continuó ejerciendo las funciones de Presidente del Jurado D. Eduardo Arroyo Muñoz, elegido al comienzo de la anterior fase. $D^{a}$. Elena Orteu había, en esta ocasión, delegado su voto en D.Clemente Lomba, Decano del Colegio Oficial de Arquitectos de Cantabria.

El jurado, de común acuerdo, decidió, en una primera tanda, examinar las propuestas preseleccionadas en la primera fase, acordándose que se procedería de forma positiva, valorando cada miembro las que debían ser consideradas premios o menciones. Esas propuestas fueron analizadas de forma conjunta, destacándose en ellas los valores que se expondrán al final de este Acta.

A continuación, el jurado procedió a votar selectivamente, descartando aquellas propuestas que, a su juicio, no podrían formar parte del elenco de los proyectos galardonados, siendo apartadas las siguientes propuestas:

ET000, HZ375, MB235, ME770, PC201, PK221, PO110, SS750, TO100, VA072, WW007, XC537, XY2342

Antes de finalizar la jornada del jueves 14 de junio, se procedió a una segunda votación en la que fueron descartados los siguientes proyectos:

AA333, LC968, LM186, MM027, MM111, PO256, QB068

Igualmente, fueron señalados aquellos que podrían obtener la calificación de finalistas. Respondían a los siguientes lemas:

AL112, AL679, BM102, EM000, FM105, GN484, HD475, KA584, LX005, LL068, NS360, OA281, OM005, PL347, PS187, RH318, VL357

Al finalizar esta jornada, D. Javier Maderuelo decidió abandonar el jurado.

\section{Viernes 15 de junio de 2001}

La jornada del 15 de junio contó con la participación de ocho miembros. D. Gerardo Mingo se incorporó a las sesiones sin ejercer su voto. El jurado comenzó esta sesión de trabajo ratificando su voluntad de otorgar los premios en función de la calidad de los proyectos, independientemente de la obtención de un reparto equilibrado de premios por emplazamientos.

Actuando conjuntamente, el jurado destacó los siguientes proyectos merecedores de la calificación de premio: AG933, AS262, HD050, LU345, PK036, XX121

A continuación, acordó otorgar la categoría de mención a las siguientes propuestas: LH004, SA007, SH611

En ambos grupos, las decisiones se tomaron por mayoría de votos y el jurado quiso señalar la cercanía en cuanto a calidad de estos nueve proyectos. 
Tras debatir y examinar tanto las propuestas descartadas como las señaladas para una posible categoría de finalistas, incluyó en la categoría de mención los proyectos presentados bajo los siguientes lemas:

ET743, GO439, MO966, SF618, TO100, XY277

El Jurado, siguiendo criterios comparativos, consideró entonces la posibilidad de variar, por inclusión o exclusión, el número de proyectos finalistas. Tras analizar de nuevo todas las propuestas, se ratificó en su juicio de que los proyectos entregados para los emplazamientos de Ceuta, Ferrol o Lorca no alcanzaban el nivel de aquellos para los que se habían otorgado las categorías de Premio y Mención.

Las razones que en cada caso habían motivado al conjunto del jurado a la consideración de estas dos categorías de reconocimientos (Premios, Menciones) se incluyen al final de este Acta.

Por mayoría de votos, el Jurado calificó como finalistas los siguientes proyectos, merecedores de ese reconocimiento, que serían incluidos en las publicaciones y exposiciones derivadas de esta edición del concurso en España:

AL112, AL679, FM105, GN484, HD475, LL068, PL347, NA194, NS360, XL012

En un segundo momento, fueron incluidos en esta categoría los siguientes proyectos:

AZ109, DZ010, EB055, FY078, HZ375, LM186, SS750, VA072.

Una vez ratificada la decisión del jurado de conceder 6 Premios, 9 Menciones y 18 Finalistas, entre el total de propuestas preseleccionadas en esta sexta edición de EUROPAN/España, en presencia de todos los miembros del jurado, se procedió a la apertura de los sobres que desvelaban el anonimato de los autores de los 33 trabajos galardonados en EUROPAN 6. Los autores de esas propuestas son los siguientes:

PREMIOS

AG933, Córdoba. María Auxiliadora GALVEZ PEREZ

AS262, Burgos. Andreas QUEDNAU, Sabine MULLER

HD050, Valencia. Eduardo DE LA PEÑA PAREJA, Antonio LLEYDA DELGADO

PK036, Barakaldo. Javier FRESNEDA PUERTO, Javier SANJUAN CALLE, Javier PEÑA GALIANO

LU345, Santa Cruz de Tenerife. Raúl DEL VALLE GONZALEZ

XX121, Toledo. Carlos ARROYO ZAPATERO, Manuel PEREZ ROMERO, Eleonora GUIDOTTI-VALORI

\section{MENCIONES}

ET743, Valencia. Paula MONTOYA SAIZ, Miguel BARAHONDA GARCIA

GO439, Burgos. Nuria RUIZ, Juan HEVIAOCHOA, Manuel GARCIADE PAREDES, 
Fernando GARCIA PINO

LH004, Valencia. Ignacio MARTIN ASUNCION, Manuel COLLADO ARPIA

MO966, Barakaldo. Manuel OCAÑA DEL VALLE

SA007, Marina de Cudeyo. Pablo MARTINEZCAPDEVILA, Renata SENTKIEWICK, Izabela WIECZOREK, David

FRANCO SANTA-CRUZ, Javier ARPA FERNANDEZ

SH611, Marina de Cudeyo. Jacobo GARCIA-GERMAN VAZQUEZ, Javier GARCIAGERMAN TRUJEDA, Borja PEÑA

SF618, Barakaldo. Federico SORIANO PELAEZ

TO100, Santa Cruz de Tenerife. Laura GIL, Dario ASSANTE, Luis AVILES

XY277, Avilés. Mario SANJUAN CALLE, Ibán CARPINTERO, José María TABUYO RODRIGUEZ, Angel SEVILLANO

FINALISTAS

GN484, Avilés. Román VILLASANA, Ana MARTINEZOBREGÓN, Ibon IBARLUCEA OCHANDIANO, Michel ARAUZO

MUÑOZ

SS750, Avilés. Jorge SUAREZ DIAZ, Lucía SALVADOR ANGUIANO

VA072, Avilés. Carlos Miguel ALBERDI, Darío MANZANO, Alexandra BERGONZOLI, Sara GARCIA MARTINEZ

HD475, Barakaldo. Clara MURADO LOPEZ, Juan ELVIRA PEÑA

HZ375, Barakaldo. Belinda TATO, Jorge LOBOS, José Luis VALLEJO

AZ109, Córdoba. Silvia COLMENARES, Carmen IZQUIERDO

FY078, Córdoba. Laura PERETTI, Giovanni MUZIO, Marie CLEMENT

LL068, Córdoba. Sasa BRADIC, Inés NIZIC

PL347, Córdoba. José Luis BEZOS ALONSO, Joaquín FUSTER NORTES

AL679, Lorca. Boris BASTIANELLI, Silvia GASPARETTO, Maryse RENIER

EB055, Marina de Cudeyo. Blanca María HERNANDEZ GARCIA, Eduardo ARILLA

ALVAREZ

NS360, Marina de Cudeyo. Alejandro ALFEREZ

AL112, Tenerife. Rubén PICADO FERNANDEZ, Ma José DE BLAS GUTIERREZ

DE LA VEGA

DZ010, Tenerife. Antoine REGNAULT, Elena FERNANDEZ, David SEVERO, Arnaud DESCOMBES

FM105, Tenerife. Francesco COSTANZO

LM186, Tenerife. Manuel SANCHEZ VERA, Lucio MORINI

XL012, Toledo. Talia DOMBRIZ MARTIALAY, Daniel DIEDRICH VALERO

NA194, Valencia. Michael GAISSER

Eduardo Arroyo Muñoz, Presidente del Jurado

David Cohn Elisabeth Galí

Gerard Maccreanor Clemente Lomba

Dolores Alonso Carlos Puente

Frédéric Bonnet Carmen Imbernón, Secretario 


\section{Comentarios del Jurado a las propuestas Premiadas y Mencionadas EUROPAN 6*}

\section{PK036 BARAKALDO}

Imagen estimulante que, moviéndose en terrenos estratégicos próximos a la escultura y al land-art, acierta en sintonizar con las expectativas de los promotores, por su efecto visual impactante y su posibilismo constructivo y funcional.

El aspecto geológico de la propuesta con sus facetados diversos y la sutil graduación erosiva de sus texturas, resultan, ciertamente, atractivas.

\section{AS262 BURGOS}

El proyecto ganador para el solar de Burgos, "Puntos \& Lazos" es uno de los pocos que resuelven con éxito el "principal conflicto del solar - pantallas versus continuidad". La Nacional I domina el área de actuación mermando el desarrollo y formando una barrera física entre la ciudad y el paisaje circundante. En esta propuesta los problemas asociados a la autopista, como el ruido, su proximidad al área y la restricción de acceso, se tratan como características que pueden explotarse, de manera que los aspectos negativos llegan a ser una ventaja. El puente sobre la autopista se transforma, de repente, en una oportunidad para ganar acceso al paisaje que hay más allá de los límites de la ciudad. La contaminación acústica, contraria a la orientación a un paisaje abierto, se acepta como una fuerza física que transforma estos elementos limítrofes en fuerzas dinámicas que se elevan por encima de la autopista para conferir una nueva imagen a la ciudad. Estas fachadas protectoras convierten los patios y jardines en ambientes más íntimos y personales con acceso directo a la zona verde circundante. El nivel de conexión de la autopista y su accesible nivel de suelo encuentran aquí una fusión única de entendimiento entre el contexto físico y el contexto psicológico. Por esta razón, el jurado ha decidido unánimemente que la solución que se propone en este proyecto puede llevarse a cabo con éxito.

\section{AG 933 CORDOBA}

Una propuesta que exprime las posibilidades fenomenológicas del habitar con unidades que albergan vegetación, arena o agua junto a espacios atípicos y excitantes que atraen al interior de la vivienda el carácter del paisaje circundante. La agrupación de dichas viviendas con su intencionada direccionalidad establece un diálogo flexible entre los rígidos límites de la ciudad y los márgenes difusos de la ribera fluvial demostrando que la reproducción del modelo propuesto puede componer un sistema de ocupación a gran escala.

\section{LU345 TENERIFE}

Se valora el análisis del problema del aprovechamiento visual que plantea el solar y la acertada proposición de la solución a nivel visual, por lo elemental de sus formas y lo sugerente de sus materiales.

Resultan más dudosos ciertos aspectos como la accesibilidad y la integración en un entorno que no es todo lo idílico y lo protohistórico que las imágenes de la 
propuesta sugieren.

\section{XX121 TOLEDO}

Una propuesta de gran interés por su condición irónico-crítica desde presupuestos de ocupación de carácter masificado y especulativo que sin embargo no le restan ninguna capacidad de viabilidad. El sistema de creación de ciudad atendiendo a factores puramente económicos es asimismo capaz de albergar programas de amplio espectro y demuestra ser un procedimiento de adaptación y optimización a cualquier territorio existente a través de instrucciones de transformación de un modelo inicial.

\section{HD050 VALENCIA}

El proyecto premiado aborda con eficacia los objetivos propuestos: la mejora de las conexiones y la creación de equipamientos urbanos ligados a la cultura y ocio a la doble escala de barrio-ciudad. Las claves del proyecto pasan por asumir que al haber crecido Valencia de espaldas al mar, la pérdida de la playa acarreaba la pérdida de la identidad del barrio. También se conservan las viviendas originales del barrio, intentando contextualizarlas con la nueva ordenación común, restañando los puntos más conflictivos como las medianeras, calles, accesos, etc. Se vale, como elemento primario, de la construcción de un equipamiento social, cultural, educativo y sanitario. Edificio y ordenación tratan de reinterpretar el lugar mediante la cultura y el arte autóctono, cultura marítima y pesquera, y así facilitar la aceptación del proyecto. Como elemento básico de la transformación, el edificio, soporte de gran versatilidad formal y con la poética recuperación del horizonte perdido, de la perspectiva, en esa cota de $8 \mathrm{~m}$ desde la que se divisa del Mediterráneo. Incorporación del horizonte y predominio de una horizontalidad confirmada por las láminas de agua. Abajo, las grandes superficies sombreadas por los toldos. En definitiva, la vida junto al mar.

\section{XY277 AVILES}

Se valora la elección de una pieza de gran escala como respuesta a las variadas solicitudes del emplazamiento, así como la capacidad de incorporación de esta pieza al tejido urbano de Avilés.

Se considera muy positiva la liberación del plano del suelo y su destino como parque público, que puede funcionar como eslabón intermedio en un futuro sistema de espacios libres urbanos que confluyan en la ría.

También resulta interesante la consideración de la vía férrea como dato de proyecto, posibilitando una relación mas fluida entre los espacios públicos.

Los amplios accesos a las viviendas, entendidos como espacios de expansión de las mismas, ofrecen dudas en cuanto a la compatibilidad con los programas y los recursos económicos de la vivienda social.

\section{SF618 BARAKALDO}

El jurado ha valorado la espléndida y generosa manera de trabajar el frente de la ría de una forma novedosa, lejos de las imágenes a las que recientemente nos 
hemos ya acostumbrado: visiones industriales, edificios barco, torres puntuando la ría, etc. El juego inteligente de texturas formado por un hábil trenzado entre las diferentes láminas de agua y la mágica veladura de las fachadas de los edificios, nos remite a la propia condición cambiante de la ría. Se valora especialmente el estudio tipológico de las viviendas propuestas.

\section{MO966 BARAKALDO}

Una propuesta de interés en el desarrollo de nuevas relaciones de filtrado entre vivienda y paisaje liberando gran parte del territorio para la creación de espacios libres y manteniendo a la vez una densidad de viviendas adecuada. La localización y agrupación de dichas viviendas plantea sin embargo dudas sobre las expectativas de conexión y apertura de la ciudad existente con los márgenes de la Ría.

\section{GO439 BURGOS.}

El jurado ha reconocido el proyecto por su capacidad de resolver los varios desafíos y conflictos del emplazamiento con una solución elegante en su sencillez. Trata con notable éxito la relación de las nuevas viviendas con la autopista elevada y la trama urbana existente, además de su relación con elementos más frágiles como el arroyo, la vía férrea en desuso y los caminos rurales.

\section{SA007 MARINA DE CUDEYO.}

El jurado ha reconocido el proyecto por su desarrollo de la tipología de la vivienda múltiple en línea, resultando en un conjunto de varios niveles sobreimpuestos que actúa en diálogo con el paisaje. Es un ejemplo particularmente sofisticado y sugerente del uso de ésta tipología, bien aplicado al emplazamiento y interesante como investigación para aplicaciones más generales.

\section{TENERIFE TO100}

Se valora la opción crítica de proponer un objeto aislado, bien identificado como elemento arquitectónico en la pendiente, objeto que responde tanto a un cierto orden geométrico ("para no añadir otro ruido al desorden existente") como a la propia configuración de la pendiente natural, aprovechando el desnivel para anclar el edificio contra la montaña, frente al mar. Este edificio de escasa altura marca en el paisaje el límite de la urbanización, formando el borde arquitectónico de la trama urbana existente y dejando mas allá la pendiente como espacio "natural". El proyecto también aprovecha la carretera ya existente para realizar el acceso rodado sin construir nuevas infraestructuras. Mas allá de los aspectos paisajísticos, se valora la propia planta que propone en un ancho importante con dos "franjas" habitables. Entre ambas, se extiende una calle de ancho variable, conectada con la terraza por unos patios que dibujan una "quinta fachada" en contacto con el terreno natural.

\section{LH OO4 VALENCIA}

Una propuesta de ocupación del territorio de carácter lúdico-ecológico con un alto interés que muestra una gran flexibilidad propositiva en la formalización de su 
idea a través de unidades individuales o colectivas. Responde asimismo a una preocupación muy actual por encontrar maneras de vivir asociadas a una óptica de transformación y control de las infraestructuras para formar parte primordial del espacio del habitar, si bien su desatención al carácter sociológico del barrio de Nazaret le resta cierta credibilidad en su posible adaptación.

\section{ET743 VALENCIA}

El jurado valora el alto nivel de innovación programática como sistema para generar nuevas dinámicas urbanas y actividades que, por otro lado, se ajustan perfectamente a la tradición de cultivo propia del lugar. También valora muy positivamente la voluntad de explorar nuevas formas de gestión, producción y regeneración social optando por la investigación de una determinada gramática arquitectónica que no se considera en absoluto efímera y obsoleta. La propuesta se ajusta perfectamente a la idea de innovación que EUROPAN debería mantener. 


\title{
EUROPAN 7 (2002). ACTA DEL FALLO DEL JURADO DE EUROPAN 7 ESPAÑA ${ }^{19}$
}

\author{
PRIMERAREUNIÓN DEL JURADO DE EUROPAN/ESPAÑA. ESCUELATÉCNICA \\ SUPERIOR DE ARQUITECTURA DE MADRID 24-27 DE JULIO DE 2003
}

En Madrid, en las aulas cedidas por la Escuela Técnica Superior de Arquitectura, tuvieron lugar las sesiones de trabajo de la primera fase del fallo de EUROPAN7/ España que transcurrieron del siguiente modo:

\section{Jueves 24 de julio de 2003}

A las 16:30 horas, en el salón de Actos de la Escuela de Arquitectura, dio comienzo, a cargo de los responsables del suelo o de las personas designadas a estos efectos, la presentación y descripción de los nueve emplazamientos españoles a concurso.

El emplazamiento de Barcelona fue expuesto por D. Santiago Juan, Dirección General de Urbanismo de la Generalitat de Catalunya y por $D^{a}$. Claudia Casadevall (Dirección General de Vivienda de la Generalitat de Catalunya) en presencia de Da . Montserrat Bono (Dirección General de Vivienda de la Generalitat de Catalunya), D. Josep Vall (Ayuntamiento de Sant Boi de Llobregat) y D. Joan Malagarriga (Ayuntamiento de Santa Coloma de Cervelló).

El emplazamiento de Burgos fue expuesto por $D^{a}$. Gema Arcusa, del Ayuntamiento de Burgos, en presencia de D. Pedro Izquierdo Alonso, $D^{a}$. María. Jesús Fernández Huesa, (Construcciones Aragón Izquierdo) y D. Alberto Sáinz de Aja (BSA Arquitectura Ingeniería y gestión, S.L.).

El emplazamiento de Guadalajara fue expuesto por D. Eduardo Aragoneses, Dirección General de Vivienda de la Junta de Comunidades de Castilla la Mancha en presencia de $\mathrm{D}^{\mathrm{a}}$. Mar García de los Ojos (Ayuntamiento de Guadalajara).

El emplazamiento de La Unión fue expuesto por Da . Carmen García Loira, Dirección General de Vivienda de la Comunidad Autónoma de la Región de Murcia.

El emplazamiento de Las Palmas fue expuesto por D. Juan Miguel Cerpa, Ayuntamiento de Las Palmas de Gran Canaria.

El emplazamiento de Luarca fue expuesto por D. Manuel Carrero de Roa, Dirección General de Vivienda del Principado de Asturias.

El emplazamiento de Santoña fue expuesto por D. Jesús Molinero y D. José María Cárdenas Arnedo, Dirección General de Arquitectura y Vivienda del Gobierno de Cantabria en presencia de Da . Miriam García (Dirección General de Urbanismo del

${ }^{19}$ EUROPAN 7 España "El reto suburbano: intensificación urbana y diversidad residencial", Ed. Gráfica Futura, Madrid, 2003, pp.14-19. 
Gobierno de Cantabria) y de D. Joaquín Bonet (Ayuntamiento de Santoña).

El emplazamiento de Vitoria fue expuesto por $D^{a}$. Isabel Pineda y D. Ernesto Salvatierra, de Ensanche XXI, en presencia de D. Alfredo Piris Pinilla y D. Miguel Angel Aguado (Ensanche XXI).

El emplazamiento de Santiago de Compostela fue expuesto por $D^{a}$. Begoña Fernández-Shaw (Secretariado de EUROPAN/España).

\section{Viernes 25 de Julio y Sábado 26 de Julio de 2003}

M. Dominique Perrault y $D^{a}$. Marta Cervelló habían analizado los proyectos unos días antes de la reunión conjunta, el 18 de Julio y el 21 de Julio, respectivamente. La Secretaria del Jurado, $D^{a}$. Carmen Imbernón, se haría portavoz de sus votaciones. Así, el día 25 de Julio estuvieron presentes D. Carlos Arroyo Zapatero, D. Javier Díaz-Llanos La Roche, Mr. Xaveer de Geyter, D. Ángel Fernández Alba, D. Fernando Márquez Cecilia, D. Gerardo Mingo, Mr. Matthias Sauerbruch.

En su primera reunión, el Jurado así constituido debatió el método de trabajo a seguir para llevar a cabo la selección de un máximo del $20 \%$ de las 286 propuestas entregadas para esta convocatoria de EUROPAN/España.

Esos proyectos seleccionados serían analizados por el Comité Científico Europeo, con ocasión del Forum de las Ciudades y de los Jurados a celebrar en Graz, Austria, entre el 14 y el 16 de noviembre de 2003.

La Secretaria del Jurado recordó que el Comité Nacional Español de EUROPAN había previsto un máximo de 6 premios y 6 menciones que habrían de ser fallados a lo largo de la segunda reunión del jurado, en Santiago de Compostela, en el mes de noviembre de 2003. Igualmente, indicó que esa sería la ocasión para designar propuestas finalistas, destinadas a ser divulgadas y publicadas a escala nacional y no aparejadas a un premio en metálico.

Fue nombrado Presidente del Jurado D. Carlos Arroyo Zapatero, Arquitecto Premiado en EUROPAN 6, Miembro de Honor del Comité Nacional Español de EUROPAN, Miembro de la comisión para la selección de los emplazamientos españoles a concurso.

Se informó de que los proyectos recibidos en el Secretariado de EUROPAN / España, se encuentran repartidos por emplazamientos del siguiente modo:

Barcelona 45, Burgos 29, Guadalajara 22, La Unión 49, Las Palmas de Gran Canaria 23, Luarca 21, Santiago de Compostela 19, Santoña 47, Vitoria 31 Igualmente, se puso en conocimiento del jurado que 7 de los 286 proyectos se recibieron fuera de plazo. 
Se trata de los proyectos correspondientes a los siguientes lemas:

FB003, QJ284, RW147, TI073, MM671, DB263, HM521

De acuerdo con el criterio del Comité Ejecutivo de EUROPAN/España, estos proyectos no fueron admitidos a concurso. Se informó al Jurado de que se había puesto en conocimiento de todos los concursantes la lista de proyectos admitidos.

El Jurado estableció los siguientes criterios para la selección de los trabajos:

- Los trabajos a seleccionar debían reunir la calidad suficiente para constituir una base de discusión global, a nivel europeo, en torno al tema de EUROPAN 7.

- Las propuestas serían preseleccionadas atendiendo a criterios de calidad y no en función de la obtención de un reparto equilibrado de premios por emplazamientos. - Los proyectos preseleccionados en esta primera fase serían la base para la selección definitiva, en el mes de noviembre de 2003, en Santiago de Compostela, de las propuestas finalistas, mencionadas y premiadas.

- Cualquier miembro del jurado podría, a lo largo del fallo, someter a un nuevo debate un proyecto eliminado.

- Se procedería a tantas rondas eliminatorias como fueran necesarias para la obtención del máximo del $20 \%$ de las propuestas.

Teniendo en cuenta estos criterios, se efectuaron dos votaciones. Al final de las sesiones de trabajo se alcanzó un total de 60 proyectos seleccionados distribuidos por emplazamientos del siguiente modo:

Barcelona 13, Burgos 7, Guadalajara 6, La Unión 9, Las Palmas de Gran Canaria 6, Luarca 6, Santiago de Compostela 3, Santoña 4, Vitoria 6 correspondientes a los lemas AF000, AL875, AU003, AV708, AZ008, BB113, BI075, BM003, CD134, CE115, CF111, CP109, DM222, EU012, FR160, GV584, HG107, HH444, HM003, HO999, II100, LG258, LJ003, LM253, LO793, LS303, LU737, MC130,ME211, NU835, NV760, OE341, PK239, QR359, QW269, RA753, RO203, RW650, SA160, SJ444, SO205, SZ002, TC003, TE666, TT949, TW973, UA701, UC003, UN002, UP123, VE243, VL572, WE514, WM525, WP007, XJ003, XY888, Z2i10.

Los autores de los proyectos correspondientes a los lemas FB003 (La Unión), DB263 (Santoña), HM521 (Luarca) y TI073 (Barcelona) justificaron con posterioridad a la celebración del Jurado que sus propuestas habían sido enviadas dentro del plazo previsto. Estos trabajos serán presentados en la segunda reunión del jurado.

\section{SEGUNDA REUNIÓN DEL JURADO DE EUROPAN/ESPAÑA} PALACIO DE CONGRESOS Y EXPOSICIONES. SANTIAGO DE COMPOSTELA 28-29 DE NOVIEMBRE DE 2003

\section{Viernes 28 de noviembre de 2003}

Se inició la sesión el viernes 28 de noviembre con la presencia de los siguientes miembros del jurado, D. Carlos Arroyo Zapatero, D. Javier Díaz-Llanos La Roche, Mr. Xaveer de Geyter, Da. Marta Cervelló, D. Fernando Márquez Cecilia, D. Gerardo 
Mingo, Mr. Matthias Sauerbruch. Asistía, también desde el inicio de la sesión, $D^{a}$. Carmen Imbernón, Secretaria General de EUROPAN/España y Secretaria del jurado y Mme. Françoise Bonnat, representante de EUROPAN Europe en el Jurado español. Continuó ejerciendo las funciones de Presidente del Jurado D. Carlos Arroyo Zapatero, elegido al comienzo de la anterior fase.

Al respecto de las cuatro propuestas incorporadas a la segunda fase del Jurado, FB003 (La Unión), DB263 (Santoña), HM521 (Luarca) y TI073 (Barcelona), el Jurado tras su análisis, decidió incorporar entre las propuestas preseleccionadas las correspondientes a los lemas DB263 y FB003.

El jurado, de común acuerdo, decidió proceder de forma positiva, destacando entre las propuestas preseleccionadas en la primera fase las que, a juicio de cada uno de los miembros, podrían ser premiadas.

Estos proyectos fueron analizados de forma conjunta, destacándose en ellos los valores que se expondrán al final de este Acta.

A continuación, el jurado procedió a votar selectivamente, descartando aquellas propuestas que, a su juicio, no podrían formar parte del elenco de los proyectos galardonados, siendo apartadas las siguientes propuestas: AF000, AL875, AU003, AV708, AZ008, BB113, BI075, CD134, CE115, CF111, CP109, DB263, DM222, GV584, HO999, II100, LG258, LJ003, LO793, LS303, MC130, ME211, MU147, NO031, NU835, OE341, RA753, RW650, SO205, TC003, TE666, TW973, UA701, UC003, VE243, VL572, WM525, XJ003, XY888

\section{Sábado 29 de noviembre de 2003}

El jurado comenzó esta sesión de trabajo ratificando su voluntad de otorgar los galardones en función de la calidad de los proyectos, independientemente de la obtención de un reparto equilibrado de premios por emplazamientos.

Actuando conjuntamente, el jurado destacó que los proyectos presentados bajo los lemas FR160, HM003, LU737, RO203, SZ002, TT949, Z2i10 eran merecedores de la calificación de premio.

A continuación, acordó otorgar la categoría de mención a las siguientes propuestas: BM003, LM253, QR359, SA160, SJ444, WE514, WP007

Se acordó, por lo tanto, con la anuencia de la Secretaria del Jurado, aumentar el número de galardones predeterminado -6 premios y 6 menciones-.

Por mayoría de votos, el Jurado calificó como finalistas los siguientes proyectos, merecedores de ese reconocimiento, que serán incluidos en las publicaciones y exposiciones derivadas de esta séptima edición del concurso en España: FB003, 
EU012, HH444, NV760, PK239, QW269, UN002, UP123.

Una vez ratificada la decisión del jurado de conceder 7 Premios, 7 Menciones y 8 Finalistas, entre el total de propuestas preseleccionadas en esta séptima edición de EUROPAN/España, en presencia de todos los miembros del jurado, se procedió a la apertura de los sobres que desvelaban el anonimato de los autores de los 23 trabajos galardonados en EUROPAN 7.

Los autores de esas propuestas son los siguientes:

\section{PREMIOS}

FR160, Luarca, David Tapias Monne, Cristina Goberna Pesudo, Darío Mateo Berciano.

HM003, Vitoria, Hugo Araujo, Marien Brieva de la Orden

LU737, La Unión, María Auxiliadora Gálvez, Izabela Wieczorek

RO203, Barcelona, Birgit Hopff, Enric Gili Fort, Angela Moragues Gregori, Hervé Meyer

SZ002, Burgos, Samuel Arriola

TT949, Guadalajara, Rubén Picado, María José de Blas

Z2i10, Santiago de Compostela, Izaskun Chinchilla

\section{MENCIONES}

BM003, Santoña, Alejandro Virseda Aizpun, Ignacio Vila Almazán

LM253, Barcelona, Maximiá Torruella, Patricio Martínez González

QR359, Guadalajara, Cristina Hidalgo, Carlos Temprano, Cristina Monjas

SA160, Santoña, Jorge de Miguel, Carlos Pastor Armengol

SJ444, Santiago de Compostela, Carlos Asensio Galvín

WE514, Vitoria-Gasteiz, Juan Hevia, Nuria Ruiz

WP007, Las Palmas de Gran Canaria, Goetz Feldmann, Thorsten Gresens, Susanne Gerstgerger

FINALISTAS

FB003, La Unión, Cédric Smal

EU012, La Unión, Anne Lemee, Estanislao Cavanillas Capilla, Ambroise Bera, David Coladas Gutiérrez

HH444, Burgos, Roberto Grossi, Fausto Delfini, Domenico Scuteri, Alessandra Turco

NV760, Barcelona, Lluis Cantallops, Marta Vicente

PK239, Guadalajara, Angel Sevillano, Iban Carpintero, Mario Sanjuán

QW269, La Unión, Nestor Montenegro, Ignacio Borrego

UN002, Luarca, José Vicente Lillo Llopis, Francisco Leiva Iborra, José Campos Rosique, Marta García Chico

UP123, Las Palmas, Thomas Kovari, Stefan Kurath, Barbara Schwab, Dominik Arioli 
Carlos Arroyo Zapatero, Presidente del Jurado

Javier Díaz-Llanos La Roche

Marta Cervelló

Gerardo Mingo

Fernando Márquez Cecilia

Xaveer de Geyter

Matthias Sauerbruch

Ángel Fernández Alba

Carmen Imbernón, Secretaria

\section{Comentarios del Jurado a las propuestas Premiadas, Mencionadas y Finalistas EUROPAN 7*}

\section{PREMIOS}

FR160 - LUARCA

En el marco del debate sobre las condiciones suburbanas que tiene lugar tanto en Europan como otros ámbitos, este proyecto resulta particularmente interesante. Los suburbios tienden a desdibujar las diferencias entre ciudad y naturaleza. Esta es la razón por la cual muchos proyectos se dedican a 'hacer' ciudad de urbanizaciones sueltas. Este no es un proyecto de densificación de áreas suburbanas. Por el contrario, desarrolla de manera muy convincente la alternativa exactamente opuesta. El suburbio es transformado en una forma de naturaleza 'construida' y habitada, fuera de la ciudad, dejando intacta la ciudad existente.

Como muchos de los emplazamientos españoles, el emplazamiento de las afueras de Luarca no forma parte de un inmenso mar de suburbios, si no de un área reducida dominada por la belleza de su naturaleza y topografía.

El primer paso de la propuesta ha sido introducir un valor añadido a dicha naturaleza. A pesar de que parece ser el mar el que influye en el bioclima existente a través del Río Negro, el lugar se vuelve mucho más domesticado de lo que es hoy en día. La naturaleza artificial que se genera así, un paraíso hecho por la mano del hombre, es la base de la nueva urbanización. Diferentes tipologías son posibles: lotes individuales, casaspatio, viviendas colectivas, todas ellas básicas y radicales en su relación con la nueva naturaleza. La distinción entre interior y exterior se vuelve borrosa, como también la distinción entre naturaleza construida y edificios. El tercer panel del proyecto muestra una serie de vistas de las condiciones de vida que se genera: raras veces un proyecto ecológico ha alcanzado semejante grado de fuerza poética.

La ausencia total de infraestructuras en el proyecto - no sólo no hay rastro de solución para enlazar el área con la ciudad existente, tampoco hay nuevas rutas para dar acceso a los edificios planteados, el sistema de infraestructura parece quedar reducido a un sistema de senderos - debe ser considerada como una exageración estilística, ya que en realidad deberían ser urgentemente integradas en la propuesta general. 


\section{HM003 - VITORIA}

El proyecto ganador en Vitoria propone, en todas las escalas de la intervención, estrategias precisas y certeras, que prometen aprovechar al máximo el potencial del emplazamiento.

Encuentra la medida justa de la intervención, conservando los trazados de autovía que tanto han fascinado a muchos concursantes, pero cambiando su velocidad, colonizando las isletas e invadiendo los viales, que se convierten en lo que denominan vial equipado. Esta operación, asimilable a la reutilización pragmática de algunos monumentos de la antigüedad clásica, aprovecha la conectividad del antiguo nudo, que se convierte en un atractor a escala urbana, para alimentar el desarrollo que se propone en el resto de la superficie de estudio.

La nueva velocidad del nudo permite una mayor complejidad de trazados y modalidades de transporte, lo que se aprovecha para recomponer el tejido circundante, fijándose más en la continuidad de los recorridos verdes, peatonales y de tráfico rodado local.

El vacío urbano se ocupa con una estrategia abierta y autorregulada, que se propone crear una morfología del bosque natural o de toallas en la playa, con una serie de parámetros económicos, de accesibilidad, soleamiento, sombra arrojada y aprovechamiento, sin duda más adecuados para esta situación entre lo urbano y lo suburbano que los basados en alineaciones y cornisas, más propios de una perspectiva central.

La 'unidad vecinal' propuesta es especialmente adecuada, con su canto-color y su cara-espejo, recogiendo además las más avanzadas investigaciones en flexibilidad de las últimas décadas para, utilizando soluciones técnicas sencillas, dar soporte a las más variadas formas de vida.

\section{LU 737 - LA UNIÓN}

El proyecto completa y explora con fortuna el límite urbanizado de la ciudad de La Unión en su parte Sur, resolviendo acertadamente los enlaces con el resto de la ciudad, e implantando en el área urbana tipologías residenciales flexibles tanto en morfología como en uso- que favorecen la integración de los distintos sectores sociales.

El diseño urbano arquitectónico propuesto subraya la identidad del lugar —la singularidad de su clima y paisaje- con la implantación de un diseño urbano que, generado por la función residencial en mayor medida, es variable y adaptable, en cada punto, a las condiciones del contorno; una topografía activa que se vincula tanto a las estructuras naturales como a las urbanas existentes, con inclusión del uso dotacional en las instalaciones del extremo Este del solar, reutilizando las naves industriales existentes.

La propuesta establece así un diálogo entre lo construido y la vertiente Norte de la sierra minera; elimina y supera la barrera del FEVE, reconvirtiendo la línea del ferrocarril de vía estrecha en la auténtica vía principal de comunicación, —una artería de tránsito rodado de vehículos que incluye carril-bici, sendas peatonales, ámbitos de aparcamientos, espacios de relación , remansos e incluso el ferrocarril, reconvertido en tranvía urbano, reduciendo su velocidad al paso por La Unión-. 
Del acertado análisis de la propuesta — urbano, natural y sensitivo- se deriva la singular apuesta por unas estrategias de diseño residencial y urbano que se fundamentan en relacionar los 'deseos del usuario' en materia espacial con oportunas 'estrategias bioclimáticas' que atienden al clima y al lugar, al ahorro energético y a la construcción saludable

\section{RO 203 - BARCELONA}

Se trata de una solución muy individual generada a través de observaciones muy generales, el estudio meticuloso del sistema natural del emplazamiento y de la estructura de tráfico alrededor del mismo.

Los autores han llegado a una solución a la vez sensible y espectacular. Los dos edificios de borde dibujan los barrios residenciales existentes y al mismo tiempo definen un espacio natural interesante que vivirá cambios

a lo largo de las distintas estaciones del año. Los edificios suponen inyecciones programáticas al barrio vecinal e introducen (con su flexibilidad y capacidad de conectar) un espíritu fresco en este contexto cargado arquitectónicamente.

La propuesta es elegante y absolutamente factible, particularmente porque tanto su actitud en el diseño como su respuesta garantizan la adaptabilidad necesaria para esta realización.

La conexión entre cuidad y naturaleza es uno de los temas recurrentes de EUROPAN 7: este proyecto no solamente sugiere una unión simbólica de estos dos elementos antagónicos, sino también busca una sinergia entre dos sistemas para desarrollar una nueva constelación urbana. Esta es una actitud que sobrepasa con creces la retórica y puede ser la respuesta correcta para este muy interesante emplazamiento de Barcelona.

\section{SZ002 - BURGOS}

Con una excelente adaptación al terreno mediante profundas incisiones en la topografía, el proyecto transforma con éxito las dificultades tridimensionales del sitio en su mayor recurso. El paisaje habitado, con una fuerte identidad, polariza la intensidad urbana hacia la nueva vía que ocupa el ferrocarril. Consigue una buena protección del ruido de la autovía y pone de manifiesto un alto nivel de entendimiento de los problemas del ámbito tratando de darle continuidad al Parque de la Quinta bajo el puente de la autovía. El escalonamiento de las viviendas y sus accesos, en función de posniveles del terreno, refuerza la inserción en el paisaje.

\section{TT949 - GUADALAJARA}

Ante la complejidad del problema planteado en el emplazamiento de Guadalajara, el jurado ha valorado de este proyecto la búsqueda de una imagen institucional pública, necesaria para que en la intervención se alíe la capacidad simbólica de la arquitectura con la de un programa funcional adecuado para este barrio.

La solución como estrategia de intervención de un 'sistema abierto' de plataformas -que asientan las diferentes construcciones sobre la topografía del terreno de modo natural y lógico—, celosías — que delimitan y tamizan los cerramientos de los 
pabellones a edificar, así como los diferentes lucernarios-y vigas de gran canto, en forma de $\mathrm{T}$-encargadas de la cubrición de los distintos espacios funcionales y verdaderas protagonistas del diseño a través de su singular disposición estructural - parece acertada, pues deviene en una afortunada imagen simbólica y de referencia para la ciudad, gracias al solapamiento de sus tres 'elementos: el Parque Botánico, que resuelve la fachada urbana al tráfico rodado que circula por la autovía A-2, (al mismo tiempo que sirve a la ciudad de barrera ambiental frente a su agresiva acción); las Piscinas públicas y los Jardines, que en su relación con el cauce del río Henares resuelven amablemente la pendiente entre las calles de la zona y la orilla del río; y las Pistas Deportivas, que en diálogo con la trama residencial existente completan el tejido urbano (aprovechando el espacio generado bajo las nuevas plataformas para incluir aparcamientos subterráneos de servicio a las viviendas del barrio).

Los mecanismos empleados, como el del control de la luz natural —las sombras, el ambiente-; el empleo de materiales austeros y ligados al lugar y al contexto; una construcción bioclimática lúdica y serena; y el potenciar como valor conceptual de la propuesta la horizontalidad en el volumen edificado resultante, han sido, de igual modo, valorados.

\section{Z2I10 - SANTIAGO DE COMPOSTELA}

La propuesta que se plantea para el Solar de A Pulleira en Santiago de Compostela, desarrolla muy acertadamente cuatro líneas estratégicas.

\section{Línea estratégica 1. Autonomía energética.}

Se pretende que resulte legible para el usuario la gestión sostenible de la energía en promociones suburbanas, básicamente, la naturaleza del clima, permite deducir que la autonomía energética, con conexiones mínimas, será posible.

Para ello, se ha dividido la propuesta en unidades con requerimientos energéticos similares: árbol solar, antenas para la telecomunicación, parking vertical y depósito de agua con capacidad para su depuración.

Todas estas instalaciones no sólo serán visibles, sino que serán uno de los acontecimientos relevantes en el paisaje, constituyendo una nueva configuración del urbanismo.

Línea estratégica 2. Optimización geográfica

Las ventajas que presenta la propuesta son: el movimiento y conducción del agua de lluvia mediante gravedad; la conservación de la escorrentía del terreno natural mediante el uso de suelos de naturaleza vegetal y mineral compactados; la adopción de recorridos mínimos para las conducciones interiores de cada unidad; y la explotación de los puntos de máxima exposición solar.

Línea estratégica 3. Elección de hábitats.

La propuesta desarrolla la ciudad jardín: campo y áreas de centralidad en una mezcla bien equilibrada. Trata de hacer posible la coexistencia dual de estos dos entornos. Cada unidad tendrá un área de ciudad bosque y de ciudad parking. 
Percepción de pasear únicamente por un bosque continuo o por un paisaje suburbano.

\section{Línea estratégica 4. Viabilidad económica}

Se plantea, aunque esquemáticamente, una idea de recuperación de la inversión con la compra-venta de espacios y arquitecturas, en principio, en unidades de habitantes por su extensión, de $1 \mathrm{Ha}$. El trabajo premiado en Santiago es el que más contundentemente ha impresionado al jurado al solucionar sistemáticamente todos los interrogantes de "el reto suburbano". ¿Cómo articular nuevas polaridades y proponer nuevos desarrollos, si consideramos que el territorio isotrópico que el desarrollo de los actuales medios de comunicación parecía preconizar, está en realidad moteado de nodos? ¿Cómo negociar con las infraestructuras, en un momento de expansión territorial parece implicar la aparición de una densa red de servicios? ¿Podemos convivir con ellas, son todas necesarias? ¿Cómo explorar los límites urbanizados, tratando de resolver el conflicto entre la vida urbana y la rural, si desde que existen las ciudades, sus habitantes nos debatimos entre la actividad de la urbe y el sosiego de la naturaleza? ¿Es posible disfrutar de los dos mundos?

\section{MENCIONES}

\section{BM003 - SANTOÑA}

El escenario del emplazamiento de Santoña es extraordinario: una pequeña y modesta ciudad al pie de una montaña que la protege del mar. La dársena y el puerto están rodeados de marismas que impiden el crecimiento de la ciudad. La idea es mantener la ciudad compacta y encontrar la escala adecuada dentro de la armonía existente.

Este proyecto es interesante porque introduce una tipología urbana diferente que trata el espacio público y las viviendas, a la vez que mantiene en mayor o menor grado la escala previa de los edificios de industrias conserveras. Cuatro bloques, que forman parte de la cuadrícula urbana existente, son tratados como una unidad abierta y pública en su planta baja y están cubiertos por una capa horizontal elevada de casas con patio. La cubierta está perforada y una serie de enormes columnas sostiene escaleras y ascensores. Una cinta de tiendas tipo pabellón, interrumpida por la cuadrícula existente, funciona como un filtro entre la calle y el 'mercado'.

La fuerza del proyecto reside en su escenario urbano: el puerto es directamente accesible desde la ciudad a través de un espacio urbano protegido; enlaza la nueva área de ocio con la cuadrícula existente. Su debilidad está en la ineficiencia de las viviendas: será necesario un gran esfuerzo para construir el complejo en su totalidad, el cual, finalmente, es de baja densidad y carente prácticamente de vistas a un maravilloso entorno. 


\section{LM253 - BARCELONA}

El proyecto elabora el límite urbano y trabaja la sección del terreno para resolver la transición desde los bloques residenciales existentes, hasta el parque central propuesto. Ello se resuelve alargando las trazas de los bloques lineales, y formando con ellas un escalonado que libera distintos tipos edificatorios y zonas ajardinadas, públicas, semi-públicas o privadas. Estos jardines intervienen a modo de costuras hasta el parque central.

La intervención se concreta en el frente de Sant Boi, sin tocar la zona de la Colonia Güell. De esta manera se consigue reestablecer un equilibrio visual respecto de los edificios de St.Boi, cuyo impacto el proyecto minimiza.

Parece particularmente interesante de esta propuesta la intervención respecto de los bloques de vivienda, como método extrapolable a situaciones similares y que consiste en "frenar" la visión perspectiva de los mismos, mediante la construcción de una base fragmentada que diluya la masa edificada

El proyecto no cuestiona las trazas de los viales previstos por el planeamiento, aunque si las entierra, dando lugar a restricciones físicas.

La presentación del proyecto es gráficamente hábil y clara, expone la información justa y necesaria para la comprensión del proyecto.

\section{QR359 - GUADALAJARA}

La propuesta pone en valor la ribera del río Henares e interrelaciona acertadamente las áreas fluvial, cívico social, de investigación, deportiva y de tránsito.

Se valora muy positivamente la adecuación al solar así como la inclusión dentro de los edificios a modo de pabellones que puntean los solares, de usos que tienen una relación directa con el terreno que ocupan suelo público en continuidad y formando parte del futuro parque fluvial.

\section{SA160 - SANTOÑA}

La propuesta demuestra un acertado análisis del emplazamiento y del entorno.

Proyecta una nueva fachada al frente marítimo, paralela a la línea del puerto de la Dársena Sur, proporcionando una protección al espacio público sobre los vientos dominantes del oeste, normalmente fríos y húmedos, dotando de una linealidad al conjunto de edificios.

La tipología de volúmenes acristalados se considera interesante al servir de límite respetuoso entre la marisma del parque natural y el puerto a un lado, y la ciudad, al otro, proporcionando si cabe aún más virtudes a las viviendas propuestas al ofrecerles vistas de ambos espacios tan unidos como diferenciados, para configurar un lugar libre de transición con el tejido urbano existente.

\section{SJ444 - SANTIAGO DE COMPOSTELA}

Este esquema propone lo que podría describirse como una condición de campo tridimensional. Un conjunto de edificios de idéntica altura y sección es distribuido a lo largo del terreno en un tejido de trama abierta.

Más o menos alineados de forma paralela al perímetro, pero relacionados entre si, estos volúmenes articulan una serie de espacios que son reminiscencias de los 
campos agrícolas construidos en las laderas de una montaña. La uniformidad de su perfil contribuye a marcar la modulación del terreno, creando una imagen fuerte y variada para ésta nueva comunidad.

Un campo de viviendas (residenciales) se superpone a otro de volúmenes de una o dos plantas para talleres, pequeñas empresas, etc., creando así una mezcla de programas dinámicos e interesantes. Junto a los diversos "parches verdes" distribuidos en espacios intersticiales entre los edificios, los volúmenes más bajos ayudan a definir el espacio espacio, a la vez que crean un grado alentador de simultaneidad de actividades y variedad de uso.

La propuesta urbana es simple pero efectiva. Parece combinar una cierta racionalidad con una disposición que asume el ambiente disperso y de bajo perfil del propio lugar. Con su materialidad sensible y su interés por las tipologías locales, parece retomar la discusión de TEAM 10 sobre el desarrollo del urbanismo moderno; no solamente por sus ideas, sino también por calidad general de su diseño y representación, este trabajo representa una contribución muy valiosa al tema debatido en Europan 7.

WE514 - VITORIA

El nudo de tráfico existente ha de revertir a la ciudad como tejido residencial, y así se plantea la propuest sobre ciertas trazas existentes se organizan tanto las zonas a edificar como las zonas verdes resultantes.

El proyecto, hábil reinterpretación del tejido actual, sitúa sobre un zócalo, piezas de una estructura no jerarquizada, una secuencia de edificios de distintas funciones y usos. Se estratifican los accesos rodados y peatonales a distinto nivel, facilitando fluidez de las circulaciones.

La propuesta aborda de manera tímida las posibilidades de las distintas capas de actividades, lo cual hubiese podido aportar mayor complejidad y riqueza de situaciones a la sección y a los edificios que allí se produjeran.

\section{WP007 - LAS PALMAS DE GRAN CANARIA}

La propuesta mejor clasificada en Las Palmas de Gran Canaria se entiende desde la sección transversal, un triangulo rectángulo que levanta una potente fachada icónica en el lado tangente a la vía rápida metropolitana, reduciendo su sección para integrarse con los tejidos locales en los otros perímetros. La hipotenusa se sitúa así en todas las escalas simultáneamente.

Toda la superficie ocupada se utiliza como espacio libre público, verde y con equipamiento de ocio, sin distinguir el que se construye con un movimiento de tierras del que se apoya en una estructura de cubierta.

El cambio de cota permite además que el espacio libre atraviese la vía rápida sin solución de continuidad, uniendo fragmentos de tejido con un recorrido verde.

Las estructuras son sencillos planos inclinados, de fácil cálculo y ejecución, que cobijan espacios de indudable potencial comercial. Una hábil configuración de los planos inclinados da a estos espacios comerciales una doble cara, que los sitúa en la frontera de lo público y lo privado, permitiendo y potenciando el uso y dominio público de las superficies generadas en el exterior. 
Por otra parte, ni su carácter icónico, ni su utilidad como generador de actividades públicas y privadas, dependen de una configuración concreta, sino de un criterio formal, que se puede adaptar a diferentes condiciones en el tiempo y en el espacio.

\section{FINALISTAS}

\section{FB003 - LA UNION}

Esta propuesta utiliza la apropiación del lugar por fases, en el tiempo, y así organiza la forma de esta ocupación.

La intervención es de bajo impacto. Se estructura de forma perpendicular a la pendiente, de manera que existan lazos de unión tanto con el paisaje natural no domesticado así como con la parte limítrofe de la ciudad hasta ahora aislada por la vía del ferrocarril.

La propuesta de formalización de la edificación es interesante por ofrecer tipologías cuyo lenguaje recuerda el de las construcciones de invernaderos, con cierta intención bioclimática y rural.

\section{EU012 - LA UNION}

La propuesta constituye un buen ejemplo de disolución de la ciudad en las colinas mediante la interpenetración de lo urbano en la naturaleza. Los espacios lineales urbanos que reproducen la geomorfología de la montaña como una prolongación menos densa de la ciudad, son ricos y flexibles. Se considera que la imagen a que da lugar la alternancia de estas "ramblas" urbanas y los espacios naturales resuelve acertadamente el borde de la ciudad.

\section{HH444 - BURGOS}

El jurado ha considerado que se trata de una propuesta interesante para resolver, de una forma específica, un espacio residual cortado al campo por una infraestructura y añadido a la ciudad.

Los "fingers buildings" conectan las diferentes cotas del terreno creando un frente urbano que se integra en la ciudad y, al disminuir de altura, se disuelven en el campo consiguiendo, al mismo tiempo, proteger las viviendas del impacto visual y sonoro de la vía de alta velocidad.

Los espacios urbanos generados entre los dedos y la variedad de tipos de viviendas son otros aciertos de la solución.

\section{NV760 - BARCELONA}

Es relevante en este proyecto su intención de encontrar una solución directamente en los bloques de los años 60 existentes, mayor problema y error del lugar.

La propuesta consiste en la regeneración de esas construcciones mediante el vaciado parcial y la inclusión de nuevos usos en las mismas. En lugar de construir se regenera el tejido existente mediante la inclusión de nuevos usos en los mismos bloques.

En cambio, parece poco congruente con esta opción la construcción de la fachada industrial con la que el proyecto cierra el frente a la carretera taponando con ella 
el acceso al corredor verde, y ocupando buena parte de su espacio.

PK239 - GUADALAJARA

La zona de actuación engloba ámbitos diferenciados por su situación intermedia entre zonas de la ciudad ya consolidadas y muy diferentes entre sí, polígono residencial, polígono industrial, el río Henares y la A II.

La propuesta desarrolla de forma muy coherente estos extremos del ámbito de actuación confiriéndole una importancia decisiva de cara a renovar la imagen de Guadalajara.

Se plantea una pieza que tiene un carácter unitario por un sistema de bandas que discurren y se configuran en función de los recorridos y necesidades de la ciudad. El tratamiento de la topografía propuesto permite la creación de ámbitos que discurren entre el interior y el exterior, donde suelo y cubierta no se distinguen, configurando un espacio continuo.

Los usos se diferencian por el carácter de la pieza que los acoge: La torre, elemento de referencia visual y el puente que se configura igualmente como elemento iconográfico.

En resumen, se trata de una solución imaginativa que consigue crear una puerta de entrada a la ciudad dotándola de identidad propia.

\section{QW269 - LA UNION}

Este proyecto propone una solución genérica para un borde entre la ciudad densificada y el campo abierto.

En La Unión, el trazo del ferrocarril se convierte en generatriz para un denso grupo de "fibras habitadas" que articula un límite fragmentado. De hecho crea como una muralla habitada. Sin embargo, contrariamente a una fortificación medieval, crea un territorio de transición en tres niveles, con una gradación en privacidad.

Una zona pública abajo, una "comunidad de vivienda" en el medio, y una cubierta privada transitable arriba, en continuidad visual con el paisaje alrededor.

El jurado ha valorado especialmente la solución de viviendas en cremallera, con unidades autónomas que se pueden sumar, uniéndose por la célula mayor, pero manteniendo cada uno su espiral/escalera independiente. Diseñada para una comunidad contemporánea de individuos, esta arquitectura modular y altamente adaptable propone una intervención espacialmente clara y urbanamente innovadora para una multiplicidad de necesidades cambiantes, si bien con una identidad fuerte.

\section{UN002 - LUARCA}

De esta propuesta el jurado ha valorado su sensibilidad poética, al plantearse respetar el sistema de crecimiento histórico de Luarca tomando como pautas la orografía y la adaptación al valle y al río Negro, manteniendo como objetivo del crecimiento urbano el conservar, en lo posible, los espacios naturales sobre los que asentaría aquel, desarrollando la nueva traza en continuidad con la ciudad tradicional y con el valleque la envuelve. El modelo de desarrollo propuesto deviene en una ciudad lineal, con el río como vertebrado del espacio y de sus 
usos, y con las edificaciones transformadas en topografía, con cubriciones verdes, ligadas a sus espacios naturales.

Para solucionar la problemática conexión con la ciudad antigua, se propone construir un nuevo centro comercial y de ocio que actúe como foco de atracción entre ambas trazas urbanas, salvando el cuello de botella que supone el puente del ferrocarril —de valor arquitectónico y paisajístico notable-, y dando fluidez al tránsito peatonal para debilitar las barreras creadas por la infraestructura ferroviaria.

De igual modo, el jurado valora la convivencia entre comercio, trabajo y vivienda como generadores urbanos, y el diseño de un sistema de viales enterrados, iluminados cenitalmente, para el tráfico rodado.

Sin embargo, el jurado estima que esta sensibilidad, presente en los objetivos, no se ha plasmado con suficiente precisión en el planeamiento, quedando la propuesta huérfana de concreción arquitectónica — espacial y formal一, y por ello, limitada en su respuesta.

\section{UP123 - LAS PALMAS DE GRAN CANARIA}

El proyecto Finalista en Las Palmas tiene en común con el mencionado la acertada colocación de los volúmenes construidos, el tratamiento indiferenciado de cubiertas y suelo como zonas verdes salpicadas de equipamiento de ocio, y una actitud semejante hacia los límites, buscando relaciones parecidas, de continuidad o ruptura, de suavidad o presencia icónica.

Tiene interés la creación de un paisaje campestre virtual, (construido sobre atrevidas estructuras portantes, llegando extremos especialmente atractivos en los campos de tenis hipotizados en la fase 2), superado el conflicto entre lo verdadero y lo falso en la era del capitalismo de ficción. La adopción de estrategias abiertas en el tiempo genera y legitima la disposición casual e hipotética de los diferentes equipamientos.

Sin embargo, para la creación de ese potencial escondido, se plantean enormes inversiones iniciales que contradicen los conceptos de flexibilidad en el tiempo, en el espacio y en el uso, que hacían atractiva la propuesta. Es lo que los concursantes llaman "traffic machine", las vías subterráneas, plantas de aparcamiento y megaestructuras portantes, rígidas y pesadas, que constituyen la compleja masa con la que se construye la nueva topografía del parque (y su imagen en la cara más metropolitana), y que son imprescindibles para que los volúmenes dedicados a centro de congreso, hotel, edificios administrativos, etc., puedan llegar a aparecer con la aparente "casualidad" que se plantea. 


\section{EUROPAN 8 (2004). FALLO DEL JURADO DE EUROPAN 8 ESPAÑA ${ }^{20}$}

FACULTAD DE CIENCIAS JURÍDICAS Y SOCIALES UNIVERSIDAD REY JUAN CARLOS, CAMPUS DE VICÁLVARO, 27-29 DE NOVIEMBRE DE 2005 y 27-28 DE ENERO DE 2006

\section{PRIMERA FASE}

\section{Jueves 27 de noviembre de 2005}

A las 16:30 horas, en el salón de Grados de la Facultad de Ciencias Jurídicas y Sociales, dio comienzo, a cargo de los responsables del suelo o de las personas designadas a estos efectos, la presentación y descripción de los ocho emplazamientos españoles a concurso.

El emplazamiento de Alcázar de San Juan fue expuesto por Da. Virginia Cavia, Dirección General de Urbanismo de la Junta de Comunidades de Castilla-La Mancha y por D. Samuel Palomares, arquitecto Municipal de Alcázar de San Juan. El emplazamiento de Cáceres fue expuesto por D. José Timón, Director General de Arquitectura y programas Especiales de Vivienda de la Agencia Extremeña de la Vivienda, el Urbanismo y el territorio y por $D^{a}$. Esther Gamero-Zúñiga, en presencia de representantes del Ayuntamiento de Cáceres y de PLACONSA.

El emplazamiento de Cartes fue expuesto por D. José María Cárdenas, Director General de Vivienda del Gobierno de Cantabria y Da Miriam García, Directora General de Urbanismo del Gobierno de Cantabria en presencia de D. Saturnino Castanedo, Alcalde de Cartes.

El emplazamiento de Ceuta fue expuesto por D. Francisco Márquez de la Rubia, gerente de Urbanismo de EMVICESA y D. Alberto Weil, arquitecto de EMVICESA. El emplazamiento de Córdoba fue expuesto por D. Juan Medina y D. Luis Valdelomar de la gerencia de Urbanismo del ayuntamiento de Córdoba.

El emplazamiento de Logroño fue expuesto por D. Luis García del Valle, Director General de Vivienda del Gobierno de La Rioja y D. Jesús Alfaro, arquitecto en presencia de los representantes del Ayuntamiento de Logroño.

El emplazamiento de Sagunto fue expuesto por D. Alberto Sanchís, de la Dirección General de Vivienda y Proyectos Urbanos y por D. José Nebot, del Ayuntamiento de Sagunto.

El emplazamiento de Valladolid fue expuesto por D. Javier González Ramiro, de S.E.P.E.S. Se contó con la asistencia y asesoramiento de D. Antonio Noriega, de ADIF.

${ }^{20}$ AA.VV. EUROPAN 8 España. Urbanidad europea y proyectos estratégicos. Ed. Ministerio de vivienda. Madrid. 2006. pp. 5-7. 


\section{Viernes 28 de Noviembre y sábado 29 de Noviembre de 2005}

Asistieron Da. Inés Sánchez de Madariaga (Ministerio de Vivienda), Da. Paula Montoya (C.S.C.A.E.), Da. Auxiliadora Gálvez, D. Manuel de Solà-Morales, D. Federico Soriano Peláez, Da. Cristina Díaz Moreno, Mr. Peter Wilson, Mr. Hrvoje Njiric, Mr. Rüdiger Lainer.

En su primera reunión, el Jurado así constituido debatió el método de trabajo a seguir para llevar a cabo la selección de un máximo del $20 \%$ de las 208 propuestas entregadas para esta convocatoria de EUROPAN/España.

Los proyectos así seleccionados serían objeto de análisis y debate con motivo del Forum de las Ciudades y de los Jurados a celebrar en Sintra, Portugal, entre el 14 y el 16 de enero de 2006.

Da. Carmen Imbernón, Secretaria del Jurado, recordó que el Comité Nacional Español de EUROPAN había previsto un máximo de 8 premios y 8 menciones que habrían de ser fallados a lo largo de la segunda reunión del jurado, en el mes de enero de 2006.

Añadió que esa sería la ocasión para designar propuestas finalistas, objeto de divulgación y publicación a escala nacional, aunque no aparejadas a un premio en metálico.

Fue nombrada Presidenta del Jurado Da. María Auxiliadora Gálvez Pérez, Arquitecta Premiada en EUROPAN 6 y EUROPAN 7, Miembro de Honor del Comité Nacional Español de EUROPAN, Miembro de la Comisión para la selección de los emplazamientos españoles a concurso, el Miembro más joven del Jurado.

Se informó de que los proyectos recibidos en el Secretariado de EUROPAN / España, se reparten por emplazamientos del siguiente modo: Alcázar de San Juan 27, Cáceres 16, Cartes 37, Ceuta 35, Córdoba 27, Logroño 26, Sagunto 22, Valladolid 18.

Igualmente, se puso en conocimiento del jurado que 3 de los 208 proyectos se recibieron fuera de plazo. Se trata de los proyectos correspondientes a los siguientes lemas: BC804, ML747, UJ717.

Estos proyectos no fueron admitidos a concurso. Se informó al Jurado de que se había puesto en conocimiento de todos los concursantes la lista de proyectos admitidos.

El Jurado estableció los siguientes criterios para la selección de los trabajos:

- Los trabajos a seleccionar debían reunir la calidad suficiente para constituir una 
base de discusión global, a nivel europeo, en torno a las temáticas de EUROPAN 8.

- Las propuestas serían preseleccionadas atendiendo a criterios de calidad y no en función de la obtención de un reparto equilibrado de premios por emplazamientos. - Los proyectos preseleccionados en esta primera fase serían la base para la selección definitiva, en la segunda reunión, de las propuestas finalistas, mencionadas y premiadas.

- Cualquier miembro del jurado podría, a lo largo del fallo, someter de nuevo a debate un proyecto eliminado.

- Se procedería a tantas rondas eliminatorias como fueran necesarias para la obtención del máximo del $20 \%$ de las propuestas.

Se efectuaron tres votaciones. Al final de las sesiones de trabajo se alcanzó un total de 45 proyectos seleccionados distribuidos por emplazamientos del siguiente modo:

Alcázar de San Juan 7, Cáceres 5, Cartes 7, Ceuta 7, Córdoba 8, Logroño 4, Sagunto 4, Valladolid 3.

Alcázar de San Juan: AR117, EO702, SJ245, TH221, UR002, US905, XO717

Cáceres: CA275, EC000, HR573, IO195, PN510

Cartes : CA012, CD778, KM330, NV135, PH007, RE766, SP000

Ceuta : CE133, CX008, DV313, LR067, LT101, MX023, TU000

Córdoba: AA007, BS410, CM777, CO123, CO205, JB928, LI055, XV969

Logroño: LO095, LO232, SC002, TP020

Sagunto: JE007, MR000, RS979, YC142

Valladolid: CC005, CP174, UB470

\section{SEGUNDA FASE}

\section{Viernes 27 de Enero de 2006}

Se inició la sesión el viernes 28 de enero con la presencia de todos los miembros del jurado, a excepción de Mr. Rüdiger Lainer, quién excusó su asistencia por cuestiones imprevistas de última hora.

Asistía, también desde el inicio de la sesión, Da. Carmen Imbernón, Secretaria General de EUROPAN/España y Secretaria del jurado, Mr. Per Kraft, representante de EUROPAN Europe en el Jurado español, y Da. Begoña Fernández-Shaw, del Secretariado de EUROPAN/España.

Continuó ejerciendo las funciones de Presidenta del Jurado Da. Auxiliadora Gálvez, elegida al comienzo de la anterior fase.

Se acordó proceder destacando los proyectos que, a juicio del jurado, eran merecedores de un premio.

Con esa orientación, se procedió al análisis de las propuestas por emplazamiento, 
acordando que cada miembro del jurado se haría cargo del análisis general tanto de la problemática de cada sitio, como de las propuestas a debate.

Se readmitirían a debate los proyectos propuestos por uno de los miembros del jurado con, al menos un voto a favor por parte de otro miembro del jurado.

Igualmente, de común acuerdo, el jurado decidió proceder de forma positiva, destacando entre las propuestas las que, a juicio de cada uno de los miembros, podrían ser premiadas o mencionadas.

Se acordó proceder a una votación; solamente los proyectos que obtuvieran un mínimo de tres votos en este turno de votos podrían aspirar a las categorías de Premio o Mención. Se acordó que podrían ser sometidos a votación para acceder a la categoría de finalistas.

$D^{a}$. Auxiliadora Gálvez se hizo portavoz de las cuestiones relativas al emplazamiento de Alcázar de San Juan. Se readmitió a debate la propuesta con el lema JB100. Permanecen en el debate 4 propuestas: AR117, EO702, SJ245, XO717.

$D^{a}$. Paula Montoya se hizo portavoz de las cuestiones relativas al emplazamiento de Cáceres-Aldea Moret. Se readmitió a debate la propuesta con el lema TF874. Permanecen en el debate 4 propuestas: CA275, HR573, IO195, PN510.

D. Manuel de Solà-Morales se hizo portavoz de las cuestiones relativas al emplazamiento de Cartes. Permanecen en el debate 7 propuestas: CA012, CD778, KM330, NV135, PH007, RE766, SP000.

D. Federico Soriano se hizo portavoz de las cuestiones relativas al emplazamiento de Ceuta-Benzú. Permanecen en el debate 4 propuestas: CE133, DV313, LT101, MX023.

Mr. Peter Wilson se hizo portavoz de las cuestiones relativas al emplazamiento de Córdoba-Fray Albino. Permanecen en el debate 3 propuestas: AA007, JB928, LI055,

Da. Cristina Díaz Moreno se hizo portavoz de las cuestiones relativas al emplazamiento de Logroño. Se readmitieron a debate las propuestas correspondientes a los lemas IA777, IN905, MP875. Permanecen en el debate 2 propuestas: IA777, LO095.

Mr. Hvroje Njiric se hizo portavoz de las cuestiones relativas al emplazamiento de Sagunto. Se readmitieron a debate las propuestas correspondientes a los lemas CS336, ND002, NS340. Permanecen en el debate 3 propuestas: CS336, JE007, MR000.

D. Federico Soriano se hizo portavoz de las cuestiones relativas al emplazamiento 
de Valladolid. Se readmitieron a debate las propuestas correspondientes a los lemas FR046, KG320. Permanecen en el debate 5 propuestas: CC005, CP714, FR046, KG320, UB470

\section{Sábado 28 de enero de 2006}

El jurado comenzó esta sesión de trabajo ratificando su voluntad de conceder un premio por emplazamiento.

Analizando de nuevo cada uno de los emplazamientos, se procedió a la votación que de los premios y las menciones:

Alcázar de San Juan: Premio, XO717 Mención, SJ245

Cáceres: Premio PN510 Mención, 10195

Cartes: Premio NV135 Mención, CD778. Mención CA012

Ceuta: Premio LT101 Mención, CE133

Córdoba: Premio SJ928. Mención, AA007

Logroño: Premio LO095

Sagunto: Premio JE007. Mención MR000

Valladolid: Premio FR046. Mención CP714

Por mayoría de 5 votos, el Jurado calificó como finalistas los siguientes proyectos, merecedores de ese reconocimiento, que serán incluidos en las publicaciones y exposiciones derivadas de esta octava edición del concurso en España: AR117, EO702, UR002, PH007, RE766, SP000, DV313, CO205, LI055, IA777, SC002, CC005, UB470.

Una vez ratificada la decisión del jurado de conceder 8 Premios, 8 Menciones y 13 Finalistas, entre el total de propuestas presentadas en esta octava edición de EUROPAN/España, en presencia de todos los miembros del jurado, la Presidenta procedió a la apertura de los sobres que desvelaban el anonimato de los autores de los 19 trabajos galardonados en EUROPAN 8.

Los autores de esas propuestas son los siguientes:

\section{PREMIOS}

FR046, Valladolid, Raúl Sánchez

JB928, Córdoba, Beatriz Brieva de la Orden, Jaime del Campo

JE007, Sagunto, Javier Guijarro, Elena Blanco

LO095, Logroño, Santiago Cifuentes

LT101, Ceuta, Juana Sánchez, Diego Jiménez, Ángela Ruiz, Pedro Romero

NV135, Cartes, Miguel Ángel Velarde, Miguel Ángel Navas

PN510, Cáceres, Cristina Goberna, Urtzi Grau

X0717, Alcázar de San Juan, Antonio Viejo, Elena Aguilar

\section{MENCIONES}


AA007, Córdoba, Enrique Moya-Angeler, Pilar Echezarreta

CA012, Cartes, Juan Miguel Tizón Garau, José Ripoll, Palma de Mallorca

CD778, Cartes, Carolina Ruiz Valdepeñas, Daren Gavira.

CE133, Ceuta, Francisco Leiva, José Luis Campos, Marta García

CP714, Valladolid, Beatriz Gómez, Fernando Rodíguez, Arturo Romero, María del Carmen Casajuana,

Marcos González, Alfonso Miguel.

IO195, Cáceres, Enrique Krahe

MR000, Sagunto, Raffaele Puggiuni, Marta Martínez.

SJ245, Alcázar de San Juan, Joaquín Esperón, Luis Basabe.

\section{FINALISTAS}

AR117, Alcázar de San Juan, David Tapias, Nuria Salvado.

EO702, Alcázar de San Juan, Emilio López, Rubén Miguel.

UR002, Alcázar de San Juan, Luis Miguel Pinto.

PH007, Cartes, Javier García Germán.

RE766, Cartes, Elena Rocchi.

SP000, Cartes, Ana Arriero, Susana Velasco, Miguel Herráiz.

DV313, Ceuta, Antonio Juárez, Mariano Fernández, Ana Martín.

CO205, Córdoba, Luz Fernández Valderrama, Marta Fernández Valderrama, Francisco Escudero.

LI055, Córdoba, Mónica García, Javier Rubio.

IA777, Logroño, Álvaro Guinea, Irma Coello.

SC002, Logroño, Marta Granda, Gonzalo Pérez.

CC005, Valladolid, Javier Peña Galiano.

UB470, Valladolid, Rodrigo Almonacid.

Firmado:

Auxiliadora Gálvez

Inés Sánchez de Madariaga

Paula Montoya

Manuel de Solà-Morales

Cristina Díaz Moreno

Hrvoje Njiric

Federico Soriano

Peter Wison 


\section{EUROPAN 9 (2006). ACTA DEL JURADO DE EUROPAN 9/ESPAÑA ${ }^{21}$ MINISTERIO DE VIVIENDAARQUERÍA DE NUEVOS MINISTERIOS}

\section{PRIMERA FASE}

13-15 DE SEPTIEMBRE DE 2007

\section{Jueves 13 de Septiembre de 2007}

A las 17:00 horas, en el Aulario de la Arquería de Nuevos Ministerios, el Presidente de EUROPAN/España, D. Rafael Pacheco, abrió la primera reunión para el Fallo del Jurado de EUROPAN 9/España, dando la bienvenida a los representantes de los emplazamientos a concurso y a los miembros del jurado y recordando el compromiso del Ministerio de Vivienda con el concurso EUROPAN.

La Secretaria General de EUROPAN/España y Secretaria del Jurado, Da. Carmen Imbernón, informó a los asistentes de que se habían recibido 176 propuestas, repartidas por emplazamientos del siguiente modo:

AMA, 21

Badajoz, 21

Calahorra, 22

La Laguna, 25

Poio, 26

Santander, 26

Soria, 35

Igualmente, recordó que el objetivo de esta primera fase del jurado era alcanzar una selección de un máximo del $20 \%$ de los proyectos, propuestas que serían analizadas en el marco del Forum de las Ciudades y de los Jurados a celebrar en Catania los días 30 de noviembre y 1 de diciembre de 2007. Tras este encuentro internacional, en el que se llama a participar a los representantes de suelo y a los miembros del jurado, el jurado se reunirá por segunda vez para destacar un máximo de 7 premios y 7 menciones.

A continuación, dio paso a la presentación y descripción, por parte de los responsables de suelo, de los 7 emplazamientos a concurso, con el ruego de que las personas designadas a estos efectos hicieran llegar a los miembros del jurado su opinión al respecto de las propuestas que cada uno de estos miembros del Comité Nacional de EUROPAN/España había tenido ocasión de examinar previamente.

El emplazamiento de AMA fue expuesto por D. Manuel Carrero de Roa, Dirección General de Urbanismo del Principado de Asturias, D. Avelino Fernández Rancaño, de HUNOSA y por el Concejal de Urbanismo del Ayuntamiento de Aller.

${ }^{21}$ AA.VV. EUROPAN 9 España. Ciudad sostenible y nuevos espacios públicos. Ed. Ministerio de vivienda. Madrid. 2008. pp. 5-7. 
El emplazamiento de Badajoz fue expuesto por D. José Timón, Director General de Arquitectura y Programas Especiales de Vivienda de la Agencia Extremeña de la Vivienda, el Urbanismo y el Territorio y por Da ${ }^{a}$. Esther Gamero-Zúñiga.

El emplazamiento de Calahorra fue expuesto por D. Luis Martínez Portillo, Concejal de Urbanismo del Ayuntamiento de Calahorra.

El emplazamiento de La Laguna fue expuesto por D. José Vargas y D. Antonio Pérez, de MUVISA y por $D^{\text {a }}$. María del Mar Luján, del Instituto Canario de Vivienda y Suelo.

El emplazamiento de Poio fue expuesto por D. Xulio Barreiro, Concejal de Urbanismo del Ayuntamiento de Poio, por la Arquitecta Municipal de Poio y por $\mathrm{D}^{\mathrm{a}}$. Marta Fernández del Instituto gallego de Vivienda y Suelo de la Xunta de Galicia.

El emplazamiento de Santander fue expuesto por D. Enrique Alonso, de la Dirección General de Vivienda del Gobierno de Cantabria.

El emplazamiento de Soria fue expuesto por $\mathrm{D}^{\mathrm{a}}$. Inés Martín, Arquitecta Municipal del Ayuntamiento de Soria.

\section{Viernes 14 de Septiembre y sábado 15 de Septiembre de 2007}

El Jurado formado por, $D^{a}$. Rita Lorite, Subdirectora de Arquitectura del Ministerio de Vivienda, Mr. Florian Beigel, D. David Franco, Da. Teresa Galí-Izard, Mr. Kaye Geipel, Da . Blanca Lleó, D. José Mateus, D. Josep Parcerisa y Da. Benedetta Tagliabue, quién se incorporó al fallo a lo largo de la mañana, acordó el método de trabajo a seguir para llevar a cabo la selección de un máximo del 20\% de las 176 propuestas entregadas para esta convocatoria de EUROPAN/España.

Da. Carmen Imbernón, Secretaria del Jurado, recordó que el Comité de EUROPAN/España había previsto otorgar un máximo de 7 premios y 7 menciones a las propuestas que habrían de ser falladas a lo largo de la segunda reunión del jurado, en el mes de diciembre de 2007.

Fue nombrado Presidente del Jurado D. David Franco, Arquitecto galardonado en EUROPAN 6 y EUROPAN 7, Miembro de la Comisión Técnica de EUROPAN/ Europa, el Miembro más joven del Jurado.

El Jurado estableció los siguientes criterios para la selección de los trabajos:

- Los trabajos a seleccionar debían reunir la calidad suficiente para constituir una base de discusión global, a nivel europeo, en torno a las temáticas de EUROPAN 9.

- Las propuestas serían preseleccionadas atendiendo a criterios de calidad y no en función de la obtención de un reparto equilibrado de premios por emplazamientos. 
- Los proyectos preseleccionados en esta primera fase serían la base para la selección definitiva, en la segunda reunión, de las propuestas finalistas, mencionadas y premiadas.

- Cualquier miembro del jurado podría, a lo largo del fallo, someter de nuevo a debate un proyecto eliminado.

- Se procedería en un primer lugar por eliminación de aquellas propuestas que no obtuvieran al menos el apoyo de dos miembros del jurado.

Tras el análisis individual de las propuestas, se procedió a la primera ronda eliminatoria en la que se alcanzó una selección de 75 proyectos, distribuidos por emplazamientos del siguiente modo:

AMA, 8 - Badajoz, 6 - Calahorra, 10 - La Laguna, 12 - Poio, 11 - Santander, 12 Soria, 16

El listado de las diferentes votaciones se incluye al final de este Acta.

Al final de la jornada del viernes día 14 se procedió a la segunda ronda eliminatoria de las propuestas presentadas para el emplazamiento de Santander, con la presencia de siete miembros del Jurado. Se acordó que serían necesarios al menos cuatro votos para la aceptación de los proyectos. D. David Franco, recordó a los demás miembros votantes las características de ese emplazamiento.

Tras el análisis y debate sobre las propuestas, quedaron preseleccionados 5 proyectos que responden a los siguientes códigos AH000, MM160, MX257, NG010, SA611.

El sábado día 15 de septiembre, se procedió con idéntico sistema en los restantes emplazamientos:

AMA. 8 miembros votantes. Se requiere la obtención de al menos 4 votos. Tras la presentación de las características del suelo a concurso por parte de $\mathrm{D}^{\mathrm{a}}$. Blanca LLeó, fueron preseleccionados los 5 proyectos que responden a los siguientes códigos: AZ867, EC123, MB734, NJ373, XX526.

BADAJOZ. 8 miembros votantes. Se requiere una mayoría de al menos 4 votos. Tras la presentación de las características del suelo a concurso por parte de D. José Mateus, fueron preseleccionados los 3 proyectos que responden a los códigos: AB508, CH852, EN371.

CALAHORRA. 8 miembros votantes. Se requiere una mayoría de al menos 4 votos. Fueron preseleccionados los 4 proyectos que responden a los códigos: CH202, SM022, TI905, XR523

LA LAGUNA. 7 miembros votantes. Se requiere una mayoría de al menos 3 votos. Tras la presentación de las características del suelo a concurso por parte de D. David Franco, fueron preseleccionados los 5 proyectos que responden a los 
códigos: Al111, DC778, EK010, NA450, VI007

POIO. 7 miembros votantes. Se requiere una mayoría de al menos 3 votos. Tras la presentación de las características del suelo a concurso por parte de D. Josep Parcerisa, fueron preseleccionados los 4 proyectos que responden a los códigos: EE707, ML378, OS171, XV168.

SORIA. 8 miembros votantes. Se requiere una mayoría de al menos 4 votos. Fueron preseleccionados los 5 proyectos que responden a los códigos: BS007, JA541, NJ075, OZ869, XX999

Al final de la jornada, se volvieron a someter a debate los proyectos OP003 para La Laguna, EE607 para Santander y BS500 para Soria, los cuales, obteniendo el número de votos requerido en la ronda eliminatoria anterior, pasaron a formar parte del conjunto de proyectos preseleccionados que se someterán a análisis en la segunda fase del Jurado.

Así, el número total de propuestas preseleccionadas fue de 34 , repartidas por emplazamientos del siguiente modo:

AMA, 5: AZ867, EC123, MB734, NJ373, XX526

Badajoz, 3: AB508, CH852, EN371

Calahorra, 4: CH202, SM022, TI905, XR523

La Laguna, 6: Al111, DC778, EK010, NA450, OP003, VI007

Poio, 4: EE707, ML378, OS171, XV168

Santander, 6: AH000, EE607, MM160, MX257, NG010, SA611

Soria, 6: BS007, BS500, JA541, NJ075, OZ869, XX999

Se levantó la sesión acordándose celebrar la segunda fase del Jurado en Catania, el día 2 de diciembre.

\section{SEGUNDA FASE}

\section{Domingo 2 de diciembre de 2007}

Centro Fieristico "Le Ciminiere". Catania, Italia

Se inició la sesión el domingo 2 de diciembre con la presencia de seis los miembros del jurado, habiendo excusado su asistencia $D^{a}$. Rita Lorite, $D^{a}$. Teresa Galí-Izard y $D^{a}$. Benedetta Tagliabue. Asistían, también desde el inicio de la sesión, Da. Carmen Imbernón, Secretaria General de EUROPAN/España y Secretaria del jurado y Da. Begoña Fernández- Shaw, Secretaria Adjunta de EUROPAN/España. Continuó ejerciendo las funciones de Presidente del Jurado D. David Franco.

El día anterior, en el marco del Foro de las Ciudades y de los Jurados, se había celebrado una reunión entre los miembros del Jurado y los representantes de los siete emplazamientos españoles a concurso, en presencia de D. Rafael Pacheco, Presidente de EUROPAN/España. 
De común acuerdo, el jurado decidió proceder de forma positiva, destacando entre las propuestas las que, a juicio de cada uno de los miembros, podrían ser premiadas o mencionadas.

Con esa orientación, se analizaron las propuestas por emplazamiento. Se acordó proceder a una votación; solamente los proyectos que obtuvieran un mínimo de cuatro votos en este turno de votos podrían aspirar a las categorías de Premio o Mención.

Analizando de nuevo cada uno de los emplazamientos, se procedió a la votación que de los premios y las menciones:

AMA: Premio, EC123 Mención, NJ373

Badajoz: Premio, AB508

Calahorra: Premio, TI905 Mención, XR523

La Laguna: Premio, CD778

Poio: Premio, OS171 Mención, EE707

Santander: Premio, SA611

Soria: Premio, XX999 Mención, NJ075

Finalmente, se sometieron los proyectos restantes a la consideración de ser calificados como finalistas, para lo cual sería necesario un mínimo de tres votos.

El Jurado calificó como finalistas los siguientes proyectos, merecedores de ese reconocimiento, que serán incluidos en las publicaciones y exposiciones derivadas de esta novena edición del concurso en España: MB734, XX526, CH852, CH202, SM022, Al111, EK010, ML378, XV168, AH000, MX257, NG010, BS007, OZ869.

Tras la decisión del jurado de conceder la totalidad de los premios y menciones previstos por la organización, se incluyeron entre la categoría de mencionados los siguientes proyectos: CH852, EK010, NG010.

Una vez ratificada la decisión del jurado de conceder 7 Premios y 7 Menciones y 11 Finalistas, entre el total de propuestas presentadas en esta novena edición de EUROPAN/España, en presencia de todos los miembros del jurado, el Presidente procedió a la apertura de los sobres que desvelaban el anonimato de los autores de los 25 trabajos galardonados en EUROPAN 9.

Los autores de esas propuestas son los siguientes:

PREMIOS

AMA,

EC123, Adelais PARERA PERELLO, Karla DIAZ, Pablo GIL MARTíNEZ

Badajoz

AB508, Enrique ARENAS LAORGA, Luis BASABE MONTALVO

Calahorra

TI905, Manuel Quintín MULA MUÑOZ

La Laguna 
CD778. Daren Juan GAVIRA PERSAD, Carolina Ruiz-Valdepeñas Guerrero Poio

OS171, Camilo Manuel REBOCHO VAZ LEIRIA

Santander

SA611, Miguel UBARRECHENA

Soria

XX999, Christian SINTES MIDMORE, David DOMÍNGUEZ FUSTER

MENCIONES

AMA

NJ373, Julio DE LA FUENTE MARTÍNEZ, Natalia GUTIÉRREZ SÁNCHEZ

Badajoz

CH852, Manuel ALVAREZ-MONTESERÍN LAHOZ, Ana PEÑALBA ESTÉBANEZ, María MALLO

ZURDO, David CÁRDENAS LORENZO, María Elisa FERNÁNDEZ RAMOS, Jorge LÓPEZ HIDALGO

Calahorra

XR523, Noelia BALDAYO NEBOT, Gregorio INDELICATO, Anne Lippmann

La Laguna

EK010, Karin FERRER, Estefanía FERRER

Poio

EE707, Emmanuel ROMERO PARRA, Eva María OLALLA DE JUAN

Santander

NG010, David ARCHILLA PÉREZ, Covadonga MARTíNEZ-PEÑALVER

Soria

NJ075, Nuria BAYO MOLINA, Judit TABERNA TORRES

FINALISTAS

AMA

MB734, Jorge MARTÍN SÁINZ DE LOS TERREROS, Elena MOSTAZO ROMEO

XX526, Carmelo RODRÍGUEZ CEDILLO

Calahorra

CH202, Fermina GARRIDO LÓPEZ, Irene ZÚÑIGASAGREDO, Elena ESCUDERO LÓPEZ

SM022, Miguel GARCÍA-REDONDO VILLAR

La Laguna

Al111, Urtzi GRAU MAGAÑA, Cristina GOBERNA PESUDO

Poio

ML378, Francisco LOZANO PERELA, Carlos MONTERO PELÁEZ

XV168, Rui Jorge BRANCO CAVALEIRO, Carlos Jorge COELHO VELOSO, Rui Filipe COELHO

VELOSO, Carina QUINTAS VIANA, Susana LAGES CORREIA

Santander

AH000, Paolo CALEO, Carlos PIANTINO, Lorenzo María ALFIERI, Pablo ROVERAN 
VIVIENDAS EUROPAN (1988-2008) I Una aproximación a los modos de vida en el cambio de siglo en España ANEXOS. DOCUMENTACIÓN

MX257, María SISTERNAS TUSELL

Soria

BS007, Marta FERNÁNDEZ-VALDERRAMA, José Francisco MONTES DE LA VEGA, Luz FERNÁNDEZ-VALDERRAMA, Francisco ESCUDERO GILETE OZ869, Manuel CIFUENTES ANTONIO, Juan Enrique ÁLVAREZ CABEZUELO 


\title{
EUROPAN 10 (2008). ACTA DEL JURADO DE EUROPAN 10/ESPAÑA ${ }^{22}$
}

\author{
PRIMERA FASE DEL JURADO DE EUROPAN 10/ESPAÑA \\ ESCUELA TÉCNICA SUPERIOR DE ARQUITECTURA DE MADRID \\ 23-25 DE JULIO DE 2009
}

\section{PRESENTACIÓN DE LOS EMPLAZAMIENTOS A CARGO DE LOS RESPONSABLES DE SUELO DEL COMITÉ NACIONAL DE EUROPAN / ESPAÑA}

A las 11:00 horas del jueves día 23 de julio, en el Salón de Actos de la Escuela Técnica Superior de Arquitectura de Madrid, Da. Carmen Imbernón, Secretaria General de EUROPAN/España y Secretaria del Jurado, abrió la primera reunión para el Fallo del Jurado de EUROPAN 10/España, dando la bienvenida a los representantes de los emplazamientos a concurso y a los miembros del jurado.

Recordó que, en España, el Comité Nacional está presidido por el Ministerio de Vivienda, siendo sus miembros las administraciones públicas (Comunidades Autónomas y Ayuntamientos). Estas, a través de sus propuestas de suelo, invitan a los jóvenes arquitectos europeos a expresar sus ideas en materia de ciudad, mediante propuestas estratégicas para espacios urbanos en vías de transformación. Situado entre la planificación urbana y la construcción de edificios, EUROPAN trabaja en lugares que cuentan, a menudo, con programas deliberadamente abiertos y flexibles con el fin de potenciar la máxima capacidad propositiva por parte de los concursantes.

En su primera fase de trabajo, el jurado tiene la misión de detectar, entre las propuestas entregadas, no solamente las que resuelven más brillantemente las cuestiones planteadas, sino las que son capaces de generar un debate europeo sobre el modo de revitalizar, regenerar o colonizar áreas de ciudad en fase de transformación.

El objetivo de esta primera fase del jurado es la selección de un máximo del $20 \%$ de los proyectos entregados, propuestas que serán analizadas en el marco del Forum de las Ciudades y de los Jurados a celebrar en Graz, Austria, durante los días 6 y 7 de noviembre de 2009.

Tras este encuentro internacional, en el que se llama a participar a los representantes de suelo y a los miembros de los diferentes jurados europeos, se celebrará la segunda reunión del jurado, al término de la cual se habrán destacado un máximo de 7 premios y 7 menciones, además de las propuestas finalistas.

El trabajo del jurado y la presentación de los emplazamientos españoles por parte de los responsables de los suelos a concurso, se han organizado siguiendo las

22 AA.VV. EUROPAN 10 España. Proyectar la urbanidad. Ed. Ministerio de la vivienda. Madrid. 2010. pp.9-15. 
tres grandes categorías que componen la temática general de EUROPAN 10, Colonización, Revitalización, Regeneración.

En España, el Jurado habrá de analizar un total de 311 propuestas clasificadas en los siguientes grupos temáticos:

\section{COLONIZACIÓN TRAZAS URBANAS:}

Taboadela 63 equipos inscritos, 34 propuestas entregadas

Valverde 93 equipos inscritos, 43 propuestas entregadas

ESCALAS DE SOSTENIBILIDAD:

Reus 90 equipos inscritos, 45 propuestas entregadas

REVITALIZACIÓN POLOS MAGNÉTICOS

Teruel 90 equipos inscritos, 34 propuestas entregadas

ESPACIOS PÚBLICOS LINEALES

Cáceres 102 equipos inscritos, 51 propuestas entregadas

REGENERACIÓN TRANSFORMACIÓN SOCIAL

Elda 65 equipos inscritos, 41 propuestas entregadas

MUTACIÓN PAISAJÍSTICA

Madrid 132 equipos inscritos, 63 propuestas entregadas

A continuación, dio comienzo la presentación y descripción, por parte de los responsables de suelo, de los 7 emplazamientos a concurso. Las personas designadas a estos efectos fueron invitadas a comunicar a los miembros del jurado su opinión al respecto de las propuestas que habían sido objeto de estudio por su parte durante los días previos a este primer encuentro.

Se recordó, igualmente, que todos los emplazamientos habían sido visitados por algún miembro del Jurado, en fechas coincidentes o no con las visitas abiertas a los concursantes inscritos al concurso.

El emplazamiento de MADRID fue presentado por los representantes del Ayuntamiento de Madrid, D. Ángel Luís Fernández Muñoz (Director General de la Oficina del Centro), $D^{\mathrm{a}}$. Ana Reguero Naredo (Jefa del Departamento de Renovación Residencial) y $D^{a}$. Mar Moralejo Marino (Adjunta al Departamento de Renovación Residencial). Tras explicar las condiciones físicas y programáticas del lugar, los responsables de la Oficina de Centro del Ayuntamiento de Madrid recalcaron lo ya expresado en la respuesta a las consultas de los concursantes, subrayando la importancia de la imagen de la Cornisa y el hecho de que se trata de un concurso de ideas que no ha de seguir estrictamente las directrices del Plan Parcial existente. Informaron de que se habían dado diferentes tipos de propuestas atendiendo al paisaje, al encuentro de la Cornisa con la ciudad, al frente de la Cornisa, a las diferentes piezas edificadas, a la topografía, además de otras propuestas singulares. De forma general, las propuestas presentadas habían cumplido el programa, aunque no el Plan Parcial. La gestión de varias de ellas podría ser asumida por el Ayuntamiento de Madrid tras el fallo del concurso. El emplazamiento había sido visitado por D. Javier Mozas. 
El emplazamiento de CÁCERES fue expuesto por $D^{a}$. Esther Gamero-Zúñiga, de la Dirección General de Arquitectura y Programas Especiales de Vivienda de la Agencia Extremeña de la Vivienda, el Urbanismo y el Territorio.

Tras explicar las características del emplazamiento, $D^{a}$. Esther Gamero recordó que los objetivos prioritarios de la propuesta son la obtención de un espacio público lineal para la ciudad de Cáceres, su relación con la ciudad existente y los nuevos desarrollos urbanos, así como la recuperación de las huertas.

El emplazamiento había sido visitado por Da. Belinda Tato Serrano.

El emplazamiento de TERUEL fue expuesto por Da Nuria Más Farré, (Directora General de Urbanismo del Gobierno de Aragón), $D^{a}$. Carmen Guillén (Técnico de la Dirección General de Urbanismo) y D. José Ramón

Anadón (Gerente, Gerencia de Urbanismo del Ayuntamiento de Teruel)

Los proyectos presentados habían sido valorados atendiendo a los siguientes criterios: Movilidad (entrada a la ciudad, conexiones con las muelas, flujos peatonales, acceso a la Vega, conexiones viarias, aparcamiento),

Entorno (puesta en valor de recursos ambientales, naturales, de interés paisajístico, resolución de la conexión entre ciudad y medio natural, configuración de la fachada de la ciudad), Programa de usos (residencial, terciario, equipamientos), Viabilidad. Se habían detectado tres grandes tipos de proyectos:

- Los que no actúan en la Vega (o bien no plantean actuación alguna, o bien se protege y revaloriza lo existente)

- Los que actúan en la Vega (Intervenciones de tipo vegetal con edificaciones de escasa entidad o impacto visual)

- Los proyectos que colonizan la Vega, con edificaciones repetitivas de gran impacto visual, o bien con un tratamiento urbano del espacio, recurriendo a geometrías rotundas.

El emplazamiento había sido visitado por Da. Margarita Jover Biboum.

El emplazamiento de ELDA fue expuesto por D. Arturo Collado López (Concejal de Relaciones Institucionales y Coordinación Municipal Ayuntamiento de EldaValencia) y por D. Alberto Sanchís Cuesta (Jefe Servicio

Rehabilitación Dirección General de Vivienda y Proyectos Urbanos). Estuvieron presentes en la presentación $D^{a}$. $M^{a}$ Jesús Rodríguez Ortiz (Directora General de Vivienda y Proyectos Urbanos), D. Eduardo Fuente Varó

(Arquitecto Dirección General de Vivienda y Proyectos Urbanos), Da. Dolores González Ruiz (Concejal de Urbanismo y Vivienda de Ayuntamiento de EldaValencia) y D. Francisco Belmar (Arquitecto del Ayuntamiento de Elda-Valencia). Se informó de que el Plan General de Elda se encuentra en fase de revisión, permitiendo así la incorporación del proyecto que se premie.

En cuanto a los objetivos a alcanzar, se señaló la necesidad de permeabilizar la trama urbana, de atender a problemas de densidad y de crear un frente urbano para la ciudad en ese punto. A su juicio, existía buen número de propuestas que resolvían satisfactoriamente estas cuestiones.

El emplazamiento había sido visitado por D. Javier García-Solera. 
El emplazamiento de TABOADELA fue expuesto por D. Ignacio Cerrada (Instituto Gallego de Vivienda y Suelo de la Xunta de Galicia), quién señaló el interés de contar con propuestas que suponen modos novedosos de intervención en el territorio gallego.

Destacó varios tipos de respuestas.

- Las que abordan la resolución mediante líneas de ocupación que se adaptan a la topografía

- Otras que ocupan puntualmente el territorio a diferentes escalas

- Algunas propuestas plantean en el entorno natural elementos de alta densidad

- Finalmente, existen propuestas que apuestan por una ocupación global del territorio mediante edificación de baja densidad.

El emplazamiento había sido visitado por D. Pablo Gallego Picard.

El emplazamiento de VALVERDE fue expuesto por $D^{a}$. María del Mar Luján (Jefa Técnica de Vivienda y Suelo del Instituto Canario de la Vivienda).

A su juicio, se habían dado tres tipos de respuestas:

- Las que proponen una ordenación regular del territorio, como una herramienta de planeamiento

- Aquellas que actúan en todo el municipio

- Las que se integran desde un punto de vista paisajístico

Recordó la importancia de la topografía del lugar, la necesidad de crear una fachada urbana, de atender a las dotaciones de espacios libres y de atención de la propuesta a la escala de Valverde.

El emplazamiento había sido visitado por D. Virgilio Gutiérrez Herreros.

El emplazamiento de REUS fue expuesto por D. Joaquim Gascó (Director General de Nuevas Promociones de Generalitat de Catalunya) y D. Jordi Bergadà (Concejal de Urbanismo del Ayuntamiento de Reus), en presencia de $D^{a}$. Pilar Carbassa (Ayuntamiento de Reus), $\mathrm{D}^{\mathrm{a}}$. Conxita Blanco (INCASOL) y $\mathrm{D}^{\mathrm{a}}$. Esther Llorens (Generalitat de Catalunya).

Los responsables de este emplazamiento subrayaron el carácter realista de la propuesta, informando de la existencia de un convenio entre el Ayuntamiento de Reus e INCASOL para el desarrollo del proyecto premiado. Expresaron que las propuestas, por lo general, adolecen de trabajo sobre el espacio público y animaron al jurado a valorar propuestas innovadoras.

El emplazamiento había sido visitado por Da. Judith Leclerc.

Tras unas palabras pronunciadas por D. Antonio Vélez Catrain, miembro del Comité Nacional de EUROPAN/España, se celebró un almuerzo conjunto por invitación del Consejo Superior de los Colegios de Arquitectos de España.

\section{CONSTITUCIÓN DEL JURADO Y COMIENZO DE LA SESIÓN PARA EL FALLO DE LA PRIMERA FASE DEL JURADO DE EUROPAN 10/ESPAÑA}

El Jurado formado por D. Javier Mozas, Da. Belinda Tato Serrano, D. Javier GarcíaSolera Vera, Da. Judith Leclerc, D. Pablo Gallego Picard, D. Virgilio Gutiérrez 
Herreros, Da. Margarita Jover Biboum, D. Franco Ghilardi y Mr. Michael Gaenssler se reunió a puerta cerrada a las $16 \mathrm{~h} 00$ del jueves día 23 de julio. Actuó como Secretaria del Jurado $D^{a}$. Carmen Imbernón.

El Jurado estableció el siguiente método de trabajo:

- Los trabajos a seleccionar debían reunir la calidad suficiente para constituir una base de discusión global, a nivel europeo, en torno a las temáticas de EUROPAN 10.

- Las propuestas serían preseleccionadas atendiendo a criterios de calidad y no en función de la obtención de un reparto equilibrado de premios por emplazamientos. - Los proyectos preseleccionados en esta primera fase serían la base para la selección definitiva, en la segunda reunión, de las propuestas finalistas, mencionadas y premiadas.

- Cualquier miembro del jurado podría, a lo largo del fallo, someter de nuevo a debate un proyecto eliminado.

- La información digital de las propuestas preseleccionadas en esta primera fase serían enviadas a cada uno de los miembros del jurado antes de la celebración de su segunda reunión en Graz.

- Junto a cada uno de los trabajos expuestos, se mostraría, si la hubiera, la ficha de valoración del responsable de suelo.

El Jurado decidió no someter a examen dos proyectos que habían sido enviados en fecha posterior al día 29 de mayo de 2009.

Fue nombrado Presidente del Jurado D. Javier García Solera Vera

\section{PRIMERA RONDA ELIMINATORIA}

Tras el análisis individual de las propuestas, se procedió a la primera ronda eliminatoria.

Se estableció examinar conjuntamente las propuestas siguiendo la clasificación temática de los emplazamientos.

En cada caso, el emplazamiento a analizar fue introducido por el miembro del jurado que había realizado la visita al lugar.

En esta primera ronda, serían eliminadas las propuestas que no hubieran obtenido al menos el apoyo de dos miembros del jurado.

Así, el viernes día 24 de julio, se alcanzó una selección de 109 proyectos, distribuidos por emplazamientos del siguiente modo:

Reus, 19 - Taboadela, 12 - Valverde, 18 - Teruel, 11 - Cáceres, 20 - Elda, 12 Madrid, 17

El listado de las diferentes votaciones se incluye al final de este Acta.

SEGUNDA RONDA ELIMINATORIA

Se requería, para esta segunda ronda, la obtención de al menos 4 votos para la 
permanencia del proyecto.

Tras los necesarios debates, el número total de propuestas preseleccionadas en la primera fase del jurado fue de 60 , repartidas por emplazamientos del siguiente modo:

REUS

Fueron preseleccionados 8 proyectos que responden a los siguientes códigos:

CA027, CJ116, FH451, FR190, HU315, OX200, PS474, TO973.

CÁCERES.

Fueron preseleccionados los 10 proyectos que responden a los siguientes códigos: CC313, CC859, DB100, DC858, EC024, EE609, RE001, RM010, XX000, ZZ777. ELDA.

Fueron preseleccionados los 9 proyectos que responden a los códigos: CD762, CL001, CO909, EE513, ET609, MO800, OO800, PC201, VV953.

MADRID

Fueron preseleccionados los 10 proyectos que responden a los códigos: BA006, DD000, HA005, KM001, LH103, MD181, NO316, OA009, QJ010, SR045.

TABOADELA.

Fueron preseleccionados los 8 proyectos que responden a los códigos: CA017, EU010, FP600, KP636, LP001, MI628, RW000, SM007.

TERUEL

Fueron preseleccionados los 6 proyectos que responden a los códigos: HU000, LC114, OI010, RN007, ST330, ZZ000 VALVERDE.

Fueron preseleccionados los 9 proyectos que responden a los códigos: AM711, AP227, AS111, BE205, DZ077, FC020, GJ570, II111, RE211

Se levantó la sesión el sábado día 25 de julio a las $18 \mathrm{~h} 00$.

\section{SEGUNDA FASE DEL JURADO DE EUROPAN 10/ESPAÑA}

STADTHALLE. GRAZ. AUSTRIA

DOMINGO 8 DE NOVIEMBRE DE 2009

La segunda reunión del jurado vino a culminar dos días de trabajo desarrollados en el marco del Forum de las Ciudades y de los Jurados, que reunió a los representantes de suelo a concurso, a los organizadores de EUROPAN y los jurados internacionales, en torno a las propuestas que habían sido preseleccionadas.

El sábado día 7 de noviembre, tuvo lugar una reunión específica de EUROPAN/ España, durante la cual los responsables de los emplazamientos españoles tuvieron ocasión de trasladar a los miembros del Jurado allí presentes sus criterios y puntos de vista sobre cada uno de los proyectos que iban a estar sometidos al fallo. Se contó con la asistencia de los responsables de Cáceres, Elda, Reus, Taboadela, Teruel y Valverde.

El domingo día 8 de Noviembre, se inició la sesión con la presencia de ocho miembros del jurado, habiendo excusado su asistencia D. Virgilio Gutiérrez Herreros. 
Asistían, también desde el inicio de la sesión, Da. Carmen Imbernón, Secretaria General de EUROPAN/España y Secretaria del jurado y Da. Begoña FernándezShaw, Secretaria Adjunta de EUROPAN/España.

Continuó ejerciendo las funciones de Presidente del Jurado D. Javier GarcíaSolera Vera.

De común acuerdo, el jurado decidió proceder de forma positiva, destacando entre las propuestas dos de las que, a juicio de cada uno de los miembros, podrían ser premiadas o mencionadas.

En cada caso, del mismo modo que en la fase anterior, el miembro del jurado interlocutor directo del responsable del emplazamiento, señaló los criterios que, a su juicio, debían imperar de cara a la decisión final.

Con esa orientación, se analizaron las propuestas que recibieron mayor número de votos, decidiéndose por consenso, en función de la calidad de las propuestas, las categorías de PREMIO y MENCIÓN.

Tras analizar de nuevo las propuestas en cada uno de los emplazamientos, se sometieron los proyectos restantes a la calificación de finalistas, para lo cual se acordó que sería necesario un mínimo de dos votos.

CÁCERES: Premio, RE001

Mención, EC024

Finalistas, CC313, CC859, DB100, EE609, ZZ777

ELDA: Premio, 00800

Mención, CL001

Finalistas, EE513, ET609

MADRID: Premio, QJ010

Finalistas, DD000, NO316, OA009, SR045

REUS: Premio, CJ116

Mención, OX200

Finalistas, CA027, FH451, FR190

TABOADELA: Mención, RW000

Finalistas, EU010, FP600, LP001, SM007

TERUEL: Premio, OI010

Mención, LC114

Finalista, ZZ000

VALVERDE: Premio, AS111

Menciones, BE205, GJ570

Finalista, FC020

Una vez ratificada la decisión del jurado de conceder 6 Premios y 7 Menciones y de destacar 20 Finalistas entre el total de propuestas presentadas a la décima edición de EUROPAN/España, en presencia de los miembros del jurado, el Presidente 
procedió a la apertura de los sobres que desvelan el anonimato de los autores de los trabajos galardonados en EUROPAN 10.

Los autores de esas propuestas son los siguientes:

PREMIOS

CÁCERES: RE001. Javier García-Germán Trujeda y Alia García-Germán Trujeda ELDA: O0800. Diego Jiménez López y Juana Sánchez Gómez MADRID: QJ010.Carolina Ruiz-Valdepeñas Guerrero, Daren Gavira Persad REUS: CJ116. Aurélien Delchet, Gimena Repetto y Alexis Traficante TERUEL: OI010. Berta Barrio y Josep Peraire VALVERDE: AS111. Silvia Alonso de los Ríos

\section{MENCIONES}

CÁCERES: EC024. Miguel Ángel Rupérez Escribano

ELDA: CL001. Emilio García Navarro

REUS: OX200. Jordi Mas Morelló y Mónica Ruiz del Amor

TABOADELA: RW000. Susana Velasco

TERUEL: LC114. Xabier Barrutieta Basurko.

VALVERDE: BE205. José Luis Bezos Alonso

GJ570. Gian-Paolo Ermolli y Jonas Fritschi

FINALISTAS

\section{CÁCERES}

CC313. Pilar Gutiérrez Pulido y Elena Pérez Palacios

CC859. Andrea Gallina, Antonio Di Bacco, Cécile Combelle, Hélène Lemouzy, Julien

Pinard, Delphine Birman y Claire Jolivet

DB100. María Carmen Ruiz Ibáñez y Antoni Bravo Rincón

EE609, Eduardo Herrezuelo de la Sierra y Eva Roense i Simó

ZZ777. Isaac Martí Alabart, Sergi Lois Alcázar y María Cifuentes Rius

ELDA

EE513. Lieven De Groote, Ana Castillo, Alberto Gil Torrano y María José Guillén ET609. Jorge Almazán, Arturo Peris, Irene Soler del Moral y Berta Prieto

MADRID

DD000. Daniel Ibáñez y Rodrigo Rubio

NO316. Severino Sebastián y Fernando Altozano

OA009. Cyril Pressacco

SR045. David Mulder (Van der Vegt) y Max Cohen de Lara

REUS

CA027. Florian Ingmar Bartholome, Ludwig Jahn y José Ulloa Davet

FH451. David Hernández Falagán

FR190. David Tapias Monné, Nuria Salvadó Aragonés y Aida Español Vilanova TABOADELA

EU010. Elena Barroso, Cruz Calleja, Fátima Plaza, Marina Otero, Ignacio González 
y Verónica Meléndez

FP600. José Juan Fructuoso, Javier Poveda, Juan Manuel Cutillas y Antonio

Pascual

LP001. Rafael Beneytez Durán

SM007. Bastien Fabas, Lucile Moreaux y Adrien Lehembre

TERUEL

ZZ000. Alejandra Julián, José Miguel Aspas Cutanda y $\mathrm{M}^{a}$ Dolores Domingo Garzarán

VALVERDE

FC020. José López Parra.

\section{Comentarios a los proyectos seleccionados EUROPAN 10*}

\section{CÁCERES}

RE001- Reactivando la Ribera Premio

El jurado valora el proyecto por ser un sistema de soluciones que intentan adaptarse a la realidad existente y no al contrario. La propuesta aborda desde operaciones de bajo presupuesto y mínima intervención física hasta otras de mayor escala y presupuesto. Se valora la capacidad de regenerar todo el eje de la Ribera a través de intervenciones de acupuntura alternativas al hecho de construir -tales como iniciativas económicas o sociales- que sin duda deben estar presentes en una operación urbana de esta escala. La propuesta rescata herramientas de otras disciplinas para abordar la revitalización de la ribera, no sólo como eje paisajístico y de conectividad, sino como estructura económica, productiva, lúdica y social.

EC024- Nadando en el río verde. Mención

La recuperación de la memoria y la potenciación de la accesibilidad universal son las apuestas principales del proyecto. La propuesta se apoya en la capacidad regeneradora de la naturaleza, planteando un catálogo de especies vegetales clasificadas según sus características y cualidades, confiando además en el color como potente herramienta de intervención. Es una interesante estrategia de regeneración de la ribera a partir de elementos naturales y puesta en valor del eje como espacio público lineal para Cáceres.

CC313- De vuelta a la Ribera. Finalista

Esta propuesta presenta un detallado análisis de la problemática actual, apostando por un gran eje vertebrador de espacios públicos como germen de una nueva cultura 'slow' para Cáceres, adquiriendo importancia la productividad agrícola vinculada a esa nueva cultura de comid 'slow'.

El jurado valora los elementos que tapizan el territorio generando unos espacios público-privados entre los mismos. Este sistema de crecimiento permite su ejecución en distintas fases, permaneciendo abierto a futuras ampliaciones.

CC859- Variaciones en las líneas. Finalista

La ribera es entendida como eje conector para peatones y ciclistas. Se valora la 
propuesta de recuperación de este espacio, ahora olvidado, como paseo para la ciudad de Cáceres al que se insertan distintos usos y actividades a lo largo de su recorrido. Se considera la resolución de las conexiones con el casco histórico muy esquemática, así como discutible la formalización residencial, por ser poco acorde con la escala y características del lugar.

DB100- Menos lapidata.... Finalista

El jurado valora el estudio y la incorporación de los elementos preexistentes a la propuesta de programa, así como la atención prestada a la movilidad. La solución residencial, por su carácter extensivo, se considera menos apropiada e ineficiente. EE609- Volar del nido. Finalista

El estudio de las preexistencias físicas y culturales es minucioso. Sin embargo, la propuesta residencial se muestra ajena al lugar y parece tener poco que ver con la morfología, escala y sección de la Ribera del marco.

\section{ZZ777- Puntos de sutura. Finalista}

Se valora positivamente la importancia que tienen las mejoras en la conectividad del eje de la Ribera con el casco histórico, aspecto escasamente abordado en los proyectos presentados. Sin embargo, el peso de lo construido en dichas conexiones parece un tanto desproporcionado y carece de la sutileza que el lugar sugiere. Los elementos de conexión dejan de ser un medio convirtiéndose en un fin.

\section{ELDA}

OO800. Premio

El jurado valora de esta propuesta su sensible aproximación a todas las circunstancias críticas del lugar, tanto en sus aspectos físicos como en la problemática social que allí se localiza. La inteligente propuesta de intervención en el barrio de Numancia, basada en una realista estrategia de esponjamiento y potenciación del espacio público como activador de una mayor cohesión social, está preñada de oportunidades permitiendo la atención pormenorizada a cada situación particular. La esmerada atención al tratamiento de todo el espacio libre resucitado con la desaparición del barrio de Tafalera, plantea la puesta en valor del monte, la vaguada y el río en una concatenación de acontecimientos posibles que aseguran su recuperación paisajística, su inserción urbana y su activación programática. Por último, el proyecto acierta de nuevo en su delicado tratamiento de los restos posibles de la demolición del barrio Tafalera, haciendo de su permanencia, integrados en las plataformas creadas y en los posibles futuros equipamientos, un poético y práctico ejercicio de conjugación de memoria y renovación.

\section{CL001. Dando Palmas. Mención}

El proyecto se presenta como un cuidadoso y atento estudio pormenorizado y realista de las posibilidades de actuación y revitalización del área de estudio. La propuesta se aproxima a cada situación parcial con un acertado ajuste entre 
propuesta proyectual y realidad social, geográfica y medioambiental, planteando, desde la inyección programática y el alojamiento, las distintas soluciones parciales. Es de señalar cómo esta actitud de gran realismo no impide que el proyecto alcance una gran coherencia general y un alto nivel de respuesta en cada parte, así como en el conjunto del área estudiada. El jurado considera que la propuesta confía en exceso en el valor de la vivienda como regeneradora del tejido completo, tapizando en exceso el territorio explorado con viviendas que, siendo de gran interés tipológico, acaban por traicionar algunas de las potencialidades que la propia propuesta plantea.

\section{EE513. Horas de esparto. Finalista}

El jurado valora la capacidad de la propuesta para hacer girar el completo de lo proyectado en torno a una renovación absoluta de las condiciones de la economía productiva. El valor de un proyecto de arquitectura que se cimienta sobre la posibilidad de reestructurar todos los aspectos que tienen que ver con un lugar, partiendo de la modificación de las condiciones en que se desarrollan las tareas productivas, y seguir tras esa idea con el desarrollo siempre coherente de las intervenciones construidas que le den sentido y lugar. Por otra parte, el jurado estima que existe una excesiva particularización de la acción general en torno a un único tema común.

\section{ET609. Inhabited park Finalista}

El proyecto presenta gran interés en el tratamiento dado a toda la intervención en el alto de Tafalera y su conexión con el valle y el resto del casco urbano, así como en su comunicación peatonal hacia el barrio de Numancia. La propuesta presenta carencias sin embargo, a juicio del jurado, en la solución dada a la ubicación de los bloques en la caída natural de la vaguada en una disparidad tipológica excesiva que pone en peligro la continuidad urbana que la propuesta persigue.

\section{MADRID}

QJ010. Statu Quo. Premio

La virtud de este proyecto ha sido conciliar una serie de factores enfrentados. Sugiere una nueva imagen para este comprometido emplazamiento, aportando el equilibrio indefinido en el que casi todo puede ocurrir y donde la distinción entre artificial y natural es una cuestión a resolver más adelante. En un primer encuadre, plantea la integración entre lo construido y el paisaje. En un segundo enfoque, asigna los espacios que corresponden al clero, a los residentes y a los turistas, identificando sus usos y posicionándolos en situaciones de concordia con lo que establece el planeamiento.

No desdeña la idea romántica de una cualificación del lugar como punto de contemplación del horizonte y, con esta intención, crea un sistema de espaciosobservatorio en el jardín situado al borde de la cornisa. El proyecto realiza de manera precisa el tallado de la topografía, la situación de la edificación en plataformas integradas y el trazado de sendas paisajísticas. El resto del espacio libre se completa con la introducción de un programa lúdico y cultural. 
La propuesta sabe mantener la necesaria ambigüedad para asumir cualquier modificación futura surgida de presiones o de conflictos de intereses. A la vez, da una respuesta firme al planeamiento vigente con el encaje físico de todos los usos previstos, pero evitando poner de manifiesto las tensiones que existen. Desdibuja intencionadamente el límite entre lleno y vacío y funde en un juego las palabras, calificando los paisajes como habitados y perfilando los edificios como prolongación de las trazas del parque.

DD000. Todos contentos. Finalista

La poética manual de la papiroflexia es el argumento flexible que utiliza esta propuesta para crear mundos delicados que intiman con el paisaje y con el volumen construido. El terreno se recubre, en este caso, con una alfombra desplegada siguiendo leyes y argumentos topográficos. Las laderas y colinas del emplazamiento adoptan geometrías variables y desarrollos verticales, duales y reglados, como si estuvieran tocados por la invertida y mágica varita que convierte en artificial al mundo de los organismos vivos. La implantación de unidades de ecosistema, productivas, inteligentes y con impredecible variabilidad sugiere universos ricos en imágenes reveladoras.

Los edificios, también por esta magia, se convierten en híbridos topográficos que conjugan funciones en su seno y que promueven una fusión íntima entre parque y programa, a costa de vaciar para luego recomponer, el terreno original. La fuerza del proyecto reside en la coherencia del discurso que cubre bajo un único manto la dualidad naturaleza-función. En cambio, produce una gratuita monitorización de los elementos paisajísticos, que exhiben al público sus cifras y que garantizan, solo en apariencia, la transparencia de los procesos. Datos e información como exhibicionismo público a partir de mediciones sobre producción y consumo.

La propuesta maneja con habilidad las mutuas influencias de los elementos de paisaje, que nadan como peces entre la vegetación preexistente. Entre ellos se trazan redes de caminos y acequias y se establecen contenciones con bancales para conseguir la integración entre la manta porosa y el paisaje esponja. La sutileza caracteriza a los elementos constructivos del programa, porque se despliegan superficialmente con ranuras abiertas para iluminar a los híbridos maclados escondidos bajo sus laderas.

NO 316. Unidad de Paisaje Equipado. Finalista

Esta propuesta se enfrenta al programa creando un sistema, que es vertical en proximidad y horizontal en la distancia. Es el resultado coherente de mantener dos visiones respecto al paisaje: la vertical y cercana, asociada con los árboles y la vegetación del ámbito y la horizontal y lejana referida a plataformas y elementos construidos. Se empeña en un sistema constructivo con materiales concretos que caracterizan el paisaje y resuelven situaciones. Las piezas básicas del diseño son tres: placas de forjado, tablestacas y vigas-palastro. Con estos elementos se contiene el terreno, se confinan los usos y se crean plataformas.

Los usos pasan por encima de los sugeridos en las bases, porque el sistema 
responde a sus dimensiones limitadas y propone nuevas actividades sociales y comunitarias menos consumidoras de grandes luces y con posibilidades para adaptarse de manera progresiva a nuevos programas.

Se valora que la arquitectura se introduzca en la esencia del lugar y que no se identifique con un tiempo concreto, ni con un estilo, que no pretenda cambiar su carácter de plataformas topográficas, ni su representación.

Se considera positivo que el proyecto extienda el ámbito de actuación a las pequeñas calles y plazoletas del entorno, hacia un campo expandido que entiende la ciudad como una deriva temporal sin barreras. Definir infraestructura como "la ley subyacente necesaria para entender un hecho" es coherente con el desarrollo teórico de la propuesta, porque considera a la ladera como una auténtica infraestructura paisajística, con dos categorías la exterior: de carácter público y abierto y la interior: construida, cerrada y restringida para unos usos concretos. El sistema aporta rigor a una infraestructura que se pretende pública, universal y flexible.

\section{OA009. A new order. Finalista}

La propuesta plantea una nueva forma de actuar sobre la ciudad histórica mediante la imposición de un nuevo orden que habla de la relación de lo regular con lo irregular. Analiza el recorrido histórico de la trama, la calle europea y los ejes urbanos, reclamando una actuación que vuelva del revés estos tradicionales instrumentos de composición. No propone una trama, ni una calle, ni un eje, sino un principio regulador, una alineación de edificios, que se sitúa en medio del irregular tejido existente, dialogando con él.

La fuerza de este proyecto radica en la contundente disposición de tres prismas alineados. Los edificios propuestos son: una torre con usos privados, un edificio con usos ligados a lo religioso y un equipamiento público de baja altura. Son edificios genéricos donde cabe todo, hasta aprovechamientos lucrativos, no previstos en el planeamiento, que en otras circunstancias podrían haber lubricado la operación. Los precisos encuentros de cada edificio con el terreno definen los límites del nuevo espacio público.

Si trazar una calle en un tejido urbano es abrir un surco, cuando una ordenación plantea la alineación de volúmenes en un vacío, se está trabajando con el mismo proceso, pero una acción más adelante, sembrando el espacio. De esta manera, lo regular no desventra a lo desigual, como ocurría históricamente con las plazas mayores o con las operaciones barrocas, sino que dialoga con lo irregular en términos de igualdad. La franqueza de este proyecto es su apuesta por la potencia de la Modernidad como generadora de ciudad y por su confianza en la arquitectura genérica. El planteamiento revuelve las tripas del centro histórico, al importar la crudeza geométrica y periférica de la tabula rasa al corazón de la ciudad.

SR045. El cementerio de la cornisa. Finalista

El significado es más importante que el programa. Este es el argumento con el que este proyecto da la vuelta a las necesidades del ámbito y llena de un vacío yermo el corazón de la cornisa. Por eso sedujo al jurado. La sociedad actual ha eliminado 
la presencia física de la muerte, pero el vacío, como rito, como meditación, como cuestionamiento del sentido de la presencia de la humanidad en el mundo, sigue siendo una parte esencial del espacio.

Dentro del texto de esta propuesta está escrita la frase: "la ciudad debe acomodar la realidad de la muerte en su propio centro". La muerte se relaciona mejor con el espacio vacío que con el lleno y los espacios vacíos suelen estar ausentes de los centros históricos. El vacío como ausencia de vida, como lugar para la memoria y el recuerdo. En este caso, el irreverente collage de la propuesta ocupa el emplazamiento mediante una rejilla de enterramientos y parques. Un columbario, un cementerio para monjes, uno para familias y otro para niños se mezclan con un jardín Zen, un jardín del viento, uno para el recuerdo y otro para el silencio.

Aunque el programa de usos se introduce comprimido en dos edificios integrados en la trama urbana, las tumbas y mausoleos son las verdaderas construcciones de este parque extremista, de este contenedor de rituales y acontecimientos, de este escaparate de la memoria y del paso del tiempo.

\section{REUS}

CJ116. Intervalos. Premio

El jurado destaca la propuesta Intervalos, que fusiona tres modos de ocupación a través de una hábil incorporación de programas híbridos propios de la situación fronteriza ciudad-campo de cultivo. La propuesta condensa la edificación en una gran megaestructura intermitente que hibrida lo residencial, los equipamientos y los usos agrícolas en la parte limítrofe con el barrio residencial de Sant Joan aislado al norte. El diseño flexible permite multitudes de usos y modalidades (privado, colectivo, individual agrupado) en unas edificaciones que recuerdan las de los campos agrícolas vecinos. Esta megaestructura densa se va disgregando hasta liberar completamente la franja central para el uso productivo del campo y reapareciendo al sur de manera intermitente en la proximidad a las vías del tren, albergando usos de apoyo al cultivo de los huertos urbanos a escala del barrio y de la ciudad de Reus simultáneamente. Desde la concepción general hasta lo particular, el proyecto es concebido desde una aproximación sostenible y ecológica y resuelve con gran flexibilidad y complejidad esta pieza de interfase urbano-rural.

OX200. No more limits. Mención

El jurado destaca la capacidad de esta propuesta para resolver las deficientes conexiones del solar debido a su delimitación por distintas vías de tren. Recurriendo a una estrategia de compresión, concentra las edificaciones en la franja norte, a continuación de la trama del barrio de Sant Joan para dejar entrar un corredor verde generoso a través de la riera que penetra en la ciudad y ocupa la mitad sur del solar en un gran parque urbano con equipamientos a escala de ciudad accesibles mediante pasos soterrados bajos las vías del tren. Resuelve el tráfico rodado con una calle que delimita las dos zonas sur/norte y que une el centro de la ciudad con la nueva rotonda de la vía de cintura. El jurado aprecia la efectividad y simplicidad de los recursos utilizados aunque desearía una mayor reflexión sobre 
la complejidad del habitar.

FR190. Camp. Finalista

El jurado valora la capacidad de esta propuesta para crecer en el tiempo, de aceptar un cierto estado inacabado e incluso de decrecimiento. Propone, en un primer tiempo, un "vivero urbano" que coloniza el solar con una estrategia generatriz que crece como una plantación de avellanos, creando un orden basado en la medida agrícola, dando sombra y comida a los futuros usuarios.

En un segundo tiempo, aparece una estructura ligera marcando, en relación con la trama de plantación, los lugares para ocupar o dejar vacío que se colonizan con la aparición del usuario.

Debido a la ligereza de la infraestructura, el proceso inverso de desmontaje y decrecimiento es posible, dejando protagonismo a la naturaleza crecida.

CA027. Pixeles Urbanos. Finalista

El jurado destaca esta propuesta dentro de las propuestas isótropas por su concepción de un urbanismo realmente híbrido entre la tipología de casas unifamiliares del barrio de Sant Joan y el tejido urbano denso del ensanche de Reus. Pensado desde criterios de sostenibilidad que van de la micro escala a la escala de barrio, desde el tratamiento de las aguas hasta la generación de su propia energía o la definición constructiva de sus fachadas, según su orientación solar, crea unas macro manzanas-jardín equipadas con distintas escalas de movilidad utilizando un sistema de asemblaje basado en un modulo constructivo simple y por lo tanto económico.

FH451. Outlet House. Finalista

Esta propuesta destaca entre todas por su concepción única de reciclaje urbano y su materialización a diferentes escalas. El jurado valora el esfuerzo para transformar el elemento

conflictivo inicial a desmantelar, las vías de tren limítrofes, en elemento principal vertebrado del nuevo barrio mediante un ferrocarril de barrio para disponer actividades móviles tales como la recogida de basuras, ocio itinerante, el mercado semanal y la distribución logística durante y después de la construcción, permitiendo así la recirculación de los materiales de construcción para limitar la producción de residuos. El modelo constructivo propuesto recicla la tipología de naves diáfanas de tipo agrícolas o ganaderas presentes en el solar.

\section{TABOADELA}

RWOOO. Rewind Galicia. Mención

Ante un entorno de formas construidas altamente interrelacionadas -agrícolas, residenciales y públicas- de pequeña escala, el jurado valora de la propuesta la resolución del conjunto residencial a través de una nueva tipología flexible en la forma y en los usos. Es de apreciar así mismo la introducción de la idea de comunidad como elemento urbano sostenible, coherente con estos principios, donde la creación del espacio público está contenida e íntimamente relacionada con la forma del espacio privado. Un encadenamiento de formas y funciones 
acordes con el propio principio de fragmentación y adaptación irregular que el territorio plantea, de sugerente formalización en su posible materialidad, peca de cierta indefinición planimétrica, así como de un exceso de tipificación de ciertas formas pretéritas extrapolables a una posible tipología mas lúdica del presente, solo entendible como posible conceptualización.

EU010. De resaca. Finalista

El jurado valora de la propuesta la estrategia urbana planteada, así como la valentía con la que se afronta la consecución de la densidad máxima requerida. La propuesta tipológica es sugerente en su flexibilidad y fragmentación volumétrica por su adaptación al terreno existente. Ante una atractiva negociación temporal de los usos agrícolas y de esparcimiento, se echa en falta, una mayor correlación con el espacio público, de menor riqueza por su aparente jerarquización con el viario propuesto y existente. Así mismo, el dimensionamiento de las supermanzanas -a valorar el riesgo - peca, en su compactación final, de una excesiva centralización en torno a unos nodos de circulación viaria carentes del mismo interés espacial que el resto del proyecto. Una mayor concreción en la materialización final de las viviendas hubiese sido de gran interés.

FP600. Farmer footprint Photo. Finalista

El proyecto presenta una actuación de conjunto completa, de gran coherencia formal, donde se integra de forma acertada una gran infraestructura puente, que resuelve acertadamente la conexión con el otro lado de la vía del tren al mismo tiempo que propone, en una menor escala, una tipología residencial similar sobre pilotes. A través de un estudio pormenorizado de los cultivos más favorables, se propone un sistema agrícola sustentable, de gran interés, que convive, en aparente armonía, con una vida urbana elevada. El jurado estima discutible las posibles relaciones que se producen entre la implantación de unas piezas, atractivas en su resolución, con un entorno agrícola propuesto de gran actividad, tanto por la nueva parcelación propuesta, que rompe con un sistema complejo ya preestablecido, así como por la falta de espacios de relación e intermediación entre estos dos claros niveles formales, de vida y usos.

LP001. Listening post. Finalista

El proyecto asume la estructura preexistente como base para una gestión ordenada, a través de una riqueza tipológica residencial de gran interés. Las piezas se adaptan a la parcelación existente incorporando el cultivo, su gestión, así como la propia vegetación como un elemento arquitectónico más. Frente a la delicadeza de las formas, de su asentamiento en el entorno, el jurado aprecia una carencia de los espacios infraestructurales, formas de relación y circulación que parecen verse sustituidas por la presencia icónica, escalar, de unas torres, llamadas de intermediación, cuestionables en un entorno geográfico tan reducido y poco accidentado, que no pueden sustituir la necesaria materialización del otro espacio público. 
SM007. Border Line. Finalista

El jurado valora la reflexión metropolitana de conjunto, donde se aprecia un interés por resolver una situación endémica de crecimiento desordenado en torno a las vías principales existentes, a través de una sugerente densificación intersticial de las mismas. Propuesta que se aleja del área de actuación intentando resolver otra forma de urbanizar el conjunto, actuando donde realmente se da el verdadero problema de déficit urbano. Se echa en falta una mayor concreción en las formas de resolución habitacional, así como una excesiva separación entre los usos residenciales y comerciales, tal vez debido a la propia separación existente entre las infraestructuras, viario y vía del tren, en las que se apoya.

\section{TERUEL}

O1010 - Genius Locci - Premio

El jurado ha valorado la intensidad, la delicadeza y la claridad de la propuesta de la que destaca los siguientes aspectos:

- El tratamiento del entorno de la estación con una propuesta de un trozo de ciudad con viviendas, equipamientos, terciario, comercial y aparcamiento público soterrado que fomentaría la intermodalidad.

- La estrategia adecuada de concentrar las construcciones en los límites de la Vega, al pie de los escarpes.

- La atención ineludible a las necesidades de comunicación transversal entre las muelas y la vega con el trazado y reconocimiento de caminos en rampa.

- La comprensión y puesta en valor de las características del paisaje productivo de la vega con una mirada contemporánea.

\section{LC114 - Fusión - Mención}

El jurado ha valorado el buen análisis de la situación urbana, estratégica y paisajística de la Vega del Turia en Teruel y ha detectado la potencialidad de la propuesta de "las Puertas" para comunicar una transformación del territorio a la ciudadanía.

Se ha valorado también positivamente la concepción de las Puertas en relación a un uso o equipamiento. A partir de la "Puerta de la Historia" que conecta la estación con el Paseo del Óvalo y la ciudad histórica, se proponen otras tres: "Puerta de las Artes", "Puerta del Mirador" y "Puerta del Turia".

Sin embargo, el jurado ha desconfiado de la propuesta en distintos aspectos, como la poca densidad en el ámbito de la estación, la propuesta de viviendas-taller poco idóneas en el escarpe identitario y la intensificación de los polos comercial y empresarial en la vega del río.

\section{ZZ000 - O2 - Finalista}

El jurado, con una valoración desigual, decidió señalar esta propuesta por el interés de su plan de usos para la revitalización del ámbito de la Vega del río Turia a su paso por Teruel. El acondicionamiento de caminos peatonales y las propuestas de usos como el Taller artesanal y exposición al aire libre, las cafeterías-quiosco, las plataformas recreativas y el área deportiva son propuestas que se han 
valorado positivamente. Sin embargo han sido más inquietantes las propuestas de residencial de baja densidad, módulos polivalentes, área docente y terciario en la vega del río Turia a su paso por Teruel.

\section{VALVERDE}

\section{AS111. MoNonoKe. Premio}

El jurado considera que el proyecto resuelve la adaptación a la pendiente del terreno, la orientación de las vistas al mar y la preservación del paisaje local, con naturalidad y economía formal. Se aplica un único recurso tipológico de piezas sesgadas iguales, que generan diversidad de espacios y entretejen las áreas comunes, los patios privados, las terrazas y las correspondientes habitaciones interiores de forma clara y proporcionada. Dicho sistema espacial, materializado a través de muros continuos y aterrazamientos, dota a la propuesta de flexibilidad, sin comprometer la coherencia del partido y su relación con el terreno; se establece asimismo una unidad de vivienda confortable con carácter propio, resguardada de los vientos dominantes y con vistas cuidadosamente enmarcadas. La propuesta paisajística complementa y enriquece el concepto arquitectónico, se respetan las escorrentías naturales y la flora del lugar, retomando la geometría local de bancales y la división de parcelas adaptadas al terreno, intrínsecas al perfil rural de la isla.

BE205. Fractalidad Social. Mención.

Se rescata en este proyecto la gran flexibilidad de agregación, diversidad de escala y usos que permite la aplicación de una trama fractal; dicha estrategia genera un sistema de ocupación de carácter plástico con clara identidad espacial y formal, creando situaciones de borde imprecisos y permeables, los cuales resuelven adecuadamente la integración con las áreas inmediatas. La virtud del proyecto parece ser también su defecto, no queda definido en la propuesta el límite real entre lo privado y lo comunitario ni tampoco los modos de acceso a las distintas unidades de viviendas; dicha ambigüedad genera ciertas dudas sobre la viabilidad de la propuesta como proyecto habitacional; esto último en relación a la funcionalidad de la planta de conjunto y niveles aceptables de privacidad entre unidades vecinas.

\section{GJ570. Terracity. Mención}

El jurado valora la propuesta de aterrazamiento a escala del barrio y su consecuente integración con la topografía. La tipología de casa patio resultante, con unidades a dos niveles, genera espacios introvertidos en planta baja y extrovertidos en la planta superior, con vistas al mar, produciendo un contraste exitoso de atmósferas entre las áreas de día y de noche; el uso de una trama ortogonal permite alta densidad de agregación y también máxima economía de superficies dentro de la unidad misma. Se cuestiona en el proyecto la longitud del borde edificado de las 3 terrazas, al igual que la omisión deliberada de apertura de huecos y/o articulación de los mismos: dichos largos muros ciegos podrían resultar demasiado herméticos y de una escala más institucional que residencial en el entorno de Valverde. Se 
cuestiona también la funcionalidad de la planta de dormitorios en relación a su privacidad y la dificultad de servirlos con luz y ventilación natural.

FC020. Factor 20. Finalista

A nivel conceptual, la idea de cubiertas continuas ajardinadas se reconoce como viable y atractiva para el entorno rural de Valverde, donde la topografía y la flora local constituyen prácticamente la esencia del lugar. El jurado destaca también la intención de los autores de integrar el componente turístico, que también pertenece al paisaje local de las islas canarias en casi todas las temporadas del año. Se cuestionan en el proyecto la mayoría de las soluciones funcionales: La indefinición de las áreas exteriores y cubiertas accesibles de techos presentan un problema práctico de uso por parte de los habitantes estables, tampoco se ilustra como posible un adecuado flujo de luz natural y ventilación en las plantas bajo terreno; el jurado considera que la propuesta en general es ingenua y no sobreviviría un eventual proceso de formalización. 


\section{ENTREVISTA AL SECRETARIADO NACIONAL DE EUROPAN ESPAÑA}

Lugar: Sede del Consejo Superior de Arquitectos de España

Fecha y hora: 21 de febrero de 2012 a las $12.30 \mathrm{~h}$

Persona: Secretaria General (Carmen Imbernón) y Secretaria Adjunta (Begoña Fernández-Shaw) del Comité Nacional de España.

\section{1. ¿Qué es Europan?}

Buena pregunta. Europan es una asociación de países europeos que convocan de manera conjunta un concurso de ideas que pretende hacer una reflexión acerca del hábitat y la ciudad europea en todas sus escalas, desde la vivienda, al barrio, la ciudad o la planificación del territorio.

\section{2. ¿Qué material existe en el archivo de Europan?}

Europan se desarrolla con pocos medios humanos y económicos en comparación con la cantidad de participantes que se presentan en el concurso. España participa en Europan desde la primera edición en el año 1989. La información existente del concurso y de los proyectos premiados está archivada en formato papel y en fotolitos, y se recoge en los catálogos. A partir del año 2000 se empezó a digitalizar toda la información disponible.

\section{3. ¿Cómo se financia Europan?}

Europan se financia a través del conjunto de la Administración Pública que forman parte del Comité Nacional en cada edición: Ministerio de Fomento, Consejo Superior de Colegios de Arquitectos de España, Sepes, Comunidades Autónomas y Ayuntamientos, con un presupuesto cerrado para dos años. El CSCAE presta apoyo administrativo, contable y jurídico y la sede del Secretariado español.

Generalmente se trabaja con pocos medios, aunque depende de cada país (algunos por ejemplo trabajan en Europan desde su propio estudio de arquitectura). Es cierto que el período de dos años es demasiado breve y apenas deja tiempo a la reflexión, recopilación y orden del material recibido después de cada convocatoria pero alargarlo a tres años actualmente se hace difícil debido a los escasos medios financieros disponibles. 


\section{4. ¿Quién trabaja en Europan?}

Actualmente en Europan se podría decir que trabajamos una persona y media. Carmen Imbernón (Secretaria general) trabaja a jornada completa y yo (secretaria adjunta) que trabajo dos días a la semana pues lo que suelo llevar a cabo es la gestión y el seguimiento de las realizaciones una vez se ha fallado el concurso.

\section{5. ¿Cómo se trabaja desde Europan, desde el lanzamiento de concurso hasta la realización?}

Este proceso es largo de definir.

En primer lugar, en Europan intervienen distintos agentes, a nivel europeo y a nivel nacional.

En Europa hay tres niveles de organización:

- Los órganos de decisión están formados por el Presidente, la Asamblea General y el Consejo. Como su nombre indica, estos órganos, en donde están representados todos los países que forman parte de Europan, proponen y votan los presupuestos, los plazos y los temas de cada una de las ediciones.

- Los órganos ejecutivos están formados por el Secretariado Europeo y los Secretariados Nacionales. El Secretariado Europeo prepara el trabajo de la Asociación y coordina las reuniones de los Secretariados, de los órganos de decisión y de los órganos consultivos. También realiza el trabajo de preparación de los foros europeos y de publicación y difusión de los resultados del concurso. Los secretariados nacionales hacen este mismo trabajo a nivel nacional, buscan los emplazamientos a concurso y hacen el seguimiento de las realizaciones

- Los órganos consultivos están formados por el Comité Científico y el Comité Técnico. El Comité Científico está a cargo del análisis de los emplazamientos presentados al concurso y de los resultados. El Comité técnico tiene a su cargo la preparación de los contenidos de los Foros Europeos.

A escala nacional, estos niveles de organización se reflejan en:

- La Presidencia de Europan, que recae en un representante del Ministerio de Fomento y el Comité Nacional.

- El Comité Ejecutivo y el Secretariado

- El Comité Científico

Cada país miembro se organiza, a nivel nacional, de manera independiente.

A escala europea, a lo largo de cada edición tienen lugar tres foros de debate:

- El Foro de las Ciudades. Previo a la convocatoria del concurso, se presentan todas las propuestas de suelo a nivel europeo, se estudia su adecuación a la temática de cada una de las ediciones se analizan las problemáticas y se debaten los programas en mesas redondas donde intervienen los representantes de suelo 
y los miembros del Comité Científico y el Comité Técnico Europeo.

- El Foro de las Ciudades y de los Jurados. Tiene lugar entre las dos reuniones del jurado, y habiéndose seleccionado un $20 \%$ de las propuestas presentadas. En el intervienen los representantes de suelo, los miembros de los jurados de los distintos países y los miembros del Comité Científico y Técnico. Se hace un análisis de las propuestas presentadas y se debate en mesas redondas los tipos de respuestas planteadas.

- El Foro de Resultados. A este foro, que se produce una vez se ha fallado el concurso, se invita a los representantes de suelo y a los equipos premiados y mencionados. En mesas redondas y conferencias se pone en común las distintas propuestas premiadas, sus similitudes y diferencias, su adecuación a las temáticas planteadas en el concurso, y su viabilidad para desarrollarse en el futuro como proyectos edificatorios o urbanos

A escala nacional tienen lugar numerosas reuniones del Comité Nacional, donde se presentan y aprueban los temas de las distintas convocatorias, los emplazamientos, los miembros del jurado, los presupuestos, etc.

\section{6. ¿Quién elige al Jurado en Europan y con qué criterios? ¿Cómo funciona?}

El Jurado lo elige el Comité Nacional basándose en un criterio de la pluralidad y de sensibilidad hacia el tema de Europan y hacia los emplazamientos presentados. El jurado está formado por nueve miembros, de los cuales hay tres extranjeros. Se intenta que haya equilibrio entre jóvenes y mayores, hombres y mujeres, arquitectos, paisajistas y urbanistas,...cuanta más variada sea la selección, mejor. Una vez confirmada la formación del jurado, al menos un miembro del mismo se traslada a cada ciudad propuesta para ver el emplazamiento y hablar con el responsable del suelo.

Previa a la primera reunión del jurado, los responsables de suelo tienen la oportunidad de analizar las propuestas presentadas. Tiene entonces lugar una reunión entre el Comité Nacional y los miembros del jurado donde se presentan los emplazamientos y se hace un examen global sobre las propuestas presentadas y su adecuación. En la primera reunión del jurado, que tiene lugar a lo largo de tres días, se hace una selección del $20 \%$ de las propuestas presentadas. Estas propuestas serán debatidas en el Foro de las ciudades y de los jurados. Con posterioridad al Foro y previo a la segunda reunión del jurado, tiene lugar otra reunión entre los miembros del Comité Nacional y el jurado donde se analizan de manera mas exhaustiva las propuestas seleccionadas.

En la segunda reunión del jurado se toman las decisiones sobre las propuestas premiadas, mencionadas y finalistas.

Una vez se hace púbico el fallo del concurso, tiene lugar una reunión a la que se invita al Jurado, representantes de la Administración Pública (representantes del suelo) y a los equipos premiados. Estos presentan los proyectos a todo el Comité Nacional y posteriormente se forman grupos de trabajo por emplazamientos. Esta 
reunión es importante porque se concreta de qué modo se pueden llevar a cabo las actuaciones y las estrategias planteadas y se pacta con los representantes de la Administración Pública el proceso posterior a seguir.

\section{7. ¿Cómo se selecciona el Comité de Expertos internacional y nacional?}

El Comité Científico y el Comité Técnico europeo los decide el Consejo Europeo teniendo en cuenta la experiencia y el currículum de los seleccionados. Entre los componentes del Comité Científico se encuentra un arquitecto español: Carlos Arroyo, y en el Comité Técnico se encuentra David Franco, también arquitecto

\section{8. ¿Cómo influye Europan en la arquitectura nacional e internacional?}

Creo que Europan influye en la arquitectura nacional e internacional a tres niveles:

-A nivel de las Administración Pública (Autonómica y Locales). En cada convocatoria se publica un folleto de divulgación que se distribuye a través de los Miembros del Comité Nacional. En él se explican los objetivos del concurso y se hace un resumen de las ediciones pasadas. El hecho de que en cada edición tengamos propuestas de suelo a concurso quiere decir que la Administración Pública está interesada en participar en esta reflexión sobre el hábitat y el espacio público en la ciudad europea.

- A nivel de los jóvenes arquitectos. Europan proporciona una plataforma para dar a conocer su trabajo tanto a nivel nacional como internacional. Una vez fallado el concurso se realiza un catálogo de resultados a escala nacional y a escala europea. Se distribuye a todas las Escuelas de Arquitectura, librerías especializadas, Colegios de Arquitectos y Bibliotecas de centros culturales, además de a los miembros del Comité Nacional. Además de las publicaciones y notas de prensa cabe recalcar que se realiza una exposición itinerante que suele presentarse en los distintos emplazamientos que han participado en el concurso.

- Finalmente, Europan influye a través de su obra realizada, que va de los proyectos de viviendas a los planeamientos urbanos. Aunque estos últimos tengan menos visibilidad son los que definirán nuestra manera de vivir en la ciudad.

\section{9. ¿De qué manera intentáis que los proyectos galardonados terminen en} realizaciones?

Europan es un concurso de ideas dotado de un premio en metálico. LaAdministración Pública que presentan suelo a concurso se compromete a hacer todo lo que está en su mano para contratar a los equipos galardonados y desarrollar las ideas premiadas. Es un "intermediario" invisible entre la Administración Pública y los 
equipos galardonados. Europan trata de involucrar a los representantes del suelo y les insta a que convoquen ese concurso de ideas.

Dependiendo de cada administración pública y su situación, podrá contratar una cosa u otra: si es una Comunidad Autónoma, Ayuntamiento, representantes de suelo, etc.). A veces lo que se hace es convocar con posterioridad concursos restringidos entre los ganadores de Europan para que realicen otras intervenciones que puedan asumir.

10. ¿Tenéis relación con los equipos galardonados con el paso del tiempo?

Sí, porque las realizaciones se extienden a lo largo del tiempo. Europan ofrece un apoyo a los equipos premiados de manera que puedan proyectar su futuro, les ofrece el apoyo que todo equipo de arquitectura joven necesita para arrancar en el mundo laboral. Europan presta ayuda a la proyección pública nacional e internacional de los equipos españoles y plantea una problemática a la administración pública.

Además es interesante constatar el alto grado de participación de los equipos españoles que, después de los equipos franceses, ocupan el segundo puesto. 
